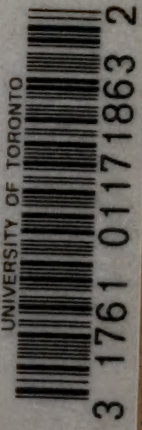




Digitized by the Internet Archive in 2007 with funding from Microsoft Corporation 




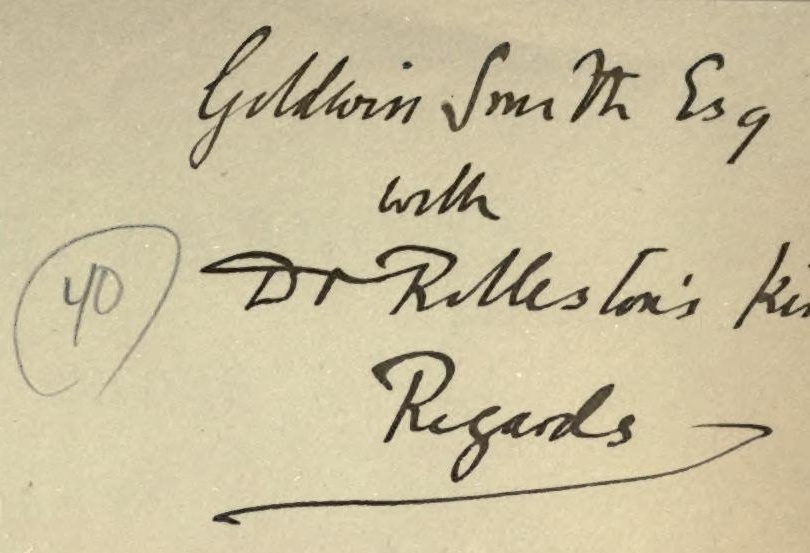

BRITISH BARROWS

$G R E N W E L L$ 
Zondon

MACMILLAN AND CO.

PUBLISHERS TO THE UNIVERSITY OF (1)xfort 


\section{BRITISH BARROWS}

A RECORD

OF THE

\section{EXAMINATION OF SEPULCHRAL MOUNDS}

IN VARIOUS PARTS OF ENGLAND

BY

WILLIAM GREENWELL, M.A., F.S.A.

TOGETHER WITH

DESCRIPTION OF FIGURES OF SKULLS

GENERAL REMARKS ON PREHISTORIC CRANIA

AND AN APPENDIX

BY

GEORGE ROLLESTON, M.D., F.R.S.

Linacre Professor of Anatomy and Physiology

and Fellow of Merton College, Oxford

\section{Brfort}

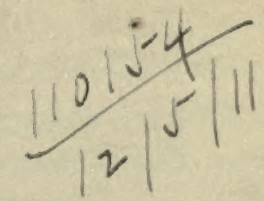

AT THE OLARENDON PRESS

M.DCCC.LXXVII

[All rights reserved] 


$$
\begin{aligned}
& \text { GN } \\
& 796 \\
& \text { G } 767
\end{aligned}
$$




\section{PREFACE.}

THE work now offered to the public will be found to contain a record of the examination of above two hundred and thirty sepulchral mounds, belonging to a period before the occupation of Britain by the Romans. A considerable part of many years has been devoted to this examination; and, I trust I may say with confidence, the faets collected during this process have been carefully and minutely observed and accurately recorded.

Though numerous barrows have been opened throughout Britain, but few accounts have been given of what has thus, from time to time, been brought to light. Many have been destroyed by shepherds and others, from motives of a mere idle curiosity, or in the delusive hope of finding treasure; still more have been destroyed, under the influence of a curiosity almost as idle, by persons indeed of better education, but who have thought that enough was gained if they found an urn to occupy a vacant place in the entrance hall, or a jet necklace or a flint arrow-point for the lady of the house to show, with other trifles, to her guests requiring amusement. Naturally in none of such cases has any record of these openings been preserved, and hence what otherwise might have grown into an almost invaluable collection of facts has been entirely lost to archæological science.

Notwithstanding this, however, some extensive series of barrow examinations have happily been undertaken and the results given to the public. Sir Richard Colt Hoare in his magnificent volumes 'Ancient Wilts' was the first systematically to explore and publish a most valuable amount of discoveries in that county and some adjoining districts. Mr. Bateman also in Derbyshire, supplemented by Mr. Carrington in Staffordshire and Mr. Ruddock in the North Riding of Yorkshire, prosecuted a large number of investigations 
in the barrows of those counties, a full account of which will be found in his "Vestiges of the Antiquities of Derbyshire" and "Ten Years' Diggings.' For Dorsetshire Mr. Warne has published, in his 'Celtic Tumuli of Dorset,' a record of many barrow-openings conducted by himself as well as by others in that county; and the same has been done for Cornwall by Mr. W. C. Borlase in 'Nenia Cornubiæ.' Besides these larger works, many notices of the examination of barrows will be found in various Archæological Journals, local as well as national. Nor would it be just to omit, though the places of sepulture there treated of belong to a period posterior to that with which my own researches have been connected, Douglas's 'Nenia Britannica,' and that most admirable account of his examination of Kentish cemeteries given by the Rev. Bryan Faussett in the 'Inventorium Sepulchrale;' a work which it is much to be regretted remained in manuscript for nearly a century after the death of its author.

The barrow-openings recorded in this book have principally been made in the East Riding of Yorkshire, a district which possesses in the Wolds a locality abundant in such remains, and where the greater part fortunately had been left uninjured, except in so far as the cultivation of the land during a comparatively short period had to some extent destroyed the surface of the mounds. In the same district a large series of barrows has been most carefully and exhaustively examined by Messrs. J. R. and R. Mortimer, of Driffield and Fimber, the results of whose labours will I hope before long be published.

Accounts of a few of the barrows more fully described in this work have already been given by me in the Journal of the Archæological Institute and in the Transactions of the Berwickshire Naturalists' Field Club, but it has been thought desirable to include these in order to render the series in each case more complete.

To this history of the opening of British barrows are appended two essays by George Rolleston, M.D., F.R.S., Linacre Professor of Anatomy and Physiology in the University of Oxford, under whose charge, in the New. Museum of that body, are deposited the skulls obtained from the various sepulchral mounds herein described. One of these essays gives a minute 'Description of Figures of the Skulls,' 
the other 'General Remarks upon the Series of Prehistoric Crania.' It would be impertinent in me to offer any remark upon their importance: the reputation of the author and his well-known intimate acquaintance with the subject make it self-evident how greatly they add to the value of this book.

And here I cannot deny myself the pleasure of testifying how, during all the course of my diggings, I have met with the most cordial co-operation from the many landowners upon whose estates the various barrows were situated. It would be impossible to specify every name, but I am bound to mention the late Earl of Carlisle, Lord Londesborough, Sir Charles Legard, Bart., Sir. Henry Boynton, Bart., Sir Tatton Sykes, Bart., Sir W. C. Trevelyan, Bart., P. F. Clennell, Esq., and Alfred Sartoris, Esq. To the occupiers also I cannot fail in making my acknowledgments for much civility and help in many ways; amongst these I would particularly name $\mathrm{Mr}$. William Lovel, of Weaverthorpe, who took a warm and constant interest in the various barrow-openings in his neighbourhood.

I am indebted to John Evans, Esq., F.R.S., for the use of the following woodcuts,-Figs. 4, 10, 11, 14, 25, 26, 28, 29, 31, 37, $38,42,43,47,87,93,99,100,104,105,107,108,109,110,111$, $113,115,116,123,124,126,145,156,157$; to the Society of Antiquaries for Figs. 6, 19, 32, 41, 55, 65, 66, 67, 68, 112; to the Royal Archæological Institute for Figs. 24, 54, 56, 75, 76, 137, $138,139,143,144,146,147,148,149,150,151,152,155$; to J. B. Davis, M.D., F.R.S., for Figs. 1, 160, 161 ; to Mr. Llewellynn Jewitt, F.S.A., for Fig. 2.

I must also express my thanks to Mr. Evans, who, to their profit, has read the sheets as they were passing through the press; also to the Rev. J. C. Atkinson, himself a diligent and careful digger in the Cleveland barrows, for revising this work in the manuscript, and for much valuable counsel; also to my neighbour the Rev. Henry Barrett, to whose critical supervision the book in its literary aspect is largely indebted for whatever of merit, in that respect, it may be thought to possess.

For the drawings of many of the urns I am greatly obliged to the Rev. W. C. Lukis, F.S.A., to whom I am sure the labour was one of love. 
I cannot take leave of a work in which is recorded the results of the labour of many years without an expression of gratitude for the happy hours and pleasurable associations that labour has begotten. Old friendships have ripened, and new ones have grown, over the graves of the ancient dead; nor can I look back to any part of my life with less of regret or greater satisfaction than that which has been passed in an endeavour to revive, in however faint a form it may be, the almost forgotten past.

\section{WILLIAM GREENWELL。}

DURHAM,

October, 1877. 


\section{CONTENTS.}

INTRODUCTION

PAGE

\section{BARROWS.}

YORKSHIRE. EAST RIDING

Parish of Kirby Underdale . . . . . . 135

" Langton : . . : . . . . . . . 136

" Kirby Grindalyth . . $\quad . \quad$. . . . . . 140

$"$ Heslerton

" Sherburn

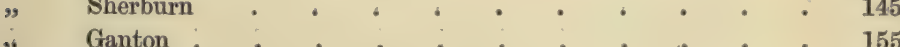

" Ganton . • • • • • • . • • 155

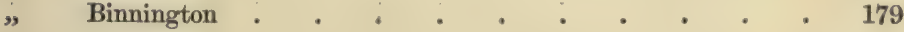

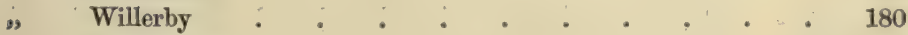

” Butterwick : $:$. $\quad$. $\quad . \quad$. . . . . . 186

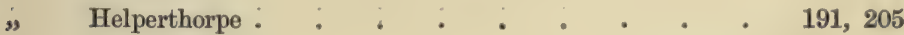

"Weaverthorpe : . : : . . . . . 192

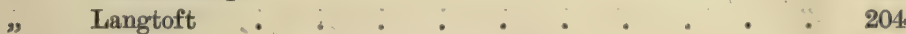

” Cowlam . . . . . . . . . . . 208

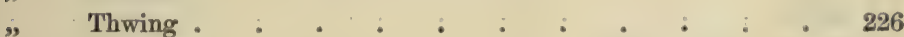

" Rudstone . . . . . . 229

" Folkton . . . 271

" Cherry Burton . 279

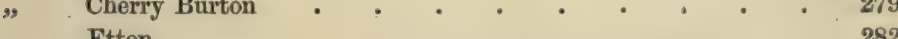

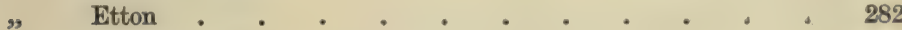

" Goodmanham . . . . . . . . . . . 286

” Londesborough . . . . . . . . . . 331

YORKSHIRE. NORTH RIDING . . . . . . . . 333

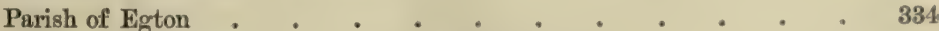

" Over Silton : . . . . . . . . . 336

" Cold Kirby . • • • • • • , • • 337

" Kilburn . . . . . . 339

" Gilling . . . . 343

"Slingsby . . . 347

"Welburn + . .

" Hutton Buscel . . . . . . . . . 357 
YORKSHIRE. WEST RIDING

Parish of Ferry Fryston

„ Rylston

CUMBERLAND .

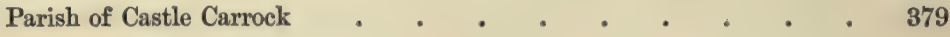

\section{WESTMORELAND}

Parish of Kirby Stephen

$\begin{array}{ll}" & \text { Warcop } \\ " & \text { Asby . } \\ " & \text { Crosby Garrett } \\ " & \text { Ravenstonedale } \\ \text { " } & \text { Orton . . } \\ \text { " } & \text { Crosby Ravensworth } \\ \text { " } & \text { Askham . }\end{array}$

NORTHUMBERLAND

Parish of Ford

Doddington

" Chatton

" Bamborough .

" Eglingham

" Alwinton

" Rothbury

" Kirk Whelpington

" Hartburn

" Chollerton

" Ovingham

DURHAM

Parish of South Shields .

GLOUCESTERSHIRE

Parish of Nether Swell . . . . . . . . . . 445

TABLE OF BARROWS, INTERMENTS, AND ARTICLES DEPOSITED WITH INTERMENTS

\section{LONG BARROWS.}

Parish of Ebberston, North Riding . . . . . . . 484

Willerby, East Riding .

"Westow, East Riding . . . . . . . . 490

" Rudstone, East Riding . . . . . . . . 497

" Kilburn, North Riding . . . . . . . . 501 
Parish of Market Weighton, East Riding PAGR

» Over Silton, North Riding . . . . . . . 509

" Crosby Garrett, Westmoreland . . . . . . 510

" Nether Swell, Gloucestershire . • . . . 513

" Eyford, Gloucestershire . . . . . . . . 514

„ Upper Swell, Gloucestershire . . . . . . . . 521

" Gilling, North Riding . . . . . . . . 550

” Kilham, East Riding . . . . . . . . 553

DESCRIPTION OF FIGURES OF SKULLS BY DR. ROLLESTON • 557

Weaverthorpe . . . . . . . . . . . 570

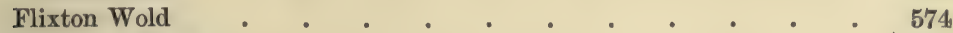

Heslerton Wold . . . . . . . . . . . 578

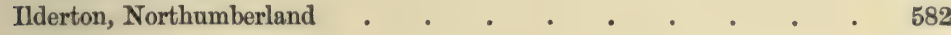

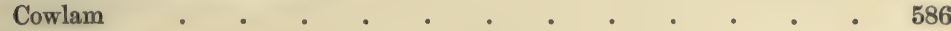

Rudstone . . . . . . . . . . . . 590,612

Castle Carrock, Cumberland . . . . . . . . . . . 598

Langton Wold . . . . . . . . . . . 602

Sherburn Wold . . . . . . . . . . . 608

Helperthorpe . . . . . . . . . . . 616

Weaverthorpe . . . . . . . . . . . 619

Ebberston . . . . . . . . . . . 622

GENERAL REMARKS UPON THE SERIES OF PREHISTORIC CRANIA BY DR. ROLLESTON . . . . . 625

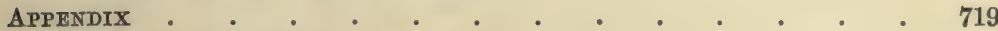

Of the Prehistoric Flora of the Country . . . . . . 720

Of the Prehistoric Fauna $\quad$. . . . . . . . . 725

Index of Authors referred to in Dr. Rolleston's Essays . . . . . 751

INDEX . . . . . . . . . . . . 755 



\section{N T R 0 D U C T I 0 N.}

THE almost universal custom of raising a mound, the so-called barrow ${ }^{1}$, over the buried dead, to mark the place where they were laid in the grave, has been variously discussed, and by many different writers. Notices of the practice have been so often collected from the works of Greek and Latin authors and other sources, that it is not necessary for me to enter upon any general consideration of the subject, except in very brief terms.

This form of memorial, monumentum are perennius, as ancient as it has been lasting, is found in almost all parts of the globe, from the extreme West of Europe to the Eastern limit of the continent of the New World. Barrows, under diverse names, line the coasts of the Mediterranean, the seats of ancient empires and civilisations, before whose rise they were in existence, and whose decay they have witnessed and outlived. So numerous are they, that they spread like a covering over the wide plains, the Steppes of Northern Asia, from the Euxine almost to the Icy Sea, where a few wandering nomads now feebly represent a population which was once large, wealthy, and powerful. The continent of India possesses them in abundance, and their buried contents present an identity in many particulars so close with those of Britain, that some have considered it as affording a proof of a near connection between the two peoples who erected them. Egypt knows them as the sepulchres of her early kings, and the Pyramids have remained, an unchanging legacy from the dead, when the wisdom of her learned exists only in the oft transmuted knowledge of many an alien race, and when her religion, her literature, her art, almost her language, the living expressions of a nation's being, have all but passed away and been forgotten. The red man of America still places his dead beneath

1 I have preferred to use the English barrow rather than the Latin tumulus, on account of the word being in the vernacular, and because tumulus does not necessarily imply a sepulchral mound. 
them, and the huge mounds, so common in some parts of that continent, are the evidences of an early civilisation, to which the marvellous ruined cities of Central America bear a stronger witness; cities which, in their elaborate and profuse though strange sculpture, give indications of an art developement so distinctive in its character, that it could scarcely have had its origin in the mind of any of the races of the Old World.

They abound in Great Britain and Ireland, differing in shape and size, and made of various materials; and are known as barrows (mounds of earth), and cairns (mounds of stone) $)^{1}$, and popularly in some parts of England as lows, houes, and tumps. They vary in size from a few feet in diameter to a miniature mountain, like Silbury Hill in Wiltshire, which covers above five acres of ground, and measures $130 \mathrm{ft}$. in perpendicular height ${ }^{2}$.

The manner in which the dead have been disposed within them differs very considerably. Sometimes the body, whether burnt or unburnt, has been placed in the mound without anything to protect it from the surrounding earth or stones. Sometimes it has been placed in a small box of stone, a cist; at other times in the hollowed trunk of a tree, or in a grave sunk below the surface of the ground; and, when a burnt body, often in an urn; whilst in some instances the mound encloses a large structure, suggestive rather of an abode for the living than of a resting-place for the dead ${ }^{3}$. Of this last

${ }^{1}$ Barrows and cairns often occur in close proximity, there being nothing in the mode of interment or in the remains found in them to imply that there was any difference in point of time between the two kinds of mound.

${ }^{2}$ Silbury Hill has been twice examined with the view of ascertaining whether it was sepulchral or not. First in 1777, when a shaft was sunk from the top to the bottom; and again in 1849, when a tunnel was carried up to the present centre, as nearly as it could be ascertained, at the level of the surface of the ground. Though it was satisfactorily proved to be artificial, no remains, which indicated that a burial had taken place beneath it, were discovered. These examinations cannot, however, be considered satisfactory as affording any conclusive evidence that it is not a sepulchral mound. The area which it covers is very large, and the primary burial, even if it was at the centre, might very easily have been missed, and by many yards, during the course of both the investigations. In the process of throwing up so large a mass of earth, the original centre could scarcely have been retained, and it is probably a considerable distance from the present one.

Stukeley mentions that an iron bridle-bit and some armour were found on the summit, the remains probably of a Saxon interment, placed there certainly long after the mound was thrown up. The occurrence of Saxon burials in the upper parts of British barrows is by no means infrequent. I have myself met with three, and very notable instances.

${ }^{3}$ Some writers, and with much probability, have regarded the sepulchral chamber as a copy of the habitation of the living, and the way in which the dead are sometimes found, arranged upon a stone bench round the chamber, as representing the manner in which they sat in their huts when alive. There certainly is a great 
mode the great chambered cairns at New Grange and Dowth, in the County of Meath, on the banks of the Boyne, and Maeshowe in the Orkneys, are the most remarkable examples in the United Kingdom.

As a rule they are circular, though at times approaching an oval form, but a long-shaped mound is common in some parts of England, and has been regarded with much probability as the earliest form of barrow, and belonging to a period before the introduction of the use of metal into the country.

It has been stated in the Preface, that the Introduction will be mainly confined to a consideration of the facts which an extended examination of the barrows of the Yorkshire Wolds has supplied, and to certain deductions which may be drawn from those facts. It becomes necessary however, in the first place, to give a description of the barrows themselves, preparatory to giving an account of their contents.

In form they are either long or circular; but as the long barrows, and the various interesting questions connected with them, are fully considered in the account of the opening of several of them, given in the sequel, the present remarks will be limited to the round barrows.

They differ considerably in outline, and the slope of the sides is sometimes very gradual, at other times quite sharp. In most cases they have become so greatly altered, during the course of years of cultivation of the surface, that it is difficult to ascertain what has been the original form; but judging from some which still remain untouched by the plough, and from the present appearance of the whole of them, they may be described as being bowl-shaped and conical ; those of the former shape being perhaps the most numerous.

resemblance between some of these receptacles for the dead, especially in Scandinavia, and the places of abode of the Eskimo and other Arctic residents. Nilsson, Stone Age, ed. Lubbock, p. $124 \mathrm{seq}$. The supposition is not one which bears in itself anything of improbability, but rather is the expression of a natural feeling. Some of the early twelfth-century grave-stones are miniature high-pitched roofs, the covering in fact of man's last home.

The same idea, connecting the dead with the living, and retaining in the grave some reminiscence of the former life, may possibly have been sought to be embodied by the use of a peculiarly shaped urn, holding the ashes of the dead,--specimens of which have been found at Albano and on Mons Crescentius in Italy, and at several places in Germany. They are imitations of huts, and have a moveable door, which was secured after the bones had been deposited within them. They belong to the Bronze Age. Birch, Ancient Pottery, vol. ii. 196, 391 1st ed., 446, 595 2nd ed.; Pigorini and Lubbock, Notes on the Hut Urns ... of Marino, Archæol. vol. xlii. p. 99; Matériaux pour l'Histoire primitive de l'Homme, $2^{\text {de }}$ Sé: vol. iv. p. 420; Lindenschmit, Alterthümer, vol, i. Heft. x. Taf. 3. 
The evidence afforded by those on the moorland to the north of the river Derwent, and which are situated at a distance of but a few miles from the chalk range of the wolds, tends likewise to show the correctness of this description.

In Wiltshire, as also, though not so commonly, in other districts of England, different forms are met with. One large series has had the name of bell-barrow given to it; but it is difficult to separate it from the conical-shaped mound, except that it has a ditch round the base. What Sir Richard Colt Hoare calls Druid barrows, consisting of one or more very small mounds having a circular bank surrounding them at some distance, do not occur upon the wolds, though it is possible that such may at one time have existed, and have been entirely destroyed by cultivation; at the same time, as they have not been met with on the moors to the north of the Derwent, it is more probable that they were always absent on the wolds. Nor do the twin barrows of Sir R. Colt Hoare, or a group of three mounds, surrounded by a ditch, which are found, though rarely, in Wiltshire, find any representatives on the wolds.

It is probable that many of the wold barrows had originally an encircling mound or ditch, or both, at the base; but if such was the case, the process of agriculture has long since destroyed all trace of them. Some such method of enclosure is very common in connection with sepulchral places throughout the whole of Britain. It is found in the shape of circles of stone, where that material is abundant; and in mounds of earth or ditches, where no suitable stone exists. The circles are placed in some cases immediately round the base of the barrow, and in others at some little distance from it ${ }^{1}$. Several barrows upon Wykeham Moor, in the North Riding of Yorkshire, and on Riccal and Skipwith commons, in the East Riding, have each a ditch round the base. The downs of Wiltshire present numerous instances of encircling mounds; and the greater number of the Cornish barrows are enclosed by rings of stone. This frequent characteristic makes it probable that the wold barrows were, many of them, originally surrounded by a similar enclosure.

Barrows differ very considerably in size, though not perhaps so much on the wolds as in other districts: those of the wolds

1 In Homeric times the custom appears to have been to first mark out the site of the tomb $(\sigma \hat{\eta} \mu a)$ in somewhat of a circular form, or, as Mr. Paley thinks, in an oval, and then to place stones round the outline. See paper by F. A. Paley, M.A., on Homeric Tumuli, in Trans. of Cambridge Phil. Soc. vol. xi. pt. 2. 
may be said to range from 20 feet to 150 feet in diameter, and from one foot to 24 feet in height .

They have been made with the materials which came the readiest to hand; and these appear to have been collected for some distance round each mound, for no indication of a hollow marks the place from whence the earth or chalk was taken. As might be expected, they are more commonly made of earth than of chalk, but it is rare to find one without some admixture of that stone, or of flint, the former no doubt frequently obtained from the grave, which is almost always found at the centre. They occur but very rarely made entirely of chalk.

With the imperfect tools and other appliances possessed by the people who erected them, the task of collecting the earth, and much more of quarrying the chalk, must have been by no means an easy one. Chalk however, from its tendency to become broken up, especially in the upper beds by cracks, is easier to work, even by means of so humble an implement as a pick of deer's-horn or a pointed stake, than might at first be supposed. I have frequently noticed indications of turfs or sods of earth having been used; in a few instances the remains of grass and other plants being distinctly visible. In some of the barrows the appearances were such as to suggest that the material was collected in small quantities, probably in baskets ${ }^{2}$, and that the mound was constructed piecemeal, here a basketfull of earth, there a few turfs, then a basketfull of chalk, then two or three blocks of flint, and so on ${ }^{3}$. In some cases the materials have been placed with greater regularity, and the way in which a barrow had gradually increased from the centre was most clearly shown by the parallel layers of different-coloured matter which were distinguishable in the section of it. I have never seen anything to lead to the conclusion that a material foreign to the spot on which the barrow was erected had been used in its construction, with the exception of slabs of stone, used in making cists, and that has occurred, within

1 The largest that I am acquainted with is Willy Houe, near Wold Newton, which is very nearly 150 feet in diameter, and about 24 feet high. It was partly opened by the late Lord Londesborough, but no interment was discovered, nor was the centre reached.

${ }^{2} \mathrm{Mr}$. Peacock noticed the same appearances in a barrow at Cleatham, Lincolnshire; see a paper by him in the Reliquary, vol. viii. p. 224.

${ }^{3}$ Is it possible that the custom of friends throwing earth on the coffin, when the words 'earth to earth' are being read, is a reminiscence or survival of the old manner of raising the barrow, when it may be supposed that those present deposited each his portion of earth, \&c. with some degree of observance? 
my experience, in only one case upon the wolds ${ }^{1}$. Nor have I ever found that the body had been placed amongst any peculiar soil, or brought in contact with any other substance than what might be obtained in close proximity to the barrow ${ }^{2}$.

It has already been suggested that it is probable the wold barrows had circles round the base, in the shape of mounds or ditches, as is not uncommon elsewhere. In some rare instances they certainly had enclosing circles within the barrow. I have met with this feature, in the form of a circle of flint stones, and of a circular trench. In both cases the circle was an incomplete one. In the ring of flint stones there was a space left vacant; in the trench, which was hollowed out of the chalk rock, there was one portion, or more, which was necessary to complete the circle, not excavated. The same peculiarity is found to exist in the barrows and cairns of other parts of England and in Scotland, and indeed this incompleteness appears to be almost invariable in connection with sepulchral circles ${ }^{3}$.

The circle, which occasionally is double, sometimes includes the whole barrow, at other times it defines the bounds of an individual burial, it may be of one out of many which have been placed within the barrow, and only encloses a portion of its area. Similar encircling mounds and trenches are found to surround spaces of ground which have been devoted to the purpose of burial, but where, apparently, no barrow has ever surmounted the graves.

1 The Rev. J. C. Atkinson, of Danby, found a barrow in Cleveland, in the North Riding, to have been made to a considerable extent of sand, basalt, and rolled pebbles, none of which materials are to be met with within several miles of the place.

${ }^{2}$ Colonel Meadows Taylor remarks that fine earth, brought from a distance, almost universally surrounded the urns and cists in the Dekhan cairns. The same feature has been supposed to have been observed in barrows in England, but, I think, without sufficient foundation. See 'Cairns, Cromlechs, \&c., in the Dekhan,' a paper by Colonel Taylor, in vol, xxiv. of the Transactions of the Royal Irish Academy; and 'Archæology of India,' Journal of the Ethnological Society, New Series, vol. i. pp. 167, 168.

3 The great circles of Avebury, Stonehenge, Callernish, \&c., are all incomplete, though perhaps it may be said that in those gigantic structures the idea there expressed was an entrance, and not incompleteness. Examples, however, where no such object as the obtaining an entrance was intended, might be multiplied indefinitely from Great Britain. The same feature is found in connection with sepulchral circles in other parts of the world. Colonel Meadows Taylor mentions it as incidental to circles in the Dekhan, $l . c$. p. 336. In a paper in Revue Archéologique, Nouvelle Série, ix. 372, entitled, Description d'un Tumulus sépulchral des Tchoudes à Arrayione sur la Kama (Russie), the following passage occurs, 'à l'in. térieur on remarque une enceinte formée par des blocs de pierre calcaire et affectant la forme d'un fer à cheval. L'ouverture, large de neuf pas, regarde le sud. Une autre petite ouverture se trouve aussi à l'est.' 
The incompleteness of these circles is so frequent a feature in their construction that it cannot be accidental. They have moreover been left incomplete in some cases in a way which most evidently shows a design in the operation; as for instance, where the circle is formed of a number of stones standing apart from each other, the space between two of them has frequently been carefully built up with one large or several smaller stones ${ }^{1}$. The effect of this is to break the continuity, or rather the uniformity, of the circle, and so to make it imperfect. This very remarkable feature, in connection with the enclosing circles, is also found to occur in the case of other remains which belong to the same period and people as the barrows. The sculptured markings engraved upon rocks, and also upon stones forming the covers of urns or cists, consist in the main of tivo types-cup-shaped hollows, and circles, more or less in number, surrounding in most cases a central cup. In almost every instance the circle is imperfect, its continuity being sometimes broken by a duct leading out from the central cup; at other times by the hollowed line of the circle stopping short when about to join at each end. The connection of these sculptured stones, if so they may be termed, with places of sepulture brings them at once into close relationship with the enclosing circles of barrows, and it is scarcely possible to imagine but that the same idea, whatever that may have been, is signified by the incomplete circle in both cases. The rings of gold and bronze, of various shapes, some of which in their construction show that the penannular form is not caused by the requirements of their use, appear to represent the same incomplete circle. In fact, if some of the gold rings were figured upon stone, they would appear in the very similitude of the circular rock sculptures ${ }^{2}$. I will attempt to give no explanation of this figure,

1 To prevent encumbering the subject with a large number of examples of circles made incomplete in this way, it may be sufficient to refer the reader to a paper hy Mr. James Logan, F.S.A., on 'Circles of Stones in Scotland, presumed to be Druidical,' printed in the Archæologia, vol. xxii. p. 198. Mention is there made, and engravings given, of several circles where this feature is quite distinct. The author calls the stone, which fills up the space hetween two of the separate stones of the circle, the altar, his view being that the circles are temples. I found in a cairn, examined by the Rev. R. J. Mapleton and myself, at Kilmartin, in Argyleshire, two circles, parallel to each other, and surrounding a cist, in which was an unburnt body. The circles were within and covered by the mound, and were both made incomplete by having the space between two of the stones built up with smaller ones. See Proceedings of Society of Antiquaries of Scotland, vol, vi. p. 339.

${ }^{2}$ For a deseription of these sculptured rocks and stones, with accurate figures of them, the reader is referred to 'Ancient British Sculptured Rocks of Northumberland,' \&c., by George Tate, F.C.S., published in the Transactions of the Berwickshire Naturalists' Club, wol. v. p. 137; to 'Arehaic Sculpturings,' hy Sir J. Y. Simprom. 
so marked and so frequent amongst the works of the early people of Britain, though I think it not improbable that whatever the Tau symbol of Egypt, the equal-limbed cross with its binding circle, and other like signs betokened, this mysterious figure may likewise have represented.

It has been suggested by some that the enclosing circles were merely made to support the mound at its base. It is only necessary to remark, in refutation of this surmise, that the circle is often within the mound, is sometimes a trench, and is, as before mentioned, nearly always incomplete. Others have, and with more reason, supposed them to be marks of taboo, a fence to preserve the habitation of the dead from desecration, but the fact that so many are within, and must always have been concealed by, the barrow, appears to be inconsistent with this explanation. I think it more probable, if the notion of a fence is to be entertained, that they were intended to prevent the exit of the spirit of those buried within, rather than to guard against disturbance from without. A dread of injury by the spirits of the dead has been very commonly felt by many savage and semi-civilised peoples; nor, indeed, is such fear unknown in our own times and even amongst ourselves; and it may well be that, by means of this symbolic figure, it was thought this danger might be averted, and the dead kept safe within the tomb.

It is usual to find the wold barrows associated in groups, of greater or less number, though a single one is not very uncommon. I have known as many as thirty and more, which, from their close proximity, might lay elaim to be considered as a group. In other parts of England they occur associated in much larger numbers, as for instance in Wiltshire, where, especially round Stonehenge, barrows are very numerous. They are not generally placed quite close together, but are separated by intervals, sometimes of several hundred feet, though occasionally two or more approach very near to each other, indeed to touching. As a rule they crown the heights, and though frequently placed on the slope of the hill, it is rare to find them in the bottom of the valley. We need not be at a loss to suggest the reason of this, for as the object of the mound itself was to be a memorial of those buried within it, so it is natural that such a position should be chosen as would allow that memorial to be generally and constantly seen.

There are certain features in connection with many, if not with

Bart.; and to 'Incised Markings on Stone,' published by direction of Algernon, Duke of Northumberland. 
all, of the barrows, which, as they do not appear to have reference to any particular burial, but rather to the sepulchral mounds themselves, though perhaps the two can scarcely be separated, it will be better to explain, before giving a description of the manner in which the interments have been made. Though, as has been stated, these features do not connect themselves immediately with the burials, they are nevertheless so commonly found in the barrows, that they must have reference to, and originate in, customs pertaining to the rites of sepulture ${ }^{1}$.

It is a frequent occurrence to find holes, sunk below the natural surface, within the area of a barrow, and not usually in close proximity to any interment, though in some instances such has been found to be the case. Sometimes as many as four or five have been met with in a single barrow. They are of various sizes, and differ in shape, but they are generally circular, about $1 \frac{1}{2} \mathrm{ft}$. in diameter, and the same in depth. In the greater number of cases they are filled with the ordinary materials of which the mound itself is composed, and contain nothing besides; but at other times pieces of animal, and much more rarely of human, bones, charcoal, potsherds, and burnt earth and stone are found in them. There is no appearance, however, of a fire having ever been kindled within them; the burnt matter, when they contain any, having evidently been placed there in that condition. Similar holes are found in the Long Barrows of the south-west of England, but I have never observed anything like them in the barrows of the North Riding or of Northumberland, common as they are in those on the wolds ${ }^{2}$. It has suggested itself to me that they may have been made as receptacles of food or of some other perishable material, and that they answered the same purpose as the vessels of pottery are supposed to have done, which are such frequent accompaniments of a burial. Their not being usually placed in close contact with the body is a fact not perhaps very consistent with this explanation of their purpose, but I am unable to offer any more likely suggestion.

The occurrence of animal bones is another frequent incident. It is rare indeed to meet with a barrow (where the material is such

I I am here reminded of a very apposite remark of M. P. Casalis de Fondouce: 'Je n'ai pas une confiance beaucoup plus grande dans celle des rites funéraires. Les auteurs sont, en général, trop disposés à attribuer à des rites funéraires tout ce qu'ils ne comprennent pas.' Matériaux pour l'Histoire de l'Homme, Sec. Série, tom. iv. 1873, p. 79.

${ }^{2}$ Colonel A. Lane Fox, F.S.A., found them in a barrow near Brighton, which contained an unburnt body, with a bronze knife. 
as to further the preservation of bone) without a considerable number of them being found scattered indiscriminately throughout the mound; and where they have not been so found, their absence is no doubt in many cases to be attributed to decay of the bones. In some barrows they are very abundant; for instance, in one at Rudstone they were literally in hundreds, placed, with flint chippings and sherds of pottery, in a dark-coloured, unctuous layer, which extended throughout the whole area of the mound, on the natural surface of the ground. They are nearly always, when of a nature that admits of such a process, broken, so as apparently to extract the marrow. There can, I think, be little doubt that these bones are the remains of feasts, held at the time of the funeral, or at some subsequent one, such as its anniversary. Practices of a like kind have been common to many different peoples, and so prevalent was the custom in some parts of Europe in the early times of Christianity that frequent orders, directed against holding feasts or sacrificing at the graves of the dead, are to be found in the Frankish Capitularies ${ }^{1}$. They may also be the remains of food offered to the dead, an observance which has extensively prevailed in many countries and in various ages. They would in this case form a part of the practice of the worship of ancestors, which has been a feature almost universal in the growth of the religious feeling of the human race, and allied always with fear. The attempt to propitiate the dead, in one way or other, with the view of averting their displeasure and warding off the danger of their inflicting injury, might be illustrated very fully and from many sources in the history of almost every people and religion. Nor is it impossible that the habit of placing arms, implements, and ornaments in the grave with the dead (of the purpose of which other explanations will be found later on), may have had its origin in ancestral worship. The prevalence of this custom has been of great service in enabling us to gain a considerable knowledge of the animals which, at the time of the erection of the barrows,

1 Even Christian priests appear to have indulged in the practice. Pope Zacharias in a letter to Boniface says, 'Pro sacrilegis itaque presbyteris, ut conscripsisti, qui tauros, hircos, diis paganorum immolabant, manducantes sacrificia mortuorum.' Magna Biblioth. Vet. Patrum, ed. 1618, viii. 130. In a capitulary of Karloman, Dux Francorum, A.D. 742, is a decree against 'sacrificia mortuorum.' Pertz, Monum. Germaniæ Historica. Legum, tom. i. p. 17. An 'Indiculus superstitionum et paganiarum,' which appears to be of the time of Karloman, A.D. 743, contains two articles which seem to refer to holding feasts at burial-places-'De sảcrilegio ad sepulchra mortuorum,' and 'De sacrilegio super defunctos, id est, dadsisas.' 1. c. p. 19. 
inhabited the country, as well as of those which had been brought into a state of domestication. I am indebted to Mr. William BoydDawkins, F.R.S., for identifying those I have discovered, a detailed account of which will be given in the sequel.

There are two other series of objects, which are found still more constantly, and even more abundantly, than the bones, and for the presence of which it is much more difficult to account; namely, flints and potsherds. They occur at times in very large quantities; the flints generally in the shape of mere chippings and waste pieces, but often as manufactured articles, such as arrowpoints, knives, saws, drills, and scrapers, \&c. The potsherds are sometimes fragments of the ordinary sepulchral pottery, but more frequently of vessels which, on account of their better firing and the absence of ornament, appear to be those of domestic utensils. Both flints and potsherds are found distributed thronghout the whole of a mound, and in some instances in such quantities as to suggest the idea that the persons who were engaged in throwing up the barrow, scattered them, from time to time, during the process. They are certainly not there accidentally '. The potsherds might be supposed to be fragments of vessels broken at the funeral or other feasts, but then we should expect to find many pieces belonging to the same vessel more frequently than is the case. I have met with the remains of at least twenty different utensils in the same barrow, whilst the fragments which belonged to any one vessel formed a very inconsiderable portion of the whole.

It is difficult to account for the occurrence of the flints and potsherds in question, except on the supposition that they symbolised some religious idea, though what that idea was we may not be able even to conjecture. A passage in Hamlet (act v. scene I) may possibly have reference to this ancient rite, though it is in the play spoken of as being unholy. Those rites, however, which are thought pious in one religion are often accounted accursed in a

1 It has been suggested that these flints eame into the barrows along with the surface soil, of which, in a great measure, many of them are formed; chippings and other pieces of used flint being, as is well known, strewn abundantly on the ground where these early people dwelt, and near to which they buried their dead. This way of accounting for their occurrence, though plausible, cannot I think be maintained, inasmuch as they are found abundantly amongst the chalk rubble of which many barrows are made, and in the chalk filling in of graves, where no surface soil is mixed with it; and also in places where flint chippings \&c. are not met with amongst the surface soil. And even where the barrow is made up of such material as is ordinarily found to contain them, and that abundantly, yet the number of them in some mounds is so very large as to preclude the idea that they can ever have been laid on the surface in quantities so great as to account for that abundance. 
new one, and it is not unlikely that this, a sacred Pagan custom, was remembered in Christian times, but was then associated with what is irreligious, just as the practice of burning the dead, because it was in use under the old system, was made illegal when Christianity became the religion of the State. The passage occurs where the priest, answering Laertes relative to the burial of Ophelia, a suicide, and therefore unholy, says :

\section{' Her death was doubtful;}

And, but that great command o'ersways the order, She should in ground unsanctified have lodged

Till the last trump; for charitable prayers, Shards, flints and pebbles should be thrown on her.'

The bodies, both burnt and unburnt, are found buried in various parts of the barrows. The central, which in case of no after disturbance is the primary, burial, was usually made in a grave, sunk to a greater or less depth in the chalk rock. This grave is either oval or circular, and its shape and size were no doubt in some measure regulated by the way in which the makers were able to work out the chalk at that particular spot. It varies considerably in size, and is found from under $3 \mathrm{ft}$. to above $10 \mathrm{ft}$. in diameter, and from $1 \mathrm{ft}$. to $10 \mathrm{ft}$. in depth, below the original surface of the ground. In some few instances the central and primary burial has been made upon the surface level, and more unfrequently still above it.

The number of burials in a barrow is very uncertain, nor is the size of the mound any criterion in that respect. A large barrow may contain a single interment, a small one several. When more bodies than one are found in the mound, they are placed at greater or less distances from the centre, upon or beneath the natural surface, or above it, at different levels. Some of these appear to have been buried when the primary interment took place, whilst others are evidently the bodies of persons interred at a time subsequent to that of the first erection of the barrow. These secondary interments have been made either by placing the body on the surface of an existing barrow, or on the surface of the ground just beyond its limits, and then covering them by adding more material to the mound; or by making an excavation into it. Secondary burials occur in all parts of a barrow, and the several levels at which they have been met with seems to show that a mound has sometimes been increased in size on two or more occasions. They have been made on all the sides of a barrow, but much more frequently 
on the south and east than on the north and west; indeed they are but rarely found on the last-mentioned sides. It is probable that the desire to face the sun guided them in this, as it has other peoples. The feeling still exists amongst ourselves; for the prejudice against burying on the north, the dark, side of the churchyard is strong in most parts of England, and it is only where the crowded state of the burial-ground has compelled it, that others than unbaptised children and suicides have been buried there. The same rule has held in ancient times in other places. Nearly all the dolmens of Brittany have the openings between the south and east points of the compass; and the avenues in the same country appear to have a like orientation ${ }^{1}$.

In most cases there is nothing to protect the body against the pressure of the overlying soil, but now and then a few large blocks of flint or thin slabs of chalk have been placed round it, thus forming a kind of rude covering; and, from the appearance of the earth immediately in contact with the bones, it would seem that turfs had sometimes been laid over the corpse. The interring in cists, that is, in coffins, made of four or more stones set on edge, with a cover, so common in other parts ${ }^{2}$, is, as might indeed be expected, almost entirely wanting upon the wolds. In a chalk district like the wolds it was impossible to procure the requisite slabs, except by bringing them from a distance with great toil. I only know of one instance, at Rudstone, where cists have occurred, there placed in a deep grave, sunk in the chalk rock, and where the stones of which they were composed must have been brought from a place at least twelve miles distant. In some rare cases wood was used as a protection to the body, after the fashion of a coffin, made out of a split and hollowed tree trunk, of which the well-known Gristhorpe burial is an example. The bottom of a grave has sometimes been laid with slabs of wood; and in one instance a wooden flooring had been placed upon short posts, driven in at the head and foot of the grave, the sides of which also showed, by the impression on the clay, that

${ }^{1}$ See a paper by the Rev. W. C. Lukis, M.A., F.S.A., on the 'Stone Avenues of Carnac,' in the Transactions of the Geological and Polytechnic Society of the West Riding of Yorkshire, 1869.

${ }_{2}$ The very natural mode of interring in cists of stone, of greater or less size, and of different shapes, has prevailed in almost all parts of the Old World, where suitable stone was to be had; nor is it necessary to give references. The same mode was adopted in the New World. Mr. Charles Rau says that in Illinois the cemeteries are generally situated on high ground, and the graves usually consist of rough limestone slabs, placed in a rectangular form, no rule as to the cardinal points being observed. Jones, Antiquities of the Southern Indians, p. 219. 
it had been lined with wood. The body seems not unfrequently to have been placed upon wood, not extending much beyond the bones, and in one case protected on each side by a thin slab of willow, there being no appearance of wood either above or beneath it; but in other cases wood, apparently planks, had been laid over the body.

What has already been said refers to unburnt bodies, but the same rule holds good with those that are burnt, except that, so far as I have observed, upon the wolds they are not found in connection with any protection of wood ${ }^{1}$; and that they are sometimes placed within an urn ${ }^{2}$, which usually is deposited standing upright, but very frequently is reversed over the bones. When the urn is met with in an upright position it is sometimes covered by a flat stone; and the mouth is now and then found to have been closed with clay, both in cases when the urn is standing on its base and when it is reversed. It is not unlikely that the mouth of the urn was occasionally covered with cloth or hide. If we may judge from the careful way in which the bones have been collected after the burning, it would only be natural to expect that some provision should have been made for protecting them from the surrounding earth, so as to keep them separate from it; though that might. be done by enclosing them in some material or other before they were deposited in the urn. Nor is it impossible that the overhanging rim may have been provided for that purpose, the cloth being drawn down as far as to that part, when a cord or thong was then passed over it and round the urn below the projecting rim. It may, however, be objected to this that if the rim was thus intended to be concealed, it would not have been, as it is almost universally, highly decorated.

In the greater number of cases the body appears to have been burnt apart from the place where the bones were ultimately deposited; but numerous instances occur where the calcined remains have been interred on the site of the funeral pile, which was frequently constructed over a hollow, previously made to contain the bones. In some rare cases the bones were not collected after

${ }^{1}$ Sir R. Colt Hoare found the deposit of burnt bones in four instances placed in what he calls a wooden box. Ancient Wilts, vol. i. pp. 122, 126, 207, 211; and in one case in a hollowed tree trunk, p. 185. The Rev. W. C. Lukis met with a burnt body, enclosed in a hollowed tree trunk, in a barrow at Collingbourne Ducis, Wiltshire. Notes on Barrow Diggings in the Parish of Collingbourne Ducis, p. 12.

${ }^{2}$ Burnt bones are found enclosed in urns much less frequently on the Wolds than in other parts of England. In Wiltshire, Sir R. Colt Hoare met with them in the proportion of one to three; and in Dorsetshire they are still more commonly placed in urns, being in the proportion of three to one. In Cleveland, Mr. Atkinson, out of fifty burials after cremation, found that the bones were deposited in an urn in thirty-two cases. 
the burning, but were left in the position they had occupied before the fire was applied, as in the barrows Nos. lxxix, lxxxvi.

A deposit of burnt bones is sometimes found to comprise the remains of more than one body, which, in some instances, are those of a woman and child, probably a mother and her offspring, but in other cases they are the bones of adults.

It is not an uncommon occurrence to find pins, generally made of bone, but sometimes of wood, with a deposit of burnt bones. In most cases they are calcined, and no doubt represent the fastening of the dress or covering in which the body was enclosed before the burning took place; but in others the pin is found to be untouched by fire, and it is probable, where this is the case, that it had served to fasten a cloth or hide in which the bones were deposited after they were collected from the funeral pile ${ }^{1}$. The remains of such cloth has occasionally been met with ${ }^{2}$. The bones are generally found to be remarkably free from any extraneous substance, even charcoal, which naturally might be looked for, being, if present at all, only in small pieces, and to a very trifling extent. This is found to be the case more especially when the bones are enclosed in an urn, eist, or hollow made in the ground, though sometimes under these circumstances much charcoal has been placed over the deposit, but not amongst the bones. When the bones, however, are widely scattered amongst soil, which is not a common occurrence, then charcoal is not unfrequently freely intermixed. It would seem from this that they must have been collected from the place of burning with more than common care. This pious and reverential custom is described by Homer ${ }^{3}$, when he speaks of the white bones of Hector being gathered up (from amongst the ashes of the funeral pile) by his brethren and compauions.

A deposit of burnt human bones is sometimes found to contain a small number of animal bones mixed up with them. From the fact that they are not present in all cases, and that when they do occur it is only in small numbers, it is probable that they are there accidentally ${ }^{4}$. When the bones of the burnt body were collected

${ }^{1}$ Homer, describing the burial of Hector, says that the bones (or the golden urn in which they were placed, for it is doubtful to which he refers) were wrapped in a suft purple cloth. Hiad, xxiv. 796.

${ }^{2}$ Hoare, Ancient Wilts, vol, i. pp. 113, 114, 169.

3 Iliad, xxiv. 793.

${ }^{4}$ It has been stated that, amongst some deposits of burnt human bones found in Scotland and Ireland, a large number of animal bones have been mixed up. I have not, however, been able to obtain any trustworthy information on the matter. 
from the funeral pile, upon which, from one cause or another, some animal bones might have been placed, these might easily and without intention be gathered up with the rest, and so become a part of the general mass of calcined bones. It is quite possible, however, that these bones may represent animals killed at the funeral and burnt with the body ${ }^{1}$. Cæsar, writing of the custom of an age later than that when the wold barrows were erected, and of another people, kindred if not in blood, at all events in many habits and practices, says, 'Funera sunt, pro cultu Gallorum, magnifica et sumptuosa; omniaque quæ vivis cordi fuisse arbitrantur, in ignem ferunt, etiam animalia ${ }^{2}$.'

Burnt bones have frequently a blue or green tinge, and this has sometimes been thought to indicate the former presence of some article of bronze, which had entirely gone to decay. The colour, however, is not owing to the bones having been in contact with bronze, but on analysis has been found to be due to the presence of phosphate of iron, a salt which can assume various tinges of blue and green. It is further to be noted that this discolouration is by no means confined to the superficial layers of the bones thus affected. The infiltration of stalagmite, sometimes to be observed in bones, cnables us to understand how a salt of iron, carried in solution into the internal structure of a bone, may there, by double decomposition with phosphate of lime, produce the salt in question.

It has already been mentioned that bodies occur at various levels in the barrows, and there can be no doubt that the burial mounds were used over a considerable period for later interments. When this has been done by making excavations in an existing barrow, great disturbance of the bodies already there has frequently taken place. A large number of eases will be found in the following record of barrow openings, where primary and other interments have been cut through, the bones broken, and the vases and other associated articles scattered, by the introduction of later burials. When this has occurred, the bones of the disturbed bodies have sometimes been treated with care, and re-interred with as much

\footnotetext{
1 A very valuable account, as illustrative in many points of what has been met with in British barrows, is contained in the Iliad, xxiii. 166-176. Homer, there writing of what Achilles did at the burning of the body of Patroclus, says that, after placing the fat of many sheep and oxen (whose carcases were heaped round the pyre) about the body of Patroclus, from head to foot, he set vessels ('food vessels'?), with honey and oil, slanting towards the bier. He then threw horses, pet dogs, and captive Trojans, after slaying them, on to the pile, to be burnt with the body of his friend.

${ }^{2}$ Comm. de Bello Gallico, vi. c. 19.
} 
reference to their proper order and position as an imperfect knowledge of the anatomy of the human body admitted, or have been collected together and laid in a heap, the skull in some cases being placed on the top; but at other times they seem to have been recklessly cut through and carelessly thrown back into the ground. If these imperfectly arranged skeletons are those of disturbed bodies, and are not to be accounted for by an explanation of their condition which will be mentioned presently, then they may be supposed to be those of ancestors or relations, which were therefore treated with respect when the barrow was opened for a subsequent burial. Many of the secondary interments must have taken place either at no great interval after the erection of the mound, or, at all events, before any change had taken place in burial customs or in the manufacture of pottery, implements, and ornaments; for such as are associated with the introduced bodies differ in no respect from those which are found to accompany the primary occupant of the barrow. There can be no doubt that the barrows have been extensively used for secondary interments, during which process bodies have been disturbed, and the bones, burnt or unburnt, have been scattered. But some of these cases of apparent disturbance suggest the idea, that a practice, which has been the custom amongst many peoples, may have prevailed in Britain. Some of the North-American tribes, for instance, collect the bones of the dead, after the flesh has decayed, and bury them in ossuaries, where very large collections of them are found. Amongst the Patagonians the habit prevailed of keeping the bones of the body, from which the flesh had been removed, and afterwards, on certain occasions, taking them to the burial-place of the tribe, where they were laid in the grave in order, together with the arms \&c. of the deceased. Even in Brittany, at the present day, some portions of the skeleton are put away in a dead-house in the churchyard, and there kept, each labelled with the name of the dead person, until they are finally buried. Similar practices have been found to exist amongst other peoples, which it is not necessary to particularise. The custom of burying in what may strictly be called ossuaries does not appear to have been in use in Britain, though in some barrows, as for instance in one at Cowlam [No. lvii], the disturbed bodies, which were numerous, presented somewhat of the appearance of such a collection of bones, though on a small scale. In many barrows the bones have been discovered, laid in that rude kind of order, already spoken of, and with a care bestowed upon them 
which it appears difficult to account for even on the supposition, mentioned above, that they are the remains of bodies of relations disturbed by the introduction of subsequent burials. They present exactly the appearance of bones, which might have had the flesh removed, in one way or another, sometime previous to that of their final interment, and then placed in order by persons whose knowledge of their precise juxtaposition was not minute. The absence of parts of the skeleton, in these instances, is also in favour of this view, for we can more readily understand that one or more bones might be lost in the interval between the removal of the flesh and their final burying, than that any should have disappeared during the process of taking up the bones and at once replacing them. Upon the whoie it may be said, that though the theory which regards these as the remains of disturbed skeletons is quite a tenable one, the other explanation possesses greater claims to be considered the true one. At the same time it is probable that in these disturbed bodies we have the evidence of both practices; and, indeed, it is scarcely possible to believe that when secondary interments took place, which the internal appearances of the barrows show to have been a very common occurrence, the displaced bones of the first occupant should in all cases have been treated with that want of reverence which it is evident they frequently met with. The pious care of relations must undoubtedly have sometimes operated to cause the bones to be taken up and re-interred with attention and respect. It is possible that in some of the cases where imperfect or irregularly-arranged skeletons have been met with, and where no signs of disturbance are apparent in the mound, they may represent persons who had died at a distance from the ordinary place of burial, and whose bodies could not at once be taken to that place. It has been the habit of many peoples to retain the bodies of those who died away from the usual cemetery of the tribe, until a suitable occasion happened to transfer them there, and it does not seem unlikely that a similar custom may have prevailed amongst the inhabitants of the wolds.

The dead were buried in the barrows both by inhumation, where the body was interred in the condition in which it was left when - life departed; and after cremation, when it had undergone the process of burning ${ }^{1}$. This applies both to primary and secondary

1 Amongst the Greeks both practices prevailed at the same time. The Romans at first buried the dead without burning them, afterwards they practised cremation, and finally reverted to the first mode; but at no time was the observance in either way universal. 
interments. Nor does the evidence afforded by the barrows show that the one process was earlier than the other ${ }^{1}$. It has been held by many archæologists that burning the body was the more frequent, if not the universal, practice during the bronze period, and, indeed, this seems to be true as regards Denmark, but the facts supplied by the wold barrows by no means corroborate that view. It is perhaps natural, and what might be expected, that, in the rudest states of society, the body, if interred at all, should be simply buried without having been subjected to the action of fire. And this is confirmed by the knowledge we possess of the burial rites of modern savages. But the whole series of the wold barrows belongs to a time when civilisation had made some considerable progress, and when there was nothing to prevent the use of so artificial a process of disposing of the body as cremation implies.

Inhumation was by far the most frequent practice upon the wolds. In some groups of barrows however-and there is nothing. connected with them to show that they are earlier or later than the general mass-cremation was the rule. For instance, at Gardham there were six burials, contained in four barrows, five being of burnt, and one of an unburnt body. At Enthorpe, in the same locality, there were twenty-eight burials in six barrows, of these eighteen were after cremation, and ten by inhumation. These six barrows, however, formed part of a much larger group, though to a certain extent they stood apart, forming, as it were, a smaller group within the larger one. The proportion of burnt to unburnt bodies, taking into account the whole series of which those at Enthorpe formed a part, was about three unburnt to two burnt. As marking the relative general proportion of burnt to unburnt bodies in the barrows I have opened on the wolds, it may suffice to mention that out of 379 burials, only 78 were after cremation, whilst 301 were by inhumation, which gives nearly 21 per cent. for burials of burnt bodies. And to show that in the wold barrows bronze is by no means more commonly found with burnt bodies than with unburnt, out of 14 instances where $I$ have discovered bronze articles associated with an interment, it was only in 2 that the body had

1 The occurrence of burial mounds, containing in one case burnt and in the other unburnt bodies, placed in close proximity and apparently belonging to the same period, has been frequently met with, and in many countries. Mr. Jones opened two mounds on the Georgian coast, in one of which the bodies had been buried unburnt, in the other where they had all been burnt together with many vases and implements. Antiquities of the Southern Indians, p. 466. 
been burnt. The proportion therefore is, that about 4 per cent. of unburnt bodies, and about $2 \frac{1}{2}$ per cent. of burnt bodies, had articles of bronze accompanying them. This question partly resolves itself into another, whether, in the main, the round barrows of the wolds belong to a time before the introduction of bronze. As the subject will be considered more at length in the sequel, it is sufficient to remark here that I see nothing to imply that they are the burial-places of a people unacquainted with bronze, and my own impression is that, as a rule, they date from a time after its introduction.

Burial by inhumation then is so much more common than burial after cremation that, as is shown by the numbers stated above, the latter only amount to rather more than a fourth of the former.

There can be no doubt that both practices prevailed at the same time, for several instances have occurred where burials after the two modes have been so intimately connected as to prove that they were contemporaneous. This is most clearly shown in five cases, where the burnt bones of one body were placed in such immediate contact with the unburnt bones of another, as to demonstrate incontestably that both must have been deposited in the grave together.

Nor is there any circumstance connecting itself with those bodies buried by inhumation and those buried after cremation which implies that they were of persons of varying conditions ${ }^{1}$. This is made quite certain by the evidence which two cist burials in a deep grave at Rudstone affords. The cists contained respectively a burnt and an unburnt body, both of adult men, each having a 'drinking cup' associated with it; the two cists having, as their construction plainly showed, been made at the same time, and with equal care. The only certainly pre-Roman burial, in a large barrow at Uncleby [No. i], was that of a burnt body in a central grave; and on Potter Brompton Wold [ No. xviii] a burnt body was also found in a large central grave, with which a fine axe-hammer of stone was deposited. In each of these cases, it is probable that the person who had undergone cremation had been of great social importance. It seems scarcely necessary to remark that many

${ }^{1}$ Amongst some semi-savage people, who practise both modes of burial at the present day, a reason is given for the different observance. 'The Curumbalen, a slave caste, who worship the hill god (Malai-déva) and the spirits of deceased ancestors, burn their dead, if good men, and bury them if bad; the latter become demons, requiring to be conciliated by sacrifice.' Sir Walter Elliot, Journal of Ethnological Society, New Series, vol. i. p. 115, quoting Buchanan's Journal, vol, ii. p. 497. 
unburnt bodies were those of persons of high rank among their people. Nor was it a question of sex; for, apart from the evidence of the bones themselves, burnt bodies have occurred which had articles buried with them, such as arrow-points and axehammers, indicating a male, whilst others have had such implements or ornaments with them as have usually been found accompanying the unburnt bodies of females; and unburnt bodies of men and women are abundant. Numerous interments of children by inhumation have been met with, but they also have very often undergone the process of burning.

It is probable, indeed almost certain, that some rule guided the practice, for it can scarcely have been a matter of accident, but we are not at present in possession of evidence to show what the rule was.

In some localities on the wolds it has been seen that cremation prevailed, though inhumation was the general custom throughout the whole district. In other parts of Yorkshire, however, cremation was all but universal; as for instance in Cleveland, where Mr. Atkinson's very extensive investigations did not produce a single instance of an unburnt body; and near Castle Howard, where a large series of barrows contained nothing but burnt bodies ${ }^{1}$.

It has been suggested, as a mode of accounting for the finding of burnt bodies associated with unburnt, that, in some cases, the dead were burnt and the bones preserved without being buried, until the proper time for performing that rite arrived ${ }^{2}$. This time has been supposed to be that of the death of the head of the family, when it became necessary to erect the sepulchral mound over him. The suggestion, however, does not appear to me a probable one, and the occurrence of such large numbers of burnt bodies in certain districts seems fatal to it, even without taking into consideration the

1 The proportion of burnt to unburnt bodies differs very considerably in various districts. The extensive series of interments, the examination of which is recorded in the works of Bateman, Hoare, Warne, and Borlase, enables us to obtain an approximately true estimate of what has been the mode of burial in the several localities to which their accounts refer. In Derbyshire the proportion is slightly in favour of unburnt bodies; in Wiltshire burnt bodies are as three to one unburnt; in Dorsetshire as four to one; and in Cornwall cremation appears to have been by far the most common usage. In the counties of Denbigh, Merioneth, and Caernarvon, cremation seems to have been almost universal. In Northumberland I have disinterred seventy-one bodies, and of these forty-five were after cremation, and twenty-six by inhumation; the proportion of burnt to unburnt bodies being, therefore, almost two to one.

${ }_{2}$ The Chinese preserve the body without burying it, until a propitious time arrives. This is discovered by the priests, who perform from time to time certain incantations (for which they are paid), with the view of ascertaining when the happy moment will oceur. As may be imagined, the burial of a rich man is often long deferred. 
fact that a single burnt body is frequently the sole occupant of a barrow, and that the principal interment is sometimes that of a child.

The way in which the unburnt body was placed in the burial mound has now to be considered. It is almost always found to have been laid upon the side, in a contracted position [fig. 1],

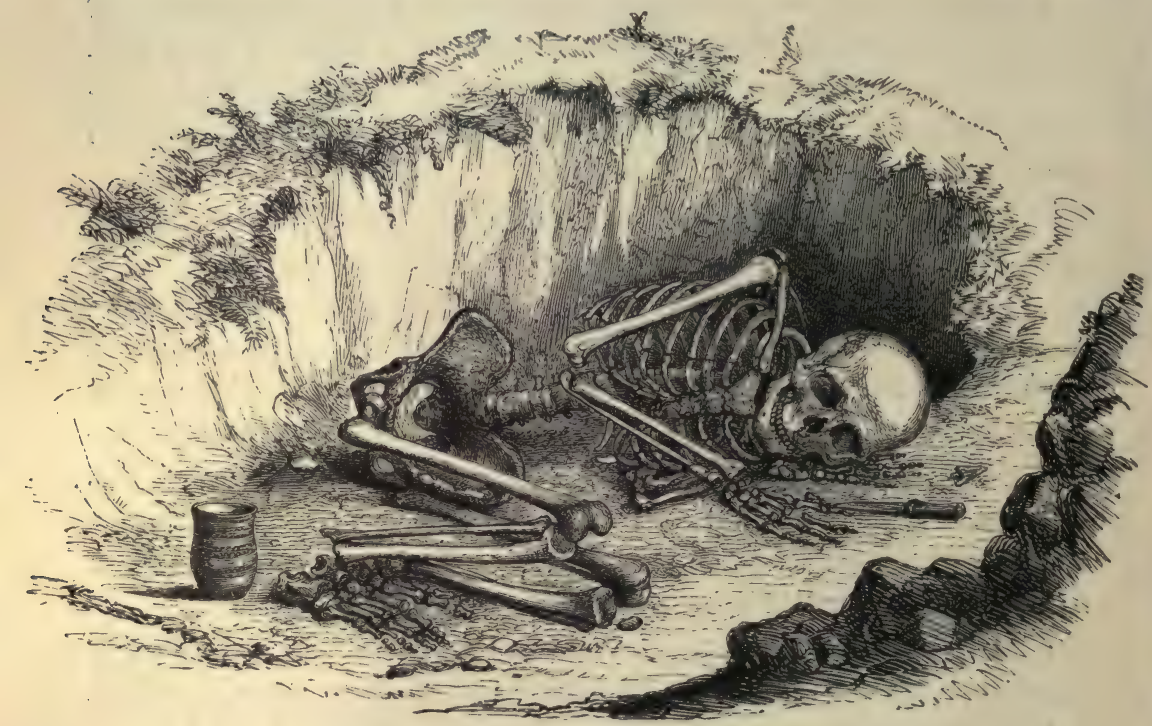

Fig. 1.

that is, with the knees drawn up towards the head, which is generally more or less bent forward; the back, however, is sometimes quite straight. So invariable is this rule, that out of 301 burials of unburnt bodies, which $I$ have examined in the barrows of the wolds, I have only met with four instances where the body had been laid at full length ${ }^{1}$.

This remarkable position of the body, which has nevertheless prevailed in many countries and at very different times, was certainly not caused by the desire to compress the body within the limits of a grave of small dimensions. In those barrows where a grave of 9 feet or 10 feet in diameter has occurred, the single body, which is all that in many instances has been buried there, is

\footnotetext{
${ }^{1} \mathrm{Mr}$. Bateman (referring to the Derbyshire barrows) says, and his experience was very large, 'nor have we seen any skeleton, accompanied by relics of the earlier ages (he is speaking of British burials), fully extended.' Ten Years' Diggings, p. 27. In Dorsetshire, on the contrary, the extended position seems to be the prevalent one. Warne, Celtic Tumuli of Dorset, passim.
} 
found to be contracted, and placed at one side of the grave, thus occupying but a very small portion of its area. Where the body has been simply laid upon the ground, and when it might have been extended at full length without any difficulty, the same bowed form is preserved. In the Gristhorpe barrow, where the man had been interred in the split and hollowed trunk of an oak-tree, and when, from the narrowness of the coffin, the usual contracted position could not be fully adopted, the knees, so far as they would admit of it, had been drawn up towards the chin. Even in the process of burning the body, the contracted position seems to have been retained; this was clearly shown in a barrow at Enthorpe [No. lxxxvi], as well as in another instance [No. lxxix]. The body had in these cases been burnt on the spot, and the calcined remains had not afterwards been collected and laid together in the ordinary manner, but left in the condition in which they remained after the burning had ceased. The bones, imperfectly consumed, and which were all quite distinct and lying in their proper order, showed that the corpse had been prepared for the funeral fire with the knees brought up towards the head, which was itself bent forward. In the barrow at Enthorpe, it appeared, from the remains of the charcoal, that the body had been burnt by placing the wood upon it, rather than by laying it upon the wood.

The position, therefore, was not due to the requirements of space, but originated in some settled principle, the meaning and purpose of which it may be said we have not the means of fully understanding, though I think a satisfactory explanation can be given. Nor does the question receive elucidation from any knowledge we possess of the cause of its adoption by modern savages, for though it is a common practice amongst many of them, no reason, except custom, is given for its use. This manner of disposing of the body has been so common and so widely diffused that it cannot be accidental. It scarcely seems to suggest itself as a natural position, and it must certainly have required in many cases very considerable force to bring the limbs into the required form. Some writers have thought that, in placing the body in the ground after this fashion, a reference was made to the way in which man lay in the womb, before he came into the world, and that as his entrance was, so his departure from this, or rather perhaps his entrance into another, world should be ${ }^{1}$. This explanation, I think, can only

1 This view is advocated by M. Fréd. Troyon in a letter to M. Alex. Bertrand, Sur l'attitude repliée dans les sépultures antiques, in the Revue Archéologique, Nouvelle 
claim a doubtful acceptance, for it is one which supposes a mental process beyond the power of the persons who originated the custom, and also would show a knowledge of the human frame such as these people, though they might be considerably advanced beyond the savage state, were not likely to possess. A more simple and, at the same time, a more probable explanation of this custom has however been offered, and which cannot be considered an unnatural or unlikely one ${ }^{1}$. Where the sleeping-place was not well protected against the cold, and when covering for the body at night was scanty and limited, the contracted position was that which was best adapted to afford warmth and comfort. In fact it has been observed that most savages sleep after that fashion. What was more natural then than that the body should be interred in the same posture in which the person was accustomed to rest in sleep, and in which, in many eases, he probably may have died ${ }^{2}$ ?

Bodies are said to have been found in Britain buried in a sitting position ${ }^{3}$. This is probably a mistaken view of the contracted body taken by persons who, seeing the head lying close to the knees, have come to the conclusion that it had fallen down upon the knees when the ligaments decayed. There seems, however, reason to suppose that they were sometimes placed in a sitting position in the chambered barrows of Scandinavia, where, in some cases, they appear to have been arranged in stone cells or stalls running round the chamber ${ }^{4}$.

A very remarkable discovery by Mr. Lukis shows that, in the Channel Islands, bodies were in some cases interred in a kneeling posture. He found in a cist, within the dolmen called Du Tus in Guernsey, tro skeletons amongst sand, with the

Série, ix. 288. He mentions, p. 294, 'la momie d'un oiseau provenant aussi de ces tombeaux Péruviens; c'était un perroquet, les pattes repliées sur le thorax et la tête ramenée vers l'aile gauche. Cette position étant evidemment celle du petit oiseau dans la coquille.'

1 Evans, Ancient Stone Implements, p. 135.

${ }^{2}$ I have learnt, on good authority, that the greater number of persons die in a more or less contracted position, and with the hands towards the chest or head.

${ }^{3} \mathrm{Mr}$. Bateman says, 'We found the primary interment ... . in a small oval excavation in the rock ... about 3 feet in depth, and not exceeding the same in its greatest diameter, consequently the body had been placed upright in a sitting or crouching posture, as was abundantly evident from the order in which the bones were found.' Ten Years' Diggings, p. 23. It seems from his using the word consequently in the way he does, that the principal reason for this supposition of Mr. Bateman was the small size of the grave, the order of the bones filling up the picture he had already formed. But the contracted body of this, not a very large, man might have been placed in the grave in question in the ordinary form without any difficulty whatever.

4 Nilsson, Stone Age, ed. Lubbock, p. 128. 
bones so arranged that the correctness of the description cannot be disputed ${ }^{1}$.

The position in which the hands have been placed varies considerably. They are found up to, and in front of, the face-and this is perhaps the most frequent position - at the neck, under the head, crossed over the chest or stomach, at the knees and hips, and extended down the side, or out from the body; in fact, arranged in almost every way in which it is possible to place the arms of a body laid upon the side, and just as they would naturally be adjusted during sleep.

There is no rule as regards the direction of the body, the head being laid with the face opposite to any point of the compass ${ }^{2}$. In the whole series of the wold barrows, 234 bodies were in a sufficient state of preservation to admit of the position of the head in this respect being ascertained, together with the side on which the body had been laid. Without having regard to the minute division of the compass points, they may be thus classed ${ }^{3}:-$

DIRECTION OF HEAD.

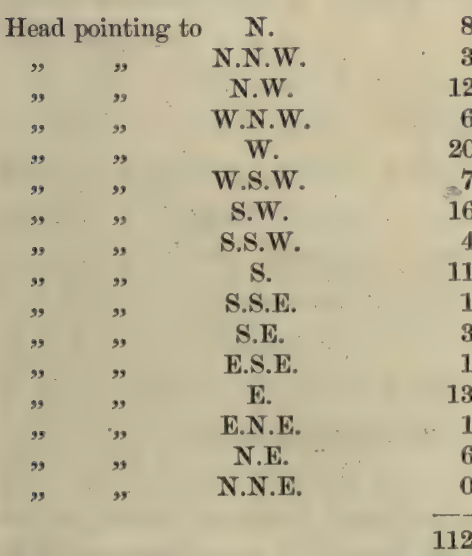

\section{ON THE RIGHT SIDE. ON THE LEFT SIDE.}

TOTAL

\begin{tabular}{rr}
8 & 11 \\
3 & 3 \\
12 & 6 \\
6 & 1 \\
20 & 5 \\
7 & 1 \\
16 & 3 \\
4 & 5 \\
11 & 8 \\
1 & 5 \\
3 & 18 \\
1 & 9 \\
13 & 24 \\
1 & 4 \\
6 & 15 \\
0 & 4 \\
\hline 12 & 122
\end{tabular}

19
6
18
7
25
8
19
9
19
6
21
10
37
5
21
4
-234

It will be seen from this table that when the head has pointed to the West or the adjoining parts to North and South of it, by far the larger number of bodies were laid on the right side;

${ }^{1}$ See a paper by Mr. Lukis in the Journal of the British Archæological Association, vol. i, where at p. 27 is an engraving of the skeletons in the position in which they were discovered.

${ }_{2}$ The direction of the head is given with reference to the line of the vertehral column, the head being regarded as the final vertebra.

${ }^{3}$ Sir R. Colt Hoare (though his observations in this respect are not very carefully recorded) appears to have found the head generally directed towards the North. 
whereas when the head pointed to the East and its adjacent parts, the larger number of bodies were laid on the left side. From this fact I infer that the habit was generally to place the body in the grave facing the sun. When the head was to North or South, the face would look to East or West according to the side on which the body was laid, the position being regulated by the time of day at which the burial took place; but when the head pointed to East or West, it must, to face the sun, have been placed, in the one case, on the left, in the other, on the right side; and so we find, as a rule, that the bodies have this relative position of side and head. It is true that such does not appear to have held good in every case; but the proportion is too large, and the facts fit in too accurately with the supposed custom, to admit of the coincidence being merely an accidental one. It is quite possible that some of the instances, where the rule seems to have been departed from, may be more apparent than real; and, moreover, it is not difficult to adduce cases where it would be impossible to place a body facing the sun; for instance, when two persons nearly connected were buried together, and where, as will be seen in the account of some of the barrows, they had been laid in the grave in front of and facing each other, one must have looked away from the sun, in order that such a position might be preserved.

The bodies, including men, women, and children, have been placed indifferently on either side; women, however, are more frequently laid on the right, whilst men and children are most commonly laid on the left side ${ }^{1}$. The whole number of burials by inhumation that I have examined in the wold barrows is 301 ; of these, 124 had been laid on the left, 112 on the right side, and 4 extended and on the back; whilst the position of 61 , owing to the decayed state of the bones, could not be determined. When these burials are further classed into sex and age (and no bodies are here taken into account except those where the sex may fairly be determined), it results that 40 men had been laid on the right side, and 52 on the left; 26 women on the right, and 19 on the left; and 12 children on the right, and 21 on the left.

Though it is most commonly found that a grave contains but

${ }^{1} \mathrm{Mr}$. Bateman appears to have found in the Derbyshire barrows that the bodies of men were generally placed on the left side; he says that he met with 'a man ... who lay with the knees drawn up, contrary to the usual custom on his right side.' Ten Years' Diggings, p. 58. Indeed in Derbyshire the body was discovered by Mr. Bateman to have been laid on the left side four times as frequently as on the right. 
a single body, it is by no means an infrequent occurrence to find two or more bodies which have evidently been all interred together, and at the same time. The inference which may be drawn from this is discussed in more than one place in the detailed account of the examination of the barrows, and need not be specially noticed here.

Barrows are sometimes met with in which, upon examination, no burial appears to have taken place, since no remains of the body are to be discovered. In the greater number of these instances there can be little doubt that, in consequence of the imperfect exploration of the mound, the place of burial has been missed, and in other cases that a small deposit of burnt bones or the almost entirely decayed bones of an unburnt body have been overlooked. Large numbers of barrows have been opened by merely cutting a narrow trench through the centre ${ }^{1}$. It will readily be understood how, in a process like this, the central burial might not be discovered; for in throwing up a mound of considerable size, that part, which was at one time the centre, might eventually be at some distance from the central point of the completed barrow. Graves have also been very frequently overlooked, the explorers not being aware that it was the habit to bury beneath the natural surface. But there are other cases, and such have occurred to myself, when the most careful examination has failed to discover any trace of an interment. These empty barrows have been spoken of as cenotaphs, monuments raised to commemorate but not to contain the dead. Mr. Kemble, holding the view that barrows were prepared beforehand, and that, from time to time, bodies were inserted in the mounds so set apart, believed that the barrows where no burials are found had never been used for interment ${ }^{2}$. Neither of these views appears to be a tenable one, and both seem modes of accounting for the absence of burials much too artificial for such a state of society as may be supposed to have existed during the ages when barrow burial was in use in Britain. With every wish to defer to the great practical knowledge of Mr. Kemble, as well as to

${ }^{1}$ It must be understood that I am not now referring to my own barrow diggings. My practice has always been to drive a trench, the width of the barrow as it was originally constituted and before it was enlarged by being ploughed down, from south to north, through and beyond the centre. I have not always thought it necessary to remove the whole of the north and west sides, as they are generally found to be destitute of secondary interments; in very many cases, however, I have turned over the whole mound.

${ }^{2}$ Horæ Ferales, p. 99, in an article upon Burial and Cremation, reprinted from the Archæological Journal, vol. xii. 
the skill with which, as a rule, his mind moulded the facts it had accumulated into a consistent and reasonable theory, I cannot but regard this opinion as being both unnatural and out of harmony with the general mass of evidence which the burial mounds afford. Nor do I see any difficulty in accounting for the absence of bones or other indications of an interment where a careful examination has shown that such evidence has not been overlooked through a careless or imperfect exploration. In the greater number of instances, however, as has already been stated, the barrows are found empty, not because they are so in reality, but because they have not been searched exhaustively ${ }^{1}$. The absence of any signs of a burial, where a barrow has been minutely and fully examined, is due, in my opinion, to the entire decay of the skeleton, in cases where no weapon, implement, ornament, or vase has accompanied the body. I have myself opened several cists where there was not the slightest trace of bone to be seen, but where the occurrence of flint, and jet, and 'food vessel' showed plainly that a body had once been placed therein ; in other cases there was absolutely nothing within the cist. In burial mounds where no cists had been constructed, and where the body had been laid in the ground without anything to mark the spot, the admission of air or some other destructive agency might easily lead to the total disappearance of the bones; and if nothing of a more lasting character had been associated with the body, to testify to its having once been there, we should then have an empty barrow-the so-called cenotaph ${ }^{2}$.

There is an incident intimately connected with burials by inhumation, which is rarely, if ever, wanting; the occurrence of charcoal, in greater or less quantities, in contact with the body ${ }^{3}$.

1 To give an instance in illustration: a barrow at Everley, Wiltshire, opened by Sir R. Colt Hoare, and by him styled a cenotaph, because he found no signs of an interment therein, has subsequently, on a more careful examination by the Rev. W. C. Lukis, F.S.A., proved to have contained a deposit of burnt bones. The deposit was discovered at the centre, in association with a flint arrow-point and an implement of deer's-horn, the bones being scattered amongst the disturbed material of the barrow, having no doubt been overlooked by the workmen in the absence of their employer.

${ }^{2}$ In a paper on 'Buried Cruciform Platforms in Yorkshire,' printed in the Yorkshire Archæological Journal, vol. ii. p. 69, the late Mr. Charles Monkman, of Malton, has suggested that these empty barrows may be botontini, erected by the agrimensores for the purposes of land division, \&c. I think it more than probable that the three mounds he cites, and which contained peculiar cruciform structures, were such landmarks. In the absence, however, of anything distinctly Roman, and the presence, moreover, of much that is evidently pre-Roman, I should have great hesitation in attributing, as a rule, these now vacant barrows to the operations of the agrimensores.

${ }^{3}$ The Abbé Cochet appears to have met with the same feature in the Frankish cemetery at Parfondeval, where 'deux ou trois squelettes paraissaient avoir été déposés 
This substance, which I have found to exist in every instance since my attention was directed to the fact, not only in Yorkshire, but in Northumberland and other places, I have little doubt would be discovered connected with every interment of an unburnt body if it was looked for. The frequency of its occurrence and the close contact between it and the body make it very improbable that its presence is accidental. It is true that charcoal is often met with scattered throughout the greater part of a sepulchral mound, when it may be supposed to represent the remains of fires on the surface of the ground, and gathered up with the material of the barrow, or to be the ashes of the fire at which the feast was cooked if such took place, and indeed it is probable that in many cases it does represent such remains. But another explanation of its occurrence may be given, and one which makes it a part of the same burning as that originating the charcoal found in the grave. It has been shown that cremation, though not the most frequent mode of burial upon the wolds, prevailed there to a considerable extent, being in some parts of the district the more common practice. In other localities in Yorkshire, and the same may be said of Britain in general, it is by far the most usual custom. The application of fire to the body was therefore one of the rites which was commonly practised in connection with burial. The extent of the burning varied much, as might be expected, and as is found to be the case in India at the present day. Sometimes the bones were reduced almost to powder, at other times they are so little consumed that each particular bone can be recognised, whilst in some cases only a part of them has been acted upon by the fire, other portions being in a perfectly uncalcined state ${ }^{1}$. It appears

dans une couche de braise et même sur des cendres.' La Normandie Souterraine, ed. 1855 , p. 308.

Charcoal has been frequently found in Christian graves, even of a comparatively late date. Durandus explains its occurrence thus: 'Carbones in testimonium, quod terra illa ad communes usus amplius redigi non potest, plus enim durat carbo sub terra quam aliud.' Rationale Divin. Offic. lib. vii. cap. 35. sect. 38. The same explanation is given by Beleth in his Explicatio Divin. Offic. cap. 161.

${ }^{1}$ Cases have been met with in more than one country in Europe where parts of the body only have been burnt, the remainder having never, apparently, been subjected to the action of fire. M. Ph. Lalande says that he found, in a tumulus, Commune de Saint-Cernin de l'Arche [Corrèze], an unburnt body, associated with bronze armlets (probably of the early iron age), where the head had been burnt, the bones of which had been enclosed in an urn, placed where the head should have been. Matériaux pour l'Hist. Prim. de l'Homme, Sec. Sér., vol. ii. p. 407. In the cemetery at Hallstatt, of the time of transition from bronze to iron, numerous instances were discovered where parts of the body were burnt, whilst others were left unburnt; nor does any rule seem to apply there; sometimes the head is burnt, at other times the body had passed 
then to have been considered sufficient that fire should be applied to the body, without reducing it completely to ashes; and if so, it is quite possible to understand how the application might in some cases be so trifling as to leave upon the bones no indications of fire having been in contact with the body ${ }^{1}$. This appears to me to afford a clue to the explanation of the occurrence of charcoal in connection with the unburnt body. It may be the remains of fire through which the corpse was passed where burning the dead had become, to some extent, a merely representative rite ${ }^{2}$. If this suggestion is the true solution of the reason why charcoal accompanies the body, then the practice of cremation was universal amongst these people, for every corpse was either burnt actually, or was subjected so far to the influence of fire that the obligation of burning was supposed to be fulfilled. The substitution of aspersion for immersion in the rite of baptism may be regarded as a somewhat analogous instance, where a partial application has taken the place of a complete one.

The whole question of fire, the purifier, in its connection with funeral rites, is of the deepest interest; and there is a large amount of evidence bearing upon it, which has been collected from many different countries and belonging to ages widely apart, but to con-

through the fire, and in other cases the head with some portions of the body, as the hands and feet, are calcined, the remainder of the skeleton being left unburnt. Von Sacken, Grabfeld von Hallstatt, pl. iv, p. 13. The same feature has been observed in graves in 'Mahren, Rheinhessen, Thüringen und Luxemburg,' where generally it was the skull that was preserved intact. Essay by Professor Unger in Mittheilungen aus dem Göttinger Anthropologischen Vereine, vol. i. p. 32, 1874.

1 'At Elze, near Hildesheim, a barrow was removed. Upon its basis there were found six holes or kists, as they are sometimes called. Five of these were nearly filled with ashes of wood, and over each a skeleton lay at full length upon its back.' Horæ Ferales, p. 98. Mr. Kemble thinks that the intention was to apply fire surreptitiously, and that the persons may have been half-converted Christians, or pagans living under Christian rule. The explanation does not, however, appear to be a probable one.

2 This idea had suggested itself to Mr. Kemble. He says, Horæ Ferales, p. 101 : ' In a vast number of burials, where interment is the rule, there are signs of cremation ... the body was not reduced to ashes, but it was singed... . I believe that we may thus best account for the few remains of charcoal (sometimes exceedingly minute) which are often found in tumuli where skeletons are deposited entire. A little fire was probably considered sufficient to symbolise the ancient rite.'

This partial burning appears to have been practised at a time possibly antecedent to that of the wold barrows, or of those interments referred to by Mr. Kemble, though the time of the burials at Solutré is very doubtful. MM. de Ferry and A. Arcelin, in a paper, 'L'âge du renne en Mâconnais,' printed in the Norwich volume of the International Congress of Prehistoric Archæology, mention, p. 342, that at Solutré, ' Qu'un grand nombre des os des squelettes portent des traces de brûlure. Ce fait vaut une étiquette, et prouve d'une façon irréfutable que les corps ont été déposés sur les foyers mal éteints, ou au moins encore chauds, avant leur enfouissement par conséquent.' 
sider it in detail is quite beyond the limits of this Introduction, and I must here be satisfied with simply alluding to it ${ }^{1}$.

Owing to the perishable nature of the material, it is difficult to come to any certain conclusion as to whether the corpse was interred in the ordinary dress of the deceased person, in something like a shroud, or without any covering. Upon the whole, it seems most probable that the body was laid in the grave clothed. Several facts bearing upon the question have been discovered. The impression of various fabries upon the oxidised surface of associated implements of bronze has afforded some information as to the nature of the clothing ${ }^{2}$. But the occurrence of bronze is so rare, and even when found is so often in the shape of drills, awls, and other articles too small to afford a surface sufficient to exhibit any impression, that we possess but scanty evidence in this respect from its presence in the grave. The finding of articles used in fastening the dress affords, however, more satisfactory proof. At Butterwick [No. xxxix], six buttons of jet and stone were found in their proper position, supposing that they fastened a dress, in front of the chest. In barrows on Ganton Wold [No. xxvii] and on Flixton Wold [No. lxxi], a button, in one case of jet, in the other of bone, was lying in front of the neck of the skeleton. In these several instances it would appear that the body had been buried in its everyday clothing. The discovery of bone pins, which, however, is uncommon ${ }^{3}$, is not a certain indication that the corpse had been dressed, for they might have equally been used to fasten something

${ }^{1}$ In illustration of the occurrence of fire in connection with burials, a few notes may be given. In some of the graves at Oberflacht, in Suabia, candlesticks were found. See Graves of the Alemanni, by W. M. Wylie, Esq., Archæol. xxxvi. 129. The well-known and common practice of placing a lamp in Roman sepulchres may also be referred to this use of fire. In a barrow at Mammen, near Viborg (c. A.D. 900), a lighted wax-candle had been deposited with the body. La Sépulture de Mammen, par J. J. A. Worsaae, Memoires de la Soc. Royale des Ant. du Nord. A Report of the Church Missionary Society says of the Arriyans or Malai-arasar, a primitive community in the mountains of Travancore, "They bury in Cromlechs, like those of Coimbratore... in this (the cromlech) is included a metal image or an oblong stone, in which the spirit of the deceased is supposed to dwell. It is deposited with offerings of milk, of ghee, \&c., a torch is lighted and then extinguished, and the top-stone put on, which is thenceforward undisturbed.' Journal of Ethnological Society, N. S., i. 109.

${ }^{2} \mathrm{Mr}$. Bateman mentions the finding of the body of ' $\mathrm{a} \operatorname{man} \ldots$ who had been interred enveloped in a skin of dark red colour, the hairy surface of which had left many traces both upon the surrounding earth, and upon the patina coating a bronze axe-shaped celt and dagger; deposited with the skeleton.' 'Ten Years' Diggings, p. 34.

${ }^{3}$ I have found twelve unburnt bodies accompanied each by a pin, and amongst burnt bones they have occurred in four cases. 
of the nature of a shroud. The association of weapons, implements, and ornaments, in cases where they occur, may be fairly considered to presuppose the presence of garments. The knowledge we possess upon the subject, from the evidence afforded by the wold barrows, may be further augmented by an account of some of the discoveries which have been made in other districts in Britain, as well as in countries beyond its limits. Remains of woollen and leathern ${ }^{1}$ garments have been found in eists and graves; and buttons and other fastenings have remained undecayed in many cases where the dress to which they were attached has perished. In a barrow at Scale House, in Craven, numerous fragments of

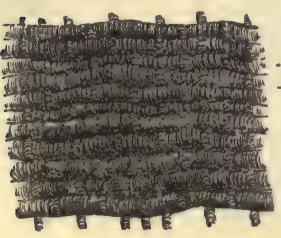

Fig. 2. $\frac{1}{1}$. woollen fabric [fig. 2], the remains, no doubt, of the dress in which the body had been interred, were met with in a hollowed oak-tree trunk. The presence of charred cloth amongst burnt bones, with other articles, such as a kind of fibula of bone, connected with the dress, shows that the body was in some cases, if not always, placed on the funeral pile in the garments worn during life. The evidence, however, is much stronger which is afforded by the contents of some tree-coffins of the bronze age found in Denmark. In one instance there the whole dress was found complete, and has been preserved, and it shows, in the long catalogue of eap, cloak, shirt, leggings, and probably boots, that the wardrobe of these ancient people was by no means slenderly provided. As to the make and shape of the dress which was worn by the occupiers of the wolds, the barrows give us no information; the only facts that we learn from the burials are, that these people, as might be expected, notwithstanding the popular notion about our naked and painted predecessors, wore clothes, and that sometimes, if not always, they were buried in them.

Fastenings for the dress have already been alluded to. They include buttons of jet, stone, and bone, in some cases highly decorated [figs. 3,4$]^{2}$; a peculiarly formed ring, the application of

${ }^{1}$ Where remains of leather have been found it is difficult in most cases, on account of the imperfect state of the material, to say whether the body had been clothed in a dress, or merely enclosed in a hide by way of shroud. At Stowborough, Dorsetshire, where a body was discovered in 1767, in a tree-coffin, it appeared to have been wrapped in skins sewed together and then passed several times round the body. Hutchins's Dorset, vol. i. p. 25.

${ }^{2}$ A small button-shaped article of jet has not unfrequently been found associated with necklaces made of beads of various shapes, and has been usually considered to 
which, as a mode of fastening the dress, is difficult to understand; these also usually are prettily ornamented [fig. 5 ]; a jet article, probably to brace the belt [fig. 6]; a kind of clasp or fibula of bone [fig. 7 ] ' ; and pins of bone or of boar's-tusk [figs. 8, 9].

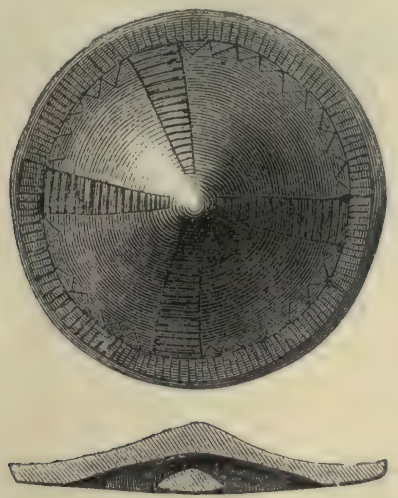

Fig. 3. $\frac{1}{1}$,

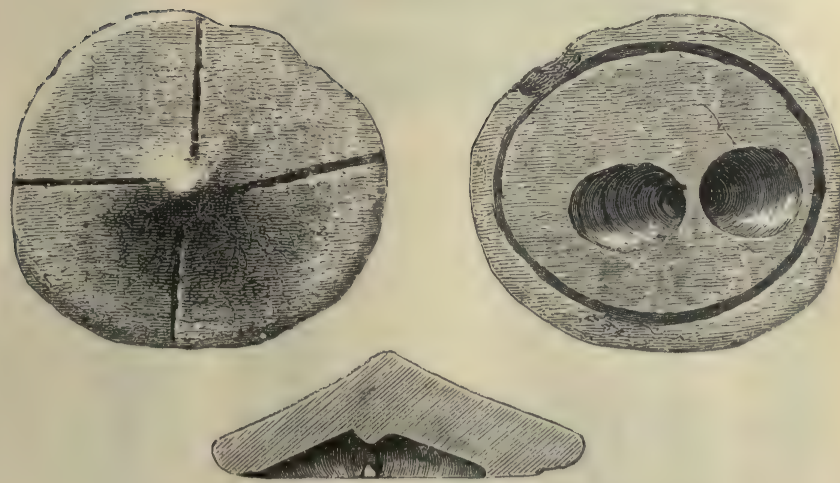

Fig. 4. $\frac{1}{1}$.

The nature of the materials of which weapons and implements were made has enabled us to obtain a considerable amount of information with respect to them. These various articles are met

have formed a portion of the necklace. Though these are precisely like buttons, and as large as some which have certainly answered that purpose, yet on account of the number found together, and of their having been mixed up with beads, it is probable that they were decorative, and not used for fastening the dress. See Bateman, Vestiges, pp. 24, 47; also Evans, Stone Impl. p. 409.

1 A gold article, which appears to correspond with these bone fastenings, was found by Sir R. Colt Hoare in Bush Barrow. Ancient Wilts, vol. i. p. 204, pl. xxvii. fig. 1. 
with, associated with the bodies, both burnt and unburnt, as well as placed, without reference to any particular interment, within and at different parts of the mound. They are numerous,
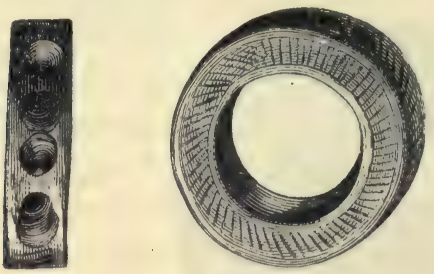

Fig. 5. ' $\frac{1}{1}$.

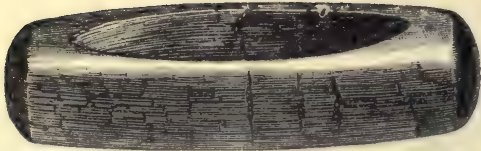

Fig. 6. $\frac{2}{3}$.
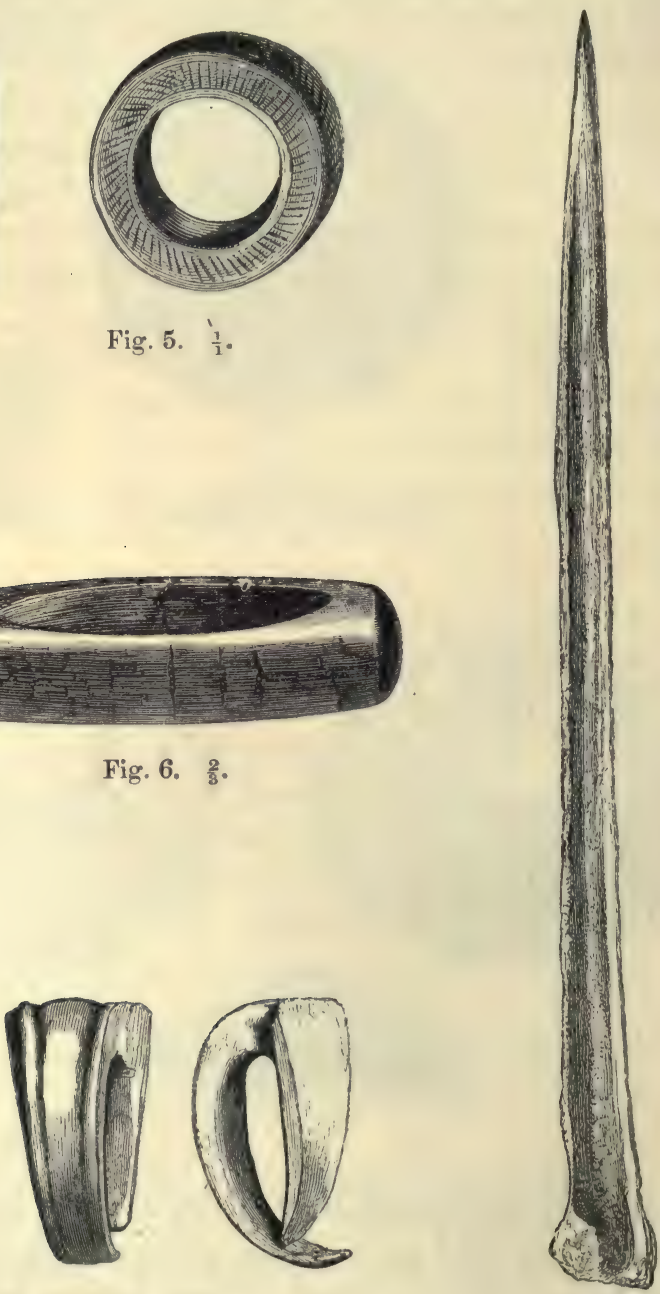

Fig. 7. $\frac{1}{2}$.

Fig. 8. $\frac{1}{1}$.

and it is difficult to say of some of them whether they should be classed in the category of weapons or of implements.

They may be divided into articles of stone, including flint; of bone or deer's-horn; and of bronze. The list of those made of other stone than flint comprises hatchets [fig. 10]; adzes [fig. 11]; 
chisels ; perforated axe-hammers [fig. 12]; grain-rubbers [fig. 13]; whetstones [fig. 14]; and hammer-stones [figs. 15, 16]. Those of flint include hatchets; scrapers, round [fig. 17], and long: [fig. 18];
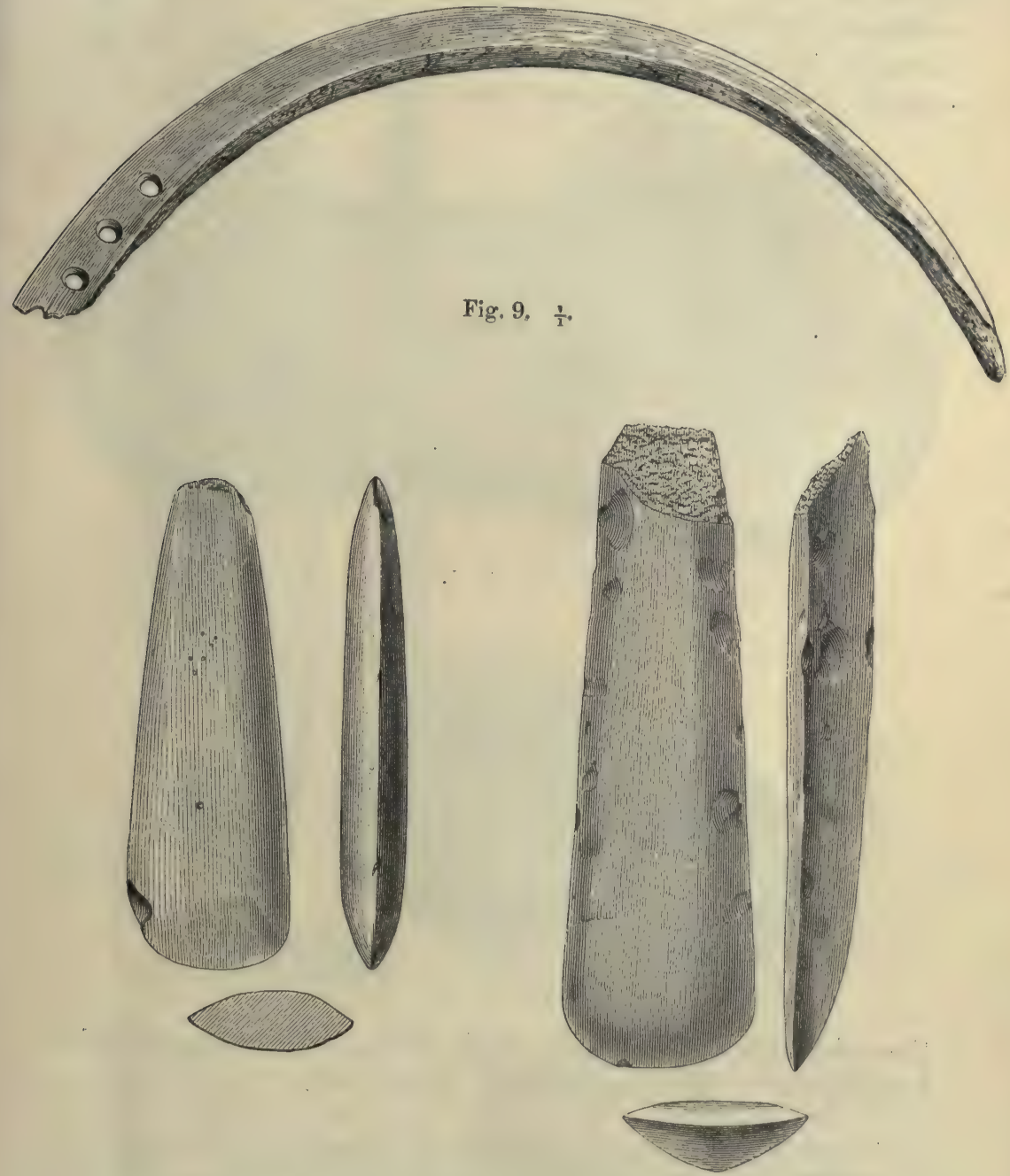

Fig. 10. $\frac{1}{2}$,

Fig. 11. $\frac{1}{2}$.

knife-daggers [fig. 19]; knives [figs. 20, 21]; saws [fig. 22]; drills [fig. 23]; fabricators or flaking tools [fig. 24] ; sling-stones (commonly so called); hammer-stones [fig. 25]; polishers [fig. 26]; arrowpoints, leaf-shaped [fig. 27], triangular [fig. 28], and barbed [fig. 29]; 
heads of darts or javelins [fig. 30]; ' flint and steel' [fig. 31]; and numerous enigmatical articles, the use of which it is not easy to make out. What may be called an implement of stone, a wrist guard [fig. 32], to protect the arm against the recoil of the bowstring, has been found so near to the wolds that it may be included amongst the articles met with in the wold barrows. It was discovered in a cist at Kelleythorpe, near Driffield, and was placed on

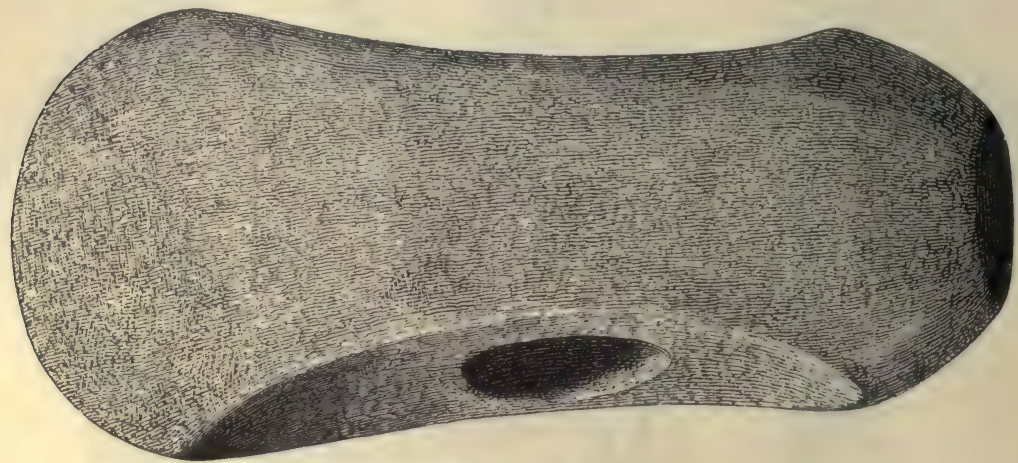

Fig. 12. $\quad \frac{2}{1}$.

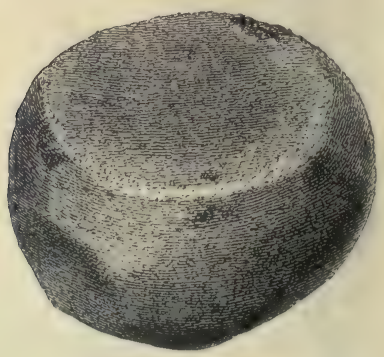

Fig. 13. $\frac{1}{2}$.

the wrist of a skeleton, with which a bronze knife-dagger, amber buttons, and a 'drinking cup' were associated '.

1 Archæologia, vol. xxxiv. p. 254. Wrist-guards have occurred in connection with an interment of an unburnt body in several instances. In Wiltshire, on Roundway Down, near Deyizes, Crania Brit. pl. 42; and near Sutton, Hoare, Ancient Wilts, vol. i. p. 103. In Hertfordshire, near Tring, Archæologia, vol. viii. p. 429, pl. xxx. In Suffolk, near Brandon-this guard is now in the Christy Collection. In Seotland, they have been met with in the Isle of Skye, Wilson, Prehistoric Annals of Scotland, vol. i. p. 223; near Cruden, Aberdeenshire, l.c., vol. i. p. 76; and near Evantown, Rossshire, Proc. Soc. Ant. of Scotland, vol. vi. p. 233. They have also been found casually in other places in Great Britain and Ireland. They have been discovered in Denmark, associated with burials. See also Evans, Stone Impl. p. 380. 
Bone and horn implements are rarely found, owing no doubt, in some measure, to their being liable to decay. I have only met. with them in the shape of a hammer, made from the lower part of a red-deer's antler [fig. 33]; what may have been a pick for ex-

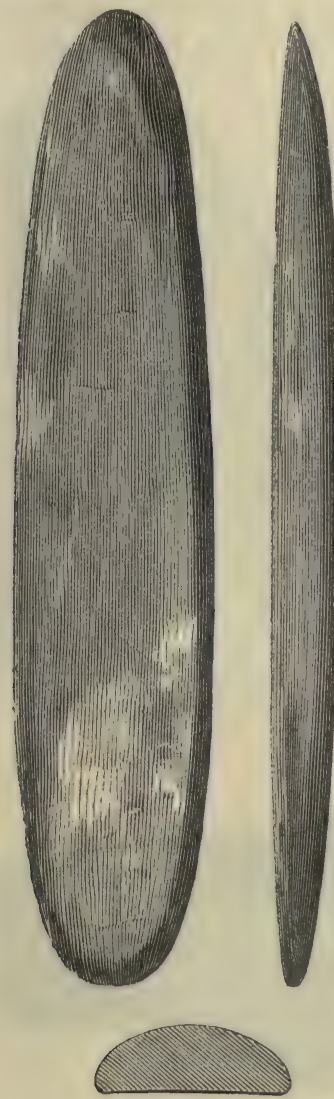

Fig. 14. $\frac{1}{1}$.

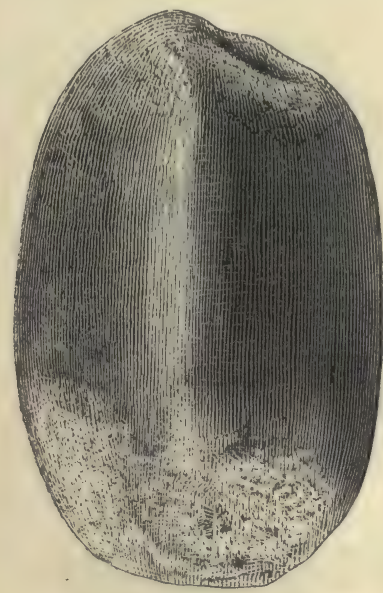

Fig. 15, $\frac{1}{1}$ :

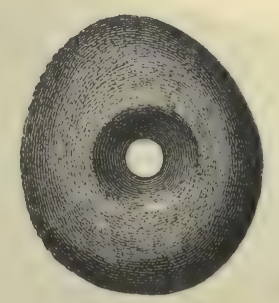

Fig. 16。 $\frac{1}{2}$.

cavating the chalk or a hoe for breaking up the ground, also made of a red-deer's antler ${ }^{1}$ [fig. 34] ; a knife or scraping instrument formed out of a split and sharpened boar's tusk; two articles

I This horn implement was found in a grave hollowed out of the chalk rock near Rudstone, and as it is identical in shape, and in the signs of wear at the end of the tine, with several which had been used as picks for excavating the chalk in the flint workings at Grime's Graves in Norfolk, it is probable that one of the purposes it had served was to make the grave in which it was found. There is however, besides the bruising at the end of the tine, so much smoothening upon the whole length of it, especially on the under side, as to give the impression that it must have been used amongst some softer material than chalk, and if so, possibly in tilling the ground. 
made of bone, which may have been used in the manufacture of pottery [figs. 35, 36] ; a cutting instrument made from an incisor tooth of a beaver; and a small chisel-like tool.

The bronze implements include knife-daggers [fig. 37]; knives; axes [fig. 38]; drills [fig. 39]; and awls or prickers [fig. 40].

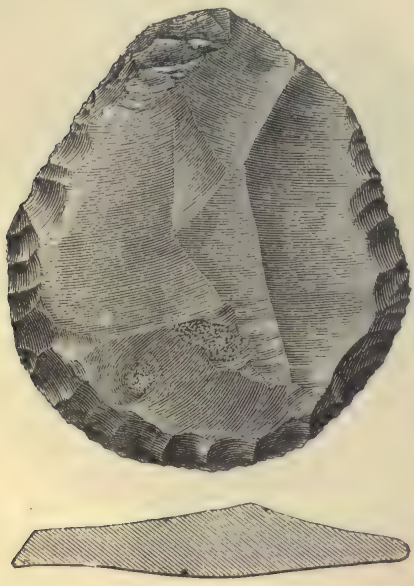

Fig. 17. $\frac{1}{1}$,

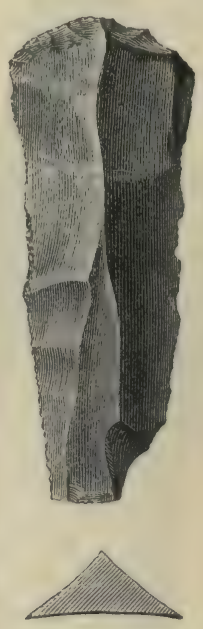

Fig. 18. $\frac{1}{1}$.

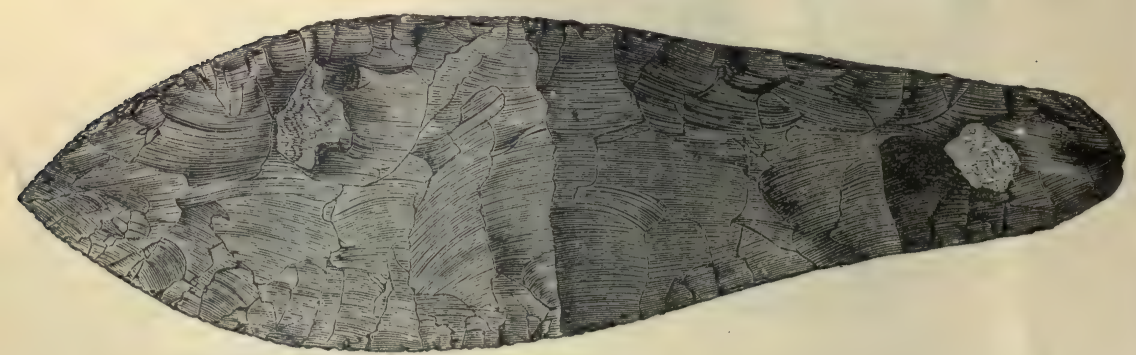

Fig. 19. $\frac{2}{3}$.

In the barrows of the wolds, though implements of any kind have been but rarely found in connection with an interment, those of stone are much more abundant than those of bronze. The converse of this appears to be the case in Wiltshire, where Sir R. Colt Hoare met with bronze implements in the proportion of two of that metal to one of stone; and though it is possible that he may have overlooked some of the smaller flint articles, still it is evident that in Wiltshire stone was less frequently deposited with the dead than was bronze. 
When any of these implements of stone, horn, or bronze have been associated with a burial, they have been discovered in various relative positions as regards the body. Knife-daggers of bronze and flint, and axe-hammers of stone or horn have been, in many cases, apparently held in the hand, with the point of the one and the edge of the other almost touching the chin. Other weapons

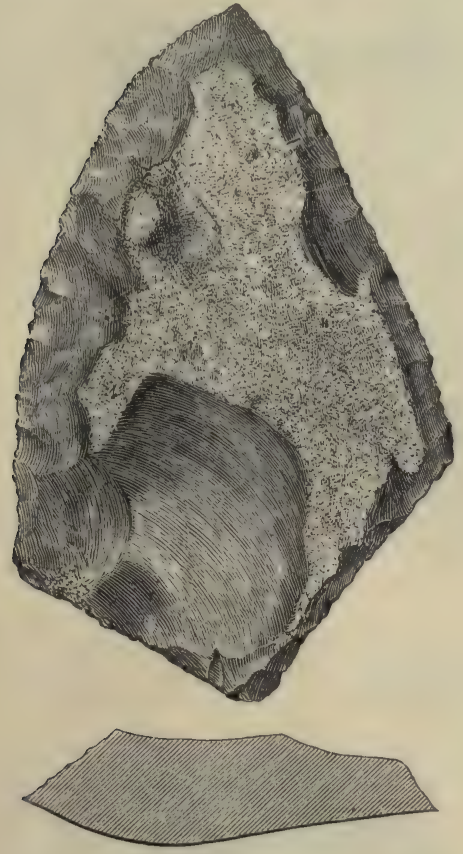

Fig. 20. $\frac{1}{2}$.

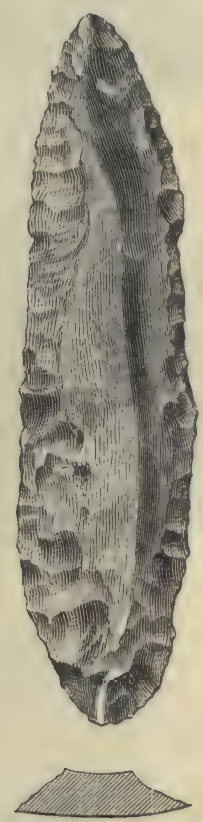

Fig. 21. $\frac{1}{1}$.

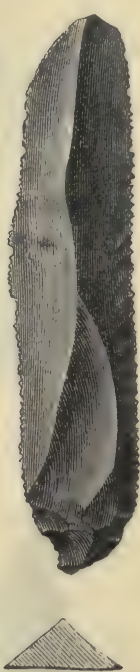

Fig. 22. $\frac{1}{1}$.

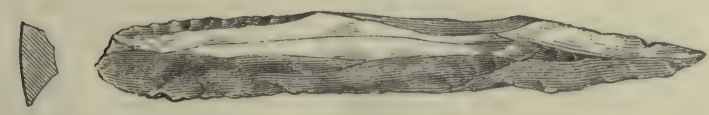

Fig. 23. $\frac{1}{3}$.

and implements have been found in front of the face and chest; behind the head, shoulders, and back; at the hips, and under the knees.

Amongst these several articles of stone, horn, and bronze, the only two which can fairly lay claim to be considered as weapons are arrow-points and the perforated axe-hammer of stone; to which may possibly be added the plain bronze axe. The knife- 
dagger, which is usually called a dagger, and believed to have been a weapon, can scarcely be regarded as being such. It is so thin in the blade, and at times the point is so much rounded, that it would ill serve the purpose to which a dagger had to be

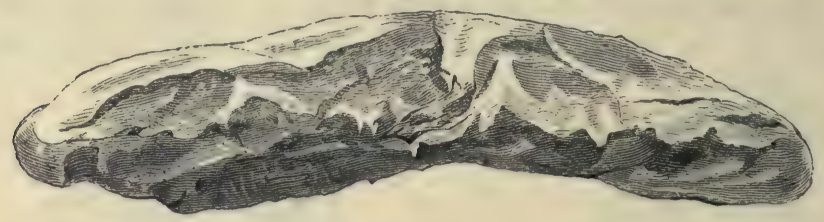

Fig. 24. $\frac{1}{1}$.

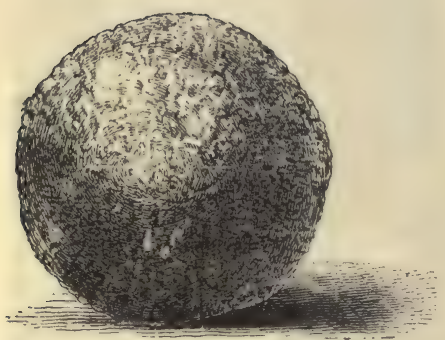

Fig. 25. $\frac{1}{2}$.

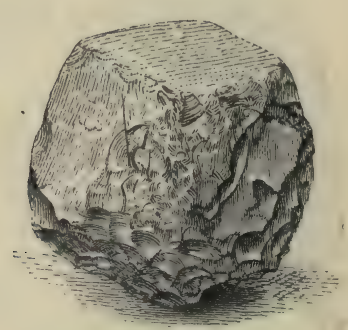

Fig. 26. $\frac{1}{2}$.

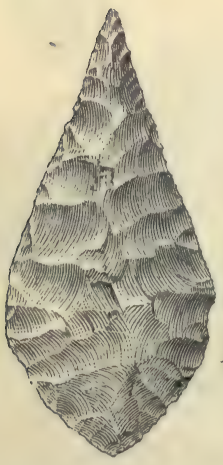

Fig. 27. $\frac{1}{1}$.

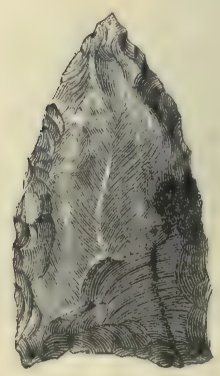

Fig. 28. $\frac{1}{1}$.

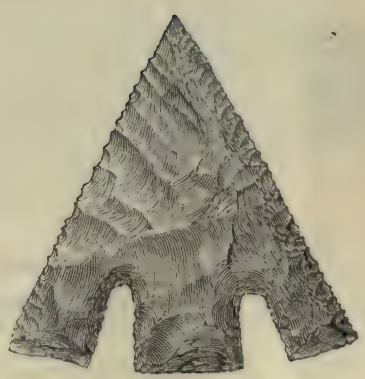

Fig. 29. $\frac{1}{1}$.

applied. It partakes much more both of the shape and character of a knife, and seems to have been intended rather for cutting than for stabbing. At the same time it probably served more than one purpose, and as the Kaffir uses the head of his assagai in a variety of ways, so we may imagine that the knife-dagger supplied the place of several different instruments. Some of these 
blades [fig. 41], however, must be regarded as daggers in the true sense of the word, though these have not been found associated
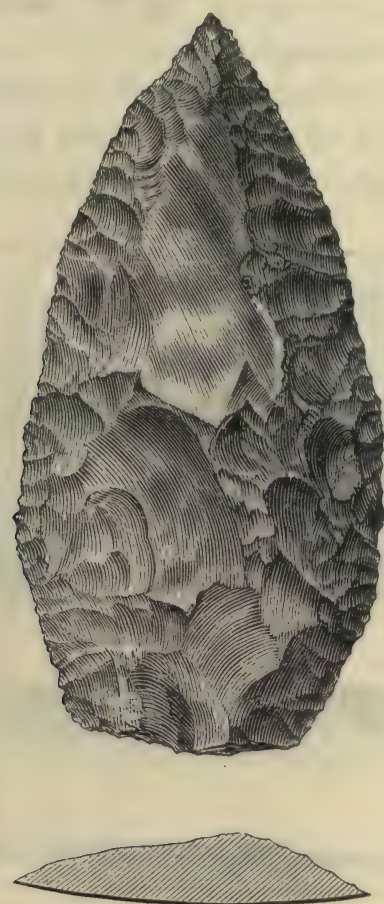

Fig. 30. $\frac{1}{2}$

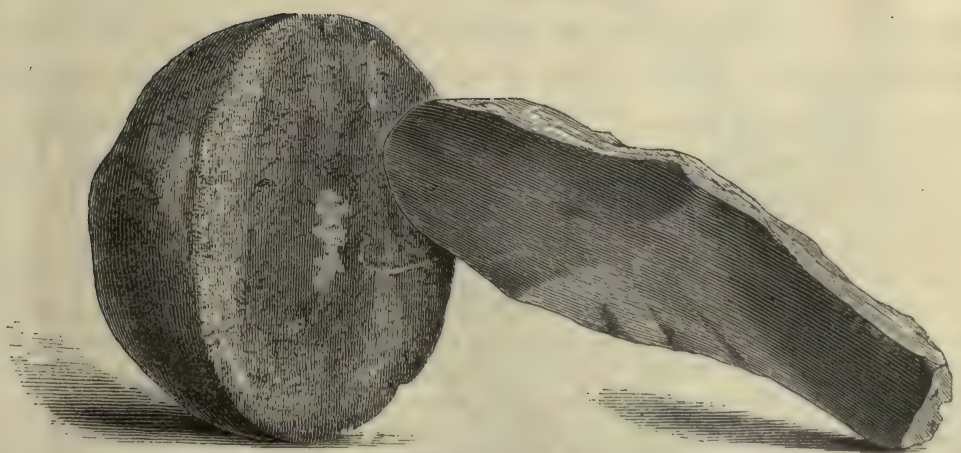

Fig. 31. $\frac{1}{1}$.

with interments in the wold barrows, so far as my own experience goes. A portion of one of these last-named blades, much stronger and thicker than those to which $I$ have applied the name of knifedagger, was discovered amongst the material of a barrow at Cowlam 
[No. lvii], but not in connection with a burial. Strong blades similar in character to that figured at p. 47 have occurred in several of the Wiltshire barrows opened by Sir Richard Colt Hoare, as well as in other parts of England ${ }^{1}$.

The perforated stone axe-hammer, on the contrary, could scarcely have been used for any other purpose than that of offence, for the edge, instead of being sharp, as in the case of the ordinary stone
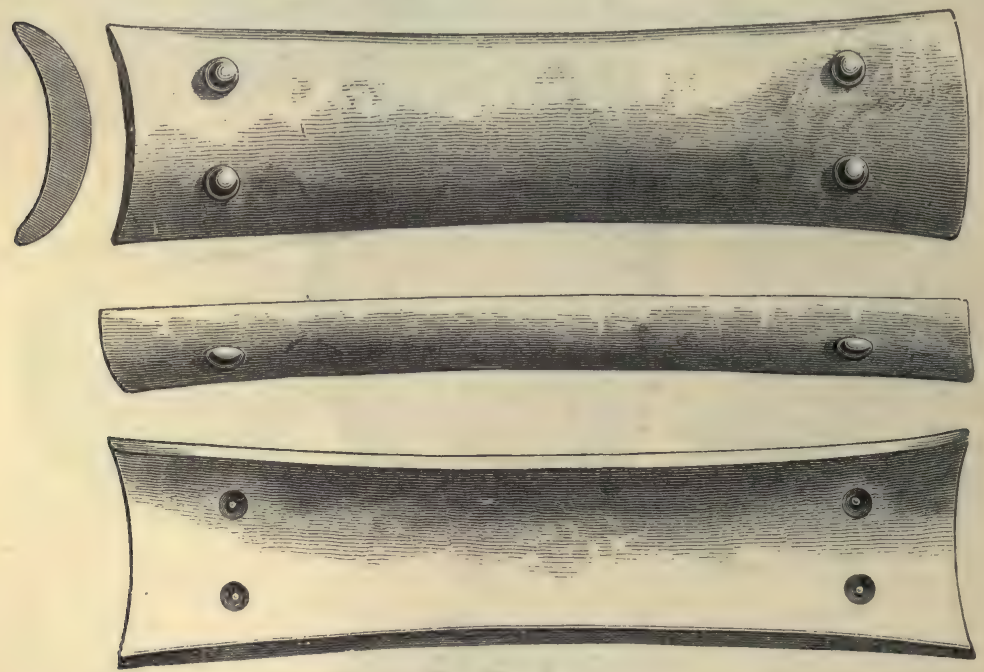

Fig. 32. $\frac{2}{3}$.

hatchet, is always rounded or squared ${ }^{2}$. This would be sufficiently efficacious for assaulting an enemy, but could never have been applied to such an use as that of cutting wood. The care bestowed upon these axe-hammers, and the ornament which is found upon some of them, are also greatly in favour of their having been used as weapons, upon which so many peoples have been in the habit of lavishing decoration.

${ }^{1}$ It is a curious circumstance, though it may be an accidental one, that all the knife-daggers found by Messrs. Bateman and Carrington in the Derbyshire and Staffordshire barrows, sixteen in number, were discovered with bodies unaccompanied by any vessel of pottery. The same is the case with those found by Mr. Ruddock on the Yorkshire moors, and by myself on the wolds and on the moors. Sir R. Colt Hoare found thirty-six daggers and knife-daggers with burnt and unburnt bodies, the larger number, as is usually the case, with burials by inhumation. With twentyfour of these no vessel of pottery occurred, five were with burnt bones enclosed in urns, one was with two bodies and a single urn, and may have been placed with either of the two, thus leaving only five instances where an urn and a dagger were found together. Of these, two were with 'drinking-cups,' two with peculiarly-shaped urns, and one with what was probably a 'food-vessel.'

${ }^{2}$ See Evans, Stone Impl. p. 175. 
The barrows are found to contain examples of almost all the stone implements which occur elsewhere. I do not remember, indeed, to have seen any article of stone which has not, in one form or another, been met with in a barrow. The contrary, however, is the case with regard to bronze. The number as well as variety of weapons and implements belonging to the bronze period, which have been discovered under many different circumstances

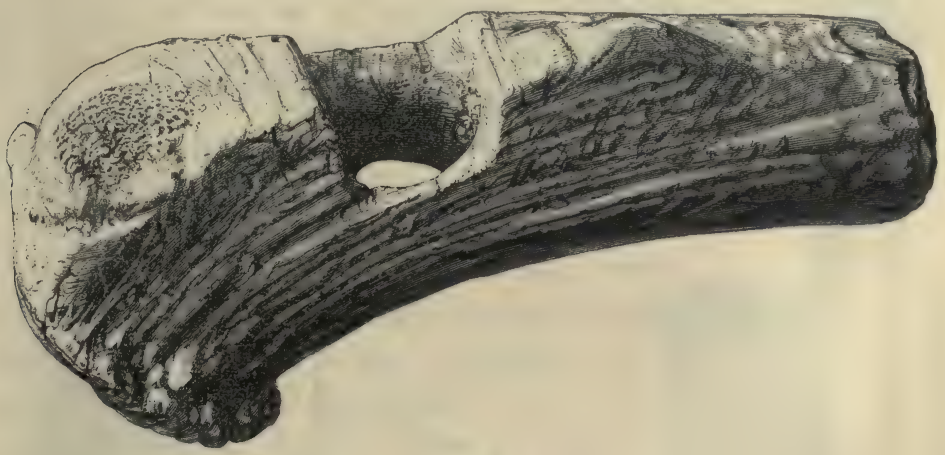

Fig. 33. $\frac{2}{3}$.

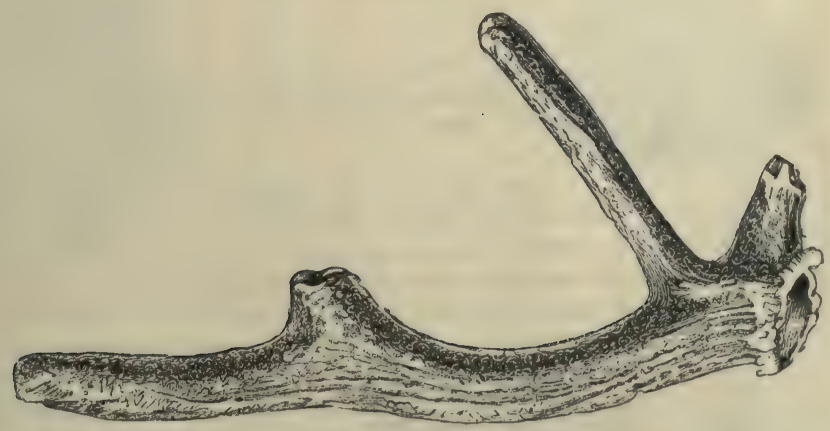

Fig. 34. $\frac{2}{6}$

and in great abundance, is very large. Not to particularise every one, it may be sufficient to mention swords, daggers, spear-heads, axes (plain, flanged, and socketed-the so-called paalstabs and celts), gouges, chisels, knives, drills, and awls. Now, out of this long list, but a very small proportion has ever been found in barrows in association with interments, or, indeed, in any part of a sepulchral mound. Those that have occurred may be comprised 
under the head of the plain axe, dagger, knife-dagger ${ }^{1}$, knife, drill, and awl.

It appears strange that out of all these implements and weapons

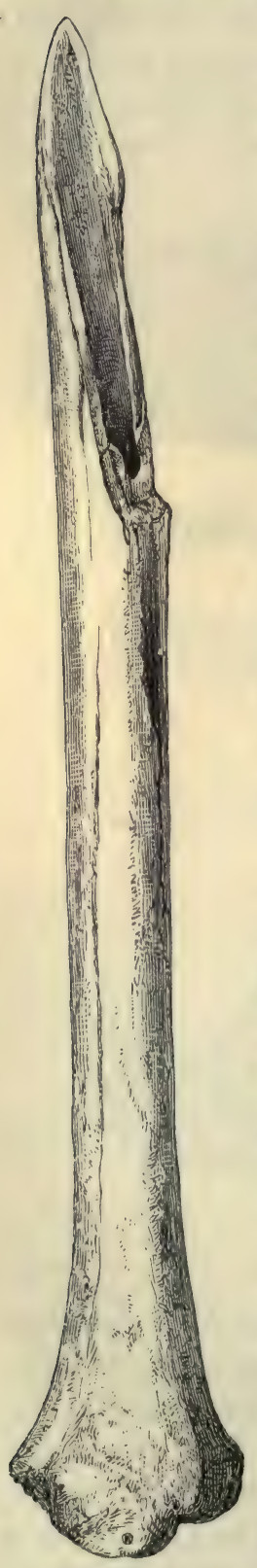

Fig. $35 . \frac{1}{1}$. belonging to the bronze period in Britain, only the six above mentioned should have been found in the barrows, and the fact is not easily to be accounted for ${ }^{2}$. It has been stated, indeed, and Dr. Daniel Wilson, in the Prehistoric Annals of Scotland, mentions it as not an uncommon occurrence, that bronze swords have been discovered in barrows, buried with the dead ${ }^{3}$. I cannot, however, find a single authentic instance of their occurrence. It is probable that a misconceived view about the finding of swords with burials has arisen from the loose way in which casual discoveries have frequently been recorded. It has happened (and I know of such a case) that a sword was found in the neighbourhood of a barrow, where it may have been lost or concealed at some other time than that when the mound was constructed, and a careless method of recording has referred it to a position

1 The knife-dagger and knife of the barrows are quite different implements from the knives which frequently form part of the hoards of bronze articles, such as swords, spearheads, \&c.

${ }^{2}$ I have only met with three doubtful instances in England of the alleged finding of a bronze socketed celt in connection with an interment. In an account of the opening of some barrows in East Devon, by the Rev. R. Kirwan, it is stated that this implement was found in the deposit made by the remains of the funeral pyre. This statement occurs in the text, but on the plate the celt is described as coming out of a kistvaen. Trans. Devon. Assoc., 1870. See also Evans, Coins Anc. Brit. p. 102; and Archæol, iv. p. 24.

To show how uncommon is its occurrence in France, it may be mentioned that in a letter from the Abbé Cochet to M. de Mortillet (Mat. pour l'hist. de l'homme, N. S. i. 73) he says that one was found by M. de Ring of Bischeim in a: barrow in the forest of Brumath, Alsace, and that it is the, only instance of the kind with which he is acquainted.

${ }^{3}$ Vol. i. p. 394. Dr. Wilson here speaks of the swords as being found broken, but in doing this he seems to confuse the contents of Danish with those of Scotch burial mounds. In Denmark it is true that bronze swords, both entire and broken, have been met with occasionally, associated with both burnt and unburnt bodies. 
in the barrow itself. Nor, indeed, would the fact that a sword was found in a barrow show that there was anything more than an accidental connection between the two. The sword might have been deposited in an already existing barrow for concealment or other purpose, just as I have known a small hoard of shillings of Queen Elizabeth to have been found in one. It is only when an article is discovered associated with an interment, or in a barrow under such circumstances as make it clear that no after-

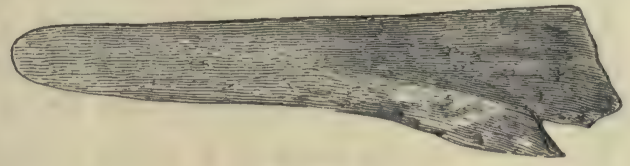

Fig. 36. $\frac{1}{1}$.

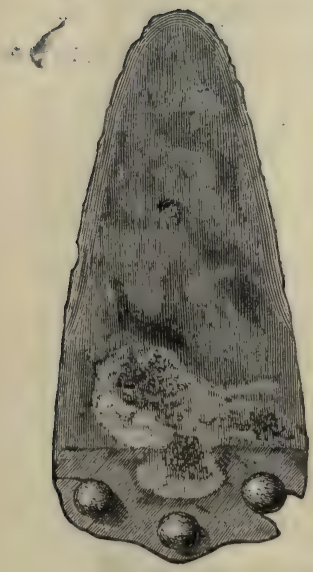

Fig. 37. $\frac{1}{2}$.

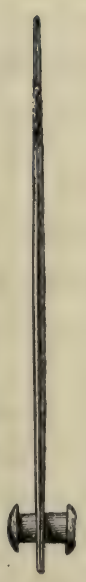

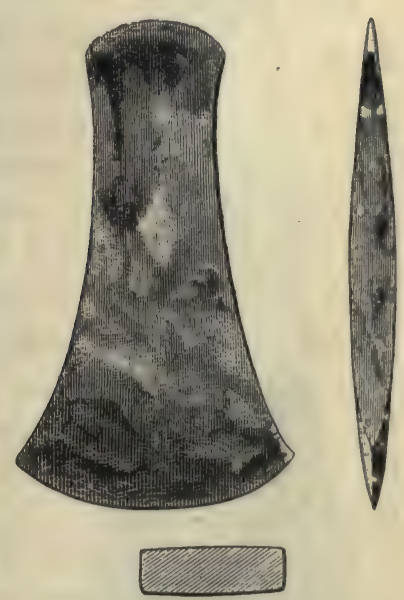

Fig. 38. $\frac{1}{2}$.

disturbance of the mound has taken place, that the article can be considered as contemporaneous with the barrow.

It has also frequently been stated that spear-heads have been met with in barrows, but in every case where I have had an opportunity of testing the report, the so-called spear-head has proved to be either one of the knife-daggers or a dagger. I have little doubt that, could all these cases be investigated, the result of the examination would be found to be the same.

The fact that so ferr of the ordinary bronze implements and weapons have been met with in the barrows is a very important one as regards the age of these sepulchral mounds; for if the barrows 
belong to the same period as that which was so prolific in the various articles of bronze mentioned above, it is difficult to understand how so small a number of them should have been met with in the mounds. It must not, however, be supposed, because in some barrows no other implements than those of stone have been found, that such barrows belong to a time be-

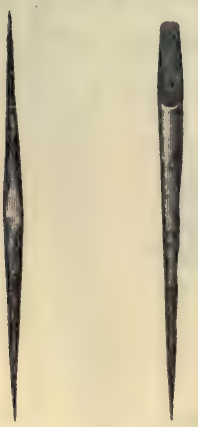
fore the introduction of bronze, for its absence by no means proves that it was unknown. In many cases there may have been small articles, such as awls or prickers, buried with the dead which have entirely gone to decay; indeed in a barrow at Rudstone, but for the stain upon the cheek bone of a woman, there would not have been the slightest evidence that anything of bronze had been buried with her, and that evidence would have been wanting unless the Fig. 39. $\frac{1}{2}$. Fig. 40. $\frac{1}{3} \cdot$ metal had been in actual contact with the bone. Many barrows also merely contain such articles of stone or of pottery as in others are found in connection with implements of bronze, and in these cases there can be little doubt that those barrows where the metal is absent, nevertheless, belong to a time when it was in use, though for one reason or another it was not placed in the sepulchral mound. The absence of bronze however might be used, and with good reason, as an argument in favour of the barrows belonging to a time, if not antecedent to its introduction, at all events to one previous to its highest developement.

In further illustration of this it may be stated, that amongst the weapons and implements forming the constituent parts of the ordinary hoards of bronze articles, there has nothing been discovered which is at all like the knife-daggers or knives of the barrows; nor, indeed, does the true dagger, also met with in the barrows, appear to have been in use at that time ${ }^{1}$. The sword appears to have served

1 The Arreton Down find, which might at first sight appear to be inconsistent with this statement, is really in favour of it. The principal part of the articles found there consisted of what have been called spear-heads, but which are, properly speaking, daggers; the remaining implements being two ordinary dagger-blades, and four axes, of the plain and early type. The find seems to belong not to the later time, when the sword, spear, \&c. were the ordinary weapons, but to the earlier one of the age of bronze, or possibly to a period between the two. The find is described, and many of the articles are figured, in Archæol. vol. xxxvi. p. 326.

A hoard of bronze articles, corresponding in many respects with those found on 
the double purpose which the two weapons in question fulfilled, and many of them are so short that they might almost be classed amongst daggers.

The circumstance that the knife-dagger, knife (of the barrows), \&c. are not found with swords, spear-heads, socketed celts, knives (of the hoards), \&c., is very difficult to account for, if they are all to be referred to the same period. It may be said that knifedaggers were manufactured specially for burial purposes, and would not therefore be likely to occur in association with the ordinary implements of daily use. The evident signs of wear upon many of them is, however, quite inconsistent with such an explanation. Again, it may be said that implements like the knife-dagger or knife (of the barrows) would be kept in use until there was but little left of them, and that therefore they would not be likely to occur in many of the hoards, which seem to have been collections of damaged and broken implements gathered together for the purpose of being recast. But articles of quite as small a size as a knife-dagger would ever be reduced to by whetting are common enough in the hoards; and it must also be remembered that many of the large finds have not been of broken articles, but of those which were quite new, or, at all events, perfect.

The plain axe has been mentioned as one of the bronze implements found in barrows, and as the facts connected with that implement have a very important learing upon the question of the age of these places of sepulture, it becomes necessary to devote some consideration to

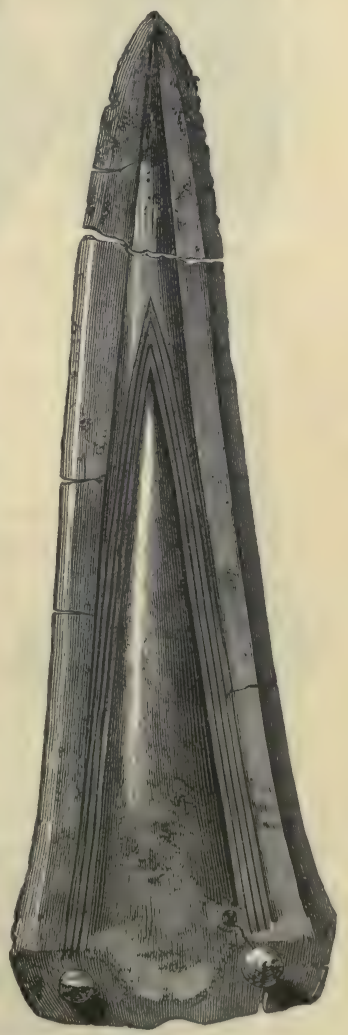

Fig. 41. \&. it. By the plain axe is meant the simple form of the implement, like that figured at p. 45, which appears to have been based

Arreton Down, was discovered at Plymstock, Devon. There were no paalstabs of the later form, no socketed celts, spear-heads nor swords, but knife-daggers, an early, though not perhaps the earliest, form of axe, a narrow chisel, \&c. Arch. Journ. xxvi. 346. 
upon the model of the earlier stone axe ${ }^{1}$. It has neither flanges at the side like fig. 42, nor a socket at the end like fig. 43 , and seems to have been hafted by inserting the smaller end into a club-like handle of wood ${ }^{2}$. The simplicity of the form, and the resemblance it hears to the stone axe, both make it probable that

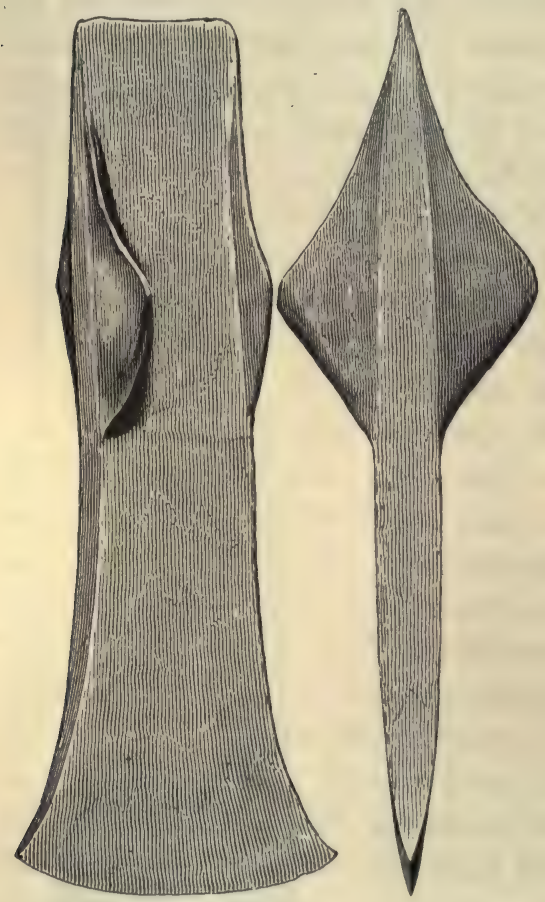

Fig. 42. $\frac{1}{2}$.

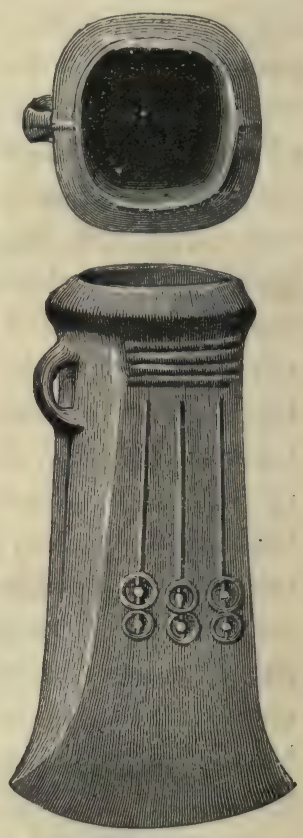

Fig. 43. $\frac{1}{2}$.

it is the earliest type of the bronze axe ${ }^{3}$. Now this form of axe is never found with swords, spear-heads, \&c. in the various hoards of bronze articles, which have been so frequently discovered; the axe in use at the same time with them, and occurring with them in these finds, is the flanged axe (paalstab), and more commonly the

1 An analogue may be found in the baluster shafts and other 'stone carrentry' of pre-Conquest churches, no doubt copied from buildings of wood; and also in some of the iron bridges of our own day, where the stone bridge has served as a model.

2 The axe found at Butterwick [No. xxxix] shows, upon the oxidised surface, the exact place at which the handle terminated, about one-third of the length from the narrower end. These axes may also have been hafted by fixing them midway into the split end of a shaft, and then binding across with thong.

${ }^{3}$ Axes of this form, made of copper or of a metal containing a very small proportion of tin, have been found, not unfrequently, in Ireland; and may be considered to belong to the transition period between the use of stone and bronze. 
socketed celt ${ }^{1}$. From this it would appear that swords and spearheads were not manufactured immediately upon the introduction or the discovery of bronze; and that the plain axe preceded them, dating, as it might seem, from the time of the earliest use of that metal. This fact is quite in accordance with the inference which has been drawn from the occurrence of the knife-dagger in the barrows, and its absence from the hoards of swords, spear-heads, socketed axes, \&c. The knife-dagger and the plain axe may both be considered, judging from their shape, to be early productions of the age of bronze, and as neither of them has been found accompanying those weapons and implements which were certainly in use during the height of that period, they may be regarded as prior to such time, and as marking an epoch during the bronze age, namely, its first developement. It has been mentioned already that the knife-dagger and the plain axe are found in the barrows, and, indeed, are the only articles of the kind which have been discovered in connection with an interment; but the two have been met with associated together accompanying a burial, a connection which seems to draw towards a single point the converging lines of evidence as to the early date of the sepulchral mounds.

The conclusion then at which we seem to arrive is, that the barrows in general belong to a period before bronze was in common use, and when that metal was scarce, and only manufactured into articles of a comparatively small size, such as those usually found in them. Indeed it is almost impossible to believe that, if the burial mounds were constructed after the time when swords, spearheads, and socketed axes were abundant, none of them should have been discovered in the barrows. If these weapons \&c. had not been plentiful, we could understand how they might never have occurred in connection with burials; but from the numbers which have been found in all parts of Britain, it is evident that they were very widely diffused and largely manufactured. This circumstance makes it difficult, indeed almost impossible, to refer to the same period the erection of the barrows and the fabrication and use of the weapons and implements in question.

1 A very valuable discovery of bronze and other articles, the whole effects in fact of a family, was made in a cave, called Heathery Burn, in the county of Durham. The series comprised almost every article of the bronze age which has been found elsewhere, either as a single specimen or one of many, besides some which have been met with in no other place. It forms, therefore, an index as it were to the age of bronze in England, and includes sword, spear-head, knife, socketed axe, gouge, chisel, \&c., but neither plain axe nor knife-dagger. 
It may be asked, if the ordinary barrows are none of them the burial-places of the people who occupied the country during the highest developement of the bronze period, where do their burialplaces exist? The question certainly is one which it is not possible to answer; but the inability to offer any explanation is not sufficient to make us, in the face of what appear to be greater difficulties, accept the view that the barrows belong to that time. There are other periods during which the people must have been buried in large numbers, and yet there is scarcely a trace left of their sepulchral remains. For instance, the time which elapsed between the introduction of iron and the full occupation of Britain by the Romans was by no means a short one, and yet the burials which can be attributed to that period are but few ${ }^{1}$.

It has been stated already that various implements of flint are found in the barrows, both associated with interments and dispersed casually amongst the materials of which the mounds are composed. There is a fact connected with these implements and of some interest in itself, which becomes of importance from the evidence it affords in relation to the cause of such articles being deposited with the dead. Those implements of flint which are found placed in immediate connection with the body appear in most instances to be perfectly new, and as if made for the burial, whilst those found in the material of the barrows and not associated with an interment have, as a rule, been evidently in use; some of them, indeed, showing abundant signs of having answered their purpose for a lengthened time. Bronze implements, on the con-

1 The Arras and Hessleskew group of barrows, opened by the Rev. Edw. W. Stillingfleet in 1816-7, contained several that belonged to the time in question, as also did at least two barrows at Cowlam, described in the sequel [Nos. 1, li]. A grave discovered in 1868, at Grimthorpe, on the western verge of the wold-range, and where in close proximity two or three other graves were met with, afforded a fine series of articles belonging to the early iron age. An account of the grave and its contents, with engravings, is given in the Reliquary, vol. ix. p. 180, by Mr. J. R. Mortimer, of Driffield, and another by Mr. Llewellyn Jewitt in Grave Mounds, in both of which however, and no doubt by an oversight, it is described as an Anglo-Saxon burial. Just beyond the range of the wolds, and not very far from where the last-mentioned graves were found, at a place called Bugthorpe, a body was discovered with which an iron sword in a bronze sheath and an enamelled bronze brooch were associated. Another interment of the same period, with some beautifully enamelled bronze articles, was found at Barlaston, in Staffordshire. Jewitt, Grave Mounds, p. 258, where again it is wrongly called Anglo-Saxon. Another burial was discovered with enamelled bronzes similar to those at Barlaston, in 1788, on Middleton Moor, Derbyshire. These few burials appear to comprise all that have been recorded of those belonging to the early iron age. Others have no doubt been met with, but it is not likely that many have been overlooked, for the nature of the articles buried with the dead in that class of interments is of a kind likely to command attention. 
trary, when discovered in a barrow, and there deposited with the dead, appear to be such as had been the property of the living, and had been in ordinary use.

Weapons and implements, either of bronze or stone, are howvever rarely found accompanying a burial. By far the greater number of bodies, whether burnt or unburnt, have been interred without anything of the kind. To show how infrequent is the occurrence of such articles, it may be stated that out of 379 burials, by inhumation and after cremation, 63 had implements of flint or other stone; 16, of bronze, one of which however was an ear-ring ${ }^{2}$; and 4 , of deer's-horn or bone; making in all (for 5 had articles both of bronze and stone) $\mathbf{7 7}$ bodies which had an implement associated with them, a very small proportion out of so large a number as that stated above. It may be well to analyse this statement more minutely. Of 301 unburnt bodies, 13 had implements of bronze, including the ear-ring; 54 had implements of flint and other stone; and 4 of deer's-horn or boar's-tusk. Of 78 burnt bodies, $2 \mathrm{had}$ implements of bronze, 7 had implements of flint, 2 had each an axe-hammer of grcenstone, and another had two rude hammerstones laid on the lid of the cist which contained the bones. In three cases where articles of bronze accompanied the body there were also implements of flint, a fourth body had an axe-hammer of stone and a bronze knife, and a fifth had a bronze knife-dagger and a whetstone, all being unburnt bodies ${ }^{2}$.

Ornaments and objects of personal decoration are sometimes found associated with burials in the barrows ${ }^{3}$. They are however much less frequently discovered than weapons and implements, and appear to be confined to those of women, at least in the barrows of the wolds. They accompany burials after cremation, as well as those by inhumation. When met with in association with a burnt body, in many cases they have not been burnt with

${ }^{1}$ In one of these cases it is impossible to say of what nature the article had been, for the former presence of the metal was only indicated by the green stain on the cheek-bone, arising from the oxidation of the bronze.

${ }^{2}$ In the large series of Wiltshire barrows opened by Sir R. Colt Hoare, twice as many burials were associated with bronze as with stone. On account of the want of care which characterises Mr. Bateman's records of the examination of Derbyshire barrows, it is difficult to arrive at any certain conclusion, though he appears to have found more interments where stone was associated with the body than he did where bronze accompanied it.

${ }^{3}$ Personal ornaments are not of frequent occurrence in the Wiltshire barrows. Sir R. Colt Hoare has recorded the examination of 350 burial-places of burnt and unburnt bodies, and he only deseribes 57 as being possessed of anything in the shape of ornament. 
it, but have been placed amongst the calcined bones, after they were collected from the funeral pile; and the same may be said of certain implements of flint. I have found three burnt bodies which had jet beads placed amongst the bones, and they showed by their perfect condition that they had never been subjected to the action of fire. It will give some idea of the rarity of ornaments when I state that out of the whole number of 379 burials,

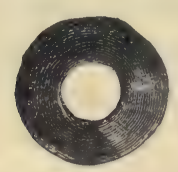

Fig. 44, $\frac{1}{1}$.

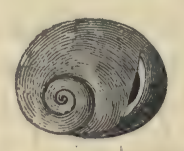

Fig. 45. 1.

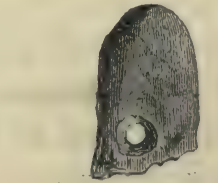

Fig. 46. $\frac{1}{2}$.

only 10 possessed anything of the kind; and out of these, 2 , in barrows at Cowlam [Nos. 1, li], belong to the early iron age; a period later than that of the ordinary barrows, which are alone taken into consideration in these introductory remarks ${ }^{1}$. The

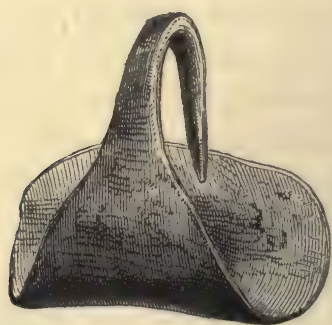

Fig. 47. $\frac{1}{2}$.

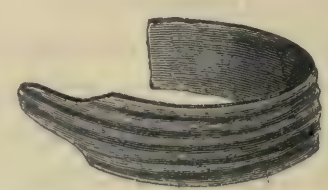

Fig. 48, $\frac{1}{1}$.

eight burials which had ornaments associated with them were as follows. One on Langton Wold [No. ii], where a woman had been buried with a humble necklace consisting of a single jet bead [fig. 44], two shells [fig. 45], a piece of a deer's-tooth pierced [fig. 46], and the vertebra of a fish, \&c. One at Cowlam [No. lviii], where a woman was interred with two bronze earrings [fig 47]; and another on Goodmanham Wold [No. exv], where what appear to have been two bronze ear-rings were found close to the head of a woman, one on each side of it [fig. 48]. Two,

${ }^{1}$ One of the barrows at Cowlam contained the body of a woman who had been buried with a necklace of glass beads. This is the only instance, so far as I know, where glass has been found in any of the wold barrows, of a time before the occupation by the Romans, except at Arras, a group of the same date as those at Cowlam. In other parts of Great Britain, however, glass beads have been discovered, which certainly belong to the same period as that of the ordinary round barrows of the wolds, that is, before the introduction of iron. 
each with a jet necklace, one being at Weaverthorpe [No. xliv], [fig. 49], the other on Goodmanham Wold [No. cxxi]. One on Flixton Wold [No.lxxi], where a young girl had four beads of bone, three of which were ornamented on each side [fig. 50]; and a woman on Goodmanham Wold [No. exvii], with a pierced pig's-tooth. Besides these instances, there were found in a disturbed barrow at

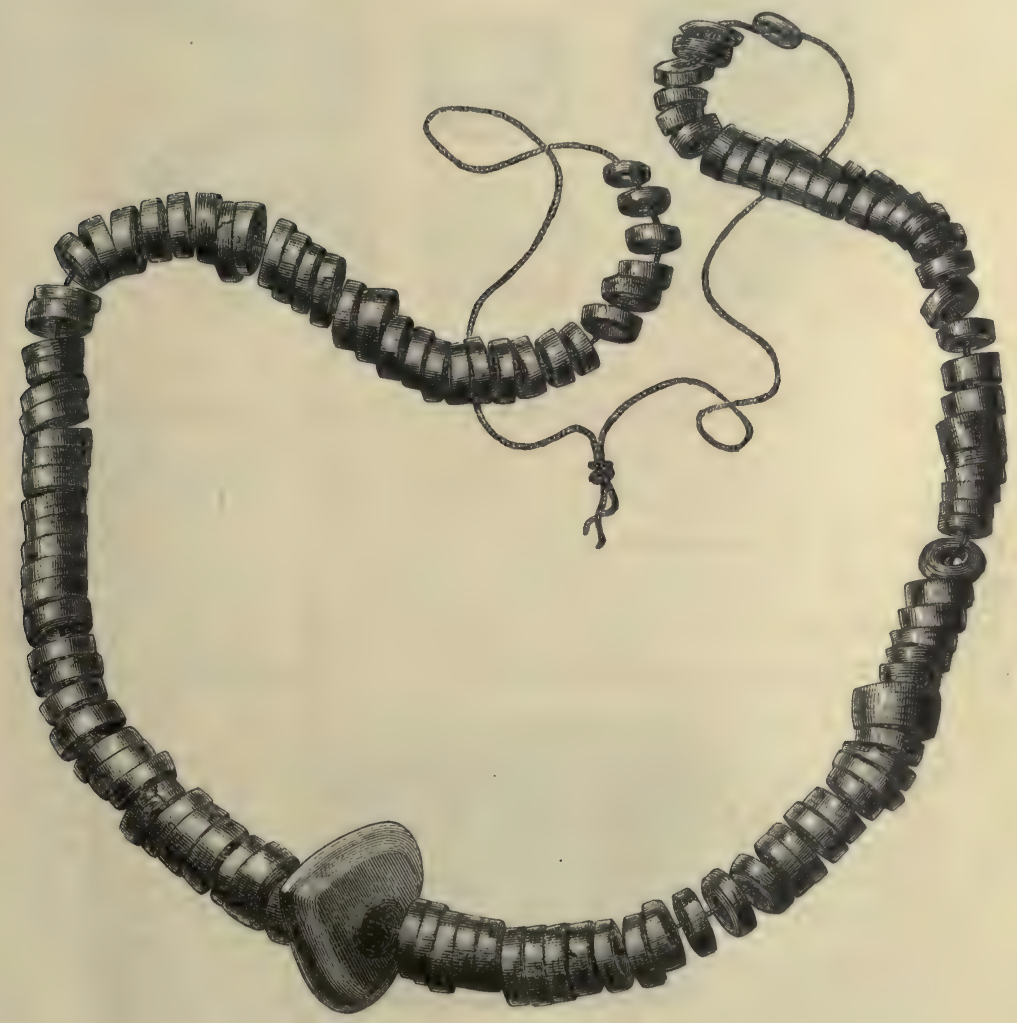

Fig، 49. $\frac{1}{2}$.

Helperthorpe two flat beads of jet [fig. 51], which had formed part of a necklace. They are ornamented with a pattern, consisting of minute punctured holes on the surface, and are similar to many which have been discovered in other parts of Britain, as in Wales ${ }^{1}$, Derbyshire ${ }^{2}$, Northumberland, and Scotland ${ }^{3}$.

1 Archæological Journal, vol, xxiv. p. 257.

${ }^{2}$ Engraved in Bateman, Vestiges, pp. 89, 92 ; Ten Years' Diggings, pp. $25,47$.

${ }^{3}$ Engraved in the Catalogue of the Museum of the Archæological Institute, at Edinburgh, p. 15. Proc. Soc. Ant. Scotland, vol. viii. pp. 409, 412; Wilson, Prehist, Annals of Scotland, vol. i. p. 435 . See Evans, Stone Impl. p. 410. 
The barrows of Wiltshire have, however, produced many more articles of personal decoration, and those of more varied and costly materials, than the wold barrows. At the same time there are many points of very close resemblance between the contents of the sepulchiral mounds of the two districts. In both are found perforated axe-hammers of stone; knife-daggers of
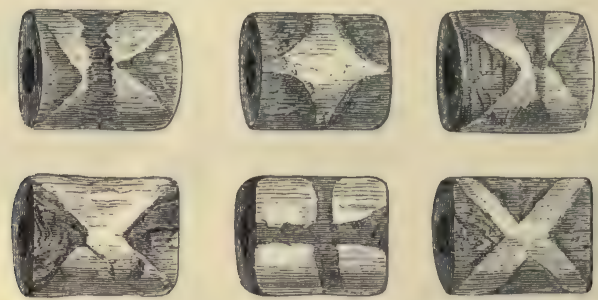

Fig. 50. $\frac{1}{2}$.

bronze and flint; barbed flint arrow-points; axes and awls of bronze; buttons and rings of jet; beads of bone, with almost identical patterns upon them; not to speak of the vessels of pottery. If the contents of the burial-hills are to be taken in evidence, and they afford the most certain we possess, the people who dwelt upon the wolds of Yorkshire appear to have been in a humbler condition and to have had less intercourse with other

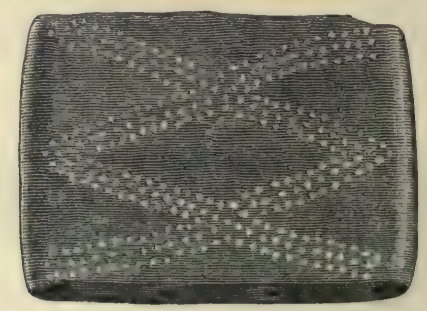

Fig. 51. $\frac{7}{3}$.

districts than the inhabitants of many parts of Britain. The Scotch cists and graves have been more prolific of ornaments, so have the Derbyshire barrows; and in fact no district, whose burial-mounds have been extensively explored, seems to have been in possession of so little bronze and so few personal decorations as the wolds, with the exception of the north-eastern moorland of Yorkshire, and Dorsetshire, with the extreme south-west of Engiand. In the barrows of other districts, and which, from their general features, may be considered as belonging to the 
same period as those of the wolds, ornaments have been discovered made of gold ${ }^{1}$, bronze, glass ${ }^{2}$, ivory, amber ${ }^{3}$, jet ${ }^{4}$, clay

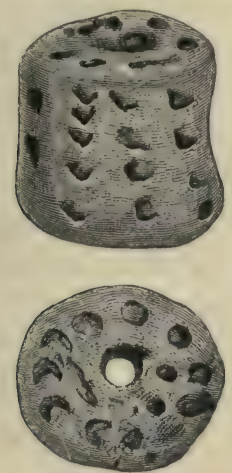

Fig. 52. $\frac{1}{1}$.

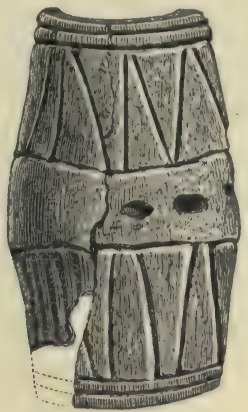

Fig. 53. $\frac{1}{1}$.

[fig. 52], and bone [fig. 53]. In the barrows of the wolds neither gold, glass, ivory, nor amber ${ }^{5}$ has been found, so far as I

1 Gold has rarely been found in any part of Britain in connection with an interment. In Wiltshire, where it has occurred most abundantly, Sir R. Colt Hoare records only six instances. A necklace of gold beads was met with in a barrow at Bircham, Norfolk; and at Cressingham, in the same county, several articles of gold were discovered in a barrow, with amber beads and bronze daggers. Proc. of Soc. of Ant., Second Series, vol. iv. p. 456. At Mold, in Flintshire, the breastplate (if such it is), now in the British Museum, is the most remarkable discovery yet made of gold in a British barrow. Archæol. xxvi. 422. Gold-headed bronze rivets had been used to fasten the stone plate of a wrist-guard to the material on which it had been fixed, in the case of an interment at Kelleythorpe, near Driffield. Archæologia, vol. xxxiv. p. 254. A necklace of rather rudely-fashioned gold beads was found in a cairn on Chesterhope Common, Northumberland. Arehæol. Eliana, vol. i. p. 1. In a cist near the Fochabers Railway Station two gold ear-rings were associated with the interment. Proc. Soc. of Ant. of Scotland, vol. viii. p. 28. At Huntiscarth, Orkney, in a cist under a barrow, four ornamented disks of gold were found with a necklace of amber beads. Proc. Soc. Ant. Scot. vol. iii. p. 195, pl. xxii.

${ }^{2}$ Beads of glass, principally of a bluish-green colour, and of peculiar shape, being like three or more beads joined together, have been discovered in several barrows in Wiltshire, associated with burnt bodies; they have also been found in Dorsetshire.

3 Amber has been found in barrows, of the same time as those of the wolds, in Wiltshire; see Hoare, Ancient Wilts, passim: at Cressingham, in Norfolk; Proc. Soc. of Ant., Second Series, vol. iv. p. 456 : at Mold, Flintshire, with the gold breastplate just above noticed; Archæol. vol. xxvi. p. 422 ; Proc. Soc. of Ant. vol. iv. p. 132, where an amber bead is figured: at Llanwyllog, Anglesea; Archæol. Cambr., Third Series, vol. xii. p. 110: and at Huntiscarth, Orkney; Proc. Soc. of Ant. of Scotland, vol. iii. pp. 183, 195, pl. xxii. See also Evans, Stone Impl. p. 413 et seqq.

${ }^{4}$ Jet or other lignite, though found not unfrequently in Scotland, the northern counties of England, and Derbyshire, has not occurred to the same extent in the Wiltshire barrows. The very pretty form of necklace, consisting principally of oblong pieces (generally engraved with dotted patterns) alternating with long cylindrical beads, which usually is made of jet, or of jet and bone, has in Wiltshire been found formed of amber.

${ }^{5}$ At Kelleythorpe, near $\mathrm{D}$ : iffield, just beyond the limits of the wolds, the late Lord 
know, nor do the bronze and bone articles possess that elaborateness of form, diversity of pattern, and skill in manufacture, which is displayed upon the necklaces and other ornaments which have been met with in many parts of Britain. A bronze knife-dagger has been found in a wold barrow, having the handle ornamented with a pattern made by minute pins of bronze, but Wiltshire has produced a similar one, where the pins or studs were made of gold ${ }^{1}$. It may also be said of the weapons and implements that, on the whole, they are inferior in design and execution; for, though the bronze knife-daggers are skilfully made, they do not equal the beautiful specimens which the Wiltshire barrows have afforded. The only articles indeed discovered in the wold barrows which can compare in beauty of design and workmanship with any found elsewhere, are the pretty jet buttons engraved with a cross pattern, and the jet rings, discovered at Thwing and Rudstone, and these are surpassed, at all events in material, by some of the Wiltshire buttons, which are made of gold ${ }^{2}$.

There is nothing in the implements and ornaments to show that there was any traffic going on between the wold-dwellers and other people at a distance, except to a very trifling extent. The bronze and jet must have been imported, but bronze has occurred in a very small quantity, and jet has not been found in many barrows, though the material itself is the product of a district lying within a few miles of the northern ridge of the wold-range. Besides, many of the so-called jet articles are not made of true jet, but of an inferior lignite. Flint, which is so abundant in the shape of weapons and implements, is not generally the product of the native chalk, though the flint of the district was used to some extent; but it is very common in the condition of rolled pebbles upon the adjoining sea-beach, and the greater part of what was used no doubt came from thence. It is singular that amber should not have been occasionally met with, for it is sometimes thrown up on the neighbouring coast, and it was used by the same people living in places much more remote than the wolds from any spot where it could have been procured.

Londesborough discovered, with an unburnt body in a cist, three amber buttons. Archæologia, vol. xxxiv. p. 255, pl. xx.

${ }^{1}$ Hoare, Ancient Wilts, vol. i. p. 204, pl. xxvii.

${ }^{2}$ l. c., vol, i. p. 99, pl. x ; p. 201, pl, xxv. 
The whole of the evidence afforded by the barrows appears to show that they are the burial-places of a people who were not possessed of much wealth of any kind. They were not likely, therefore, to have any abundance either of bronze or of those materials of which personal decorations are usually made. Their intercourse, in the way of traffic, with people at a distance must have been very limited. Nor is such a condition difficult to account for. The district is not one producing any substance which could well be made a subject of barter or exchange. Its productions in the way of animals, or of anything which in such a state of society constituted wealth, were possessed by other districts, and probably in greater abundance. The inhabitants of the wolds had no gold, no copper, no flint, no jet, and very possibly no hides or grain to spare, so that there was nothing which they could offer in exchange; and, indeed, it is difficult to understand how they obtained their bronze and jet except by the plunder of their neighbours.

Weapons, implements, and ornaments, it has been seen, are sometimes found deposited in the barrows with the dead. The custom has usually been accounted for by the explanation, that it was the result of a belief in an after state of existence of the same nature as that which had just terminated, and where such things would again be required; that when he passed to the happy hunting-fields where the buffalo and the elk roamed in herds unnumbered, and which no slaughter could make less, he might have 'his faithful dng to bear him company;' that when he joined the departed brave in the halls of Odin, there to quaff without satiety the ever-replenished mead from the skull of his enemy, he might bear with him the trusty sword, the unerring arrow, wherewith to subdue the foes that never failed and yet were ever vanquished. The practice has been all but universal; every ancient burial-place testifies to it ${ }^{1}$; almost every modern savage grave gives the like evidence of the custom ${ }^{2}$. To archæo-

1 One of the latest notices of the occurrence of this practice in Europe is contained in a deed of contract, bearing date A.D. 1249, between the newly converted Prussians and the Knights of the Teutonic Order: the former promise 'quod ipsi et heredes eorum in mortuis comburendis vel subterrandis, cum equis, sive hominibus, vel cum armis, seu vestibus, vel quibuscumque aliis preciosis rebus, vel etiam in aliis quibuscumque, ritus gentilium de cetero non servabunt, sed mortuos suos juxta morem Christianorum in cemeteriis sepelient et non extra.' Dreger, Codex Diplomat. Pomeraniæ, pp. 286-294, No. 191, quoted by W. M. Wylie in an essay on the burning and burial of the dead, Archæologia, vol. xxxvii. p. 463.

${ }^{2}$ An interesting account of the burial of 'The Stung Serpent,' a chief of the 
logical science it has been of inestimable service. What should we know of ancient Egypt, of her cultivation, her art, her manufactures, except so far as the imperishable monuments of stone bear witness, had not the tombs preserved an endless storehouse of pictures as well as of the very things themselves those pictures represent. Denmark's stone, bronze, and iron ages might have remained a subject of dispute amongst the learned, but for the barrows and their buried contents, which have handed down to us a book in whose record of flint and metal we may again read somewhat of the history of the past. Our own English ancestors might, no doubt, have been understood by us in many of their great characteristics, in their obedience to law, their love of justice and of freedom, and their aptitude for self-government, for these by an unswerving tradition have passed down, by slow gradations of change, unto ourselves. We might have known something of their poetry and other writings, for Cædmon and Beda and Alcuin had lived and written, and letters had early taken root amongst them. We might have recognised their energy, their devotion, their strong religious feeling, which made them the teachers of a new and purer faith to those beyond their borders; for all Europa bears testimony to the great missionary labours of the English, when Wilfrid, Willebrord, and Boniface became the apostles of the Gospel to many a heathen land. But without the wondrous museum of gold, and silver, and iron, and precious stone, and glass, and bronze, and ivory, which the cemeteries of Kent, of East-Anglia, and of middle England have so carefully preserved to us, what should we have known of English progress in many a developement of artistic workmanship? How should we have become cognisant of their wondrous skill in goldsmith's-work; their tasteful application of metal, stone, and glass to the enrichment of personal ornaments; their knowledge of glass manufacture in beads and vessels of that material $^{1}$; their high cultivation in art; their great practical acquaintance with the mystery of the smith?

Natehez, who was interred with his wives, weapons, \&c., is given by Du Pratz, History of Louisiana, vol. ii. p. 216, Lond. 1763, and quoted by Jones, Antiquities of the Southern Indians, pp. 105-107. Mr. Jones states, p. 185, 'The practice of depositing in the grave all articles which the deceased deemed most valuable obtained among all the Southern tribes.'

1 It is perhaps questionable whether the beads and glass vessels found in English graves were not of foreign manufacture. It is certain that a very great similarity exists between those found in England and those which have occurred so plentifully in the cemeteries of north - eastern France and the Rhine district.' Similarity of 
It is certain that amongst some of the many peoples who have been in the halit of depositing various articles with the dead, a belief that they might be of use in another world has been the motive which prompted the action. With others a dislike or superstitious dread, attaching to the use of what had belonged to the dead, was the reason which caused them to place such things with the body in the grave ${ }^{3}$. Though it is quite possible that either one or the other, or both, of these feelings might have led the dwellers on the wolds to adopt the practice, there is nevertheless a circumstance which it is difficult to account for on such grounds. It will have been observed that it is only upon rare occasions that anything whatever has been found associated with a burial; whilst in several of these instances the articles are merely such as were connected, in the shape of fastenings, with the dress or other covering in which the body had been clothed or the corpse invested. In the large number of 379 burials, of burnt and unburnt bodies, not more than 94 were found to be thus accompanied; and, of these, 15 had nothing more than pins or buttons with them. It appears strange, if either of the reasons stated was that which led to the depositing of different articles with the dead, that so few of them should have been thus provided. If it were thought that in another world persons would pass through a state of existence similar to that which they had lived upon earth, and that it was therefore neces:ary to send them into that second state equipped with the essential means of such existence, it is difficult to understand why so few persons were laid in the grave with these provisions for the necessities of that after life. This difficulty becomes greater when we consider the labour that was bestowed upon the barrows; showing, as it does, that neither eare nor trouble was spared upon that which was connected with the funeral rites. Or, if it was believed to be unlucky for the survivors to make use of those things which had been the property of the deceased, and that for this reason such things were buried with them, then we

make does not, however, always imply that such things came from the same manufactory. And besides, though there is a very great general resemblance, a close examination of a large series of these articles discovered in the two countries will show many points of difference, sufficient, I think, to imply that they were not all made in the same workshop.

${ }^{1} \mathrm{Mr}$. Whymper stated, at the Norwich Meeting of the British Association (1868), that the Greenlander has a great objection to use the property of the dead, and that, in accordance with this feeling, their goods were deposited in their graves. Flint Chips, p. $278 n$. 
must suppose that by far the greater number of persons buried in the barrows were possessed of neither weapons, implements, nor ornaments-which it is quite impossible to conceive. The circumstance already mentioned, that a large number of the articles deposited with the dead are quite new, and to all appearance made for the occasion, is a fact which also militates very strongly against this explanation of their occurrence.

Another reason has been adduced for this apparently capricious custom of sometimes placing various articles in the grave, namely, that a pious and affectionate feeling prompted it; it has been suggested that those things which were daily associated with them when living, were laid beside them by their friends when they were buried. Nor, perhaps, is it unnatural or contrary to what we know has been frequently done even in our own days, that promptings like these should have ruled at such a time. The arrow with which the hunter went forth to provide for the sustenance of himself and of his family; the scraper or the awl with which his wife prepared the skins and put together the garments for his clothing; the necklace or other ornament worn to make more pleasing those charms she had by nature's gift; the bright-coloured berries which made a plaything for the child-all had that association with those who were gone as might not unfitly cause them to be placed in the grave by the survivors who mourned their loss. To this explanation the same objection applies as has been urged above, that many of the articles are new. The bronze implements and the ornaments indeed appear to have been in use, but by far the greater part of those of flint had almost certainly been made for the occasion of the burial, since they show, in every part of them, such sharpness in the chipping, both of the edges and of the point, as could not have existed if they had ever been subjected to use. It is not possible to speak unhesitatingly upon this interesting but mysterious subject; and though we have made the graves give up their dead, and thereby have unfolded some of the secrets of the life of those who were laid to rest beneath these ancient mounds, yet there are others, still to be unravelled, which a larger assemblage of observed facts and a more ingenious speculation may perhaps hereafter explain. At the same time I think that, taking all the facts into consideration, and having regard to the reason which causes some semi-savage people at the present day to practise the same custom, the probability is strongly in favour of the opinion which considers these articles as having been deposited with the 
dead for an after use in another state of existence ${ }^{1}$; though of course that does not prevent other causes, such as those mentioned, from having also had their influence on certain occasions.

A more frequent accompaniment of the body, whether burnt or unburnt, than either weapon, implement, or ornament, is a vessel of earthenware. This is found, in the greater number of cases of unburnt bodies, to be placed in front or at the back of the head; but occasionally behind the back, in front of the chest or knees, and sometimes, though rarely, at the feet. In a few instances a sepulchral vase has occurred in a barrow not in close proximity with any interment. It is usually placed upright, but is found not unfrequently on the side, a position which appears to have been caused by its having been overthrown by the pressure of the surrounding earth.

Vessels of pottery are associated with burnt bodies in two different ways: they occur containing the bones, and are also met with accompanying them, much after the fashion in which they are found with unburnt bodies. They are in this case placed on the top or at the side of deposits of burnt bones, and frequently amongst them, even where the bones themselves are enclosed in an urn.

The vessels vary almost indefinitely in size, shape, and ornamentation, as they do in the composition of the clay and the rudeness or skill of their manufacture.

They have been divided into cinerary urns, 'incense cups,' 'food vessels;' and 'drinking cups.' This nomenclature is to some extent, and as regards some of them, misleading; but it has become so commonly used as to render it difficult, and perhaps unadvisable, to alter it. If the intention of these vessels or the object with which they have been buried with the dead could be distinctly ascertained, then it would become imperative to make such an alteration in the names given to them as would bring the names into harmony with their actual purpose. But as it is impossible to say, with absolute certainty, what they were originally intended for, if indeed they ever had any purpose beyond the sepulchral one; or to explain, in every case, the use they fulfilled when deposited with the body; it is perhaps better. to adhere to the existing nomenclature. It must however be premised that it is merely a conventional one, and the reader must be guarded against forming any

1 The whole question connected with this and kindred practices is very fully illustrated and discussed in Tylor's Primitive Culture, in the chapters on Animism. 
conclusion as to the purpose of the vessel from the name which has been popularly assigned to it.

The cinerary urn (to which name no objection can be made, since it fully answers to its use) and the 'incense cup ' have hitherto been found to accompany burnt bodies, thongh on Langton Wold [No. ii], and in a few other cases, a vessel which is in every respect of form and ornament a cinerary urn was placed close to an unburnt body. The 'food vessel' and 'drinking cup' are met with in association alike with burnt and unburnt bodies, though it is very rare to find a 'drinking cup' accompanying burnt bones. I have only found it so deposited in one barrow. [No. lxii], at Rudstone, where three bodies, one unburnt and two burnt, were placed in a deep grave, each having a 'drinking cup' of very similar shape and ornamentation buried with it.

Though, as has been stated, these vessels are found with burials much more frequently than are weapons, implements, and ornaments, they are by no means associated with the majority of interments. Thus out of the large number of bodies, burnt and unburnt, met with in the series of wold barrows, an account of which is contained in this volume, amounting to 379 , only 108 had any vessel of pottery buried with them, and of these 9 were cinerary urns holding the ashes of the dead.

The four classes of vessels mentioned above have been discovered; slightly varying in form and style of ornamentation, in many localities from the Orkney Islands to the extreme south-west of England, and (except 'drinking cups') in Ireland. In the last-named country they are, and especially the 'food vessels,' upon the whole of better workmanship, and are more elaborately and tastefully ornamented than in most parts of Great Britain. Many of the 'food vessels' however found in Argyleshire and in other districts of the southwest of Scotland, as might be perhaps expected, are very Irish in character, and may claim to be equally fine in the paste and delicate in the workmanship with those from Ireland.

Beyond the limits of the United Kingdom they are represented by vessels of a very different character. In the Channel Islands the type approaches to that which is found in the dolmens and other sepulchral places of Brittany ${ }^{1}$. This type, which occurs more

${ }^{1}$ Some few of the Guernsey sepulchral vessels, however, somewhat resemble those found in Britain. One type, and the same occurs in Brittany, where it is not unusual, has much in common with the 'drinking cup;' and another is not unlike the Dorsetshire cinerary urns. See a paper by Mr. F. C. Lukis in the Archæological Journal, vol. i. pp. 142, 222. 
or less throughout France, is very distinet from that of the British sepulchral pottery. In Denmark and in Holland and North Germany, amongst the vessels belonging to a time before the introduction of iron, some are found which have a greater resemblance to those of our own cairns and barrows; but though there is a certain general similarity of form, and still more of ornament, the difference between those of the two countries is well marked ${ }^{1}$.

The distinction between the pottery of the barrows and that of Roman manufacture made in England is as well defined as is possible in vessels equally made of clay. The shape, the ornamentation, the paste of the British and Roman ware possess scarcely anything in common. The same may be said of the so-called Anglo-Saxon pottery, which has many features in common with Frankish ware, and with that found in the older seats of our English ancestors on the Elbe and in adjoining districts. In colour, form, and mode of decoration, as well as in the paste, it is so di:ferent from that of the British sepulchral mounds, that no one who has the slightest acquaintance with the two could ever mistake between them.

Before a detailed description of these vessels and the classes into which they are divided is entered upon, it is necessary to make a few general remarks upon them with reference to those features they po-sess in common. But, be?ore doing this, it is desirable to remove a false but very common impression with regard to their manufacture. They were at one time almcst universally, and are still occasionaly, spoken of as being sun-dried. This is not the case with any of them, for they have all invariably undergone, more or less, the action of fire; though, in some instances, this has taken place to a very trifling extent. They have not been baked in a kiln, but at an open fire; and the larger vessels frequently show on their upper part a tinge of black colour, cansed by the smoke of the wood with which they were burnt.

They have been all hand-made, not one showing any sign of the use of the wheel; and taking this into consideration, many of them are surprising specimens of the potter's skill.

As a rule, they are more or less ornamented, it being rare to find one which is quite plain,

${ }^{1}$ In Denmark, as also in Guelderland, vases much like our own 'drinking cups ' have occurred. In the style and manner of their ornamentation they are very similar to ours, as also in their general shape, though they are rather squatter than the British specimens, 
The clay of which they are made differs much, both in its quality and in the preparation, by means of tempering, which it has undergone. As the vessels were probably manufactured on the spot, the clay necessarily varied with the several localities; and as greater or less skill was at times employed, and they were more or less hastily made, these differences are only such as might be expected. In the greater number of all the vessels, and in the whole of the larger ones, broken stone in various proportions is found to have been mixed with the clay. In some cases there is almost as much broken stone as clay in the composition. The stone usually consists of such as was at hand; on the wolds, chalk and flint; and in other places, quartz, sandstone, granite, porphyry, or other rocks. The object of this mixture was to prevent the pottery from cracking in the baking, and it also had the effect of making the elay more firm before the firing, so that the shape of the vessel was better preserved. The size of the pieces of stone varies considerably : they are sometimes as large as a pea, at other times almost as fine as sand. In the better-worked clay, of which the 'drinking' cups' and some of the 'food vessels' are made, and where the walls of the vase are thin, the broken stone is wanting; and as a rule it may be said, the thicker and coarser the pottery, the more stone there is in its composition. Some of the vessels appear to have been made from one mass of clay, and at once; but others show that they were formed of separate pieces laid together, the sides being as it were gradually built up. This is apparent from the smooth and rounded edges of the pieces into which a vessel has sometimes separated from long exposure to damp in the ground and from the pressure of the earth upon it, there being a tendency for it to come asunder at those parts where the several pieces of which it was formed had originally been joined. In many of the cinerary urns the clay appears to have been made use of without having been at all tempered; but the finer vessels have had the clay in many cases carefully prepared. Some of the pottery seems to have been made by overlaying a coarser and ill-worked clay with a coating of finer paste; and it is not improbable that in many cases the vessel was shaped at the first out of inferior clay and partly dried, and that afterwards an additional layer of bettertempered clay was laid over the surface, upon which the ornamental patterns were executed, the whole being then fired.

The colour varies to a great extent; it is generally not very unlike that of the clay in its natural state, and is then often of a 
brownish yellow, and at times of a grey tone; it ranges, however, through all the intermediate tints, and in the better-burnt speeimens is sometimes almost red. The fracture shows that the firing has been almost always very imperfect, the inside, except in some of the thinner ware, being usually black. There is no instance where any process of artificial colouring appears to have been employed $^{1}$; nor has there been ever seen any appearance of true glazing. Upon most of the 'drinking cups,' and also upon some of the other vessels, there is however found a polished surface which almost amounts to glazing. This may have been produced by rubbing the hand over the partially-dried vase, but more probably by the use of a smooth stone, or an implement of bone like fig. 35 .

The ornamentation of the pottery, which will however be considered more in detail under the description of each class of vessel, has never been found to exhibit any representation of animal or vegetable form. It consists principally of combinations of straight lines in an almost inconceivable variety. The patterns have been made by a sharp-pointed instrument drawn over the moist clay; by stamping with a narrow piece of bone or hard wood, cut into alternate raised and sunk squares, or simply notched; by rows of dotted markings, round, oval, and triangular, of greater or less size; by the impression of the finger nails ; and most commonly by impressions of a twisted thong, generally made of a strip of hide, but certainly in many cases of string manufactured out of some vegetable fibre, and consisting in some cases of two if not three plaits. Curved lines and circular markings, though they occur now and then, are uncommon, the pattern being generally made up of straight lines arranged in cross, zigzag, chevron, saltire, reticulated, and herring-bone fashion.

It has been suggested that the ornamentation originated in an imitation of basket-work, for the manufacture of which Britain was celebrated; the bascauda, largely exported in Roman times, being not vessels of pottery, but made of wicker-work. This does not seem to me likely; for, apart from the fact that the sepulchral ware in question dates from a time long antecedent to that when these baskets were made, the ornament is precisely that which would be developed by the art instincts of a people in a comparatively low

1 Messrs. Blackmore and Stevens found in some pits at Highfield, near Salisbury, fragments of pottery which were coloured. Their impression is, and for many reasons it appears to be a true one, that the pits belong to a time after the introduction of iron. 
state of civilisation, and is such as could most easily be produced by the simple tools they possessed. It bears a strong resemblance to the patterns found upon some of the bronze axes and on the gold articles belonging to the same period, and with which it probably had a kindred origin. The decorations upon the iron knives \&c. of some of the tribes of Central Africa, and upon the clubs and paddles of the islanders of the South Seas, have much in common with the ornamental patterns upon the British pottery; and it would seem as if, in certain stages of progress, the human mind without any objective influence manifests in different individuals and communities results very similar in their developement.

The sepulchral pottery, as has already been stated, may be divided into Cinerary Urns, 'Incense Cups,' ' Food Vessels,' and 'Drinking Cups.'

These different vessels have been found in the wold barrows in the following numbers. 'Food vessels' are by far the most frequent. In this class I include all those vessels which are associated with unburnt bodies, except 'drinking cups ;' and those which accompany burnt bodies, except 'cinerary urns ;' and 'incense cups,' whatever the form may be. Of these 73 have been met with, 57 with unburnt and 16 with burnt bodies. 'Drinking cups' are the next most numerous, and 24 have occurred; 22 being associated with unburnt bodies, and 2 with burnt ones. Nine cinerary urns have been found, enclosing the deposit of burnt bones; and 12 vessels of the type of the cinerary urn were associated with interments, 2 with unburnt bodies, and 10 with burnt ones, but not containing any of the bones: these, however, are included amongst the 73 ' food vessels' noticed above. The rarest class is the 'incense cup,' of which only 6 were discovered in the barrows I have examined on the wolds. The exact converse of this appears, from Sir R. Colt Hoare's account of the barrows, to have been the case in Wiltshire, where the order is reversed, 'incense cups' being the most common vessel, and 'food vessels' the rarest. The Dorsetshire barrows also seem to contain very few 'food vessels;' and 'drinking cups' and 'incense cups' are also very uncommon.

These classes differ very much from each other, as also do the vessels of each class amongst themselves. It is therefore desirable to give a more minute description of them than has hitherto been attempted.

The Cinerary Urns, those vessels which contain a deposit of burnt bones, are of different sizes, and vary to some extent in 
shape. They range in height from five or six inches to about three feet; the breadth at the widest part being usually about the same as the height. The most common shape is that of two truncated cones, placed the one upon the other, the broadest parts in apposition, the upper rather overlapping the lower and being about half its depth [fig. 54]. The mouth is therefore

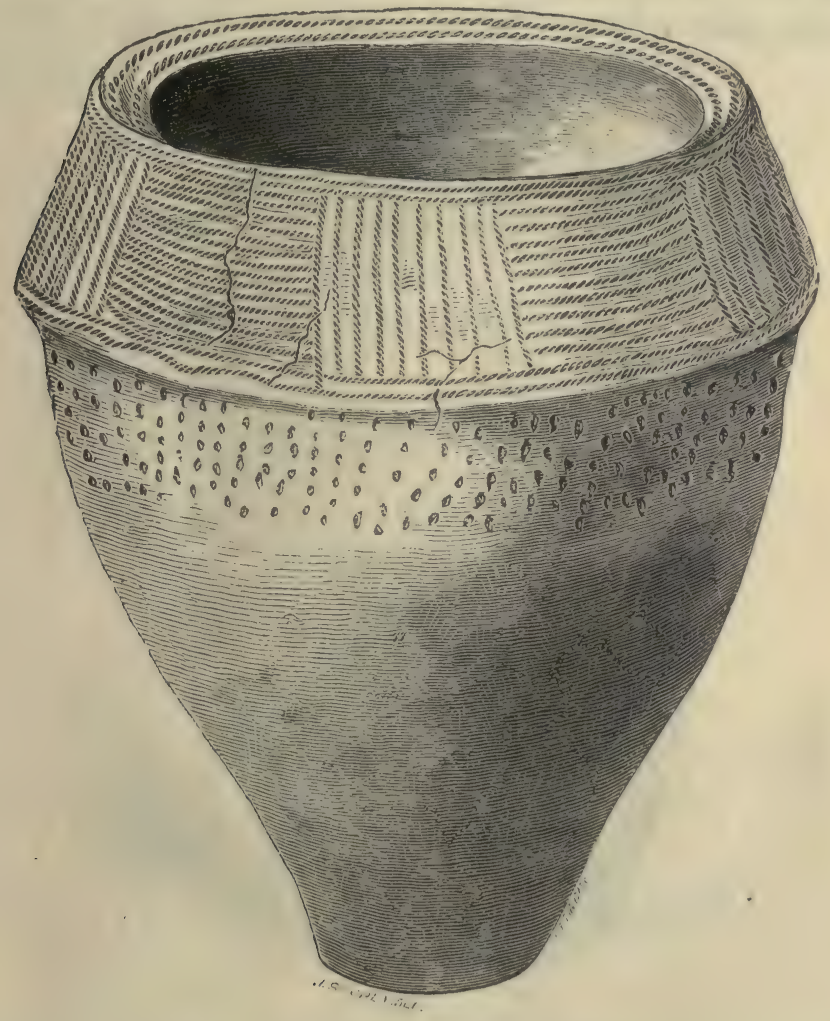

Fig. 54. $\frac{1}{5}$.

contracted, and the upper cone constitutes the rim, which is overhanging. The ornamentation is very often confined to the rim, but is also frequently continued below it, and in some cases extends over the whole surface of the urn; the inner part of the lip of the rim has also, in many cases, a pattern upon it. The bottom of the urn is small in comparison with the mouth, and is usually not above one-third of its diameter. This form is found distributed over nearly the whole of Britain; but in Dorsetshire and the 
neighbouring districts a much more inelegant shape is prevalent, which has no overhanging rim and much straighter sides [fig. 55]. A second form [fig. 56] differs somewhat from that first described. It lias an overhanging rim, but does not present that feature in so marked a degree as in the first type ; and the sides of the urn below the rim, instead of sloping gradually to the bottom, have at that part a concave belt of greater or less depth, from the lower part of which they contract to the bottom of the urn. The over-

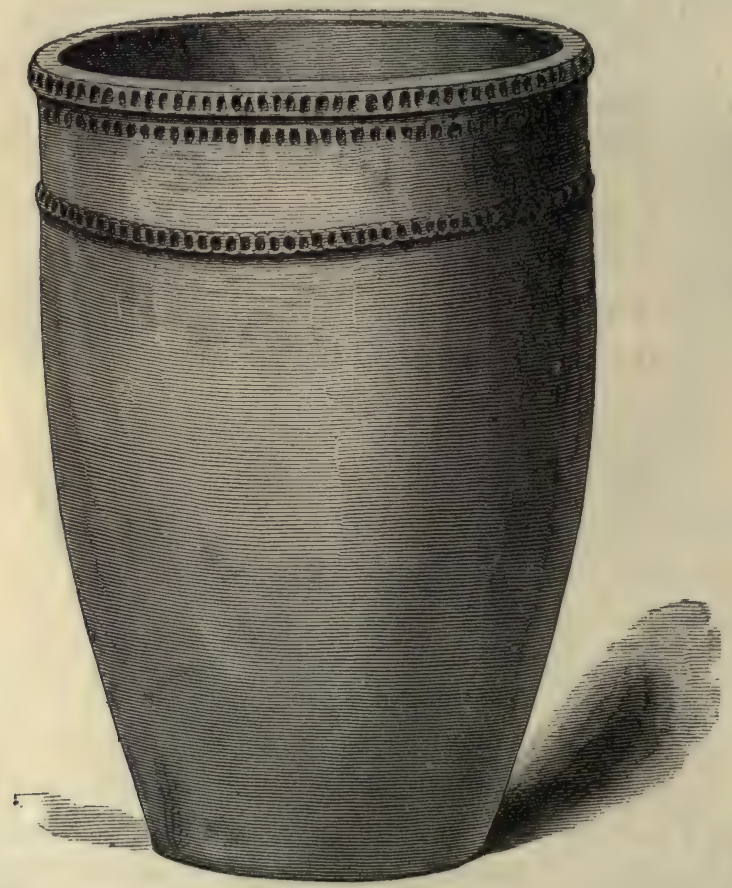

Fig. $55 . \quad \frac{1}{7}$.

hanging rim may be said to be the principal characteristic of the cinerary urns.

There are numerous minor varieties found in different parts of Britain [figs. 57, 58], and perhaps the south-western counties of England show a more distinctly marked departure from the normal types than any other district. In Cornwall and Dorsetshire they are frequently found with handles, or rather perforated projections, round the upper part of the urn. I have not known this type to have occurred on the wolds, or anywhere in the north of 
Britain ${ }^{1}$. In the south-west of Ergland they have been made with semicircular handles in slight relief placed near to the top, apparently to lift them by, and the same form occurs in Gloucestershire and Norfolk. Some have been met with, but very rarely, and never, so far as I know, on the wolds, which have unperforated projections round the rim, presenting in this respect much the same appearance as some of the 'food vessels,' in which this is so common. I possess a cinerary urn, found at Scalby in the North Riding, which has the uncommon

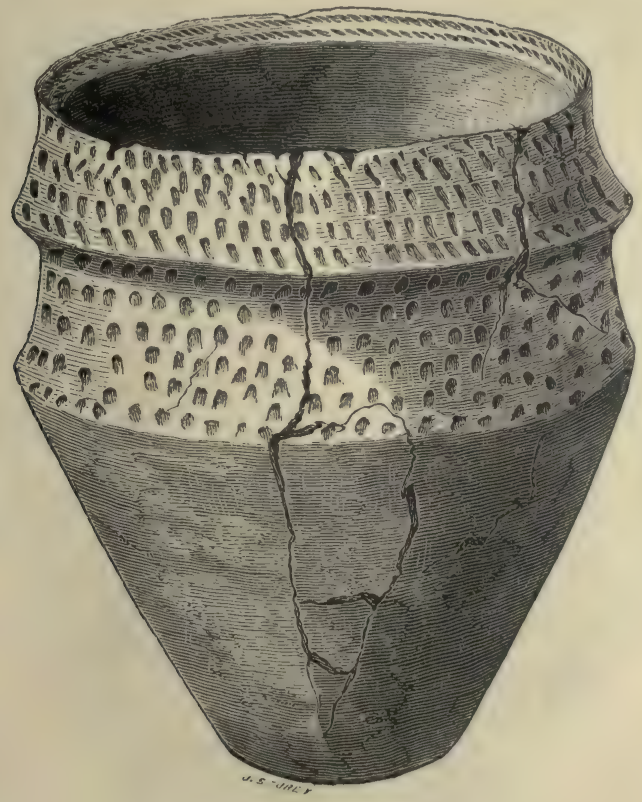

Fig. 56. ริ

feature of possessing two holes, $1 \frac{1}{4}$ in. apart, pierced through the rim near to the top. Others having the same peculiarity have been discovered in different parts of England. The object of these holes in many cases has evidently been to repair a cracked vessel. This cannot however have been the purpose in all cases, for in some of those I have had an opportunity of examining the holes have been made before the vessel was burnt.

1 Mr. Llewellyn Jewitt figures one in Grave Mounds, p. 95, fig. 98, from Darley Dale, Derbyshire, which has four pierced ears; it measures $10 \frac{1}{2}$ inches in height: an 'incense cup' with a handle was discovered with it. 
Several cinerary urns have occurred in Dorsetshire, Wiltshire, and Sussex which have a cross, generally in relief, upon the bottom on the inside; this remarkable feature does not appear to have been observed upon any of those found in other parts of England or in Scotland. As will be noticed in the sequel, the cross in various forms has formed a part of the decoration of some of the sepulchral vessels of the other classes, but there is a great difference in the way in which it has been applied

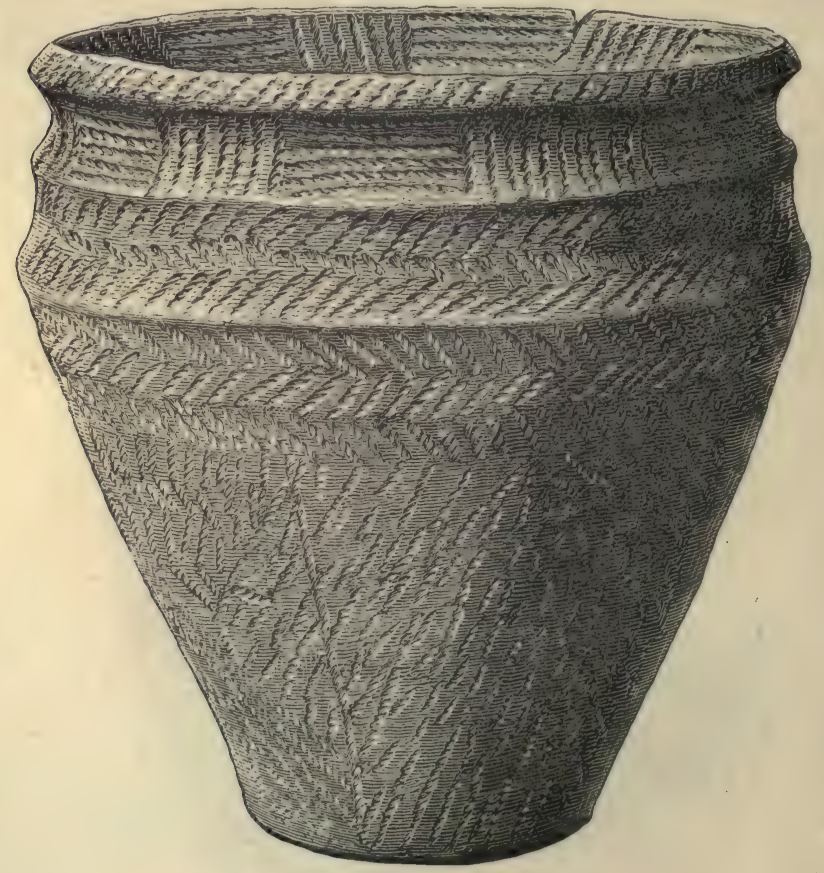

Fig. 57. $\frac{1}{3}$.

on the cinerary urns and on the 'incense cups,' 'food vessels,' and 'drinking cups.'

The clay of which the cinerary urns are made is generally coarse, and in most of them has never, apparently, been tempered to any extent. There is usually a great quantity of broken stone, sometimes in large pieces, mixed with the clay. The walls of these urns are in most cases thick, at times remarkably so, even to the extent of above an inch.

The urns are rarely found to be quite destitute of ornament, though it is frequently scanty and ill applied, giving the im- 
pression that they were made hastily. The ornamental patterns upon them vary in an almost indefinite degree; so much so in fact that it may be said of them that no two are exactly alike.

The most common forms of ornament are alternate series of parallel horizontal and vertical lines (like heraldic enmponé, if it were engraved as of gules and azure); now and then in a double series (as counter-componé); triangles set in rows (or

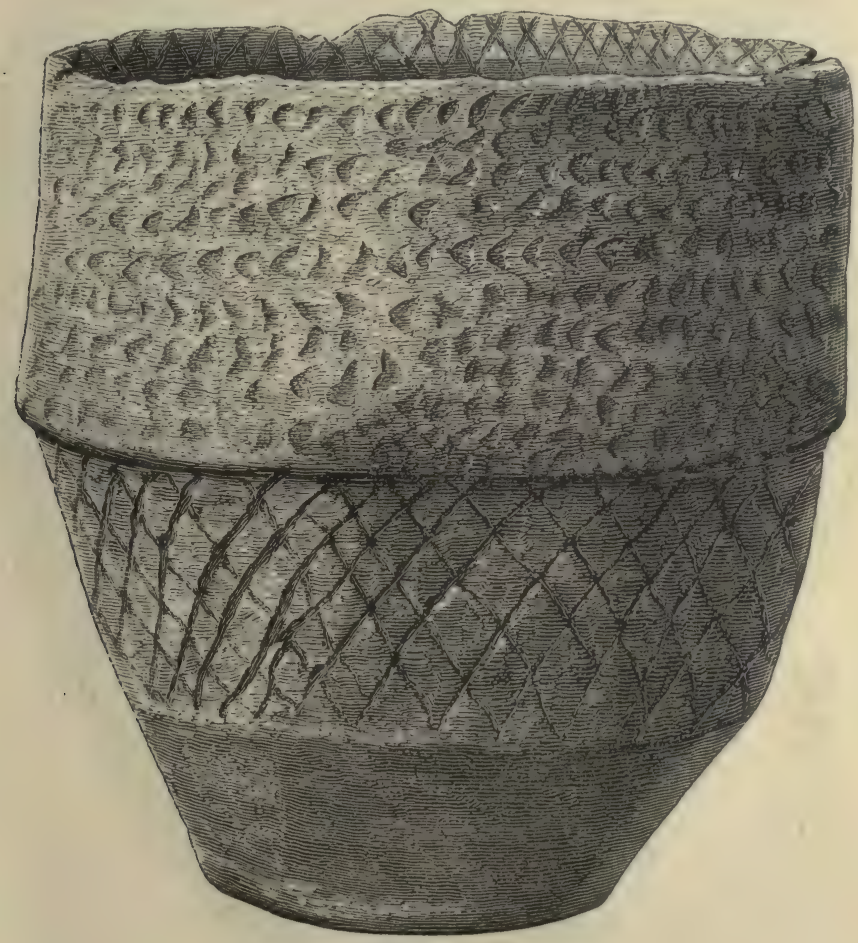

Fig. 58. $\frac{\pi}{2}$.

rather what heralds call a dancetté line of partition), the triangular spaces formed being filled with parallel diagonal lines, which have a different direction in each alternate space (like alternate representations of heraldic purpure and vert); rows of round or oval impressions encircling the urn; lines forming a reticulated pattern; lines placed herring-bone fashion, or in a zigzag. The lines are often made by impressions of twisted thong or cord, but sometimes are drawn on the clay with a sharp-pointed instrument. In some rare cases raised ribs occur 
upon the rim [fig. 59], and one from Rosebrough, Northumberland, has a series of figures in relief [fig. 60].

The larger cinerary urns contain in some instances, besides the deposit of burnt bones, a second vessel. This is often of the same form as the urn containing it, though of course it is smaller; but more frequently it is one of the so-called 'incense cups.' When it is of the form of the larger cinerary urn, it is

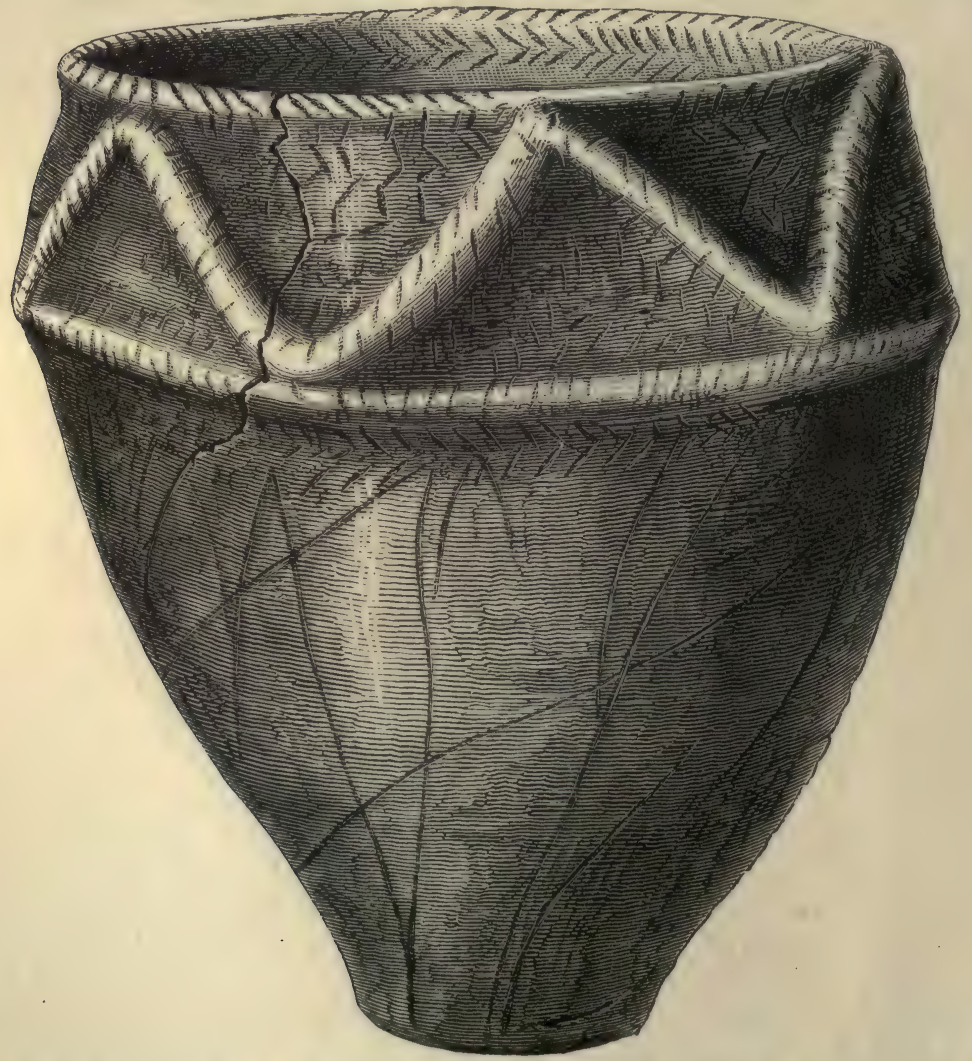

Fig. 59. 交.

generally reversed upon the bones. I have met with an instance where such a smaller vessel, quite empty, was placed by the side of the larger urn. When the contained vessel is an 'incense cup,' it is indifferently found upright, reversed, laid on the side, or placed on the top of, or amongst, the bones. A very small urn of precisely the same form and style of ornament as the cinerary urn, in fact quite a miniature one, about 4 inches high [fig. 61], 
has occurred with a deposit of burnt bones, but not containing any of them, and placed above or amongst them. Several of these were found by me in a group of barrows at Enthorpe, near Goodmanham. I have met with three instances of a vessel like a cinerary urn in form accompanying an unburnt body; they were all of compara-



Fig. 60. 4.

tively small size. In the Orkney Islands vessels of stone have been found answering the purpose of einerary urns.

There has occasionally been found on the inside of the cinerary urns a deposit, sometimes of considerable thickness, of blackcoloured carbonaceous matter. It has the appearance as if a flame, sending forth a large proportion of smoke, had been burning within the vessel for a lengthened period. It is very difficult 
to account for this deposit, which could scarcely originate in anything arising from the calcined bones themselves.

It is by no means the rule to find the remains of a burnt body to be enclosed within an urn, either on the wolds or elsewhere. Out of 78 burnt bodies which occurred in the wold barrows, only 9 were deposited in urns. A cinerary urn, found in a barrow on Sherburn Wold [No. xviii], contained a bronze awl amongst the bones, which itself showed no signs of having been/subjected to the action of fire.

The second class of vessels, that to which the name of 'Incense

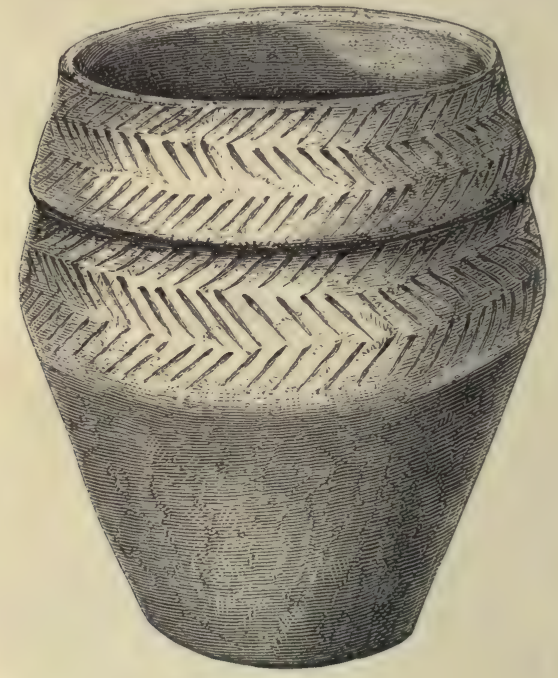

Fig. 61. $\frac{1}{2}$.

Cup' has been applied, has been found in the Orkney Islands, and from thence throughout the whole of Britain, to the extreme limit on the south and west; they are, however, very uncommon in Dorsetshire and the neighbouring districts to the north and west of that county. They also occur in Ireland. They do not, however, appear amongst the various forms of sepulchral pottery which have been discovered in Scandinavia, Germany, and France. In the barrows on the wolds they are not numerous, and were associated with but 6 out of 78 burials after cremation.

They differ considerably in size; and are found measuring from little more than an inch to about four inches in diameter, and from one inch to above three inches in height. They vary 
also in shape; but the most common form is one which expands from the mouth towards the middle, and when at or near that part gradually contracts again towards the bottom, where the width is much the same as it is at the mouth, though sometimes it is narrower at that part [fig. 62]. Another form has

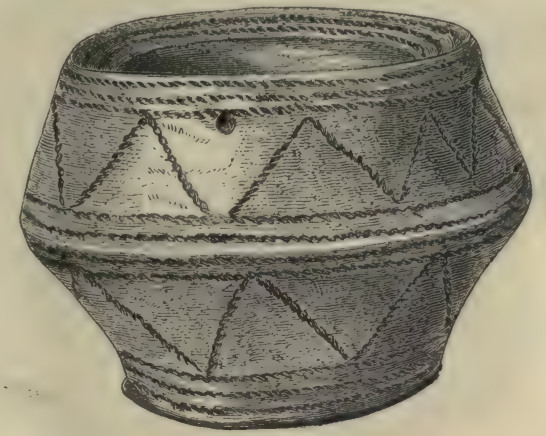

Fig. 62. 궁.

nearly straight sides, narrowing, however, towards the top [fig. 63]. Another is of a flattened globular form [fig. 64]. There are numerous varieties, not materially differing from the typical forms, which it would be tedious as well as useless to particularise. One variety however, found in Wiltshire and the

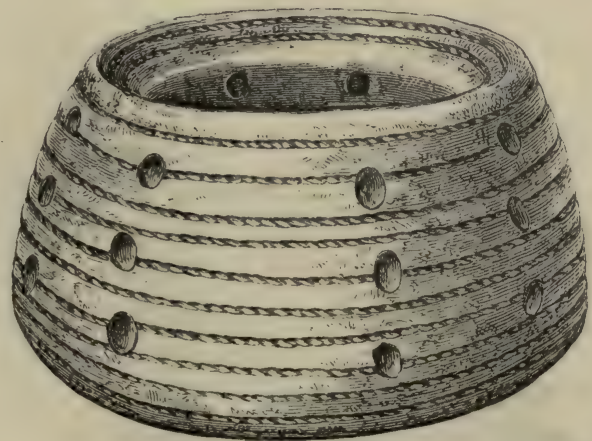

Fig. 63 . $\frac{2}{3}$.

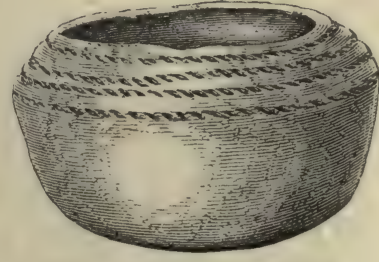

Fig. 64. $\frac{1}{2}$.

adjoining districts, it may be well to notice. It is markedly distinct in shape from the ordinary 'incense cup,' though it has some features corresponding with it. The appearance of this type is not unlike that of a saucer, with the foot deepened to about a third of the height of the whole vessel; it is generally 
perforated with two holes, just above the foot, and some are ornamented on the bottom ${ }^{1}$ [figs. 65, 66].

The clay of which the 'incense cups' are made differs a good deal in fineness, but it is generally of much better quality than

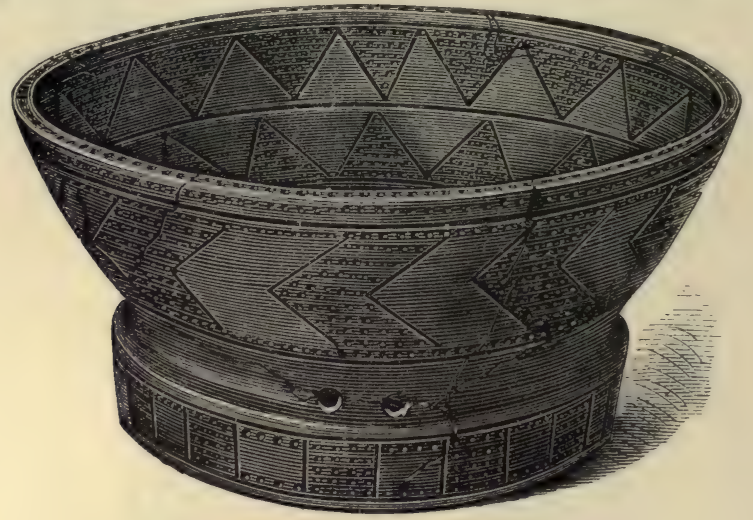

Fig. 65. $\frac{2}{3}$.

that of the cinerary urns. The colour varies from an ashen grey to red, and depends in a great measure upon the greater or less degree of firing to which they have been subjected, as well as to the different nature of the clay of which they are formed. Though broken stone is sometimes mixed with the clay, it is not usually present.

The ornamentation consists of almost all the patterns noticed in the account of the cinerary urns, with many others in addition. The markings, as has already been mentioned under the description of the cinerary urns, are made with a pointed instrument in lines drawn upon the moist clay; frequently by impressions of twisted thong or cord, and sometimes by punctured dots. Many of them have the pattern extended on to the bottom; a very rare feature in the vessels of the other classes. This pattern on the bottom assumes peculiar forms, of which the cross is by no means the most uncommon. That figure, which has the effect of quartering the space it covers, can scarcely be regarded as being anything more than ornamental, though it has been in use in many different countries as a religious symbol in times long antecedent to Christianity. The form

\footnotetext{
1 Two specimens are figured in Hoare's Ancient Wilts, pls. xviii, xxxiii, fig. 3, and three others in Archæologia, vol, xliii. pp. 363-4.
} 
is one which is easily made upon clay, and which would oceur to the maker as a means of decoration almost as readily as any other; yet it is very rarely found amongst the many and varied designs upon the cinerary urns and other vessels, and

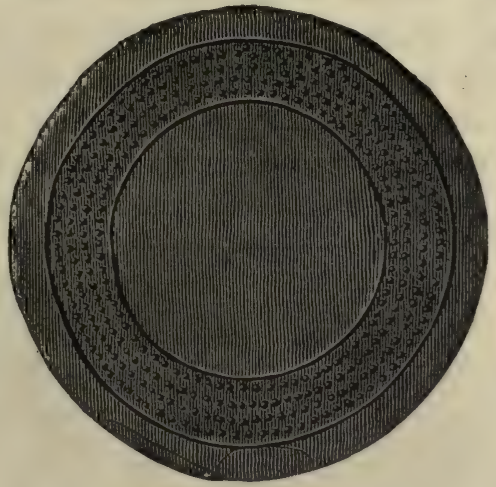

Fig. 66. 옹.

not upon any of them, including the 'incense cups,' except on the bottom ${ }^{1}$. Several have occurred, and in various parts of

1 Some instances of the occurrence of a cross pattern upon sepulchral vessels are brought together in this note, and some others will be found in a succeeding one. I have met with it upon the bottom of two 'food vessels,' discovered in Northumberland, in one of which it almost assumes the form of the fylfot [fig. 79]. Mr. Bateman mentions it as existing on a 'food vessel' from Newton-upon-Raweliffe, in the North Riding of Yorkshire. Ten Years' Diggings, p. 285. It occurs upon the inside of an urn from Worgret, near Wareham. Warne, Celtic Tumuli of Dorset-Tumuli Opened at Various Periods, p. 29. The cinerary urn noticed by Hoare, Ancient Wilts, vol. i. p. 241, and found at Woodyates, has a cross on the bottom of the inside of the vessel, made by the impression of a twisted thong. One from Roke Down, Dorset (Mr. Durden's Collection at Blandford), has a cross in relief on the bottom of the inside; and another similar one was found on King's Down, Badbury, Dorset. Amongst a number of fragments of many different vessels (some of them ornamented with a zigzag pattern of twisted-thong impressions, now in the British Museum, and found in Brixham Cave, but under what circumstances is not recorded) is the bottom of a large and thick vase which has on the inside a raised cross, with a circular depression at the intersection of the limbs. The same figure, and applied in the same way, has been met with on Irish urns : one is figured, Proc. Soc. of Ant., Second Series, vol. ii. p. 5.

Not to mention other instances where the cross has occurred in one form or another on vessels of pottery, it may suffice to refer the reader to Hydriotaphia Cambrensis (reprinted from Arch. Cambr., Third Series, vol. xiv), pp. 40, 62 seq. Mr. Stanley and Mr. Way have there collected a large number of instances. Perhaps in some of these cases it would be more correct to say that the circular bottom of the vessel is quartered, than that it is marked with a cross, though by the process of quartering itself that figure is formed. In these instances the quarters are frequently filled in with lines arranged vertically and horizontally in alternate series, or to speak heraldically, first and fourth vertical lines, second and third horizontal lines. The 
the country, having open work all round the side, the piereings taking their place as part of the ornamental work of the vessel ${ }^{1}$. [fig. 67]. Some of them are perfectly plain.

There is one feature very common in the 'incense cups,' but which very rarely occurs in any of the other classes of fictile vessels. They are often perforated with holes ${ }^{2}$. These, which are usually two in number, are found at different places on the sides. They are most commonly near the top, but often midway down one side, and sometimes near the bottom of the vessel. A second pair of these perforations occurs now and then opposite

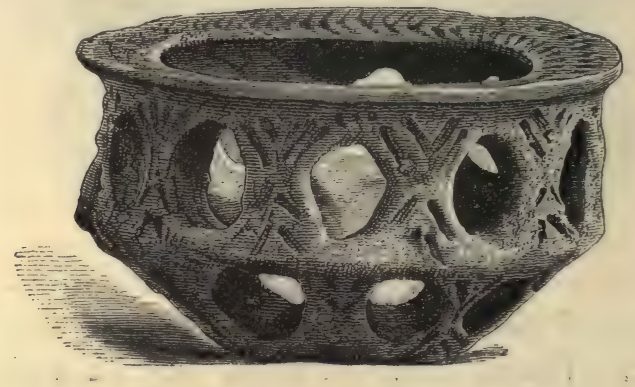

Fig. 67. ․․․

to the first pair, and at other times three sets of two holes are placed at intervals in the sides. In one example [fig. 63], which

bottom of a cup with this pattern upon it, found on the site of a Lake Dwelling, on the Uberlinger See, is figured in Keller's Lake Dwellings, ed. Lee, pl, xxx. fig. 6.

1 Pierced 'incense cups' have been found near Dewlish (and this one forms the frontispiece to Warne's Celtic Tumuli of Dorset): at Normanton, near Amesbury; Hoare, Ancient Wilts, vol. i. p. 201, pl. xxx : at Bulford, Wilts [fig. 67], which also has the bottom ornamented with a central raised point, and concentric rings round it; Archæological Journal, vol. vi. p. 319: at Great Shefford, Berkshire; Journal of Archæological Association, vol. xxii. p. 459: at Stainton Moor, Derbyshire; Archæol. vol. viii.p. 59: at Bryn Seiont, Caernarvonshire; Hydriot. Cambr.p. 40 : on the Moors near Scarborough, now in the Scarborough Museum : at Com-Boots, near Hackness, North Riding; Archæol. vol. xxx. p. 458. One with slits on the lower part, found at Clayton Hill, Sussex, is figured in the Archæological Journal, vol, xix. p. 185. They have also been met with in Ireland; one, discovered in a larger vessel, together with burnt bones, at Killucken, County Tyrone, is figured Proc. Soc. of Ant. of Scotland, vol. ix. p. 197; another, but an imperfect one, also from Ireland, is noticed on the same page.

${ }^{2}$ A very remarkable feature, connected with these perforations, occurs in one found by the Rev. W. C. Lukis, in a barrow on Melmerby Common, in the North Riding. ' On one side of the cup at its base are two small holes, about one inch apart, which appear to have passed through to the inside; but before the vessel was baked a thin coating of clay was smeared over the inside and the holes are obliterated there. Within the cup was the fragment of another still smaller cup, also rudely and not so carefully ornamented.' The bottom of this curious 'incense cup' has a cross pattern upon it. Flint Implements and Tumuli of Wath, p. 6. 
I met with in a barrow near Castle Howard [No. exlviii], are twenty-seven perforations, in sets of three, arranged vertically and at intervals over the whole 'cup.' A very similar vessel, so far as the perforations are concerned, having four rows of small holes encireling it, was found in a barrow with a deposit of burnt bones at Hutton Cranswick, on the wolds ${ }^{1}$.

One, discovered by Sir R. Colt Hoare in a barrow near Woodyates, Dorsetshire, has the upper part overhanging, and through the edge of this projecting rim (so to call it) the holes are pierced vertically ${ }^{2}$. A vessel, not, however, possessing much

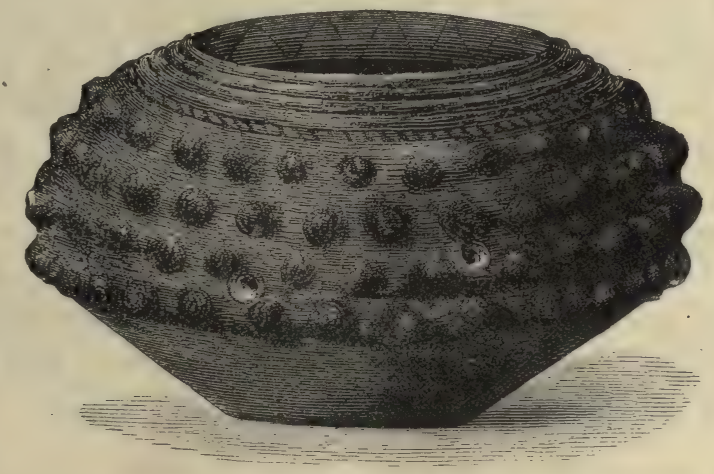

Fig. 68. ․․․

of the form of the 'incense cup,' though found with a deposit of burnt bones inside a larger urn, with vertical perforations through two slightly projecting ears, was met with in a barrow [No. cliv] on Wykeham Moor, North Riding, and is figured in the sequel. Vessels somewhat similar have occurred in Ireland. Some are of very peculiar form; for instance, three found by Sir R. Colt Hoare in the Wiltshire barrows have a grape-like pattern in relief upon them [fig. 68 $]^{3}$; another, also met with by the same explorer, has a division in the middle, by which it is made into two cups, each provided with two perforations close to the division, and therefore just above the bottom of each

1 Proceedings of Yorkshire Antiquarian Club; it is engraved, Reliquiæ Ant. Eboracenses, by W. Bowman, p. 38.

${ }^{2}$ Ancient Wilts, pl, xxxiii. fig. 4 .

${ }^{3}$ Figured in Ancient Wilts, pl. xi. p. 99; pl. xxiv. p. 199. Two similarly ornamented vessels, found near Amesbury, in the same county, are engraved in the Proceedings of the Archæological Institute Meeting at Salisbury, p. 108, figs. 2, 3. Another occurred at Priddy, in Somersetshire, and is now in the British Museum. 
respective cup ${ }^{1}$. Sir $R$. Colt Hoare describes one found at Lake, Wiltshire, 'which is perforated at the bottom like a cullender, and has two holes on the sides ${ }^{2}$ '. A very curiously. ornamented one was discovered at Meinau'r Gwyr, Pembrokeshire; it is drum-shaped, and has vertical ribs in relief all round the sides ${ }^{3}$.

'Incense cups,' when discovered, invariably * accompany deposits of burnt bones, placed both amongst and upon them, but scarcely ever, except accidentally, containing them ${ }^{5}$. They have been found not unfrequently with the burnt bones inside a cinerary urn. They have sometimes been met with in pairs; in the cases where this has occurred, it is probable that the deposit of burnt bones contained the remains of two bodies. I am acquainted with one instance where an 'incense cup' had apparently been burnt with the body, amongst the bones of which, themselves enclosed in a cinerary urn, it was found; but except in that single case, so far as I know, these vessels have been placed with the burnt bones, after the latter had beèn collected from the funeral pile ${ }^{6}$. They have often occurred in association with bronze articles, such as knife-daggers, awls, \&c., and at other times with implements of flint and ornaments of jet.

${ }^{1}$ Figured, Ancient Wilts, pl. xiii. p. 114.

${ }^{2}$ Figured, Ancient Wilts, pl. xxx. p. 209.

3 Figured, Hydriotaphia Cambrensis, p. 41.

4 An 'incense cup' is said to have been found by Mr. Ruddock, near Pickering, in the North Riding of Yorkshire, with an unburnt body. Mr. Bateman tells tas, at p. 227 of Ten Years' Diggings, where the relation occurs:- 'Were it not for the extreme accuracy of Mr. Ruddock's notes, I should feel disposed to think that the skeleton had undergone combustion, as the incense cup has uniformly been found with such.' At page 214 of the same book Mr. Bateman says, 'From the vagueness of the original notes (Mr. Ruddock's) it is uncertain whether the human remains found with these articles were calcined or not.' It is clear therefore that no confidence can be placed in the account which states that the 'incense cup' was found with an unburnt body. Mr. Bateman is, however, doubly inconsistent with regard to this fact, for in another of his books (Vestiges, p. 39) he says, 'Amongst the bones of these four skeletons (unburnt) a small rude incense cup was found, which is of rather unusual form, being perforated with two holes on each side, opposite each other.'

${ }_{5}^{5}$ The Rev. J. C. Atkinson met with one in Cleveland, covered by a flat piece of charcoal evidently designedly placed there, which contained a single burnt human tooth.

${ }^{6} \mathrm{Mr}$. Bateman records the finding of a small vase, which had 'passed through the fire,' in company with a deposit of burnt bones. This may possibly have been an 'incense cup.' Ten Years' Diggings, p. 161. He also mentions 'the fact that portions of earthen vessels were sometimes burnt along with human bodies ;' l.c. p. 190. Sir R. Colt Hoare, Ancient Wilts, pl. xviii, figures an 'incense cup,' which he says (vol. i. p. 174) 'has been burnt and cracked, probably by the heat of the funeral fire.' 
Various opinions have been expressed as to their use, none of which can be regarded as altogether satisfactory. Some of these are grounded upon the belief that the vessels, which accompany burials were once used for domestic purposes. As I cannot assent to that view, any considerations arising from their supposed domestic use are not, in my opinion, of much value in the argument. The whole question of the domestic origin of the sepulchral vessels is, however, more fully considered hereafter, I will therefore say nothing more in this place than to express my dissent from that theory.

The 'incense cups,' as indeed the name given to them implies, have been regarded as vessels in which to burn incense, aromatic oils, or perfumes; and it has been conjectured that they were suspended over the funeral pile. This is the view propounded by Sir Richard Colt Hoare, by whom the name was first given to them '. Mr. Birch, in 'Ancient Pottery and Porcelain 2,' appears to regard them as pots or lamps, though it is doubtful whether he refers, in the passage in question, to 'incense cups' or 'food vessels.' By others they have been regarded as the receptacles of some particular part of the human body, such as the ashes of the heart. The Hon. W. Owen Stanley and Mr. Albert Way, in a valuable essay upon Ancient Interments and Sepulchral Urns, found in Anglesea and North Wales, printed in the Archæologia Cambrensis $^{3}$, seem to lean to the belief that they may have been chafers, "for conveying fire, whether a small quantity of glowing embers, or some inflammable substance, in which the latent spark might for awhile be retained, such for instance as touchwood, fungus, or the like,' with which to kindle the funeral fire.

That they were incense or perfume burners appears to imply a state of refinement to which we can scarcely consider the people who used them to have attained; and though the sepulchral remains show the great importance that was attached to burial and its attendant rites, it is improbable that fumigation, used either as concealing the odour of the burning body or as part of a religious ceremoniy, was practised ${ }^{4}$. The objections to the

1 Ancient Wilts, vol. i. pp. 25, 209.

${ }^{2}$ First Edit., vol. ii. p. 380 ; second Edit., p. 587.

3 Third Series, vol. xiv. Revised for private distribution, under the title of Hydriotaphia Cambrensis, \&c., from notices collected by the Hon. William Owen Stanley, M.P., with additional observations by Albert Way, M.A., F.S.A.

* Mr. Way mentions, in the essay just above referred to, that from the information of Mr. Lodge, a gentleman long resident in India, it appears that 'it is not unusual 
opinion which regards them as lamps are very strong. It is quite possible that a light may have formed part of the ceremonial attendant upon the interment of the dead, but as 'incense cups' are accompaniments of burials after cremation, their application in the capacity of a lamp appears to be supererogatory. The nature of the vessels themselves seems to preclude the idea that they could ever have answered any such purpose. The occurrence of ornament upon the bottom, which is found at that part much more frequently upon them than upon any other of the sepulchral vessels, affords a presumption that they were meant to be seen from kelow, and may seem to favour the theory that they were lamps, but it can only be regarded as corroborative evidence at the most. The circumstance that they are frequently perforated, as if for suspension, has also been urged in support of their having been used as lamps, but the perforations occur as often close to the bottom or near the middle as at the top, and therefore cannot be considered as made for that exclusive purpose. The fact that these perforations consist not only of two or of four, placed in pairs opposite each other, but sometimes of a large number over the whole of the sides of the vessel, makes their intention as a means of suspension more than problematical. It seems impossible to separate these smaller perforations from the larger piercings which, as has already been stated, occur in some of the 'incense cups.' Nor could a lamp have holes close to or in the bottom, for its very nature entails upon it the necessity of preserving the oil from being wasted; a requirement which surely could never be answered by a vessel with a bottom like a cullender. One of the strongest objections, however, to their having been so used appears to be this, that there has never been found upon them any appearance of their having served for such a purpose. It could not be expected, indeed, that the wick should have remained after so many centuries of exposure to various disintegrating influences; but the marks of the smoke from it would have been found, just as they are still seen upon the Roman lamps of earthenware.

That they were intended to contain some especial part of the body is in itself so unlikely, and has so little beyond mere

to place upon the breast of the corpse a small cup containing some powerful perfume, whereby the disgusting and insalubrious stench might be remedied.' Mr. Way, however, pertinently adds, 'whence were perfumes or unguents to be procured in the neolithic or later stone age, to which the vessels under consideration appear mostly to belong.' l.e. p. 72. 
conjecture to recommend it, that it is not worthy of any serious. consideration. Indeed no part of the body except bone could be recovered after the burning, and as a rule no remains of bone are found in these vessels, unless it has got in accidentally from their having been placed amongst the deposit.

The explanation of Mr. Stanley and Mr. Albert Way appears to me to possess, upon the whole, the best claims to acceptance; and until some more likely one is suggested, or some facts come to light which render it untenable, I feel inclined to adopt it, as, at all events, a provisional explanation of the purpose of these enigmatical vessels. The burning of the dead was certainly not practised merely to dispose of the body, but was a custom which had more or less of a religious character about it. The rite, doubtless, was gone through with some degree of form and solemn observance. The application of fire to the body, to a greater or less extent, appears to have been universal, and shows what a deep significancy there was in it with reference to the dead. It is therefore not an unnatural supposition that the fire which was to consume the body should be brought to the pile with a certain amount of ceremony, and that it might have been taken there from the place where it had been kindled in accordance with some especial usage ${ }^{x}$. The fact that 'incense cups' are always associated with burials after cremation, brings them into intimate connection with the burning of the body, and perhaps may be considered to favour the view which regards them as the means of conveying the fire to kindle the funeral pile. Neither the form nor the peculiarity of the holes and piercings is inconsistent with this explanation of their use. Their size is what we might expect to find in vessels made for the purpose of carrying a piece of ignited touchwood or other suitable material, and the holes and piercings are not ill adapted for keeping it, by means of a draught, in a state of ignition.

The vases to which the name of 'Food Vessel' has been applied are found associated both with burnt and unburnt bodies, though

1 The account of the funeral of Narayan Wasudeo, a member of the Legislative Council of Bombay, contains a very interesting record of such a practice as it has been supposed was current in Britain. 'The sacred fire, which had been kindled with due ceremonies at the house, was carried in front in a brazen vessel by the deceased's son.... While this (the making of the funeral pile) was being done, a number of torches of sandal wood were being carefully ignited by the son of the deceased at the sacred fire, which he had brought with him for the purpose.... The friends applied matches to the sandal-wood brands and, when they blazed up, set fire to the combustibles.' Times of India, Sept. 1, 1874. 
most commonly with the latter. They are by far the most frequent of the sepulchral vessels met with in the barrows of the wolds. In the 73 cases where they have occurred in that series of barrows, they were all, with the exception of 16 , associated with unburnt bodies, and these 16 include 9 which were not of a purely 'food vessel' type. The proportion has not been so great, though still very large, being 12 with unburnt to 5 with burnt bodies, in the barrows I have opened in other parts of England; and the same appears to have been the case in the Derbyshire and Staffordshire barrows, in which Mr. Bateman and Mr. Carrington discovered 25 , and of these 19 were placed with unburnt bodies. In the large series of Cleveland barrows, however, in which, as has already been mentioned, Mr. Atkinson met with no burials by inhumation, though the number of burnt bodies he found was very great, there was not one which had a distinetive 'food vessel' accompanying it. They seem to have been very rarely met with. in the south of England; and they are of infrequent occurrence in East-Anglia, where the kindred 'drinking cup' is also, but not commonly, found. Two or three vessels, which probably answered the same purpose as this class is supposed to have done, were all that were discovered by Sir. R. Colt Hoare in Wiltshire; nor do they appear to have been more frequently found in Dorsetshire and the other southwestern counties. They are, however, common in the northern parts of England, as they are in Scotland. In Ireland they are also numerous, many of them being artistically made and very beautifully ornamented.

When they are deposited with burials after cremation, they do not contain any of the bones, but are placed sometimes amongst them, but more frequently upon or at the side of them ${ }^{1}$. There is no difference in the form or style of ornament between those found with burnt and those found with unburnt bodies.

They vary in size from about $3 \mathrm{in}$. to $8 \mathrm{in}$. in height, and are more diversified in shape than those of any other class. The prevailing type is one which is in form like figs. $69,70,71$, sometimes, but not always, contracting towards the mouth. This type has frequently projecting knobs or ears, of a greater or less number, placed round the shoulder of the vase, which are sometimes

${ }^{2}$ Mr. Bateman, speaking of one, says, 'It is of that class of vessel indifferently deposited with human remains, burnt or unburnt, and which may probably have contained food or drink, but never the remains, as is the case with cinerary urns.' Ten Years' Diggings, p. 19 . 
perforated, and at other times without any piercing ${ }^{1}$. Those with pierced ears must, I think, be regarded as the earlier, the object of the piercing being to allow a thong or cord to be passed through

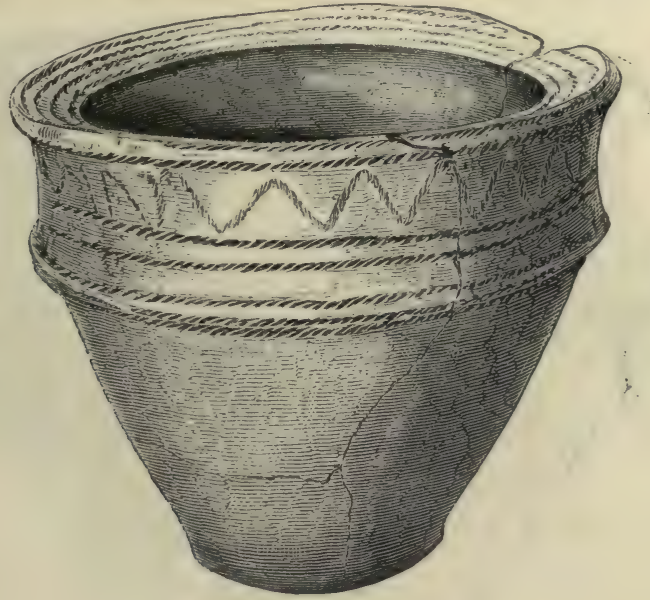

Fig. 69. $\frac{1}{2}$.

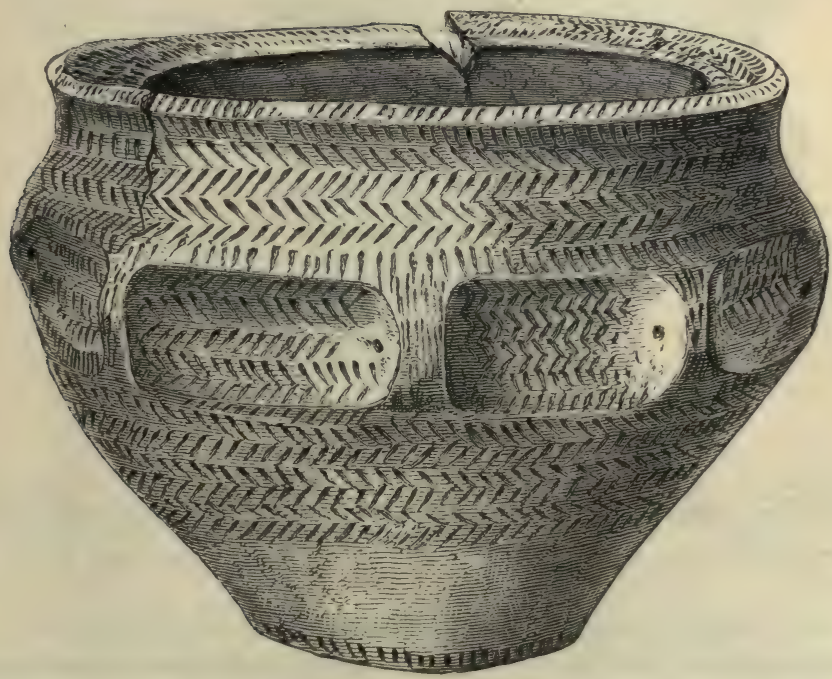

Fig. 70. $\frac{1}{2}$.

1 One of this type, having the rare peculiarity of two series of pierced ears, one above the other, the ears being placed alternately, was found in a barrow on Seamer Moor, in the North Riding. It is figured in the Journal of the British Archrological Association, vol. iv. p. 102. 
the holes, by which to suspend them ${ }^{1}$. When they ceased to be suspended, the ears were still retained, in accordance with the common principle of survival, but were not pierced, becoming mere
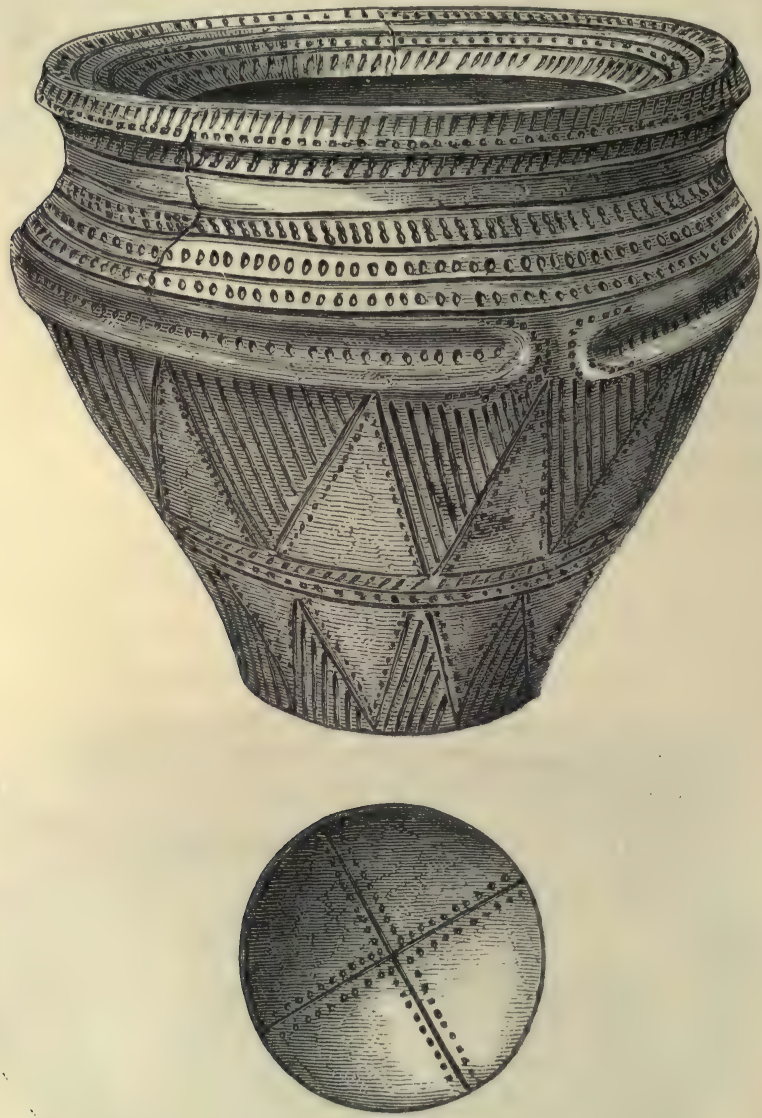

Fig. 71. $\frac{1}{2}$.

ornamental appendages, and indeed, as such, they are very effective. I discovered two, in separate barrows, on Goodmanham Wold [Nos.

1 Vessels, usually of small size, perforated evidently for suspension, have been found in Denmark, in burial chambers of the Stone Age, where they are associated with unburnt bodies. It is probable that they served the same purpose, of holding food, as did the British 'food-vessels.' I have seen vases, in shape and general style of ornamentation almost like that class of 'food-vessel' which has the projecting knobs round the shoulder, taken from graves near Tolima, United States of Columbia. They are perforated for suspension near to the rim, and have also a groove on the bottom corresponding to the holes above, in order the better to keep the cord, which held them up, in its place. 
cii, ciii], which had evidently been made by the same workman, where in one case the ears were pierced, in the other being left unpierced. The holes, however, are so small in some of them, that it would be very difficult to pass a thong through them. Many of this type are very well and symmetrically made, and the ornament also is applied with much taste; and they may be said to excel in fineness of paste, care in manufacture, and beauty of ornament any 'food vessels' of the other types which are found upon the wolds

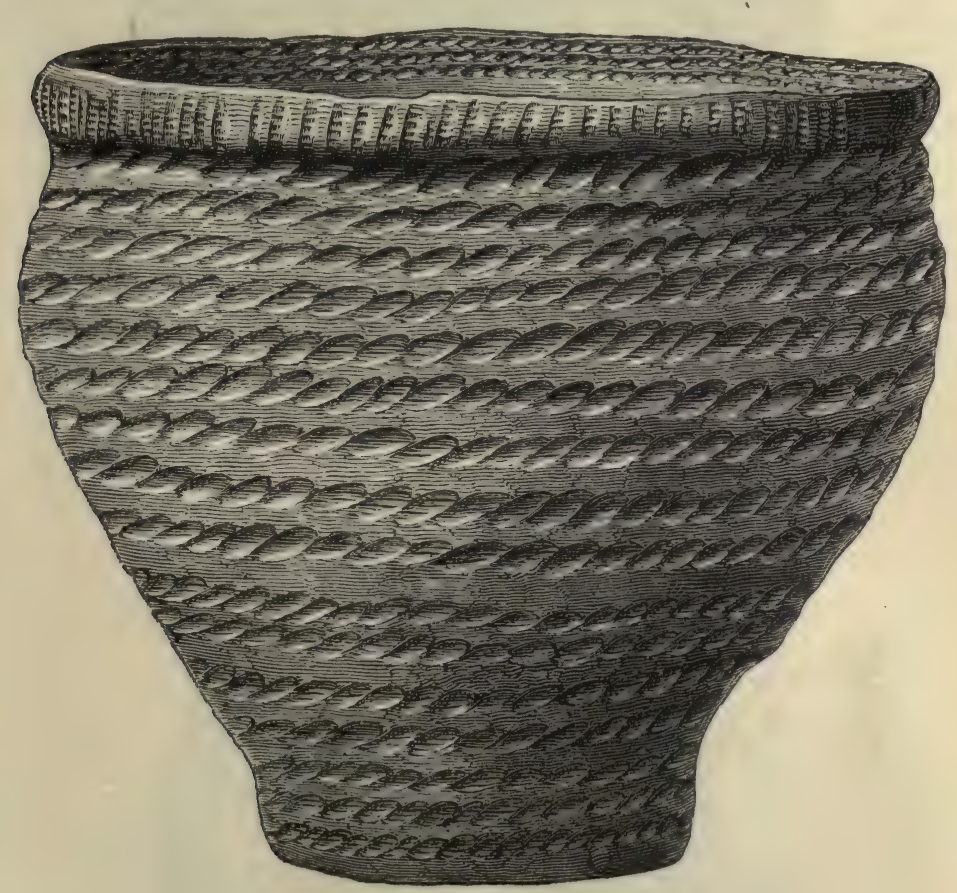

Fig. 72. $\frac{1}{2}$.

and in other parts of Yorkshire. In Northumberland, however, and in the south-west of Scotland, a class of 'food vessel,' rather bowlshaped in form and without ears, being very similar to many of the Irish specimens, is perhaps still more beautifully, as it is certainly more elaborately, ornamented. Another common type in the wold barrows, and more frequently found there than in other parts of England, is one which approaches somewhat to the globular shape, though it is higher than it is wide [fig. 72]. It is made of coarser clay, and is less skilfully manufactured than the lastmentioned class; the ornamentation also is not so carefully designed, 
and shows but little taste in its application. There are numbers also which cannot be classed with any type, as they differ amongst themselves, and more or less from any of the before-mentioned forms, as fig. 73. Others are of very peculiar shape, and of rare

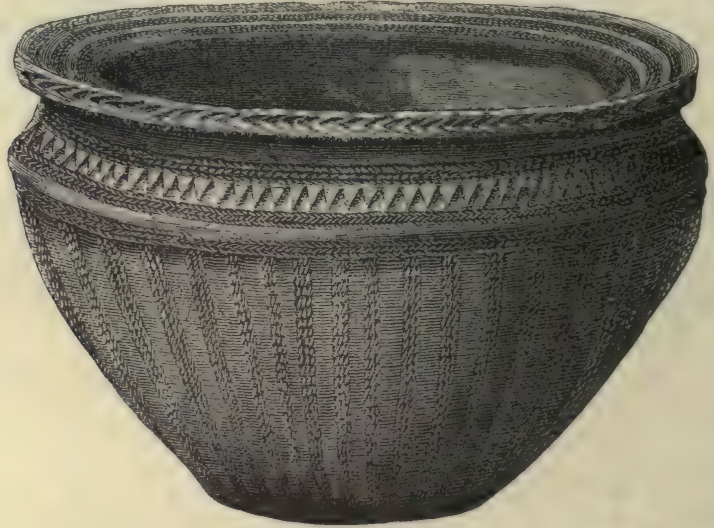

Fig. 73. $\frac{1}{2}$.

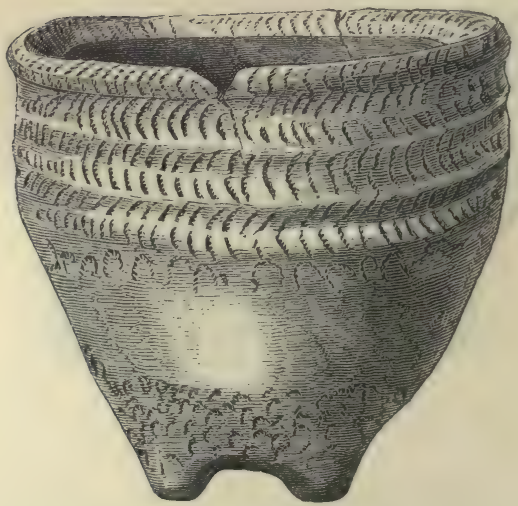

Fig. 74. $\frac{1}{3}$.

occurrence. For instance, they have been found with four feet, one of these occurred in a barrow at Weaverthorpe [No. xliii], [fig. $74]^{1}$; and two very singular vessels, one discovered at Heighington, Lincolnshire $[\text { figs. } 75,76]^{2}$, the other near Corbridge, in

${ }^{1}$ I have seen a second one of this form, found in a barrow at Amotherby, near Malton, in the North Riding.

${ }^{2}$ Archæol. Journal, vol. xxvi. p. 288. 
Northumberland ${ }^{1}$, have four perforated feet, as if it were intended to hang the vase up with the mouth downwards. In a barrow on Potter Brompton. Wold [No. xxi] were two small ones having the extremely rare addition of a cover or lid [fig. 77]; and another

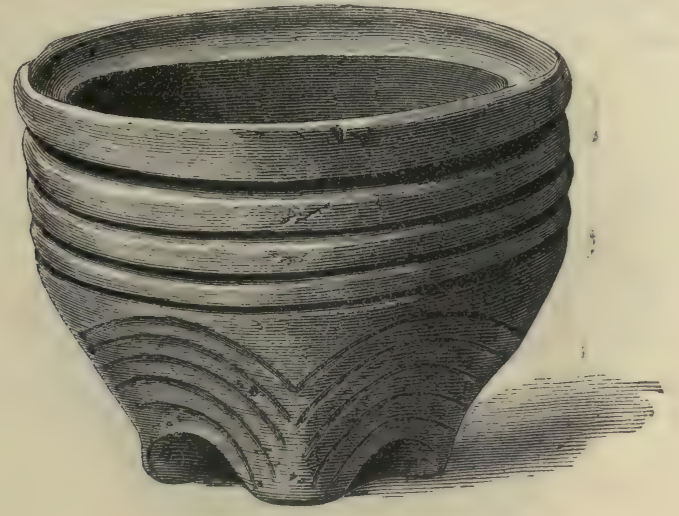

Fig. $75 . \frac{1}{3}$.

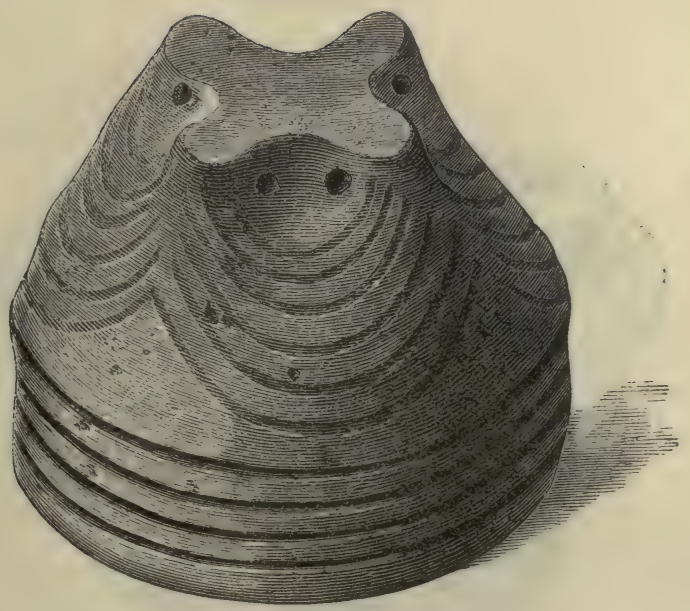

Fig. $76 . \quad \frac{1}{8} \cdot$

instance of the same addition to the vase was met with in one of the barrows on Goodmanham Wold [No. xeviii]. One from Doddington, Northumberland [fig. 78], has four handles, scarcely large enough to hold it by, and yet ton large if made merely for the 
purpose of suspension ${ }^{x}$. The same county has produced a large number of abnormal forms of 'food vessels,' but it is unnecessary to describe every variety; engravings of two of them are given,

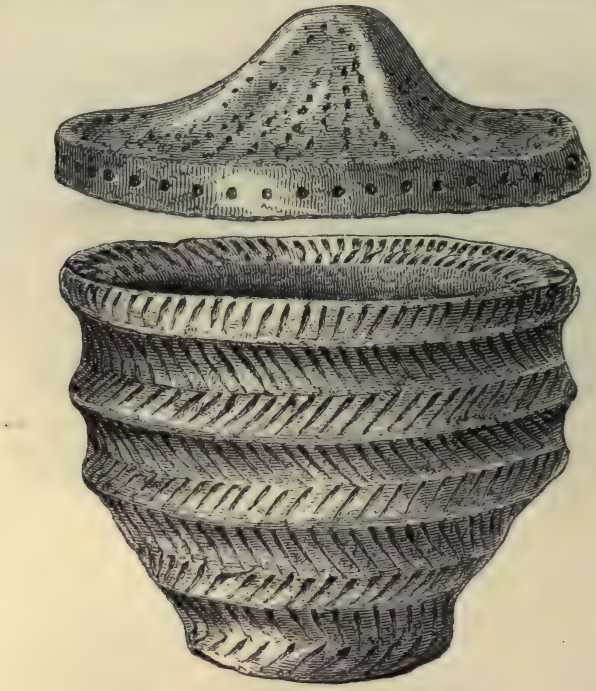

Fig. 77, $\frac{3}{4}$.

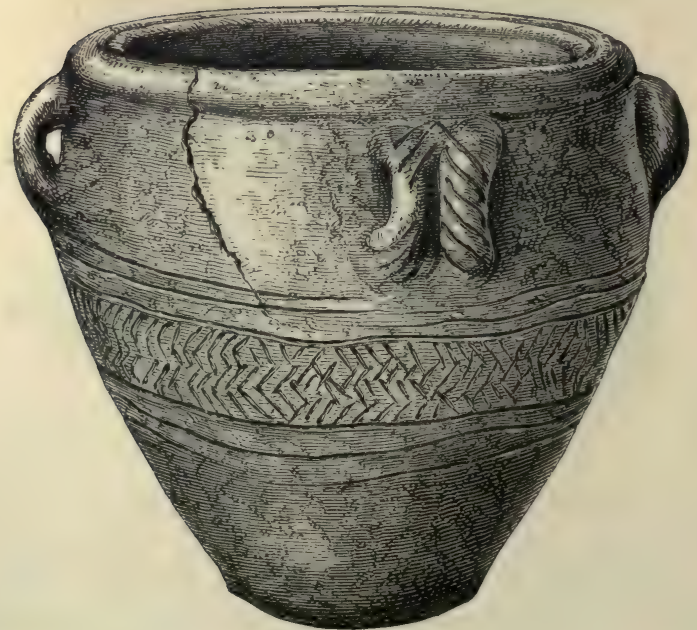

Fig. 78. $\frac{1}{3}$.

1 One, somewhat similar, having four handles, or rather large loops, found at Wetton Hill, Staffordshire, is engraved in Bateman's Ten Years' Diggings, p. 139. 
one of which [fig. 79] was found at Hepple, in the parish of Rothbury; the other [fig. 80] at Ford.

The clay of which they are composed is as different in quality as are the vessels themselves; for while some are extremely rude, and made of coarse unworked clay, others are elegant in shape, graceful in the style of ornamentation, and the paste fine and
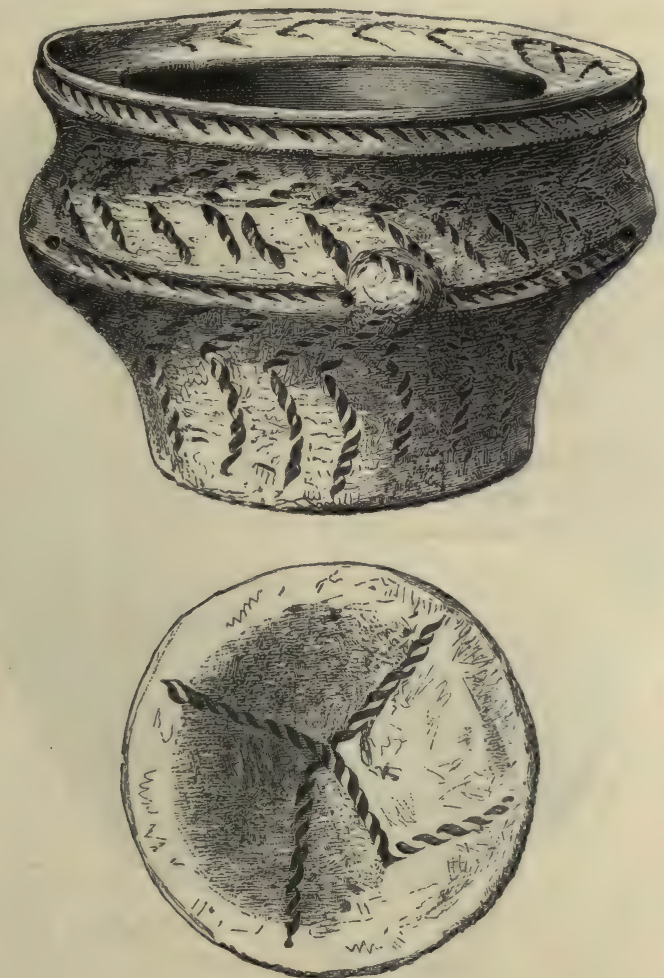

Fig. $79 . \quad \frac{7}{1}$.

well-tempered. The better specimens have no mixture, or scarcely any, of broken stone in the clay, but others have the clay full of it, and are frequently, in material and imperfect firing, no better than the worst-made cinerary urns. Vases of the two qualities are often found in the same barrow; indeed it is no uncommon occurrence to discover together, and apparently deposited at the same time, a 'food vessel' beautiful in its shape and ornament, and another ill-formed and with a pattern upon it of the rudest deseription. 
It is quite impossible to give anything like a complete account of the ornamental designs found upon them, for they are endless. Amongst the most common are lines of short impressions, arranged herring-bone fashion, and encompassing and covering the vessel; lines drawn round the vessel, having between them dotted impressions or short lines, usually sloping; zigzag lines, with various markings within them; variously formed lines of impressions made

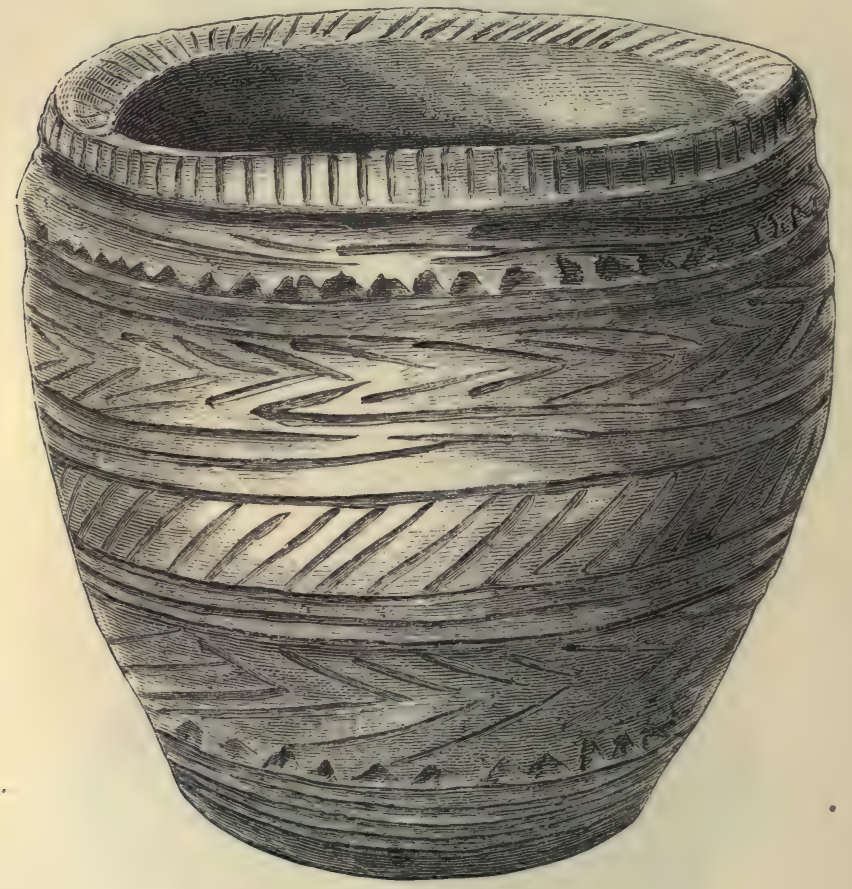

Fig. 80. $\frac{1}{2}$.

by a piece of bone or wood and giving a triangular or oval-shaped mark. The ornamentation is sometimes confined to the upper part of the vase, but more frequently it covers the whole, and is found on the inside of the lip of the rim, and in rare instances on the bottom of the vessel. The patterns have been made by thong or cord impressions, by lines drawn with a pointed instrument, and by dotted markings. In colour the vessels vary as much as those of the other classes of sepulchral pottery. They are ashen-grey, yellowish brown, straw-coloured, dark brown, and almost as red as pale brick:

The position they occupy relative to the body differs consider- 
ably; they are met with before and behind the head; in front of the chest; behind the shoulders and back; in front of the knees; and at the feet. The most frequent place, however, is near the head.

Though it is not possible to say with absolute certainty what was the purpose for which they were placed in the grave, a more probable reason of their occurrence there can be assigned than any that has been suggested with regard to the 'incense cup.' The name given to them, there can be little doubt, answers to their use-namely, that of containing food for the dead. In several instances a dark-coloured substance has been found in them, and in others a black deposit is to be observed on the inside near to the bottom, which may easily be the remains of animal or vegetable matter: unfortunately, an analysis does no more than show that such is the nature of the deposit. This fact, however, that remains of such a nature are found in them, goes far to prove that they were receptacles of food; for in what other shape is it likely that any animal or vegetable substance would be placed in connection with the dead? That food, or what could scarcely be anything else, was sometimes deposited with the body, is shown by the occurrence of the remains of portions of the bones of animals, such as pig and goat, found in the grave together with those of the buried person. Where I have met with such relics in close connection with the body, no vessel of pottery was present. Though I would not insist upon the practices of modern savages as being, except to a limited extent, any illustration of the burial usages of the early people of Britain, they have nevertheless some value. The North American Indian tribes, we know, place a bag of provisions with the dead, and this custom may very well have prevailed in our own country at the time of the erection of the barrows; for there is nothing connected with these people, so far as we have the means of judging, which makes it unlikely that such should have been their custom too ${ }^{1}$.

Whatever may have been the purpose for which the 'food vessel' was deposited in the grave, the same, there can be little doubt, was

1 Food, in a very distinctive form, has been met with in graves in different countries. In a cemetery at Oberflacht in Suabia, porridge, pears, and bones of animals were found in many of the coffins. Graves of the Alemanni, by W. M. Wylie, Esq., Archæol. vol. xxxvi. p. 129. The contents of Egyptian tombs bear abundant testimony to the practice, even cooked provisions have occurred therein. Maize and other vegetable products have frequently been discovered in the Peruvian cemeteries, as for instance at Arica. 
answered by the next class of sepulchral vessel, the 'Drinking Cup.' Though not so commonly met with as the 'food vessel,' it is nevertheless sufficiently abundant; I have found it associated with burials in the wold barrows in 24 cases, 2 of these being burials after cremation. It occurs throughout the whole of Britain, and varies less in each different locality than those of the other classes of

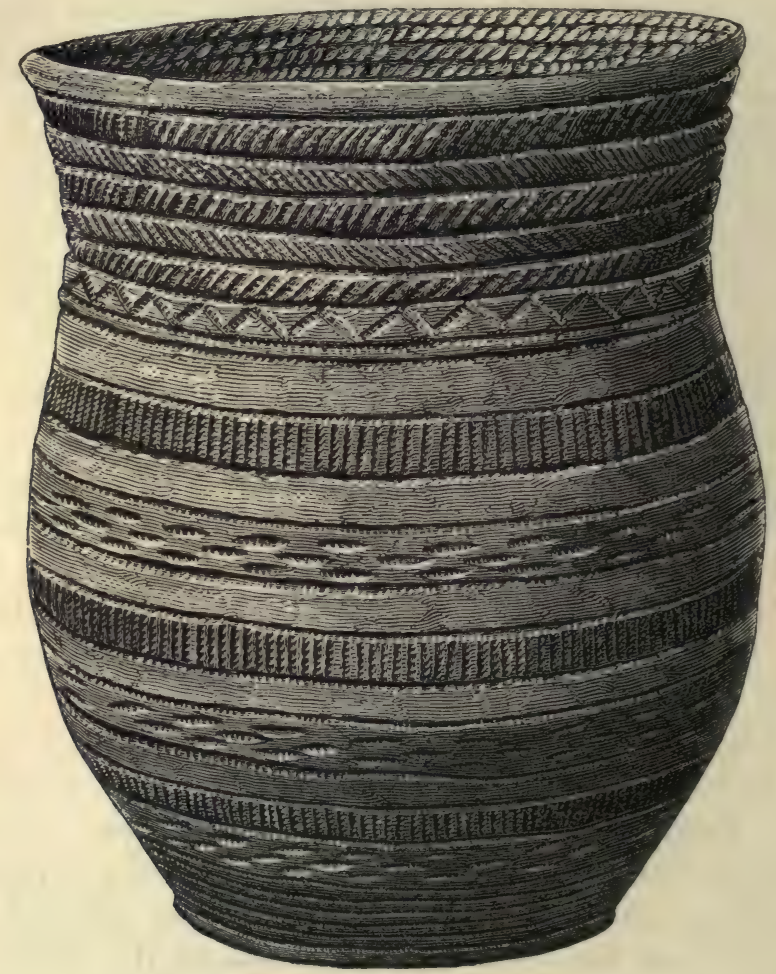

Fig. 81. $\frac{1}{2}$.

sepulchral pottery. 'Drinking cups' have been met with in Wiltshire and in Argyleshire so identical in shape and ornamentation, that a representation of one might almost stand for the other; and I possess two, one from Northumberland, the other from Argyleshire, which are not easily to be distinguished from each other. 'Drinking cups' do not appear to have been met with in Ireland; but a form of vessel approaching them in shape and ornamentation has been found in the dolmens of Guernsey and Brittany. In Holland and North Germany somewhat similar vases, though not 
so elegant in form as those from Britain, have been discovered not unfrequently in the sepulchral mounds ${ }^{1}$.

There is a considerable difference in their size, and they vary. in height from $5 \mathrm{in}$. to $10 \mathrm{in}$. In shape they arrange themselves into two principal forms, though there is a great general similarity between the two. The one [fig. 81] is more flowing and easy in outline, narrowing from the mouth to about the middle, then gradually swelling, and then again narrowing towards the bottom;

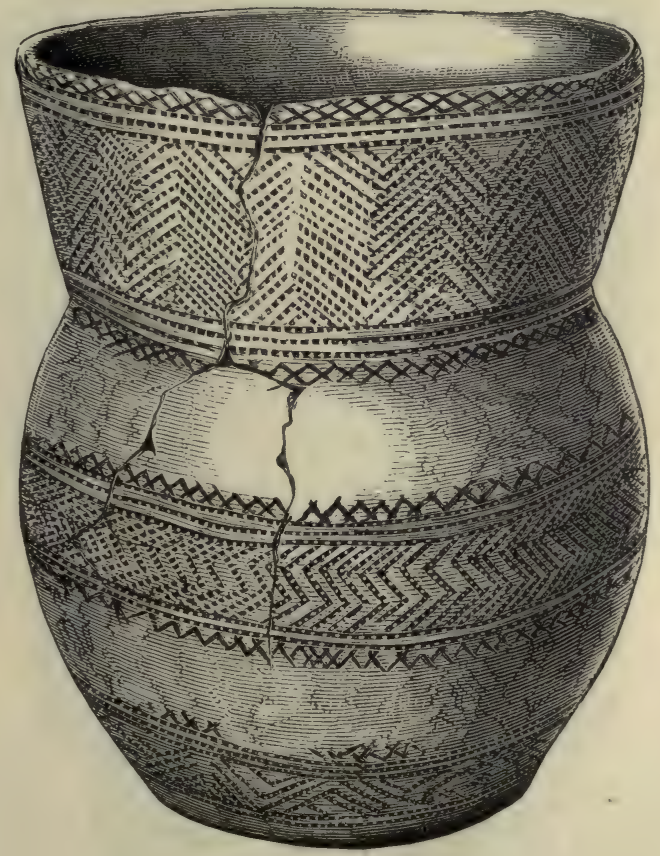

Fig. 82 . $\frac{1}{2}$.

the other form [fig. 82] is rounder than the last near to the bottom, and from the upper part of this globular portion of the vessel the sides widen towards the mouth without any curvature.

There are other forms [figs. 83, 84, 85] which vary more or less from these two, but which do not frequently occur. Some of a very distinctive shape have been met with; one of which, having a handle, may be mentioned. I have only found one of this type

1 There is a vessel in the British Museum, ornamented with a pattern of twistedthong impressions, very much like the ordinary British 'drinking cup.' It was found at Bennedorf, near Merseberg. 
[fig. 86], in a barrow on Goodmanham Wold [No. cxiii], and one other at least has occurred on the wolds. Two vessels of this form, almost alike in shape and ornament, have been discovered, one near Pickering, in the North Riding ${ }^{1}$, the other in the Isle of Ely ${ }^{2}$. In the Mayer Collection, at Liverpool, there is one said to have been found near Whitby. A fragment of one having the

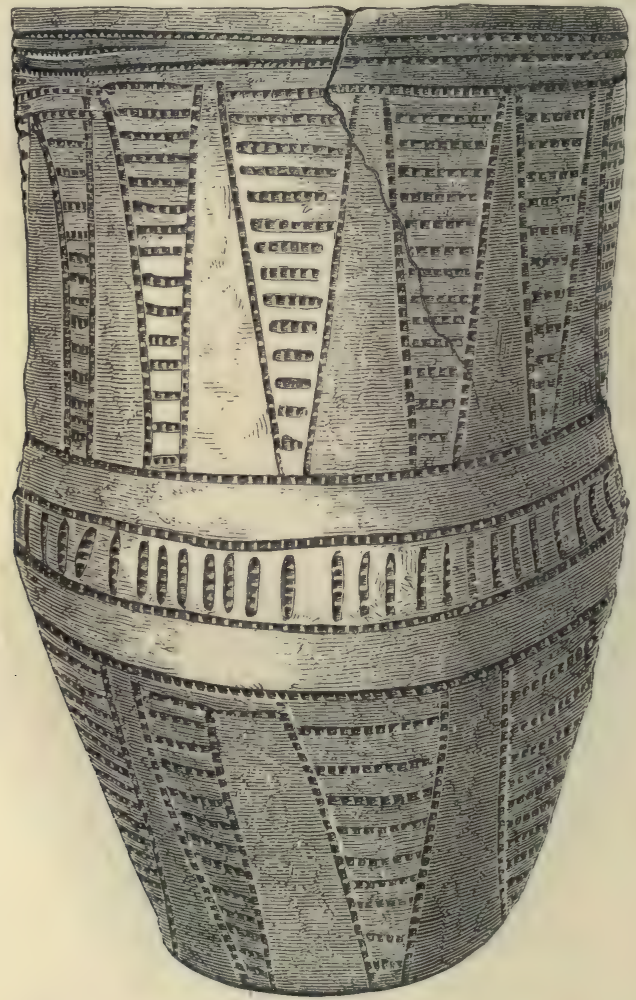

Fig. 83. $\frac{1}{2}$.

handle complete was found near Appleford, Berks, and is now in the British Museum, where is a perfect one almost identical; once in the Klemm Collection, and discovered at Spittswitz. Somewhat similar vessels have been met with in Dorsetshire ${ }^{3}$. A very small vase, which perhaps may be classed with the 'drinking cups,' was found by Mr. W. C. Borlase in a barrow on Denzell Downs, near St. Columb, Cornwall, accompanying a deposit of burnt bones,

1 Engraved in Bateman's 'Ten Years' Diggings, p. 209.

2 Engraved in Archæological Journal, vol. xix. p. 364.

3 Warne, Celtic Tumuli of Dorset, pp. 37, 71, of 'Tumuli Opened at Various Periods.' 
some of which it is said to have contained; though it is quite possible they may have got into it accidentally ${ }^{1}$; and one somewhat similar, and quite plain, was discovered by the Rev. W. C.

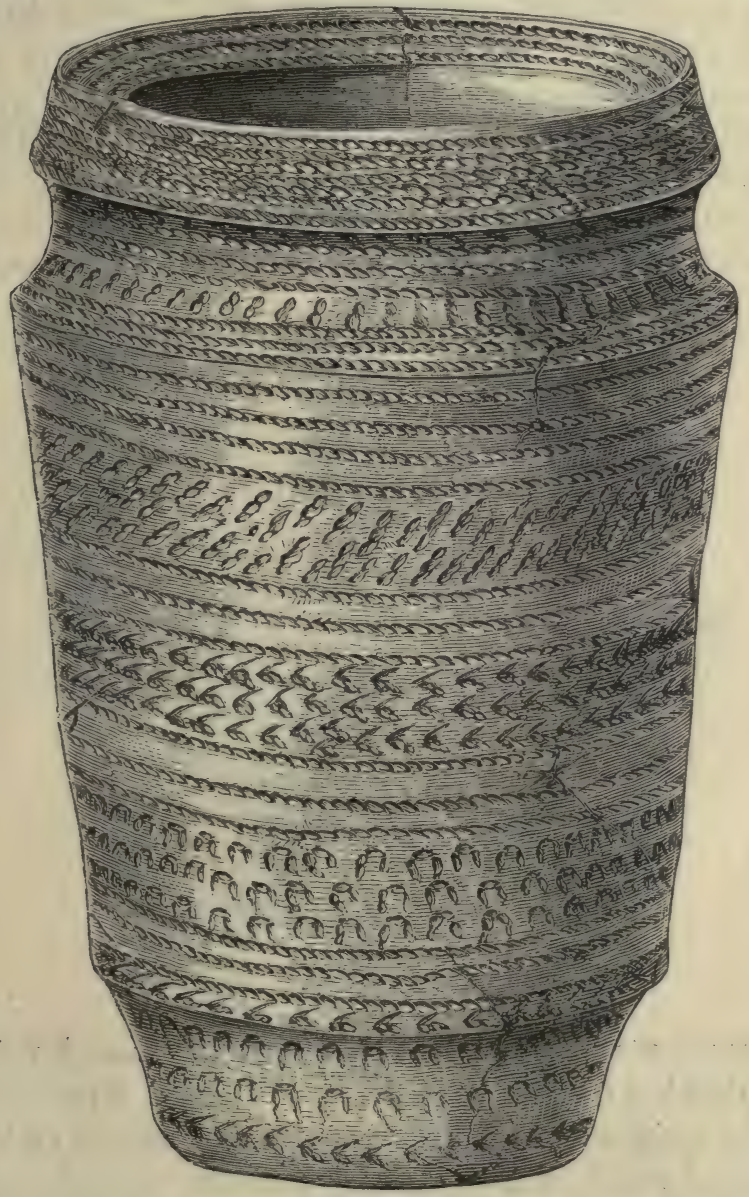

Fig. 84. $\frac{1}{2}$.

Lukis in a barrow at Collingbourne Ducis, Wilts, with the burnt bones of a child ${ }^{2}$. A vessel made of shale, found on Broad Down, near Honiton ${ }^{3}$, the amber cup from Hove, near Brighton ${ }^{4}$, and

1 Nenia Cornubiæ, p. 246, where it is figured.

${ }^{2}$ Wilts Archæological Magazine, x. p. 90.

${ }^{3}$ Arch. Journal, vol. xxv. p. 296 ; Trans. Devon. Assoc., vol. ii. p. 635 ; Evans, Stone Impl. p. 399. The so-called vessel of wood found in a tree-coffin in the King Barrow, Stowborough, was probably, like that from the barrow on Broad Down, made of shale.

${ }^{4}$ Sussex Arch. Coll., vol. ix. p. 120 ; Arch. Journal, vol, xiii. p. 183; vol. xv. p. 90 ; Evans, Stone Impl, p. 403. 
the gold vase found in a barrow at Rillaton, Cornwall [figs. 87, $88]^{1}$, may all possibly be included in this class of sepulchral vessels.

The 'drinking cups' are usually thin in the walls, very neatly made, of fine paste, and generally much better fired than those of any other class of sepulchral pottery; nor do they, as a rule, contain any broken stone mixed amongst the clay, though it does sometimes occur, and then very finely pounded, almost like sand. The colour is very frequently of a pale yellowish brown, but they are often dark brown, and gradually change from that, by a greater or less admixture of red, until in some of them that colour predominates.

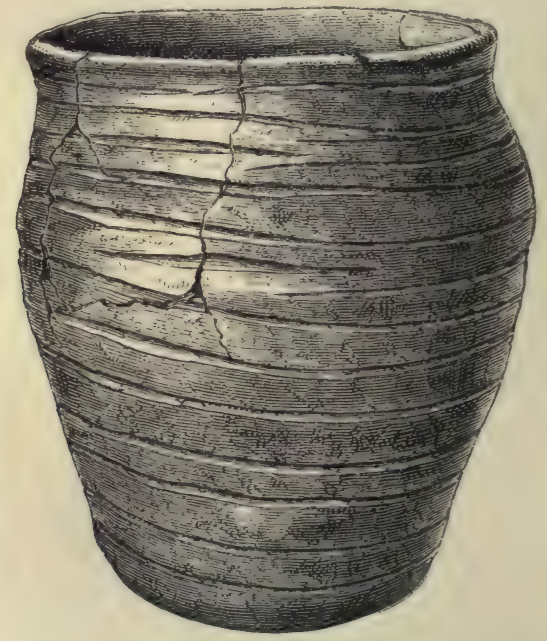

Fig. 85. $\frac{1}{3}$.

The ornamentation upon them is very varied, though not more so perhaps than it is found to be on the ' food vessels.' A better idea however of the designs upon them (as indeed is the case with all the classes of sepulchral vessels) will be obtained from the engravings than any words can give. They are almost always ornamented over the whole surface from top to bottom, sometimes to a considerable depth within the rim, and now and then on the bottom itself. I have met with one instance on the wolds of a 'drinking cup' ornamented on the bottom; it was found near Goodmanham [No. exvi]; the pattern was divided into quarters by a cross [figs. 89,90$]^{2}$.

${ }^{2}$ Arch. Journal, vol. xxiv. p. 189; Evans, Stone Impl. p. 402.

${ }_{2}$ One found at Kelleythorpe, East Riding, in a eist, with the skeleton of a man, a bronze knife-dagger, \&c., is ornamented on the bottom with a cross pattern. Another from Edgefield-by-Holt, Norfolk, in the possession of Mr. Fitch, F.S.A., of Norwich, 
The lines of the various designs have been made by similar instruments, and by the like impressions, as those upon the 'food vessels ;' a very common marking appears to have been formed by a notched or toothed strip of bone being pressed upon the moist clay.

It is very rare to find them associated with burials after crema-

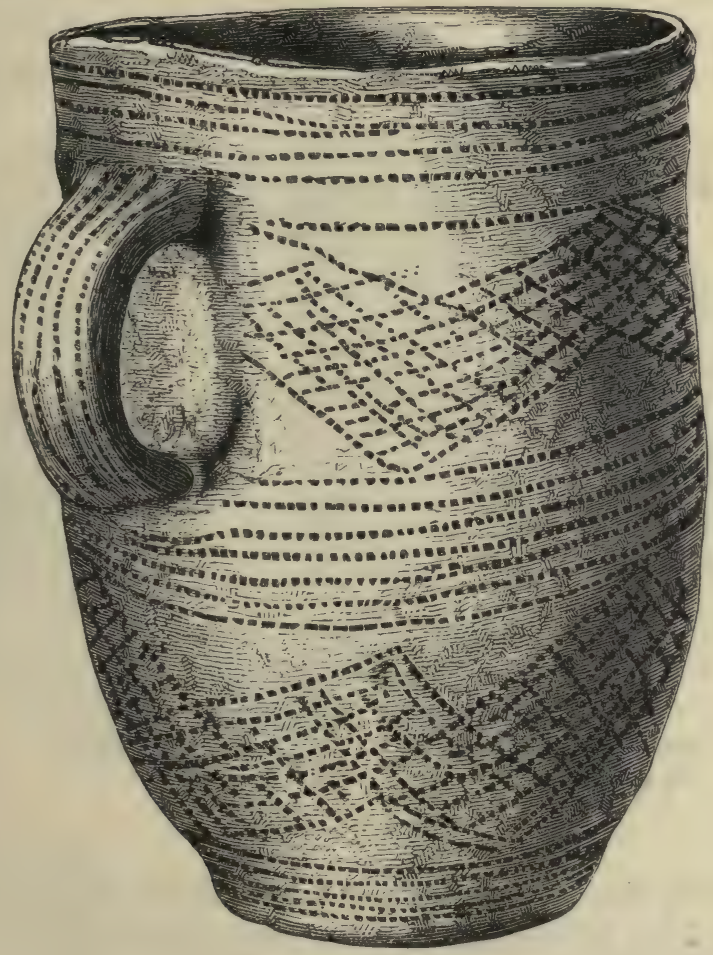

Fig. 86. $\frac{1}{2}$.

tion. In a barrow at Rudstone [No. lxii], a burnt and unburnt body were discovered in adjoining cists; with each was a 'drinking cup' of similar shape and character, and outside the cists was a second deposit of burnt bones, having with it another like cup. I have met with 27 'drinking cups' during the course of my barrow investigations in various places, but the two instances above

has a cross-shaped figure on the bottom; and one found in Elk Low, Derbyshire, has the bottom covered with an ornament of a peculiar pattern; it is figured by Jewitt, Grave Mounds, pp. 103, 104, figs. 110, 111. A fragment of one, now in the British Museum, found at West Lodge Gate, has a pattern on the bottom formed by two lozenge-shaped figures placed together side by side. 
mentioned are the only ones wheré $I$ have found that kind of sepulchral vessel associated with a burnt body. The same appears to be the rule in other districts. Messrs. Bateman and Carrington discovered 18 in Derbyshire and Staffordshire, all with unburnt bodies. Sir R. Colt Hoare found 30 in Wiltshire, only four of them deposited with burials after cremation, two of which occurred in combination with two 'incense cups' in a grave with numerous burnt bones.

As in the case of the 'food vessels,' they are found in juxta-

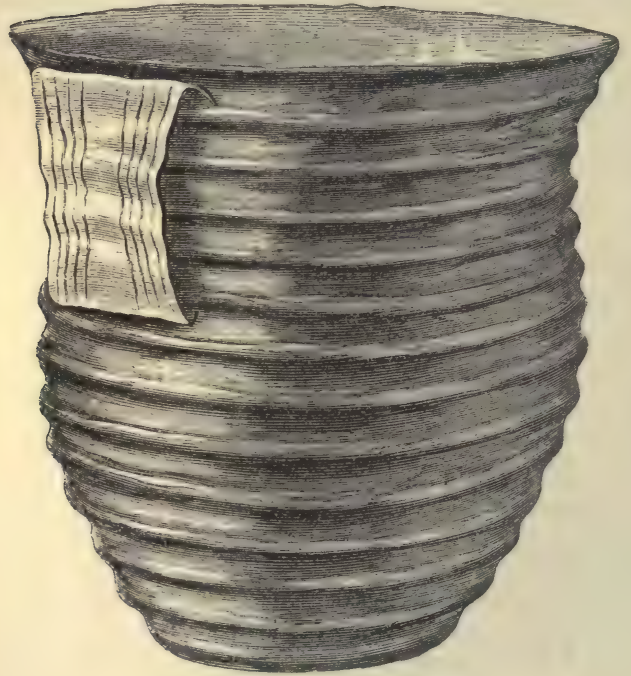

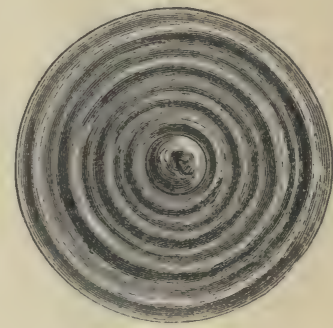

Fig. 88.

Fig. 87. Height $3 \frac{1}{4}$ inches.

position with almost every part of the skeleton; the most frequent place of deposit being near the head, either in front of it or behind. They are also, like the 'food vessels,' sometimes placed on the side, but I think they cannot have originally been deposited in that position, but may have fallen over by the pressure of the surrounding earth; the upright position certainly seems to be the most natural one. They have been, though rarely, met with at some distance apart from any interment: an instance of this will be found to have occurred in a barrow [No. xcix] on Goodmanham Wold.

In considering the purpose they fulfilled when buried in connection with the dead, they must be regarded as forming one part of that class of which the 'food vessel' forms another. Whatever was the purpose of the one, the same, there cannot be any 
doubt, was that of the other; and it can scarcely be questioned that they were the receptacles of food, and as such were placed in the grave. Like the 'food vessels' they have occasionally been found to contain a dark-coloured substance, which has all the appearance of being the remains of solid food, and which analysis has shown to be sometimes of animal, at other times of vegetable, origin. No liquid could have left such a residuum; and in fact the vessels are too porous in texture ever to have retained fluid for any length of time. It has been suggested
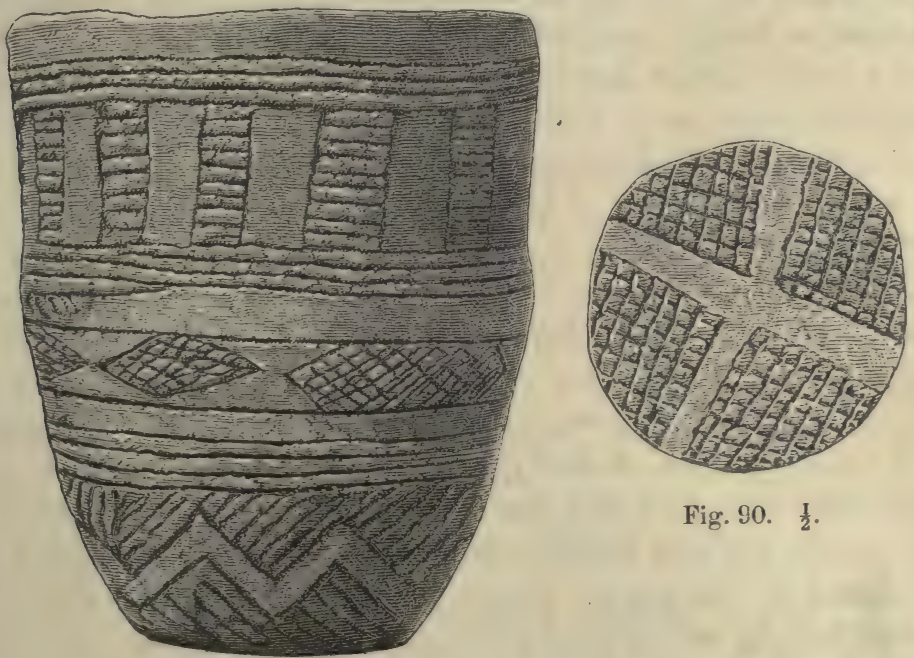

Fig. 90. $\frac{1}{2}$.

Fig. 89. $\frac{\mathrm{I}}{2}$.

that they were intended to hold a light; but besides their inappropriateness for any such use, there has never been seen upon them, or found in them, anything which favours such a supposition. A very remarkable burial, in a cist at Broomend, near Inverurie, Aberdeenshire, may help us towards a solution of the question ${ }^{1}$. The cist contained two skeletons, of a man and an infant, with two 'drinking cups;' hanging over the edge of the larger vessel, which was associated with the adult body, was an article which at first was supposed to be a lamp. The cup-like end was outside the vase, and the long tang-like handle was recurved over the edge, and hung down on the inside. At the bottom of both 'drinking cups' was some black earthy matter;

\footnotetext{
${ }^{1}$ Proc. Soc. of Ant. of Scotland, vol. vii. p. 116, where an engraving of the larger
} 'drinking-cup,' and of the horn spoon, there called a lamp, is given. 
and in the larger one, in addition, were some pieces of decayed bone. I think there can be no doubt that this curious article must be regarded as a spoon or ladle, and that it had been employed in putting food into or taking it out of the vessel over the edge of which it was hanging. The handle had, no doubt, been originally straight, but had become bent during the time it had remained in the cist. The idea that it was a lamp, now I believe discarded, appears to have originated in the present and accidentally curved appearance of the handle; the absence of any signs of burning, at what may be called the nozzle, if it had been a lamp, appears to be fatal to its being regarded as having served in that capacity.

Retaining the name provisionally, I should class the 'drinking cups' with the 'food vessels,' as having both been intended for the same purpose, that of holding food of some kind for the use of the dead. That they were not placed in the grave empty is self-evident, and the remains found in them show that something of a more or less solid nature had been originally deposited there. No explanation has ever been given of their presence in connection with interments so satisfactory as that which regards them as receptacles of food; and it may be accepted, without much hesitation, as being the true one.

It is more difficult, however, to understand with what object food was placed in the grave. It has generally been regarded as deposited there to sustain the buried person on the passage to another world; but if so, then it could only be considered as representative, for the quantity provided would ill suffice for such a journey. And the same difficulty suggests itself, though not so strongly as it did in the case of weapons and implements associated with interments, that if these several articles were needed by and provided for the dead, how does it happen that so small a number of persons were furnished with that which, it might be supposed, was equally necessary for all. This objection is not of so much force in respect of food as it is of weapons, \&c., for the requisite provision might have been placed in the majority of cases with the body, either in a basket or bag, or without anything to hold it; and, therefore, would leave no trace of its former presence. Another reason, and perhaps a more probable one, has been adduced in explanation of the custom. It has been a common practice to offer food to the dead, of whom most peoples, in certain states of mind and stages of culture, have felt much dread; a feeling indeed 
which is shared by many even in our own country and at the present day. The desire to propitiate them, so that they might not injure the living, has strongly ruled in many different ages and countries; and one mode of effecting this was by the offering of various things, and amongst them food. The subject is so trite that there needs no reference to particular instances as showing the custom ; it is familiar alike to the student of classical literature, to those who have made acquaintance with early Christian enactments, and to all who have investigated the history of modern savages. It is probable then, that in the 'food vessel' and 'drinking cup' we see the vases where the offering of food was supplied, which in other cases was placed in the grave without any such enduring receptacle. Nor is it impossible that the various weapons, implements, and ornaments discovered with the bodies may have been deposited there in accordance with the same belief which made the food vase so frequent an accompaniment of the dead.

The question whether these various sepulchral vessels were especially made for the purposes of burial, or were originally manufactured for domestic use, has been a subject of controversy amongst those who have given the matter consideration. The greater number of writers have regarded them as having been fabricated for the dead, and not as having ever served the wants of the living, and with them I concur. The late Mr. Albert Way, who took the opposite view, brought forward, in the essay on Welsh sepulture already referred to, several strong reasons in favour of their primary domestic purpose. He there adduces the Roman practice, and thinks it 'highly improbable that, in times of low and inartificial conditions, any objects or fictile vessels should have been specially fabricated for funeral rites ${ }^{1}$ ' Mr. Way was so high an authority, and had so much experience and had paid such attention to the subject, that his opinion is of the highest value, and I differ from his conclusions with great hesitation. But on the whole, though there is certainly much to be said in favour of their original domestic use, at all events as regards some of the vessels, I think the balance of evidence is against their having been manufactured for any other than sepulchral purposes. One of the principal objections to their having been made for domestic use is the coarseness, porousness, and friability of the paste, which in many of them is so great that it seems

\footnotetext{
Hydriotaphia Cambrensis, p. 70.
} 
impossible they can ever have served any other than a temporary purpose, and one not admitting of their being much handled. Some of the cinerary urns and 'food vessels' have been only very partially exposed to the action of fire, sometimes indeed having been scarcely altered by heat from the natural condition of the clay. This coarseness and fragileness characterise almost all the cinerary urns and a large number of the 'food vessels.' It is true indeed that many of the latter, and nearly all the 'drinking' cups,' are of better-tempered and finer clay, and have been subjected to much more complete firing, but even the strongest of these are but ill adapted for most household work, and would certainly not bear the knocking about to which such vessels must necessarily be submitted. Nor do any of them seem, from their shape, to be well suited for such purposes as domestic utensils are intended for. The cinerary urns would undoubtedly answer no end, which can be imagined, except for storing away grain or some other vegetable products; but the very small size of some of them precludes any such idea. Nor is the shape, with its invariably narrow bottom, at all what would be chosen for such a purpose. The Swiss Lake Dwellings have produced large numbers of vessels, of all sizes, and belonging both to the stone and bronze age, which had been made by those lake-dwellers for the ordinary use of the household. These are all of quite a different nature from the pottery of the barrows; and, as might be expected from the purpose for which they were fabricated, though many are very rudely made, yet they are much better baked, and of a more enduring character, than the sepulchral vessels in question. Mr. Way suggests that the over-hanging rim, so characteristic a feature in the cinerary urns, was intended as a means of supporting the vessel by passing a thong or some such appliance round the urn, underneath the projecting part of it. The objections to this view appear to be many. In the first place it scarcely seems to be a natural mode of suspending such a vessel, and the rim in many cases projects too slightly to give sufficient security to the fastening; the urns also are much too fragile, and the clay is wanting in that sufficient cohesion which would allow the vessel, when filled with even a light substance, to be suspended in that way. The peculiar appearance the cinerary urns present, with the almost universal overhanging rim, giving them as it does so marked a character, I cannot regard as caused by the requirements of 
the vessel for such a use. I have suggested before that a covering of cloth or hide may have been placed over the mouth of the vessel, and if that was the case, then the projecting rim afforded a means of keeping such a covering more firmly in its place, by passing a cord or thong round the vessel below such projecting part.

Enough has already been said in the account of the 'incense cups' to show how ill adapted they are for any domestic purpose; nor indeed has any one suggested an explanation of their everyday use which bears the least appearance of probability.

In considering the 'food vessels' as being originally intended to serve as ordinary household utensils, the same objection may be brought against them as has been brought against the cinerary urns - that it is difficult to understand to what domestic use they could have been applied. Their shape, the small size of some of them, the thickness of the walls, the inconvenient width of the lip of the rim, would make them very unsuitable vessels in the economy of daily life. We cannot regard them as having been made to serve at table, for their form renders them almost useless for such a purpose. They could not have been used in cooking, for apart from the fact that none of them show signs of having been placed upon a fire, they could not bear its action. Liquids they cannot have held on account of their porousness. They might indeed have contained some semi-fluid mess, like porridge, but the narrowness of many of them, especially at the bottom, makes such a supposition unlikely.

It may be said that the perforated ears round the shoulder, with which so many are provided, are inconsistent with their having been made purely for burial uses, inasmuch as there would be no occasion that vessels intended to be placed in the grave should be constructed with the means of suspending them. This objection to their being considered entirely as sepulchral vessels is certainly a very strong one, nor do I pretend to answer it. At the same time it appears to militate equally against their having been intended for domestic use, for it is impossible to understand what office in the household could have been served by the suspension of such vessels.

The last class, the 'drinking cup,' has by far the best claim to be considered a domestic vessel in its primary intention; but, on the whole, it can searcely be regarded as having been one. If it would hold water (and no doubt many of them would do 
so temporarily), it might be drunk from, for the thinness of the walls and its shape make it not unsuitable for that purpose. But if it is on the whole better fired, and in consequence harder, than the other classes, many of these 'cups' are, nevertheless, much too porous to enable any liquid to be retained for more than a very short time. As vessels for eating from they would be most inconvenient, on account of their height and comparative narrowness.

The profuseness of ornament, which is lavished upon even the least highly decorated of these several vessels, is a fact which seems to be more in favour of their sepulchral than of their domestic intention. It is not probable that the amount of labour which must have been bestowed upon them would have been expended on utensils for daily use, and such as must necessarily have been subjected to various accidents almost every hour. On the contrary, it is just what we would naturally look for in vessels intended to be associated with the dead, about whose burial no expenditure of time or labour was thought too great. The special manufacture of vessels to be deposited with the dead has prevailed in other countries, abundant evidence of which is found for instance in Greek and Etruscan tombs. In our own country we find the practice to have been common at a time long subsequent to that of the barrows of the wolds. The narrow-necked and frequently highly ornamented urns, which contain the burnt remains of those whom the late $\mathrm{Mr}$. Kemble justly considered the pagan Anglo-Saxons, are certainly sepulchral in their origin as well as in their use.

But perhaps the strongest objection to their having fulfilled a purpose in the household, is the fact that they possess but little in common with the pottery, which, without much doubt, is domestic [figs. 91, 92]. It is true that not very much of this has been discovered, but quite enough has been found to enable us to judge pretty accurately of its character. It has not indeed been proved conclusively that the people who occupied the hut circles and pit dwellings were those who erected the barrows so often met with in close proximity to them, but if we may judge, as I think we fairly may, from the identity of the flint implements found in each, there can be little doubt that they were, the one the dwelling-place, the other the burial-place of the same people. Now the pottery which has been discovered on the site of dwelling-places is a dark-coloured, hard-baked, perfectly 
plain ware, without ornament of any kind, is in fact just what we would expect domestic pottery to be, and has nothing in which it resembles the sepulchral vessels. And more than this, so far as I know of my own experience or can learn from that of others, no whole vessel, or even fragments, of the ordinary sepul-

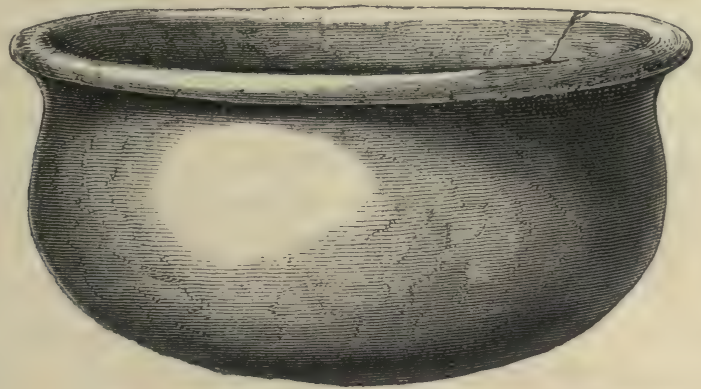

Fig. $91, \frac{1}{4}$.

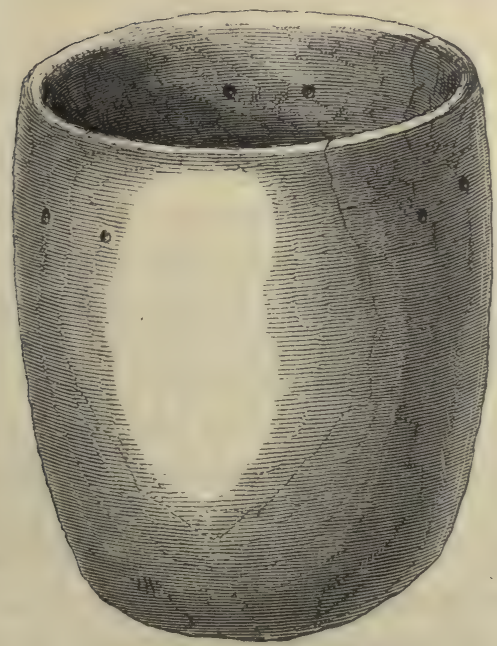

Fig. 92. $\frac{1}{2}$.

chral pottery of the barrows or other places of sepulture has ever been met with in connection with places of habitation. A discovery was made in the county of Durham which affords most valuable evidence upon this point. A cave in the limestone had been the habitation of a family, during the bronze age, for a lengthened period, if we may judge from the large quantity of animal bones, the remains of its food, found therein. These 
people seem to have come to a sudden and untimely end, by the cave becoming flooded, and not only were they themselves left there, until the working away of the rock revealed their presence, but also their whole belongings, weapons, implements, ornaments, together with the whole batterie de cuisine in pots and pans, This pottery, which was very abundant and which presented a great variety of different vessels, was in perfect agreement with that which has been found in other places of habitation, but had nothing in common with the pottery of the barrows, except that there was the same admixture of broken stone in its composition. Not a single vessel showed any trace of ornament, but all were plain, strong, and useful, such as we might look for in the domestic economy. Is it possible that, if cinerary urns, 'food vessels,' and 'drinking cups' were the ordinary utensils of daily use, we should not have frequently found them in other situations than burial mounds and cists?

It has already been mentioned that potsherds are met with, and sometimes in large quantities, scattered indiscriminately amongst the material of the barrows. These are in many cases fragments of vessels of similar shape and manufacture to those found on the site of dwelling-places, and are almost certainly the remains of domestic pottery. Pieces of 'drinking cups,' cinerary urns, \&c. are also discovered in the barrows, but these are often, if not in all cases, portions of disturbed sepulchral vessels, broken by the introduction of secondary interments. Two quite distinct kinds of pottery then are found, belonging unquestionably to the same period, since both are met with under similar circumstances, in one and the same barrow. One of these, from the resemblance it bears to the ware occurring in the hut-circles and pit-dwellings, must be regarded as that made for domestic use; the other is invariably found in association, more or less close, with interments. The one is only on the rarest occasions discovered in intimate connection with the buried dead; the other never in connection with their dwellingplaces when they were living; can we hesitate then to say that the first was manufactured for use in life, the second for one purpose or another after that life had passed away?

The conclusion to which all the evidence we are able to put together appears to lead is, that cinerary urns, 'incense cups,' 'food vessels,' and 'drinking cups' were especially made for the burial, and that they had no place in the house, nor were ever 
intended for its occupants when alive; and if any exception is to be taken to this, that the 'drinking cup' is the only vessel which can possibly come within that limit. I have, however, little hesitation in asserting that it is also sepulchral.

Vessels have occasionally been met with, associated with interments, which may have been originally domestic, at all events they possess the characteristic features of that kind of pottery. This occurrence is only what might be looked for, and indeed it is surprising that it has not more frequently taken place. It seems to show how rigid was the observance which regulated the character of the vessels deposited with the dead. But, from one cause or another, the occasion must sometimes have arisen when no vase, properly sepulchral, could be obtained, and therefore a domestic one was made to serve in its stead. The slightest acquaintance with Roman burials will show how common it is to find ordinary household vessels answering to a sepulchral use.

In the description of the different substances found in barrows, it was mentioned that animal bones (and usually, when they are those which once contained marrow, split open) are met with scattered, here and there, throughout the material of which the mound is formed. It was also said that these are probably the relies of a feast, held either at the time of the burial, or on some subsequent occasion, possibly at its anniversary. They thus represent what may, so far as flesh is concerned, be considered as the food of the people then occupying the wolds. A fact of very considerable importance, concerning the condition and state of civilisation of the early inhabitants of the wolds, is thus established.

The bones which have been found are those of the ox (bos longifions); of another species of ox, probably a cross between Los longifrons and the urus; of the pig (sus scrofa); of the goat or sheep, for it is difficult, without the head, to distinguish between the two species; of the horse (equus caballus); and of the dog (canis familiaris); all of them being domesticated animals. The most frequent bones are those of the ox, followed by those of pig, and then of goat; the horse and dog being very uncommon. Of wild animals, the only bones discovered, and those very sparingly, are of the red-deer (cervus elaphus). That this animal was aburdant is shown by the numerous remains of its antlers which have occurred, but though the horn was thus utilised, the flesh seems to have formed but a small item in 
the dietary of these people. The horn of the roe-deer (cervus capreolus) has been met with in two barrows. The antlers found in the barrows (and the same was the case at Grime's Graves) are almost always shed ones, it being very rare to find one which has been taken from a slain animal. The abundance of the antlers shows how plentiful the beast was, the rarity of any but shed horns appears to indicate how seldom it was captured. The evidence of the Swiss Lake Dwellings points in the same direction. At Allensbach in the Überlinger See, says Dr. Keller, numbers of red-deer horns were met with, but 'by far the largest proportion appears to have been parts of horns which had been shed, pieces attached to the skull are very rare ${ }^{1}$.'

The result of a critical examination of these bones shows very clearly that a different state of existence prevailed on the wolds from what was generally believed to have been the case. It was commonly thought that these people subsisted principally by the chase; and though it was not doubted that they possessed domesticated animals, it was scarcely believed that the flesh of such was the main support of these early wold-dwellers. Such appears, however, undoubtedly to have been the case, for we cannot imagine that the bones found in the barrows represent other than their ordinary and daily food. The chase must, however, have been followed very extensively by the wold - inhabitants, as is shown by the abundance of arrow-points which are found scattered about in every part of the district. These were no doubt used equally in war, but it is impossible to suppose that the enormous numbers met with can all have been intended for solely warlike purposes. Many were probably expended not in the pursuit of the larger animals, but of birds, and amongst them the bustard, which until quite lately was an occupant of the wolds, as it was of the downs of Wiltshire. The bones which occurred at Grime's Graves (a series of flint workings in Norfolk) strongly corroborate the testimony afforded by the barrows, for they are identical in the two places. The pits at Grime's Graves correspond in point of time with the large majority of the wold barrows, if not exactly, at all events substantially, and therefore the evidence we obtain from them in this respect is of great value as illustrating the history we learn from the barrows ${ }^{2}$.

In this Introduction, as also in the detailed account of the

1 Keller, Lake Dwellings, ed. Lee, p. 97.

${ }^{2}$ Grime's Graves, Journal of Ethnological Society, N. S., vol. ii. p. 419. 
examination of the barrows, various remarks have been made, incidentally, concerning the social condition of the people who erected these burial-mounds, their food, clothing, arms, implements, ornaments, and other accessories of daily life. The barrows, indeed, only give us a very imperfect, and at times but a doubtful, outline with respect to some of these subjects. Sufficient evidence, however, has been brought together to admit of some conclusions being arrived at which are based upon the secure foundation of facts. A brief account then of what we appear to have learned concerning the people and their progress in civilisation, their art and manufactures, their social habits and their polity as evidenced by the contents of the barrows, may not be out of place.

That they lived in an organised condition of society may be considered as quite certain; and, as a necessity of such a state, they must have been under the government of a head, most probably the chief of a sept or clan. They had unquestionably long passed beyond the stage when the family is the only community, and they were ruled by an order and constraint embracing wider bounds than those comprised within the authority of relationship in its more limited sense. The magnitude of the burialmounds would in itself imply this, as, from the amount of continued labour bestowed upon them, they could never have been erected except by a community which included several families. The very extensive and strongly constructed defensive arrangements, so abundant on the wolds, enclosing in many instances large tracts of country within their lines, are strongly indicative of a combination which necessitates an union of very considerable bodies of men; and there is every reason to believe that these works and the barrows were constructed by the same people. Within what may perhaps be designated as the larger federation, held together by a common origin and mutual interest, there were doubtless several smaller tribal divisions, ruled over by their respective chiefs, either independent, or more or less under the authority of the federal head. It may also be that there were still more minute subdivisions, where the family government might prevail, and where the interest and property in the land would be parcelled out into tracts not larger than what is comprised within contiguous ranges of high land, in some cases not more extensive perhaps than the present parishes. To the heads of these smaller communities, if such existed, the greater number of the barrows must probably be attributed, if the supposition 
is correct which regards them as the burial-places, not of the mass of the people, but of those who occupied a position of authority, of whatever nature that might be, amongst them. This view appears to be most consistent with facts, for it cannot be supposed for a moment that the whole population was buried in the sepulchral mounds. Had that been the ease, the barrows would have been far more abundant than they are, even though the time during which the practice was in use was very short. But as it is evident that the period when burials in the barrows took place was a lengthened one, it becomes still more certain that only a very small part of the population received such a distinction. These mounds must be regarded as the places of sepulture of chiefs of tribes, clans, and families, or of other people in authority claiming and being allowed a position of respect, and of those who were nearly connected with them, as wives, children, and personal dependants. Some of the barrows, indeed, appear to have been in use over a lengthened period, and assume somewhat of the character of a family burying-place. The mass of the community were probably buried at no great depth beneath the surface, and with no mound over them, or at all events a very trifling one, to mark the spot. Nor is it likely that anything in the shape of implement, ornament, or pottery was deposited with them. Under these circumstances it is impossible to identify their burying-places. Skeletons, however, have very frequently been found in places where there was no visible mound or any appearance to show that such had formerly existed, and these bodies may very possibly represent the humbler members of the population. In some instances large numbers of burials have been discovered together, constituting what may be denominated as cemeteries, and consisting both of burnt and unburnt bodies; places like these may be regarded perhaps as the common burial-place of the community, the heads of which may have been interred in adjacent barrows ${ }^{1}$. In many parts both of England and Scotland, where the land has never been under cultivation, it is not uncommon to find large numbers of small mounds in groups, which are usually accompanied by one or more larger mounds; in the latter, burials, frequently

1 At Rimbury, in Dorsetshire, a large number of cinerary urns were discovered without any apparent barrows overlying them, constituting in fact a cemetery; the same mode of interment was met with on Lancaster Moor; at Garlands, near Carlisle ; and at St. Andrews in Fifeshire; at all of which places many burnt bodies and a number of urns were found: 
placed in cists, with which vessels of pottery and other articles are associated, have been met with, but in the smaller mounds, any indication, beyond the presence of charcoal, that a body had once been placed below them has very rarely occurred. In these cases it would appear as if the small mounds covered the bodies of the poorer and humbler members of the tribe, placed in the grave without any accompaniment, and where the bones have gone entirely to decay, whereas the larger mound, with its cists or other more special places of interment, was the monumental record of the more important persons of the community. In addition to the burials which are found simply made in the ground, without any weapon, implement, or vessel of pottery associated with them, others have been met with, in eists and graves, sunk below the surface of the ground, but having no mound over them, and which, to judge from the various articles deposited with the body, may be supposed to be those of people of some social distinction. Nor does the time when these burials must have taken place appear to differ from that of the barrows, if the character of the pottery and other things associated with the dead are to be considered as conclusive evidence, for these are identical in the two cases. It may be that some of these burials have once had a barrow over them, and no doubt many of them had, but in numerous instances it does not seem likely that there can ever have been a mound at the place; they are frequently, however, met with on the summit of a natural swell of the land, itself a mound, and so fulfilling one requirement of a barrow, - the furnishing a conspicuous landmark. It seems, if we may judge from this, that the two customs of burying under barrows, and in simple graves without any mound to distinguish them, were practised at the same time, though we can scarcely suppose that the two modes were applied indifferently to persons of the same importance, for the very mound itself appears to make a distinction.

It is quite possible that such a government as has been described might have existed amongst people in the condition of hunters, without domesticated animals and ignorant of agriculture, though an organisation like that supposed is more consistent with a state of greater progress. Still it is certain that the inhabitants of the wolds had advanced beyond the hunting stage. Wild animals indeed, as had already been stated, seem to have formed a very small part of their food. What we learn from the barrows as to the condition 
of the people of the wolds is very strongly corroborated by the much more extensive series of facts which have been brought to light by an examination of the Swiss Lake Dwellings. The two peoples appear to have been in much the same state of civilisation, especially if we have regard to those stations in Switzerland where the inhabitants had only just passed from the stone age to a knowledge of bronze. Both were possessed of domesticated animals, both cultivated grain, manufactured cloth and pottery, but without the aid of the wheel, and used implements of flint and other stone as well as of deer'shorn, all in each country very similar in their character.

It seems quite certain that grain of some description was cultivated by the dwellers on the wolds, and it is probable that other vegetables were used by them. Terraces of a peculiar construction are found throughout large and various districts of Britain. They still remain in some parts of the wolds, as for instance near Carnaby, though modern cultivation has in most cases destroyed all traces of them. They are abundantly distributed over other districts, as will be found more fully noticed in the sequel. These terraces have been considered by many persons, and I think with every probability, to be the places upon which some cereal crop was grown under a system of agriculture not quite intelligible to us. Some of these terraces, however, belong to a much later period, and are to be referred to the way in which the land in the common field of the village, where there was no division by a fence, was ploughed. But the proof that these people cultivated grain does not depend upon this alone. There is more conclusive evidence of it afforded by the stones found in such abundance, and which seem to have been used for bruising corn or some like seed ${ }^{1}$. They have been met with not only on the surface of the ground, but in several instances in the barrows. It is not always easy to distinguish between stones which have been used as hammers and for taking the larger flakes of flint from the block, and those which have been employed in bruising or grinding grain. Some, however, show signs of wear of such a nature as could not have been produced by hammering, but just such as would accrue from a process of rubbing. The specimen figured here [fig. 93], belonging to the class of rubbers, has been very ingeniously fitted for its work. The stone is rather unwieldy, and to make it the better adapted for being held securely in the hand, a groove has been cut on one side, in

${ }^{1}$ It is possible, however, that these ridged stones may have been used for bruising roots or for mashing bones. See Evans, Stone Impl, pp. 221 seqq. 
which the thumb or little finger might be placed, as one or the other end of it was to be used, a better purchase being thus obtained. Besides the smaller grinding stones, the larger ones have also been found upon which the grain was pounded or ground.

I am not aware that a quern, or hand mill-stone, has ever been discovered in a barrow upon the wolds, though they have frequently been met with in the hut-circles (the foundations of houses) and in the camps or other fortified places of many parts of Britain. The
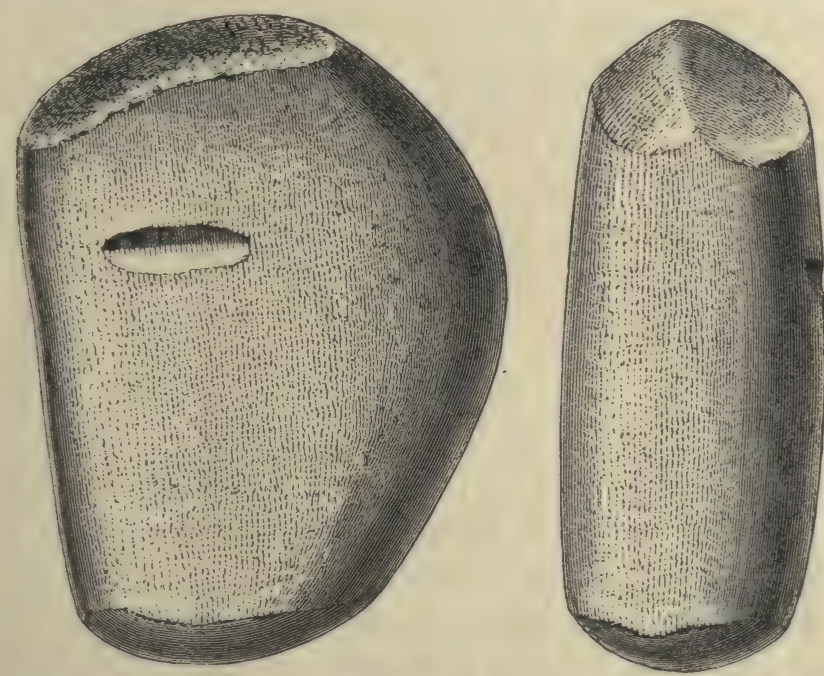

Fig. 93. $\frac{1}{2}$.

small hand mill-stones indeed have very rarely been found on the wolds under any circumstances. This fact, which is a remarkable one when their abundance in other localities is considered, may possibly arise from the absence in the district of stone suitable for such a purpose.

It has been mentioned that these people possessed a variety of domesticated animals, upon the flesh of which to some extent they lived. It is probable that milk formed an important article of food, and in connection with this, an interesting circumstance which was observed at Grime's Graves may be mentioned. A very large proportion of the numerous bones found there were of the ox, and nearly all were those of animals of but a few days old. This seems to imply that they were not able or willing to keep the 
calves, a necessity which most probably arose from the milk of the mothers being used by the people themselves, though it might also have arisen from a scarcity of winter food.

Their dress, the use of metal, their weapons, implements, ornaments, and pottery have already been treated of at some length, so that it is only necessary here to give a slight account of them. That woollen, and probably linen, fabrics were manufactured is evident from the remains of such which have been discovered. The evidence is indeed but scanty, as might be expected, on account of the perishable nature of the material; portions, however, of woven stuffs have been found with deposits of burnt bones, either the remainder of the dress of the person or of some wrapping in which the bones had been collected from the funeral pile. In one of the barrows at Weaverthorpe [No. xliii], the half of a clay spindle-whorl was met with, which may be supposed to indicate a knowledge of spinning. They further appear to have been clothed in garments which had made some considerable advance beyond such as were merely wrapped round the body; for, in a grave at Butterwick [No. xxxix], six buttons of jet and stone were found placed in a line in front of the chest of the buried man, showing that the vestment was to some extent fitted to the form of the wearer, and had been fashioned into shape with somewhat of sartorial skill. Their dress appears to have been fastened in a variety of ways. Buttons and pins have occurred in many instances; and a ring with perforations on the side [fig. 5, p. 34] has sometimes been met with, usually in connection with buttons. An oblong narrow article, made of jet or other lignite, having a slit, which widens towards the middle, and occupies about two-thirds of the whole length, has been found on the wolds accompanying a body [fig. 6, p. 34]; and also in other places in Britain ${ }^{1}$. They have probably been used in some way for fastening the dress, a belt perhaps having been passed through the slit. A ring of jet from a barrow at Rudstone [No. lxiii], which is too small for an armlet, had possibly been made for the same purpose, though its form is not quite so suitable as the oblong one would be. Sir R. Colt Hoare discovered, in a barrow at Upton Lovell, what he considered to be gold boxes ${ }^{2}$; and somewhat similar objects, though smaller, were found in a barrow at Cres-

1 One from the Isle of Skye is figured in Wilson's Prehistoric Annals of Scotland, vol. i. p. 441.

${ }_{\mathrm{L}}^{2}$ Ancient Wilts, vcl. i. p. 99. pl. $\mathrm{x}$. 
singham in Norfolk ${ }^{1}$; but they may very possibly have been buttons, the more solid part having been made of wood upon which the thin gold plating was laid; what are undoubtedly buttons, of a conical form, and made in the way I have suggested, of wood and gold, have occurred in the Wiltshire barrows ${ }^{2}$. What may be called a fibula of bone [fig. 7, p. 34] has also been found, and always, so far as I know, with burnt bodies. No bronze fibulæ or any fastenings of that nature have been discovered in barrows of the bronze age, though they occur in those of the early time of iron; but a few buckles, small and of a simple form, show that, as might be expected, so very natural a mode of connection was known ${ }^{3}$. The dress was no doubt fastened more commonly by tags or laces, but of such things it is not to be expected that any trace would be left.

The implements and weapons of bronze show that they had attained to a high perfection in the process of casting, and give evidence of no little progress in metallurgy; whilst the pottery is quite equal to what has been discovered in other parts of Britain, though perhaps the designs upon some of the vessels do not show so much artistic skill as is seen upon those from the south-west of Scotland. It manifests, however, a long-eontinued experience in the manufacture of fictile ware. The ornamentation upon the vases and urns is not wanting in a certain tasteful arrangement, but in the ignorance of the use of the wheel, in the imperfect firing, in the absence of glazing, and of any other form of design in the patterns than simple combinations of lines or of circular markings, it cannot be said that they had attained to any great perfection in the art of the potter.

The personal ornaments, which have however occurred in a very few instances, give indications of some artistic power, though developed after a simple fashion. They have consisted of necklaces, generally made of jet, or other and inferior lignite; of buttons and rings of jet, in some cases tastefully decorated, and therefore having a claim to be classed under the head of ornaments ; of ear-rings of bronze; of beads and pendants of bone, jet, and other substances, not found in sufficient numbers to constitute a necklace; and of some humbler articles, such as perforated teeth.

${ }^{1}$ Proc. Soc. of Ant., 2nd Ser., vol. iv. p. 456.

${ }^{2}$ Ancient Wilts, vol. i. p. 99. pl. x ; p. 201. pl. xxxv.

${ }^{3}$ A sinall bronze buckle, which had been used for fastening the wrist-guarl, was found in a cist at Kelleythorpe. Archæologia, vol. xxxiv. p. 254. 
The whole evidence of the barrows appears to show that the people living on the wolds were, to some extent, isolated from the rest of the country, with which they seem to have held little intercourse; this state of things originating partly in the natural features of the district in which they dwelt, surrounded, as it was on all sides, by low-lying ground, swampy and largely covered with wood. They were apparently not possessed of much in the shape of gold, bronze, amber, or glass. Their condition may perhaps be described as that of people who were living in the pastoral state, but at the same time cultivating grain, though probably not extensively. Their elothing no doubt consisted largely of skins, though they certainly used textile fabrics; and such ornaments as they possessed were of a simple, though by no means of an unartistic, description. The presence of a lump of ochre, which has been found in more than one instance associated with the body, may perhaps be considered as affording some evidence of the use of colour as a means of personal adornment; nor is it easy to account for its occurrence on any other supposition. When these people are compared with the inhabitants of some other districts in Britain, as for instance of Wiltshire, and even of Derbyshire, who, to judge by the pottery, implements, and ornaments, must have been occupying the country at the same time, they cannot be regarded as having been in possession of the same amount of wealth of various kinds, as of bronze and other materials, or to have arrived at quite the same height of cultivation.

It cannot be expected that the contents of the burial mounds should give much information upon. the social relations of these people, the position the wife occupied in the family, and questions akin to this. Some few inferences may, however, be drawn from the facts which the barrows have disclosed. For instance, the central and indeed the sole burial in a barrow upon Heslerton Wold [No. iv], was that of a very young child, placed in a grave sunk in the chalk; and in the largest barrow I have opened on the wolds, at Rudstone [No. lxvii], the primary burial, over which the whole mound had been raised, was that of an infant ${ }^{1}$. Numerous other instances have occurred where quite young children had been buried with associated vases, and in a manner which betokens that much care was bestowed upon the burial, as in a barrow at Rudstone

${ }^{1} \mathrm{Mr}$. Jones records the fact that in a barrow in Liberty County, Georgia, U.S.A., the sole interment was that of a young child, whose bones were enclosed in an urn. Antiquities of the Southern Indians, p. 455. 
[No. Ixiii], where the grave had been lined out with wood. I have met with other cases elsewhere; for instance, the central cist in a barrow at Ford, Northumberland [No. clxxxvii], was oceupied by the skeleton of an infant, having a 'food vessel' with it, whilst round the eist were seven burnt bodies, deposited in as many cinerary urns, in one of which was a flint implement.

From these and similar instances we may gather that the family tie had much influence with these people, and that the child of the chief or other person of distinction held an important position in the estimation of the tribe. The affection of the father might prompt him to honour with the full ceremonial of the burial rites the child whose early death he mourned, but unless the social importance of the infant had been likewise recognised in the eyes of the people, it is scarcely likely that so high a mark of consideration as a separate barrow implies would have been accorded to so young a member of the community. Perhaps it may not be considered to be an unfair inference to regard a circumstance like this as indicating that something like an hereditary headship prevailed amongst them.

The great labour and pains bestowed upon the burial of the dead, the large mound, the deep grave, the various attendant ceremonies of the funeral, may not necessarily show any high advance in civilisation, for in very rude conditions of society the disposal of the body after death has generally been attended with somewhat of care, and regarded as requiring the presence of some rites of burial. But, making allowance for this, we cannot look upon the barrows and their varied contents without being impressed with the belief that the semi-savage state had been well-nigh passed, and that the dawn of an advanced civilisation was approaching. The pottery, with its simple and yet effective ornamentation, the bronze knife-dagger and awl, the necklace of jet, the buttons tastefully decorated, the ear-ring of metal, may all be regarded as heralds of cultivation and refinement, even as the east is flecked with streaks of gold and crimson before the morning sun breaks forth in all his splendour.

There are, on the other hand, some features pointing to a condition of things which ill accords with much advance beyond savagery, though to the practices these would seem to indicate we might find a parallel amongst people who, in some of the processes of mental developement, have been second to few. It can scarcely be questioned that it was the habit to slay at the funeral and to bury with the 
dead man, wives, children, and others, probably slaves ${ }^{1}$. The frequent occurrence of several bodies, all certainly interred at the same time, the finding of a man and woman in adjoining graves, which must have been excavated together, or of two persons of different sexes in the same grave, with the remains of children, or with deposits of burnt bones, are incidents difficult to interpret in any other way. Nor has the practice been so uncommon that we need feel much hesitation in attributing it to the ancient dwellers upon the wolds. The custom of suttee which still, in spite of the most stringent enactments, lingers in India, shows that, under an elaborate religious system and in highly organised communities, a habit so repugnant to our ideas has nevertheless prevailed. That it was in use amongst the ancient Scythians, the account of the burial of their kings given by Herodotus (and amply confirmed by the examination of the burial mounds of the countries occupied by that people) abundantly proves ${ }^{2}$. That women, however, were not in the condition of slaves, but held a position of trust as the equals in some degree of the husband, may perhaps be considered as not improbable, when the manner in which they seem to have received burial in the barrows is remembered. They have been found interred apart from any male, and occupying an important position in the burial mounds, in some cases a woman being the sole tenant of a barrow, - a circumstance which is quite inconsistent with their place in the house being merely a servile one.

The barrows do not afford much information upon which to build any theory respecting their religious ideas, nor indeed could

${ }^{1}$ Colonel Meadows Taylor found, in a large number of the sepulchral places he examined in the Dekhan, the remains of bodies, with the bones disturbed and lying confusedly about. In many cases the skulls were separate from their bodies. The conclusion at which he arrives is, that these fragmentary skeletons are the remains of persons slain at the burial of a chief person. Cairns, Cromlechs, \&c. in the Dekhan, Transactions of the Royal Irish Academy, vol. xxiv. p. 339.

${ }^{2}$ Herodotus, iv. c. 71. It may not be out of place to give an account of the burial of a Fiji chief. 'The dead chief lay in state, with a dead wife by his side, on a raised platform; the corpse of his mother (who had been strangled) on a bier at his feet, and a murdered servant on a mat in the midst of the house. A large grave was dug in the foundation of a house near by, in which the servant was laid first, and upon her the other three corpses, wrapped and wound up together.' Calvert, Fiji and the Fijians, vol. ii. p. 301. The same practice appears to have prevailed as late as the eighth century among the Wends. Boniface, the Apostle of Germany, in a letter to Ethibald, King of the Mercians, says: 'Winedi ... tam magno zelo matrimonii amorem mutuum servant, ut mulier, viro proprio mortuo, vivere recuset, et laudabilis mulier inter illas esse judicatur, quæ propria manu sibi mortem intulit, ut in una strue pariter ardeat eum viro suo.' Bonifacii Epist., in Magna Bibliotheca Veterum Patrum, viii. 74. 
much be looked for. The practice of burying various articles in the grave and of placing a vase, the supposed receptacle of food, beside the dead, has usually been looked upon as proof of a belief in a future state of existence. It necessarily follows that if a belief in a future state is proved by the occurrence of weapons, implements, ornaments and food associated with the buried persons, that second life must be supposed to have been similar in kind to the first one which had just ended. In this future world there were enemies against whom the warrior must be prepared in arms, there were animals which he must be provided with the means of capturing, there were husbands and friends to be charmed by the added decoration of ornament and dress, there were happy hours of childhood to be brightened by such simple pleasures as gladden the young heart. It may well be that a hope like this took something of its sting from the dread forecast of death. A similar belief has been shared by many a different race, in ages far apart, in many a varying clime, and under forms of religious faith which have agreed in little beyond this natural expectation. The evidence which the barrows afford cannot, however, be regarded as perfectly conclusive in favour of this view; and, indeed, there is much that appears to be inconsistent with it. This objection, which has already been stated, is one not easily to be set aside; namely, that if the different articles found with the bodies were placed there to be of use in an after-state of existence, it is difficult to understand why the majority of persons were sent on their journey entirely unprovided with those things which it was thought were necessary for them when they had arrived in another world. The subject, however, has been discussed previously, and it is superfluous to say more here, than that the custom by itself does not prove there was any belief in a future state of the same nature as that which had been already gone through, still less does it show a belief in any future of a different kind. At the same time I think there is a very strong presumption in favour of the former view, to which, I am bound to say, I myself incline.

One of the most important and interesting subjects of enquiry which a knowledge of the contents of the barrows has enabled us to discuss is that of the people themselves, with reference to their physical characteristics. Some description therefore of their form, stature, and general appearance is necessary to complete, as far as is possible, the imperfect picture we have hitherto been able to present. There are, as has already been mentioned, two classes of 
barrows upon the wolds, so different in their appearance and construction, as to suggest at once, without any further investigation of their contents, that they belong to different periods of time, and the probability that they are the burial-places of different peoples. The one is eminently a long mound, the other is circular in its outline; the former being the grave-hills of a markedly dolicho-cephalic (long-headed) people, the latter producing skulls both dolicho-cephalic and brachy-cephalic (round-headed). The long barrows and the skull which is found in them are so fully described in the detailed account of that class of mounds contained in this volume, that it is unnecess ury to enter upon any consideration of them in this place. Nor do I propose to give anything more than a very brief notice of the skulls from the round barrows, as the whole subject is thoroughly discussed by Professor Rolleston in the valuable and exhaustive essay with which he has enriched this volume.

The round barrows, then, contain two very distinct forms of skull, a long and a round one, together with other less characteristic forms which may be supposed to have belonged to people who were descended from inter-marriages between persons whose heads were of the two different types in question. The dolicho-cephalic head of the round barrows does not differ from the dolicho-cephalic head of the long barrows. It would appear from this, that if, as there is every reason to believe is the case, the long barrows are the burialplaces of the oldest occupants of the wolds (at all events in neolithic times ${ }^{1}$ ), the long-headed people of the round barrows are the representatives of those persons who buried in the earlier long-shaped mounds. This people was probably intruded upon and conquered by the more powerfully made round-headed folk, who, as is nearly always found to be the case, would in course of time become intermixed with them, and with whom in the end they would become identified as one people. This appears to be the

1 There is no evidence that the wolds were peopled in palæolithic times; none of the flint implements of the drift, so characteristic in their shape, have been discovered there, nor indeed in any other part of Yorkshire. Remains of the fauna of the period, during which in other districts of England man was the contemporary of the mammoth and other extinct mammals, have been met with on the very borders of the wolds at Bridlington, and at Bielbecks, near Market Weighton; they have also occurred elsewhere in the county, but up to the present time, with the exception of two doubtful flints from Bridlington, no trace of man has been found. At the same time it by no means follows that man did not live in Yorkshire with the mammoth, and it is quite possible that abundant proof of such a companionship may yet be discovered. 
most reasonable, in fact the only, way of accounting for the finding of the bones of the long-headed people in the round barrows. These dolicho-cephalic heads of the round barrows cannot belong to the later Anglian immigrants, of whom the present population of the wolds is no doubt to a large extent composed, and who have left traces of their early, and probably pre-Christian, places of sepulture in several localities in the district; and this for more than one reason. In the first place, the heads of the barrows and those of the Anglian cemeteries, though both falling under the general designation of heing dolicho-cephalic, possess nevertheless, within that wide limit, other features so characteristic and well-marked, as to demand their separation into two distinct forms of skull, a result which certainly could not occur if both were of the same unaltered stock. Again, the Anglian invaders of the fifth and following century had been possessed of a knowledge of iron for some considerable time previous to that date, and were equipped with a full armament of that metal, as indeed their places of burial most abundantly show. But the long-headed people whose bodies are found in the round barrows, when any weapon or implement has been discovered with them, are seen to have been provided with nothing beyond those made of stone or bronze, identical with such as are discovered in association with the round-headed occupants of the same grave-mounds. The pottery also, so very well defined in its character, is quite distinct in shape, material, and ornamentation from that of the Anglian cemeteries, whilst it is precisely the same in all respects with that which is found with round-headed people in the barrows. It is true that Angles have sometimes made use of the earlier British barrows in which to inter their own dead; but when that has been the case, there is not the least difficulty in distinguishing between the burials of the later disturbers of the mound and those of the original occupants; and it is quite impossible that any confusion between the two distinct classes of interments could occur in the mind of any one to whom the facts incidental to barrow burial are familiar.

The extensive series of defensive works, commencing near Flamborough and extending over the whole of the wold district, has a very important bearing upon the question of the occupation of this part of England. These lines of fortification, so far as the North-eastern portion of them is concerned, have been very carefully surveyed by Colonel A. Lane Fox, F.S.A. His opinion is that these earthworks and their arrangement for defensive 
purposes are only to be explained on the supposition that they were made by a body of men advancing from the East, and gradually entrenching themselves as they extended their progress towards the West. If this view is correct, and the evidence of these arrangements considered strategically is certainly strongly in its favour, it appears to necessitate the occupation of the wolds by a people who, coming oversea, had landed upon the adjoining coast. A body so large as to have constructed the fortifications in question cannot be supposed to have arrived there haphazard; they must have had some previous knowledge of the country, and there must have been an intention of settling in it before the invaders left their own shores. It may be said that we have such a body arriving there in historic times, and that to them are to be attributed the works now under consideration. As is well known, the Angles, coming from the mouth of the Elbe, in the exact parallel of latitude with Flamborough Head, and leaving their ancient seats in the country which borders on that river in the lower part of its course, landed in England in considerable numbers, and gradually possessed themselves of South-eastern Yorkshire amongst other districts. Are they then to be looked upon as the invading people who threw up these large and stronglyconstructed series of mounds and ditches? I cannot think that there are any sufficient grounds for attributing such an origin to them, but that, on the contrary, there are strong reasons which seem to be inconsistent with it. It is scarcely to be looked for that an invading people would practise any new mode of entrenchment upon their first arrival, and therefore we would expect to find in the country from which they came some arrangements for defence similar to those in question. But in that part of Europe from which it is known the Angles and other nearlyconnected tribes emigrated into this country, very few works at all resembling these in question are to be found. It is true that the great line of the Dannewerk runs across from sea to sea, separating the northern part of the peninsula from the rest of the continent; but if in later times it was ever anything more than a divisional or boundary work, it seems probable it represents a line of defence constructed at a time antecedent to the Scandinavian occupation of Denmark. Besides the Dannewerk, there are still existing the remains of two defensive lines, apparently to protect the land of the Angles against an attack from the south; namely, the Kograben, on the middle water- 
shed, a little to the south of the Dannewerk, and the Oster Wall, between the Schlei and the Eckerfordern Harbour. There are also other old boundary walls and earth-works in different parts of the same country. These facts may seem to militate against what has been stated above, nor do I deny that they possess some weight; but at the same time, they may, as I have remarked of the Dannewerk, be defensive works of an earlier time than the Teutonic settlement of those parts. Having then due regard to this supposition and to the fact that, on the whole, fortified places are uncommon within the country occupied by our ancestors in their older seats, I cannot assent to the view which would attribute the wold entrenchments to the Anglian invaders. It does not appear that it was ever the habit of that branch of the human family, to which the designation of Teutonic has been commonly applied, and to which the Angles belonged, to depend upon an elaborate system of fortification for their defence, nor do we find that they adopted it even when they came into possession of countries where such arrangements were abundant, and which they must have found to be no trifling hinderances to their progress of conquest. We ourselves, mainly a Teutonic people, and showing our origin in all the spirit of our institutions and mode of government, good and bad, have never heartily entered upon any system of defending the country by fortified places, and have always placed more reliance upon the arm of flesh and our wooden walls than upon those elaborate stone and earth-works which other nations have carried to such perfection. To speak roundly, there were no castles in England before the Conquest by William and his Normans, who originally of kindred stock with the Saxon, Angle, and Jute, had nevertheless lost most of their Norse blood by intermarriage, and who had become as Gallic in their habits and speech as in their blood.

There is nothing which has ever been found, so far as I know, in connection with the entrenchments of the wolds, enabling us to attribute them with certainty to any time or people. The remains of the implements which were used in their construction, and some of which must probably have been met with within the mounds when they were levelled in the course of cultivation, have never been observed, so that any information which the occurrence of such things as broken picks of deer's-horn or stone axes, if they belong to the time when such were in use, 
would supply is wanting. Many burials have, however, been found placed in the mounds, some of which, on account of the various articles deposited with them, there can be no hesitation in attributing to the Anglian population; whilst those with which nothing has occurred may, on account of the type of the skull and the way in which the body has been interred, be safely attributed to the same people. This fact seems to be a strong argument against considering these lines of entrenchment to be of Anglian origin; for it appears unlikely that the persons who threw up the mounds as fortifications would use them as places of burial. At the same time it may be said that the descendants of the people who originally constructed them for defence might, when their necessity for such a purpose had passed away, have buried their dead in them.

We must, I think, look to some other people than the Angles for the invaders who erected these defensive works; and we seem naturally brought to regard the brachy-cephalic occupants of the round barrows as the probable constructors. It seems certain that an earlier long-headed people were intruded upon by a round-headed one, nor do we find until the coming in of the Angles any proof that the wolds had ever been occupied by other than these two markedly different peoples; for the Roman settlement of the district, as indeed might be expected, does not appear to have sensibly affected the character of the population. If then we reject the Angles as the authors of these defences, we are reduced to the round-headed folk as their constructors, for the earlier people whom they conquered, if they were the first occupants of the country, would not require to erect any such system of fortifications as these in question are found to be. This brachy-cephalic race, if they are to be regarded as the people who erected the wold fortifications, must have arrived from the opposite shores of the continent, and we may expect to find there people possessing the same characteristies. Nor shall we have to travel far in our search after them, for in the modern Danish head is exhibited the same peculiarity of type as is found to exist in the round skull of the barrows, a form which is also presented by many of the inhabitants of South Germany and Switzerland.

At the time when it was the custom to bury under round barrows, and when the body was interred both by inhumation and after cremation, the wolds were inhabited, as has already been more than once stated, by two stocks of people, having characteristic features of the most distinctive kind; the one being brachy-cephalic, the other dolicho-cephalic. Nor can it 
be said that the one was much more numerous than the other, as heads of the two types have been found in the barrows in about equal proportions. In this respect the wolds give a somewhat different testimony to that which is afforded by the round barrows in other parts of Britain; although the weapons, implements, ornaments, and pottery associated with burials in the various districts, including the wolds, are so identical as to show that the people who made and used them must have arrived at a very similar state of culture, and must also have been eonnected by one tie or another. By far the larger number of skulls which have been recovered from the barrows and cists of the greater part of Britain are brachy-cephalic, so much so, indeed, as to have caused Dr. Thurnam, whose experience was considerable, to use the expression 'round barrows, round skulls '.' If we are to judge from the barrows themselves, the long-headed people who buried in the long barrows must have been more numerous in some other parts of England than on the wolds, as for instance in Wiltshire and the adjoining country, where sepulchral mounds of this shape are ruuch more plentiful than they are in East Yorkshire. On the other hand, the dolicho-cephalic head is far more abundant in the round barrows of the wolds than in the similar-shaped mounds of the South-west of England. The conclusion then at which we seem to arrive appears to be this-that the earlier long-headed people were more completely eradicated by the intrusive roundheads in Wiltshire than they were in East Yorkshire, unless, which is not probable, the balance in the latter country was restored by later immigrations of the dolicho-cephalic people.

When we come to consider the physical characteristics of these two distinct peoples we observe at once a wide difference in their appearance. The long-headed one does not seem to have been either so tall or so strongly made as the other. The average height of the first may be taken to be about $5 \mathrm{ft}$. 6 in.; that of the other as about an inch more. The dolicho-cephalic people were also of a somewhat softer outline, in all the features of the head and face, than the more rugged brachy-cephalic people. The cheek

1 'The form of the skull, from the bowl-shaped, bell-shaped, and other circular barrows of pre-Roman Britain, scarcely requires extensive illustration; being on all hands admitted to be brachy-cephalous. This was the decided opinion of the late Mr. Bateman; and it is even insisted on by Dr. D. Wilson.... My friend and colleague Dr. Barnard Davis ... regards the brachy-cephalous as the "typical form of cranium of the Ancient Briton.", Thurnam, Principal Forms of British and Gaulish Skulls-Memoirs of the Anthropological Society of London, vol. i. p. 149. 
bones are by no means prominent, nor, as a rule, are the supraciliary ridges so much or so early developed as in the round-headed skull, both of which would make the face soft in its expression. The forehead is of an average height and breadth, rather higher than broad however in its general proportions. The head is long, as indeed the term given to it implies, and has the parietal bosses quite rounded off. The occipital region of the skull is prolonged in a marked degree, and adds much to the lengthened appearance of the head. Taken as a whole, it may be said that regularity and smoothness of outline is the main characteristic; and that those prominences are wanting which must have given such a harshness of feature to the brachy-cephalic head.

This differs, in almost every particular, from that just described. The lower jaw is massive, and in a certain degree square at the chin. The malar bones are prominent; and the supraciliary ridges strongly and early marked; thus affording, in the rugged and fierce expression which the face must have presented, a strong contrast to the pleasing appearance of the other people. The forehead is broad, though not low. The head is remarkably short and square. The occiput is so much flattened as to have suggested to some that it is due to an artificial process, such as the habit of placing the infant with its head resting at the back against a board or some other contrivance; or to the child having been carried for long during the period of infancy.

The skull of both types is capacious, and the different parts are well balanced; nor is there anything in it to lead to the belief that either people was wanting in mental power.

The identity of skull-form, as well as of weapons, implements, ornaments, and pottery discovered in various parts of Britain has been already briefly alluded to, but it may be well to discuss this subject a little more fully. Notwithstanding the abundance of long-headed skulls in the round barrows of the wolds, it may nevertheless be affirmed that the characteristic form there, and which associates itself with that class of barrows very markedly, is the round one. Throughout all the rest of Britain, and in Ireland so far as we know anything of the skulls found in the barrows of that country, which however is very little, the brachy-cephalic head, as has already been stated, is emphatically that of the round barrows. The pottery shows an equal identity, for, though there are many and varied patterns of vessels in different districts, yet in their main features, of fabric, shape, and 
ornamentation, the sepulchral vases show a wonderful resemblance throughout the whole United Kingdom. The weapons, implements, and ornaments also bear clear testimony to the same fact; nor is this identity one which could have been produced merely by human brains and human hands operating upon a common material and for a common purpose, whilst living under very similar circumstances, and being in much the same conditions of progress and cultivation. On the contrary, they show such an individuality in form and manufacture, as well as in the style of the ornamentation and the way in which it has been applied, as to imply not only a near race-connection, as manifested in the processes of mental developement and by a welldefined idiosyncrasy in respect of art application, but also an intercourse both constant and continued.

We seem to learn from this very remarkable identity, which appears to characterise both the people themselves and their productions, that, although there might be in some parts an intruding population, and in others the remains of an earlier one, the main body of the inhabitants of Britain at the time of the use of round barrow burial, before the introduction of iron, was of a markedly brachy-cephalic type. At the same time it must not be overlooked, that in the Early Iron Age, so far at least as the limited number of interments which have been discovered and noticed enable us to judge, the skull-form seems to have been dolicho-cephalic. This condition may have been brought about, and probably was, by the fact that the intruding round-headed people, smaller as they may have been in number, were gradually absorbed by the earlier and more numerous race whom, by force of one advantage or another, they had overcome. This subdued long-headed people may very possibly, in the earlier times of the conquest, have been kept in a servile condition, and therefore were not interred in the barrows, the place of sepulture reserved for the ruling race by whom they were held in subjection, and hence the numerical superiority of brachy-cephalic heads in the barrows. But as time went on and intermixture between the two peoples became common, a change would gradually take place in the racial characteristics, until at length the features of the more numerous body, that is to say the dolicho-cephalic, would become the predominant type of the united people.

What appears to have occurred in Britain may be further illustrated by what has taken place within historic times in 
France. A population, perhaps not homogeneous, was conquered by Rome, and so far brought under the influence of that power, that not only the political organization of the country became Roman, but the ancient language of the people was changed into that of the conquerors. Afterwards a large part of Gaul was overrun by, and brought into subjection to, the Franks. But at present, though the language of the Roman has remained and, to some extent modified, is now that of France, yet the old stock has again asserted its supremacy, and the modern Frenchman is, in the main, as much a Gaul, in form, feature and character, as he was when Rome first set foot in the land. Yet if we were to judge by the sepulchral remains of large districts of France, we might suppose that in the seventh and succeeding centuries there were scarcely any inhabitants except those of Frankish origin.

The whole question discussed above is, however, not only a very interesting but also a very difficult one, and we must, I think, be content to wait until we possess more full and accurate information before we can attempt anything more than a tentative solution of it.

The last question to be considered, and it is a very important one, is the date of the round barrows. It is, of course, impossible to attribute to them any but an approximate date; and even then, the evidence is wanting which would enable us to say more than that the period during which burying in them was practised is earlier than another period, itself to some extent an uncertain one. If we can find an era, whose place in the chronology of Britain may be regarded as more or less fixed, we have a starting-point from which to proceed. The time of the introduction of iron appears to afford such an era. The use of this metal was known in Britain at the time of Julius Cæsar's invasion of the country, in the year в.c. 55; and its introduction may be placed, with some degree of confidence, as dating from about two or three centuries before the birth of Christ. The use of bronze for weapons and implements, which preceded this time, must have lasted over a lengthened period, for it is not possible to account for the large numbers of articles of that metal which have been found throughout the country, and the high perfection in manufacturing it which had been attained, upon any other supposition. If 700 years is allowed as the time during which bronze was the 
metal used for making cutting instruments (and this estimate is probably under rather than above the truth), the date of the introduction of bronze may be estimated as being somewhere about the year B.c. 1000. It has been previously shown that, as regards the erection of the round barrows, the evidence appears to favour the view that the period must have been one when bronze was scarce, and had only lately become known. It is not impossible, indeed, that some of them belong to an age before bronze was discovered, and that they may date from a time several centuries earlier than that which has been fixed upon as the era of its introduction. This naturally leads to the question as to whether there was ever in Britain a neolithic age, when metal was unknown, or whether all the ground stone axes are contemporaneous with the use of bronze. The subject however is beyond the limits of this Introduction, nor do we at present, I think, possess the information necessary to enable us to arrive at any certain conclusion upon this very difficult matter of enquiry. I have myself no doubt that there was a neolithic age in Britain, when no metal was in use, and to that time I would attribute, though not with any degree of positiveness, the burial-mounds to which the name of Long Barrow has been given.

With respect to the age of the round barrows, there is a greater probability, I believe, of post-dating than of ante-dating them; and we need not fear that we are attributing too high an antiquity to them, if we say that they belong to a period which centres more or less in B.c. 500. The absence of silver and coins (the latter of which have not occurred except in a few and doubtful instances), though it is only negative evidence, is still strongly in favour of an early date. Silver appears to have become generally known about the same time that iron was first smelted and used for weapons and implements, and the introduction of coins as a medium of exchange seems to have taken place much about the same time, which in Britain may be considered as not earlier than B.c. 250. It appears scarcely possible, if the barrows belong to a time posterior to the knowledge and use of iron, silver and coins, that these several articles should not have been found in some of the many barrows which have been examined in Britain. It may be said that there was no native British coinage in the more northern parts of the island until after the Roman invasion, and therefore it could not be expected that coins should be discovered in those parts; but they have not been met with in the numerous barrows which have 
been opened in those districts of Britain where coins were struck and where they have been found in abundance. Iron and silver however were both of them known and used throughout the whole country. That they belong to a time before the Roman occupation of Britain appears to be absolutely certain ${ }^{1}$ (notwithstanding what some writers have said to the contrary), from the well-established fact, that neither the pottery, weapons, implements, ornaments, nor anything found in connection with the burials in the barrows shows the very slightest trace of Roman manufacture or even of Roman influence. It must be remembered also, when this fact is taken into consideration, that the wolds are not a tract of country far removed from the centres of Roman rule in Britain, but that the important station and settlement at Malton is upon their very outskirts, whilst they are only a few miles removed from the metropolis of York. In conclusion it may be said, that at whatever time they were erected, one thing is certain, that they are the burial-mounds of a people who occupied the wolds antecedent to the conquest of Britain by the Romans.

${ }^{1}$ I am speaking here with reference to the age of the wold barrows, though I believe the same may be said of similar sepulchral mounds in the greater part of Britain. It is possible, however, that in some remote districts the characteristic features of early burial may have been found in connection with interments of comparatively late times, and that such things as are justly considered to indicate a preRoman interment on the wolds or in Wiltshire, may in other places have occurred with a burial of a much later date. For instance, in a cist under a barrow on Morvah Hill, Cornwall, Mr. Borlase found, together with a burnt body enclosed in an urn of a type not unusual in that district, several Roman coins, one of which was of Constantine the Great (A.D. 306-337). Mr. Borlase is confident that the cist had never been disturbed since its formation until opened by himself. If then the integrity of the burial-place is granted, we have in this instance a case where the older mode of interment and the fashion of the pottery were continued down to a late period during the Roman occupation of Britain. Nenia Cornubiæ, p. 251. 


\section{YORKSHIRE. EAST RIDING.}

\section{THE WOLDS.}

The barrows which I am about to describe are situated upon the Wolds of the East Riding of Yorkshire, a district lying on the south side of the valley of the river Derwent, and opposite, at a distance of some miles, to the range of oolitic hills upon which some of the barrows described in other parts of this book are placed. An extensive examination of the northern, north-eastern, and south-western portions of this district has been made, and a large number of its sepulchral remains, as the following account will show, have been explored.

This tract of country, consisting of swelling and rounded chalk hills, interspersed with waterless valleys, and covered, before cultivation had in recent times brought it under the plough, with a stunted vegetation of short grass, furze and ling, but with little wood, occupies a considerable space in East Yorkshire. It is bounded, on the north by the valley of the Derwent, on the east by the sea and the flat lands of Holderness, on the south by the alluvial valley of the Humber, and on the west by the great plain of York.

A district such as this, wanting in one great requisite for permanent occupation, namely water, and possessing, through a want of shelter and its sparse vegetation, only a limited capability for harbouring and feeding any large number of wild or domesticated animals, would appear to have been, at a time when agriculture must have been exceedingly limited, but little adapted to furnish a dwelling-place for an extensive population. Notwithstanding these apparent disadvantages, however, the wolds show manifold signs of having been occupied at an early period by a numerous people. This appears, not only from the sepulchral 
mounds, which are still, after years of exposure to the destructive agency of the plough and of removal for agricultural purposes, sufficiently abundant, but also from the widely-diffused series of defensive works-ramparts and ditches-with which the wolds are covered. The multitudes of flint implements and chippings, which it is no exaggeration to say are found by thousands, also point to an occupation which must have been lengthened as well as extensive.

In the absence of other grounds of explanation of this fact, we must probably look to the naturally strong and easily defended positions which the district affords, for one of the main reasons why its early occupants selected it for their place of abode. It was nearly inaccessible on account of the flat, and consequently swampy, ground which surrounded it on all sides; and besides this, in the thick coverts, which must at that time have existed on those low-lying lands - a fact which is demonstrated by the frequent occurrence of trunks of trees and brushwood found in the peat-there was supplied the requisite shelter for deer, wild swine, and other animals, which formed, no doubt to some extent, an element in the food of a people by whom the processes of agriculture were but very slightly pursued. At the same time it must be admitted, that the evidence of the barrows makes it quite certain that these people were possessed of domesticated animals of various kinds, and if we are to judge by the bones found in the sepulchral mounds, it appears that the flesh of wild animals formed a very small item in their food, when compared with that of oxen, goats, and swine. With a few exceptions, the numerous bones which have been met with in the barrows are those of domesticated animals.

The dryness of the soil was also, no doubt, a great inducement to a people whose habitations were of a very imperfect kind, and to whom a wet or swampy situation must have been both inconvenient and unhealthy. Nor can it be doubted that the comparative absence of wood was a circumstance which must have materially influenced settlers, such as we may consider the early wolddwellers to have been, in their choice of a place of abode. To men who were in possession of no cutting instruments better than axes made of stone, or at the best of bronze, the clearing of land from forest trees, and even brushwood, must have presented almost insuperable obstacles. And as in the humblest stages of agricuitural and pastoral life a certain proportion of land must necessarily 
be free from wood, it may easily be understood that a tract of country which already fulfilled this requirement must have been a most desirable location for people in the earlier periods of civilisation. It has been remarked that those parts of England which appear to ourselves to be the least adapted to support a population, have been the most extensively occupied in primitive times, as for instance the wolds of Yorkshire, the downs of the southern counties, and the moorland of many different localities. The explanation of this seems to be that all these several districts were more or less free from wood, and were therefore ready for occupation without the labour, to these people a very severe and difficult one, of clearing the ground.

In the following account of barrow-opening operations I propose to take the successive groups of sepulchral mounds in a sort of order, commencing from the point most to the west, and proceeding in an easterly direction, along the northern border of the wolds, leaving those which have been subjected to examination towards the south-eastern and southern parts to be last described.

Parish of Kirby Underdale. Ord. Map (one-inch scale) xciII. N.E.

I. One of the most interesting barrows in some respects that I have opened was in the parish of Kirby Underdale, and situated at Uncleby, on the western ridge of the wolds, where it overlooks the plain towards York. I must, however, be content with giving details only as to a very small part of the contents of this grave-mound, because I do not intend, in the present account, to enter upon any description of Roman or post-Roman places of interment.

The barrow in question had, at a long time subsequent to its original construction, been made use of for burial purposes by a community of Angles (presumably the ancient inhalitants of what is now called Kirby), who had placed in it the bodies of above seventy men, women, and children, some of whom, it would appear, had belonged to the poorer classes of the community, whilst others had certainly been persons of wealth and importance. Quite a small museum of warlike, domestic, and personal relics was furnished by the results of a fortnight's digging, and some remarkable features in connection with Anglian interments were ascertained and recorded. Of these I will, however, only mention 
one, viz. that, contrary to the usual Anglian practice, the greater number of the buried persons had been interred in a contracted position, and not at their full length.

The barrow was $94 \mathrm{ft}$. in diameter, but only $2 \mathrm{ft} .10 \mathrm{in}$. high, having, within the recollection of the present occupier of the land, lost some feet of its original height. At a distance of $30 \mathrm{ft}$. southby-east from the centre, there was a deposit of burnt bones, those of an adult, laid in a round heap, $13 \mathrm{in}$. in diameter, upon the natural surface of the ground. With the bones was placed a bone pin, also burnt, and perforated with a large eye. At the centre was a grave, of a slightly oval form, sunk into the chalk rock to a depth of $6 \mathrm{ft}$. The longest diameter, in a direction southwest by north-east, was $6 \frac{1}{2} \mathrm{ft}$., the other $6 \mathrm{ft}$. At a distance of $3 \frac{1}{2} \mathrm{ft}$. above the bottom were the two pelvic bones of a horse; and at the bottom, about the middle of the grave, were two large flint stones, one foot apart, lying between which was a deposit of the burnt bones of an adult. Twenty-eight feet north-east of the centre, on the natural surface, was found a small polished greenstone axe, $3 \frac{1}{8} \mathrm{in}$. long, and $1 \frac{3}{4}$ in. wide at the cutting edge; and not fur from it a fragment of a 'drinking cup,' together with some flint chippings, a round scraper, and a long flake which showed many signs of use along one edge.

\section{Parish of Langton. Ord. Map. xcin. n.e.}

One of the great wold entrenchments runs across the well-known Langton race-course, in a direction almost due north and south. Just over the crown of the hill it is in a very perfect condition, and consists of four banks and three ditches.

II. To the north-west of this earth-work, at a distance of about $50 \mathrm{yds}$., is a barrow, the north side of which has been partly removed in order to level that part of the course. The other portion of it had been ploughed over, and very numerous fragments of 'Anglo-Saxon' pottery were strewed about immediately beneath the surface, the remains no doubt of somewhat superficial interments, disturbed by the ordinary processes of cultivation. The barrow was $60 \mathrm{ft}$. in diameter and $5 \frac{1}{2} \mathrm{ft}$. high, and formed of oolitic rubble and soil. At the centre, and placed on the natural surface, was the body of a man in the prime of life, laid on the left side, the 
head to N.N.W. ${ }^{1}$, and with the hands placed on the top of the head. Behind the head there was a small flint; flake. The skull, which is dolicho-cephalic and orthognathous, shows an extensive wound on the right side of the frontal bone, which was probably made by a metal weapon, but also might have been caused by some such implement as a stone axe. The present appearance of the bone shows that he must have lived two or three months after he received the blow, which was, therefore, possibly not the cause of his death. Just behind the head was a circular hole ${ }^{2}, 2 \mathrm{ft}$. deep and $3 \mathrm{ft}$. in diameter, filled in with sand; and close by the feet was a similar hole, but six inches deeper, and filled in with some broken pieces of stone in addition to the sand. Both above and below the body was a considerable quantity of charcoal. To the north-east of the body, and close in front of it, was a rudely-constructed wall about $3 \mathrm{ft}$. high, made of flat stones set on their edges, and five or six deep. This wall ran, for a distance of more than nine feet, in a direction nearly east and west. Immediately to the south-west of the body, the outer edge indeed overlying it, was a kind of cairn ${ }^{3}, 10 \mathrm{ft}$. in diameter and $3 \mathrm{ft}$. high, composed of oolitic rubble, with an external layer of yellow clayey soil, by which last substance the skeleton was overlaid. Beneath the eairn was a large quantity of burnt earth and charcoal, as if a fire had been lighted on the spot. About $15 \mathrm{ft}$. south-east-bysouth from the first body a second was met with. This was that of a woman ${ }^{4}$, of advanced age, which had been deposited about $9 \mathrm{in}$.

1 The compass direction (magnetic) is taken along the line of the vertebral column, and it is the crown of the head which is spoken of as being to such and such a point of the compass. The body must in all cases, unless it is specified to the contrary, be regarded as placed on the side in a contracted position, with the knees drawn up more or less towards the face, the back being in general slightly bowed.

${ }^{2}$ It will be noticed in the account of the long barrows that circular and oval holes were met with in some of them. The same has been found to be the case in the long barrows of the south-west of England. In the sequel it will be seen that they are by no means uncommon in the round barrows of the wolds, and the same feature was remarked by Sir Richard Colt Hoare in at least one instance in Wiltshire. In a barrow near Amesbury, he says, ' on the floor lay a skeleton ... and near it was a small oblong cist (hole), without any deposit in it.' Ancient Wilts, vol, i. p. 123.

3 Smaller mounds enclosed within the larger one have occurred in other barrows on the wolds, as for instance on Duggleby Wold [No. iii] and at Rudstone [No. lxiii]. Mr. Bateman notices that, at Gib Low, 'the tumulus had been originally raised over four smaller mounds.' Ten Years' Diggings, p. 18. They are not usually placed over an interment.

4 The skull is dolicho-cephalic, and in a very slight degree prognathous. Allowing for the difference of sex, there is a strong resemblance between this skull and that of the man lately noticed, so great indeed as to suggest the probability of there having been a near relationship between them. 
above the natural surface, upon a layer of flat stones, and with a similar layer above it, by which means it was to some extent protected from the pressure of the soil. The body had been laid on the right side, with the head to S.W., the right hand was across the chest, the left up to the face. Immediately about the bones was a noticeable quantity of charcoal. In front of the waist, and lying close together, as though at the burial they might have been placed in a bag, were several articles, evidently the implements and ornaments of the woman with whom they had been buried. They consisted of three bronze awls or prickers ${ }^{1}$; two bone instruments, one fashioned from a boar's tusk, $3 \frac{3}{4}$ in. from point to point with a groove at each end, and possibly being the bow of a drill, though more probably a pin [fig. 94], the other made from a beaver's

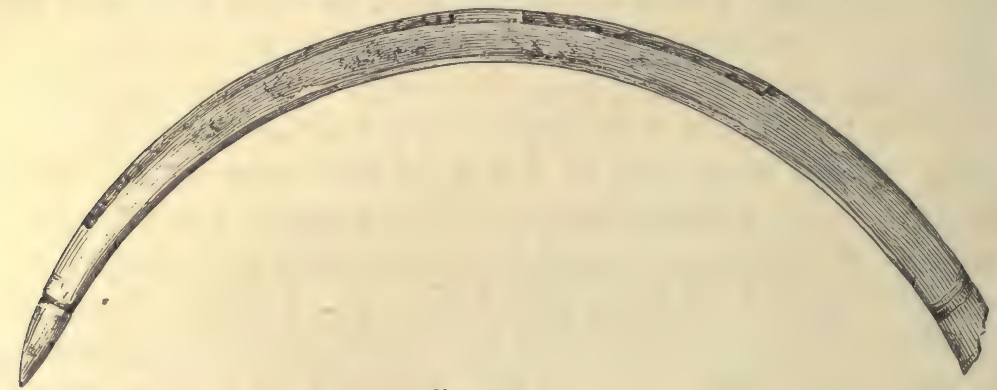

Fig. 94. $\frac{1}{1}$.

tooth $1 \frac{7}{8}$ in. long, curved and narrow, and having a sharp cutting edge $\frac{1}{4}$ in. broad; a flat circular jet bead [fig. 44]; a piece of an animal's tooth, pierced [fig. 46]; a nerita, pierced [fig 45 $]^{2}$;

${ }^{1}$ I have met with similar instruments in other barrows on the wolds, as at Sherburn [No. xii], Rudstone [No. lxii], and Goodmanham [No. exii]. One is noticed and figured in the Reliquary, for Oct. 1868, from a barrow near Fimber on the Wolds. Sir R. Colt Hoare records the finding of several, which he calls pins, associated with burials after cremation; one is figured, Ancient Wilts, vol. i. pl. xii, and shows it to be identical with those from this barrow. Mr. Bateman met with them in the Derbyshire barrows, some having the remains of the wooden handle still upon them. Vestiges, p. 105; Ten Years' Diggings, pp. 67, 72, 107, 155, 171. They are frequently found in the sepulchral mounds of Denmark accompanying burnt bodies. Though they have usually been called pins, they are by no means well adapted for any purpose to which pins would be applied, and I have little doubt that they are awls or prickers, and were used for piercing leather or other material in the operation of sewing.

${ }^{2}$ Sir R. Colt Hoare met with a single nerita in the Wiltshire barrows. Ancient Wilts, vol. i. p. 68. A necklace, consisting of a number of perforated shells, was found with a skeleton at Knock-Maraidhe in the Phœenix Park, Dublin. Crania Brit., pl. 22; Wilde, Cat. of Ant. Museum of Royal Irish Acad., p. 183.

A skeleton discovered in a cave at Mentone and another at Cro-Magnon, both of which have been attributed, though I scarcely think on quite sufficient grounds, to the palæolithic age, had been buried with similar necklaces. 
a piece of a dentalium ${ }^{1}$; a portion of a belemnite rubbed down; one of the vertebræ of a fish; and three cowries (Cypraa Europaa) ${ }^{2}$. Only one of the awls is perfect, the others having lost somewhat of their substance by oxidation. The entire awl [fig. 95] is one inch

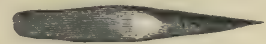

Fig. 95. ㄴ.

long, the flat tang for insertion in the handle taking up $\frac{5}{8}$ in. of the entire length.

About $6 \mathrm{ft}$. south of the remains last mentioned was a third body, that of a very old person, probably a woman, with a markedly brachy-cephalic head ${ }^{3}$. This was laid on the left side upon a rough pavement of small stones-placed on the natural surface. The head, on either side of which stood an upright stone, pointed a little south of east, and the hands were up to the face. In front of the knees was a vessel of pottery, lying on its side, and with the bottom towards the body. It is of the type of the cinerary urn, in shape like fig. 56, a vessel which is very rarely found with an unburnt body, and is $7 \frac{1}{4} \mathrm{in}$. high, $5 \frac{1}{2}$ in. wide at the mouth, $6 \frac{1}{2}$ in. at the bottom of the overhanging rim, and $3 \mathrm{in}$. at the bottom of the vessel. The rim, $1 \frac{3}{4}$ in. deep, is ornamented with parallel sloping lines, over which are impressed two lines, parallel to each other, about an inch apart, and encompassing the urn. Below the rim another line goes round the urn, from which shallow loops depend, $2 \frac{3}{4}$ in. long and not quite $\frac{1}{2}$ in. deep. The impressions are those of loosely-twisted thong.

Between this interment and the body of the woman was the same kind of wall as that found near to the first body. It ran in a direction east and west for a distance of about six feet. Two feet west of the third body there was a circular hole, $3 \mathrm{ft}$. in diameter and

1 Sir R. Colt Hoare found, whether with a burnt or unburnt body is not stated, ' a little dagger of brass,' several clay beads, and 'a great quantity of curious little shells, in shape like the Hirlas horn used by the Britons.' Ancient Wilts, vol.i. p. 114. pl. xiii. The shell he figures is evidently a dentalium.

${ }^{2}$ Amongst the burnt bones in an urn under a barrow three miles west of Dorchester, was 'a small cowrie shell, which had been perforated, and worn probably as a bead.' It had been 'subjected to the action of fire.' Warne, Celtic Tumuli of DorsetTumuli Opened at Various Periods, p. 45 ; extracted from a paper, Archæol., vol. xxx. p. 327 , where the shell is figured, pl. xvii. fig. $e$.

${ }^{3}$ The skull shows all the signs of extreme age; all the sutures are effaced. The lower maxillary, all the teeth having been wanting for many years, had become attenuated to a very extraordinary degree, from the complete absorption of the alveolar process. 
$2 \mathrm{ft}$. deep, filled with broken stones and rubble, with larger and flat stones on the top. About $8 \mathrm{ft}$. within the external line of the barrow, on its south-west side, were many traces of fire, such as burnt earth and stones, and amongst them a portion of a human skull also burnt. Throughout the whole barrow, but the least so on the east side, the natural surface showed extensive signs of burning. Some animal bones, and amongst them the tooth of an ox (bos longifrons), were found in the barrow, and a single piece of pottery, but no flint chippings.

\section{Parish of Kirby Grindalyth. Ord. Map. xciv. n.w.}

III. Upon Duggleby Wold there was at one time a group of three barrows lying very close together. Of these, one was removed several years since, and of the two remaining I opened the larger. This was $74 \mathrm{ft}$. in diameter and $6 \mathrm{ft}$. high. The upper part consisted of layers of loamy earth, below which the material employed was very stiff clay, with chalk and flints intermixed. Twenty-five feet south of the centre was an oblong hollow, with rounded ends, excavated in the chalk, $6 \mathrm{ft}$. by $4 \frac{3}{4} \mathrm{ft}$. and $2 \frac{1}{2} \mathrm{ft}$. deep, and having a direction south-west by north-east. Like nearly all of these enigmatical holes, it contained nothing besides the filling-in of earth and clay. Twelve feet south of the centre there was another hole, $2 \mathrm{ft}$. in diameter and $1 \frac{1}{2} \mathrm{ft}$. deep, containing, like the larger one, nothing more than the filling-in. At the centre was a flat-topped conical mound, composed of chalk rubble, $1 \frac{1}{2} \mathrm{ft}$. high, and $4 \mathrm{ft}$. in diameter at the top. Upon the flat summit was a layer of charcoal, and upon it was deposited the body apparently of a man, laid on the right side with the head to W., but in such a decayed state that the position of the hands could not be ascertained. At the hips were two flint flakes, and close to the body were four flint chippings and three water-worn quartz pebbles. Beyond the head were four holes, made apparently by the ends of stakes, similar to some found in a grave under a barrow on Ganton Wold, and which are fully described in the sequel. These now under notice were $10 \mathrm{in}$. deep, and varied from $1 \frac{1}{2} \mathrm{in}$. to $2 \mathrm{in}$. in diameter. Three of them were angular and one round, and the remains of the decayed wood in the holes were quite distinct. On both the east and west sides of the central mound was a similar one, but without any layer of charcoal, and showing no signs of a body having ever been placed upon either of them. Within the barrow 
were a few potsherds, some chippings of flint, a well-formed flint flake, $2 \frac{3}{4}$ in. long, much worn by use along both edges, and a thin piece of sandstone, $4 \mathrm{in}$. long, $1 \frac{3}{8} \mathrm{in}$. wide at the narrower end, and $1 \frac{3}{4}$ in. at the broader, the latter being rounded. The surface is quite smooth, apparently from use, and the stone seems as though it might have served for rubbing down hides, or some similar purpose.

\section{Parish of Heslerton. Ord. Map. xcv. s.w.}

IV. I commenced operations on a large series of barrows placed upon the edge of the chalk range and overlooking the valley of the Derwent, by opening one on West Heslerton Wold. It was $42 \mathrm{ft}$. in diameter, and still, though somewhat ploughed down, $3 \mathrm{ft}$. high, and was composed of chalk-rubble above and plain earth below. At the centre was an oval grave, having a direction northwest by south-east, $3 \mathrm{ft}$. $2 \mathrm{in}$. long by $2 \mathrm{ft}$. $4 \mathrm{in}$. wide, and sunk $1 \frac{1}{2} \mathrm{ft}$. into the chalk rock. At the bottom of the grave was the body of a young child ${ }^{1}$, about $2 \frac{1}{2}$ years old, laid on the right side, and with the head to N.W. In front of the knees was placed a large quantity of round dark objects, apparently the seed of some plant, bearing indeed a strong resemblance to the fruit of the juniper ${ }^{2}$. Just above the grave two ox-teeth were met with. On the north side of the barrow were portions of two adult femurs, which may have belonged to a body that had been disturbed when a partial opening, of which very evident signs were found, had been made many years before. In the barrow was a very well made long flint scraper.

V. About 300 yards to the east of the last barrow was another, oral in shape, and having a direction north-north-east by south-

${ }^{1}$ It is not very uncommon to find that the primary interment in a barrow has been of a child, sometimes of very tender years. I have met with it myself at Ford, Northumberland [No. elxxxvii], and at Rudstone [No. lxvii], under a very large grave mound. Other explorers have met with the same occurrence. In a cist at the centre of the barrow, and no doubt the primary interment, was 'the skeleton of a child, apparently about ten years of age; above this was a drinking cup.' Bateman, Vestiges, p. 52. In a grave, $5 \mathrm{ft}$. deep, at the centre of a large barrow, was ' the skeleton of a child, apparently not more than two or three years old, accompanied by a drinking cup.' Hoare, Ancient Wilts, vol. i. p. 210.

${ }^{2}$ Similar deposits have occurred elsewhere. In a cist at Terrachie, near Stonehaven, with a contracted body, were 'not fewer than 150 small black balls, which, on examination, proved to be vegetable, and were most probably acorns.' Proc. Soc. of Ant. of Scotland, vol. i. p. 140. 
south-west, $83 \mathrm{ft}$. long, $67 \mathrm{ft}$. wide, and $2 \frac{1}{2} \mathrm{ft}$. high. It was formed principally of earth, but with some admixture of chalk, especially at the south end. The mound contained a single burial, deposited in a grave at the centre. This grave was oval, running east and west, $8 \mathrm{ft}$. by $4 \frac{1}{2} \mathrm{ft}$., and $3 \mathrm{ft}$. decp. It was filled in with chalk. On the bottom at the east end was the body of a man in the middle period of life, laid upon the left side, with the head to E.S.E., the right hand across the chest, the left up to the chin. In front of the face was a 'food vessel,' still containing some dark-coloured matter, the remains, there can be no doubt, of what had been placed in it at the time of burial. Below the body, and extending beyond it on either side for a short space, was a thin seam of a dark substance, having very much the appearance of decayed leather. This was probably all that was left of what had been the buried man's dress ; who if not interred in his garment of skin, may have been first wrapped in a hide, of which this was the remains ${ }^{1}$. The ' food vessel ' [fig. 70] is $4 \frac{3}{4} \mathrm{in}$. high, 6 in. wide at the mouth, and $2 \frac{3}{4}$ in. at the bottom, and has nine perforated ears at the shoulder. It is covered, for a space of $3 \frac{1}{2}$ in. from the top, with short lines in bands encircling the vessel, and arranged herring-bone wise. The ears have similar lines upon them, but arranged vertically, and the inside of the rim is ornamented in the same way as the body of the vessel; at the bottom a row of short vertical lines encompasses it. The lines have been made by a sharp-pointed tool drawn on the moist clay towards the workman. Sixteen feet west of the centre, and $1 \frac{1}{4} \mathrm{ft}$. above the natural surface, was found the bottom and some other portions of a vessel of pottery, but there was no appearance of a body having ever been buried at the place. Throughout the whole of the mound, and upon the natural surface also, were pieces of charcoal; and here and there, in the material of the barrow, were chippings of flint. There were also met with a few broken animal bones ${ }^{2}$, some potsherds, about the half of a round jet bead, $\frac{7}{8}$ in. in diameter, having the perforation drilled from each side, several flint scrapers, and two saws, one of them most regularly and delicately serrated, and showing in the glazing upon the teeth that it had been long in use.

VI. About a quarter of a mile east of the barrow just noticed was

1 The occurrence of leather or hide with ancient interments is not unfrequent. Some instances will be found recorded in the Introduction, pp. 31, 32.

${ }^{2}$ The bones are of ox (bos longifrons), and of pig (sus serofa domesticus). 
another, which on examination presented some singular features. It is at no great distance from a long barrow, which was partly removed prior to the year 1868, and entirely destroyed in that year, when several characteristics very similar to those of a long barrow which I examined on Willerby Wold were diselosed.

The round barrow was $70 \mathrm{ft}$. in diameter, $3 \frac{1}{4} \mathrm{ft}$. high, and was made up of earth and broken flint. On the east side of the mound was a very remarkable trench sunk into the chalk rock. It commenced at a point $25 \mathrm{ft}$. east-by-south from the centre, and extended for $16 \mathrm{ft}$. in a north-east direction. At the south-west end (where it had a kind of offset or extension towards the southwest, $3 \mathrm{ft}$. long, $2 \mathrm{ft}$. wide, and $2 \mathrm{ft}$. deep) it was $5 \frac{3}{4} \mathrm{ft}$. deep, $3 \mathrm{ft}$. wide at the top, and $1 \frac{3}{4} \mathrm{ft}$. at the bottom. Towards the north-east end it became gradually shallower and narrower, diminishing to $2 \mathrm{ft}$. in depth and $1 \mathrm{ft}$. in width, widening again however and deepening at its extremity into a hole $2 \mathrm{ft}$. wide and $4 \mathrm{ft}$. deep. Midway along the line of this trench was a row of large blocks of flint, lying close together and $1 \frac{1}{2} \mathrm{ft}$. above the bottom, having underneath them a considerable number of potsherds. The whole of the trench was filled with burnt earth, burnt chalk, and charcoal. The fire had been applied however to this material before it had been placed in the trench, for there was not the slightest trace of burning on the sides of the trench, although the heat to which the burnt chalk and earth had been subjected had evidently been very intense. Throughout the trench, but especially (as just noticed) beneath the flints, were many broken pieces of pottery, principally of a dark-coloured ware, and certainly the fragments of domestic utensils. Amongst these were the broken portions of one vessel in particular, in sufficient number to allow of its being re-constructed; the several pieces were not lying together, but were dispersed throughout the greater part of the trench. This vessel [fig. 91] is hand-made, with a rounded bottom, $5 \mathrm{in.} \mathrm{high,} \mathrm{and} 10 \mathrm{in}$. wide at the mouth; the lip or rim turns over. It is of a palishbrown colour, and the paste is remarkably fine and without any admixture of broken stone ; and in point of density it is so light as to rival in that respect the best Greek pottery. I have never met with anything quite like it, in shape, colour, or paste ${ }^{1}$. Mr. Tindall,

1 It will be observed that the occurrence of dark-coloured plain pottery, presumably the remains of domestic vessels, is a common feature in the wold barrows. The remains are however so fragmentary that I have never been able to reconstruct a vessel, but I believe, judging from the curvature of the fragments, that many of 
of Bridlington, who from his knowledge of clay, as a pipe-maker, is competent to speak on the subject, tells me that there is a clay at Speeton which produces a paste like this, and that he knows of no other clay in the district which would make such a ware. I should however be inclined to think that the clay had been obtained nearer to the barrow than Speeton. At the south-west end of the trench, and on its west side, was a sort of extension of it, of an apsidal form towards the west, $6 \mathrm{ft}$. long, $6 \mathrm{ft}$. wide, and $8 \mathrm{in}$. deep ; this was filled with burnt earth and charcoal, which indeed rose above the natural surface as high as the present surface of the barrow, and was co-extensive with the hollow. There were no potsherds in it, and, as in the case of the trench, the burning did not appear to have taken place on the spot. On the south side of the hollow lay a log of partially burnt oak wood, $3 \mathrm{ft}$. long and 8 in. square. Another hole occurred $16 \mathrm{ft}$. east-by-south from the centre. It was oval, $2 \mathrm{ft}$. long from north to south by $1 \mathrm{ft}$. broad, and $1 \frac{3}{4} \mathrm{ft}$. deep. The filling-in was burnt earth, having amongst it a very few burnt bones, apparently animal. At a point $12 \mathrm{ft}$. northwest of the centre, and $1 \frac{1}{2} \mathrm{ft}$. above the surface, there was a large quantity of pieces of dark-coloured plain pottery, the remains of several vessels, all of them probably domestic. Fifteen feet west-bynorth of the centre, and a little above the natural surface, lay a 'drinking cup,' much broken by the pressure of the earth and badly decayed. There was nothing to suggest that a body had ever been buried at the spot; as from the nature of the soil it might have been expected that some at least of the bones would have been found if ever a body had been laid there. It is of course possible that the vase may have been placed in the mound in connection with the central and sole interment found in it, though the occurrence is very unusual. I have however met with other instances in which a vessel has been placed in the barrow apart from a body, as in one on Ganton Wold and in another at Cowlam. At the centre was the body of a young person, laid on the left side, the head to $\mathrm{W}$. by $\mathrm{N}$. The bones were very much decayed. The body had been placed on the level of the natural surface, but the chalk had been removed below it to a depth of $1 \frac{1}{2} \mathrm{ft}$., the hollow thus produced having been filled in with stiff clayey soil. In the barrow were several chippings, and a knife-shaped implement of flint with a curved edge, carefully chipped along both back and front.

them, like this in question, have been round-bottomed; the lip also is generally, like that in the figure, roll-shaped, slightly curving over. 
The trench, with its filling-in of burnt earth and ehalk, its potsherds and charcoal, presents a very interesting subject for speculation. It will be seen from the description of many of the barrows noticed in this volume, that enigmatical holes, usually filled with earth and stone that have not been burnt, are of frequent occurrence, but trenches or holes filled up with burnt matter are by no means so common, though occasionally met with. Deposits of burnt earth \&c. upon the natural surface, together with fragments of domestic pottery and bones of animals, have been found in some of the wold barrows; and these probably originated in the self-same funeral practice as gave rise to the trench in the barrow lately under notice. Were they connected with a feast held at the burial, or on later commemorative occasions? May the broken vessels and animal bones be regarded as favouring such a view?

\section{Parish of Sherburn. Ord. Map. xcv. s.w.}

The three barrows next to be noticed were not opened by myself, but by the Rev. Frederick Porter, Vicar of Yedingham, and the late Mr. Charles Monkman of Malton, both of whom have had some experience in the examination of barrows, and whose accuracy of observation may be fully depended upon. I include them in the present description because they are situated in the immediate vicinity of a large series opened by myself, and also because the skulls and other remains found in them have: come into my possession.

At a short distance to the north-west of these barrows, and close to where the long barrow shortly before noticed once stood, was a round one, which was opened by Mr. Ruddock in 1851. An account of the contents is given by Mr. Bateman in his Ten Years' Diggings, p. 230, where it is recorded that fifteen skeletons were found at the centre. I examined it again when it was being removed for agricultural purposes. It was $80 \mathrm{ft}$. in diameter, and within it, with a radius of $30 \mathrm{ft}$., was a circle of chalk stones which had an opening $9 \mathrm{ft}$. in width on the east side. Eighteen feet south-east of the centre and $1 \frac{1}{2} \mathrm{ft}$. above the surface was a body, on the right side, the head to $W$., the hands up to the face. Twenty feet south-south-east of the centre and lying on the surface was a skull which had evidently been disturbed at an early period; no other bones of the body were present. Below 
the skull was an oval hole, north and south, $5 \mathrm{ft}$. by $3 \frac{1}{2} \mathrm{ft}$., and $2 \frac{1}{2} \mathrm{ft}$. deep, containing nothing beyond earth and chalk, the materials of which the barrow was formed. At the centre were two holes, $1 \frac{1}{2} \mathrm{ft}$. apart, lying in a direction north-east and southwest; one was $5 \mathrm{ft}$. long and $3 \frac{1}{2} \mathrm{ft}$. wide, the other $4 \frac{1}{2} \mathrm{ft}$. long and $3 \mathrm{ft}$. wide, both being $2 \frac{1}{2} \mathrm{ft}$. deep, and having their long diameter north-west by south-east. Like the first-mentioned hole, they contained nothing except earth and chalk.

VII. The first of the three barrows opened by Messrs. Porter and Monkman was $60 \mathrm{ft}$. in diameter, and had been ploughed down to a height of not more than $1 \frac{1}{2} \mathrm{ft}$. About $18 \mathrm{ft}$. from the east side of the mound, and laid upon the natural surface, was found a large deposit of broken human bones, the remains of not less than eight bodies, as was proved by the presence of portions of as many different skulls. All these, together with some animal bones ${ }^{1}$, were scattered about in the greatest confusion, and, in the opinion of the explorers, had been deposited so originally. It is of course possible they might be the remains of bodies which had been disturbed by the insertion of secondary interments and re-buried; still, if this had been the case, we should scarcely have expected to meet with so many bodies; nor indeed did the examination of the barrow show that there had been any disturbance sufficiently extensive to occasion the removal of so many as eight previously buried bodies. At the centre of the barrow and upon the natural surface there was a large quantity of dark-coloured and perfectly plain pottery, the remains of many different vessels which had, it was evident, been placed there in the fragmentary condition in which they were found. They were spread over an area of about $6 \mathrm{ft}$. square. A few pieces of a human skull were also met with close to the centre. To the north, south-east, and south-west of the centre were three holes, marking the angles of a triangle; they were sunk $1 \frac{1}{2} \mathrm{ft}$. below the surface, and contained nothing in addition to the chalk which had been dug out in sinking them. Close to the north hole was the skull of a pig, some other animal bones, and a round flint scraper. West of the centre was the body of a young woman, from 20 to 25 years of age, laid in a slight depression of the surface, on the left side, with the hands up to the face. The head was protected by two large blocks of flint, placed roof-fashion over it. Near the

1 The bones are of one goat or sheep, and of three pigs. 
body were six flakes and a well-formed but slightly chipped knife. Close to the edge of the barrow, on the north-west side, was the body of a young person, about 17 years of age, of doubtful sex, laid on the right side, the hands crossed over the breast. This body was laid on the natural surface, and there was a good deal of burnt earth and charcoal below it. In front of the knees was a 'drinking cup,' in shape like fig. 120 ; it is $8 \frac{1}{2}$ in. high, 6 in. wide at the mouth, and $3 \frac{1}{8}$ in. at the bottom, and ornamented to within $2 \frac{1}{2}$ in. of the bottom with five bands of a reticulated pattern, alternating with four series of six encompassing lines, all of which have been made by a notched strip of bone or wood.

VIII. The second barrow was $50 \mathrm{ft}$. in diameter and $2 \mathrm{ft}$. high, but, like the first, had been much lowered by ploughing. At a distance of a few feet from the east side was a deposit of broken and scattered human bones, the remains of at least five bodies, presenting the same appearances as those found in a like position in the barrow last described. They had been placed on a layer of clay, with interspersed particles of charcoal, which rested on the natural surface and covered a space of about $8 \mathrm{ft}$. square. Throughout a great part of the area of the barrow detached human teeth were met with, strewed upon the natural surface. Fifteen feet south-east of the centre there was a hole, filled with chalk; and at about the same distance north-east of the centre was another hole, also filled with chalk, amongst which some animal bones occurred ${ }^{1}$. Immediately south of this hole there was a good deal of charcoal lying on the natural surface, together with part of a human skull, some portions of ribs, and a few pieces of plain dark-coloured pottery. At the centre was an oval hollow, lying north and south, $5 \mathrm{ft}$. by $3 \mathrm{ft}$., and $2 \frac{1}{2} \mathrm{ft}$. deep. It was filled with chalk rubble, amongst which were two flint chippings; and at the bottom was a single piece of pottery, with some slight traces of human bones, probably the remains of the primary interment. In the material of the barrow several flint chippings were found.

IX. The last of these three barrows was $60 \mathrm{ft}$. in diameter and $2 \mathrm{ft}$. high, and, like the others, much worn down by the plough. Twenty-two feet south-east of the centre, and laid upon the natural surface, were some remains of a much disturbed and decayed

1 The bones are those of three oxen (bos longifrons), 
body. With the bones were two flint chippings and some pieces of charcoal. Twenty feet south-by-west of the centre were some human bones, but so much gone to decay that it was impossible to make out whether or no an entire body had been buried there. With them was a long flint scraper. At the centre was an oval grave, its longest diameter lying east and west, $3 \mathrm{ft}$. by $2 \mathrm{ft}$. and $1 \mathrm{ft}$. deep. In it were two bodies, one that of an aged man, the other that of a woman considerably younger, being probably under tiventy years of age. The man had been laid on the right side,

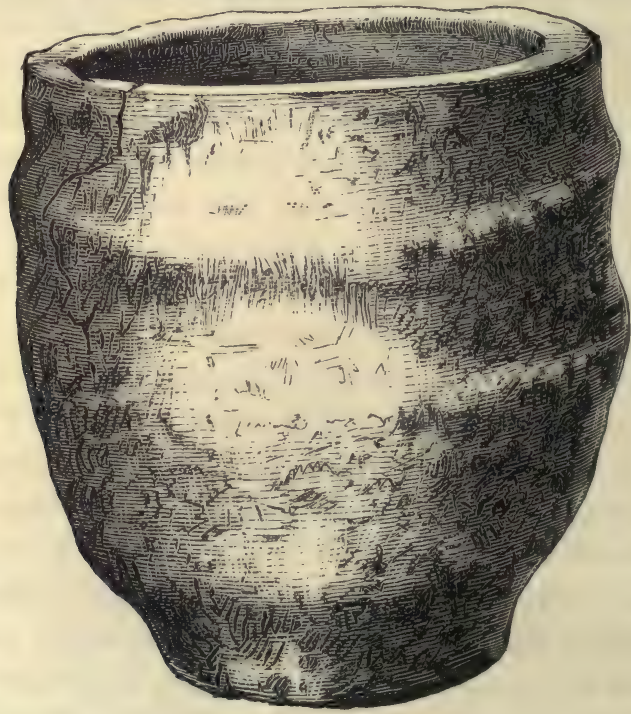

Fig. $96 . \quad \frac{1}{2}$.

with the head to W.; in front of the face was a vessel of welltempered and well-baked clay, without any admixture of comminuted stone, of dark colour and perfectly plain, except in so far as the presence of two encircling ribs may be looked on as an ornament. It is 5 in. high, $4 \frac{3}{4}$ in., wide at the mouth, and 3 in. at the bottom [fig. 96]. The woman had also been laid on the right side, but with the head to $\mathrm{E}$. In the barrow were two pieces of plain pottery, a few flint chippings, and many animal bones ${ }^{1}$.

X. Situated at no great distance from the barrow just noticed, but somewhat to the east of it, was one opened under my own supervision, and which proved to be little more than a natural swell of

\footnotetext{
1 The bones are those of several oxen (bos longifrons), all adult animals.
} 
the wold, taken advantage of and artificially enlarged to a slight extent. In its present form it is an oval mound, with a north and south direction, about $90 \mathrm{ft}$. by $74 \mathrm{ft}$. At the centre the chalk rock rises to the surface, and it did not seem as if any addition had ever been made at that point. Eighteen feet west-south-west from this assumed centre was an adult body, laid on the left side, upon the natural surface, with the head to S.E., and the hands crossed over each other at the waist. Below the head was a chipping of flint. In contact with this body and lying in front of its face and chest was the burnt body of an adult, some of the bones of which were lying under the arms of the unburnt one. It thus became evident that the unburnt body must have been deposited in point of succession after the burnt body, and not less evident was it, from the general appearance of the bones of each body, that both had been buried on the same occasion. The added soil above these bodies did not exceed a foot in actual thickness; but they may originally have been further from the surface, as some of the soil would naturally be removed by the action of the plough. In the mound were some broken bones of an adult ox, some of them gnawed, most probably by dogs; several flint chippings, and a long and rather irregularly formed flint scraper, the edge of which was somewhat smoothened by use.

XI. The barrow now about to be described seems to have been partly ploughed out of its original position, down the sharp slope of the hill upon the extreme verge of which it is placed. It was $40 \mathrm{ft}$. in diameter and $1 \frac{1}{2} \mathrm{ft}$. high, and was made of chalk rubble. At a distance of $14 \mathrm{ft}$. east-north-east of the present centre was the head of a young child, none of the other bones of the body being present; whilst immediately under it, and resting upon the rock, were the burnt remains of another child. In contact with the latter was a 'food vessel,' in shape like fig. 69, lying on its side, with the mouth to the east, and close to the child's head. It is $6 \frac{1}{4} \mathrm{in}$. high, $6 \frac{1}{2} \mathrm{in}$. wide at the mouth, and $3 \mathrm{in}$. at the bottom, where it slightly widens. The inside of the lip of the rim has three and the outside two encircling lines; below these are two zigzag encircling lines, and below these again two other encircling lines of semicircular markings, forming two rows of arches; all the impressions having been made by the application of a twisted thong. The remainder of the vase for a depth of $4 \frac{1}{4}$ in. is quite plain. It is impossible to say with which of the two burials this vessel was associated, as it was in like 
proximity to either. It is probable however that it accompanied the unburnt body. Touching the child's head were the feet of a third body, of a person of full growth, laid on the right side, and with the head to $W$. The heels of this body were in the closest vicinity of the 'food vessel.' No part of the skeleton was left, except the legs, part of the lower jaw, and the left temporal bone.

XII. About a mile south-west of the barrow just described, but separated from it by a deep valley, was a single mound, placed on the summit of the hill, upon the range of high land running between the valley of the Derwent and the great Wold valley, which pursues a direction west and east past Lutton, Weaverthorpe, Wold Newton, and other places in the same line. This barrow was $56 \mathrm{ft}$. in diameter and $2 \mathrm{ft}$. high, and consisted of earth with some chalk. It had been much ploughed down. At a distance of $21 \mathrm{ft}$. north-west of the centre was found the body of an adult, probably a man, which had been laid on the right side on the natural surface, the head being to S.W. Underneath the head were three flint implements; the first, which seems to be a knife, has been carefully chipped all along the edge, except at the end opposite to that at which it was struck to separate it from the core, it is $2 \frac{7}{8}$ in. long and $1 \frac{1}{4}$ in. wide; the other two were a round scraper, and a flake which shows, all along the edge, signs of having been actually in use. At the centre and placed upon the level of the natural surface was a cinerary urn, reversed [fig. 97], enclosing a deposit of the burnt bones of an adult, and amongst them was a bronze awl, $1 \frac{5}{8}$ in. long [fig. 41], the flattened end of which, intended for insertion in the handle, is just above a quarter of an inch in length. The urn, which is better fired than usual, is of rather uncommon proportions, being narrow in comparison with its height. It is $13 \frac{1}{2} \mathrm{in}$. high, $8 \frac{3}{4} \mathrm{in}$. wide at the mouth, and $4 \mathrm{in}$. at the bottom. The upper part, for a depth of $5 \mathrm{in}$., is ornamented with encompassing lines, arranged herring-bone fashion, made by a sharp-pointed tool. Immediately underneath the urn was an oval grave, cut into the rock, and filled in with clayey soil and a little chalk. It was $7 \mathrm{ft}$. by $6 \mathrm{ft}$., running north-east by south-west, and $1 \frac{3}{4} \mathrm{ft}$. deep. At the bottom was found the body of a young person, about 15 years of age, laid on the right side, the head to $\mathrm{N}$. by E., and the hands up to the face. In front of the knees there was a 'food vessel.' It is shaped somewhat like fig. 69, $5 \frac{3}{4}$ in. high, 6 in. wide at the mouth, and $2 \frac{3}{4}$ in. at the bottom. 
The inside of the rim, which is $1 \mathrm{in}$. deep, is ornamented with four encircling lines arranged in pairs, and the upper part of the vessel for a depth of $2 \mathrm{in}$, where a groove runs round it, has irregular impressions upon it. The whole of the markings are made by the application of twisted thong. Just in front of the chest was a flint knife, $2 \frac{3}{8} \mathrm{in}$. long and $\frac{5}{8}$ in. wide, and in general shape much like figure 98 ; one face is left just as it was struck off from the core, the other is carefully flaked along both planes;

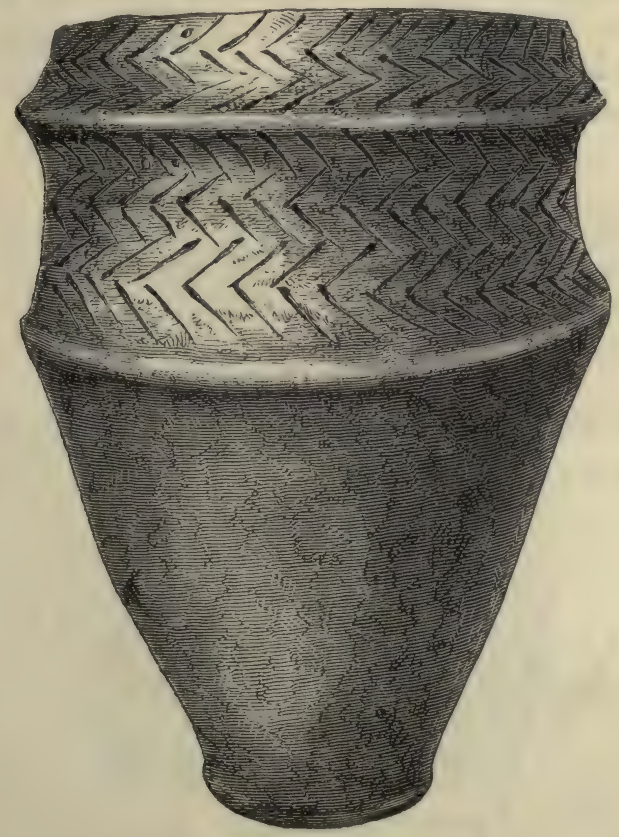

Fig. 97. $\frac{1}{4}$.

it shows no trace of wear, and seems as if it had been made specially for the burial. Immediately to the west of the legs of the lastmentioned body, and in actual contact with it, was that of a younger person, one whose age did not probably exceed ten years; this was laid on the left side, and with the head to W.S.W. The bodies were both at the south side of the grave, and there was a considerable quantity of charcoal near them. Some broken bones of an ox were also in the grave; and amongst the materials of the barrow were several flint chippings and four round scrapers.

The relative ages of the two persons in the grave was such as to preclude the idea that they were mother and child; but we may 
suppose them to have been nearly related, perhaps brother and sister, or two sisters. The burnt body immediately above the grave was probably that of a woman, for bronze awls have usually been found associated with female interments; and it is possible that we have in this barrow the burials of a family: the mother in the cinerary urn, two children in the grave, and the father, who must have died later, buried near the north-west side, with the flint instruments accompanying the body. The conjunction of burnt and unburnt bodies need cause no difficulty, for we have so many instances of inhumation and cremation contemporaneously practised as to show that their concurrent adoption was by no means uncommon.

Rather more than a quarter of a mile to the north-east of the barrow last but one noticed were six others, three of which lay on Sherburn, the remaining three on Potter Brompton Wold. I examined the whole group.

XIII. The first was $90 \mathrm{ft}$. in diameter and $2 \frac{1}{2} \mathrm{ft}$. high, but had been much ploughed down; it was composed of earth. Two feet south of the centre and one foot above the natural surface were two red-deer antlers laid together ${ }^{1}$. Immediately west of them was an oval grave, lying north-west by south-east, $4 \frac{1}{2} \mathrm{ft}$. by $3 \frac{1}{2} \mathrm{ft}$., and sunk to a depth of $4 \mathrm{ft}$. into the chalk rock. On the bottom, at the north-west end, was the body of a woman, from 18 to 24 years old, laid on the right side, with the head to W., the right hand in front of the knees and the left on the right elbow. Upon the wrist of the right arm, and just in front of the knees, was a ' food vessel' [fig. 72]. It is very substantially made, being more than half an inch thick, and is $6 \frac{1}{2} \mathrm{in}$. high, $7 \mathrm{in}$. wide at the mouth, and $3 \frac{1}{4} \mathrm{in}$. at the bottom. The inside of the lip is ornamented with three encircling lines of twisted-thong marks, the outside with a row of short vertical impressions of pieces of thicker thong but very closely twisted. The whole surface of the body of the vase is covered with sixteen encompassing lines of a very thick and loosely-twisted cord, apparently made of some vegetable fibre. Immediately behind the back of the body and underneath it was a quantity of burnt

\footnotetext{
${ }^{1}$ In a barrow at Warren Hill, near Mildenhall, Suffolk, Mr. Henry Prigg, junior, discovered a body associated with a 'food vessel' in a grave. Over the body were placed eighteen red-deer antlers, as if to protect it. Journ. Suffolk Inst. of Archæology, vol, iv. p. 289.
} 
bones ${ }^{1}$. With them was deposited an implement, which may be a javelin-head of flint, calcined [fig. 98]; it is $3 \frac{1}{4} \mathrm{in}$. long and $\frac{7}{8}$ in. wide at the broadest part, and has been made from a flake, triangular in section, the broadest side of which has been left as it was when struck from the core, while the edges of the two smaller planes of cleavage, where they run into that of the broader side, have been very carefully flaked all along to the point ${ }^{2}$.

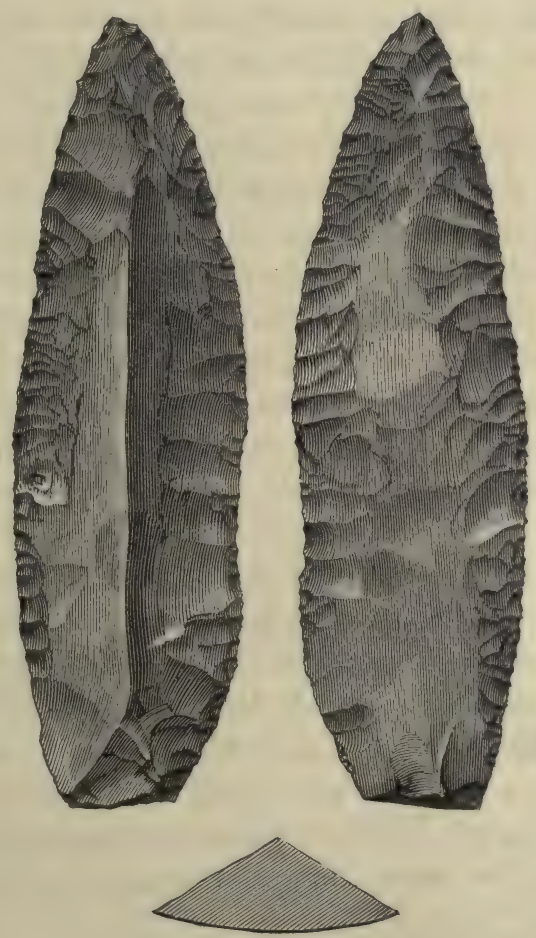

Fig. 98. $\frac{1}{1}$.

Two feet south-west of the first grave was a second, an oval one; $5 \mathrm{ft}$. by $4 \frac{1}{4} \mathrm{ft}$., the direction of the longer axis being north-east by south-west, and $3 \mathrm{ft}$. $10 \mathrm{in}$. deep. In it on the bottom, at the

1 The bones are those of a person nearly, if not quite, full grown, together with a few fragments of what seem to be those of a young goat or deer.

2 The occurrence of burnt and unburnt bodies in close juxtaposition, and evidently deposited at the same time, will be noticed under the account of several barrows in this volume. The same circumstance has been met with by other explorers. In a barrow on Acklam Wold, in the East Riding, opened by the Yorkshire Antiquarian Club, the knees of an unburnt body are stated to have been found charred by a deposit of burnt bones placed close against them. Procter, Proc. Yorkshire Antiquarian Club, 
south-west end, was the body of a young man, from 20 to 25 years of age, laid on the left side, and with the head to S.S.W., the right hand in front of the knees, the left just below the chest. Upon the right hand was placed a ' food vessel,' shaped somewhat like fig. 69, but having two raised ribs instead of one. It is very thick, and is roughly ornamented over the upper two inches with short and irregularly-placed impressions of loosely-twisted and very thick thong; below these is a zigzag line, $1 \frac{1}{2}$ in. deep, encompassing the vessel, irregularly drawn with some sharp-pointed instrument. The vessel is $6 \frac{1}{4} \mathrm{in}$. high, $7 \mathrm{in}$. wide at the mouth, and $3 \frac{1}{2}$ in. at the bottom. There was a good deal of charcoal in both the graves. In the substance of the barrow, here and there, were found animal bones ${ }^{1}$, potsherds, a small flake struck off from a ground stone axe, several flint chippings, and seven flint saws, some of them showing by their smoothed and polished teething that they had seen much service. There were also amongst the material of the barrow a small oval flint scraper, and two much larger of the same shape, one of which had been so much used at the end that the edge is quite rounded and blunt.

If it may be allowed to hazard a conjecture,-and it is scarcely possible to withhold the imagination from all play in a case such as is presented by the contents of this barrow, - we may without extravagance suppose that in these two adjoining graves were deposited the bodies of a man and his wife. They were both young, and it is by no means impossible that the wife may have sacrificed herself at the funeral of her husband, in order to accompany him into the unknown land on his journey to which he had but now entered; while in the burnt bones we may have the remains of a slave, killed at the same time, and under the influence of like

1854, p. 3. In a central cist in a barrow was a 'large and strong human skeleton ... with a coarse urn; at the foot of the skeleton lay a large heap of calcined human bones, which, on examination, proved to be the remains of two children. Near them ... an urn was deposited.' Bateman, Vestiges, p. 49. In a cist was a 'skeleton of a young person, ... and a deposit of burnt human bones. Between the two was a small vase of coarse clay.' Bateman, Ten Years' Diggings, p. 37. In a grave was a 'skeleton of a full-sized person ... a few inches above this skeleton was a deposit of calcined human bones, apparently interred at the same time as it.' $l . c . p .56$. In a barrow 'was a skeleton ... and near the skull a deposit of calcined human bones.... We have here a double interment, by inhumation and cremation, suggesting a barbarous rite.' $l$. $c$. p. 175 . In a barrow on Arbor Hill was 'a skeleton accompanied by a deposit of calcined bones.' $l$. c. p. 187. Mr. Warne mentions in a note that Mr. Medhurst discovered, in a barrow on the Ridgeway, a skeleton ' with the remains of an infant by its side, an urn containing burnt bones placed between the legs.' Celtic Tumuli of Dorset, p. 33.

1 The bones are those of several oxen (bos longifrons), and of one goat or sheep. 
motives ${ }^{1}$. The three bodies appear to have been, unquestionably, buried together, for there was an entire absence of all those appearances which present themselves when an interment clearly subsequent to the primary one has taken place in a barrow. We shall moreover find instances in other barrows apparently indicating the same practice as that which may have been followed in this case ; and it is by no means so inconsistent with what we know to have been the custom in ancient days, and yet to prevail in some countries in modern times, as to cause us to hesitate about adopting it on the score of its being an unnatural hypothesis.

XIV. The second in this group of barrows was not very regular in shape, having been more ploughed down on one side than on the other. It was about $70 \mathrm{ft}$. in diameter, $2 \frac{1}{2} \mathrm{ft}$. high, and was made of earth. At a point $10 \mathrm{ft}$. south-east from the present centre was a deposit of the burnt bones of an adult, which was no doubt originally the central and primary, as it was the only, burial in the mound. It was laid upon disturbed soil, which constituted the filling-in of what appeared to be a natural depression in the original surface. In the barrow were a few potsherds and a round flint scraper.

$\mathrm{XV}$. The third barrow, about $100 \mathrm{yds}$. south-west of the last, was of very slight elevation, but appeared to have been about $60 \mathrm{ft}$. in diameter. At the centre, in an irregularly-shaped but to some extent circular hollow, $5 \mathrm{ft}$. in diameter and $1 \frac{1}{2} \mathrm{ft}$. deep, was a deposit of burnt bones, placed close to the south-west side of the cavity. The bones were those of a child about 12 years old, together with three fragments of bone belonging to a goat or sheep, also calcined.

\section{Parish of Ganton. Ord. Map. xcv. s.w.}

XVI. The fourth barrow lay about 50 yds. east of that first described, but was situated upon Potter Brompton Wold. It was

1 Places of sepulture presenting very similar features to this have been met with elsewhere. At Newbigging, near Kirkwall, Orkney, Mr. Petrie found in a cist, below a barrow, two bodies, both apparently males, one, the shorter, in part overlying the other. In front of the knees of the smaller body was a deposit of burnt bones, which must have been placed there before the unburnt body was laid in the cist. At Isbister, Orkney, the same explorer found in a cist, beneath a barrow, two bodies, both males. In a second eist, about $5 \mathrm{ft}$. from the first, was the body of a woman, whose bones seemed to have been partly burnt. A short distance from these two cists was a third, 
$70 \mathrm{ft}$. in diameter, $1 \frac{1}{2} \mathrm{ft}$. high, and made of earth and chalk. From the manner in which the mound had been ploughed down it is not easy to say where the original centre had been, and it is most probable that the only interment met with, although it lay $14 \mathrm{ft}$. to the east of the present centre, was the original and central one. It was that of a person in middle life, who was laid on the natural surface, on the left side, with the head to S.S.W.; the right hand was in front of the face, the left laid under the thighs. Behind the head of the adult was placed that of a very young child, being all of the body that had not gone to decay ${ }^{1}$. Behind the child's head, which was placed to S.W., and on the left side, was a rudely-made bone pin, $2 \frac{5}{8}$ in. long.

In this case it is probable that we have the interment of a parent and child, but the imperfect condition of the bones makes it impossible to say whether the adult was male or female.

In the barrow were a fragment of pottery, a knife-like implement of flint, $1 \frac{1}{2}$ in. long and rather triangular in shape, a round scraper, and another one, long, narrow, and well-shaped, exactly like fig. 18, and a flint arrow-point [fig. 28], of a type not commonly found

containing a deposit of burnt bones. Mr. Petrie thinks these were the bodies of a great man and a slave, and of a wife and another slave or slaves. Proc. Soc. of Ant. Scotland, vol. vi. pp. 412-417.

1 The occurrence of children buried with adults, both male and female, will be found noticed in several places in this volume; similar instances have been met with by others. In a cist was 'the skeleton of a man, in the prime of life ;' with him were a drinking cup, a flint implement, a dagger of flint, three barbed arrow-points, and three bone implements ; 'close to the pelvis (of the man) lay the remains of an infant.' Bateman, Vestiges, p. 59. The primary interment in a cist below a barrow on Middleton Moor, 'consisted of a female, in the prime of life, and a child, about four years of age ... the child was placed above her, and rather behind her shoulders.' Bateman, Ten Years' Diggings, p. 24. The central interment in Blake Low was ' of a very young woman, or rather of a girl ... at the head was a drinking cup ... and along with the skeleton were the bones of an infant.' $l$. $c$. p. 41. In a grave in Rusden Low was 'the skeleton of a young female ... before the face were indications of the skeleton of a very young child.' $t$. $c$. p. 44. In a cist were 'skeletons of two infants and an adult.... Immediately under lay another adult human skeleton.... This, the lowest interment, was evidently a male, the one next above presents female characteristics, and both, together with the children, presented unmistakeable evidence of having been interred at the same time, so that we have some reason to suppose that the family was immolated at the funeral of its head.' $l$. c. p. 78. Within a cist in a barrow north of Pickering, North Riding, 'were two skeletons; the principal one (an adult) laid on its left side ... the other skeleton was that of an infant, and lay behind the former.' $l$. $c$. p. 210. In a barrow near Pickering was 'a skeleton ... with a stone adze or celt.... It is also to be remarked that at the head and feet of this interment were two more human skeletons of very small size, which illustrates similar discoveries made in Derbyshire and Staffordshire barrows.' l.c. p. 221. Near Warminster, in a grave, were 'discovered the remains of an infant, and by its side those of a female adult, probably its mother.' Hoare, Ancient Wilts, vol. i. p. 68. 
in Yorkshire, having the base slightly hollowed; a form inviting comparison with that which is so common, though more fully developed, in many of the most beautifully shaped of the Irish and Danish arrow-points.

XVII. The fifth barrow was a little to the east of the last named, and had been ploughed down after a very irregular manner, so as to have become of an oval form, $90 \mathrm{ft}$. by $50 \mathrm{ft}$., and only $1 \mathrm{ft}$. high. It was composed of earth, with a few chalk stones. Nine feet southeast of the present centre part of a skull was met with, the remains of a body which had been destroyed by the plough. Fifteen feet east of the centre were portions of a vessel of pottery, which had been deposited a little above the natural surface, and had been broken and scattered by the plough. It had been a 'food vessel,' of good shape and workmanship, and with pierced ears round the shoulder. At the centre was a shallow grave, north-west by southeast in direction, $6 \mathrm{ft}$. by $5 \mathrm{ft}$., and $6 \mathrm{in}$. deep. In it was a body, laid on the right side, with the head to S.W. and the hands up to the face. In the process of inserting this interment another adult body had been in part disturbed, portions of it being still in situ, immediately to the east of the secondary interment. The original occupant of the grave, an adult of uncertain sex, had also been placed on the right side, the head being to S.W.; a vase had been deposited with the body, the greater part of which was found broken and scattered, and lying underneath the head of the inserted body. It is $6 \frac{3}{4} \mathrm{in}$. high, a little more in width at the mouth, and $3 \mathrm{in}$. at the bottom. The upper part is ornamented immediately below the lip with a row of impressions, apparently made by the end of a piece of bone or wood triangular in section, and there is another similar row $2 \frac{1}{2} \mathrm{in}$. below the first, the space between being filled up by three bands of vertical lines of different lengths, those of the upper rows being the shortest; the inside of the lip of the rim has a series of vertical lines running round it. The lower part for a depth of $4 \frac{1}{4} \mathrm{in}$. is covered with an irregular reticulated pattern. The whole of the ornamentation, except that due to a triangular-ended tool, has been made with a pointed instrument drawn over the clay when soft. Above the grave was a number of large flint blocks. Immediately to the east of the last-mentioned grave was another, very shallow and scarcely to be defined. In it was the body of an adult, laid on the right side, with the head to N.W., the right hand under the hip, the left 
up to the face. In the barrow itself were some flint chippings, and a very beautifully flaked javelin-head or knife [fig. 30]. One face had never been touched after being struck off from the core, the other had been very carefully and minutely chipped over nearly the whole surface, whilst the end is worked up to a very sharp point.

XVIII. The last barrow of this group was situated about $80 \mathrm{yds}$. north of that last mentioned. It was $60 \mathrm{ft}$. in diameter, $2 \mathrm{ft}$. high, and composed of earth and chalk. Near the outside of the mound, on the east and south sides, was a great quantity of blocks of flint. At the centre was a grave, $6 \mathrm{ft}$. in diameter and the same in depth, covered over with large flints, and having a considerable number of the same at the bottom. It was principally filled in with chalk

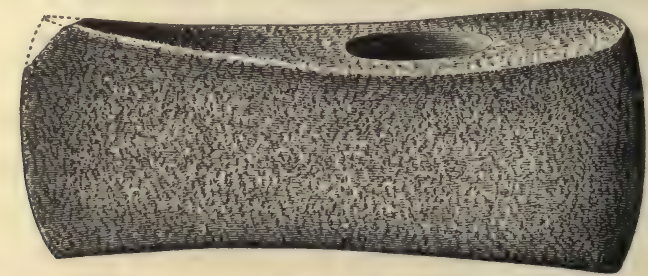

Fig. 99. $\frac{1}{2}$.

rubble (the material removed in the process of making the grave), amongst which were some broken human bones, two fragments of different earthenware vessels, and a single flint chipping. One foot and a half above the bottom of the grave, and rather to the south of the centre, was a burnt body; the bones, those of a full-grown person, were laid in a small round heap, $14 \mathrm{in}$. in diameter. Just beyond this heap, on the south-west side, was placed a perforated greenstone axe-hammer [fig. 99], which had been burnt with the body ${ }^{1}$. It is 5 in. long and 2 in. wide at the

${ }^{1}$ Axe-hammers have occurred in other barrows on the wolds, as will be seen in the sequel, in two cases [Nos. lviii, lxviii] associated with unburnt bodies, and in one [No. lxxix], like this, with a burial after cremation. They have also been met with accompanying burnt bodies, as well in Yorkshire as in other parts of England; somé of these discoveries are here noted. Three have been found by the Rev. J. C. Atkinson in barrows in Cleveland, in the North Riding, one of which is here figured [fig. 100]; in these cases the weapon had been burnt with the corpse. Under a barrow near Stourton in Wiltshire, in a grave with a burnt body, a bronze knife-dagger and a perforated stone axe-hammer were associated. Hoare, Ancient Wilts, vol, i. p. 39, pl. i. In a barrow near Heytesbury a cinerary urn was found inverted over a deposit of burnt bones and an axe-hammer of stone. $l . c . p .79$, pl. viii. In a barrow near the last was a deposit of burnt bones and an axe-hammer of stone. l. c. p. 79, pl. viii. In a cist below a barrow at Winterbourne Steepleton, which contained ashes and calcined human 
cutting edge, which is rounded and widens gradually from the middle of the weapon. The hole for the handle is $1 \frac{1}{4}$ in. in width, and narrows very slightly to the centre, having been drilled from both sides. In the barrow was a square-shaped flint scraper.

I am inclined to think, as has been already stated in the Introduction, that this kind of axe-hammer was meant for the purposes of war. Having their edges rounded they could not have been adapted for cutting wood, or indeed for any except an offensive use,

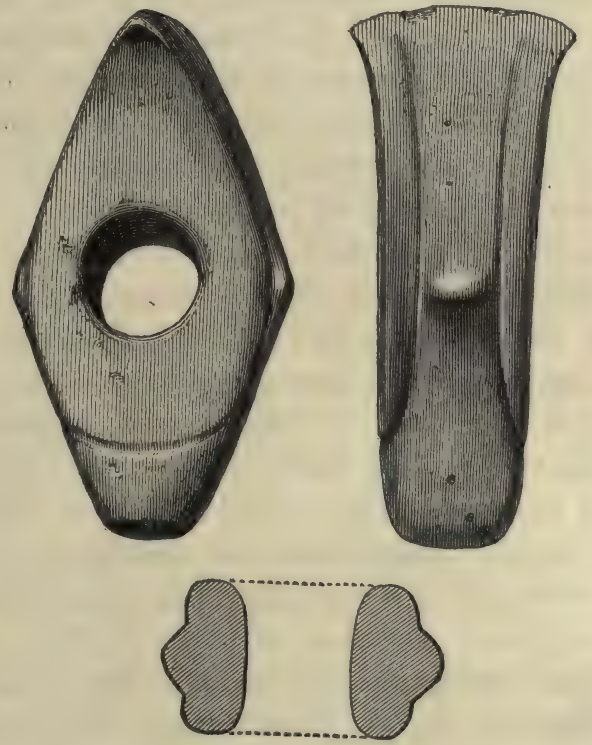

Fig. 100. $\frac{1}{2}$.

and there is certainly nothing in the fact that they are found associated with interments inconsistent with the presumption that they have been weapons of war. For in days when every man was armed, and when individual prowess was of more importance than at a time when the change in the character of those arms and the consequent alteration in military tactics have merged the individual in the mass, what more natural than that, when the

bones, was a pierced axe of greenstone. 'This is the first of its kind that has as yet been found in the tumuli of Dorset.' Warne, Celtic Tumuli of Dorset, p. 56, engr. p. 63. One was discovered with a bronze knife in an urn containing burnt bones, under a barrow at Winwick, Lancashire. Journ. of Arch. Inst., vol. xviii. p. 158. In a barrow near Throwley, amongst a deposit of burnt bones in an urn were two bone pins, a bronze awl, and a 'double-edged axe of basaltic stone,' which had been burnt with the body. Bateman, Ten Years' Diggings, p. 155. A very fine one was found with a deposit of burnt bones within a stone circle at Crithie, Aberdeenshire. Proc. Soc. of Ant. Scotland, vol. ii. p. 306. 
warrior was at last laid in the grave, the weapon with which he had won renown and smitten the foes of his tribe should be there deposited at his side?

They are always beautifully made, and with great symmetry; sometimes with simple but tasteful ornamentation, which is possibly another reason for accounting them weapons of war rather than implements for every-day use. All races of men, in the gradual progress from the untutored ways of savage life to the greater refinements of civilisation, have not only bestowed unusual pains on making beautiful their choicest possessions, or in enhancing the natural beauty of their women by the further adornment of various decorations, jewels and gold, but have specially enriched their swords, their spears, all their warlike equipment, with the choicest art at their command. On the other hand, the simple hatchet, the so-called celt, of stone, without perforation, but possessing a sharp-cutting edge, has been but rarely found buried with its owner; although it may not unfrequently have occurred amongst the materials of which the burial mound is composed. We are almost constrained to regard these hatchets, or celts, as being, in the main, implements for ordinary use, such as cutting down trees and working wood in other ways, or not improbably in the various processes of agriculture; although of course they may have served at times quite other purposes: they may have often dealt a death-blow to an ox or other animal, or even to an enemy in a hand-to-hand struggle. Nay, even at the present day, with all our wealth of mechanical contrivances, we are continually putting the selfsame article to a variety of uses: and such must have been far more frequently the case in a ruder and more imperfectly-supplied state of society; just as the African savage of to-day uses the head of his spear not only as a knife, but makes it serve the purposes of a variety of tools.

The group of barrows next dealt with is also situated upon Potter Brompton Wold, and about a mile east of the group lately under notice. It consisted originally of five mounds, one having been removed in the course of agricultural operations several years ago. The remaining four were all examined by me. They had been more or less ploughed down, and some secondary burials had most probably been destroyed in consequence. 
XIX. The first one was $70 \mathrm{ft}$. in diameter and $1 \mathrm{ft}$. high, and was made up of earth. At the centre, in an oval hollow $2 \mathrm{ft}$. by $1 \frac{1}{2} \mathrm{ft}$. and $\frac{1}{2} \mathrm{ft}$. deep, was a deposit of burnt bones, those of an adult of small size, with which was found a bone-pin also burnt. The body had been burnt on the spot, and a great quantity of charcoal in large lumps was placed above, below, and round the bones; upon the top of which was an urn laid on its side, the mouth to the south. It is in shape much like fig. 58, $6 \mathrm{in}$. high, $5 \mathrm{in}$. wide at the mouth, and $4 \mathrm{in}$. at the bottom, and has an overhanging rim $2 \frac{1}{4}$ in. deep, and is entirely devoid of ornament. In the barrow were several flint chippings, a barbed arrow-point of flint, and two long scrapers, one of them worn quite smooth at the end by use.

$\mathrm{XX}$. The second barrow was $42 \mathrm{ft}$. in diameter and $14 \mathrm{in}$. high, and was made of earth. Fourteen feet south-west-by-west from the centre was the body of an aged person, laid on the right side, upon the natural surface of the ground. The head lay to S. by W., but the bones were too much deeayed to allow the position of the hands to be made out. In a very slight hollow, $14 \mathrm{in}$. in diameter, at the centre, there was a burnt body, that of an adult, and about 6 in. above the bones was a thin flat piece of bronze, of indeterminate shape. In the barrow were three flint scrapers, one round, another long, and the third of irregular form.

XXI. The third harrow, which lay about 150 yds. north-west of the last, and upon the verge of the brow of the chalk escarpment overlooking the valley of the Derwent, was one very prolific in interments, and which presented moreover many and novel features of interest. It was $60 \mathrm{ft}$. in diameter and $3 \mathrm{ft}$. high, and was made up of chalk rubble and flint. Seven feet south-east of the centre, and $2 \mathrm{ft}$. above the natural surface, was the body of a child, probably a boy, of above six years old, laid on the left side, the head to E., and with the hands towards the knees. At the crown of the head was deposited a 'food vessel' [fig. 69]. It is $3 \frac{3}{4}$ in. high, $4_{4}^{3}$ in. wide at the mouth, and 2 in. at the bottom. The inside of the rim and the upper part of the outside of the vase for a depth of $1 \frac{1}{2}$ in. have encompassing lines of twisted-thong impressions, a wavy line of the same impression occurring between the two upper and five lower lines on the outside. Over the head of the body and the vase, and to some extent protecting them, were placed two large blocks of flint. About $3 \mathrm{ft}$. east of the child's body were 
the bones of a second body, an aduit, probably a woman, which had been very imperfectly burnt. They were laid in a round heap $18 \mathrm{in}$. in diameter, on the level of the natural surface, and were carefully covered over with chalk and flint stones. Amongst the human bones was the radius of a domestic pig, also burnt. Immediately east of this pile of burnt bones was the body of a child, of

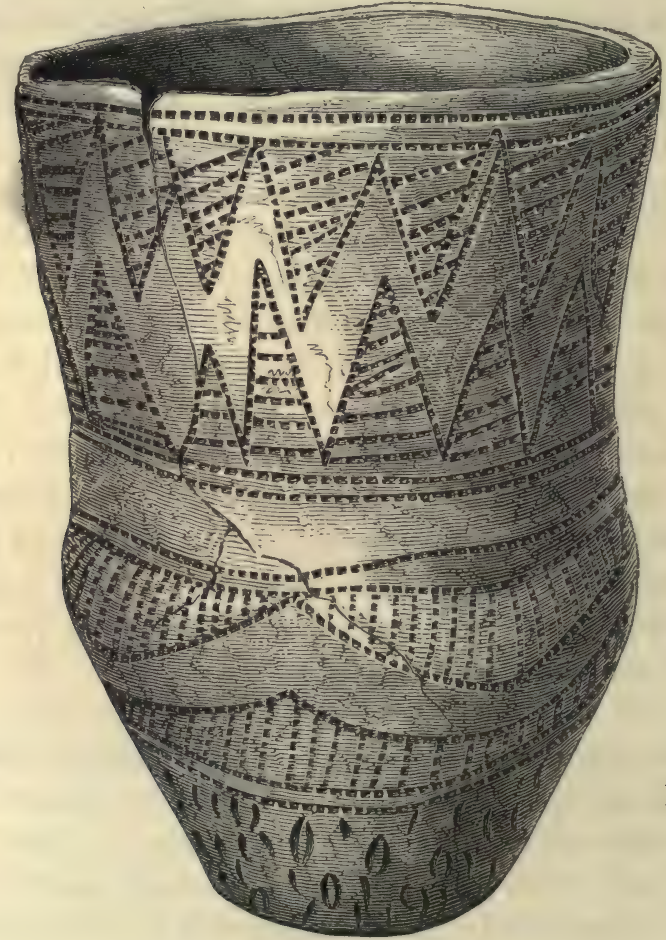

Fig. 101. $\frac{1}{2}$.

less than six years old, laid on the left side, the head to N.N.E., the right hand upon the knees, the left under the face. Below these bodies there was another, that of a young man, about 25 years of age, which was laid on the left side, the head to E., and the hands up to the face. Behind the head was a 'drinking' cup', and below the cup a flint knife. The vessel [fig. 101] is $6 \frac{3}{4} \mathrm{in}$. high, 5 in. wide at the mouth, and $2 \frac{1}{2}$ in. at the bottom. The pattern upon it, which will best be understood from the engraving, is made on the upper part by impressions of a notched strip of bone or wood, and on the lower part by markings apparently the result of 
the application of the end of a finger nail. Round the body, and especially-near the head, was a good deal of charcoal. These three bodies, it should be said, were in a grave, $5 \frac{1}{2} \mathrm{ft}$. in diameter, and sunk into the chalk to a depth of $3 \frac{1}{2} \mathrm{ft}$. Eight feet south of the centre lay a body, $2 \mathrm{ft}$. below the ordinary surface level, in a sort of hollow ; either a natural depression in the surface, or one artificially produced. The body, probably that of a woman past middle life, was laid on the right side, with the head to S.W., the right hand under the knees, and the left up to the face. In front of the face was a 'food vessel,' which together with the head was carefully protected by chalk stones arranged round them. The vessel, which is shaped somewhat like fig. 69 , is $4 \frac{3}{8} \mathrm{in}$. high, $4 \frac{1}{2} \mathrm{in}$. wide at the mouth, and $2 \frac{1}{4} \mathrm{in}$. at the bottom. It is ornamented on the inside of the rim with sloping lines, and on the upper two inches of the outside with short lines of twisted-thong impressions, arranged in four bands, after a rough herring-bone fashion, and encompassing the vessel. Sixteen feet south-south-west-by-south of the centre was the body of a woman, about 20 years of age, placed in a shallow grave, of not quite $1 \mathrm{ft}$. in depth. The body was laid on the right side, with the head to S.W., and the hands up to the face. There was a great quantity of charcoal round the body, and especially near the head. At the centre of the barrow was an oval grave, lying east and west, $8 \mathrm{ft}$. by $6 \frac{1}{2} \mathrm{ft}$., and $3 \mathrm{ft}$. deep. At the eastern end and on the bottom of the grave was the body of a young man, probably under 20 years of age, laid on the left side, the head to E., with the right hand upon the knees, and the left in front of the face. Before the face was a 'food vessel,' approaching in shape to fig. 72. It is $6 \frac{1}{4}$ in. high, the same in width at the mouth, and $3 \mathrm{in}$. wide at the bottom. The inside of the rim has two encircling rows of very short lines, arranged roughly chevron-wise; the upper part of the outside of the vase, for a depth of $1 \frac{1}{2}$ in., has four encompassing lines, arranged in pairs three-quarters of an inch apart, of small oval dots. At the west end of the grave was the body of a young man, about 20 years of age, laid on the right side, with the head to N.W., and the hands up to the face. The head of this body was immediately west of the feet of that first described. In front of the knees was a barbed arrow-point of flint. Fifteen feet east-north-east of the centre were laid two bodies facing each other ${ }^{1}$. They were placed on the level of the

${ }^{1}$ Instances have occurred in other places where bodies had been placed in a more or less intimate association such as that in which these were found. In a grave were 
natural surface, but at the spot there was a hollow, $2 \frac{1}{2} \mathrm{ft}$. deep, which had been filled up to the ordinary level, and upon that the bodies were laid The one, the remains of a man about 20 years of age, was on the left side, with the head to $\mathrm{S}$. This body was laid partly over the other, which was that of a woman, about 17 years of age, his legs being placed above hers. She was laid on the right side, her head being to S.E. Her hands were up to the face of the man, and it appeared as though his head had been held between them. The left hand of the man was under his own hip, and his right hand upon the hips of the woman. The two bodies together occupied a space of no greater extent than $3 \mathrm{ft} .8 \mathrm{in}$. by $1 \mathrm{ft}$. $10 \mathrm{in}$. Between the bodies were two small 'food vessels,' each with a cover ${ }^{1}$. One of these was set between

s the skeletons of a large man, ... and that of a younger person by his right side. From the position of their heads they seemed to have been placed in the affectionate attitude of embrace, as the two skulls nearly touched each other.' In the grave were a bronze dagger-knife, two gold ornaments, a stone with two perforations, one at each end, a bone implement, a drinking cup, and 'a great deal of charred wood.' Hoare, Ancient Wilts, vol. i. p. 44, pl. ii. Near Warminster in a barrow 'were two skeletons . . . the head of the smallest reclining on the breast of the other.' $l$. $c$. vol. i. p. 68 . In a grave were two skeletons: 'the first appeared to have been a stout man, the latter, being much smaller, was probably a female, and perhaps his wife.' In the grave were a large number of bones, pointed and perforated, three celts of flint, sharpening stones, an axe-hammer of stone, a jet ring, jet and bone beads, and a small bronze pin. $l$. $c$. vol. i. p. 75 , pls. v, vi, vii. In a grave at the centre of a barrow were two bodies, one on the left, the other on the right side, and 'each having the head in the opposite direction. That which lay on the right side was . . the skeleton of a slender young person ... the other was the skeleton of a much more robust person.' Bateman, Ten Years' Diggings, p. 68. In a grave below a barrow near Cawthorn Camps, North Riding, 'were two skeletons, deposited with their heads to the south, the skull of one lying on the breast of the other. Near the head of each was a small vase.' $l$. $c$. p. 207. 'Two skeletons lay side by side, evidently those of a man and a woman ... the bodies touched each other... the head of each leaned towards the other, so that the foreheads touched so intimately that the blade of a knife could not be pressed between them. The right arm of the man lay across his breast, that of the woman by her right side, over which his left arm was crossed, apparently to clasp the left hand of the woman, whose arm was bent in that direction across the body.' Warne, Celtic Tumuli of Dorset-Tumuli Opened at Various Periods, p. 62.

1 Vases with covers have very rarely been met with in Britain; they have occurred in Wiltshire and Derbyshire as well as in Yorkshire. I have met with another instance on the wolds, near Goodmanham [No. xeviii]; and I believe two other vessels with covers have been found in barrows on the wolds by Mr. Mortimer. 'A food vessel' with a cover was discovered in a barrow on Acklam Wold, in the East Riding. The vase is figured in Phillips's Rivers and Mountains of Yorkshire, pl, 33, and is now in the York Museum, but the cover appears to have been lost. In a barrow near Little Durnford were three urns, one containing a deposit of burnt bones, and another of them having 'a cover or lid ... richly ornamented with indentations and zigzags. This may be considered a very interesting discovery, and is the first instance we have yet seen of a cover to a cup or vase.' Hoare, Ancient Wilts, vol, i. p. 221. One in the Museum at Dorchester, but having no note of the place of its discovery, which however was probably in Dorsetshire, is figured in Journ, Arch. Inst., vol. xxv. p. 52. 
their chests, the other between their hips. Beneath the shoulders of the man there lay a boar's tusk and a small round quartz pebble. The two vessels are almost identical in shape, size, and ornamentation; as also are their covers. The vase [fig. 77] is $2 \frac{1}{4}$ in. high, 3 in. wide at the mouth, and $1 \frac{1}{2}$ in. at the bottom. It is entirely covered on the outside, as well as on the inside of the rim, with lines, arranged herring - bone wise, and made by a sharp-pointed tool drawn towards the maker in the moist clay. The cover, which has a handle to raise it by, is $3 \frac{1}{4} \mathrm{in}$. in diameter, and has a pattern, made by dotted impressions, two lines of which run round it, one on the edge, the other near to and parallel with it ; from the latter encircling line, others, placed in pairs, converge towards the handle. It will be observed from the engraving that there is a want of uniformity in the ornamentation of the vase and of the cover, and this is still more apparent in the originals. The colour and nature of the clay also differs very materially; the vases being of a very pale brown, the covers of a very dark brown. It would therefore appear probable that they did not proceed from the hands of the same workman.

In this case we can have little hesitation in regarding the burial as that of a man and his wife, who, one in life, in death had not been divided. They had both died in their prime, and may very possibly have been childless. And if so, their very attitude in the grave betokening the strong bond of affection which had linked them together in life, and all analogy leading us to the conclusion that, in their rude, untutored system of belief, that connection was not to be dissolved even through 'the grave and gate of death,' are we to think harshly of the possible self-sacrifice which, now that she was deprived of what had made the old life most desirable to her, would, as she thought, enable her to follow into a new one him whose love had been her happiness, and to whom she hoped to be in the future, as she had been in the past, the loving help-mate, the sharer of his toils and pleasures?

Eleven feet east-north-east of the centre was the body of a very young child, the head to W. Twelve feet north-east-by-east of the

A vase with a cover is stated to have been found at Stanton Moor, Derbyshire. Archæol., vol. viii. p. 62. A very beautiful 'food vessel' with a cover, discovered at Cairn Thierna, County Cork, is figured in the Journ. of the Arch. Inst., vol. vi. p. 191. In a cist at Danesford was found a deposit of burnt bones, and a very fine and elaborately ornamented urn with a cover, having ' $a$ handle or loop at the top to lift it by.' Kilkenny Journ of Arch., N. S., vol. iii. p. 169. In Denmark urns with lids are not very uncommon, and they have occurred in Germany and Italy. 
centre was the body of another child, about 3 years old, laid on the left side, with the head to $\mathrm{E}$. Behind the head was a 'drinking cup' [fig. 83]. It is $7 \frac{3}{4}$ in. high, $5 \frac{1}{4}$ in. wide at the mouth, and $3 \frac{1}{4}$ in. at the bottom. The ornamentation, which will be best understood from the figure, is made by the application of a notched strip of bone or wood. Twenty-one feet east-north-east of the centre was the body of a third and very young child, placed in a shallow grave, with the head to E.N.E. The character of this grave was renarkable, for it was sunk below the level of what had the appearance of a trench, which ran in a direction east-north-east by west-south-west, from a point about $8 \mathrm{ft}$. east-north-east of the centre, for a distance of $15 \mathrm{ft}$. The trench was about $5 \mathrm{ft}$. wide, but rather irregular, and $2 \mathrm{ft}$. deep, and in it were also the bodies of the two other children just above mentioned. On the south-west side of the mound there was at one spot a considerable deposit of large and small flint flakes and chippings, 118 in all, and amongst them were several worked flints, four long and two round scrapers. Amongst the materials of the barrow, at various places, were three flint saws, three flint flakes showing signs of much use in scraping, and a beautifully-formed long scraper. In the central grave were several bones, all split open, belonging to six adult oxen.

XXII. The last barrow in this group was a little to the south of the others. It was $54 \mathrm{ft}$. in diameter, $1 \mathrm{ft}$. high, and made up of earth, chalk rubble, and flint blocks, the latter principally on the south-east side. Within the mound was a circular trench, having an inner diameter of $23 \mathrm{ft}$., $2 \frac{1}{2} \mathrm{ft}$. deep, and varying from $1 \frac{1}{2} \mathrm{ft}$. to $2 \frac{1}{4} \mathrm{ft}$. in width. It was sunk into the rock, and had been filled in again with the chalk which had been removed in forming it. It was incomplete on the south-south-east side, where a space of $8 \mathrm{ft}$. in length had never been excavated. At the bottom of this trench, at a point which was marked by a slight increase in depth and width, and was $13 \mathrm{ft}$. east-by-south from the centre, was the body of a man, about 65 years of age, laid on the right side, and with the head to $\mathrm{S}$. by E., the hands being placed in front of the hips. In the trench a few occasional pieces of charcoal were met with. Six feet east-by-south of the centre, on the natural surface, but with a layer of flints both above and below it, was the body of probably a male, from 16 to 18 years of age, laid on the left side, the head to E. and the hands up to the face. Seven feet east-north- 
east of the centre, and just above the natural surface, was found half of the lower jaw of an aged person, and two metacarpal bones. At the centre was an oval grave, $8 \frac{1}{2} \mathrm{ft}$. by $6 \frac{1}{2} \mathrm{ft}$., running east and west, and $3 \frac{1}{2} \mathrm{ft}$. deep. Amongst the filling-in of the grave, and particularly near the top, were numerous disturbed bones of two bodies and six pieces of a 'drinking cup.' Six inches from the south side of the grave, and at a depth of $2 \mathrm{ft} .3 \mathrm{in}$. from the bottom, were the bones of an adult woman, very imperfectly burnt; and a little to the north of these, and rather lower, was a large portion of a red-deer's antler. At the bottom of the grave there was a body of an aged woman, laid on the left side, with the head to E., and close to the east side of the grave; the hands were near to the hips. Just above this body was part of a second red-deer's antler, and a rather peculiar flint implement. This flint is $2 \frac{1}{2} \mathrm{in}$. long and half-an-inch wide; it is carefully chipped along both edges and to a point; the other end, which has not been much chipped, has had one side rubbed quite smooth by wear. It would appear to have been an implement of long-continued daily use, the original edges of which had become blunted and had then been rechipped; for the existing edges are as sharp as if they had been worked only yesterday.

There was, it should be observed, distinct evidence here of the disturbance of the primary burials in the process or for the purpose of putting in the secondary ones. The scattered bones of at least two bodies and the fragments of the 'drinking cup' found in the grave plainly show this; and it is probable that the wrought flint just described had been associated with one of them. In the grave and in different parts of the barrow were pieces of charcoal; the grave also contained some broken bones of two adult oxen.

XXIII. About half a mile to the south-east of the barrow last described was an inconspicuous one, $50 \mathrm{ft}$. in diameter, $1 \mathrm{ft}$. high, but much ploughed down, and made of earth and chalk. At a distance of $14 \mathrm{ft}$. south-south-east from the centre was the body of a man, about 60 years old, laid on the right side, with the head to S.W. by S., the right hand up to the face, and the left to the knees. Near the head was a large quantity of charcoal. The body was placed in a slight hollow, but on the level of the natural surface; this hollow was not more than $4 \mathrm{in}$. deep, and was filled in with dark-coloured earth, containing potsherds, flint chippings, and broken animal bones. The black deposit extended from the 
hollow to a distance of $7 \mathrm{ft}$. west of it, having a width of about $2 \mathrm{ft}$., and amongst it were many fragments of plain, dark-coloured pottery, flint chippings, and animal bones, some of which were charred. There were also several pieces of sandstone which had been burnt, and had splintered during the burning, reminding me of what I have observed in other barrows, as at Cowlam [No. lvii] and Rudstone [No. lxi]; wherein, moreover, plain, dark-coloured pottery, like that under notice, also occurred. These burnt and splintered fragments seem to have been portions of stones which might have been used for rubbing or grinding, as they show signs of use on their smoothened surface.

Thirteen feet east-south-east from the centre was the body of a young person, probably a female, laid upon the natural surface, on the right side, with the head to S., the right hand up to the face, the left to the knees. In front of the face was a 'food vessel.' It is rudely formed, shaped somewhat like fig. $69,4 \frac{1}{2} \mathrm{in}$. high, $5 \frac{1}{2}$ in. wide at the mouth, and $2 \frac{3}{4} \mathrm{in}$. at the bottom. It is entirely covered with twisted-thong impressions, very irregularly placed, more or less vertically, except at the upper part of the vase and on the inside of the rim, where they encompass it in lines, three on the outside and two on the inside. About the head and upper parts of the body were large flint stones, and the whole of the lower part of the body was covered over with similar blocks. Near the body were some charred animal bones; and $2 \mathrm{ft}$. west of the head were the horncores and frontal bone of an adult $o x^{1}$ (bos longifrons). At a point $6 \mathrm{ft}$. south-east of the centre there was a spot, $2 \frac{1}{2} \mathrm{ft}$. in diameter, where the natural surface of the ground was much reddened by the action of fire. Throughout the whole mound was found a quantity of black, apparently burnt, matter, similar to that recorded as occurring beneath the first body, and in it many flint chippings, potsherds, and animal bones ${ }^{2}$. At a distance of $5 \mathrm{ft}$. south of the centre, parts of the thigh bones of a young person were found: these were not in position, and as no burial was discovered at the centre, it is possible that the central interment may

$1 \mathrm{Mr}$. Bateman records the finding of the head, or of part of the head, of an ox in three barrows in Derbyshire. Vestiges, p. 82; Ten Years' Diggings, pp. 126, 129. Sir R. Colt Hoare found in a barrow near Amesbury the skeletons of two children, each laid on the head of an ox. Ancient Wilts, vol. i. p. 199 .

2 The animal bones found here and in the hollow below the body are those of oxen (bos longifrons), goat or sheep, and pig (sus scrofa domesticus). All of those which would contain marrow have been, as indeed is almost always the case with the bones found in the wold barrows, designedly split open. 
have been previously disturbed, and that these portions of thigh bones belonged to the primary burial. This is, however, a mere conjecture, as no signs of disturbance at the centre were observed. In the barrow there was found a piece of sandstone, which had been used for hammering or pounding.

The next group of barrows examined was on Ganton Wold, and lay about a mile north-east of the last one. The group was an extensive one. The largest barrow in the series had been removed many years ago, when a number of bodies are said to have been discovered, and at least one vessel of pottery, which is now in a museum at Huddersfield. I examined the remainder, which, like the others in the district, mainly contained burials by inhumation.

XXIV. The first, and that one which was situated the furthest to the south, was $40 \mathrm{ft}$. in diameter, $1 \mathrm{ft}$. high, having been like the rest much ploughed down, and was made of earth. Immediately south of the centre, and upon the level of the natural surface, was an earthenware vase, around which was a large quantity of burnt earth, and amongst this, but widely scattered, were a few human bones, slightly charred, and quite black. The vessel, in shape like fig. 97 , is $5 \frac{5}{8} \mathrm{in}$. high, 5 in. wide at the mouth, and $2 \frac{3}{4} \mathrm{in}$. at the bottom. The inside of the rim, which is $1 \frac{1}{4}$ in. deep, is eovered with round dotted impressions. The upper part of the vessel is ornamented for a depth of $2 \frac{1}{2}$ in. with lines made by a sharp-pointed tool, arranged in a rough herring-bone fashion. At the centre was a grave, lying north-east and south-west, $4 \mathrm{ft}$. by $3 \mathrm{ft}$., and $1 \frac{1}{2} \mathrm{ft}$. deep. In it was the body of a very aged man, laid on the left side, with the head to S.W., the right hand to the knees and the left under the head; in front of the face was a bone-pin, $3 \frac{3}{4}$ in. long [fig. 102]. Amongst the filling-in of the grave were several pieces of slightlyburnt bone, similar in colour, and in other respects, to those found near the vase. Judging from the appearance of the barrow, and these scattered bones, it would seem that the grave had been made after the deposition of the burnt body, and that the remains of it had been disturbed in making the grave. Upon this supposition, the primary interment had been one after cremation.

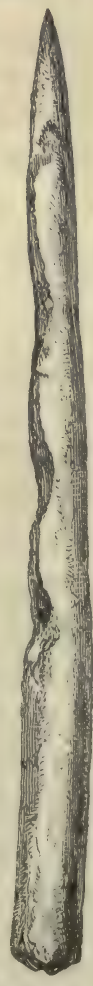

Fig. 102. $\frac{1}{3}$. 
XXV. The second barrow, 60 yds. north-east of that just described, was $100 \mathrm{ft}$. in diameter, $2 \frac{1}{2} \mathrm{ft}$. high, and was made of sand. Just south of the centre was a deposit of burnt bones, those of a child not much above ten years of age, laid in a round heap, $1 \frac{1}{2} \mathrm{ft}$. in diameter, upon the natural surface; a piece of calcined flint was amongst the bones. At the centre was found an oval grave, lying north-west by south-east, $4 \mathrm{ft}$. by $3 \frac{1}{4} \mathrm{ft}$., and $2 \frac{1}{4} \mathrm{ft}$. deep. On elearing this grave out, a very novel feature presented itself. It had been sunk in a bed of clay, and at the north-west end five short stakes, and at the opposite end six, had been driven in. Upon the supports thus furnished it seemed as if a platform of wood had rested, the remains of which, in the shape of a dark-coloured deposit (proved by analysis to be of vegetable origin), covered the bottom of the grave. Upon this platform the body had been placed, and the purpose of this unusual provision for supporting the body may have been to keep it out of the wet, which would be likely to accumulate in a grave dug in so retentive a material as the clay at the place. I must recall attention to the fact that the graves on the wolds are, in most cases, hollowed out in the chalk, which is quite sufficiently provided with means of natural drainage to allow water to run freely through it; and, as a rule, the body seems to have been laid on the chalk-floor of the grave without the introduction of anything except the clothes of the buried person. In the present case, however, the sides of the grave also had been lined with planks, the impression of which was left on the clay to a degree sufficient to enable me to secure an accurate cast. The stakes themselves were entirely decayed, leaving only a small quantity of darkcoloured matter at the bottom of each hole; and thus there was no difficulty in obtaining a cast, in plaster-of-Paris, from a mould so novel, exactly reproducing the form and dimensions of the stake as originally driven into the clay. The stakes had been made out of small trees, about $3 \mathrm{in}$. in diameter, and were $14 \mathrm{in.} \mathrm{long,} \mathrm{of}$ which length 10 inches had been driven into the clay and 4 inches left protruding. The ends had been brought to a point by four cuts, which are so cleanly made and after so workmanlike a fashion, that not only must a metal axe I think have been used, but used by a man to whom the art of wood-cutting was familiar. The length of the cut surfaces is 7 inches, and the stakes had been brought to a very sharp point. The series or row of stakes, five in number, at the head of the grave reached over a width of $1 \mathrm{ft} .8 \mathrm{in}$., while the six at the foot occupied a space of $2 \frac{1}{2} \mathrm{ft}$. In the grave, 
and resting on the dark-coloured matter before mentioned, was the body of an adult, laid on the right side, the head to N.W., and close to that end of the grave; the bones were too much decayed to allow the position of the hands to be noted. In front of the face was a 'food vessel,' on its side, and with the mouth towards the head of the body. It is shaped like fig. 72, though not so globular, and is $5 \frac{1}{2} \mathrm{in}$. high, $5 \mathrm{in}$. wide at the mouth, and $2 \frac{3}{4} \mathrm{in}$. at the bottom ; made in the rudest fashion, and of badly-wrought clay. The only ornamentation upon it is a row of short vertical lines round the inside of the rim, another similar one encompassing the outside of it, and a third about midway between the top and bottom; they have all been made by a sharp-pointed instrument. In the grave, and especially near the body, charcoal was found in scattered pieces. There were also a large number of flint chippings amongst the material of the barrow, and above the grave were four very well-formed round scrapers of flint, one worn quite smooth at the edge by use, two long scrapers, and a peculiarly-formed flint, $2 \frac{1}{2}$ in. long, carefully chipped along both edges for $1 \frac{3}{4} \mathrm{in}$. so as to form a point, the remaining parts being left as when it was struck off from the core; it has somewhat the appearance of an unfinished javelin-head.

XXVI. The third barrow was close to the last, and east of it. It was $80 \mathrm{ft}$. in diameter, $2 \frac{1}{2} \mathrm{ft}$. high, and was made of chall rubble and clayey earth. Nineteen feet south-south-west of the centre, and $1 \mathrm{ft}$. above the natural surface, was a deposit of burnt bones, laid in a round heap of about 9 in. in diameter. Upon the bones, at their west side, was an 'incense cup,' very much decayed, but of which enough remains to allow the size and ornamentation to be determined. In shape it is somewhat like fig. 63, but wider in proportion at the mouth, and is $1 \frac{5}{8} \mathrm{in}$. high, and more than double that in width. The upper half is ornamented with a band of vertical lines placed between one encircling line above and three below them, all of twisted-thong impressions. About $1 \mathrm{ft}$. east of these burnt bones was the head of a young person, laid on the right side, and pointing to the north if there had been a body attached. In front of the face, the point touching the teeth, was a well-formed barbed arrow-point of flint, $1 \frac{3}{8}$ in. long. There was no trace of the presence of any other bones, nor did it seem that any part of the body, except the head, had ever been deposited at the spot. At the centre, and upon the natural surface, was an 
adult body, laid on the left side, and with the head to W.N.W. It was too decayed to allow the position of the hands to be made out. Underneath the shoulders was an oval flint knife, $1 \frac{3}{4}$ in. long, very carefully chipped over the convex surface for a space of $\frac{3}{4}$ in. from the pointed end. Large flint blocks were placed both over and beneath the body. About $5 \mathrm{ft}$. east of this last was the body of a young child, laid on the right side, with the head to W. Close to its back, and partly surrounding it, were the burnt remains of a full-sized person. In actual contact with the child's head was another body, its face being the part in contact; this, so far as could be made out from such bones as were still undecayed, was that of a woman, laid on the left side, the head to E.N.E., the left hand on the breast, but having the right arm extended from the hips, and holding the head of a second and younger child with the hand. Just behind the back of this body was the lower jaw of a young person. All these bodies or parts of bodies were placed upon the natural surface. Nine feet north-west of the centre, and also laid on the natural surface, was the head of a body on its left side, and in front of it was a 'food vessel.' It is shaped like fig. $69,4 \mathrm{in}$. high, $4 \frac{\mathrm{l}}{4} \mathrm{in}$. wide at the mouth, and $2 \frac{1}{8} \mathrm{in}$. at the bottom, and is ornamented on the inside of the lip of the rim and on the upper part of the vase with two encircling rows of short lines, made with the end of a pointed tool. There was no trace of the rest of the body in this case, nor was there any reason for supposing that any other of the bones had ever been placed there. From the fact of two heads and a lower jaw having been found separated from the other parts of the bodies to which they respectively belonged, it is possible that the barrow had been disturbed in order to put in some secondary burials, and that a certain amount of pains had been taken to replace the most important part, I mean the head, and even to put back the vase and the arrow-point, which had originally accompanied two of the interments. What is here supposed would not be without parallel in other barrows, for it will be seen in future pages that other instances of disturbance have occurred in which the bones have afterwards been replaced, in some cases with the obvious attempt to put the several bones removed back again into their due relative positions. The secondary or introduced burials, in the case before us, supposing them to be such, were probably those of the woman and the two children, together with that of the burnt body, which was placed in immediate contact with one of the children. There can be little doubt that in this barrow we have the bodies of 
a mother and her children ; and it is at least supposable that they were killed at the time of her interment; though of course it is quite possible that they may all have died at the same time, either by disease or by the mischances of war. The occurrence of the same facts in other barrows, and indeed the comparative frequency of their occurrence, make the supposition that the children had been killed at the time of their mother's death or burial the more probable. There is another explanation of the occurrence of the fragmentary bodies discovered in this barrow, which perhaps may be thought as probable as that their condition was caused by the introduction of secondary interments. They may have been the remains of bodies previously deposited at some other place, and afterwards brought to this barrow for final interment. The system of twice burying the body has not been an infrequent one, and the practice of some modern savages may be cited to show that it still exists. The question is however more fully discussed in other parts of this volume, to which the reader is referred. In the barrow under notice, it should be remarked, were some lines of chalk rubble, arranged in a sort of rude wall-fashion. Some flint chippings were dispersed amongst its material, and also a rough flint flake, very carefully chipped at one end to a sharp point, so as to form a drill or piercing implement; there was also a round piece of sandstone, $2 \frac{3}{4}$ in. in diameter, which had been much used in the process of pounding or grinding.

The two barrows next to be described were situated about $200 \mathrm{yds}$. north of the last, and in near connection with one before mentioned as having been removed about 30 years ago; the three had formed a small group in themselves.

XXVII. The first, and smallest of the three, was $48 \mathrm{ft}$. in diameter, $3 \mathrm{ft}$. high, and was made up of flint rubble and mould; and from the very dark colour, due to the presence of a large quantity of decayed vegetable matter, it is probable that the mould had originally been turfs. At the centre, $1 \frac{1}{2} \mathrm{ft}$. above the natural surface, was a deposit of burnt bones, with some unburnt ones in company with them. The burnt bones comprised the remains of at least two bodies, for portions of two distinct lower jaws formed part of the deposit; and a critical examination shows the bones to be those of a very large and strongly-made man, and of another smaller person, probably a woman. Amongst the bones were fragments of a large cinerary urn, the rim of which had been ornamented with alternate series of vertical and 
horizontal lines of twisted-thong impressions. There was also a long narrow flint knife, of a beantiful tortoise-shell colour [fig. 21]. The knife is $2 \frac{7}{8} \mathrm{in}$. long and nearly $\frac{3}{4} \mathrm{in}$. wide, left untouched on one face and as it came off from the core, and carefully chipped along the other face, on both edges, to a blunt point at each end. These bones, both burnt and unburnt, were clearly the remains of burials which had been disturbed by the introduction of later interments; and one, if not both, of the burnt bodies had been enclosed in the urn. The knife, if such a term may be applied to the flint in question, is one of a class of flint implements of which $I$ have found several (besides being aware of the occurrence of others) associated with burnt bodies, but which had not themselves been subjected to the action of fire ${ }^{1}$. On the other hand, so far as my experience serves, the arrow-points found in company with burnt bodies are always calcined. This fact is at least worthy of remark, although it is possible that further investigations may reveal instances to the contrary, notwithstanding the unvarying testimony of my own personal experience.

Immediately below these disturbed bodies, and placed upon the natural surface, was the body of a man, in middle life, laid on the right side, and with the head to $\mathrm{E}$.; the right arm was extended down the side, the left hand upon the knees. At the back of the skeleton was part of the skull of a child, about 6 years of age, belonging to a body which had been disturbed. Three feet east of the head of the body there was an oval hole, $4 \mathrm{ft}$. by $3 \frac{1}{2} \mathrm{ft}$., and $2 \mathrm{ft}$. deep, which contained nothing beyond the ordinary material of the barrow. Over the hole however there was placed a vessel, probably a domestic one, of well-worked clay, and well-baked [fig. 92]. It is quite plain, is $4 \mathrm{in}$. high, $3 \frac{3}{4} \mathrm{in}$. wide at the mouth, and $3 \frac{1}{4} \mathrm{in}$. at the bottom, and has six holes, in pairs, close to the rim. Four feet west of the centre, and $2 \mathrm{ft}$. above the natural surface, was the body of a young man, about 25 years of age, laid on the right side, the hands touching the face. In front of the upper part of the chest was a jet button, $\frac{3}{4}$ in. in diameter, bearing as fine a polish and being as sound as if made only yesterday. It had no doubt fastened the dress in which the corpse had been buried, and a like instance will be found in the sequel, where a man had been buried with six similarly-shaped but larger buttons, placed in front of his ehest.

1 The calcined implement found on Sherburn Wold, and figured at p. 153, appears to belong to a different class from these knife-like articles. It is much thicker, rising into a ridge at the back, and was more probably intended as a point to a dart. 
Near the head of the body under notice were a few pieces of a richly-decorated vase. There was also a good deal of charcoal upon the hips and upper part of the thigh bones, and some large flints were roughly disposed over the body, probably by way of protection. About $3 \mathrm{ft}$. west-north-west of the centre was a second oval hole, $4 \mathrm{ft}$. by $3 \mathrm{ft}$., and $2 \mathrm{ft}$. deep, which contained nothing except chalk rubble and mould. Just north of the centre were many broken bones of the body of an adult man, which had evidently been disturbed, and to which the broken fragments of the vase, mentioned above as met with near the head of the last-named body, may be referred; nor is it unlikely that the unburnt bones found amongst the disturbed burnt ones may have belonged to this body. In the barrow a part of a red-deer's antler was met with.

XXVIII. The second barrow was $75 \mathrm{ft}$. in diameter, $4 \mathrm{ft}$. high, and, like the last, was made of flint rubble and mould, the latter of the same dark colour as in the former instance. At a point $18 \mathrm{ft}$. south-by-east from the centre, and $1 \mathrm{ft}$. above the natural surface, was a body, apparently that of a woman, laid on the right side; the bones were too much decayed to allow the position of the hands to be made out. Behind and touching the lower part of the back was a roughly-made and irregularly-formed round scraper of flint, and close in front of the body was a single fragment of a 'drinking eup,' ornamented like fig. 83. Again, $18 \mathrm{ft}$. west-south-west from the centre, and just below the present surface of the barrow, was found a cinerary urn, filled with the burnt bones of an adult; the upper part of the urn had been destroyed by the plough ; the overhanging rim, 2 in. deep, has had on the outside a pattern like that on fig. 54, of alternate series of vertical and horizontal lines, and is further ornamented to the same depth on the inside by encircling lines, all of twisted thong. At a point $7 \mathrm{ft}$. south-south-west of the centre, and $3 \mathrm{ft}$. above the natural surface, there was a further deposit of burnt bones, also of an adult, disposed in a round heap $1 \mathrm{ft}$. in diameter. A few feet south-west of the present centre were found several bodies laid very close together, and placed either in a natural depression in the original surface, or in a slight artificiallyformed hollow. These probably constituted the original interments, and the deposits had to some extent been disturbed by the introduction of a later burial. The first body, that of a man, was $7 \mathrm{ft}$. south-west of the present centre, and was laid in a contracted position on the right side, with the head to $\mathrm{E}$. The legs were 
crossed in a peculiar manner, right to left and left to right, the feet being bent back under the hips, a position which might result if the body had been buried in a sitting posture. That it had not been so buried, however, the position of the rest of the body, clearly laid on its side, sufficiently proved. The arms were too much decayed to permit it to be seen how they had been arranged. A second body, also that of a man, past the middle period of life and of great strength, was laid on the right side, with the knees close to the head of the first, the head being to N.W., the right hand in front of the chest, the left under the head. Both the thigh bones had been broken during life, and were re-united. Behind the head was a plain vase, which had almost gone back to its original clay. A third body, that of a strongly-made young man, about 25 years of age, was laid on the right side, the head to N.E., the lower part of the back touching the vase just mentioned; the right hand was up to the face, the left under the head. Laid across the feet of the second body was the neck of a fourth; this, a strongly-made man in the middle period of life, was laid on the left side, with the head to N.W., the hands in front of the chest, and clasping each other, the right over the left. This body lay about $7 \mathrm{ft}$. to the south of the centre, and its legs were cut away by the introduction of a body which I shall proceed to notice immediately. To the east of the fourth body were numbers of broken human bones, parts of skulls (amongst them that of a child), all of them the remains of bodies most probably disturbed by the secondary central interment; whilst due to the same act of disturbance, was the fragmentary condition of a body, the head of which, with a few of the cervical vertebræ in position, was found $9 \mathrm{ft}$. south of the centre, and laid upon the natural surface. The skull (that of a man past the middle period of life) was placed on its left side. Four feet south-east-by-south of the centre was the body of a man, the introduction of which had no doubt caused the disturbance above mentioned. It was laid on the right side, with the head to $\mathrm{E}$., but the bones of the arms were too much decayed to allow their position to be inferred. Close to, and in some cases touching, this body were numerous remains of human bones belonging to several disturbed bodies. In front of the chest were a rubbing-stone of oolitic sandstone, of a texture not unlike pumice, a flint saw, two ordinary flakes, one a long and wellformed one, having the edge along the whole of one side worn smooth by use, and a flat nodule of flint, from which flakes had been struck off, but which seems to have been afterwards used as 
a hammer-stone. These all appeared to be associated with the body under notice, but they may have been originally placed with one or other of those which had been disturbed, as had certainly been the case with a pin $5 \frac{1}{8} \mathrm{in}$. long, made from the leg-bone of a heron or bittern [fig. 8], and several pieces of a 'drinking cup,' found at a little distance from the body, just to the east of which was the lower jaw of a child, together with its right femur and a part of the sacrum. At a point $7 \frac{1}{2} \mathrm{ft}$. south-west of the centre was a hole, $2 \mathrm{ft}$. in diameter and $1 \frac{1}{2} \mathrm{ft}$. deep; it was just southwest of the bodies above described. Over all the central part of the barrow, and above the interments, were placed, with obvious intention, a number of large flints. In the substance of the barrow just north of the centre was found a large part of a red-deer's antler.

The central, and what may be considered the primary, interments must have comprised, inclusive of the remains of a child, no less than seven bodies, four being so far uninjured by the disturbance due to the secondary central burial, that the way in which they had been placed in the grave could be ascertained with fair precision. They had all evidently been buried at one time, for it is impossible that, lying in such close proximity, in one case actually overlying one another, they could have been interred at different times : because, as is obvious, had the barrow been opened in order to lay a fresh body or bodies alongside or upon those already in the grave, some disturbance of the latter must have taken place during the operation. I conclude then that these several persons had all been interred at the same time; and the question arises-to what cause or causes was the circumstance due? It is of course possible that they may have died simultaneously of some epidemic, or have been killed in an onslaught of an enemy. But there is a third supposition, which to my mind possesses greater probability, as being fully in accordance with funeral customs which we believe to have prevailed amongst the primitive inhabitants of the country. I mean that the greater number of the bodies were those of victims slain at the funeral of the chief or other important person in whose honour the barrow was erected. I have already noticed some facts which seem at least to imply that a custom of this kind was actually prevalent, and I shall have occasion to draw the same inference from other barrows situated in the same locality. It is of course a matter of simple conjecture in the main; but in the questions which arise 
from our attempts to arrive at some knowledge of the mode of life, state of culture, and habits of a people from the remains and other objects revealed to us by an examination of their burial-places, questions which are necessarily or in their essence tentative, it is alike impossible and undesirable not to start theories. And indeed no sensible evil can arise from such a proceeding, unless we attempt to square our facts to our hypotheses, or allow ourselves to become so wedded to the latter that we refuse to throw them aside when they are found to be inconsistent with other facts which our investigations may be the means of bringing to light.

The three barrows next examined were about $300 \mathrm{yds}$. to the east of the last three, and were separated from each other by intervals of about $80 \mathrm{yds}$.

XXIX. The first was $60 \mathrm{ft}$. in diameter, $1 \frac{1}{2} \mathrm{ft}$. high, and was made of earth. It had been used, long after the period of its original formation, as the burial-place of an Anglian woman, the sole remains of whose body consisted of a single tooth, found just below the surface of the mound at a point $12 \mathrm{ft}$. south of the centre. The associated articles however were in greater abundance, and consisted of portions of the dress, of woollen fabric, in which she had been buried ; three cruciform fibulæ and a waist-belt clasp, all of bronze, the last gilded; a necklace of amber and glass beads, a spindlewhorl of clay, and two vases, one quite plain, the other ornamented after the usual fashion of the so-called Anglo-Saxon pottery. At the centre, in an oval hollow running east and west, $3 \frac{1}{2} \mathrm{ft}$. by $2 \mathrm{ft} .10 \mathrm{in}$., and $1 \mathrm{ft}$. deep, was a deposit of calcined bones, the remains of an adult body which had been burned on the spot. Upon the bones, at the east end of the deposit, was an 'incense cup,' in a reversed position [fig. 103]. The cup is $1 \frac{3}{4} \mathrm{in}$. high, $2 \frac{3}{4}$ in. wide at the mouth, and $2 \mathrm{in}$. at the bottom. It has four perforations near the top, in pairs, opposite each other. The upper part for a depth of $1 \frac{1}{8} \mathrm{in}$. is ornamented with alternate series of vertical and horizontal lines, made by dotted impressions. Amongst the bones, at their western limit, was a calcined flint flake. Underneath the burnt body there was a grave, having a direction north-west by south-east, $7 \mathrm{ft}$. by $5 \mathrm{ft}$., and $3 \frac{1}{2} \mathrm{ft}$. deep. On the bottom of the grave at the west end was the body of an adult, laid on the right 
side, the head to W., and the hands up to the face. The grave was filled in with earth, clay, and flints.

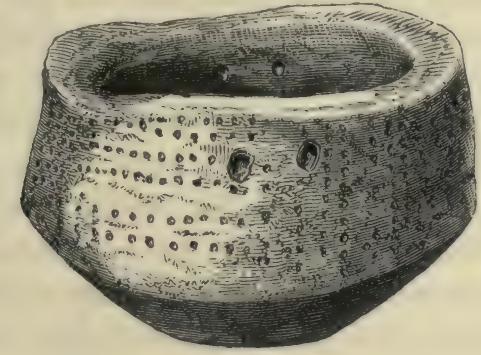

Fig. 103. $\frac{2}{3}$.

XXX. The second barrow was $45 \mathrm{ft}$. in diameter, $1 \mathrm{ft}$. high, and made of earth. At the centre, in a hollow about 9 in. deep, and rumning north and south, $2 \mathrm{ft}$. $4 \mathrm{in}$. by $1 \mathrm{ft} .10 \mathrm{in}$., was a deposit of bones, the remains of the body of an adult, which had been burned on the spot. Lying upon them, at their northern limit, was an oval flint knife, calcined. It is $2 \frac{1}{8} \mathrm{in}$. long by $1 \frac{1}{4} \mathrm{in}$. wide, and very carefully chipped all round the edge except at the butt. Amongst the material of the barrow was part of a leaf-shaped arrow-point of flint.

\section{Parish of Binnington. Ord. Map. xcv. s.w.}

XXXI. The third barrow, which, though in a different parish from the last, was but a very short distance from it, was $54 \mathrm{ft}$. in diameter, $1 \frac{1}{2} \mathrm{ft}$. high, and made of earth. Throughout the whole area of the mound the natural surface of the ground was covered with large flint blocks, while amongst them were many chippings of flint and a small broken honestone axe, $3 \frac{1}{2}$ in. long. A little to the west of the centre there was a great deal of burnt earth and charcoal. At the centre was a pile of large flints, forming a small cairn, under which was a deposit of the calcined bones of an adult, laid in a round heap, $8 \mathrm{in}$. in diameter. Below this burnt body was a hollow, tending north-west by south-east, $5 \frac{1}{4} \mathrm{ft}$. by $3 \frac{3}{4} \mathrm{ft}$., and $1 \frac{1}{2} \mathrm{ft}$. deep, which contained nothing beyond the filling-in (of earth), except some charcoal and a single flint chipping. On the north side of the barrow, which had been removed by the occupier of the land, two vases were found, but whether in company with burnt or unburnt bodies I could not ascertain. They are both of the 'food 
:vessel' type. The larger, in shape like fig. 69, but having two raised ribs, is $5 \mathrm{in}$. high, $5 \frac{1}{4} \mathrm{in}$. wide at the mouth, and $2 \frac{3}{4} \mathrm{in}$. at the bottom. The upper part has two bands of short inclining oval impressions, one above each rib, encircling the vase, and the inside of the rim has two lines of thong-impressions, arranged chevron fashion. The smaller one, a pretty little vase like fig. 70, is $2 \frac{1}{4} \mathrm{in}$. high, 3 in. wide at the mouth, and $1 \frac{1}{2}$ in. at the bottom. It has five unpierced ears at the shoulder, which have each two dotted impressions upon them, as if to simulate perforations. This peculiar and interesting feature seems to represent a time of transition between the pierced and the unpierced ears (when, though no longer used for suspension, the ears remained as an ornamental feature), the appearance but not the perforation itself being retained. The vase is ornamented over the entire surface; the inside of the lip of the rim has two encompassing lines, and the top and bottom of the vessel have each three similar lines, the space between the two series being occupied by two bands of vertical lines, divided by a single encircling line; all the impressions are due to a finely-twisted thong.

\section{Parish of Willerby. Ord. Map. xcv. s.w.}

The next group, still proceeding towards the east, consisted of a long barrow, described elsewhere in this volume, and nine of round form. One of them, a very large mound, was partially opened by the late Lord Londesborough, with what results I am not aware. They were all situated on the same ridge as those last under notice, though not, as in their case, overlooking the valley of the Derwent, inasmuch as an outlying spur of the chalk hill, separated from the main range by a deep ravine, lies to the north of that on which these barrows are placed.

XXXII. The first was $72 \mathrm{ft}$. in diameter, $3 \mathrm{ft}$. high, and was made of earth. At a point $6 \mathrm{ft}$. west of the present, but which may be assumed to have been the original, centre, was a large quantity of charcoal, lying at about the level of the natural surface, and covering a number of flint blocks placed above a shallow grave. These flints were immediately covered by a layer of clay, $1 \frac{1}{2} \mathrm{ft}$. thick, and over that was a stratum of smaller flints. The grave was a simple depression in the surface, of about $1 \mathrm{ft}$. deep, and in it was a body, laid on the left side, with the head to S. by E.; the 
bones however were too much decayed to allow the position of the hands to be ascertained. Near the face lay some remains of a 'drinking cup,' but so disintegrated that it was impossible to decide whether it had been entire when deposited with the body or not; though, from its relative position to the face, it is reasonable to assume that it was. On the south-east side of the barrow, at a depth of $1 \mathrm{ft}$. below its surface, was a most beautiful green-coloured honestone adze, almost approaching to a gouge, with a polish upon: its surface like that of glass. There is an old fracture at the smaller end, and it is now 6 in. long, and $1 \frac{3}{4}$ in. wide at the cutting edge [fig. 11]. In the barrow were also found a small knife-like instrument of flint, and a small round flint scraper.

XXXIII. The second barrow was situated a little to the south-east of the last. It was $64 \mathrm{ft}$. in diameter, $3 \mathrm{ft}$. high, and made of earth. At the centre was a grave, of an oval form, lying east and west, $8 \mathrm{ft}$. by $7 \mathrm{ft}$., and $5 \mathrm{ft}$. deep. I will commence by describing the contents of this grave, because by doing so it will, I think, be easier to give an intelligible account of the order of the burials in the mound. There had evidently been, as will appear in the course of the account, a good deal of disturbance in the grave, subsequently to its first application to sepulchral purposes, by the introduction of after interments. At a depth of $2 \mathrm{ft}$. the remains of what had apparently been a wooden platform were met with: this occurred in the shape of a thin layer of dark-coloured matter, with remains of woody fibre in it, running horizontally through the grave at that part. Upon it, and at the west side of the grave, lay the body of a child, of about 7 or 8 years old, placed on the left side, with the head to N.N.E., and the hands up to the face. This body seemed to have been at some time displaced and then relaid; for one of the temporal bones was lying at some distance apart from the rest of the head, a circumstance not to be accounted for on the hypothesis of any shrinking of the material which filled in the grave, that being, up to this point, simply earth. At a depth of $1 \mathrm{ft}$. below the (assumed) wooden platform, a large fragment of the thigh bone of an ox (bos longifrons) was found, and a little lower still, and $1 \mathrm{ft}$. more to the west, was a mass of charcoal, covering a space of 5 in. square, and in company with it a fragment of an earthenware vase. Below the platform the grave was filled in with earth and chalk, each in separate deposits. At the bottom of the grave, on the north side, was the body of a 
woman in middle life, laid on the left side, with the head to E.S.E. by E., and having the hands up to the face. At the head was the body of a child, about 6 years old, which had been disturbed and

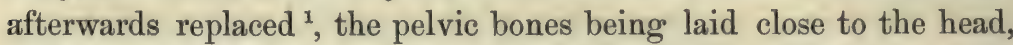
and the right tibia reversed. At her feet was another child, about 3 or 4 years old, and behind her back a third, about 2 years old. These two latter children seemed not to have been disturbed, but the bones were very much decayed, so much so that their position could not be very certainly made out, though it was clear they had been interred in the customary contracted manner. Almost touching the feet of the female body were the knees of, possibly, a man, who had been buried lying on the right side, with the head to W.S.W. This body also had been disturbed and replaced in a sort of rude order, the two femurs being in their proper places, but reversed. Laid upon these last bones were those of yet a fourth child, older apparently than any of the others; but whether it too had ever been disturbed it was impossible to decide, owing to the very decayed condition of the bones.

From the manner in which these several bodies were placed, it would appear that the original occupants of the grave had been the supposed man, and perhaps two of the children, and that it had been re-opened to put in the woman and the remaining children; and further, that in order to do this the child whose body was found at a higher level had also been subjected to removal. We may conjecture that a near tie of relationship had bound together the whole of the persons thus buried in one grave, possibly a man, his wife and children; but in this instance there is not anything to lead us to the conclusion that a wife and her children had been immolated at the funeral of the husband and father.

But to resume the account. Next, it would seem, after the grave had been finally filled in, and most likely not very long after that operation in point of time (for the shrinking of the grave, to be referred to presently, was probably due, in some measure at least, to the decay of the flesh of the bodies buried at its bottom), two other interments

\footnotetext{
${ }^{1}$ Several instances of a similar disturbance and replacement of skeletons will be found recorded in the sequel. The same feature occurred to Mr. Bateman in the Derbyshire barrows; in particular he mentions that in Rusden Lowe, 'it was evident that the grave had been occupied by a previous tenant, whose bones, together with the remains of another drinking cup beautifully decorated, and a bit of stag's-horn, had been collected and placed under one of the large stones that covered the grave. This had clearly been done at the time when the female was buried.' Ten Years' Diggings, p. 44. See alsó pp. 58, 73.
} 
had been placed partly over it. On the south side of the grave, to some extent in a hollow $1 \frac{1}{2} \mathrm{ft}$. deep, and partly over the edge of the grave, was the body of a man, about 40 years of age, laid on the left side, with the head to S.E., and the hands in front of the chest. The lower part of the back, which was slightly within the edge of the grave, had sunk $8 \mathrm{in}$. below the level of the rest of the body. On the south-east side of the grave was the body of an aged woman, which had been laid on the right side, with the head to W.N.W., and the hands up to the face. The body was placed partly over the grave, and in consequence the head and neck had sunk $14 \mathrm{in}$. below the level at which the rest of the body reposed. On the north-east side of the grave, and $2 \mathrm{ft}$. higher than the level of the natural surface, was a cinerary urn, reversed, and containing the calcined bones of an adult. The urn was very much broken and decayed, but it was plain that it had had an overhanging rim, ornamented with alternate series of vertical and horizontal lines of thongimpressions. In the grave were some bones of two adult oxen; a round scraper, part of a second one, a 'slingstone,' and the end of a sharp-pointed and carefully-chipped narrow implement, all of flint.

XXXIV. The third barrow lay about a quarter of a mile to the south-east of the last. It was $45 \mathrm{ft}$. in diameter, $2 \mathrm{ft}$. high, and composed of chalk-rubble and earth. At a spot $8 \mathrm{ft}$. east of the centre, and about $6 \mathrm{in}$. above the natural surface, were two bodies of young persons, under 12 and 20 years of age respectively, the younger laid just in the rear of the elder, the face of the one being close to the back of the head of the other. They were both laid on the left side, with the heads to S.S.W., and their hands up to the face. About $1 \mathrm{ft}$. in front of the elder was a third body, that of a child about 4 years old, also laid on the left side, and with the head to S.S.W. Facing the child was the body of, almost certainly, a woman, not less than 60 years of age, laid on the right side, the head to $\mathrm{S}$. The right arm was extended down the side, and the left laid upon the thigh. The right hand of the youngest child was close up to the face of the adult, and the left under the child's own right elbow, the arms and knees being placed upon the right arm of the adult. The knees of the adult were laid a little over the knees of the eldest of the children, and the youngest child was placed between the knees and face of the adult, about whose head there was a quantity of charcoal. In front of the face of the eldest of the children was one half of the bottom of 
an earthenware vessel. The four bodies together occupied but a very small space: from hip to hip of the two outside bodies the distance was but $3 \mathrm{ft}$. $7 \mathrm{in}$., and between the corresponding heads only $3 \frac{1}{4} \mathrm{ft}$.

At the centre was a grave, sunk in the chalk, $5 \mathrm{ft}$. in diameter and $4 \mathrm{ft}$. deep. Amongst the filling-in of the grave were the scattered remains of a body, which had been disturbed in the process of inserting that which was subsequently found at the bottom. The last-named body was that of a man, between 25 and 30 years of age, laid on the left side, with the head to N.W., the right hand being placed upon the breast, and the left up to the face. The body was deposited upon a flooring of chalk flags, arranged upon the solid chalk floor of the bottom of the grave, and it had been, when buried, covered with sods of turf, the decayed remains of which admitted of easy identification; the rest of the filling-in of the grave consisted of chalk.

XXXV. The fourth barrow was placed a little to the north of that last named. It was $68 \mathrm{ft}$. in diameter, $3 \frac{1}{2} \mathrm{ft}$. in height, and formed of earth. At the centre was an oval grave sunk in the chalk, running east and west, $6 \mathrm{ft}$. by $5 \mathrm{ft}$., and $2 \frac{1}{2} \mathrm{ft}$. deep; in it, on the bottom, was an adult body very much decayed, lying on the right side, with the head to $W$. In front of the face was a ' food vessel.' It is of the type of fig. $71,4 \frac{5}{8} \mathrm{in}$. high, $5 \frac{1}{2}$ in. wide at the mouth, and $2 \frac{3}{8}$ in. at the bottom, having four pierced ears at the shoulder. It is entirely covered with a pattern formed by impressions of twisted thong. The inside of the rim has four encircling lines upon it, and the vase itself has encircling lines, having between them bands of short inclining lines, with a single zigzag encircling line near to the bottom, below which are five encircling lines. Behind and touching the head were six flints, two of them well worked; one, possibly a knife, $1 \frac{7}{8}$ in. long, carefully chipped over the whole of the one face, the other being left as when it was struck off from the core; another, having also somewhat of the knife form, is of the same length as the first, but not so well flaked; the others being mere chippings. The grave was filled in with earth, and covered over on the top with very stiff clay, amongst which were many flint chippings, potsherds, and pieces of charcoal. Above this clay were several fragments of a vase, which may have been broken and scattered in rabbitdigging; certainly there was a rabbit-burrow close to it. Amongst the materials of the barrow, here and there, flint chippings were 
observed, together with a flint saw, a single piece of pottery, and considerable traces of chareoal.

XXXVI. The fifth barrow was about 100 yds. east of the last, and, with the next, was situated in the parish of Forden. It was $60 \mathrm{ft}$. in diameter, $3 \mathrm{ft}$. high, and made up of earth and chalkrubble. At the centre was an oval grave, north-west by south-east, $5 \frac{1}{2} \mathrm{ft}$. by $4 \frac{3}{4} \mathrm{ft}$., and $3 \mathrm{ft}$. deep. At the north-west end, on the bottom of the grave, where a thin layer of clavey soil had accumulated, was the impression of the bones of a body, not a single fragment of which however was remaining. This is a valuable illustration of the way in which a barrow may be found entirely destitute of any trace of the body which once occupied it; in this case, if it had not been for the accidental presence of the clay in the grave, there would not have been the slightest indication that a body had ever been placed in it. The grave was filled in with flints, clay, and earth: and it may here be observed that wherever there is vegetable mould in a grave near the body, it is usually found to be very much decayed; but where the body is surrounded with chalk, the bones are generally well preserved. Amongst the materials of the barrow were several flint chippings.

XXXVII. Another barrow in the close vicinity of that last noticed was thoroughly examined at a great expense of time and labour. It was $100 \mathrm{ft}$. in diameter, $5 \mathrm{ft}$. high, and composed of earth and chalk. The only discovery made was of a single interment of an unburnt body, $15 \mathrm{ft}$. south of the centre, and placed just below the present surface of the mound. The bones had been so much disturbed by the plough that nothing could be made out with regard to the position of the body. If ever there had been a central interment, it must have been situated much above the level of the natural surface, and had been totally removed by the plough. The nature of the material of the barrow was such as to lead to the conclusion that at least some trace of bones would have been met with if ever there had been a second interment in the existing mound. There certainly was no grave, for the solid rock was reached, and there was no trace of any excaration upon it. Several bones belonging to three oxen (bos longifrons) were dispersed amongst the materials of which the barrow was formed.

XXXVIII. The seventh and last barrow of this group was a little to the north of the two last, but in the parish of Willerby, and close 
to the east end of a long barrow before referred to. It had been opened at the centre by the late Lord Londesborough, who found in it two bodies; one with a 'food vessel' accompanying it ${ }^{1}$. I reexamined it throughout, and found the bones of both bodies replaced at the centre. One of them had been originally laid upon the natural surface, and was that of a strongly-built, middle-aged man, the head markedly brachy-cephalic. The barrow yielded no other interment, and nothing more that four round scrapers, some flint chippings, and potsherds was obtained from it.

\section{Parish of Butterwick. Ord. Map. xcv. s.w.}

XXXIX. This barrow, which was placed singly, was situated on moderately high ground, to the north of the great wold valley already referred to. Though standing alone, it was not very far removed from those on Sherburn Wold, the opening of which has been before described; it lay to the south-east of them. It was $56 \mathrm{ft}$. in diameter, $2 \mathrm{ft}$. high, and made of earth. At a point a little south of the centre, a rude wall of small chalk stones, $1 \frac{1}{2} \mathrm{ft}$. high, ran through the barrow, in a direction east-south-east by west-northwest. At the centre there was a grave, sunk into the chalk, $10 \mathrm{ft}$. in diameter, and $5 \frac{1}{2} \mathrm{ft}$. deep. Near the centre of the grave, and placed on its floor, was the body of a young man, laid on the left side, the head to N.E., and with the hands in front of the breast. The head and upper part of the body had been covered with turf, and the bones were in consequence much decayed. The rest of the bones were quite sound, having been covered with chalk, with which the grave was filled. Along the back of the body was a line of chalk flags set on edge. In the right hand was held, by the handle, a bronze knife-dagger [fig. 37], the point of which touched the chin. The handle had been made of ox-horn, the impression of which, showing the grain most distinctly, is still quite plainly to be seen upon the oxidised surface of the metal. The blade had been fastened to the handle by three bronze rivets, which still remain in the holes, and the haft terminates upon the blade in the usual semi-lunar fashion. This instrument or weapon is of very thin metal, highly polished, and the edges are quite sharp; it is $4 \frac{1}{2}$ in. long, and 2 in. wide where the blade joins the handle, and

\footnotetext{
${ }_{1}$ The vase is engraved in the Journal of the British Arch. Assoc., vol. iv. p. 107.
} 
the point has a rounded end. When deposited with its dead owner it had been encased in a wooden sheath, the remains of which, though completely decayed, were sufficiently apparent. Like most of the so-called daggers which have been found in company with buried bodies, this appears to be too short and too weak to have served the purpose to which a dagger proper would commonly be put; and this is, as it seems to me, a conclusive reason for thinking they ought rather to be looked upon as knives, for which they are well fitted, equally by their thin blades and sharp edges. Upon the blade was laid a flint knife; it is formed from a broad flake, $2 \frac{3}{4} \mathrm{in}$. long, which has the original skin of the flint left on one face: both the edges are carefully chipped along nearly the whole length. Below the blade was a bronze drill or pricker [fig. 104],

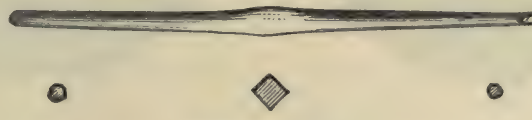

Fig. 104, $\frac{1}{1}$.

$2 \frac{3}{8}$ in. long ${ }^{1}$. The section at the middle is square; it then becomes round and, tapering in each direction, terminates in a sharp point at both ends ${ }^{2}$. In front of the chest were six round buttons, five of jet and one of oolitic sandstone, which had been applied to fasten the man's dress ${ }^{3}$. The jet buttons ${ }^{4}$ [fig. 105] vary in size, from $1 \frac{1}{8}$ in. to $1 \frac{3}{4}$ in. in diameter, and are slightly conical in form. They have two holes worked in obliquely at the back, one from

1 The engraving does not show the sharp-pointed ends in consequence of the oxidised metal having decayed since the implement was discovered.

${ }^{2}$ I have found four like this but smaller, one in a barrow on Flixton Wold [No. Ixxi], two in one barrow at Rudstone [No. lxii], and the fourth on Goodmanham Wold [No. cxv]. One was met with by Mr. Bateman in a grave under a barrow near High Needham, Derbyshire, where was 'a skeleton ... a at the right shoulder were three instruments of flint, and a small bronze awl, tapering each way from the middle, which is square.' Ten Years' Diggings, p. 85. Similar instruments are commonly met with in the Danish barrows, where they are associated with burials after cremation.

${ }^{3}$ It will be found in the sequel that, in a barrow at Rudstone [No. Ixviii], a similar conjunction of a bronze knife-dagger and jet buttons was met with. Mr. Bateman, in his account of a barrow on Alsop Moor, Derbyshire, mentions the finding of a skeleton at the centre, and that 'close to the right arm lay a large dagger of brass ... close to this dagger were two highly polished ornaments made from a kind of bituminous shale ... circular, and moulded round the edges, having a round elevation on the front to allow of two perforations, which meet in an oblique direction, on the back.' Vestiges, pp. 68, 69.

4 The button figured has been a failure in the first instance, so far as the perforation is concerned, and that has been remedied by a second boring. 
either side, so as to meet at the centre, without penetrating to the front $^{1}$. The stone button [fig. 4] is $1 \frac{1}{2}$ in. in diameter, and is formed exactly like those of jet, only that it has a slight ornament due to four engraved lines, which quarter the face and nearly meet at the apex, constituting in fact a cruciform pattern ${ }^{2}$. At the hips was an axe-blade of bronze ${ }^{3}$ [fig. 38]. The handle, which had
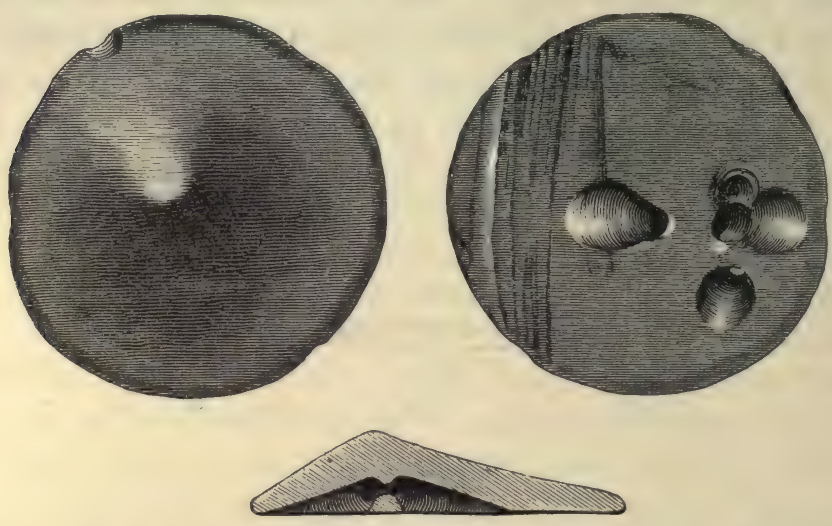

Fig. 105. $\frac{1}{2}$.

been under $2 \mathrm{ft}$. in length, could be plainly traced by means of a dark line of decayed wood, extending from the hips towards the

${ }^{1}$ Buttons of this form are by no means unfrequent. I have met with them in six instances on the wolds, and in three in Northumberland. They are also made of bone after the same fashion, and in Wiltshire Sir R. Colt Hoare found them made of wood plated with gold. Ancient Wilts, vol. i. p. 99, pl. x ; p. 201, pl. xxxv. fig. 1.

${ }^{2}$ A similar pattern, but more skilfully executed, and occurring upon jet buttons, will be found noticed in the account of a barrow at Thwing [No. $1 x]$, and of one at Rudstone [No. lxviii].

${ }^{3}$ So far as I know, this is the only instance of the occurrence of a bronze axe in association with an interment which has been met with on the wolds. Indeed they have very rarely been found under such circumstances in any part of Britain; some instances, however, are here noted. In a barrow at Normanton was a male skeleton, with a bronze axe-head near the shoulders, a dagger and spear-head of bronze, some bone and gold articles, and a pierced stone. Hoare, Ancient Wilts, vol. i. p. 203, pl. xxvi. Near Wilsford, in a grave was a burnt body, with a small bronze axe, pin, and a ring of bone. $l$.c. p. 208, pl. xxviii. In a barrow, also near Wilsford, was a skeleton, with a bronze axe, a stone hammer, \&c. $l$. $c$. p. 209 , pl. xxix. In a barrow called Borther Lowe, near Middleton-by-Yolgrave, Derbyshire, was found a skeleton with a plain coarse urn, a flint arrow-point, and a 'diminutive bronze celt.' Bateman, Vestiges, p. 48. On Parwich Moor, Derbyshire, in a grave under a barrow was the skeleton of a man, 'and close to the head were one small bead of jet, and a circular flint; in contact with the left upper arm lay a bronze dagger, with a very sharp edge, having two rivets for the attachment of the handle, which was of horn, the impression of the grain of that substance being quite distinct around the studs. About the middle of the left thigh bone was a bronze celt, which is of the plainest axe-shaped type.' Bateman, Ten Years' Diggings, p. 35. 
heels; moreover, from the presence of decayed wood on the sides of the blade, it would seem as if the axe had been protected by a wooden sheath. To all appearance the weapon had been worn slung from the waist. The blade is of the simplest form, modelled on the pattern of the stone axe, and may, it is probable, be regarded as the earliest type of bronze axe, antecedently to the appearance of either flanges or socket. It is $4 \mathrm{in}$. long, $2 \frac{3}{8} \mathrm{in}$. wide at the cutting edge, and $1 \frac{1}{8}$ in. at the smaller end. It had evidently been fixed into a solid handle to a depth of two inches, and that part of the blade which had been inserted into the handle has a perfectly different appearance on the oxidised surface of the metal from that part which has been exposed. The wood of the handle had no doubt remained for many centuries more or less undecayed, and so had prevented that end of the axe-head covered by it from being acted upon, by one agency or another, to the same extent that the exposed end had been.

In the grave, but not in close connection with the body, were several flint chippings, a long flint scraper, much used, three pieces of a richly-decorated 'food vessel,' and some charcoal. On the bottom of the grave, at the east side, was a layer of dark matter like decayed wood, $2 \mathrm{ft}$. long, $9 \mathrm{in}$. wide, and $1 \mathrm{in}$. thick. In the material of the barrow were several bones, belonging to four oxen and one pig, together with half the lower jaw of an adult bos longifrons.

In regard to the variety of articles found associated with an individual interment, this is one of the most instructive $I$ have met with; and it enables us to bring together the knife-dagger and the simple axe-head, and to class them as belonging to one and the same, and that an early, time in the Bronze Age. From the type of either of these implements singly, we might well assume it to be an early specimen of metal-work, but the additional support given to this view, from the circumstance of their being associated, is of considerable force. The fact of a flint implement forming a part of the buried man's equipment would not in itself prove that the burial belonged to the early bronze period; because, as is fully ascertained, both flint and other stone were in use for certain purposes throughout the whole of the Bronze Age. Still of course, so far as it is significant of date, it is in favour of an early one. We seem to learn, from the concomitants of this burial, what the general nature of barrow burials ever tends to provethough not to the same extent, for it is seldom that so many 
objects are found with a single body - that it was not the usual habit to bury weapons of war with the dead. There seems to be in this case certainly nothing that can be considered a purely warlike instrument, although I admit quite unreservedly that the axe may have been applied to battle uses. Indeed the only article found associated with an interment, and that alike with burnt and unburnt bodies, which cannot be regarded as intended for any other purposes than those of war, is the perforated stone axe-hammer, which from its rounded or squared edge could not have been used for cutting wood or any like purpose, but which still is well adapted for use in battle. As I have elsewhere remarked, the very careful way in which these axe-hammers are finished and the presence of more or less ornamentation upon some of them are also facts in support of the conclusion that they have been weapons of war: for it has always been on such objects that people in the earlier stages of civilisation have delighted to bestow decoration. The arrow-point of flint, not unfrequently found in the grave, may, it is true, be said to have been employed in war, and to be an example in contradiction of what is above advanced. But it must be remembered that the arrow was necessarily in much more frequent use in the chase than in battle, and it may have had its place by the body of its owner in its character of subserving towards the sustenance of human life, rather than in that of aiding in destroying it. We do not find in the burial mounds of the Bronze Age those articles which are emphatically 'weapons of war,' the sword and the spear for instance. Certainly the occurrence of bronze swords in barrows is mentioned by Professor Wilson as having been ascertained in Scotland; but I cannot say that the instances he adduces appear to me at all satisfactory, nor can I find a single case, wherein a sword is said to have been found in association with a buried body, depending upon evidence which may justly be regarded as trustworthy. In Denmark, indeed, it is not very uncommon to find the bronze sword buried with its deceased owner; in some instances broken, as if to intimate that its use was ended ${ }^{1}$. If ever we might have expected to find weapons of war buried with the dead, it would surely have been in such a barrow as I have just described; for it covered the remains of a strongly-built and

${ }^{1}$ If it was the belief of these people that what we call inanimate objects were possessed of a soul or spirit, then the purpose in breaking the sword might be to enable the soul of the sword to accompany the soul of the deceased warrior into the land of spirits. 
powerfully-made young man, in the very prime of life, who moreover, from the associated articles found with his body, and from the very burial-mound itseif, would appear to have been a man of importance amongst his people, and necessarily therefore, in such times, a man of war ${ }^{1}$.

\section{Parish of Helperthorpe. Ord. Map. xcv. s.w.}

The two barrows next to be described were situated some miles to the west of the last, but upon the same tract of high land, between the valley of the Derwent and the great wold valley; upon the crown however, and not upon the slope, of the hill.

XL. The first examined was $72 \mathrm{ft}$. in diameter, $3 \mathrm{ft}$. high, and made principally of earth, having some chalk near the centre. It contained a single interment, which was placed in a grave at the centre; this was oval, lying north and south, $6 \mathrm{ft}$. by $4 \frac{3}{4} \mathrm{ft}$. and $3 \mathrm{ft}$. deep, and filled in with earth and some chalk rubble. At the bottom was the body of a young man, laid upon the left side, with the head to $\mathrm{N}$.; the right hand was up to the chin, the left behind and at the back of the head, with the fingers doubled in. In the mound were some flint chippings, a small barbed arrow-point of flint, and two sherds of pottery.

XLI. The second barrow was only a few yards to the south of the last. It was $69 \mathrm{ft}$. in diameter, $3 \mathrm{ft}$. high, and made of earth, with some chalk intermixed. At the centre, about $9 \mathrm{in}$. below the surface of the mound, was the body of a child, about 12 years of age, laid on the right side, with the head to $\mathrm{S}$., but so much decayed that the position of the hands could not be made out. Immediately in the rear of it was a second body, that of an adult, also laid on the right side, and with the head in the same direction as that of the first ; in this case also the arrangement of the hands could not be ascertained. In front of the face was a barbed arrow-point of flint, $1 \frac{1}{4}$ in. long. Below these bodies there was a grave, of an irregularly circular form, $4 \mathrm{ft}$. in diameter and $2 \mathrm{ft}$. deep, which had been filled in with chalk. In it was the body of a man, past the middle period of life, laid on the left side,

1. This difficult question is more fully considered in the Introduction, to which the reader is referred. 
the head to $\mathrm{N}$., the right arm across the body, the fingers resting on the loins, the left hand up to the face. The head and feet were both in contact with the sides of the grave, and, consequently, lay rather higher than the rest of the body. In front of the face was what seems to be part of a flint knife, $2 \mathrm{in}$. long and chipped to a sharp edge along that side which remained. At the head was the tine of a red-deer's antler, $8 \mathrm{in}$. long, partly cut and partly broken off from the beam; while another tine, also $8 \mathrm{in}$. long, partly sawn and partly broken off, lay at the feet. From the position in which they were found they had probably been once applied to some special use, although it may be vain to speculate what that use was. It is possible that they may have been employed in flaking flint, for the ends are worn quite smooth, though that may have been done during life by the animal rubbing them against trees. In the grave there were also a part of the pelvic bones and one of the femurs of a child.

\section{Parish of Weaverthorpe. Ord. Map. xciv. N.w.}

The series of barrows next to be described is a large one, and extends through the parishes of Weaverthorpe, Helperthorpe, Langtoft, and Cowlam, along the ridge of high land lying south of the great wold valley. The whole district, to judge from the number of barrows it contains and the numerous earthworks which intersect it, as also from the amazing quantity of flint implements and chippings scattered about on the surface in every part, must have been thickly peopled and over a long space of time.

XLII. The first barrow examined was in the parish of Weaverthorpe, about a mile to the south of the village, and standing upon a rising piece of land, although not upon the ridge of the hill. It was $60 \mathrm{ft}$. in diameter, $4 \mathrm{ft}$. high, and formed of earth, with an intermixture of some chalk stones. Twelve feet south-east from the centre, and extending for about $5 \mathrm{ft}$. towards that point, was a layer of soft black mould about $4 \mathrm{ft}$. wide, placed on the natural surface, and varying in thickness from 2 in. to 6 in. A great deal of charcoal in small grains lay amongst it, with many broken animal bones, and numerous flint flakes and chippings, amongst which was a long, oval, carefully-worked scraper. About the middle of this deposit were the remains of what seemed to have been when first 
placed there an entire vessel of plain, dark-coloured pottery, but too much disintegrated to admit of any determination as to its original shape or size, thongh it had probably been not unlike fig. 91 . Between this black deposit and the centre of the barrow was another deposit of like matter, but smaller in extent and thinner. At a point $5 \mathrm{ft}$. south-south-west of the centre, and upon the natural surface, was the occipital portion of the skull of a young person, and close to it some other bones, a right femur, the iliac bones, \&c.; while at the other end of the femur was the skull of a small-sized man, in the middle period of life. In elose contiguity to this lay a water-worn oval quartzite pebble, one end of which had been much used for pounding or grinding; the other end being less, but still distinctly, abraded in like manner. It is $4 \frac{1}{4} \mathrm{in}$. long and $3 \mathrm{in}$. wide. At the centre of the barrow, on the natural surface, was the body of a strongly-made man, past the middle period of life, laid on the left side, with the head to $\mathbf{E}$., the right hand across the lower part of the chest, and the left on the right elbow. Behind the head was a 'drinking eup,' in form like fig. 120, $7 \frac{3}{4}$ in. high, $5 \frac{1}{2}$ in. wide at the mouth, and $3 \frac{1}{4}$ in. at the bottom. It is ornamented over nearly the whole of the upper 5 in. with encompassing, intersecting, vertical and zigzag lines, all made by impressions of a nærrow notched strip of bone or wood. Immediately above the body, and again in a second deposit $1 \frac{1}{2} \mathrm{ft}$. above that, were numerous portions of human bones, and amongst them part of a skull. The introduction of the body found at the centre had led to the disturbance of two, if not three, previously buried bodies, with one of which the pounder had probably been deposited. Amongst the materials of the mound were several flint chippings, a round seraper, a number of animal bones ${ }^{1}$, and many fragments of pottery, principally like those already described, and consisting of portions of several dark-coloured, well-baked, plain vessels apparently domestic.

XLIII. The next barrow was about half a mile south-east of the last, and proved very prolific in interments. Like the last, although at a higher level, it was not on the crown of the hill. It was $54 \mathrm{ft}$. in diameter, $4 \mathrm{ft}$. high, though a good deal ploughed down, and made of earth, with an admixture of some chalk. At a point $19 \mathrm{ft}$. south-west of the centre was a ' food vessel,' set upright, and

1 The animal bones, which include those found in the deposit of dark-coloured mould, belong to a large number of oxen (bos longifrons), some of them young ones, and to two pigs. All the marrow-containing bones have been split open. 
upon the natural surface, but not near to any interment. It is shaped like fig. 71, with five unpierced ears at the shoulders; $4 \frac{3}{4}$ in. high, $5 \frac{3}{8}$ in. wide at the mouth, and $2 \frac{1}{4}$ in. at the bottom. The ornamentation is confined to the upper two inches of the vase and to the inside of the rim, and consists on the outside of ten encircling lines of thong-impressions and two of dotted markings, one between the first and second, the other between the fourth and fifth lines of thong-impressions. The inside of the rim has a single encircling line of dots between two encireling lines of thongimpressions, whilst the outside of the lip has upon it a series of short vertical lines. Fifteen feet south of the centre, and about $1 \mathrm{ft}$. above the natural surface, was a body, probably that of a man about 20 to 25 years of age, lying on the right side, with the head to $W$., the left hand crossed over and clasping the right, and both up to the face. Above the knees was a very peculiar vase which must be classed amongst the 'food vessels' [fig. 74]. It has four feet set upon a round bottom; and is $5 \frac{1}{2} \mathrm{in}$. high, and $5 \frac{7}{8} \mathrm{in}$. wide at the mouth. The upper part is ornamented with a herring-bone pattern of thong-impressions, and below is an encompassing band of semicircular markings; the vase then becomes plain, until within $1 \frac{1}{2}$ in. of the bottom, when it is covered over the whole remaining space with semicireular markings similar to those on the upper part, and, like them, made with finely-twisted thong. Fifteen feet east-south-east from the eentre, and just above the natural surface, was the body of a child, too much decayed to admit of its position being determined ${ }^{1}$. Six feet south-west of the centre, and $2 \frac{1}{2} \mathrm{ft}$. above the natural surface, was the body of a man in middle life, laid on the left side, with the head to E.; the hands were up to the face, the left over the right and clasping it, the fingers being doubled in. Belind the head were two flint implements elaborately chipped: the one is apparently a knife, flaked to a sharp edge along both sides, one of which is curved, and is $2 \frac{7}{8}$ in. long and $1 \frac{3}{4}$ in. wide [fig. 20]; the other has originally been larger, and had been broken before it was buried; it is now $2 \frac{1}{4} \mathrm{in}$. long and $1 \frac{1}{4} \mathrm{in}$. wide, and is of a triangular shape, and chipped over both faces. Under the knees was a flint flake, $2 \frac{1}{4}$ in. long, very much worn along both edges by use. Nine feet west-south-west of the centre was the body of a

${ }^{1}$ In the further account of this barrow, where no specific mention is made of the position of the body, or of its head or hands, it must be understood that the bones were too much decayed to allow those facts to be ascertained. 
child, placed $1 \frac{1}{2} \mathrm{ft}$. above the natural surface. Nine feet east of the centre, and upon the natural surface, was laid the body of an old woman, on the right side; the head was to E., and the hands up to the face. Behind the head was a round flint scraper. At a point $5 \mathrm{ft}$. east-south-east of the centre, and $2 \mathrm{ft}$. above the natural surface, was the body of an adult, lying on the left side, with the head to W., and the hands up to the face; upon them was placed a thick, well-chipped flint implement, $2 \frac{1}{8}$ in. long and $\frac{3}{4}$ in. wide, of knife-like form ; and above it a 'food vessel,' $4 \frac{1}{4}$ in. high, $5 \frac{1}{2}$ in. wide at the mouth, and 3 in. at the bottom, and in shape like fig. 69, but with two raised ribs. The upper part for a depth of $1 \frac{1}{2} \mathrm{in}$. is ornamented with three encompassing bands of short vertical lines of twisted-thong impressions; the inside of the rim has two similar bands, having between them an encompassing line of the same impression. About the body were a few fragments of burnt bone. Nine feet east-north-east of the centre, and $2 \mathrm{ft}$. above the natural surface, was the body of a strongly-made man in the middle period of life, laid on the left side, with the head to $\mathbf{E}$., and the hands clasping each other and up to the face. Fifteen feet east-north-east of the centre was the body of a child, laid on the left side, at a height of $1 \mathrm{ft}$. above the natural surface. Eighteen feet north-north-east of the centre, at the same level, was the body of another child; $9 \mathrm{ft}$. north-west of the centre, and $2 \mathrm{ft}$. above the natural surface, was the body of a third child, laid upon the right side ; while at a point $12 \mathrm{ft}$. northeast of the centre, and at the same level as the last, was the body of yet a fourth child, laid on the right side, with the head to the west. At the centre was an oval grave, running east and west, $9 \mathrm{ft}$. by $6 \frac{1}{2} \mathrm{ft}$. and $5 \mathrm{ft}$. deep, sunk into the chalk, the excavated material from which, beyond what had served to fill it in again, was regularly piled up, like a wall, on the north side of the grave. On the bottom, at the south-west side, lay the body of a large and powerfully-made man, past the middle period of life. At the knees was a large, thin, and well-chipped flint knife [fig. 106], the edge worn by use, $3 \frac{3}{4}$ in. long and $1 \frac{3}{4}$ in. wide, with a rounded point; and nearer the head was a large oval flint flake, which also shows signs of se on one edge. The bones were not all in their proper order, nor did it seem as if the body when deposited in the grave had been vested with its flesh, or connected by the ligaments in all its parts. There was a story of a former tenant of the farm having dug into the barrow and come upon a skeleton, the head of which he held up 
to the light, saying that it should once more behold the sun; but the appearance of the grave, which seemed to be undisturbed, scarcely gave warrant to the notion that, supposing the story to be true, this had been the body so treated. I should rather be inclined to think that in this case, as in others which have been met with, the body had in the first instance been deposited at some other place, and then brought, in a more or less perfect condition, to its final burying-place. Amongst the material of the mound were many flint chippings ; five round scrapers, and one oval, lefthanded one; a most symmetrically-formed and beautifully-flaked

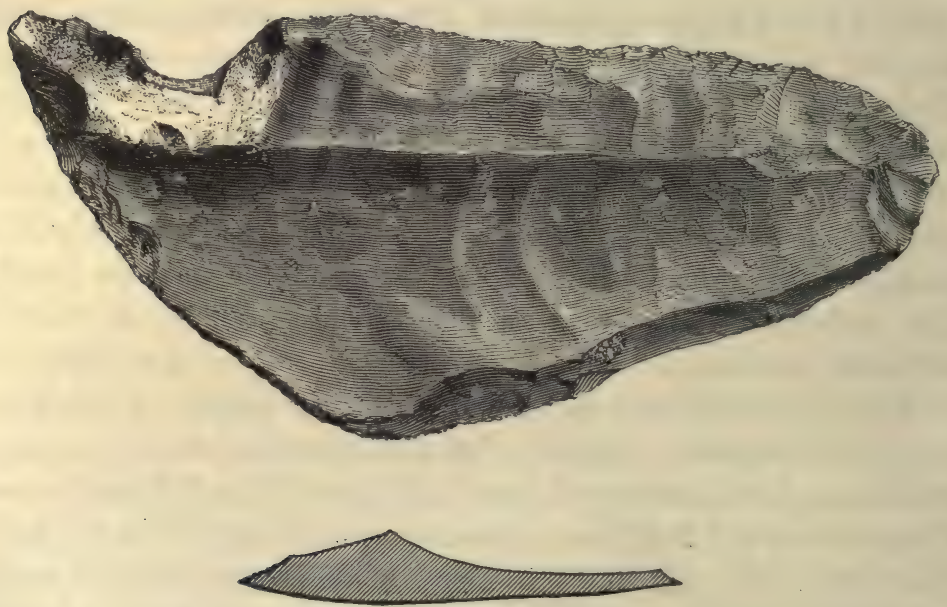

Fig. 106. $\frac{1}{2}$.

willow-leaf-shaped arrow-point of flint, precisely like fig. 114, $2 \frac{1}{8}$ in. long and $\frac{3}{4}$ in. wide; the half of a spindle-whorl, of baked clay, $2 \mathrm{in}$. in diameter ; some charcoal, several fragments of pottery, and many broken bones belonging to four oxen and three goats or sheep, all of them adults.

In this barrow there were twelve unburnt bodies, half of which were those of children, and probably one burnt one, in all thirteen; and so far as could be judged from the appearance of the mound, there did not seem to have been any disturbance occasioned by the insertion of secondary interments, all of these as it would appear having been placed on the then existing surface of the barrow, to which, as each new burial took place, fresh additions of earth were made. At least this theory seems to account for the way in which the mound may be supposed to have gradually grown to its present 
size, and for the various depths at which the several bodies were found. It was in all probability a family burial-place, and it must have been in use as such for a period extending at least over the life-times of three generations. With so large a number of interments it would have been reasonable to look for the oceurrence of some article of bronze; and the more so as several of the bodies were aocompanied by implements. I should not however, from the entire absence of bronze, be inclined to attribute the formation of this barrow to a time at which that metal was at yet unknown, on grounds which I have stated in the Introduction. We may not be wrong however in placing the epoch during which the mound was in process of use for a burial-place as one early in the bronze period, notwithstanding the fact that all the objects found in it are of such a nature as were commonly manufactured quite down to the end of that time.

The proportion of children is large. But without any assumption that their death was by violence on the burial of their mother, we may remind ourselves how in the then comparatively rude state of life, and with occasional scarcity of food, the number of children who arrived at maturity must have been very much smaller than it is at present. Moreover, we do not find in this barrow any instance of a child laid by the side of its parent, a circumstance we meet with in others, and in which case it seems not unlikely that death was inflicted at the time of the funeral of the father or mother.

XLIV. The next barrow was about a quarter of a mile to the east of the last, and, like it, not on the crown of the hill. It was $42 \mathrm{ft}$. in diameter, $1 \frac{1}{2} \mathrm{ft}$. high, and composed of earth and chalk-rubble. Twelve feet east-north-east of the centre, and laid on the left side, upon the natural surface, was the body of an adult with the head to N.N.E., the right hand at the back of the head and the left up to the face. Touching the knees were two flints; one of them may best be classed under the head of scraper, though it is not of the usual form, being made out of a broad flake and having a straight edge ${ }^{1}$; the other is one of those enigmatical tools to which it is difficult to assign any certain use, it may have been intended as a borer, or to tip the end of a dart, being carefully chipped along both edges to a fine point, one face is left in the same condition in which it was when struck off from the core; they are

1 The implement, fig. 225, Evans, Ancient Stone Implements, is almost a counterpart of this. 
both $1 \frac{3}{4}$ in. long. Close to the flints was a bone pin, 3 in. long. At the centre, in a very shallow hollow, was the body of a young woman, laid upon the right side, with the head to E., and the hands up to the face. Behind the head was a 'food vessel,' something in shape like fig. 69 , but perfectly plain, $5 \mathrm{in}$. high, $5 \frac{7}{\mathrm{~s}} \mathrm{in}$. wide at the mouth, and $2 \frac{1}{2}$ in. at the bottom. Round her neck was a necklace of jet beads [fig. 49], consisting of 119 small flat circular disks, slightly increasing in size from the ends of the necklace to the middle, where was a triangular pendant, also of jet ${ }^{1}$. Immediately to the east of this body, but at a slightly higher level, was another, that of an adult. It was laid upon the left side, with the head to E., the hands being up to the face. The plough had just touched it and taken off the legs, which had been placed a little higher than the rest of the body. A flint implement was found where the

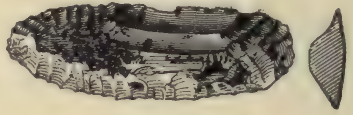

Fig. 107. $\frac{1}{2}$.

knees had been, and had evidently been deposited under them; a position in which, associated with a burial noticed in the account of the last barrow, a somewhat similar flint was discovered. This implement [fig. 107], to which the name of knife may perhaps be given, is $2 \frac{1}{4}$ in. long, very carefully made, being chipped along both sides and also round the ends, and is an excellent specimen of the class to which it belongs. At a point $5 \mathrm{ft}$. west of the centre was the body of a strongly-built but aged man, laid on the natural surface, upon the right side, and with the head to W. Close to

I I found a second necklace identical with this, except in the pendant being slightly different in shape, with the body of a young woman in a grave on Goodmanham Wold [No. exxi]. Another precisely like this was found in a grave under a barrow at Fimber, on the Wolds. With the skeleton were a 'food vessel' and a small bronze awl or pricker. The necklace is engraved in the Reliquary, vol. ix. pl. x. p. 65. In the Museum of the Society of Antiquaries of Scotland are three similar triangular pendants of lignite; one found at Rothie, Aberdeenshire, another at Bogheadly, Kincardine, and the third at Balgay, near Dundee; this last was associated with plates and 'bugles' also of lignite, forming an elaborate necklace; in the cist in which the interment had been made was an urn. Proc. Soc. Ant. Seotland, vol. viii. p. 412. In a cist within a chamber enclosed in a long horned-cairn at Yarhouse, Caithness, were found an urn, and a necklace of beads of lignite, of which seventy were recovered. Those figured are identical in shape with the beads from this barrow. l. c. vol. vii. p. 498. Similarly formed disks, of various materials, have served the purpose of ornaments, sometimes by themselves, and sometimes in connection with other forms, not only amongst the early inhabitants of Britain and other countries, but with modern savages. 
this body was part of the lower jaw of a very old person; but whether the body to which it belonged had been destroyed by the plough, or in the process of inserting that of the aged man just referred to, it was not possible to decide. Due north and south of the body, about $\mathrm{l} \mathrm{ft}$. distant from it, were two circular holes, each $3 \mathrm{ft}$. in diameter and $1 \frac{1}{2} \mathrm{ft}$. deep. In one of them, that to the north, was a piece of the shoulder-blade of a pig ; in the other, part of a human metacarpal bone. Amongst the material of the barrow were several flint chippings and potsherds, together with a considerable quantity of oharcoal. It would seem that a vase had been destroyed by the plough, as many pieces of such a vessel were found scattered about in one particular place on the east side of the mound and amongst the soil which had been turned over in the course of ploughing.

XLV. The barrow next to be noticed lay about a quarter of a mile south-east of the last, and was placed on the crown of the hill. It was $54 \mathrm{ft}$. in diameter, $2 \mathrm{ft}$. high, and made of earth with some addition of chalk. Twelve feet south of the centre, and laid on the natural surface, was the body of a child, too much decayed to permit the position to be noted. At a distance of $9 \mathrm{ft}$. southwest of the centre was the body of another and very young child, in an oval hollow, $1 \frac{1}{2} \mathrm{ft}$. by $1 \mathrm{ft}$., and $8 \mathrm{in}$. deep, but in the same decayed condition as the last. About $1 \mathrm{ft}$. north-west of this body, and probably in intended connection with it, was a 'food vessel,' laid upon its side, and having the mouth turned to the north-east. It is shaped like fig. 71, with four unpierced ears at the shoulder; $4 \mathrm{in}$. high, $5 \mathrm{in}$. wide at the mouth, and $2 \frac{3}{8} \mathrm{in}$. at the bottom. The upper part of the vessel for a depth of $1 \frac{3}{4} \mathrm{in}$., and the inside of the rim, are ornamented with lines, almost touching each other, arranged herring-bone fashion, and made by the impression of very thin and closely-twisted thong. Round the vase were large numbers of bones of the vole. At the centre was an oval grave, lying north and south, $7 \frac{1}{2} \mathrm{ft}$. by $5 \frac{3}{4} \mathrm{ft}$., and $1 \frac{3}{4} \mathrm{ft}$. deep. In it, on the bottom, was a body so much decayed that nothing could be determined about it, except that it was an adult and had been buried in a contracted position. Together with it, and also in a very decayed condition, was a 'food vessel.' There are however sufficient remains left to show that it had been in shape like fig. 69 , but with two ribs, and about $5 \frac{1}{2}$ in. high. The ornamentation, which is confined to the inside of the lip and 
to the upper two inches of the vase, consists of three encircling bands of short lines of thong-impressions placed vertically. The inside of the lip has two encireling bands of the same impression, the lines being arranged as chevrons set on edge. In the grave was the head of a badger, and on the south-east side, at the edge of the grave, a red-deer's antler. Intermixed in the material of the mound, here and there, were flint chippings, potsherds, pieces of charcoal, and some broken bones of two oxen, one a young animal.

XLVI. The barrow $\mathrm{n} \in \mathrm{xt}$ in succession to this was placed $220 \mathrm{yds}$. to the east of it, and was $70 \mathrm{ft}$. in diameter, $4 \mathrm{ft}$. high, and made up of earth and chalk. Fifteen feet west-by-south of the centre, and $1 \frac{1}{2} \mathrm{ft}$. above the natural surface, was a vase, a perfectly plain vessel; directly below this, and upon the natural surface, was part of a second vase, also quite plain and very much like the first in respect of fabric and paste; both these vessels being in such a decayed condition that neither size nor shape could be made out. Nine feet south-east of the centre, and upon the natural surface, was the body of a young man, from 20 to 24 years of age, laid on the right side, with the head to N.E., and the hands (the right clasping the left) raised to the face, in front of which was a flint flake. Not far from this body, at a point $9 \mathrm{ft}$. south of the centre, was a fragment of a human skull, and with it a flint flake. Three feet east of the plain vase first above mentioned, and at the same level with it, was the body of a very young child, much decayed and affording no certain evidence as to its position. Twelve feet south-west of the centre there lay another child, at the same level (about $1 \frac{1}{2} \mathrm{ft}$. above the natural surface), and in the same decayed condition. Just to the south of the centre, and about $1 \frac{1}{2} \mathrm{ft}$. above the natural surface, was the body of a woman, from 25 to 30 years of age, laid upon the right side, the hands being up to the face. Touching the back of the head was a water-rolled quartzite pebble, $2 \frac{1}{4} \mathrm{in}$. long and $1 \frac{1}{2}$ in. broad [fig. 15], which had been in much use as a hammer or knapping-stone, being worn down at both ends; and behind the neck was a long flint flake, chipped along one edge, and showing most distinct signs of wear. Below this body and extending to the south of it, and $3 \mathrm{ft}$. south of the present centre, was an oval grave, lying east and west, $6 \frac{1}{2} \mathrm{ft}$. by $4 \frac{1}{2} \mathrm{ft}$. and $2 \mathrm{ft}$. deep. This grave had been sunk through a body, which had probably been the primary and central interment, the lower parts of which 
still remained in their proper order and position, on the natural surface, at the north side of the grave; other parts of the same body, portions of the skull, \&c., being mixed amongst the filling-in of the upper part of the grave; with these disturbed human bones were some broken ox bones. At the bottom of the grave, and at the west end, was the body of a strongly-made man, past the middle period of life, laid upon the right side, with the head to W., the right hand upon the left elbow and the left hand upon the stomach. Behind the neck was a large and well-shaped flint flake, which, from its form and sharp edge, would well answer the purpose of a knife; and at the knees were some pieces of a human skull, probably belonging to the body which had been cut through in making the grave. Near the centre of the barrow, and just to the south of it, was a great quantity of charcoal. Twenty-one feet north-east of the centre, and $1 \mathrm{ft}$. above the natural surface, was the body of a very large and strongly-built man, but so decayed that nothing could be discovered about it except that it had been placed in the usual contracted position. In the mound, here and there, were some few flint chippings, charcoal, the tine of a red-deer's antler, and broken bones belonging to several adult oxen.

XLVII. The barrow now to be described, and which proved to be a very remarkable one, was about $300 \mathrm{yds}$. to the south east of the last. It was $80 \mathrm{ft}$. in diameter, $3 \frac{1}{2}$ feet high, and made up of earth, with a little chalk-rubble intermixed. Just within the edge of the mound there was an oval trench, $70 \mathrm{ft}$. across from east to west, and $60 \mathrm{ft}$. from north to south. It was $3 \mathrm{ft}$. wide and $3 \frac{1}{2} \mathrm{ft}$. deep, and was sunk to a depth of $2 \mathrm{ft}$. into the solid chalk, the upper $1 \frac{1}{2} \mathrm{ft}$. being cut through the soil overlying the chalk. On account of the highway cutting off a portion of the barrow it was impossible to examine its south-eastern quarter completely, so that the trench could not be traced through its entire extent; neither could it be ascertained whether, like that found in a barrow on Potter Brompton Wold [No. xxii], there was a space left unexcavated so as to render the circle incomplete. At the bottom of the trench, on the west side, were the two halves of a red-deer's antler. The lower half has the brow tine left on, the other tines being broken off. There are evident signs of use at the point of the tine and at the back of the burr, and there can searcely be a doubt that it had served as a pick, and that the trench had in 
part been excavated with it ${ }^{1}$. Near to the same place were some of the teeth and the lower jaw of an adult ox (bos longifrons); while in other parts of the trench charcoal was met with. In the substance of the barrow, and nearly throughout its whole extent, were numerous flint chippings, together with a flint saw and a great many round scrapers, sixteen in all, several of them quite small. There were also a very large number of fragments of plain dark-coloured pottery, amongst which were two pierced ears or handles of a vessel. The bones of several oxen, of one goat or sheep, and of one red-deer were also found in the substance of the mound. About the centre, for a foot in height above the natural surface, the earth was exceedingly hard, with an appearance suggesting the idea of its having been puddled. I have met with the same kind of compact earth in two barrows at Rudstone [Nos. lxiii, lxviii], and I have conjectured that it might be due to the mound having been thrown up in very wet weather, when the soil in a moist condition became puddled by the constant treading of the people employed upon it. No trace whatever of an interment could be discovered, although the whole mound, except the comparatively small portion cut off by the road, was turned over down to the chalk rock, the labour of six men and of two hard-working volunteers having been expended on it through a period of five days.

It was the most perplexing barrow I have ever met with; and but for my complete disbelief that monuments of a more artificial age, such as cenotaphs, had any existence during the era of these burial mounds, I should feel that it offers a problem very difficult to solve on any other supposition. It is certainly impossible that the site of a burial could have been overlooked in the exhaustive examination to which the barrow was subjected; and the part left unopened, through necessity, was so small and so remote from the centre, that nothing except a secondary burial could have been looked for there. The only conjecture which seems to me admissible is, that a body had been deposited upon the natural surface, without any vase, weapon, implement, or ornament accompanying it, and that every trace of the human remains had perished. That, under certain circumstances, the bones themselves go entirely to decay leaving no trace whatever behind them, I have ample

${ }^{1}$ A somewhat similar portion of a deer's antler, but more evidently an instrument, was found in a grave at Rudstone [No. 1xi], described in the sequel; to which description and the accompanying note the reader is referred. 
proof. In cists under cairns, where the air obtains free admission through the interstices of the surrounding stones, and in cists in sandy soil, where again the conditions favour the admission of air, it is very rare indeed to find any portion of the body left; although in a few cases one may meet with a fragment or two of the skull or of a femur, or other of the more solid bones, serving to prove that a body had once occupied the cist. Again, as has already been observed, where the bones have been deposited in a deep grave and enveloped with mould in which there is a considerable proportion of vegetable matter, they are usually found much decayed; as also where the body has been interred in wood and laid in a wet place, in consequence of the earthy constituents of the bone being dissolved by the vegetable acid of the decaying wood, brought to act upon them by the percolation of water. I have met with one very curious instance of the change which had taken place in the bones of a human body, enclosed in a split and hollowed oak tree-trunk and buried in swampy ground. Several rude coffins of this description were taken up near Featherstone Castle, Northumberland, and no trace whatever of a body was found in any of them, until at last one occurred in which the bones were left in their original form, but quite soft: while, on drying, as they shrivelled up, they assumed the appearance of old shoe-leather, such as may be picked up off a rubbish-heap. Bones discovered in peat-bogs have often been found in the same condition, the phosphate of lime entirely decomposed, while the gelatinous portion of the bone has been preserved. The skeleton of a roe-deer, found in Thorne Marsh, in the West Riding, and now preserved in the York Museum, is a specimen of bone in the condition referred to. I have observed that buried bones are in the best state of preservation when the body has been deposited in a stone cist constructed below the surface of the ground in strong clayey soil, or where the burial has taken place in a grave sunk in the chalk and filled in again with the material excavated in making it. I must however confess that the explanation just given of the absence of any signs of an interment in the barrow under notice, namely that the bones had gone to decay, is not quite satisfactory, for the nature of the material of the barrow was such that I should have expected to find the bones in good condition; and indeed the animal bones which were met with in several different parts of the mound were all in an excellent state of preservation, some of them still retaining the gelatinous part of the bone. 


\section{Parish of Langtoft. Ord. Map. xciv. N.w.}

XLVIII. The next barrow, which was situated a little to the south-east of the last, though in a different parish, had been dug into in recent times at the centre, but there were so many peculiar features connected with it that I am reluctant to omit all mention of its contents. It was $70 \mathrm{ft}$. in diameter, $1 \frac{1}{2} \mathrm{ft}$. high, and made of earth. Twelve feet east-south-east of the centre was a circular hole, $2 \frac{1}{2} \mathrm{ft}$. in diameter; three feet east of it was a second, $2 \mathrm{ft}$. in diameter ; and three feet east-south-east of it a third, also $2 \mathrm{ft}$. in diameter. They were all sunk to a depth of $2 \mathrm{ft}$. below the natural surface, and were filled in with chalk-rubble, amongst which there was some charcoal. Over and round about these three holes lay a great quantity of burnt earth and charcoal, together with a few burnt bones. Eight feet south-sonth-east of the centre, in a slight depression of the surface, were two bodies, with some fragments of a 'drinking cup,' and a good deal of charcoal : these no doubt had been the central burials. Both the bodies had been disturbed, probably by the persons who had dug into the barrow, and who had left, in evidence of their work, half of a horse-shoe and a piece of glazed pottery. One of the two bodies had been that of a large man; the other, of a young person about 16 years old. Beneath these two disturbed bodies was a circular hole, $1 \mathrm{ft} .4 \mathrm{in}$. in diameter and $14 \mathrm{in}$. deep, filled in with burnt earth and charcoal, amongst which were some human bones, unburnt. Fifteen feet east of the centre, and $4 \mathrm{ft}$. north of the second of the holes first above noticed, was a very much larger one, running in a direction north-east and south-west, $7 \frac{1}{2} \mathrm{ft}$. long by $2 \mathrm{ft}$. wide, and nearly $2 \mathrm{ft}$. deep. It was filled with chalk, burnt earth, and charcoal, and there was one single fragment of a vase in it. Two feet north-west of the disturbed bones were the leg and feet bones of a body, which had been laid upon the left side, and with the head to W. Close to the feet, on the north, were three thigh bones and a leg bone laid in a sort of order, all probably displaced from their original site by the opening above mentioned. Six feet south-south-west of the centre was a sixth hole, tending northnorth-east by south-south-west, $4 \frac{1}{2} \mathrm{ft}$. by $3 \frac{1}{2} \mathrm{ft}$., and $3 \mathrm{ft}$. deep. It was filled in, like the others, with chalk, burnt earth and charcoal, and contained besides this the knee-cap of a young person. It will be remarked that there were in this barrow more than the usual 
number of the curious and puzzling holes which have been so frequently noticed before. They are clearly not graves; for in by far the greater number of instances no trace whatever of human bone has been found in them; and in those cases where any such occur, they appear to be accidentally present. They have been met with in the long barrows of the south-west of England; but either they do not exist, or they have not been noticed, in the Derbyshire and Staffordshire barrows, so large a number of which are described in Mr. Bateman's two volumes. It is open to surmise that they may have been intended to serve the same purpose which the vessels of pottery buried with unburnt and (in some cases) with burnt bodies are supposed to have fulfilled, that, namely, of holding provisions for the use of the buried person. I am not able to say the supposition appears to me a very plausible one; but I am equally unable to offer any conjecture of a more reasonable nature or supported by any tangible evidence.

\section{Parish of Helperthorpe. Ord. Map. xctv. N.w.}

XLIX. The barrow I next proceed to deseribe was situated on the south bank of a small valley which runs parallel with the great wold valley, and about half a mile to the south of it. Although there are some barrows at no very great distance from it, this one stood quite alone. It was $54 \mathrm{ft}$. in diameter, $1 \frac{1}{2} \mathrm{ft}$. high, and was made of earth and some chalk. There were several interments in it, of both burnt and unburnt bodies, and it had been disturbed in early times, probably not long after its original construction, with the object of inserting secondary interments. All the burials had been made in a line running east-south-east by west-north-west through the centre of the mound. Eighteen feet east-south-east from the centre were the remains of a burnt body, or possibly of more than one body, which had been burnt on the spot. Mixed chalk and flint had been laid upon the bones and then fired, the whole by this process having become compacted into a substance nearly as hard as stone, and presenting many features in common with those of the calcined chalk and flint in the long barrow on Willerby Wold and in others described in this volume. Indeed it is quite possible that the original interments may have belonged to the same period as that when it was the custom to bury after this fashion and under long mounds. This may indeed, in the first instance, have been a 
small long barrow, which had been taken advantage of in later times, when it was again used as a place of burial, and by the additions then made to it turned into a round barrow. A similar process had taken place at Westow, where a long mound had become a round one in consequence of subsequent burials, as will be found by reference to the account of the barrow opened by me at that place. A true long barrow once existed not very far from the barrow now under notice, which presented features analogous to those of the ordinary wold mounds of that character. The burnt bones lately referred to occupied a space of $3 \frac{1}{2} \mathrm{ft}$. square, and the burning extended up to the knees of the body of a strongly-made man about 30 years of age, who was laid on the left side, $13 \mathrm{ft}$. east-south-east from the centre, the head being to N.W., the right hand on the left arm, and the left hand up to the face. At the crown of the head was a bone pin, $3 \frac{1}{2}$ in. long, and a small quartz pebble. There was a good deal of charcoal about the body, especially at the head, above which lay the left femur of a young person, while in front of the head, and also at the hip, was a single piece of burnt bone. At a point $7 \mathrm{ft}$. east-south-east of the centre was the body of a young child, about $2 \frac{1}{2}$ years old, partly disturbed, and immediately eastsouth-east of it were three skulls, placed in contact with each other. so as to present the trefoil figure. That one which was furthest to the west was placed on its base, some cervical vertebræ and others from amongst the upper bones of the body being in connection with it and apparently in situ. This skull was that of, probably, a boy, about 15 years old; the other two skulls, those of older persons, one quite an aged woman, were placed on their crowns, and no bones of their respective bodies were present ${ }^{1}$. Beneath the three skulls there was an oval hollow, $3 \frac{1}{2} \mathrm{ft}$. by $2 \frac{1}{2} \mathrm{ft}$. and $1 \frac{1}{2} \mathrm{ft}$. deep, which contained burnt earth, some charcoal, and a few calcined bones. This was, it is probable, the central point of the barrow, and the disturbance of the several bodies above noticed was possibly caused by the placing a burnt body in this hollow, a few

${ }^{1}$ Instances analogous to this have been met with in other parts of England. Mr. Bateman says that in a grave below a barrow near Monsel Dale 'were two small human crania, placed side by side, near a drinking cup.... It is singular that no trace either of the lower jaws or of any other parts of the skeleton could be seen, though no disarrangement had ever taken place in this part of the mound, and it is certain that the crania alone had been buried there. At a little distance from them was the skeleton of a child and one cylindrical jet bead.' Ten Years' Diggings, p. 76. In a barrow at Steepleton, in Dorsetshire, Mr. Warne found an urn containing a deposit of burnt bones, and ' resting upon it was a perfect human skull, which showed no appearance of the action of fire,' Celtic Tumuli of Dorse p. 45. 
of the bones of which were found in it. The unburnt body, with the bone pin, there can be little doubt, was also an introduced one, for disturbed bones were found about it. Six feet west-north-west of the centre was a body, laid upon the natural surface, as indeed were all the others previously mentioned. It was that of a strongly-made old man, who was laid upon the left side, with the head to the east. The left hand was up to the face, the right in front of the knees, and holding a bronze knife-dagger, the point of which was touching the chin [fig. 108]. Three bronze rivets; $\frac{3}{8}$ in. long, which had fastened the two plates forming the sides of the ox-horn handle, were within the bones of the hand, and just clear of the hand was the bone termination of the handle ${ }^{1}$ [fig. 109], $1 \frac{7}{8}$ in. long and $\frac{5}{8}$ in. deep, which had been affixed to it by two pegs, probably of wood. The blade had been fastened to the handle (which had the usual semi-lunar termination) by other two bronze rivets; these are still in the holes of the blade and are $\frac{5}{16}$ in. long. This knife-dagger, $4 \frac{1}{8}$ in. long, is very thin, and has almost

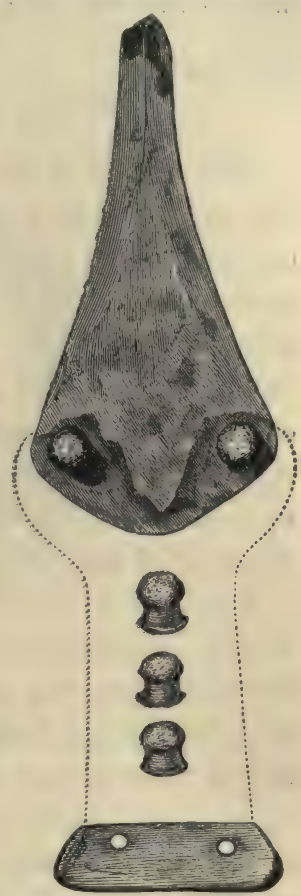

Fig. 108. $\frac{1}{2}$. certainly been brought to its present sharply-pointed form by longcontinued use and whetting ${ }^{2}$. It is the same type of instrument, more intended for cutting than for stabbing, as that found in the barrow at Butterwick [No. xxxix] with the bronze axe and drill; indeed, before it was so much whetted away it was

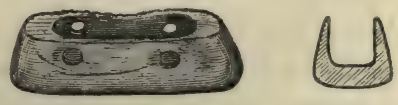

Fig. 109. $\frac{1}{2}$. probably not unlike that, so far at least as the blade is concerned.

${ }^{1}$ Bone terminations of the handle similar to this have been met with in barrows on the wolds, at Garton and at Bishop Burton, and are engraved, Archæol., vol. xliii.p. 441, figs. 143, 145. One was found in the tree-coffin from Gristhorpe, and is now in the Scarborough Museum; it is figured in Crania Brit., pl. 52. They have oceurred in the barrows on the moors in the North Riding, and one from thence is in the possession of Mr. Kendall of Pickering. Outside of Yorkshire they have been found in Derbyshire and Wiltshire, and a very beautiful one, but made of amber, was discovered by Mr. Spence Bate, F.R.S., in a barrow on Dartmoor.

${ }^{2}$ So far as can be judged from the exceedingly rude woodeut, one very like this was found in Carder Lowe, near Hartington, Derbyshire. Bateman, Vestiges, p. 63. 
Under the head were two chalk stones set on edge, and there were some bones of a pig near the body. In the material of the mound were some flint chippings and two sherds of pottery.

\section{Parish of Cowlam. Ord. Map. xciv. N.w.}

The group of barrows now to be described was situated about two miles to the south of that one last under notice, and contained certainly two, and probably four, grave-mounds, which proved to belong to a period considerably later than those which have been already dealt with. I mean that of the Early Iron Age. These barrows are of the same date, approximately, and produced articles of precisely the same character as a very remarkable series at Arras and Hessleskew, on the south range of the wolds, which were opened by the late Rev. Edward W. Stillingfleet and others, in the years 1816 and $1817^{1}$.

I will first describe the four barrows just adverted to, all of which I believe belong to the early time of iron, although, from the circumstance that no associated objects were discovered together with the buried bodies in two of the barrows, I cannot positively affirm that all four can certainly be attributed to that period.

L. The first was $22 \mathrm{ft}$. in diameter, $2 \mathrm{ft}$. high, and made up of chalk-rubble. At the centre, and placed on the natural surface, was the body of an aged woman, laid upon the left side, with the head to N.E.; and the hands up to the face. On the wrist of the right arm was a bronze armlet [fig. 110], and near the chin a bronze fibula, with an iron pin [fig. 111]. At the neck were seventy glass beads of a deep blue colour, and, except in one instance, having a zigzag pattern in white. The bead excepted, which also was the largest, has a series of annulets round it, which had been of white glass, still perceptible though the glass has almost entirely gone to decay [fig. 112]. Several beads of exactly similar fashion, both as to the zigzag pattern and the encircling line of annulets, were found at Arras $^{2}$. The pin of the fibula had originally been of bronze, this

1 The articles found in the barrows at Arras, and which fell to the share of the Rev. E. W. Stillingfleet, are now, by his gift, in the York Museum. A short account of the opening of this very extensive and valuable group of barrows will be found in the Proceedings of the York Meeting of the Arch. Inst., p. 26, and in Crania Brit., pl. 7.

${ }^{2}$ Very similar beads have occurred in the cemetery at Hallstatt, which belongs to the early time of iron. Von Sacken, Grabfeld von Hallstatt, pl. xvii. figs. 32, 37. They have also been found in a cemetery at Marzabotto. Gozzadini, pl. xv. fig. 13. 
however had been broken and replaced by a pin of iron, the one end of which had been inserted into a piece of wood placed within the coil constituting the spring with which fibulæ of this form were customarily fitted. In the barrow were a few flint chippings, and

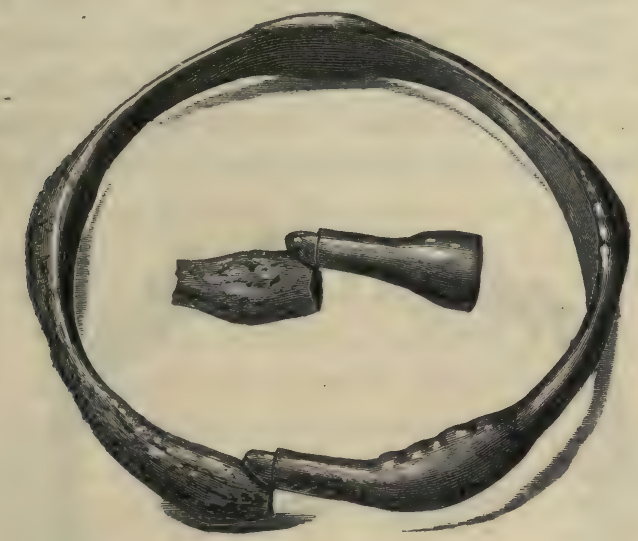

Fig. 110. $\frac{2}{1}$.

a very large number of sherds, principally of a plain, hard-baked, and dark-coloured kind of pottery, but some of a fine, porous, and lightcoloured kind, like that figured p. 107, fig. 91. Very little of it

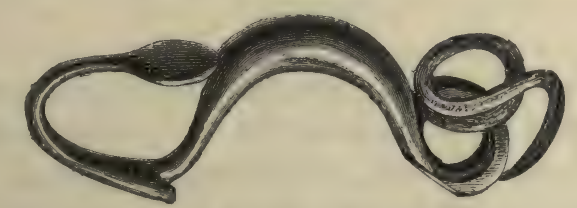

Fig. 111. $\frac{1}{1}$.

had much admixture of broken stone, and the greater part had none. A small fragment, $1 \frac{3}{8} \mathrm{in}$. long, triangular in section, of an armlet of lignite was also found.

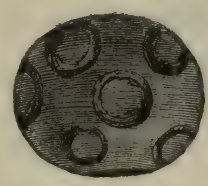

Fig. 112. $\frac{3}{1}$.

LI. The second barrow was $24 \mathrm{ft}$. in diameter, $1 \mathrm{ft}$. high, and, like the first, made of chalk-rubble. On the south side was a trench, running east and west, $5 \mathrm{ft}$. long, $1 \frac{1}{4} \mathrm{ft}$. wide, and $3 \mathrm{ft}$. deep. 
In it were several sherds of the same kind of pottery as in the last barrow, and many broken bones of several oxen, of goat or sheep, of two pigs, and of two horses. At the centre of the mound, on the natural surface, was the body of a woman in the middle period of life, laid upon the left side, with the head to $\mathrm{N}$. and the hands up to the face. Upon the wrist of the right arm was a bronze armlet [fig. 113] of very beautiful and delicate workmanship, and having a patina like glass in its polish, of blue, green, and olive colour. It is exactly similar, except in being of more skilful fabric, to some

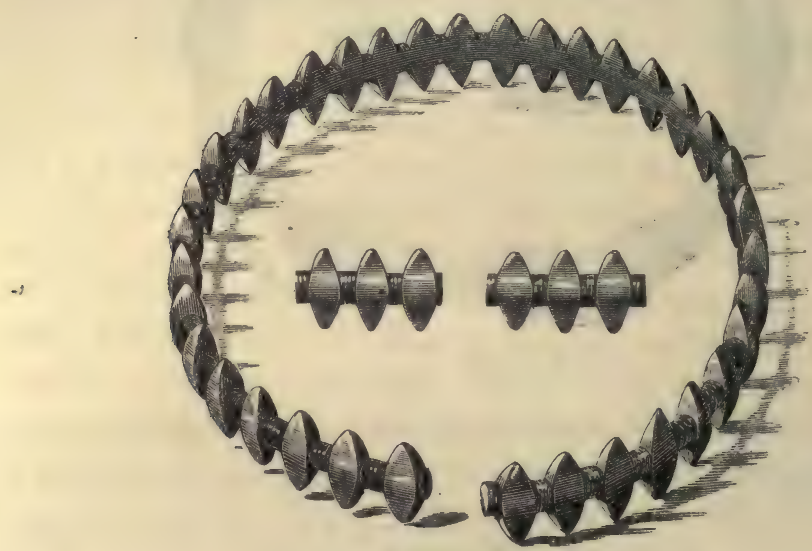

Fig. 113. $\frac{1}{1}$.

found at Arras. The body when laid in its last resting-place had been very much contracted, and only occupied, measuring from the ends of the toes to the back of the head, a space of $35 \mathrm{in}$. About and beneath the hips were some pieces of a plain, dark-coloured, and hard-baked vessel. Immediately to the west of, and extending partly underneath, the body was a hollow, running east and west, $7 \mathrm{ft}$. by $4 \mathrm{ft}$. and $3 \mathrm{ft}$. deep, in which were flint chippings, charcoal, fragments of the same dark-coloured pottery as that mentioned above, and many broken bones belonging to four oxen, one goat or sheep, and one young horse.

LII. The third barrow was $32 \mathrm{ft}$. in diameter, $2 \mathrm{ft}$. high, and made up of earth and chalk. About $4 \mathrm{ft}$. south-east of the centre was an oval hole, $3 \mathrm{ft}$. by $2 \mathrm{ft}$. and $1 \frac{1}{2} \mathrm{ft}$. deep, containing amongst the filling-in, charcoal, flint chippings, and some bones of an adult ox. Another hole, $5 \mathrm{ft}$. long by $3 \mathrm{ft}$. wide at the west and $1 \mathrm{ft}$. wide at the east end and of the same depth as the first, was met with 
about $4 \mathrm{ft}$. west of the centre; in it, and especially at the east end, was much burnt earth and a quantity of charcoal, evidently resulting from a fire which had been lighted in the hole and had reddened its sides and the surrounding earth for some distance. In this hole also were flint chippings, fragments of dark-coloured plain pottery, and many broken bones belonging to several oxen, one sheep or goat, and three horses, all adult animals. At the centre, and upon the natural surface, was the body of a woman about 30 years of age, laid on the left side, with the head to N.E; the right arm was down the side, the hand being flat with the palm uppermost and the fingers touching the knees; the left arm was extended at a right angle from the side, the hand being laid flat as in the case of the other. Underneath the body were several fragments of two, if not three, plain, hard-baked, and dark-coloured vessels with lips turned over like that of fig. 91, and having no broken stone mixed with the clay. Amongst the material of the mound was a well-formed, long and narrow flint scraper [fig. 18], showing signs of much use along one side.

LIII. The last barrow of this group was $42 \mathrm{ft}$. in diameter, $1 \mathrm{ft}$. high, and made of earth. At the eentre, on the natural surface, lay the body of a woman in the middle period of life, on the left side, with the head to $\mathrm{N}$., and the hands just above the knees. In contact with the body was the usual accompaniment of charcoal. Amongst the material of the mound were a very well-made small oval flint scraper; pieces of two or three vessels of pottery of the same kind as that found in the last barrow; the tine of a red-deer's antler, $4 \frac{1}{2}$ in. long, cut off from the horn, and rubbed smooth towards the point as if by use ; and several split bones of oxen.

There was nothing in these four barrows to show that they belonged to a period different from that of the ordinary class, so many of which have been already described, except the glass beads, the fibula and the armlets; the occurrence of the bones of the horse is also unusual, though it has occasionally been met with in the barrows. The bodies were in the contracted position so universal throughout the burials of the wolds; the usual accompaniments of charcoal, flint chippings and potsherds were found here also ; and, although the pottery was of a different ware from that of which the common cinerary urns, 'food vessels,' and 'drinking cups' are made, yet I have met with the same kind of hard, well-baked, darkcoloured, plain pottery in barrows of the ordinary kind. The holes 
too were like those which have been so often noticed, except that one had been made use of for lighting a large fire in, and that they contained more animal bones, potsherds, and chippings of flint than perhaps is common. Had the bodies occurred without the necklace, fibula, or armlets, I should not have hesitated the least about classing these four barrows with the other barrows in the immediate vicinity, which were of the time of stone, or more probably of bronze, and contained implements of flint and earthenware vessels of the ordinary round barrow type.

This important inference may perhaps not unfairly be deduced from these facts:-That no new people had come in with iron, but that acquaintance with and use of this metal were gradually developed amongst an originally bronze-using people, either according to the natural process of improvement characteristic of man, or through knowledge gained by contact and intercourse, in whatever way, with people who had already attained to a higher grade of civilisation.

The number of burials discovered in Britain which may be attributed with any certainty to the early time of the use of iron is very small, and this contrasts strongly with what is found to be the case in some parts of Germany, in Switzerland, France and Italy, and seems to imply that the period which elapsed between the introduction of iron and the time when Britain became more or less under Roman rule and influence was but short. Still, even upon this supposition, it is difficult to account for the paucity of burials belonging to the time in question. A greater number seem to have been discovered in Yorkshire than in all the rest of England '.

There is a fact in connection with the form of skull of the people of the Early Iron Age which it may be well to notice here-it is dolicho-cephalic; nor does it differ from many of the skulls which have been found in some of the barrows belonging to a time antecedent to the introduction of iron into Britain, and in those barrows discovered with other skulls of a markedly brachy-cephalic type. An explanation of this has suggested itself to me, which however I lay before the reader with some hesitation. It has been held by most of those who have considered the subject that the form of skull belonging to the earliest occupants of the country in neolithic times is a typically dolicho-cephalic one. In this I entirely agree,

${ }^{1}$ An account of all the burials of the period in question with which I am acquainted will be found in the Introduction, p. $50 \mathrm{n}$. 
as will be seen in other parts of this volume where the subject is more fully discussed. This long-headed race appears to have been intruded upon and conquered by a round-headed one, probably possessing a knowledge of bronze, to which in part may have been due the success of their invasion. That these conquerors did not extirpate the long-headed people is evident from the abundant remains of the latter found in the barrows of the time of bronze; and it would appear that ultimately the two races became so mixed up and connected as to form one people. If this was the case, by a natural process the more numerous race would in the end absorb the other, until at length, with some exceptions to be accounted for by well-known laws, the whole population would become one, not only in the accidents of civilisation and government, but practically in blood also. In this way it appears to me that we may account for the skull type of the Early Iron Age without the necessity of requiring any immigration into Britain or its conquest after the time of the presumed occupation by the bronze-using round-headed people already referred to. It may well have happened that a more numerous population was conquered by a smaller body of betterarmed invaders, but that in course of time the former absorbed the latter, so that at last they became the sole inhabitants of the country; and thus, without any fresh invasion of a long-headed race, we may have Britain again in the Early Iron Age occupied by a people who, so far as the form of head is concerned, seem to represent the earlier if not the original possessors of the land.

LIV. The next barrow, which was placed closely adjoining the three first of the group just described, but which I assign to an earlier date, was $50 \mathrm{ft}$. in diameter, $2 \frac{1}{2} \mathrm{ft}$. high, and made of earth and chalk. At the centre, laid on the right side, upon the natural surface, was the body, probably of a woman past the middle period of life, the head of which was to S.S.W.; the right hand being under the head, the left arm extended down the side, and the hand on the hips. At the feet was much charcoal. In the substance of the mound there were a few flint chippings, a great many potsherds, and a single bone of goat or sheep.

LV. This barrow was one of a small group of three, the largest of which still remains unopened, on account of its being planted with trees. They are situated not quite a quarter of a mile to the south of the five last mentioned. The first one opened was $46 \mathrm{ft}$. 
in diameter, $2 \mathrm{ft}$. high, and made of earth. At the centre there was an oval grave, north-west by south-east, $7 \mathrm{ft}$. in the longer diameter, $4 \mathrm{ft}$. wide, and $2 \frac{1}{2} \mathrm{ft}$. deep. In it was the body of an adult, laid on the left side, with the head to S.E., the right hand up to the face, and the left on the chest. In the making of this grave a burnt adult body and the unburnt one of a child had been displaced; remains of both, together with pieces of a 'drinking cup' and of a cinerary urn, being found in the filling-in of the grave.

LVI. Close to this was another barrow, $50 \mathrm{ft}$. in diameter, $1 \frac{1}{2} \mathrm{ft}$. high, and made of earth. At the centre, in a slight hollow, $4 \frac{1}{2}$ by $4 \mathrm{ft}$. and only $4 \mathrm{in}$. deep, were two bodies. The first, an adult male between 24 and 30 years of age, was laid on the right side, and had the head to N.W., the right hand being in front of the face but not close to it, the left arm extended and with the fingers touching the knees. Between the right hand and the face was a vessel of pottery, so much decayed that nothing more can be made out with regard to it than that it appears to have been of the type of 'food vessel,' of small size and covered over the whole surface with a pattern of an irregularly-reticulated character made by a sharp-pointed tool. The head of the second body, also that of a man about the same age as the first, almost touched the vase, and was to S.E.; the body was laid on the left side, and with the hands up to the face. Under this body was a large quantity of darkcoloured matter like decayed wood, and it is probable that in this, as in other cases, the body had been placed upon wooden planks. Close to these two bodies were some scattered bones of an adult male and of a child. In the material of the barrow were a few bones of ox, some flint chippings, and one potsherd.

From the position of these two bodies, interred in the same grave and with their heads almost in contact, it seems reasonable to infer that it was the burial-place of two persons nearly related, and probably, from their age, brothers. It would seem from the fact that some bones of a man and child were found close to the two bodies that they had been secondary interments, and that the first occupants of the barrow had been disturbed for their burial.

LVII. The next barrow, which lay about half a mile to the north-west of the four lately described and attributed to the Early Iron Age, had never been ploughed over. It was $56 \mathrm{ft}$. in diameter, $6 \mathrm{ft}$. high, and made of earth. The greater part of the northern 
half of it had however been removed for the purpose of laying the material on the land, but nothing calling for notice had been at that time observed. Still, the natural surface had never been reached, and hence the burials in the part of the mound specified had not been destroyed. It was one of the most prolific barrows in regard to the number of interments that $I$ have opened, and it presented a number of very interesting, though enigmatical, features. In consequence of the removal of the earth down to within a very short distance of the bodies at the part above referred to they were much decayed; but there was no difficulty in making out how they had been placed, as to all the main particulars, although in some respects, such as the position of the hands and arms, it was not in all cases possible to discover with absolute precision the direction in which they had been laid. About $16 \mathrm{ft}$. north-west of the centre, and upon the level of the natural surface, was a body, probably of a female past the middle period of life, laid on the left side, with the head to N., the arms standing out from the side and almost parallel with the thigh bones. Close to the fingers and knees, which were near together, was the head of a second body, that of a girl of about 18 years of age, also laid on the left side, with the head to S.; this body had either been disturbed and relaid in a sort of rude order, or had been an imperfect skeleton when buried, some of the bones being absent; which may be accounted for, not on the ground of decay, but either from their not having been replaced with the rest, or from their never having been in the barrow at all. Close to this body were some fragments of pottery, and upon the right femur was placed the tusk of a boar, split and sharpened at the edge by rubbing, and forming what had no doubt served the purposes of a knife ${ }^{1}$. I have seen similar implements made from boars' tusks, and associated with bronze swords, spear-heads, and the like, which were found in a cave at Heathery Burn, near Stanhope, in the county of Durham. It lay in front of the chest of the first body, and may have been interred with it, although lying on the thigh bone of the other. Below these bodies, a hollow, $3 \mathrm{ft}$. in diameter and $1 \mathrm{ft}$. deep, was disclosed, which contained, at a level equidistant from the bottom and the surface, the body of a man between 24 and 30 years of age, laid upon the

${ }^{1}$ Mr. Bateman records the finding of a like article in Derbyshire. 'Upon a pavement of thin flat stones ... lay the skeleton of a tall and strongly-built man.... Near his feet was the tusk of a large boar, rubbed down on the inner surface to about half the natural thickness,' Ten Years' Diggings, p. 131. 
right side, and having the head to W.S.W., the hands being up to the face. Upon the surface of this grave, as well as immediately beneath and about the two bodies first named, was a great deal of charcoal, many broken human bones, and numerous fragments of pottery. Two feet north-west of the two bodies first named, and a little above their level, was a pavement of small thin slabs of chalk, extending in a direction north-west by south-east for a length of $9 \frac{1}{2} \mathrm{ft}$., with a width of $3 \frac{1}{2} \mathrm{ft}$. Upon this pavement several bodies were laid. At its south-eastern extremity, and at a distance of about $2 \mathrm{ft}$. from the two bodies first discovered, was the body of a person of doubtful sex past middle age, deposited upon the left side, and with the head to $\mathrm{E}$. Close to the back of the head of this was the head of a second body, much disturbed and decayed, and not otherwise admitting of identification of position. Touching the knees of the first was the back of the head of a third body, that of a man past the middle period of life, laid upon the right side, and with the head to S.W.; while upon the hips of the same first body was the upper part of a fourth, an adult, laid on the left side, and with the head to $\mathrm{E}$. The hips of a fifth skeleton were close to the hips of the first; no head in connection with it was however to be found; the body, so far as any portion of it had ever been laid there, having been placed on the right side. These bodies occupied a space extending to a distance of $27 \mathrm{ft}$. from the centre, in a northwestern direction, and from the displaced condition of the bones they appeared (as has been already remarked) to have been disturbed and then replaced, if not brought from some previous place of burial. Some sort of order had been observed in the disposition or replacement, but many of the bones were not laid in their proper positions, and some were altogether wanting. So far as could be ascertained, the hands seemed to have been placed up to the heads. It is not very easy to understand the cause of this extensive disturbance; for it was not called for in the process of excavating the shallow grave disclosed. It is of course possible that the body first mentioned was an introduced one, and that the displacement recorded may have been due to that burial. The pavement too may have been there from the first, and the original interments deposited upon it. It is however possible, indeed probable, that the fragmentary and disturbed condition of these bodies, as well as of those presently to be described, may be due to quite another cause than that just mentioned, the probability of which will be discussed later on. 
After having completed the examination of this part of the mound, I then proceeded to remove all the south side, as also such part of the north side as had not been already carted away. During this process a large number of burials were met with, the majority showing the same signs of displacement and imperfectness as those already described. It will perhaps be best to commence any detailed account by beginning at the centre, and describing the several interments as they occurred with reference to that point. Upon the natural surface and at the centre were the remains of a body, that of a young man of strong make, which had been disturbed and replaced. It was laid upon the right side, the head being to $\mathrm{E}$. There was no lower jaw present, the elbow end of the right humerus touched the face, and the knee end of the right femur was also close to the face, the tibias were laid alongside the femurs, but reversed, and the ball of the left femur was not in the socket of the hip-bone, and was also turned outwards. In front of and almost touching the face was the head of a hammer made from the burr end of a red-deer's antler ${ }^{1}[$ fig. 33]. It has been formed out of a shed horn, the brow tine having been eut off. Through that part of the horn a roughly-circular hole, $\frac{3}{4}$ in. in diameter, has been pierced to admit the handle, and the horn has been cut off at a distance of $6 \mathrm{in}$. from the burr end. From the

${ }^{1}$ Somewhat similar implements have occurred in Derbyshire and Wiltshire, and I have found one in a cairn in Westmoreland. $\mathrm{Mr}$. Bateman records that ' a skeleton in a cist had in the angle of the knees a hammer-head ingeniously constructed out of the lower part of the horn of a noble red-deer : one end of this instrument is rounded and polished, the other is cut into a diamond pattern similar to the wafer-stamps used by attorneys.' With the same interment were associated two boar's-tusks, two flint arrow-points, two flint axes polished at the cutting edges, two 'spear-heads' of flint, two flint ' knives polished on the edge, one of them serrated on the back, and a drinking cup.' Vestiges, p. 42. Sir R. Colt Hoare found at Cop Head, near Warminster, at the south-east side of a barrow, a skeleton, with which were deposited 'some fragments of stags' horns, the butt-end of one of which had been cut off and perforated, and from its appearance used as a hammer.' Ancient Wilts, vol. i. p. 68. The Rev. W. C. Lukis, M.A., F.S.A., met with a hammer of deer's-horn, not very unlike that noticed in the text, in a barrow at Collingbourne Ducis, Wiltshire; it was deposited with a burnt body, which appeared to have been placed in a hollowed tree-trunk, the hammer being laid by the side of the bones. Wiltshire Archæol. Magazine, vol. $x$. p. 96, pl. iii. fig. 4. One not very unlike the Cowlam specimen was discovered with a skeleton, a bronze sword, \&c., in a cist at Veuxhaulles, Côte d'Or. Les Sépultures anté-historiques de Veuxhaulles, par Ed. Flouest. Matériaux pour l'Histoire primitive de l'Homme, 2nd Sér., vol. iv. p. 265, pl. xx. fig. 1.

Deer's-horn hammers have been found in considerable numbers in various places where the circumstances of their deposit have been such as to tend to their preservation, as for example in the rivers Thames and Seine, in peat-mosses in Denmark, and on the site of the Swiss Lake Dwellings. Indeed, as might be expected, the antler of the red-deer was very freely used both by the people of the Stone and Bronze Age as a material in the manufacture of several different implements. 
marks of the cutting, and the way in which the brow tine has been removed and the hole pierced through, flint tools appear to have been used in forming the implement; and most of the cuts seem as if made by a flint saw, rather than with a sharp-edged flake, although some few of them may be due to the employment of the last-named implement. The hammer shows signs of having been much used, the part from whence the brow tine springs and the burr at the same place being worn quite smooth. The other end is also much smoothened at the edges, and has been splintered in four places. It must therefore have bren in constant use, for no merely occasional employment could have worn away the burr and the part of the horn near it to the extent described, and hence it would appear that it may be more safely regarded as an implement rather than a weapon; and if a suggestion may be hazarded, I should be inclined to suppose that it may have been an instrument with which flint flakes were struck off from the block, in the first process of the fabrication of implements of that material. Six feet east of the centre and upon the natural surface, were numerous fragments of dark-coloured, plain pottery, lying close together, and which had probably, at the time of deposit, constituted an entire vessel. Ten feet south-east of the centre was a hole, $2 \frac{1}{2} \mathrm{ft}$. in diameter and $1 \frac{1}{2} \mathrm{ft}$. deep, containing nothing but the same material as that of the mound itself. Six feet west of the centre, and about $1 \mathrm{ft}$. above the natural surface, was the body of a young person, laid on the right side, with the head to S.W.; behind the head was a round flint scraper. Six feet north of the centre, and upon the natural surface, was the body of an adult, almost certainly a female ; it was laid upon the left side, the head to E., the right arm was extended at a right angle from the side, and the left hand was up to the face; under the hips was a very beautifully-made willowleaf-shaped arrow-point of flint [fig. 27], $1 \frac{7}{8}$ in. long and $\frac{7}{8}$ in. wide. The ankle end of the right tibia was placed in contact with the hip, and in company with it was an astragalus; the left tibia was in its proper position; the head of the right femur had the ball end out of the socket, and was turned outwards; all these displacements showing that some, at all events, of the bones had been relaid. There can be little doubt that the body was that of a woman, and therefore the occurrence of an arrow-point associated with the interment is remarkable. The body however had unquestionably been at one time disturbed and replaced, and it is more than probable that the arrow-point had no connection with it beyond its 
accidental position near the bones. At a distance of $4 \mathrm{ft}$. northwest from the head of this body was the head of another, that of an aged female, laid on the right side, the head to W., with a bonepin in front of the face, and having none of the bones of the body associated with it. The head in question was itself laid upon the upper part of the thigh-bones of another body, that of a small and slightly-made man in the middle period of life. This last body was laid on the right side, with the head to W.S.W., and the hands up to the face. There was but one femur and one iliac bone, but neither of the tibias seemed ever to have been disturbed. All these bodies had a good deal of charcoal about them, and were deposited upon the natural surface. Two feet north-east from the head of the last body was that of a child, laid on its left side, and with the head to S.S.E. About $2 \frac{1}{2} \mathrm{ft}$. north from the same body was another child, laid on the right side, the head to E., but, unlike the rest, placed at a height of about $1 \mathrm{ft}$. above the natural surface. A little to the west of it, but at a lower level, was a body without a head and laid on the right side, the hands being placed in front of where the head naturally would have been, and which, if present, would have pointed to W.S.W. This body, which was that of a large man, and certainly not that to which the separate head above mentioned had belonged, was laid about 6 in. above the natural surface, and the knees were about $1 \mathrm{ft}$. to the rear of the head of the body, on the thigh-bones of which the bodiless head was placed. Upon the hips of the child first mentioned was the head of another child, the bones of which were so much decayed, that nothing more could be made out as to its position beyond the fact that the head was to S.E. The whole of the burials, these last mentioned as well as those found on the north side of the barrow laid upon the pavement, were placed more or less in a line running south-east by north-west.

A vessel of pottery was discovered, reversed, and not near any interment, at a point $24 \mathrm{ft}$. south-west of the centre and just above the natural surface. It is of rather peculiar shape, not unlike the lower half of fig. $69,2 \frac{3}{4}$ in. high, $4 \frac{1}{2}$ in. wide at the mouth, and $2 \frac{1}{2}$ in. at the bottom; the upper part for an inch in depth is ornamented with irregularly-formed twisted-thong impressions, placed roughly herring-bone fashion. A very large number of flint flakes and chippings were found dispersed throughout the barrow, besides two arrow-points, one a beautifully-formed example [fig. 114], $1 \frac{5}{8}$ in. long and $\frac{3}{4} \mathrm{in}$. wide, the other smaller and less elongated. There were 
dispersed, at various places in the mound, twelve round scrapers; two drills, one [fig. 23] a long and narrow one; a cube of flint,

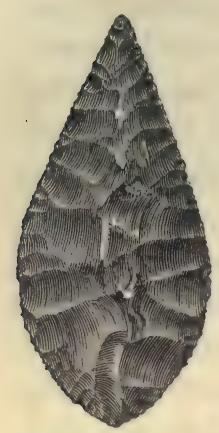

Fig. 114. $\frac{1}{1}$. $1 \frac{3}{4}$ in. square [fig. 26], which has one face partly ground smooth, having probably been used as a polisher; a piece of oolitic sandstone, showing signs of use in rubbing or grinding; an oval water-rolled quartzite pebble, worn at the ends by hammering or pounding; together with several burnt and broken stones having a smoothened surface, and which I have met with in the same condition in other barrows. A curious stone, flat and not unlike a shoemaker's lapstone, was also found; it has been very much used in rubbing down what can scarcely have been anything harder than hide; the whole of its surface, on both the faces and the sides, is worn into shallow hollows and is perfectly smooth; it is $8 \frac{1}{2} \mathrm{in}$. long, $3 \mathrm{in}$. wide, and about 1 in. thick. On the south side of the barrow and about $8 \mathrm{in}$. below the surface of the mound, a large bronze rivet, $\frac{7}{8}$ in. long, was met with, which had most probably belonged to a fine bronze fluted dagger, the middle portion of which, $3 \frac{3}{4}$ in. long, was found at the same depth near the centre of the mound. Large numbers of bones, belonging to twelve oxen and three horses, and innumerable sherds of pottery, principally of plain, dark-coloured ware, occurred throughout the entire barrow. Amongst these are many pieces of two vessels, which may have been complete when first deposited in the barrow; they are plain and dark-coloured, with a recurved lip, like that of fig. 91, and they may very possibly have been of the same shape. There were also found several fragments of at least two 'drinking cups,' and a single sherd of what appears, from the pattern upon it, to have been a cinerary urn.

The number of interments discovered in this barrow was, as will have been observed, a large one, and the disturbed condition of nearly all of the bodies was very remarkable. It is difficult to understand how the insertion of any body or bodies could have caused the disturbance which was apparent, for the whole of the skeletons had most certainly been moved and replaced. There seemed to be no reason for supposing that these evidences of disturbance had originated in any opening made, whether from curiosity or other motives, in modern times: indeed the whole barrow presented unmistakeable testimony that many centuries must have 
elapsed since the earth of which it was composed had been subjected to any process of removal. Nor is it likely, if the barrow had been opened for other purposes than those of burial, that the bodies which were disturbed by such act would have been relaid with attention to the due order of the constituent bones. The mound may have been in use as a burying-place for some length of time; and it is possible that it had been opened at various places, and probably, if so opened, oftener than once, in order to introduce fresh interments, though it is not easy to decide which the introduced interments were. These appearances may, however, be accounted for in another way. All the bodies may have been previously deposited, either under or above ground, at some other place, and may have afterwards been removed to where they were discovered, for none seemed to be complete or to have all their bones in proper order. On this supposition the barrow was an ossuary, though not on a large scale, nor having the bones placed all together in one common mass, as is usual in such a mode of final disposition of the bones. Similar conditions with regard to the bones have been met with in other barrows, and though I would not insist upon the ossuary view as explaining all the circumstances of the different cases, it appears on the whole to present fewer difficulties than any other theory, and it has the merit of being in accordance with a not uncommon practice.

The large quantity of fragments of pottery also deserves special remark. It was, nearly all of it, of the well-baked, unornamented, dark-coloured ware, of which several of the barrows in this locality as well as others elsewhere on the wolds have afforded specimens, but which is by no means so common in average barrows as the lighter-coloured, inferior kind of pottery, frequently characterised by the presence of ornamentation, and usually constituting portions of cinerary urns or other sepulchral vessels. I strongly incline to the opinion that this plain ware appertained to vessels for domestic use, which were necessarily better fired than those which I believe were specially made for burial purposes. This subject has been however more fully considered in the Introduction.

The two barrows next in order were situated upon the same ridge of high land as that whereon the last seven were placed, but about a mile to the west of them. 
LVIII. The first was $66 \mathrm{ft}$. in diameter, $2 \mathrm{ft}$. high, and composed of earth and chalk-rubble. Six feet south of the centre and upon the natural surface, was the body of an adult, laid on the left side, and with the head to S., the hands being up to the face. Three feet north of this was a burnt body, also of an adult, the bones being laid in a round heap $10 \mathrm{in}$. in diameter, placed $8 \mathrm{in}$. above the natural surface: amongst the bones were two potsherds. Six feet south-east of the centre, and upon the natural surface, was a body, laid on the right side, and with the head to W. It was that of a young person and very much decayed. Nine feet west
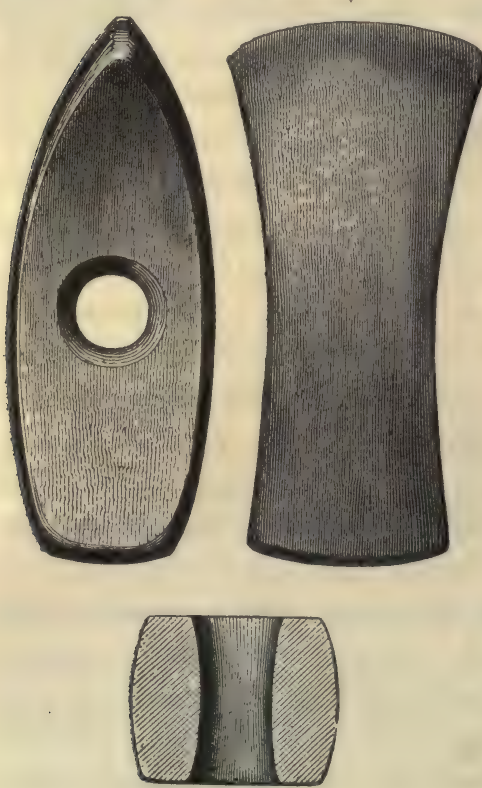

Fig. 115. $\frac{1}{2}$. of the centre, and 8 in. above the natural surface, was a second burnt body, also of an adult, the bones being laid in a round heap about 10 in. in diameter. Nearly coincident with the centre was an oval grave, $8 \frac{1}{2} \mathrm{ft}$. by $6 \mathrm{ft}$., the long diameter being north. west and south-east, and $3 \frac{3}{4} \mathrm{ft}$. deep. At the south-east end of the grave on the bottom, was the body of a young man from 18 to 24 years of age, laid upon the left side, and with the head to S.E., the hands being up to the face. In front of the face was a perforated axe-hammer of green-stone ${ }^{1}$, the edge of which touched the face [fig. 115]; behind the head were two small round scrapers of flint, a flint flake, and three shapeless pieces of jet. The axe-hammer is $4 \frac{1}{4} \mathrm{in}$. long, and $2 \frac{1}{4}$ in. wide at the edge, which

${ }^{1}$ I have met with a second perforated axe-hammer in connection with the body of a man in a grave at Rudstone [No. lxviii], where a bronze knife was associated with it. Though not commonly found, they have occurred in other parts of England accompanying unburnt bodies. Mr. W. C. Borlase discovered a very beautiful one in a barrow at Trevelgue, Cornwall. Nenia Cornubiæ, p. 87. In Wiltshire Sir R. Colt Hoare found one, in company with a bronze pin and several bone implements, in a barrow at Upton Lovel. Ancient Wilts, vol. i. p. 76, pl. v; at Rolston he discovered $a$ skeleton in a grave, and 'on the right side of the head lay a small black stone hatchet.' $l$. $c$., vol. i. p. 174, pl. xx ; at Wilsford he found a skeleton with 'a hammer of dark-coloured stone and a brass celt.' $l$. c., vol. i. p. 209. Mr. Bateman found in a barrow near Hartington, a skeleton, laid on the cover-stones of a grave, near the 
has been purposely squared; the other end being also squared. The hole for the shaft has been drilled from both sides, and is $\frac{7}{8}$ in. wide, slightly narrowing towards the middle. The grave was filled in with earth, and a quantity of charcoal surrounded the body. Amongst the earth in the grave were some bones of a disturbed. body, three potsherds, and a small and imperfect conical button of jet, $\frac{1}{2}$ in. in diameter, having the usual perforation at the back; it had probably fastened the dress of the person whose body had either been displaced in making the grave or by the introduction of a new tenant therein.

Immediately to the north of this grave, and connected with it by an opening $2 \mathrm{ft}$. wide, was a second grave ${ }^{1}$. This was also oval, running north-east by south-west, $6 \mathrm{ft}$. by $4 \frac{1}{2} \mathrm{ft}$. and $3 \mathrm{ft}$. deep. At the north-east side of it and on the bottom, was a body, probably that of a woman, but the bones were so much decayed that nothing more, with respect to their position, could be made out than that the body had been placed in the usual contracted form, and with the head directed to the north-east. Touching the temporal bones, which were stained green by the contact, were two ear-rings of bronze ${ }^{2}$ [fig. 47]. They have been made by beating the one

upper part of which was ' a very elegantly formed axe-head of granite, with a hole for the shaft, and a very fine bronze dagger.' Ten Years' Diggings, p. 24. I possess a very beautifully formed axe-hammer of quartzite [fig. 116], discovered with a skeleton in a cist at Seghill, Northumberland.

${ }^{1}$ A discovery was made in Dorsetshire of two graves which possess much in common with these at Cowlam; the two were found under a barrow, each containing an urn and a deposit of burnt bones. 'We cannot,' says Mr. Warne, 'avoid suggesting that, in this instance, it is not improbable but that they respectively contained the ashes of a chieftain and of his favourite wife. On the present occasion the idea being confirmed by the remarkable fact that the cists communicated with each other, the thin wall of separation being perforated by a cireular opening 3 in. in diameter.' Celtic Tumuli of Dorset-Communications from Personal Friends, p. 8. The same feature has been observed in Peruvian graves. Mr. Hutchinson says that in a large necropolis at Paràrà, in the valley of the Rimac, the graves were connected by a hole 6 in. in diameter. Journ. Anthrop. Inst., vol, iv. p. 448.

${ }^{2}$ Ear-rings have very rarely been met with in barrows, and this, with another pair found in a barrow on Goodmanham Wold [No. cxv], are the only two I have discovered. The following recorded instances have however occurred to me. In a grave below a barrow near Buxton, Derbyshire, 'was a female skeleton ... between the head and the knees was a broken drinking cup.... Both mastoid bones were dyed green from contact with two small pieces of thin bronze, bent in the middle just sufficiently to clasp the edge or lobe of the ear.' Bateman, Ten Years' Diggings, p. 80. In a eist, sunk about $3 \mathrm{ft}$. deep into a natural sandy hillock, near Orton-on-the-Spey, in the railway cutting close to the Fochabers Station, Morayshire, were two gold ear-rings ; one is now in the Museum of the Society of Antiquaries of Scotland. The body, which had been an unburnt one, had gone entirely to decay. The ear-ring is engraved, Proc. Soc. of Ant. of Scotland, vol, viii. p. 30. In Sir W. Wilde's Catalogue of the Antiquities of Gold, in the collection of the Royal Irish Academy, p. 40, fig. 570, is 
end of a piece of bronze flat, and forming the other end into a pinshaped termination. This pin had been passed through the lobe of the ear and then bent round, the other and flat end being bent over it. Thus the ear-ring must have been permanently fixed in the ear. Behind the head were two formless pieces of jet. Under
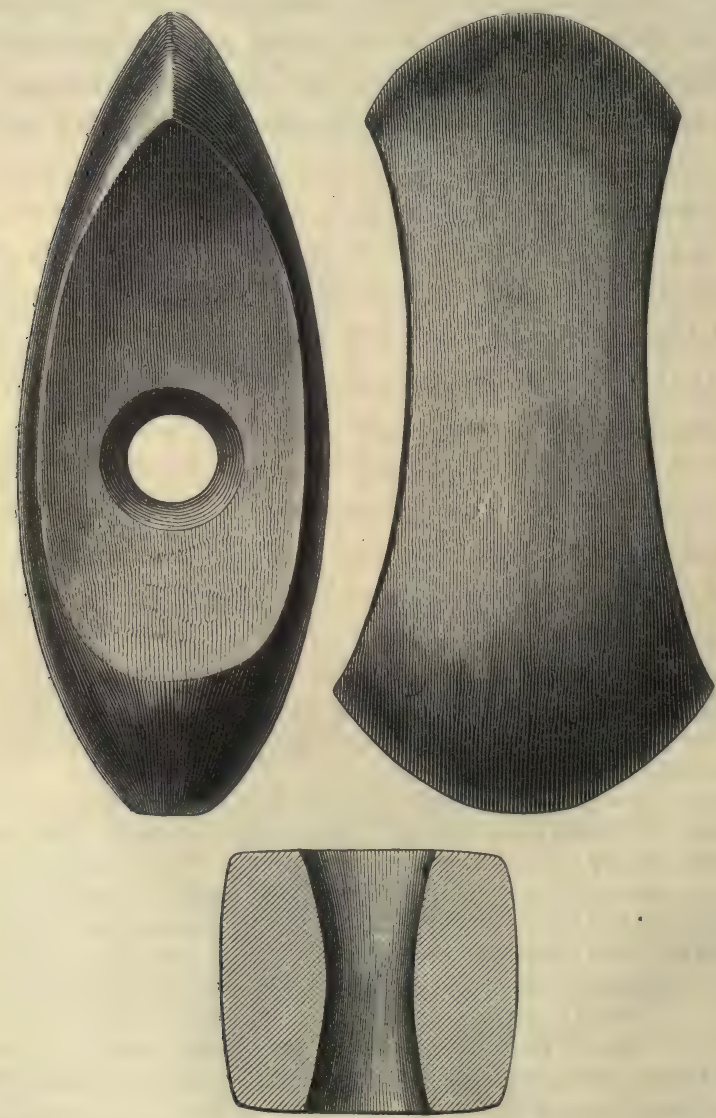

Fig. 116. $\frac{I}{2}$.

the body, and covering the bottom of the grave, was a great quantity of decayed wood, the grave having evidently, as in other cases, been floored with that material.

It would seem probable that in this barrow we have the graves of a man and his wife. The connecting opening between them

an engraving of what is evidently an ear-ring, but which has been, probably since the finding of it, flattened out. It is quite plain, and has a loop at the top. I have seen another, a similar one, in the collection of Mr. Welsh, at Dromore. 
appears to imply some such relationship; and we may fairly assume that the body in contact with which the ear-rings were found was that of a woman: had the bones been less decayed, assumption would of course have given place to certainty. It cannot however be positively asserted that both the burials had taken place at the same time, and thus we are without any very strong presumptive evidence in this case that the wife had been killed on the occasion of her husband's funeral, though it is highly probable that the graves were contemporaneous. This barrow affords another instance of the fact that, after the introduction of bronze, axe-hammers of stone continued to be used.

In the material of the mound, here and there, were many flint cores, flakes, and chippings, as well as two drills; two round scrapers; a broad leaf-shaped arrow-point, all of flint; and a flat circular piece of stone, struck off from a water-rolled quartzite pebble, and which had been used for both polishing and hammering; it is 4 in. in diameter.

LIX. The second barrow was $70 \mathrm{ft}$. in diameter, $1 \frac{1}{2} \mathrm{ft}$. high, and made up of earth and chalk-rubble. Sixteen feet south-south-west of the centre, and upon the natural surface, was the body of a person of full size, laid on the right side, with the head to W., and the hands up to the face. Two feet behind the back of this body was the skull of a child. Touching the face of the child, with the cutting edge towards it, was a narrow chisel-like implement of hone-stone. It is $3 \frac{3}{4}$ in. long, and $\frac{1}{4}$ in. wide at the edge, which is slightly splintered, probably by use; it is ground over the whole surface. Ten feet south-east of the centre was one of those enigmatical holes, so often referred to in earlier pages, $2 \frac{1}{2} \mathrm{ft}$. in diameter and $2 \frac{3}{4} \mathrm{ft}$. deep; in it was some charcoal, and near the top a flint chipping and some bones of a pig. Six feet north-west of the centre was the body of a strongly-made man in middle life, laid on the natural surface, and upon the left side, the head being to $\mathrm{E}$., the right hand to the knees, the fingers however turned up towards the face, the left hand in front of the face, the fingers doubled in. Behind the head was a small round flint scraper and a very well made oval flint knife, 2 in. long and $1 \frac{1}{4} \mathrm{in}$. wide, and carefully flaked over the whole of the convex face. Nine feet west of the centre, and placed upon the natural surface, were parts of the pelvic bones, a clavicle, and several other bones, the remains of a body which had been disturbed, either by rabbit-digging or 
in the act of inserting the body last described. Immediately to the west of that body, the feet of which in fact projected beyond the edge of the excavation now to be mentioned, was an oval grave, which had no doubt been originally central; but the centre, as is not unusual, had afterwards been lost in the process of adding to the dimensions of the mound. It was north-west by south-east, $7 \frac{3}{4} \mathrm{ft}$. by $7 \mathrm{ft}$. and $3 \frac{3}{4} \mathrm{ft}$. deep. At the bottom was the body of a strongly-made man in the middle period of life, laid on the left side, with the head to S.E., and close to the south-east side of the grave; the hands were up to the face. The body seemed to have been surrounded by wood on all sides, but not apparently covered over with it. Outside this wooden casing lay chalk-rubble, but within it, and over the body, there was a good deal of earth mixed with the chalk. The bones seemed to have been removed and afterwards replaced; for the sacrum was close to the left scapula, and there were no vertebræ between the cervical and the lumbar region of the back bone, the bones of the neck and those of the lower part of the back being in immediate connection. In the filling-in of the grave was a well-chipped knife of flint; it is $2 \frac{1}{8}$ in. long, $1 \frac{1}{8}$ in. wide at the broadest part, and comes to a sharper point than is usual in such implements, so as in some degree to partake of the character of a javelin-head.

The circumstances of this interment present some difficulties which are not readily to be explained. Bodies which have been disturbed and replaced are not unfrequently found, but in such cases there is often a cause sufficiently apparent for that disturbance in the presence of an introduced body. In this instance, however, there was nothing of that kind to account for the evidently imperfect and replaced condition of the bones. It would seem as if the body had been interred in some other place in the first instance, and had afterwards been removed to the place where the bones were now found. Amongst the materials of the barrow were a number of flint chippings, flakes, and cores; an oval scraper of the same material which had passed through the fire; two drills, a saw, and two enigmatical articles, one possibly a knife, the other a slingstone.

Parish or Thwing. Ord. Map. xcv. s.w.

LX. The barrow now to be described was situated towards the easternmost range of the wolds, and at a distance of several miles 
from those last noticed. It was in the parish of Thwing, but very near its northern boundary, and close to the village of Wold Newton. About half a mile east from it is a very large barrow, called Willy Howe, which was partly opened by the late Lord Londesborough, but without the discovery of any interment, the centre not having been reached; while about $300 \mathrm{yds}$. to the north is another barrow, much above the ordinary size, though still not to be compared in that respect with Willy Howe.

The barrow was placed nearly on the level of the great wold valley, on a piece of ground sloping down towards the north, and was $70 \mathrm{ft}$. in diameter, $1 \frac{3}{4} \mathrm{ft}$. high, and made of earth. It had lost several feet of its height, through the action of the plough, within man's recollection; and during the course of this lowering some secondary interments had been disturbed. Within the mound, and with a radius of $19 \mathrm{ft}$., was an encircling trench, excavated in the chalk rock to a depth of $2 \frac{1}{2} \mathrm{ft}$., and with a width of $4 \mathrm{ft}$. at the top and $2 \mathrm{ft}$. at the bottom. As the examination of this trench was not carried out through the whole of its length, it is impossible to say whether it was a perfect circle, or, like that on Potter Brompton Wold [No. xxii], was incomplete. The first interment met with was one of a man, laid on the right side, at a point $5 \frac{1}{2} \mathrm{ft}$. eastby-north from the centre, and placed $1 \mathrm{ft}$. above the natural surface. The head pointed to the north, the right hand was down to the knees, the left up to the face. Thirteen feet and a-half west-northwest of the centre was a second body, that of an adult of uncertain sex, laid on the left side, with the head to E.S.E., the right hand up to the face, and the left under the corresponding thigh. It was deposited a little above the natural surface, and there was a good deal of charcoal at the back of the head. At the feet was a 'drinking cup,' the upper part of which had been cut away by the plough. At the centre was a grave, $7 \mathrm{ft}$. in diameter and $4 \mathrm{ft}$. in depth. In the middle of it, $1 \mathrm{ft}$. below the surface-level of the ground and therefore $3 \mathrm{ft}$. above the bottom of the grave, was the body of a person of uncertain sex and in middle life, laid on the left side, with the head to E.S.E., the right hand up to the face, the left under the hips, and having the fingers doubled in. Within the bones of the left hand, and no doubt once held in it, was a small article, so much decayed that nothing could be made out regarding it beyond the fact that wood had entered into its composition. Upon the middle of the right arm were laid two articles of jet, a button [fig. 3], and a ring [fig. 5], the latter placed upon the former. The 
button is very beautifully ornamented with a cross pattern ${ }^{1}$, formed by delicately-engraved lines, and is very similar to one found, together with a ring, in a barrow at Rudstone [No. lxviii]. The ring is also engraved with lines over the entire surface, and has two perforations in the side, similar to that at the back of the button, as shown in the section. The supposed use of these rings, which have been found in Wiltshire and Derbyshire as well as on the wolds, will be found discussed a little further on in the account of the Rudstone barrow. Near the feet of the body were numerous fragments of a 'drinking cup,' which did not however seem to have been deposited with this interment, but with an earlier one, disturbed in the process of inserting the body now under notice; many pieces of the same vessel were met with in various parts of the grave. About $8 \mathrm{in}$. beneath the body was a great quantity of charcoal. No undisturbed skeleton lay at the bottom of the grave; but part of a skull, two femurs, two tibias, and several other bones showed that a former occupant had been displaced, and most probably when the body above noticed was buried. It is strange indeed that the disturbance should have been extended to the very bottom of the grave, when the inserted body had been placed fully $3 \mathrm{ft}$. above that level, and that the bottom of the grave having been reached, the secondary interment should not have been made there. There cannot however be any doubt about the fact that the bones met with at the bottom were not in their natural position,

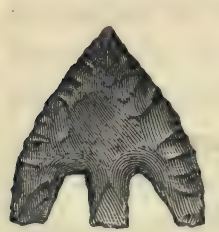

Fig. 117. $\frac{1}{1}$. for they were broken and scattered at wide intervals. In the grave, and not far from the bottom, were three small and very beautifully-made barbed arrow-points of flint [fig. 117], which very possibly had been associated with the primary interment. Amongst the material of the barrow were a few sherds of plain pottery and a single piece of a cinerary urn, a few flint chippings, and several bones of oxen and of goats or sheep, one being the core of an ox-horn.

1 On a bronze vase found, with other things, at Rönninge, Denmark, is a cross, surrounded by a border, the whole pattern being almost identical with that on the button. The vase has at the centre of the cross a dot with two circles round it, a feature which seems almost necessary when such a design is exhibited on a flat surface, but which the conical button naturally presents in its raised central point. Another bronze vase with a similar cross figure upon it was found at Siem, Denmark. The vases are figured in Madsen, Afbildninger. 


\section{Parish of Rudstone. Ord. Map. xciv. N.w.}

LXI. This barrow was situated still further towards the eastern verge of the wold range, and about two miles to the south-east of that last described. It was near two long barrows, the examination of which is elsewhere recorded. It was a solitary one, and placed on the slope of the hill towards the north. In diameter it was $66 \mathrm{ft}$., in height $2 \mathrm{ft}$., and it consisted almost entirely of chalk-rubble. At a distance of $16 \mathrm{ft}$. south-south-east from the centre, and laid upon the natural surface, was a deposit of burnt earth, which extended over a space of several feet.towards the north-east; amongst it were flint chippings, a leaf-shaped flint arrow-point, and a quantity of dark-coloured plain pottery of the same description as that found in other barrows. Twenty-one feet south-east of the centre was an oval hole, running west-south-west by eastnorth-east, $4 \mathrm{ft}$. by $2 \mathrm{ft}$. and $1 \frac{1}{2} \mathrm{ft}$. deep. On the surface of the filling-in had been much burning: in the hole itself were flint chippings, potsherds, and charcoal. Eight feet and a-half southsouth-west of the centre, and about a foot above the natural surface, was the body of a child about 4 years of age, laid on the left side, with the head to E. Eight feet and a-half south-east by east from the centre, and about $10 \mathrm{in}$. above the natural surface, the head being about $4 \mathrm{in}$. higher than the other parts, was the body of a young man from 20 to 25 years of age, laid on the left side, with the head to N.E., and the hands up to the face. Underneath the right tibia were two much worn articles of inferior jet, or some other kind of lignite, which had probably been used in fastening the dress. One of them, which is $\frac{7}{8}$ in. in diameter [fig. 118], is like the ordinary buttons of the period, but pierced at the back from the edge to near the centre, and not, as the buttons usually are, with both piercings within the edge. The other is a ring ${ }^{1}$ [ fig. 119], $1 \frac{1}{4}$ in. wide, and having a hole pierced through from back to front

\footnotetext{
${ }^{1}$ Rings of a similar form, and even ornamented after the same fashion, have been met with in Wiltshire and other parts of England. Sir R. Colt Hoare describes and figures some in Ancient Wilts, vol.i. pp. 172, 289, pl. xiii, xix, xxxiv. Another found at Winterbourn Monkton, in the same county, is figured in Crania Britannica, pl. 58. It was associated with an unburnt male body, three jet buttons, a flint knife, an ovoid stone with flattened ends, and two 'drinking cups.' One figured in Jewitt's Grave Mounds, p. 126, fig. 176, was found in a barrow at Tissington, Derbyshire. A jet ring, apparently of the same kind, associated with an urn, barbed arrow-points of flint and other articles, accompanied a skeleton discovered in 1764 at the Grove, near Tring. Archæol., vol, viii. p. 429, pl, xxx.
} 
running into another pierced through parallel to and just within the edge. It is ornamented on both sides with incised lines, some of which cross so as to form a saltire pattern. Although the position in which these articles were found scarcely seems to indicate the place at which they would be met with if they had been used to fasten the dress in which the man had been buried, still I think that must have been the purpose to which they were ordinarily applied. It will be remarked in the account of one of the barrows presently to be described, as well as in that last under notice [Nos. lx, lxviii], that a somewhat similar ring was found in connection with buttons, both ring and buttons having been placed in the grave, though not having apparently been at the time of the

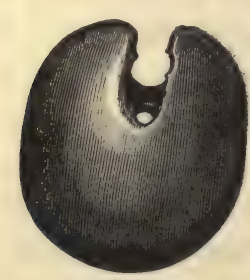

Fig. 118. $\frac{1}{1}$.

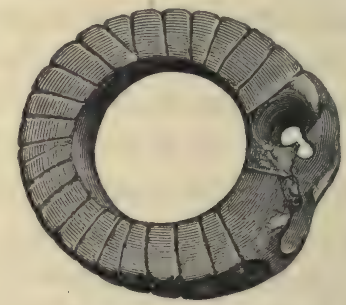

Fig. 119. $\frac{1}{1}$.

burial in use as parts of the dress. At a point $4 \mathrm{ft}$. south-east from the head of the man, and at the same level, was the head of a large adult ox (bos longifrons) and a bone of a young pig. Ten feet east by south from the centre, and upon the natural surface, was the body of a man about 55 years of age, laid on the left side, with the head to N.W., the right hand being up to the face and the left to the knees. Large pieces of chalk were placed over the upper part of the body. Some bones of a disturbed body were found near the body under notice, and also several fragments of broken burnt stone, which showed signs of having been previously used in the process of polishing. Immediately to the west of this body were the disturbed bones of a strongly-made man, deposited in a heap, and having a great deal of charcoal and much burnt earth about them. Underneath these bones was a hole, $1 \mathrm{ft}$. in diameter and $1 \frac{1}{2} \mathrm{ft}$. deep, filled in with earth, amongst which was much charcoal and a human finger-bone. Nine feet east by south from the present centre, but at a point which no doubt had been the original centre, was an oval grave, running west-north-west and east-south-east, $7 \mathrm{ft}$. by $4 \frac{1}{2} \mathrm{ft}$, and $2 \mathrm{ft}$. deep, in which, and near the west-north-west end, 
was the body, probably of a woman, about 30 years of age and $5 \mathrm{ft}$. 7 in. in height, laid on the right side, with the head to W.S.W., and the hands up to the face. Behind the head was a 'drinking' cup.' It is like fig. 120 , but narrower, $7 \frac{7}{8}$ in. high, 5 in. wide at the mouth, and $3 \mathrm{in}$. at the bottom. The ornamentation is simple and occurs at intervals. Immediately below the lip are six grooved lines encircling the vessel, made by a blunt-ended tool drawn over the moist clay. One inch and a-half below these lines are four other encircling lines, made by a notched piece of bone or wood; a blank space of one inch then occurs, beneath which are eight encircling lines, similar to those last mentioned. At the bottom is an encircling zigzag consisting of three parallel lines, one inch and a-half deep, of the same toothed impressions. In advance of but in close contact with the knees was an instrument made from the shed antler of a large red-deer [fig. 34]. It is $19 \mathrm{in}$. long, and has been partly cut and partly burnt and broken through at the points of severance. The brow tine has been broken off, the next one, which is $7 \frac{1}{2}$ in. long, being left. This implement shows, by the rubbed sides and splintered end of the tine, signs of having been much used, and at the part where it has been grasped by the hand it is worn smooth ${ }^{1}$. It would have formed a most efficacious war-club; but it is very doubtful whether that could have been its use. It most probably has served the purpose of a pick as well as of a hoe or cultivator, the smoothness of that part of the tine which would have come most into use seeming to show that it had been long employed amongst some soft material, such as earth. The bruised end of the tine implies use amongst some harder material than earth, and it is by no means improbable that it was the instrument employed in making the grave, and that its purpose having been served it was placed there with its once owner. A somewhat similar occurrence may be noted in the account of the barrow immediately following this, where some large hammer-stones, with which the slabs forming two cists had apparently been split, were laid upon the cover

${ }^{1}$ I discovered a number of implements very similar to this in a pit with galleries in connection with it, one of a large series, at a place called Grime's Graves, near Weeting, Norfolk. The workings in which they were found had been made to obtain flint for the fabrication of instruments of that stone; and the deer's-horn tools had been used for excavating the chalk into which the pits were sunk, and for breaking up the bed of flint. They were in fact picks and hammers combined in one tool. See Journal of Ethnological Society, N. S., vol. ii. p. 419. I possess one found in a grave with a skeleton and 'food vessel' at Tosson, Northumberland; and I have on several oceasions met with splinters from the ends of the tines of antlers, which probably had been broken off in excavating the chalk of which the barrows were in part made. 
of one of the cists. In the grave were several bones of a body which had been disturbed.

Seventeen feet north-east from the centre, and on the surface, was the body, probably of a woman about 55 years of age, laid on the right side, with the head to W.N.W., having the hands in front of the stomach, the fingers of both hands mutually touching. Close behind the back of the hips was a bone-pin, $2 \frac{1}{2} \mathrm{in}$. long, laid upon four flints, all in contact; one of them is a well-made pear-shaped scraper, another a knife-like implement, curved on one edge, and $2 \frac{1}{4}$ in. long, the other two are mere chippings. At the right hand was a triangular-shaped flint, chipped along two of its edges, and probably a scraper; while beneath the knees there lay a large and broad flint flake. At the present centre, which, as noticed above, was about $9 \mathrm{ft}$. north-west by west from the original centre, assuming that point to be marked by the presence of the grave, was a very large quantity of broken pottery, dark-coloured and plain, like that which has been several times noticed already. The fragments were laid upon the natural surface, and appeared to form the remains of what had been originally deposited as two entire vessels. Twelve feet north of the grave, in a hole $14 \mathrm{in}$. in diameter and $1 \frac{1}{2} \mathrm{ft}$. deep, was a burnt body, that of an adult; amongst the bones were several pieces of calcined flint, one of which was evidently part of an implement, as indeed they may all have been, whilst immediately above the bones was an unburnt flint flake very. much worn by use along both edges. Fifteen feet north of the grave was a hole, $1 \mathrm{ft}$. in diameter and the same in depth, in which was a large quantity of charcoal. Fires had evidently been lighted on the natural surface over nearly the whole extent covered by the barrow, and the earth was very much reddened in consequence, burnt chalk being mixed amongst it. Innumerable potsherds of the dark-coloured plain ware and flint chippings were found throughout the barrow, together with two water-rolled quartzite pebbles, which had been used as hammer-stones; a flat stone quite smoothened, probably by the process of rubbing, $6 \frac{1}{4}$ in. by $5 \frac{1}{4}$ in., and $1 \frac{1}{4}$ in. thick; and a round flint scraper. Scattered here and there in the mound were the broken bones of several oxen (los longifrons), some of them young animals, and of four pigs.

On the ridge of the wolds, where the chalk range slopes sharply away to the flat land of Holderness, and near the division between the parishes of Rudstone and Burton Agnes, is a group of barrows 
which follows more or less the line of the crest of the hill. There are first three, very near together and standing the furthest to the west, then a single one, and still more to the east another. Somewhat to the south-east of the last are two long mounds, almost parallel, their northern ends gradually losing themselves in the surface-level, but connected together at their southern ends by another long mound. Then about half a mile to the east-northeast is a very large barrow, while other three are placed at considerable intervals still further to the east. One of this group, that the most towards the west, was almost entirely removed many years ago, when bones are said to have been found in large quantities: part also of one of the long mounds was taken away fifty years since in order to fill in a neighbouring chalk-pit, but finding some human bones, the workmen were stopped, leaving it little disturbed except at one end. I opened seven of the round barrows which remained untouched, and also the long mounds.

The position which the barrows occupy is a very striking one, and must always have been so. The men who raised these funeral mounds looked on the one side over the swelling upland of the wold, bleak, grey, and treeless, their eye taking in on many a distant ridge the burial-places of chiefs of other, though perhaps kindred, tribes; whilst upon an outerop of rock, lifting itself out of the valley just beneath them, rose the lofty monolith which now stands in Rudstone churchyard, even then it may be hoar and lichen-covered, and to them equally speechless, as to its origin and meaning, as it is to ourselves at the present day. Or possibly they might look upon it with traditionary knowledge of its purport, or even have helped to raise it from its bed, where, laid ages before, it told of a mighty cataclysm, and how it had wandered far from its original home, borne over the waves on some buoyant iceship. There it stood, telling them perchance that at its base was laid to his rest a mightier warrior than him they were entombing on the height above; or it may have spoken to them as the symbol of a belief, according to which their lives were regulated, and marked the place it stood upon as holy ground. If they looked to the south there was nothing but a dreary tract of marsh-land, which seemed almost interminable, wherein however, amidst the coarse vegetation and brushwood, the deer and the wild swine had their haunt, and where the beaver made a habitation almost equal in point of construction to those they had themselves the skill to form. Beyond was the sea, as yet enlivened by no sail. 
A very different sight met our eye, when on a bright frosty day in November, with a strong north-east wind sweeping over the hills, we commenced opening the barrows. Below us was, as of old, the mighty stone, ancient of days; but side by side with it stood the shrine of a purer faith, a more humane teaching; whilst round it rose in the clear air from many a chimney the pale blue line of smoke, suggestive of comforts those older people never dreamed of. The cold and cheerless wold, with its flocks of bustards and flights of dotterel, had given place to bright-green cultured fields, and flocks of sheep, and teams of horses turning up the rich brown mould in preparation for the golden sheaves of the next coming harvest. And just as great a change had taken place in the other direction, in what had been the dreary swamps of the old days. There the rough sedges, and rank growth of rush and reed, and the thickets of the water-loving alder and the willow were replaced by fields teeming with agricultural wealth, and diversified by hedgerows broken up by the varying forms of oak and ash and elm-tree. Far away rose the towers of Beverley, the beautiful minster, the creation of a belief and culture which, unlike that of the people who raised the Rudstone, has not died away. Still further in the distance, and dimly seen in the haze of the far-off horizon, were tall chimneys, and the smoke which marked where Hull, with its commerce and manufactures, was in itself more stirring and changing than was all the world with which these ancient wold-dwellers were acquainted. In the distance still, but nearer to us, was the Bay of Bridlington, where hundreds of ships were lying at anchor, kept there by the wind which forbade a course to the north. There they were, laden with the products and goods of many a land, manned by the sons of many a clime, making the whole world akin in purpose and pursuit. As we looked, the thought could not but be stirred-How much have we changed from those who, in the dark past, raised the mound on which we are standing, and which they thought would speak with no faltering tongue to all future time! How much more from us will those have changed who, thousands of years hence, may stand on the self-same spot, and to whom our boasted knowledge may seem as feeble and as strange as we think theirs who laid beside the ashes of the departed the food they thought he needed for the journey to the unknown land.

LXII. The first barrow of this group which I examined was 
that which lies to the north-west of, and nearest to, the long mounds above referred to. It was $66 \mathrm{ft}$. in diameter, and still, though much worn down by the plough, $4 \frac{1}{2} \mathrm{ft}$. high; and was composed of chalk and earth. After cutting away the mound, almost to its whole width, from the south-east side towards the centre, at a distance of $25 \mathrm{ft}$. from that point the barrow was found to be there made entirely of chalk-rubble, a state of things which continued through a space of $9 \mathrm{ft}$., when the chalk gave way to a pile of earth. This pile or mound, $16 \mathrm{ft}$. in diameter, rising gradually from the natural surface of the ground, attained a height of $3 \frac{1}{2} \mathrm{ft}$. at the centre; the upper and outer part of the barrow itself continuing to be formed of chalk. In consequence of the existence of this inner mound of earth, certain signs of the disturbance of the original barrow, to be more fully referred to afterwards, were plainly perceptible.

At a distance of $4 \mathrm{ft}$. south-west of the centre, and at a height of $4 \mathrm{ft}$. above the surface-level of the ground, was a body, probably that of a woman, laid on the left side, with the head to N.W., the right hand up to the face and the left under the hips. In front of the face was a 'food vessel,' and just in advance of the chest a small bronze awl or pricker. The 'food vessel' is rudely made, and somewhat in shape like fig. 72, but having two raised ribs. It is $5 \frac{1}{8} \mathrm{in}$. high, $6 \frac{1}{4} \mathrm{in}$. wide at the mouth, and $2 \frac{5}{8} \mathrm{in}$. at the bottom, and is ornamented over the whole surface with thick looselytwisted thong-impressions arranged more or less in the form of encompassing lines, the two raised ribs having each short inclining lines upon them; the inside of the lip of the rim has a series of similarly-formed short vertical lines upon it. The awl is $1 \frac{1}{2} \mathrm{in}$. long, similar to fig. 40, having a flattened tang for insertion into the handle, which is $\frac{5}{8} \mathrm{in}$. long; the other end is round, and tapers gradually to a sharp point. Six feet north-east of the centre, and within reach of the plough, were some few remains of the body of a large and powerfully-made man in middle life; the only parts of the skull which were left being the frontal bone and the right temporal; the remainder, with many of the other bones of the body, having been destroyed in ploughing. On approaching the centre it was found that a circular cutting, $9 \mathrm{ft}$. in diameter, had been made into the barrow, coinciding exactly with the outline of the grave, which it was afterwards found had been excavated in the underlying chalk. This cutting, which must have been made subsequently to the first erection of the mound, 
was distinctly indicated, not only by the filling-in, consisting of chalk and presenting a marked contrast to the earth through which the cutting passed, but also by the very clear proofs afforded by the sides that the original mound of earth had been eut through, as also that the sides of the cutting had been plastered over with a thin layer of clay, or else that water had been thrown against them, and that then, while still wet, they had been rubbed over with the hand or some smooth instrument. Three feet above the level of the natural surface, and running through the whole extent of the cutting, was a layer of burnt earth and charcoal 5 in. thick, below which and towards the sides of the cutting (although in actual contact with the sides the material was chalk-rubble) the filling-in consisted of earth. The middle portion however, having a diameter of more than $3 \mathrm{ft}$., was pure and loose chalk-grit, which rested on a concave or dish-shaped bed of charcoal about 2 in. in thickness; this layer of charcoal was about $2 \mathrm{ft}$. above the surfacelevel at the sides, but came down almost to that level at the centre. Nine inches above the charcoal, and on the east side of the cutting, was the body of a young child, laid on the left side, with the head to E. by S. More towards the centre of the cutting, at a lower level than the child, and all but resting upon the charcoal, was the body of, probably, a woman, above 55 years of age, which was laid on the left side, with the head to E.N.E., the right hand being across the neck and below the chin, the fingers doubled in, and the left to the knees. In front of the chest, between the face and the knees, were a flint knife and two chippings of flint, and underneath them a bronze drill or awl. The knife is made from a thin outside flake, very carefully chipped all round the edges, the original skin of the nodule being left untouched except at that part; one side is curved, and the other straight; it is $2 \frac{1}{4}$ in. long and $1 \frac{1}{8}$ in. wide. The drill, similar to fig. 39 , is $1 \frac{1}{4}$ in. long, square at the middle, and tapering to a point at each end. To the rear of the hips was a second bronze drill or awl and a flint chipping, and close to them, though nearer to the heels of the body, was a 'drinking-cup.' The drill is like fig. 39 , but much shorter in proportion to its thickness; $\frac{3}{4}$ in. long, square at the middle, and tapering to a point at each end, and had the remains of its wooden handle still left upon it. The 'drinking cup' [fig. 85] is of uncommon pattern, and is covered from top to bottom with encompassing grooved lines, made by a narrow-edged piece of bone. or wood drawn over the moist clay. It is 7 in. high, 6 in. wide at 
the mouth, and $4 \frac{1}{4}$ in. at the bottom. Through the introduction of this body just above noticed, which must have taken place subsequently to the making of the cutting, the body, probably of a man, already interred within its limits had been in part disturbed. He must have been laid with his head to S.E., and on the left side, and some of the bones still remained in their natural position; the left femur, with the knee-cap in situ, was there, showing that the hips must have been about the place occupied by the knees of the woman; the scapula, humerus, radius, and ulna of the left arm and also the scapula of the right were in position; the left hand having been placed under the femur, where the bones composing it were still lying. The head must have been near the place where the second bronze drill and the 'drinking cup' were found, and it is possible that both these articles may have been deposited with the supposed male body; although from the nature of the implement I should be more inclined to connect it with that of the female. Still nearer to the centre of the cutting, just above the level of the natural surface, and resting immediately upon the bed of charcoal mentioned above, was the body of a young woman, from 18 to 24 years of age, laid upon the left side, with the head to E., and both hands up to and in front of the chest. Behind the head was a 'drinking cup' [fig. 82], and under the feet a flint knife. The 'cup' is 6 in. high, 5 in. wide at the mouth, and 3 in. at the bottom. The ornamentation, which is principally made with a notched strip of bone or wood, and partly with a sharp-pointed tool, will be better understood from the figure than from any description. The knife, which has one side curved, is chipped to a very sharp edge on that side; it is $1 \frac{5}{8} \mathrm{in}$. long and $\frac{7}{8}$ in. wide. All these interments had been made within the limits of the cutting, and one of them appears to have been even subsequent to the cutting itself. Amongst the filling-in of the cutting were found, scattered about, the fragments of a 'drinking-cup,' the bones, some entire some broken, of more than one body, and a bone-pin, all of which must be referred to interments which had been disturbed in making the cutting. The general character of the ornamentation upon the fragments of the vessel just named is identical with that of the other 'drinking-cups' which accompanied the undisturbed and later interments; and it is therefore evident that no great length of time had elapsed between the erection of the barrow and the subsequent burials in it; or else that during the more considerable period of time, if that may be assumed, no 
change had taken place in the form and ornamentation of sepulchral vessels. It is however, on the whole, more probable that the secondary interments were of people who had been near relatives of those over whom the mound was first raised, and that the disturbance of the barrow for these took place at no great interval of time after it was first thrown up.

At a distance of $4 \mathrm{ft}$. east of the edge of this cutting, and $2 \mathrm{ft}$. above the natural surface, were found some fragments of a human skull, which seemed to have formed no part of a body buried entire at the place, but rather to have been laid there as fragmentary bones; there being no signs of any disturbance of the mound at the point in question to account for them as parts of a body which had ever been removed.

At the centre, and conterminous with the circuit of the cutting so often before mentioned, was a grave $9 \mathrm{ft}$. in diameter, excavated in the chalk, which it was evident had either been first made, or else enlarged when the eutting itself was sunk through the barrow. This was made clear not only by the fact that the sides of the cutting through the mound and those of the grave were conterminous, but also from the remains of disturbed and broken-up bones and vases which occurred at various places throughout the whole of the filling-in of the excavation, from the level of the surface of the ground downwards. The upper part of the grave for a depth of $2 \mathrm{ft}$., on the south side, was filled in with earth; while, on the north side, it was filled in with pure chalk to the same depth. Below this was chalk with some admixture of earth. At a depth of $4 \frac{1}{2} \mathrm{ft}$. four flags of oolitic sandstone were met with, laid flat, and filling up the greater part of the area of the grave. The upper one was $2 \mathrm{ft}$. by $1 \mathrm{ft}$. $10 \mathrm{in}$., and was placed upon the edge of another, which was $3 \mathrm{ft} .10 \mathrm{in}$. by $3 \mathrm{ft} .6 \mathrm{in}$; the second of these flags overlaid a third, $3 \mathrm{ft} .8 \mathrm{in}$. by $3 \mathrm{ft} .3 \mathrm{in}$., both showing very distinct marks of fire upon the upper surface, the burning being more evident upon the lower one; to the south-east of these was the fourth stone, $4 \mathrm{ft}$. $8 \mathrm{in}$. by $1 \mathrm{ft}$. $9 \mathrm{in}$; and on the south side of the grave, but standing on their edges, with a slight inclination towards the side, were two similar slabs, one of them $2 \mathrm{ft}$. broad, the other $2 \mathrm{ft} .4 \mathrm{in}$., the first being $2 \mathrm{ft} .2 \mathrm{in}$. in length, and the other $3 \mathrm{ft} .4 \mathrm{in}$. These last stones rested at the same level as the four which were laid flat. Under these stones the grave was filled in with earth, and on the bottom, $6 \mathrm{ft}$. below the stones and $10 \frac{1}{2} \mathrm{ft}$. below the surface of the ground, were placed two eists, made of 
slabs of stone like those first named. The sides of the grave, it should be remarked, appeared to have been plastered in the same way as those of the cutting above it, and presented a similar smooth surface.

The cists ran through the middle of the grave in a direction north-north-west by south-south-east; and the ends of the cists were in contact with the sides of the grave. The first cist, or that to the north, was $3 \mathrm{ft} .10 \mathrm{in}$. long by $2 \mathrm{ft} .1 \mathrm{in}$. wide, and $1 \mathrm{ft} .8 \mathrm{in}$. deep; it was formed of one slab on the east side, $4 \mathrm{ft} .7 \mathrm{in}$. long, one on the west, $4 \frac{1}{2} \mathrm{ft}$. long, and two end slabs, each of a length rather exceeding the width of the cist; it had two slabs on the bottom, one $2 \mathrm{ft} .10 \mathrm{in}$. long, the other $1 \mathrm{ft} .2 \mathrm{in}$.; while the cover-stone was rather larger than the area of the cist, only, as it was broken in pieces in the effort of raising it, the exact dimensions could not be taken. The same also must be said of the cover of the second cist. Between the two cists was a space of $10 \mathrm{in}$. in width, the boundary of which on the one side was formed by the east sidestone of the first cist, on the other by the west side-stone of the second cist. This cist was $3 \mathrm{ft} .8 \mathrm{in}$. long by $2 \mathrm{ft} .7 \mathrm{in}$. wide, and $1 \mathrm{ft} .10 \mathrm{in}$. deep; it was formed by one slab on the west side, $4 \mathrm{ft} .11 \mathrm{in}$. long, one on the east side, $3 \mathrm{ft} .10 \mathrm{in}$. long, and two slabs at each end, overlapping each other; the bottom was made with one slab, whilst another formed the cover. Over the cists for a depth of 4 in. was a layer of chalk, the rest of the filling-in, as noticed above, consisting of earth. Just above it, at the west and east sides of the south end of the cover of the second cist, though not actually in contact with it, were two large water-rolled pebbles of whinstone, of a reniform shape, but still further adapted for the affixing of a handle, or for being the more readily held in the hand, by having a part of their substance carefully chipped away about the middle. The edges of these chipped places have been hammered to make them smooth; either to prevent their injuring the hand, if intended to be used in that way, or else to preserve the fastening of the handle from being abraded, if the intention was to facilitate their use by such an appendage. They weigh respectively $7 \mathrm{lb} .4 \mathrm{oz}$. and $5 \mathrm{lb} .6 \mathrm{oz}^{1}$. In the first cist, at the south

1 Mr. George Petrie met with more than one instance in Orkney where a somewhat similar stone implement was placed at the end of cists containing skeletons ; in one of these cases a vase was associated with the body. Proc. Soc. of Ant. of Scotland, vol. vii. p. 135. Mr. Anderson, in a paper on the excavation of cairns in Caithness, $l$. $c$., vol. ix. p. 294, says, "The bottom of the cist and the two end stones had been roughly dressed to fit, by blows applied along the edges of the slabs on opposite sides. On the 
end; was laid the body of an aged man, on the left side, the head being to S., and with both the hands up to the face. Behind his head, and in the south-east corner of the cist, was a 'drinking cup,' standing upright; and in front of the face an oblong piece of ironstone, which had been subjected to the action of fire. A smaller piece of the same kind of stone, also burnt, was placed outside the end of each cist, as well as in the space spoken of above as intervening between them. In front of the feet of the man was the body of a very young child, and before the middle part of the leg was another and still younger child. The 'drinking cup,' similar in shape and ornamentation to fig. 120, but narrower, is $7 \frac{3}{4}$ in. high, 5 in. wide at the mouth, and 3 in. at the bottom. The ornamentation, which covers the whole surface to within one inch from the bottom, is composed principally of series of encircling lines, varied by bands of lines inclining in reversed directions, of bands of lozenges and of plain bands; the impressions being those of a notched piece of bone or wood. In the centre of the second eist was a deposit of burnt bones, laid in an oval heap, $19 \mathrm{in}$. by $12 \mathrm{in}$; the principal part of the deposit consisted of the bones of an adult male, with some few of another human body, and three fragments from the interior of the frontal sinus of an ox. In the south-east corner of the cist was placed a 'drinking cup,' standing upright, which, like that in the first cist, contained some darkcoloured matter, the remains, it is to be presumed, of whatever had been originally deposited in them ${ }^{1}$. The 'drinking cup' is $8 \frac{1}{2}$ in. high, $6 \frac{1}{4}$ in. wide at the mouth, and $3 \frac{3}{8}$ in. at the bottom [fig. 120]. This fine specimen of the class of vessel to which it belongs is very beautifully ornamented, the nature of which will best be understood from the engraving; as in the preceding vessel, the pattern has all been made by the application of a notched piece of bone or wood. On the east side of the grave and between it and the side of the first cist, $4 \mathrm{in}$. above the bottom, was a second burnt body; that of a strongly-made adult man; and about $1 \mathrm{ft}$. to the southsouth-east of the deposit of bones was a 'drinking cup,' which is in shape like fig. 120, but narrower though widening more at the mouth, $7 \frac{3}{1}$ in. high, $5 \frac{1}{2}$ in. wide at the mouth, and $2 \frac{7}{8}$ in.

middle of the covering-slab we found an oblong water-rolled stone, naturally shaped, but which bears marks on both its ends of having been used as a hammer, and which seemed to be the hammer with which the coffin was made.'

${ }_{1}$ This dark-coloured matter has been shown by analysis to contain a large quantity of nitrogen, and is therefore probably of animal origin. 
at the bottom. The pattern has for the most part been made by the use of a similarly notched piece of bone or wood as on the two preceding vessels. Just below the rim is a band of vertical lines, with a vandyked edge at the top nearly one inch deep; then come six encircling lines made by a pointed tool

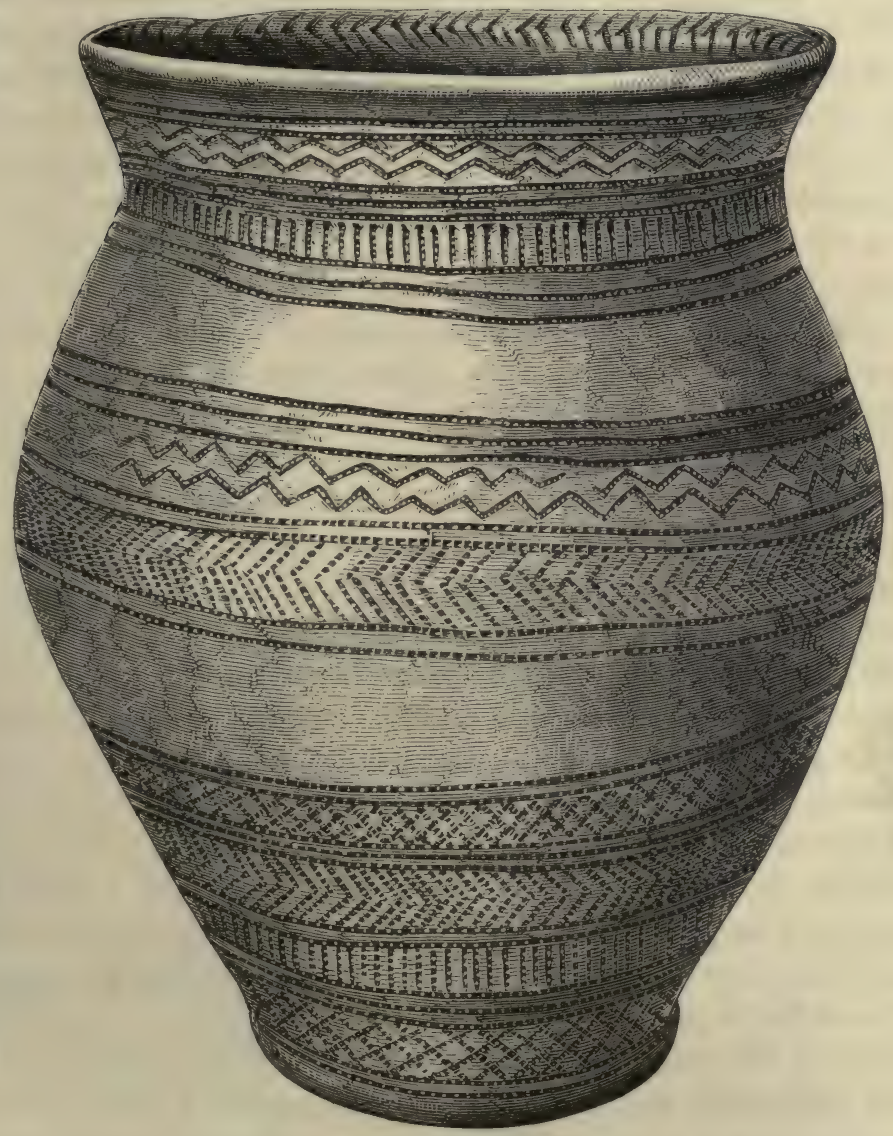

Fig. 120. $\frac{1}{2}$,

drawn over the moist clay; then for a depth of 2 in. is a pattern exactly like the upper part of fig. 82 , having three encircling lines below; then for one inch in depth is the same pattern as on fig. 82, then three encircling lines, with the same pattern again below them; then come five encircling lines, then a pattern one inch deep somewhat like that on fig. 86 , and then three encircling lines just above the bottom. Immediately above the burnt bones, 
though not in actual contact with them, was a water-rolled pebble of whinstone, similar in shape to those found on the lid of the second cist, but which had not, like them, been chipped at the narrowest part; it weighs $6 \mathrm{lb} .8 \mathrm{oz}$. It is difficult to believe that these rude and cumbrous implements can have served more than a mere temporary purpose; nor is there any appearance about them, beyond a slight abrasion at the end of one, of their having been used. They were probably the instruments by aid of which the slabs were split to fit them for their places in the construction of the cists, and when they had answered that end, they had been deposited with the bodies at the burial of which they had thus been made serviceable. A somewhat similar instance, where the implement apparently used in making the grave had been placed in it, has been mentioned in the account of the last preceding barrow. The sandstone slabs, some of which showed by their peculiarly weathered surface that they had been taken from the sea-beach, could not have been obtained nearer than Filey Brigg, which is about twelve miles distant from the barrow. The transportation of them thence must have been a work of time and labour, especially to people who could have possessed nothing but the simplest appliances for effecting the carriage of weighty objects. Still there would be no unsurmountable difficulty in the way of bringing them over the wolds from Filey, and their size and number are as nothing compared to what we see in other places as constituting parts of erections which must be attributed to the early inhabitants of Britain. For instance, the moving of the great monolith in Rudstone churehyard, even supposing it had been brought to its present site from the distance of only a mile or two, must have been a much more difficult operation than the bringing of the slabs in question over a space of twelve miles.

This is the only instance throughout my examination of the wold barrows in which I have met with anything like a cist: in fact, the absence of suitable stone is in itself sufficient to account for such a mode of burial not having been adopted, common as it is found to be in all districts where a supply of stone adapted to such a purpose is met with. And indeed it seems strange in this case, where a deep grave had been sunk into the chalk, that it should have been considered necessary to undertake all the additional toil of constructing cists within the grave, when such constructions seemed in no way necessary for the protection of the interred bodies. I have seen in limestone districts something 
which may be considered more or less analogous; namely, that a hollow has been first made in the limestone rock, and then lined with slabs of sandstone. Such cases speak very emphatically of the great care which was shown in the burials of these people, and of the importance they attached to the due disposal of their dead; to which indeed the entire system of barrow-burial testifies in the strongest way. This particular case appears moreover to point to the eminent position which must have been occupied amongst the tribe by the tenant of a tomb which had been constructed at so great an amount of labour.

To proceed with the description. Just west of the second cist were some bones of a full-grown person, as also some of a young child; but they were merely fragmentary, and probably the remains of disturbed bodies, numerous other and like relics of which were found, as has been noticed, in the filling-in of the grave. From the discovery of these remains of disturbed bodies and of the fragments of a 'drinking cup,' not only in the filling-in of the grave but also in that of the cutting through the barrow above the grave, it seems quite impossible to consider the cist burials as the primary ones. This conclusion is further confirmed by the fact that the cutting through the barrow and the outline of the grave itself were conterminous; for it is scarcely likely that, assuming the grave to be co-existent with the formation of the barrow, any cutting afterwards made into the mound from above should have coincided exactly with the dimensions and outline of a pre-existing grave. I therefore regard the grave and the cists it contained as secondary: though they probably received the bodies of people of as great importance as the person or persons over whom the barrow was originally raised. Is it possible to form any reasonable conjecture as to the relative positions of these people when living? If it had not been for the great care bestowed on the second cist burial, and the 'drinking cups' accompanying the two burnt bodies, we might have concluded that there was contained in the first cist the body of a man, probably the chief of the tribe, together with two of his children; and that the burnt bones within the second eist and those outside the first comprised the remains of slaves or dependants who, with the children, had been killed at the funeral. Nor perhaps are the facts inconsistent with this view. The five burials had evidently been made at once, and it is scarcely possible to conceive in this, any more than in previously mentioned instances, that all the persons buried had died at one and the same 
time, in the ordinary course of nature. It has been suggested that raembers of a family, chancing to die before its head, might be burnt at the time of their decease, and their ashes preserved until the period of his death, when they would be buried in company with his body. This might have been the case in the instances now under consideration, so far as the burnt bodies are eoncerned; but it does not account for the presence of the unburnt bones of the children. Besides, in other instances, several bodies have been found, all unburnt, but certainly all buried at the same time; and of course it would not be possible to keep dead bodies for any length of time without first burning them, or at least reducing them to the condition of mummies or skeletons. Moreover, if we suppose that such bodies might have been placed in some receptacle until the time arrived for their final deposition in the grave, the bones could scarcely have been found as in many cases we really do find them in the barrowsnamely, in such relative positions as to afford the most certain evidence that they must still have been invested with their covering of flesh and with the ligaments attached when finally laid to rest. It will have been observed that in one of the Cowlam barrows [No. lvii], and in one of those on Willerby Wold [No. xxxiii], as well as in others, bodies were discovered whieh, from the irregular way in which the bones were disposed, showed that they had been removed from a previous place of deposit; and such facts might appear to favour the view that in some instances persons were not buried at the period of their death, but were kept until what was considered a more suitable, or the proper, time had arrived for the performance of the rite. Certainly such an interpretation may be given of the facts as they are presented in some barrows; but there is another explanation to be given of the facts as presented in others. It is probable that these improperly jointed and sometimes incomplete skeletons are the remains of disturbed bodies, which had been replaced with a certain amount of care, though with little anatomical skill, this careful re-interment being possibly due to their being near of kin to the person the introduction of whose body into the barrow had caused the disturbance. Taking all the facts into consideration, I am inclined to think that in many of the cases where we find several bodies, either burnt or unburnt, or both, which have all been buried at the same time, some of them are those of wives, children, or slaves who had been put to death at the funeral of the chief or other person with whose body they are associated in the grave. 
The finding of 'drinking cups' in connection with burials after cremation is of very infrequent occurrence : indeed, I do not know of any previous instance on the wolds in which such a conjunction has been observed.

Amongst the material of the barrow were several animal bones ${ }^{1}$; many flint chippings, two round scrapers, six saws, and a knife, all of flint. Besides these articles there was a pounder or rubbingstone [fig. 13]; it is formed from a water-rolled quartzite pebble, of flattened globular shape, and shows signs of having been a long time in use, as it is worn into a great number of facets all round the edge. Many sherds of pottery were found scattered throughout the whole of the mound.

LXIII. The next barrow of this group opened by me was a little more than 200 yards west-south-west of the last. It was $78 \mathrm{ft}$. in diameter, and still $6 \frac{\mathrm{x}}{2} \mathrm{ft}$. high, notwithstanding the action of the plough, and was principally formed of earth, having however some chalk rubble on the south side near the surface of the mound, and layers of chalk in other parts. The whole of the barrow on the south and east sides, with a considerable portion of the north side, was turned over to beyond the centre, but the remaining section was not disturbed: I cannot therefore speak positively, as if the fact had been ascertained, that the trench about to be described went entirely round the mound in its circuit; but from the analogy of some other similar trenches met with in my researches, I may say that I have little doubt that it did so $^{2}$. The trench was drawn with a radius which varied from $18 \mathrm{ft}$. to $27 \mathrm{ft}$. from the centre, measuring from the inside edge; as it extended towards the east side the radius lengthened, and at a point east-south-east from the centre it attained the length of $29 \mathrm{ft}$. It was about $4 \mathrm{ft}$. wide at the top, varying between $2 \mathrm{ft}$. and $3 \mathrm{ft}$. in width at the bottom, and was sunk into the chalk rock to a depth of $3 \frac{1}{2} \mathrm{ft}$. The measure-

1 The animal bones, those which had contained marrow being split open, comprised a large number of bos longifrons, and a single bone of a pig; all the animals had been adults with the exception of one of the oxen; a single ox bone was calcined.

${ }^{2}$ I have met with three other instances where a trench was found surrounding the inner portion of a barrow, one on Potter Brompton Wold [No. xxii], another in one of the Weaverthorpe series [No. xlvii], and the third at Thwing [No. Ix]. A somewhat similar feature was discovered in a barrow in the parish of Edderstone, Rossshire, where a ditch, $3 \mathrm{ft}$. deep, seemed to surround the mound. In the ditch was found an urn containing burnt bones and some pieces of bronze. At the centre of the berrow was a cist, with burnt bones, a piece of bronze, apparently the point of a blade, and a glass bead. Proc. Soc. of Ant. Scotland, vol. v. p. 311. 
ments given place it $14 \mathrm{ft}$., more or less, within the outer circumference of the barrow. It was formed into compartments by narrow divisions of chalk left undisturbed ${ }^{1}$; these, so far as the trench was examined, proved to be four in number, each $1 \frac{1}{2} \mathrm{ft}$. wide and $2 \mathrm{ft}$. in height, and consequently not reaching to the level of the natural surface. The distances between them varied: one of them, lying south-west by west from the centre, being $16 \mathrm{ft}$. from the next, which lay south-south-west from the centre; this in its turn being 14 ft. from its other neighbour, which was south-south-east from the same point, and $12 \mathrm{ft}$. from the fourth, which lay south-east of the centre. Immediately to the south of the south-south-east division was an extension of the trench, in the shape of an oval hole, lying north-west by south-east, $5 \frac{1}{2} \mathrm{ft}$. long, $4 \frac{1}{2} \mathrm{ft}$. wide, and $2 \frac{1}{2} \mathrm{ft}$. deep, which had in it some flint chippings and charcoal. At various points the trench itself contained animal bones, flint chippings, and a few disturbed human bones.

There were some very peculiar features in this barrow, such as I have not often met with, and which are not easy of explanation. Within the circuit of the trench and extending over it, at the level of the natural surface, was a stratum of what seemed to be puddled earth, $8 \mathrm{in}$. in thickness. I think there can be no doubt that, in one way or another, designedly or otherwise, it had been tempered with water, for no earth that had not gone through that process could have been so hard and compact ${ }^{2}$. Above this was a layer of fine chalk gravel, 3 in. to $6 \mathrm{in}$. thick, then another layer of tempered earth $9 \mathrm{in}$. thick, then $3 \mathrm{in}$. to $7 \mathrm{in}$. of chalk, and then the ordinary earth of which the bulk of the mound was composed. At

1 This appears to correspond with some openings which existed in an encircling wall within a cairn at Spottiswood, Berwickshire. The cairn contained deposits of burnt bones and an urn. Proc. Soc. Ant. Scotland, vol. v. p. 222.

${ }^{2}$ I have met with the same kind of hardened earth in another barrow of this group [No. lxviii], described further on, and in a barrow at Weaverthorpe [No. xlvii]. Mr. Bateman mentions some instances where 'tempered earth' had been used in the Derbyshire barrows, by which expression I suppose he means something like what was noticed in this mound. Ten Years' Diggings, pp. 34, 36. The same condition of earth has been observed in barrows in France. 'Sous ces deux mètres de pierres mélangées de gravier et de terreau, nous avons rencontré une calotte très compacte de terre glaise battue, épaisse de $0^{\mathrm{m}}, 15$ à $0^{\mathrm{m}}, 20$, uniformément répandue sur la construction sous-jacente, comme pour la mieux défendre des influences extérieures, et notamment de l'infiltration des eaux. Le même procédé a été, vous le savez, souvent employé pour le même but au profit des tumulus Armoricains, témoin le fameux Mané-Lud.' Les Fouilles du Magny-Lambert (Côte d'Or)-Revue Archéologique, N. S., vol. xxiv. p. 354. The probable explanation seems to be that these barrows were erected during very wet weather, and that the soil became puddled by the constant trampling of the persons employed in throwing it up when in a wet state. 
first sight it seemed as if the original surface-soil had been removed entirely, for the lowermost layer of tempered earth rested immediately upon the chalk rock, but I am inclined to think that this condition was caused (as suggested in the preceding note) by the accidental puddling of the old surface-mould during the throwing up of the barrow in wet weather.

To the south of the centre, and with its edge resting on the inner edge of the trench (which at that point was $27 \mathrm{ft}$. from the centre), was a smaller mound, enclosed within the larger. It was placed upon a natural swell of the chalk, and was $21 \mathrm{ft}$. in diameter and $2 \mathrm{ft}$. high, and made of tempered earth, then chalk, and then tempered earth again. Contrary to expectation there was no burial beneath it; nor was there anything to indicate why the ordinary process of throwing up the barrow had been deviated from at this point. It must have been made before the larger mound was raised over it, and it might naturally have been expected to cover an interment, but I have met with other instances where a smaller mound within a larger has proved to be equally destitute of a burial beneath it. Just over the trench, but at a height of $3 \mathrm{ft}$. above its surface, and at a distance of $30 \mathrm{ft}$. east-south-east from the centre, was the body of probably a man, laid on the right side, with the head to S.S.W. It was very much decayed, and being not far below the surface of the barrow, it had been partly destroyed, probably in the operation of driving in stakes for sheep-nets. No part of the head was left, with the exception of the lower jaw. The vertebral column, the pelvic bones, and the femurs were lying undisturbed, but the tibias, \&c. were gone. At a point $16 \mathrm{ft}$. southeast-by-east from the centre, in a hollow $3 \mathrm{ft}$. in diameter, and descending 4 in. below the level of the natural surface, was the body of a very young child, laid on the right side, and with the head to $\mathrm{S}$. Before the face was a small and somewhat rudely made 'drinking cup;' it is in shape like fig. $122,5 \frac{7}{8}$ in. high, $3 \frac{3}{4}$ in. wide at the mouth, and $2 \frac{5}{8}$ in. at the bottom. The pattern, which has been made by a notched instrument of bone or wood, consists of four encircling lines in pairs at the top of the cup, having a plain slightly-projecting rib between each pair; below these are triangular-shaped figures, $1 \mathrm{in}$. high, touching each other at the base, and filled in with a reticulated pattern; then come three encircling lines, then a plain band half-an-inch deep, then five encircling lines, then a zigzag band of two lines, and then four encireling lines at the bottom. Eleven feet and a-half south-east of the 
centre, and $1 \mathrm{ft}$. above the surface-level, was the body of a woman in the middle period of life, lying on the right side, with the head to N.E. by E. ; the right hand was up to the face, the left extended to the knees and having the fingers doubled in; behind the head was a bone pin, $2 \frac{1}{2}$ in. long. A few inches higher than this body, and over it, was part of the lower jaw of a child. Above the body was a layer of chalk $14 \mathrm{in}$. thick, which indeed extended throughout the barrow within the limits of the trench at this part. Six feet south-south-east of the centre, and 16 in. above the surface, laid in a circular hollow cut through the layer of chalk just above mentioned, and resting on the tempered earth beneath, was the body of probably an aged woman, laid on the left side, and with the head to E.S.E., the right hand, having the fingers doubled in, being between the face and the knees, and the left hand towards the hips. Almost precisely between this last body and that of the firstmentioned woman, at a point $7 \frac{1}{2} \mathrm{ft}$. south-east-by-east from the centre, and at a height of $1 \mathrm{ft} .8 \mathrm{in}$. above the surface, was another body, that of a young person, laid on the right side, the head to S. by W., the hands up to the face. Four feet south of the centre, and placed at the surface-level, was the body of a man about 55 years of age, laid on the left side, with the head to S.E. by S., the right hand being to the knees and the left up to the face. Three inches higher than this body, and $1 \mathrm{ft}$. to the east of its head but probably having no immediate connection with it, was an oval tool-stone [fig. 16], with a perforated hole at the centre, which has been drilled from each side. It is $2 \frac{1}{4} \mathrm{in}$. by $2 \mathrm{in}$. and $\frac{7}{8}$ in. thick, the perforation widening from $\frac{1}{4}$ in. at the middle part to $\frac{3}{4}$ in. at each surface. Directly over the last body, and $1 \mathrm{ft}$. higher than it, was another body, that of a child in the period of the first dentition, laid on the left side, with the head to N. It was too much decayed to allow of the position of the hands being noted. Four feet east of a central grave, of which I am about to speak, and $2 \frac{1}{2} \mathrm{ft}$. above the surface-level, were a human radius and some portions of a 'drinking eup ;' they were lying almost immediately above the body of a man, past the middle period of life, placed on the natural surface, and on the right side, with the head to N.N.W., and the hands in front of the knees. On the east side, and within the compass of the grave, but at a height of $6 \mathrm{in}$. above the level of the natural surface, was the body of a man about 55 years of age, laid on the right side, with the head to $W$., the right hand being under the head, and the left, the fingers of which were doubled in, up to the 
middle of the humerus of the right arm. In front of the face there was a 'food vessel,' while just between it and the face was a most beautiful barbed arrow-point of flint [fig. 29], which was lying with its point away from the body. It might be surmised from its position, and that of the man's right hand, that the shaft had been held in the hand when he was arranged for his last rest. Close by the arrow-point was part of an ammonite, which, from its worn appearance, may in life have been carried as a charm, and in death deposited, as such, with its owner. 'This body had been laid between two planks, apparently of willow; they were each $3 \frac{1}{2} \mathrm{ft}$. long, and placed $1 \frac{x}{2} \mathrm{ft}$. apart. There had, however, been no plank either above or beneath the body. In immediate contact with the body was a good deal of charcoal, which indeed was abundant in connection with all the interments in this barrow. The 'food vessel' is somewhat in shape like fig. 71 , but wider in proportion to the height, and having five perforated ears at the shoulder. It is $4_{\frac{3}{4}}^{3}$ in. high, $6 \frac{1}{2}$ in. wide at the mouth, and $2 \frac{3}{4}$ in. at the bottom. The inside of the lip of the rim has two pairs of encompassing lines of thong-impressions, the space between the pairs being plain. The edge of the rim has one pair of similar lines, and the shoulder has two pairs, having between them a band of herring-bone pattern, made with a sharp-pointed tool; the lines forming the pairs are placed close together, and have been made by impressions of twisted-thong. Below the shoulder the vase is plain.

The grave at the centre of the barrow, of which I now proceed to speak, was oval, east and west in direction, $6 \frac{1}{2} \mathrm{ft}$. long by $5 \frac{1}{2} \mathrm{ft}$. in width. As in the case of the last preceding barrow, the mound had been cut through, and the cutting was conterminous with the grave, while in the filling-in of the grave itself and of the cutting above it were fragments of a 'drinking cup', and the broken and disturbed bones of at least two bodies, one being that of a very young child. In the case of this barrow, as also in that of the last one, it was quite evident that the burials in the grave were secondary ones; and it is also equally impossible in either case to say whether or not a grave had existed at the first formation of the barrow. Judging however from the general nature of the wold barrows, it is almost certain that there had been one, which was possibly enlarged when the time came for depositing the secondary burials. At the centre of the grave, and $3 \frac{1}{2} \mathrm{ft}$. below the surface-level, were the remains of the burnt body of an old woman, laid in a round heap, $13 \mathrm{in}$. in diameter, having the calcined point of a bone pin 
amongst them. At the bottom of the grave, which was $5 \mathrm{ft}$. deep, and on the east side of it, was the body of an adult of uncertain sex, laid in a shallow dish-shaped hollow, lined with burnt matter and charcoal. The body was placed on the left side, with the head to S.E., the right hand up to the face and the left under the hips. Behind the back, but beyond the limits of the hollow in which the body was deposited, was a very beautifully formed and exceedingly thin oval flint scraper. I scarcely think it had been deposited with the body, but that it is rather to be regarded as one of those implements which are casually found in barrows, and of which a very large number had been scattered in this grave-mound; it may however have been originally associated with one of the bodies disturbed in depositing the secondary interments. It is $2 \frac{1}{2} \mathrm{in}$. long, in shape something like a spear-point, and has been carefully chipped all round the edge.

Sixteen feet east-by-north of the centre, measuring from centre to centre, was a mound of chalk, $17 \mathrm{ft}$. in diameter and $3 \mathrm{ft}$. high, forming a small barrow within the larger one. Under it, at the centre and upon the natural surface, was the body of a woman, of about the middle period of life, laid on the left side, the head to S. by E., the right hand being under the head, the left in the direction of the head but having the fingers pointing towards the elbow of the right arm. The body was very slightly contracted, the back being perfectly straight, and the knees, instead of being drawn up towards the face, were turned in the opposite direction, as if the body, having been laid upon the left side, had been held firm in that position, whilst the legs were violently wrenched round until they were brought into the position they would have occupied had the body been laid upon the right side. The knees were about $8 \mathrm{in}$. higher than the back. Twelve feet north-east of the centre, and still under the smaller mound, and upon the surface-level, was the body of another woman, of about the same age as the last, laid upon the left side, with the head to N.W.; the right hand was in front of the knees, which, as in the former instance, were higher than the rest of the body, the left hand being under the hips. About $1 \mathrm{ft}$. north of the edge of the grave before described was a hole, excavated in the chalk, $6 \mathrm{ft}$. in diameter and $5 \mathrm{ft}$. deep. It was filled in with chalk rubble, and contained nothing beyond the filling-in, except two flint chippings and a large quantity of charcoal. Twentythree feet south of the centre were some fragments of a cinerary urn; and $18 \mathrm{ft}$. south-south-west of the same point were some 
broken human bones, showing that the barrow had been disturbed in other places as well as at the centre.

In the material of the mound there were numerous animal bones $^{1}$ and chippings of flint; as also a very large quantity of implements of stone and flint, comprising one quartzite hammerstone; three pounders or rubbers; a willow-leaf-shaped arrowpoint; seven saws; two drills, one of them curved; thirteen round scrapers [figs. 17, 121] (one of them being very fine and large, and another showing in its smoothened edge the signs of longcontinued use); three long scrapers (one 3 in. in length); four knives; three flat circular-shaped flints, such as have usually been called 'sling-stones;' and four other worked flints, of which it is not easy to say what they have been intended for. There were also three fragments of stone axes, one of them a large chipping from a hone-stone implement, another a part of the edge of one of greenstone, and the

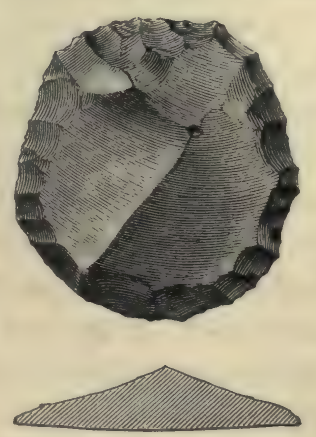

Fig. 121. $\frac{1}{2}$. third a piece out of the middle of the edge of a very sharp flint axe. A ring of some kind of lignite, brownish-black in colour, was met with $9 \mathrm{ft}$. south-west of the centre and $2 \mathrm{ft}$. above the surfacelevel; it is $1 \frac{3}{4} \mathrm{in}$. wide in the inner diameter, $2 \frac{1}{4} \mathrm{in}$. in the outer, and oval-shaped in section ${ }^{2}$. The small size of this ring seems to preclude the idea that it can have been intended for an armlet, and it is not unlikely that it may have served some purpose in fastening the dress; or possibly it may have been used merely as a pendent ornament.

The two barrows examined next were those adjoining that before alluded to as having been opened many years since, and with it forming a smaller group of three lying close together; they are situated furthest to the west of the whole series constituting the larger group.

1 The bones comprised those of several oxen (bos longifrons), still more of goat or sheep, also of twelve pigs and two hares. The marrow-containing bones were all split open, and amongst the ox bones was a calcined one. With few exceptions all the animals had been young.

${ }^{2} \mathrm{Mr}$. Bateman records the finding of 'a ring, about $1 \frac{1}{2}$ in. diameter inside, cut from a flat piece of black shale, and fragments of another ring like it,' in a barrow near Pickering, in the North Riding. 'Ten Years' Diggings, p. 229. 
LXIV. The first was $70 \mathrm{ft}$. in diameter, $2 \frac{1}{2} \mathrm{ft}$. high, and was composed of earth, except at a point near the centre where it consisted of chalk which formed a smaller mound enclosed within the larger. This inner mound was about $18 \mathrm{ft}$. in diameter, $1 \frac{1}{2} \mathrm{ft}$. high, and covered the grave which will presently be described. At a point $13 \mathrm{ft}$. south-east from the centre, and one foot above the natural surface, was a single human pelvic bone. Twenty-six feet south of the centre, and also $1 \mathrm{ft}$. above the surface, was the body of a woman in middle life, laid on the right side, with the head to E. by S., the right hand being in front of the face, with the fingers doubled in, and the left arm over the right. Upon the right cheekbone there was a discolouration, caused by the oxidation of some bronze article which had gone entirely to decay, having probably been of small size, and possibly a pricker or awl. At a point which had no doubt originally been the centre, but which now was $4 \mathrm{ft}$. south-east of it, was a grave, having a direction south-east by north-west, $10 \mathrm{ft}$. long, $8 \mathrm{ft}$. wide, and $7 \frac{1}{2} \mathrm{ft}$. deep, and filled in with chalk. Dispersed throughout the whole of the grave were numerous bones of the skeleton of a large-sized man, as also charcoal in great abundance, there being a very large quantity at one place, on the east side, and $5 \frac{1}{4} \mathrm{ft}$. below the surface. At the bottom and nearly in the middle of the grave was the body of an aged man, laid on the right side, with the head to S.E., and the hands up to the face. Behind the head was a small flint knife, $1 \frac{1}{2}$ in. long, quite unused, and seeming as though it had been made for the purpose of the burial; while at the crown of the head, below it, and also behind the neck, were small flint chippings. A good deal of charcoal lay about the head and underneath it, and just beyond the feet were some remains of wood, but in too decayed a state to admit of the original form being made out.

In the material of the barrow were two pieces of a 'drinking' cup,' many flint chippings, six round scrapers, five saws, two knifelike implements, and some articles of uncertain use,-all of flint. A bone pin occurred, not connected with any interment; and another implement of bone [fig. 35], $6 \frac{1}{4} \mathrm{in}$. long, which somewhat resembles a spatula in shape, and bears upon its surface the signs of long-continued use. It is difficult to assign any certain purpose to it, but it may very probably have been a tool for the fabrication or ornamenting of pottery.

LXV. The second barrow was $55 \mathrm{ft}$. in diameter, $1 \frac{1}{2} \mathrm{ft}$. high, 
and made of earth and chalk. It contained a single interment, placed at the centre in a grave which lay east and west, having a length of $10 \mathrm{ft}$., a width of $4 \frac{1}{2} \mathrm{ft}$., and a depth of $7 \mathrm{ft}$. At the bottom and placed centrally was the body of a man about 30 years of age, laid on the left side, with the head to E.S.E.; the right hand was up to the face and the left towards the feet. In front of the middle of the right leg was a flint knife, $2 \frac{1}{4} \mathrm{in}$. long, and before the face a flint ehipping. Amongst the ehalk with which the grave was filled in were many disturbed bones of a small-sized adult, probably a female, and also pieces of a 'drinking cup,' together with charcoal and some remains of wood. Within the grave, and $2 \mathrm{ft}$. below the surface-level, was a piece of a reddeer's antler, showing signs of having been worked, but too much decayed to permit of its purpose being ascertained, the presumption merely being that it had been an implement of some sort. Still within the grave, but at a depth of $5 \mathrm{ft}$., was a broken tine of another antler, probably a piece of one of the tools used in making the grave. At a place $18 \mathrm{ft}$. south-east of the centre, and $1 \mathrm{ft}$. above the surface-level, was part of a child's skull; and $21 \mathrm{ft}$. south-east of the same point, and $9 \mathrm{in}$. above the surface, were two large portions of red-deer horns, both from antlers that had been shed, of which, though much decayed, enough remained to show that they had been shaped, and were not merely broken fragments. A few pieces of a cinerary urn were also met with, here and there, and also many sherds of plain, dark-coloured pottery; two saws, and five scrapers of flint; two fabricators for flaking flint; a piece out of the edge of a calcined flint axe ; another piece out of the middle of a large and well-chipped arrow-point; and several flint implements of uncertain description.

It has already been mentioned that somewhat to the east of the barrows last named there were some large mounds, evidently artificial, and which might be a priori assumed to be sepulchral in their intention. These also were examined, and, although burials were found in them, it is very doubtful if any of these could be regarded in the light of primary interments.

LXVI. The principal mound had an east and west direction, either of the two extremities being of greater elevation than the middle part. The extreme length of the mound was $137 \mathrm{ft}$., with a mean breadth of $40 \mathrm{ft}$., the west end being $4 \frac{1}{2} \mathrm{ft}$. in height, and 
the east $5 \frac{1}{2} \mathrm{ft}$. At the west end the mound was formed entirely of earth; the east end, and the remainder of the mound to within $40 \mathrm{ft}$. of the west end, being made of earth up the middle and of chalk on both sides. At the west end, and below the centre of what had something of the appearance of a round barrow raised upon the surface of the long mound, and $2 \mathrm{ft}$. above the level of

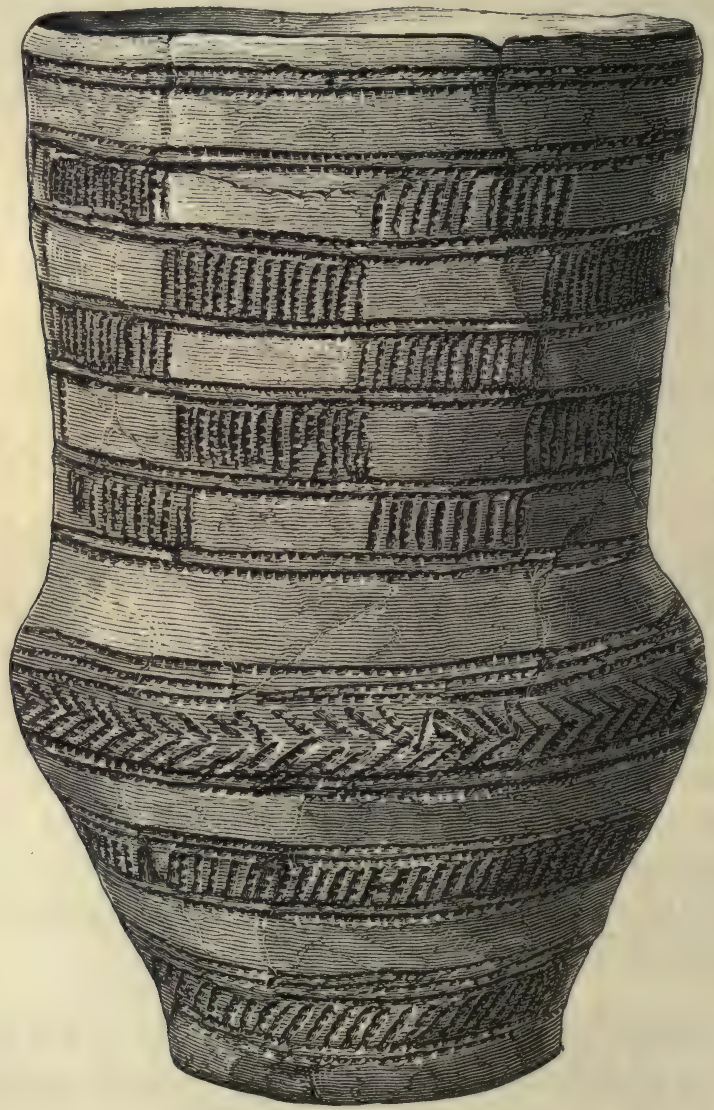

Fig. 122. $\frac{1}{2}$.

the natural surface, was the body of a young adult woman, laid on the right side, with the head to W., and the hands up to the face. Just in front of the right tibia was a 'drinking cup' [fig. 122]. It is $8 \frac{1}{2} \mathrm{in}$. high, $5 \frac{1}{2}$ in. wide at the mouth, and $3 \frac{1}{4}$ in. at the bottom; the upper part has nearly straight sides, and the vessel becomes somewhat bulbous-shaped below the middle; the upper part is ornamented with seven encircling bands, the two outside 
ones quite plain, the inner ones consisting of alternate oblong spaces, one plain, the other marked with vertical lines of impressions made by a notched instrument, these spaces being counterchanged on the bands. The widest portion of the bulbous part has an encireling band of chevrons set on edge, and below that are four bands, alternately plain and marked with lines slightly inelining to the right. All the bands are separated by two encircling lines of notched impressions. At a level 6 in. higher (the head lying above the woman's knees) was the body of a child, 8 or 9 years old, laid with the head to E.S.E. Immediately above the head, though not in actual contact with the bones, but still I think associated with the body, was a flint knife, $1 \frac{3}{4}$ in. long. Much charcoal was found about both the bodies. Underneath the woman, and at the level of the natural surface, lying east and west, was a beam of wood, $5 \frac{3}{4} \mathrm{ft}$. long, and $9 \mathrm{in}$. wide by 4 in. thick; and just above it was a hollow space, $7 \mathrm{in}$. deep, which was probably due to the settling of the filling-in of a grave over the top of which the beam was laid. The grave lay north-west-by-west and south-eastby-east, and was $7 \mathrm{ft}$. long, $4 \frac{1}{2} \mathrm{ft}$. wide, and $2 \mathrm{ft}$. deep. In it on the bottom, and close to the north-west end, was the body of an adult of uncertain sex, laid on the right side, with the head to W., and the hands up to the face. Behind the head was a 'drinking cup ;' in front of the chest two round flint scrapers and a chipping; at the knees one round scraper and a chipping; and at the feet a small oval scraper. The 'drinking eup,' in form somewhat like fig. 82 , is $7 \frac{1}{4}$ in. high, $5 \frac{1}{2}$ in. wide at the mouth, and $3 \frac{1}{4}$ in. at the bottom. At the top two lines of notched impressions encircle the vessel; then there is a band formed by a series of vertical lines, of the same markings, $1 \frac{1}{4} \mathrm{in}$. in length; then four plain grooved lines and below these five toothed lines encircle it, occupying a space of $1 \frac{1}{2}$ in.; below them a series of vertical lines, similar to those above but shorter, covers a space of $\frac{7}{8}$ in., having below a row of very short lines inclining to the right, with four encircling lines intervening ; below which, for a space of $2 \frac{3}{4}$ in., the vessel is plain. Just beyond the feet of this body were the bones of a young woman which had been disturbed and relaid. They were placed in a heap, the skull being on the top of the other bones. In the grave scattered pieces of charcoal were seen, here and there. The appearances suggested that a cutting had been made into an already existing grave, but not extending quite to its sides: the original grave seemed to have been filled in with earth, and through this 
the secondary cutting had been made, that being filled in with chalk. It is almost certain that the occupant of the primary grave was the woman whose bones had been disturbed and replaced, and that the cutting of secondary date had been made when the body was buried whose skeleton was found at the north-west end.

Seventy-six feet east of the grave, about the middle of the mound, and $4 \frac{1}{2} \mathrm{ft}$. above the natural surface, were many bones belonging to a man of large stature, together with others of a child's body, and a single piece of burnt bone. They were all laid in a heap, and had evidently been moved and redeposited. Immediately south of them, but at a slightly lower level, was the body of a ehild, during the period of the first dentition, laid on its left side, with the head to E.S.E. It is not improbable that the interment of the child had led to the disturbance of the other bodies. On the south side of the mound, $68 \mathrm{ft}$. east of the centre of the grave and $1 \mathrm{ft}$. above the surface-level, was a single human metacarpal bone.

A second mound, $190 \mathrm{ft}$. long by $50 \mathrm{ft}$. wide, and $4 \mathrm{ft}$. high, extended from the west end of the mound just described, towards the north, where it gradualiy died away into the natural surface of the ground. There was no burial found in it, although flint chippings, charcoal, and fragments of pottery occurred in several different places. It should be remarked that in the first of these mounds numerous bones of ox and pig with a few of dog, flint chippings, sherds of plain, dark-coloured pottery, and charcoal were met with throughout the whole of its length, and principally at the level of the natural surface. Amongst the flint objects were five round scrapers and a pointed tool.

It seems difficult to account for these extensive and peculiarly arranged mounds upon any other supposition than that they were intended for sepulchral purposes ; indeed, the presence of charcoal, broken animal bones, potsherds, and flint implements and chippings in them makes any other conclusion difficult of adoption. But with the exception of the grave at the west end of the first mound, and its contents, the other burials were all clearly secondary and subsequent to the formation of the mounds; and even the grave itself was not certainly a primary one, made before the throwing up of that part of the mound; although there were some appearances which seemed to favour that view. The round barrowlike form of the west end, under which the grave was excavated, had however in itself a secondary appearance, and from the circum- 
stance that it was formed in a different way from the rest of the mound-being made entirely of earth-it is not improbable that it was an addition made to the west end of an already existing pile ${ }^{1}$. If this burial were not the primary one, then no interment which can be regarded as such was discovered. It does not however seem probable that all these large accumulations of earth and chalk, extending in different directions, were merely adjuncts to the memorial of a single burial, and that occupying a position like the one in question. At the same time it may be stated that in many of the long barrows, and indeed in some of the round ones, that part which is devoted to the immediate place of sepulture bears a very small proportion to the mound itself. I can however offer no explanation which bears the semblance of probability, and I must leave it to the ingenuity of the reader to form his own conclusion as to the object of this collection of material, which must have required the continued labour of a large number of people over a considerable period of time. In conclusion I would observe that the examination was so thoroughly exhaustive that there cannot be any hesitation whatever in saying that no burial-place has remained undiscovered beneath the mounds.

LXVII. The next barrow, the largest of the group, lay about half a mile to the north-east of the long mounds just described. It was $100 \mathrm{ft}$. in diameter and $9 \mathrm{ft}$. high, and was formed entirely of chalk, with the exception of a layer of dark fatty earth which rested on the natural surface, and was of a thickness varying between $1 \mathrm{ft}$. and $2 \frac{1}{2} \mathrm{ft}$. There was no trace of any hollow in the neighbourhood from whence so large a mass of chalk could have been obtained as that required to form this barrow. The chalk employed must however have been quarried from a considerable depth, for the material over a great part of the mound was of a description that does not occur in the upper chalk beds of the locality. There can be but little doubt that it was obtained close by, and it would therefore seem as if the place from which it had been obtained had been afterwards filled up again. There is no difficulty in understanding how the chalk was excavated, for the remains of the tools were found amongst the material composing the barrow, in the shape of broken tines of red-deer antlers and splinters originating in their breakage. In a grave underneath a barrow about three

${ }_{1}$ Upon a long barrow, in the same parish, there was placed at the west end a very similar mound, under which was found a body with a 'food vessel.' 
miles distant from that now under notice, it will be remembered that a pick of deer's-horn was found laid at the buried person's knees, the instrument no doubt with which the grave had been dug (see $\mathrm{p}$. 231 ); and I have met with several instances where broken splinters of deer's antlers have occurred amongst the chalk filling-in of graves.

This barrow produced a large number of burials, all of them, with one exception, appearing to be secondary, and many of them mere insertions. They were all placed at a very slight depth beneath the present surface of the mound.

At a distance of $14 \mathrm{ft}$. south-west of the centre was the body of a man, placed $6 \mathrm{ft}$. above the natural surface, and laid on his right side, with the head to W.N.W., and the hands up to the face. At the crown of the head was a 'food vessel,' and behind the head a long flint scraper, made from the outside of a nodule of flint, the end only being chipped into shape. The 'food vessel' is in shape like fig. 71, with six unpierced ears at the shoulder, $5 \frac{1}{4}$ in. high, $6 \frac{1}{4}$ in. wide at the mouth, and $3 \mathrm{in}$. at the bottom. It is covered over the whole surface and on the inside of the lip of the rim with very short lines of twisted-thong impressions arranged herring-bone fashion. The body had been inserted in the barrow, which, as has already been observed, was made of chalk, and the hollow in which it was placed had been filled in with earth, but along the back of the body some large flat pieces of chalk were set on edge. Twentyseven feet west-by-south of the centre, and $4 \frac{1}{2} \mathrm{ft}$. above the surface, was the body of another man, laid on the left side, with the head to N.N.W., the right hand being up to the face and the left on the right arm. At the feet was a very beautifully-formed oval flint knife, $2 \frac{1}{8}$ in. long, very evenly and skilfully serrated along one edge. Twenty-one feet west-south-west from the centre, and $6 \mathrm{ft}$. above the ground-level, was the body of a woman, laid on the right side, with the head to N.W. by N.; the right arm was extended and the hand placed under the knees, the left hand being up to the face. Between the head and the knees was a 'food vessel.' This body was evidently an insertion, and was deposited in a hollow filled in with earth, having a thin chalk flag laid over the knees and the vessel. This, which is very rudely made, is shaped much like an ordinary flower-pot, $4 \frac{1}{4} \mathrm{in}$. high, $5 \frac{1}{2} \mathrm{in}$. wide at the mouth, and $3 \mathrm{in}$. at the bottom, and is ornamented over the whole surface and on the inside of the lip of the rim with encircling lines of impressions of very coarsely-twisted thong. Close to the last body were the remains of a disturbed one, with many pieces of a 'drinking-cup,' 
which had probably been associated with it; it has been ornamented over the whole surface with bands at intervals, consisting of encircling lines made by a roughly-toothed piece of bone or wood. Twenty-one feet west-by-south from the centre, and $6 \mathrm{ft}$. above the natural surface, was the body of a second woman, laid on the right side, with the head to $\mathrm{N}$. by $\mathrm{W}$.; the hands were crossed in front of where the hips had been, but these, together with the bones of the legs, had been cut away by the introduction of the interment last mentioned. Behind the head was a 'drinking cup,' $4 \frac{1}{4}$ in. high, 4 in. wide at the mouth, and $2 \frac{1}{2}$ in. at the bottom. It is in shape like fig. 81, and is ornamented over the whole surface by encircling lines of twisted-thong impressions. Twelve feet south-south-east from the centre, and $6 \frac{1}{4} \mathrm{ft}$. above the natural surface, was the body of a child, about 3 years old, laid on its right side, with the head to S.S.W. Seven feet and a-half south-south-east from the centre, and $7 \mathrm{ft}$. above the surface, was the body of another child, rather younger than the last, also laid on its right side, with the head to $\mathrm{N}$. by $\mathrm{E}$. On the same level, $6 \mathrm{ft}$. south-east-by-south of the centre, and apparently in the undisturbed chalk of the mound, was still another child, about a year old. Just west of this, but about a foot higher, was part of the skull of another child of about the same age; whilst $4 \mathrm{ft}$. east-south-east of the centre, and nearly at the same height as the two children's bodies just named, were two other children, laid close together, the elder in front of the younger, both on their left sides, and with their heads to N.E. by E., and the hands of both up to their respective faces. Between the face of one and the back of the head of the other were two flint chippings. These bodies also were placed apparently in the undisturbed chalk of the mound. Six feet east of the centre, and at the same level with the last-named children, was yet another child; while $3 \mathrm{ft}$. west of it were several disturbed bones of another child. Seven feet and a half north-north-east from the centre, and at the same distance above the ground-level, was the body of a young woman, the epiphyses of the thigh bones not being united; she was laid on the right side, with the head to S.W. by S., the right hand being under the corresponding thigh, and the left on the chest. Between the face and the knees was a 'food vessel.' It is shaped like fig. 71, with four unpierced ears at the shoulder, $5 \frac{1}{8} \mathrm{in}$. high, $5 \frac{1}{2}$ in. wide at the mouth, and $3 \mathrm{in}$. at the bottom. The ornamentation is applied over the whole surface and on the inside of the lip of the rim, and is made by short lines drawn by a pointed instrument, and 
arranged herring-bone fashion on the outside of the vessel, and on the inside of the rim by a series of lozenges (their longer axes touching at the points) placed between two bands of short lines inclining inwards. Seven feet north-north-east of the present centre, but no doubt eoineident with the original one, and elearly the primary interment, was the body of a child, scarcely a year old, on its left side, with the head to N. by E. It was placed on the natural surface in a slight hollow, with a direction of west-north-west by eastsouth-east, $5 \mathrm{ft}$. long and $3 \mathrm{ft}$. wide, and lined with wood, which towards the east end was charred. Close to the child, also towards the east end of the hollow, were some of the bones of, apparently, a young woman, placed certainly with some regard to their proper order, but by no means presenting such an appearance as would imply that when the interment took place there had been an entire body. The head was on its left side, but there sas no lower jaw with it; the other bones were in such a position as to show that it had been intended to lay the body on the right side, but there was no left femur, no vertebræ, and none of the bones of the arms, except the left humerus. The bones still remaining were in such a sound condition as to render it impossible to suppose that those which were wanting had perished by decay, so that there can be no room for doubt that when the child was buried eertain parts of the skeleton of another body had been placed in assaciation with it, the bones probably of one removed from some other place of deposit, and possibly those of the mother.

The size of this barrow was such as (presumably at least) to indicate the importance of the person over whose body it had been raised; and yet there seems every reason to conclude that the person in question was a child of very tender years ${ }^{1}$. Possibly the child may have been the offspring of the chief of some powerful tribe, destined, if life had been spared, to rule in his turn over the people whose bodily toil contributed to the erection of this gigantic funeral memorial. Nor is the conjecture an improbable one which would regard the bones of the young female as those of the mother, who had died before her child, and whose bones had been disinterred from their previous resting-place in order that they might be laid

${ }^{1}$ Sir R. Colt Hoare records the discovery of the body of a very young child in a deep grave at the centre of a large barrow at Lake. He says, "The history of this tumulus, which our learned Doctor (Stukeley) would, from its superior size and beautiful form, have styled a King Barrow, shows what little regard we ought to pay to system; for here, at the vast depth of nearly $14 \mathrm{ft}$., we find only the deposit of an infant, accompanied by a single drinking cup.' Ancient Wilts, vol. i. p. 210. 
by the side of her child's lifeless body. Assuming the probability of these conjectures, the eircumstances would seem to point to a stage of progress quite inconsistent with the idea of an utterly uncultured or savage people; indeed, they would imply something like hereditary rule, or at least a state of society in which the son of the chief was regarded by the community as having especial claims on their regard and respect, and whose burial-place it was fitting to honour with a more than ordinary observance.

At a distance of $15 \mathrm{ft}$. north-east of the eentre, and $6 \frac{1}{2} \mathrm{ft}$. above the natural surface, was the body of a child, very much decayed; close to the head was a small and perfectly plain vessel, $3 \frac{3}{8} \mathrm{in}$. high, $3 \frac{5}{8} \mathrm{in}$. wide at the mouth, $4 \frac{1}{2} \mathrm{in}$. at a distance of $1 \frac{1}{2} \mathrm{in}$. below the mouth, and $2 \frac{1}{2} \mathrm{in}$. at the bottom. One foot and a-half east of the last was another child, also mueh decayed; at the head, and probably in front of the face, was a small 'drinking cup', in form like fig. $120,4 \frac{7}{8}$ in. high, $3 \frac{3}{4}$ in. wide at the mouth, and $2 \frac{1}{2}$ in. at the bottom. It is ornamented to within $1 \frac{1}{2} \mathrm{in}$. of the bottom with four zigzag and two saltire-formed lines encompassing the vase, and alternating with a series of four plain eneircling lines, the whole slightly marked and made by a sharp-pointed tool. Twenty-one feet and a-half east-by-north from the centre, and $6 \frac{1}{2} \mathrm{ft}$. above the level of the ground, was the body of a man, laid on the back and at full length, with the head to W. by N. One foot north of the last was another man; and $1 \frac{\mathrm{l}}{2} \mathrm{ft}$. to the north of the second was a third man's body, both of which, like the first, were laid at full length on their backs, and with the head in the same direction; the hands in all three cases being placed on the hips. Two feet north-west of the third man was a fourth, laid on the right side in a contracted position, with the head to S.W., and the hands up to the face. Just beyond the feet of the three extended bodies there was another, the bones of which were too mueh disturbed by the plough to admit of the position of the body being ascertained. It is not improbable that the three bodies laid at full length, and indeed the other two as well, were those of Angles, placed in the mound many centuries after its construction. In the absence of any associated relics this is of course mere conjecture; but it is one which at least may safely be hazarded, inasmuch as the position was so exactly that of Anglian burials in general, and as it was by no means an uncommon thing for the later settlers to make use of earlier burial-mounds in which to inter their own dead.

It has already been mentioned that there was a deposit of dark 
fatty earth upon the level of the ground, extending throughout the whole barrow, and increasing in depth up to the centre, where it attained a thickness of $2 \frac{1}{2} \mathrm{ft}$. This deposit was full of burnt earth and charcoal in every part; but there was more evidence of burning in that part which immediately overlaid the natural surface. There were also in it a very large number of animal bones ${ }^{1}$, as well as sherds of pottery, principally of plain dark-coloured ware, flint implements, and chippings of the same material. Amongst the implements must be numbered 79 saws [fig. 22]; 17 scrapers; 3 leaf-shaped arrow-points; 2 pointed tools (probably for boring); several flint articles of uncertain purpose; a hammer-stone; and a piece of a greenstone axe. Many of the saws are very delicately serrated, some along both edges, and showing by the glaze upon the edge that they had been in use. The number of saws was very surprising, and far exceeded the aggregate of those obtained from all the barrows I have opened; and it is by no means easy to give any reasonable explanation of the phenomenon.

LXVIII. The next barrow was situated about a quarter of a mile to the south-east of the last. It had been much dug into in pursuit of rabbits, and in one part a trench had been cut through it down to the level of the ground. It nevertheless proved one of the most prolific and interesting mounds I have ever examined. It was $40 \mathrm{ft}$. in diameter and $3 \frac{1}{2} \mathrm{ft}$. high, the lower 18 inches being of earth, the remaining or upper portion of chalk. The earth which overlaid the graves was so compact that it was only broken up with great difficulty, and had all the appearance of having been intentionally puddled; although it is more probable that this condition had been caused by the material having been put together in very wet weather, and much trampled on in the process. It will be remembered that a similar appearance was noticed in a barrow at Weaverthorpe [No. xlvii], as also in the second barrow of the present group [No. lxiii].

At a distance of $7 \frac{1}{2} \mathrm{ft}$. south-west of the centre, and $1 \frac{1}{2} \mathrm{ft}$. above the surface-level, was the body of an adult, laid on the right side, with the head to N.N.W.; but the hands were so much decayed

1 The bones are - of red deer, four, and two teeth; of goat or sheep, twelve, and six teeth; of horse, four; of dog (canis familiaris), two; of pig (sus scrofa domesticus), sixty-five, and thirty teeth; of ox (bos longifrons), one hundred and thirty, and fortyone teeth; and of another species of ox, either of the urus type or of a cross between that species and bos longifrons, a domestic variety, and of larger size than has been before met with in the barrows of the wolds. 
as to prevent their position being ascertained. Seven feet south-westby-west from the centre, and at the same level, was a child's body, too much decayed to allow anything more to be determined. Two feet south of the centre, and upon the level of the natural surface, was the body of a man, laid on its right side, with the head to S.W., the hands being up to the face. On the ground-level at the centre, and just over the middle of the first grave (to be noticed presently), was a child, laid on the left side, with the head to S.W., and the hands up to the face. There was a great deal of burnt earth and charcoal both above and below the body; and throughout all this part of the mound were the disturbed and broken bones of two bodies, one being of an adult, the other of a child. Immediately beneath the child was an oval grave, north-east and south-west, $8 \mathrm{ft}$. by $4 \frac{1}{2} \mathrm{ft}$. at the bottom, and $9 \mathrm{ft}$. by $8 \frac{1}{2} \mathrm{ft}$. at the surface-level, and $6 \frac{1}{2} \mathrm{ft}$. deep. It was filled in with chalk. At the bottom of the grave, about the middle, was the body of a man, laid on the left side, with the head to S.E. by E., the right hand being up to the face and the left on the upper part of the stomach. About midway between the knees and the face were several articles, some of which had apparently once been employed in fastening the dress. They were placed upon each other in the following order. On the top was a long and narrow implement of mica-schist, ground over the whole surface [fig. $14]$; it may very possibly have been a whetstone. The under surface is flat and the upper one convex, and it decreases in width from the middle to the ends, which are rounded; the flat surface is hollowed to some, though a trifling, extent, and there are slight scratches
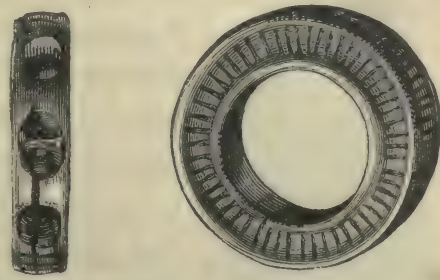

Fig. 123. $\frac{1}{1}$. upon it which may have been caused by its having been used for whetting. ${ }^{1}$. Immediately below it was a very prettily engraved jet ring [fig. 123], with two perforations in the side, similar to those in the jet buttons as shown in the section below. This ring

${ }^{1}$ Two similarly-shaped stones, one remarkably like the Rudstone specimen, were found by Sir R. Colt Hoare in a barrow in Wiltshire. They were associated with an unburnt body, with which were also deposited a 'drinking cup,' a large button and a 'pulley bead,' both of jet, and a flint rudely chipped, as if for a dagger or spear. Ancient Wilts, vol. i. p. 118, pl. xiv. There is a great resemblance between the objects discovered in the above Wiltshire barrow and that at Rudstone, though the two burials do not correspond in all the accidents.

Mr. Evans regards these articles as whetstones, or for polishing. Ancient, 
is altogether similar to one found in the same locality, and described at p. 228, and much like to another described at p. 230. Below the ring was a plain jet button, $1 \frac{7}{8}$ in. in diameter, and in shape like fig. 124, placed face upwards; and again below that a second
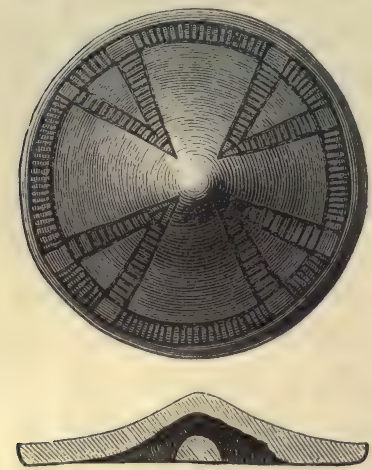

Fig. 124. $\frac{1}{2}$. button, lying with the face downwards [fig. 124]; this last, as will be seen from the figure, is very beautifully engraved with a cross pattern, and corresponds very closely with one found at Thwing, and figured p. 33. A little nearer to the face were two articles, a 'flint and steel' [fig. 31], not hitherto noticed as such in their relative capacities, though they have been before found with ancient British interments. The steel had been made from a round nodule of iron pyrites, split in half; the flint was placed below the split nodule, which rested upon it, the flat surface being downwards; the flint is $2 \frac{1}{4} \mathrm{in}$. long and $\frac{3}{4}$ in. square. Both

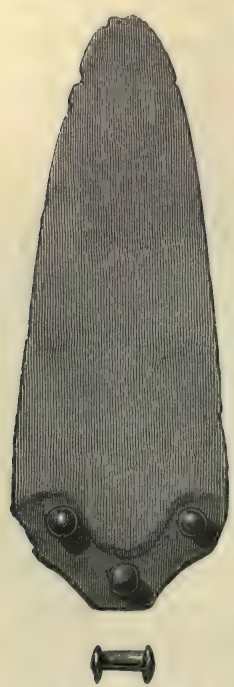

Fig. 125. $\frac{7}{2}$. show signs of continued use in their worn and smoothened edges, but the spark of fire seems principally to have been obtained by rubbing the end of the flint along the flat face of the nodule, which is worn into a considerable groove in consequence. The nodule has had a portion ground off on the rounded surface, probably in order to remove a projecting piece which rendered it inconvenient to handle. Still nearer to the face, the point however directed away from it, lay a bronze knife-dagger [fig. 125], resting on some substance which has the appearance of moss. This implement is $4 \frac{7}{8} \mathrm{in}$. long, and $1 \frac{5}{8}$ in. wide at the point where the handle has joined the blade in the usual semilunar form, and where it has been fixed by three bronze rivets, the two sides having been further fastened together by two additional rivets, one of which is figured with the blade.

The handle had been made of ox-horn, the impression left by

Stone Implements, p. 239. Some implements evidently whetstones, at times perforated, have been met with in the Wiltshire barrows, and now and then accompanying bronze knife-daggers. 
the texture of that material being still apparent upon the oxidised metal. The two rivets are severally, and without including the heads, $\frac{8}{16}$ in. and $\frac{7}{16}$ in. long, and thus the thickness of the handle is given. On the bottom of the grave was a quantity of eharcoal.

At the south-west end of the first grave there was an extension, forming a second one, not so deep as the first by a foot. It extended $7 \mathrm{ft}$. to the south-west, with a width of $4 \frac{1}{2} \mathrm{ft}$. At the north-east end of it was the body of a man, laid on the left side, with the head to S.E., the right hand being up to the face and the left on the stomach. The body was but slightly contracted, the head being $3 \frac{1}{2} \mathrm{ft}$. away from the knees. Behind the back were two jet buttons, placed one upon the other; they are both plain, and are respectively $1 \frac{7}{8}$ in. and $1 \frac{1}{2}$ in. in diameter, the larger one being more conically shaped than the other. Close to them, on the north, was another 'flint and steel,' almost identical in form and appearance with those found in the preceding grave, but both of the latter showing signs of having been a longer time in use. As in the first instance, the nodule of pyrites was placed upon the flint. On the north side of the grave last described, being also an extension of the first one, in a north-east-by-north direction, was a third grave, a foot less in depth than the second, and consequently not more than $4 \frac{1}{2} \mathrm{ft}$. deep. It was $5 \mathrm{ft}$. long and $5 \frac{1}{2} \mathrm{ft}$. wide, and contained the body of a large and very powerfully made old man, laid on the left side, with the head to N.E. by E., the right hand being upon the head, the left up to the face. In front of the face was placed a bronze knife, which had been fastened to its handle of ox-horn by a single rivet. The metal is a good deal oxidised, and the exact length of the blade cannot be ascertained with certainty, but it has probably been about $3 \frac{1}{2}$ in. long; it is one inch wide where the handle joined the blade, which has terminated with a straight end, and not in the semilunar form. The point of the knife, which is rounded, was turned away from the face of the man. Behind the shoulders was a perforated axe-hammer of micaceous grit, $5 \frac{1}{4} \mathrm{in}$. long and $1 \frac{7}{8}$ in. thick $^{1}$ [fig. 126]. The edge, if such a term can be applied to what has a rounded form, was turned away from the body, and the

1 A similar conjunction of implements has occurred in other places in England. Mr. Bateman found two interments where a perforated axe-hammer and a bronze knife-dagger were associated; one in Carden Lowe, near Hartington; Vestiges, p. 63 ; the other at Parcelly Hay, also near Hartington; Ten Years' Diggings, p. 24. Sir R. Colt Hoare met with the two implements in question in a barrow near Selwood, but there associated with a burial after cremation. Ancient Wilts, vol. i. p. 39, pl. i. 
weapon was laid with the perforation in a vertical position. Close to it was a flint tool of elongated triangular form, $1 \frac{3}{4}$ in. long, and chipped along both edges. In the material of the barrow were some sherds of pottery, two round flint scrapers, and some bones of goat or sheep, ox, dog, and pig, all of domesticated animals.

This barrow presented some features which seem to require a more particular notice than the mere record of their occurrence. The most important matter is the discovery of two articles which

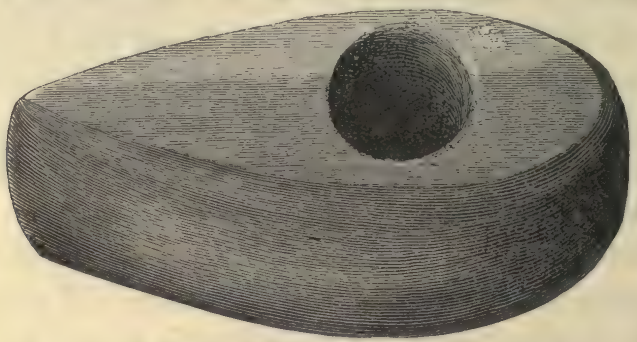

Fig. 126. 남.

eannot have been anything else than a 'flint and steel,' the means of producing fire. So far as I know, this is the first instance of anything of the kind appertaining to the bronze age having been specially recorded ${ }^{1}$; and although the probability that in these

1 Though the occurrence of pyrites of iron and flint.in barrows had been already remarked, it does not seem to have suggested the purpose to which these materials had been applied. Mr. Bateman, for instance, mentions that in a barrow on Elton Moor, near the head of a body 'was a piece of spherical iron pyrites, now for the first time noticed as being found with other relies in the British tumuli.' In the rear of the same body was 'a flat piece of polished iron ore, a small celt of flint, with the peculiarity of having a round polished edge instead of a cutting one as is usual ; a beautifully-chipped cutting tool, twenty-one circular instruments, almost all neatly chipped, and seventeen pieces or rude instruments, all of flint.' Vestiges, p. 53. In Green Lowe, behind the shoulders of a skeleton was 'a piece of spherical pyrites or iron ore ... and a flint instrument of the circular-headed form.' l. c., p. 59. In Dowe Lowe a skeleton 'was accompanied by a fluted brass dagger . . . and an amulet or ornament of iron ore, with a large flint implement, which had seen a good deal of service.'.l. c., p. 96. In Wiltshire Sir R. Colt Hoare found in a barrow at Brigmilston, ' a long piece of flint and a pyrites, both evidently smoothed by use.' Ancient Wilts, vol. i. p. 195. A half nodule of pyrites, showing signs of use, after the same fashion as those from Rudstone, was discovered in a barrow on Lambourne Down, Berkshire, and is now in the British Museum. Another, having a deep groove worn on the flat surface, was met with in company with an urn and a bronze dagger, in a barrow at Angrowse Mullion, Cornwall. Borlase, Nenia Cornubiæ, p. $235 . \quad$ Lord Rosehill found with a burnt body in a cist at Tyneside Farm, near Minto, Roxburghshire, a slice of a nodule of iron pyrites, together with a long and thick flint flake, apparently 'a flint and steel.' I myself found a piece of iron ore, held in the hand of a skeleton, and a long thick flake of flint, evidently 'a flint and steel,' in a cairn [No. clxxiv] on Crosby Garrett Fell, Westmoreland. See Erans, Stone Impl., pp. 14, 281, seqq: 
early ages fire was obtained by such a process may have suggested itself to many, as it had indeed to myself, still, before this discovery of the 'flint and steel' unmistakeably adapted and also used for that purpose, there was no tangible evidence of the fact. This evidence seems now to be supplied by the contents of the present barrow; for not only were the two materials-the flint and the iron pyrites-found in such juxtaposition as to imply connection the one with the other, but both by their appearance clearly indicate the nature of that connection and mutual use; the bruised and smoothened edges and ends of the flints and the grooved surface of the pyrites showing tokens of long-continued reciprocal friction. It is true that certain ores of iron have long been employed by savage tribes as a source from which to obtain a red pigment, whether for their own personal adornment or for colouring articles of dress and implements, but the particular ore to which the nodules under notice belong is not adapted for producing any. pigment when in a fresh and unoxidised condition; neither are the appearances of wear upon the pyrites those that would have resulted from a scraping process necessary in the preparation of such a substance. There certainly are the marks of what may perhaps be called scraping along the middle of the fractured surface of the nodules; but that is just the part where the ore would be quite fresh and unoxidised, and therefore the least available for use as providing a pigment. The marks in question have no doubt been made, as has already been mentioned, by rubbing the flint rapidly across the flat surface in the process of obtaining the required spark. The value of the evidence is further enhanced by the fact that like articles occurred in connection with two separate interments under precisely similar circumstances and with exactly identical appearances of use upon them. It might naturally be expected that a people who had so far progressed in civilisation, as the various remains belonging to the bronze period attest that the inhabitants of Britain had at that time arrived, would have attained to some better mode of producing fire than the tedious process of rubbing two sticks together, or even by the use of a fire drill. There was however no evidence to show in what improved way so important an essential to human existence, especially in a elimate like ours, might have been obtained at the time in question, until this important discovery in the barrow at Rudstone supplied the interesting fact. It might seem strange that a people who were dealing in this manner with an ore of iron should not 
have made the discovery of the possibility of smelting it, if we did not bear in mind that the different pyritic ores are intractable enough to bid defiance to the appliances of modern science.

Although perhaps not of equal value as evidence touching the condition of the people of this early period with the discovery just passed under notice, still the occurrence of a bronze implement associated with one of stone is not without its interest. It is well known that during the bronze age flint and other varieties of stone were used for the fabrication of such weapons and tools as would have been made of metal had it been more readily procurable; still, every additional fact illustrative of this point is important, as adding one more to a number which is by no means too great. The stone implement, exclusive of the smaller articles of flint, which has been most commonly found associated with bronze, is (as was the case in the barrow now under notice) the perforated axe-hammer, an implement which must I think be classed as a weapon of war, for which purpose it would obviously at such a period be almost as efficacious as if made of bronze.

The jet articles, especially the ring and one of the buttons, are of great beauty, and show not only considerable skill in their manufacture, but much taste in the style of ornament adopted in each case. The ring, with the parallel lines engraved upon its faces and side, is really a very pretty object; and the pattern with which it is decorated is so well suited to the art-requirements of such an article as to show that the person who made it must have been not only well acquainted with, but much under the influence of, the true principles of ornamentation as applied to objects of personal use. The same may be said of the engraved button, the simple ornamentation upon which is just such as to add to its beauty without overloading it, while the conical form of the upper surface of the button seems fittingly to call for the application of such a pattern as has been placed upon it. The cross in this case is most probably simply decorative, and although it is certain that from a very early time this figure was used as a symbol, and although it occurs frequently upon various manufactured articles of the bronze period, and more especially on the bottoms of fictile vessels, I should not be inclined to suppose that anything more than an ornamental purpose was intended in the cases just referred to ${ }^{1}$.

1 Two previous instances where the cross has occurred on buttons in the wold barrows may be referred to; at Butterwick [No. xxxix] on a stone button, and at Thwing [No. $\mathrm{x}]$ on one of jet. Sir R. Colt Hoare found two thin gold disks, which 
There can be no doubt that the ring, with the perforations on the side, was used in some way for fastening the dress; rings of this kind have so constantly been found together with buttons that they can scarcely be separated from them when their original purpose is considered. The manner of use is however not so easy of explanation, though it is possible that a thong being fixed on each side of a garment which was open in front, one of them may have been passed through one of the perforations, whilst the opposite thong was passed through the other, the two thongs being then tied, and leaving the ring to hang in front of the dress, serving, like a modern brooch, equally for use and ornament.

LXIX. The last barrow of the group which was opened, being the last but one towards the east, was situated about $\frac{3}{4}$ mile eastby-south from that just described. It was $60 \mathrm{ft}$. in diameter, $3 \frac{1}{2} \mathrm{ft}$. high, and was composed entirely of earth. It contained two interments at the centre, those of an unburnt and a burnt body. The former (the only instance in my experience except three, where the all but universal rule of eontracting the body was departed from) was laid in a shallow grave, west-south-west by east-north-east, $6 \frac{1}{2} \mathrm{ft}$. long and $3 \frac{1}{2} \mathrm{ft}$. wide ; at the east end it was $1 \frac{1}{4} \mathrm{ft}$. deep, and it decreased gradually in depth until at the west end, where the head was placed, it rose to the level of the original surface. The body deposited in it was that of a young man about 25 years of age, who was laid on his back and at full length, the head being a little brought forward on to the chest, and the hands up to each side of the head. On the left side, in contact with the body, and extending from 6 in. above to the same distance below the knees, were the bones of the burnt body of an adult male. At the right hip was a 'food vessel,' and on the left side, between the arm and the chest, was a flint knife. The vase is, though more rudely made, in shape much like fig. 70, but has four unpierced ears. It is $4 \frac{1}{4} \mathrm{in}$. high, 6 in. wide at the mouth, and $3 \frac{1}{4}$ in. at the bottom. It is entirely covered with ornament, including the inside of the lip

seem to have been the coating of wooden buttons, having a cross engraved on each, in a barrow in Wiltshire, associated with a small bronze knife-dagger and a 'drinking cup,' accompanying an unburnt body. Ancient Wilts, vol. i. p. 99, pl. x, xi.

In all these cases where this figure has been found upon buttons I am inclined to consider it as being purely decorative, though it has been used extensively, and in many countries and at different times, as a religious symbol. The subject of the use of the cross in early times is very fully treated by G. de Mortillet, 'Le signe de la Croix avant le Christianisme,' and in an article 'On the Pre-Christian Cross,' in the Edinburgh Review, vol, exxxi.p. 222. 
of the rim, which has four lines of thong-impressions running round it. The outside has a herring-bone pattern upon it, made by short thong-impressions, except at the shoulder including the ears, where it has four rows of vesica-shaped vertical markings made by a sharp-pointed tool. The knife, which is of the form of fig. 21, though not so long proportionately, is most beautifully chipped over the whole of its convex surface, and has an edge, produced by very minute flaking, quite as sharp as one of steel. There was a great quantity of charcoal at both the head and feet of the body.

It will have been remarked that in the barrow described a few pages before a very large number of flint saws were found; in the barrow now under notice there were no fewer than twenty-four round scrapers. Besides these, there were, together with innumerable chippings, a long leaf-shaped arrow-point, a javelin-head, a single-winged arrow-point (or whatever that class of flint implement may have been), very much like fig. 340 in Evans's Stone Implements, a knife [fig. 127], several flints of enigmatical purpose,

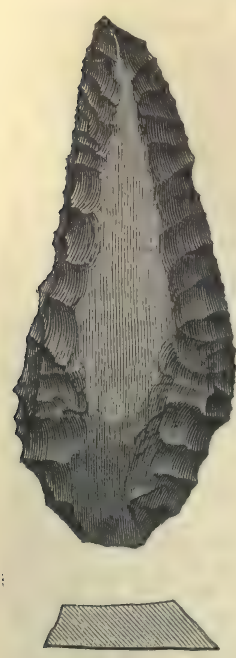

Fig. 127. ㄱ. a flat oval piece of fine-grained sandstone, 3 in. in length, which had been used on one face for polishing, and from the appearance probably for polishing metal, and at the ends for hammering, together with another flat irregularlyshaped piece of similar stone $2 \frac{3}{4} \mathrm{in}$. long, in which, on the flat side, a hollow has been wrought, while on the opposite side another hollow has just been commenced. Amongst the material of the barrow were also some sherds of plain dark-coloured pottery and some bones of ox and pig.

The position of the body, being at full length, in connection with the undoubted antiquity of the interment, is a very unusual one, indeed the only case of the kind, with three exceptions, that I have met with in above three hundred interments which I have examined on the wolds and elsewhere. Rare instances of its occurrence have been noted in different parts of England, where, as in this case, there could be no doubt that the burials were pre-Roman. The ordinary fashion of burial in an extended position was however to some extent deviated from in the present instance, for the hands, instead of being laid at the full length of the arm alongside the 
body or upon the hips, were, as is commonly the case with contracted bodies, placed at the side of the head, which also, as noticed above, was bent a little forward. Still, the change from the ordinary position is remarkable, and does not readily admit of explanation; and all that can be said is that, under the most rigid observance of rule or custom, aberrant cases will occasionally occur -in common speech, 'There is no rule without an exception.'

\section{PARish of Folzton. Ord. Map. xcv. s.w.}

There still remain, though many have been removed in the course of agricultural operations, a considerable number of barrows upon Folkton and Flixton Wolds, some of which, especially one called Sharp Howe, are of large dimensions. Of these I examined three upon Flixton Wold, situated about a mile to the north-east of those on Willerby Wold, described at p. 185. The first of these, called Elf Howe, had been removed to a great extent, and the grave had been dug out before I had an opportunity of examining it. I however got an account of what was diseovered 'from the foreman on the farm, and I was able personally to inspect a small portion which had not been disturbed. The barrow had been $60 \mathrm{ft}$. in diameter and $6 \mathrm{ft}$. high, and was made of earth and chalk. Near the centre a deposit of burnt bones was met with, over which some large flints were placed; this was at a depth of $4 \mathrm{ft}$., and as a great quantity of burnt earth was observed immediately round the bones, it is probable that the body had been burnt on the spot where the bones were placed. Two unburnt bodies were found on the south side of the mound, with one of which a vessel of pottery was associated. At a distance of $17 \mathrm{ft}$. south-south-east of the centre $I$ found the body of a strongly-made man, laid on the right side, with the head to $\mathrm{S}$. and the hands to the knees; the body was placed about 6 in. above the natural surface. Immediately below the head was the body of a very young child, the bones of which were too much decayed to admit of anything being made out beyond the fact that it was a child's body which was laid there. Still lower, and on the natural surface, was a patella, a radius, and some other bones of a body, which had been disturbed, probably in the interring of the person who was found buried above. At the centre was a grave, lying north-west and south-east, $7 \mathrm{ft}$. by $6 \frac{1}{2} \mathrm{ft}$. and $2 \frac{1}{2} \mathrm{ft}$. deep. On the bottom at the north side was the body of 
a strongly-made man in the middle period of life, whose head, a typically brachy-cephalic one, was to $\mathrm{S}$., but my informant could not remember on which side the body was laid; at the head was a 'food vessel,' which, from the fragments that have been preserved, must have been a rudely-made one with unusually thick walls.

LXX. The next barrow, which was about a quarter of a mile to the south of the last, was placed upon the steep slope of a valley which runs up from the village of Forden, and upon a piece of ground which had never been under the plough. It was therefore of its original size, though an attempt had been made to open it, which had not however interfered with many of the numerous interments it was found to contain. It was $28 \mathrm{ft}$. in diameter, $3 \frac{1}{2} \mathrm{ft}$. high, and made of chalk and earth. Thirteen feet south of the centre, and upon the surface-level, was a small sepulchral vessel, which had no doubt been associated with an interment, most probably that of a child, whose bones had however gone entirely to decay. The vessel, roughly in shape like fig. 69 , is 4 in. high, $5 \mathrm{in}$. wide at the mouth, and $2 \frac{1}{2}$ in. at the bottom, and is perfectly plain, except on the inside of the rim, where are some lines rudely and irregularly made. At a distance of $8 \frac{1}{2} \mathrm{ft}$. southsouth-west of the centre, and at the same level as the vase just mentioned, were the much decayed remains of the bones of a child under a year old, with which was associated a 'food vessel,' so much broken and disintegrated that nothing more can be said of it than that it had been small and ornamented on the upper part with encircling lines of the usual thong-impressions. At a higher level than the last, being $1 \frac{1}{2} \mathrm{ft}$. above the surface of the ground, and $9 \mathrm{ft}$. south-south-east of the centre, was the body of another very young child, in the same decayed condition as that of the last one ; with this interment also was a 'food vessel.' It is rudely made, in form approaching to fig. $69,3 \frac{3}{4}$ in. high, $4 \frac{3}{4}$ in. wide at the mouth, and $2 \frac{3}{4} \mathrm{in}$. at the bottom; the upper part has two encircling zigzag lines, and below these the vessel is covered with parallel lines, arranged vertically, all being made by thongimpressions. At the same distance from the centre as the last interment, but in a direction south-east-by-south, and laid on the surface-level, was the body of yet another child, with the head to S.E. Upon the same level, and $5 \mathrm{ft}$. south-west-by-south of the centre, was the body of a young woman from 18 to 20 years 
of age, laid on the left side, the head to S.S.E., and the hands on the chest. At a distance of $7 \mathrm{ft}$. west-by-south of the centre, and $1 \frac{1}{2} \mathrm{ft}$. above the natural surface, were two bodies, both placed on the left side, and having the heads to N. by W. The one, that of a strongly-made man past the middle period of life, had the arms crossed in front of the ehest, and upon them and laid between the knees and head was the second body, that of a boy or girl below the age of puberty, whose hands were to the knees. Nine feet east of the centre, and deposited on the natural surface, was the body of a young person, probably a boy about 17 or 18 years of age, laid on the right side, having the head to E., and the hands up to the face; in contact with this body were some burnt bones. At the same level, and $7 \mathrm{ft}$. north-east-by-north of the centre, was a body, probably that of a woman between 40 and 45 years of age, laid on the left side, the head to E.S.E., and the hands to the knees. In front of the face was a 'drinking cup,' of a novel form [fig. 84]. It is $8 \frac{1}{2} \mathrm{in}$. high, $5 \mathrm{in}$. wide at the mouth. $3 \frac{1}{4}$ in. at the bottom, and is ornamented over the whole surface; the nature of the ornamentation will best be understood from the figure. The pattern is formed by impressions of twisted thong, aided in some parts by a sharppointed tool. Just above the surface-level, and $9 \frac{1}{2} \mathrm{ft}$. north-by-west of the centre, was the body of a child, laid on the left side, the head to W. by S. In front of the face was a 'food vessel,' $4 \frac{1}{2}$ in. high, $4 \frac{3}{4}$ in. wide at the mouth and $2 \frac{3}{4}$ in. at the bottom. It is shaped roughly like fig. 71 , and is but slightly ornamented, having a row of dotted impressions running round the inside of the lip of the rim, the outside of which has three encircling lines of thong-impressions upon it; at the shoulder are two encircling rows of short lines, inclining to the right, made by a bluntly-pointed tool. At a distance of $7 \mathrm{ft}$. north-north-west of the centre, and $1 \mathrm{ft}$. above the natural surface, was the body of a large man, laid on the left side, and whose head, when there, must have been to $\mathrm{W}$. by $\mathrm{N}$. The head and part of the back had however been cut away when the partial opening before alluded to had been made. Another body, that of a woman, seems to have been discovered on the same occasion, for portions of the skulls and other bones of three adults (some of them clearly belonging to that one a part of whose skeleton was still left undisturbed) had been collected together, and put into a hole made below the pelvis of the partially removed body. Immediately north-west of the present centre was the edge of a grave, lying north-by-west and south-by-east, $5 \frac{1}{2} \mathrm{ft}$. by $4 \frac{1}{2} \mathrm{ft}$. and 
$3 \frac{1}{2} \mathrm{ft}$. deep. Close to the north side of the grave, and just below its surface, was a deposit of burnt bones, those of a child at least twelve years old, and immediately underneath them, at a depth of 6 in., was a 'food vessel,' in form like fig. 69, quite destitute of ornamentation, $3 \frac{5}{8}$ in. high, $4 \frac{7}{8} \mathrm{in}$. wide at the mouth, and $2 \frac{1}{2} \mathrm{in}$. at the bottom. Though not in actual contact with the bones, there can be scarcely any doubt that the vessel was intended to be associated with the interment; and though it is not usual to meet with the vase separate from the body, yet it has been found in other instances a little apart from it. At the bottom of the grave, which was flagged with chalk slabs, and on the south side of it, was the body of a young man about 24 years of age, laid on the right side, with the head to S.S.E., the hands being up to the face. In front of the chest was a curved pin, made from the tusk of a boar [fig. 9]; it has three holes and the broken part of a fourth perforated through it at the broader end. From its form, and the place where it was found, there can be little doubt that it had served to fasten the dress of the buried person. Below the head was part of another boar's tusk, which has been rubbed down to a sharp edge on one side, and which seems to have been intended for a knife or some similar instrument. It will be remembered that an article of the same kind was met with in one of the Cowlam barrows [No. Ivii]. In front of the face were some of the bones of the right fore-leg of a young pig ${ }^{1}$, possibly the remains of food deposited with the dead man; as the several bones were in their proper order, it is probable that the flesh was still upon them when they were placed in the grave. Within the grave, but not connected with the body, were some bones of pig and the tooth of an ox; and also a bone implement [fig. 36]. A few potsherds occurred amongst the material of the barrow.

LXXI. On the opposite side of the narrow valley before mentioned, and, like the last barrow, situated upon a piece of wold which had never been cultivated, was another grave-mound. It was placed just to the west of one of the entrenchments so abundant on the wolds, and it had apparently been constructed at an earlier period than the mound which formed part of the defensive work, for the side of the barrow appeared to have been partly cut away

\footnotetext{
${ }^{1}$ In a grave under a barrow at Arras, East Riding, a body was discovered, and ' close to the upper part of the skeleton was part of the skull and two or three bones of the foreleg of a young pig.' Crania Brit., pl. 6, 7. p. 7.
} 
at that point. It was $36 \mathrm{ft}$. in diameter, $5 \mathrm{ft}$. high, and made of chalk and earth; the barrow at a distance of $12 \mathrm{ft}$. south-west of the centre being entirely formed of chalk, which gradually decreased towards the north-east, until, at a point a little beyond and to the east of the centre, it consisted wholly of earth. At a depth of one foot above the natural surface, and $8 \frac{1}{2} \mathrm{ft}$. south-by-east of the centre, was the body of a young person about 14 years of age, laid on the left side, with the head to E. by S., the right hand being on the hips, the left to the right elbow; it was covered over with chalk slabs. At the same level as the last body, and $7 \frac{1}{2} \mathrm{ft}$. south-west-bysouth of the centre, was the body of a child about a year old, laid with the head to S. Close to the child, and chiefly near its head, were many bones of a large man, having evidently been disturbed and replaced, and which probably belonged to a partially dismembered body found $6 \frac{1}{2} \mathrm{ft}$. south-west-by-west of the centre. This body (that of a man of considerable strength and at least 30 years of age), as well as could be judged from what was left of it, had been placed on the right side, with the head to W. by N., the right hand being to the hips, the left arm extended down the side. The lower part of the body had been cut away; and the bones which were found close to the child corresponded in size with those of this skeleton, and they were moreover the bones which were absent from it; the upper part had not been interfered with. To the south of the centre, and about $1 \frac{1}{2} \mathrm{ft}$. above the surface-level, were a number of calcined human bones widely scattered. A foot higher than the last-named body, but a little nearer to the centre, was another body, probably that of a boy from 16 to 18 years of age, laid on the right side, with the head to W.N.W., the hands being in front of the chest. At a distance of $9 \mathrm{ft}$. south-south-west of the present centre of the barrow, measuring to its own centre, was an oval grave, north-west and south-east, $9 \frac{1}{2} \mathrm{ft}$. by $6 \mathrm{ft}$. and $5 \mathrm{ft}$. deep, principally filled in with chalk. At a depth of $4 \mathrm{ft}$., and placed about the middle of the grave, was the body of a young woman from 18 to 20 years of age, laid on the right side, the head to S., the hands up to the face, in front of which was a 'food vessel.' Below the head was a round flint scraper, at the right elbow three bone beads, and below the hips a fourth bone bead and a small bronze drill or awl. The body had flat pieces of chalk set round it, and just in front of the hips were the bones of the right fore-leg and some of the ribs of a young pig, and an astragalus of a goat or sheep; the remains, no doubt, of food placed 
in the grave at the burial. In the account of the last-described barrow a similar occurrence will be found noted. The 'food vessel,' which is in its general form somewhat like fig. 71, has six slightlyprojecting pierced ears at the shoulder, which are more than the usual depth, being $1 \frac{1}{4} \mathrm{in}$. deep. The vase is $4 \frac{7}{8} \mathrm{in}$. high, $5 \frac{1}{4} \mathrm{in}$. wide at the mouth and $3 \frac{3}{8}$ in. at the bottom. The inside of the lip has two encircling lines made by impressions of short pieces of twisted thong nearly touching each other; similar impressions, but arranged vertically, are placed on the edge of the lip. The remainder of the vase to within $1 \frac{3}{4} \mathrm{in}$. of the bottom is covered with twelve encompassing lines of thong-impressions, and the space below that has on it lines of similar impressions, but arranged vertically and slightly radiating from the bottom. The three bone beads first found have patterns upon them [fig. 50], principally of various forms of the cross, worked upon both faces; this has been effected by burning part of the surface with a sharp-pointed implement, so that the device shows in white on a dark ground, or black on a white ground; the fourth bead, which was found under the hips, though of precisely the same shape and size as the other three, is quite plain. The drill [fig. 39] is square at the middle, then becomes round, and tapers away to a very fine point at each end; it is $1 \frac{5}{8}$ in. long. A foot below the last body, and on the bottom of the grave, was the body of an aged and powerfully-made man, laid on the left side, the head, which was close to the north-east end of the grave, being to N.E. by E.; the arms were crossed, the hands being placed upon the opposite elbows. Turfs had been laid over and round the body. Near to the head, but scarcely in connection with the interment, were the half of a flint knife and a round scraper of the same material. They had probably been at one time associated with one or both of two disturbed bodies (an adult and a child), abundant remains of which were met with throughout the filling-in of the grave.

At the centre of the barrow, for about a space of $5 \mathrm{ft}$. in diameter, and above $6 \mathrm{in}$. in depth, and commencing $16 \mathrm{in}$. below the surface of the mound, was a deposit of dark-coloured earth, containing a great quantity of charcoal and other burnt matter. In this deposit were many large fragments of imperfectly calcined human bones, namely, parts of a skull, a tibia, femur and humerus, apparently belonging to a single adult body. They were widely scattered, here and there, and did not present anything like the appearance of an ordinary interment of a burnt body. About the middle of 
this dark mass, and $4 \mathrm{ft}$. above the surface-level, was the body of probably a man, about 25 to 30 years of age, laid on the left side, with the head to E.N.E., and the hands up to the face. In front of the knees was a vessel of pottery, too much broken and decayed to admit of either its size or shape being accurately defined. It has much of the form of a einerary urn, having an overhanging rim which is ornamented with four encircling rows of oval impressions in pairs, and having a similar row below the rim; it appears to have been about $5 \mathrm{in}$. high.

Five feet north of the centre, and about $1 \mathrm{ft}$. above the surfacelevel, was the body of a young child, the head being to $\mathbf{S}$. At a distance of $8 \mathrm{ft}$. north-west of the present centre of the barrow was the centre of a second grave, which probably had been originally at the point from whence the mound was commenced, but which, in consequence of the barrow having been placed on the sharp slope of the hill, and the material having a tendency to fall towards the south-east down the slope, had thus become so far as $8 \mathrm{ft}$. distant from the present centre. Before describing the contents of this grave it will be necessary to mention that $8 \mathrm{ft}$. north-north-east of the centre, and at a level of $1 \mathrm{ft}$. above the surface of the ground, were found the remains of a body, part of which had been removed, and the skull apparently belonging to which was subsequently discovered in the grave. The body was laid on the right side, the head having been to $\mathrm{N}$. when the skull was present; the lower jaw, the vertebral column, the right femur, the bones of the pelvis and the tibias were however there, and in their proper positions. Upon the knees was a small round flint scraper. At a distance of $6 \mathrm{ft}$. north-by-west from the centre, and within the limits of the grave just above mentioned, being $1 \frac{1}{2} \mathrm{ft}$. below the surface-level, was the body of a man past the middle period of life, laid on the left side, the head to E.S.E., with the hands up to the face. The back was not bowed forward as is usual, but was quite straight, and the femurs stood out at right angles from it. Just beyond the knees was a skull, probably of a man in the middle period of life, with no lower jaw, and which there cannot be much doubt belonged to the body previously described as having been found without a skull, and which had been in part disturbed when this body had been placed in the grave. In front of the face of the undisturbed body, indeed touching the teeth, were two round flint scrapers, whilst under the head was a third and larger one. A line of decayed wood, lying parallel to the body and in front of it, 
about $2 \mathrm{ft}$. long, may very possibly represent what had once been a club, or other implenent of wood. Throughout that part of the barrow which was above the grave, and in the grave itself down to the level of the last-described interment, were several disturbed bones of two bodies, an adult and a child. The grave was oval, having a direction east-by-south and west-by-north, $6 \mathrm{ft}$. long, $4 \frac{3}{4} \mathrm{ft}$. wide, and $4 \mathrm{ft}$. deep. At the bottom and about the centre was the body of a man in the middle period of life, laid on the right side, with the head to N.E. by E., and the hands in front of the chest. Under the neck was a small conical bone button $\frac{1}{2}$ in. in diameter, similar in shape to the jet buttons which have been frequently met with, and before described. Behind the shoulders was a 'food vessel.' The head had been protected by three flat pieces of chalk set on edge, with another laid upon them, and the vase was placed just outside them. Close to the feet were the 'trotters' of a young pig, making the third instance in the two barrows now under notice where portions of animal food had apparently been deposited in connection with the interments.

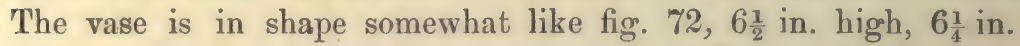
wide at the mouth, and $3 \mathrm{in}$. at the bottom. The inside of the lip has three encircling lines of thong-impressions, very irregularly placed. The whole vessel is covered with slightly-made impressions of loosely-twisted thong, arranged without any order and forming no pattern. The paste is full of large pieces of stone, and the vessel is as rude and badly manufactured as it is possible to conceive. There was an absence of chippings or implements of flint amongst the material of this mound, as was also the case in the barrow last deseribed, but a few pieces of different kinds of pottery were found here and there. The jaw of a large dog and the tooth of an ox were also met with amongst the undisturbed material.

The discovery of the beads, with their peculiar marking, requires a more special notice than has yet been given to them. The cross which in various forms appears upon them must, I think, be regarded merely as ornamental, and not as having any symbolical meaning, though it does not in this instance seem to fit in with the form of the article to which it is applied so naturally as upon the buttons already noticed. I am inclined to think that the very variety itself under which the form occurs is in favour of its being decorative, for had it been intended to serve as a representation or symbol of some religious or other idea, it seems searcely likely that 
it would have been so carefully varied in each instance, nor would the primary and simple form have been so much departed from. This is the first time that I have met with the cross, except as an ornament upon buttons and upon the bottoms of sepulchral vessels, but a very remarkable instance of the discovery of articles all but identical is recorded by Sir R. Colt Hoare ${ }^{1}$, who found four bone objects in a barrow in Wiltshire, which can only be regarded as beads, though they are not perforated. As in the case of those under notice, three of them were ornamented and one plain, and the ornament is so much alike in both the Yorkshire and Wiltshire specimens that the one set might almost pass for the other. This identity is very notervorthy, for though with the same people, at the same time, and living under much the same conditions, it might naturally be looked for that the various articles of domestic, agricultural, and warlike purpose should partake of the same shape, and even be decorated after much the same fashion, it is nevertheless striking to find that two sets of beads, discovered in places so widely separated as Yorkshire and Wiltshire, should be not only the same in shape, number, and material, as well as in the style of ornamentation, but even in the absence of all pattern upon one of the beads in each set. It would almost seem as though there had been something more in this instance than a general intercourse or community of thought between the two places in question. At the same time, it must be remembered that there is a very striking resemblance between many manufactured articles belonging to this period and occurring over wide areas.

\section{Parish of Cherry Burton. Ord. Map. xcrv. s.w.}

The group of barrows to be now described is situated on a different part of the wolds from any yet examined, being placed towards the south-eastern boundary of the chalk range. They were eight in number, six of them being placed in a line, running east and west, at no great distance from each other; the other two lying a little further to the north. They were situated upon Cherry Burton Wold, and about half-a-mile to the south of the site of the village of Gardham, one of those now destroyed centres of a comparatively late population of which several are to be met with 
on the wolds ${ }^{1}$. The remains of the village, in the shape of foundations of houses and other enclosures, show that it had been of considerable size.

I opened seven of the group, finding that three of them had been already dug into and the burials disturbed. The eighth also presented some appearances of having been tampered with, and was consequently left unexplored.

LXXII. To commence with that which lay most to the east. It was $49 \mathrm{ft}$. in diameter, $3 \frac{1}{2} \mathrm{ft}$. high, and made of earth and chalk. At the centre, in an oval hollow, lying east and west, $4 \frac{3}{4} \mathrm{ft}$. by $3 \frac{1}{4} \mathrm{ft}$. and $1 \mathrm{ft}$. deep, was the body of a large and strongly-made middle-aged man, laid upon the left side, with the head to S.E. and the hands up to the face. There was a good deal of burnt earth and chareoal about the body.

LXXIII. The second barrow, just west of the last, was $46 \mathrm{ft}$. in diameter, $3 \mathrm{ft}$. high, and made of earth with a little chalk intermixed. Three feet and a-half east-north-east from the centre, and $2 \frac{1}{2} \mathrm{ft}$. above the natural surface, was a cinerary urn reversed, and containing the burnt bones of a very young ehild. It was too much decayed to admit of the exact size being ascertained. The ornamentation, which is confined to the overhanging rim, is of a herring-bone pattern, and has been made with a sharp-pointed tool. Three and a-half feet west-south-west of the centre, and at the same level as the last, was another cinerary urn also reversed, and filled with the burnt bones of a person of mature age. This urn was likewise in the same decayed condition as the last, and is ornamented upon and immediately below the overhanging rim with a herring-bone pattern of twisted-thong impressions. Flint blocks had been placed round the two urns, but the bottoms of both had been destroyed by the plough. Between the urns, but nearer to the more eastern one, was a circular hollow $1 \frac{3}{4} \mathrm{ft}$. in diameter and $1 \frac{1}{2} \mathrm{ft}$. deep, filled in with burnt earth and some charcoal placed around a third cinerary urn also reversed, and containing the burnt bones of a young person. This vessel, in shape like fig. 61, and of good form and manufacture, is $11 \frac{1}{4} \mathrm{in}$.

1 It is difficult to say when these villages became deserted, but it is not unlikely that it took place in the fifteenth and early part of the sixteenth century, when the great impulse given to the trade in wool, through commercial intercourse with the Low Countries, had caused a large proportion of the arable land to be thrown into sheep farms. 
high, 9 in. wide at the mouth, and $3 \frac{3}{4}$ in. at the bottom. The rim, which is 2 in. deep, has upon it a reticulated pattern placed between double encompassing lines. The lip of the rim has on the outside one encircling line, and on the inside two, of oval impressions; below those on the inside is an eneircling line, immediately below which is a band of loops, each $1 \frac{1}{2} \mathrm{in}$. deep and $\frac{1}{2}$ in. wide, forming a series of arches, having below them an encircling line similar to that above. Below the rim are five encompassing lines, rather irregularly placed, and below these lines a row of oval marks encircles the urn. The pattern, except that made by the oval marking, is due to impressions of twisted thong. In the hollow above named was part of a human frontal bone, unburnt. The barrow had charcoal mixed in its material throughout; some pieces of the antler of a red-deer were found in it.

LXXIV. The fourth barrow in the line was $20 \mathrm{ft}$. in diameter, $1 \frac{1}{2} \mathrm{ft}$. high, and made of earth. At the centre was a very slight depression in the natural surface, and in it were deposited the remains of the burnt body of an adult, laid in a round heap about 10 in. in diameter. The body had been burnt on the spot, the hollow having been first made.

LXXV. This barrow, one of the two placed to the north of the line of six before referred to, was $46 \mathrm{ft}$. in diameter, $2 \frac{1}{2} \mathrm{ft}$. high, and made of earth. Just above the natural surface was a layer of calcined chalk and flint about 6 in. thick, which was very hard, being nearly as compact as slag. It extended over the greater part of the area of the barrow. At the centre, below this hard layer, was a slight hollow, showing within and around it abundant evidence of sustained heat; a funeral pile having clearly been built over the hollow and a body burnt on the spot. In the hollow there were a very few burnt bones of a full-grown person, and when the imperfect way in which they were burnt is considered, it seems scarcely probable that all the remains of the body could have been placed there. Some portions of a cinerary urn were found amongst the soil disturbed by the plough.

The three barrows which on examination proved to have been opened on some previous occasion presented no features worthy of special notice, and have therefore not been particularly described. They had all contained burials after cremation. 
It will be remarked that, contrary to the ordinary custom of burial on the wolds, this group was found to contain, with one exception, bodies which had been interred after having been burnt. In the seven barrows which were examined nine places of interment were met with, and of these there was but one where an unburnt body had been buried. The same departure from the prevailing custom will be found in a section of a large group of barrows to be presently described, where thirteen burials in five barrows had all been after cremation.

\section{Parish of Etton. Ord. Map. xciv. s.w.}

About a mile to the north-east of the village of Etton there are five small barrows lying a little apart from each other. Two of

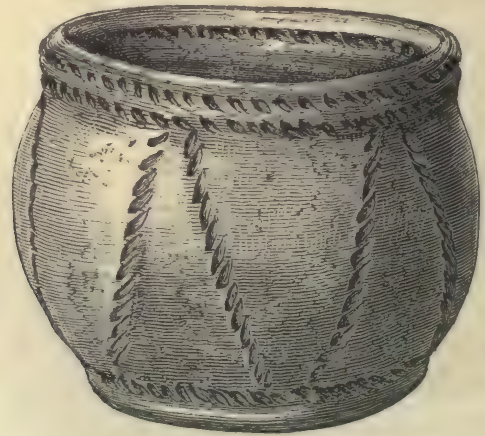

Fig. 128. $\frac{?}{3}$.

them had been opened many years ago with I know not what result, the remaining three $\mathrm{I}$ examined.

LXXVI. The first was $50 \mathrm{ft}$. in diameter, $1 \frac{1}{2} \mathrm{ft}$. high, and made of earth. It contained a single interment at the centre, that of an adult woman. The body had been burnt on the spot, over a hollow $3 \mathrm{ft}$. wide and $9 \mathrm{in}$. deep, in which the bones were found deposited. At the west side of this hollow, with some charcoal placed round it, was a small vessel of pottery [fig. 128], and amongst the bones was a broad flint flake calcined. The site of the funeral pile, which was very clearly defined by the reddened earth, occupied a space of $7 \mathrm{ft}$. in diameter. In the barrow were found the half of a long flint seraper and several flint chippings. 
LXXVII. The second barrow was $46 \mathrm{ft}$. in diameter, $1 \frac{1}{4} \mathrm{ft}$. high, and, like the last and the next to be noticed, made of earth. At the centre, upon the natural surface, was the body of a strongly-made and very tall man of advanced age, laid on the right side with the head to N.; the right hand was at the knees, the left on the hips. The body was only slightly contracted, the distance between the crown of the head and the knees being $4 \frac{1}{2} \mathrm{ft}$.

LXXVIII. The last barrow of the group was $45 \mathrm{ft}$. in diameter and $1 \frac{1}{2} \mathrm{ft}$. high. It contained, like the other two, a single interment, that of a strongly-made man past middle life, who had been laid on the right side in a very shallow grave, with the head to N. The bones were too much decayed to admit of the position of the hands being ascertained.

LXXIX. About two miles to the north of the group of barrows near Gardham lately described, and situated upon Etton Wold, are four if not more sepulchral mounds, three of which I examined. The first was $60 \mathrm{ft}$. in diameter, $1 \frac{3}{4} \mathrm{ft}$. high, and made of earth with some chalk and flint stones intermixed. At a distance of $14 \mathrm{ft}$. south-west-by-south from the centre, and laid upon the natural surface, were a few burnt bones of an adult, with some burnt chalk close to them. At what had no doubt originally been the centre, though now $8 \frac{1}{2} \mathrm{ft}$. west-by-south of the present centre, were the remains of a burnt body, placed in a hollow about $2 \frac{1}{2} \mathrm{ft}$. in diameter, and excavated to a depth of $10 \mathrm{in}$. below the natural surface. The body, probably of a male adult, had been burnt on the spot, and the bones had never been removed from the place where the body had been laid on the wood of the funeral pile, abundant remains of which, in the shape of charcoal, were found beneath the bones. The body had been placed in the usual contracted position, on the right side, with the head to N.E. by E., and behind the hips was found a vessel of pottery, whilst close to the bones of the chest was a small piece of bronze, apparently the remains of a drill or awl, which had been burnt with the body. With the human bones were found the burnt scapula, radius, and ulna of a young pig, probably. the remains of food deposited on the funeral pile. It will be remembered that in two of the barrows on Flixton Wold [Nos. 1xx, lxxi] a similar deposit was met with, though there the animal bones, as well as those of the buried hody, were 
unburnt. The vessel, a rudely-made one, is of the type of the cinerary urn, like fig. $56,6 \frac{3}{4}$ in. high, 5 in. wide at the mouth, and $3 \mathrm{in}$. at the bottom. Two lines encompass the inside of the lip of the overhanging rim, whieh is $1 \frac{5}{8} \mathrm{in}$. deep, and the outside of the lip has a single encircling line, whilst below is a pattern of triangular spaces filled in with lines, like that described at p. 71 . All the lines are made by impressions of twisted thong. There appeared to be something like a circular wall of flints and chalk, but very irregularly formed, enclosing the place of burning, its diameter being about $11 \mathrm{ft}$. Amongst the material of the mound was a fragment of a 'food vessel,' and another of a cinerary urn.

The two barrows next to be described were situated about halfa-mile to the west of the last one; but, unlike it, they were placed in a valley, upon a deposit of chalk gravel. As was found to be the case in the last barrow, and in almost all those at Gardham, these contained interments after cremation.

LXXX. The first was oval in form, being $70 \mathrm{ft}$. by $62 \mathrm{ft}$.: this was probably due to the action of the plough, and not to any departure from the ordinary round shape in its original construction. It was still, though much reduced by cultivation within the last few years, $4 \mathrm{ft}$. high ; and it had a further elevation from its having been erected upon a knoll. It was composed principally of earth, with some chalk and flint interspersed. At the centre was a deposit of burnt bones, those of an adult, probably a man, placed in a circular hollow $1 \frac{3}{4} \mathrm{ft}$. in diameter and sunk to a depth of about $1 \mathrm{ft}$. below the surface of the ground. The body had been burnt on the spot, and the bones then collected and deposited in the hollow which had been first made; over the bones was laid a large quantity of chareoal, the remains no doubt of the funeral pile.

LXXXI. The second barrow was $60 \mathrm{ft}$. in diameter and still $3 \frac{1}{2} \mathrm{ft}$. high, though, like the last, it had been much reduced in height by the action of the plough. It was composed of earth, with some chalk and flint intermixed. At the centre was a hollow, excavated in the chalk gravel, $14 \mathrm{in}$. in diameter and $1 \frac{1}{2} \mathrm{ft}$. deep, in which was a deposit of the burnt bones of a child, not above three years old, resting upon a layer, $2 \mathrm{in}$. thick, of black-coloured sand full of pieces of charcoal, and having another layer, 8 in. thick, of 
similarly-coloured sand over the bones. The body had not been burnt on the spot.

LXXXII. About a mile to the north-west of the two barrows last described I examined another. It was placed upon the slope of the hill about two-thirds from the bottom, and was $46 \mathrm{ft}$. in diameter, and still $1 \frac{1}{2} \mathrm{ft}$. high, though much ploughed down. It was made up of earth, with a little chalk here and there. In it two graves were discovered, lying $8 \mathrm{ft}$. apart, and being respectively north and south of the centre, which was midway between them. That to the south was $4 \frac{1}{1} \mathrm{ft}$. long, $2 \frac{1}{2} \mathrm{ft}$. wide, and $2 \frac{1}{4} \mathrm{ft}$. deep, and had the longer axis east and west. In it, on the bottom and at the middle, was a deposit of burnt bones, those of two bodies, one an adult woman, the other a child under 7 years of age; they were laid in a round heap, $13 \mathrm{in}$. in diameter. Amongst the bones was deposited a flint knife, unburnt [fig. 129], $2 \frac{7}{8}$ in. long and $\frac{7}{8}$ in. wide, by far the most beautiful speeimen I have yet met with; it is very delicately flaked over the whole of the convex surface, the edges being serrated with the greatest skill and regularity. It is another example of those implements which, when associated with interments after cremation, have been usually found to be themselves unburnt.

The northern grave was $4 \mathrm{ft}$. long, $2 \frac{3}{4} \mathrm{ft}$. wide, and $2 \mathrm{ft}$. deep, with the longer axis in a direction north-north-west and southsouth-east. The grave was covered over at the top with large blocks of flint, amongst which was placed about the third part of what had been, when complete, one of that class of vessels to which the name of 'food vessel' has been given. The fragment was quite perfect, and comprised a portion reaching from the rim to the bottom of the vase, and it must have been when deposited there in the same imperfect condition in which it was discovered. It is $5 \mathrm{in}$. high, and has been about $6 \mathrm{in}$. wide at the mouth, and is ornamented to a depth of $2 \frac{1}{2} \mathrm{in}$. with ten encircling rows of lines of twisted-thong impressions arranged herring-bone fashion, the inside of the lip of the rim being similarly ornamented. On the bottom of the grave, and at the northern end, was the body of 
a child, a little under three years old, laid on the left side, with the head to N.N.W. Close to the hips was a round urinary calculus of the ordinary character, about the size of a large pea. Near to the front of the neck was a bone pin, very much decayed.

\section{Parlsh of Goodmanham. Ord. Map. xoIv. s.w.}

We arrive now at a very large group of barrows situated upon Goodmanham Wold, and lying to the north of that last described. There are still above forty, and it is known that some have been entirely removed for agricultural purposes, no trace of them being now left at the sites on which they were once placed. A few of those remaining were opened by the late Lord Londesborough and others, a record of which will be found in vol. xxxiv. of the Archæologia, p. 256.

The whole district is replete with archæological interest. Lines of entrenchments abound, showing, in connection with the numerous sepulchral mounds, that the country "was largely settled in prehistoric times. In the immediate vicinity, at Arras and Hessleskew, were discovered in 1815 and the two following years the largest number of burials belonging to the Early Iron Age which has been met with in England. The remains of chariots, beautifully ornamented fibulæ and armlets, with other articles (testifying to the artistic feeling and manufacturing skill of those people), give evidence of a population which had attained to is degree of cultivation that it has not been usual to attribute to the inhabitants of Britain before the Roman occupation. Of the time when this country was a province of the Roman Empire not many remains have been discovered in the district in question, but cemeteries of burnt and unburnt bodies, the former enclosed in characteristic urns, and isolated burials, where numerous ornaments and articles of personal use have been abundantly met with, show that it was largely occupied by an early Anglian population. It did not indeed require the aid of archæological research to prove this, for historical records tell us that Goodmanham was one of the principal sacred places of pagan Northumbria; and in connection with the missionary Paulinus, it was the spot with which one of the most picturesque and interesting stories detailed by Bæda is connected ${ }^{1}$. 
There is a remarkable fact connected with the pre-historic occupation of this district of the wolds, and one which it is not easy to explain, and that is the great scarcity of implements of flint or other stone throughout the whole of this portion of the chalk range. Whereas, in other parts of the same tract of high land, implements are found abundantly, in this part they are of very rare occurrence; and this is shown most clearly not only by their infrequency upon the surface of the land, but also by the small number that an extensive examination of the barrows has brought to light. It is impossible to account for this scarcity of implements on the supposition that the country was not so thickly peopled here as elsewhere on the wolds, for other and equally convincing evidenees of occupation are as abundant, if indeed they are not even more so; nor is it easy to understand what more perishable material could have been used in the place of stone, and which it might be supposed had gone to decay. Were the absence of implements noticeable merely in the barrows, that would not have created much difficulty, for the custom of placing such articles in association with the dead is so capricious, that it is impossible to draw any safe conclusion from the contents of the sepulchral mounds as to the general diffusion of any especial instruments of warlike, domestic, or agricultural use in any particular locality. But that does not hold good with regard to the casual finding of the implements in question during the course of the ordinary operations of the farm; for had they been in common use at any time, it is certain that they must have been found, here as well as elsewhere, when the land was turned over, and when they would naturally become exposed upon the surface of the ground. I can offer no solution of this difficulty, and I must leave it to the more ingenious speculation of others, as an interesting, though by no means an easy, subject of enquiry.

The first five barrows which I examined were those lying the furthest to the east of the whole series, and contained, as has already been noticed, burials after cremation.

LXXXIII. The first was $48 \mathrm{ft}$. in diameter, $3 \frac{1}{2} \mathrm{ft}$. high, and made of earth with some flints amongst it. Thirteen feet east of the centre, and about 6 in. above the natural surface, was a small vessel of pottery, standing upright and surrounded with burnt earth and charcoal. The vessel is in shape like fig. 130; the overhanging rim, to which the ornamentation is confined, being $2 \mathrm{in}$. 
deep. The urn itself is $6 \frac{1}{4} \mathrm{in}$. high, $4 \frac{1}{2} \mathrm{in}$. wide at the mouth, and $3 \frac{1}{4}$ in. at the bottom. The pattern consists of lines placed very irregularly, but apparently representing the triangular figure described at p. 71 , and is made by small punctured markings. One foot west of this, with its bottom on a level with the top of the last, was a second vessel, also placed upright, and surrounded with burnt earth and chareoal. This vessel is a miniature einerary urn, in shape like fig. 61 . It is $4 \frac{1}{4} \mathrm{in}$. high, $3 \frac{5}{8} \mathrm{in}$. wide at the mouth, and $2 \frac{3}{8} \mathrm{in}$. at the bottom. The overhanging rim is completely covered with eneompassing lines of twisted-thong impressions, placed very elose together; below the rim a zigzag line $1 \mathrm{in}$. deep, of thong-impression, encircles the vessel. The remains of the two burnt bodies, with which the urns had been deposited, singularly scanty in quantity, were placed amongst the burnt earth, and close to their respective vases. In the first case the bones were those of a young person; in the second, those of a child. With the bones of the former was a piece of calcined flint. There was no trace of an interment at the centre of the mound, and the original surface of the ground had not been disturbed to make a grave. Amongst the materials of the barrow were two flint chippings and a well-formed long flint scraper.

LXXXIV. The second barrow was $36 \mathrm{ft}$. in diameter, $2 \mathrm{ft}$. high, and made of earth. Fifteen feet east-south-east of the centre was a deposit of burnt bones, very few in number, laid upon the natural surface, and covering a space of about one foot in diameter; the body had been burnt on the spot. Eleven feet south of the centre, and at a level of one foot above the natural surface, was a second burnt body, of which the remains, as in the case just mentioned, were very scanty; this also had been burnt on the spot. Four feet and a-half east of this was a third burnt body, that of an adult, laid at the same level as the last-named, and though the bones were in excess of those in the other cases, still they were very few in number; this body had also been burnt on the spot. Nine feet south-east of the centre, and at the same level as the last two bodies, was a vessel of pottery, laid upon its side with the mouth to the east, and beneath it lay an 'incense cup.' The vessel is somewhat like fig. 58 , but not having so deep a rim, $4 \frac{1}{2}$ in. high, $4 \frac{1}{8}$ in. wide at the mouth, and $2 \frac{1}{2}$ in. at the bottom. The rim, $1 \frac{3}{8}$ in. deep, is ornamented with three bands of lines, arranged vertically, and made by a sharp-pointed tool; below them, 
for the space of an inch, the vessel is marked with oval punctures irregularly placed. The 'incense cup' is $1 \frac{1}{4} \mathrm{in}$. high, and $2 \frac{1}{2} \mathrm{in}$. wide at the mouth; it has perfectly straight sides, and is quite unornamented, except on the flat top of the rim, which has some irregular marks upon it. There had been much burning at the place where the two vessels were laid, and they were surrounded by burnt earth and charcoal on all sides; but there was only one single piece of burnt bone, which lay in contact with the side of the upper vase. Six feet east of the centre, and at a height of 16 in. above the natural surface, was a burnt body, the bones of which, those of a person of full age, were laid in a round heap $9 \mathrm{in}$. in diameter. Amongst them was a calcined flint knife, $1 \frac{7}{8}$ in. long and $\frac{3}{4}$ in. wide, having one edge curved. This body had also been burnt on the spot. Six feet west-south-west of the centre, and at the same level as the last, was another burnt body, the remains being disposed around a vessel of pottery, which was standing upright, but did not contain any of the bones; this body, that of a young person, had been burnt on the spot. The vessel, which is in shape much like the last, has an overhanging rim $1 \frac{1}{4}$ in. deep, and is $3 \frac{1}{2}$ in. high, $3 \frac{7}{8} \mathrm{in}$. wide at the mouth, and $2 \frac{3}{4} \mathrm{in}$. at the bottom, being quite devoid of ornamentation. Six feet east-north-east of the centre, and placed upon the natural surface, was a burnt body, which, unlike the others, had not been burnt on the spot. The bones, those of an adult, were laid in a round heap $10 \mathrm{in.}$ in diameter. At the centre, and $1 \frac{1}{2} \mathrm{ft}$. above the natural surface, was a vessel of pottery reversed, set amongst burnt earth and charcoal, with a very few burnt bones; the body to which these remains belonged had been burnt on the spot. The vessel [fig. 61] is very beautifully made, a most perfect cinerary urn in miniature. It is $4 \frac{1}{2} \mathrm{in}$. high, $3 \frac{5}{8}$ in. wide at the mouth, and $2 \frac{3}{8}$ in. at the bottom. The ornamentation, which is confined to the upper part of the urn, consists of a herring-bone pattern, the lines of which have been made by a sharp-pointed tool. It will be observed that both in this and the last-described barrow the remains of the bones were exceedingly scanty, in some cases being almost entirely wanting. The character of the vessels of pottery presents another point of connection between the several burials; the features also of these vessels are so marked, and they are themselves so different from those usually found accompanying burnt bodies but not enclosing the bones, that they may be fairly supposed to have proceeded, if not from the hands of the same 
maker, at all events from what may be designated as one manufactory. These two facts seem to lead to the inference that no great length of time had elapsed between the burials in these two barrows; and possibly one or more of those about to be described may be included in the same category.

LXXXV. The third barrow was $42 \mathrm{ft}$. in diameter, $2 \mathrm{ft}$. high, and made of earth. At the centre, and upon the natural surface, which at this point was a swell of the chalk rising higher than the adjoining rock, was a deposit of burnt bones, consisting of the calcined remains of two children, one of whom had died during the period of the first dentition; the bodies had been burnt on the spot. Amongst the bones was a vessel of pottery standing upright and set upon a second one, which was laid on its side, with the mouth to the west, both being rude and ill manufactured. The first vase is of the cinerary type, like fig. 130, with an overhanging rim, and perfectly plain ; it is $6 \frac{1}{4} \mathrm{in}$. high, $5 \mathrm{in}$. wide at the mouth, and $3 \frac{1}{4} \mathrm{in}$. at the bottom. The second vase is also of the cinerary type, with an overhanging rim, and, like the first, quite devoid of ornamentation. It is $8 \frac{1}{4} \mathrm{in}$. high, $5 \frac{3}{4} \mathrm{in}$. wide at the mouth, and $2 \frac{3}{4} \mathrm{in}$. at the bottom. In this case the presence of two sepulchral vessels, in association with the bones, is to be accounted for by the fact that they represented two bodies. Cases however have been met with where a single interment has been accompanied by more than one vessel, and in this group of barrows it will be found that in a grave where a woman and child were buried there were three 'drinking cups.'

This is not the first instance where the principal interment in a barrow has been that of a child; the most remarkable one being in the large mound at Rudstone [No. Ixvii], where the burial was that of an infant. Here there were two children, who may be supposed to have died about the same time, and who cannot, when the important nature of the sepulchral monument is considered, have been other than the children of a person of importance in the community. A fact like this, and especially when it is taken in connection with similar instances, appears to me to be of considerable importance, when the social condition and the place in civilisation of these people are in question; nor do I think it would be unfair to regard it as affording evidence that they had advanced beyond the state of semi-savage life.

LXXXVI. The fourth barrow was $57 \mathrm{ft}$. in diameter, $4 \frac{1}{2} \mathrm{ft}$. high, and made of earth, with some chalk intermixed. At the centre was 
a circular hollow, $3 \frac{1}{2} \mathrm{ft}$. in diameter, and about $9 \mathrm{in}$. deep, made in an artificial mound, which had been in existence before the barrow was raised; the summit of this mound being $3 \mathrm{ft}$. above the level of the natural surface. In the hollow was the body of a very large adult man, with delicately-made teeth; it had been burned, though not to such an extent but that all the bones and their position could be recognised without the least difficulty ; they were all still in their proper places, having evidently never been moved since the application of fire to the corpse ${ }^{1}$. The body was laid on the right side, the head to S.W., and the hands up to the face, in front of which was an urn standing upright. On the bottom of the

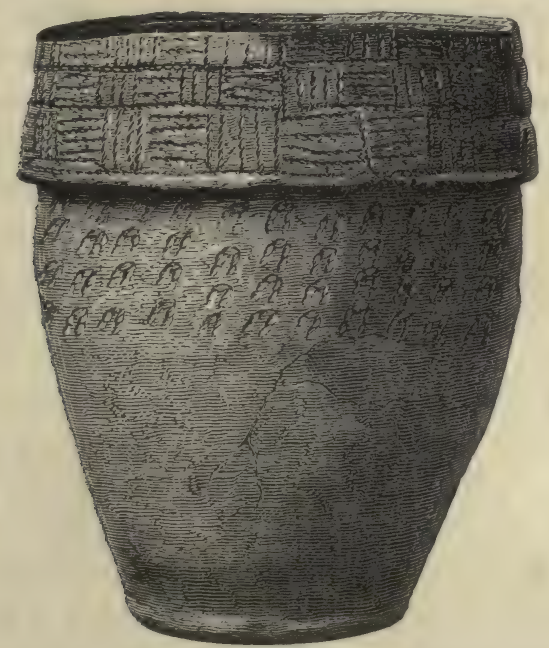

Fig. 130. $\frac{1}{3} \cdot$

hollow, below the bones, was a great quantity of charcoal, and the earth all round the hollow was much reddened by the action of fire. The urn [fig. 130] is of the cinerary type, with an overhanging

${ }^{1}$ It will be remembered that in the barrow on Etton Wold [No. Ixxix] a body was found in a similar condition to this. The same feature has occurred in Derbyshire, where in a barrow at Dale, near Stanton, Mr. Bateman says there 'lay two skeletons in a line, one at the feet of the other, which presented a mode of sepulture different from any yet found in our researches, from having been intentionally subjected to the action of fire upon the spot, in such a manner as to preserve the bones in their natural order, entire and unwarped by the heat. They were surrounded by charcoal and earth, to which a red colour had been imparted by the operation. ... All deposits of burnt bones previously found by us have been strictly calcined ... and have generally been gathered into a heap, or placed within an urn; so that here we find an exception to the general rule perfectly inexplicable.' Ten Years' Diggings, p. 125. It is unfortunate that Mr. Bateman does not record the position of the bones, and it is therefore impossible to say whether the bodies, like that described in the text, had been placed on the funeral pile in the usual contracted form. 
rim, $7 \frac{1}{2}$ in. high, $5 \frac{3}{4}$ in. wide at the mouth, and $3 \frac{1}{2}$ in. at the bottom. The rim is ornamented with three bands of alternate series of vertical and horizontal lines of thong-impressions counterchanged; below the rim the urn is marked, for a space of an inch in depth, with four encompassing rows of thong-impressions horseshoe-shaped. Amongst the materials of the barrow were a single potsherd, a flint core, and a round but flattened water-rolled quartz pebble, 2 in. in diameter, which has the centre of each face roughened by picking, probably to enable it to be the more firmly held between the finger and thumb. It shows many signs of use all round the edge, such as might have been produced by the action of taking flakes off a block of flint.

This was one of the most curious burials it has been my fortune to meet with, and it appears to supply some information as to the way in which the body was laid upon the funeral pile. It also suggests some considerations connected with cremation, which it may not be out of place here to entertain and weigh. It would appear then that the body was placed upon the wood before the burning, in the same contracted position in which I have, except in four instances, invariably found unburnt bodies deposited in their graves. Every bone could be identified most clearly, and each limb had been arranged after a fashion which, as we have seen, has been a very common one in the barrows. The knees were drawn up towards the head, which was brought somewhat forward towards the chest, and the hands were placed up to the face. The accompanying urn also occupied a position which is not unfrequent in the case of inhumed bodies, namely, in front of the face. In this remarkable cremated interment we thus obtain another point of contact between the practice of cremation and inhumation, in addition to those which similarity of weapons, implements, ornaments, and pottery, in either case deposited, has hitherto afforded, and one which seems to be even more important than they are. Whatever may have been the object or purport of placing the body in the ground in the contracted position, it was evidently thought to be a matter of equal importance, and to be equally observed, when the body was first subjected to the process of burning. It will have been observed that this flexed position of the body could not have originated in any mere desire to get it into as small a space as possible, for there are many instances, in the accounts above given, where in a grave more than fully long enough to have allowed a man of the largest stature to be laid at full 
length, the body has yet been placed quite at one side of the grave, and has occupied but a very small proportion of the entire excavated space. Some other reason then, rather than a mere desire to economise space, must be enquired for as the motive or object aimed at by these people in placing their dead in the grave in the position under notice; a position, moreover, such as to entail an arrangement of the limbs by no means easy of accomplishment, except when the body was manipulated immediately after death, which assuredly in a great many cases-such as death in the heat of battle or at a distance from home-could not have been very readily effected.

Although no proof may have been required, other than the almost unvarying circumstances themselves, under which the inhumed bodies are found, to demonstrate that there must have been some object or reason, quite independent of a desire to save space and consequently labour also, for placing the bodies of the dead in the remarkable position we are discussing, yet it is satisfactory to have the further confirmation afforded us by the arrangement of the body in this most note-worthy instance of cremation. For it enables us to assume with confidence that it was held to be a matter of equal importance, not to say necessity, that the body should be thus contracted even previously to burning, and when no visible evidence of such a disposition would ordinarily remain. I have thought it right to make these remarks here, though the whole subject is more fully discussed in the Introduction (p. 22), where I have also stated what in my opinion was the motive which induced the adoption of the contracted position referred to.

LXXXVII. The fifth barrow was $69 \mathrm{ft}$. in diameter, though only $1 \frac{1}{2} \mathrm{ft}$. high; it had no doubt been considerably ploughed down, but it must always have been of slight elevation in comparison with its area. At the centre, in a hollow, $2 \frac{1}{4} \mathrm{ft}$. in diameter, and sunk below the natural surface to a depth of $3 \mathrm{ft}$., was a deposit of the burnt bones of an adult, having some flint blocks arranged over them. The body had been burnt on the spot, the hollow having been first made, and the fire must have been very intense, for the ground was much altered in colour by it, and that too over a considerable space.

LXXXVIII. The next barrow, which was situated within a 
short distance of the one last noticed, departed from the rule which characterised the preceding five sepulchral mounds, and was the first of a series where the greater number of burials were by inhumation. It was $56 \mathrm{ft}$. in diameter, $2 \mathrm{ft}$. high, and made almost entirely of earth. At the centre was an oval grave, lying east and west, $10 \mathrm{ft}$. by $8 \mathrm{ft}$. and $4 \mathrm{ft}$. deep. On the bottom, at the east end, was the much decayed body apparently of a man, laid on the left side, the head to S.E., and the hands up to the face. Immediately over the bones was a large quantity of charcoal. In the grave, a little higher than the body just mentioned, was part of a human skull, but no other remains of the body to which it had belonged were met with either in the grave or in the mound itself, though it had probably been connected with an interment disturbed in making the grave, or in opening it to place therein a secondary burial.

LXXXIX. Another barrow of this group proved to be very prolific of interments, and possessed in addition some features of more than ordinary interest. It was $80 \mathrm{ft}$. in diameter, $4 \mathrm{ft}$. high, and was composed of earth, with here and there small deposits of chalk in layers. It was evident that the mound had originally been a smaller one, and that upon the surface of this several bodies had been burnt, additional material being afterwards added to cover the interments. This was distinctly shown not only by the difference between the colour of the earth forming the body of the barrow and that of the outer portion, but also by the presence of a dark line, which ran through it at a level of $3 \mathrm{ft}$. above the natural surface near the centre, and which was due to the remains of charcoal and partially-burnt earth, resulting from the fires made on the surface of the first mound to consume the bodies whose remains, as has already been stated, were found within it.

At a distance of $15 \mathrm{ft}$. south-by-east from the centre, and so near to the present surface of the barrow that the plough had disturbed it, were the fragments of a vessel of pottery; this had probably once been associated with an unburnt body, all trace of which had however disappeared. The vessel is somewhat like fig. 69, but has two raised ribs instead of one, and is quite plain; it is $6 \frac{1}{2}$ in. high, $5 \frac{1}{2}$ in. wide at the mouth, and $2 \frac{3}{4}$ in. at the bottom. Eighteen and a-half feet south-east-by-south from the centre, and $14 \mathrm{in}$. below the present surface of the barrow, was the spot where a body had been burnt, the remains of which were found in a hollow, $1 \frac{3}{4} \mathrm{ft}$. 
wide and $14 \mathrm{in}$. deep, excavated in the earlier mound already mentioned. The bones were those of an adult of uncertain sex, and amongst them was a piece of calcined flint, showing signs of work upon the edge. The hollow had been made, as in the case presently to be noticed, before the body was burnt, and the bones after cremation had been gathered together from the funeral pile and placed within it. The way in which the burning had been effected was evidenced by the deep red colour, gradually changing into black, with which the inside of the hollow was tinged, the colour extending to the earth around it for a space of about $4 \mathrm{ft}$. in diameter. Amongst the bones, and near the middle of the deposit, was a small vessel of pottery [fig. 131]. It is difficult to say to what class this

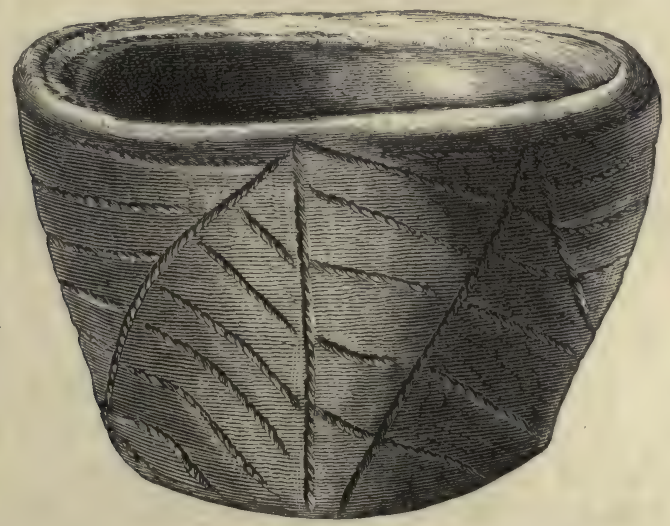

Fig. 131. $\frac{1}{1}$.

vase is to be attributed, for though it possesses somewhat of the appearance of an 'incense cup,' it has much in common with the 'food vessel.' In others of this group it will have been observed that anomalous forms of sepulchral vessels were met with, and specimens resembling the cinerary urn, in form though not in size, were found associated with burials after cremation, but not containing any of the bones; and in this barrow a small urn of the cinerary type accompanied an unburnt body. The vase is $1 \frac{1}{2}$ in. high, $2 \frac{1}{2}$ in. wide at the mouth, and $1 \frac{3}{4}$ in. at the bottom. The ornamentation is due to the impression of twisted-thong. At the same distance from the centre, but south-south-west of it, and at the same level as the burnt body just described, was a second one, that of a person, probably a female, of small size, under 25 years of age. The bones were placed in a hollow, $1 \mathrm{ft} .8 \mathrm{in}$. in diameter, and sunk to a depth 
of $1 \mathrm{ft} .5 \mathrm{in}$. below the surface of the original mound. This body also had been burnt on the spot, and the appearances, indicating the manner in which the burning had taken place, were the same as in the last case. Amongst the bones was an 'incense cup,' $2 \frac{1}{2}$ in. high, $2 \frac{3}{4}$ in. wide at the mouth, and $2 \frac{1}{2}$ in. at the bottom. It is ornamented on the inside of the lip with a row of irregular oval impressions; on the outside immediately below the lip are three encircling lines, and just below the widest part of the vessel, $1 \frac{1}{2}$ in. from the top, are three similar lines, the space between the two series being filled in with a pattern like the triangular one described p. 71; the impressions have been made with a sharppointed tool. The remainder of the vessel, for a depth of $\frac{3}{4}$ in., is quite plain. At a distance of $17 \frac{1}{4} \mathrm{ft}$. south-west of the centre, and at the same level as the last two, was a third burnt body, that of an adult, probably a male, placed in a hollow $1 \frac{3}{4} \mathrm{ft}$. wide and $1 \frac{1}{4} \mathrm{ft}$. deep. This body had not been burnt on the spot. At the west side of the hollow, and about 9 in. above the bottom, was an ' incense cup' [fig. 62] amongst the bones, the remains of the skull being those in immediate contact with it. It is $2 \frac{3}{8}$ in. high, $2 \frac{5}{8} \mathrm{in}$. wide at the mouth, and $2 \mathrm{in}$. at the bottom. The pattern is due to the impression of twisted-thong. There are two holes, $2 \mathrm{in}$. apart, pierced from the edge of the lowest of the three lines which encircle the vessel below the lip, to the middle of the inside of the lip, a novel position in my experience for such perforations. Ten feet south of the centre, and $1 \mathrm{ft}$. above the natural surface, was the body of a very aged person of uncertain sex, laid on the left side, with the head to N. by W., the right hand being up to the face, and the left under the head. At a distance of $11 \frac{1}{2} \mathrm{ft}$. south-east of the centre, and upon the natural surface, was a second body, that of a person of uncertain sex, between 20 and 24 years of age; it was laid on the right side, with the head to S.S.W., the hands being up to the face. In front of the head and chest there was a large flint block; and under the head and back, and extending beyond them, were the remains of wood, upon which that part of the body had been laid. The length of this deposit was $4 \mathrm{ft}$., but there was no appearance of wood having covered the body, or of its having been placed under the thighs and legs. Seven and a-half feet east of the centre, and $9 \mathrm{in}$. above the natural surface, was the body of an aged woman, laid upon the left side, with the head to N.E.; the arms were crossed, the right hand being under the left humerus, the left hand in the hollow of the right 
elbow. At the crown of the head, but a little behind and above it, was a vessel of pottery reversed. It is in form a perfect cinerary urn, like fig. $56,5 \frac{1}{2}$ in. high, $5 \frac{1}{4}$ in. wide at the mouth, and 3 in. at the bottom. The rim has three encompassing rows of short lines made with a sharp-pointed tool, arranged herring-bone fashion, and the part immediately below the rim has two similar rows continuing the same pattern. At the back of the neck was a pendent ornament of lignite, very neatly made; it is somewhat like a flat plummet, $\frac{3}{4}$ in. long, $\frac{1}{2}$ in. wide at the bottom, $\frac{3}{16}$ in. at the top, and $\frac{3}{16}$ in. thick; the bottom is rounded, and the perforation near the top has been drilled from both sides ${ }^{1}$. Three feet south of the centre, $1 \mathrm{ft} .8 \mathrm{in}$. above the surface-level, and $1 \mathrm{ft}$. $2 \mathrm{in}$. below the dark line above mentioned, and therefore within the limits of the original barrow, was the mastoid process of the right temporal bone of a child, the last undecayed remains of the body once deposited there. It did not appear as if this interment had been inserted into the original barrow, for there were no signs of the very regular lines of the material of the mound having been cut through. A vessel of pottery had been associated with the body; it is in shape a cinerary urn, somerwat like fig. $56 ; 4 \frac{1}{4}$ in. high, $4 \mathrm{in}$. wide at the mouth, and $2 \frac{1}{2} \mathrm{in}$. at the bottom. The overhanging rim has three encompassing bands of short marks, arranged in a rough herring-bone fashion; below the rim a zigzag line, 1 in. deep, encompasses the vase; all the marking has been done with a pointed instrument. Seven feet east-south-east of the centre was a deposit of burnt bones, those of an adult, almost certainly a female, laid on the natural surface in a round heap $13 \mathrm{in}$. in diameter; the body had not been burnt on the spot. Three feet nearer to the centre, and at the same level as the burnt body, was an unburnt body of a young person, laid on the right side, with the head to E.S.E., the hands being in front of the chest. The back of this body was laid to the back of a large and strongly-made man, who had been placed on the left side, with the head to S.S.E., but the head and upper portion of the man as well as the lower parts of the younger person were wanting, having

${ }_{1}^{1}$ I found a somewhat similar-shaped ornament, but more rudely fashioned, and of inferior material, in a barrow on Wykeham Moor, but not associated with any interment. Pendent ornaments have occurred in Wiltshire made of gold, and also of amber, and of gold and amber combined; and one of jet, almost the counterpart of this in question, was found, with some cylindrical beads, associated with a burnt body in a barrow on Tan Hill, North Wilts; it is engraved in Archæol., vol. xliii. p. 510. fig. 200. 
apparently been cut away. The hips of both bodies were in contact, and the knees of the man were six inches north of the head of the other body. It is difficult to account for the destruction of portions of these two bodies in consequence of any disturbance of the barrow; the grave discovered a little to the north of the present centre was not within the limits of the space which would have been occupied by the bodies in question, nor was there any appearance of the mound above them having ever been disturbed. There can be no doubt, I think, that the bodies had in the first instance been placed in the barrow in a complete state, for those bones which were left must have had the flesh, or at least the ligaments, upon them when they were buried, all the several bones being in their natural order and juxtaposition, and the missing parts in each corresponding with those which would have disappeared from a cut being made through two bodies placed as they had been. In other barrows it has not been of infrequent occurrence to find skeletons which must have been removed from their first place of burial and then re-interred where they were met with, but in those cases the bones show by their want of proper order that such disturbance had taken place. No scattered bones or portions of bones which might be supposed to belong to these two bodies were found in any part of the mound. On the whole, it is probable that the partial destruction of the bodies in question was caused, in some way or other which was not apparent, by the making of the grave discovered in their immediate though not close vicinity.

Four and a-half feet south-west-by-south of the centre, and on the natural surface, was the body of a child about 7 years of age, laid on the right side, with the head to E. by S., and having the hands up to the face. Immediately south-south-west of the centre, and placed in a hollow, $2 \mathrm{ft}$. in diameter and sunk $14 \mathrm{in}$. below the surface of the original barrow, upon which it had been burnt (the hollow having been first made), were the calcined remains of the body of a young person about 18 years of age; and with the human bones a single piece of the bone of a pig, also burnt. Amongst the bones, towards the upper part of the deposit, was a very beautiful axe-hammer of basalt [fig. 12], $4 \mathrm{in}$. long, and having the hole for the handle drilled from each side. It had passed through the fire with its owner, but had not suffered beyond having its colour slightly changed in the process. The pointed end of a bone pin was also found amongst the bones. 
The instrument, to which the name of war-axe may properly be " given, for reasons stated in another place, is the fourth of the kind which I have met with in the wold barrows, two having been associated with burnt bodies and two with unburnt.

A little to the north of the present centre, but no doubt representing what had originally been the central and commencing point of the barrow, was an oblong grave, sunk through the surface-soil, for a depth of $8 \mathrm{in}$, on to the underlying chalk rock. It was $8 \mathrm{ft}$. long and $2 \mathrm{ft}$. $8 \mathrm{in}$. wide, having the longer axis east-north-east and west-south-west. In it were two bodies, laid in the unusual extended position on the back. The one a young and probably a male person, below 17 years of age, had the head to W.S.W., the legs being crossed above the knees, the right over the left; the other, a boy between 8 and 10 years of age, was laid in the opposite direction, and to the south of the first, the head being to E.N.E., the left knee of the elder slightly overlying the hips of the other. The feet of the younger person were close to the head of the older, the head being opposite to the lower part of the legs of that body. The hands of both were placed on their respective stomachs. Behind the head of the younger was a small round flint scraper; and on the left side of the head a bone pin, much decayed. At the right knee of the older person, and touching it, was a piece of a nodule of sandstone, which had been subjected to fire. It appeared to have been placed designedly where it was discovered, but what its use may have been, or the object with which it was buried with the dead person, may not be possible to understand.

The position of these two bodies, laid at full length, is a very unusual one, and it will be remarked that the other burials in this barrow had been made in the ordinary contracted fashion, with the bodies placed on the side; perhaps it would be an unfair inference to suppose that there was any difference of tribe, or much difference of time, between the several interments in this sepulchral mound ; the extended position is so very infrequent that we cannot regard it as being more than an individual peculiarity, and not implying any change in the ordinary mode of interment beyond the burial in question. From the intimate connection in the grave between the two bodies, a near relationship in life may fairly be assumed, and it is probable, though the distinetive marks of sex in the older person were not quite certain, that they were brothers. Amongst the material of the barrow were several pieces of plain pottery, some of it dark-coloured, and a single fragment 
of a 'drinking cup.' A round flint scraper and a chipping from a ground stone axe were also found in the mound. Some bones of a young and some of an old ox, and of a goat or sheep, were met with.

XC. This barrow, one of the larger of the group and lying the furthest to the south, was found to contain, as is frequently the case with the larger-sized burial mounds, a single interment. It may very possibly have been used for secondary burials all trace of which had disappeared under the lowering process to which it had been subjected during many years by the action of the plough. If any such had once existed they must have been quite superficial, and made probably long after the construction of the mound. It was $100 \mathrm{ft}$. in diameter, and still $8 \mathrm{ft}$. high, and was formed of very tenacious clayey earth. At the centre, in a shallow hollow sunk through the surface-soil on to the chalk rock, and which had been lined with wood, was the body of a strongly-made man, about 30 years of age, laid on the right side, with the head to S.W. by W., the hands meeting on the hips. Between the face and the knees, and touching the right knee, was a 'food vessel,' upon which was lying a small piece of animal bone; whilst close to the right shoulder was a flint flake, which appeared to have been intentionally placed with the body, being underneath the remains of wood which, apparently in the shape of planks, had been laid over the body. The vase is in shape much like fig. 70, but without any ears at the shoulder; it is $5 \frac{1}{4}$ in. high, 7 in. wide at the mouth, and $2 \frac{3}{4}$ in. at the bottom. The ornamentation is all due to impressions of twisted-thong, and consists of four encircling lines on the inside of the lip of the rim, whilst the outside has a pattern similar to that on fig. 70, and extending to where the ears are placed on that vase. Then follows, at the shoulder, a zigzag line which has the alternate spaces filled in with lines parallel to the sides of the reversed triangles of which the spaces consist. Below, for a depth of $1 \frac{3}{4}$ in., there is a pattern similar to that on the correspondiug part of fig. 70 ; the remainder of the vase being plain.

If we may judge from the size of the barrow, and perhaps also from the circumstance that it was devoted to a sole occupant, it may I think be fairly presumed that the body was that of a chief of a tribe or other person of note and importance. In this barrow it will be observed there was no grave, and the same is frequently found to be the case in the higher and larger burial mounds. 
Is it possible that in those barrows where it was intended to heap above the body a large mass of earth or stone, it was not thought necessary to protect it further by placing it in a grave?

XCI. The next barrow, though of large size, proved to be quite barren, so far as any traces of a skeleton or of burnt bones were concerned. It was $100 \mathrm{ft}$. in diameter, still $4 \frac{1}{2} \mathrm{ft}$. high, and was made of very tenacious clayey earth. At a distance of $11 \mathrm{ft}$. south-east-by-south from the present centre, and $1 \mathrm{ft}$. above the natural surface, a 'food vessel' was found. It is somewhat in shape like fig. 69 , but quite plain, except that it has a narrow raised band encireling it $1 \frac{1}{4} \mathrm{in}$. below the rim, and is $4 \frac{1}{4} \mathrm{in}$. high, 5 in. wide at the mouth, and $2 \frac{5}{8}$ in. at the bottom. The spot where the vase was found may easily represent the place from which the mound had originally been commenced to be thrown up, the central point having been lost in piling up so large a mass. There was no indication however that a body had ever been placed near the vase, though it is possible that the bones might have gone entirely to decay, leaving no trace of their former existence. For reasons which are stated in the Introduction I am not inclined to believe that cenotaphs were ever erected by these people, and, if this view be correct, then there can be no doubt that a body had once been interred in this mound ; and the presence of a sepulchral vessel makes that presumption the more probable. Amongst the materials of the barrow were a leaf-shaped arrow-point and a round scraper, both of flint.

XCII. The next barrow - they are described in order, proceeding northwards-was also a large one, being $86 \mathrm{ft}$. in diameter, $5 \mathrm{ft}$. high, and made of earth. At the centre, and $1 \frac{1}{2} \mathrm{ft}$. above the surface-level, in a shallow oval hollow, lying east and west, $4 \mathrm{ft}$. by $2 \mathrm{ft}$., and lined with wood, was the body of a very strongly-made man about 30 years of age, laid on the right side, with the head to W. by S., the right hand to the middle of the thigh, the left hand being within the hollow of the sacrum; the back was not bowed. In front of the chest was a small oval flint scraper. Immediately under this body, and on the level of the surface, was a deposit of burnt bones, those of an adult, probably a woman, laid in a round heap $11 \mathrm{in.}$ in diameter. Below them was a shallow oval hollow sunk through the original surface-mould, lying northwest and south-east, $5 \frac{1}{2} \mathrm{ft}$. by $1 \frac{1}{4} \mathrm{ft}$. It was lined with wood, like 
that in No. xc, and in it, about the middle, was the body of a young boy or girl, laid on the right side with the head to N.W., the arms being too much gone to decay to allow their position to be defined. In front of the hips was a small but well-chipped flint knife, $1 \frac{3}{4} \mathrm{in}$. long and $\frac{5}{8} \mathrm{in}$. wide, flat on one face and convex on the other. In this barrow we find inhumation alternating with cremation, the primary interment of an unburnt body being overlaid by a burnt one, and that again by a second unburnt body. What lapse of time, if any, had taken place between these several burials it is impossible to say.

XCIII. This barrow was $66 \mathrm{ft}$. in diameter, $3 \frac{1}{2} \mathrm{ft}$. high, and made of earth. At a distance of $14 \mathrm{ft}$. south-by-west from the centre, and just below the surface of the barrow, was a vessel of pottery, apparently a small cinerary urn, but in so decayed a condition that nothing can be made out with certainty either as regards its shape or size. Nine feet west-by-north of the centre, and $3 \mathrm{ft}$. above the natural surface, was a cinerary urn reversed, and containing the remains of a burnt body, that of an adult of uncertain sex. It had been so much destroyed by the plough that but little remained of it. The overhanging rim has been ornamented with a very roughly-formed pattern of lines made by a pointed tool, arranged herring-bone fashion, the inside of the lip of the rim having two encompassing lines of twisted-thong impressions. At the centre, and placed on the natural surface, was a cinerary urn standing upright, and containing a very small quantity of burnt bones. The urn, which has been very rudely made and imperfectly fired, was in so rotten and disintegrated a state that nothing beyond the fact that it had been a vessel of pottery of the cinerary type could be ascertained concerning it. Amongst the material of the barrow were found a fragment of the rim of another cinerary urn, marked with a triangular-spaced pattern of thong-impressions, and a long flint scraper.

XCIV. The next barrow was $68 \mathrm{ft}$. in diameter, $4 \frac{1}{2} \mathrm{ft}$. high, and made of earth. Fifteen feet from the centre, and to the east of it, one foot above the natural surface, was a 'food vessel,' without any trace of an accompanying body. The vase, coarsely made, is similar in shape to fig. $69,5 \frac{1}{2}$ in. high, the same in width at the mouth, and $2 \frac{3}{8} \mathrm{in}$. wide at the bottom. The inside of the lip has upon it two encircling lines of loosely-twisted thong-impressions. 
The outside of the vase for a depth of $3 \mathrm{in}$. is ornamented with two encircling bands, consisting of vertical lines of similar impressions to those on the lip. At the centre of the barrow was the body of a powerfully-made man beyond middle life, laid on the back at full length, in a slight hollow sunk below the natural surface and which had been lined with wood. The head was to the west, the right hand on the stomach, the left arm gone too much to decay to allow of its position being traced. On the right side of the head was a 'food vessel,' laid on its side, and having the mouth elosed with clay; and under it were two small round flint scrapers. The vase in general shape is not unlike that just above described, but is much more carefully manufactured and elegantly formed; it is $6 \frac{1}{2}$ in. high, the same in width at the mouth, and 3 in. wide at the bottom. On the inside of the lip of the rim, which is nearly an inch wide, are six encircling lines of very finely-twisted thong-impressions, in sets of three each. On the outside of the rim, just below the lip, which has a similar line upon it, is an encircling line of short vertical and coarser thong-impressions; then comes an encircling line of the coarser thong-impressions, then three sets, each of three encircling lines of the same fine impressions as those inside the lip, and then, commencing below the shoulder, three bands of short lines of coarse thong-impressions, arranged slightly herring-bone fashion ; the remainder of the vase, $3 \frac{1}{2} \mathrm{in}$. in depth, is quite plain. The inside towards the bottom is encrusted with a deposit of black earbonaceous-looking matter, which on analysis has proved to contain a large quantity of nitrogen, and is therefore probably of animal origin.

This barrow produced the fourth instance within my experience (three of them being in this group) where the body had been interred at full length. In this case, as in one at Rudstone [No. lxix], a 'food vessel' and an implement of flint were associated with the interment; and as the vessels and implements are quite of the same character as those ordinarily found with contracted bodies, it is evident that all these burials, if they do not belong to precisely the same period, at all events belong to people who were living under the same conditions, manufacturing the same kind of pottery, and using similar implements. In fact, the interments in question are such as are ordinarily found in the round barrows of the wolds, but in these instances, for some reason or other not now capable of explanation, the usual custom of contracting the body had been departed from. 
$\mathrm{XCV}$. The next barrow was $54 \mathrm{ft}$. in diameter, $3 \frac{3}{4} \mathrm{ft}$. high, and made of earth. At the centre was a grave of somewhat irregular form. It had a direction south-east-by-south and north-west-by-north, and was $7 \frac{1}{4} \mathrm{ft}$. lang, and $4 \mathrm{ft}$. wide, except towards the south end, where there was an extension to the west for a width of $2 \frac{1}{4} \mathrm{ft}$., and extending $4 \mathrm{ft}$. from the south ; the whole grave being $6 \mathrm{ft}$. deep. In it, and just below the level of the natural surface, was a body so much decayed that nothing whatever could be made out concerning it, except that it was that of an adult. On the bottom, at the south end, was the body of an old man, laid on the right side, with the head to S. by E.; the arms were too much decayed to allow of their position being ascertained. The grave was filled in with chalk, and near the bottom were two splinters of red-deer's antler, probably broken off from picks which had been used in making the grave.

XCVI. The next barrow was a smaller one than any yet described, being only $39 \mathrm{ft}$. in diameter ; it was $1 \frac{1}{2} \mathrm{ft}$. high, and principally made of earth. At the centre was a pile of large flints which covered a grave of an oval form, having a direction south-east-bysouth and north-west-by-north, $5 \frac{1}{2} \mathrm{ft}$. by $3 \frac{3}{4} \mathrm{ft}$. and $5 \mathrm{ft}$. deep. It was filled in with chalk and a little earth, and at the centre on the bottom was a deposit of burnt bones, those of a woman beyond 30 years of age, placed in a round heap $12 \mathrm{in}$. in diameter. Amongst the chalk filling-in was a splinter from a red-deer's antler.

XCVII. This, one of the larger mounds, was about $100 \mathrm{ft}$. in diameter, and still, after having been under cultivation for more than seventy years, $8 \frac{1}{2} \mathrm{ft}$. high ; it was made of earth, with a considerable mixture of flint-rubble. It contained a single interment, that of a man about 30 years of age, who had been laid at the centre in a shallow hollow sunk through the surface soil on to the chalk rock, and lined with wood, which did not however cover the body. He was placed on the right side, the head being to W.S.W., and the hands in front of the chest. Upon the right hand was a 'food vessel,' and at the crown of the head, and no doubt associated with the body, a long flint flake. The vase is in shape somewhat like fig. 70, but narrower in proportion, being $5 \frac{3}{4}$ in. high, $6 \frac{1}{2}$ in. wide at the rim, and $2 \frac{5}{8}$ in. at the bottom; it has four unperforated ears at the shoulder. The ornamentation is entirely 
formed by impressions of thin and closely-twisted thong. The inside of the lip has eight encircling lines upon it, whilst the outside has three. Below the lip, for a space of $3 \frac{1}{2}$ in., the pattern ennsists of bands of short lines arranged herring-bone fashion; except on the ears, which have each eight parallel vertical lines upon them. The remainder of the vase is covered with short archshaped figures, placed rather irregularly, but having a tendency to form encircling bands.

There is a considerable resemblance between this barrow and one [No. xc] previously described, and that in more than one important particular. Both were of large size, and each contained a single interment at the centre, placed in a shallow depression carried through the surface-soil on to the rock and lined with wood. Each body had a 'food vessel' deposited in front of it, and each a flint flake intentionally associated with the body. Whether any more than an ordinary connection of burial usages existed between the two mounds it may be rash to assert, still the features are so similar in both as to suggest that there may have been, whether of tribe, family or position, a near relationship of one kind or another between the two men interred in these barrows.

XCVIII. This barrow was $46 \mathrm{ft}$. in diameter, $1 \mathrm{ft}$. high, and made of earth. At the centre was an oval grave, lying westnorth-west and east-south-east, $7 \mathrm{ft}$. by $4 \frac{1}{2} \mathrm{ft}$., and $3 \frac{1}{2} \mathrm{ft}$. deep. At that side of the grave which was furthest to the west, upon the level of the natural surface of the ground, and at the very edge of the cutting for the grave, was a deposit of burnt bones, those of an adult woman, upon the south side of which, just in contact with them, was a vessel of pottery, having a cover to it [fig. 132]. The vessel is so much decayed that nothing remains beyond the lower part of it; the cover is complete. On the north-west side of the grave, at the level of the natural surface and just without the limits of the cutting, was a 'food vessel' [fig. 73]. There were no remains of bones in association with it, but it is possible that it may have been originally placed in connection with an unburnt body deposited within the limits of the cutting. This body may have been disturbed when the grave was made, many bones having been discovered throughout the material which filled it in. On the bottom of the grave and towards the west end of it was found the body of a man above 30 years of age, laid on the left side, the head being to E.S.E., and the hands 
up to the face. In the grave were also found the first two molars of a small ox.

The pottery discovered in this barrow requires a more than ordinary description. It is the best manufactured and the most delicately ornamented of any that I have hitherto met with. The clay, although it has not resisted the various disintegrating agencies to which it has been subjected so well as that of much coarser and worse-made vessels, has apparently been well tempered and is without any mixture of broken stone in its composition. The shape of the complete vessel, as will be seen from the engraving, is elegant, and its symmetry is such as to show the hand of a master

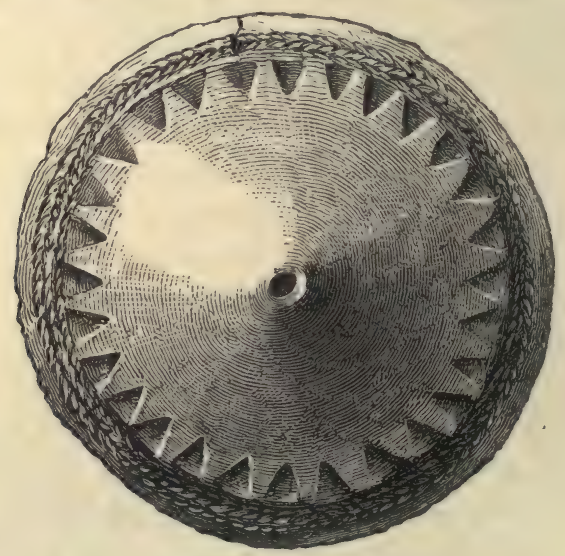

Fig. 132. $\frac{1}{1}$.

in its fabrication. The ornamentation is very tastefully applied and with great judgment, and in the delicate arrangement of its pattern and the skill with which that has been carried out it much exceeds the most of even the finer specimens of the fictile ware of the period. It is $3 \frac{1}{2} \mathrm{in}$. high, $5 \frac{3}{8} \mathrm{in}$. wide at the rim, and $2 \frac{1}{2}$ in. at the bottom. The ornamentation is so well represented in the engraving, that it is only necessary to say that the markings on the inside of the lip of the rim consist of three lines of impressions of very delicately-twisted thong or cord apparently of three plaits, applied close together; and that a similar series encircles the vase close to the bottom. The vase which had the cover attached to it is unfortunately in so fragmentary a state that neither its shape nor size can be ascertained; it has had, so far as can be judged from the lower part, which is all that remains, straight sides for above two inches from the bottom; in what 
way it narrowed to the width of the cover, if indeed that ever quite closed the mouth, it is impossible to say, and it is difficult to understand how any vessel in shape like the ordinary sepulchral ones could have narrowed to the extent required for the cover to fit the mouth. The vase is $3 \frac{1}{2} \mathrm{in}$. wide at the bottom, the cover being $2 \frac{1}{8}$ in, wide. The ornamentation, so much of it as is left, is confined to the lowest part, and occupies a space $\frac{7}{8}$ in. deep; it consists of an encireling band of two rows of triangular impressions, the bases being in juxtaposition, and the whole forming a lozenge-shaped mark divided through the centre; below are two sets, each of three encircling lines of very minute thong-impressions. The cover, which is conical, will be best understood from the figure; the triangular-shaped impressions upon it are made by the same tool as those on the vessel just above described. It is evident, when the composition and colour of the paste as well as the style of ornament and the way in which the pattern has been applied are all taken into consideration, that these several articles of fictile ware have proceeded from the hand of the same artist, and that a very skilful one and possessed of much taste and judgment. They afford indeed very conclusive evidence of the perfection to which in some respects these people had brought the fabrication of pottery. It might be thought that the vessels in question belonged to a later time than that during which the ordinary sepulchral ware of the barrows was manufactured, and indeed it is possible that they may have been made during the latter part of that period. Their superiority however may be equally due to individual skill and taste, and they may have been produced at the same time as other and much ruder specimens of the potter's art. It is no uncommon occurrence to find in the same barrow, and under circumstances which show that the several vessels are the products of the same period, some which evidence abundant skill, whilst others might have been made by the veriest tyro in the trade. On the whole it is probable that the vessels in question were produced at a time when the cultivation of the people of the wolds had reached its highest developement antecedent to the introduction of iron, and before the corresponding advantages attending the use of that metal had brought about a still further advance in the arts and appliances of life. The ornamentation, though it has been most skilfully disposed and possesses something of an individual character, is nevertheless such as does not separate itself in any marked way from the usual forms and 
patterns which are found on the various classes of vessels ordinarily discovered in the barrows.

XCIX. The next barrow was $60 \mathrm{ft}$. in diameter, $4 \mathrm{ft}$. high; and made of earth with a little chalk intermixed. It had been partially opened by some previous explorer, and the grave, to be afterwards described, had been then to a considerable extent examined; in that part of the barrow without the grave, which had been dug into on the same occasion, two unburnt bodies had been interred; the remains of which, in the bones of a large man and of a child, were found seattered amongst the disturbed soil. Three bodies had also been discovered in the grave, and the bones belonging to them were met with here and there in that part of the grave which had been opened by the first explorer. One had been that of a young person, the other two those of large men, the one an adult, the other younger; of the latter the legs and feet still remained in their proper position, $2 \frac{1}{2} \mathrm{ft}$. below the surface-level, that part of the grave not having been disturbed. The grave was a large one, lying north-north-west and south-south-east, $10 \frac{1}{2} \mathrm{ft}$. by $5 \mathrm{ft}$., and $5 \frac{1}{4} \mathrm{ft}$. deep. In it, at a depth of $4 \mathrm{ft}$. from the surface-level of the ground and towards the north end, was the body of a strongly-made man about 30 years of age, laid on the left side with the head to N., the hands being up to the face, in front of which was the occipital part of the skull of a young person about 14 years of age. This bone probably belonged to the youngest body, of which portions were found scattered in the grave, and if so, they are the remains of a person whose bones had been first disturbed to put in another body, before they were again removed by the explorer who had dug into the barrow on some former occasion. On the bottom of the grave at the south end was the body of a woman under 30 years of age, laid on the right side, the head being to N.W. The head of this body appeared to be the only part which was in its original position, for the tibias and femurs had their proximal ends close to the skull and the second cervical vertebra (the axis) was two feet away from the head. This disturbance seemed to have been caused by the introduction of the body of a child of 2 or $2 \frac{1}{2}$ years of age, also laid on the right side, and whose head, which was to N.W., was placed $2 \mathrm{ft}$. from the head of the woman. Close to the face of the woman was a 'drinking cup' [fig. 133], another was close to the child's face [fig. 134], and $2 \mathrm{ft}$. north of the woman's 
head was a third [fig. 81]. These vessels, as will be seen from the figures, are very fine and varied specimens of the class to which they belong. They differ amongst themselves not only in their form and ornamentation, but also in the quality of the paste; that found close to the woman being much harder and more friable than the other two, which appears to be due to the large quantity of sand mixed with the elay, and which gives quite a gritty feeling to the pottery.

The two bodies found at the bottom of the grave can scarcely be

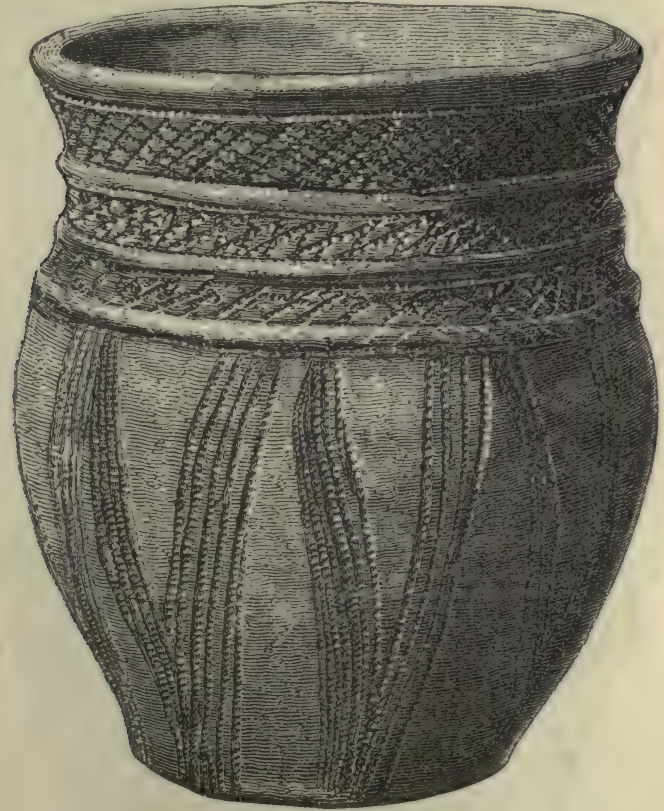

Fig. 133. $\frac{1}{2}$.

regarded as other than those of a mother and child, the former of whom appears to have died first; the grave being afterwards opened and her bones partly displaced to insert close by her the body of the child. The third 'drinking cup' was not intimately associated with either of the bodies, though it was probably connected with that of the woman; instances have been met with in other barrows where more than one sepulchral vessel has been found accompanying a single burial ${ }^{1}$. The ornamentation upon

${ }^{1}$ It may suffice to mention one instance in illustration of this fact. In a cist with the skeleton of a girl about nine years old, found at North Sunderland, Northumberland, three 'drinking cups' were discovered. Trans. of Berwickshire Naturalists' Club, vol. iv. p. 428. pl, xiii. 
the three 'drinking cups' is entirely formed by the application of a notched piece of bone or hard wood, with the exception of that on the inside of fig. 81 , which is due to the impression of twisted-thong; the decoration of the inside of the lip (unusual in this class of vessel) extends to a depth of 2 in. down the side. The whole three, as is the case with many of the 'drinking cups,' have a polish on the surface which almost amounts to a glaze,

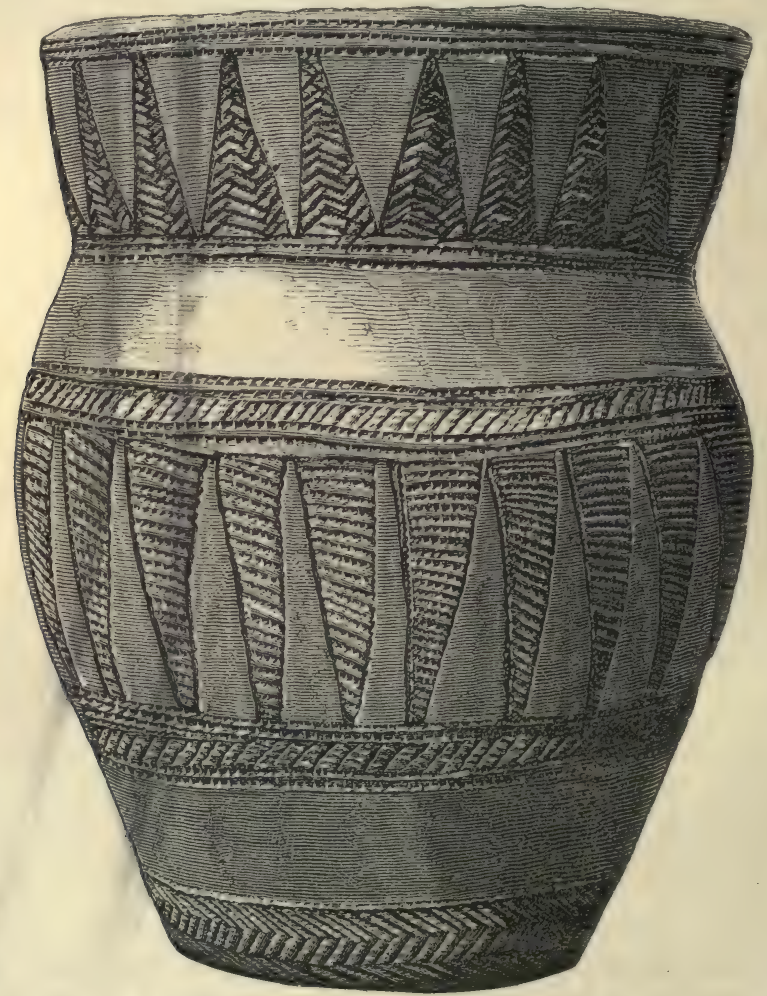

Fig. 134. $\frac{1}{2}$.

and which must have been intentionally produced, probably by rubbing the partly dried clay with a bone instrument or a smooth piece of hard stone. The first vessel, that associated with the woman, is $5 \frac{3}{4} \mathrm{in}$. high, $4 \frac{5}{8} \mathrm{in}$. wide at the mouth, and $3 \frac{1}{8} \mathrm{in}$. at the bottom. The second, which accompanied the child, is $8 \mathrm{in}$. high, $5 \frac{3}{4}$ in. wide at the mouth, and $3 \frac{1}{2}$ in. at the bottom. The third, which was placed somewhat apart from the bodies, is $6 \frac{7}{8} \mathrm{in}$. high, $5 \frac{5}{8} \mathrm{in}$. wide at the mouth, and $3 \frac{7}{8}$ in. at the bottom. The two first vessels 
contained a quantity of dark-coloured matter, which has been analysed, and appears to have been of vegetable origin.

A large barrow about $70 \mathrm{ft}$. in diameter was found to have been previously opened, and as no remains of burnt bones were discovered, it is most probable that the burial or burials had been by inhumation. It contained a grave at the centre.

C. Another barrow proved, though it was quite undisturbed, to be very unproductive, since no interment was discovered in it. The mound was $45 \mathrm{ft}$. in diameter, $2 \frac{1}{2} \mathrm{ft}$. high, and made of earth. At a distance of $8 \frac{1}{2} \mathrm{ft}$. north-east-by-north from the centre, in a slight depression on the surface of the ground, was found a vessel of pottery of a rather rude description. It is $4 \frac{1}{8} \mathrm{in}$. high, $4 \frac{3}{4}$ in. wide at the mouth, and $4 \mathrm{in}$. at the bottom. The ornamentation consists of three encircling lines of thong-impressions, very roughly applied, below the lip; then at the shoulder is a row of oval impressions which goes round the vase; then come two encircling lines, similar to the first three; and then a band of lines $2 \frac{1}{2}$ in. long of the same impressions, slightly inclining to the left, covers the rest of the vessel. Seven feet south-west of the centre a single piece of burnt bone was found on the natural surface, but whether it is human or animal it is not now possible to decide.

CI. The next barrow had been the largest of the whole group, and was $120 \mathrm{ft}$. in diameter. It had been almost entirely removed, about 30 years ago, by the then tenant, when some unburnt bodies and two vessels of pottery were discovered. From the information I received from a person who was present when it was carted away to be spread on the land, the whole central part of the mound showed evident signs of the material having been burnt, of which I myself found the strongest corroboration in what was still left of it untouched. For a space of about $30 \mathrm{ft}$. in diameter the whole surface of the ground at the centre was very much reddened by the action of fire, and the material above the surface showed the same signs of burning. Through this burnt matter was sunk a grave, lying north-west-by-west and south-east-by-east, $11 \frac{1}{2} \mathrm{ft}$. by $6 \frac{3}{4} \mathrm{ft}$. and $8 \mathrm{ft}$. deep. It had apparently been originally filled in with chalk, which again appeared to have been partly taken out, so as to form a funnel-shaped excavation, to within $4 \mathrm{ft}$. of the bottom; this 
being filled in with earth and containing a very large proportion of burnt soil and charcoal. On the bottom of the grave, at the middle, was the body of a large and old man, laid on the left side, the head to S.E., the hands being up to the face; the back was straight. The body was surrounded by large blocks of flint. There was a great amount of exostosis upon the shaft of the left tibia, agglutinating the fibula in the lower third of its length, and forming another deposit of great size upon the inner side of the foramen nutritivum, as well as smaller growths in the interval between these points of the shaft.

CII. This barrow was one of the larger of the group, being $82 \mathrm{ft}$. in diameter, and still, after having undergone the action of the plough for many years, $6 \mathrm{ft}$. high ; it was composed entirely of earth. No interment was met with except one at the centre, and it is not an infrequent occurrence, as has been already noted, to find the larger barrows by no means so prolific of burials as the smaller ones. The central interment was that of a young man, about 18 years of age, of considerable strength. The body had been placed in a hollow made in the surface-soil 7 in. deep, the length being $5 \mathrm{ft}$., and the width $1 \mathrm{ft} .10 \mathrm{in}$; the longer diameter was west-north-west and east-south-east. It had been lined with wood, upon which the body was laid on the right side, with the head to W.N.W., and the hands up to the face, in front of which was a flint knife very carefully flaked over the whole of the convex surface. It is $2 \frac{1}{2} \mathrm{in}$. long and $\frac{3}{4} \mathrm{in}$. wide, and the butt-end is chipped to a sharp edge. Behind the crown of the head, about 6 in. from it, and laid on the side, with its mouth towards the head, was a 'food vessel,' which still contained some dark-coloured matter, proved by analysis to be of vegetable origin, and most probably the remains of food once deposited in it. The vase is so like one found in the next barrow, about to be described, that the one might almost pass for the other, the only difference between them being that this has the ears perforated, and that the lowest band, that one close to the bottom, is wanting, the vase being plain at that part. It is $4 \mathrm{in}$. high, $5 \frac{1}{4} \mathrm{in}$. wide at the mouth, and $2 \frac{1}{2} \mathrm{in}$. at the bottom, which is similarly marked to that of the vessel found in the next barrow.

CIII. This barrow, also a large one, was situated a little to the west of the last; it was $80 \mathrm{ft}$. in diameter, $4 \mathrm{ft}$. high, and made of 
earth, with some admixture of chalk and flint. At a distance of $16 \mathrm{ft}$. south-east-by-east from the centre, and one foot above the natural surface, was the body of a woman, about the middle period of life, laid on the right side, with the head to N.E. by N., the right hand between the upper part of the thighs, the left up to the face. Close to the bones of the pelvis was a urinary calculus of the ordinary description, about the size and shape of a horse-bean. Upon the left temporal bone, which was stained by the contact, was the much oxidised remnant of a bronze awl or pricker, of which the sharp end, $\frac{5}{8} \mathrm{in}$. in length, is left. At the centre was a shallow grave, sunk through the surface-soil for a depth of $8 \mathrm{in}$. on to the chalk rock; it had a direction east and west, and was $7 \frac{3}{4} \mathrm{ft}$. long and $2 \mathrm{ft}$. wide. It was lined throughout with wood, and the body deposited therein had also been covered over with wood. There had been nothing like a coffin, either made out of a hollowed tree trunk or constructed of wooden boards, but thin slabs had apparently been placed, without being joined together, underneath and above the body. The body, which was laid on the left side at the middle of the grave, was that of a man in or a little past the middle period of life; the head was to $W$. and the hands up to the face, the fingers extending underneath the head. In front of the face was a 'food vessel,' still containing a dark-coloured deposit, of vegetable origin, probably the remains of food. The vase, like fig. 70 but with three unpierced ears, is a very beautifully made specimen of this class of vessel, $4 \frac{1}{4} \mathrm{in}$. high, $5 \frac{1}{2} \mathrm{in}$. wide at the mouth, and $2 \frac{3}{8}$ in. at the bottom, which has upon it a central boss $1 \mathrm{in}$. in diameter, with a hollow $\frac{5}{8} \mathrm{in}$. wide between it and the edge. The inside of the lip of the rim is ornamented with two encircling rows of dotted impressions, separated from each other, and each bordered by two lines closely applied of very fine cordmarkings, so placed as to give them a feathered appearance. The outside of the lip has a band of short vertical cord-impressions bordered by a single line of the same. Below this, for a space of $1 \mathrm{in}$., the vase is covered (except the ears which have vertical lines upon them) with closely applied encircling lines of fine cordmarkings; then come seven bands of short lines slightly inclining, each band in reversed order, and separated, except the last one, from each other by an encircling line of cord-impression; then for nearly half an inch the vase is plain; and below, at the bottom, is a band of short lines inclining to the right. The resemblance between this and the similar vessel found in the 
barrow last described is so complete, in respect of size, shape, style of ornament, and manner of fabrication, that there can be little doubt that they must both have proceeded from the hands of the same workman. If this supposition be true, it would appear that no great length of time had elapsed between the erection of the two barrows; a fact which is not without a certain significance when the period during which the same mode of interment in the barrows and the character of the pottery contained in them is under consideration. It might be said that if we have two separate barrows in a group, the principal interment in one of which and the only interment in the other are so near in point of time that the vessel of pottery associated with each must have been made by the same hand, the burials in the whole group can scarcely have extended over any very long space of time; and indeed the argument is not without force. The circumstance is a singular one in my experience, for I have never before met with two vases which could fairly be claimed as the productions of the same maker, except in instances where they have occurred in the same barrow. Nor should I feel inclined, without much fuller evidence than this isolated case affords, to limit the time during which the particular mode of burial met with in the wold barrows prevailed to so short a period as might seem to be implied by the discovery of two vases made by the same potter in two barrows of a group. The circumstance that one of these vessels has the ears pierced, whilst the other has them left without any perforation, is not easy of explanation, supposing them to have been the work of the same hand. I have stated elsewhere that the unpierced ear is a survival, and have regarded those vessels which have the ears pierced as the earlier ones, but in this instance the two classes appear to have been contemporaneous, though we may perhaps regard them as having been manufactured at a time when the provision for suspension was dying out. The lining out of the grave with wood, though by no means of common occurrence in the barrows of the wolds generally, was found in several of the sepulchral mounds on Goodmanham Wold; the wood however does not appear, except in this instance, to have covered the body, but only to have been placed around and under it. Amongst the material of the barrow the incisor of a pig was met with.

The next six barrows were situated a little further to the west 
than those which have been already described, but forming a part of the same large group.

CIV. The first was $56 \mathrm{ft}$. in diameter, $2 \mathrm{ft}$. high, and made up of earth, with some little chalk. At the centre was a grave, running nearly due east and west, $5 \frac{1}{2} \mathrm{ft}$. long, $4 \mathrm{ft}$. wide, and $2 \mathrm{ft}$. $4 \mathrm{in}$. deep. Nine inches higher than the top of the grave, and over the middle of it, was a deposit of burnt bones, laid in a round heap $13 \mathrm{in.}$ in diameter; they are those of an adult, probably a female. On the bottom of the grave, and at the middle of it, was the body of a man of great strength, past the middle period of life, laid on the right side, with the head to $\mathrm{W}$. by $\mathrm{S}$., the right hand being between the left thigh and leg, and the left hand across the right elbow.

CV. This was in one respect the most remarkable barrow I have examined on the wolds, inasmuch as the diameter of the top of the grave was nearly as great as that of the whole mound, which was $48 \mathrm{ft}$., the height not being above one foot. The grave was $36 \mathrm{ft}$. wide at the top, and decreased, by five successive stages or steps, to a width of $14 \mathrm{ft}$. at the bottom, the depth being $4 \mathrm{ft} .8 \mathrm{in}$. Running round more than one-half of the circuit of the grave, from a point south-south-west of the centre to beyond the opposite northnorth-eastern point, was a trench, varying in depth from $1 \mathrm{ft} .9 \mathrm{in}$. to $2 \mathrm{ft}$., and $1 \mathrm{ft} .8 \mathrm{in}$. wide, the outer edge of which coincided with the edge of the bottom of the grave. The trench was filled in with chalk-rubble, as indeed was nearly the whole of the grave, and badgers had made an earth in the trench, finding it easier to work amongst the loose material there than in the undisturbed chalk rock; the head of one of these animals and several other bones were met with. On the bottom of the grave (if that name ought to be given to the excavation), and $2 \mathrm{ft}$. north of the centre, was the body of a man in the middle period of life, laid on the left side, with the head to S. by W., and the hands up to the face, the fingers being doubled in. Amongst the material which filled in the grave were many bones of a young red-deer, and a piece of a skull and some other human bones; and at one place a great part of the bones of the right leg of a young and small-sized ox and the right tibia of a pig were met with. At the bottom of the grave were the bones of several animals, including badger, red-deer, ox, young pig, hare, and also bones of pigeon and of two gallinaceous birds; these last, 
and probably the remains of hare, had probably been carried there by the badgers who had made their earth in the barrow.

The size of this large excavation and the way in which it had been made were both peculiar, and not easily to be accounted for on the supposition that it was from the first merely intended for a grave. It is possible that it had originally been a place of habitation, and afterwards used for burial purposes. For the requirements of habitation the gradual descent by a series of steps appears to fit it to some extent; and if this explanation of its first intention is correct, then the trench may have been made with the object of keeping it dry, by acting as a drain. Some of the chambered tombs of Scandinavia are supposed to have been first constructed as living places; and this excavation may supply a similar instance of a secondary use of a dwelling as a place for the disposal of the dead in this country also. But it is not necessary to suppose that a pitdwelling actually in use as a habitation had been taken to make a grave for its once owner; it may have become disused as a place of abode, and being found suitable for a grave may have been taken to serve in that capacity. It certainly seems unlikely that so much apparently unnecessary labour should have been expended to make a grave, since one equally serviceable might have been excavated at a very much less cost. This argument must not however be pressed too far, for we find numerous instances where a much larger grave than the burial of a single person required has nevertheless been excavated for only one interment. When the size of the hollow is taken into consideration in connection with other features, such as the descending series of steps and the trench at the bottom, the view which regards it as having been once a place of habitation is not by any means an improbable one.

CVI. A barrow closely adjoining to the last, $62 \mathrm{ft}$. in diameter, $2 \frac{1}{2} \mathrm{ft}$. high, and made of earth and chalk, was found on examination to have been previously opened at the centre, when at least two bodies had been discovered. One undisturbed body was however met with $5 \frac{3}{4} \mathrm{ft}$. west-south-west of the centre, and $14 \mathrm{in}$. above the natural surface. It was that of a young woman about 22 years of age, laid on the right side, the head being to $\mathrm{E}$. by N., the right hand up to the face, the left on the chest. Amongst the material disturbed by the former opening were three pieces of pottery, not however the remains of one vessel but apparently having been mere sherds when deposited in the mound; whilst in the undisturbed 
part of the barrow were found several bones of a large and old ox and some of a young one, and the frontal bone of a young ruminant, which has more the appearance of sheep than of goat.

CVII. The next barrow was $80 \mathrm{ft}$. in diameter, $3 \frac{1}{2} \mathrm{ft}$. high, and made entirely of earth. At the centre was a shallow grave, $6 \mathrm{ft}$. in diameter, and sunk to a depth of $10 \mathrm{in}$. through the surface-soil on to the chalk rock. Two feet below the surface of the barrow, and over the top of the grave, was a very remarkable and diminutive vessel of pottery, quite plain, $1 \mathrm{in}$. high, $\frac{7}{8} \mathrm{in}$. wide at the mouth, the same at the bottom, and swelling a little at the middle [fig. 135].

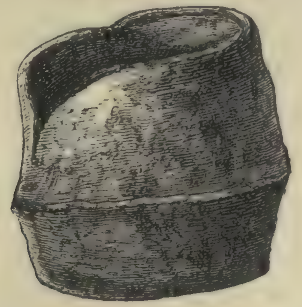

Fig. 135. $\frac{1}{1}$.

It is vain to conjecture to what use so very minute a vessel could have ever been put; it was not found in connection with an interment, for though above the grave it was not even within its limits, much less in association with the body found therein. It was simply placed amongst the material of the barrow as any casual piece of pottery or flint chipping might have been, and whether it was deposited there without any nearer relation to a burial than such articles may be supposed to have had it is quite impossible to say ${ }^{1}$. At the bottom of the grave was the body of a large and strongly-built man, laid on the left side, with the head to S.E.; the hands were too much decayed to admit of their position being ascertained. Amongst the material of the barrow were three pieces of plain dark-coloured pottery and some bones of a young child, also of red-deer and of a fox.

CVIII. Closely adjoining the last was a barrow $48 \mathrm{ft}$. in diameter and $1 \mathrm{ft}$. high. It had apparently been disturbed on a previous

${ }^{1}$ In the York Museum is a vessel almost the counterpart of this. It was found in a barrow at Hutton Cranswick, in the East Riding. Proc. of Yorkshire Philos. Soc. 1847-54, p. 185. 
occasion, for some burnt bones, discovered at the centre and upon the natural surface, were so few in number and scattered so widely, that it seems improbable they were in their original condition. The bones were of two bodies, one an adult, the other a young person. With the bones were two pieces of pottery, one a portion of a cinerary urn. The barrow however, if it had ever been opened, must have undergone that process very many years ago, for the earth was as solidly compacted as in those which have never been disturbed.

CIX. The next barrow was $56 \mathrm{ft}$. in diameter, $1 \mathrm{ft}$. 9 in. high, and made of earth. On the natural surface, at the centre of the mound, were the remains of the body of a child about eight years of age, which had been burnt on the spot. They were placed in a round heap $12 \mathrm{in}$. in diameter, and surrounded by large pieces of charcoal. Upon the bones was laid a vessel of pottery, and amongst them was a pin (calcined) made from the wing bone of a bird, and a worked piece of burnt flint evidently part of a small implement. The vase is in shape like fig. $130,6 \frac{1}{4} \mathrm{in}$. high, $4 \frac{5}{8} \mathrm{in}$. wide at the mouth, and $2 \frac{3}{4} \mathrm{in}$. at the bottom. The ornamentation is confined to the overhanging rim, and consists of alternate series of vertical and horizontal lines of thong-impressions similar to those on fig. 54 . In the material of the mound was a single bone of a red-deer.

CX. This barrow was $58 \mathrm{ft}$. in diameter, $2 \mathrm{ft}$. high, and made of earth and chalk. At a distance of $13 \mathrm{ft}$. east-by-south from the centre was the body of a man of great strength, from 25 to 30 years of age, laid on the right side, with the head to N. by E., the hands being up to the face; the body was placed a foot above the surface of the ground. At a little higher level than the last, and just east of the centre, was a second body, that of a tall man of very great strength, from 20 to 25 years of age, laid on the left side, and having the head to E. by S., the hands being in front of the chest, the fingers doubled in. Close to the face was a small round flint scraper. At the centre, and placed in a very shallow grave, was the body of a man about 35 years of age, laid on the right side, the head being to $\mathrm{S}$. W. by W.; the right arm was extended down the side, the left crossed over the stomach. The body was but slightly contracted, there being a distance of $3 \mathrm{ft} .9 \mathrm{in}$. between the crown of the head and the right knee, and one of $2 \mathrm{ft}$. $8 \mathrm{in}$. between the chin and the left knee. The left thigh was laid over the right, the 
left ankle being also over the right. Behind the head was a wellmade flint knife, $2 \frac{7}{8}$ in. long and 1 in. wide; the one side is left as when it was struck off from the block, the other, which is to some extent convex, is finely flaked over nearly the whole surface. Amongst the material of the barrow, near to the centre but not connected with any of the interments, was an axe of hone-stone, $4 \frac{1}{4} \mathrm{in}$. long and $2 \frac{1}{2}$ in. wide at the cutting edge, where it has been ground, the remainder of the implement having merely been chipped into shape.

CXI. The next barrow was $50 \mathrm{ft}$. in diameter, $1 \frac{1}{4} \mathrm{ft}$. high, and made of earth, with some chalk here and there. On the natural surface of the ground, $15 \mathrm{ft}$. south of the centre, was placed the body of a man about 30 years of age, laid on the right side, with the head to W.S.W.; the right hand was up to the face and the left at the knees. The distance between the crown of the head and the heels was $3 \frac{1}{2} \mathrm{ft}$. In a grave, $11 \mathrm{ft}$. east of the centre, was a second body, that of a woman under 30 years of age, laid on the left side, with the head to N.E. by N.; the right hand was up to the face, the left extended out at a right angle from the body. The grave was $5 \frac{1}{4} \mathrm{ft}$. long, $3 \mathrm{ft}$. $2 \mathrm{in}$. wide, and $1 \frac{1}{4} \mathrm{ft}$. deep, and had a direction north-by-east and south-by-west, the head of the body being at the north end. Eight feet south-south-east of the centre, and on the natural surface, was the body of a child from 2 to 3 years of age, laid on the left side, the head being to E. Behind the head was a 'food vessel' of peculiar shape, but well made and of fine paste. It approaches in shape to fig. 64 , and is $2 \frac{1}{4} \mathrm{in}$. high, $3 \frac{1}{2}$ in. wide at the mouth, 4 in. at the widest part, and $1 \frac{7}{8}$ in. at the bottom. Six grooves encompass the upper $1 \frac{1}{2} \mathrm{in}$., and covering the whole vessel including the grooves is a pattern of bands (23 in number) of short lines arranged herring-bone fashion, made with a very finelypointed tool. On the level of the natural surface, $5 \mathrm{ft}$. south-southeast of the centre, was the body of a child, about the same age as the last, laid on the left side, the head being to $\mathbf{S}$. by E., and the hands up to the face; behind the shoulders was a bone pin, $7 \frac{3}{4} \mathrm{in}$. long, made from the leg-bone of a goat or sheep. At a point $3 \mathrm{ft}$. south-south-east from the present centre, but probably representing the original centre, was the body of a young woman from 18 to 22 years of age, laid on the left side in a hollow a little below the surface-level. The head was to N. E. by E., and rested on the left hand, the right hand being up to the face, in front of which was a 
' food vessel,' whilst close to the neck was a roughly-made round flint scraper. There was a great quantity of charcoal immediately above the body. The vase, in shape like fig. 71 , with four unpierced ears at the shoulder, is $5 \frac{1}{2} \mathrm{in}$. high, $5 \frac{3}{4} \mathrm{in}$. wide at the mouth, and $2 \frac{5}{8} \mathrm{in}$. at the bottom. The inside of the lip of the rim has upon it four encircling bands of lines arranged herring-bone fashion; the outside of the vessel has upon the upper half bands of lines similarly arranged, whilst the lower half has the bands with the lines all sloping to the right; the whole having been made with a sharp-pointed tool. Three and a-half feet south-west-bywest from the centre, and placed at the surface-level, was the body of a woman past the middle period of life, laid on the left side, with the head to N.E. The arms had been crossed on the stomach, the bones of the left hand being within the hollow of the sacrum. In front of the face was a large flint block. The three last-described burials had been made over a hole, excavated to a depth of $3 \frac{1}{2} \mathrm{ft}$., having a direction north-east and south-west, and being $11 \mathrm{ft}$. long and $3 \mathrm{ft}$. wide, and sloping at the south-west end gradually upwards to the level of the surface. In this hole, at a depth of $1 \mathrm{ft}$., was a great quantity of burnt matter, amongst which were potsherds, bones and the tooth of an ox, and much charcoal; in the hole, but not amongst the burnt matter, were potsherds, bones of ox, of sheep or goat, and of pig. Under the head of the last-mentioued body, and beneath the large flint block, were some fragments of a 'food vessel,' whilst underneath the back was a single piece of a large and thick cinerary urn. It is very difficult to say which, if any, of these bodies represented the primary interment, but on the whole that of the young woman appears to have the best claim to be so considered. On the natural surface, $11 \frac{1}{2} \mathrm{ft}$. southwest-by-south of the centre, was the body of a young person of uncertain sex and under 18 years of age, laid on the right side, with the head to E. At a distance of $12 \mathrm{ft}$. south-west of the centre, and placed on the natural surface, was a large flint block, which overlaid the much decayed remains of a child. Also on the natural surface, and $16 \mathrm{ft}$. south-south-west of the centre, were some remains of a body, probably that of a man past middle life, which had gone so much to decay that neither the side on which it was laid nor the direction of the head could be ascertained; close to the head was a round flint scraper. Amongst the material of the barrow were some potsherds, and many bones of ox, of goat or sheep, and of pig. 
CXII. The next barrow was barely distinguishable, having originally been of very slight elevation, and being now almost levelled by the plough. It appeared to have had a diameter of about $40 \mathrm{ft}$., and was $9 \mathrm{in}$. high. At the centre, on the level of the natural surface, was the body of an old woman, laid on the left side, with the head to N.N.E., but the bones were too much decayed to enable anything more to be ascertained concerning it. In front of the face was a small but prettily-made flint knife, $1 \frac{3}{4}$ in. long and $\frac{3}{4}$ in. wide, flaked carefully over the whole of the convex face. Close to the body of the woman was part of the lower jaw of a child about 10 years of age, some pieces of the scapula of a goat or sheep, and a few potsherds. Below was an oblong grave, lying north-east by south-west, $6 \frac{1}{2} \mathrm{ft}$. long, $3 \frac{3}{4} \mathrm{ft}$. wide, and $1 \frac{1}{2} \mathrm{ft}$. deep. At the bottom, and near to the south end of it, was the body of a woman past the middle period of life, laid on the right side, the back being straight, with the head to S. W. by S., and the hands up to the face. Behind the head was a bronze awl or pricker like fig. $40,1 \frac{5}{8}$ in. long, the tang for insertion into the handle being $\frac{1}{2}$ in. long. At a rather higher level, but still behind the head, was a large, roughly-made, round flint scraper, which probably had not been deposited with the body. In the grave were many disturbed bones of the body of a young person, the femurs and tibias of which were placed together, in their proper relative positions, a little above the breast of the woman just described. Ten feet south-westby-south from the centre was a hole, $2 \frac{1}{2} \mathrm{ft}$. in diameter and the same deep, the sides of which showed signs of burning upon them; in it was a considerable quantity of charcoal and several pieces of burnt flint.

CXIII. This, also a small barrow, being now only $42 \mathrm{ft}$. in diameter and $1 \frac{1}{2} \mathrm{ft}$. high, was made of earth and chalk. It had been placed on a natural rise of the ground where the chalk rock came to the day, and the grave, to be noticed presently; was excavated immediately to the south-west of that point. Five feet south-east of the centre, and on the natural surface, was the body of a man past the middle period of life, laid on the left side, with the head to N.E., the hands being up to the face. Behind the shoulders was a 'drinking cup' having a handle, the first of the kind I have met with. It [fig. 86] is $7 \frac{1}{8}$ in. high, $5 \frac{1}{4}$ in. wide at the mouth, and 3 in. at the bottom; the ornamentation, which is perfectly rendered by the engraving, is due to the application of a 
notched piece of bone or wood. Under it was a flint flake $2 \frac{1}{4}$ in. long, which, though there is no secondary flaking upon it, shows signs of use and has probably served the purposes of a knife. At the centre, and a little above the level of the natural surface, was the body of probably a woman, past the middle period of life, laid on the right side, the head being to E.N.E., and the hands crossed on the stomach. Behind the head was placed a 'food vessel' [fig. 136] of peculiar form, and roughly made of badly-wrought clay. It is $6 \frac{3}{4}$ in. high, the same in width at the mouth, and $3 \frac{1}{2}$ in. at the bottom, and has six unpierced ears close to the top. The form

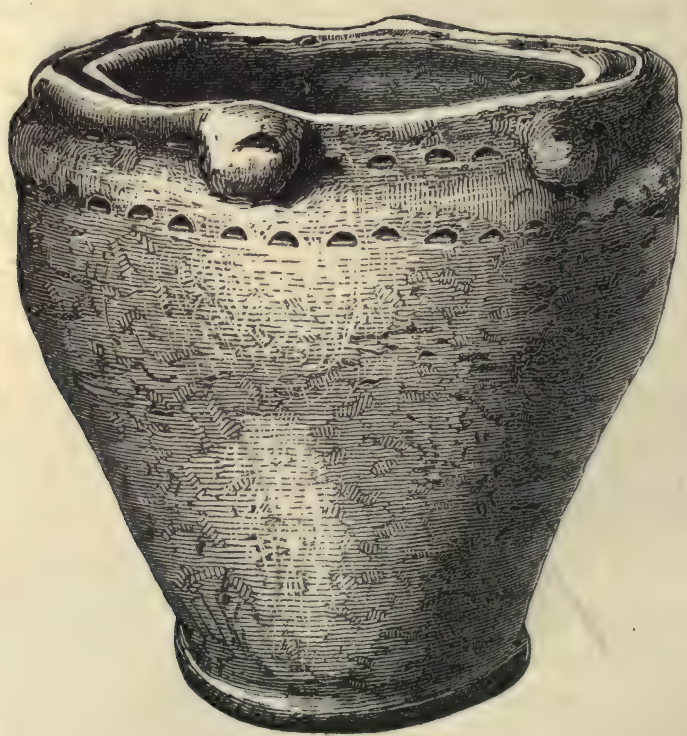

Fig. 136. $\frac{2}{3}$.

and ornamentation, made by the application of a semicircularended implement, will be easily understood from the figure. Above the body were some human bones, burnt and unburnt, the remains probably of bodies disturbed by the introduction of that just noticed, and several pieces of a 'drinking cup.' Below this body, which was placed over the east side of it, was a grave, covered with blocks of flint. It was $8 \mathrm{ft}$. long, $5 \mathrm{ft}$. wide, $3 \frac{3}{4} \mathrm{ft}$. deep, and had a direction east and west. At the east side of the grave, the head and hips resting on the edge of it, was the body of an old man, whose head was to N.E. by N., laid on the left side, with the hands up to the face. The legs and other parts of the body had settled down, by the shrinking of the materials in the 
grave, to a depth of nine inches below the head and hips. There were remains of wood underneath but not above the body. About six inches north of the head of the last-described body, but at a little higher level, was the skull of the disturbed body of a woman, in or beyond the middle period of life, some of whose other bones, consisting of a femur, tibia, fibula, the pelvic bones, and two humeri, were laid alongside each other, $7 \mathrm{ft}$. apart from the skull, and at the south side of the grave. At the west end of the grave was the body of a strongly-made old man, laid on the left side, with the head to S.E. by S., the hands being crossed over each other and placed on the hips. The knees rested on the edge of the grave, and the upper part of the body had sunk nearly a foot below them, in consequence of the settling of the materials with which the grave was filled, as in the case of the body just above noticed. To the same cause was probably due a dislocation of the radius of the left arm, which crossed the corresponding ulna at an angle of about $45^{\circ}$. This body, like the last, had been laid upon wood. Many of the bones were much affected by exostosis, and three of the dorsal vertebræ were glued together in consequence. On the bottom of the grave, and placed about the middle of it, was the body of a strongly-made man past the middle period of life, laid on the left side, with the head to E. by S.; the right hand was on the stomach, but the left was too much decayed to allow of its position being determined. The head, on the decomposition of the flesh and ligaments, had been pressed six inches back from the lower jaw, which still occupied its proper relative position. There were appearances as if the south end of the grave had been laid with wood. In the grave were several bones belonging to the right foreleg of a goat or sheep, and a tooth of the same animal ; amongst the material of the barrow were some bones of ox.

CXIV. This barrow was $58 \mathrm{ft}$. in diameter, $2 \frac{1}{2} \mathrm{ft}$. high, and made of earth and chalk. Just below the surface of the mound at the centre was a cinerary urn reversed, the bottom of which had been destroyed by the plough; it contained the burnt bones of an adult of small size. The rim, which is overhanging and $2 \frac{1}{2} \mathrm{in}$. deep, has been ornamented on both the outside and inside with a pattern consisting of alternate series of vertical and horizontal lines of twisted-thong impressions; this pattern covers the whole of the outside of the rim, and extends for above an inch lower on the inside. About $4 \mathrm{ft}$. south of the urn, ard placed on the level of the 
natural surface, were the remains of two unburnt bodies, one being that of a child about eight years old, the other of a woman in the middle period of life, but both so much decayed that nothing about their position could be ascertained. Below the urn was an oblong grave, lying north-east and south-west, $5 \mathrm{ft}$. long, $2 \frac{1}{2} \mathrm{ft}$. wide, and the same in depth. It contained the body of a child about 8 years old, laid on the right side, the head being to N.W. by W., and the hands up to the face, in front of which was a 'food vessel.' It is shaped like fig. 69, and has six perforated ears at the shoulder, being $4 \frac{1}{2}$ in. high, 5 in. wide at the mouth, and 3 in. at the bottom. It is ornamented for a space of $3 \mathrm{in}$. from the top with twenty parallel encireling lines of twisted-thong impressions, the ears having, some of them three and others four, short vertical lines of the same impressions upon them; the remainder of the vase is perfectly plain.

CXV. This barrow was scarcely to be distinguished from the surrounding ground, having no doubt originally been but of slight elevation, and now very much ploughed down. It appeared to have been about $50 \mathrm{ft}$. in diameter, and was not above $1 \mathrm{ft}$. high. Twelve feet south-south-east of the centre, and placed on the surface-level, was the body of a woman about 24 years of age, laid on the left side, with the head to E. by S., the arms being crossed on the hips. In front of the face was a 'food vessel,' which is in shape like fig. $70,5 \frac{5}{8}$ in. high, 6 in. wide at the mouth, and $2 \frac{7}{9}$ in. at the bottom, having four unperforated ears at the shoulder. It is ornamented over the whole surface (except the ears) and on the inside of the lip of the rim with bands of lines of finely-twisted thong-impressions arranged herring-bone fashion; the ears have short vertical lines of the same impressions upon them. Behind the crown of the head was found a bronze drill or awl like fig. 39, having a square centre and finishing at each end in a sharp point. It is $1_{\frac{5}{16}}$ in. long, the two ends being of unequal lengths, for if the division is taken at the middle of the square central part, one end is $\frac{9}{16} \mathrm{in}$. long, the other $\frac{1}{1} \frac{4}{8}$ in. ; in other implements of the same kind which I have met with the two ends are of equal length. At the right ear was a portion of a bronze article [fig. 48], and under the left shoulder were pieces of a second and similar one. There can be little doubt that they are ear-rings, though it is not easy to understand how they were attached; their size and lightness however, as well as. the position in which they were placed, appear to warrant their 
being considered as such decorations. Six feet south of the centre, and on the natural surface, was the body of a very strongly-made man past the middle period of life, laid on the left side, with the head to S.E., the right hand being on the knees, the left at the right shoulder and the fingers turned towards it. At the feet was a vessel of pottery in a fragmentary state, as indeed it must have been when placed in the barrow. There is nothing left but the bottom (4 in. wide) and about the same in height of the sides; it is entirely covered with impressions, made apparently by the fingernail, arranged in lines surrounding the vessel. At the centre, but much destroyed by the plough, were some bones of a child and pieces of a 'food vessel,' and immediately underneath them and on the natural surface, with some flint stones placed over it, was the body of an adult, probably a man, laid on the left side; there was no head, but if present it would have pointed to N.E. ; it did not however appear as if that part of the body had ever been buried there. The arms were crossed in front of the stomach, and on the knees was part of the skull of a different body, of which another portion was found not very far from it.

The two following barrows, a little to the north-east of the last, were situated upon a road, set apart on the division of the wold, called the Kiplingeotes Race-course. It gets its name from annual races held there to contest for a sum, the interest of money subscribed by a number of the Yorkshire gentry in the sixteenth century, and it may lay claim to be one of the earliest race-courses in England, though its reputation has now sunk to but a low ebb. In consequence of the piece of ground in question having never been under the plough the barrows were of their original size, and they presented somewhat novel features.

CXVI. The first was $23 \mathrm{ft}$. in diameter and $1 \mathrm{ft}$. high. It was covered over the whole surface with blocks of flint, and the number which had been used in that operation implies a considerable excavation of the chalk rock from which they must have been taken, for they did not present the characteristics of flints which had been lying on the surface for any length of time. Upon the level of the natural surface was found the body apparently of a small-sized woman, but, in consequence of the exposure to atmospheric and other agencies to which the shallowness of the burial had subjected the body, it was so much decayed that nothing as to its position 
could be ascertained. At the head, but whether before or behind it could not be determined, was a drinking cup [figs. 89, 90] of rather rude workmanship, but having the rare peculiarity of being ornamented on the bottom. It is $5 \frac{3}{8} \mathrm{in}$. high, $4 \frac{1}{4} \mathrm{in}$. wide at the mouth, and $2 \frac{5}{8}$ in. at the bottom. The ornamentation, which will be better understood from the engraving than from any description, has been made by lines drawn with a pointed tool. Under this body, which was placed at the centre of the mound, was a grave, lying north-west-by-north and south-east-by-south, $6 \mathrm{ft}$. by $2 \frac{3}{4} \mathrm{ft}$. and $2 \frac{3}{4} \mathrm{ft}$. in depth. In it, on the bottom, was the body of a stronglymade adult man, which had without doubt been placed there in a fragmentary and disturbed condition; there was no skull, no humerus or other bones of the arms, only one femur and one tibia, together with the bones of the pelvis and several vertebræ, but all mixed up together and out of place. It is very difficult to account for the condition in which the bones were found, nor does the overlying burial explain the appearances, for even had that been a secondary interment and thus necessitating the reopening of the barrow in order to insert it, the depth at which it was placed did not require the grave to be meddled with in order so to deposit it. The only conjecture I can offer is that the bones in the grave had belonged to a body buried at first in some other place, and that, on the occasion of the burial of the woman, who may have been related in some near way to the man, his remains were removed to the spot where it was purposed to bury her, and there re-interred previously to her burial.

CXVII. This barrow, like the last, was entirely covered over with blocks of flint; it was $19 \mathrm{ft}$. in diameter, $1 \frac{1}{2} \mathrm{ft}$. high, and made of chalk, with some flints and earth intermixed. At the centre, and placed a little below the level of the natural surface, was a rude sort of cist, formed of flint blocks and chalk, lying north-west and south-east, $3 \mathrm{ft}$. by $1 \frac{3}{4} \mathrm{ft}$. In it was the body of a woman above 30 years of age, laid on the right side, with the head to N.W. by W.; the right hand was under the head, the left extended out from and at a right angle to the chest. In front of the neck was the tooth of a pig, perforated at the root-end where it was also rubbed smooth, once doubtless the humble ornament of this British woman. The occurrence of perforated animal teeth, though they have not before been met with by me in any barrow which I 
have examined, is not without precedent ${ }^{1}$. Such natural deeorations are common to savage and semi-savage people in all parts of the world, and indeed I have seen an Australian necklace of kangaroo teeth, which forms by no means an inelegant ornament; and radiating as it would do when placed round the neck, and the white colour of the teeth shining and glancing in the light, it doubtless added no slight additional grace to the dusky beauty it adorned. Teeth of dogs, wolves and bears have been abundantly discovered on the site of the Swiss Lake Dwellings; and I have several horse and dog teeth, found in a cave in the county of Durham, together with a large number of bronze weapons and implements, several ornaments of bronze, and two of gold. Below this body was a grave, lying north-north-west and south-southeast, $7 \mathrm{ft}$. by $2 \frac{1}{2} \mathrm{ft}$. and $2 \frac{3}{4} \mathrm{ft}$. deep. In it, on the bottom and about the middle, was the body of a young man between 18 and 20 years of age, laid on the left side, with the head to S.S.E. and the hands up to the face. This barrow, instead of being placed as is usual upon a swell on the surface, had been made in a slight depression, and was therefore not so conspicuous as it would otherwise have been.

The two barrows just described give us reason to believe that the existing sepulchral mounds by no means represent the number of those which were originally on the wolds. If the land upon which these two were placed had been subjected to the action of the plough for but a very few years, there would not have been the slightest trace of them remaining; and it is possible that numerous similarly-sized barrows may have already wholly disappeared in the course of cultivation. This may also explain the fact that graves are sometimes found in the chalk rock, where there is now no appearance remaining of any mound above them.

The three barrows about to be described were situated close to the last two, though beyond the limits of the road set apart as a race-course, the two first being to the west, the third to the east of the road.

CXVIII. The first was $48 \mathrm{ft}$. in diameter, $2 \frac{1}{2} \mathrm{ft}$. high, and made

1 A canine tooth of a large dog or wolf, perforated through the middle, now in the York Museum, was discovered in a barrow at Hutton Cranswick, in the East Riding. Proc. of Yorkshire Phil. Soc. 1847-54, p. 185. A necklace, consisting of seventeen perforated teeth of wolf or dog, was found by Sir R. Colt Hoare in a Wiltshire barrow. Ancient Wilts, vol. i. p. 214. 
of earth. At the centre was a grave, the longer axis of which was north-west-by-north and south-east-by-south, $7 \mathrm{ft}$. long, $2 \frac{1}{2} \mathrm{ft}$. wide, and $2 \frac{1}{4} \mathrm{ft}$. deep. The grave had been lined on the bottom with wood, and upon that at the southern end had been laid the body of a young person of uncertain sex, placed on the right side, the head to S.E. by E., and the hands up to the face. Behind and at the crown of the head was a 'food vessel,' rudely made, and in shape somewhat like fig. 69 but narrower, 7 in. high, 6 in. wide at the rim, and $3 \mathrm{in}$. at the bottom. The ornamentation, which is confined to the upper $2 \frac{1}{2}$ in. of the vase, consists of two bands of lines on the inside and one on the edge of the lip, and five below the lip, all encireling the vessel, and made with very short pieces of thick cord placed vertically. In the grave, and close to the head of the body, was some yellowish-red ochre, a substance which has been met with in connection with other burials. Some potsherds of plain darkcoloured ware occurred amongst the material of the mound, and there were also found the humerus of a small-sized horse, some bones of red-deer, pig, and of a very large dog.

CXIX. The second barrow was very slight in elevation, not being above $6 \mathrm{in}$. high, and the area was not easily to be determined; it appeared however to have had a diameter of about $50 \mathrm{ft}$. It was difficult also to fix upon any place as the exact centre, though it is probable that the grave which it contained was the point from which the mound originated. Four feet to the east of this grave a circular hollow, $3 \frac{1}{2} \mathrm{ft}$. in width and $2 \frac{1}{2} \mathrm{ft}$. deep, had been excavated in the chalk rock, and then filled in again with chalk-rubble and earth; it contained nothing beyond the filling-in, and was probably one of those holes, though of a rather larger size than ordinary, which have so frequently been met with in other barrows on the wolds. The grave, like those found in the barrows close adjoining, was oblong, with a direction north-by-west and south-by-east, $6 \frac{3}{4} \mathrm{ft}$. long, $3 \frac{1}{4} \mathrm{ft}$. wide, and $4 \mathrm{ft}$. deep ; it was filled in principally with earth. At the north end was the body of a young person about 14 years of age, laid on the right side, with the head to N.N.W., the right hand being at the hips, the left up to the face. At the feet was a ' food vessel.' The remains of wood were found alongside the body and round the head and feet, but there was no trace of its having ever been placed above or below the body. The vase is like fig. 69, and is $5 \frac{1}{4} \mathrm{in}$. high, $6 \frac{1}{4} \mathrm{in}$. wide at the mouth, and $3 \frac{3}{8}$ in. at the bottom. The inside of the lip has two rows of dotted 
impressions encompassing it. A plain raised rib encircles the vase at the mouth, and $1 \frac{3}{4}$ in. below it is another. Between the ribs, and touching the lower side of one and the upper side of the other, are encompassing lines, having between them a zigzag line 1 in. deep; and below the second rib is another zigzag line similar to the first but not so deep; all the impressions are those of twisted-thong.

CXX. The third barrow was so much levelled by the plough, and had probably been at first so low in elevation, that it is impossible to say what its width and height may have been. Like the two mounds on the race-course, it had apparently been covered over with blocks of flint, for many of them were scattered about on the surface of the ground where the barrow had been placed. Within the limits of the mound, and representing no doubt the original centre, was a large grave, lying north-east and south-west, $7 \frac{1}{4} \mathrm{ft}$. long, $5 \mathrm{ft}$. wide, and $6 \mathrm{ft}$. deep. It was entirely filled in for a depth of $1 \frac{1}{2} \mathrm{ft}$. from the top with blocks of flint, and below them with chalkrubble and some little earth. Amongst the flints was a considerable portion of a human skull, broken but the pieces lying together, belonging to probably a male past the middle period of life. On the bottom of the grave at the middle was the body of an aged and strongly-made man, laid on the left side, the head to E.N.E., the hands being up to the face. In front of and touching the arms were some burnt bones belonging to a young man. Large flint blocks were placed in front of the body and behind the head and shoulders. In the grave were some of the basi-cranial bones of an ox, and a broken piece off the point of the tine of a red-deer's antler, probably part of a pick used in excavating the grave; similar instances have occurred elsewhere in the wold barrows.

CXXI. This barrow, to which the name of Money Hill is attached, was situated at a little distance to the south-east of the main body of the group of barrows, many of which have been just described, and upon the highest part of the ridge. The name is not, as might be supposed, derived from a fancied belief that a treasure was contained in it, but from the fact that forming a conspicuous object on the boundary line of two estates, when the boundaries were being perambulated money was scrambled for at the spot, in order to impress the better upon the memory of the persons assembled the limits of the manor. A less pleasant mode of fixing such a fact upon the recollection of the children who were 
present on these occasions was that commonly resorted to. The mound, which had never been ploughed over, was not circular, being $44 \mathrm{ft}$. long by $32 \mathrm{ft}$. broad, and having a direction east-by-south and north-by-west; it was $6 \mathrm{ft}$. high, and made of earth and chalk. Immediately below the surface of the mound numerous bones belonging to several bodies were met with, the remains of later interments, which had been disturbed in digging for rabbits and in planting the trees with which the mound was at one time covered. At a distance of $12 \frac{1}{2} \mathrm{ft}$. south-by-east from the centre, and $2 \mathrm{ft}$. below the surface of the barrow, was the body of an aged woman, laid with the head to $\mathrm{E}$. Immediately under the hips of this body, and 8 in. below it, was a vessel of pottery reversed. It is in shape like an ordinary flower-pot, quite plain, $4 \frac{5}{8} \mathrm{in}$. high, $5 \frac{1}{8}$ in. wide at the mouth, and $3 \frac{1}{4}$ in. at the bottom. Behind the back of this body were some parts of a child's skull. At the same distance south-east-by-south of the centre, and upon the natural surface, was a deposit of burnt bones, those of an adult, probably a woman. Eleven feet south-east-by-east from the centre, and $2 \frac{1}{2} \mathrm{ft}$. below the surface of the barrow, was the body of a child about 8 years of age, which had the head to $\mathrm{E}$., but of which the bones were too much decayed to allow the position of the body in other respects to be made out. About $8 \mathrm{in}$. below the head of this child was a vessel of pottery. It is too much decayed to admit of more being said of it than that it has been of small size and ornamented on the upper part with short lines made by a pointed tool. Just west of the centre, and $2 \mathrm{ft}$. below the surface of the barrow, was the skull belonging to the disturbed body of a man in middle life, several bones of which, as well as the bones of another body, were found throughout the mound at this part, and even down to the natural surface. It is possible that these bodies had been disturbed in making the grave which was met with at the centre. This was $6 \mathrm{ft}$. long, $3 \mathrm{ft}$. wide, and the same in depth, having a direction north-north-west and south-south-east, and was filled in with chalk. On the bottom, and about the centre of the grave, was the body of a girl about 17 years of age, laid on the right side, her head to W.N.W., and the hands up to the face. Round her neck were 124 beads of jet, all of which were small circular thin perforated disks, except a larger central one, semicircular in form, with two grooves across its flat top. But for the pendant being rounder and having these grooves, the necklace is almost identical with one found in a barrow at Weaverthorpe and figured p. 53. The 
bottom of the grave appeared to have been lined with wood, the remains of which, in the shape of a dark-coloured layer, covered the chalk floor. Some lumps of a yellow substance, which proved on analysis to be ochre, were met with on the bottom of the grave and close to the body.

\section{Parish of Londesborough. Ord. Map. xciv. s.w.}

CXXII. About one mile and a-half to the north of the large group of barrows upon Goodmanham Wold, just before described, there had originally been three sepulchral mounds. Two of them had been removed about thirty years ago, but the site of both was still apparent; the third remained, as it has been for many years past, untouched even by the plough, being situated in an old grasspasture. It was $45 \mathrm{ft}$. in diameter, $2 \frac{1}{2} \mathrm{ft}$. high, and was made of earth with a little chalk. Six feet south of the centre some disturbed human bones of a person below 20 years of age, and amongst them part of a skull, were found $9 \mathrm{in}$. above the natural surface. At the centre was a grave, lying south-east and northwest, $5 \frac{1}{2} \mathrm{ft}$. long, $3 \frac{3}{4} \mathrm{ft}$. wide, and $2 \frac{3}{4} \mathrm{ft}$. deep. On the bottom, at the middle, was the body of a child from 12 to 14 years of age, laid on the left side, the head being to S.E., the right hand up to the face, and the left extended down the side. In front of the face was a ' food vessel.' It is in shape somewhat after the fashion of fig. 69, and is very rudely made of coarse clay. It is $6 \frac{1}{4} \mathrm{in}$. high, $5 \frac{1}{2} \mathrm{in}$. wide at the mouth, and $3 \frac{1}{2} \mathrm{in}$. at the bottom. The inside of the lip has two encircling lines of twisted-thong impressions, and above and below the raised rib, which is $1 \frac{1}{4}$ in. below the mouth, is a band of short lines of thong-impressions sloping to the right.

CXXIII. I succeeded in finding a grave in one of the removed barrows (in the other I did not find one, but the site of the mound was not well defined, and a grave may possibly still remain there). A number of fragments of what has once been a well-made ' food vessel' were met with on the south side of the remains of the barrow. It has been profusely ornamented with a herring-bone pattern, made by bands of lines of twisted-thong impressions. The grave had a direction south-by-east and north-by-west, with an offset towards the west, not quite at the middle of that side. The length was $12 \frac{1}{2} \mathrm{ft}$., the width $4 \mathrm{ft} .9 \mathrm{in}$. ; the size of the offset, which commenced $6 \mathrm{ft}$. $8 \mathrm{in}$. from the south end of the 
grave, being $2 \frac{1}{2} \mathrm{ft}$. wide and $3 \frac{1}{4} \mathrm{ft}$. long; the extreme width of the grave, including the length of the offset, being at that part $7 \mathrm{ft}$. $10 \mathrm{in}$; the depth was $3 \frac{1}{4} \mathrm{ft}$. On the bottom was the body of a young man about 24 years of age, laid on the right side, the head, which was to S.W. by S., being close to the corner of the offset on the south; the hands were under the hips. The body was very slightly contracted, the back and thighs being straight, and the legs alone drawn up. Under the body were the remains of wood with which that part of the grave had apparently been lined. 


\section{YORKSHIRE. NORTH RIDING.}

Before describing the few barrows I examined in Cleveland, a district extremely rich in various remains of pre-Roman times, I propose very briefly to notice some discoveries made by other explorers, in order that the reader may become acquainted with the mode of burial which appears to have been adopted in that part of Yorkshire. A very large number of barrows have been most systematically and carefully opened by the Rev. J. C. Atkinson of Danby, some of the results of which were published by him in the Gentleman's Magazine ${ }^{1}$. Others have been opened by different persons, amongst them by Mr. Ord, author of the History of Cleveland, who has recorded some facts in that work ${ }^{2}$. The examination of these barrows has shown that, without any exception, the interments in the extensive district in question have been after cremation, the bones having been placed in urns and cists, and more frequently without any protection, at the centre and other parts of the barrow. Nor, so far as I can learn (and I believe I can speak with certainty on the point), has any article of bronze or other metal been discovered with any of the sepulchral deposits, except in the case about to be mentioned. The only instance that I know of where an unburnt body appears to have been met with in Cleveland was near Egton Bridge, where in widening a road at a place called Orchard Hills the workmen came upon a cist. It contained a 'drinking cup,' a portion of which has been preserved ${ }^{3}$, and three pieces of bronze, probably the remains of a knife-dagger. There was nothing left in the shape of bones; from which I infer

1 Vols. Ixii. 84; Ixiii. 16.

2 Ord's Hist. of Cleveland, p. 106.

3 'The fragment of the 'drinking cup' is engraved in the Journal of the Archrological Institute, vol. xxii. p. 262, fig. 18. 
that the body had not been burnt, for bones which have been calcined seem never to go to decay.

\section{Parish of Egton. Ord. Map. xcvi. n.e.}

CXXIV. About two miles south-west of Egton Bridge, and close by the side of the road leading across the moor, is a barrow called William Howe. It was entirely composed of stones, being what would be called further north a cairn; a large quantity of the stones had been removed in order to form the road above mentioned. When this was in process of making (about 1820) several vessels of pottery are said to have been found in the barrow. The mound had originally been about $80 \mathrm{ft}$. in diameter, and was still $6 \mathrm{ft}$. high. On the south-east side, $23 \mathrm{ft}$. from the centre, a deposit of the burnt bones of an adult was discovered; they were laid upon the surface of the ground, and spread in a scattered fashion over a space of quite $3 \mathrm{ft}$. in diameter, a rather unusual feature, the remains of a burnt body being generally collected together and placed in a heap.

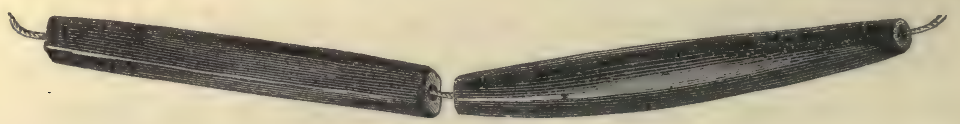

Fig. 137. $\frac{1}{1}$.

Some fragments of charcoal were interspersed amongst the bones, and in contact with them, lying at intervals of several inches apart, were fifteen jet beads [fig. 137]. These no doubt had once formed the necklace of the woman whose calcined remains were here deposited. The beads did not show the slightest trace of the action of fire, and must have been removed from the cord on which they had been strung and strewn amongst the burnt bones after they had become cold. This is by no means an uncommon occurrence; and not only ornaments such as these but implements of flint are sometimes found accompanying deposits of burnt bones, which have not themselves passed through the funeral fire. Fourteen of these beads are nearly cylindrical in shape, only swelling a little towards the middle, and they vary from 1 in. to $1 \frac{3}{4}$ in. in length ; the remaining bead presents a square section. They are all perforated with great nicety, and this together with the minuteness of the bore makes it more than probable that the drilling had been 
effected by the aid of a metal instrument, and if so the metal must undoubtedly have been bronze. Another interment, consisting of the burnt bones of a person of moderate size and probably under thirty years of age, was found immediately east of the present centre and about $3 \mathrm{ft}$. above the natural surface. This deposit, which from its position was in all probability the primary one, was placed without any protection amongst the stones of which the barrow was constructed. About the centre of the deposit of bones was a vessel of pottery, which did not however contain any of them; it is of the type to which the name of 'food vessel' has been applied, and is rudely made, in shape somewhat like fig. 69 , $5 \frac{1}{4}$ in. high, $5 \frac{3}{4}$ in. wide at the mouth, and $2 \frac{3}{4}$ in. at the bottom. It is ornamented near to the top with two pairs of encircling lines of impressions, placed half-an-inch apart, made apparently by a squareended piece of wood. The inside of the lip of the rim bears a row of similar impressions. Amongst the material of the barrow some calcined chippings of flint were met with.

CXXV. Upon Egton South Moors are placed in close contiguity three barrows which bear the name of the 'Three Howes.' I examined the northernmost one of them, which was $68 \mathrm{ft}$. in diameter and $7 \frac{1}{2} \mathrm{ft}$. high. It was composed of alternate layers of sand and what had apparently once been turfs, with here and there, but at wide intervals, a stone or two. It was evident that the mound had never been in the slightest degree disturbed since it was first erected, for the successive layers of yellow sand and darkcoloured turf were perfectly unbroken. Twenty-five feet south of the centre of the mound, and only $14 \mathrm{in}$. below its surface, was a deposit of burnt bones laid in a round heap about $1 \mathrm{ft}$. in diameter. Nine feet east of the present centre, and $4 \mathrm{ft}$. above the natural surface, was a second deposit of burnt bones, also laid in a round heap $10 \mathrm{in}$. in diameter. There seems to be little room for doubt that this had been the primary interment and had originally been placed at the centre of the barrow, which however, as is not unfrequently found to be the case, had been lost in throwing up the mound. A single fragment of a calcined flint-chipping was the only article in the whole mass of this large barrow which showed any signs of handiwork.

It will be observed that both in this and in the preceding barrow the supposed original interment had been placed, not as is usually the case in a hollow sunk below the surface or else upon the natural 
surface, but at some height above it. There must consequently have been a mound existing previously to the interment of the deposit of burnt bones which appeared in either barrow to constitute the primary burial. This feature, though by no means a common one, has nevertheless occurred to me in a few other instances, as well as to others who have examined barrows in different parts of England .

\section{Parish of Over Silton. Ord. Map. xovi. n.w.}

CXXVI. On the moorland occupying the high ridge of oolitic limestone above Kepwick are several barrows, amongst them a long one which will be found described in another part of this volume. I examined one of the round barrows, the only one remaining quite undisturbed. It was $64 \mathrm{ft}$. in diameter, $5 \frac{3}{4} \mathrm{ft}$. high, and was made of clayey sand. At the centre and $1 \frac{1}{2} \mathrm{ft}$. below the surface of the mound, placed in a hollow $8 \mathrm{in}$. in diameter and 6 in. deep, was a deposit of burnt bones, those of a person of uncertain sex under 24 years of age. Five feet south-east-by-east from the centre was a cinerary urn standing upright, at a distance of $3 \frac{1}{2} \mathrm{ft}$. above the surface of the ground, filled with the burnt remains of another young person about 20 year's of age, and amongst the bones was a long narrow flint flake calcined. The upper part of the urn was quite destroyed, apparently by persons digging for rabbits, so that it cannot be said what ornamentation, if any, was upon the rim. Immediately underneath, and in contact with the urn, were some other burnt bones, but it was not possible to say whether or not they belonged to the same body as that whose bones were within the urn. Many flint chippings, both burnt and unburnt, were found

${ }^{2}$ Mr. Bateman records some instances in Ten Years' Diggings. In a large barrow on Middleton Moor the interment was found near the top of the mound. l.c., p. 18. In his account of another barrow he says, 'The hunter chief, who, with one of his dogs, was deposited high up in this considerable mound, was interred in accordance with a previously observed custom.' l.c., p. 110. Another large barrow he says had no other trace of an interment than some burnt bones about a foot below the surface of the mound. $l . c .$, p. 175 . In a barrow $120 \mathrm{ft}$. in diameter and $18 \mathrm{ft}$. high, at a depth of $5 \mathrm{ft}$. and at the centre, were found some 'small pieces of an urn and a few pieces of calcined human bone.... Besides these we observed nothing; and it does not appear that any interment had ever been deposited on the natural level, in which respect the barrow resembles many other large mounds of earth in which an interment by cremation has been made at a high level or near the summit.' l.c., p. 183. A barrow near Pickering, in the North Riding, is stated to have contained no other interment than one by cremation 'just beneath the summit.' l.c., p. 217. 
near the urn. At the bottom of the barrow, on the natural surface, the whole central part was covered with remains of birch branches, some of which had been of considerable size, the bark being as fresh in appearance as if it had been but newly placed there. It might naturally be supposed that these branches had been laid there to support a body, if, as seems likely, there had been an interment at the spot, but there was no trace left of the bones. The barrow was wet at the place in question, but nevertheless I should have expected to have found some remains of the bones, though certainly under the circumstances they might have been but slight. A square-ended short flake of flint unburnt and a flint scraper burnt were met with in the barrow.

\section{Parish of Cold Kirby. Ord. Map. xcvi. s.w.}

Upon the well-known Hambleton training-ground, near Thirsk, are several barrows placed in a most commanding position at the verge of the lime-stone cliff which there overlooks the great plain of York. An ancient earth-work known as the Casten Dike runs parallel, for a distance of some miles, with the range of the cliffs. At the very edge of the crag, which itself forms one side of the defences, a small fortified place is situated. Most of the barrows there have been opened, but so far as I know without any but a very trifling account of the results having been recorded ${ }^{1}$.

CXXVII. I examined one of those which had been left untouched. It was $30 \mathrm{ft}$. in diameter, $4 \mathrm{ft}$. high, and was made of stones; these consisted of limestone flags of various sizes laid flat upon each other. At the centre the flag-stones became larger, and were arranged in a circular form sloping and overlapping each other from the central point; this inner cairn, so to call it, having a diameter of $12 \mathrm{ft}$. Below the stones was a layer of clay, from 6 in. to 8 in. thick, placed upon the natural surface. No trace of an interment was discovered, and the only explanation I can offer (which

${ }^{1}$ A paper by the late Mr. Denny, Curator of the Leeds Museum, 'Notice of Early British Tumuli,' \&c., contains an account of the opening of several barrows in the same locality, and amongst them of one on the Hambleton training-ground, close to an entrenchment called the Cleve Dike, in which was a cinerary urn, and amongst the burnt bones in it a smaller vessel. The paper was read before the West Riding Geological and Polytechnic Society, Nov. 22, 1865, and is printed in the Proceedings of the Society for that year, p. 488. 
I believe to be the true one) is that an unburnt body had been deposited upon the layer of clay and then covered over with the large flag-stones, and that in consequence of the free admission of air and water, and from other disintegrating causes, due to the pervious nature of the overlying material, the bones had gone entirely to decay. Some pieces of charcoal and two chippings of flint were found amongst the material of the mound.

CXXVIII. About half-a-mile to the south of the last-described

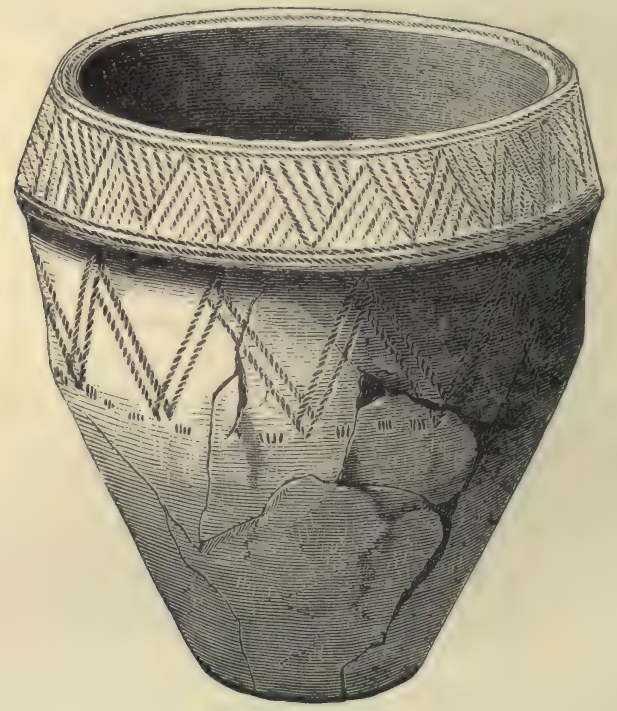

Fig. 138. $\frac{1}{6}$.

barrow was another, on the left hand of the road ascending Sutton Brow and within a few yards of the edge of the cliff. It was $44 \mathrm{ft}$. in diameter, $5 \mathrm{ft}$. high, and was formed of earth and clay with a few stones intermingled. Three feet east-south-east of the centre, and having its mouth placed but $1 \mathrm{ft}$. below the surface of the barrow, was a cinerary urn standing upright. It was filled to the top with a deposit of the burnt bones of a person of full age but of small size. The urn [fig. 138] is $12 \mathrm{in.} \mathrm{high,} 9 \mathrm{in}$. wide at the mouth, and $4 \mathrm{in}$. at the bottom, with an overhanging rim ornamented on the inside of the lip with one encircling line, and on the outside with two at the top and as many at the bottom, the space between being marked out into a series of triangles, alter- 
nately placed, each filled in with parallel diagonal lines. Below the rim a space of $3 \frac{1}{4} \mathrm{in}$. deep is occupied by a double zigzag line, having below that a row of short lines set about half-an-inch apart. All the impressions are those of twisted-thong. At the centre of the mound and just beneath its surface were a few stones placed together for the protection of a second cinerary urn, whose top was met with $2 \mathrm{ft}$. below them. The urn [fig. 54], which stood upright, was earefully packed round with clay and chareoal in large pieces ${ }^{1}$. It was deposited about $1 \mathrm{ft}$. above the natural surface, the intervening space having been filled in with well-worked clay. The bones which it contained, those of a young person of averàge size, were so completely burnt that they occupied a space of only a few inches at the bottom of the urn, which is however no less than $16 \mathrm{in}$. high, $12 \frac{1}{2}$ in. wide at the mouth, $16 \mathrm{in}$. at the bottom of the overhanging rim, and $4 \frac{1}{2}$ in. at the bottom. The pattern on it, which will be best understood from the figure, is made on the rim by impressions of twisted-thong, and below the rim by markings made with an oval-ended instrument of bone or wood. Amongst the material of the barrow were found scattered here and there numerous chippings of flint, a round flint scraper, and various sherds of pottery.

\section{Parish of Kilburn. Ord. Map. xCVI. s.w.}

Further south than the site of the last barrow, and forming part of the continuation of the high land of the Hambleton range of hills, is Wass Moor. The moorland is here bounded on the east by the valley of the Rye, and numerous remains indicating an early occupation have been placed upon it. Amongst these are many barrows, most of which have been opened at some former time, and without anything more than a very imperfect record having been preserved. So far as can be learned from this slight account, and supplementing it from the recollection of people living in the neighbourhood who remember the opening of some of them, the greater number, if not the whole, appear to have contained burials after cremation. In this they correspond to what has been found to be the rule in Cleveland, as has already been stated; and

1 Under a cairn near Swansea, in a hollow excavated below the natural surface, an urn was found packed round with charcoal, which filled up the space between the urn and the sides of the hole. Archæol, Cambr., 3rd Ser., vol. ii. p. 63. 
also with what I have myself observed upon the opposite high ground, on Grimston Moor, near Gilling, and rather further south on the same range of hills, on Slingsby Moor.

I examined three of the barrows on Wass Moor which remained more or less undisturbed, as well as a fourth situated about two miles south of them, an account of which will be found amongst the series of long-barrow notices. The three barrows just specified are placed about 30 yards apart, lying in a line which runs northeast by south-west.

CXXIX. The first, that which lies the furthest to the northeast, was bowl-shaped, $56 \mathrm{ft}$. in diameter and $5 \mathrm{ft}$. high; and the land having never been under the plough, it was of its original size and form. The outer part was formed of small stones (such as are abundantly found scattered on the surface of the adjoining ground) with a very slight intermixture of earth. Beneath the stones was a most regularly-constructed mound, composed of alternate layers of yellow and white coloured sand interspersed with many pieces of charcoal. This inner mound was $29 \mathrm{ft}$. in diameter, and rose at its apex to within a foot of the top of the barrow. The spot over which the first commencement of the mound had been made was most clearly marked; but there was not the slightest indication that, either at that place or at any other part of the barrow, there had ever been an interment. It is quite impossible that any burial after cremation can have been made in the mound, for, as I have remarked in other places, burnt bones appear to be indestructible. Indeed I may say that, in the course of a very large experience, I have never noticed any change to have taken place in calcined bones under whatever circumstances they have been placed. The only explanation I can give (one which I have had to offer in the case of a barrow lately noticed) is that an unburnt body had been laid on the natural surface of the ground, and that every trace of it had disappeared; a circumstance of by no means uncommon occurrence where free admission of atmospheric influences is afforded to the body by reason of the porous nature of the covering matter. I must however admit that in this barrow, on account of the nature of the material, I should have expected to have found some remains of the bones.

It has been held by some, as I have already stated in the Introduction, that these now empty and tenantless barrows are cenotaphs; that, in other words, no interment has ever 
taken place within them. Such a practice surely belongs to an age wherein the state of culture must have been much more artificial both in sentiment and habits than any by which we can imagine the people who erected these barrows to have been influenced. And indeed the non-occurrence of any signs of a body is so reasonably accounted for by the total decay of the bones that we need not look for any other or more recondite explanation. Amongst the materials of which the mound was formed were many chippings of flint, a flat rubber or polisher of oolitic sandstone, and a square piece of the same stone, $7 \mathrm{in}$. by $5 \mathrm{in}$. and over 2 in. thick, which has a circular pit or cup-marking on each face, 2 in. wide and $1 \frac{1}{2}$ in. deep. As I found in another of these barrows several other stones similarly marked, I will leave any further account of these enigmatical figures until I come to the description of the barrow in question.

CXXX. The second barrow was $44 \mathrm{ft}$. in diameter, $4 \mathrm{ft}$. high, and was entirely made of sand. At a distance of $4 \mathrm{ft}$. west of the centre, and about 3 in. above the natural surface, was a very large quantity of charcoal, which extended for more than $4 \mathrm{ft}$. in a direction north and south. This mass of charcoal consisted to some extent of portions of trunks of oak trees, some of them not thoroughly charred throughout. One of them was above $4 \mathrm{ft}$. long, and still nearly a foot wide, and $4 \mathrm{in}$. in thickness. Immediately east of this mass of charcoal the natural surface showed signs of burning, which became more evident towards the centre of the barrow, where in a circular hollow $2 \frac{1}{2} \mathrm{ft}$. wide and $1 \mathrm{ft}$. $3 \mathrm{in}$. deep were the remains of the burnt bones of an adult, probably a man. The body had been burnt on the spot, the wood of the pile having been laid over the top of the previously formed hollow.

CXXXI. The third barrow was $42 \mathrm{ft}$. in diameter. It had been very much disturbed in recent times for the sake of the stones which formed it. There was no trace of any interment remaining, but, from the way in which the mound had been turned over, it could searcely be expected that any undisturbed burial would be met with. On the whole it is probable that the interment in this, as in the first described barrow, had been by inhumation, and that all the bones had disappeared through decay. If a burnt body had ever been interred in the mound, it might have been expected that, notwithstanding the disturbance to which it had been subjected, some 
pieces of the calcined bones would have been found, if not in situ, still scattered amongst the material of which the barrow was composed. A stone was found on the east side of the mound having two grooves upon one face, which quarter it and form a cross; the grooves appear to have been made by grinding the edge of some sharp implement, and it is possible they may have been used for sharpening the edge of a flint or other stone axe.

A remarkable feature in this barrow was the very large number of stones (more than twenty), of various sizes, from 5 in. to $18 \mathrm{in}$. square, and of different and irregular shapes, on which pit or cupmarkings had been formed ${ }^{1}$. These hollows were both circular and oval, and differed in size from 1 in. in diameter to 3 in., and their depth was about 2 in. The oval pits, as a rule, were not very regular in outline. Some of the stones had only one pit-marking upon them, others had as many as six; on some they were quite separate from each other, on others they were connected by a shallow but wide groove. They were all formed in a soft and very light oolitic sandstone, and the pits were in most cases as fresh as if only made yesterday, showing most distinctly the marks of the tool, which appeared to have been a sharp-pointed instrument and very probably of flint. It is not easy to attribute any special purpose to these stones or to their markings. The condition of the pits, showing no signs of wear (for had anything been ground or rubbed in them

${ }^{1}$ Colonel A. Lane Fox has two similarly-marked stones, which came from a barrow on Wykeham Moor in the North Riding; and others with circular markings in addition to the pits or cups were found in a barrow on Claughton Moor; in both these cases the barrows in which they occurred contained interments after cremation. In a barrow at Way Hag on Ayton Moor, also in the North Riding, and in another in the same locality, several stones marked with like pits occurred. The barrows contained burnt bodies, and one had a circular enclosure round it within the mound. See Journ. of Archæol. Assoc., vol. vi. p. 1, where some of the stones are engraved. In a small cairn near Kirk Whelpington, Northumberland, hereafter described [No. ccx], a burnt body enclosed in an urn inverted was placed upon a small flat stone, upon the under surface of which was cut a shallow pit, exactly like some of these described in the text. Stones with the same pit-markings on them have been found covering interments after cremation, at Black Heddon near Stamfordham, and near Ford, both in Northumberland. In a barrow on Dornoch Links, near the town of Dornoch, Mr. Lawson Tait found upon a cist-cover several pits or cups, which had still in them the marks of the tool. Proc. Soc. of Ant. of Scotland, vol. vii. p. 270. Several cupmarked stones occurred in a cairn on the farm of Greenloan near Belchan, Lower Cabrach, Aberdeenshire. Proc. Soc. of Ant. of London, 2nd Ser., vol. vi. p. 257. Mr. Bateman records the finding of two stones, each with a cup-shaped depression, in barrows, one of them in connection with a deposit of burnt bones. Ten Years' Diggings, pp. 172, 178. Two stones with concentric circular markings upon them were discovered, covering each a burial after cremation, on Came Down, Dorsetshire. Warne, Celtic Tumuli of Dorset, p. 37 . 
the marks of the tooling upon so soft a stone would have been speedily effaced), seems to preclude the idea that they were intended for any domestic or manufacturing process. On the whole I prefer to regard them as symbolic representations; though as to what their significancy may be I confess myself unable to offer anything more than conjecture. They present a marked resemblance to the similarly-shaped pits which, found sometimes alone and sometimes in connection with incomplete circles, have been discovered so extensively in Northumberland, Yorkshire, Argyleshire, Kerry, and other parts of the United Kingdom. In many cases these markings occur upon rocks, but they have been very frequently found upon detached stones of greater or less size, and in a large number of instances, some of which are recorded in the preceding note, they are connected with burials after cremation; sometimes covering the deposit of bones, sometimes placed beneath it, and sometimes forming the side or cover of a cist within which the bones were deposited. This connection with burial, always a sacred rite, seems to bring them within the class of symbolic representations; in other words, suggests the notion that they are or may have been figures, after a very rude and conventional manner, of some object embodying an idea that involved the deepest and most esoteric principle of the religion held by these people. The tau symbol of Egypt, the pinecone of Assyria, the triangular-shaped stone of India, the cross of Christianity, outward expressions of that which has been in almost every religion its most sacred belief, may well have been, however different in form, yet the same in essence with these mysterious pits and circles ${ }^{1}$.

\section{Parish of Gilling. Ord. Map. xcvi. s.e.}

Upon the opposite side of the valley to that on which the lastdescribed barrows were placed, and rather further to the southwest, is Grimston Moor. Many evidences of occupation in early times are still to be seen upon that part which has not been cultivated. A line of entrenchment runs across the moor in a direction east and west, consisting of a mound and ditch, and close by it are several barrows, six of which I opened, and four rectangular mounds with rounded corners, not apparently sepul-

\footnotetext{
1 A very complete account of these markings, with careful and numerous figures of the different varieties, will be found in the works referred to in a note at p. 7 .
} 
chral, one of which I examined. It was $99 \mathrm{ft}$. long, $15 \mathrm{ft}$. wide, and $2 \mathrm{ft}$. high, and had a trench $3 \mathrm{ft}$. wide round it. It was placed in a direction north-north-west by south-south-east. Though evidently artificial, nothing whatever was found in it. In several parts of Westmoreland there exist groups of similarly-shaped mounds, there called Giants' Graves, but those I have seen are much smaller than these on Grimston Moor. Many of those in Westmoreland have been examined by myself and others, but in no case that $I$ am aware of has anything whatever been discovered in them.

CXXXII. The first of the six barrows I opened was $47 \mathrm{ft}$. in diameter, $4 \mathrm{ft}$. high, and was formed, like all the rest, of sand. A circle of stones resting on the surface of the ground and standing apart from each other, $37 \mathrm{ft}$. in diameter, encompassed the mound, but was placed within and partly covered by it. Six feet south of the centre, and immediately beneath the surface of the barrow, was a cinerary urn very much decayed. It was placed upright, and was filled with burnt bones so much calcined as almost to be reduced to powder; amongst them was deposited a flake of flint calcined. Seven feet south-east of the centre, and like the last close below the surface, was a second cinerary urn, in the same decayed condition as the other. It too was filled with burnt bones, and amongst them was a calcined round scraper of flint. No interment, either at the centre or anywhere on or beneath the natural surface, was met with. The urns, in consequence of their nearness to the surface of the barrow, were too much disintegrated to permit of their size being ascertained. They were however of the usual character of cinerary urns, having an overhanging rim ornamented with the common impressions of twisted-thong. Several chippings of flint, both burnt and unburnt, were found amongst the material of the mound.

CXXXIII. The second barrow was $70 \mathrm{ft}$. in diameter and $4 \frac{1}{2} \mathrm{ft}$. high. It was formed differently from the ordinary bowlshaped mounds, being quite flat on the top, where it had a diameter of $24 \mathrm{ft}$. It had been so constructed in the first instance, for the moor had never been under the plough, and there were no signs whatever of the barrow having ever been interfered with since its erection. Eighteen feet south-east of the centre and $1 \frac{1}{2} \mathrm{ft}$. below the surface of the mound was a vessel of pottery: 
in a very decayed condition; it was laid on its side, the mouth being turned to the south-west. Fifteen feet south-east of the centre and about $1 \mathrm{ft}$. below the surface of the barrow were two deposits of burnt bones, so much calcined as to be almost reduced to powder. They were placed close together, each laid in a round heap of about $10 \mathrm{in}$. in diameter. With one of them was deposited an implement (probably a knife) of flint unburnt; it is $2 \frac{1}{8} \mathrm{in}$. long by $1 \mathrm{in}$. wide at the broader end, and gradually decreases in width to the other end, which is rounded. It is carefully chipped to a sharp edge along both sides and over the entire back at the rounded and smaller end; the other face is as it came off from the block, with no secondary working upon it. It is not impossible that the vase, which was found not more than $3 \mathrm{ft}$. from these burials after cremation, may have been associated with one of them; it has sometimes occurred to me to find a vase placed a little distance apart from the burial which it apparently accompanied. Twelve feet south of the centre and $1 \frac{1}{2} \mathrm{ft}$. below the surface of the barrow was another deposit of burnt bones laid in an oval heap $12 \mathrm{in.} \mathrm{by} 10 \mathrm{in}$. At the same distance from the centre as the last but south-west of it, and immediately beneath the surface of the mound, was a cinerary urn of the usual shape, very much decayed and broken; it was filled with the burnt bones of an adult. At the centre was an oval hollow, sunk $1 \mathrm{ft}$. below the natural surface; it was $3 \frac{1}{2} \mathrm{ft}$. by $2 \mathrm{ft}$., the longer diameter being east and west, and contained the remains of a burnt body, those of an adult, and no doubt the primary interment. In the substance of the barrow, with other fragments of flint, was part of a beautifully-flaked and very thin leaf-shaped arrow-point.

CXXXIV. The third barrow was $52 \mathrm{ft}$. in diameter and $3 \frac{3}{4} \mathrm{ft}$. high. About $17 \mathrm{ft}$. east of the centre was a pile of stones $2 \frac{1}{2} \mathrm{ft}$. wide and $2 \mathrm{ft}$. high; beneath this, and at the height of one foot above the natural surface, was a deposit of the burnt bones of a young person; they were laid in a circular heap $14 \mathrm{in}$. in diameter. There was no indication that a burial had ever been made at the centre. In the material of the barrow were some chippings of flint, both burnt and unburnt.

CXXXV. The fourth barrow was much smaller, being only $18 \mathrm{ft}$. in diameter and $1 \frac{1}{2} \mathrm{ft}$. high. At the centre were six stones, set on edge in an oval form, forming a sort of cist $3 \mathrm{ft}$. by $2 \frac{3}{4} \mathrm{ft}$, 
with a single stone employed as a cover. The cist contained no trace of the body at one time no doubt deposited in it, and which had probably been an unburnt one and had gone entirely to decay; a circumstance (as noticed a few pages back) of by no means uncommon occurrence in cases of cist or other places of burial made in porous soil and not far from the surface. Some unburnt flint chippings were found amongst the material of which the barrow was composed.

CXXXVI. The next barrow was $42 \mathrm{ft}$. in diameter and $2 \mathrm{ft}$. high. It was very flat, though still decidedly curvilinear in outline, and not level-topped like the second one of this group. On the east side was a quantity of stones, not however arranged in any order. At the centre was a circular hollow, $2 \frac{1}{2} \mathrm{ft}$. in diameter and sunk $14 \mathrm{in}$. below the natural surface. In it were deposited the bones of a burnt body, that of an adult, and upon them was placed an 'incense cup' reversed. It had almost gone back to its first condition of clay, and neither pattern nor dimensions could be made out. The hollow itself, which had been formed in the sand, was lined with clay; the body had been burnt over the hole, the clay having been converted by the action of the fire into a substance nearly as hard as brick. In the material of the barrow were found some chippings of unburnt flint.

CXXXVII. The sixth and last barrow was $56 \mathrm{ft}$. in diameter and $3 \mathrm{ft}$. high. At the centre was a hollow slightly oval in form, being $4 \frac{1}{2} \mathrm{ft}$. by $4 \mathrm{ft}$., and sunk $1 \mathrm{ft}$. below the natural surface. In it were placed the very completely calcined remains of a burnt body, upon which was laid a 'food vessel.' It is well made and delicately ornamented, in shape like fig. 71 , with four unpierced ears, $4 \frac{1}{2}$ in. high, $5 \mathrm{in}$. wide at the rim, and $2 \frac{3}{8}$ in. at the bottom. The inside of the lip of the rim has three encircling bands of short twisted-thong markings arranged herring-bone fashion. The outside of the lip has a single band of sloping thong-marks on the edge, whilst below that and above the shoulder is another band of the same marks sloping in the contrary direction, and forming with the band on the outside of the lip a series of chevrons on edge encompassing the vase; next comes a band of upright horseshoe-shaped marks, having below it an encircling line of fine twisted-thong impression, and then a band of short upright thongmarkings. On the shoulder are two bands of similar marks, 
which are continued over the ears. Below the shoulder are three bands similar to those on the inside of the lip but made with finer thong, and then come six bands of horse-shoe-shaped marks, the lines of each band sloping alternately in the contrary direction and forming a kind of herring-bone pattern. Below this the vase is plain for a space of $1 \frac{1}{2}$ in., and then at the bottom is a band of horse-shoe-shaped marks placed upright.

It will have been remarked that in this group with one exception, namely the empty cist in the fourth barrow, the interments were all of burnt bodies; and the same will be found to be the rule in the barrows upon the range of hills further to the south, near Castle Howard. It would therefore appear that burning the body was the custom which prevailed with the people whose burialmounds occur upon the high land which lies between the plain of York and the valley of the Rye; although from an account of the opening of some mounds near Newburgh, a few miles to the north of Grimston Moor, which is given in Gill's 'Vallis Eboracensis,' it would seem that the body had been interred unburnt in the majority of instances at that place. The question of the contemporaneous use of the two modes of burial has been discussed in the Introduction, and it is sufficient here to note the fact of the occasional deposit of burnt and unburnt bodies in close proximity.

\section{Parish of Suingsby. Ord. Map. xcvi. s.e.}

Another group of barrows, to which reference has just been made, is situated upon Hall and Slingsby Moors, near Castle Howard, about four miles east of the group last described. The usual practice of placing the mounds containing these ancient interments upon high ground has been broken through in this case, for the barrows about to be noticed are found in a small valley, formed by a tributary of the Derwent which runs from north to south through the oolitic range of high land lying to the east of the plain of York. The barrows with one exception were not upon the lowest ground in the valley, but on the slope of the hill-sides which skirt it; in no case however were they upon the ridge or even high up the side of the flanking hills.

CXXXVIII. The first barrow was $56 \mathrm{ft}$. in diameter, $5 \mathrm{ft}$. high, and was made of mingled sand and clay very firmly compacted. 
The mound had been previously disturbed by a small opening having been made about the middle, which had resulted in the discovery of the central interments. These-for there had probably been more than one body buried-consisted of burnt bones which had been contained in, or associated with, four vessels of pottery. The burials had originally been made at the centre of the barrow, in a circular hollow $2 \mathrm{ft}$. in diameter and sunk $1 \mathrm{ft}$. below the natural surface. At the bottom of this hollow there still remained the lower part of a cinerary urn which had not been removed by the first explorers, and immediately under it was a round flint scraper unburnt [fig. 139]. The disturbed

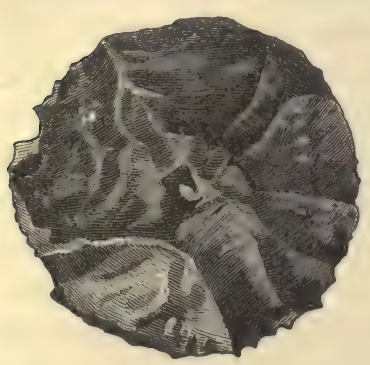

Fig. 139. $\frac{1}{1}$. bones together with several fragments of the sepulchral vessels ${ }^{1}$ had been replaced in a hole made just below the surface of the barrow, a little south of the centre; amongst the burnt bones were several pieces of calcined flint. Above the central deposit, and immediately beneath the surface of the mound, several stones had been placed with some regularity of arrangement. Fifteen feet south-east-by-south of the centre and $2 \mathrm{ft}$. below the surface of the barrow was a cinerary urn, set upright and filled with the burnt bones of a small person of full age, probably a woman; amongst them was a flint knife calcined, smaller but identical in shape with one found

1 Two of them have been large einerary urns, the other two being smaller vessels. The first of the large urns has been a very fine one, with an overhanging rim $3 \frac{1}{4}$ in. deep ornamented with five lines of short sharp-ended oval impressions encircling the urn, whilst the inside of the lip has upon it a similar line of impressions nearly circular. Below the rim for a space of 3 in., as much as now remains, the urn has lines of impressions similar to those on the rim. The other large urn has had an overhanging rim ornamented with lines of thong-impressions, those on the only piece which is left being horizontal; the inside of the lip has had three if not more similar lines round it. One of the smaller vessels has on the overhanging rim (which is $1 \frac{5}{8}$ in. deep) two lines at the top and three at the bottom of impressions made with a very delicate cord, the intermediate space being filled up with three bands of short lines placed vertically and herring-bone fashion, each band being separated from the other by a line similar to the encompassing one on the upper and lower parts of the rim. The lip also has on the inside an encompassing line like those on the rim. A small fragment, probably belonging to the same vessel, has a reticulated pattern of delicate cord or twisted-thong impressions, and below this three encompassing lines of the same impressions. The second of the smaller vessels has had its overhanging rim (which is $1 \frac{1}{2}$ in. deep) ornamented with lines of very fine cord-impressions encompassing the urn. 
on Wykeham Moor and figured at p. 359. This one is $3 \frac{3}{8}$ in. long and $1 \frac{1}{4}$ in. wide at the broadest part. The urn, very rudely made and in shape like fig. 54, is $13 \frac{1}{4}$ in. high, 12 in. wide at the mouth, $13 \frac{1}{2}$ in. at the bottom of the overhanging rim, and $4 \mathrm{in}$. at the bottom. The rim, $3 \mathrm{in}$. deep, is ornamented with twistedthong impressions irregularly placed and not forming any distinct pattern. In the material of the barrow were several chippings of flint and a small round scraper, all unburnt.

CXXXIX. The second barrow was $16 \mathrm{ft}$. in diameter, $1 \frac{1}{4} \mathrm{ft}$. high, and was made of sand. The sole interment-a burnt body-was placed at the centre in a hollow about $12 \mathrm{in}$. in diameter and sunk $6 \mathrm{in}$. below the surface of the ground. Over this hollow, and extending beyond the limits of the place of deposit, was a layer of charcoal about an inch thick; above the charcoal, and continuing over the entire area of the barrow, was a layer of clay and sand about 4 in. thick, evidently indurated by the action of fire. Amongst the materials of the mound was a piece of calcined flint.

CXL. The third barrow was near to the last one, being only some $50 \mathrm{yds}$. south of it. It was $60 \mathrm{ft}$. in diameter, $7 \frac{1}{2} \mathrm{ft}$. high, and made of very loose sand. Three feet below the surface of the mound was a layer of mixed sand, clay, and gravel, $1 \frac{1}{2} \mathrm{ft}$. thick, consolidated into a hard mass by the agency of fire ${ }^{1}$. This extended throughout all that part of the barrow which was examined (more than one half of it) on the south and east sides, but at the centre it was almost as hard and as red-coloured as ordinary brick, and must have been subjected to strong and longcontinued heat before it could have undergone so great a change. There was therefore in this barrow a burnt layer like to that described in the last one; but the interment in the present case was above and not beneath the burnt matter. The calcined remains of the body, reduced to a small quantity by the process of burning, were deposited at the centre and were placed immediately upon the burnt layer, $4 \frac{1}{2} \mathrm{ft}$. above the natural surface. With the bones was a rather rudely-formed but well-baked 'food

${ }^{1} \mathrm{Mr}$. Bateman met with a somewhat similar layer in a barrow in Derbyshire. 'About a yard from the bottom a thin ferruginous seam ran through the mound, perfectly solid and hard, like pottery which might, possibly, be the effect of heat.' Ten Years' Diggings, p. 62. 
vessel,' somewhat in form like fig. 69 , but having two raised ribs; and touching it was a flint scraper unburnt, 2 in. long and $1 \frac{1}{4}$ in. wide. The vase ${ }^{1}$ is $5 \frac{1}{8}$ in. high, 6 in. wide at the mouth, and $3 \frac{3}{8} \mathrm{in}$. at the bottom. The inside of the lip has two encircling rows of markings and the outside has one; immediately below that is a second row, the marks being rather longer; then above and below the second rib is a similar row. The impressions by which the pattern is formed appear to have been made by a square-ended piece of bone or hard wood; some apparently having been produced by the application of the end and others by that of the side of such an instrument.

The burnt layer extending throughout the area of the barrow is a very singular feature. Indeed, besides these two cases I have met with but one other [No. lxxv]. It is not an infrequent occurrence to find places in a barrow where burning has taken place; but these are limited to a comparatively small area, and do not show signs of having been subjected to so large and long-continued a fire as must have been maintained in these two mounds. The smaller areas of burning $I$ am now speaking of may have been the places where a body had been burnt previously to burial, or where a funeral feast was cooked. But we cannot on like grounds account for the fires which must have been required to produce the effects noted in the present burnt layers. Deposits of burnt bones are also frequently found placed on the site where the pile upon which they were burnt had stood, but in none of the many instances that $I$ have met with where this has occurred was there anything approaching to the remarkable appearance in these barrows, both in respect of the unusually large area over which the burning had extended and of the intensity of the burning itself.

CXLI. The fourth barrow was $57 \mathrm{ft}$. in diameter, $5 \frac{1}{2} \mathrm{ft}$. high, and made of sand. At the centre and laid upon the natural surface was the primary and only interment, that of the burnt body of an adult, the bones of which were placed in a round heap about $10 \mathrm{in}$. in diameter.

CXLII. The fifth barrow was $16 \mathrm{ft}$. in diameter, $1 \mathrm{ft}$. high, and made of sand. At the centre and (as in the last mound) laid upon

1 It is engraved in Arch. Journ., vol. xxii. p. 252, fig. 17. 
the natural surface was a deposit of burnt bones rather widely scattered and mixed with charcoal; they were those of a person of mature age and of uncertain sex.

CXLIII. The sixth barrow was also small, being $18 \mathrm{ft}$. in diameter and $1 \frac{1}{2} \mathrm{ft}$. high; it was made of sand. At the centre, in a hole $3 \mathrm{ft}$. in diameter and sunk $1 \frac{1}{2} \mathrm{ft}$. below the surface of the ground, were some of the burnt bones of an adult, which (as in the case of the preceding interment) were much scattered amongst the burnt earth and charcual with which the hole was filled; there was a single piece of unburnt flint in contact with the bones. The body had been burnt on the spot, the hollow having been first excavated. Three feet east-south-east of the hole in which the bones were deposited and just above the natural surface was a perfectly plain vessel of pottery, placed with its mouth downwards and with some charcoal about it; it is shaped much like an ordinary cup without a handle, and is $3 \frac{7}{8} \mathrm{in}$. high, $3 \frac{3}{4}$ in. wide at the mouth, and $2 \frac{1}{2}$ in. at the bottom. It is very different in many respects from the ordinary sepulchral vessels, and it may well have been originally intended for domestic use.

CXLIV. The seventh barrow was $32 \mathrm{ft}$. in diameter, $3 \frac{1}{2} \mathrm{ft}$. high, and made of sand. At the centre was a circular hollow $2 \mathrm{ft}$. in diameter and sunk $1 \mathrm{ft}$. into the ground. It contained amongst charcoal and burnt earth a deposit of burnt bones laid close together, the remains of the body of a young person which had been burnt on the spot; the hole having been made after the burning had taken place. Upon the bones at the south side of the deposit was an 'incense cup' [fig. 64]. It is $1 \frac{3}{8}$ in. high, $1 \frac{7}{8}$ in. wide at the mouth, $2 \frac{3}{4}$ in. at the widest part, and 2 in. at the bottom. The four encompassing lines below the mouth have been made by the impression of finely-twisted thong.

The next six barrows were situated near together and about a mile to the south-east of those last described. With the exception of that first to be noticed they were all very inconspicuous, requiring a practised eye to detect that they were more than natural ground-swellings and that there was anything artificial about them. Though something of their present low elevation is no doubt due to the continued action of the plough over a very light sandy soil, yet they must always lave been small in area and low in height. 
CXLV. The first one was $47 \mathrm{ft}$. in diameter, $2 \mathrm{ft}$. high, and was composed of sand. It was placed upon a natural rise of the ground, and had lost some of its original height by having been for a long time under cultivation. Fifteen feet south of the centre was a cinerary urn set upright and resting on the natural surface; the upper part of it had been entirely destroyed by the plough. What remained of it was filled with a deposit of burnt bones, those of a person about the time of puberty; amongst which were found a barbed arrow-point of flint calcined [fig. 140]; a flint

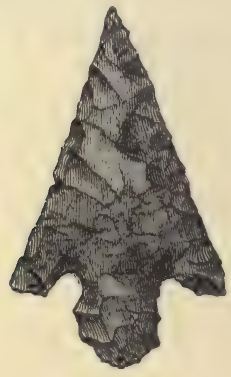

Fig. 140. $\frac{1}{1}$.

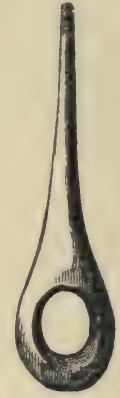

Fig. 141. $\frac{1}{2}$.

scraper, oval-shaped and thin, unburnt; a calcined bone pin [fig. 141] $1 \frac{5}{8}$ in. long, with a large eye at the head $\frac{1}{4}$ in. in diameter; and a bone fibula calcined [fig. 7]. This curious dress-fastener, for such no doubt it is, has been very ingeniously made from the articulating end of a small animal bone, and, as will be seen from the engraving, is neatly formed ${ }^{1}$. About $11 \mathrm{ft}$. south-east

${ }^{1}$ Similar fibulæ have been found, though rarely, elsewhere. One was discovered, itself calcined, with a burnt body in a barrow on Melmerby Common, North Riding, by the Rev. W. C. Lukis. A second one, also calcined, now in the collection of Mr. Dotchon, Whitby, was found in a previously disturbed barrow near Robin Hood's Bay, North Riding; there were burnt bones and a single cylindrical jet bead close by it, and it had probably accompanied them. These articles have occurred in Wilts; in a barrow previously disturbed Sir R. Colt Hoare found 'a piece of ivory resembling the handle of a cup;' it was in a grave, but it is not stated whether the burial was after cremation or not. Ancient Wilts, vol. i. p. 200. pl. xxiv. He records the finding of another in a grave with a burnt body, where were 'two articles in high preservation. The one resembles in shape a small lance-head, the other is like the handle of a cup. The latter is the third article of the sort we have discovered.' l. c., p. 200. pl. xxiv. From the engraving, the second article appears to be identical in shape with that noticed in the text, as also is Mr. Lukis's. I have one, calcined, given to me by Professor Rolleston, found, with a deposit of burnt bones and a calcined flint flake worked on the edge, in a grave at Wytham near Oxford, where many burials of unburnt bodies have been discovered, some of them associated with flint implements. 
of the centre was an urn, laid on its side upon the natural surface and protected by two stones, one set on the north side of it, the other on the south. It is rudely made, $6 \frac{3}{4}$ in. high, $6 \mathrm{in}$. wide at the mouth, and $3 \mathrm{in}$. at the bottom, in form something like fig. 56 : The upper part for a depth of $3 \mathrm{in}$. is ornamented by impressions of loosely-twisted thong, irregularly placed and very close together. Three feet north-west of the centre was a cinerary urn reversed, and filled with burnt bones belonging to two adults. It was placed about a foot above the natural surface, and the bottom had been destroyed by the plough. It is $12 \frac{1}{4}$ in. wide at the mouth, and the upper part for a depth of $4 \frac{1}{2}$ in. is covered with thong-impressions irregularly made and forming no definite pattern. The inside of the overhanging rim, $2 \frac{1}{4} \mathrm{in}$. deep, has a pattern of alternate series of vertical and horizontal lines of twisted-thong impressions, like fig. 54; the horizontal series are however nearly three times the width of the vertical. This was probably the central and primary interment, the true centre having been lost in the process of throwing up the mound. The farmer occupying the land had, some time before I opened the barrow, dug into the centre but found nothing, and within the limits of the very narrow cutting he had made there were no signs of a burial having ever taken place. There was nothing but a single potsherd in the sand which he had disturbed.

CXLVI. The second barrow was $16 \mathrm{ft}$. in diameter and $1 \mathrm{ft}$. high, and was set upon a natural swell of the land. At the centre, in a hollow $1 \mathrm{ft}$. in diameter and sunk to the same depth below the surface, was a deposit of the burnt bones of a child, covered over with large flat pieces of charcoal. The body had been burnt on the spot, the hole having been first made.

CXLVII. The third barrow did not apparently rise much above the natural surface (at the spot rather higher than the adjoining ground), any added material having been removed in ploughing. In a hollow $2 \mathrm{ft}$. in diameter and $1 \frac{1}{2} \mathrm{ft}$. deep was a deposit of the burnt bones of an adult about 25 years of age, resting upon a flat stone placed $10 \mathrm{in}$. above the bottom of the hollow. Beneath this stone was a second deposit of burnt bones, those of a nearly full-grown person; with a part of the leg-bone of probably a deer, also calcined; amongst them on the south side was laid an 'incense 'cup.' It is in shape much like one found in the next barrow, 
but is quite plain, with the exception of having a circular boss, with a raised rib surrounding it, at the centre of the bottom on the outside. In the inside, corresponding to the boss on the outside, is a cup-shaped depression $1 \frac{3}{8}$ in. in diameter and nearly half an inch deep. The vessel is $1 \frac{1}{2} \mathrm{in}$. high, $2 \frac{7}{8} \mathrm{in}$. wide at the mouth, and $3 \frac{1}{4}$ in. at the bottom.

CXLVIII. Like the last, the present barrow was very inconspicuous: to cursory observation it was only a natural rise of the ground of circular form; though no doubt there had once been some addition made to the ordinary surface-soil. In a hollow $2 \mathrm{ft}$. in diameter and sunk to a depth of $1 \mathrm{ft}$. and which was filled in with burnt earth, was a deposit of the burnt bones of an adult woman, very much calcined. The body had been burnt on the spot, the hole having been first made. Immediately above the bones though not in contact with them, some burnt earth intervening, was placed an 'incense cup.' This, though most symmetrically formed and tastefully ornamented, is made of clay, which has become so much disintegrated that no very exact measurement or description can be given of it. It seems however to have been in shape like fig. $62,2 \frac{5}{8}$ in. wide at the mouth, and gradually widening for a depth of $1 \frac{1}{4}$ in., when it narrows again towards the bottom. The inside of the lip has two encircling lines upon it, and the upper part of the vessel is an exact counterpart in miniature of the overhanging rim of fig. 138; the lower part is plain. The pattern is made by impressions most regularly applied of a very delicately-twisted thong. There still remains one hole pierced through the side at the middle of the cup, and there may have been another. Amongst the bones and surrounded by fragments of the skull was a second 'incense cup' [fig. 63]. It is pierced with twenty-seven holes in nine vertical rows of three each, and is ornamented over the whole surface with parallel encircling lines of twisted-thong impressions. On the bottom, at the outside, is a circular raised ring $1 \frac{3}{4}$ in. in diameter, and on the inside is a similar ring of the same size. The cup is $1 \frac{3}{4}$ in. high, $2 \frac{3}{4}$ in. wide at the mouth, and $3 \frac{3}{8}$ in. at the bottom.

CXLIX. The fifth barrow was scarcely more apparent than the last. In a hollow $2 \mathrm{ft}$. in diameter and $8 \mathrm{in}$. deep was a deposit of the burnt bones of a child 6 or 7 years old, above which, on the 
south-west side of the hole and overlying the bones of the skull, was an 'incense cup' [fig. 142]. It is $1 \frac{3}{4}$ in. high, $2 \frac{1}{4}$ in. wide at the mouth, and $2 \mathrm{in}$. at the bottom. The whole surface including the bottom is covered with punctured dots, those on the sides in parallel encompassing lines, those on the bottom irregularly placed. The body had been burnt on the spot, the hole having

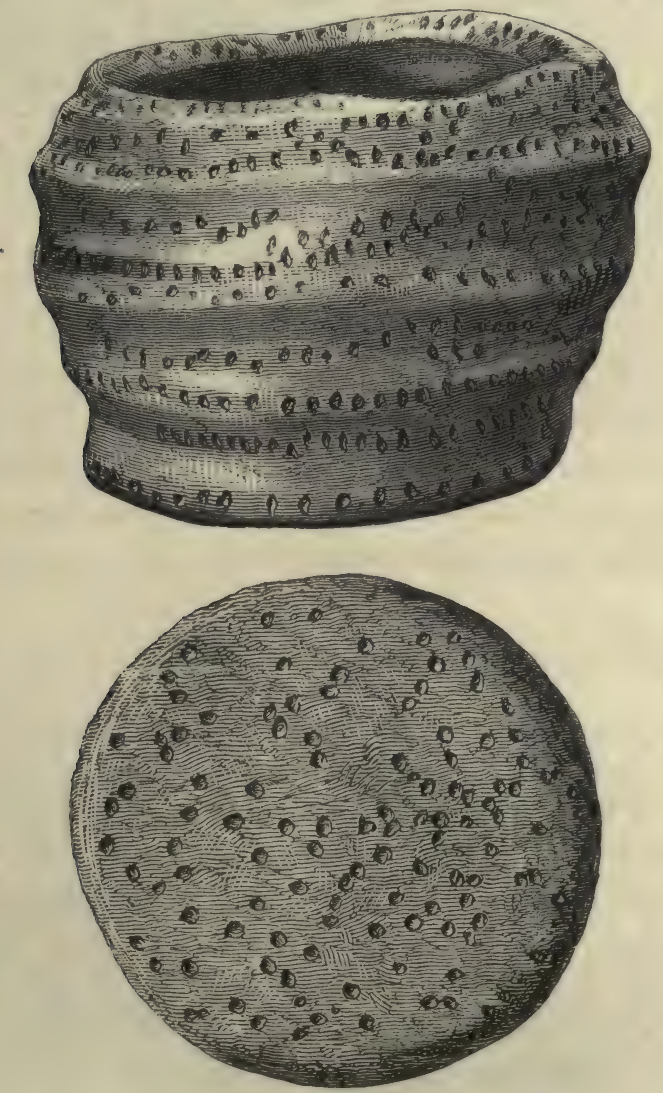

Fig. 142. ․

been first excavated, and much charcoal in large lumps lay about and over the hole.

CL. The sixth barrow was $24 \mathrm{ft}$. in diameter, $1 \frac{1}{2} \mathrm{ft}$. high, and was composed of sand. At the centre was a hollow $2 \mathrm{ft}$. in diameter and sunk $1 \frac{1}{2} \mathrm{ft}$. below the surface of the ground. It contained a deposit of burnt bones, those of an adult, amongst 
which was a small round scraper of flint unburnt. The body had been burnt on the spot, but the hole had been excavated after the burning of the body had taken place.

The whole of the interments in these two groups of barrows, it will be observed, were burials after cremation, a practice which appears to have been the rule in this part of Yorkshire. The number of 'incense cups' found with the interments is a remarkable feature, being very much beyond the ordinary proportion. In the case [No. cxlviii] where two 'incense cups' were discovered accompanying a single deposit of burnt bones, it is probable that the remains of two bodies had been placed there. The bones however had been so completely burnt and thereby reduced to such very small fragments, that it was impossible to ascertain with certainty whether they were the remains of more than one body. In other instances where two vessels have been met with associated with a single deposit of burnt bones it has been found that two bodies were present, so that it is probable there had been two in the barrow in question; though it may be remarked that more than one vessel has been sometimes found accompanying a single unburnt body.

\section{Parish of Whiburn. Ord. Map. XCIII. N.E.}

CLI. The barrow now to be described was situated at Carmire, near Castle Howard. It was bowl-shaped, $62 \mathrm{ft}$. in diameter, and $7 \mathrm{ft}$. high; it had never been ploughed over, and was probably of its original height. For a depth of about $4 \mathrm{ft}$. below the surface it was composed of soft earth, very much like what might have been formed from decayed turfs; below that it consisted of very hard and solidly-compacted sand and clay. The only burial discovered in the mound, notwithstanding a most thorough and searching examination, was that of a burnt body enclosed in a cinerary urn which had been very much broken and injured in digging for rabbits. The urn had been deposited at the centre of the barrow at a depth of not more than $1 \frac{1}{2} \mathrm{ft}$. beneath the surface of the mound, and though the exact size cannot be determined, enough remains to show that it had been one of unusual character. The overhanging rim, which is $2 \frac{3}{4} \mathrm{in}$. deep, is ornamented with alternate series of vertical and horizontal lines; the series of vertical lines having a vertically-placed zigzag. line overrunning them; while both above and below these alter- 
nating series is a single encircling line. The inside of the lip, $\frac{3}{4}$ in. deep, has an encircling line at the top and another at the bottom, the space between being filled in with short diagonal lines inclining to the right. All these impressions are due to twisted-thong. Below the overhanging rim the urn is quite plain for a space of an inch in depth, but below that is a pattern made of circular impressions apparently formed with the end of a piece of reed cleanly cut across. The singular feature is, that on the inside of the urn, commencing $2 \frac{1}{2}$ in. below the rim, is a similar pattern to that just described, and like it made apparently with a piece of reed. How far this ornamentation extended on either the outside or inside of the urn it is, on account of its fragmentary condition, impossible to say. Abundant traces of burnt matter were met with throughout the barrow; amongst the material of which were a few potsherds, and a very large number of flint chippings (some of them calcined), including eight unburnt round scrapers.

\section{Parish of Hutton Buscel. Ord. Map. xcv. s.w.}

Along the same range of high land upon which is placed the Scamridge Long Barrow, but a few miles further to the east, is continued the series of barrows to which reference is made in the account of that barrow given in another part of this volume, a series which extends as far as the tract of moorland lying between Troutsdale and the valley of the Derwent. A glance at the map referred to above will show how thickly the district in question is studded with grave-mounds. Most of them have been rifled by the mere curiosity-hunter, and it is to be feared that no record of what was found in them has been preserved. A few however still remained unopened up to a recent period, and of the examination of some of these I now proceed to give an account.

CLII. On Wykeham Moor are three houes called 'The Three Tremblers,' standing a few yards apart from each other. The two smaller had been partially opened some years ago, but the third remained untouched. It lies the most to the south of the three, and is bowl-shaped, $98 \mathrm{ft}$. in diameter and $11 \mathrm{ft}$. high-no doubt its original elevation. It was formed entirely of sand, with a few easual stones here and there. About $16 \mathrm{ft}$. from the outside of 
the barrow and contained within the mound and covered by it was a circle of stones, which I have little doubt surrounds the mound, but as I did not examine the whole circumference, I cannot of course assert positively that it does so ${ }^{1}$. Twenty-four feet south-east of the centre was a small cist placed $3 \mathrm{ft}$. above the natural surface. It was $2 \mathrm{ft}$. long by $13 \mathrm{in}$. wide and the same in depth, and was formed by a flag-stone at the bottom, upon which rested two stones set on edge, constituting two sides, and a.cover-stone over them. Within the cist, which was filled with sand, was a food vessel [fig. 143], lying on its side. It is

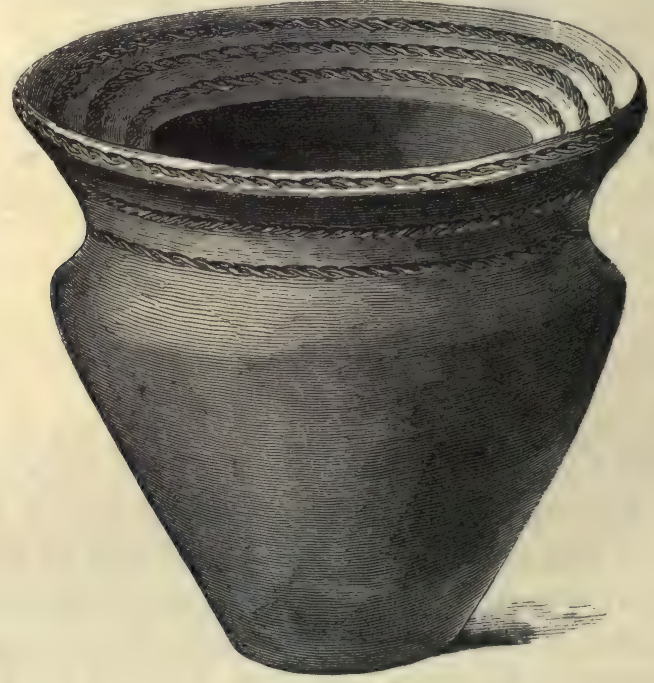

Fig. 143. $\frac{1}{2}$.

$4 \frac{1}{8}$ in. high, 5 in. wide at the mouth, and 2 in. at the bottom; the lip is unusually wide at the inside, being $1 \frac{1}{8} \mathrm{in}$., and is ornamented with three encircling lines of twisted-thong impressions. The rim has a similar line on the edge; whilst below it are two lines of thong-impressions, also encompassing the vase. No trace of bone or other indication of an interment was found in the cist. There can however be scarcely any doubt that an unburnt body had originally been deposited in it; and judging by the size of the cist it must have been that of a young child. From the nature of the material of which the barrow was composed,

1 The subject of these encircling rings of stone or earth is fully discussed in the Introduction. 
a light and porous sand, it could scarcely be expected that any remains of the bones would be left. At a spot $8 \mathrm{ft}$. south-east of the centre and $4 \mathrm{ft}$. above the natural surface, a large quantity of burnt earth and charcoal was met with. Two feet south-east of the centre, $4 \mathrm{ft}$. below the summit, and $7 \mathrm{ft}$. above the natural surface, a bronze dagger [fig. 144] and a large and beautifully flaked flint knife [fig. 145] were discovered lying side by side. No remains of bone nor other signs of a burial beyond the two implements just mentioned were found. The same cause-free admission of air and other agencies - as had destroyed all trace

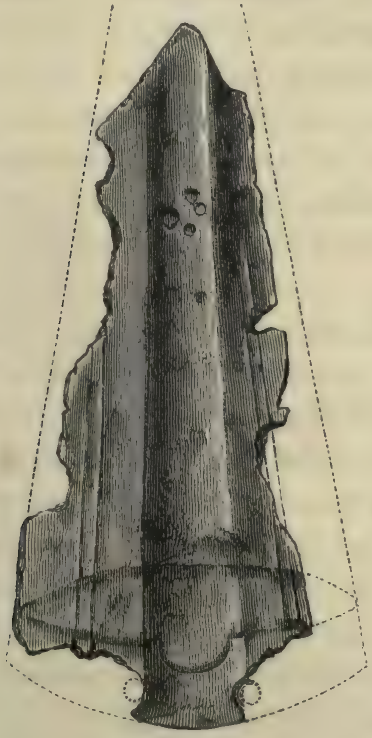

Fig. 144. $\frac{1}{2}$.

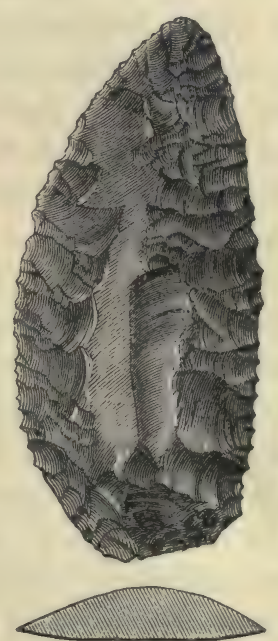

Fig. 145. 항.

of the body in the cist will also fully account for the absence of any part of the skeleton in this case. The dagger has originally been about $8 \mathrm{in}$. long, but has lost some portion of its length by oxidation. It had been deposited enclosed in its wooden sheath, portions of which were still upon it when found ${ }^{1}$. The line where the haft-probably of wood or ox-horn-had met the sheath is very apparent; it is of the semilunar form, a common one in the handles

${ }^{1} \mathrm{Mr}$. Bateman records the finding of a similar blade, and says, 'when deposited it had been enclosed in a wooden sheath, the remains of which were very perceptible at the time of its discovery.' Vestiges, p. 90. Sir R. Colt Hoare mentions the occurrence of the remains of the wooden sheath upon several of these instruments. Ancient Wilts, vol. i. pp. 39, 185, 194, 239. 
of bronze weapons. The handle or haft had been attached either by rivets of some perishable material such as wood ${ }^{1}$, or by thongs of leather or cord ${ }^{2}$. One of the holes for the attachment of the blade to the handle still remains, and another has perished through the oxidation of the metal. The blade, which is moderately thick, is further strengthened by a central rib, which has on each side of it two incised lines. From the thickness of the blade, and its having apparently terminated in a sharp point, this instrument seems to possess more of the characteristics of the true dagger, than of the knife-dagger, with its thin blade and rounded end, which is the implement most commonly discovered in the barrows; and perhaps it ought to be designated as a dagger. The flint knife, $4 \frac{1}{2}$ in. long and 2 in. wide at the broadest part, has been removed from the core at one stroke, and that face has not been retouched by the maker; the other is carefully flaked over the whole surface, which has a ridge up the middle, and from the way in which the flakes have been removed it has resulted that the edges are serrated.

The occurrence of these two implements in conjunction affords a valuable, though by no means an uncommon, illustration of the contemporaneous use of implements of bronze and stone. During even the period of highest cultivation in the Bronze Age, and much more when that metal had only lately become known, it is I think certain that implements and weapons of flint and other stone were still in common use. Bronze, from the nature of its composition and the scarcity of one of its constituents, must always have been an expensive material; and the poorer members of the community would probably have no other implements besides those of stone, whilst the richer would have some of bronze in addition. All who are acquainted with our early remains will have observed that no bronze arrow-heads have been found in Britain ${ }^{3}$, whilst, on the

${ }^{1}$ In a barrow on Bincombe Down, opened in 1784, a bronze knife-dagger was discovered. 'It had been fixed to a shaft by three wooden pegs, one of which remained in the perforation when found.' Mr. Warne quotes this from some unpublished minutes of the Society of Antiquaries, 1784, p. 51. Celtic Tumuli of Dorset-Tumuli Opened at Various Periods, p. 7.

${ }^{2}$ In a barrow not far distant from the Three Tremblers Mr. Harland found with the remains of a burnt body a small bronze knife which had still adhering to it some portions of cord partly charred, apparently the remains of what had formed the attachment of the handle.

${ }^{3}$ Sir R. Colt Hoare figures a bronze article which he calls an arrow-head; but judging from the broadness of the blade at the part where the rivet-holes are placed for the purpose of attachment to the shaft or handle, I should rather incline to think 
eontrary, flint arrow-points are most abundant; as also that heads of spears or javelins of flint, of which material they might have been as easily fabricated as arrow-heads, are rare ${ }^{1}$. The explanation I believe is this : the articles which a man retained by him when in use, such as his sword, spear, and axe, were made of the more valuable material, bronze; while such as he projected to a distance from himself, and which were therefore liable to be lost, such as arrow-points, were made of the commoner material, flint. Knives also of a certain kind and implements for scraping hides or bone would continue to be made of flint long after the introduction of bronze, because for such purposes flint presented a very useful as well as cheap material, and one almost as good as bronze.

The primary interment was found on the natural surface, immediately beneath the bronze dagger and flint knife, and $11 \mathrm{ft}$. below the surface of the barrow. The body had been buried unburnt, but all the bones were so much decomposed that the only trace left of it was a thin layer of a dark-coloured substance, mixed with small particles of a whitish colour, which felt greasy to the touch, and proved on analysis to contain animal matter. With this was discovered a small thin fragment of bronze, so- much oxidised that it is impossible to say what it may have been, though probably it was the remains of a small knife. In the material of the barrow at different parts, a few potsherds, a barbed arrowpoint, and some chippings of flint, as well as numerous pieces of charcoal, were met with.

CLIII. The most northern of 'The Three Tremblers' was found on examination to have been previously dug into at the centre, nor have I been able to ascertain what was discovered there. The barrow was $62 \mathrm{ft}$. in diameter, $6 \mathrm{ft}$. high, and made of sand. A circle of stones, placed within the mound on the natural surface at

it has been a small knife. Ancient Wilts, vol. i. pl. xxxii. fig. 1. Toy weapons and implements have sometimes been found in barrows; and indeed are very commonly discovered in Denmark; a miniature bronze dagger, smaller than this object from Wiltshire, will be seen figured in Worsaae, Nordiske Oldsager, pl. 33. No. 152. A remarkably diminutive bronze celt, evidently a toy or ornament, found at Arras in the East Riding, is engraved in the Transactions of the Archæological Institute, York Meeting, Museum Catalogue, p. 21. A bronze instrument, which seems almost like an arrow-head, but having been probably a small knife, was found at Broughton, Lincolnshire, and is figured in Journ. of Arch. Inst., vol. viii. p. 346. The finding of a few specimens of bronze arrow-heads would not however militate against the view taken in the text.

${ }^{1}$ I am inclined to regard most if not all of the larger flint blades, to which the name of spear-head has frequently been attached, as having been intended for knives. 
a distance of $14 \mathrm{ft}$. from the outer circumference, enclosed the central portion of the barrow. At a distance of $19 \mathrm{ft}$. south of the centre a cinerary urn was met with, in a reversed position, and containing a deposit of burnt bones, those of a person above 20 years of age. It was placed not more than $1 \mathrm{ft}$. below the surface of the mound, and in consequence the bottom of it had been much injured by digging for rabbits. The urn, a large one, approaching in form to fig. 56 , is $16 \mathrm{in}$. high and $15 \frac{3}{4}$ in. wide at the mouth; it is very well made and shows great skill in its fabrication, especially when its size and the circumstance that it is hand-made are taken into consideration. For a depth of 6 in. below the rim it is ornamented with nine encompassing rows of impressions made by a round-ended instrument applied obliquely from below. The inside of the lip, which is $2 \mathrm{in}$. deep, has two similar rows of impressions, but formed with an oblong-ended instrument, the marks being each $\frac{3}{4}$ in. long and $\frac{1}{4}$ in. wide; on the edge of the lip, and also between the two rows on the inside, is a band of short diagonal lines or strokes inclining to the right, made with a sharp-pointed tool. On the south-east side of the barrow, and just within the stone circle above-named, a triangularshaped pendant of inferior jet or some other lignite was met with, laid under a flat stone placed on the natural surface. It is rather roughly fashioned, and is $1 \frac{1}{4} \mathrm{in}$. long, $1 \mathrm{in}$. wide at the lower part, and perforated near to the top. Not far from it, and lying together, were two peculiarly-formed scrapers and a knife, $2 \frac{1}{4}$ in. long and curved on one edge, all of flint; it is possible that the two implements I have called scrapers may have been knives, and perhaps they are better adapted for cutting than for scraping.

About a mile to the north of 'The Three Tremblers,' upon the verge of the ground which slopes rapidly into Troutsdale, were three barrows placed close together.

CLIV. The first, $30 \mathrm{ft}$. in diameter and $4 \mathrm{ft}$. high, was entirely made of small stones, and had a circle of much larger stones round the base. The several interments it was found to contain were laid upon a flooring of small pebble-stones resting on the natural surface. Nine feet north-west of the centre was a deposit of burnt bones, covering a space of about $15 \mathrm{in}$. in diameter. Six feet northby-east from the centre was a second deposit of burnt bones, rather widely scattered over an area about $3 \mathrm{ft}$. in diameter. In each 
case the body was that of an adult of uncertain sex. Amongst them were some fragments of pottery and a 'food vessel' [fig. 146]; it is $5 \frac{1}{8} \mathrm{in}$. high, $5 \frac{7}{8}$ in. wide at the mouth, and $3 \mathrm{in}$. at the bottom; the pattern is all made by impressions of twisted-thong. With this interment was associated a pointed oval unburnt flint implement, flat on one face and untouched by secondary flaking, and having the other face, which is convex, carefully flaked over the whole surface. It is $1 \frac{1}{2} \mathrm{in}$. long and $\frac{3}{4} \mathrm{in}$. broad, and must be regarded $I$ think as a knife, and is of a type of which $I$ have seen several specimens, found with burnt bodies but always themselves unburnt. About $8 \mathrm{ft}$. west of the centre and $2 \mathrm{ft}$. above the natural surface, laid amongst the stones composing the mound, were two unburnt-or very partially burnt-bones, portions of a

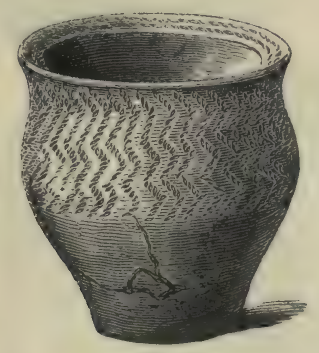

Fig. 146. $\frac{1}{5}$.

tibia and an ulna. They seemed to have been placed where they were found as separate bones and during the process of raising the barrow, for there was not the slightest trace of disturbance; nor did the appearance of the mound at the place, or any other circumstance, warrant the conclusion that an entire body had ever been deposited there. At the centre was a circle of stones set on edge, $4 \mathrm{ft}$. in diameter, and resting upon the natural surface ${ }^{1}$. Within this circle, and on the west side, was an urn so much broken and decayed that only a small part of it could be preserved. It was filled with burnt bones; while placed upon them and serving as a

${ }^{1}$ Similar instances have been met with elsewhere, some of which are noticed in other parts of this book. In Derbyshire Mr. Bateman found within a barrow at Flax Dale a circle of stones surrounding the centre, within which was a deposit of burnt bones in an urn. Ten Years' Diggings, p. 63. Mr. Warne records a case in Dorsetshire, where within a barrow a circle of stones was found $10 \mathrm{ft}$. in diameter enclosing the centre of the mound, where was a cist with an urn. Celtic Tumuli of Dorset, p. 33. 
kind of cover was a smaller one, which was reversed [fig. 147]. It is quite plain, $3 \frac{1}{2}$ in. high, the same in width at the mouth, and $2 \frac{1}{4}$ in. at the bottom, and has two ears on opposite sides, perforated, not as is usually the case with a horizontal piercing but vertically ${ }^{1}$. The larger urn had been ornamented after a fashion which is not very common in such vessels, having had an encircling line formed by a series of wide loops [fig. 148]. Amongst the burnt bones was a single piece of calcined flint. On the east side of the space within the circle was another cinerary urn, like the first placed on the natural surface, and also filled with burnt bones. It was however so much decayed that neither shape, size, nor pattern of

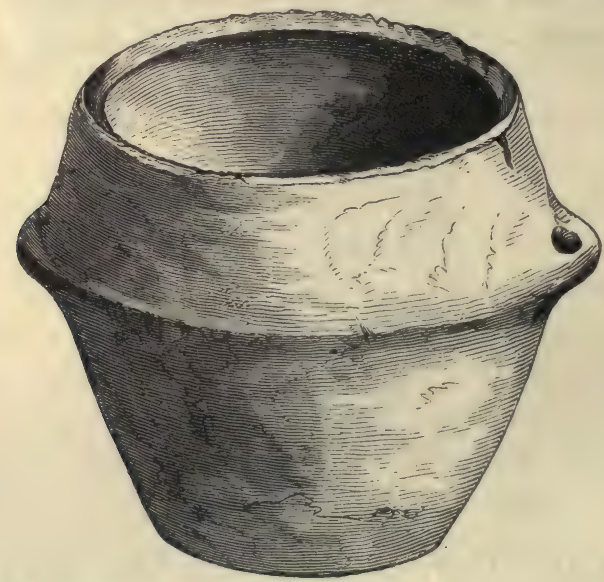

Fig. 147. $\frac{1}{2}$.

ornamentation could be made out. Three feet east of the circle and $2 \mathrm{ft}$. above the natural surface was a single piece of pottery. Over the circle and the space included within it, the stones composing the mound were much burnt, and a considerable quantity of burnt earth was mixed with them. Upon the flooring of pebblestones mentioned above, but not associated with the burnt bones, was a flat oval-shaped quartz pebble, $1 \frac{3}{4}$ in. long and $1 \frac{3}{8}$ in. wide; it is much bruised all round the edge, but more so at either end than elsewhere. It has been used for hammering, or more probably in the process of taking off flakes of flint from the block.

${ }_{1}^{1}$ Vessels possessing the same peculiarity of having the holes made vertically through a projection have been found in other places. At Broughton, in Hampshire, a vessel not very unlike this was met with associated with a deposit of burnt bones. Journ. of Arch. Inst., vol. ix. p. 11. 
The other two barrows were placed each on a natural rise of the: ground, and their artificial portion consisted of a few stones placed on the top, so as to give a little additional height to the hill.

CLV. The first was $16 \mathrm{ft}$. in diameter. At the centre, in a hollow $2 \mathrm{ft}$. wide and sunk to a depth of $1 \frac{1}{4} \mathrm{ft}$. below the natural surface, was a deposit of the burnt bones of an adult, and amongst them a single piece of calcined flint.

CLVI. The second was oblong in shape, $16 \mathrm{ft}$. by $12 \mathrm{ft}$., and had a hollow at the centre, $1 \frac{1}{2} \mathrm{ft}$. in diameter and $2 \mathrm{ft}$. deep. It contained a deposit of burnt bones, those of an adult, and amongst them were four flint chippings which had passed through the fire;

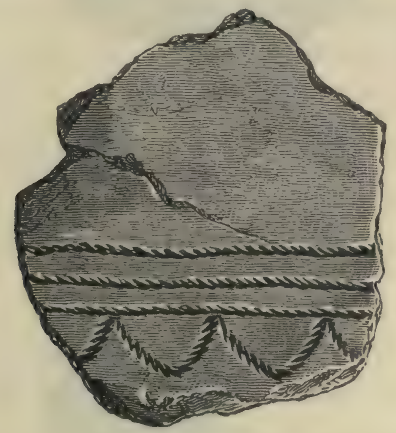

Fig. 148. 궁.

they did not appear to have ever formed part of implements, but had apparently when calcined been merely refuse pieces.

Not quite a mile east of ' The Three Tremblers' were two barrows near together, being only thirty yards apart.

CLVII. The first was $27 \mathrm{ft}$. in diameter and $4 \mathrm{ft}$. high, having on the south side an additional portion, which projected about $5 \mathrm{ft}$. beyond the original circumference of the mound, and had evidently: been added subsequently to its first construction. The whole barrow was made of sand. Within the limits of the added portion, about $8 \mathrm{ft}$. south-west of the centre of the barrow, and, as it appeared, placed upon the surface of the mound as originally formed and then covered over with the secondary material, was a deposit of burnt bones scattered rather sparsely over an area of $1 \frac{1}{2} \mathrm{ft}$. in diameter. Amongst the bones, which were those of an 
adult of small size, was an 'incense cup' [fig. 149], 2 in. high, the same in width at the mouth, $3 \frac{1}{4}$ in. about the middle, and $2 \frac{1}{4}$ in. at the bottom; it is ornamented rather irregularly, and the lines forming the pattern have been produced by means of a sharppointed instrument. With the bones were also associated a small

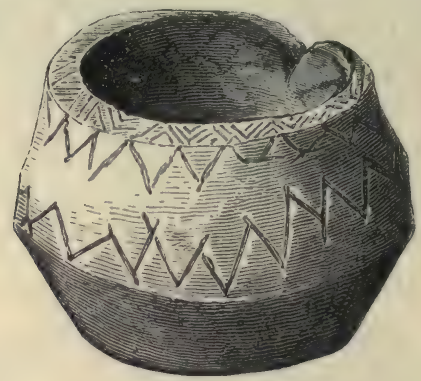

Fig. 149. $\frac{1}{2}$.

flake of flint, calcined, a piece of bronze, which has been subjected to the action of fire, and in consequence is much oxidised and decayed, and which seems to have formed part of a small awl or

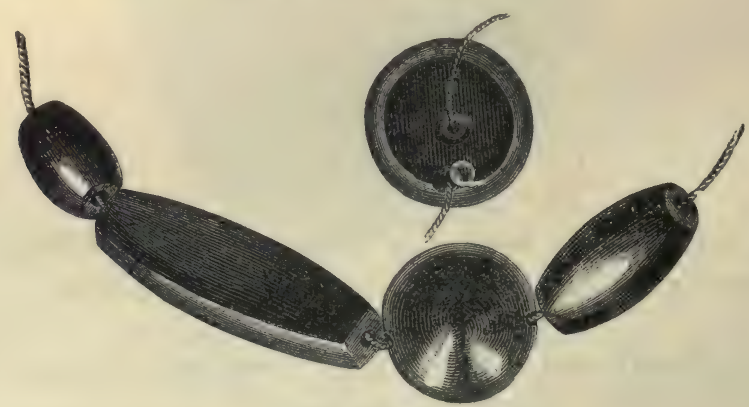

Fig. 150. $\frac{1}{1}$.

pricker ${ }^{1}$, and four jet beads [fig. 150]. Two of them are cylindrical of different lengths, another is oblong and foursided, and the fourth is button-shaped, having the perforation

$1 \mathrm{Mr}$. Bateman mentions the occurrence of what he calls a bronze pin, in connection with a deposit of burnt bones and an 'incense cup,' in two Derbyshire barrows. Vestiges, p. 34; Ten Years' Diggings, p. 130. I think it probable that in these and other cases where the article discovered is spoken of as a pin, that the instrument is really an awl or pricker. The fragment which was met with in the barrow now under notice is so small that it is impossible to state positively what it may originally have been; but in those instances where I have found complete implements, such as this fragment may well have formed a portion of, they have always been awls or prickers. 
at the back pierced from the middle to the side ${ }^{1}$. Eight feet north-east of the centre, and one foot below the surface of the barrow, was an urn lying amongst a deposit of burnt bones. This vessel is rudely made, quite plain and without any rim; it is $4 \frac{3}{4}$ in. wide at the mouth, $2 \frac{3}{4}$ in. at the bottom, and 5 in. high. Amongst the bones were four pieces of calcined flint, which bear the appearance of having been portions of fabricated implements, and a flint chipping unburnt. At the centre, and $1 \mathrm{ft}$. below the surface of the barrow, were many portions of three urns, apparently cinerary, in company with burnt bones, the urns seeming to have been broken by the introduction of a secondary interment. One of these vessels has had an overhanging rim, and is ornamented, both upon the rim and below it, with impressions of an oval-pointed instrument; the other two have twisted-thong markings upon them. The introduced burial was found $2 \mathrm{ft}$. south-east of the centre, at which point, and $2 \mathrm{ft}$. below the surface of the barrow, was placed a flat stone covering a cinerary urn standing upright and carefully packed round with charcoal. The urn was about one-third full of burnt bones, the remains of a person scarcely of full age, and either of a female or a man of small stature; the space remaining above them was occupied partly

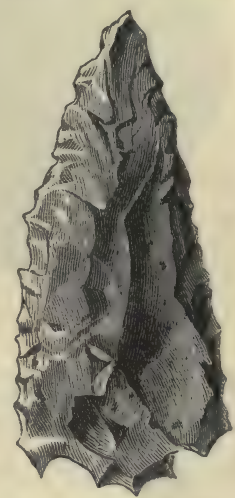

Fig. 151. $\frac{1}{1}$. by charcoal, and partly by a second urn in an inverted position, full of earth, with a few burnt bones. Amongst the bones in the larger or inclosing urn was a burnt flint [fig. 151], which may have been a knife ${ }^{2}$. It has lost part of its broader end during the process of burning; one face is flat, just as it was taken off from the core, the other is carefully flaked along both edges to a point at the end. The larger vessel [fig. 56] is $12 \frac{1}{2}$ in. high, $10 \frac{3}{4}$ in. wide at the mouth, and $3 \frac{7}{8}$ in. at the bottom. The two encircling lines on the inside of the lip of the rim have

1 This jet article might have been considered as a button and not a bead, if the perforation at the back had not run through to the side. In several instances what would ordinarily have been regarded as buttons have been discovered in close connection with other jet objects which evidently formed portions of necklaces, and have been in those cases classed as beads.

${ }^{2}$ A similarly-shaped flint implement was found in an urn with burnt bones, under a barrow at Broughton, in Lincolnshire. It is noticed in the Journal of the Arch. Inst., vol. viii. p. 344, and is there called an arrow-head. 
been made by the application of a twisted thong; the impressions on the overhanging rim appear to have been made with the end of a roughly-pointed tool drawn towards the maker, those on the part below the rim were probably made by a knot tied in a thong, though it is not easy to say precisely in what way they have been formed. The smaller urn [fig. 152], of the same general shape as the larger, is $7 \mathrm{in}$. high, 6 in.

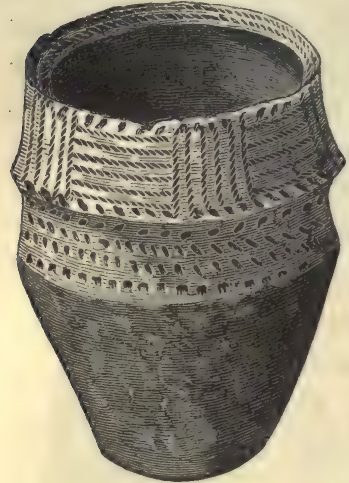

Fig. 152. $\frac{1}{5}$. wide at the mouth, and $3 \frac{1}{4}$ in. at the bottom; some of the impressions upon it have been made with twisted thong, and others apparently with a piece of bone or wood having somewhat: of a square end, the edge having been sometimes used for that purpose, and sometimes one of the corners. Immediately south-east of the larger urn, and like it placed upon the natural surface, was a small cinerary urn, very rudely made, standing upright; it was filled with burnt bones, and had others lying around it, as though it had not been able to contain all the remains of the body, which was that of a young person. It is somewhat like fig. 56, 6 $\frac{3}{4}$ in. high, $5 \frac{1}{2}$ in. wide at the mouth, 3 in. at the bottom, and $6 \frac{1}{8}$ in. at the lower part of the overhanging rim, which is marked with irregularly-placed impressions of looselytwisted thong arranged after a rude herring-bone fashion. About $6 \mathrm{ft}$. south-west of the centre, and immediately below the surface of the barrow, were laid three flat stones, and beneath them was a deposit of the burnt bones of an adult, with a small cinerary urn much crushed and decayed. In shape it is roughly like fig. 54, rudely made, $7 \frac{1}{2}$ in. high, $5 \frac{3}{4}$ in. in diameter at the mouth, $7 \frac{1}{2}$ in. at the base of the overhanging rim (which is $1 \frac{3}{4}$ in. deep), and 3 in. wide at the bottom. The overhanging rim has an encompassing line round the top, the remainder being occupied by alternate series of vertical and horizontal lines, all of thong-impressions; the rest of the urn is plain. Amongst the bones were a portion of a large and well-made barbed arrow-point and three other fragments of flint, the whole calcined. The barrow throughout presented many evidences of much burning. On the south side a great quantity of burnt earth and stones was laid on the natural surface; and on the north side were large masses of charcoal; in fact, for 
about $5 \mathrm{ft}$. in width and $1 \mathrm{ft}$. in depth and reaching from one side of the mound to the other, the entire material was charcoal. Many of the pieces were of considerable dimensions, one fragment of oak being 11 in. long by 7 in. wide and as much in thickness.

CLVIII. The second barrow was $28 \mathrm{ft}$. in diameter, $4 \frac{1}{2} \mathrm{ft}$. high, and made of sand, having a circle of stones round its base. About $2 \mathrm{ft}$. south of the centre, and resting upon the natural surface, was a cinerary urn standing upright, and containing the burnt remains of a person of moderate size and from 25 to 30 years of age. It is like fig. 56, but has the rim almost as wide at the top as at the bottom, and is $12 \frac{1}{2} \mathrm{in}$. high, $11 \mathrm{in}$. wide at the mouth, $11 \frac{1}{4}$ in. at the bottom of the overhanging rim (which is $3 \frac{3}{4}$ in. in depth), and $5 \frac{1}{2} \mathrm{in}$. at the bottom. The rim has five irregularlyformed rows of circular or dot-shaped impressions encompassing it; below the rim the urn slightly widens for a space of $2 \frac{1}{2}$ in., and then slopes away to the bottom; there is no ornamentation except on the rim. Amongst the bones two small fragments of calcined flint were discovered.

CLIX. About 400 yards to the west of the last was a third barrow, $18 \mathrm{ft}$. in diameter, $2 \mathrm{ft}$. high, and made of earth with a few stones intermingled. At the centre, and upon the natural surface, was a deposit of burnt bones, and with them an urn, laid upon its side, the mouth being turned towards the south. In it were placed a few of the bones of the burnt body, principally portions of the skull. Amongst the bones not contained in the urn were a leafshaped arrow-point and a flint chipping, both of them calcined. The urn, which is similar in form to fig. 56 , but wider at the bottom, is $4 \frac{7}{8} \mathrm{in}$. high, $4 \mathrm{in}$. wide at the mouth, and $2 \frac{5}{8} \mathrm{in}$. at the bottom. The inside of the rim has on the lip an encompassing zigzag line; the rim itself, $1 \frac{1}{4}$ in. deep, has at the top an encircling line, and below is ornamented with a pattern in triangles of alternate series of $V$-shaped and horizontal lines; below the rim for a space of an inch there is a reticulated pattern, the remainder of the urn being quite plain; all the lines have been made with a sharp-pointed instrument.

CLX. About a mile south-east of the barrow last described was one $27 \mathrm{ft}$. in diameter, $2 \frac{1}{2} \mathrm{ft}$. high, made of sand with a few stones, and having a circular trench, $3 \frac{1}{2} \mathrm{ft}$. wide and $2 \frac{1}{2} \mathrm{ft}$. deep, round the 
base ${ }^{1}$. At the centre, and $1 \frac{1}{2} \mathrm{ft}$. below the surface of the barrow, was a small urn reversed over a deposit of burnt bones, some of which were contained within it, together with a calcined flint chipping. The urn is a small perfectly plain vessel of reddish colour and well-baked clay, $4 \frac{1}{4} \mathrm{in}$. high, $4 \frac{1}{2} \mathrm{in}$. wide at the mouth, and $3 \frac{1}{4}$ in. at the bottom, and may well have been originally intended for domestic use. About $1 \frac{1}{2} \mathrm{ft}$. south of this, and in a hollow $1 \frac{1}{2} \mathrm{ft}$. in diameter and sunk $2 \mathrm{ft}$. below the natural surface, was a deposit of burnt bones with some charcoal intermixed, and lying upon the top of the bones was an urn, on its side and with the mouth turned towards the south-west. This vessel, shaped like fig. 152 , is $6 \frac{1}{4}$ in. high, $4 \frac{1}{2}$ in. wide at the mouth, $5 \frac{5}{8}$ in. at the bottom of the rim (which is $1 \frac{3}{4}$ in. deep), and $3 \mathrm{in}$. at the bottom. The lip of the rim has a zigzag line encircling it, and the rim itself is ornamented with a wide reticulated pattern; a space below the rim, for a depth of $1 \frac{3}{4}$ in., is occupied by a zigzag line, having below it two encompassing lines placed close together; all the lines have been made by a toothed instrument of the nature of a comb, or possibly by distinct punctures made with a sharp-pointed tool. The hollow had a ring of stones round it, placed on the natural surface; and at one time a flat stone had apparently covered the hole, but had been displaced probably when the upper interment had been made in the mound.

${ }^{1}$ Many of the barrows in this locality have a square trench with rounded corners at the base of the mound. The same shaped trench surrounds a large number of small barrows on Riccal and Skipwith Commons, which on examination proved to contain burials after cremation. 


\section{YORKSHIRE. WEST RIDING.}

\section{Parish of Ferry Fryston. Ord. Map. Lxxxyli. n.w.}

CLXI. This barrow, the only one I have opened in the district, was placed upon a knoll of limestone on the slope of the hill which rises from the river Aire near Ferrybridge. It was situated in 'Roundhill Field,' which evidently takes its name from the barrow. In the year 1811 it had been partly removed by the then tenant, who found it inconvenient to plough over; but he met with so many bones in the course of his operations that he desisted from the work, taking care to have the bones he had disturbed re-interred in Fryston Churchyard. One of these bodies is said to have been 'in armour,' and it is very probable that the finding of the skeleton of an Anglian man, with his sword, shield-boss and knife, may have given rise to the report. In the year 1863 the barrow was again opened to some extent by two persons belonging to the neighbourhood, who found at the centre, and not above a foot below the surface of the mound, two bodies interred at full length, the one overlying the other. Not very far from these skeletons were some portions of red-deer antlers, and fragments of two vessels, one a cinerary urn $10 \mathrm{in}$. high, the other a smaller one $3 \mathrm{in}$. high, and of a type customarily found with burnt bodies. The feet of the two skeletons had been previously dug away, and the urns were not in their proper positions, having evidently been removed from some other part of the barrow to the place at which they were found. It is not unlikely that this had taken place in 1811, when the farmer began to remove the mound. These two bodies, the upper one being that of a large-sized adult man, the under one of a shorter but more strongly framed person, were probably Angles and introduced long after the erection of the barrow. About $18 \mathrm{in}$. to the left of these, but at a somewhat greater depth, was a third body, also laid 
at full length, and with the head-as was the case likewise with the two former bodies-to the west. Below these burials, and $4 \mathrm{ft}$. beneath the surface of the barrow, was a cist, formed of four stones set on edge and covered by a fifth; the cist was $3 \frac{1}{4} \mathrm{ft}$. long, $2 \mathrm{ft}$. wide at one end, $1 \mathrm{ft} .5 \mathrm{in}$. at the other, and the same in depth. It was filled with fine gravel, and on the bottom was the body of an adult male in a contracted position, the head being to the south; in front of the chest was a 'food vessel,' and near it a flint knife $2 \frac{1}{2}$ in. long and $1 \frac{1}{2}$ in. wide. The bottom of the cist was paved with small stones; and below and around it were many fragments of human bones with potsherds and pieces of charcoal, all of which seems to imply that in the putting in of this cist an earlier interment had been disturbed. On the north side of the barrow were found two cinerary urns filled with burnt bones. One, which is perfect [fig. 58], is $6 \frac{1}{2} \mathrm{in}$. high, $5 \frac{1}{2}$ in. wide at the mouth, and $3 \frac{3}{4}$ in. at the bottom. On the lip of the rim is an encircling row of saltire-shaped markings placed close together, and made with a sharp-pointed instrument. The rim, which is $3 \mathrm{in}$. deep, is ornamented with ten encompassing rows of rudely cuneiform markings, due apparently to the application of a triangular-ended piece of wood or bone; for a space of $2 \mathrm{in}$. below the rim the urn is covered with a reticulated pattern made by an instrument similar to that with which those on the lip are to be attributed; below this the urn is plain. The other one, a much better manufactured vessel, is too imperfect to allow anything more being said of it than that it has been much larger than the last-mentioned urn, and that the upper part has been ornamented with thong-impressions.

When I commenced the examination of what was remaining of the barrow it was $54 \mathrm{ft}$. in diameter and $7 \mathrm{ft}$. high, having originally been both wider and higher, but to what extent I could obtain no sufficient information. About $12 \mathrm{ft}$. south-east of the present centre was a deposit of burnt bones, those of a child at the period of the first dentition, laid upon a flat stone just above the natural surface. Six feet south of the centre, and also just above the natural surface, was the body of a man laid upon the right side, with the head to the south and the hands up to the face; behind the lower part of the back was a 'food vessel.' Beneath the vase, and extending under the bones of the unburnt body, was a deposit of burnt bones, those of a strong adult man; the two bodies having most certainly both been placed in the mound at the same time. It is not possible to affirm with which of the two the 'food vessel' 
was specially associated, for it was equally in contact with both ; the presumption however is that it belonged to the unburnt body. It is a very beautifully made vase, like fig. $71,4 \frac{1}{4} \mathrm{in}$. high, $5 \frac{1}{4}$ in. wide at the mouth, where it is rather narrower than at the shoulder, and $2 \frac{1}{4} \mathrm{in}$. at the bottom, which is hollowed; there are four perforated ears at the shoulder. It is entirely covered (including the lip which has four of them) with encompassing rows of very short lines arranged herring-bone fashion and made with a pointed tool; there are twenty-seven rows on the outside of the vase, and they overrun the ears. A little to the east of where the cist was found in 1863, was a large flat stone, covering a deposit of dark-coloured earthy matter; and somewhat to the south of this was another stone covering a similar deposit, and below it a layer ( $5 \mathrm{in}$. thick) of fine sand. The two stones were placed about a foot above the natural surface. At the centre, and sunk into the limestone rock, was a grave $6 \mathrm{ft}$. in diameter and $2 \frac{3}{4} \mathrm{ft}$. deep. In it, towards the west, was a body laid on the right side, with the head to S.W., and having the hands up to the face. At the feet was a 'drinking cup' on its side, and in the angle between the right femur and tibia, allowing for the contracted position of the body, was a small and thin bronze awl or pricker much oxidised; it is now $1 \frac{1}{16}$ in. long. The 'drinking cup,' in shape much like fig. 81 , is $6 \frac{5}{8}$ in. high, $4 \frac{3}{4}$ in. wide at the mouth, and $2 \frac{3}{4} \mathrm{in}$. at the bottom. The upper part for a depth of $2 \frac{1}{2} \mathrm{in}$. has three bands of vertical lines, each band placed between two encompassing lines; below there is a zigzag of two lines, the lower triangular spaces of which are filled in with short lines, not placed very regularly; below this is a plain band $\frac{3}{4} \mathrm{in}$. deep, then two bands of vertical lines, each placed between two lines as on the upper part; and the lowest portion for a space of 2 in. has a band of vertical lines nearly $2 \mathrm{in}$. long, over which is an encompassing line very irregularly drawn. The whole of the impressions are made by a notched piece of bone, an instrument which has been very commonly used in the decoration of this class of sepulchral vessels. There was a good deal of charcoal about the body; and above and near the sides of the grave were numerous remains of unburnt human bones, probably due to the disturbance of a previously buried person by the interment of the body met with in the grave.

This barrow presented many features in common with those on the wolds. For instance, the two burial customs, after cremation and by inhumation, were evidenced, and in one case both had 
clearly been in use at the same time. The association of the bronze awl with a 'drinking cup' is also paralleled in one of the Rudstone barrows, and the subsequent disturbance of the mound in order to insert in it secondary burials, apparently of the same people as those over whom it was first erected, is a matter of no infrequent occurrence.

\section{Parish of Rylston. Ord. Map. xcit. N.w.}

The district of Craven in the West Riding of Yorkshire, in which the barrow now about to be deseribed is situated, is one abounding in various remains of pre-historic times. Discoveries of stone and bronze weapons and implements have occurred from time to time in the immediate neighbourhood of the barrow, and other sepulchral mounds still exist, some of which yet remain unopened, but the greater number have been more or less destroyed by curiosity-hunters, without any note of their construction or contents having been preserved.

There are also abundant examples of those peculiar terraces which, formed on the slope of hill-sides, were at one time supposed to mark the ancient levels of water, but which are notwithstanding clearly of artificial origin. The most common explanation of them, one indeed which has obtained almost general acceptance, is that they are terraces made in the processes of cultivation. It is not very easy to understand why such elaborate works, calling for no slight expenditure of labour, should have been constructed to aid the growth of any crop; for though in some cases, where they occur upon a steep hill-side, they might be needed to prevent the washing away of the soil when it was broken up and therefore more subject to the action of water, in other cases they are found upon slopes lying at such an angle as obviously to preclude the necessity for such a provision. They have been compared to the vine-terraces in Rhine-land, and it has been supposed that soil was artificially collected upon them as it is there, though I have never myself seen any indications of such a method having been practised. They are met with spread over a very wide area. I have noticed them in the East Riding, in Westmoreland (where, near Kirby Stephen, they cover large tracts of ground), in Durham, and Northumberland. Indeed, in the county last named some of them are found, on the precipitous sides of the porphyritic hills on the banks of the river Breamish, at such an elevation as to make it difficult to believe that 
any cereal crop could ever have been grown upon them. They have also been attributed to the way in which the separate portions of land in the common field of a village have been ploughed; by which process, at the side of each portion, a bank of greater or less size was gradually thrown up. Some of them, I have no doubt, are the result of such a mode of ploughing, but a large number are evidently due to some different practice, and indeed in many cases they have undoubtedly been cut out of the hill side.

CLXII. The barrow now under notice, which is situated at Scale House, near Rylston, had been dug into at the centre, by the tenant, about a year before I subjected it to examination; and to this disturbance is due in some measure the unsatisfactory condition in which the remains were found. It was $30 \mathrm{ft}$. in diameter, $5 \mathrm{ft}$. high, and was made of clay; having a shallow trench close to the base and completely encircling the mound. Immediately beneath the surface of the barrow, at the centre, there was a layer of flat stones, about $6 \mathrm{ft}$. in diameter, earefully arranged. Under these stones the clay was firmly compacted, and rested upon a thin stratum of dark-coloured earthy matter which was very fully charged with charcoal. Beneath this again was a layer of finer clay, or rather of elay which appeared to have undergone a process of tempering. Below this finer clay, and carefully embedded in it, was an oaken coffin laid upon clay, and to some extent supported by a few stones, the whole being placed in a slight hollow sunk below the surface of the ground. The coffin was formed of the trunk of an oak tree split in two and then hollowed out. It was $7 \frac{1}{4} \mathrm{ft}$. long and $1 \mathrm{ft}$. 11 in. wide; the trunk had been cut off at each end and then partially rounded, but on the outside no attempt at squaring or other workmanship had interfered with the natural surface of the timber. The hollow within was $6 \mathrm{ft}$. $4 \mathrm{in}$. Iong and $1 \mathrm{ft}$. wide, roughly hewn out, and still showing the marks of the tool employed; the ends inside were finished off square. It was not possible to make out the precise nature of the tool which had been employed, but the appearances warranted the conclusion that it had been a narrow-edged metal implement. The coffin was very much broken, in consequence of the disturbance before mentioned; it was however still sufficiently entire to allow its arrangement to be seen. It was laid north and south, having the thicker end-where the head of the enclosed body had no doubt been placed-to the south. The body had entirely gone to decay, and nothing was observed 
which might have formed a constituent part of it except an unctuous whitish substance, which chemical analysis has proved to be of animal origin ${ }^{1}$. The corpse had been enveloped in a woollen fabric, enough of which remained to show that it had reached from head to foot [fig. 2]. It was very rotten, and partly on that account, and partly by reason of the infiltration of earth which had found its way into the coffin through the breakage occurring when the barrow was first opened, and which had become mixed up with the cloth, it was impossible to recover any but small pieces of it, or to prove whether the body had been laid in the grave in its ordinary dress or simply wrapped in a shroud. It is on the whole probable that in this case, as in those of some tree-burials discovered in Denmark, the person had been interred in the dress worn by him in daily life, though perhaps it may be alleged that the absence of anything like a button or other fastening is rather against that view. The material is now of a dark-brown colour, due most likely to the tannin in the oak of the coffin; whilst to the acid generated in the decaying wood and set free by the percolation of water is perhaps to be attributed the total disappearance of the bones. There was nothing found in the coffin besides the woollen stuff; nor, with the exception of pieces of charcoal and some burnt earth, was anything met with foreign to the ordinary material of the rest of the barrow.

In the absence of any associated articles in the coffin, or of potsherds or flints in the mound itself, it is difficult to assign a precise date or period to this remarkable burial. But if we take the general shape and construction of the barrow into eonsideration, as also the encircling diteh, the presence of chareoal and other indications of burning, I see no reason for hesitating to refer it to the people whose usual custom it was to place the body of the dead person in a stone cist or in a grave within the barrow; merely supposing that in this and in a few other instances they departed from their ordinary practice in favour of a wooden receptacle ${ }^{2}$. And

${ }^{1}$ Near to Featherstone Castle, Northumberland, at a place called Wyden Eels, where several wooden coffins similar to this have been found in a wet situation, the bones had decayed entirely away, except in one instance, where however all the earthy part had disappeared, leaving the bones in the condition of a substance very much resembling old leather. The hollows within the bones were filled with the mineral Vivianite. Bones which have been met with in peat bogs have sometimes been found to be in the same condition, the change in them being due to the action of the carbonic acid generated in the peat.

2 It may not be without use to bring together in a note other cases, in this country and in Denmark, where burials in tree-coffins of a time before the introduction of iron 
when we compare this burial with some others found in this country, and with those which have occurred in Denmark, we can further have little doubt about attributing it to the time when bronze was in use for weapons and implements. The mode of interment in the hollowed trunk of a tree placed within a barrow is no doubt rare, although burials in eleft and hollowed trees placed in the ground without any superincumbent grave-mound are not so uncommon ${ }^{1}$; many of these however are not to be referred to a very early period, and indeed probably belong to a time several centuries after the Christian era.

have occurred. In Yorkshire the most noteworthy is the well-known Gristhorpe burial, the remains from which (including a bronze knife) are preserved in the Scarborough Museum, and which are engraved, together with a plate of the skull and a full account of the discovery, in Crania Britannica, as well as in a monograph by Professor Williamson, F.R.S., of Owens College, Manchester. I am acquainted with three other cases in Yorkshire where an oak coffin has been found in a barrow. One was at Sunderlandwick, near Driffield, where I believe nothing besides the skeleton was met with. A second was discovered on the wolds near Fimber, by Mr. J. R. Mortimer. It was under a mound which had been previously disturbed, and where, in a hollow sunk in the rock, a coffin made from a cleft and hollowed oak tree was met with, unfortunately much damaged by the former opening; with the remains of the coffin were fragments of bones and some portions of an urn. The third was in a barrow called 'Centre Hill,' at West Tanfield, near Ripon, where the Rev. W. C. Lukis in 1864 found the remains of a body lying N.E. and S.W., and placed within a wooden coffin, probably the trunk of a tree. It had been placed in a cavity $1 \frac{1}{2} \mathrm{ft}$. deep. With the body were associated a vessel of pottery and a flint implement. In the southern parts of England the same mode of interment was sometimes adopted; at Hove, near Brighton, a tree-coffin was found to contain a skeleton, with which were associated an axe-hammer of stone, a knife-dagger of bronze, a whetstone, and an amber cup. Sussex Arch. Coll., vol. ix. p. 120. Sir R. Colt Hoare met with three instances in Wiltshire where a barrow contained a body placed in a hollowed treetrunk; with each of these bronze articles were deposited. Ancient Wilts, vol. i. pp. 52, 122, 125. Mr. Lukis also found one in the same county at Collingbourne Ducis. In Dorsetshire, in a grave-mound called 'King Barrow' at Stowborough, which was opened in 1767, was discovered an oaken trunk hollowed, in which were the remains of a body wrapped in deer's-skins sewed together, and apparently passed several times round the corpse. At the south-east end of the coffin was a small wooden or probably shale vessel of very unusual character, which is figured in Hutchins's Dorset, vol. i. p. 25. When we pass beyond the limits of Britain we find, in Denmark, still more interesting burials to have been made in tree-coffins. The bodies there were found to have been placed in the grave with the different articles of clothing which had been worn during life, together with bronze swords and other implements of bronze and flint. The coffins and other things connected with interments of this kind in two barrows called 'Trenhöi' and 'Kongehöi' will be seen engraved in Madsen's beautiful book, 'Afbildninger af Danske Oldsager og Mindesmærker,' and some of them are reproduced in Sir John Lubbock's Prehistoric Times (3rd ed.), pp. 46, 47, 49. A discovery very similar to these last mentioned was made at Bolderup, near Haderslev, and will be found deseribed in Nordisk Tidskrift for Oldkyndighed, vol. iii.

1 They have been discovered in Yorkshire, at Selby and near Beverley. In other parts of England they have repeatedly occurred. 


\section{CUMBERLAND.}

THE succeeding pages contain a record of a series of barrows opened in the counties of Cumberland, Westmoreland, Northumberland, and Durham; the first three prolific in barrows and other remains of pre-historic times, although but a very small number of their sepulchral mounds have as yet been carefully examined. Inasmuch as in each of the three counties specified many of the grave-mounds have been made with stones-being what are usually termed 'cairns' -it is not a matter of surprise that most of them have disappeared under the extension of the area of cultivation, their material having been employed in the making of walls and for draining purposes. In the greater number of cases no record of what was discovered during this course of destruction and removal has been preserved, but in a few instances the finding of an urn, an implement, or a skeleton has attracted the attention of some person in the vicinity more curious and enquiring than his fellows, and who has given an account of their occurrence in the Iocal newspaper.

In Northumberland, where, upon the higher land principally utilised as sheep-walks, large numbers of sepulchral mounds are found, nearly the whole of them have been rifled by the shepherds, partly in the vain quest of buried treasure, and partly to while away, in the gratification of an unintelligent curiosity, the long hours spent on the hill-side when in charge of their flocks. Had we been still in possession of the great number of cairns and barrows which remained untouched to within a hundred years of the present day, a minute and critical examination of them might have solved many a problem connected with the early history of the inhabitants of pre-Roman Britain, which can now only be vaguely and doubtfully dealt with by tentatively placing together, with many links of connection wanting, the scattered facts collected by the careful 
and observant explorer. Still however there is much remaining, a systematic investigation of which will it is to be expected add greatly to our stores of information. Accidental discoveries also, due to the operations of the ploughman or the drainer, in cases where no outward memorial gives intimation of the burial below, will continue not only to be made, but also it is to be hoped recorded, and consequently brought under the observation of those who are capable of appreciating their value.

\section{Parish of Castle Carrock. Ord. Map. cVi. s.e.}

The only opportunity I have had of examining a sepulchral deposit beneath a barrow in the county of Cumberland occurred at Castle Carrock, near to Brampton. Discoveries of burials in cists had from time to time been made in this neighbourhood, but had scarcely attracted notice beyond the immediate locality.

CLXIII. In the year 1865, in the process of cultivating a field called Leafy Hill, the cover-stone of an unsuspected cist was touched by the plough. The cist had been constructed in a natural rise of the land, the cover-stone being but a few inches below the surface. It was of the ordinary form, made with four stones set on edge with a single large slab over all, and was placed in a direction north-east and south-west. It contained the body of an old man laid on the left side, with the head to N.E., having one arm extended, the other across the chest. Behind the head was a 'drinking cup' laid on its side; this was broken into several pieces in order that each of the men working in the field might have a portion. From some of the pieces $I$ succeeded in recovering I have been enabled to make out the size, form, and ornamentation of the vessel with sufficient exactness. It is in shape like fig. 81, but widening more towards the mouth, and must have been about $7 \frac{1}{2}$ in. high, and is $5 \frac{1}{4}$ in. wide at the mouth ; it is ornamented over the whole surface with narrow encircling bands defined by a grooved line on each side of them, every fourth band having upon it short sloping lines, these being arranged on the bands alternately from right to left and from left to right. On the bottom of the cist was some charcoal.

CLXIV. About fifty yards to the south of the cist just described was another swell or rising point of land, upon the summit of 
which had been raised a small mound of stones and earth

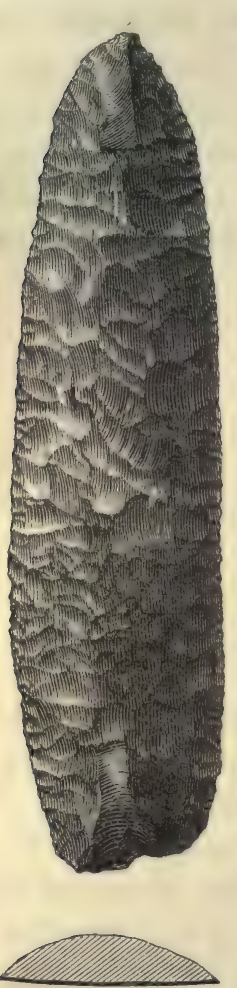

Fig. 153. ㄱ. about $1 \frac{1}{2} \mathrm{ft}$. high and $8 \mathrm{ft}$. in diameter. Below this was an oval hollow $3 \mathrm{ft}$. by $2 \frac{1}{2} \mathrm{ft}$., sunk $1 \mathrm{ft}$. $4 \mathrm{in}$. below the natural surface, and having a direction north-east by southwest. It was filled in with dark-coloured mould and a few stones, below which on the bottom was a deposit of burnt bones belonging to an adult of small size. Beneath the bones, and apparently having been placed there before they were laid in the hollow, was a very beautifully-made flint knife [fig. 153], $3 \frac{3}{8}$ in. long and $\frac{3}{4}$ in. wide at the broadest part. The one face is flat and left in the same condition as when newly struck off from the core; the other, which is convex, has been most delicately and skilfully chipped over the whole surface. There is no appearance upon it of its ever having been actually used, and it would seem to have been made new for the purposes of the burial. It is one of that class of flint implements which I have met with on several occasions, and which when accompanying a burnt body have still in no case themselves passed through the fire. 


\section{WEST M ORELAND.}

THe county of Westmoreland, like its neighbour Cumberland, as it is rich in memorials of the Roman dominion, abounds also in still earlier remains; and it is probable that the number of camps constructed by the Roman invaders was due to the necessity of holding in check a large and organised native population, which was rendered all the more formidable from the opportunities of defence afforded by the natural formation and condition of the country. Cairns and barrows are abundant, and circles of stone and other megalithic structures still exist, the scanty remains of a much larger number, some of which have disappeared within the limits of living memory. The great circle of 'Long Meg and her Daughters' is still almost entire, and on one of the stones composing it are several of the pits and circular markings which have been already referred to. Arthur's Round Table near Penrith ${ }^{\text {, }}$ and the adjoining circular mound of Mayburgh with the standing stone in the centre, are both remarkable works, the latter of which, though it has suffered to some extent by persons who have applied to other purposes the stones originally belonging to it, still presents its general features sufficiently well defined to allow its form and size, if not its use, to be determined. The large series of standing stones at Shap however, once consisting of at least a circle and an avenue, is now almost entirely destroyed; but from such parts of it as are left, and from old accounts and the traditional

${ }^{1}$ It consists of a mound about $300 \mathrm{ft}$. in diameter, within which is a broad platform, and beyond it a ditch enclosing a flat space $175 \mathrm{ft}$. in diameter. It is now partly destroyed by a road, which cuts off a portion of it, but was complete a hundred years ago, when it had two entrances opposite each other. Three similar constructions (one perfect, the others more or less destroyed), almost identical in shape with Arthur's Round Table, still exist at Thornborough, near Tanfield, in the North Riding of Yorkshire; and two more are to be seen on Hutton Moor, near Ripon, not many miles from those at Thornborough. 
knowledge of the place, the Rev. James Simpson, LL.D., has been enabled to reconstruct it in a valuable paper on 'The Antiquities of Shap 1'. In the same parish, at Gunnerkeld, is a double circle of granite boulders still remaining almost entire, and other similar structures are to be seen in the neighbourhood.

I have opened several barrows and cairns in the county, some of which presented features of marked interest and novelty, though on the whole they show an identity of ancient burial usages with those in other parts of Britain.

\section{Parish of Kirby Stephen. Ord. Map. xcvir. N.w.}

Upon Ashfell, near Kirby Stephen, are a few sepulchral mounds, three of which had remained untouched up to the period of my examination of them.

CLXV. The first, of the bowl-shaped form, was $55 \mathrm{ft}$. in diameter, $5 \mathrm{ft}$. high, and was composed of clayey soil. The only interment discovered was $17 \mathrm{ft}$. east-south-east of the centre, where about $2 \mathrm{ft}$. above the natural surface was a deposit of the burnt bones of an adult placed in a round heap $1 \mathrm{ft}$. in diameter. No flint chippings or potsherds were met with in the mound.

CLXVI. The second barrow was situated about a mile to the south of the last and, together with the two next described, was placed on the highest part of the ridge of limestone which there overhangs Ravenstonedale. It was $31 \mathrm{ft}$. in diameter, $4 \mathrm{ft}$. high, and was made of limestone-rubble and soil. At the centre and placed upon the natural surface was a rudely-formed cist of limestone slabs, which however contained nothing. The interment had without any doubt been one of an unburnt body, which had gone entirely to decay in consequence of the free admission of air and other destructive agencies through the loose materials composing the mound.

CLXVII. The third barrow was about 300 yards further along the ridge in an eastern direction from the last. It was $30 \mathrm{ft}$. in diameter, $4 \mathrm{ft}$. high, and composed of stones and earth. At the centre was a grave cut into the limestone rock, which at that particular point rose somewhat above the general level of the

\footnotetext{
${ }^{1}$ Printed in the Carlisle volume of the Proceedings of the Archxological Institute.
} 
adjoining ground. The grave was $3 \frac{1}{2} \mathrm{ft}$. long, $2 \mathrm{ft}$. wide, and $2 \frac{1}{2} \mathrm{ft}$. deep, the longer axis running in a direction north and south. It had been filled in with earth and stones, and on the bottom was laid the body of an aged man on the right side, with the head to $S$., the right hand being under the chin and the left upon the knees. In the filling-in of the grave were some pieces of charcoal, a few small fragments of animal bone not of sufficient size to be identified, and portions of a red-deer's antler.

CLXVIII. The fourth barrow was placed upon the same ridge, and lay rather to the west of the second. It was smaller than the others, being only $18 \mathrm{ft}$. in diameter and $2 \frac{1}{2} \mathrm{ft}$. high; it had a circle of small stones set round the base, itself being made of stones and earth. On digging into it, signs of former disturbance immediately appeared; and it soon became quite evident that at some time or other it had been completely turned over. The remains of bones, both burnt and unburnt, showed that it had contained at least two burials, one after eremation, the other by inhumation.

About two miles from the barrows just noticed, and situated upon a piece of haugh-land in Mallerstang, close by the side of the river Eden and barely out of reach of a high flood, are two cairns. The position is a most unusual one for the site of sepulchral mounds, the rule with regard to them being, as it is almost superfluous to remark, that they are nearly always placed upon high ground. The larger one of these two cairns, which is still $60 \mathrm{ft}$. in diameter, notwithstanding the fact that a large quantity of stones has been removed from it for various purposes, yet remains to a great extent unexplored.

CLXIX. About fifty yards distant from it lies the second, a much smaller one. It was only $15 \mathrm{ft}$. in diameter, $1 \frac{1}{2} \mathrm{ft}$. high, and had at the base some stones larger than those employed in its ordinary material, being probably the remains of an enclosing circle. At the centre, and sunk $1 \frac{1}{4} \mathrm{ft}$. below the natural surface, was a round hollow, $1 \frac{1}{2} \mathrm{ft}$. in diameter, covered over by a flat stone. In it was a deposit of burnt bones, not laid together, but scattered amongst the earth with which the hole was filled. The bones are those of a child in the period of the first dentition; with them was a piece of calcined bone, pierced with two holes, being 
probably a portion of a pin. Lying above them, and on the north side, was an 'incense cup.' It is somewhat decayed at the top, so that the size cannot be exactly determined, but it has probably been about $2 \mathrm{in}$. high. There is still left one perforation, placed a little above the middle of the vessel, and it may once have had a second. The whole surface is covered with a somewhat irregular pattern, the lower part being apparently a zigzag encircling line, formed by punctures or dots made with a sharp-pointed tool. The bottom, $1 \frac{3}{4}$ in. in diameter, is also ornamented with a reticulated design of delicately-twisted thong-impressions.

CLXX. Upon a hill called Wiseber, about $1 \frac{1}{2}$ mile to the south of the village of Kirby Stephen, and in the immediate neighbourhood of all the barrows just described, though standing quite apart from any other mound, was one $28 \mathrm{ft}$. in diameter, $1 \frac{1}{2} \mathrm{ft}$. high, and made up of stones and earth. It had originally been higher, a part having been removed for the purpose of obtaining stones for walling. On examination it proved to be of quite a different character from those hitherto noticed, and presented features of unusual occurrence in burial mounds. At the centre, in a hollow sunk $2 \frac{1}{4} \mathrm{ft}$. below the natural surface, was placed a sort of wooden coffin, lying north-west and south-east. It was $6 \mathrm{ft}$. long, $2 \frac{1}{4} \mathrm{ft}$. wide at the north-west end, and $1 \frac{3}{4} \mathrm{ft}$. at the other; and at a point $3 \frac{1}{2} \mathrm{ft}$. from the wider end there were two circular holes, $2 \mathrm{in}$. in diameter and $2 \mathrm{in}$. apart, pierced through it. The coffin, if so it may be termed, was a good deal decayed. It appeared to have been made out of a thick slab of wood slightly hollowed. Across the north-west end was placed a short plank, and two others, each $2 \frac{1}{2} \mathrm{ft}$. long, were laid on either side at that end, thus making the coffin at this part, where no doubt the head of the body had once been, rather deeper than it was elsewhere. There was no cover to it. Where the head must have been, if placed in the direction above indicated, were the remains of a small and shallow bronze bowl made of very thin metal, but so much destroyed by oxidation that it is impossible to restore its shape. About the position the chest would have occupied a single glass bead was discovered; it is of a bluish colour, thickly splashed over with red and yellow. The cutting in which the coffin was deposited appeared to have been made through an existing deposit of burnt bones, some of them being found on the south-west side rather above and close to the coffin, whilst some were beneath its edge; in immediate 
proximity to the bones, though probably not connected with the deposit, a small unburnt leaf-shaped flint arrow-point was met with. The coffin was covered with a layer of blue clay, whilst on each side of it there was placed some clay of a very yellow colour. Annongst the material of the barrow a small flint chipping was discovered.

It is not easy to assign a positive date to the burial in the coffin, for the bowl is only fragmentary, and beads are very uncertain tests of age, the same patterns having prevailed during long periods of time. Upon the whole, however, I incline to attribute it to a postRoman and possibly Anglian date; and I believe the burial of an unburnt body had been made in a previously existing sepulchral mound where the original interment had been one after cremation.

\section{Parish of Warcop. Ord. Map. CII. s.e.}

At Sandford in the parish of Warcop, some miles lower down the valley of the Eden than Kirby Stephen, are two barrows closely adjoining each other and situated upon rising ground. One was opened in 1766, when an apparently 'Anglo-Saxon' interment was found close beneath the surface. With the remains of the body were associated some portions of an urn, a sword, a spear-head and another iron article which the explorer could not identify, though it may possibly have been a knife. At the bottom, under a small cairn of stones placed within the larger mound, was a deposit of burnt bones ${ }^{1}$. It appears probable that in this barrow, as in that last described, an older British place of sepulture had been made use of by one of the later occupants of the country; in both cases the earlier burial being after cremation, the later by inhumation.

CLXXI. The other barrow I examined myself: it was $72 \mathrm{ft}$. in diameter, and still, though to some degree ploughed down, $5 \mathrm{ft}$. in height; it was composed of sand. The only burial contained in it was of an unburnt body (or perhaps of two); for though the bones were so much decayed as to render it impossible to distinguish their relative positions, they seemed to cover a space too wide to have been occupied by merely a single skeleton. These remains were found at the centre of the mound and laid upon the natural surface; a good deal of charcoal was scattered in juxtapusition with the 
bones. A single piece of flint - a mere chipping - was all that showed signs of man's handiwork amongst the material of the barrow.

\section{Parish of Asby. Ord. Map. cit. s.w.}

I opened a cairn at a place called Sail-bottom, not very far from Great Asby, where there are many indications of early occupation, and where some time previously to my visit the workmen getting stones had found a skeleton, placed beneath a large stone under a cairn. It was laid at full length, and had at the waist an iron knife; a fact from which it may be inferred that the interment was that of an 'Anglo-Saxon.'

CLXXII. The cairn opened by me was $34 \mathrm{ft}$. in diameter, $3 \mathrm{ft}$. high, and had a circle of stones round the base. At a distance of $5 \mathrm{ft}$. east-south-east of the centre, and laid just above the natural surface, were several bones of two bodies, placed in the cairn without any order; a circumstance which may be accounted for either by the supposition that the barrow had been rifled at some previous time, or more probably on the ground of disturbance occasioned by the introduction of the remains of the burnt body of an adult which were discovered at the centre. This burnt body was deposited in an oval hollow lying north-east and south-west, $1 \mathrm{ft} .9 \mathrm{in}$. by $1 \mathrm{ft}$. 4 in., and sunk $6 \mathrm{in}$. below the natural surface. In the substance of the cairn, which was raised upon a natural mound of gravel, were some few bones of an ox.

\section{Parish of Crosby Garrett. Ord. Map. xcvil. N.w.}

This parish, a considerable part of which consists of high-lying grass fells on the limestone, has produced a large number of interments which may be referred to an early date. They may be classed as belonging to pre-Roman, 'Late Keltic ' possibly of the period of the early Roman occupation, and Anglian times. The 'Late Keltic' burials were discovered in the year 1873, in a cutting close to the village of Crosby Garrett, on the Settle and Carlisle branch of the Midland Railway. They consisted of three unburnt bodies, interred in the contracted position on their sides, about three feet below the surface of the ground, there being no apparent mound at the place. Upon the right arm of one of the bodies was a bronze penannular armlet, oval in section, and unornamented 
except in having a series of notches along both edges. It appeared to have been a long time in use, for it was much worn, and seemed as though it had originally been made for a larger arm than that on which it was found, for the ends overlapped in a way which showed that they had not originally been intended to do so.

Most of the cairns have been opened, with what results I know not, but some remained more or less intact.

CLXXIII. The first I examined was situated on the verge of a lower escarpment of the limestone overlooking Ravenstonedale, and was a very enigmatical burial mound, inasmuch as no undisturbed body was found within it. It was $36 \mathrm{ft}$. in diameter, $4 \mathrm{ft}$. high, and was formed principally of limestone with some sandstone blocks intermixed. At the centre, and only one foot below the apex of the cairn, was a burnt body, undoubtedly that of an Angle, as is shown by the iron knife, buckle, shears, and bridle-bit which accompanied the interment. The bones are those of a boy or girl about the age of puberty, and judging from some of the articles found with the body it was probably that of a boy. It might have been supposed that the introduction of this body into an alreadyexisting mound had caused the fragmentary condition of the bones to be presently described, had not the cairn presented the most evident signs of never having been disturbed since the time when it was first thrown up, except at the place where the burnt bones were met with. The limestone flags were placed in the most regular order, overlapping each other, commencing from some laid quite flat at the centre and upon the natural surface of the ground. Such a disposition as this could scarcely have occurred if the cairn had ever been meddled with except very superficially.

At a distance of $10 \frac{3}{4} \mathrm{ft}$. from the centre to south-west-by-west of it, and a foot below the surface of the mound, were some broken and disjointed bones of a man in middle life and others of an older and more feebly made person. One foot further to the south-west, and at a level about 9 in. lower, were some other broken bones belonging to two bodies, principally those of an adult man; whilst immediately west of these last was another similar deposit. Four feet six inches south-east of the centre, and about $2 \frac{1}{2} \mathrm{ft}$. below the surface of the cairn, was still another deposit of broken and fragmentary bones; and $6 \mathrm{ft}$. west of the centre, and about the same level as the last, were some pieces of the lower jaw of a very aged 
woman, and close by them some other bones, which possibly all belonged to her; with these was the pre-molar of an ox. Just south of the centre, and a foot above the natural surface, were several bones broken and fragmentary like those already described. Close to the centre, $8 \mathrm{in}$. above the natural surface, and just under the edge of the flag-stones, laid flat as already described, were parts of three skulls, those of an old person, of a child about seven years old, and of an infant; together with some other bones, including part of the upper jaw of an aged person, unburnt, and two pieces of burnt bone. In the cairn, dispersed in various parts of it, were numerous bones of ox and some of a kid or lamb.

There was no appearance of a body in its entirety ever having been placed within the mound; nor were any of the smaller bones, such as those of the hand and foot, met with at all in it. The inference which it seems almost necessary to draw from these appearances is, that the bodies had originally been deposited at some other place and afterwards had been transferred to this burial mound. Somewhat similar instances have occurred elsewhere in the course of my barrow explorations, and though it certainly was not the general rule amongst the pre-Roman occupants of Britain to follow such a custom, it is quite possible that this practice, which has prevailed amongst several peoples widely differing in race, place, and condition, may have at times been adopted in this country also.

Another cairn, situated about half-a-mile to the north-east of that last described, was $42 \mathrm{ft}$. in diameter, but the height could not be measured in consequence of its having been opened two years ago by a gentleman at that time resident in the neighbourhood. I was unable to get any very accurate information as to what had been met with on the occasion, beyond the fact that more than one unburnt body had been discovered. This indeed was sufficiently apparent from the remains of bones which were still lying about. I think it advisable to record this, as it tends to show that inhumation was the prevailing mode of interment in the locality, as will be more clearly evidenced by the contents of other cairns.

About a mile to the north-east of the last-described cairn are three others, which have all undergone very serious disturbance, in consequence of the larger stones having been removed from them for the purpose of building a wall to divide Crosby Garrett from 
Ravenstonedale Common. Somewhat to the east of them, and at no great distance from a small sheet of water called Sunbiggin Tarn, is a very large long barrow, an account of the examination of which will be found in that part of this volume devoted to that class of sepulchral mound.

The position of these cairns is a very striking one, standing as they do fronted by the range of mountains which here divide Westmoreland from Yorkshire, and having the grand outline of Wildbore Fell and the hills on the further side of Mallerstang on the one side, while the distant mountains beyond Shap close the view in the opposite direction. To the north the eye is almost at once stopped by the precipitous scaurs on Asby and Orton Fells, where the huge sheets of bare limestone rocks, alternating between pale purple and a warm white as the shadow or the sunshine falls upon them, give a weird though attractive interest to the scene.

CLXXIV. The first of the three cairns was of rather an unusual form, being markedly oval, $66 \mathrm{ft}$. long and $40 \mathrm{ft}$. wide, with the longer diameter north and south. It is placed upon an outcrop of the limestone rock, and looks higher than it really is, there being now not more than $1 \frac{1}{2} \mathrm{ft}$. of added material. At one time it was no doubt several feet higher, but it has been reduced to its present low elevation by the action of the stone-waller, to whom is also to be attributed the broken and disturbed condition in which many of the bones were found. They were met with scattered throughout the whole of the southern part of the mound and for a space of $7 \mathrm{ft}$. north of the centre. There cannot have been fewer than a dozen unburnt and burnt interments in the cairn, as shown by the remains of the bones, and it is probable that there were more. At a distance of $23 \frac{1}{2} \mathrm{ft}$. south-south-east of the centre, and laid upon the natural surface, was the body of a strongly-made and aged man, which though much disturbed still showed the position in which it had been originally placed. The body was deposited on the left side, with the head to S.S.W., and the hands up to and in front of the face. Close to the face was a bone pin with a large perforated head, and two boar's-tusks, one certainly that of a wild animal, and showing signs of having been adapted to some purpose, though to what it is difficult to say; the other possibly that of a domestic pig, and unwrought. All these articles had been broken by pulling out the large stones which had been placed over the body, and portions of the pin and of the tusks were missing. In near proximity to 
this body were the completely scattered remains of three others, two adults and a child. Fourteen feet south of the centre and upon the natural surface was another partially disturbed body, of which the lower part of the vertebral column, the head, the finger-bones, the sacrum, and the femurs were still in their original position. The body, that of a young man about twenty years of age, had been laid on the right side, the head being to N.E., and the hands up to the face. Five feet south of the present centre, but probably at what had in the first instance been the centre, and if so then the primary interment, was the body of a young man from twenty to twenty-four years of age, which had happily almost entirely

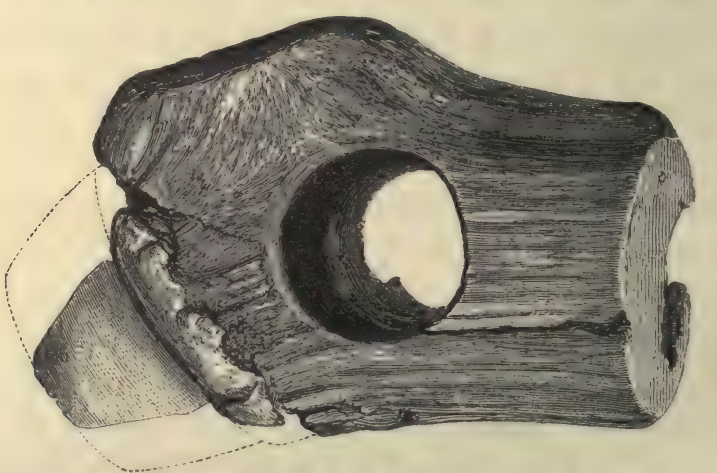

Fig. 154. 올.

escaped disturbance. He was laid on the right side, with the head to N. and the hands up to the face. In front of the knees was a hammer, made from the brow end of a red-deer's antler [fig. 154]. It is very carefully formed from the horn of probably a slain animal, for part of the skull is still attached to the horn, and has been worked into a round projection at one end of the hammer. The hole for the handle is very exactly perforated, and is $1 \frac{1}{4}$ in. wide, the length of the implement itself being $3 \frac{5}{8}$ in ${ }^{1}$. Between the humerus and the radius and ulna of the right arm was a long and thick piece of chert, triangular in section, and having the lower end worn quite smooth by long-continued use. It is $3 \frac{3}{4}$ in. long, and has some of the old skin of the chert nodule still remaining

1 Deer's-horn has been freely used by the people of the stone age for the manufacture of hammers, axes, as well as stone-axe and other sockets. Such articles have been frequently found in this country, as also in France, Denmark, Switzerland, and other parts of Europe. A hammer almost identical with the one in question, discovered at Yverdun in the bed of the Thiele, is figured in Troyon, Habitations Lacustres, pl. iv. fig. 15. 
on one face. In the right hand was a piece of iron ore much oxidised, no doubt the 'steel' with which, in combination with the chert flake just described, this Ancient Briton had obtained fire. This is the third instance where I have met with a man buried with his 'flint and steel,' the other two having both been in one barrow near Rudstone [No. Ixviii]. In front of the face was another and thin flake of chert; it is $2 \frac{1}{2}$ in. long, $\frac{7}{8}$ in. wide, chipped along both edges, and has most probably served the purpose of a knife. Close to the body was half of the lower jaw of a young fox. With many other unburnt human bones scattered in various parts of the cairn were found some burnt bones of an adult and of two children. In the cairn were also found a bone pin, $5 \frac{1}{4} \mathrm{in}$. long; some bones and teeth of ox, red-deer, and of a small horse; and three sherds of pottery of the ordinary description.

CLXXV. The next cairn, like the last, had been robbed of the greater part of the stones of which it had been composed. It was $27 \mathrm{ft}$. in diameter, and, placed upon an outcrop of the limestone rock, was still about $1 \frac{1}{2} \mathrm{ft}$. high. It contained a single interment of an unburnt body, that of a very strongly made man past the middle period of life, who had been laid on the natural surface at the centre of the mound. Amongst the broken and scattered bones was a piece of a 'drinking cup,' very possibly a part of what had once been a whole vessel deposited with the buried person, the rest having been carried off by the people who had removed the greater part of the cairn.

CLXXVI. The last of the three cairns was $80 \mathrm{yds}$. distant to the east of that just described, and placed like it on an outcrop of rock ; it was $23 \mathrm{ft}$. in diameter, and still about $1 \mathrm{ft}$. high. The whole of the mound to the south of the centre was full of broken and scattered human bones, of which those of an adult and of a child can be identified, together with many bones of ox and goat. At the centre and laid on the natural surface was the burnt body of an adult woman, and immediately overlying the calcined bones and in contact with them were the unburnt bodies of two infants. All round and over these bodies were the bones of water-voles in hundreds-so numerous indeed were they that at the point indicated the material of the cairn seemed almost to consist entirely of them. Amongst them was the head of a foumart (mustela putorius), the lower and part of the upper jaw of a cat, probably 
the wild species, and half the lower jaw of a large dog, and the same of a goat. The foumart must have been much larger, and the cat smaller, than their representatives now existing. At a short distance from the burnt bones, but in that part of the cairn which had been completely disturbed, was a single bead of what appears from its colour and other characteristics to be jet, but which is wanting in the electric property of that material, and therefore probably made of some inferior kind of lignite. It is oblong ( $1 \frac{3}{8}$ in. long and $\frac{3}{4}$ in. wide), flat, perforated longitudinally by four holes, and though quite plain is in other respects like fig. 51 on p. 54. There can be no doubt that at one time it had formed part of a necklace in combination with others like it and with cylindrically-shaped beads; necklaces of this description, having at times the large flat beads highly decorated, have been met with not unfrequently in various parts of Britain. Not far distant from the bead was a bone pin perforated at the head, and still, though it has lost quite one-fourth part of its length, $5 \frac{1}{2}$ in. long; together with this was found a small bone chisel, $2 \frac{1}{2}$ in. long, and, $\frac{1}{4}$ in. wide at the cutting edge; and also about one-third part of a novel article made from the leg bone of some animal, having a pattern which will be best understood from the engraving [fig. 53]. It has probably been an ornament, though the perforations, three of which exist upon that portion still remaining, may suggest some other purpose. These holes are not pierced through the bone from front to back, but are made in the thickness of it, being so connected with each other that a thong or string could be run through from one outer hole to the other; in this respect it agrees with the ring figured on p. 34. The pattern is a very characteristic one, and is not unlike what is found on some of the 'drinking cups' of the round barrows. I have never before met with anything like it, nor have I seen any description of a similar article. The os calcis and another bone of a wild boar, both gnawed apparently by a dog, were found in the cairn.

Though so much destroyed by the removal of its greater part, this cairn nevertheless presents some features of considerable importance. The close juxtaposition of the burnt and the unburnt bodies makes it quite certain that the several interments must have taken place at the same time, and we have thus another instance, and from a new district, of the absolute contemporaneity. of the two modes of burial, by inhumation and after cremation. 
Were the bodies those of a mother and her infant children? It is not unlikely. It has been asserted by some writers that the bodies of infants were never burnt, facts do not however support that view in its integrity, yet we have in this instance the unburnt bodies of infants accompanying the burnt remains of an adult. The bone ornament, or whatever else it may have been, is not only an unusual but an interesting article, and seems to show that the powers of ornamentation as exhibited by these people were but limited, and that they had made no great advancement in art. Though it may be said that the pattern is one equally appropriate for fictile vessels and for such an object as this in question, yet I think we might have looked for some different application of ornament to productions so dissimilar as a vase of pottery and a bead of bone. That these people had made some, and that a decided, progress in cultivation is shown in many ways and by divers productions of their skill, nor can it be denied that art had been developed amongst them beyond a mere rudimentary effort; yet it is certain that they had not advanced to the same point in these matters (and if so, then probably not in others) as had the inhabitants of France, Switzerland, Germany, and Denmark, when those people were passing through a somewhat similar stage of progress.

If it were certain that the oblong bead was made of true jet, we should have had in it evidence of traffic, through one channel or other, between these dwellers amongst the hills of Westmoreland and the inhabitants of other, though not very distant, parts of Britain, and that they were not so isolated, in what must then have been a very wild and inaccessible country, as we might at first sight have imagined. That a considerable and constant intercourse was at that time kept up between places far apart we have in many ways very sufficient proof; the wide diffusion of implements and weapons of flint would indeed alone show it conclusively, still every additional fact has its value and must not be overlooked.

\section{Parish of Ravenstonedale. Ord. Map. xcviti. n.e.}

CLXXVII. Upon the common belonging to the parish of Ravenstonedale, and situated about two miles to the south-west of the last described cairns, a single barrow remained, apparently quite undisturbed. It stood on a piece of ground called Hardrig, 
and was $26 \mathrm{ft}$. in diameter, $2 \frac{1}{2} \mathrm{ft}$. high, and was made of earth with a few stones principally near to the top. It contained but one interment, that of a woman of at least 24 years of age, the remains of whose burnt body were enclosed in an urn, inverted upon a small flagstone placed $10 \mathrm{in}$. above the natural surface. Amongst the bones was a bead made of clay [fig. 52], which no doubt had been on the body when the process of cremation had been undergone. It is made of the same clay as that of which the urn is composed, and has undergone the same process of baking at an open fire. The urn is somewhat in form like fig. 56, having an overhanging rim $2 \mathrm{in}$. deep; it is $10 \frac{1}{4} \mathrm{in}$. high, $8 \frac{1}{1} \mathrm{in}$. wide at the mouth, $9 \frac{1}{4}$ in. at the broadest part, $3 \frac{1}{4}$ in. at the bottom, and is entirely without ornamentation.

A very marked difference will be observed between this sepulchral mound and those last described. They were made entirely of stone, this almost entirely of earth; and whilst the burials in the stone mounds were principally by inhumation, the single one in this was after cremation. Though it would be rash to infer from these points of difference that the mounds in question were the burialplaces of distinct tribes, it is probable that there was a point of divergence between these two kinds of sepulchral mounds, if not in respect of the people who erected them, at all events in point of time. Perhaps this is more a matter of impression than of reasoning, and, as such, something must be allowed to the effect produced on the minds of the persons witnessing the exploration of the cairns and barrows by the appearances then presented and which no description can convey.

\section{Parish of Orton. Ord. Map. xcviri. N.E.}

On the opposite range of hills to the north of the last-described cairns are several others, all of which appear to have been more or less disturbed at some distant period; two of them were however subjected to a further examination, and not altogether without profitable results accruing.

CLXXVIII. The first, on the summit of the ridge overhanging the homestead of Sunbiggin, was $50 \mathrm{ft}$. in diameter, but the height could not be ascertained in consequence of the cairn having been opened at the centre down to the level of the natural surface. 
During this process the unburnt bodies of three adults had been met with, as was evidenced by the scattered bones thrown out with the displaced stones. Though originally constructed in earlier times, it had been made use of, probably many centuries after its erection, by the later Anglian settlers in the district, three of whose burials were discovered on the sides and not much below the surface of the mound. The bodies were those of a man past middle life, of an aged woman, and of a child. They were interred at full length, laid on the back in very shallow graves; those in which the adults had been buried having stones set on edge along the sides and behind the head of the body; if there had ever been covers they had been removed. The bodies had been placed with the heads approximately to the west, varying from N.N.W. to N.W. by W., the hands in all cases being on the hips; nothing in the shape of weapon or implernent was found with them. At the centre of the cairn was a grave excavated to a depth of $2 \mathrm{ft}$. in the limestone rock; it was $8 \mathrm{ft}$. long and $5 \mathrm{ft}$. wide, the long diameter being north and south. On the bottom, with the head $1 \mathrm{ft} .8 \mathrm{in}$. from the south end of the grave, was the body of a young man 17 or 18 years of age, who had been above $6 \mathrm{ft}$. in height. He was laid on the left side, with the head to $\mathbf{S}$. and the hands up to the face. At the crown of the head was an implement made of chert; it is formed from a thick flake, somewhat triangular in shape, $2 \frac{3}{8}$ in. long and $\frac{6}{8} \mathrm{in}$. wide at the broadest part; it has been carefully chipped along all its edges upon one face, the other being left untouched as it came off from the block. One end is flaked to a point, and it may be designated as a scraper and boring tool combined. Close to the body was charcoal in small quantities.

CLXXIX. Another cairn situated somewhat lower on the limestone range and a little to the east of the last, on the hill called Little Kinman, was found to have been completely opened, and from the appearances it presented, many years ago. It was $32 \mathrm{ft}$. in diameter, and now about $2 \frac{1}{2} \mathrm{ft}$. high. The remains of two bodies were found scattered amongst the disturbed materials of the mound. At the centre, and placed upon the natural surface, was a cist, $3 \mathrm{ft} .10 \mathrm{in}$. long, $2 \mathrm{ft} .3 \mathrm{in}$. wide, and $2 \mathrm{ft}$. $2 \mathrm{in}$. deep, formed of four stones set on edge, and having a direction south-west and north-east; the cover or covers had been removed by the previous explorers. Portions of three bodies were found within the cist 
and in close proximity to it. One body, that of a strongly made man about 30 years of age, had the left foot still in its place and in contact with the south corner of the cist; he had apparently been laid on the left side with the head to N.E. The other two bodies, one of which was probably that of a female under 20 years of age, had most likely been discovered outside the cist, into which some of the bones had been thrown by the persons who had then opened it. Some charcoal was found on the bottom of the cist. Amongst the disturbed material, and close to the side of the cist, an implement made from a metamorphic rock was met with, and which may possibly have originally been placed in the cist in association with the man who had been interred therein. It is $5 \mathrm{in}$. long, $\frac{5}{8} \mathrm{in}$. wide, $\frac{2}{8} \mathrm{in}$. thick, and widens a little at each end, where it is ground to a cutting edge and shows signs of having been used. If it had not been provided with the cutting edge at each end I should have been inclined to regard it as a whetstone, both on account of its shape and material, but there can be little doubt that it has been a chisel, and the appearance of its having been used at both ends is in favour of that idea. Indiscriminately placed in the cairn were some bones of ox and goat, and a portion of a large red-deer's antler which had part of the frontal bone attached to it.

\section{Parish of Crosby Ravensworth. Ord. Map. cil. s.w.}

Immediately to the north of the parish of Orton is that of Crosby Ravensworth, the division being the high ridge of limestone rock upon which the last-described cairns were situated. Like the neighbouring parishes of Orton, Asby, and Shap, it once abounded in various remains of early occupation-cairns, circles of stones ${ }^{1}$, and structures as to the purpose of which it is in vain even to form a conjecture. Those which still exist form but a small portion of what once constituted its 'pre-historic' relics, for the enclosing of the land with stone walls has been here, as elsewhere, a most destructive agent. Hammers, axes, and other implements of stone have occurred but sparingly; the greater part of the parish however being pasture-land, there is not much opportunity for their discovery. A bronze javelin-head was found in

${ }^{1}$ Some of these have been described by Mr. Soden Smith in a paper in the Journal of the Arch. Inst., vol, xxvii.p. 200. 
a crevice of the rock on Gaythorn Plain ; and at no great distance, in a similar eleft on Orton Scar, a very fine and large silver fibula and a torque (now in the Museum of the Society of Antiquaries) were discovered ${ }^{1}$. At Harbyrn Rigg, a long and broad bronze blade, of a form which has not uncommonly been met with in Ireland, was found in draining. Near to a spring, a little to the east of the village of Crosby Ravensworth, two of the curious and enigmatical spoon-shaped bronze articles of the 'Late Keltic' period were dug up; they are described and figured in an exhaustive paper by the late Mr. Albert Way, in the Journal of the Royal Archæological Institute, vol. xxvi. p. 62. In connection with these peculiar bronze articles, which have usually been found deposited in pairs, it may be mentioned that on more than. one occasion they have been met with near to springs of water.

I examined three of the cairns still remaining, all of which proved to have been disturbed by previous explorers. The two first were situated on Gaythorn Plain, a tract of high land which borders on the parish of Asby.

CLXXX. One was $25 \mathrm{ft}$. in diameter, $2 \mathrm{ft}$. high, and had once been surrounded at the base by a circle of stones, four of which (one of them a granite boulder) still remained. At the centre, and laid upon the natural surface, were the scattered and broken bones of the unburnt body of an adult, which had been discovered and displaced when the eairn had first been opened.

CLXXXI. The second cairn was $34 \mathrm{ft}$. in diameter and $3 \mathrm{ft}$. high ; like the first, it had once had a circle of stones round the base. At a distance of $8 \frac{1}{2} \mathrm{ft}$. south-east of the centre, and placed $1 \frac{3}{4} \mathrm{ft}$. above the surface of the ground, was a cinerary urn containing the burnt remains of an adult, probably a woman. The urn was so much decayed that nothing beyond the fact that such a vessel had once existed could be ascertained. At the centre and laid upon the natural surface, which at the place was an outcrop of limestone-rock rising a little above the surrounding ground-level, were many broken and scattered bones, their condition being due to a previous opening which had been made into the centre of the cairn. They had belonged to two bodies, one an adult male, the other probably a male and under twenty years of age. In

1 Journ, of Arch. Inst., vol, ix. p. 90, where the fibula is engraved. 
the cairn, but not closely connected with any of the interments, were some bones of an ox.

Near to these cairns is another, known as Hollin Stump, formerly a prominent object and landmark on the moorland trackway between Great Asby and Crosby Ravensworth. It was opened some years ago, and amongst the human bones, which were placed in a cist made of slabs of sandstone, the skull of a horse is said to have been found.

A mound made entirely of earth, $24 \mathrm{ft}$. in diameter and $4 \mathrm{ft}$. high, proved to be quite barren of any burial remains; it had every appearance of having been a sepulchral mound, nor was the nature of the material such as might be expected to have caused the entire decay of bones. It was placed on the highest part of Crosby Moor, close to a well-defined trackway, which can be traced for more than a mile, and appears to have been a road connecting the Roman station at Borrow Bridge, one mile south of Tebay, and the station at Kirby Thore or Clifton.

CLXXXII. A cairn at the head of Oddendale, called Seal Howe, was also examined; some other cairns very much destroyed are in the immediate vicinity, and about 300 yards to the west is a double circle of stones. The place is traditionally spoken of as the site of a great battle, and there are extensive mounds of stone and earth thrown up as if for the purpose of entrenchment. Between the cairn and the circle there runs an ancient road which, following the high ground as much as possible and avoiding the valleys, was one of the main lines of route from Clifton to Borrow Bridge. Along it the army of Charles II. marched on its way south before the battle of Worcester, and the place where the army halted for breakfast, at a copious spring on the moor (one of the sources of the Lyvennet), is marked by a stone with an inscription recording the event.

The position which this eairn occupies is very striking, and the scene, as viewed on the afternoon when the mound was opened, was one not easily to be forgotten by the explorers. As the sun lowered towards the mountains in the west a flood of golden light was thrown upon the moorland up to our very feet, tinging the purple of the heather with a richer hue, and adding a more than common warmth to the red and grey lichen-covered boulders of Shap 
granite which lie like flocks of sheep upon the turf. Clouds, themselves aglow with the level rays of the setting sun, threw broad patches of shade upon the illumined ground, and made the sunshine more vivid by the contrast. To the east was the broad and heavy range of Cross Fell, fronted and broken by the three sharp cones of Murton, Knock, and Dufton Pikes, and over which, at its northern end, the far distant mountains of Cheviot were just to be distinguished. Stretching down in the direction of the broad valley of the Eden, and converging in the wooded hollow in which lies the village of Crosby Ravensworth, the spire of its church just peeping from out the trees, were the tributary valleys of Oddendale and Crosby Gill. The former, with its grey stone walls and clumps of trees, marking the site where the slated roof and curl of blue smoke showed that some statesman had his home; the latter, the deep rocky gorge of the Lyvennet as it speeds from its sources on the moor, its sides clothed with natural wood, the representative of larger forests, where the ancient Briton had hunted the stag and boar, and where in later days Sir Lancelot Threlkeld, a local magnate of Tudor times, had his hunting-lodge. On the south, Ravenstonedale and Tebay Fells closed the view, deeply furrowed by precipitous side-valleys winding far away into the bosom of the hills, and coloured with green and purple and gold under the light and shadow of sun and cloud. Westward over Shap, with its scattered monoliths once forming an avenue and circle, and its ruined abbey, alike companions in decay, the eye, overlooking the intervening valleys of Wet Sleddale and Swindale, passed across the great hollow in which lies Hawes Water to the flat-topped ridge of High Street, relieved at one place by the sharp point of Kidsty Pike. Further on to the north-west was Saddleback, the ancient Blencathra, with Skiddaw just seen beyond it; and then Carrock Fell, and flatter land carrying the eye along almost into Scotland.

The cairn in question was $35 \mathrm{ft}$. in diameter, and now $2 \mathrm{ft}$. high. At a distance of $9 \frac{1}{2} \mathrm{ft}$. south of the centre, and placed on the natural surface, were the burnt remains of the bodies of an adult woman and an infant-in all probability a mother and child-enclosed in an urn ${ }^{1}$, which was too much decayed to admit of any description

1 Instances where the burnt bodies of (presumably) a woman and an infant have been placed together in the grave have occurred elsewhere; I note two. At Port Dafarch, Anglesea, a large urn was found filled with burnt bones, and having a smaller urn within it. The burnt bones were those of an adult about twenty-four 
being given of it. At the centre, which had been previously: disturbed, were the unburnt bones of an adult man, laid on the rock, there coming to the surface. In the cairn, here and there, were some bones of an adult ox.

\section{Parish of Askham. Ord. Map. cir. s.w.}

A considerable tract of land which has never been brought under cultivation, called Moor Divock, still retains upon it a number of various structures of pre-historic times, though many have disappeared through their having consisted of stones and so been found useful for a variety of purposes. They include cairns-locally called 'raises'-circles, and standing stones. Most of the gravemounds have been disturbed, and two of the raises lately examined were found to contain burials. On one part of the moor there is still to be seen a circular space, $68 \mathrm{ft}$. in diameter, enclosed with an earthen mound of very slight elevation, the entire area being paved with water-rolled stones ${ }^{1}$. At the south-east side of it is a monolith, called the Cop-stone, $5 \mathrm{ft}$. high.

CLXXXIII. About 400 yards to the north-west of this monolith is a circle of stones, ten in number, each about $3 \mathrm{ft}$. high, standing apart and enclosing a space of $18 \mathrm{ft}$. in diameter. This circle it is probable surrounded in the first instance the base of a cairn, remains of which may be seen in a number of cobble-stones covering the space within the circle. On examination, a bollow was found at the centre $2 \mathrm{ft}$. in diameter and as much in depth, sunk below the natural surface; in it were deposited the remains of the burnt body of an adult, and overlying the bones was a layer of fine sand about 3 in. in thickness, upon which was placed a 'food vessel' laid on its side and with its mouth to the west. It is in shape like fig. $71,5 \frac{1}{2}$ in. high, 6 in. wide at the mouth; and $2 \frac{5}{8}$ in. at the bottom which is slightly cupped. There are four unpierced ears at the shoulder. It is very symmetrically made,

years of age and those of an infant, and with them were some bones of a small dog. Journ. of Arch. Inst., vol. vi. p. 232. A similar discovery was made in $\mathbf{1 8 4 7}$ at Knocknecoura, Carlow, where one urn was found inside another, and the deposit of burnt bones within included those of an adult and of an infant. Wilde, Cat. Mus. Royal Irish Academy, p. 180.

1 'In Algeria... . we find ... stone circles, in which the floors are paved.' Lubbock, Prehistoric Times (3rd ed.), p. 127, quoting ' Recueil des Notices et Mémoires de la Société Archéologique de la Province de Constantine,' 1863, p. 214. 
and the ornament is applied with great skill and delicacy. The pattern, which covers the entire vase including the lip of the rim and the ears, consists of encircling bands of short lines of finely twisted-thong impressions arranged herring-bone fashion. Both the bands and the lines forming them are placed close together, and the general effect is very rich and at the same time tasteful. It is one of the best specimens of its class that I have met with, and nearly approaches in beauty to that which $I$ have referred to above as resembling it in shape. In the hollow there were also found two fragments of another vessel. 


\section{NORTHUMBERLAND.}

The whole county of Northumberland abounds in various remains of primitive occupation, consisting of fortified places, of greater or less size and differing considerably in the nature of their defensive arrangements ; of hut-circles (the foundations of dwellings), sometimes placed within the camps, at other times having no provision for defence; of circles of stone, stone rows (alignments), and single standing stones (monoliths); of rocks and loose stones marked with pits or cups, with circles surrounding pits and with like figures; and of cairns, barrows, and cists placed in the ground without any super-imposed mound to mark out the burial-place. In addition to these evidences of an early and extensive population, the same is attested by weapons and implements of flint and other stone, as well as of bronze, which have all been discovered in many places and in considerable abundance.

There is perhaps no part of the county which is more prolific of these and other indications of occupation than the parish of Ford and the adjacent district. It possesses a large amount of fertile soil, with considerable tracts of high land amply provided with positions of great natural strength, and has the river Till, a stream well stocked with fish of various kinds, running through it. In its immediate proximity is the mountain range of Cheviot, whose ancient forest would naturally abound with game of the larger kinds. The district therefore would almost of necessity be early and extensively peopled.

We find here, in addition to two circles of stones, a monolith on the field of Flodden, which tradition (not much to be depended on) speaks of as marking the place where King James fell in that disastrous battle. The very hill on which the Scottish army was entrenched the night before the fight is surmounted by a large and strong series of mounds and ditches of ancient British origin, which 
may have served at one time to defend the southern against his more northern foe, as in after days it served the purpose of the north against the south. Two other monoliths, one at Yevering and one at Humbleton, both marking the site of events long since forgotten and hidden in the far past, are still in local tradition made to testify to border conflicts in which the Percy and the Douglas fought. Here are the seats (Yevering and Milfield) where the kings of Northumbria dwelt, but at which not a trace remains to mark where the royal houses stood; and close by flows the Glen, in whose stream the thousands that flocked to his preaching were baptized by Paulinus. The whole country indeed teems with historic, as it does with pre-historic, interest, and every spot is marked as classic ground. Inscribed rocks are abundant, and one, just beyond the limits of the parish of Ford, at Rowtin Lynn, was the first which attracted so much attention as to be the means of bringing those mysterious earvings before the antiquarian world at the meeting of the Archæological Institute at Newcastle-on-Tyne in 1852. The same markings, engraved upon the under side of stones forming the covers to deposits of burnt bones, have occurred very near to the village of Ford. Numerous interments both of burnt and unburnt bodies, sometimes associated with sepulchral vessels, have been found in barrows, or simply deposited in the ground without any covering mound. In one instance that I am acquainted with a very beautiful and elaborate necklace of jet accompanied the burial, the larger and oblong pieces of which were engraved with patterns characteristic of the finer and most artistic specimens of that class of ornament.

\section{Parish of Ford, Ord. Map. cx. s.w.}

Several of the barrows which had not been previously opened were examined by me, and of these I now proceed to give an account.

CLXXXIV. The first was upon Etall Moor, and placed on the outerop of the carboniferous limestone which here forms a ridge. The barrow was $16 \mathrm{ft}$. in diameter, $2 \frac{1}{2} \mathrm{ft}$. high, and made of earth with a few intermingled stones. The mound had been partially disturbed at the top, in consequence of having been used by the Ordnance Surveyors as a site for a surveying post; and to this must be attributed the destruction of a 'drinking cup' of very 
peculiar pattern, the remains of which were met with seattered about a foot below the summit of the barrow and a little to the west of the centre. It had without doubt originally accompanied an unburnt body, all trace of which had however disappeared. The pattern has covered the whole vessel, and consists of lines in pairs, placed vertically and horizontally, each pair at a little distance from the other; the effect is to mark off the surface into plain oblong sections (the longer side being vertical) bordered by two lines; the lines are formed of ring-shaped impressions, made apparently by the section of a reed which has had two nicks cut in it opposite each other, the circle being thus broken at two points. Immediately to the east of this, and just above the level of the natural surface, was a cinerary urn standing upright, and having both within and around it burnt bones with some pieces of chareoal amongst them. The urn, somewhat like fig. 54 in shape, is perfectly plain, with an overhanging rim 2 in. deep, and is $7 \frac{3}{4}$ in. high, $5 \frac{3}{4}$ in. wide at the mouth, and $3 \frac{5}{8}$ in. at the bottom. Directly beneath this urn, indeed all but touching it, was a much larger one, placed-like all those to be mentioned presently-in an oblong hollow sunk below the natural surface. It was standing upright and contained the bones of a burnt body, those of an adult, amongst which was a small fragment of bronze much oxidized, probably the remains of an awl or pricker; whilst just outside the top of the rim of the urn was the pointed end of a calcined bone pin, which had no doubt been connected with the burnt body. The urn, in shape like that last described, is $14 \frac{1}{4} \mathrm{in}$. high, $10 \frac{1}{2} \mathrm{in}$. wide at the mouth, and $4 \mathrm{in}$. at the bottom; it has an overhanging rim $3 \frac{1}{2}$ in. deep, which is ornamented on the inside of the lip by a band of short sloping lines, and on the outside by a zigzag line occupying the whole depth of the rim, the triangular spaces formed by which are filled in with parallel lines, the pattern being identical with that on the upper part of fig. 138, except that it has only one encircling line, instead of two, above and below the triangular spaces; the whole of the lines are due to the application of twistedthong. Placed between the side of this last-mentioned urn and a flat stone set on edge, and partially crushed by pressure, was a small urn standing upright and quite empty. It is in shape like the last, but more rudely made, and is $7 \mathrm{in}$. high, $4 \frac{1}{2} \mathrm{in}$. wide at the mouth and 3 in. at the bottom, and has an overhanging rim $1 \frac{5}{8}$ in. deep, which is roughly ornamented with the same pattern as that on the last one; it has in addition an encircling band of short vertical 
lines of thong-impressions upon the body of the vessel immediately below the rim. It cannot be doubted that there was some kind of connection between this and the larger urn with its sepulchral contents; it is however difficult to say what office the smaller vessel fulfilled; although most probably, whatever may have caused a small urn to be placed with the burnt bones inside a larger one or with a simple deposit of burnt bones in a barrow, the same object was aimed at by the second and smaller urn in this case. At a distance of half-a-foot east of the flat stone was placed another cinerary urn, also in an upright position. It was filled with burnt bones, amongst which was found a very rudely made and perfectly plain 'incense cup' [fig. 155] of globular shape, 2 in. high and $2 \frac{3}{4}$ in. wide. The cinerary urn is of very coarse make and form,

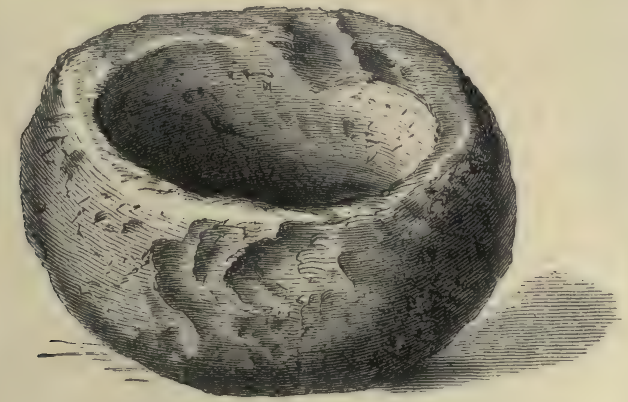

Fig. 155.

of the type of fig. 54, $9 \frac{1}{4}$ in. high, $7 \frac{1}{4}$ in. wide at the mouth, and $3 \frac{7}{8}$ in. at the bottom; it has an overhanging rim $1 \frac{3}{4}$ in. deep, which is roughly ornamented with alternate series of vertical and horizontal lines of twisted-thong impressions. Some inches north of this was another cinerary urn, so much decayed that only a few portions remained at all entire. The overhanging rim, $1 \frac{5}{8}$ in. deep, is covered with a reticulated pattern of impressions of twistedthong; and the body of the urn below the rim is marked irregularly with scattered oval indentations. From the decayed condition of this and the broken state of the last urn, and from their close contiguity, it is impossible to say whether each had contained the remains of a burnt body, or that the one had been placed alongside the other as in a former instance. It is more probable however that each had once held the bones of a burnt body. As has been before stated, all these interments had been made in an oblong hollow, sunk 16 in. below the natural 
surface; it had an east and west direction, and was $2 \frac{3}{4} \mathrm{ft}$. long by $2 \mathrm{ft}$. wide, having a rough covering of stones over it. Immediately east of this hollow was a cist $1 \frac{1}{2} \mathrm{ft}$. square, formed of four stones set on edge and with a single cover-stone. It was filled with sand, amongst which were the scattered remains of the burnt body of an adult, with some pieces of charcoal. In the material of the barrow were discovered a single chipping of flint, and 2 flat kidney-shaped stone, $6 \frac{1}{2}$ in. long and $2 \frac{3}{4}$ in. wide, worn quite smooth on the flatter face, and showing signs of having been much used in rubbing some (apparently) soft material; it may possibly have served in the dressing or preparation of skins.

The contents of this barrow, so small in its dimensions, present a large assemblage of burnt bodies in one sepulehral mound, and it is very rare that such a number have been found in any Northumberland grave-hill. The burials contained within the oblong hollow may perhaps be supposed to have all taken place at the same time, and if so we have two, or more probably three, bodies interred together. The 'drinking cup,' the upper plain urn, and the cist may represent subsequent interments ; and it is not perhaps unreasonable to regard the mound as the burying-place of a family, where in the larger urn with its accompanying smaller one were contained the remains of the principal person, who had been consigned to the grave with one or more of his family or dependents, the other and presumably later burials being those of descendants or other relatives ${ }^{1}$.

Upon Ford Common, lying on the slope of the hill and a little to the east of the village, several cinerary urns and 'incense cups' have from time to time been accidentally discovered in the process of enclosure or in winning stone for building walls. I examined two small barrows which had been left until then undisturbed.

CLXXXV. The first was placed upon a knoll on the highest part of the common, in a field which had been taken off from it and brought under cultivation a few years before. The traces of the barrow, which must always have been a very small one, were only slight, and the upper surface of the cover-stone of a cist had been touched by the plough and lay partly exposed. On removing this stone the cist, constructed of four slabs of sandstone set on

1 An account of this barrow, with figures of some of the urns, has appeared in the Proceedings of the Berwickshire Naturalists' Club, vol, v. p. 195. 
edge, was revealed. It lay north-east and south-west, being $2 \mathrm{ft}$. $2 \mathrm{in}$. long by $1 \mathrm{ft} .10 \mathrm{in}$. wide, and was filled with gravelly sand; amongst this were the remains of a burnt body, the bones not placed together but scattered about. In the cist were also found some pieces of charcoal, a single potsherd of the ordinary character, and a very beautiful knife [fig. 156] of transparent honey-coloured flint, $2 \frac{1}{2}$ in. long and $\frac{7}{8}$ in. wide at the broadest part. It is flat on one face, which has not been retouched after it was struck off from the core, while the other and convex face is most delicately flaked over its whole surface ${ }^{1}$. It is an example of that kind of implement which, when associated with burnt bones, I have always found to be itself unburnt.

CLXXXYI. Between the last-mentioned barrow and the village of Ford, and lower down the slope of the hill, was placed, upon a slight natural elevation, the second of the barrows adverted to above. It was $14 \mathrm{ft}$. in diameter, $1 \frac{1}{2} \mathrm{ft}$. high, and made of earth and stones. Five feet south-east of the centre were two deposits of burnt bones, lying $14 \mathrm{in}$. apart, and placed upon the natural surface. At the centre, and at the same level as the two former ones,

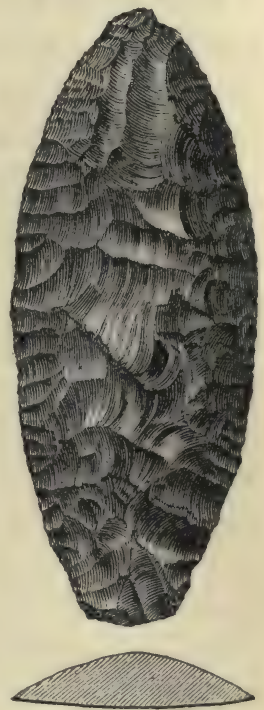

Fig. 156. $\frac{1}{1}$. was another burnt body, that of a woman about 24 years of age, the remains of which were enclosed in a cinerary urn standing upright. It is very rudely made, in shape like fig. $130,8 \frac{1}{4}$ in. high, $7 \frac{1}{4}$ in. wide at the mouth, and 4 in. at the bottom, with an overhanging rim $2 \frac{3}{4}$ in. deep, to which the ornamentation, consisting of alternate series of vertical and horizontal lines of impressions of twistedthong, is confined; the inside of the lip of the rim has two encircling lines of the same impressions upon it. Amongst the bones was a piece of calcined flint, and just outside the rim of the urn were four jet beads, three of them of a cylindrical form, respectively $\frac{4}{8}$ in., $\frac{5}{8}$ in., and $\frac{6}{8}$ in. long, the fourth shaped like a slightly conical button, almost identical in form with that which is figured at p. 366, though smaller.

1 A knife almost identical with this was found in an urn with burnt bones in a barrow at Bryn Bugailen Fawr, in the parish of Llangollen, Denbyshire. It is figured at p. 218 of Arch. Cambr., vol. xiv. 3rd Series. 
The two barrows next to be described were situated at Broomhill, about a mile and a-half to the south-west of the last, upon the ridge of the sandstone rock which there skirts the valley of the Till, and in close proximity to ground in which several burials have been discovered ${ }^{1}$; where, moreover, flint implements and chippings are met with on the surface whenever it is disturbed.

CLXXXVII. The first barrow, the upper part of which was entirely formed of stones, the lower having much earth intermingled with them, was $16 \mathrm{ft}$. in diameter and $3 \mathrm{ft}$. in height. It was enclosed at the base by a circle of stones set on edge and placed close to each other. The diameter of the circle being $12 \mathrm{ft}$., the extreme edge of the barrow extended only a little beyond the line of encircling stones, which projected above the surface of the mound. The primary interment was found at the centre of the barrow ; it was contained in a cist, the bottom of which was formed by the original surface of the ground. The cist was made of four sandstone slabs set on edge, with a single massive flag for a cover, which bore on its upper surface the signs of fire; the joints at the angles were filled up with clay. The cist lay north and south, and was $2 \mathrm{ft} .11 \mathrm{in}$. long, $2 \mathrm{ft}$. wide, and $1 \mathrm{ft}$. 7 in. in depth. At its northern end were two portions of the skull of a child about two years old, and close to them was placed a 'food vessel' standing upright and quite empty. There cannot be a doubt that the whole body had been originally deposited in the cist, and that nearly all the bones had disappeared through decay, leaving only that portion of the skeleton which, on account of the texture of the bone, has frequently been found to have resisted longer than any other part the action of various disintegrating agents to which the body has

${ }^{1}$ I possess two urns found many years ago at Broomridge, in a circular hollow sunk in the ground and lined with clay. The larger urn, which stood upright, had the smaller one reversed within it over the deposit of burnt bones contained therein. It is $9 \frac{1}{4} \mathrm{in}$. high, $7 \mathrm{in}$. wide at the mouth, and $3 \frac{1}{2} \mathrm{in}$. at the bottom; in form it approaches to fig. 56 ; the upper part is ornamented with lines of twisted-thong impressions arranged herring-bone fashion. The inside of the rim is ornamented to the unusual depth of $1 \frac{1}{2}$ in. with a diamond-shaped pattern placed between two lines which encircle the vessel, all of twisted-thong markings. The smaller urn is $5 \mathrm{in}$. high, $4 \frac{3}{4} \mathrm{in}$. wide at the mouth, and $2 \frac{1}{4} \mathrm{in}$. at the bottom; and has the upper half ornamented with encompassing lines with short vertical lines below them, all the markings being due to twisted-thong impressions. Another burial after cremation was met with about the same time, not very far from this just above mentioned. An 'incense cup' was associated with the burnt bones; it is $2 \mathrm{in}$. high, $2 \frac{3}{4} \mathrm{in}$. wide at the mouth, and $2 \frac{1}{4}$ in. at the bottom. The upper half has five encircling lines of twistedthong impressions upon it, which are crossed by four sets, each consisting of four vertical lines of similar impressions; the lower half is plain. Just below the mouth are two perforations, the one placed above the other. 
been subjected. The vase in shape and ornamentation is very much like fig. 161 , being $3 \frac{7}{8}$ in. high, $4 \frac{1}{4}$ in. wide at the mouth, and $1 \frac{7}{8}$ in. at the bottom; it is covered over the whole surface with impressions made by a sharp-pointed instrument, forming encircling bands arranged herring-bone fashion; a grooved line encircles it at the shoulder, and two bands similar to those on the outside are found on the inside of the lip. Round the cist, and between it and the enclosing circle, were six burnt bodies which were placed in the same number of urns, all (with one exception) standing upright, and three of them covered, each with a small flat stone. They were however so much decayed that only one could be removed; this was the one found inverted, the mouth being closed with clay. It contained the calcined remains of a young person about seventeen years of age, and amongst the bones were the pointed end of a bone pin and a flint flake ( $2 \frac{1}{8} \mathrm{in}$. long and $\frac{3}{8}$ in. wide) secondarily worked along both edges; these articles had both passed through the fire. The urn, in shape like fig. 56 , is very rudely made, $10 \frac{1}{4} \mathrm{in}$. high, $8 \frac{1}{2}$ in. wide at the mouth, and $3 \frac{1}{2}$ in. at the bottom. On its upper part, for a depth of four inches, it is ronghly ornamented with an irregularly-formed herring-bone pattern of five bands of lines produced by the application of a sharp-pointed instrument, and on the inside of the lip is a row of vertical lines similarly formed. Without the circle of stones, on the east side of the barrow, was another cinerary urn filled with burnt bones, but so much decayed that it could not be preserved. A great quantity of burnt earth was met with in the barrow ${ }^{1}$.

The fact that a very young child occupied the most important position in the barrow is not a singular one; similar cases having occurred in several of the sepulchral mounds an examination of which is recorded in this volume. From the care with which this cist was constructed and the pains bestowed upon it, as also from the presence of an enclosing circle, with the deposits of burnt bodies surrounding the primary interment, it may be reasonably inferred that this was the burying-place of the much-beloved child of a man of high standing amongst his people; and it is not improbable that the burnt bodies were those of dependents slain at the funeral, and possibly with the view that they might in another world continue to render those services they had before been accustomed to perform.

1 For an account of this barrow, with figures of the urns, \&c., see Proc. of Berwickshire Nat. Club, vol. iv. p. 390. 
CLXXXVIII. The second barrow, almost identical in size with the last, was situated $125 \mathrm{yds}$. north of it, and was formed in like manner and of the same materials, except that there was in this case no enclosing stone-circle. Upon the natural surface there was placed a thin layer (about 2 in. thick) of burnt earth with embedded calcined bones and charcoal, and containing an extraordinary quantity of potsherds, chippings of flint, and what appears to be a javelin-head of flint [fig. 157], all unburnt. The javelin-head, if it

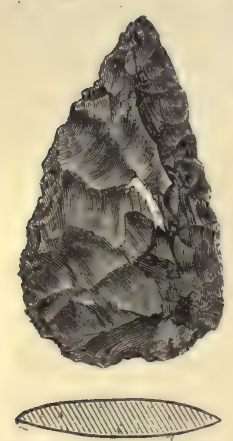

Fig. 157. $\frac{1}{2}$. be such, is $2 \frac{3}{4}$ in. long and $1 \frac{5}{8}$ in. wide at the butt-end, and is boldly flaked over the surface, having finer chipping round the edges. The layer of burnt matter did not extend throughout the whole area of the barrow, but was found in patches; and there was no place at which it could be said that the entire bones of a burnt body had been laid. It was quite impossible to form an idea how many bodies had been deposited in the mound, on account of the scattered way in which the bones were dispersed. The potsherds belonged to a very large number of different vessels, which varied both in colour and in form but had all been of plain hard-baked pottery, quite unlike that of which the sepulchral vases are made, and had the appearance of fragments of domestic vessels. The manner in which the bones were disposed was certainly very peculiar, nor do I remember in the course of my experience to have seen anything like it. The whole of them had however certainly been deposited at one time, for there was no appearance of any disturbance of the mound having ever taken place.

\section{Parish of Doddington. Ord. Map. cx. s.e.}

This parish, which adjoins Ford, the river Till forming a part of its northern boundary, has proved to be perhaps more prolific in pre-historic remains than even Ford itself. There are several camps of varied form, some in a very perfect state, and affording much valuable evidence of the mode of fortification adopted by the early occupants of the district. Part of a stone-circle still exists; and sculptured rocks with pit-markings and concentric circles engraved upon them are very abundant. Barrows also are numerous, but they have all been long since rifled, and without any record of their 
contents having been preserved. In some of these disturbed gravemounds I found portions of cinerary urns and burnt bones, and I should be inclined to think, judging from the remains still left in them, that the burials had been principally after cremation. Cists containing unburnt bodies, placed in the ground without any apparent grave-hill above them, have also been met with by casual discoveries from deep ploughing or in the course of other agricultural operations. The most remarkable of them, so far as I know, was one of which the contents have come into my possession through the kindness of the late Rev. William Proctor, junior, of Doddington, to whom the archæological world is deeply indebted for the discovery of many of the circular-marked rocks in the district, as well as for their careful preservation.

CLXXXIX. The cist was found, June 21, 1867, in a sandy knoll, upon the slope of the hill rising from the river Till, and in close proximity to one of the rocks engraved with the circular markings. It lay east and west, being $3 \frac{1}{2} \mathrm{ft}$. long and $3 \mathrm{ft}$. wide, and was made of five side stones with a sixth as a cover. The body, one of small size but probably of a man between 24 and 30 years of age, was placed in it on the right side, with the head to $W$. The person in this eist had apparently been interred in a leathern dress, parts of which showing the stitching were still existing at the time of the opening of the grave. Close to the head was what must probably be classed as a food vessel, though of peculiar form [fig. 78]. It is $6 \frac{3}{4} \mathrm{in}$. high, 7 in, wide at the mouth, and $3 \frac{1}{2}$ in. at the bottom. Just below the rim are four handles. It is ornamented on that part immediately below the handles with a band of four rows of lines arranged herring-bone fashion, above and below which are three encircling lines; the pattern does not however quite surround the vessel, apparently through an accidental failure of the impression; one of the handles has a chevron pattern upon it; the whole of the lines have been made by a sharppointed tool rather irregularly drawn over the moist clay. There were also found in the cist a chipping of flint and a knife of the same material, carefully flaked along one edge (which is slightly curved) and at the point. It is in general form very like fig. 145, and is $2 \frac{7}{8} \mathrm{in}$. long and $1 \frac{1}{8} \mathrm{in}$. wide at the broadest part; the one face remains as it was when struck off from the core, the other, which is convex, has been partly chipped over, and has still some of the original white skin of the flint nodule left upon it. 


\section{Parish of Chatton. Ord. Map. cx. s.e.}

About two miles higher up the valley of the Till than the site of the interment just described, but on the other (left) bank of the river, is a remarkable assemblage of early remains, consisting of a very interesting example of a fortified place crowning the hill called Whitsun Bank, several series of sculptured rock-markings, and sundry barrows. These last, to the number of six, were opened by me, the examination proving that most of them had been previously disturbed, although enough remained to show the nature of the burials they had contained.

CXC. One, composed of sandy soil, was $15 \mathrm{ft}$. in diameter and $2 \frac{1}{2} \mathrm{ft}$. high. It had at the centre (the bottom being on the level of the ground) a cist lying north-east and south-west, made of five stones set on edge and covered with two other slabs; it was $3 \mathrm{ft}$. long, $2 \mathrm{ft} .8 \mathrm{in}$. wide, $1 \frac{1}{2} \mathrm{ft}$. deep, and was filled with fine white sand. It had been rifled on some former occasion, though the cist had not been cleared out, and had once no doubt contained an unburnt body the bones of which had gone entirely to decay.

CXCI. A second was $16 \mathrm{ft}$. in diameter, $3 \mathrm{ft}$. high, and made up of earth and stones, having a circle of larger stones set round the base. At the centre, upon the ground-level, was a cist lying east and west, and made of five side stones with a cover. It had been previously opened, but had originally held a burnt body, the remains of which were found scattered about, both inside and outside the cist.

CXCII. One barrow of very small size proved however to have been left untouched. It was $8 \mathrm{ft}$. in diameter, about $10 \mathrm{in}$. high, and was made of earth, with a few stones placed upon the top. Just above the natural surface, at the centre, was a flat stone having another underneath it, which proved to be the cover of a small cist, $14 \mathrm{in}$. square and $10 \mathrm{in.}$ deep, sunk into the ground and formed with four sandstone slabs set on edge. The lower portion of the cist was filled to a depth of $3 \frac{1}{2}$ in. with sand, upon which were earth and small water-rolled pebbles; and amongst these were the bones of the burnt body of a person in middle life, accompanied by a portion of a lozenge-shaped piece of flint, possibly part of an arrow-point, that had been passed through the fire. 


\section{Parish of Bamborodgh. Ord. Map. cx. s.e.}

The site of the sepulchral mounds about to be described is second to none in interest, whether we have regard to the natural features of the country in which they are placed, or to the bistorical and other associations with which so many of the neighbouring localities are invested. They are found upon Lucker Moor, on the farms of Rayheugh and Rosebrough, and form a group of considerable extent, the cairns being of varied size. To the west the ground rises to Ross Castle, a hill just outside the park of Chillingham, crowned with an ancient British fort, whilst further to the west and north the eye takes in Hedgehope, Dunmore, and Yevering Bell, and other mountains of the Cheviots. Far away to the north, and beyond the Tweed, the horizon line which bounds the view is formed by the high range of the Lammermuir. To the east, with a rich and fertile tract of lower-lying ground intervening, is the sea, with Lindisfarne or Holy Island, the seat of the earliest missionary settlement in Northumberland, and hallowed by the saintly life and the untiring labours of St. Cuthbert. Further down the coast to the south is Bamborough, whose ancient castle still rises from its rocky eminence and grandly dominates the scene, a worthy representative of the residence of the Saxon kings of Northumbria, and in later times the capital of the Earldom of Northumberland: Stretching away to the east, out to seaward, are the Farne Islands, upon one of which St. Cuthbert passed many years in solitude and self-denial, and where he died; whilst another of them in our own days has been made memorable by an heroic deed; when Grace Darling braved all the perils of the tempest in rescuing the survivors of the stranded 'Eorfarshire.' The towers of Dunstanborough Castle, raised on a crag of basalt overhanging the sea; form the last point of interest along the coast to the south.

CXCIII. The principal cairns, as regards size, are three upon Rayheugh, placed in a line nearly north-west and south-east, and one upon Rosebrough, about half-a-mile to the south of them. That which is situated the furthest to the north-west was opened by Major Luard-Selby in 1862. It is $62 \mathrm{ft}$. in diameter, and had once been about $10 \mathrm{ft}$. high. He discovered at the centre, upon the level of the natural surface, a cist made of four stones set on edge, having two stones on the bottom and a single cover-stone, which 
projected $8 \mathrm{in}$. beyond the sides of the cist; all the stones were of shale, except the two end ones which were of sandstone. The cist was $4 \mathrm{ft}$. long, $2 \mathrm{ft} .8 \mathrm{in}$. wide, $2 \mathrm{ft} .4 \mathrm{in}$. deep, and had its longer axis east and west. In it was a skeleton, laid on the left side with the head to E., which appeared to have been placed upon a small flat stone as if for a pillow. Behind the shoulders was a 'drinking' cup' of an ordinary form, like fig. 120; it is quite fragmentary, but appears to have been originally about 8 in. high. Major Luard-Selby found that the whole cairn showed signs of careful construction, the stones not being merely thrown on without order as is frequently the case. The cist was covered by large stones sloping inwards, and there was the appearance as if a circle of stones had encompassed the cairn near to the outer edge. On making a further examination, I found amongst the stones composing the cairn an oval quartzite pebble, $3 \frac{1}{2}$ in. long and 3 in. wide, which had served as a hammer, and showed signs of having been much used at one end. I also met with several flat pieces of sandstone, from 6 in. to $10 \mathrm{in}$. long, which seemed to have been in use for polishing or grinding, the surfaces being worn quite smooth.

CXCIV. The second cairn was situated $244 \mathrm{ft}$. south-east of the last; it is $62 \mathrm{ft}$. in diameter, and had originally been about the same height (10 ft.) as the preceding one. It was partially opened by Major Luard-Selby, who however did not reach the surfacelevel at the centre. I completed the examination, and found an oblong hollow at the centre excavated in the clay sub-soil and filled in with stones. It had a direction west-by-north and eastby-south, and was $4 \frac{3}{4} \mathrm{ft}$. long, $3 \frac{1}{2} \mathrm{ft}$. wide, and $2 \frac{1}{4} \mathrm{ft}$. deep. At the south-east corner was an oval hole sunk to a depth of $1 \frac{3}{4} \mathrm{ft}$. below the bottom of the grave; it was $1 \mathrm{ft}$. $8 \mathrm{in}$. long and $11 \mathrm{in}$. wide, having the same direction as the grave itself, and was filled in with clay and stones. There was no trace remaining of the body which had no doubt once occupied the grave, the bones (unburnt) having gone entirely to decay; nor apparently had anything been interred with the body. Major Luard-Selby discovered a whetstone, $3 \frac{6}{8}$ in. long, amongst the stones composing the cairn, and I met with several flat stones similar to those in the last-described cairn, and like them worn quite smooth.

CXCV. The third cairn, lying $201 \mathrm{ft}$. south-east of the last, is $55 \mathrm{ft}$. in diameter, and about the same height as the other two. It 
had been opened by Mr. Dennis, the tenant of Rosebrough, who discovered a rudely-formed cist at the centre, which however contained nothing - the bones apparently having gone entirely to decay.

CXCVI. The fourth is situated in a wood about half-a-mile to the south of the last three, and was also opened by Mr. Dennis. It is $60 \mathrm{ft}$. in diameter, and about $10 \mathrm{ft}$. high. At the centre was a cist, placed on the natural surface, made of four stones set on edge with a single cover-stone. The cist, which has a direction east-bynorth and west-by-south, is $3 \frac{1}{2} \mathrm{ft}$. long, $1 \mathrm{ft}$. 7 in. wide, and $2 \mathrm{ft}$. $1 \mathrm{in}$. deep ; the cover-stone is $6 \frac{1}{2} \mathrm{ft}$. long, $4 \frac{1}{2} \mathrm{ft}$. wide, and averages $1 \mathrm{ft}$. in thickness. In the cist a very few unburnt bones were found, the only remains of the body once contained within it, and some pieces of burnt stone.

Major Luard-Selby opened some of the smaller cairns, which are numerous, and found in one a large cinerary urn partly filled with burnt bones and covered by a pentagonal-shaped stone. In another there was a vessel of pottery ornamented with six encircling bands of short impressions inclining to the right.

CXCVII. A little distance to the south of the large cairn in the wood opened by Mr. Dennis was a smaller one, placed upon a piece of rising ground on the moor belonging to the farm of Rosebrough, and which appeared never to have been disturbed until I opened it. Amongst the stones principally composing it was some earth, probably rather due to the decay of the vegetable growth with which in a long course of years it had become invested, than to any intentional admixture in the first instance. It was $25 \mathrm{ft}$. in diameter and $3 \mathrm{ft}$. high. At the centre a cinerary urn was discovered, inverted over a deposit of burnt bones (those of two adults, one probably a woman), and resting upon a flat sandstone slab which ultimately proved to be the cover of a cist. The urn [fig. $60]$ is $15 \mathrm{in}$. high, $12 \frac{1}{2} \mathrm{in}$. wide at the mouth, and $4 \mathrm{in}$. at the bottom. It is a very remarkable specimen of the class to which it belongs, and is the first that I have seen which has the peculiar but effective ornament seen upon the rim. This consists of two series of figures in relief, encompassing the urn at the top and bottom of the rim. The urn is well made, and the ornamentation is applied with some taste and skill, nor is it often in this type of vessel that the whole of it is covered with a pattern. Amongst the burnt 
bones was a flint knife, unburnt, of a square form, roughly made from a short and broad flake, two of the edges being chipped to give it the requisite sharpness; it is $1 \frac{3}{4} \mathrm{in}$. long and $1 \frac{1}{4} \mathrm{in}$. wide. Below the slab upon which the urn was placed was a cist; it was sunk to a depth of two feet below the natural surface, the cover being upon the level of the ground. It consisted of four sandstone slabs set on edge, and had a direction east and west, being $3 \mathrm{ft} .3 \frac{1}{2} \mathrm{in}$. long and $2 \mathrm{ft} .3 \frac{1}{2}$ in. wide; the cover was $4 \mathrm{ft}$. 4 in. long, $3 \mathrm{ft}$. 4 in. wide, and 10 in. thick. The body contained within it, of which but a very few

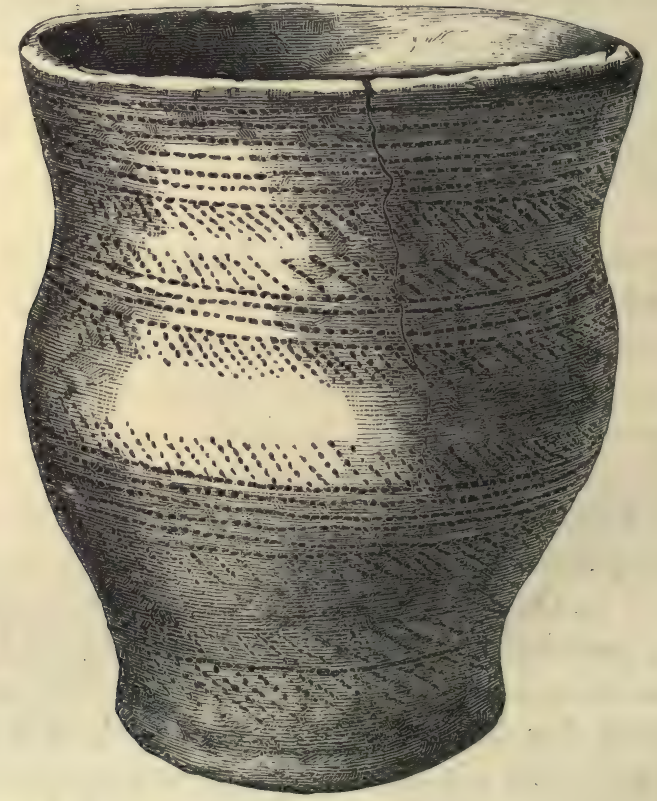

Fig. 158. $\frac{1}{2}$.

traces were visible, had been placed upon a thin layer of small gravel and then covered over with fine sand, amongst which was a good deal of charcoal interspersed; the sand rose to within a foot of the top of the cist. The body had apparently been laid on the right side, with the head to $\mathrm{E}$. and touching the east end of the cist; before the face, if the body had been placed on the right side, was a 'drinking cup,' deposited upright in the north-east corner [fig. 158]. It is $5 \frac{1}{2} \mathrm{in}$. high, $5 \mathrm{in}$. wide at the mouth, and $3 \mathrm{in}$. at the bottom, where it widens a little. The ornamentation is due to the impression of a notched piece of bone or wood. On the bottom of the cairn, at the south side of the cist-cover, was a flat piece of 
sandstone, $9 \frac{1}{2}$ in. long and 5 in. wide, similar to those found in the other eairns, and which was quite smooth and even polished on one surface by use.

CXCVIII. Another cairn, $18 \mathrm{ft}$. in diameter and $3 \mathrm{ft}$. high, was situated about a mile to the east of the last. At the centre and on the natural surface a cinerary urn was discovered, standing upright and covered with a small flat piece of sandstone. It contained the burnt bones of a person of uncertain sex from 18 to 20 years of age, and amongst them were portions of at least two, and possibly of three, calcined bone pins. The urn, in shape like fig. 130, is $6 \frac{1}{2}$ in. high, $6 \mathrm{in}$. wide at the mouth, and $4 \mathrm{in}$. at the bottom. The overhanging rim, $1 \frac{7}{8}$ in. deep, is ornamented with two encircling lines on the inside of the lip, and on the outside by alternate series of vertical and horizontal lines placed between two encircling lines above and two below, like the pattern on fig. 54. Immediately below the rim are two encircling lines. All the impressions are those of twisted-thong. Two feet south-south-west of the centre, and on the natural surface, was a piece of another urn very much decayed; there were no remains of bones near it, nor is it probable that a whole vessel had been deposited at the place.

CXCIX. A smaller cairn close to the last, $13 \mathrm{ft}$. in diameter and $2 \frac{1}{2} \mathrm{ft}$. high, produced no remains of the body which had once, there can be little doubt, been placed in it. At the centre the stones were found to have been carefully arranged over and round a shallow oval hollow, excavated in the surface-soil, $2 \frac{1}{2} \mathrm{ft}$. long and $2 \mathrm{ft}$. wide, and which was lined with a thin layer of charcoal. Upon this layer it is probable the body had rested, but from the free admission of air and wet, the bones had gone to decay without leaving any trace of their former presence. It will be remembered that in the case of the larger cairn just described, and where the body had been protected by a cist, and was moreover covered by a much greater quantity of overlying material than this in question, the bones had gone very much to decay, in fact leaving little more than a soft yellowish-coloured substance to represent them.

I examined three other cairns, respectively $19 \mathrm{ft} ., 17 \mathrm{ft}$., and $14 \mathrm{ft}$. in diameter, and from $1 \frac{1}{2} \mathrm{ft}$. to $2 \frac{1}{2} \mathrm{ft}$. high. Though they had never been disturbed before, there was no trace of a burial found in them further than the presence of charcoal, which may itself be. 
taken to indicate their sepulchral purpose. In these three instances, as in many others where the same feature has occurred, I have no doubt whatever that they had each been occupied by an unburnt body, the bones of which had totally disappeared through the action of the various disintegrating agencies to which, during a long period, they had been subjected.

\section{Parish of Eglingham. Ord. Map. cix. n.w.}

Ascending the valley of the before-mentioned river, which however at this part has not assumed the name of Till, but is called the Breamish, we arrive at a locality rich in varied relics of the far past. The whole of the right bank of the stream has its rocky and precipitous boundary crowned with fortified places, some of them of remarkable interest, and preserving their principal features untouched except by time. Closely adjoining to the peculiar double camp on Bewick Hill is one of the largest series of circular rock-sculptures yet discovered, and cairns and other sepulchral places have been very abundant on the adjoining moorland. Most of them have been opened by the shepherds, under the delusive hope of finding treasure. I possess a fragment of a 'drinking cup' from one of the cairns, in which were two cists, the cover-stone of one exhibiting the almost unique feature of the use of a tool upon it, in the shape of a groove cut with a sharp-pointed instrument round its narrower end, no doubt with the object of facilitating its being dragged the more easily up the side of the hill upon the summit of which the cairn is placed.

CC. Somewhat lower down the hill than the cairn just referred to, and upon a piece of rising ground near to the shepherd's house called Blawearie, is a circle ( $36 \mathrm{ft}$. in diameter) of stones set on edge, some of them being in contact with each other, whilst others stand apart. Within the circle were a number of ordinary cobblestones (such as might be gathered from the surface of the ground), the remains probably of a cairn which had been removed to aid in the building of a neighbouring wall. Some years ago a cist was discovered at the centre, which contained a vessel of pottery now lost. I examined the whole of the remaining space within the circle, and met with three other cists. The first was $9 \frac{1}{2} \mathrm{ft}$. southwest of the centre, and was placed north-west and south-east; it was formed of four slabs of sandstone set on edge, with a fifth for 
a cover, the upper surface of which was level with that of the ground. One of the side-stones had a single small stone set upon it, and another had several, in order to make the two sides up to the required height. The cist was $3 \mathrm{ft} .4 \mathrm{in}$. long, $1 \mathrm{ft}$. 10. in. wide, and the same in depth. On the bottom was placed a layer of sand about $4 \mathrm{in}$. in thickness, almost covered by which and lying on its side at the north corner was a 'food vessel,' the mouth being turned towards the centre of the cist. There was not the slightest trace of bone to be seen; but a few pieces of charcoal were found amongst the sand. The vase is in shape and ornamentation like fig. 161, but narrower proportionately to its height, and is $6 \frac{1}{4}$ in. high, 6 in. wide at the mouth, and $3 \mathrm{in}$. at the bottom; it is entirely covered (including the inside of the lip), except for an inch and a-half at the bottom, with encircling bands of lines arranged herringbone fashion, and produced by the application of a sharp-pointed instrument. Three feet west of this last was another cist, also placed north-west and south-east, $2 \frac{3}{4} \mathrm{ft}$. long, $2 \frac{1}{4} \mathrm{ft}$. wide, and $1 \frac{1}{4} \mathrm{ft}$. deep. It had two side-stones, and a short one only at the north-west end. The cover-stone had probably been removed at some former time. On the bottom was a deposit of about $6 \mathrm{in}$. of sand, amongst which, at the north corner, was found a necklace of beads [fig. 159], more than a hundred of which were obtained. Ten of them are cylindrical in shape, varying in length between $\frac{1}{1} \frac{1}{6} \mathrm{in}$. and $1 \mathrm{in}$., and are made of jet; the others are thin flat disks of various sizes, from $\frac{3}{16} \mathrm{in}$. to $\frac{8}{18}$ in. in diameter, and are made of shale. They had been arranged in successive series of ten round beads, then a long one, then ten round ones again, and so on. Near the middle of the cist, amongst the sand, was a flint knife carefully chipped along both edges; it is now $1 \frac{3}{4}$ in. long and $\frac{3}{4}$ in. wide, but has had a piece broken off the smaller end, the fracture having occurred before it was placed in the grave. Again, in this case, no remains whatever of the body were found. At a distance of $12 \frac{3}{4} \mathrm{ft}$. from the centre, and to the north-west of it, was a third cist, lying north-east and south-west, $2 \mathrm{ft}$. $4 \mathrm{in}$. long, $1 \mathrm{ft} .5 \mathrm{in}$. wide, and the same in depth; it was formed of four side-stones and a cover. There was a layer of sand $6 \mathrm{in}$. deep on the bottom, but it contained nothing beyond a few pieces of charcoal. It will be remarked that in none of these three cists was any trace of bone detected : the burials had been of unburnt bodies which had all undergone complete decomposition.

Several other mounds in the same neighbourhood, all of them of a class of which a large number have been opened by me in different 
localities, were submitted to examination. These mounds, which are almost invariably wanting in any signs of an interment beyond pieces of charcoal and burnt stone (if indeed such are to be considered as strictly indicative of burial), are usually found associated in groups, sometimes in very considerable numbers. They are of small size and slight elevation, and frequently have one or more of

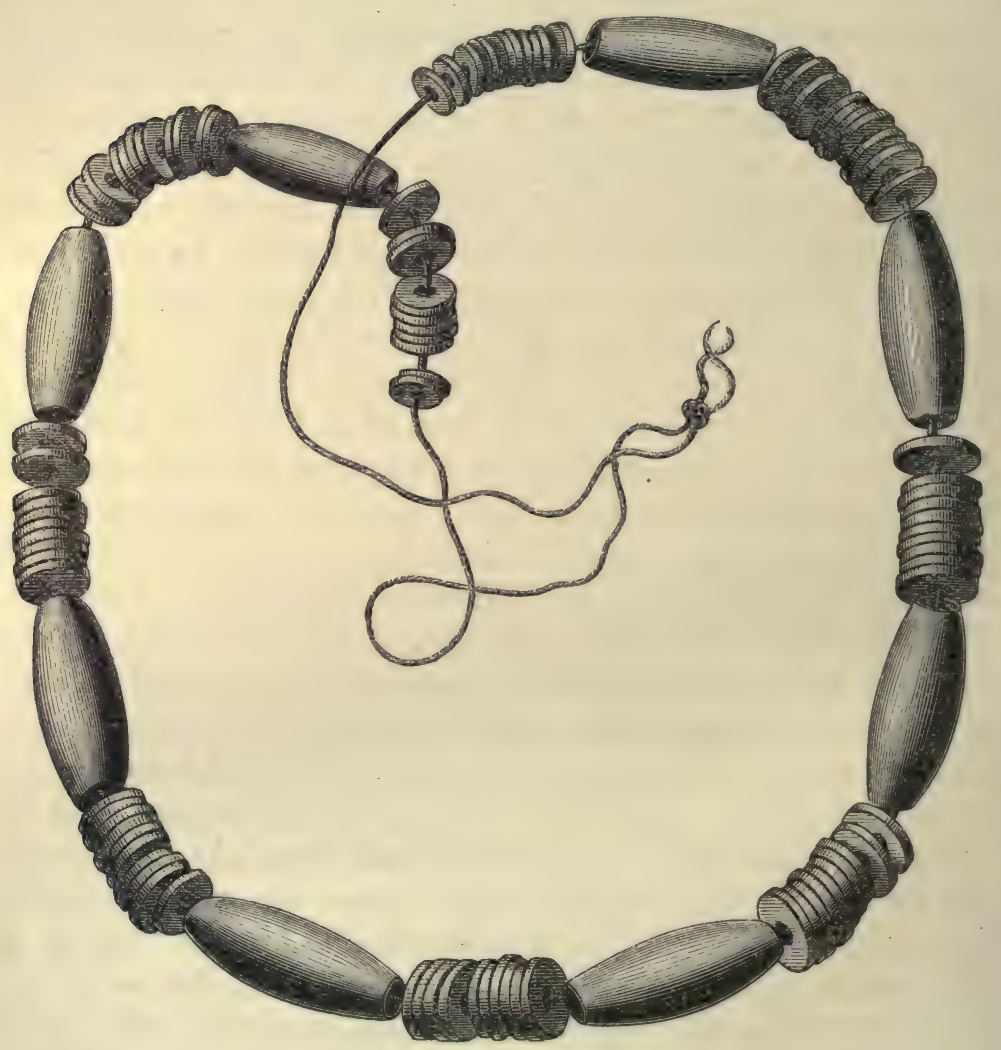

Fig. 159. $\frac{1}{2}$.

much larger size placed amongst them, these latter being generally found to contain cists. They are clearly artificial, and are sometimes very carefully constructed, with stones overlapping one another in a regular series commencing from the centre. It is my belief that they have originally covered unburnt bodies, which had been placed on the surface of the ground without being enclosed in a cist or having any similar protection, and without (as the rule) having either vase or implement buried with them; and to the circum- 
stance that the bodies had been interred under conditions facilitating almost unimpeded admission of air and moisture $I$ attribute the entire absence of any remains of the bones. It is not unreasonable perhaps to regard grave-mounds of this description as the burial-places of the humbler classes; the accompanying larger cairns or barrows with cists, when such exist, being those which most probably contained the bodies of chiefs or other persons of importance in the community ${ }^{1}$.

CCI. Not very far to the south of the camp at Old Bewick, on the north-east side of Harehope Hill, are the remains of a cairn, the greater portion of which has been removed for the purpose of building stone walls. It is $20 \mathrm{ft}$. in diameter, and has a circle of stones round the base. A large cist was found within it at the centre, the cover-stone of which was on the level of the natural surface. The eist lay north-east and south-west, and was $4 \frac{1}{2} \mathrm{ft}$. long, $2 \frac{3}{4} \mathrm{ft}$. wide, and as much in depth. A hollow had been excavated beneath the surface and then lined with four flags of sandstone, the bottom being covered with another. At the northeast end was a flint knife, chipped along both edges and at one end, which is rounded; it is of an oblong form, the corners having been removed, and is $2 \frac{3}{4} \mathrm{in}$. long and $1 \frac{3}{8} \mathrm{in}$. wide. No trace of the body was discovered, and nothing was seen in the cist besides the knife, except a little charcoal and a single small

1 Similar groups occur in other parts of England and in Scotland, all of which have proved equally barren as to contained remains. I have myself examined many in Northumberland, Westmoreland, and Yorkshire. In a letter from the Rev. J. M. Joass, of Golspie, he says, 'I know a great many groups of tumuli, in the counties of Inverness, Ross, and Sutherland, almost always associated with hut-circles. The majority are about $2 \mathrm{ft}$. or $3 \mathrm{ft}$. in height, and $6 \mathrm{ft}$. or $8 \mathrm{ft}$. in diameter, containing a good deal of earth in their structure, and generally thinly covered with turf. As a rule I have found nothing in them. Near, or within, these groups I have seen large cairns, chiefly made of stones, and seldom turf-covered. These often contain cists, sometimes double. They are called "Kings' Cairns," and have in most cases been disturbed by treasure-seekers, rabbit-hunters, or those who wanted, for drain-covers or other purposes, the flags they expected to find there.' Mr. Joass further accounts for the absence of bones in these small tumuli on the same principle as I do. See also Proceedings of Soc. of Antiquaries of Scotland, vol. vi. p. 387. On different parts of Danby South Moors (North Riding) these small houes occur in large numbers. Not a few have been opened by the Rev. J. C. Atkinson of Danby, and in no case has anything been found, except small scattered pieces of charcoal, and in one solitary instance a flint scraper. Nearly, or quite, thirty were removed about fifty years since on the moor just south of Danby Castle, for the sake of the stones mainly composing them. These were all of the same barren character, as also many more, removed for like purposes, within the last twenty-five years in the same locality. Still fully a hundred are believed to remain. 
fragment of pottery. Here again the free admission of air and moisture would account for the entire disappearance of the bones ${ }^{1}$.

\section{Parish of Alwinton. Ord. Map. criti. s.e.}

The valley of the Coquet is another district affording abundant evidences of having been largely settled at an early period. On both sides of the valley, at and above Rothbury, fortified places are numerous, while the ridges of the enclosing hills show upon the horizon-line the cairns which cover the burial-places of the ancient occupants. Implements of both stone and bronze have been met with frequently, and cists and urns have revealed themselves to the eye of the ploughman or the stone-quarrier, who satisfied himself with telling his neighbours of some imaginary battle, and that he had seen with his own eyes the bones of the slain; and thus in many instances a tradition of a fight has been created from the simple fact of the finding of a few human bones thus casually disinterred. Rock-markings, both of the pit and the circle description, are to be seen in at least three localities; and what is called 'The Five Kings' has probably formed part of what once constituted a megalithic circle.

CCII. The accidental discovery of a cist in ploughing at Harbottle Peels led me to examine the site, and I found that upon the spot had once been placed a cairn which, within man's recollection, had been removed to furnish the materials of a neighbouring wall. The place indeed proved to be prolific of interments, though not productive of anything in the shape of weapon or implement. In consequence of the entire removal of the cairn, it was impossible to make out where the centre had been or what the limits of its circumference. The measurements given are therefore made without reference to any centre, assumed or real, and only with regard to the position of one of the burials relatively to another. The bodies had been principally interred in cists; the first of which was placed north-east and south-west, and was $2 \frac{3}{4} \mathrm{ft}$. long, $2 \frac{1}{4} \mathrm{ft}$. wide, and $11 \mathrm{in}$. deep. It was made of four stones set on edge, with one at the bottom and another as a cover. Like all the others, it was sunk to its full depth below the surface. At the west corner was found a 'food vessel;' but no remains

\footnotetext{
${ }^{1}$ For an account of this barrow, with a figure of the knife, see Proc. of Berwickshire Nat. Club, vol. v. p. 201.
} 
of the body were discovered in this or in any other part of the site of the barrow which was explored. The cists were too near the surface and too much exposed to the admission of air and moisture to have allowed any unburnt bones to have remained undecomposed. The vase is somewhat in shape like fig. $69,6 \mathrm{in}$. high, $6 \frac{1}{2}$ in. wide at the mouth, and $3 \frac{1}{4} \mathrm{in}$. at the bottom; it is covered over the entire surface with encircling lines of oval impressions. At a distance of $4 \frac{1}{2} \mathrm{ft}$. north of the last (the measurements being from centre to centre) was a second cist, quite like it in structure, lying north and south; it was $3 \frac{1}{2} \mathrm{ft}$. long, $2 \frac{1}{4} \mathrm{ft}$. wide, and $1 \mathrm{ft}$. $7 \mathrm{in}$. in depth. In the south-west corner was a 'food vessel,' in shape like fig. 71,5 in. high, $6 \frac{1}{2}$ in. wide at the mouth, and $2 \frac{3}{4}$ in. at the bottom. It has four thick and unpierced ears at the shoulder, and is covered for a space of $3 \frac{1}{2}$ in. below the rim (the pattern being carried over the lip of the rim and the ears) with encircling bands of lines, made by a sharp-pointed instrument, arranged herring-bone fashion. On the inside of the sandstone slab forming the south side of the cist was a very peculiar figure cut in outline with some fine-pointed tool, the marks left by which are as sharp as if made only yesterday. It is reniform, or perhaps more like the shape of a human foot, $5 \frac{3}{4}$ in. long, and 3 in. wide at the broadest part. It is possibly an abnormal form of the sculptured pits and circles so often referred to, which, though they have usually their place on rocks and earth-fast stones or 'standing stones,' have on several occasions been found in association with burials, and often engraved on the underside of a stone placed as a cover for a cinerary urn or a deposit of burnt bones. I have not hitherto known them to have been found in connection with an unburnt body; but allowing for this, and for the variation in form of the marking, I should still be inclined to refer the one in question to the same class of symbolic figures, assuming them to be such. Immediately north of the cist just noticed was a cinerary urn reversed, and full of the burnt bones of an adult; it was so far sunk into the ground that its rim was $1 \frac{1}{2} \mathrm{ft}$. below the natural surface. Though very much decayed, sufficient was left of it when discovered to show that it had been $1 \mathrm{ft} .4 \mathrm{in}$. high, and ornamented on the overhanging rim with lines of twisted-thong impressions arranged in a pattern of chevrons set on edge. Three feet south-east of the cist was a deposit of burnt bones, the remains of a child, laid upon the natural surface in a round heap $8 \mathrm{in}$. wide. Six feet and a-half north-west of the same cist (the second) was a 'food vessel' [fig. 71], placed on the surface 
of the ground, with no visible remains of the body which it had no doubt once accompanied. It has four unpierced ears at the shoulder, and is $4 \frac{7}{8}$ in. high, $5 \frac{5}{8}$ in. wide at the mouth, and $2 \frac{1}{4}$ in. at the bottom. It is, with one exception, the most beautiful specimen of its class, both in fabric and ornamentation, I have ever met with. The style of decoration will be best understood by a reference to the figure; the markings appear to be due to different applications of the same pointed instrument, which has sometimes been drawn over the moist clay, at other times inserted directly into it, by which means both lines and dots have been produced. It possesses the unusual feature of being ornamented on the bottom, where is a cross, formed by two transverse lines, with a series of dots along each side of the limbs ${ }^{1}$. This rarely occurs on vessels of any kind; the class to which the name of 'incense cup' has been given being that where such ornamentation is most commonly applied; a few 'drinking cups' also possess this feature, as also do some cinerary urns and 'food vessels.' Ten feet north-north-east of the second cist was a third, constructed in the same way, lying west-northwest and east-south-east, being $3 \mathrm{ft}$. $2 \mathrm{in}$. long, $1 \frac{1}{4} \mathrm{ft}$. wide, and the same in depth. The cover-stone had been displaced by the plough at some former time. At the north corner was a 'food vessel,' a rude representation in its form of fig. 71 ; it is 5 in. high, nearly the same in width at the mouth, and $2 \frac{1}{4}$ in. at the bottom, and has four unpierced ears at the shoulder. It is ornamented over the whole surface (including the inside of the lip) with a rather carelessly-drawn herring-bone pattern composed of lines made by a sharp-pointed tool. Eighteen feet north of the last was a fourth cist, lying north and south, $3 \mathrm{ft}$. in length, $2 \mathrm{ft}$. wide, and $2 \frac{1}{4} \mathrm{ft}$. deep, the cover-stone of which had also been removed. There was nothing found in it. At a distance of $6 \frac{1}{2} \mathrm{ft}$. north-west from the cist first named, and placed on the natural surface, was a 'food vessel,' somewhat like fig. 71, but having no ears; it is $6 \frac{1}{4}$ in. high, the same in width at the mouth, and $2 \frac{2}{3}$ in. at the

${ }^{1}$ I possess a very small 'food vessel' with four perforated ears, being only $1 \frac{3}{4} \mathrm{in}$. high, $2 \frac{1}{2}$ in. wide at the mouth, and $1 \frac{5}{8} \mathrm{in}$. at the bottom, on which is a cross of twisted-thong impressions [fig. 79]. It was found near Hepple, in the valley of the Coquet. Mr. Bateman records the finding of a similar vase at Newton-uponRaweliffe, in the North Riding, with an unburnt body; it is, he says, 'decorated at the bottom in a very singular manner, by the intersection of two bands, each composed of three rows of punctures at right angles, so as to form a cross - a design I have never seen on any other specimen of primæval fictile art.' Ten Years' Diggings, p. 212. Other instances will be found noticed in the Introduction. 
bottom. The upper part, for a depth of $2 \frac{1}{4}$ in., is ornamented with a herring-bone pattern of finely-drawn lines made by a sharppointed instrument, the rest of the vase being plain. Nine feet north-west-by-west from this vase was a deposit of burnt bones, those of an adult, probably a man, laid upon the natural surface.

Thus it appears that the cairn had covered nine interments, six of unburnt and three of burnt bodies; and it is not a little singular that no weapon, implement, or ornament was met with in association with any of the burials. This fact (and there are many others like it) is certainly a difficult one to explain when the question with regard to the purpose of placing various articles with the dead is considered, and the view is held that they were meant to be of service in another scene or stage of existence. For here we have a number of burials taking place under circumstances implying much pains and labour in the disposition of the several interments, and yet we find that nothing which might be supposed to be needed for a future use had been deposited with the dead. On the whole, fully admitting all the difficulties in the way, and not being at all able to explain them even to myself, I incline to the belief that, where weapons, implements, and ornaments are found accompanying an interment, they were placed there under the impression that in an after-life they would, in one way or another, be useful to the person with whose body they were associated. The subject however will be found more fully discussed in the Introduction.

In the mound, or rather in what was left of it, were found two chippings of flint (one of them showing on its edge signs of use), and a thin disk of fine-grained sandstone, $2 \frac{1}{2}$ in. in diameter and $\frac{1}{2}$ in. in thickness, with a shallow depression at the centre on each side. It is worn quite smooth (apparently by rubbing) the whole way round, on the edge as well as on the surface of both faces; it can scarcely have been a 'tool-stone,' like the circular and oval implements of somewhat similar appearance so frequently found in Ireland and Denmark, for there are no signs upon it of its having been used for hammering.

CCIII. On the side of the river Coquet, opposite to that on which the last-described cairn was situated, and to the west of the village of Harbottle, upon a spur of the higher ridge which bounds the valley, were placed two cairns. One had been completely rifled long ago; the other I examined. It was $32 \mathrm{ft}$. in diameter, and still $2 \frac{1}{2} \mathrm{ft}$. high, though some of the stones had been removed from 
off the top. There was a circle of stones round the base. At a spot $7 \frac{1}{2} \mathrm{ft}$. east of the centre, and on the natural surface, was a deposit of the burnt bones of an adult laid in a round heap $1 \mathrm{ft}$. in diameter. Three feet south-east-by-south of the centre, and 9 in. above the surface-level, was a second deposit of burnt bones, those of an adult, laid like the first in a round heap and also $1 \mathrm{ft}$. in diameter. On the natural surface, and immediately beneath this deposit, were a few burnt bones, apparently belonging to a burial distinct from that found above them. Three feet north-west of the centre was a large earth-fast stone, having a flat stone laid alongside of it to the north-east. From this point the cairn had been commenced by regular courses of stones set on edge and inclining inwards. There was no appearance of there ever having been an interment at the centre. The second deposit of burnt bones was however placed just beyond the edge of the flat stone above-mentioned, and it was probably the primary interment.

Lower down the valley of the Coquet, upon the same side of the river as the last-described cairn, and still in the parish of Alwinton, is Holystone Common, lying to the west of the village and of the well where Paulinus is said to have baptized large numbers of the neighbouring people. There are several cairns upon the common, many of which have been opened with I know not what results. There were still about four or five which did not appear to have been materially interfered with, and of these I examined two.

CCIV. The first was $24 \mathrm{ft}$. in diameter, $3 \frac{3}{4} \mathrm{ft}$. high, and formed of stones with a slight admixture of earth. At a distance of $5 \frac{1}{2} \mathrm{ft}$. south-south-east from the centre was found a hollow made beneath the natural surface of the ground, $14 \mathrm{in}$. in diameter and $12 \mathrm{in.} \mathrm{deep,}$ containing the burnt bones of an adult, the body belonging to which had been burnt on the spot and over the already existing hole. Close to this, being $4 \mathrm{ft}$. south-south-east of the centre, was a second burnt body, also that of an adult, laid in a circular heap $10 \mathrm{in}$. in diameter, and at a height of $8 \mathrm{in}$. above the natural surface. At the centre of the barrow, and within a hollow, excavated for that purpose to a depth of $1 \frac{1}{2} \mathrm{ft}$., was a cist, having the coverstone level with the surface of the ground. It was placed north-west and south-east, $2 \mathrm{ft}$. long and $14 \mathrm{in}$. wide, and was made of four side-stones and a cover. It was filled with fine sand, amongst which were scattered here and there some pieces of 
clay and of charcoal. At the east corner was placed a ' food vessel,' laid on its side, with the mouth to the south. At the south corner was a round hollow space, as if the head (supposing an unburnt body to have ever occupied the cist) might once have been deposited at the spot; there was however no trace of unburnt bone anywhere in the cist, but at the south-east end a few burnt bones were found: The vase is in shape like fig. 71 , and has four unpierced ears at the shoulder; it is 4 in. high, $4 \frac{3}{4}$ in. wide at the mouth, and $2 \frac{1}{2}$ in. at the bottom. The upper part, for a space of 1 in. extending as far as the shoulder, and the inside of the lip, are both ornamented with encircling bands of lines arranged herring-bone fashion. At the shoulder, and passing over the ears, are three encircling rows of dotted impressions. The lower part has a pattern which consists of vertical lines, each of them having short lines sloping from it on either side, the effect being to give a kind of feather-like appearance to the ornamentation. All the lines have been made with a sharppointed instrument.

CCV. The second cairn was $24 \mathrm{ft}$. in diameter, and only $1 \frac{1}{2} \mathrm{ft}$. high, having lost somewhat of its original height through the removal of the stones of which it was principally constituted. Eight feet south-east of the centre, in a hole 14in. in diameter and sunk to a depth of $2 \mathrm{ft}$. below the natural surface, was a deposit of burnt bones, amongst which were four pieces of flint, also calcined, probably the remains of an implement, and a perforated piece of burnt bone, apparently part of a pin, and made from a metatarsal of a red-deer. The bones are those of two adults of small size, probably women, and of a child; some bones, also calcined, of a young goat or sheep were amongst the human bones. They consisted of a tibia, astragalus, os calcis and metatarsal, all belonging to the same leg, and the presumption is that part of an animal, in the shape of food, had been placed with the human bodies on the funeral pile. A similar occurrence, but there in connection with unburnt bones, will be found noted in the account of two barrows on Flixton Wold [Nos. lxx, lxxi]. The hole in which these bodies were contained was lined with thin and small pieces of stone, and had two slabs laid on the bottom, and two small covers placed beneath a larger one on the top. Eight feet south-south-east of the centre was another deposit of burnt bones, laid on the natural surface in a round heap $12 \mathrm{in}$. in diameter. Amongst the bones, which were those of certainly two, and perhaps of three, adult bodies, were three 
pieces of calcined flint, which had been parts of one or more implements. Five feet east-by-south of the centre was a small vessel of pottery, placed upright on the natural surface, having a considerable quantity of charcoal about it and a few pieces within it. Between this vessel and the hole above described many evidences of burning were seen upon the earth and stones. Four feet south of the centre were the burnt bones of a young person, laid upon the natural surface in a round heap $11 \mathrm{in}$. in diameter. Amongst the bones were two pieces of calcined flint and a portion of a bone pin, also burnt. On the south-east side of this deposit, but placed a little above the bones, was a vessel of pottery which had within it, besides some charcoal, a smaller vessel, laid on its side. The smaller vessel is in shape a miniature cinerary urn, being $3 \frac{3}{8}$ in. high, $2 \frac{3}{4}$ in. wide at the mouth, and 2 in. at the bottom. The overhanging rim, which is $1 \mathrm{in}$. deep, and the body of the urn for a space of $\frac{1}{2}$ in. below the rim, are both ornamented with vertical lines of twisted-thong impressions, the lower series being edged at the bottom with an encircling line of the same impression. The larger urn, which is $6 \frac{1}{4}$ in. high, $4 \frac{1}{2}$ in. wide at the mouth, and 3 in. at the bottom, has an overhanging rim $1 \frac{1}{8} \mathrm{in}$. deep, ornamented at the top and bottom with a double encircling line, the space between being filled in with a band of lines sloping to the left; below the rim is another double line, and $1 \frac{5}{8}$ in. lower a similar one, the intervening space being occupied by a reticulated pattern; all the impressions are of twisted-thong. Though the urn is somewhat rudely made and of badly-tempered clay, the ornamentation is skilfully applied and very effective. At the centre, upon the natural surface, was a fourth deposit of burnt bones, those of an adult, and placed upon the bones was a vessel of pottery. It is quite plain, with a very slight indication of a rim made by the contracting of the urn at the place where the bottom of a rim would ordinarily have been; it is $4 \frac{1}{8}$ in. high, $4 \frac{1}{4}$ in. wide at the mouth, and $2 \frac{3}{4}$ in. at the bottom. All these vessels were much decayed, and one of them so crushed and broken that nothing could be made out concerning it except that it was of small size, of the ordinary fabric and material, and ornamented after the usual fashion with thong-impressions.

\section{Parish of Rothbery. Ord. Map. cix. s.w.}

Lower down the valley, and in the angle formed by the confluence of the river Coquet and Thropton Burn, is Cartington Fell, 
on which are the remains of several cairns and barrows, together with a rock showing circular markings now nearly effaced. I opened two grave-hills out of a group of three, placed nearly together in rather an unusual position, in a hollow between the hills.

CCVI. The first was $34 \mathrm{ft}$. in diameter, $3 \mathrm{ft}$. high, and was constructed entirely of stones. At the centre was a cist, the cover of which was placed $10 \mathrm{in}$. below the level of the ground. It lay north and south, and was $3 \mathrm{ft} .2 \mathrm{in}$. long, $2 \mathrm{ft}$. 2 in. wide, and $2 \mathrm{ft}$. deep. The cist had but three side-stones, the north end of it having been formed simply by the side of the cutting made into the earth. The body (that of a full-grown person) which had once occupied it had gone almost entirely to decay, nothing being left beyond the middle portion of the right femur. Within the cist were some pieces of charcoal and of burnt stone, and both above and around it was a considerable quantity of charcoal with a few burnt stones. One foot and a-half south of the edge of the coverstone of the cist were the remains of the burnt body of an adult of uncertain sex, laid on the level of the natural surface, but having below them a hollow 13 in. in diameter and $14 \mathrm{in}$. deep, which was filled in with burnt earth. The body had been burnt on the spot, and charcoal in large quantities was found above the bones, with a flat stone over all.

CCVII. The second cairn had a circle of eight stones (the inner diameter of which was $14 \frac{1}{2} \mathrm{ft}$.) round the base. The greater part of the mound of stones, if such a structure had originally filled the space within the circle, had been removed many years ago, but without disturbance of the place of interment. This was found at the centre where, in a hollow, $1 \frac{1}{2} \mathrm{ft}$. in diameter and $1 \frac{3}{4} \mathrm{ft}$. deep, was a deposit of burnt bones, those of a person in middle life, with some pieces of charcoal amongst them. It is open to doubt if the space within the circle had ever been more completely filled up with stones than was found to be the case at the time of the opening; and it is certainly possible that no cairn had ever existed, and that the sepulchral place had been marked by merely a circle of large stones, with a few smaller ones laid on the surface. It is difficult to account for the destruction of the cairn, if one had ever been erected, for there was near the spot (not a very accessible one) no wall in the building of which the stones composing it could 
have been used, and it might have been expected that any one taking away the stones of the cairn would also have removed the stones of the circle. Burials have certainly been found placed within circles, of one kind or another, where no mound had, apparently, ever been raised over them.

On the south side of the Coquet, almost opposite to the village of Rothbury, and occupying the top of a hill which forms an outlying member of Simonside, is the camp of Lordenshaws, an early entrenched place of an irregular oval form, with mounds and ditches surrounding it, and having within it the remains of hut circles, the foundations of the dwelling-places of the old occupiers of the camp. In close proximity, and apparently connected with the camp, are some curious walls and mounds, of a character not easy to determine. Three lines of stones, placed apart, are still to be seen, which (although the stones composing them are but of small size) appear to be representatives of the megalithic linear structures found elsewhere, and of which the lines of Carnac are the grandest and best known examples. Several rocks marked with pits and circles, connected in many instances by grooves, are in the immediate vicinity of the camp; and below, on the sloping hillside, at a place called Burgh Hill, are some cairns, two of which, being still undisturbed, were examined.

CCVIII. The first was $32 \mathrm{ft}$. in diameter and $5 \mathrm{ft}$. high. At the centre a cist was met with, lying almost due east and west, the slight variation from that direction being to north and south. It was $3 \mathrm{ft} .8 \mathrm{in}$. long, $1 \mathrm{ft} .10 \mathrm{in}$. wide, and $2 \mathrm{ft} .3 \mathrm{in}$. deep, formed of four side-stones and a large cover, the original surface of the ground constituting the bottom. It contained nothing whatever, the body once deposited therein having gone entirely to decay.

CCIX. The second, which was within 20 yds. of the former one, was $26 \mathrm{ft}$. in diameter and $4 \mathrm{ft}$. high. At the centre was a cist, which lay east-north-east by west-south-west, and was $2 \mathrm{ft} .8 \mathrm{in}$. long, $1 \mathrm{ft} .8 \mathrm{in}$. wide, and $1 \frac{1}{2} \mathrm{ft}$. deep, the bottom, as in the former case, being formed by the natural surface of the ground. It was made with four side-stones and a cover ( $3 \mathrm{ft}$. long by $2 \frac{1}{4} \mathrm{ft}$. wide), upon which was laid a smaller flagstone. The cist was completely filled in with fine sand. No trace of bone was discovered, the body having totally gone to decay; but amongst the sand was a little eharcoal together with two small pieces of pottery. 
Like the cairns at Harbottle and those on Holystone Common; these four on Cartington Fell and at Burgh Hill were quite barren of implements, weapons, or ornaments ; but these last, unlike the former, had no vessels of pottery associated with the interments. I should not however, from this circumstance, be inclined either to attribute them to an earlier period than other mounds which have proved more prolific in articles usually found accompanying burials, or to suppose that they were the sepulchral places of poorer persons. It is so common to find even in the same barrow, as well as in the same group of barrows, one body with which articles of use or ornament have been associated, whilst the rest have had nothing at all buried with them-the other features of the several interments being entirely identical-that I cannot attempt to explain the circumstance by a difference alone of time or of social condition.
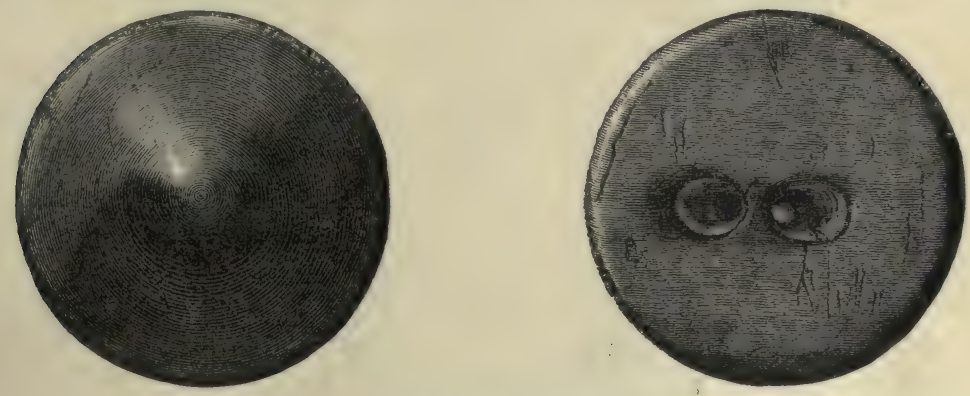

Fig. 160. $\frac{1}{1}$.

It may be mentioned that burials have been met with in the locality where the last-described barrows are situated in which various objects were found accompanying the interments. Thus, at Great Tosson, which is about two miles from Lordenshaws, four cists were discovered excavated in the limestone rock, there being no present appearance of any mound having covered the cists ${ }^{x}$. In one of them was the body of probably a woman, the cist containing in addition a jet button [fig. 160] and a 'food vessel' [fig. 161]. Another held a body, with a jet button similar to, though rather smaller than, the last-mentioned one. There was also in this cist a 'food vessel,' in shape like fig. $68 ; 8 \frac{3}{8}$ in. high, $7 \frac{3}{4}$ in. wide at the mouth, and $3 \frac{1}{2}$ in. at the bottom; it is ornamented on the inside of

1 The skull from the first of these cists at Great Tosson and several of the associated artieles are engraved in Crania Britannica, pl. 54, where is also a full account of the whole discovery. 
the lip with four encircling lines of twisted-thong impressions, and on the upper three inches of the vessel with bands of lines arranged herring-bone fashion, and made by the application of very thick and loosely-twisted thong. In the same cist was an instrument precisely like that found in a grave at Rudstone [fig. 34], and made from the antler of a very large red-deer. The other two cists contained each the remains of an unburnt body, but with no associated article in either case. An iron javelin or spear-head and a small bronze buckle are said to have been found in one of the

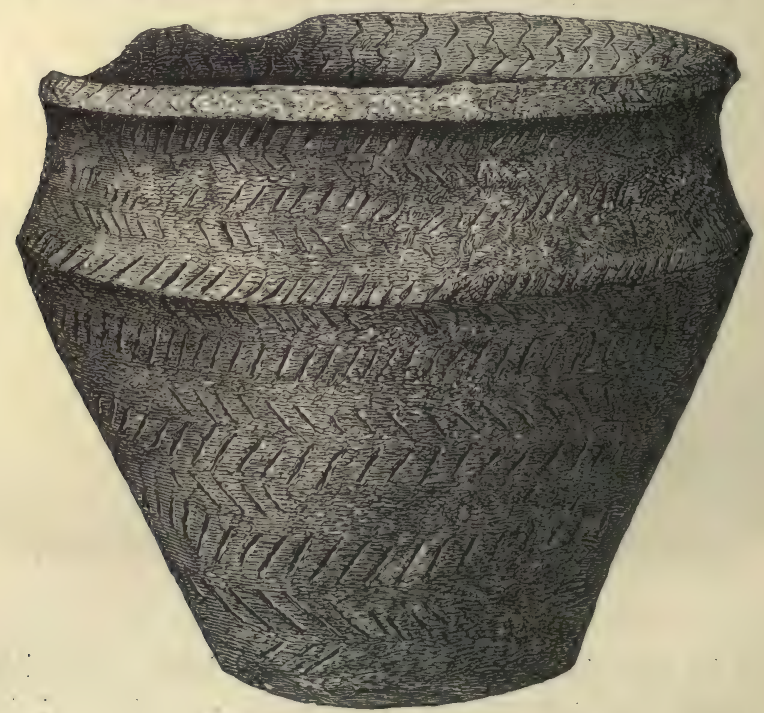

Fig. 161. $\frac{1}{2}$.

cists, but both the objects named seem to be so evidently of later date as to make it probable that they belonged to some post-Roman interments which had taken place at the spot many centuries later than the era which saw the construction of the cists in which the vases and buttons were found. It is a fact that some bodies interred at full length and with the heads to the west were discovered at the same place, and it is more than likely that with one of them the iron spear-head had been associated. The cists were brought to light by workmen quarrying limestone, and the account given to me was by no means a clear one as regarded the spear-head and buckle. In a quarry near Hepple, not four miles distant, several undoubted Anglian burials have been met with. 
Very near to Tosson, and placed between two rocks, two bronze leaf-shaped swords were found, together with three rings of the same metal (probably used in fastening the sword to a belt), and two pommels of sword-handles made of lead. On the opposite side of the Coquet, but rather lower down the valley, another bronze sword and two bronze rings were discovered in some works undertaken by Sir W. G. Armstrong, F.R.S., at Cragside. I possess a 'drinking cup' found in a cist at Old Rothbury; and I have heard of other sepulchral vessels and some stone implements having been met with in the neighbourhood.

\section{Parish of Kirk Whelpington. Ord. Map. cv. n.w.}

CCX. I opened a barrow at a place called 'The Fawns' in this parish. It was $39 \mathrm{ft}$. in diameter, $3 \mathrm{ft}$. high, and was made of stones and earth. Ten feet south-south-west of the centre was a hollow, 14 in. in diameter and sunk $18 \mathrm{in}$. below the natural surface, which contained the remains of the burnt body of an adult, the cremation of which had taken place on the spot; amongst the bones was a piece of calcined flint. One foot and a-half west of this was an urn inverted over a flat stone placed on the natural surface, and containing the burnt bones of a very young child. The urn did not seem to have been entire when it was placed in the mound, the whole rim having been broken off. Upon the under side of the flat stone on which the urn rested a pit-marking is engraved, the tool-marks being as fresh as if made only yesterday. It is one of those figures which have already been frequently referred to, and this is another instance where they have been found in connection with burials after cremation. The centre of the barrow had been disturbed, though not as far down as the natural surface, by the insertion of a rubbing-post for cattle on the top of it, and to this is probably due the destruction of a cinerary urn, which had once contained a burnt body; portions of the rim of the urn and some burnt bones having been found at that place. There was however no other burial at the centre, either on the natural surface or sunk below it.

CCXI. At Catcherside, in the same parish, I examined a small cairn, which was $29 \mathrm{ft}$. in diameter, and only $1 \frac{1}{2} \mathrm{ft}$. high, many of the stones composing it having been removed to build a neighbouring wall. It had a certain amount of earth in its 
composition, and originally there had been a circle of stones surrounding it at the base; three of which are still left standing, whilst the holes from whence other three have been removed are still distinguishable. At a point $9 \mathrm{ft}$. east of the centre, in a hollow sunk 14 in. below the surface and covered by a flat stone, was a einerary urn reversed. It contained a deposit of burnt bones. The urn is in shape like fig. $59,14 \frac{3}{8}$ in. high, $12 \frac{3}{4}$ in. wide at the mouth, and $3 \frac{1}{2}$ in. at the bottom. The inside of the lip of the rim ( $1 \frac{1}{2}$ in. deep) has two encircling lines of twisted-thong impressions upon it, and a similar line is on the edge of the lip. The upper part of the urn, for a space of five inches, is ornamented with four encompassing rows of round dotted impressions. Five feet north-east of the centre was a second deposit of burnt bones, laid on a flat stone which rested on the natural surface, and having a cinerary urn reversed over them. Three flat stones were placed as a protection round the urn, but notwithstanding this it was so much disintegrated that nothing more could be made out with respect to it than that the rim, which has been at least $2 \frac{1}{2}$ in. deep, is ornamented with an irregular pattern of dots made by the application of an oval-ended instrument. The bones in both cases were reduced to a very small quantity, having been subjected to a severe and long-continued action of fire.

\section{Parish of Hartburn. Ord. Map. cix. s.w.}

CCXII. A small barrow near Green Leighton proved on examination to have been partially rifled; it was $20 \mathrm{ft}$. in diameter, $2 \mathrm{ft}$. high, and was made of limestone, sandstone and earth. At a point $9 \frac{1}{2} \mathrm{ft}$. east-by-south from the centre, and laid on the top of the limestone rock, was a vessel of pottery, having no remains of bones associated with it. In shape it is like fig. 57, but is rudely made, with very thick walls, $10 \mathrm{in}$. high, $8 \frac{8}{4}$ in. wide at the mouth and $3 \frac{1}{4}$ in. at the bottom. On the inside of the lip are two encircling lines of impressions made apparently by the end of a piece of wood roughly cut. The outside of the vase is decorated to a depth of $4 \frac{1}{2}$ in. with three encircling lines of the same impressions, and below them with four lines of markings made probably by the same instrument, first pressed into the clay and then drawn down towards the workman. At the centre there was an irregularlyshaped hollow made in the rock, $8 \mathrm{in}$. deep, and averaging $3 \mathrm{ft}$. in length by $2 \mathrm{ft}$. in width. Nothing was within it except the 
material of the mound, but it had evidently been previously opened. It had probably contained an unburnt body; for had the bones been burnt, some of them would almost certainly have been left. Several pieces of burnt stone were found in the barrow.

About a quarter of a mile from the barrow just described, and higher up the slope of the hill, was a very peculiar structure, which proved to be sepulchral, though probably belonging to a time later than that when the barrow had been constructed. Upon the surface of the ground was an oblong space surrounded on all sides but the west by stones, ten in number, set nearly close together; the direction being east-by-south and west-by-north, with a length of $5 \mathrm{ft} .8 \mathrm{in}$. and a width of $2 \frac{1}{2} \mathrm{ft}$; and having a few stones laid on the surface within the enclosure. The surrounding stones were absent at the west end, and no other stones occurred until, at a distance of $5 \mathrm{ft}$. from that point, two other stones, together $4 \frac{1}{2} \mathrm{ft}$. long, were placed in a line north and south. Within the enclosure first described the subsoil was excavated to a depth of $1 \frac{3}{4} \mathrm{ft}$. at the east end, and sloping upwards to a depth of only $8 \mathrm{in}$. at the west end. In this grave an unburnt adult body had been placed, apparently laid at full length, with the head to W., but so much decayed that nothing more regarding it could be determined. To the west of the body the ground was undisturbed for a space of $2 \frac{1}{2} \mathrm{ft}$., and then occurred an oval hollow, $4 \mathrm{ft}$. $3 \mathrm{in}$. long and $2 \mathrm{ft}$. $4 \mathrm{in}$. wide, the long diameter being almost due north and south, the west side coming nearly up to the two long stones above referred to. This hollow was sunk $1 \frac{1}{2} \mathrm{ft}$., partly into the rock; and at the north end was a circular hole excavated ten inches deeper than the rest of the hollow. There was nothing in it more than earth and stones, except some fragments of charcoal scattered here and there, nor was there any appearance as though a body, either burnt or unburnt, had ever been deposited therein. I am inclined to attribute the burial to Anglian times, though, in the absence of anything in the shape of weapon, implement, or ornament, it is impossible to come to any certain eonclusion on that point.

\section{Parish of Chollerton. Ord. Map. cvi. N.E.}

The valley of the North Tyne, like many other districts in Northumberland already noticed, has been very extensively occupied in pre-historic times, as is clearly shown by the existence of F f 2 
numerous camps, hut-circles, terraces and burial-mounds. The older histories and the recollection of people still living tell of circles of stones which have now disappeared; but a very fine monolith still remains near Swinburn, in the immediate vicinity of several cairns, which have produced cists, one of them containing a jet necklace and other articles. Higher up the valley similar remains have been met with, and I possess a very fine specimen of a 'drinking cup' which was discovered at Smalesmouth in a cist with an unburnt body. At Warkshaugh, near to the village of Wark, a low and flat barrow (on its being removed by the tenant) was found to contain burials both of burnt and unburnt bodies, one of the former being deposited in a cinerary urn, whilst there was associated with one of the latter a peculiarly-marked 'food vessel "' On Chesterhope Common, the unusual occurrence of gold was met with, in the shape of a necklace of globular beads of that metal; they are of various sizes, and the perforation in them seems to show that they must have been strung upon a cord or thong of more than ordinary thickness. The discovery was made in a cairn, but it is not mentioned, in the account given, whether the body had been burnt or was an unburnt one ${ }^{2}$.

CCXIII. I have only had an opportunity of opening one barrow in this district. It was situated about a mile to the east of Chollerton, and was $36 \mathrm{ft}$. in diameter, $3 \frac{1}{2} \mathrm{ft}$. high, and constructed of stones and earth, the upper part of the mound being entirely made of stones. Twelve feet south of the centre was a deposit of the burnt bones of an adult, laid upon the natural surface and covered with a flat stone $1 \frac{1}{2} \mathrm{ft}$. long by $1 \frac{1}{4} \mathrm{ft}$. wide. Nine feet south-south-east of the centre a cinerary urn was discovered, standing upright upon the natural surface and containing the calcined remains of a young person. The urn was so much decayed that nothing more can be said of it than that it had the usual overhanging rim, which was ornamented with alternate series of horizontal and vertical lines of twisted-thong impressions like the pattern on fig. 54. At the centre was a cist, the bottom of which was formed by the surface of the ground; it lay north-west and south-east, and was $3 \mathrm{ft} .10 \mathrm{in}$. long, $2 \mathrm{ft}$. $4 \mathrm{in}$. wide at the northwest end, $2 \mathrm{ft}$. wide at the other end, and $2 \frac{1}{4} \mathrm{ft}$. deep. It was

${ }^{1}$ See a paper by the Rev. G. Rome Hall, in Archæologia Atliana, N. S., vol. vii. p. 3.

${ }^{2}$ Arch. Fll, vol. i. p. 1. 
rather irregularly shaped, and made with seven flag-stones set on edge, with two cover-stones, the one overlying the other; the upper one being $3 \mathrm{ft}$. $5 \mathrm{in}$. long and $2 \mathrm{ft}$. 2 in. wide, the under one $3 \mathrm{ft}$. $5 \mathrm{in}$. long and $2 \frac{1}{2} \mathrm{ft}$. wide. In the cist there was nothing left of the unburnt body which had originally been deposited in it, except a few pieces of the larger and more solid bones of the arms and legs of apparently a full-grown person. The head appeared to have been laid at the north-west end of the cist. In this instance, as in many others, we have the occurrence of both burnt and unburnt bodies in the same grave-mound, and probably quite contemporaneous. A flint flake showing signs of use was met with near to, but not inside, the cist.

\section{Parish of Ovingham. Ord. Map. Ct. s.w.}

CCXIV. At Broomhouses in the parish of Ovingham, and close to the grand mediæval castle of Prudhoe, the 'caput baroniæ' of the great house of Umfraville, upon a knoll which there overhangs the river Tyne, a very prolific place of sepulture was accidentally discovered. The farmer fortunately, on meeting with the first interment, stopped the operations he was proceeding with, and I was consequently enabled to make a careful examination of the place of burial. Though there was not any appearance of a barrow, I think it probable that one had formerly existed on the site, and that during a long course of cultivation the artificial part of the mound had become levelled; indeed, as I ascertained, a few stones had, until quite recently, still remained lying on the surface of the ground above the cists, showing that the grave-hill had been to some extent formed of stones.

The first interment I met with was in a cist, lying east-northeast and west-south-west, $3 \frac{1}{2} \mathrm{ft}$. long, $2 \mathrm{ft} .4 \mathrm{in}$. wide, and $1 \mathrm{ft} .9 \mathrm{in}$. deep. It was constructed of four large slabs of sandstone and two smaller ones, with three cover-stones, a larger one overlying the other two; this was $4 \mathrm{ft}$. long and $2 \mathrm{ft} .10 \mathrm{in}$. wide, the smaller ones measuring respectively $2 \mathrm{ft}$. $7 \mathrm{in}$. by $2 \mathrm{ft}$. $6 \mathrm{in}$. and $2 \mathrm{ft}$. $4 \mathrm{in}$. by $2 \mathrm{ft}$. $2 \mathrm{in}$. ; the cover-stones in this, as also in the other cists, were placed beneath the level of the natural surface. There was no trace of the body left in the cist, which contained nothing beyond some pieces of charcoal. Nine feet west of the cist (the measurements being all taken from the centre of one cist or urn to the centre of another) was a cinerary urn reversed, and filled with burnt 
bones, those of an adult; above it was placed a whinstone boulder, rounded in form and nearly $2 \mathrm{ft}$. in diameter, which was packed closely round with smaller stones. The rim of the urn was $4 \mathrm{ft}$. below the surface of the ground. Amongst the bones was an unburnt flint knife of a square form, $1 \frac{7}{8} \mathrm{in}$. long and $1 \frac{1}{2} \mathrm{in}$. wide, and finely chipped along the edge opposite to that where the bulb shows the blow had been applied to detach the flake, out of which it is made, from the core. The urn [fig. 57] is an unusually fine specimen of a cinerary vessel, and one which presents some peculiarities, the form being rather that of a tall 'food vessel' than of a cinerary urn. It is $9 \frac{1}{2} \mathrm{in}$. high, $8 \mathrm{in}$. wide at the rim, and $4 \frac{1}{4} \mathrm{in}$. at the bottom; and the whole surface is covered with ornamentation. The inside of the lip (one inch deep) has a pattern consisting of alternate series of vertical and horizontal lines, the same pattern being repeated on the outside of the rim; below this, for a space of $2 \frac{3}{4}$ in. in depth, the pattern is formed of lines arranged herring-bone fashion; and from thence to the bottom of the urn the markings are irregular, forming no very distinct figure. All the impressions have been made by the application of closely-twisted thong. Ten feet northwest of the cist was a second cinerary urn, also reversed, and, like the first, covered by a whinstone boulder 17 in. long by 16 in. wide; it was filled with the burnt bones of a full-grown person. The urn [fig. 59] is $15 \mathrm{in}$. high, $13 \mathrm{in}$. wide at the mouth, and $4 \mathrm{in}$. at the bottom, and possesses the rare feature of having raised bands upon the rim ${ }^{1}$; these have been applied when the clay had become partly dried, the union in consequence not being very complete. Fourteen feet from the cist already noted was a second, lying east-south-east and west-north-west, $3 \mathrm{ft}$. 7 in. long, $2 \mathrm{ft}$. 9 in. wide, and $1 \mathrm{ft} .4 \mathrm{in}$. deep. It was formed with six slabs of sandstone and a cover, $5 \mathrm{ft}$. by $3 \mathrm{ft} .5 \mathrm{in}$., which was placed $14 \mathrm{in}$. below the natural surface; the bottom was paved with small pebble-stones. There were no traces of bone remaining in this cist also. Six feet south-southwest of the first was a third cist, with an east and west direction, made with six stones set on edge and two cover-stones, the upper

\footnotetext{
${ }^{1}$ Cinerary urns with raised bands have occurred in the north of England and the south of Scotland, though by no means frequently. I possess one found many years ago near Ford, Northumberland. One discovered at Spottiswood, Berwickshire, is figured in the Proc. of the Society of Ant. of Scotland, vol. v. pl. ix ; and another from Belhelvie, Fifeshire, is engraved at p. 13, Cat. of Exhibition of the Edinburgh Meeting of the Archæol. Institute. One, having a raised chevron pattern, is noticed by Pennant, as having been discovered near Banff, filled with burnt bones. Tour in Scotland, p. 140. pl. xii. A very fine one, found, in enlarging the reservoir for the Sunderland Water-works, on Humbleton Hill, is noticed in the text, p. 440.
} 
one being a whinstone boulder $22 \mathrm{in}$. in diameter, the lower a sandstone flag. The bottom of the cist was $4 \mathrm{ft}$. below the surface of the ground, and the contents were a deposit of burnt bones, those of a young person of uncertain sex, placed upon a layer of fine sand 8 in. thick. Fourteen feet south-by-west from the first eist was a fourth, lying north and south, $2 \mathrm{ft} .3 \mathrm{in}$. long, $1 \mathrm{ft} .5 \mathrm{in}$. wide, and $1 \mathrm{ft} .2 \mathrm{in}$. deep. It was made with four side-stones and a cover, the latter being $2 \mathrm{ft} .10 \mathrm{in}$. long and $2 \mathrm{ft} .2 \mathrm{in}$. wide, and having two whinstone boulders laid upon it. This cist also was paved with pebble-stones, the bottom being $4 \mathrm{ft}$. below the natural surface. It contained a deposit of burnt bones, those of an adult.

In this place of burial again we note the occurrence of bodies interred some by inhumation and others after cremation : still it is desirable to offer the remark, that although it is by no means improbable that the whole of the interments met with may have taken place at the same time, it is quite as likely that the knoll may have been used on several successive occasions for burial purposes. The absence of any implement or other associated article, except in one case, may also be noted. 


\section{DURHAM.}

THe county of Durham, though it lies between districts which abound in the various remains of pre-Roman times, and though it presents natural features apparently well adapting it for early occupation, is strangely deficient as well in the weapons and implements of stone and bronze using people, as in the dwellingplaces of the living and the graves of the dead. Comparatively very few articles in stone or bronze have been found within the limits of the county, and so far as I know, not above eight places of burial have been met with during the various operations of agricultural and other work. The west of the county, consisting of a tract of high land which has never been cultivated, would in other and similarly-eircumstanced parts of England have been occupied with the cairns and barrows of the people who once lived there; but such memorials of the dead are almost entirely if not altogether wanting on the Durham moorlands. Camps or other fortified places are very uncommon, and seem, with the exception of some of doubtful date on Cockfield Fell, to be confined to the valley of the Wear. Before giving an account of the examination of the only barrow which has come under my own notice, it may be well briefly to put on record the few facts relating to ancient sepulture with which I have become acquainted.

In the year 1814 some urns, apparently, from the description given of them ${ }^{1}$, Ancient British, were discovered on Tunstall Hill, near Sunderland, accompanying burnt bodies; and in the year 1873 at Humbleton Hill, in elose proximity to Tunstall Hill, three cinerary urns, one of uncommon type, with a raised zigzag band upon the overhanging rim, were found in enlarging

1 Surtees, Hist. of Durham, vol. i. p. 249. 
the reservoir of the water-works at the place:-they are preserved in the Sunderland Museum.

About a mile from Tunstall and Humbleton Hills a small natural mound of sand and gravel, called Steeple Hill, rises abruptly from the surrounding somewhat flat land. In removing this, in February 18\%6, a cist was accidentally discovered, and the sepulchral remains it contained were carefully collected and preserved by Mr. W. J. Cordner, the contractor. Some slight addition of stones and earth had been made to the top of the mound, constituting a small barrow which covered the burial-place. The cist, which had an east and west direction, was about $4 \mathrm{ft}$. long, by $2 \frac{1}{2} \mathrm{ft}$. wide, and not quite as much in depth. It had been sunk to some extent into the natural mound, at the place consisting of gravel which formed the bottom of the cist. It was constructed of four whinstone boulders two on each side, of two end stones and a large cover, all of limestone. In it was the skeleton of a man past middle life, laid in the contracted position with the head to W. Two 'food vessels' had been deposited close to the chest of the man, and in them were found some few of the burnt bones of a child under twelve years of age. The one vase is $4 \frac{3}{4} \mathrm{in}$. high, $5 \frac{1}{4}$ in. wide at the mouth, and $2 \frac{1}{2}$ in. at the bottom. It is in shape very much like fig. 71 , and has five unpierced ears at the shoulder. The whole surface, as also the inside of the lip of the rim, is covered with ornament, consisting of a pattern of bands of lines, made by a sharp-pointed instrument, arranged herring-bone fashion. The other, which is $5 \frac{1}{4} \mathrm{in}$. high, the same in width at the mouth, and $2 \frac{5}{8}$ in. at the bottom, is not so well manufactured or so completely baked as the former. It is ornamented as far as the shoulder with eight encompassing lines of twisted-thong impressions, a similar line is placed on the edge of the lip of the rim, and three others encompass the inside of the lip. The remaining part of the vase is covered with vertical lines of the same impressions, slightly radiating from the bottom. A second skeleton, that of a woman past middle life, was discovered about three feet to the west of the cist. This body also had been laid with the head to W., but nothing more connected with the position could be ascertained. Some stones, but not arranged after the form of a cist, had been placed round the body. It is not improbable that the burials in this mound represent those of a man, his wife and their child, and perhaps the fact that two bodies had been interred in the cist may explain the occurrence of two vessels of pottery. At Hetton, 
not very far from this burial-place, a barrow was removed several years ago, when I believe some urns were met with; and three barrows in the same neighbourhood still remain unopened. This district appears to have produced more burials and burial-places of pre-Roman times than any other part of the county of Durham; and indeed if all the county had been equally prolific of such remains, the observation $I$ have made at the commencement of this account would not have been called for.

I possess a fragment of a cinerary urn from near Trimdon Grange; and I have information of the discovery of a skeleton in a cist under a large barrow at Bradley Hall in the parish of Ryton. Closely adjoining the churchyard of Ryton another large barrow still remains unopened. A short cist also was found near Sherburn.

\section{Parish of South ShieldD. Ord. Map. cv. s.e.}

CCXV. The only burial-mound I have had an opportunity of personally examining was at the Trow Rocks near Westoe, where a barrow was placed almost on the edge of the magnesian limestone cliff overhanging the sea, about a mile south of the river Tyne. It was $30 \mathrm{ft}$. in diameter, $3 \mathrm{ft}$. high, and made of earth with some stones intermixed. At the centre was a cist, consisting of six stones set on edge, two on each side and one at each end, with two cover-stones; some thin pieces of stone were set on the side stones to make the top level and to support the covers. The cist lay north-north-west and south-south-east, and was $4 \mathrm{ft}$. long, $2 \mathrm{ft}$. wide, and $1 \mathrm{ft} .10 \mathrm{in}$. deep, sunk into the clay which there overlies the limestone, the covers being on the level of the natural surface. In it was a skeleton, apparently of a man, very much decayed, laid on the right side, with the head to S.E.; in front of the face was a flint knife; there were also, as indeed is almost always found to be the case, some pieces of charcoal in the cist. The knife, which is in form much like fig. 163, has been made from an outside flake, some of the crust of the original flint nodule being still left along the middle part of the convex face; it has been carefully chipped along both edges, but not at the rounded end opposite to the bulb of percussion. It is $2 \frac{3}{8}$ in. long and $1 \frac{1}{4}$ in. wide. 


\section{GLOUCESTERSHIRE.}

THe northern part of Gloucestershire, where it borders upon Oxfordshire, Worcestershire, and Warwickshire, and which is traversed by part of the oolitic range of the Cotswold Hills, has been left almost entirely unexplored with respect to the evidence it affords of early occupation, and especially as regards places of sepulture. Numerous remains however, both of those things which have relation to the living and of the mounds which mark the sites where the dead have been deposited, still exist, though many of the barrows have disappeared, entirely or in part, through the various processes of agriculture. No signs of primitive occupation are perhaps more striking than the almost imperishable articles of flint and other stone, which in so many cases have alone been left to tell us that, in times before the record of written evidence existed, and when even the more uncertain testimony of tradition had died away, man had lived upon the earth. Such implements are found scattered widely and in abundance throughout almost every part of the district in question, and we owe it to the energy and intelligence of the Rev. David Royce, Vicar of Nether Swell, that numerous examples of them have been sought out and preserved. His collection comprises a very large and varied assortment of flint arrow-points, knives, scrapers, and other articles of uncertain use, brought together from his own and neighbouring parishes. In connection with this there is a circumstance which requires to be noticed, and which it is very difficult to account for. Axes, adzes, and others of the larger implements are almost entirely wanting. Mr. Royce has had collected for him for some years past, by the labourers engaged in agricultural operations, every article which attracted their attention as being different from 
the ordinary pieces of stone found on the surface of the ground. Thousands of arrow-points, chippings of flint, fragments of pottery, and even natural but peculiarly-shaped bits of stone have been brought to him; but amongst all this numerous assemblage, only two portions of axes have come into his possession, and not a single whole one. Where an occupation appears to have been extensive and long-continued, as may fairly be inferred to have been the case here, from the large number of certain implements which have been met with, it is remarkable that others of a different but equally important class should be so uncommon. This is the more strange when it is considered that in other localities where one kind is abundant the other is relatively and, in proportion to an assumed requirement, equally numerous. Nor is it easy to understand how a population which it might be supposed would require axes to cut down trees, adzes to work upon the wood, and hoes to break up the soil, equally with other people who appear to have lived under much the same conditions, was able to construct the essential requisites of domestic life, or to obtain some of the main products of the soil, without such tools. I do not believe it would be possible to find a parallel to this in any other part of Britain, at all events in so great a degree; nor can I discover anything in the natural features of the district which would seem to remove it out of the ordinary conditions of other parts of the country, where both larger and smaller implements of stone are equally, though relatively, abundant. The same may be said of the later implements of bronze, which appear to have been discovered very exceptionally, a fact which may be considered in connection with the almost entire absence of the larger kinds of stone implements. The very infrequent occurrence of both of these classes can scarcely have arisen from any sparseness of population, for that, judging by other and sufficient data, was certainly considerable ${ }^{1}$.

Sepulchral remains are numerous, and many barrows still remain of both kinds, long and round, the former, as is always the case, bearing a very small numerical proportion to the latter. An account of the examination of four long barrows will be found in that part of this volume which is devoted to the class in question. Some features of a remarkable and instructive nature presented themselves; and the evidence afforded by them with regard to the

${ }^{1}$ In connection with this subject it may be noticed that in Kent and Sussex, and generally in the district south of the Thames, arrow-points are of the very rarest occurrence. 
form of the skull, and the apparent unity of the people who occupied the country at the time of the erection of these long barrows, was of a very conclusive kind.

The round barrows, which as a rule occupy the prominent natural position usually characterising sepulchral structures, are pretty generally dispersed throughout all the high land of the district. In consequence of their having been made of stone, they have suffered much at the hands of those who built the walls of the fields in which they are found, as also from having had the larger stones taken out of them to remove obstructions to the plough, and thus most of the secondary interments, placed in them after the first throwing up of the mound, have disappeared. It was only in one case (which indeed was the single undisturbed barrow I saw) that the mound was intact, and in consequence a valuable discovery of two secondary burials was made.

The number of round barrows subjected to examination was only small, and therefore it would be unsafe to base any certain conclusions upon evidence so little abundant. At the same time it is probable that they form a substantially correct index of the whole number, and we may fairly infer from their contents that the prevailing practice as regards the deposition of the dead was burial after cremation, and that here, as in other places, the body so treated was sometimes placed in an urn, at other times was laid in the ground without any such protection, and that in some instances an implement was associated with the interment.

\section{Parish of Nether Swell. Ord. Map. xliv. N.e.}

In the parish of Nether Swell, on a piece of ground called the Cow Common, and which until within the last twenty years was unbroken pasture-land, nine barrows are still remaining, one of them being a long barrow; of these I opened five. They are placed close together, four of them in fact overlapping each other, so as to give the impression at first sight that the four mounds were really one and formed a long barrow. A more careful examination convinced me that they were four separate barrows, which subsequently proved to be the case. I have not before met with an instance where a series of barrows impinged in this way one upon another. They were placed in a direction north-east and south-west, and measured from end to end $152 \mathrm{ft}$., 
the mound at the south-west end being a little out of the line towards the west.

CCXVI. This last-named barrow was $44 \mathrm{ft}$. in diameter, $5 \frac{3}{4} \mathrm{ft}$. high, and had never been disturbed in any way. The outer part was entirely made of stone, the oolitic slabs being laid with much regularity, sloping towards the apex. Into the original mound two secondary interments had been inserted, the limits of the excavated hollow ( $2 \frac{1}{2} \mathrm{ft}$. wide and $2 \mathrm{ft}$. deep) being distinctly marked by the filling-in, which to a large extent consisted of earth. These two later burials were placed $5 \frac{1}{2} \mathrm{ft}$. south-by-west of the centre, and consisted of two burnt bodies, each enclosed in an urn. The upper one was inverted upon a flat stone, and the bottom of the vessel was almost exposed, not being more than $4 \mathrm{in}$. below the surface of the mound. Immediately beneath this stone was the bottom of the second urn, inverted like the first upon a flat stone, which was placed $3 \frac{1}{2} \mathrm{ft}$. above the natural level of the ground. The bones in the upper urn were those of an aged person, and there had been exostosis of the dorsal vertebræ and anchylosis of two of the cervical vertebræ. The urn is $13 \mathrm{in}$. high, $8 \frac{1}{2} \mathrm{in}$. wide at the mouth, and $5 \frac{1}{2}$ in. at the bottom. The only ornamentation upon it consists of a band of impressions made by the finger-nail or by a narrow sharp-edged instrument, which encircles the vessel 2 in. below the mouth. The body contained in the lower urn is that of an adult. Amongst the bones was a bronze knife which had been burnt with the body. It is oval in shape, $2 \frac{7}{8} \mathrm{in}$. long (including the tang for insertion into the handle, $\frac{3}{4} \mathrm{in}$. long), and $1 \frac{3}{8}$ in. wide. It is quite plain, showing no great skill in its manufacture, and is of a humbler character than similar implements which have not unfrequently been met with accompanying interments both of burnt and unburnt bodies ${ }^{1}$. The urn is $21 \mathrm{in}$. high, $14 \mathrm{in}$. wide at the mouth, and $7 \frac{1}{2}$ in. at the bottom. It is encircled by two raised ribs, one 5 in. below the mouth, the second one 6 in. below the first. The space between the mouth and the upper rib has upon it four equidistant arch-shaped projections or loops $4 \frac{3}{8}$ in. high, and is further ornamented, outside the loops, with a pattern made by impressions

\footnotetext{
1 Two knives almost identical with this were found, each in an urn with a deposit of burnt bones, near St. Andrews, Fifeshire, where a large number of interments after cremation were discovered. The knives and many of the urns there found are preserved in the Museum of the United Colleges at St. Andrews. Two knives very similar to the Gloucestershire specimen, but rather better made, have been discovered in barrows on the Yorkshire wolds.
} 
of twisted-thong, and consisting of a zigzag line, with its triangular spaces filled in with lines each parallel to those of the zigzag; within the loops is a pattern of horizontal lines of thongimpressions crossed by others placed diagonally. The space between the upper and lower rib has four similarly-shaped loops $5 \frac{3}{8}$ in. high and alternating with those above, and between two of them near the top are the remains of a short horizontal raised rib about $1 \frac{1}{2}$ in. long. It should be here observed that, when the height of the urns is taken into consideration with the depth of the hollow in which they were placed, the second interment could not have been made until, from the subsidence of the overlying material, the urn, containing the first interment, had been crushed and flattened. This fact would seem to imply that the two burials were not contemporaneous. At a depth of $2 \frac{1}{2} \mathrm{ft}$. from the surface of the barrow the material was entirely earth. This inner mound was $9 \mathrm{ft}$. in diameter, and covered another pile of stones $6 \frac{1}{4} \mathrm{ft}$. in diameter and $2 \frac{1}{2} \mathrm{ft}$. high, the stones of which were arranged sloping towards the centre. The whole barrow thus consisted of a mound of stone overlaid by a coating of earth 9 in. thick, and that again covered by stones. The innermost mound was placed over a central grave sunk into the rock to a depth of $2 \mathrm{ft}$.; it was of an oval form, widening from $3 \mathrm{ft} .2 \mathrm{in}$. by $2 \mathrm{ft}$. at the bottom, to $4 \mathrm{ft}$. by $3 \mathrm{ft}$. at the top, the direction being north-north-east and south-south-west. It was carefully lined at the sides with flagstones (eleven principal and two smaller ones), and it was also flagged at the bottom, but there were no cover-stones. On the bottom was the body of a man past middle life, laid on the left side, the head being to N.N.E. and close to that end of the grave, with the hands up to and in front of the face. The grave was filled in with earth, and many pieces of charcoal were found close to the bones. In that part of the barrow which was made of earth were discovered, a duckbill-shaped flint scraper $1 \frac{3}{4}$ in. long, very carefully made; a burnt flint, which has probably formed part of a similar implement; an oval and flat quartzite pebble $1 \frac{1}{4}$ in. long, much bruised at one end by use, probably in flaking flint; and a piece of the rim of a vessel of pottery ornamented with twistedthong impressions. Some few chippings of flint were found in other parts of the barrow.

CCXVII. The next adjoining mound to the north-east proved to be of very remarkable construction, and not easy of explanation 
as to its primary use. It was $36 \mathrm{ft}$. in diameter and about $2 \mathrm{ft}$. high, but it had lost much of its upper portion from having served as a quarry from which to build a neighbouring wall; and the same may be said of the three barrows next to be described. The mound was most carefully made with large flat stones laid in a sloping position, and inclining towards the centre up to a point $3 \frac{1}{2} \mathrm{ft}$. outside the walls of the chamber presently to be described. The stones then became much smaller, and were placed at the back of the walls of the chamber without any especial order being observed. Upon the natural surface of the ground, throughout the whole area of the mound, charcoal was found scattered in abundance. At the centre was a circular chamber, carefully constructed of thin oolitic slabs, laid without any mortar or clay between them, and forming an excellent example of dry-walling. Though the general form of the chamber was circular, it consisted of six faces of straight wall, which, with the space where the entrance occurs, made it, strictly speaking, heptagonal. The chamber was sunk $2 \mathrm{ft} .8 \mathrm{in}$. into the ground, and the height to where the roof had commenced to narrow was $3 \mathrm{ft} .10 \mathrm{in}$. The roof had been constructed by laying large flagstones gradually projecting inwards until they joined at the centre, forming what has been called a bee-hive roof. This mode of constructing a roof is by no means an uncommon one both in early habitations and burial-places, and was necessitated partly by want of sufficiently large slabs to cover over a space when they had to be laid across from side to side, and partly by the desire to obtain increased height without raising the walls. The bottom was partly flagged at the south-west side, the remaining portion being formed by the natural rock; this flagging being probably due to the irregularity of the level at that part of the bottom rather than to any intentional design. The chamber was $5 \mathrm{ft} .8 \mathrm{in}$. wide, and had a passage leading into it on the northwest side; the whole length of the passage, with the width of the chamber added to it, was $19 \mathrm{ft} .5 \mathrm{in}$. The passage was $2 \frac{3}{4} \mathrm{ft}$. wide at its entrance into the chamber, and narrowed to $2 \frac{1}{2} \mathrm{ft}$. at the opposite end. It sloped gradually, from a depth of $2 \mathrm{ft} .8 \mathrm{in}$. at its entrance into the chamber, up to the original level of the ground. On the north side the passage was walled in the same manner as the chamber, but on the south the rock into which it was cut formed the side. On the north side of the chamber the stones were reddened by the action of fire, but not to any great extent, and on that part of the floor were remains of charcoal. 
The chamber was filled with stones and earth, the roof having partly given way or having been in part removed, when the mound had been used as a quarry. On the floor were found two portions of iron shoes, the one a horse-shoe, the other that of an ox, four short iron nails, two ordinary pins, a piece of the shank of a tobacco pipe, some few sheep bones, and a single piece of coarse pottery, certainly not modern, but of what date it is difficult to speak precisely, though it is probably pre-Roman.

Two important questions present themselves for consideration in connection with this mound and its contents. Is it of ancient or of comparatively modern construction; and if ancient, was it originally intended as a place of abode for the living or to contain the bodies of the dead? I think there can be little doubt with regard to the first question, and that, notwithstanding the modern articles found in it, the chamber was built in very early times, and is probably of the same date as the barrows which abutted upon it on each side. The roof, constructed with care and after a substantial fashion, had most likely remained complete until the removal of the upper part of the mound, when from the stones being taken away to build walls it had been destroyed. If this was the case, the chamber would ordinarily be vacant, and the entrance being open it would be accessible and resorted to, for shelter or other purposes, by persons in charge of the cattle which were depastured on the common or by the children of the neighbouring cottages. In this way the appearance of fire on the side and the occurrence of such modern trifles as have been enumerated may very naturally be accounted for. As against its having been constructed in modern times, it may be urged, and very forcibly, that such a mode of erecting any place of shelter for shepherds or others has not been in use in the district; nor indeed would such a building have been suitable for any purpose of that kind, both on account of its being sunk below the level of the ground and completely covered by a large mound, and from its not having any outlook. There can I think be no doubt whatever of its antiquity, and that probably a very high one. It is not the only structure of the kind which has been met with in this locality, for in a long barrow close by (a description of which is given in the part of this work devoted to that class of mounds) what appears to have been a chamber of similar construction was discovered, but destroyed before I had an opportunity of seeing it. A drawing was taken at the time of its 
discovery, and judging by that and from what I have learned from persons who saw it, it is probable that in size, shape, and manner of construction it was almost a counterpart of the chamber now under consideration. Was it then originally intended as a dwelling-place? I think an answer in the negative must be given. The size is too small to fulfil even the humblest requirements of habitation; and though the marks of fire on the side and the charcoal on the floor might seem to favour such a view, that occurrence is probably to be explained by the fact that the persons who in modern times had access to it had lighted a fire there. The extent of discolouration on the side consequent on the action of burning was too trifling to imply more than what might have resulted from the kindling of even a single fire. The bee-hive houses, examples of which still exist in Cornwall, the Western Islands of Scotland, and Ireland, are very similar in form and mode of construction to this, but they are of larger size and not buried under a mound of stones or earth. The position it occupied, between two ordinary sepulchral mounds, is more in favour of its having been made to contain the dead than to afford a habitation for the living, though it is very possible that it was in shape and some other respects a copy of a dwellingplace. On the whole, this chamber appears to me to have been made to contain the interment of one or more bodies, and those probably such as had not undergone cremation. Had the bodies been burnt, it is almost certain that some remains of the bones would have been met with on the floor, or between the stones with which part of the bottom was laid, whereas if the chamber was accessible and resorted to from time to time, as indeed the articles found in it seem to indicate, it is probable that any remains of unburnt bones would have either gone to decay in consequence of the free admission of air, or would have been removed by those who frequented it. Supposing then that it was a place of sepulture, it appears to form a link between the earlier and the later class of barrows, as they exist in this part of Britain. I here assume it as granted (for reasons that are stated elsewhere in this book) that the long barrow is the earliest form of sepulchral mound, so far at all events as is implied in the statement that in the later 'pre-historic times' that class of barrow was not in use except where an earlier mound may have been taken advantage of for the interment of later burials. At the same time it may be stated that in some districts of Britain, as for instance Caithness, 
Argyleshire, and other places in Scotland, and Gower in South Wales $^{1}$, certain sepulchral mounds, whose interior arrangements for the deposition of the dead are similar to those in the long barrows, are more or less of a circular form. The principal feature which marks the difference between the earlier and later mode of burial in barrows of a time before the introduction of iron, and where stone receptacles for the body have been constructed within the mound, appears to be this. In the earlier places of sepulture the bodies, burnt or unburnt, have been deposited in what may be called chambers, that is, in receptacles which are not entirely closed, and into which in many cases access was had by a gallery or passage; in the later ones the bodies were placed in a cist, that is, a receptacle entirely closed, and into which it was not intended that access in the future should be had. In the former case the intention seems to have been the introduction from time to time of additional burials; in the latter case the sealing up, as it were, of the body or bodies in the first instance buried in the tomb, and the keeping them apart from any other later interment, seems to be indicated.

The mound now under consideration, which, from its position between and impinging upon two other barrows, may be supposed to belong to the same period as they do, though that cannot be predicated with certainty, possessed a place of burial (if it were a sepulchral mound) in a chamber with a passage leading into it, and it would have to be classed amongst those of the earlier mode described above. It does not therefore appear to be an unlikely supposition to regard it as belonging to a time of transition, when the older manner of burial was being replaced by another one; nor is it improbable that this change was consequent upon the presence of a different and, it may be, of a conquering race. It has not usually been the case that the conqueror has extirpated the conquered, in many instances indeed the vanquished has in the end absorbed the victor, whose blood has at length, by intermarriage of the smaller in number with the larger, become one with it. When such a condition of things existed as two races living together under one rule and mixing in the most intimate way with each other, it might often happen that the one would still (for a time at least) retain many of its own customs, and certainly amongst them not the least likely to be

${ }^{1}$ See Description of the Park Cwm Tumulus, by Sir John Lubbock, M.P., F.R.S., Journ. of Ethnol. Soc., N.S., vol. ii. p. 416. 
continued would be the manner of burial. We may therefore in this barrow have the burial-place of a family of the earlier longheaded race, the kindred of those who interred their dead in the adjoining long barrow, living side by side with the intruders, and still keeping up their own mode of burial. As has already been stated, it appears probable that a similarly constructed chamber existed in the long barrow just referred to ; and if this was so, we have the fact of one round barrow, closely in connection with others which contained burials after the ordinary round barrow fashion, possessing a feature strictly analogous to one discovered in what must be regarded as a long barrow of the ordinary kind.

CCXVIII. Closely adjoining the mound just above deseribed, the two in fact overlapping, the one the other (though which had been first thrown up it was impossible to say), was a barrow $36 \mathrm{ft}$. in diameter and $4 \mathrm{ft}$. high. It was made of stone on the exterior, and had an earthen mound within it $13 \mathrm{ft}$. in diameter and $3 \frac{1}{2} \mathrm{ft}$. high. At a distance of $10 \frac{1}{2} \mathrm{ft}$. west-north-west of the centre, and $6 \mathrm{in}$. above the surface-level, was the burnt body of an adult, probably a female: the bones were enclosed by small flag-stones, carefully placed amongst the general mass of stones of which the barrow at this part was composed. At the centre was the burnt body of a young person under 17 years of age, of uncertain sex; it had been burnt on the spot, and the signs of fire in the reddened earth extended over a space of $8 \mathrm{ft}$. in diameter. The bones were deposited in a circular hole $1 \mathrm{ft}$. wide and $16 \mathrm{in}$. deep, which had been made after the burning of the body had taken place, a circumstance contrary to the usual mode, which was, when the bones were deposited on the site of the ustrinum, to prepare the hole in which the bones were afterwards to be placed before the burning of the body was effected. Amongst the bones was a pin $3 \frac{1}{4}$ in. long, made from the leg-bone of a goat or sheep; it was calcined, and had probably fastened the dress or shroud in which the corpse was wrapped. Several ox bones were found amongst the material of the mound.

CCXIX. The next barrow, which was in contact with the last and to the north-east of it, was $34 \mathrm{ft}$. in diameter, $2 \mathrm{ft}$. high, and composed entirely of stones, arranged carefully from the centre. At that point, scattered widely over a space of $2 \mathrm{ft}$. in diameter and placed on the natural surface, were the burnt bones, very 
few in number, of an adult; this body had not been burnt on the spot.

CCXX. The last barrow of this group was situated a few feet to the south-east of that just described, and was not in contact with it. The stones of which it was made had been almost entirely removed, but the size of the mound was well marked and showed a diameter of $36 \mathrm{ft}$. At the centre, the site of the funeral pile was very apparent, and covered an area $6 \mathrm{ft}$. in diameter. At the middle of this a circular hollow, $2 \mathrm{ft}$. wide and only $6 \mathrm{in}$. deep, had been made after the burning had taken place. In it were the burnt bones of an adult, probably a male; they were not laid close together, but mixed up with the earth which filled the hollow. On the top of the deposit was a bone pin unburnt, $5 \frac{5}{8}$ in. long. If it had not been for the way in which the bones were scattered, this might be supposed to have been used to fasten a cloth or piece of hide in which they had been placed after having been collected from the funeral pile, and it is still probable that it had served some such purpose. 


\section{NOTE.}

WHILE this sheet was passing through the press, a very important discovery was accidentally made of a 'Late Keltic' interment, at Arras, in the East Riding of Yorkshire, and in close proximity to a number of burials found by the Rev. E. W. Stillingfleet in 1816-17, which are shortly noticed at pp. $50 \mathrm{n}$. and 208 of this work. I have, since the discovery, visited the place, and obtained, with a single exception, everything that was met with; and from what I observed myself, as well as from careful enquiries made on the spot, I am enabled to give what I believe is a substantially accurate account of the grave and its contents.

There appeared to have been a small barrow, about $14 \mathrm{ft}$. in diameter and $1 \frac{1}{2} \mathrm{ft}$. high, underneath which a grave had been sunk into the chalk rock; it was circular, $12 \mathrm{ft}$. in diameter and $3 \mathrm{ft}$. deep. On the bottom was deposited the skeleton of probably a woman on the left side, with the head to W., and the left hand up to the face. The workmen were decidedly of opinion that the body had been laid at full length, though certainly the contracted position was that which was usually adopted at the time of these burials. Mr. Stillingfleet however records that, in one of the Arras barrows, a man was found buried with the remains of a chariot, and placed in the grave at full length, and from some notes of his which I have seen other bodies appear to have been interred in the same position. Immediately behind the head were numerous bones, the remains of what had apparently been, when interred, the fore-part of the carcases of two tame pigs. Below the head was a mirror, made of iron, with a handle of the same metal having a loop, $\frac{1}{2}$ in. wide, at the end. The mirror is circular, $6 \frac{3}{4} \mathrm{in}$. in diameter, and the handle, which is square in section, is $6 \frac{1}{4} \mathrm{in}$. long. Where the handle is fixed to the mirror there is an ornamental plating of bronze, and a similarly shaped but smaller piece is applied where the loop is attached at the end of the handle; the bronze plating is fastened to the iron by small rivets, also of bronze. Bronze mirrors of the Early Iron Period, in some instances highly decorated with the peculiar and characteristic designs of that time, have been discovered in various places in Britain, but this is the first occurrence but one that $I$ am acquainted with where an iron mirror has been 
found, nor indeed do I know of any previous case in Britain, beyond that mentioned in the note, where a mirror of any kind has been associated with an interment ${ }^{1}$. Behind the back of the body were placed two wheels laid slightly overlapping each other. They have been about $2 \mathrm{ft} .8 \mathrm{in}$. in diameter, and the tires, of iron, $1 \frac{5}{8} \mathrm{in}$. wide, are slightly bent over at the edge. The naves, of wood, $5 \frac{1}{8}$ in. in diameter, have been bound in each case with two bronze hoops, which have a raised rib at the middle, and are $1 \frac{3}{4}$ in. wide; the hoops are rivetted by two bronze pins $1 \mathrm{in}$. long, which have also served to fasten them on to the wood. The metal is so thin that the hoops can only have been ornamental. The wheels without doubt had been once attached to a chariot, but of it no other portion was found, or indeed appeared to have been ever deposited in the grave. In front of the chest of the woman were two snaffle-bits made of bronze. They differ somewhat in size, the one measuring $9 \frac{1}{2}$ in., the other a little more. They are exceedingly well manufactured, and consist each of two rings $\left(2 \frac{1}{4} \mathrm{in}\right.$. wide in the inner diameter) to which the reins were attached, passing through a pearshaped bar $2 \frac{1}{4}$ in. long, the smaller end of which forms a loop. Two small round knobs are fixed on each ring (about $1 \mathrm{in}$. apart), apparently to prevent them from moving through the bar. It is probable that the rings are made of iron plated with bronze, at least the similarly shaped bit now in the York Museum is so constructed. The central part of the bit consists of a piece of bronze ( $2 \mathrm{in}$. long) with a raised grooved rib at the middle, and a loop at each end in which the corresponding loops of the bars work ${ }^{2}$. Two other articles of bronze were discovered, one of them by the workmen (who subsequently lost it), the other by myself in causing the material thrown out of the grave to be again turned over and carefully examined. This latter is an ornamented ring of bronze and iron, through which the reins had probably passed. Similar rings were found abundantly in the large hoards of 'Late Keltic' objects discovered at Polden Hill, Somerset, Westhall, Suffolk, and Stanwick, Yorkshire, as well as in other places ${ }^{3}$. The ring is $2 \frac{1}{4}$ in. in diameter, the flat and unornamented

${ }^{1}$ Mr. Stillingfleet found a very similar mirror in one of the barrows at Arras, opened in 1816, but which seems to have been made entirely of iron. In some MS. notes of his, now in the Library of the Philosophical Society of York, is a slight sketch of it, from which it appears to have had two perforations, one at the end of the handle, the other where the handle joins the mirror itself. He says :- ' It is like a modern hand-screen. The diameter of the circular part is about $7 \frac{1}{4} \mathrm{in}$, the length of the handle, including the perforations, $5 \frac{x}{2}$ in.; the outer diameter of the two perforations $1 \frac{1}{2}$ in., the inner diameter $\frac{3}{4}$ in.'

2 The bit is identical in form with one also found at Arras, and engraved in Crania Britannica, fig. 10 on the plate of 'Objects from Barrows at Arras.'

3 Some are engraved in Horæ Ferales, pl. $\mathrm{xx}$, and one, precisely similar in form to that under notice, and also found at Arras, is figured in Crania Britannica, plate of 'Objects found in Barrows at Arras,' fig. 13. 
portion, of iron, being $1 \frac{1}{2}$ in. long. The article which was unfortunately lost was made of very thin bronze, and shaped like a round box lid; it was a little more than $1 \mathrm{in}$. in diameter, and not quite as much in depth. When found it had the remains of wood still within it, and there were two long thin pins on opposite sides by which it had been fastened to the wood. The workmen described it as being just like the metal end of a whip shank, and it is not improbable that it had originally served that purpose.

The principal features connected with this interment, though differing in some respects, have a marked resemblance to those in the two instances where Mr. Stillingfleet met with the remains of a chariot. In all the three cases the wheels of the chariot and the bits of the horses were found, in one of those opened in 1816-17 the skeletons of the horses themselves having been discovered. The remains of pig, in one shape or another, occurred in all the three, as also in a fourth interment recorded by Dr. Thurnam in the Crania Britannica, and portions of the horsetrappings appear also to have been found in each case. In that barrow in which the horses had been buried, many more articles connected with the chariot seem to have been placed in the grave than in either of the other two ; indeed it is possible that the whole of the chariot had been deposited there. In the other barrow opened in 1816-17 the man was laid upon what seems to have been his shield, the boss of bronze and the iron rim having been preserved. The mirror constitutes an almost singular and a very interesting feature in the burial under notice ${ }^{1}$. As has been stated already, in one of the graves at Arras it would appear that the whole of the chariot, with the horses, had been buried, but in the other two nothing more than the wheels seem to have been placed in the grave. Certainly the horses themselves had not been interred, for their bones must have remained as perfectly preserved as those of the buried person. In a small barrow I opened at Beverley, in 1875, the same mode of burial had apparently been adopted, for in that instance the two wheels of the chariot and what is almost certainly an iron bit were the only articles discovered in the grave. In that barrow however no bones, either of man or beast, were found, but from the nature of the soil it might have been expected that they would have gone entirely to decay. It is strange that a part only of a chariot should be buried with the owner, but such seems to have been the case, for it is almost impossible but that many more articles of metal should have been discovered, if the whole chariot had ever been there, inasmuch as a

${ }^{1}$ Mr. Faussett found, with the body of a woman, in a grave at Gilton, Kent, a mirror, made of mixed metal, in shape much like this under notice. The burial was, however, a Teutonic one. It is described in Inventorium Sepulchrale, p. 31, and engraved at pl. xiii. fig. 12. 
vehicle of that kind could not have been put together without bolts, rings, and other such like things being used in its construction. In two cases the bits of the horses were placed in the grave without the animals themselves, and this being so, why may not a part of the chariot have been put in, as representing the whole vehicle, equally with the bits; as representing the horses? Mirrors have been found in Etruscan tombs as well as in Egyptian, and in the latter associated with male interments. In the barrow under notice it is not absolutely certain whether the buried person had been a man or woman, though the remains of the body seem to indicate the latter, and it would therefore be rash to enter into any consideration of the occurrence of a chariot with a female or of a mirror with a male.

I have received the accompanying note as to the character of the skeleton, together with some remarks relative to the animal bones, from Professor Rolleston :-

' On the whole there is no doubt, after an examination of all the bones, that we have here the skeleton of a woman probably between 35 and 40 , of about $5 \mathrm{ft}$. in height, of small cranial capacity, but considerable muscular strength. Similar skeletons, about the sex and the ownership of which there is no question, are not rare in modern times.

'The animal bones found with this skeleton were the entire left half of the skull, together with part of the right half of a skull of a domestic pig (sus scrofa female) about 18 months old, the left half of a lower jaw probably belonging to the same pig; another left half of a lower jaw, and part of the occipital and parietal region of a second pig of the same age; a left scapula, two left humeri, two left radii, two left ulnæ, and some phalanges. Portions of the skulls, therefore, and of the left forelegs of two pigs, certainly or nearly certainly domestic animals, were found in the interment. The nearly perfect half skull enables us to be as nearly certain as it is possible to be that we are dealing here with tame animals; and this renders it probable that the remains of swine found in other late Keltic interments from this district were not trophies or relics or implements from wild animals, but simply the remains of tame animals eaten at the grave.-Oxford, May I3, 1876.' 


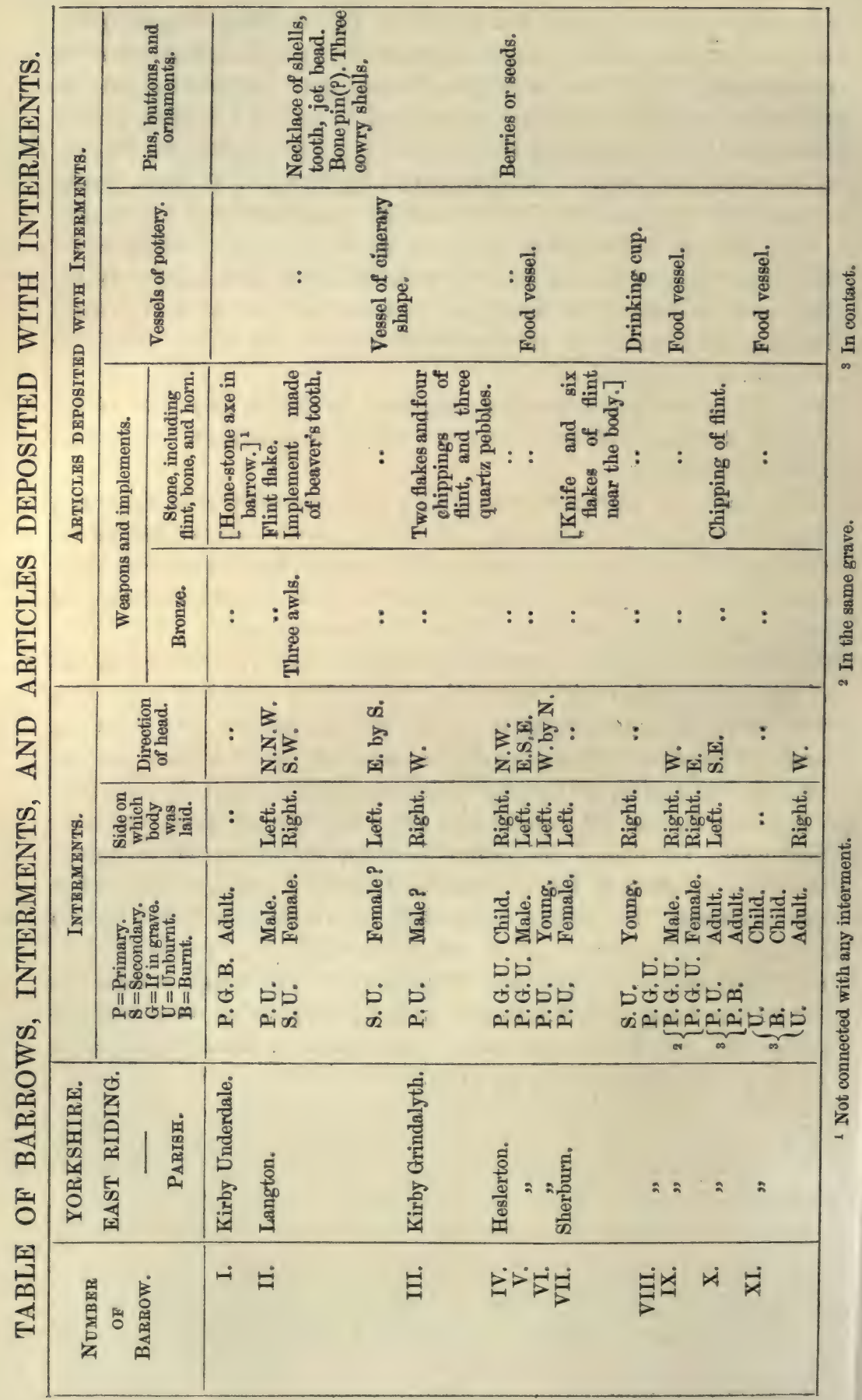




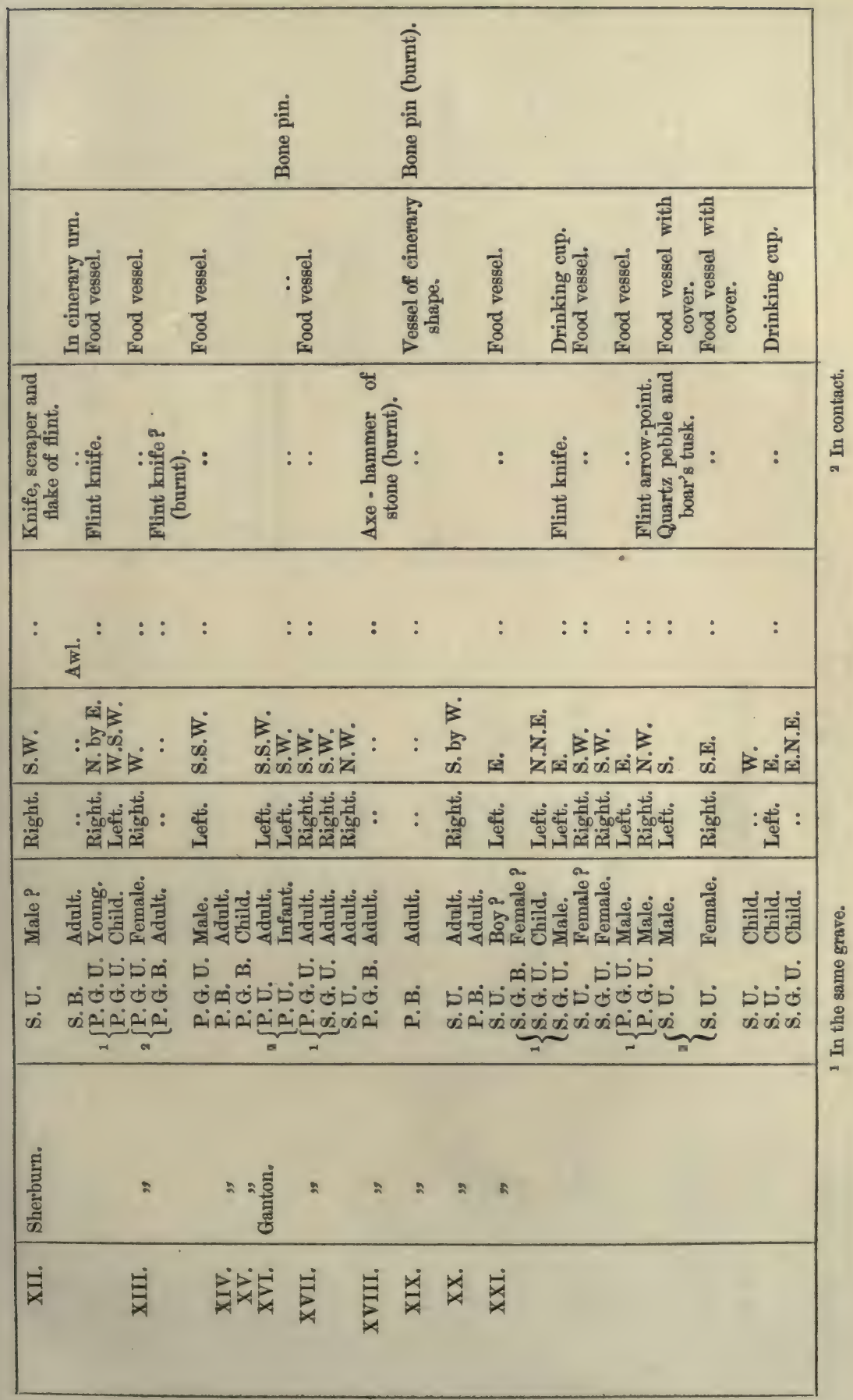




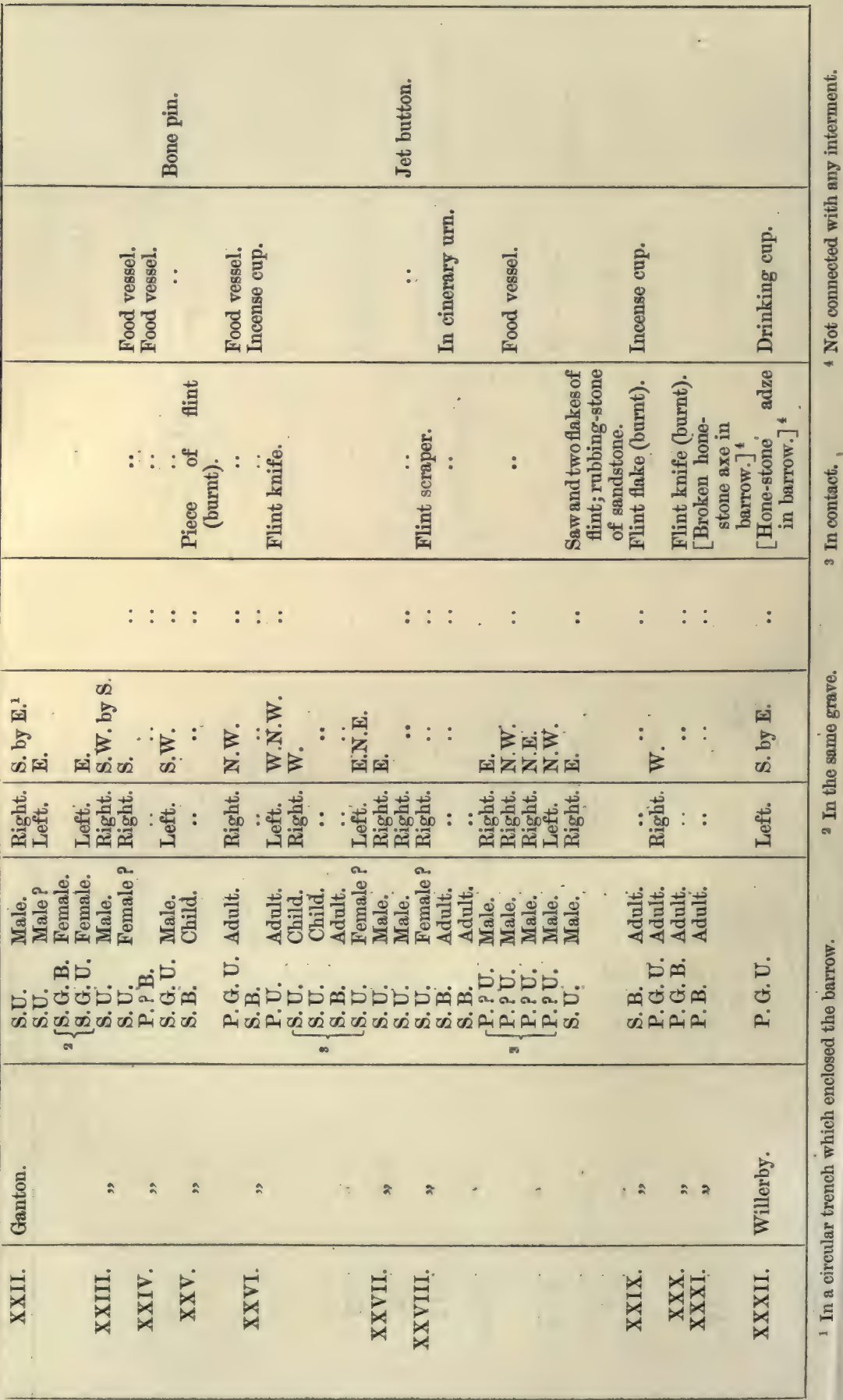




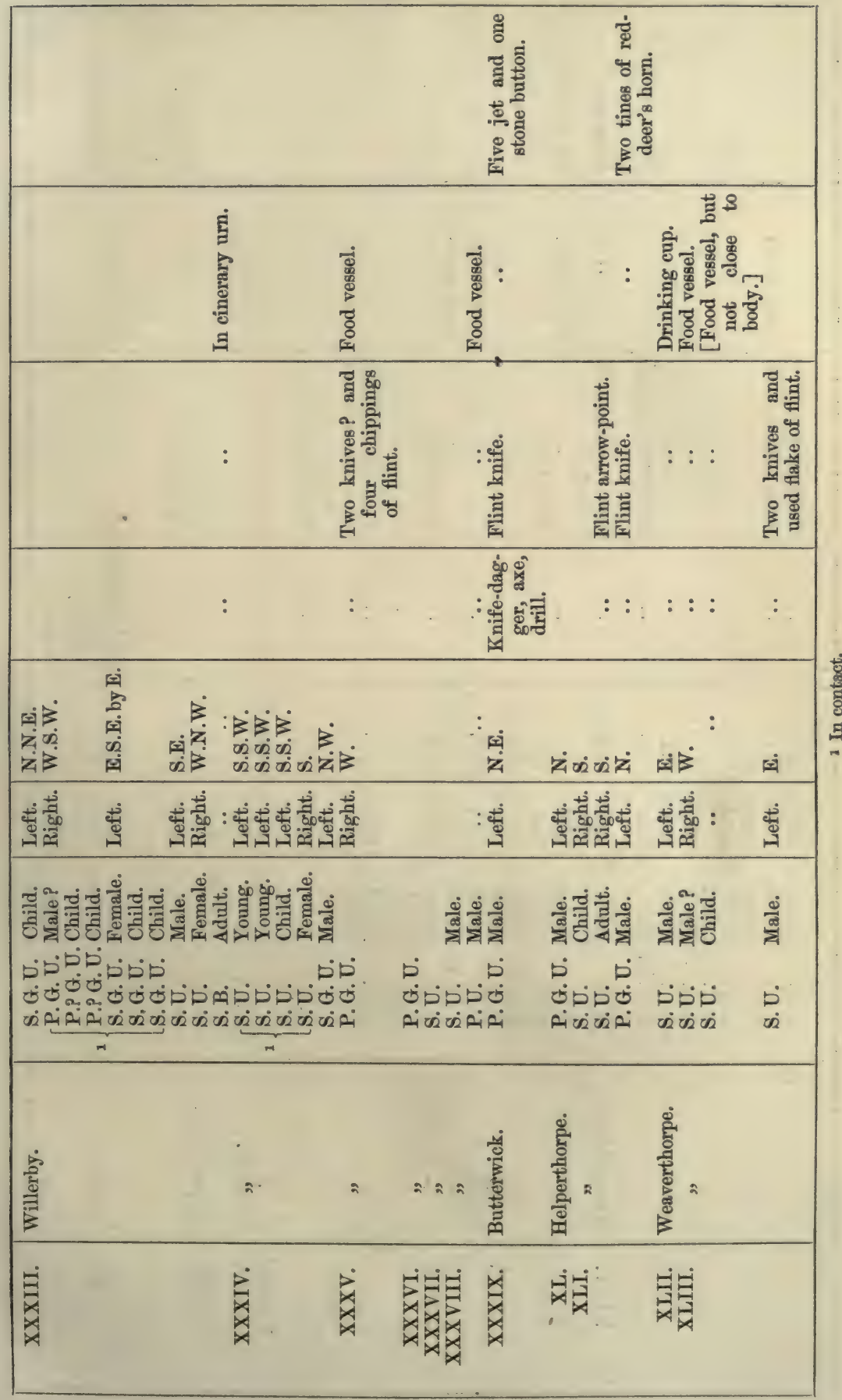




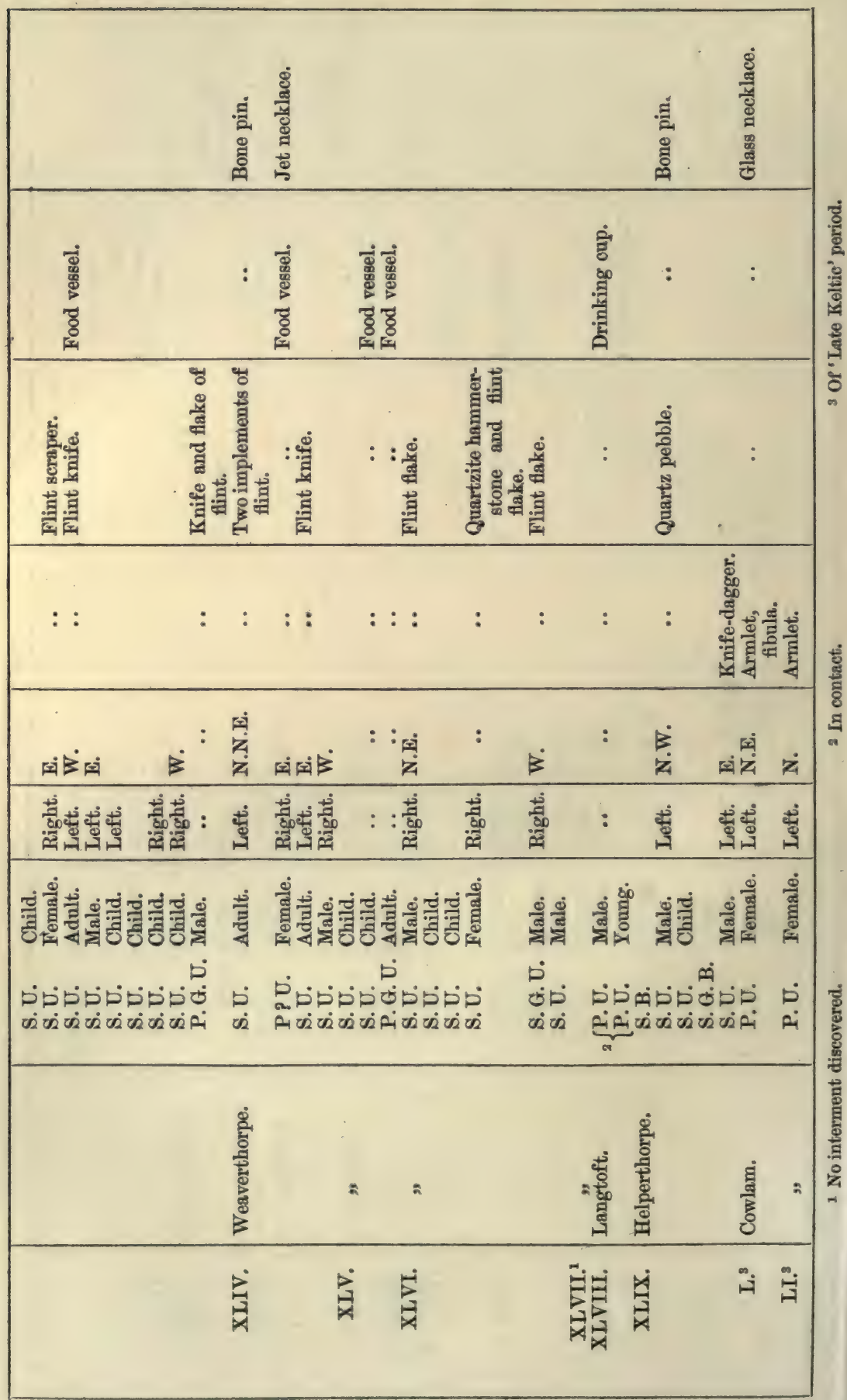


AND ARTICLES DEPOSITED WITH INTERMENTS.

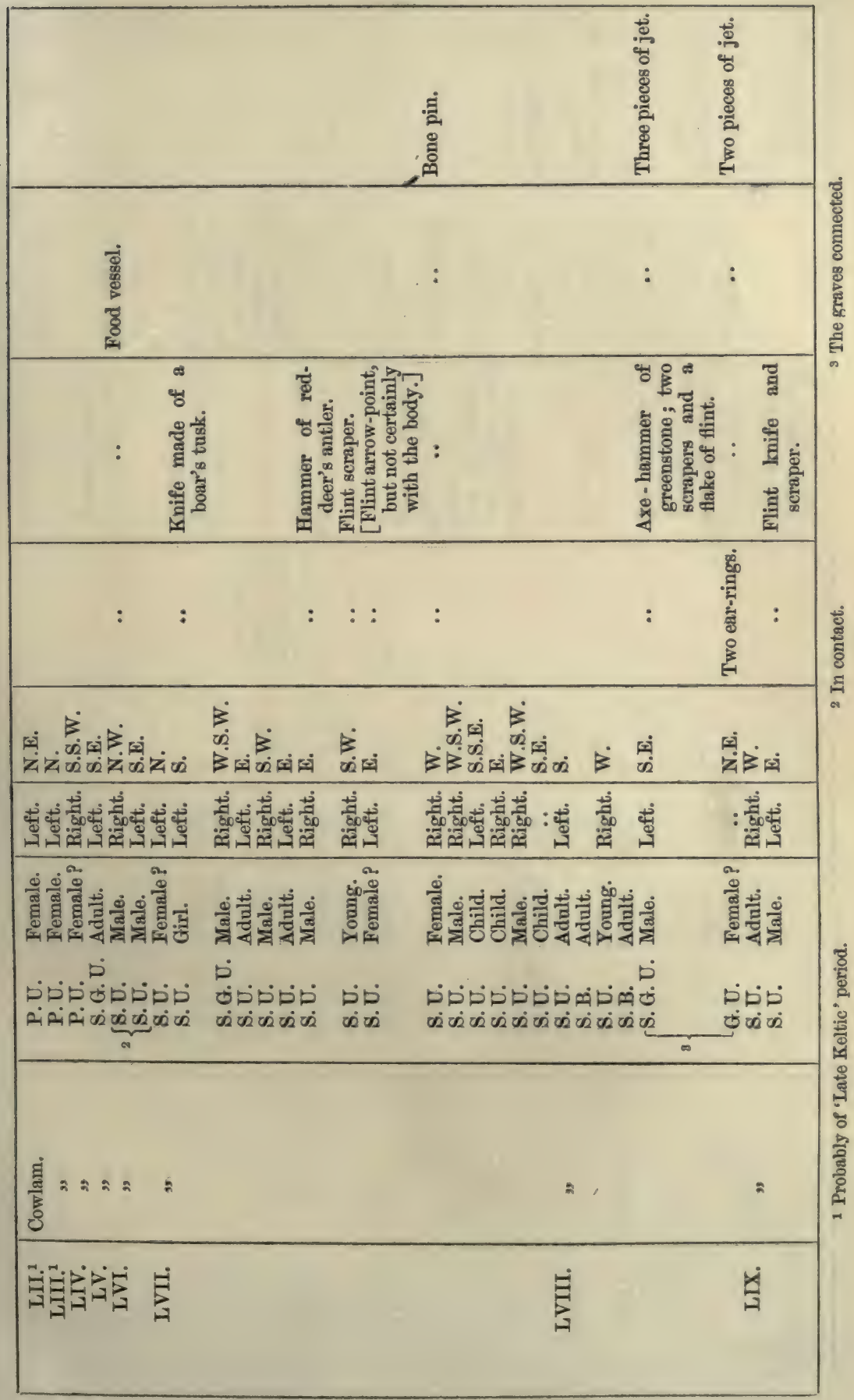




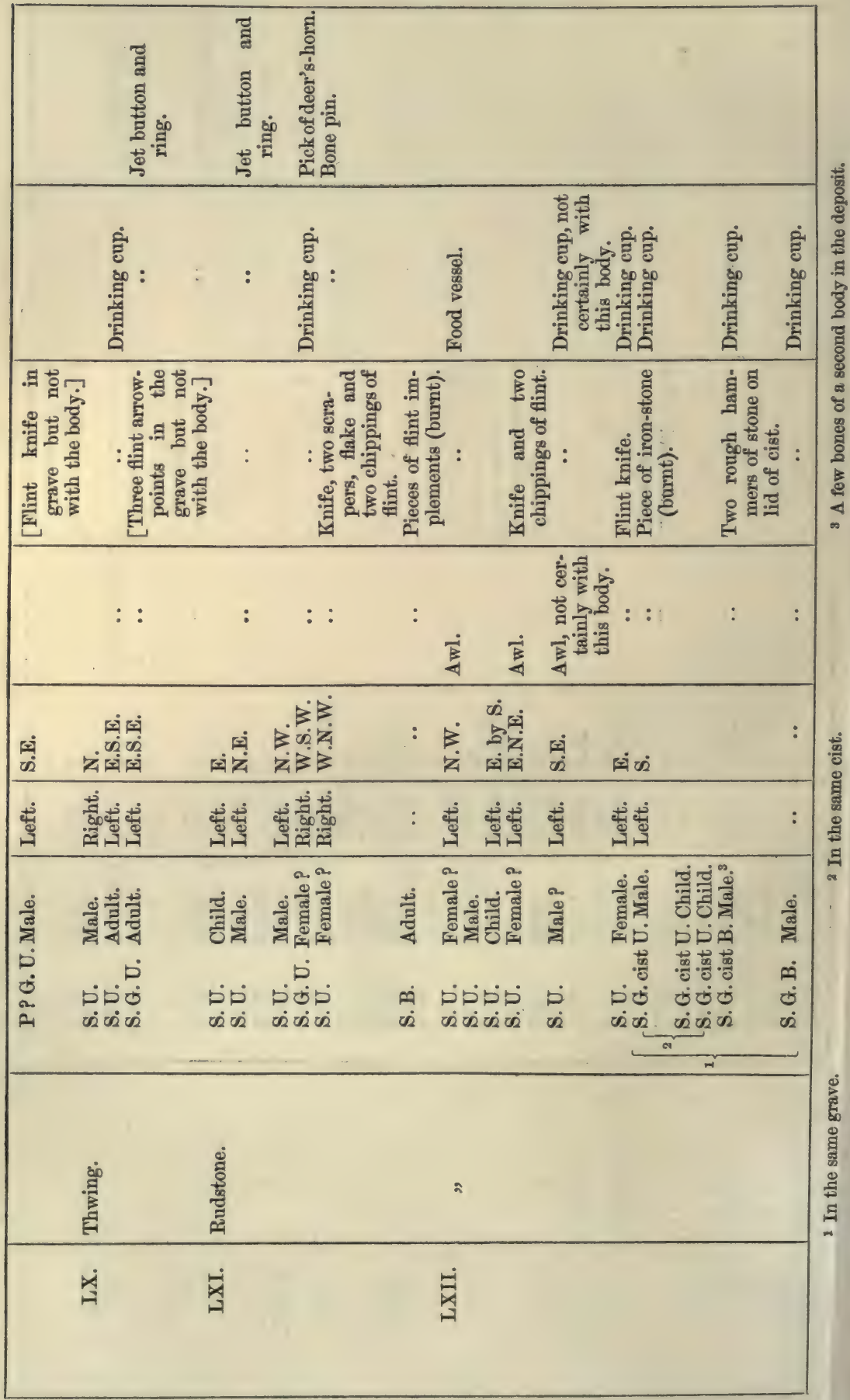




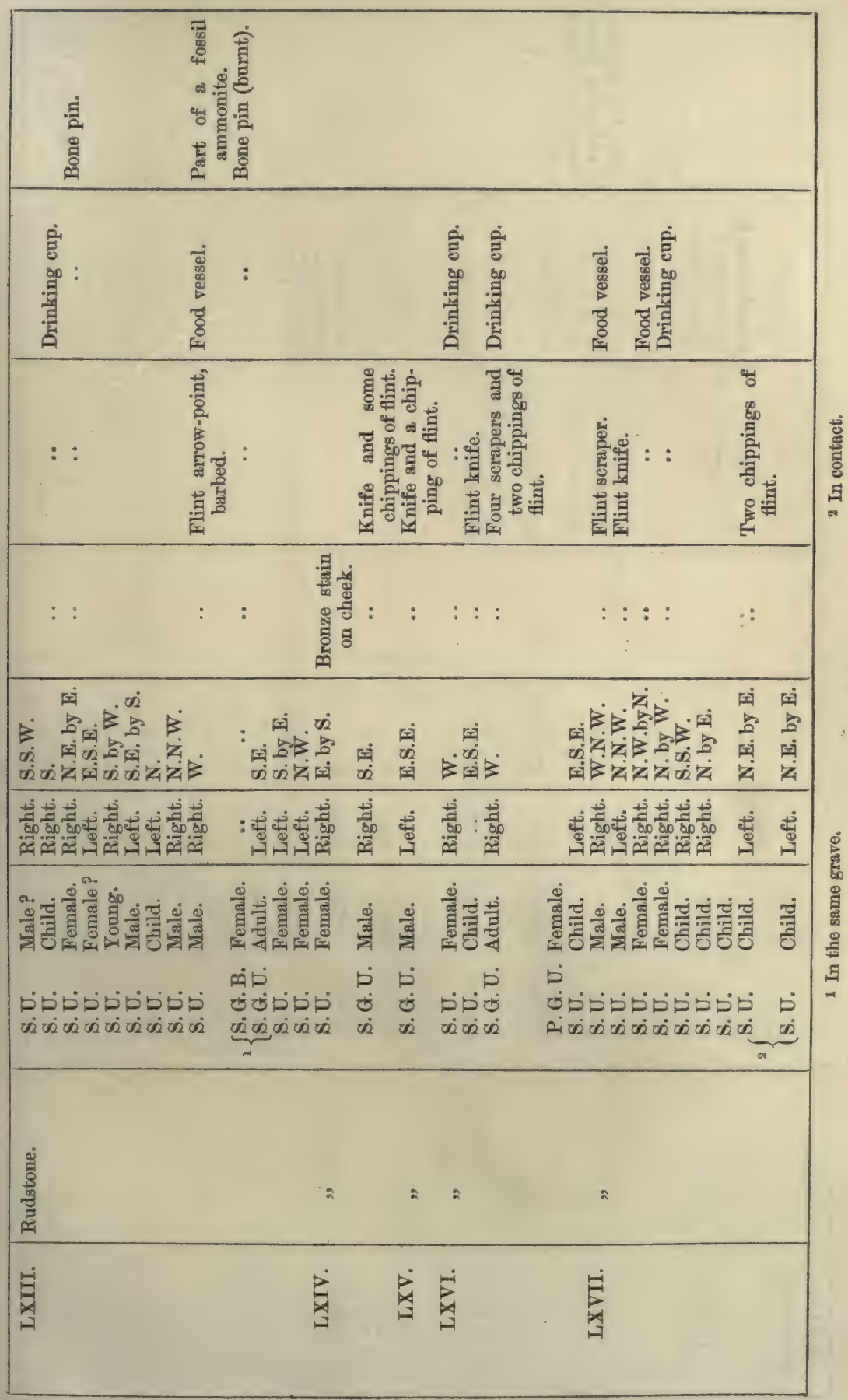




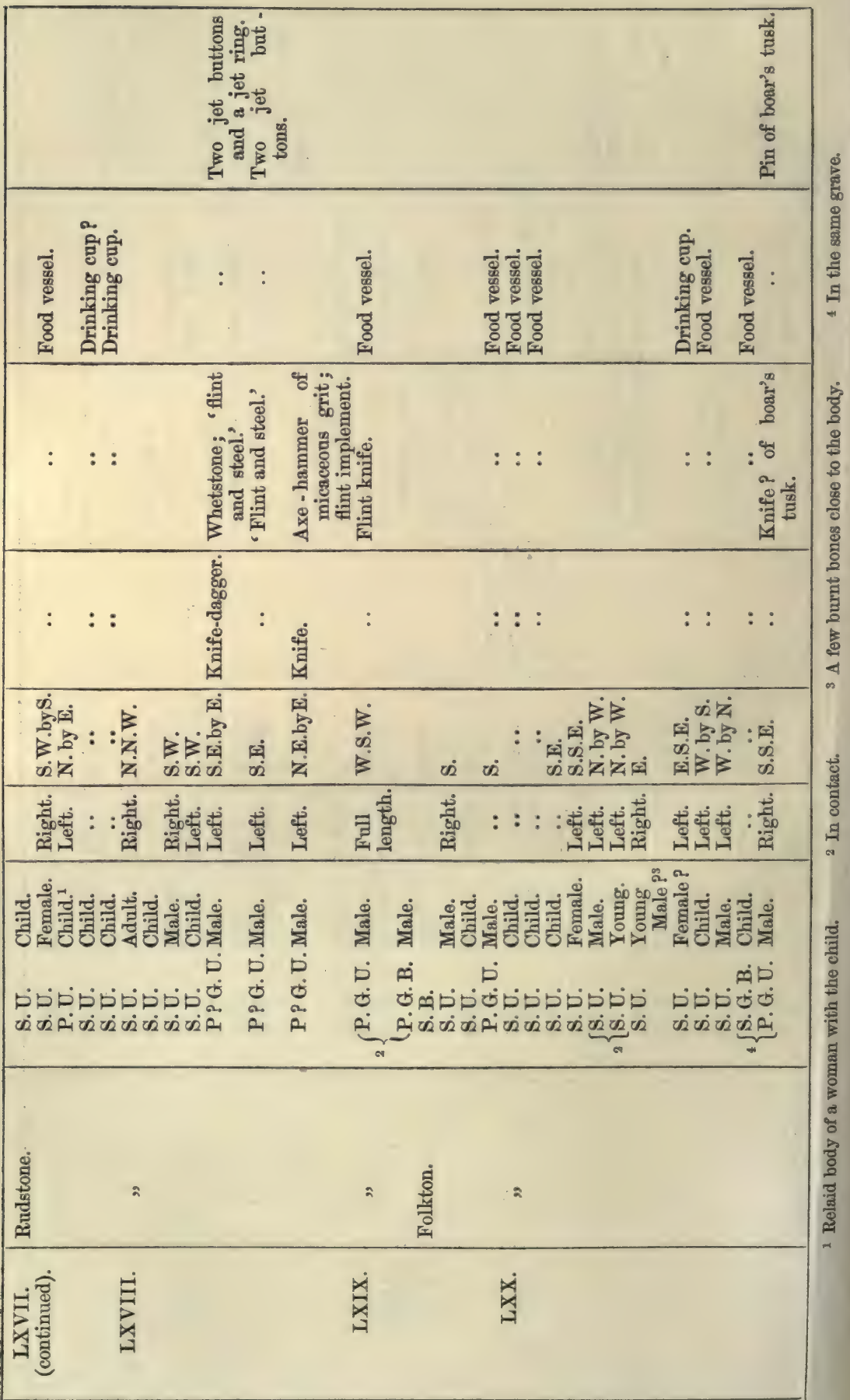




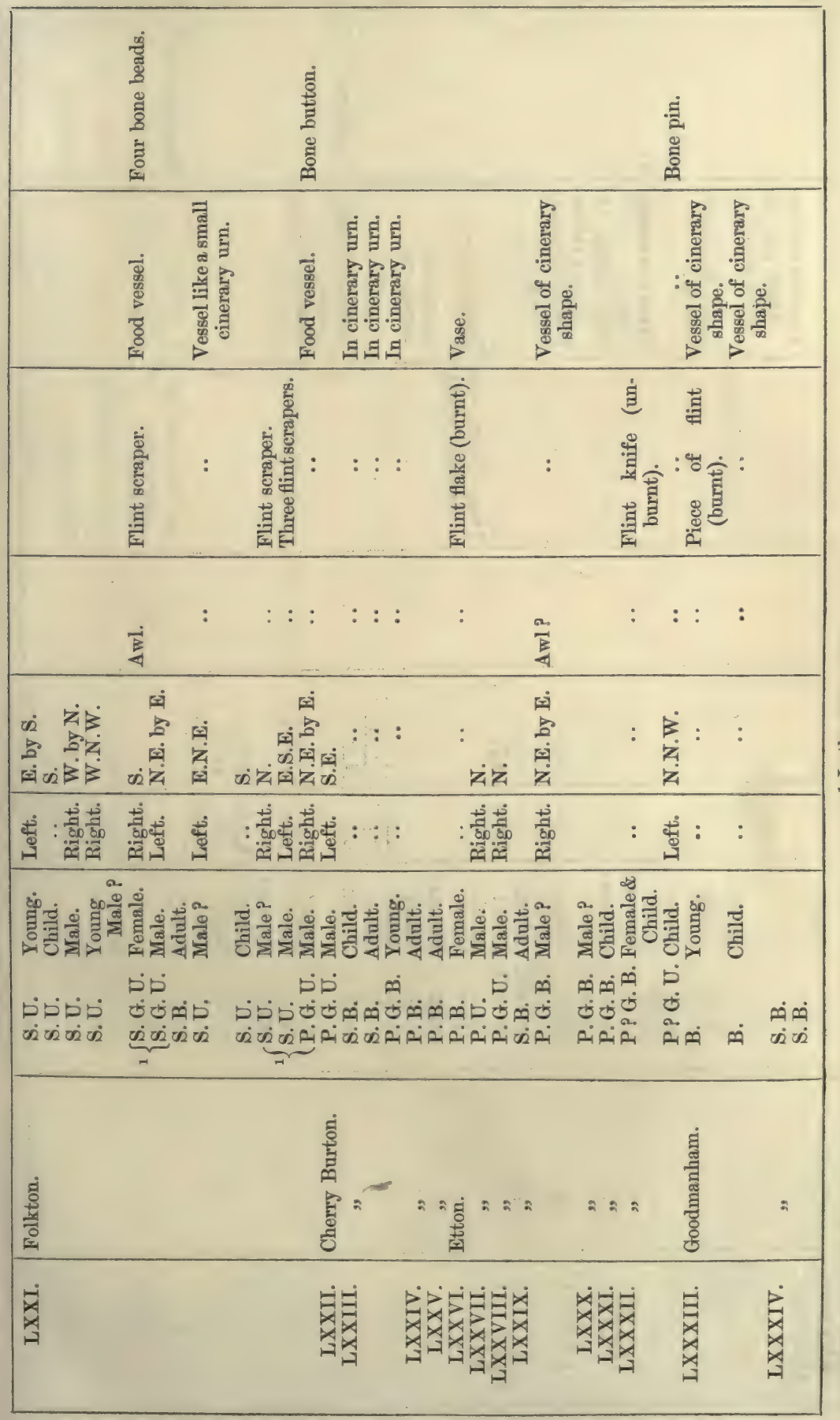




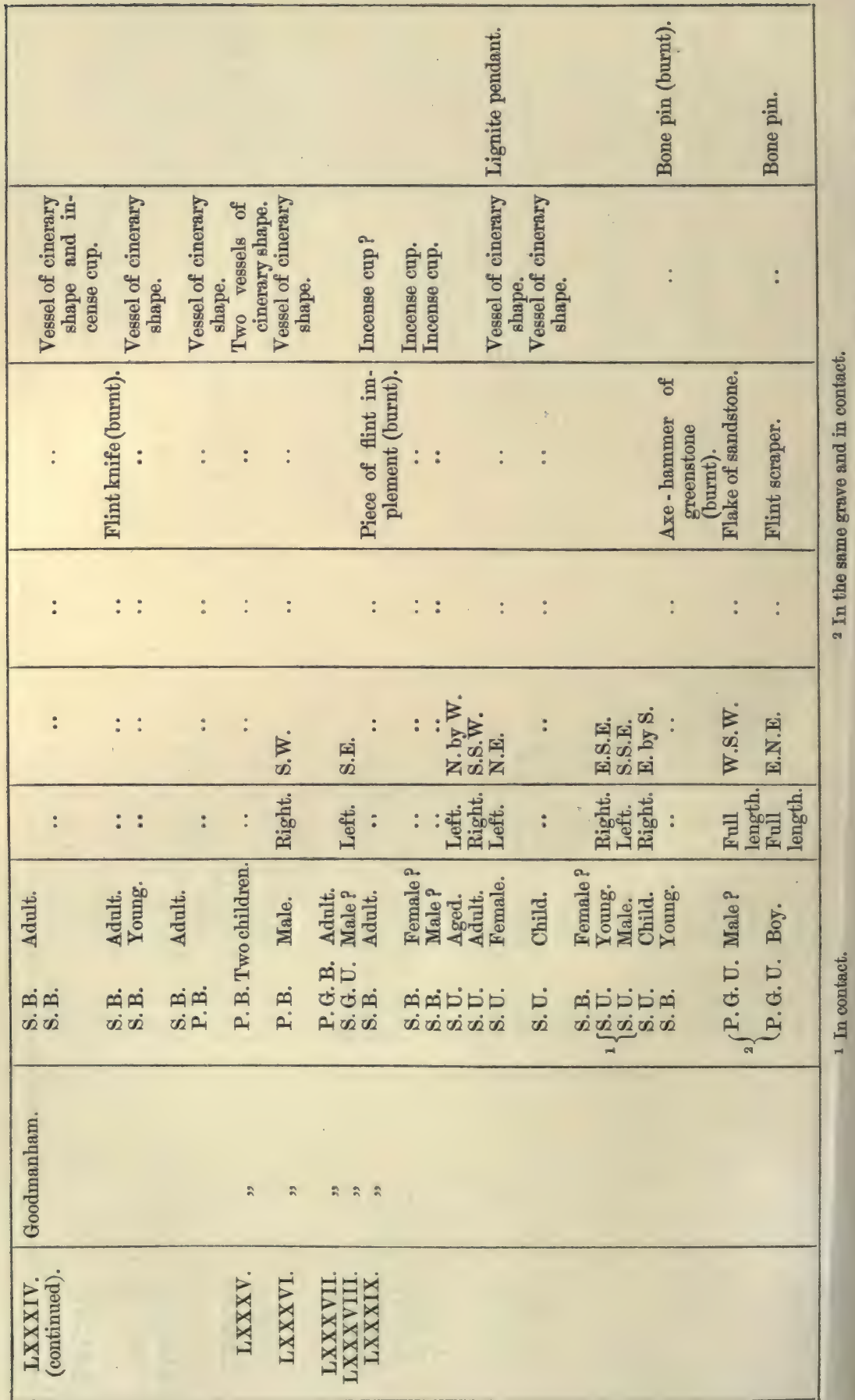




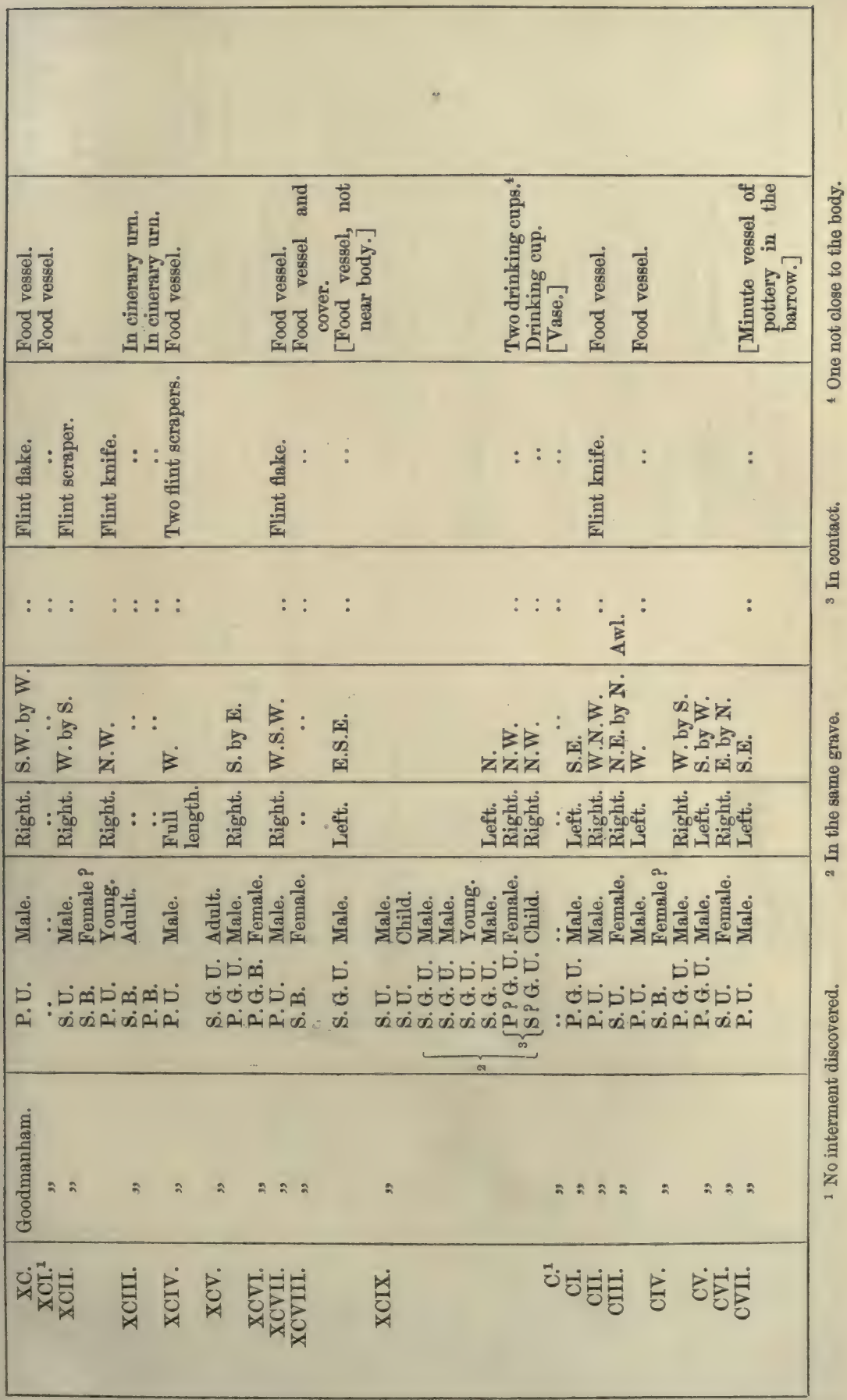




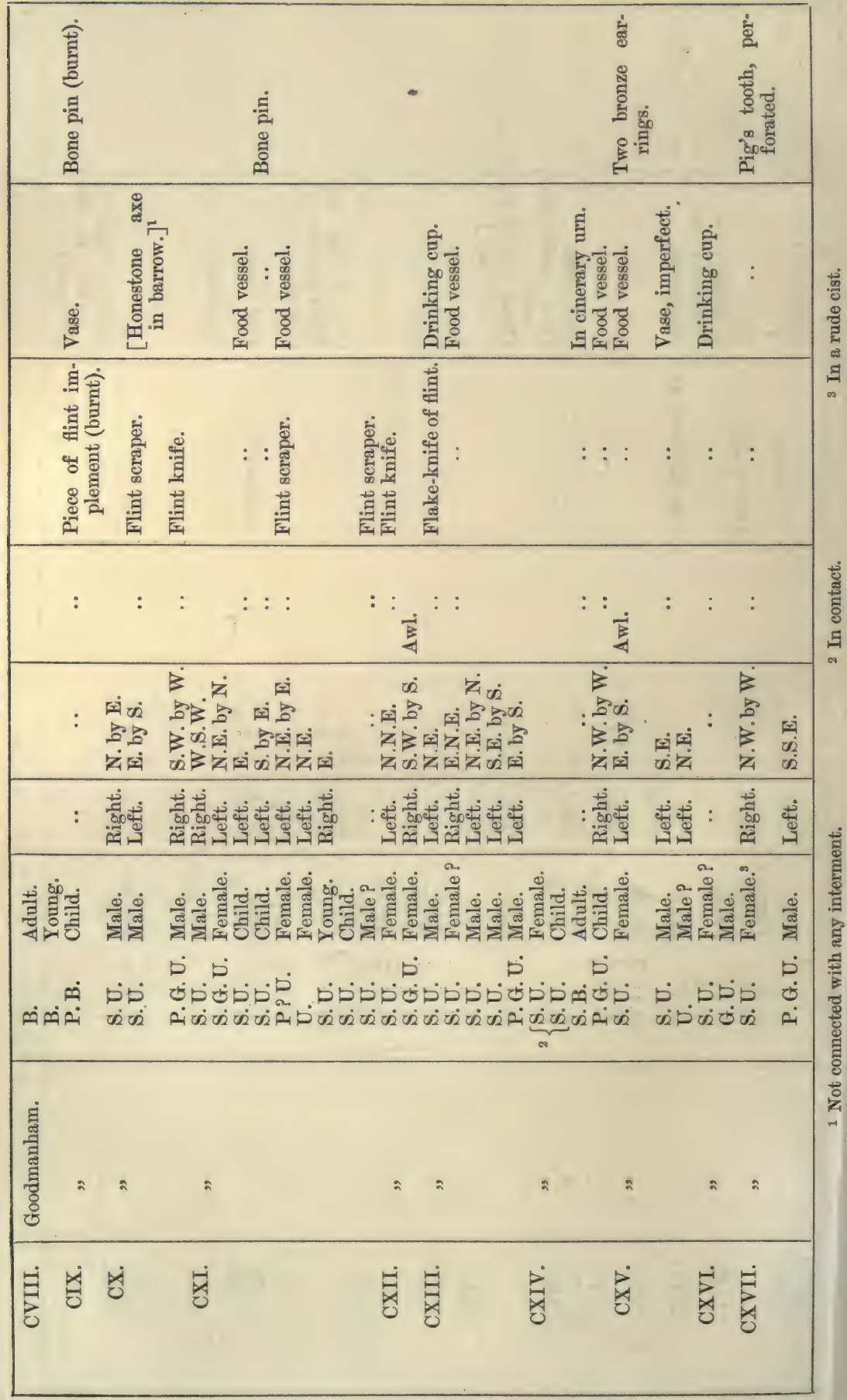




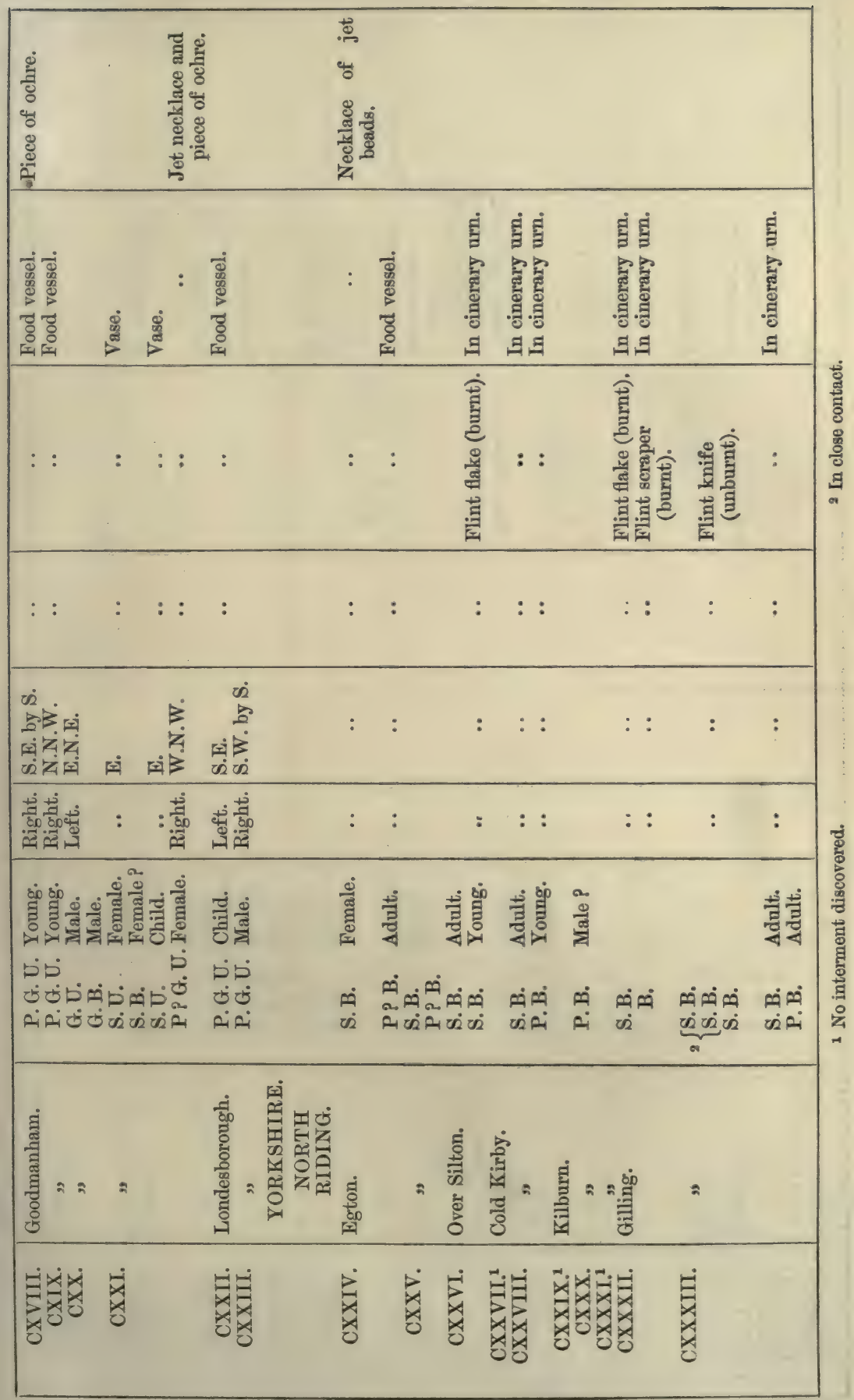




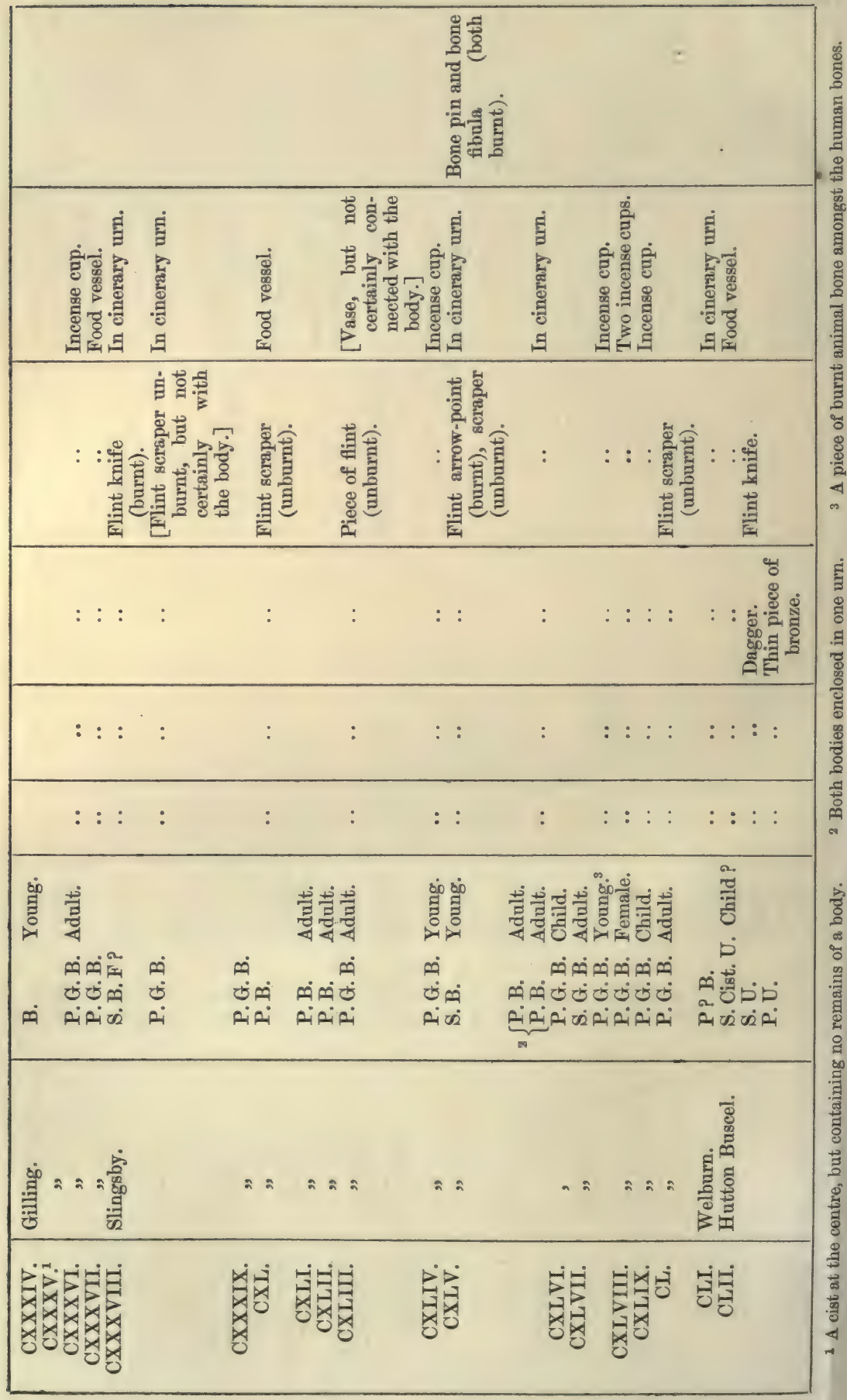




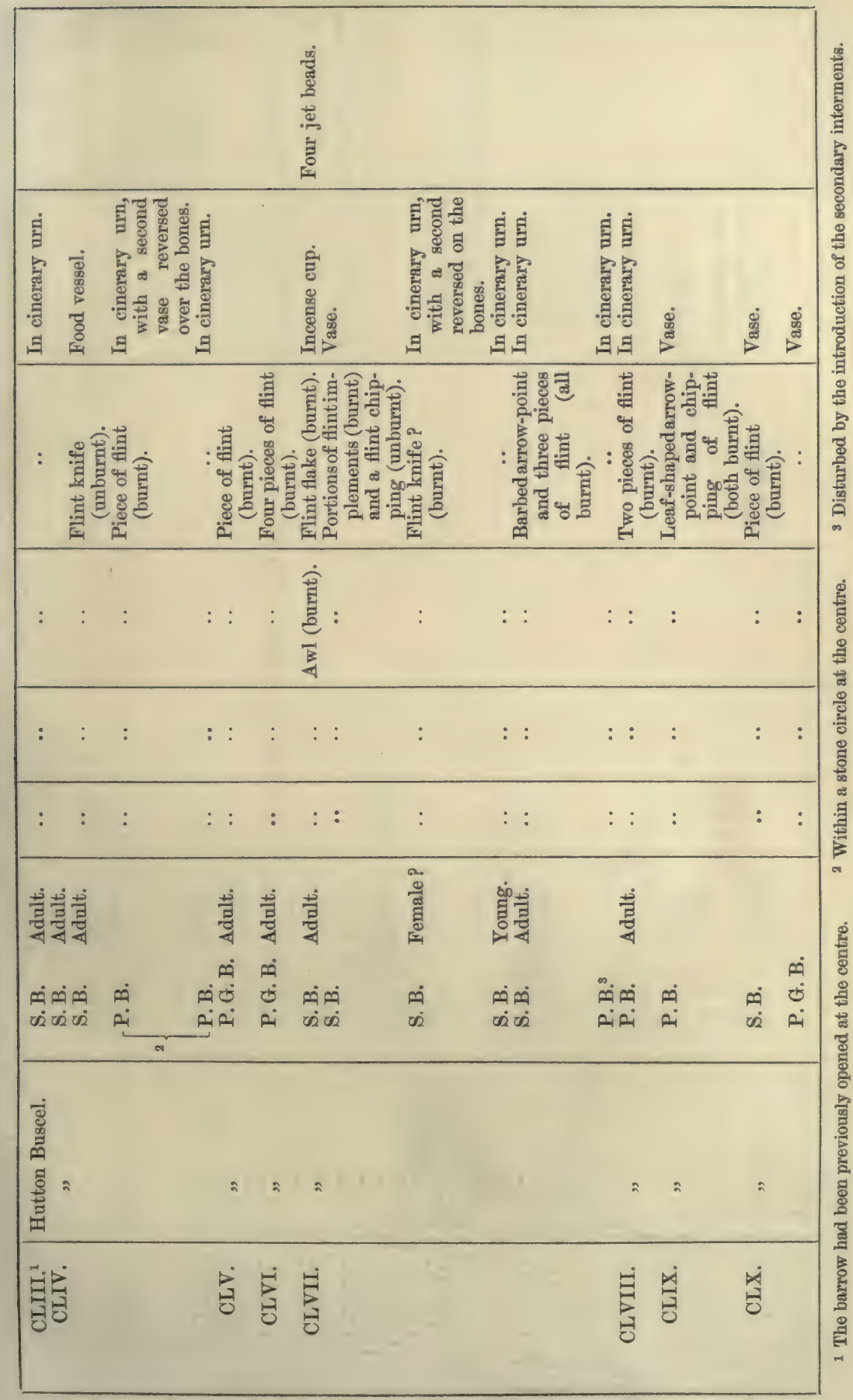




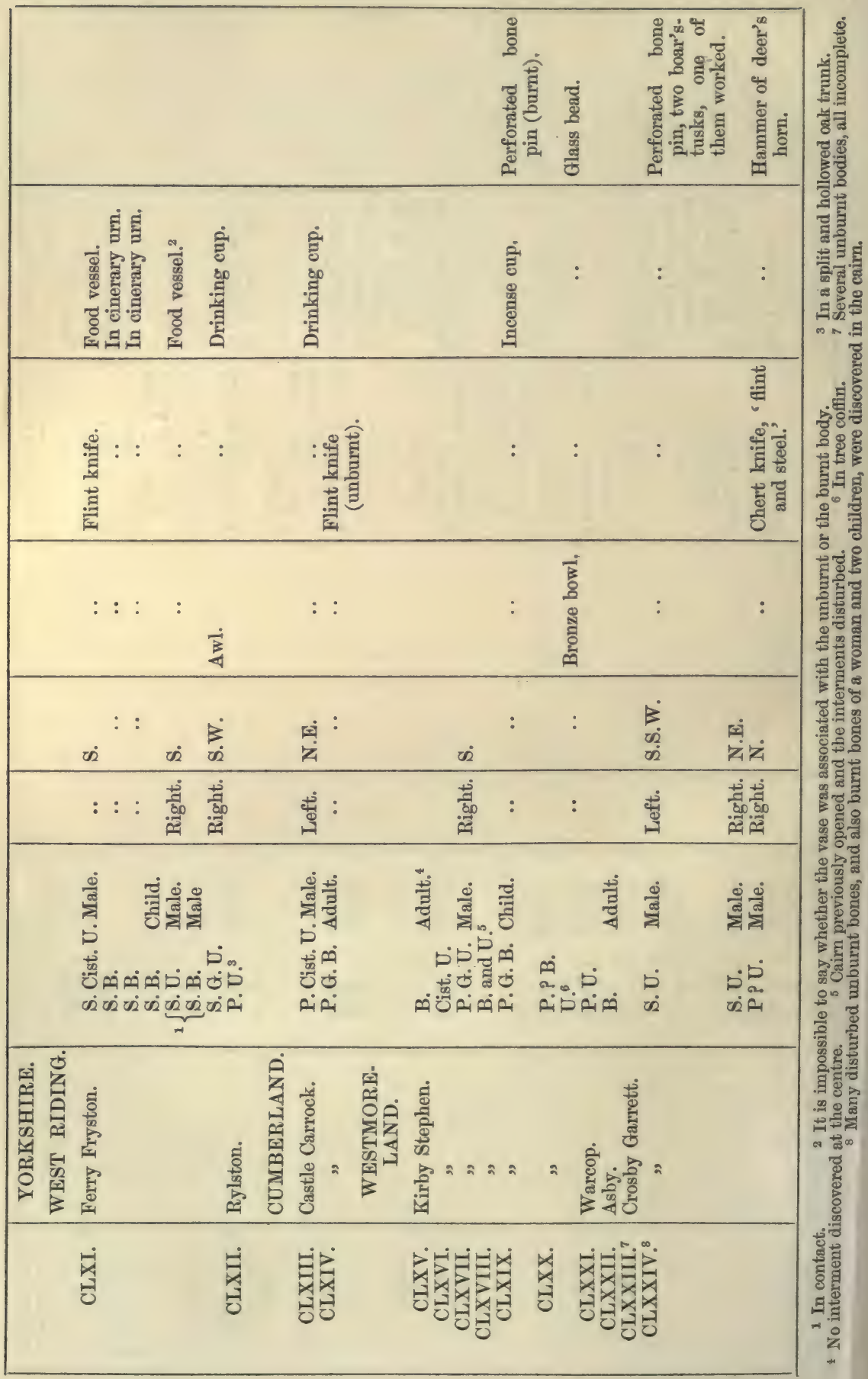




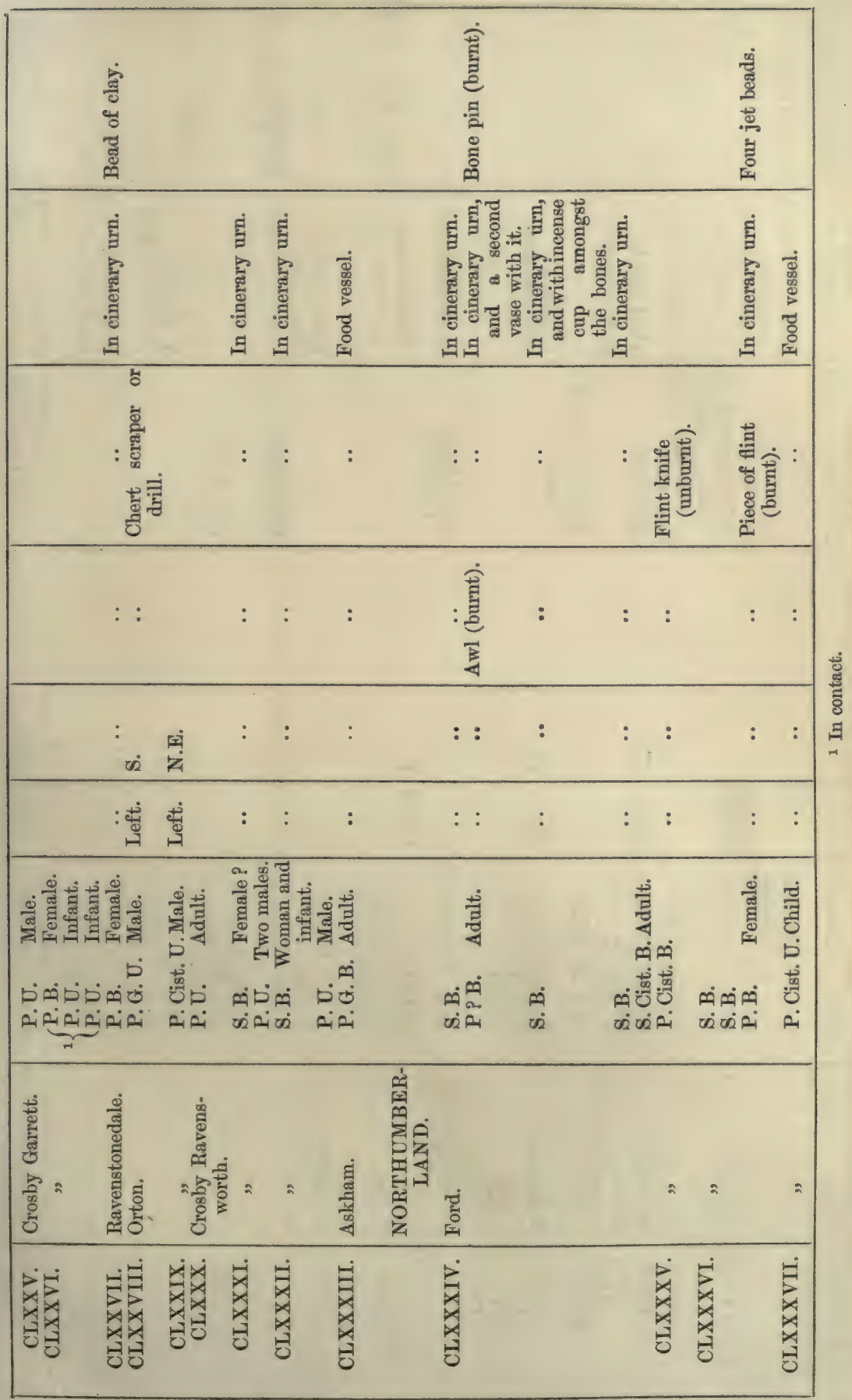


TABLE OF BARROWS, INTERMENTS,

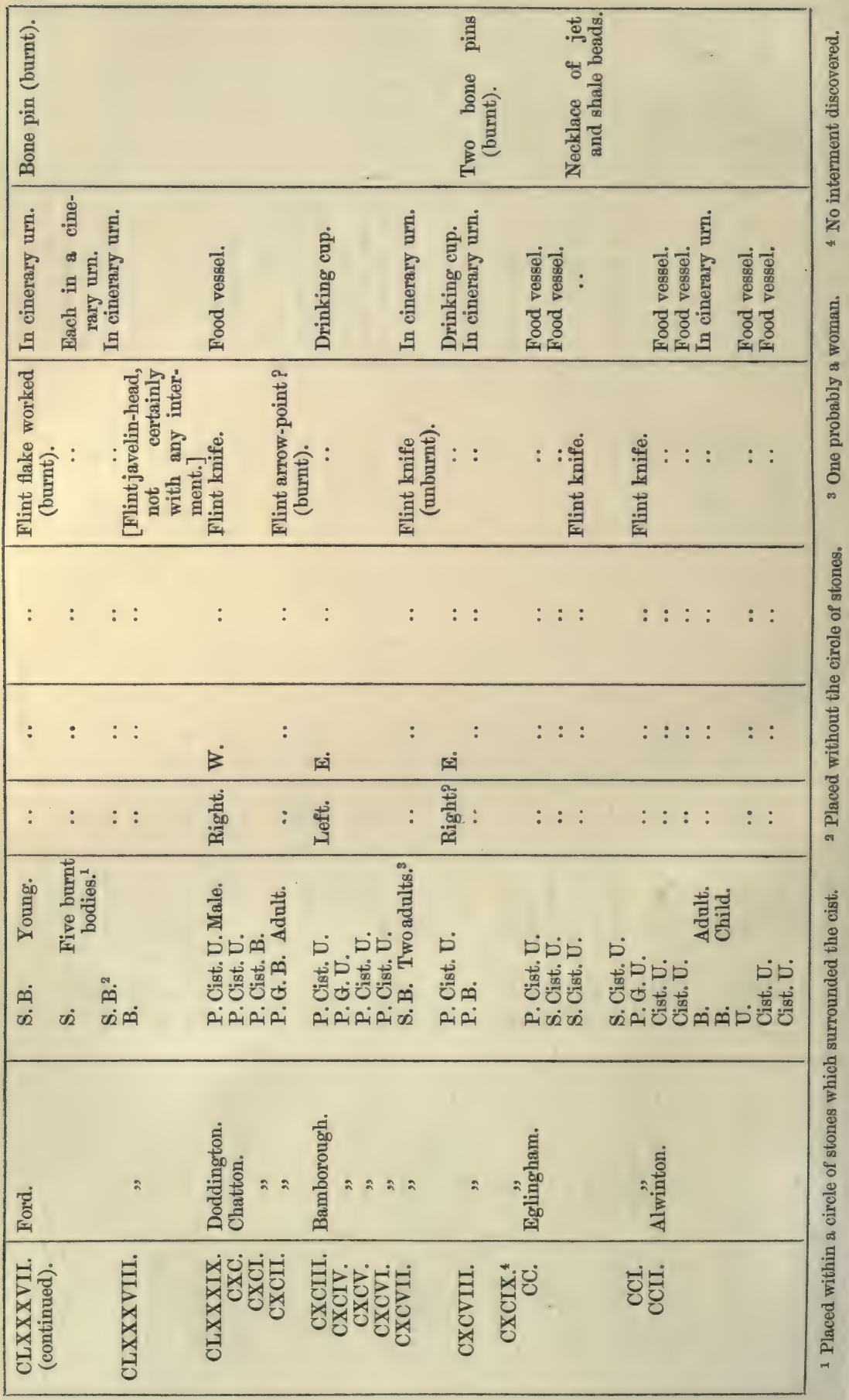




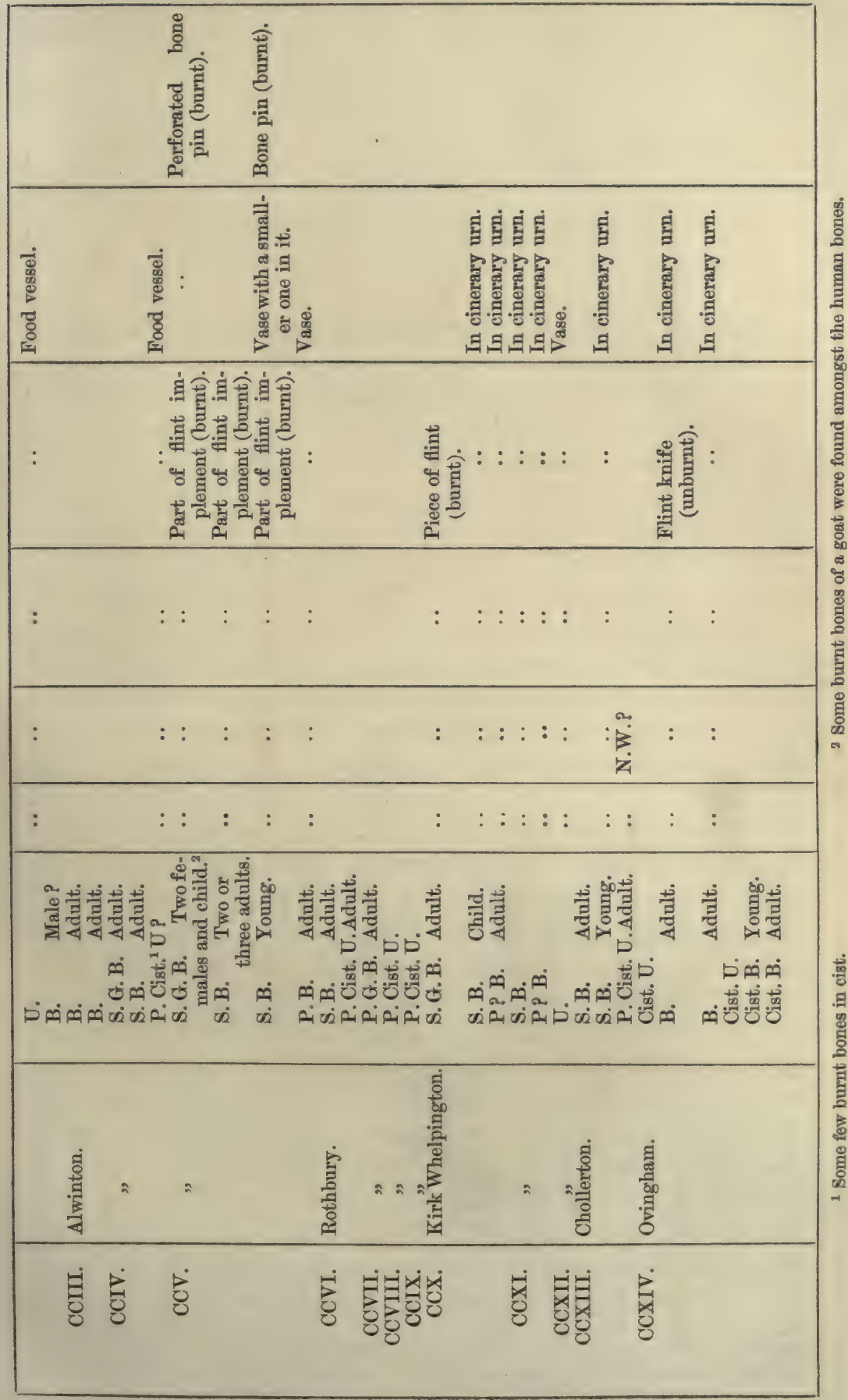




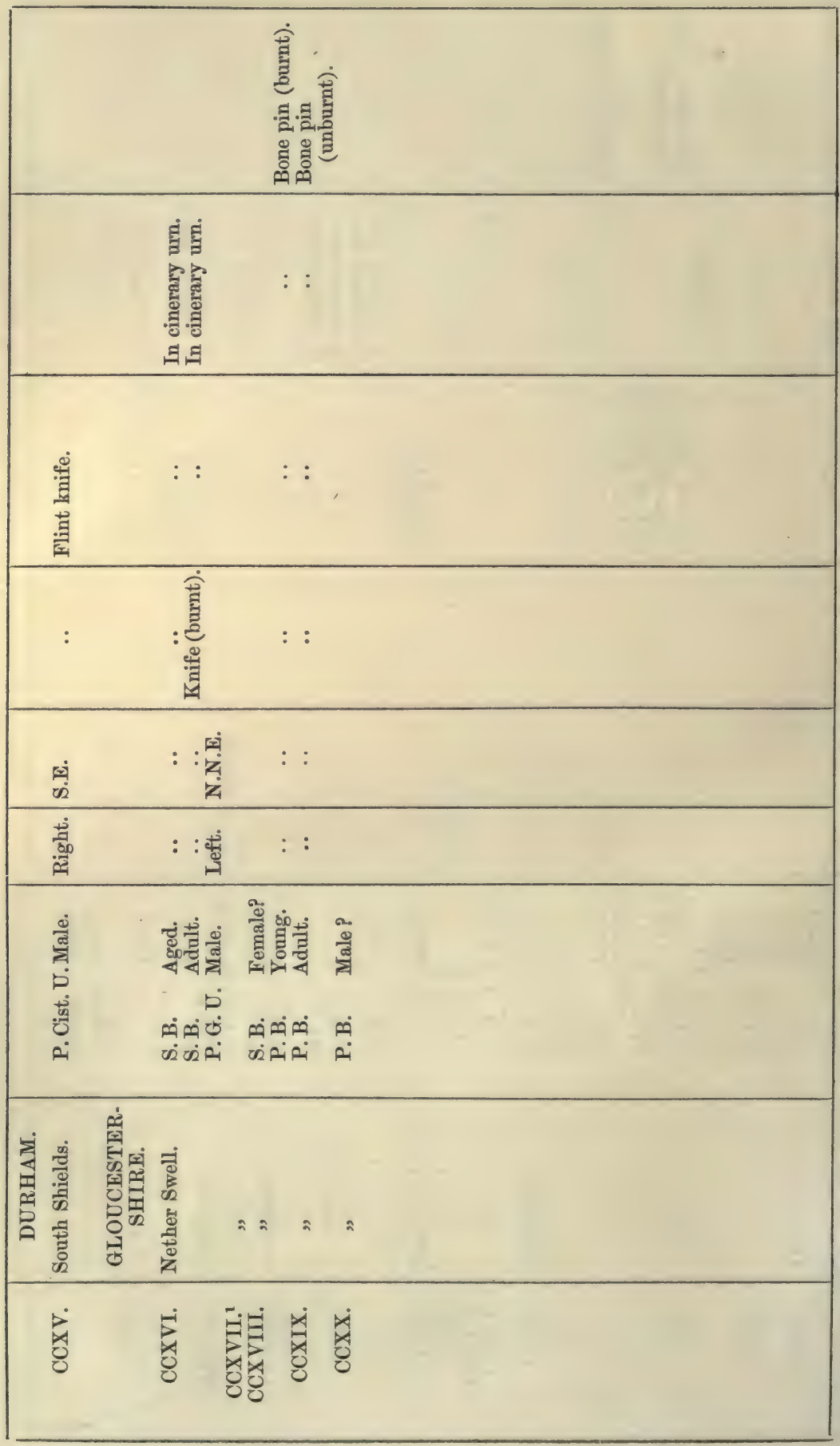




\section{L $0 \mathrm{NG}$ B ARR 0 W S.}

THe class of barrows, the examination of some of which I am about to describe, is one not by any means common in Yorkshire, nor indeed, save very exceptionally, in any part of Britain. They occur, however, in very considerable numbers in some of the southwestern counties of England, and are especially abundant in Wiltshire, Gloucestershire, and Dorsetshire; they are also found, but more sparingly, in Caithness. To this class of sepulchral mound, on account of its form, the name of Long Barrow has been given. The long barrows of one district in the south-west of England, namely North Wiltshire and Gloucestershire (and the same may be said of those in Caithness), having many points of resemblance with those I have examined in Yorkshire and Westmoreland, possess one distinctive feature which is wanting in the latter counties. They are frequently found to contain a chamber, of varied shape and of greater or less extent, constructed of stone, within which the primary interments have taken place. The chamber has in many instances a passage or gallery leading into it from, or near to, the exterior of the barrow. This feature is entirely wanting, within my experience, in the Yorkshire long barrows, as it is in those of South Wiltshire and Dorsetshire. This important difference is not, however, in all probability, due to any diversity in time or people, but to local circumstances and other conditions by which it was regulated. For while large blocks of stone, suitable for erecting such a structure as I have mentioned, are abundant in North Wiltshire and the adjoining county, they are not met with in South Wiltshire and the neighbouring district in Dorsetshire, any more than they are in some of those localities where the long barrows I have examined are situated. For the same reason the smaller receptacles of stone (cists) so common in many parts of Britain are all but unknown on the chalk-range of the Yorkshire Wolds ${ }^{1}$. I

\footnotetext{
${ }^{1}$ It would be well if a clear distinction in terms could be made between the two classes of receptacles for interments which are met with in the barrows. The one,
} 
have known long barrows, however, to occur without a chamber where suitable stone for making one was abundant, as for instance on Kepwick Moor [No. cexxvii] and Raiset Pike [No. cexxviii], where in the former instance the burials were by inbumation and in the latter after cremation. In the same way the round barrows of a later time, situated in districts where large slabs of stone well adapted for making cists are abundant, are frequently found to have the interments within them placed in the mound without any such protection.

Before entering upon a specific description of the long barrows I have opened, it will be necessary to mention another way in which these sepulchral mounds in Yorkshire differ, and that very materially, from those in the south-west of England. In the latter the long barrows have been found to contain, in almost every instance, bodies which have not been subjected to burning, whilst in Yorkshire, in every case except one, they have been, in a greater or less degree, submitted to the action of fire. In the long barrows of Caithness, as well as in those round ones there which may be supposed to be contemporaneous, burial by inhumation and after cremation seems to have been indifferently practised. Nor does the evidence show that the one mode was earlier than the other.

It has already been stated that long barrows exist in Caithness ${ }^{1}$. They agree with those in England in being, as a rule, placed approximately east and west, also in having one end, and that the east, broader and higher than the other, as well as in other particulars. They are also frequently provided with walls, which enclose and support them, and have sometimes the peculiarity of having what have been termed 'horns.' These are formed by the enclosing walls

having a gallery or other entrance leading or opening into it, by means of which it was intended that access might be had from time to time for burial or for other purposes, it would be best always to call a chamber. The other, which is closed in on all sides, a stone box in fact, and which, when once the body or bodies for whose reception it was constructed were placed within it, was not meant to be again opened, should always be called a cist. The two different receptacles are found to arrange themselves co-ordinately with the two classes of barrows which may be attributed to an earlier and later period in ante-historic times, not only in Britain but in Scandinavia, Germany, Holland, France, and other countries of Europe. The chamber is characteristic of the long barrow and of some of the round barrows which, like the long barrows, appear to belong to a time antecedent to a knowledge of metal; whilst the cist is characteristic of the later round barrows, in which very frequently articles of bronze are found associated with the interments, and which, if they do not belong exclusively to a period after the introduction of metal, are the burial-places of a time not long previous to its use.

${ }^{1}$ See papers by Mr. Joseph Anderson, Proc. Soc. of Ant. of Scotland, vol. vi. p. 442, vol. vii. p. 480; Memoirs of Anthrop. Soc. of London, vol. ii. p. 226. 
inclining outwards at the ends and then being returned with a curve inwards, making at the point in question a figure something like the conventional representation of the broader end of the human heart. This curve usually constitutes the mode of approach into the burial chamber when it is placed at the end of the mound ${ }^{1}$. The same remarkable feature is found in some of the long barrows of the south-west of England, and two in Gloucestershire, which certainly possessed it, are described in the sequel. In these two cases however, as well as in others, the 'horned' end had no opening, the walling being carried completely unbroken round the end of the barrow ${ }^{2}$. In some of the round or short cairns in Caithness the same mode of construction, with enclosing walls and recurved entrances leading into chambers, exists, indeed they are in all particulars, except in shape, like the 'horned' long cairns. It seems scarcely possible to attribute these long and short cairns, both possessing this marked characteristic, to any widely differing or distant times; and when the nature of the interments which occur in both kinds, and other circumstances attending them, are taken into consideration, they must, I think, be regarded as belonging in the main to the same period. A very close connection thus appears to exist between the long barrows and certain of the short or round barrows of Britain, not only in respect of the enclosing walls and recurved entrances of the chambers, but also on account of their both possessing chambers as opposed to other stone receptacles for the dead, and from the absence of metal, and from other characteristics, as for instance the scarcity of vessels of pottery, in association with the interments. A like connection appears also to exist between the British long barrows and the chambered burial mounds of some other countries of Europe, and it may be desirable to discuss this subject a little more fully. In the south of Sweden and in Denmark barrows with chambers and passages or galleries, resèmbling, ceteris paribus, those found in Britain, are abundant, and many of them have been examined. These Scandinavian chambered mounds, like the long barrows of Britain and those round ones which probably belong to the same period, have pro-

1 In the long barrows at Uley in Gloucestershire, and Stoney Littleton in Somersetshire, the recurved end formed the entrance into the chamber, or in these cases rather chambers.

${ }^{2}$ Other two long barrows at Nether Swell, besides those referred to, appear to have had the recurved ends without any opening into a chamber, and the same feature was present in those at Ablington, Belas Knap near Charlton Abbots, and Rodmarton, all in Gloucestershire, and at Littleton Drew in Wiltshire. 
duced, in association with unburnt bodies, numerous implements and weapons. These implements are all made of stone or bone, nothing whatever of metal having been discovered; nor can there be any doubt, when the many burials which have been disinterred and the abundance of associated articles are taken into consideration, that these barrows belong to a time antecedent in that country to a knowledge of any metal, gold perhaps excepted. And as the long barrows of Britain and the chambered mounds of Scandinavia agree in this particular, that metal is alsent in each, so do the barrows in both countries, which belong to a time when bronze had come into use, agree in an equally characteristic feature. At that time the burning of the dead was in Scandinavia the prevailing though not universal custom, whilst in Britain cremation and inhumation were practised in something like equal proportions. In both countries, however, the custom of interring the dead in chambers had passed away, and whenever the bodies were placed within a receptacle of stone, that took the form of a cist. So far then as the construction of the burial mounds of the two countries is concerned, reference being made to the long barrows of the one and the chambered barrows of the other, and having regard also to the occurrence in each case of no other implements or weapons than those of stone or bone, they might be considered as the places of sepulture of one and the same people. But when the crania are taken into consideration, the identity between the people of Scandinavia and Britain, at the time of the construction of the barrows in question, cannot be admitted. The skulls are as markedly different as any two series of crania can be; the skull of the long barrows of Britain being emphatically dolicho-cephalic, the skull of the chambered barrows of Scandinavia being, with few exceptions, as emphatically brachy-cephalic, and presenting many features in common with the ordinary head of the later and round barrows of Britain, which in the main probably belong to a time after the introduction of bronze. This fact seems to be quite inconsistent with the theory which would make what have been called the dolmen-builders a single race which dispersed itself along the western shores of Europe, from Sweden even as far as Algeria. It is indeed true that there is a very remarkable identity in many respects between the several examples of the particular class of burial mounds we are now considering in the countries just above referred to, but in the absence of identity of skull-form it appears impossible that they can have been constructed by the same people. 
Fully admitting that the resemblance can scarcely be due to a mere accident, or to an instinctive power by which human minds and hands, with a common purpose and the same appliances and similar conditions of life, produce results almost the same, I should incline to regard the like features in the barrows in question as the result of a wide-spread and continued intercourse between different peoples living under somewhat the same state of cultivation. Passing by the Hunebedden (giants' graves) abundant in the Province of Drenthe in Holland, which seem to belong to the same class of sepulchral places as the chambered barrows of Denmark, but of the original contents of which not much is known in consequence of their having been for long past open and subject to being rifled, we arrive at a very large number of chambered barrows, both of the long and round form, in the west of France, including the Channel Islands, which are spread from Brittany to the Gulf of Lyons. All the evidence we possess, which amounts to a large aggregate of facts derived from an examination of these mounds, shows very conclusively that they are the burial-places of people unacquainted with metal; for though abundance of stone implements have been found in some of the chambers, no article of bronze, much less of iron, has been discovered. But when the skulls are taken into consideration, it becomes apparent that, unlike the long barrows of Britain, they are the burial-places of more than one race. Both brachy-cephalic and dolicho-cephalic heads have been met with in apparently undisturbed chambers, nor can it be said that one type is much more abundant than the other. This fact again seems to point to intercourse and admixture, rather than identity of race, as being the source of the same mode of interment. It is not necessary to make any remarks on the apparently similar sepulchral mounds and chambers of Spain and Portugal, nor indeed have we the information which would enable us to come to any certain conclusion in regard to them. It may suffice again to draw attention to the fact that throughout a large area on the west of Europe there exist numerous burial-places under mounds both of a long and of a round form, which, when the receptacle for enclosing the body or bodies is made of stone, is constituted by a chamber and not by a cist, and that nothing whatever of metal except gold has ever been discovered in them. 
Parish of Ebberston, North Riding. Ord. Map. xcv. s.w.

The first long barrow I opened was situated in a district which is very rich in various remains of early occupation. The Scamridge Dykes, an extensive series of mounds and ditches, forming part of a great system of fortification, apparently intended to protect an invading body advancing from the east, and presenting many features in common with the wold entrenchments on the opposite side of the river Derwent, are situated very near to the barrow. The adjoining moorland is thickly sprinkled with round barrows, all of which have at some time or other been opened, with what results I know not; while cultivation has, within the last few years, destroyed a large number, the very sites of which can now, only with great difficulty, be distinguished. On the surface of the ground flint implements are most abundant, and there is probably no place in England which has produced more arrow-points, scrapers, rubbers, and other stone articles, than the country in the neighbourhood of the Seamridge Dykes.

CCXXI. The barrow is placed nearly due east and west, and is 165 $\mathrm{ft}$. long, with a breadth of $46 \mathrm{ft}$. at the west and $54 \mathrm{ft}$. at the east end, whilst the height rises from $7 \mathrm{ft}$. at the west end to $9 \mathrm{ft}$. at the east. It is formed-with the exception presently to be specified-of oolitic rubble, with some mixture of clay and earth. It had also a thin layer of mould over its surface, due probably to the decay of the vegetable growth of many centuries. On account of the large size of the mound, and from its having been one of the first barrows I opened in Yorkshire, I did not make the same exhaustive examination I have since judged it necessary to carry out in all my later investigations of grave-mounds. In this case I proceeded by cutting a series of wide trenches into the mound, a system I have long since abandoned in favour of that of completely turning over every portion of the barrow throughout its whole width, though not always carrying the cutting entirely through to the further side. I have no doubt, however, that in the present instance all the primary interments were discovered, and that nothing of any material importance, so far as the original purpose of the barrow is concerned, was overlooked.

The examination was commenced by making a cut, $12 \mathrm{ft}$. wide, through the barrow, near to the west end. This, as I had anticipated, from a knowledge of what has occurred in many of the long 
barrows of Wilts and Gloucestershire, brought no signs of an interment to light ${ }^{1}$. About $5 \mathrm{ft}$. from the exterior, on the north side, was found a regularly-built wall of limestone flags, carefully embedded in clay. This wall was $8 \mathrm{ft}$. in thickness, and on reaching its inner side the rubble and clay, of which the mound was mainly formed, was again reached. I am unable to say how far this wall extended along the side of the mound; but it stretched beyond the cut on either side, and may very possibly have been carried along the entire length of the barrow ${ }^{2}$. A second cut was next made at about $20 \mathrm{ft}$. from the east end and on the south side, at a place where a slight opening had been made on some previous occasion. Just beyond the limit of this former cutting (which extended to a distance of $15 \mathrm{ft}$. from the outside) and disturbed to some extent by the falling down of the rubble at the end of it, was an unburnt body, laid $2 \mathrm{ft}$. below the surface of the mound. On account of this disturbance it could not be ascertained with certainty whether the body had been interred at full length or in a contracted position; but I think, from the narrow compass within which the bones were placed, it is scarcely possible that it had been laid at full length. There can be no doubt, however, that it was a secondary interment, and, probably, not made by the people who originally raised the mound. It was quite apart from the rest of the bodies, and at some distance from the central line of the barrow where the principal deposit of bones was found. The skull, also, is of quite a different type from all the other skulls met with in the barrow, this having a cephalic index of 80 , whilst the rest are all markedly dolicho-cephalic.

On coming near the central line of the barrow a difference in the material was observed; the mixed rubble, clay, and earth, closely

${ }^{1}$ I am here speaking of the experience of other explorers. Since I opened the Ebberston long barrow I have, in examining some others in North Gloucestershire, found that the rule of the primary interment having been made at the larger end of the mound by no means holds good in all cases.

${ }^{2}$ The long barrows at Stoney Littleton, Somersetshire, and Uley, Gloucestershire, described in the Arch. Journal, vol. vi. p. 315, had round them a dry wall of horizontal courses of stone, from $2 \mathrm{ft}$. to $3 \mathrm{ft}$. in height. The barrow at West Kennet, Wiltshire, seems to have had a similar wall of horizontal courses, with large upright stones at intervals. See paper on Long Barrows, by Dr. Thurnam, Archæologia, vol. xxxviii. Dry walling, running throughout a great extent of the mound, was met with in the long barrows at Rodmarton and Ablington, Gloucestershire. It will be seen from the account, in the sequel, of the examination of three barrows at Upper and Nether Swell, Gloucestershire, that a wall surrounded the mound. Similar features have occurred in the chambered cairns of Caithness. See Proc. Soc. of Ant. of Scotland, vol. vi. p. 442 ; vol. vii. p. 480. 
compacted-so closely, in fact, that working it was almost like quarrying stone-gave place to loose oolitic rubble, which lay in a deposit $3 \frac{1}{2} \mathrm{ft}$. broad, running, for about $40 \mathrm{ft}$., east and west, from the east end of the mound and along the central line of the barrow. This deposit was $3 \mathrm{ft}$. in height, and had above it a layer, $2 \mathrm{ft}$. in thickness, of earth and small stones, while it rested upon a thick stratum of yellow clay which itself was laid upon the natural surface. Under this oolitic rubble, and lying upon the clay, were found the original interments; the mode of burial and the state of the bodies proving to be very remarkable. Amongst the loose rubble were deposited the remains of at least fourteen bodies, not laid in any order, but with the component bones broken, scattered, and lying in the most confused manner; half a jaw, for instance, upon part of a thigh bone, and a fragment of a skull amidst the bones of a foot, whilst other portions of apparently the same skull were found some distance apart. Nor was this disarrangement due to any disturbance of the barrow after its erection: on the contrary, there were most certain indications that the bones had been originally deposited exactly as they were found. From the dislocated and broken state in which they occurred there can be little doubt that, before they were entombed, the flesh had been removed; and this fact suggests a theory which will presently be considered. The opening was cut into the before-mentioned deposit of oolitic rubble somewhere about its middle point, and as the investigation was carried on towards the east, there were found signs of burning, at first slight but gradually becoming more evident, attested by the occurrence of burnt clay, stones and bones, together with charcoal, until at the east end the oolitic limestone had become lime and all trace of bone had disappeared. Beyond the limits of this line of burnt stone and clay (which was, as before mentioned, $3 \frac{1}{2} \mathrm{ft}$. wide), the contiguous and enclosing material on each side of it showed only very slight traces of burning. The transition, indeed, was very marked, and the passage from matter burnt in the highest degree to that almost untouched by fire was as distinct and welldefined as it could be. The same feature will be found to have existed in other long barrows presently to be described.

As the exploration advanced from the point where the eutting first touched the line of rubble (there unaffected by fire) towards the west, the deposit of bones, which were also unburnt, became gradually more sparing, until, before reaching the end of the rubble, all remains of them had ceased. At its west end the line 
of rubble expanded into a regularly constructed cairn of stones, carefully laid in order from a central point, and placed upon the stratum of clay already mentioned. The diameter of this cairn was $18 \mathrm{ft}$., and its centre was $49 \mathrm{ft}$. from the east end of the barrow. There was nothing found beneath it, nor was there any indication that a body had ever rested there. The cairn itself, being enclosed within the larger mound, must have been first constructed; and no doubt was made at the same time as the line of oolitic rubble, of which, indeed, it seemed to form a part ${ }^{1}$. An examination of that portion of the barrow which lay to the west of the cairn disclosed merely the continued employment of the same material as had been used in other parts, namely, the firmly-compacted oolitic rubble, clay and earth; nor was there anything to show that burials had taken place beyond it. No trace of metal, no fragment of pottery, no piece of flint, was met with in the entire barrow, so far as it was examined.

Before making any remarks upon the singular facts afforded by this barrow, and before entering on any enquiry as to the relative age of the long barrows, and the information we seem to gain from a knowledge of their contents, I think it best to give a detailed account of the examination of some other barrows of that class in Yorkshire, Westmoreland, and Gloucestershire. In doing this I shall depart from the rule to which $I$ have adhered in the account of the round barrows, that of describing them in the order of their locality. I think I can thus best bring before the reader the several facts they disclose; and the plan will not, moreover, be materially departed from, as the whole number I have opened amounts in all to no more than twelve.

\section{Parish of Willerby, East Riding. Ord. Map. xcv. s.w.}

CCXXII. Upon Willerby Wold, in close proximity to several round barrows, most of which $I$ have opened, is a single long one.

1 At the time this cairn was an inexplicable feature, but subsequent examinations of long barrows, especially of those at Westow and Crosby Garrett, seem to explain its use. It is clear that the long barrows, where cremation was practised, were so constructed that the bodies might be burnt after they were covered by the mound. To ensure this, it was necessary to carry the burning along the line of the deposit of the bodies. This was effected by arranging the stones somewhat after the fashion of a flue, so as to create a draught, for which purpose a vent was required at the end opposite to that where the fire was applied. Provision for carrying this out appears, in the case of the present barrow, to have been made by the cairu in question. 
It is $132 \mathrm{ft}$. long, $50 \mathrm{ft}$. wide at the east, and $40 \mathrm{ft}$. at the west end, where the height is $5 \frac{1}{2} \mathrm{ft}$., the opposite end being $7 \mathrm{ft}$. high. A shallow trench was observed along both sides of the mound, but it was not continued round the ends. This feature is frequently found in connection with the long barrows of Wiltshire, and ean scarcely be considered as merely accidental. The mound was composed of chalk-rubble, flints, and earth. It may be well, before describing the primary burials, to say that what was no doubt a secondary one was met with, at a place $38 \mathrm{ft}$. distant from the east end, on the central line of the barrow, and $2 \mathrm{ft}$. below its surface. It was that of an unburnt body, laid on the back, but inclining to the left side, the legs drawn up, the hands erossed upon the chest, and the head to $\mathbf{E}$. It was very much broken up by rabbit digging, and the skull in consequence was only fragmentary.

Along the central line of the barrow, and commencing at the east end, where the action of fire had been the strongest, was a deposit of calcined chalk and flint, $3 \frac{1}{2} \mathrm{ft}$. wide, and about $4 \mathrm{ft}$. high, resting upon the natural surface. The evidence of burning became gradually less towards the west. At a point $30 \mathrm{ft}$. from the east end there was a large quantity of charcoal in lumps, placed just above the natural surface and covering some burnt bones. Beyond this point, although the deposit of chalk and flint still continued, there were no signs of the action of fire. As was found to be the case in the Scamridge long barrow just above described, the mesial deposit of chalk and flint in this mound was perfectly distinct from the general material of the barrow ; and the burning, even in that part where it had been the strongest, had affected the enclosing chalk rubble and earth only in the slightest degree. The mass of burnt chalk and flint was in some places so hard that it required the vigorous use of the pick-axe to break it up; whilst in others it was of a soft and, to the touch, of a greasy character, and of a most beautiful pale greenish-yellow colour; this proved, on analysis, to be merely burnt chalk and silex. At the bottom of the calcined matter, and mainly about $14 \mathrm{ft}$. from the east end of the barrow, were numerous fragments of human bones, evidently disjointed and dislocated, and probably incomplete before they had been there deposited. They were placed amongst the burnt chalk and flint, sometimes enclosed in the hard calcined mass as fossils are in the rock ${ }^{1}$. Two fragments of a plain, apparently round-

1 A long barrow was removed, in the course of agricultural operations, on Heslerton Wold, in the years 1862 and 1867. From the account given me by Mr. Dunhill, the 
bottomed earthenware vessel (one a piece of the rim) and a bone pin were enclosed in the calcined chalk together with the bones.

The way in which the bones were disposed in the burnt chalk and flint has been mentioned; but the bones themselves present some characteristic features which require to be noticed. In this, as in all the long barrows, and where the bones have been subjected to the action of fire whilst placed under an overlying mass, there is a marked difference in their appearance from what is presented by those which have been burnt on a pile and where the air had free access during the process, these latter being such as are found in the deposits of burnt bones met with in the round barrows. No description will convey a precise impression of the difference between them, but it is one which cannot be mistaken by those acquainted with the two kinds of calcined bones.

At a distance of $38 \mathrm{ft}$. from the east end, and $2 \mathrm{ft}$. above the natural surface, and amongst the material of which the mass of the barrow was composed, was part of a red-deer's antler, together with some human bones-a femur, pelvic bones, and lumbar vertebræ; while, just above these, were some portions of animal bone

tenant, and from what I learned from the workmen, precisely the same features occurred there as in the barrow on Willerby Wold. There was a narrow deposit of hard burnt chalk, running along the mesial line of the mound, from the east end for some distance towards the west (the barrow lying east and west, the east end being the broadest and highest), in which were seen numerous remains of burnt bones; but there was no appearance of an entire skeleton; the bones seemed on the contrary to be dislocated and broken. Some interments of unburnt bodies, probably secondary, were found at various points near the surface of the barrow; but, with the exception of the scattered bones enclosed in the burnt chalk at the east end, there was no burial found on the natural surface throughout the entire mound. Also, at the east end of a long barrow, removed several years ago, near Helperthorpe, the same peculiar deposit of calcined chalk was observed, having amongst it some broken bones. The calcined matter was so novel in its appearance that the people of the neighbourhood preserved specimens of it about their houses, thinking it was some petrified substance, on account of the resemblance it bore to the concretions formed by springs highly charged with carbonate of lime.

Sir R. Colt Hoare found bones deposited much after this fashion in what was probably a long barrow, though not a very typical one. This barrow on Winterbourne Stoke Down, near Amesbury, was 104 ft. long, $64 \mathrm{ft}$. wide at its larger end and $45 \mathrm{ft}$. at the smaller, running nearly east and west, with the broader end to the east. In it was ' a rude conical pile of large flints, embedded in a kind of mortar made of the marly chalk dug near the spot. This rude pile was not more than $5 \mathrm{ft}$. in the base, and about $2 \mathrm{ft}$ high in the highest part, and was raised upon a floor on which had been an intense fire, so as to make it red like brick. . . . . . . We very unexpectedly found the remains of the Briton below, and were much astonished at seeing several pieces of burned bones intermixed with great masses of mortar, a circumstance entirely curious, and so novel that we knew not how to decide upon the original intent of the barrow. ...... On exploring this barrow further to the east we found two deep cists containing an immense quantity of wood ashes, and large pieces of charred wood, but no other signs of an interment.'-Anc. Wilts, i. 117. 
and a single fragment of a plain earthenware vessel. All these objects lay below the place where the contracted body was buried; but they did not appear to have been deposited subsequently to the first construction of the barrow.

It will be observed that there is a great similarity between this barrow and that at Seamridge, as to the way in which the original interments appear to have been deposited. In both there were the disjointed, scattered, and perhaps broken bones laid below, and partly amongst, a line of stones running east and west through the centre of the longer axis of the mound. We have also in both cases evidence that fire had been applied at the east end to this linear mass of stone with wood interspersed, so that the bones had been scorched or burnt by the igniting of the limestone or chalk overlying them. In both eases the bones, as has been said, were disjointed and displaced, and had probably been deprived of the flesh before they were laid, in the one instance, on the natural surface, in the other, on a layer of clay. It is not easy to understand how the fire was applied to the overlying deposit of stone, the more so when it is considered that this deposit itself was placed within a large mass of ineombustible matter. My opinion for some time (in fact until I examined the barrow next to be described) was that the deposit of stone which overlaid and enclosed the bones was set on fire by wood placed partly beneath and partly upon it, and that afterwards the general mass of the barrow was thrown upon the ignited stone, by which process that part in contact with the burning stone was to a certain extent altered by heat. I am now inclined to think that a different process was adopted, the manner of which will be presently explained.

\section{Parish of Westow, East Riding. Ord. Map. xciII. n.e.}

At a distance of not quite a mile east of the village of Westow, on the slope of the oolitic hill which bounds the valley of the Derwent on the south, are two barrows, the one of oval, the other of the ordinary round bowl-shaped, form. Not very far from the site of these mounds was discovered, about thirty years ago, a large hoard of bronze implements, consisting of socketed axes (celts) of different types, gouges, and chisels. Many of them are preserved in the York Museum, but a greater number were dispersed. There was, probably, no connection between the people buried in either of the two barrows and the owner of the bronze 
articles, himself most likely a dealer in such things; the mounds having been, very possibly, in existence many eenturies before the bronze implements were cast.

CCXXIII. The oval barrow was $75 \mathrm{ft}$. in length and $40 \mathrm{ft}$. in width, and had a direction south-east and north-west. It proved to be, in some of its features, one of the most interesting sepulchral mounds that I have examined, and seems to clear up the difficulty as regards the manner in which the burning of the bodies in the long barrows was accomplished. It had originally been a long barrow, of the ustal proportions as to length and breadth; but, at a time subsequent to that of its construction, it had been added to on the south side, for the purpose of placing in it some additional interments. In consequence of this addition, the form had become altered from that of a long mound to that of an oval one. The additional part was made of earth.

Before describing the manner in which the original long barrow was constructed, and the way in which the primary interments had been made, it will be well to give in detail the circumstances connected with the several secondary burials found in the added portion. At a distance of $14 \frac{1}{2} \mathrm{ft}$. south-south-west of the present centre, an oval cist was met with, placed on the natural surface of the ground. It was formed by ten oolitic flag-stones set on edge, and had two similar stones for a cover, and was paved at the bottom with three more. It was $3 \mathrm{ft} .10 \mathrm{in}$. long, $2 \mathrm{ft} .10 \mathrm{in}$. wide, and $1 \frac{1}{2} \mathrm{ft}$. deep, and had a direction east-south-east and west-northwest. In it was the body of a child, about ten years old, laid on the right side, the head to W. by N., the hands being to the hips; the head was placed close to the south-west side of the cist. There were also some few disturbed bones of a second and adult body in the cist. At the same distance south-south-east of the centre was a second cist, formed like the first, but having only eight stones for the sides, with three as covers, and the bottom, which was a foot above the surface-level, paved with a number of small flags. It had a direction south-west-by-west and north-east-by-east, and was $3 \mathrm{ft}$. long, $2 \mathrm{ft}$. wide, and $1 \mathrm{ft}$. deep. In it was the body of probably a woman, at least twenty years of age, laid on the left side, the head to W.S.W., and the hands to the hips. Just above the level of this cist, and a little to the east of it, were some disturbed human bones, and the core of an ox-horn, with other ox-bones; under them, and alongside a large slab set on its edge, 
and on the natural surface, was much burnt earth. A third cist was discovered $16 \frac{1}{2} \mathrm{ft}$. south-east of the centre. It was placed $3 \mathrm{ft}$. above the surface-level, and consisted of two side slabs, and one across the corner, with three flags on the bottom; the cover stones and the other side stones had, probably, been removed when the mound was ploughed over, as the top was so close to the surface that they must have come in contact with the plough. It was $2 \mathrm{ft} .8 \mathrm{in}$. by $2 \mathrm{ft} .6 \mathrm{in}$., and $1 \mathrm{ft}$. deep; and on the bottom was the body of a woman, past the middle period of life, laid on the right side, the head to $\mathrm{S} . \mathrm{W}$. by W., the hands being on the hips; some few burnt bones were likewise found in the cist. In that part of the barrow which I have presumed to be of a later construction than the original mound, and where the cist-burials were met with, several flint chippings and some pieces of plain dark-coloured pottery occurred.

It remains now to describe the primary long barrow and the way in which the burials had taken place within it. The same manner of disposing of the bodies had been followed in this as in the two last-described barrows; the burials had been made in a deposit running through the centre of the longer diameter of the mound, at its eastern extremity. There were, however, some features in this differing from what was observed at Scamridge and on Willerby Wold. The mound was not quite east and west, having a slight deviation towards the south at the one end and towards the north at the other. I will however, for the sake of brevity, speak of the barrow and the mesial deposit in which the burials were placed, and which had the same direction as the enclosing mound, as being east and west: in this, as in all the other long barrows I have examined in Yorkshire, the east end being that where the interments had been made. The mesial deposit commenced just within the eastern verge of the mound, and continued, for a distance of about $30 \mathrm{ft}$., towards the west, where it ceased. It had a general width of $4 \frac{1}{2} \mathrm{ft}$., and reached to the present surface of the barrow. The commencement of this deposit at the east end requires a careful and minute description, which I now proceed to give. At a distance of about $11 \mathrm{ft}$. south from the place where the deposit had its beginning, measuring from the middle of the line of that deposit, an excavation was met with, running south-by-west and north-by-east, $6 \frac{1}{2} \mathrm{ft}$. wide at the top, and continuing of that width for a depth of $1 \mathrm{ft}$., when it narrowed to a width of $4 \frac{1}{2} \mathrm{ft}$. on the east side, and was sunk $13 \mathrm{in}$. lower into the rock; this oblong 
excavation consequently being of two levels on the bottom. Against the edge of the higher part, their lower ends being placed on the bottom of the deeper stage of the excavation, were three slabs, placed in a continuous line, of the same kind of stone (oolitic sandstone) as that in which the excavation was made. They were of different sizes; that furthest to the south was $2 \mathrm{ft}$. $9 \mathrm{in}$. long and $2 \mathrm{ft} .3 \mathrm{in}$. high, the next $2 \mathrm{ft} .8 \mathrm{in}$. long and $2 \mathrm{ft}$. high, the third and most northern one being $1 \frac{1}{2} \mathrm{ft}$. long and $2 \mathrm{ft}$. high. They all, therefore, rose above the level of the bottom of the upper stage of the excavation, and one of them above that of the natural surface. I will not pretend to give any explanation of the purpose of these slabs thus carefully placed : it may be they were simply set against the edge of the hollow, from which they had been taken, as being the least troublesome way of disposing of them, the object of the excavation being not so much to obtain width as depth. The deeper part of this trench was filled with burnt earth and stones to within 6 in. of the line of slabs, where the deposit was found to be untouched by fire; but above the level of the deeper part the whole trench, up to the level of the natural surface, was filled with burnt matter; no bones, however, were met with in any part of the excavation. This trench continued towards the north for a distance of $2 \mathrm{ft} .9 \mathrm{in}$. beyond the end of the line of slabs, and had an extension, running at a right angle towards the west, for a distance of $8 \mathrm{ft}$., of the same width ( $2 \mathrm{ft} .9 \mathrm{in}$.) and depth ( $2 \mathrm{ft} .1 \mathrm{in}$.) as the trench itself. This extension was also filled with burnt matter up to the level of the natural surface, but it contained no bones. To the north of what may be called the elbow of the trench was a deeper excavation, which went down 12 in. lower into the rock; the bottom being about $3 \mathrm{ft}$. below the level of the surface of the ground. This was found to be the commencement of the mesial deposit which ran through the central part of the original mound, and within which the burials were contained. The beginning then of the burial deposit, which was just within the eastern end of the mound, consisted of a trench $4 \frac{1}{2} \mathrm{ft}$. wide and $3 \mathrm{ft}$. deep ; it was filled in with burnt earth, stones, and charcoal, and this reached up to the present surface of the barrow. A few ealcined bones, not certainly human, were met with close to the east end, but not in any quantity and much scattered. The excavated part gradually lessened in depth towards the west, until, at a distance of $12 \mathrm{ft}$. from the commencement, it lost itself in the surface. Above this trench, and beyond its limits westward, 
extending over the whole length of the mesial deposit which contained the burials, was a pile of oolitic slabs, arranged in a sloping fashion from the middle to the outside, forming a roofshaped ridge, $4 \frac{1}{2} \mathrm{ft}$. wide, and rising to the surface of the barrow. Under this, and resting upon a pavement of flag-stones $2 \frac{1}{2} \mathrm{ft}$. wide, which extended from a point $12 \mathrm{ft}$. west of the commencement of the mesial deposit to the end of the same, for a distance of $18 \mathrm{ft}$., the principal part of the burials were discovered. Below the flagstones the surface-soil was reddened by the action of fire, to a depth of about $6 \mathrm{in}$. Great quantities of charcoal were found all along the outside of the burnt matter and underneath the pile of stones arranged roof-fashion, to which allusion has been already made. Without this pile, the material of the containing mound, consisting principally of earth, was also reddened by heat, the discoloured earth sometimes running for more than a foot in an irregular fashion into the surrounding and unaltered material.

The principal primary burials commenced with the flagging, $12 \mathrm{ft}$. west of the eastern end of the mesial deposit. The first met with consisted of a large number of calcined bones belonging to three bodies, irregularly disposed, and not presenting the appearance of having been complete when first deposited in the mound, though this appearance might be caused by the three bodies being laid in close juxtaposition. They were placed on the flagging above mentioned, which was at this point about $2 \mathrm{ft}$. above the level of the natural surface, and were covered over with burnt soil of a very fine description, having much of the appearance of what burnt turfs would have resulted in : over this was the ridge-shaped pile of flag-stones. The bones, which are those of two young women (one 18 to 20 , the other 20 to 24 years of age) and of an infant, extended over a space of about $5 \mathrm{ft}$. in length, and $2 \frac{1}{2} \mathrm{ft}$. in width, that of the pavement. About $9 \mathrm{ft}$. west of the first deposit of bones was a body, laid on the right side, in the ordinary contracted position, with the head to N.W. The bones were completely calcined, though still remaining in their natural order, and were covered, as in the case of those last mentioned, by fine burnt earth and the ridge-shape pile of stone. The body was that of an adult, probably a man. Immediately to the west of this last was a second body, that of an adult, of no great strength and of uncertain sex, presenting the same features as the former one. It was also laid on the right side, but with the head to N.E. ; the heads of both bodies being almost in immediate contact. Close by the second 
body, but still further to the west, was the body of a child, with the milk dentition, burnt like the two last. The signs of burning began to be less evident about this point, though the action of fire had still been considerable. One foot to the west of the child were some burnt bones of a strongly-made adult man, but only fragmentary ones, and never having formed (though all the bones of one leg were present) a perfect body when placed in the barrow. The flagging still continued, having gradually declined from a height of $3 \mathrm{ft}$. until where it ceased it rested upon the natural surface. The evidence of fire became gradually more and more scanty, and, at a distance of $30 \mathrm{ft}$. from the commencement of the mesial deposit, the burning, flagging, and the ridge-shaped pile of stones disappeared together, the ordinary earthen material of the mound taking their place. A single piece of plain pottery occurred in the burnt matter at the east end of the deposit.

The peculiar arrangements of this long barrow appear to give an explanation of the way in which the burning of the bodies in these mounds had taken place. It seems to have been done in this manner. The bodies, sometimes in a complete state, at other times fragmentary and the bones disjointed, were laid at or above the level of the natural surface, on a thick layer of clay, or, as in this case, on a pavement of flag-stones; upon them were placed, as here and at Rudstone, turfs or earth, and upon that again stone; there does not appear, in all cases, to have been any intervening turfs, the stone itself lying immediately upon the bones. Wood was placed amongst, alongside, and underneath the stone, the evident remains of it, in the shape of charcoal, being found abundantly in some parts; and in others, where charcoal is wanting, it is probable that the intense burning had consumed the wood too perfectly for any remains beyond a white ash to be left. Over and upon this covering deposit of stone was then thrown up the ordinary material of the barrow. It is not easy to say positively how the fire was applied in the first instance, but it is not unlikely that the cross trench at the south-east end of the mesial deposit in this barrow and in that of Raiset Pike, and the holes found in a similar position in those at Rudstone, Market Weighton, and Kilburn, were connected with the ignition of the pile. In the Market Weighton long barrow, opened by Professor Rolleston, and which I had an opportunity of inspecting from time to time as the work went on, there seemed to have been a further provision for continuing the operation of burning by 
means of side openings along the line of the mesial deposit. The mode of arrangement of the stones, in the form of a ridge-shaped pile, by means of which a draught might be kept up, and which corresponds to the manner of placing the limestone, in some description of kilns, for burning at the present day, seems to show how the fire would gradually spread from the place where it commenced until it reached the limit sought to be attained. This complete ignition was not always effected, for in the case of the Scamridge and Rudstone barrows the burning gradually decreased in intensity towards the west end of the deposit of bones, where it was found to have died out, leaving them entirely uncalcined. Even in the present instance there was an evident lessening of the action of fire, though it had not altogether ceased, before the end of the stones arranged to carry out the burning was reached. It is probable that at the end of the deposit furthest from that where the fire was applied, there was a construction of the nature of a chimney through which to carry the draught; of this, however, I have not met with any distinct signs, though there was somewhat of such an arrangement in this barrow, and to which the workmen gave the name of chimney. In a long barrow however on Crosby Garrett Fell, described later on, there was an evident provision for creating a draught, made by narrow chimney-shaped upright flues connected with the line of burning along the centre of the mound. The way in which the ordinary material of the mound was affected by heat appears to make it certain that the whole of the barrow was thrown up before the fire was applied; and though it does not seem to be an easy operation to ignite any material covered up by incombustible matter in the way in which it is found to be enclosed in these barrows, yet when the peculiar arrangement of the stones immediately overlying the bones is considered, it does not appear to be at all impossible. The men who were employed in opening this barrow were accustomed to burn lime; and they all agreed that there would be no difficulty in setting on fire and igniting the deposit in which the bones were placed, even though that was covered by the ordinary material of the mound; indeed, it became quite clear to them how the operation had been completed before my own doubts on the subject were resolved.

In this barrow it seemed almost certain that some of the bodies belonging to the primary interments had been buried in an entire condition, and with the bones in their proper order and juxtaposition, whilst the bones of others were in the same broken and 
dislocated state in which they have been observed in many long barrows, not only in Yorkshire but in other parts of England.

\section{Parish of Rudstone, East Riding. Ord. Map. xciv. N.w.}

CCXXIV. The long barrow now to be described was, both in shape and in the peculiar nature of its construction and contents, a very remarkable one. In reality, it consists of two long mounds joined together, and forming a V-shaped structure. The interments contained in it were confined to what I will call the northern limb. This, which ran in a direction west-north-west and east-south-east, was $210 \mathrm{ft}$. long by $75 \mathrm{ft}$. wide at the east and $45 \mathrm{ft}$. at the west end; and, having been much ploughed down, it is now but $4 \mathrm{ft}$. in height at the east, and decreases to about $1 \mathrm{ft}$. at the western extremity. It is made of earth and chalk. The south limb, also composed of earth and chalk, and running in a direction north-east and south-west, is $255 \mathrm{ft}$. long by $35 \mathrm{ft}$. in width, and $1 \mathrm{ft}$. in height where it joins the east end of the northern limb, but attains a height of $3 \frac{1}{2} \mathrm{ft}$. and a width of $45 \mathrm{ft}$. at its other extremity. On the south side of the northern limb, and at its eastern end, was a good deal of broken 'Anglo-Saxon' pottery, lying at various depths, some of it almost as low as the natural surface. It was not, however, found beyond the part specified, and it is not improbable that an existing mound had been used as a burial-place by the Anglian people of the neighbourhood, and that their interments, being near the surface, had been entirely ploughed away. At the same time it must be remarked that this explanation does not fully account for the occurrence of these potsherds at the level where some of them were met with.

In order to make the structure of the mound and the position of its contents intelligible, a point of measurement was taken from the centre of an imaginary circular mound at the east end of the north limb, making it $75 \mathrm{ft}$. in diameter, which was the width of the mound itself at this part; and to this central point all the measurements quoted in the following account refer.

Before describing the interments which were met with in the mound, I will first proceed to give an account of several holes, of different sizes, which occurred at various parts of the barrow. Some were of much the same nature as those so frequently discovered in the ordinary round barrows on the wolds; the same enigmatical excavations have also been found in some of the long K k 
barrows of the south-west of England, but I have not seen them in any other of the true long barrows which $I$ have myself examined. One hole, however, was very much larger than ordinary, and appeared to correspond to what was observed in the long barrows at Westow, near Wass, and on Crosby Garrett Fell. The first hole was $21 \mathrm{ft}$. south-west of the centre-point above mentioned, and was of an oval form, $3 \mathrm{ft}$. by $2 \mathrm{ft}$., and $2 \mathrm{ft}$. deep; it was filled up with chalk, earth, and charcoal. A second, $1 \mathrm{ft}$. east of the first, was $2 \mathrm{ft} .8 \mathrm{in}$. in diameter and $2 \mathrm{ft}$. deep; it was filled with the same materials as the first. A third was $21 \mathrm{ft}$. west-south-west of the centre-point, $2 \mathrm{ft} .9 \mathrm{in}$. in diameter, and of the same depth and having the same contents as the first two. A fourth was $9 \mathrm{ft}$. south-east of the centre-point, and of an oval form, north-north-east by south-south-west, $4 \mathrm{ft}$. by $2 \frac{1}{2} \mathrm{ft}$., and $14 \mathrm{in}$. deep. It was filled with burnt soil and charcoal, and on the surface of the filling-in were found two flint flakes and some burnt bones. A fifth was $15 \mathrm{ft}$. north-west of the centre-point, $4 \mathrm{ft}$. by $3 \mathrm{ft}$., and $1 \frac{1}{2} \mathrm{ft}$. deep, and was filled in with earth and chalk.

At a distance of $18 \mathrm{ft}$. east-south-east of the centre-point was the western side of what proved to be a large hole. It was not very far from the eastern end of the mound, and presented some very curious features. It was $12 \mathrm{ft}$. long and $6 \mathrm{ft}$. wide (running northeast-by-north and south-west-by-south), and had a depth of $4 \mathrm{ft} .9$ in. Round the sides it was filled in with loose chalk-rubble and mixed chalk and earth, all of which was slightly altered by the action of fire. The middle part, however, for a space of $8 \mathrm{ft}$. by $4 \frac{1}{2} \mathrm{ft}$., was a mass of fine earth (very much like the remains of burnt turfs) and calcined chalk, together with charcoal in very large pieces; the charcoal being most abundant, and in some places continuous, between the completely burnt matter at the centre and the partially burnt chalk and earth round the sides. With the exception of a very few calcined bones, it contained nothing besides the charcoal, burnt earth, and chalk. It is not very easy to understand the way in which the burning had been managed; but, so far as could be made out, the process seems to have been as follows. A hollow had been excavated in the chalk rock, and then filled in, at the centre, with turfs and chalk-rubble; round this wood had been placed, a space being left between the wood and the sides of the hollow, which was then filled in with chalk-rubble and earth. The wood being then ignited, the matter within it became completely burnt, whilst that without, being of less combustible materials, was not so much 
affected by the burning. The fire within this hollow was probably connected with the burning of the bodies afterwards discovered, and which constituted the primary interments of the barrow. Indeed, it was most likely synchronous with the funeral fire, if it was not itself, as seems probable, the starting-point of the fire then employed. This hole and its contents bear a strong resemblance to what was observed in the excavated trench at the east end of the barrow last described, and both, there can be little doubt, originated in the same purpose.

Commencing about $2 \mathrm{ft}$. to the east of, and therefore beyond, the edge of the hollow just described, was a deposit of burnt earth and chalk, $6 \mathrm{ft}$. in width and $2 \frac{1}{2} \mathrm{ft}$. in depth, which, resting on the natural surface, ran in a direction west-north-west towards the west end of the mound and along its mesial line, being parallel with, and enclosed within, the verge of the northern limb of the barrow. The material of this deposit not only differed from the general mass of the mound in which it was enclosed, in being burnt, but in its having been originally composed of substances of another character, much less compact and more combustible than the earth and chalk of the barrow itself. As has been stated, it ran quite over the hollow, and its northern boundary was conterminous with the northern edge of the hollow itself. The complete burning of this linear deposit extended towards the west for about $14 \mathrm{ft}$., and then the action of fire became less apparent, until at last it died entirely away. The same materials however, although no longer showing any signs of burning, continued to be employed in the formation of a deposit, retaining the same dimensions and direction; the whole deposit, burnt and unburnt, reaching in length to a point $38 \mathrm{ft}$. distant from its commencement just east of the large hollow. The intention, no doubt, had been that the entire deposit should become ignited, but here, as was also the case at Scamridge, the burning had ceased from some cause or other (most probably from insufficient draught) before it reached the point to which it was meant to extend.

Throughout the whole length of this deposit, although more abundantly in some places than in others, were the broken and dislocated remains of several human bodies, all laid upon the natural surface. In some instances a few of the bones were in juxtaposition and in their proper order, but only in one ease was there anything approaching to an entire body; and, generally speaking, nothing more than fragmentary and disjointed portions K $\mathrm{k} 2$ 
were met with. At the east end, where the calcination was complete, the burnt bones were mixed up with the burnt earth in the same way, though not enclosed in the same hard mass, as in the long barrow on Willerby Wold. This would arise from the different nature of the material composing the deposit, which consisted principally of turf, with a little chalk and no flint, the latter being a substance which does not occur in the chalk of the district. As the deposit was examined progressively towards the west, and the burnt matter became gradually less in quantity and at last entirely ceased, the bones still continued to be calcined, until, at a distance of about $30 \mathrm{ft}$. from the east end of the deposit, some bones quite unburnt were met with, though others were still calcined; while, still further to the west, the bones were all, with a very.few exceptions, untouched by the fire. The occurrence of some few burnt bones laid close by the larger number of unburnt ones, and where the overlying material was not affected by fire, is a circumstance in which this barrow differs from that at Scamridge, where no burnt bones were found after the enclosing and covering deposit had ceased to manifest any signs of burning. It would seem then almost necessary to conclude that in the barrow now under notice, when the bodies were placed on the surface, to be covered over by the turfs and chalk and then to be burnt along with this deposit, that some bones previously calcined had been laid there with them.

I now proceed to note particularly the position in which the various remains of burnt and unburnt bodies were found, and the very extraordinary way in which some of the latter were deposited. Here I may premise that the bones were most numerous at the two ends of the deposit, very few having been found for a space of about $10 \mathrm{ft}$. in the middle. Eighteen feet east-south-east of the centrepoint before fixed upon as a basis of measurement, and just upon the edge of the large hole before described, was a body (or, more probably, only part of one) imperfectly burnt, though all the bones were to some extent calcined. A little to the west of this was a skull, perfectly burnt, and apparently having all the bones of the head present. Four feet west of this was another skull, having the finger bones and those of the back, belonging probably to the same body, in their proper position. All the bones were completely calcined. No more bones were met with until at a place $2 \frac{1}{2} \mathrm{ft}$. eastsouth-east of the centre-point a few burnt bones occurred. There was, again, an absence of bones up to a distance of $10 \mathrm{ft}$. west- 
north-west of the centre-point, where the unburnt skull of a man of middle age was found, placed on the right side, there being no lower jaw with the head. Several unburnt bones, not in any order however, were close to the head. The skull is a very typical long-headed one, with a cephalic index of 68 . One foot further west was the unburnt skull of an aged man, also laid on the right side. With the head was a lower jaw, occupying its proper position, but which did not belong to it; the jaw really appertaining to it being met with at a distance of $2 \mathrm{ft}$. south of the head; whilst about a foot to the west was the lower jaw belonging to the skull first named. In front of the face were portions of another unburnt skull, and about a foot to the south of it was part of a burnt skull. The skull of the second man was very similar in form to that of the first, the cephalic index being 70. Fourteen feet westsouth-west from the centre-point was the skull of a child about ten years old, unburnt, the lower jaw of which was placed at the back of the head. With the exception of the bones found close to the first-named skull, no other bones were met with in connection with any of the heads.

A deposit of calcined bones of the ordinary kind, of the time of the round barrows (when the body was usually burnt on some other spot, and the bones then collected and placed in the ground), was met with $3 \mathrm{ft}$. north-by-east of the centre-point, and $1 \mathrm{ft}$. above the natural surface. They were placed in a round heap, $14 \mathrm{in}$. in diameter. This was probably a secondary interment, and possibly made long subsequent to the erection of the mound. About $1 \mathrm{ft}$. south-by-west from this deposit, but on the natural surface, a few unburnt and some imperfectly burnt bones were discovered.

In the south limb of the barrow there was not the slightest indication that any burial had ever taken place.

\section{Parish of Kilburn, North Riding. Ord. Map. xcvi. s.e.}

CCXXV. The barrow now about to be described (situated on the hill above Wass), which, in the peculiar disposition of the human remains found in it, presented very much the same features as the long barrows of which an account has already been given, differed from them however in two particulars. It was unlike them in shape, being rather oval than long, about $60 \mathrm{ft}$. in length by $45 \mathrm{ft}$. in width; the longer diameter running in a direction north and south; whilst the deposit of bones, instead of being found at the 
higher and broader end, was, on the contrary, at the narrower end, of which also it must be recorded that it was so low in elevation as to lose itself imperceptibly in the general level of the surface of the ground. The mound was made up of oolite rubble-many of the flags being very large-and of clayey sand. It is now, at the northernmost and highest end, $4 \frac{1}{2} \mathrm{ft}$. high, but has originally been much higher, a great quantity of stones having been, at different times, taken away from it. Some years ago, the tenant, $\mathrm{Mr}$. Pickersgill, discovered a cist on the south-east side, at a distance of about $14 \mathrm{ft}$. from the highest part of the mound. It was placed about $2 \frac{1}{2} \mathrm{ft}$. above the natural surface, and was formed of four flagstones set on edge, with one large cover-stone, the bottom being paved with small stones. It contained a skeleton in a contracted position, with the head laid to the north. This was, no doubt, a secondary interment, made long after the mound had been raised over the primary burials. All the remaining part of the barrow was very thoroughly examined under my own supervision, and it was found that the remains of bones were confined to a line which ran midway through the mound for a certain distance from the extreme south towards the north. This deposit of bones commenced at the point where, as above noticed, the barrow died away into the natural level of the ground. At this place was an irregularlyshaped hollow, excavated $2 \frac{1}{2} \mathrm{ft}$. below the surface; it was east and west, being $6 \mathrm{ft}$. long by $3 \mathrm{ft}$. wide, and had an offset at the west end of the south side $3 \frac{1}{2} \mathrm{ft}$. long by $3 \frac{1}{2} \mathrm{ft}$. wide, thus forming a figure somewhat like the letter $\mathrm{L}$. It was filled with burnt earth and stones, having here and there, mixed up with the general mass, pieces of charcoal and a few scattered burnt human bones, together with a single piece of unburnt animal bone. At the upper part, about the level of the natural surface, were two fragments of plain darkcoloured pottery, and, $1 \mathrm{ft}$. below them, another similar piece, part of the rim of a vessel. Excavated holes, something of the same character as this in question, and occupying the same position with regard to the place of burial, have been already described in the account of the Westow and Rudstone long barrows; and (as I have already remarked) I should be inclined to consider this one, as well as the other two, to have been designed with a view to aid in the application of fire to the deposit of bones it was sought to calcine, after the manner practised in the long barrows.

From this hollow there extended towards the north a linear deposit of burnt earth and stone, $3 \frac{1}{4} \mathrm{ft}$. wide, and reaching upwards 
from the original level of the ground to the present surface of the barrow; this material had undergone the action of a very fierce fire, to which intense burning the absence of charcoal is probably to be attributed. At a distance of $11 \mathrm{ft}$. north from the centre of the hollow already described was a second one, of oval form, $3 \frac{1}{2} \mathrm{ft}$. by $2 \frac{3}{4} \mathrm{ft}$. and $2 \mathrm{ft}$. deep, running east-by-north and west-by-south. Like the first, it was filled with burnt earth and stones, having charcoal scattered here and there amongst the filling in, together with a few pieces of burnt bone and a single fragment of plain dark-coloured pottery near the top. Two feet from the northern edge of this hollow was a third, also oval, lying north and south, $4 \mathrm{ft}$. long by $3 \mathrm{ft}$. wide, and $3 \mathrm{ft}$. deep. This, like the other two, was filled with burnt matter, having in it a few pieces of burnt bone and a fragment of the same kind of pottery as that found in the other holes. At the northern extremity of this hollow, which was $18 \frac{1}{2} \mathrm{ft}$. from the highest part of the barrow, the linear deposit of burnt matter ceased, the place where it terminated being situated at a distance of $20 \mathrm{ft}$. from the southern edge of the first hollow. All these holes, it must be remembered, were placed beneath the line of the deposit which contained the burials, and would appear to have been so arranged with the purpose of keeping up a draught to aid in the burning. The burials, in the shape of a large quantity of burnt bones, broken and scattered, as in similar deposits in the long barrows already described, were found placed as well in the lowermost layer of the burnt earth and stones, as beneath it upon the natural surface of the ground, in confused intermixture with earth, clayey sand, and stones. At the south end of the linear deposit the calcined bones were more frequently met with amongst the burnt stones above the surface, whilst at the north end they were confined to the bottom, and rested on the natural surface. At one point, a little to the south of the second hole, was part of an upper jaw and the whole of a lower jaw, with the left temporal bone, these being found lying close together, with a portion of skull placed a little distance from them; two cervical vertebræ lay 8 in. apart, and near the bones just mentioned, but no other vertebræ or any other bones of the body were present. There was no appearance, indeed, in any part of the linear deposit as if a whole body had ever been placed there. The natural surface soil beneath the burnt deposit, as also the ordinary material of the barrow in immediate contact with it, were to some extent affected by fire, though the signs of burning were trifling when compared with the 
appearance of the material of the linear deposit itself, which had evidently been subjected to a most intense heat, further evidence of which was afforded by the almost entire absence of charcoal, showing that the whole of the wood employed had been reduced to ashes. Although some difficulties suggest themselves in connection with the trifling extent of burning manifested on the surrounding earth and stones, yet I think the explanation of the way in which the fire had been applied to the bones, and to the deposit enclosing and covering them, which is given in the account of the Westow barrow [No. cexxiii], is that which is most consistent with the facts disclosed in the whole series of these most peculiar burial-mounds.

At a place $6 \mathrm{ft}$. distant west-by-south from the highest point of the barrow was a deposit of whitish clayey sand, laid upon the natural surface, and which contained, scattered here and there, a good deal of charcoal and several portions of animal bones. Commencing just to the north of this, a kind of wall, $3 \mathrm{ft}$. wide, faced on the outside with flag-stones set on edge, ran through all the higher part of the mound for a length of $12 \mathrm{ft}$., parallel to, and at a distance of $3 \mathrm{ft}$. from, the mesial line of the long diameter of the barrow, and therefore north and south. At a like distance on the other, or north, side of the mesial line was a second wall, which was neither quite so long nor so regularly built as the first, but, nevertheless, perfectly distinct in its formation from the rest of the mound. Both these walls reached from the surface of the ground to that of the barrow. Amongst the material of the mound were scattered some flint chippings, and at the north-west side was a single piece of thick pottery, black inside, and having pieces of broken stone mixed with the clay.

It will have been observed that in this, as in other long barrows before described, there was, apparently, no burial of what seemed to have been an unmutilated body, all the bones having been, before they were deposited in the mound, more or less disjointed, and in some cases perhaps fractured. The same very extraordinary circumstance has been noticed in some of the long barrows of the south-west of England. It is very difficult to understand how any ordinary mode of burial could result in such a state of things. In these cases then, where nothing except incomplete skeletons and disjointed and sometimes fragmentary bones have occurred, what probable explanation of so anomalous a condition can be given? The view which regards them as ossuaries, though on a small scale 
and of a peculiar kind, seems to be that which best fits in with the circumstances of the case; it being possible that the bodies had been first buried at some other spot before they were deposited in this their last resting-place. Under such a condition of things it might very easily happen that all the bones were not brought from the place where they had been first deposited, or they might have been there exposed, without any covering of earth or stone, and therefore subject to. various actions and casualties, by means of which some portion of the bones would be likely to be destroyed. Nor does the finding at one time of some complete skeletons, and at another time nothing but incomplete ones, present any difficulty, for such different conditions might readily occur, and from more than one cause. In some cases it might be that certain bodies were taken in the first instance to what was to be the final place of burial, whilst other bodies were removed from a previous place of deposit, and in this way it might happen that there would be perfect and imperfect skeletons discovered in juxtaposition. In other cases, where all the bodies had been removed, some might have remained complete, whilst others had lost, by one accident or another, some of their component parts. The custom of twice burying the dead has prevailed in so many different countries, and at times so widely divided, that we need not reject this explanation on the ground of its being contrary to usage.

Parish of Market Weighton, East Riding. Ord. Map. xciv. s.w.

CCXXVI. This barrow was examined by Professor Rolleston, to whose notes I am indebted for the details given in the present account. I had myself however frequent opportunities of seeing the operations during their progress.

The barrow was placed on the slope of the hill which rises towards the east from flat land which at one time has been a morass, representing an earlier lake or other sheet of water, and wherein, at Bielbecks and other places, numerous animal remains, constituting parts of an ancient fauna which included the mammoth, have been abundantly discovered. The mound had a direction nearly due east and west, and was $110 \mathrm{ft}$. long, $75 \mathrm{ft}$. wide at the east and $62 \mathrm{ft}$. at the west end, and varied in height from $1 \mathrm{ft}$. $8 \mathrm{in}$. to $2 \mathrm{ft}$. $2 \mathrm{in}$., having been very much ploughed down. At the east end it was formed of a deposit of chalk-rubble down the mesial line of the barrow, varying from $2 \frac{3}{4} \mathrm{ft}$. to $5 \frac{1}{2} \mathrm{ft}$. in 
width, and reaching in height to the present surface of the mound. This deposit, on the level of the natural surface, commenced at the extreme east end, and continued for a length of $66 \mathrm{ft}$. towards the west, and in it were contained, at different depths, the human and some of the animal bones to be more particularly mentioned hereafter. Amongst the chalk-rubble, which had been subjected to the very severe action of fire, was interspersed much charcoal and other burnt matter. Beyond, to north and south of this mesial deposit, the material was sandy soil, whilst beyond that again the mound was composed of chalk-rubble, which constituted the outer part of the barrow. To westwards of the end of the mesial deposit, the whole of the remainder of the barrow consisted of chalk-rubble and sandy soil, but not placed in the regular way observed at the east end, neither was there any deposit of chalk-rubble down the centre at that part of the mound.

It may perhaps be well, before entering upon a detailed account of the different interments found in the barrow, to direct attention to the way in which the cremation of the bodies seemed to have taken place, as evidenced both by the appearances here presented and by the analogy of some other similarly-shaped mounds. Especial reference may be made to those on Willerby Wold [No. cexxii], at Westow [No. cexxiii], Rudstone [No. cexxiv], Wass [No. cexxv], and Crosby Garrett [No. cexxviii]. The bodies then, either entire or in a greater or less degree dismembered and incomplete, appear to have been placed under and partly amongst chalk-rubble and wood, the former so arranged as to enable a draught to carry on the fire from the place of ignition to the other end of that part of the mound sought to be subjected to its action. Further provision for keeping the fire alight was apparently made by excavating hollows at intervals along the line of the deposit, a feature which was also observed in the long barrow at Wass, and in a less degree in that on Crosby Garrett Fell. Over the mesial deposit of chalk and wood was then placed a less combustible material, sandy soil, the object being presumably to confine the burning to that portion of the barrow in which the bodies were contained. Lastly, when the mound was completed, fire appears to have been applied to the east end of the mesial deposit, and the burning of the bones effected by carrying on the fire throughout its whole length.

The fire had no doubt originated in a trench which was found at the extreme east end, sunk into the chalk rock to a depth of $5 \frac{1}{2} \mathrm{ft}$. This trench had a north and south direction, and was $6 \mathrm{ft}$. 
$10 \mathrm{in}$. long at the top and $5 \mathrm{ft} .10 \mathrm{in}$. at the bottom, and being $3 \mathrm{ft}$. 10 in. wide at the bottom, it gradually sloped upwards towards the west until, at a distance of $9 \frac{1}{2} \mathrm{ft}$. from its eastern side, it rose to the level of the natural surface of the ground. A somewhat similar trench or hollow was discovered in the barrows at Rudstone, Westow, Wass, and Crosby Garrett. It was filled with burnt chalk, charcoal, and black sooty matter, and on the bottom was found a piece of plain, dark-coloured pottery, the paste of which was full of broken stone. At the point where the trench rose to the level of the natural surface ( $9 \frac{1}{2} \mathrm{ft}$. from the east end) the mesial deposit had a width of $7 \frac{1}{2} \mathrm{ft}$., caused by an extension towards the north, and here were found the bones of an adult and of a child. The skulls of another adult and child and some ox bones were met with $2 \frac{1}{2} \mathrm{ft}$. further to the west. At a distance of $16 \frac{1}{2} \mathrm{ft}$. from the east end a trench, $4 \frac{1}{2} \mathrm{ft}$. long and $2 \frac{1}{2} \mathrm{ft}$. wide, had been made transversely to the mesial deposit (there $5 \frac{1}{2} \mathrm{ft}$. wide) and sunk to a depth of $1 \frac{1}{4} \mathrm{ft}$. below it. In the trench, amongst burnt earth and charcoal, were the bones of a young person, whilst immediately above it, amongst the chalk-rubble, were the bones of an adult woman. Three and one-quarter feet west of this, where the burnt part of the mesial deposit was only $2 \frac{3}{4} \mathrm{ft}$. wide, were the bones of an adult man. Immediately west of this the deposit widened to $6 \frac{1}{2} \mathrm{ft}$. by an extension towards the north. Twenty-one feet from the east end were the bones of three adults, one of them having all the bones present and in their proper order, and close to them, to the west, were the remains of four bodies. Nine feet further to the west were the bones of an adult woman. Just west of this body was another transverse trench, $3 \mathrm{ft} .10 \mathrm{in}$. long, $1 \mathrm{ft}$. $7 \mathrm{in}$. wide, and $1 \frac{1}{4} \mathrm{ft}$. deep, and in it were the skull and lower jaw of a child, together with a single piece of plain pottery. Immediately over this the chalk stones had a cist-like form, and underneath them were a human jaw and some ox bones. Thirty-two feet from the east end was still another transverse trench, $3 \frac{1}{2} \mathrm{ft}$. long, $2 \mathrm{ft}$. wide, and sunk $3 \frac{1}{2} \mathrm{ft}$. below the surface. In it, amongst the burnt chalk and charcoal, were the remains of two adults, one of which seemed to have been a complete body when it had been interred, apparently in a sitting posture. There were also found in the trench bones of red deer, ox, and goat, three pieces of plain pottery, one a portion of the rim of a dark-coloured and probably round-bottomed vessel, the other two of a reddish colour. Close to, but not in, the trench was a single piece of brown-coloured, thong-marked pottery, precisely 
like that so frequently found in the ordinary round barrows. Ten feet further west were the bones of an adult woman and of a child. Another trench, $2 \mathrm{ft}$. $10 \mathrm{in}$. long, $2 \frac{1}{2} \mathrm{ft}$. wide, and $1 \mathrm{ft}$. deep, was met with $58 \mathrm{ft}$. from the east end, which contained some human bones. The last deposit of bones was $60 \mathrm{ft}$. from the east end, and consisted of those of an adult and of a child. In all, parts of twenty-six bodies were discovered, and of these twenty-one were within $32 \mathrm{ft}$., whilst seventeen were within $17 \mathrm{ft}$., of the east end. In the material of the barrow many unburnt bones of deer, $\mathrm{ox}$, pig, and goat were met with, and a bone pin $3 \frac{1}{8}$ in. long.

Though possessing, as it does, many features in common with other long barrows containing burials after cremation, there are two points in this barrow which require special notice. The one, which however is not perhaps of very much importance, is the number of burials met with in it, a much larger one than is common in this class of sepulchral mounds. No difficulty need be created by this fact if the view is a correct one which supposes that, in the case of many of the bodies, they had originally been deposited at some other place and only at a later time brought to their final place of burial. The other fact, and one of considerable importance when the relative age of the long barrow has to be considered, is the finding, in the apparently undisturbed material, of a piece of pottery which differs in no respect from that ordinarily discovered in the round barrows. Pottery, in any shape, has not very frequently been met with in the long barrows, and indeed, as its presence is a very distinctive feature of the round barrows, so its absence may be said to characterise the long ones. In the chambered long barrow at West Kennet, Dr. Thurnam it is true discovered great quantities of potsherds, and many of them marked with the ordinary patterns of the sepulchral pottery of the round barrows. But the fact of their being found in a chamber to which access might be had, and which might have been used for burial purposes at any time after its construction, renders it quite impossible to base any argument, from this particular instance, as to the contemporaneous use of this kind of pottery and that of burial in long barrows. When pottery, however, is found under circumstances which imply that it must have been deposited in the burial mound at the time of its first erection, then it has a very important bearing upon the question of the date of the class of barrows in which it is so discovered. In the barrow now under notice a piece of pottery of the same character in every respect as 
that usually found in quite another class of burial mound was discovered. Does this fact show that, as a rule, the two classes belong to the same period? I do not think it would be safe to come to such a conclusion upon a fact so isolated as the one in question. It is indeed quite possible that this piece of pottery may have had no connection with the first construction of the barrow, but that it may have worked its way down, in one way or another, to the place where it was met with, from a more superficial part of the mound, where it may have been placed in association with an interment made long after the primary throwing up of the barrow. Without supposing that any extensive disturbance had taken place, it is nevertheless by no means improbable that a badger, fox, rabbit, or rat may have been the agent by which it was thus transferred from one place in the mound to another, and this seems to me by far the most probable explanation. At the same time, it may be that this long barrow was constructed, during the time when round-barrow burial was the customary one, by people belonging to possibly an earlier stock, who had still retained their old mode of burial though they had adopted in other ways the habits and appliances of the later and probably more cultivated people to whom the round barrows are to be attributed. A somewhat similar intercalation of burial usages appears to be evidenced by the occurrence of a peculiarly-formed chamber in two barrows, the one a round, the other a long one, at Nether Swell, and which is noticed and remarked upon at p. 451.

Parish of Over Silton, North Riding. Ord. Map. xcti. N.w.

CCXXVII. The district in which this barrow is situated abounds in sepulchral mounds of the round form, and of probably a later date than this one now under notice. The round barrows have produced burials after cremation and by inhumation, the former in some instances enclosed in cinerary urns. Contrary to what I have found to be the rule in Yorkshire, the bodies had been interred in this long barrow without apparently having been in any degree subjected to the action of fire.

The barrow was placed south-east and north-west, and was $103 \mathrm{ft}$. long, with a width of $30 \mathrm{ft}$. at the east and $25 \mathrm{ft}$. at the west end. It did not appear to have ever been ploughed over, and was most likely of about its original height, the highest point, where it had an elevation of $4 \mathrm{ft}$. and a width of about $32 \mathrm{ft}$, being $40 \mathrm{ft}$. from 
the east end. The burials, which were discovered along the mesial line of the barrow and towards the east end, had been placed on the natural surface, but the turf appeared to have been pared off, there being no layer of dark mould overlying the sandy soil, such as would naturally have been found if the old surface had been left intact. The mound was made of earth, but there were some stones along the middle of the barrow over that part where the burial deposits had been made. No signs of an interment, except a few slight remains of what seemed to be very much decayed bone, were met with until, at a distance of $15 \mathrm{ft}$. from the east end, the tibia of an adult was discovered, $3 \mathrm{ft}$. west of which was part of a lower jaw, both these bones being laid 6 in. above the surface. A flint flake was found very near the bones, but not apparently associated with them. At a distance of $21 \mathrm{ft}$. from the east end was a large portion of the bones of probably a man, past middle life ; they were not in their proper order, nor did it appear as if they had been connected by flesh or ligaments, or had formed an entire skeleton, when deposited in the mound. A flint flake and some stones were found near to these bones. Close to these last, in fact immediately to the west of them, were the similarly disjointed and imperfect bones of a person about the time of puberty; and almost in contact with them were some bones, not many in number, of another person of the same age. The last interment was found $23 \frac{1}{2} \mathrm{ft}$. from the east end, and consisted of the bones of a young person, also disjointed and fragmentary.

Thus at least five bodies seem to have been buried in the barrow, but none of them had been placed there in a complete condition, all having the appearance as though they had been brought from some previous place of deposit. This feature, a by no means infrequent one in long barrows as well as in some round ones, has been so fully commented on in other places that it is not necessary here to make any further remarks upon it.

Parish of Crosby Garrett, Westmoreland. Ord. Map. xcvit. n.w.

CCXXVIII. Long barrows are of very rare occurrence in the north-western parts of England, neither am I aware that they have been found in the adjoining counties of Durham and Northumberland. A very large and in some respects remarkable one, called Raiset Pike, situated in the parish of Crosby Garrett, Westmoreland, was examined by Professor Rolleston and myself. It was placed 
on a piece of rising ground about half-a-mile from Sunbiggin Tarn, and was composed of limestone and sandstone, some of the stones being of large size. It had a direction south-east and north-west, and was $179 \mathrm{ft}$. long, $62 \mathrm{ft}$. wide at the south-east end; $36 \mathrm{ft}$. at the north-west end, the highest part ( $10 \mathrm{ft} .8 \mathrm{in}$.) being $30 \mathrm{ft}$. from the south-east end. Below this highest part, $39 \mathrm{ft}$. from the end of the barrow, and rising $6 \mathrm{ft}$. above the surface level, with the top $4 \mathrm{ft}$. below the surface of the mound, was a large slab of sandstone (menhir), placed transversely to the line of the barrow, and apparently forming the termination of the primary burial deposits. These had all been made along the mesial line of the mound upon the natural surface (the turf, as in the last case, having probably been first removed) and under a structure, from $3 \frac{1}{2} \mathrm{ft}$. to $4 \mathrm{ft}$. wide, formed in that peculiar manner which has been observed in some other barrows. The general features of that part of the mound in which the burials had taken place were very much like what has been found to be the arrangement in several of the long barrows an account of which is given earlier in this book, reference more especially being had to those at Westow [No. cexxiii], Rudstone [No. cexxiv], Wass [No. cexxv], and Market Weighton [No. cexxvi]. The human remains had been placed on the surface, and then over them stones and wood had been piled in such a manner as to facilitate the burning of the bones along the whole line of the deposit. In the barrow now under notice, what may be regarded as flues had been formed, at close intervals, by an evidently designed arrangement of the stones. These rose from the level of the deposit of bones through the overlying limestones up to the surface of the mound, the object clearly being to keep up a draught so that the fire might not die out before all the bones had been subjected to its action. The origin of the burning appeared here, as at Rudstone, Market Weighton, Westow, and Wass, to have taken place in a trench excavated below the surface transversely to the line of the mesial deposit. This trench was placed $8 \mathrm{ft}$. from the south-east end of the mound, and was $7 \mathrm{ft} .10 \mathrm{in}$. long, about $3 \mathrm{ft}$. wide, and $2 \mathrm{ft}$. deep, having at the middle a portion $2 \frac{1}{2} \mathrm{ft}$. long, sunk $1 \frac{1}{2} \mathrm{ft}$. below the bottom, thus making the trench at that point $3 \frac{1}{2} \mathrm{ft}$. deep. It was full of burnt earth, burnt stones, and charcoal, and at the lowest part were two small pieces of calcined bone, but whether human or animal it is not easy to decide. At the western edge of the trench the mesial deposit commenced, having a width of about $4 \mathrm{ft}$., and although the whole was completely burnt, no. 
remains of bones were discovered until a point $26 \frac{1}{2} \mathrm{ft}$. from the south-east end was reached, immediately to the west of a hollow, $2 \frac{1}{4} \mathrm{ft}$. by $2 \frac{3}{4} \mathrm{ft}$., and sunk $2 \frac{1}{4} \mathrm{ft}$. below the surface, and in which was a great quantity of charcoal. The object of this hollow, examples of which have occurred in other long barrows, as for instance at Market Weighton and Wass, seems to have been to aid in the carrying on of the burning. Between the western edge of the hollow and the 'menhir' the whole of the interments were met with ; they consisted of certainly six, and possibly of seven, bodies, all of which, with the exception of two, and those themselves doubtful, had been placed in the barrow in the condition of deposits of disconnected and incomplete bones. In some cases the bones were laid on the surface, in others on flat stones, and in several instances small flat stones had been inserted between the bones. As at Willerby Wold and Market Weighton, the bones were frequently encased with charcoal in a mass of calcined limestone. The bodies interred had been those of three adults and three younger persons, and possibly of a fourth. Two of the adults were strongly-made males, the third, probably a male, of slighter make than the other two.

As has already been observed, the primary burials and the burning along the mesial line ceased at the 'menhir,' but beyond to the west of it many remains of bones were discovered, all apparently belonging to secondary burials. A few feet west of the 'menhir,' and $7 \mathrm{ft}$. above the natural surface, a few burnt bones were met with; these appeared to have been burnt elsewhere and placed in the barrow afterwards. The western portion of the mound was made of larger stones than the eastern, and at a place $80 \mathrm{ft}$. northwest of the 'menhir' was a large sandstone slab, $4 \mathrm{ft}$. $10 \mathrm{in.} \mathrm{long,}$ $3 \mathrm{ft}$. wide at the base whilst narrowing to a point at the other end, and rising $3 \frac{1}{2} \mathrm{ft}$. above the surface of the ground. Throughout all that part of the mound which was to the west of the 'menhir' many unburnt human bones, principally of children, were discovered at various levels, some being on the original surface of the ground. The children's bones were less scattered than those of the adults, which in some cases were found as separate bones, and frequently placed under large flag-stones. All these bones were incomplete, and no entire skeleton seemed to have ever been interred; they presented much the same appearance as did those which were met with in a round barrow [No. clxxiii] about two miles distant. In the barrow, but all superficially placed, bones of ox, horse, goat 
or sheep, pig, foumart, water-vole, and grouse were discovered. No piece of pottery or flint occurred in any part of the mound.

Parish of Nether Sweld, Gloucestershire. Ord. Map. xliv. N.E.

CCXXIX. This barrow ${ }^{1}$ is situated in the same field, the Cow Common, in which the round barrows, already described pp. 446 seq., are placed. It had been to some extent removed at the eastern end in the years $1867-8$, and at the same time had undergone a partial examination by the Rev. David Royce, the Vicar of the parish. It is probable, if we may judge from the recollection of some of the persons employed about it at that time, that it had originally terminated at the east end in the same 'horned' fashion as was found to characterise the three barrows next to be described. It has a direction E.S.E. and W.N.W., and must have been about $150 \mathrm{ft}$. long, $77 \mathrm{ft}$. 'wide at the east and $40 \mathrm{ft}$. wide at the west end ; being now, at the highest point, that where the sepulchral chamber was found, about $5 \mathrm{ft}$. high. It had originally no doubt been higher. It is entirely composed of limestone slabs and rubble, and is surrounded by a carefully constructed wall or facing, made of thin oolitic slates, laid in horizontal courses, which at one time in all probability was continued entirely round the barrow. This cannot now be traced at the west end, and has disappeared at the east end in consequence of the total destruction of the mound at that part. This wall or facing, when first laid bare, was about $2 \frac{1}{4} \mathrm{ft}$. high on the south side, but not so much on the north, having possibly there undergone a greater amount of disintegration; it had no doubt originally been higher than it was anywhere found to be when discovered. The primary interments appear to have been principally deposited in and near to a chamber on the north side, which was examined by Mr. Royce in 1867. It was found at a point $55 \mathrm{ft}$. from the east end, and it had a passage or entrance leading into it from the outside of the barrow, the enclosing wall being pierced, and turning inwards, at the place. The sides of the chamber were constructed of large upright slabs of stone, one being as much as $3 \frac{1}{2} \mathrm{ft}$. by $2 \mathrm{ft}$. $4 \mathrm{in}$., but how the roof had been formed it

${ }^{1}$ I have given only a short account of this and of the two following barrows because Professor Rolleston has already printed a most exhaustive and valuable description of them in a paper 'On the People of the Long Barrow Period,' Journ. Anthrop. Institute, vol, v. p. 120. 
is impossible to say, in consequence of its having been destroyed before any one interested in such structures had an opportunity of seeing it. The chamber, which was partly removed before Dr. Rolleston and I examined it, is said to have been about $3 \mathrm{ft}$. square. It contained three skeletons; whilst outside, and to the southwest of it, the remains of other five bodies were found in 1867 and 1874. There was a certain careful arrangement of the stones, forming in fact a wall, on each side of these last-mentioned bones, the easternmost one being in a line with the east side of the chamber. Whether these walls were intentionally made for the purpose of containing the interments, or were merely such as were found abundantly in the barrow next but one to be described, it is impossible to say; these latter were clearly constructed to enable the persons making the barrow the more readily and safely to effect their purpose, just in fact in the same way as we found that the modern labourers, in opening the barrow, arranged the stones they removed in the process. Another and remarkable chamber was met with in 1868, but was destroyed before I first saw the barrow in 1874. It was placed $30 \mathrm{ft}$. from the east end of the mound and to the north of the mesial line ; and was $6 \mathrm{ft}$. by $4 \mathrm{ft}$. $8 \mathrm{in}$., of an oval form, and having a direction very nearly due north and south. Like the enclosing wall or facing, it was constructed of thin slates of stone in horizontal courses. From the description given of it and a drawing made by $\mathrm{Mr}$. Royce at the time of its discovery, it appears to have borne, in many particulars, a strong resemblance to one found in an adjoining round barrow described p. 448. It contained some human bones of two adults and of an infant, molars of an ox, one molar of a goat or sheep, a single bone of probably a weasel, and two flint flakes. Several fragments of pottery and some peculiar cigar-shaped pieces of imperfectly burnt clay, probably the supports of vessels whilst undergoing the operation of firing, were discovered towards the west end of the mound, and not much below its surface. All these probably belonged to a time subsequent to that of the erection of the barrow, as a coin of Constantine certainly did which was found near the same place.

\section{Parish of Eyford, Gloucestershire. Ord. Map. Xliv. n.E.}

CCXXX. This barrow, which was not quite a mile distant from that last described, had, like it, some round barrows in its immediate neighbourhood. It was made of oolitic rubble and slabs of 
the same stone, but had been much disturbed by having been ploughed over, to aid in which process many of the larger stones had been removed. It has a direction E.N.E. and W.S.W., and is $108 \mathrm{ft}$. long, $44 \mathrm{ft}$. wide at the east and $24 \mathrm{ft}$. at the west end, being now in no part above $3 \frac{1}{2} \mathrm{ft}$. high. It was surrounded by a wall or facing of thin oolitic slates, which in some places consisted of as many as fourteen horizontal courses. At the east end the wall assumed the 'horned' form, the north-eastern limb being slightly narrower and longer than the other. At the extreme west end the wall was not observable; the barrow, however, had been much destroyed by ploughing at that part, being in fact almost entirely removed, and it is probable that originally the wall had extended round that end also. The mound had been constructed with a certain amount of care, for the stones were arranged sloping gently inwards from each side towards the middle. Four receptacles for the dead were discovered in the barrow, to all of which I have no hesitation in applying the term chamber, since all were incomplete at one end or side, and in this feature differed from the cist with its perfect box-like construction. In three of them it is true there was no passage leading into them, but the absence of completeness in the enclosing walls of the chamber, whether there be a passage in connection with it or not, as opposed to the completeness of the walls of the cist, appears to me to mark the distinction between the stone burial receptacle of the long barrows and that of the later round barrows.

As the eastern portion of the mound was examined more especially under Professor Rolleston's superintendence, though I was myself present, and as the notes were taken by him, I prefer to extract from his paper in the Journal of the Anthropological Institute the account he there gives of what was observed in that part of the barrow.

'At about 17 or 18 feet westwards from the centre point of the eastward end were found some bones of a child, with the milk dentition in place, about $2 \mathrm{ft}$. or half-way down in the barrow. Parts also of an ulna, of a tibia, of the phalanges, and of both temporals of an adult, were found at about the same distance from the east end, and at a point a little south by west of the middle line. In the middle line of the barrow at this distance from the east end was a blackish seam of about $6 \mathrm{ft} .6 \mathrm{in}$. in width, containing bones, but limited in the eastward direction by masses of stones, under which also were found a few fragments of human 
bones, adult and young. Amongst the bones from this part of the barrow was one fragment of burnt bone, possibly human, as well as some teeth of ox and horse. These teeth, as also the human temporals, were stained by the manganic oxide. These appearances were difficult of interpretation until we came upon the ruins of a "chamber," about $6 \mathrm{ft}$. or so further to the north-west, the destruction of which, and the scattering the contents of which, may explain the blackening of the central strip of the barrow observed here, as also the presence of the human bones. The single burnt bone, whether human or not, may have been an accidental importation. Some adult teeth of bos, from the south side of the barrow, found together, are beautifully coloured by the manganic oxide. A piece of the parietal of a human subject, beyond the period of childhood at least, was found at the bottom, to the south of the middle line, under the slaty, slantingly-arranged rubble, not under the central deposit, at a point about $27 \mathrm{ft}$. from the centre point of the eastward end. On a level with it, as regards the longer axis of the barrow, but close to its northern wall, we came upon a stone, $4 \mathrm{ft} .9 \mathrm{in}$. long, $3 \mathrm{ft}$. $2 \mathrm{in}$. high, placed on its edge, and sunk some way into the natural soil. It had its long axis at right-angles to that of the barrow, the wall of which, as afterwards discovered, formed a passage, $4 \mathrm{ft} .2 \mathrm{in}$. wide, leading down to it. Another large stone, $2 \mathrm{ft} .10 \mathrm{in}$. long, $3 \mathrm{ft} .3 \mathrm{in}$. high, also standing on its edge, abutted on the inner end of the first stone, and projected in a south-westerly direction into the barrow; and two other large stones were lying flat near the upright ones ${ }^{1}$.

'On this day (Sept. 28) the Rev. David Royce came upon the boundary-wall, which had two prolongations inwards, to meet the chamber represented by the large stones mentioned above, and formed thus a passage $4 \mathrm{ft}$. 2 in. wide .... At a distance of $46 \mathrm{ft}$. from the apex of the re-entering angle, in the centre of the east end, we found the skeleton of a child, of about five or six years of age, lying just outside the boundary-wall, on the south side of the barrow. The child had been buried in the contracted position, and had been laid on the right side, with one hand at its face and the other upon its hip. The teeth have the same purplish blackening,

${ }^{1}$ I insert the substance of a note I made at the time to the effect that there were four stones, from $2 \mathrm{ft}$. by $1 \mathrm{ft}$. $10 \mathrm{in}$. to $1 \mathrm{ft}$. $8 \mathrm{in}$. by $1 \mathrm{ft}$. $4 \mathrm{in}$. (one of them overlying another), placed on the surface of the ground, and a fifth, rather larger, $2 \mathrm{ft}$. above the surface, all close to the two upright stones; and that these were the remains of a chamber, $8 \mathrm{ft}$. long, $2 \mathrm{ft}$. $8 \mathrm{in}$. wide, and $2 \frac{1}{4} \mathrm{ft}$. deep, and flagged on the bottom. (W.G.) 
due to manganese, upon them, which has been so often observed in these long-barrow bones from chambers.

'On this day (Sept. 29) we came upon what I believe may have been the ruins of a "cist," i. e. of a closed grave, walled in with slabs, and without any passage leading to the exterior such as has been noted in the other barrows, and also in this, and as would have justified us in speaking of it as a chamber ${ }^{1}$. It was $80 \mathrm{ft}$. from the re-entering angle at the eastward end, and being about $5 \mathrm{ft} .6 \mathrm{in}$. by $4 \mathrm{ft}$., had its long axis at right angles to, and in the middle line of the barrow. In this cist were found parts of two adult human skeletons, one belonging to a strong man, the other to a woman past the middle period of life; of the skeletons of three children of from seven or eight years of age ; of one child of about two years of age or less; of a dog's skeleton, lying in situ, and close to the bones of the old woman; also scattered bones of ox and sheep. The bones themselves, closely packed at first, had been much disturbed subsequently, as had also the cist itself. An indication of this was furnished to us by the discovery of the fragments of a drinking-cup only a couple of inches from the surface of the soil over the barrow. This cup was of a not uncommon pattern, thong-made; and with its paste red outside and black inwards, but was somewhat thicker than "drinking-cups" are usually. It had probably been interred with a body of a later period than those buried in the cist, and had come into the position in which we found it in consequence of agricultural or other disturbance of the place. To such other disturbance the following appearances seemed to speak. The bones seemed in a few cases to have been left, partially at least, in situ; but in many cases I found a few bones between a couple of slates, the lower of which, in its turn, overlaid a second set of bones. This would appear to be explicable by supposing that, the roof of the cist being removed, its contents were taken out partially, and then thrown in again, with any rubble which came to hand, so as to fill the cist up again ${ }^{2}$. It is not safe to say what the precise size of the cist

${ }^{1}$ I must here express my dissent from this view of Dr. Rolleston, the stones which had once composed this receptacle were much displaced, and seemed to me rather to represent the remains of an incompletely closed structure than of a perfect one, in fact they had formed a chamber and not a cist. (W. G.)

${ }^{2}$ I have met with the same peculiar feature in barrows where there certainly had not been any disturbance of the mound, as for instance in a round barrow at Crosby Garrett, described p. 388; and the same occurred in a long barrow [No. cexxviii], also at Crosby Garrett, where the burnt bones in some instances were placed both above and underneath a flat stone. (W. G.) 
had been originally, but it may have been somewhere about $\mathbf{5} \mathrm{ft}$. by $4 \mathrm{ft}$. The bones contained in it, when examined by me, were disposed as follows:-The first bones come upon were bones of children, some of which had apparently been left in situ, and upon the left side, whilst others had as evidently been disturbed. As there were no less than three children with the first permanent molar in use, but with no more, or with only the first incisor of the second set in addition, and consequently all three between seven and eight years of age, in this eist and the western half of it, and, besides them, a child of two years or something less, it is a little difficult to be quite sure how many of so many similar bones had been placed in situ. None of all the bones lay upon the natural ground, but all had a flagstone interposed between them and it. On the south side, and, I think, at the south-west angle, part of the lower jaw of a strong adult and the atlas were found near each other. Farther east, under one large flagstone, were lying the patella of a strong adult male and some bones of a skull of a child. Of course, these bones must have been disturbed to get thus into company with each other, and with no other bones between the flagstones. In the middle of the cist were found some of the bones of a youngish dog, and amongst them its lower jaw, which show it to have been about the size of an English mastiff; and in the same situation were bones of ox, of sheep, and of several human subjects, young and old. But the most striking "find" in the cist was in the north-east corner. There, between two large stones, were found, lying in situ, the femora, humeri, ulnæ, radii, clavicles, pelvis, ribs, and many vertebræ of a woman past the middle period of life. She had been laid on her left side; and between her chest and the north wall of the cist lay the pelvis and leg bones of a young dog.... The woman had been laid so that her skull just projected beyond the slab upon which the upper trunk bones were laid; and the skull had just escaped from being smashed, when the top stone fell in, at the cost of being carried off, probably by some mediæval or later tomb-riflers, and so lost to us. Half the lower jaw was still in situ, and has been recovered.'

Two feet to the north of the chamber, the contents of which have been just described, was a third chamber, placed $82 \mathrm{ft}$. from the re-entering angle of the east end of the barrow. It had a direction north-by-west and south-by-east. The north end, which was open, that is, having no upright stone to fill up the space, came up to within $2 \mathrm{ft}$. of the enclosing wall of the barrow. At that 
end the chamber was $2 \mathrm{ft}$. $8 \mathrm{in}$. wide, and it continued of that width for a distance of $3 \mathrm{ft} .8 \mathrm{in}$., when it increased to a width of $5 \mathrm{ft} .5 \mathrm{in}$; the total length being $7 \mathrm{ft} .8 \mathrm{in}$. It was $1 \frac{1}{2} \mathrm{ft}$. deep, and was flagged on the bottom, the stones being placed on the original surface of the ground. In consequence of the disturbance to which the barrow had been subjected, it is impossible to say how the chamber had been roofed in. Within it were found the remains of ten bodies ${ }^{1}$, three being those of women, and all, with the exception of one (that of a boy or girl of eleven or twelve years of age), above the age of puberty. Close in front of the neck of one of the bodies, that of a woman, placed at the south-west corner of the chamber, was a bead, probably of Kimmeridge shale or similar substance [fig. 162]: as the bones of

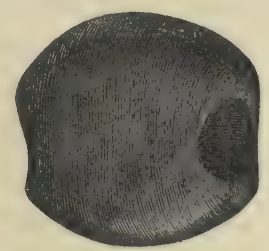

Fig. 162. $\frac{1}{1}$.

another body were intermixed with those of the woman, it is not possible to say with certainty that the bead had been buried with her, though the probability is strongly in favour of such being the case. The bead is slightly oval in outline and much flattened, the perforation has been made from both ends, and is very wide, having no doubt been made with a flint borer. The whole of the bones of these bodies were so broken and mixed up, both on account of their having been originally laid very close together and from their having become crushed by the pressure of the stones lying upon them, that it is difficult to say whether any one of them had been interred in its entirety. There can be no doubt that some of the bones had been held together by their ligaments when they were deposited in the chamber, because they were found in their proper relative juxtaposition, but in no case could it be said that a complete body had been buried. The appearances presented seemed to indicate that bodies, which had been previously interred elsewhere, had been afterwards brought, when the flesh and other softer parts had become decayed, and re-interred,

${ }^{1}$ A full description of the bones, with some details of the way in which they occurred, will be found in Professor Rolleston's paper before referred to, p. 160. 
where they were found, in the condition of more or less complete skeletons.

Opposite to this chamber, and within $1 \frac{1}{2} \mathrm{ft}$. of the south wall of the barrow, a fourth chamber was met with. It had an east and west direction, and was $3 \mathrm{ft}$. $2 \mathrm{in}$. long, $3 \mathrm{ft}$. wide, and $1 \mathrm{ft}$. deep. There was no stone on the north end or side, and it was therefore to that extent incomplete. It contained the body of a young person, between twelve and sixteen years of age, laid on the right side, with the head to E. by S., the hands being up to the face. In front of the knees was part of a vessel of pottery, including a considerable portion of the rim, which had not been less than 9 in. in diameter. It is dark-coloured and quite plain, having some broken stone mixed with the clay; the bottom has been rounded and the rim has a recurved lip. It differs entirely from the ordinary sepulchral ware of the round barrows, but corresponds with pottery I have found in the condition of pieces of broken vessels on several occasions in the barrows of the Yorkshire Wolds. It has been in general shape not unlike fig. 91, though not so flat on the bottom and somewhat deeper.

The occurrence of the bead is one which requires a more than ordinary notice. It is, so far as I know, the first time that anything in the shape of an ornament has been discovered in connection with a primary interment in a long barrow. That the burials, in the chamber in which it was found, belong to the people who ordinarily buried in that form of sepulchral mound, cannot I think be questioned. For apart from the way in which the interments appear to have been made, certainly not after the ordinary round barrow fashion, the type of the skulls is emphatically that of the earlier people to whom the long barrows are attributed. It is a remarkable circumstance, and one not easy to account for, that ornaments should be almost entirely wanting in association with long barrow burials, and this becomes more difficult to explain when it is considered that in the chambers of the Stone Age (corresponding in that respect with our long barrows) of Scandinavia and France, beads of various materials and shapes are by no means unfrequent. On the other hand, it must be remembered that weapons, implements, and pottery are also of very rare occurrence in the same class of British burial mounds, whilst they are common in those of the countries just referred to. 
Parish of Upper Swell, Gloucestershire. Ord. Map. Xliv. N.e.

CCXXXI. In the description of this barrow and its contents I have made free use of Professor Rolleston's paper before referred to, at the same time having recourse to my own notes and what my recollection suggests. It was larger than the two as yet described, being $173 \mathrm{ft}$. in its extreme length, and $158 \mathrm{ft}$. from the apex of the central concavity of the 'horns' to the west end. Its greatest width, which occurs at a point about $20 \mathrm{ft}$. west of a line drawn across the ends of the 'horns,' is $57 \mathrm{ft}$., and the narrowest part is at the extreme west end, where it is $32 \mathrm{ft}$. across. The height, probably almost the original one, is from $8 \frac{1}{2} \mathrm{ft}$. to $6 \mathrm{ft}$., the greatest elevation being towards the east end. Its direction is east-bynorth and west-by-south. The barrow, which is made of oolitic rubble and slabs, is surrounded by a wall or facing, which at the east end reached to a height of $5 \mathrm{ft}$., where it assumed the same 'horned' form as in the barrow last described; the southern 'horn' being wider and longer than the northern. The wall or facing has been made of thin oolitic slates very carefully arranged; this being especially noticeable at the east end in the concavity within the 'horns,' where it has been most beautifully constructed and had a very imposing appearance when it was first exposed to view. This is the more remarkable as it is evident that it was not intended to be seen after it was made, for it had been encased by a backing of fine small stones for a thickness of $2 \mathrm{ft}$. and beyond that by larger stones, the whole intentionally arranged, and not caused by the disintegration of the mound itself. Before the barrow was opened, the east end presented an ordinary rounded form, there being no indication of the enclosing wall with its 'horns.' It is not possible to decide positively whether the wall also on the sides of the barrow had been encased at first in the way in which we found it to be, or whether the outlying material at that part had merely accumulated by the falling down of the mound. On the whole I think it more probable that there was originally a casing to the wall, for otherwise the frost of even two or three winters would have broken it up more than it was found to be when uncovered. The barrow itself was carefully constructed, and was full of what may be called walls, which, occurring as they did in one case at least in the form of a passage, at first induced us to hope that we had found the entrance into a chamber near to the east end. Further 
examination, however, showed very plainly that the transverse walls were merely thrown up to facilitate the operations of the people constructing the barrow, and for their own greater convenience and safety. Along the middle line of the barrow, at all events for a certain part of its length if not for the whole, a row of large flag-stones had been placed upright, and against them on either side other large stones were arranged sloping, in a roofshaped fashion, towards the central ones, forming what may be called the back-bone of the mound.

In the whole of this large barrow but one place of primary interment was discovered, and though it is possible that others may exist, I think it is scarcely likely that they do, for it was tested in a number of places without any indications of other burials being met with. This one, in the shape of a chamber, was placed $24 \mathrm{ft}$. from the west end and on the north side of the barrow, from which it had a passage leading into it. The chamber, constructed of large and thick oolitic slabs set upright, was $7 \mathrm{ft}$. long and $4 \mathrm{ft}$. wide, having a direction nearly due north and south. It was about $3 \mathrm{ft}$. $8 \mathrm{in}$. high, measuring to the point where the roof commenced to narrow. The passage, $2 \frac{1}{2} \mathrm{ft}$. in width, was difficult to define as regards its length, for some of the stones had been removed, but it appeared to have been as long ( $7 \mathrm{ft}$.) as the chamber itself; nor could it be ascertained whether it opened out to the exterior of the barrow or not. At the place where the passage joined the chamber there was a kind of doorway, made by a large flag-stone set on edge, which crossed the entrance at a height of $1 \frac{1}{4} \mathrm{ft}$. above the floor; the object of this was probably to aid in supporting the roof of the chamber ${ }^{1}$. The passage was flagged, the floor being on the natural surface, but the chamber was not flagged. The chamber was first discovered many years ago, when the barrow was used as a quarry by a man who had contracted to build the walls of the fields enclosed from the common. Working one day upon it and getting out some large stones, he all at once dropped into a cavity, and found himself to his horror amongst a mass of human bones. He had broken through the roof of the chamber, which had been constructed, on a not uncommon plan in early burialplaces and habitations, by placing flat stones gradually projecting, the one beyond the other, until they joined at the centre, forming

${ }^{1}$ A good idea of the chamber and passage will be got from an engraving in the fifth volume of the Journ. Anthrop. Institute, pl, v. fig. 3. 
what has been called a bee-hive roof. The chamber remained accessible for several years, and during that time many of the bones were carried off. In clearing it out completely in 1874, we found that at least nine bodies had been buried within it, portions of as many being still left, together with some bones of goat or sheep, $o x$ and pig, and two small pieces of plain pottery, all probably belonging to the time when the interments had taken place. The passage, however, had escaped rifling, and the almost perfect skeleton of a man, about thirty years of age, was discovered, whose head, laid to S.W. by S., was about $1 \frac{1}{2} \mathrm{ft}$. from the entrance into the chamber. He had been placed, in a very contracted position, on the left side, having the right hand up to the face, and the left at the elbow of the right arm. Underneath the lower part of his back was the skeleton of a child, about two or three years of age, with the head to N., and having the bones of the upper part of the body in their proper order. Close to the child's head was the arm bone of a woman, from eighteen to twenty-four years of age, of whose skeleton the lower vertebræ and pelvic bones were in situ. Other of her bones, together with some bones of goat or sheep and the jaw of a young pig, were lying about in a disturbed condition. Thus it appears that in the first instance a woman and a child had been buried in the passage, and that afterwards the man's body had been interred there, during which process some portions of the previously buried bodies had become displaced.

As belonging to the first formation of the barrow, the following objects may be noted: a piece of plain pottery, found $6 \mathrm{ft}$. deep between two of the before-mentioned transverse walls, and a piece of red-deer's antler, showing signs of having been cut, met with amongst the small stones and clay there forming the material of the barrow, about $6 \mathrm{ft}$. south of the end of the chamber, and near the south side of the mound.

Some burials of a much later date than that of the construction of the barrow were discovered, and also a vessel of pottery, which possibly at one time accompanied a body now totally gone to decay. It was found just over the facing of the north 'horn,' near to its eastern extremity, and not much below the present surface of the mound. It is somewhat of the 'drinking cup' type, $4 \mathrm{in}$. high, $4 \frac{3}{4} \mathrm{in}$. wide at the mouth, and $2 \frac{1}{4} \mathrm{in}$. at the bottom, and ornamented over the whole surface with lines forming no distinct pattern. On the upper part of the vessel these have been made 
with a sharp-pointed instrument, and on the remainder of it by impressions of a notched strip of bone or wood. The remains of three bodies (evidently Saxons, as indicated by the articles associated with one of them) were discovered, in November 1874, close beneath the surface of the barrow, and about $18 \mathrm{ft}$. from the reentering angle of the 'horned' east end. One of them was that of a woman, about thirty years of age, with whom two bronze buckles, an iron knife, and an amber bead had been buried, and to whom may also have belonged a stone spindle-whorl found near to the place but $4 \mathrm{ft}$. below the surface. The other bodies were those of an old man and of an infant, both of which Dr. Rolleston thinks had been disturbed and replaced when the body of the woman was interred.

[CCXXXII. ${ }^{1}$ A fourth long barrow, situated about half-a-mile to the northwards of the village of Nether Swell, and at a less distance to the W.S.W. from the village of Upper Swell, was examined in the autumn of 1875 and the spring of 1876 by the Rev. David Royce and myself. The barrow was visited by Canon Greenwell, and a plan which has been of great use to me was taken of it by Sir Henry Dryden, Bart. This Upper Swell barrow, like the barrows Nos. ecxxx, cexxxi, had its larger end prolonged into two horns, but it differed from those and from all other non-cremation long barrows which I have seen or read of, in having its place for the reception of dead bodies, not upon the surface of, but sunk into the natural ground. It is probably owing to this peculiarity that its contents have suffered, as I believe, scarcely at all since it was disused by the race or tribe of men who piled it up. The barrow occupies part of the top and part of the downward slope of a small hill, known as 'Hayle Knap,' upon the estate of Alfred Sartoris, Esq., for whose permission to examine it our acknowledgments are due.

The extreme length of the barrow may be taken as having been a little over $120 \mathrm{ft}$; and its extreme breadth, at the end with horns, as $40 \mathrm{ft}$. Its long axis runs from N.N.E. to S.S.W., its larger and horned end lying at the N.N.E, and having a maximum width at the base of its horns of $40 \mathrm{ft}$. Its width at the smaller end is about $15 \mathrm{ft} .6$ in. less than at the larger. The exact

1 The account of this barrow, contained within brackets, is by Professor Rolleston. 
distance from the convex extremity of one of the horns to the extreme point to which the smaller end of the barrow was traceable in a S.S.W. direction was $119 \mathrm{ft}$. : the barrow, however, must be supposed to have suffered some diminution of its length at its narrower and lower end from agricultural and other operations entailing the removal of stones. The line of a sunken transverse zone, discovered by making a longitudinal section of the mound, was found to divide the barrow into two segments of nearly equal length, and in this zone were found the primary interments which were the raison d'être of the construction of the mound. This barrow, therefore, resembles the other long barrows in this neighbourhood, and differs from those described by Sir R. C. Hoare in Wiltshire, and from most of those in Caithness described by Mr. J. Anderson ${ }^{1}$, in not having its principal interment in that part of the structure upon which the principal trouble had been expended; that is to say, at its doubly-horned N.N.E. end. Its greatest height above the surface of the ground was about $5 \mathrm{ft}$., a height which it attains at a distance of about $16 \mathrm{ft}$. from the centre of the N.N.E. end. This maximum elevation it maintains for a considerable space occupied by large trees, Scotch firs and beeches, amongst the roots of which, however, a sufficiently large number of exploratory excavations were made to assure us that no interments were left unexamined in the region covered by them. Erom its maximum elevation of $5 \mathrm{ft}$. the barrow slopes away gradually to a height of $2 \mathrm{ft} .4 \mathrm{in}$. at a distance of $60 \mathrm{ft}$. from its extreme N.N.E. point; and in this plane the transverse zone containing interments was found intersecting the barrow. Beyond this line the barrow did not exceed a height of $2 \mathrm{ft}$.; but there can be little doubt, inasmuch as till quite recent times a wall of modern construction ran across the long axis of the barrow about this very level, that the barrow must have suffered considerable diminution of its pristine proportions by furnishing materials for the building of this wall, if not of others in the neighbourhood. The barrow sloped again from its highest point down to a height of $4 \mathrm{ft}$. at its horned end; but here too some diminution may reasonably be accounted for by a reference to quarrying operations. A wall, made of the flags of the lower oolite laid in horizontal rows, bounded the barrow at its N.N.E. end and along its sides, being somewhat under $4 \mathrm{ft}$. in height in the former, and

${ }^{1}$ Proceedings of Society of Antiquaries of Scotland, vol. vii. p. 485. 
sinking to $2 \mathrm{ft}$., and indeed, as now left, much lower in the latter regions ${ }^{1}$.

The Rev. David Royce, of Nether Swell, discovered not only the horns at the N.N.E. end of the barrow, but after making several exploratory cuttings into the deeper part of the barrow with no other result than that of finding three superficially-placed Saxon interments, he came upon the primary interment whilst carrying a trench down the middle line or central axis of the tumulus from its narrower S.S.W. end upwards. This primary burial was contained, as already stated, in a sunken transverse zone, and merited thus, what burials in long barrows do not usually merit, the title of an 'interment.' Examination and excavations carried on subsequently to its first discovery, partly by Mr. Royce and partly by me, showed us that this interment had had provided for it a trench about $28 \mathrm{ft}$. long, $6 \mathrm{ft}$. $4 \mathrm{in}$. wide, and $2 \mathrm{ft}$. deep, which ran across the long axis of the barrow from W.N.W. to E.S.E., but fell short of reaching its lateral boundary walls by a space at either end of about $6 \mathrm{ft}$. This latter space at either end of the trench-grave corresponded with a kind of passage or gallery somewhat narrower than the grave and limited by oolitic slabs set on edge. Like the grave it was filled up with rubble, and it contained also some bones, but these may be considered to have been put there in the process of displacing some of the earlier for later primary interments. The lateral boundary walls had been carried, probably at a height of $2 \mathrm{ft}$., their greatest height as now standing, uninterruptedly past the ends of these passages: whether in their pristine condition some sort of indication may not have been furnished by them of the difference between the contents of the barrow in this and in other segments of its length is matter for conjecture. But it may be remarked that a segment of a barrow, which was from time to time disturbed for successive interments, would of itself assume an appearance sufficiently different from that

1 A reference to the plans given by Mr. Joseph Anderson, Proc. Soc. Ant. Scotland, vol. vii. 1868, pl. Ixi ; or by Dr. Thurnam, Proc. Soc. Ant. London, April 1868, and Archæologia, xlii. 1869; or by Sir John Lubbock, Journ. Ethn. Soc. Lond., vol. ii. pl. xxvii. 1870; or by myself, Journ. Anthrop. Inst., vol. v. p. 120, October 1875, will enable the reader to understand the construction of these 'horned cairns' or barrows better than any description. In the present instance, the more eastwardly placed of the two horns at the N.N.E. end had been nearly entirely destroyed by quarrying; the relations however of the remaining horn and the lateral walls coupled with what we had to guide us in the proportions of the horns of the other barrows in this neighbourhood enabled us to form a very probable, howbeit conjectural restoration of the half obliterated end. 
of the parts not so disturbed, even though its upper surface might be maintained at the same level.

From the trench-grave, and from various depths in it, and to some extent from the passages leading to it, we obtained evidence of the presence of 14 adult human bodies, 10 of the skulls or calvaria of which either have admitted of reconstruction or were too complete to require it, and of the bodies of 5 children. Intermingled with the human bones were found bones of the roe (Cervus capreolus), red deer (Cervus elaphus), ox (Bos taurus), wild boar (Sus scrofa, var. ferus), goat (Capra hircus), pig (Sus scrofa, var. domesticus). In the rubble were also found some bone-implements such as we may suppose to have been used for flaying and for cleaning the hides of the animals above mentioned, and also for removing the bark from trees for use in hut-building and roofing, and a bone pin : a considerable number of worked and weathered flints; one vessel for domestic use, of coarse pottery ${ }^{1}$ and rude type, but, as it is scarcely necessary to state, no traces of any metallic weapon or implement.

One skeleton was found undisturbed and surrounded by other human bones so disposed, and in such numbers, as to make it clear that the skeletons they had belonged to had been displaced to make room for it. And this cardinal fact shows that, as regards this barrow at least, the theory of 'Successive Interments,' the theory proposed by Professor Nilsson ${ }^{2}$ to account for the appearances often presented by the multitude of often irregularly scattered human bones found in barrows of the Stone and Bone-implement Period, is the true one.

The first human remains (1) to be found lay in the middle line of the trench, which was also about the middle line of the barrow. They comprised a number of bones which gave proof of the presence and of the disturbance of three human skeletons, one of which had belonged to an infant, one to a man in the middle period of life, and one to an aged woman. With them had been irregularly intermingled bones of ox, pig, and red deer. One human skull, that representing the man in the middle period of life, has been partially reconstructed from this set of bones, though it is much

${ }^{1}$ Fragments of pottery were found outside the limiting wall opposite either end of the grave, and in especial abundance opposite the east end of it, indicating perhaps, as do certain other considerations, that access was most ordinarily made to the grave from this side.

${ }^{2}$ Early Inhabitants of Scandinavia, ed. Lubbock, pp. 167-169; Journal of Anthropological Society, vol. v. p. 134, Oct. 1875. 
waterworn on the right side; it is eminently dolicho-cephalic, with an extreme length of $7 \cdot 6^{\prime \prime}$, an extreme breadth of $5 \cdot 2^{\prime \prime}$, a latitudinal index of 68 , and a circumference of $21 \cdot 3 "$. A lower jaw, with teeth closely corresponding in wear and size to those in the upper jaw of this skull, was found in this barrow, but at a considerable distance from the skull and other bones.

A second set of bones (2) was found about a foot away in an E.S.E. direction from 'No. 1,' with which they had, so far as we can judge, become partially intermingled. For some of the bones referred to as No. 1 had belonged to an old woman, and may very well be part of the skeleton of the same sex and age which we have now to speak of. In this second collection of bones, which $\mathrm{Mr}$. Royce found 'in no form-all confused,' I find, firstly, one skull with the lower jaw of an old woman, to whom two fibulæ, two clavicles, and two humeri, all with old breakages upon them, also found here, may very well have belonged, as well as the bones of the second adult skeleton represented in set No. 1; and, secondly, a very long calvarium which lay at a deeper level than the first one found at No. 2, and which appears to have belonged to a young man. With these bones, as with two other sets of bones to be hereinafter mentioned as 'No. 4' and 'A,' evidence of injuries received and repaired during life was found : in this case the evidence was furnished by an ulna which had been broken and repaired. A patella of an ox, probably a domesticated animal, was found with these bones, as also with another set, 'No. 4,' found at no great distance from them; and further remains of domesticated animals were presented to us in parts of the skull and of the upper jaw of a kid (Capra hircus), with its milk dentition just worn out. It is of importance to note that, whilst the latter of these skulls is so exceedingly long and narrow as to merit the name 'Cymbo-cephalic,' applied by Professor Daniel Wilson to such skulls in $1850^{1}$, its length being $7 \cdot 9^{\prime \prime}$, with a parietal arc of nearly $6^{\prime \prime}$, though its sagittal suture is open as well as its coronal, the female skull, on the other hand, is a skull which, without being brachy-cephalic by mere measurement of the proportions of length and breadth, is yet a short and a small skull, with an extreme length of $6.9^{\prime \prime}$, an extreme breadth of $5 \cdot 1^{\prime \prime}$, a parietal are of $5 \cdot 1^{\prime \prime}$, and a circumference of but $19^{\circ} 6^{\prime \prime}$. It is perhaps to the presence of female skulls such

1 British Association Report, 1850, p. 143. The word above quoted as an equivalent to 'boat-shaped' has been, in memoirs of a date later than 1850, altered into 'Cymbe-cephalic,' or, more frequently, 'Kumbe-cephalic.' 
as this in long barrows and in other interments of the same period, that we may ascribe some of the statements which have been made as to the co-existence of brachy-cephalic with dolichocephalic crania in these early times.

The third interment (3) was undisturbed, the sole instance in this barrow. A very nearly perfect skeleton of a woman between 20 and 25 years of age and $5 \mathrm{ft}$. in stature, with a low dolichocephalic cranium, was found a little to the E.S.E. of 'No. 2,' lying upon the right side with the face northwards, occupying, with the knees drawn up, a space of $3 \mathrm{ft}$., and having one arm lying across the body. The Rev. David Royce, who discovered and removed it, reports thus as to the arrangement of the stones about the skeleton: "Some pains had been taken with the resting-place. The stones at the feet lay in the form of pitching; under the body they were flat, but at the sides they lay sloping outwards. A large projecting stone over the head appeared to have been laid for protection of the skull. This piece of construction was $2 \mathrm{ft} .9 \mathrm{in}$. across at the head, and $1 \mathrm{ft} .3 \mathrm{in}$. across at the feet.' The protection which this construction had furnished had been sufficient to preserve the bones from the great wearing away which the drip of water, acting on surfaces gnawed by rodents, has produced in many of the bones from this barrow, without keeping them so entirely intact as to make one suspect that they are of a materially later date than these others. One tibia, one femur, and both fibulæ, as well as some other bones, have, though found in situ, old breakages with the fracture-surfaces stained with oxide of iron, showing that the breakages which have so greatly multiplied the number of osteological specimens from this barrow are not by any means all to be ascribed to the rough handling which displacement on behalf of fresh interments implies. Some of the bones of this skeleton have suffered from the gnawing of voles, some from the boring and channelling of the larvæ of some beetle, which has reproduced in a minor degree the ravages of Anobium in the wood, and Hylargus or Scolytus in the bark of trees. One of the tibiæ shows some slight blackening, due probably to the same agency as that which has very extensively and strikingly affected many of the other skeletons from this barrow, viz. the manganic oxide. These particulars go some way, when coupled with the contracted position of the skeleton, towards proving that this skeleton is of the same race and date as the others found in this barrow. As will be more fully explained elsewhere, the cranial characters of 
the occupants of this barrow vary very considerably; but it is remarkable that when we make allowances for sexual differences, such as smaller size, and specially, lesser height, and such as the lesser obliquity of the forehead and the parieto-occipital region, this skull is remarkably like the one already spoken of as No. 1 .

In the immediate neighbourhood of the undisturbed skeleton (No. 3), so near indeed as to have got partly intermingled with it, four skeletons were found, more or less numerously represented by bones of the trunk and limbs, and comprising two tolerably perfect dolicho-cephalic male calvariæ, labelled ' $4 a$ ' and ' $4 b$,' each of which is water-worn on both sides, showing that when disturbed it was not replaced on the same side which it had previously laid upon, and between which a strong resemblance subsists, suggesting that they may have belonged to near relatives. The greater part of the bones were reported to me as having had over them 'one of the sloping stones at the back of No. 3,' mentioned above, and No. 4 was simply spoken of as 'lying under No. 3.' I had myself the advantage of examining this eollection of bones nearly as they had been left when the skeleton 'No. 3' was put into the grave; and from the way in which these bones, which I removed myself, were arranged, it was clear to me that though they had been taken up and replaced without any knowledge of the anatomical relation of, at least, the long bones, a good deal of care and painstaking had been bestowed upon their rearrangement. The skulls lay apart from the lower jaws, and were in relation to other bones which they do not normally touch, and in many cases the long bones had their proximal and distal ends oceupying the reverse of their natural allocation. But, mal-arranged as they were, it was still plain that they had been deliberately taken up, and as deliberately laid down again in the positions in which we found them. The peculiar physical, and more or less mutually antagonistic, condition to which the bones had been exposed in this barrow are well represented in this particular collection of bones. In some cases these bones were seen to have suffered very much from water wear, to such an extent in some cases as to render it almost impossible to identify the bones affected; but in some of the long bones, whilst one segment of the bone might be almost eaten or entirely eaten through, another segment was to be seen retaining, where it had been protected by an overlying slab, its outlines and even its texture unimpaired and unaltered. By noting this curious combination of decay and immunity from decay, we are prevented from laying 
undue stress upon the presence or absence of these peculiarities as indications of the age of any of the interments. A left ulna and a right radius from this collection of bones show badly-united fractures. With the human bones were found bones of the roe (Cervus capreohus) and the patella of an ox.

Two more skulls, labelled 'A' and ' B' respectively, were found at the E.S.E. end of the trench-grave, holding much the same relation to aggregations of other bones as those held by skulls ' $4 a$ ' and ' $4, b$ ' to the bones in their immediate neighbourhood. Skull 'A,' which bears a considerable resemblance to the skull ' No. 2,' and, like it, belonged probably to an old woman, was found in a fragmentary state only $8 \mathrm{in}$. below the surface, whilst underneath lay, in a space of $2 \mathrm{ft}$. 8 in., a confused mass of bones-lower jaw, ulna, femur, radius, all disturbed-representing two children and two adults by bones other than lower jaws; whilst by reference to these we find three adults and one child represented. About a foot and a half from the skull 'A,' but at a deeper level, another skull, ' $B$,' likewise the skull of an old woman, but of larger size, was found, illustrating the fact that one female skull from these early burials often is very much larger than another found in the same surroundings. With the skull ' $B$ ' came an elbow-joint, the three bones composing which were much deformed by exostosis, the result of disease or violence; as also a right clavicle, which had been fractured and repaired with a false joint. In the space between skulls ' $A$ ' and ' $B$ ' and that occupied by the bones labelled ' 3 ' and ' 4 ' were found, above ' $B$,' parts of a vessel of rude pottery. With the skull and bones labelled ' $A$ ' came bones of pig, roe, and goat.

This is a very short account of the remains of at least eleven skeletons found in the S.E. half of the grave-trench; nearly as many, eight to wit, were found in the W.N.W. half. The first of these, 'No. 5,' is represented by a long calvaria, much worn and somewhat distorted, of an aged man; immediately underneath which one thigh bone was found, and three others below this one. With the deepest lying of these three femora, a tibia also was found. The arrangement of the bones and stones in this half of the trenchgrave differed somewhat from that in the other, in that the bones were more completely separated from each other by the interposition of the layers of the stones. It seems likely, considering this arrangement, together with the tendency usually shown in ancient, as indeed in modern interments, to bury so that the rays of the sun may strike directly upon the grave, that the north-west portion 
may have been used for the reception only of displaced bodies, which would, by the process of removal from one half of the trench to the other, get more intimately intermingled with the rubble than others not so transported. The bones of children were noted to be mixed up indiscriminately with those of adults, as well as with rubble, as though several skeletons had been removed together and confusedly; but I have not been able to refer any of the bones found in the one half to the skeletons represented in the other half of the trench; and we are therefore justified, perhaps, in holding that eight interments, three of children and five of adults, should be assigned by us to this half of the trench-grave. In the aggregation of bones labelled 'No. 6,' two humeri with perforated olecranic fossæ were found, and with them a portion of a very old upper jaw. Both the arm and the jaw bones may very likely have belonged to an aged female, it being in females of priscan times, as Professor Broca ${ }^{1}$ has remarked, that this perforation is most commonly observed, and it being readily intelligible that in hardlyworked and often scantily-fed individuals, such as the females in savage tribes, such an absorption would be likely to take place. A large proportion of the bones from this part of the trench showed old breakages, their broken surfaces being stained, like the other surfaces, with oxide of iron.

Out of a number of bones found at the W.N.W. end of the trench-grave one calvarium has been recovered and labelled 'No. 8.' It is chiefly remarkable as having been considerably though equably flattened till it has come to resemble in contour and proportion a skull once in the hands of Dr. Buckland, now in the Oxford University Museum, and referred to by Professor Nilsson (British Assoc. Report, 1847, p. 32), as having been found $500 \mathrm{ft}$. down in a tin mine, and as illustrating the type of the race which he supposes to have been second in order of time amongst the inhabitants of Scandinavia. With these bones were mixed up the bones, and, notably, the horn cores, of a goat, Capra hircus; the human bones representing skeletons of two children between eight and twelve years of age, of one infant, and of three adults. Many of these bones were much stained with the manganic oxide. Some of those bones found thus at the extreme W.N.W. end of the grave were found to fit with bones belonging to skeletons, represented, not in the W.N.W. end of the grave itself, but in the gallery leading to it from the exterior, and in the part

1. Mémoires, vol. ii. p. 364, 1874. 
of that gallery near the exterior. In the deposit thus found externally to the grave itself, parts of two skeletons were found, one of which had belonged to a very powerful man, the other to a very feeble subject. As the presence of bones in the gallery leading into the grave may furnish some clue to the method, if not of the primary introduction of the bones into the grave, still to that of their remaniement, it may be well to specify some of the very large number, no less than 207 in all, which it contained. In this gallery then there were found three human clavicles, all of exceeding feebleness, and one badly reunited after fracture; a distally injured and exostotic radius, a similarly conditioned fibula ; two anchylosed cervical and some other vertebræ from a very aged subject; three patellæ, two ossa calcis and other foot bones. All however admitted of being referred to one or other of the two skeletons represented by the two skulls Nos. 5 and 8 , found in the grave at the W.N.W. end into which this passage opened; and there is consequently no reason to suppose that they are anything else than parts of those two skeletons, disturbed possibly to make room for another skeleton which may even have held the same place at this end as skeleton ' No. 3' did at the other end of the trench. This however is but conjecture: a survey of the entire collection of bones, from one end of the transverse zone to the other, does, I think, help us to making a tolerably certain conclusion as to the way in which they came to have the arrangement we observed. Taking all the bones of whatever kind which we took out of this primary interment, amounting in all to very many hundreds, and arranging them, after they had been labelled according to the position they had occupied, on a long table, so as to be able easily to compare one set of bones with another, and avoid thus the risks of either underrating or overrating the number of bodies represented, I was able to show that the lower jaws alone gave evidence of the presence in the series of four more adult skeletons than did the reconstructed calvariæ. Similarly it was clear that there were more long bones, humeri, femora, and tibice, than could be assigned to so few as ten adults. And these numbers seem to me to prove that the 'Ossuary Theory,' a theory in accordance with which the bodies found in non-cremation long barrows were deposited in them at one time and not successively, and consequently must have been stored or stacked away somewhere else till a sufficient number were available for such disposal of them, does not apply to this barrow, as I was ${ }^{1}$ once inclined

1 See Journal of the Anthropological Institute, vol. v. p. 137, Oct. 1875. 
to think it may do to others of the same period. For in a collection of bones from a modern ossuary the number of calvarice will, I think, be always found to exceed the number of lower jaws; these latter bones, as palæontological as much as modern osteological investigations have taught us, having a great tendency to separate themselves from the skulls to which they properly belong. The same may be said of the long bones; but precisely the reverse of all this is what we have found in this Upper Swell Barrow.

That a number of bodies must have been stored away, and then simultaneously disposed of, there is no doubt as regards the long barrows in which cremation was practised; the structure of these barrows implies unity of deposition and simultaneity of ignition. And, as regards tribes which did not practise cremation, there can be no doubt that the accidents of war, the difficulties entailed by expeditions to a distance, when such expeditions were undertaken, and perhaps, above all, the increase in mortality which severe weather must have produced in those, as it does in these days, may frequently have left them with a number of dead bodies upon their hands, and without the usual facilities for disposing of them. Out of such difficulties the practice of storing the dead would naturally develope itself. But the bodies thus temporarily stored away would be finally buried either before or after the mutual attachments of their bones had been destroyed by decomposition. If the former had been the case as regards this barrow, the various skeletons represented in it would have maintained the normal relations of their constituent parts, which they have not done here; if the latter, those constituent parts would not have maintained the numerical proportions which we have here found them to do ${ }^{1}$.

But, secondly, the intimate intermingling and interstratification of the human bones with the rubble filling up the trench-grave in this Upper Swell Barrow is a fact which, when coupled with the second fact of one skeleton, which we have no reason to think was of a different period, having been found undisturbed in it, appears to me to necessitate the conclusion that the Successive Interments Theory is the true one for this barrow at least: the only non-cremation barrow with bones in a tolerable state of preservation which $I$ have been fortunate enough to see with reasonable grounds for holding

1 I am not prepared however to say that the same numerical proportions have always ruled in other long barrows, even when they have escaped disturbance by later races. For the separation of the lower jaws in Red Indian ossuaries, see Professor D. Wilson, Canadian Journal, 1861-On the Huron Race. 
that it had escaped material disturbance by races later than its original erectors and occupants. For it is easy to understand how, as a grave filled up with rubble was from time to time reopened to admit a fresh tenant, the bones of two or three of the least recently deposited and most completely forgotten previous occupants might come to be intermingled more or less confusedly, firstly with each other, and secondly with the rubble, accordingly as more or less care was bestowed upon the task of displacing them to make room for the new arrival. I had observed and recorded ${ }^{1}$ an interstratification of bones and rubble similar to that existing here in other non-cremation barrows; these latter, however, bore marks of having suffered from later, possibly mediæval treasureseeking disturbers; the undisturbed condition, however, of this barrow eliminates this hypothesis, and shuts us up to one which, like the one above sketched out, recognises the fact that this burial-place was found by us in the condition it was left in when it was last used in neolithic times for purposes of interment.

As so much hinges upon the question whether this barrow was really in an undisturbed condition when examined by us, it may be well to state distinctly our reasons for holding that though the part of the barrow containing these interments may have lost something of its original elevation by being used for walling, or by being ploughed over, it remained otherwise much as the men its original constructors had left it. Firstly, then, otherwise the single undisturbed skeleton in the contracted position would not have been found by us in situ. A similarly-placed skeleton may, it is true, have been removed from a similarly-placed site at the W.N.W end of the trench-grave, but there is reason to think that a body would not be interred on the non-sunny side of the barrow; whilst there is no positive reason for supposing that any such interment did actually take place there. And, secondly, the fact of Saxon interments, with the characteristic insignia, having been found in the middle line and seventeen feet from the N.N.E. end of the barrow, and sunk into it, as was the fashion of our forefathers, shallowly, shows plainly enough that it had never suffered from any systematic exploration for treasure, or for any other purpose, till the time of our investigation.

The barrow, then, may be taken as a fairly illustrative specimen of the horned variety of Long Barrow-a variety of the tumulus of the Non-metallic Period which is represented in Caithness,

1 Journal of Anthropological Institute, vol, vii. pp. 156-157, Oct. 1875. 
as described by Mr. Joseph Anderson, as well as in the Southwest of England, and found to contain there interments similarly arranged, and pottery and implements of a similar type and rudeness, to those which we have found here. The peculiarity of the form of these barrows suggests to us that some idea was at one time or other symbolised by it; or by some form like to it, of which the one with which we are familiar may be only a 'survival' in a comparatively rudimentary state. As to what that idea may have been I have no suggestion to offer. A superstition, even when new, embodies itself often in a grotesque representation; and the meaning of this embodiment, which may not have been very directly evident even to contemporaries not acquainted with its history, may, it will be easily understood, soon become wholly undecipherable in after ages. This Upper Swell Barrow, however, differs from the other horned cairns in Caithness, Wiltshire, and Gloucestershire, in having its grave sunk below the surface of the natural ground, instead of being represented by a chamber with upright slabs for its walls, and placed on the surface and defended by the piling of stones round it. A few slabs appear to have been set on edge on either side of the passages or galleries leading to or serving to indicate the way into the place. of burial from the outside; but the grave itself was sunk into the ground, and, as the breakages in some of the bones even of the perfect skeleton show, the bodies were only very imperfectly protected from the pressure of the rubble in which we found them embedded, even when first put into the grave. The idea therefore of making the house for the dead as like as it might be to the house for the living, the idea which appears as shown by Professor Nilsson ${ }^{1}$ to have lain at the foundation of the erection of chambered barrows, was not acted upon when this barrow was formed ${ }^{2}$. But there is no doubt that it

1 Prim. Inhab. Scandinavia, chap. iv. ed. Lubbock.

${ }^{2}$ As in the horned long cairns of Caithness, and as in the other unchambered noncremation long barrows examined in England, so in this barrow we have to note the absence of any of that, whether thong-, cord-, or finger-nail patterned pottery which has been found in the horned short cairns of Caithness, in several chambered long barrows in England, and by myself in one cremation long barrow at Market Weighton in the East Riding of Yorkshire. The absence of patterned pottery from the horned long cairns of the north of Scotland may, as these cairns are probably earlier in date than the shorter ones with the same type of ground-plan, seem something of an argument for considering the non-chambered English long barrows which, like this one, are similarly destitute of such ornamented ware to be similarly earlier in date than the chambered barrows which possess it. But it must be observed, firstly, that if anteriority in date would account for this barrow's having no chamber, whilst the barrow ccxxxii, close by, had a large one, it will not explain its having its interments in a 
belongs to a very early period; one in which the use of metals was unknown, in which stone and bone implements were in use, together with coarse pottery, and in which the goat, the pig, and the ox furnished food as domestic animals, but were supplemented, and that largely, in that function by the roe, the red deer, and the wild boar. The dog was not found in this as it was in another of the long barrows of this locality.

M. E. Dupont ${ }^{1}$ appears to have persuaded himself that the earlier stone ages were times when war was less usual than in these later ones; and it may seem a little difficult to explain the presence in four out of so small a number as fourteen adult skeletons, of traces of such injuries as the breakage of collar-bones, of fore-arms, and of elbow-joints, merely by a reference to the accidents incidental to battles with wild beasts.

Abundant, however, as are the traces of severe injuries to the upper limbs which were received and recovered from by the people buried in this barrow, I have never observed in any of the many crania obtained in this district from interments of this neolithic period any lesions of the calvariæ which appeared to have been inflicted during the lifetime of their owners. But as evidence of injuries of the living skull, both recovered from and not, is unmistakeable enough and common enough in series both of ancient and of modern crania, the absence of such injuries in this series, distinguished as it is by the presence in it of so many otherwise injured bones, is

sunken grave; and, secondly, that it is unsafe for us, considering how very small has been the quantity of patterned pottery found either in the Scottish short cairns or in the English chambered long barrows, or in the single cremation barrow above mentioned, to stake much upon the fact of its not having been found in the other kind of barrows under comparison. The similarity of this pottery, whether found in Caithness, the East Riding of Yorkshire, Gloucestershire, or Wiltshire, is a fact of less doubtful interpretation and greater significance; especially when we couple with it a consideration of the similarity of weapons and implements, of the similarity of the ground-plans of the Scottish horned cairns and of so many of the Gloucestershire, Wiltshire and Somersetshire long barrows, and finally of the similarity of the skulls from the neolithic tumuli of all these localities. These similarities are the more surprising when we recollect how difficult intercommunication must have been at the period when they existed.

See however for East Riding pottery p. 509 supra and p. 544 infra.

For the pottery of the horned cairns of Caithness, see J. Anderson, Proc. Soc. Ant. Scot. vol. vii. June, 1868, pp. 505-511 ; Mem. Soc. Anth. Lond. iii. p. 220.

For figures of long barrow pottery of Wiltshire, see Dr. Thurnam, Archæologia, xxxviii. 417; Crania Britannica, Pl. 50, p. 3.

For figures of that of Gloucestershire, see Professor Buckman, Nympsfield Tumu-

lus, Proceedings of Cotteswold Naturalists' Club, vol. iii. p. 187, 1863.

For a rationale of the uniformity observable in practices of savage tribes, see Bagehot, 'Physics and Politics,' p. 156 seqq., 1872.

${ }^{1}$ L'Homme pendant les Ages de la Pierre, 2nd ed., p. 236, 1872. 
a remarkable matter. And I incline to connect this absence of injuries to the cranial vault, observed here, with the singular paucity of any of the stone weapons best calculated to inflict such injuries, axes, namely, or hatchets, in collections of the stone-implements of this district. The penetrating power of a stone-headed arrow is greater by far than we are, previous to experience ${ }^{1}$, inclined to believe; still its chances of inflicting either a fatal or a disabling wound are, owing to its liability to be deflected, smaller when it strikes such a surface as that of a cranial vault than when it strikes almost any other part of the body except the limbs. Hence an archer ordinarily would aim either at the face or at the trunk; and hence, perhaps, as the wars of this district at this period would appear to have been carried on with the missile weapons still found in abundance on its surface, we may explain the absence of the cranial injuries which hand-to-hand fighting produces so plentifully.

On the other hand, a suspicion has sometimes crossed my mind to the effect that the absence of such weapons as axes and hatchets may be explicable by supposing that the people thus destitute of them may have been living peaceable (because isolated) lives. And the all but total absence in this district of any evidence of the practice at this period of cremation ${ }^{2}$ may be held to point towards the same explanation, which however leaves the limb-lesions unaccounted for.

It has not been possible to assign any of the long bones with perfect certainty to any of the skulls except in the case of the undisturbed skeleton. This skeleton was a female skeleton, and its femur with a length of $16 \cdot 5^{\prime \prime}$ gives its owner a stature of $5^{\prime}$. A considerably stronger femur, which there is some reason for assigning to one of the male skulls, ' $4 a$ ' and ' $4 b$,' gives a stature of $4^{\prime} 11^{\prime \prime}$ to its owner. None of the femora, however, give evidence of a stature above $5^{\prime} 4^{\prime \prime}$, and only one gives even this. In this particular of shortness of stature these stone-using people, males and females, interred in this barrow, resemble the Bretons as described by Professor Broca ${ }^{3}$ and Dr. Beddoe ${ }^{4}$; and in the subequality of the stature of the two sexes they illustrate the principle that, where the stature is low, it is nearly identical for the two sexes. But the fact that these conditions are not reproduced in the other

${ }^{1}$ See Report of Surgical Cases in U. S. A. Army, p. 163, Washington, 1871.

${ }^{2}$ See K. F. Hermann, Antiq., pp. 204-206, eit. Grimm, über das Verbrennen der Leichen : Kleinere Schriften, Band ii. p. 288, 1865, in a note added to this edition of his exquisite Memoir, first published in the Berlin Abhandlungen for 1849.

${ }^{3}$ Mémoires d'Anthropologie, vol. i. p. 323, 1871.

4 Memoirs Anth. Soc. London, vol. iii. p. 361. 
barrows of the same period in the immediate neighbourhood in which male skeletons of as much as $5^{\prime} 6^{\prime \prime}$ were found, accompanied by female skeletons as short as $4^{\prime} 10^{\prime \prime}$, shows us how much care is requisite before generalizing upon these topics. It is, however, possible, or even probable, that the shortness of the stature of the occupants of this barrow may have been a family peculiarity, each barrow having not improbably been the burial-place of the chiefs of a single clan or horde, which clan or horde or family may in this particular case have been distinguished by shortness of stature.

All the ten skulls recovered or restored from the remains in this barrow are dolicho-cephalic by measurement; but it is of greater conseyuence to state that they are all equally free from any of the peculiarities which characterise the brachy-cephalic type, in the way of contour and otherwise, as distinguished from simple proportion. Of the ten skulls, five undoubtedly belonged to men, and of these one only to a man below 25 years of age; of the other four, one belonged to a man between 25 and 30 , and the other three to men past the period of middle life. Of the other five skulls, four undoubtedly are skulls of women, and of these three were aged women ; the remaining skull is most probably a woman's, and an old woman's, but in this case it is not possible to be quite certain as to the sex. This is a large proportion of aged bodies; and coupling with this the consideration of the similarly large proportion of fractured and repaired bones mentioned above as suggestive of exposure to the accidents of war, we may suppose that the absence of younger skeletons in a due proportion is to be ascribed to their owners having perished in fighting at a distance from their homes. Perhaps the most striking point suggested by a survey of these ten skulls in a single coup d'ceil is the very considerable variety which exists amongst them, though they can all be ranked under the title of 'dolicho-cephalic.' Amongst the female skulls two very different forms are at once put into contrast, one of them a larger, the other a markedly smaller form; the owners of the larger skulls we must suppose to have been better fed and cared for, and less ill-treated, especially in their younger days, than the others; it may remain a subject for speculation in what way such a hold upon the respect of the other members of the tribe was established by the less favoured and fortunate women as to secure for them after death admission 'to the tombs of the kings.' The male skulls are all large skulls, and whilst all are dolicho-cephalic, two are exaggeratedly so, and would have 
been called 'cymbo-cephalic' by Professor Wilson when he employed that term in 1850 before the British Association. In one of these, 'No. $2 a$,' the skull of a young man, the principal sutures, longitudinal as well as transverse, are entirely free from anchylosis, showing thereby that the form of the skull in these 'scapho-cephali' depends upon that of the brain, and not vice versâ. The other three male crania belong to that elongated vaulted variety of skull, of which the Engis skull, the 'Hohberg typus' of His and Rütimeyer, and the 'Grave Row' skulls of Professor Ecker, may be taken as familiar examples. The sex of the tenth skull appears to me to be doubtful, though I incline to think it to have been a female's. This skull, as already observed, is closely similar in proportion and contour to a skull referred to by Professor Nilsson as existing in Dr. Buckland's 'rich museum,' at the time of the Meeting of the British Association in Oxford in 1847 (see Report, p. 32), and as having come from a depth of 500 feet in a tin mine in Cornwall. It is of importance to note that skulls of this kind are reported by Professor Nilsson $(l . c$.$) to have been found, as we have found them here, in$ the same place with the boat-shaped heads which he, nevertheless, ascribes to an earlier epoch; and as we have no reason for thinking that any one of the skulls from this interment differs materially in point of date from any other, we are driven to the conclusion that the dolicho-cephalic type enjoyed considerable elasticity as to its limits even in times which are sometimes supposed to have been marked by great uniformity in cranial conformation.

The lower jaws from this barrow give perhaps as unmistakeable evidence of the 'priscan' character of the skulls as any other part of their organization. They are nearly all marked by a deficient development of the region of the chin, but they do not present that disproportionate development of the alveolar part of the symphysial region which is so marked in many long-barrow specimens, nor have they that thickening of the ramus in the molar region which may often be noted in jaws of this early period in this country and elsewhere. On the other hand, a second peculiarity rarely to be seen in the lower jaws of cultured races is present in several of these, namely, the shortness of the coronoid process. The deficient development of the chin would be paralleled very commonly in the lower jaws of the dolicho-cephalic Hindoos proper and of the African races; but in these latter races the coronoid process would usually pass behind the zygomatic arch when the jaw was shut, which would not be the case in these nor in many other long- 
barrow skulls, which here find a parallel in Eskimo crania. When a series of such lower jaws as these is placed together opposite a series from round barrows, or from modern sources, a most instructive contrast is formed for the observer, who might sum up his generalisations by saying that though some one or more of what are usually considered to be marks of degradation in the eonformation of a lower jaw may be absent, some one or more will invariably, or all but invariably, be present in a 'priscan' lower jaw, and in such a degree or in such number as to enable us to recognise it as such; and that those marks of degradation will as rarely be found combined in the lower jaw of any one recent savage race, but that they will be found scattered and distributed amongst several such races, who cannot be supposed to be much more nearly connected , by blood than they are in space.]

Two other long barrows, so far at least as their shape is concerned, remain to be described; but as their contents did not present any features characteristic of this class of sepulchral mounds, beyond the shape, I have thought it best to defer an account of them until I have made some general remarks upon the subject of long barrows, and the manner of burial found to prevail in them.

There are several questions connected with these Yorkshire and other long barrows just described which merit special consideration; and it may help us to an easier and more advantageous speculation about them, if we call to mind and compare the results of the examination of similarly-shaped burial mounds in other districts of Britain. There is one point of difference, already noticed, between the Northern and the South-western long barrows, regarded in the aggregate, which must be mentioned at the outset; and at the first glance it might seem, from this very important dissimilarity, that they must belong, in the two localities, to different ages, if not to distinct peoples, or even races. I think, however, that the remarkable features which they so evidently possess in common, may go further to indicate identity of time and people than the single point of difference does towards suggesting absence of contemporaneity or diversity of race. The dissimilarity I refer to consists in this: that in the barrows just described as opened by Professor Rolleston and myself in Yorkshire and Cumberland, as well as in the two cases on Sherburn Wold and near Helperthorpe (p. $480 n$.), the bones (with one exception, on Kepwick Moor [No. cexxvii]) evidently were in- 
tended to be burnt, and, in the main, had undergone the sustained action of fire; whilst in the long barrows of Wiltshire, Gloucestershire, and other neighbouring counties, the bodies in all of them, with a very few exceptions ${ }^{1}$, had been buried unburnt. That the practices of burial after cremation and by simple inhumation do not of themselves prove any difference in either time or people is abundantly shown by the fact that both modes are frequently met with, not only in the same barrow, but also in cases of burial so closely connected that two bodies, disposed of in the two diverse manners under notice, must undoubtedly have been buried at one and the same time. This will be seen by reference to the account of the examination of many of the round barrows as recorded in this volume, which, however, belong to a different period from that when burial in the long barrows was in practice. Nor has the contemporaneous use of cremation and inhumation been confined to Britain : the evidence is conclusive on this point as regards Denmark, Germany, France, and other countries of Europe, not to mention America. The Greeks and Romans, as is well known, used both modes at the same time.

The points of resemblance between all the long barrows hitherto examined throughout England are many and important. In the first place, there is the shape: they are very long in comparison with their breadth; and, as connected with this, it should be remarked that they are almost always placed, at least approximately, with their long diameter running east and west; and that the east end is both broader and higher than the west. The inter-

1 In the Knook long barrow Mr. Cunnington found in 1801 ' a large quantity of burnt bones.' Archæologia, vol, xv. p. 345. Sir R. Colt Hoare gives further notes of it. Ancient Wilts, vol. i. p. 83. The barrow was lately reopened by Dr. Thurnam, who met with 'burnt bones and many scattered brittle flints, some of a red, others of a blackish-grey colour, as if scorched by heat.' Archæol., vol. xlii. p. 193. In a long barrow at Tilshead, Dr. Thurnam found, at the east end, 'a pile of large flint stones, beneath which, and on a pavement of similar flints, many of them of a red and blue colour, and very rotten and brittle in texture, was a large pile of burnt human bones. ... It was observed that the fragments of burnt bones were much larger than those so common in the circular barrows, and that they were far from being so completely incinerated.' At the same level, but about $2 \mathrm{ft}$. from the burnt bones, were portions of a female skeleton, the skull of which showed signs of having been cleft during life, and which was in many fragments. The same pile of flints covered both the burnt and unburnt bones: $l$. c., p. 191. In a long barrow within the earthwork called Bratton Castle, Dr. Thurnam found on the natural level, and just beyond an opening made some time before by Mr. Cunnington, ' a heap of imperfectly burnt, or rather charred human bones, as many, perhaps, as would be left by the incineration of one or two adult bodies.' With reference to the bones in these three instances, Dr. Thurnam remarks, 'the cremation seems to have been of an imperfect and defective sort, quite different from that of the round barrow period :' $l$. c., p. 192. 
ments again, at any rate those which can undoubtedly be regarded as primary, are generally at the east end, though there are certainly remarkable instances to the contrary ${ }^{1}$. The bones also are very frequently disjointed and sometimes lie apart from each other, as if the bodies had been dismembered, and the flesh removed from the bones before they were placed in the mound; nor in many cases are all the bones of the body present. Besides which, the bones in some instances are said to show (though $I$ think this is very doubtful) signs of having been violently fractured before, or immediately upon, death ${ }^{2}$. The type of the skulls too is a very marked one; they are eminently dolicho-cephalic ${ }^{3}$; and possess other equally characteristic features. I believe no primary interment found in a long barrow has produced a brachy-cephalic cranium, though that form of head is so common in the round barrows, whilst dolicho-cephalic heads have occurred abundantly in them. Further, no trace of metal has been found in connection with the buried bodies, or, indeed, in any undisturbed part of a long barrow ${ }^{4}$. Weapons and implements are also of very rare occurrence; and I am only acquainted with one instance where anything in the shape of an ornament has been met with. Pottery of any kind is very infrequent, and, contrary to the practice of the time of the ordinary round barrows, does not appear, except on the rarest occasions ${ }^{5}$, to have been placed in the shape of vessels in

1 Mr. Cunnington, in a letter in the Archæologia, vol. xv. p. 338, observes that nearly all the long barrows in his district of Wiltshire stand east and west, the east end being the widest; and that out of eleven opened by him, nine had the skeletons at the east end.

${ }^{2}$ In the South-west of England, cleft and broken skulls are said to have been found in a long barrow, near Haytesbury, by Mr. Cunnington. Hoare, Ancient Wilts, vol. i. p. 88; and in those of West Kennet, Littleton Drew, Uley, Tilshead, and Rodmarton. Crania Britannica, pl. 59. Dr. Thurnam has also, since the publication of the work just referred to, stated that he has found like cleft skulls in a long barrow, on Fyfield Hill, near Pewsey, Wiltshire.

${ }^{3}$ In addition to the long barrows described in this volume, the long barrows of Derbyshire and Staffordshire, if any of those recorded by Mr. Bateman can strictly be called such, have produced dolicho-cephalic skulls. Bateman, Vestiges, pp. 46, 47, 91, 103; Ten Years' Diggings, pp. 94, 144. The long barrows of the South-west of England have also been found to contain the same shaped skulls. See papers by Dr. Thurnam, Crania Britannica, passim; Archæol., vol. xxxviii. p. 415; vol. xlii. p. 161; Arch. Journal, vol. xi. p. 315; Memoirs of Anthropological Society of London, vol. i. pp. 120, 459.

* Sir R. Colt Hoare says, "We have invariably found the sepulchral deposit placed under the east end of the tumulus, and the interments to consist of skeletons, buried in an irregular and promiscuous manner, and unaccompanied by those fine urns, gilt daggers, \&c., which have rewarded our labours in the bowl and bell-shaped barrows.' Archæol., vol. xix. p. 43.

${ }_{5}^{5}$ Dr. Thurnam records only a single instance, where a plain semi-globular shaped 
association with an interment. The fragmentary pieces which have now and then been met with amongst the apparently undisturbed material of the mound, and sometimes in close contact with the bones of the buried bodies, are usually of a dark-coloured ware, and invariably, in my experience, plain ${ }^{1}$, differing in that respect from the sepulchral pottery of the round barrows; they seem to have been portions of round-bottomed vessels, with a recurved lip. Less important points of resemblance may be found in the trench which runs along the sides of the mound, but is not continued round the ends, as well as in the occurrence within the barrows of dry walling or facing of stone, and of enclosing walls.

The disjointed state of the bones and the broken skulls, the several pieces being sometimes found quite detached from each other-a condition of things obviously inconsistent with the idea that the bodies had been buried with the flesh still upon themhas suggested practices at the time of burial which, though repugnant to our own notions, have, nevertheless, been so universal in the history of savage, and even semi-savage tribes, that we need not be surprised at finding traces of their prevalence in Britain. I refer to cannibalism. It appeared to Dr. Thurnam that there were in these broken and scattered fragments of skulls and disconnected bones the relies of barbarous feasts, held at the time of the interment, when slaves, captives, or even wives were slain and eaten. In what other way, he argued, could the various circumstances connected with these deposits be reasonably accounted for? Dr. Thurnam also adduced some passages from ancient writers to show that 'anthropophagism was practised in the British Islands ${ }^{2}$,' though these all refer to a time long posterior to that to which the long barrows can be attributed.

I confess that I was for long so impressed with the force of Dr. Thurnam's arguments, as based upon the appearance of violent fracture, which he thought he had found sufficiently manifested upon many of the skulls from long barrows, that I accepted his conclusions as to the cause of that appearance. Nor, indeed, though I have now adopted another explanation of the remark-

vessel was found with skeletons in a long barrow at Norton Bavant, Wilts. Archæol, vol. xlii. p. 195.

${ }^{1}$ A piece of thong-marked pottery was found in a long barrow at Market Weighton by Professor Rolleston, but, for reasons which I have stated at p. 509, I think it possible that it may have only been accidentally present where it was discovered.

${ }^{2}$ Diodorus Siculus, lib. v. cap. 32 ; Strabo, lib. iv. cap. 5. sec. 4; Plinius, lib. vii. sec. 2 ; lib. xxx. sec. 4 ; Hieronymus adv. Jovinianum, lib. ii. 
able appearance and condition of the buried bones of this class of sepulchral mounds, do I think his argument is altogether without weight. That Dr. Thurnam found signs of violent breakage upon a few skulls he exhumed or examined, perhaps, may not be doubted, but in the greater number of instances where he thought he saw evidence of fracture inflicted before or at the time of death, I believe the fractures are the result of pressure upon bones which have partially undergone, whilst covered up, the action of fire ${ }^{1}$. The sharp edges and the porcellanous appearance which Dr. Thurnam thought was the effect of a blow upon fresh bone, I am clearly of opinion, after careful examination of numerous bones which have been imperfectly burnt, is the result of pressure upon them when in that condition. Some of the bones upon which Dr. Thurnam based his conclusion, and which he regarded as being quite free from any effect of burning, have certainly undergone, though not to a great extent, the action of fire. That the finding of a small number of skulls cleft, or otherwise showing the effects of violence undergone during the life of the persons so treated, is any proof that they had been killed at the time of the funeral and for the purposes of a funeral feast, no one, probably, would insist upon. People were slain in battle, or in consequence of a private feud or quarrel, then as now, and these infrequent fractured skulls may well be the result of such accidents. Had the long barrows, as a rule, contained one or more complete skeletons, surrounded by, or associated with, others which showed evidence of having been those of persons killed by violence and broken up as if for use at a feast, then we might have concluded with some probability that it was the habit of these people to immolate, for one purpose or another, certain persons at the time of a funeral. But no such appearances present themselves. In many cases, no doubt, the bodies seem to have been deposited in the long barrows in an imperfect condition, and in some instances all appear to be incomplete; but though the bones do not in these cases constitute an entire skeleton, yet there are no signs upon them of any violent action, such as might have been looked for if they had been killed at the funeral and for the purposes of a feast. In other cases the bodies are complete, and, from the due juxtaposition of the bones, appear to have been placed in

${ }^{1}$ I am indebted to Professor Rolleston for having first drawn my attention to the peculiar way in which bones partially charred under certain conditions become broken by pressure; a circumstance which first led me to modify my views with regard to the question of the violent breakage of bones from the long barrows. 
the grave when still held together by ligaments if not by the flesh itself.

There is, however, as I have more than once stated before, another and equally probable explanation of the fragmentary and dislocated condition in which on certain occasions the remains of the bodies are found in the long barrows. These sepulchral mounds may not be the primary place of burial of all the bodies discovered in them. In some cases all the bodies may previously have been kept in another place of deposit, for more reasons than one; in other cases, one or more bodies may, in the first instance, have been buried in the barrow, whilst others, those of relations, friends, or dependants, may, on the occasion of the funeral, have been transferred to the barrow from the place where up to that time they had been preserved.

This explanation seems to me to account for all the appearances which present themselves in the sepulchral deposits in the long barrows, whether the bodies have been burnt or not. Nor is the practice one which has not recommended itself to many and widely separated peoples. The custom of burying in ossuaries the remains of bodies in the first instance deposited elsewhere, is so well known, and has been so fully considered in other places in this volume, that I need but refer to it here.

Another explanation has been given of the way in which the bones in the long barrows have been found to be disturbed, and of their incomplete and even fragmentary condition. Professor Rolleston appears, from an estimate of the numerical proportions in which many of the bones, and notably the lower jaws and some of the long bones, are present in at least one of these barrows, to have convinced himself that the Successive Interments Theory, advocated by Professor Nilsson ${ }^{1}$, must be accepted at all events for that barrow. He thinks, however, that inclemencies of weather and the accidents of war must, in the very nature of things, have occasionally necessitated the practice of storing away dead bodies in temporary receptacles, and have thus given rise to the establishment of ossuaries. It appears to these authorities that the successive deposition of bodies in the chambers will account for all the appearances met with, the bones of the earlier buried bodies having been disturbed by the introduction of later interments, made from time to time. Against the theory of these receptacles being of the

1 Stone Age of Scandinavia, ed. Lubbock, p. 163. 
nature of ossuaries, Nilsson objects that the association of weapons, implements, and ornaments with the bodies is inconsistent with their having been first deposited in some other spot, and only afterwards brought to their final place of burial. Fully admitting the force of this objection, I think it is, nevertheless, quite possible that such articles may have been buried with the removed bones, either as having been brought with them from their first burialplace, or as having been deposited with them anew when they were finally laid in the grave. But the case of the long barrows is a different one in several respects.

As has already been stated, weapons, implements, and ornaments are only of the rarest occurrence, and so the objection of Nilsson on this ground scarcely seems to apply, so far at least as England is concerned. Again, the bodies in many of the long barrows have not been placed in chambers, but laid on the surface of the ground, and then covered with earth. In cases such as these it is evident that, when no signs of disturbance are visible in the mound, the dislocation and fragmentary state of the bones cannot have been caused by anything like successive interments, but that they must have been in the same incomplete state, in which they are found, when they were first deposited in the barrow. The case of the long barrows where cremation has been practised is equally strong, for there again the burning of the bodies must have taken place at one and the same time, and yet we unquestionably find imperfect and disconnected bones in the burial deposits contained in them. If the chambered long barrows containing burials by inhumation separated themselves, in other particulars than that, from the unchambered ones of the same class, and also from the barrows containing burials after cremation, it might perhaps be possible to explain the displacement and imperfection of the skeletons in the chambers by the theory above referred to, though then, I think, scarcely with much probability. But when the whole resolve themselves into one class, and cannot certainly be demonstrably separated from each other either with reference to time or people, I cannot admit that the practice of successive interments will adequately account for all the appearances presented. Nor will this theory explain the occurrence of skeletons which are wanting in some of the principal and in many cases the least perishable bones. It is true that in the round barrows the remains of what have been, when placed in the grave, complete bodies are found in every stage of decay, even to a total disappearance of the bones: 
but in the cases where some bones remain they are those which from the nature of their structure might be expected to resist decay the longest, whereas in the long barrows, on the contrary, such bones as those of the thigh and leg are sometimes wanting, whilst the skull is found almost complete, even in its thinner and most perishable parts. At the same time it cannot be doubted that successive interments may frequently have taken place in the chambered long barrows, and that the very act of a new burial must have more or less disturbed the bones of the bodies previously interred therein. Indeed, the nature of a chamber having an entrance into it implies in itself a provision for the deposition of successive interments. It is probable however that in the disturbed, disjointed, and incomplete skeletons we have the result of more than one practice.

It is almost certain, as has been stated already, that in the long barrows we have the earliest sepulchral mounds to be met with in England. The great extent of the barrow itself, and the disproportion between the size of the mound and that part of it to which the primary burials seem to be confined, though not perhaps a certain evidence of high antiquity, yet is more in accord with an early than a later time. But other proofs tending to show the great age of this class of places of burial are not wanting. It has been observed before that weapons, implements, and ornaments of any kind are extremely rare in the long barrows; but no trace whatever of metal has been found associated with the primary interments contained in them. The presumption then is, that the long barrows were constructed by a people to whom metal was unknown. At the same time I fully admit that the absence of metal in any given set of barrows is not in itself a proof that the persons who erected them were ignorant of its use; for it is not an infrequent occurrence to find a number of round barrows containing nothing of metal, when from many other circumstances connected with them we can have no doubt that it was known at the time when they were made. The case of the long barrows, however, is quite a different one, since the absence of metal in them is an universal, not an exceptional, feature; and so many of them have been examined as to make that fact one of very great value. Indeed it seems scarcely possible to believe that, had metal been known, it should never have occurred in any of the numerous long barrows which have been explored with great care in different parts of England. The evidence afforded by the chambered barrows of Scandinavia, France, and other countries, places 
of sepulture which, as has already been remarked, appear to have much in common with the long barrows, has a very important bearing on this question. Though weapons and implements of stone are of very common occurrence in them, in which respect they differ materially from the long barrows, no articles of metal except gold have ever been found, and they may certainly be attributed to a time when bronze and iron were unknown. Nor can the absence of metal be accounted for from its decay, because when bronze itself entirely disappears, which only happens when the implements made of it are of a very small size, there is always left the striking colour of the oxide of copper staining the material with which the metal had once been in contact. Pottery again seems to have been but little in use, at all events for burial purposes; for it is of the rarest occurrence in the long barrows, and when it is present, it is not, except very occasionally, in the shape of whole vessels but of mere fragments. In the round barrows, on the contrary, it is extremely common, not only as sherds of pottery, but as complete vases. The inferences derivable from the absence of metal, and the rarity of pottery, are carried still further by the character of the skulls found in the long barrows as contrasted with those occurring in the round ones. In these latter the skulls most frequently met with are brachy-cephalic : whilst, as regards the true or original burials in the former, the brachy-cephalic head has not been found at all. Certainly long-headed skulls have occurred in round barrows - in those of the Wolds, indeed, almost as commonly as round heads; but assuming the dolicho-cephalic to be the type of skull belonging to the earlier people, this is precisely what might have been, nay, must have been, looked for; inasmuch as while it is reasonable to conclude that the earlier class of sepulchral mounds is likely to produce but one type of skull (the case of the long barrows), it is equally reasonable to expect to find two or more types in the later class; because it is impossible to suppose the round-headed people either could, or would, attempt to entirely extirpate their predecessors from the moment of their own secured conquest or possession. Either as slaves, or as co-occupants of the country, in virtue of compact or of, at least, temporarily successful resistance, the long-heads would continue to exist; and, therefore, by hereditary transmission through intermarriage of the two races, skulls with more or less of the dolicho-cephalic character would for ages continue to recur. So that, independently of the fact that many of the round 
barrows are unquestionably due to the age of bronze, whilst, in all probability, the whole of them belong to that period, the argument as to the greater antiquity of the long barrows from the type of skull, the only one found in them, is all but conclusive. I believe, then, that we may safely assign the long barrows to a time when metal was as yet unknown in England, and when the conditions of life, consequent on the absence of one of the principal elements of progress in civilisation, were much inferior to those attained to after bronze had been introduced.

It was mentioned, before these general remarks on the nature of the long barrows and their contained interments were commenced, that there were two mounds yet to be described which only in a superficial way fulfilled the condition of long barrows. The first of them I believe was a true long barrow, though no primary burial was discovered in it; as to the second, I have considerable doubt whether it was more than a mound of the roundbarrow period, though of an unusual shape.

\section{Parish of Gilling, North Riding. Ord. Map. xcvi. s.e.}

CCXXXIII. This barrow is situated upon a high tract of sandy ground, about a mile to the south of the village of Yearsley, and also about the same distance to the north of a group of round barrows on Grimston Moor, the examination of which is described p. 343. The district, it may be remarked, abounds in prehistoric sepulchral and other remains. Several of the barrows in the immediate neighbourhood were opened some years ago, a partial record of the examination of them being preserved in Gill's 'Vallis Eboracensis,' from which account it appears that interments, both after cremation and by inhumation, were met with. Moreover, when a part of Yearsley Common was being brought under cultivation, during the years 1868, 1869, several burials, made in cists, were discovered; they were placed below the surface of the ground, but were unmarked by the presence of any mound. In four of these cases, of which I had an account from the workmen, three of the bodies contained in the cists had been placed in them at full length, the fourth being in a contracted posture. The cists were made of flat stones set on edge, with cover-stones, and there was nothing whatever in the shape of implement, ornament, or pottery found 
in them. In the absence of any associated articles, it is impossible to assign with anything like confidence even an approximate date to these burials; but I should be inclined, on the whole, from the slight indications available, to consider them as Anglian interments, and not perhaps earlier than the seventh or eighth century of the present era.

The barrow, which was examined very thoroughly, was outwardly a most characteristic specimen of the class of burial mounds to which it may be supposed to belong, except as to its orientation; the direction of its longer diameter being very nearly due north and south, the southern end having a greater width and higher elevation than the opposite one. The total length was $140 \mathrm{ft}$., and it was $60 \mathrm{ft}$. wide and $8 \mathrm{ft}$. high at the south end, and $40 \mathrm{ft}$. wide and $5 \mathrm{ft}$. high at the north. It was made up entirely of very light and pervious sand. The entire mound was surrounded by a line of stones, in some parts four deep, which rested upon the natural surface, and were concealed within the material of the barrow. At the broadest part of the mound the distance between the two sides of this enclosing belt of stones was $41 \mathrm{ft}$., and at the north and narrower end it was $27 \mathrm{ft}$. At a distance of $20 \mathrm{ft}$. from the south end of the barrow, and $6 \mathrm{ft}$. from the enclosing belt on the west side, was a line of flat stones laid upon white-coloured fine sand, just above the level of the natural surface, running for a length of $10 \mathrm{ft}$. parallel to the enclosing belt.

A very careful and extensive search failed to discover any trace of an original interment, which, if any such had ever existed, had probably been by inhumation, and therefore contrary to the usual habit of the people who erected these long mounds in North and East Yorkshire. For, had the bodies been interred in the way which we have seen was followed at Scamridge, Willerby Wold, Westow, Rudstone, Wass, and Market Weighton, abundant traces, in the shape not only of burnt bones, but of burnt earth and stones, would certainly have been found. It is possible, supposing this to have been truly a long barrow, which there seems good reason for believing it to have been, that the bones placed in the mound, without any application of fire to them, had, in consequence of the nature of the overlying mound, composed of light sand, gone entirely to decay. As the total destruction of bones, under certain conditions, is commented upon elsewhere, it is not necessary to repeat the argument further than to state that in sandy soil it is very rare to find any trace of buried bones, even when they have 
been consigned to the earth much more recently than we must of necessity assume could have been the case in this barrow.

It is, however, not impossible that the primary place of interment may, notwithstanding that a large part of the mound was examined, have escaped discovery. It may have been placed near to the side at the smaller end of the barrow, as was the case in one of the Gloucestershire barrows [No. cexxxi] before described, and so have been passed over; for at the time that I opened the mound my attention was more directed to the wider and higher part, with reference to the place of burial (though I examined the central portion of the smaller end) than a larger experience has since shown me was desirable.

Some flint chippings, charcoal, burnt stone, and a few charred acorns were met with in the mound. The acorns, by their appearance, showed that the barrow must have been erected after they had been shed; and the probability therefore is, that the construction took place late in the autumn.

Although nothing was found which could be supposed to have reference to a primary interment, what, there can be little doubt, had been a secondary burial, and one probably made long after the throwing up of the mound, occurred at the south end of the barrow, immediately beneath its highest point, and at a distance of $39 \mathrm{ft}$. from the middle of the longer axis of the mound. This burial had been of an unburnt body, but there was not the smallest trace of bone left. The body had been enclosed in a cist, formed of eight flat stones; but as these had in part given way, it was impossible to ascertain the exact dimensions of the cist; it could not, however, have been quite $4 \mathrm{ft}$. in length. The slabs of which the bottom was composed were laid $4 \mathrm{ft}$. above the natural surface. Within the cist was a 'food vessel ;' it is in shape like fig. 70, having four perforated ears at the shoulder, and is $5 \frac{1}{2} \mathrm{in}$. high, $7 \mathrm{in}$. wide at the mouth, and $3 \frac{1}{4} \mathrm{in}$. at the bottom. It is ornamented on the inside of the lip with four encompassing lines, and on the outside with one similar line having below it a band of very short lines inclining to the left. The upper part of the vase for a depth of $2 \frac{1}{2}$ in. has upon it a pattern formed by alternate series of vertical and horizontal lines; the series of vertical lines (which overrun the ears) being not one-half the breadth of the other series. All the impressions are due to twisted thong. Also within the cist were three flints, one (fig. 163) a very well-formed implement which, although it is rather thick, can scarcely be anything but a 
knife; the second (fig. 164), wider and thinner and not quite so well worked, is more certainly a knife; the third is a simple flake.

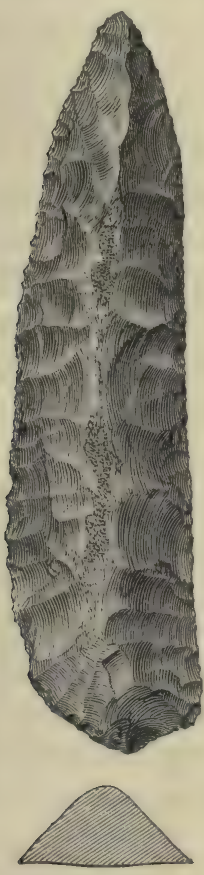

Fig. 163. $\frac{1}{1}$.

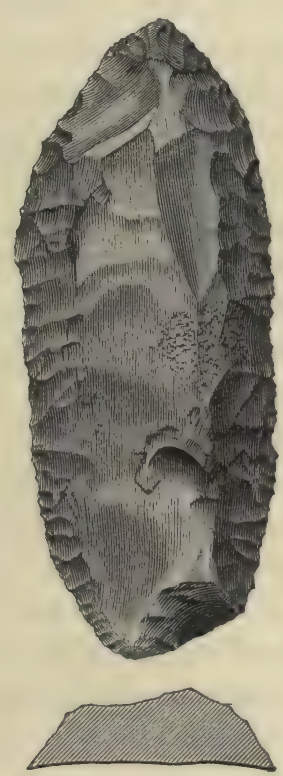

Fig. 164. $\frac{1}{1}$.

Parish of Kilham, East Riding. Ord. Map. xciv. n.w.

CCXXXIV. On the farm of Dotterill Park there is a mound which has all the outward appearance of an ordinary long barrow, though its contents, as will be seen from the following account, searcely warrant its being so reckoned. I have however thought it best to include it amongst the barrows of that class, though it has nothing beyond its shape in common with those sepulchral mounds, and though it belong's, there can be little doubt, to the same period as the round barrows.

It is $170 \mathrm{ft}$. long, having a direction of N.E. by E. and S.W. by W., and is $60 \mathrm{ft}$. wide at the north-east end, and $45 \mathrm{ft}$. at the opposite one: though much reduced by ploughing, it is still $4 \mathrm{ft}$. high at the wider end, and $3 \mathrm{ft}$. at the other extremity. The measurements specified below are taken from the point of inter- 
section of two lines, one drawn along the mesial line of the barrow, from N.E. to S.W., the other drawn across that line at its middle. For a distance of $57 \mathrm{ft}$. from the north-east end the barrow was constructed thus: along the middle the substance, having a width of $3 \mathrm{ft}$., consisted of chalk rubble; on either side of the chalk was a deposit of earth, $6 \mathrm{ft}$. in width; and outside the earth there was chalk again, for a width of $7 \mathrm{ft}$.; outside of this was a trench, $3 \mathrm{ft}$. wide and $2 \frac{1}{2} \mathrm{ft}$. deep, sunk into the chalk rock, and filled with earth; over the trench, and abutting on the chalk, the mound was composed of earth from that point to the outside. The trench was from $10 \mathrm{ft}$. to $15 \mathrm{ft}$. within the outermost limit of the barrow; but it did not run round the ends of the mound. Beyond the point above mentioned ( $57 \mathrm{ft}$. from the north-east end) the barrow was made up of chalk rubble, with here and there a considerable intermixture of earth, but by no means in regular lines of deposit, as was the case at the north-eastern part. At the extreme south-western end there was what looked very much like a small round barrow superimposed upon the end of the long mound, and causing it to be at that point rather wider and higher than it would have been had the ordinary form of the barrow been preserved. And, indeed, the interment found at the south-west end appears to countenance the idea that a secondary burial had taken place there, and that this small mound had been raised over it.

Several holes, sunk below the natural surface, occurred at various points within the barrow, which I will proceed to mention in detail before giving an account of the burials ${ }^{1}$. The holes were all about $2 \mathrm{ft}$. deep, and varied from $1 \mathrm{ft}$. $6 \mathrm{in}$. to $2 \mathrm{ft}$. $2 \mathrm{in}$. in diameter; they contained nothing but earth and stone, and (in two of them) a little charcoal. One was $75 \mathrm{ft}$. east-north-east from the centre; a second $62 \mathrm{ft}$. east-by-north; a third $60 \mathrm{ft}$. east-north-east by north; a fourth $53 \mathrm{ft}$. east-by-north; a fifth $45 \mathrm{ft}$. east-by-north; and a sixth $30 \mathrm{ft}$. east-by-south.

The barrow had once been planted with trees, which had been stubbed up, and when this was done the workmen came upon

1 It will be remembered that in the account of the round barrows it was stated that many of them contained holes in which no deposit of a body or of burnt bones was found. The same feature was observed by Sir R. Colt Hoare in the long barrows of Wiltshire, though he does not appear to have observed them in the round barrows. He says, speaking of a long barrow at Corton, where, at the east end, eight skeletons were met with, 'they had been deposited on the floor of the barrow between two exeavations in the natural soil, of an oval form and seven feet apart.' Ancient Wilts, vol. i. p. 102. Dr. Thurnam also found similar holes in some of the long barrows he opened in the south-west of England. 
several bodies. This circumstance will of itself account for the disturbed condition of some of the deposits of bones which were met with. At a distance of $58 \mathrm{ft}$. east-north-east from the centre, and $12 \mathrm{ft}$. south of the mesial line, was the body of an aged man, laid on the left side, about $1 \mathrm{ft}$. above the natural surface; the head was to W., the hands touching the knees, the back being straight, but the knees drawn up towards the chin. The bones were placed upon a layer of soil about 2 in. thick, which again was laid upon chalk slabs; under them was the skeleton of probably another man, past the middle period of life, which rested on the natural surface. It was placed on the right side, with the head to W.S.W., and the hands up to the face. Fifty-three feet north-east by east from the centre, and on the mesial line, at about $1 \frac{1}{2} \mathrm{ft}$. above the natural surface, were several fragments of a plain vessel of dark-coloured pottery, shallow and very wide, and apparently having been roundbottomed. The shape is most unusual, but unfortunately so large a portion is wanting, that the exact form cannot with certainty be made out. Two feet due west of the remains of this vessel was a body which had been partly disturbed. Four of the lumbar vertebræ were in position, and lying on the natural surface; the other bones were found at different levels, almost up to the surface of the barrow; some few burnt bones were mingled amongst them. About $1 \frac{1}{2} \mathrm{ft}$. north of this body, and $9 \mathrm{in}$. above the natural surface, was a deposit of burnt bones. I think it is not improbable that in the disturbed unburnt body we have the interment in connection with which the peculiar-shaped vessel was deposited, and that it had been displaced in the process of putting in the burnt body; whilst both of them had latterly been more or less scattered during the operation of stubbing up the trees. Fifty-two feet and a-half eastby-north from the centre, and $16 \mathrm{ft}$. south of the mesial line, was the body of an aged female, from 60 to 70 years of age, laid on the right side, about 9 in. above the natural surface. The back was straight, but the knees were drawn up, the head being to W., the arms crossed over the chest, and the fingers under the humerus of each respective arm. In front of the face, and touching the teeth, was a very neatly-made oval flint scraper or knife, $1 \frac{3}{4} \mathrm{in}$. long and $\frac{7}{8}$ in. wide. Thirty-five feet north-east by east of the centre, and on the mesial line, $6 \mathrm{in}$. above the natural surface, was the body of a young person, apparently partly disturbed; the head, lying to E., did not appear to have ever been moved. Thirty-one feet and a-half north-east by east of the centre, and one foot south of the mesial 
line, a disturbed body was met with, placed about 6 in. above the natural surface. It appeared to be the body of a girl, about 18 years of age, and amongst the bones were those of a young child; while a little to the east were some of the bones-a femur, lower jaw, \&c. - of a second child. Sixteen feet east-north-east of the centre, and five feet south of the mesial line, was the body, probably of an aged female, laid one foot above the natural surface, on the left side, the head to $\mathrm{N}$. by W., the hands being up to the face, and turned outwards at right angles to the wrists. Six feet south-west by west of the centre, and on the mesial line, about a foot above the natural surface, lay the disturbed body of an aged woman, in company with the bones of which were four pieces of what had once been a very fine ' food vessel' with pierced ears.

At the west end of the barrow, and rising about a foot above the due level of the long barrow proper, if such this mound ever had been, was (as noticed before) what looked like a small round barrow placed upon the end of the existing long mound. Beneath it, and only just above the natural surface, was the body, probably of a girl under 16 years of age, laid on the right side, the head to W. by S., the right hand up to the face, the left hand on the hips. In front of the face was a 'food vessel.' It is roughly made, of coarse badly-wrought clay, and is $7 \frac{1}{4} \mathrm{in}$. high, $8 \mathrm{in}$. wide at the mouth, and 3 in. at the bottom. It is in shape like fig. 69 , but with two ribs an inch apart, and is very slightly ornamented with short vertical lines, in pairs, drawn with a pointed instrument, at intervals of from $\frac{1}{2}$ in. to $\frac{3}{4}$ in., upon the two projecting ribs.

There were no potsherds, and only a few flint chippings, found in the mound; but charcoal occurred in considerable quantities in various parts, not however as the remains of fires made on the spot, but brought from others lighted elsewhere. Some few bones of a small $\mathrm{ox}$ and two roe-deer's antlers were also found.

Except in shape, and perhaps in the construction of the mound at the north-east end, this barrow has nothing in eommon with the long barrows already described. There were no dislocated or imperfect bodies, and, so far as could be made out, there did not seem to have been any primary interment besides that of the body with the dark-coloured, unusual-shaped vessel-if indeed it be safe to regard that as being such. Neither had there been any burning of bodies on the spot; the single burnt body found-most probably a secondary interment-having been burnt at some other place, and the bones then collected and inserted in the barrow. 


\section{DESCRIPTION OF FIGURES OF SKULLS.}

G. ROLLESTON, M.D., F.R.S. 



\section{DESCRIPTION OF FIGURES OF SKULLS.}

ELEVEN skulls and two calvariæ from thirteen barrows examined by Canon Greenwell have been selected for description by myself, and drawn and engraved by Mr. W. H. Wesley. Four of the skulls and both the calvariæ are of the dolicho-cephalic, and the remaining seven of the brachy-cephalic type. Four views have been given of each of the eleven skulls; the incomplete state of the two calvariæ rendered it useless to attempt to give more than two views of each of them. The four views given are the profile view, the so-called norma lateralis; the view from above, the norma verticalis; the view from in front, the norma frontalis; and the view from behind, the norma occipitalis. Views have not been given of the norma basalis, the base of the skulls having very ordinarily suffered so much posthumous injury as greatly to impair the value of such a view of them.

Each skull has been drawn in the position most commonly adopted by craniographers, in which a vertical line drawn from the centre of the auditory meatus passes through the plane of the junction of the coronal and sagittal sutures ${ }^{1}$. The horizontal plane obtained by drawing a line from the centre of the auditory meatus at right angles to this vertical line will pass at a slightly variable distance above the floor of the nostrils, and will be found ordinarily, though not invariably, to be parallel with the horizontal plane which would be obtained from a consideration of the visual axis, or from the direction of the fronto-ethmoidal suture as proposed by Professor Good$\operatorname{sir}^{2}$, or from a horizontal surface touching the skull at its occipital

${ }^{1}$ For the most recent Memoir which has appeared upon the question of the true horizontal plane of the human skull, see Archiv für Anthropologie, Bd. ix. 1876. Die horizontal Ebene des menschlichlen Schädels, von Dr. Schmidt in Essen. To the extensive bibliography there given should be added a reference to Professor Busk's Address to the Anthropological Institute, January 1874 (given in Journal of Institute, vol. iii. p. 522), where especial reference is made to Dr. von Ihering's views upon the subject which have been put forward by him in the Archiv für Anthropologie, vol. v. 1872, and the Zeitschrift für Ethnologie, 1873. See also Aeby, Archiv für Anthropologie, vol. vi. p. 295, 1874; Gosse, Déformations artificielles du Crâne, pp. 7, 59. 1855. In brachycephalic skulls with vertical foreheads the true vertical line often falls a little way behind the coronal suture.

${ }^{2}$ Memoirs, 1868, vol. i. p. 247. 
condyles and at the posterior border of its occipital foramen, as proposed by Professor Cleland ${ }^{1}$.

The principal measurements taken have been :-

\section{Measurements of Calvaria.}

Extreme length.

Fronto-inial length.

Extreme breadth.

Vertical height.

Absolute height.

Basi-cranial axis.

Circumference.
Cubical capacity.

Frontal arc.

Parietal arc.

Occipital arc.

Minimum frontal width.

Maximum frontal width.

Maximum occipital width.

II. Measurements of Face.

Length of face: 'naso-alveolar' line.

Breadth of face : interzygomatic line.

'Basio-subnasal' line ${ }^{2}$.

'Basio-alveolar' line.

Height of orbit.

Width of orbit.

Length of nose.

Width of nose.

Lower jaw, interangular diameter.

Lower jaw, depth at symphysis.

Lower jaw, width of ramus.

\section{Indices.}

Length-breadth index: 'cephalic index.'

Antero-posterior index.

Where any of these measurements have been omitted, it will be understood that the damaged condition of the skull prevented them from being taken.

It will be well, as some differences exist in the practice of craniographers as to the exact points whence their measurements are taken, to specify, in cases where such differences have existed, what the points are whence and to which the measurements given in the subjoined descriptions have been taken.

The 'extreme length' has been taken neither from the frontonasal suture, as Professor Virchow takes it ${ }^{3}$, nor from the 'glabella' strictly so called, i. e. from the interspace separating or connecting, as the case may be, the two supraciliary ridges, but from a spot immediately above that area-just, in fact, where the upper part of the frontal begins to rise into it. This appears to be the most reasonable spot to take for an antero-posterior measurement of the brain-case, as the applied arm of the compasses comes there

${ }^{1}$ See Phil. Trans., vol. elx. p. 121, 1870.

2 For explanation of the words 'Basio-subnasal' and 'Basio-alveolar' see p. 584 infra.

s Archiv für Anthropologie, vol, iv. p. 59, 1870. 
into nearer relations with the cavity containing the cerebrum than at either of the two other points specified. The most posteriorly placed part of the skull, whatever it may be short of an exaggeratedly developed occipital spine, is the point to which the other arm of the compasses is applied for this measurement. This point will sometimes be found at the base and on the upper surface of the external occipital 'spine,' or ' protuberance,' or 'inion,' in cases in which the superior occipital squama is flat and takes a perpendicular direction: and here what may be called the 'fronto-inial' diameter is identical with the 'fronto-postremal' or extreme length of the skull. It is usually in brachy-cephalic skulls that this is the case; it is however by no means rare in the dolicho-cephalic forms. Sometimes, as in the more typical dolicho-cephalie skulls, the most posteriorly placed point of the skull is to be found upon the superior squama occipitis, which in these cases is as markedly convex as in the other class of cases it is markedly flat; and here a difference, which may amount to as much as half an inch, may exist between the 'fronto-inial' and the extreme length. This difference has been considered to furnish a measure of 'occipital dolichocephaly 1,' or of the extent to which the posterior cerebral lobes overlap the cerebellum. It must be remarked, however, that in some skulls, where we find the occipital spine taking the form of a broad transversely running ridge, in which the linea suprema ${ }^{2}$ of Merkel are fused with the linece superiores nuche, the slightness of the difference between the two cranial measurements in question may cause us to under-estimate the extent of the cerebral overlap, and that, except in those rare cases in which the 'fronto-inial' diameter can be taken to a 'tuberculum linearum' as distinguished from a 'protuberantia occipitalis externa,' it is always necessary to compare the internal with the external surface of the skull.

The extreme breadth has in these skulls been taken upon the parietal bones, either in 'well-filled' skulls at some point abutting upon the posterior edge of the squamous portion of the temporal bone, or in 'ill-filled' skulls at the tuberosities. The squamous portion of the temporal has very frequently in old skulls become separated a little from the parietal, and it is rendered consequently

1 For ' Occipital dolicho-cephaly,' see Gratiolet, Bullet. Soc. Anth. Paris, ii. p. 254, 1861; Broca, ibid. iv. pp. 49-56, 1863, or his collected Mémoires, ii. p. 27, 1864; British Association Report for 1875, p. 152.

${ }^{2}$ For explanation of these terms, see Dr. Fr. Merkel, 'Die Linea nuchæ suprema,' 1871. 
unfit to be taken as a surface to measure from. The extreme breadth therefore being always the extreme parietal breadth, it has been unnecessary to have a separate entry for this as for the corresponding frontal and occipital diameters.

The anterior margin of the occipital foramen has been frequently so much injured in these ancient skulls as to render it impossible to take their actual or 'absolute' height from the plane of the foramen magnum. In these cases the so-called 'upright' height of Professors V. Baer ${ }^{1}, \mathrm{His}^{2}$, and Ecker ${ }^{3}$, taken by placing one arm of the beam-compasses upon the posterior border of the occipital foramen and at right angles to a vertical line passing from the middle of the auditory foramen to the junction of the coronal and sagittal sutures, and the other upon the most distant part of the cranial vault, becomes of especial importance. This measurement is, of course, somewhat greater than that of the 'actual' or 'absolute' height as usually taken from the plane of the foramen magnum-a point to be borne in mind when we compare the height and breadth of these skulls with those dimensions in other series.

The imperfect state of the skulls has similarly rendered it impossible in many cases to take the measurements of the basicranial axis, or of the cubical capacity.

The minimum frontal width has been taken from a spot immediately behind the external angular process of the frontal bone, and below the temporal ridge on one side, to the corresponding spot on the other. The maximum has been taken between two points below the temporal ridge at the coronal suture.

The maximum parietal width is, as stated above, given under the head of 'Extreme Breadth;' the maximum occipital is taken from the point ('asterion' of MM. Broca and Topinard) where the occipital, parietal, and temporal bones of one side meet, to the corresponding point on the other; i. e. between the two most distant points of the lambdoid suture.

It is not unusual to give a number of 'indices' stating the proportions existing between various measures of length in addition to that usually called the 'Cephalic Index,' which gives the relation of the breadth of the calvaria to the length taken as 100 . Thus we have an index of the relation of the height to the length and of the height to the breadth; a 'nasal index;' an 'orbital

1 Zusammenkunft einiger Anthropologen, p. 50, Leipzig, 1861.

${ }^{2}$ Crania Helvetica, p. 7, 1864.

s Crania Germaniæ Meridional. Occident., p. 3, 1865. 
index;' and a 'maxillary ${ }^{1}$ index,' giving the relations of the basicranial line to a line passing from the middle of the anterior border of the foramen magnum, the 'basion' of Broca, to the nasal spine. The value of these measurements is beyond question; but as the important point in each of these cases is simply one of greater or less magnitude, oscillating within narrow limits, the inconvenience of additional statements of proportion is not counterbalanced by much corresponding advantage. I have, however, given one measurement of proportions in addition to the 'Cephalic Index ;' and this, which I have called the 'Antero-posterior Index,' gives the relation which is held to the extreme length of the skull by that part of the extreme length which lies anteriorly to the auditory foramen. The extreme length being taken as above described, it is divided into an anterior and a posterior segment by a line passing as a tangent to the anterior border of the auditory meatus, and prolonged so as to cut the line of extreme length at right angles. The proportions between these segments may be very readily obtained by fitting an indicator to one of the longer sides of M. Broca's 'cadre à maxima ${ }^{2}$ ', and, when the instrument is so applied as to take the extreme length, adjusting the indicator so as to run as a tangent to the anterior edge of the auditory meatus. The vertical line thus obtained falls always some way behind the junction of the coronal and sagittal sutures; but though it fails thus to coincide with the vertical line chosen for placing the skull in for the purpose of drawing, it does coincide very nearly with the line which might be drawn across the external surface of the cerebral hemisphere for limiting posteriorly the area which is most favourably conditioned as to irrigation with arterialised blood. The segments therefore into which it divides the line of extreme length may be held to correspond respectively to more and to less favourably nourished and actively operating segments of the cerebral hemispheres, and the statement of their relative proportions as expressed in the 'Antero-posterior Index' assumes considerable importance.

The indications as to prognathism and its absence furnished by the 'maxillary index' of Virchow and the 'gnathic index' of Busk (Journal Anthrop. Instit. London, Jan. 1874, p. 496) are both

1 Virchow, Archiv für Anthropologie, vol. iv. p. 63, 1870.

${ }^{2}$ For description of this useful instrument, see Bulletin Soc. Anthrop. Paris, tom. iv. (2de Série), pp. 101-104, 1869 ; or Mémoires d'Anthropologie par Paul Broca, tom. i. p. $152,1871$. 
easily obtained by comparison of the three measurements, (a) of the basi-cranial axis taken from the middle of the anterior border of the occipital foramen, the 'basion' of Professor Broca, to the fronto-nasal suture; (b) of the 'basio-subnasal' line measured from the 'basion' to the base of the nasal spine; and (c) of the 'basio-alveolar line' measured from the 'basion' to the edge of the alveolar process of the upper jaw. A fourth facial measurement, that of the length from the fronto-nasal suture to the edge of the alveolar process of the upper jaw, which may be called the 'nasoalveolar' line, together with the three others just given, enables us to construct two 'facial triangles.' In some cases where the anterior margin of the foramen magnum has been wanting, the facial angles, with apices respectively at the base of the nasal spine and at the fore-edge of the alveolar border of the upper jaw, have been taken by Professor Broca's Nouveau Goniomètre, described and figured in the Bullet. Soc. Anth. Paris, t. v. $1^{\text {re }}$ Série, 1861, pp. 943-946, or in his collected Mémoires d'Anthropologie, tom. i. pp. 106-109, 1871'.

The stature has usually been calculated from an estimate of the length of the femur as being $27 \cdot 5$ to 100 of the entire length of the body. By another method, that of adding the lengths of the femur and tibia together, multiplying by two, and then adding an inch for the calcaneal integument, we obtain sometimes an identical, sometimes a slightly lower stature-estimate. The length of the femur has been measured ${ }^{2}$ from the point at which the head of the bone abuts upon one flat surface to the middle point of another flat surface which touches the distal ends of both the condyles. The length of the tibia has been taken from the level of the femoral articular-surface to that of the astragalar, as by Professor Huxley, l.c. p. 146, and Langer, l.c. p. 65. In some few cases, in which none of the other long bones were available for measurement, the length of the humerus, from the upper surface of its

${ }^{1}$ For alveolar prognathism and its linear measurement, see Topinard, L'Anthropologie, p. 303, 1876, and Sasse, Archiv für Anthropologie, ix. p. 9, 1876.

${ }_{2}$ This measurement, as taken by Professor Huxley (Prehistoric Remains of Caithness, p. 147), appears to be preferable for the purpose in question to that taken by Virchow (Archiv für Anthropologie, vol. vi. p. 18) from the trochanter major to the external condyle; or by Liharzig, from the same point to the middle of the patella (Gesetz des Wachsthum, p. 321, 1862) ; or by Langer (Wachsthum des Menschlichen Skelets, Denkschrift Kais. Akad. Wiss. Wien, Math. Nat. Klass., Bd. xxi. S. A. pp. 59, 87), from the apex of the trochanter major to the middle of a line drawn as above as a tangent to the two condyles; or by Lissauer (Alt-Pommer. Schädel, p. 8, 1872), from the uppermost point of the head of the femur to the under edge of the inner condyle. 
head to the middle of the distal articular surface, has been taken as being $19 \cdot 5$ to the stature as 100 , as given by Professor Humphry, Human Skeleton, p. 108, 1858.

As regards the sex of the skulls described and figured, there can, it is believed, be little ambiguity even irrespectively of any indications which the long bones and pelvis may have afforded. These indications have of course always been taken into account, where it was possible to do so, in the determination of the sex, not only of each figured and described skull, but also of every other skull mentioned in this book which has been sent to me for verification. In some cases ${ }^{1}$ it may be unsafe, in the absence

1 The skull of an Anglo-Saxon woman found by me at Frilford [Archæologia, vol. xvii. p. 440, 1870], buried with the insignia of the female sex, would I think be referred to the male sex by most craniologists if the bones of the trunk and limbs (to say nothing of the archæological surroundings) had not been available for reference and comparison, as fortunately they were and are in the University Museum, 'No. xxii. Jan. 6, 1869.' Similarly I have more than once had skulls of savage races put into my hands which I had every reason to believe had belonged to females, but which, from a consideration of the skull-characters alone, I should have supposed to have belonged to men. As I have elsewhere observed, however (see Journal of Anthropological Institute, vol.v. p. 123, October 1875), female skulls of savage races are by no means always thus similar to male either in size, texture, or contour; the class of cases indeed characterized by similarity or subequality is perhaps only a little more numerous, at all events amongst priscan skulls, than the class characterized by disproportionate smallness. As Welcker has abserved (Archiv für Anthropologie, vol. i. p. 127, 1866), the cases where ambiguity arises are cases in which female skulls have assumed, or must be supposed to have assumed, male characters; it is only very rarely that we are in any danger of supposing a skull to be female which is really male. On the other hand, the words of His (Crania Helvetica, p. 9, 1864), 'Die Geschlectsbestim:nung nach dem blossen Ansehen führt allzuleicht zu Willkürhrlichkeiten als dass man sich darauf verlassen könnte,' seem to me to rate the value of an unassisted cranioscopy in the question of sex a little lower than it really deserves. And the argument by which he supports this view, drawn from the fact that skulls which had been classed by competent observers as undoubtedly female could nevertheless be proved to have come from an interment on a battlefield, is by no means convincing. The German woman was told (see Tacitus, Germania, p. 18), on the occasion of her marriage, by tangible symbols as well as by mere words, 'venire se laborum periculorumque sociam, idem in pace, idem in prclio passuram ausuramque.' The same community of risks, we are told by numerous ancient writers, e.g. Diodorus ${ }^{1}$, Strabo ${ }^{2}$, Plutarch ${ }^{3}$, and others, was run by both sexes amongst Celtic tribes; and I find it recorded of a Celtic invasion ${ }^{4}$, which took place little more than

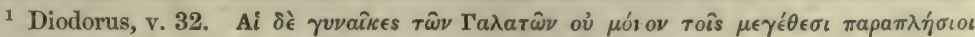

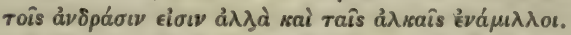

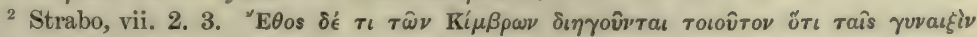

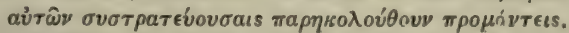

$s$ Plutarch, Marius, 27. The details of the slaughters of Aquæ Sextiæ and Vercellæ are too well known to need quoting: ' nec minus cum uxoribus eorum pugna quam cum ipsis fuit,' says Florus, iii. 3. See also Ammianus Marcellinus, xv. c. 12.

4 'The Kingdome's Weekly Intelligencer,' Friday, March 31, 1613; a Parliamentarian newspaper, quoted in a 'Letter on the Discovery of the Skeletons at Barber's Bridge,' by W. H. Price, Esq., M.P. Gloucester, 1868. 
of the bones of the trunk and limbs, to pronounce as to the sex of a skull, and it is much more unsafe, as the disputes relative to the Engis skull show, to pronounce positively in cases where the lower jaw and even the base of the skull with the mastoids and the facial bones are wanting also. When such cases have occurred amongst the skulls submitted to me, I have spoken of the sex as ' uncertain ;' this uncertainty however does not seem to me to attach to any of the figured skulls or calvariæ.

The skulls which have been selected for figuring will put into contrast not only the peculiarities of male and female crania, but also those due to differences in years; special regard having been had in their arrangement to the importance of distinguishing between ethnical characters and those dependent upon age by ranking the skulls of each type in the order of their seniority.

The following works and memoirs may be consulted as to points distinguishing male from female crania :-

Humphry, Human Skeleton, 1858, pp. 103-232.

V. Baer, Crania Selecta, Mem. Acad. Imp. St. Petersburg, tom. viii. 1859, p. 259.

Welcker, Wachsthum und Bau des Menschlichen Schädels, 1862, pp. 65, 141. Archiv für Anthropologie, Bd. i. 1866, pp. 110 and 120-127. B. Davis, Ibid., Bd. ii. p. 25.

Ecker, Ibid. p. 82, and Bd.ii.p. 110, 1867, and Crania Germaniæ Meridionalis Oecidentalis, 1865, p. 78.

Aeby, Schädelformen, 1867, pp. 10-12. Archiv für Anthropologie, vi. 1872, p. 302.

Cleland, Phil. Trans., 1870, pp. 124-132, 161-164.

Weisbach, Archiv für Anthropologie, Bd.i.1866, pp. 191 and 285. Archiv für Anthropologie, Bd. iii. 1868, p. 61.

With tables such as those given by Dr. Aitken, On the Growth of the Recruit, 1862, pp. 36-38, and by Welcker, Archiv für Anthropologie, i. p. 119, 1864, there is very little difficulty in determining with a high degree of probability the age of skulls below 30 years of age, if the bones of the trunk and limbs are available as well as the cranium. This, however, has by no means always been the case with the skulls of this series; still the condition of the teeth furnishes us with a fair indication for an approximate estimate

200 years ago and ended much as the one just referred to as recorded by Plutarch, that 'amongst the Welsh were found many women which had knives near half a yard long to effect some notable massacres with them.' Mr. W. P. Price has enabled me to prove the truth of this statement by an examination of the skeletons of these invaders. 
of the age of their owner up to the age mentioned. When the teeth all alike have begun to show marks of wear, but the inner and outer surfaces of the skull still retain some smoothness and glossiness, I have spoken of the skull as belonging to a person in the ' early portion of middle life,' meaning thereby a period from 30 to 40 . Greater wear of the teeth as yet unaccompanied with serious senile changes I have spoken of as characterising 'later middle life,' a period between 40 and 50. The commencement of senile changes I have noted by speaking of the skull as having belonged to a person 'past middle life,' their greater development by speaking of the skull as that of an 'aged' person. In priscan, as indeed, according to Dr. E. Zuckerkandl (Reise der Österreich. Freg. Novara, 1875, p. 117), in modern skulls, both of civilised and savage races, the obliteration of the sutures of the skull takes place at any time within a period extending over no less a time than the twenty years from the age of 20 to that of 40 . Dr. Thurnam showed (Nat. Hist. Rev., April 1865; Mem. Soc. Anth. Lond., vol. iii. 1867-9, p. 70 ; see also Virehow, Arehiv für Anthropologie, v. p. 535, 1872) that the British, like some other dolicho-cephalic skulls, had a great tendency to premature obliteration of the main sutures, and these facts have been kept in view in making estimates of the ages of the skulls, and especially of the calvariæ, which have been put into my hands.

For a description of senile changes in the cranium, may be consulted Welcker, Archiv für Anthropologie, i. p. 119, 1866; Virchow, Verhandlungen Phys. Med. Gesellschaft zu Wurzburg, iv. 354, 1853, Ueber die Involutionskrankheit (Malum senile) der platten Knochen, namentlich des Schädels, or Gesamm. Abhand., p. 1010 : eqq., 1856; Lucæ, Schädel Abnorm., Form. xiii. and xiv, p. 31, 1857; and Cleland, Phil. Trans., pp. 136, 160, 162, 1870.

The 'basilar angle' of Professor Broca, taken in the manner recommended by him (Révue d'Anthropologie, ii. 2. p. 202, 1873; Instructions Craniologiques, Mém. Soc. Anth. Paris, tom. ii. $2^{\text {de }}$ Série, 1875, pp. 90-93, or Topinard, L'Anthropologie, pp. 54, 307, 1876), has been added to some of the lists of measurements. It expresses well in the inverse ratio of its numbers the greater or less extent of the cranial curvature or antero-posterior arch described by the cerebral hemispheres. Its rationale is well illustrated by such figures as those given by Ecker, Archiv für Anthropologie, iv. 1870, p. 301 , fig. 39 , p. 303, fig. 40 , and by the figures in the two plates appended to that paper, Ueber die verschiedene Krïmmung des Schädel- 
rohres und über die Stellung des Schädels auf die Wirbelsäule beim Neger und beim Europäer. The same indication is given in a less precise way by placing a skull with the grinding surface of its upper-jaw teeth upon a flat surface and then observing whether it is the occipital condyles or the conceptacula cerebelli which furnish a support to the back part of the skull when it is brought down on to that surface. This method however of estimating the extent of cranial curvature is not rarely likely to mislead us. For in skulls of adults, and especially of male adults, the occipital condyles are often found to have increased considerably in a downward direction; and such skulls may then come, when placed as above directed, to rest upon them, owing, not to any deficiency in the cranial curvature or length of the brain, but simply to this outgrowing of the condyles which is developed in aid of the maintenance of the balance of the head in the horizontal position, as pointed out by Professor Cleland, Phil. Trans. 1870, p. 161.

Of the several norma, the norma lateralis or profile view of a skull is the most important, giving as it does, firstly, the most characteristic view of the upper and lower jaw, secondly, the relation of height to length, and, thirdly, the picturesque peculiarities of the antero-posterior curve of the cranial vault ${ }^{1}$. The upper contour line, in fact, of a brachy-cephalic skull viewed in profile, dipping away, as it does, more or less abruptly downwards in a plane but a little posterior to that of the parietal tubera, distinguishes such a skull from dolicho-cephalic forms as sharply as the proportion seen, in its vertical norma, to be borne by its transverse to its longitudinal diameter. The possession in fact of such a contour line may justify us in considering a skull to belong to the brachy-cephalic division and in speaking of it as 'brachy-cephalic by contour,' even though its extreme breadth may bear a less favourable ratio than that of 80 to 100 of its extreme length.

It may be well to state here that the ' precipitous sinking' away of this contour line is very frequently due to an abrupt curvature of the parietal bones exclusively; and that, contrary to what has sometimes been laid down, the superior occipital squama may be 'full and globular' in a brachy-cephalic skull, standing out in a plane posterior to that occupied by the posterior portion of the parietals,

1 Cleland, Phil. Trans. 1870, p. 145, and Retzius, Ethnolog. Schriften, pp. 118-121, eit. in loco. 
and constituting thus what has been called a 'capsuläres Hinterhaupt $^{1}$.'

Further, if it is incorrect to speak of flatness of the superior squama occipitis as being characteristic of brachy-cephalic crania, it is equally incorrect to say the like of the inferior squama forming the conceptacula cerebelli, or to say that tumidity of this region is characteristic of female skulls. For male brachy-cephalic skulls very frequently have their conceptacula cerebelli prominently convex outwardly, as the great relative and absolute height of such skulls and the great downward pressure of their cerebral hemispheres would have led us to expect.

1 Virchow, Archiv für Anthropologie, iv. 84, and note to p. 573, infra. 


\section{WEAVERTHORPE.}

[xlvi. 1. p. 200.]

SKULL OF A MAN BETWEEN TWENTY AND TWENTY-FOUR YEARS OF AGE AND 5 IT, $8 \mathrm{IN}$. IN STATURE.
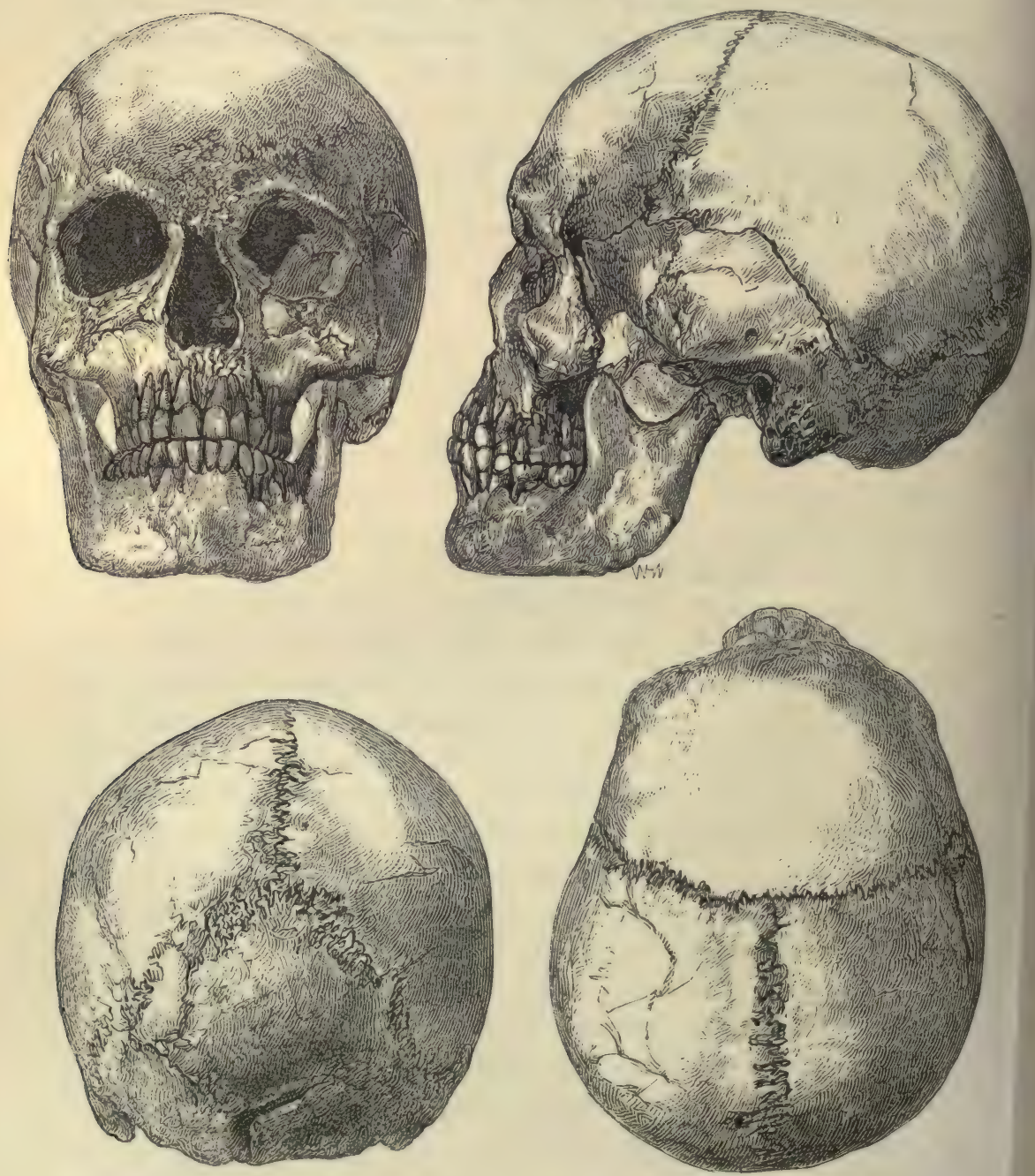


\section{WEAVERTHORPE.}

[xlvi. 1. p. 200.]

SKULL OF A MAN BETWEEN TWENTY AND TWENTY-FOUR YEARS OF AGE AND 5 FT. 8 IN. IN STATURE.

\section{Measurements of Calvaria.}

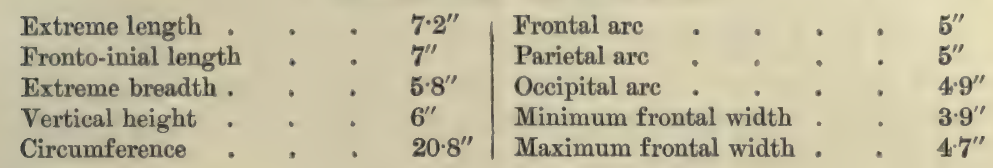

\section{Measurements of Face.}

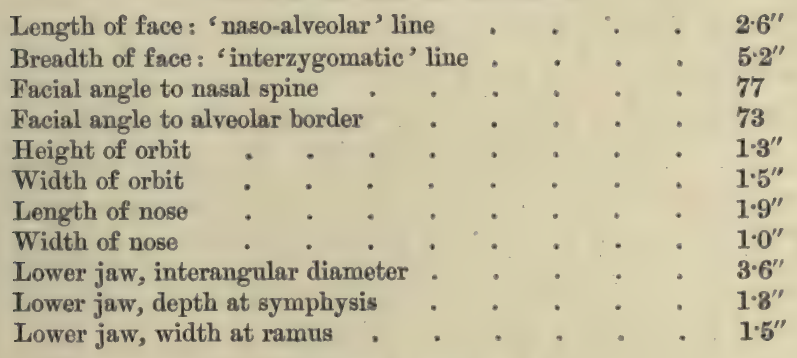

\section{Indices.}

Length-breadth index : 'cephalic index' . . . 80

Antero-posterior index, approximatively . . . . 51

This skull and the one next to be described (Flixton Wold, lxxi. 5) belong respectively to a young man and a young woman of the brachy-cephalic type, and of about the same age, viz. from 20 to 24 years of age, the age and the sex both having been determined by an examination of the trunk and limbs as well as of the cranial bones. They may be taken therefore as good illustrations of the form of the brachy-cephalic type in early maturity, as the skull Heslerton Wold, p. 598, may be taken to illustrate this type in the earlier portion of middle life; the skulls 'Ilderton,' 'Cowlam, lix. 3,' and 'Rudstone, lxiii. 9,' its form in the later periods of middle age ; and 'Castle Carrock, ccxiii. 1,' its peculiarities as modified by senile changes.

The owner of this skull must have been a young man of very great muscular strength, the femur being flanged out into a large flat process anteriorly to the upper part of the insertion of the glutæus maximus, and the linea aspera attaining similarly large proportions, though traces of the anchyloses of its head and epiphyses are still visible. It may be remarked that Dr. Holder, in 
his description ${ }^{1}$ of the brachy-cephalic type at present existing in Wurtemberg, and called by him the 'Ligurian,' says that in them the upper third of the femur is flattened from before backwards, but it may be doubted whether this peculiarity has any morphological value. I have noted it in skeletons of dolicho-cephalic individuals who could not have been of any very great muscular development, except possibly as regards the particular muscle named. The cristæ ilii and the ischial epiphyses are not yet perfectly anchylosed, though they still adhere to the os innominatum. One wisdom tooth only has come into actual use, the other three being still in their alveoli. The basi-cranial bones are lost, and nothing therefore can be said as to the closure of the spheno-basilar suture. Viewed in the norma lateralis, the dip in the parieto-occipital region, though more abrupt than it would be even in a female specimen of the dolicho-cephalic type, is yet a little more oblique, not only than are female, but also than we shall find the more mature brachy-cephalic males to be. The forehead has the obliquity so frequent in strong male skulls of every type, and, contrary to what is usually laid down ${ }^{2}$ as to young skulls, the frontal sinuses are already largely developed, and, as is usual in this type, separated from each other by a broad and shallow glabellar furrow.

The lower jaw contrasts by the height of its coronoid relatively to the zygomatic arch, and by the form of its chin as well as by the measurements given above, with the female skull, Flixton, iii. 6 , next to be described, illustrating herein the principle that sexual as well as other characters are often as distinctly recognizable in the lower jaw as anywhere else in the skeleton. The larger size of the mastoids is well seen in the skull on the side not shown in the drawing; the large size of its air-cells is, however, well shown on the injured side figured. There appears to have been some right parieto-occipital flattening, due probably to the carrying of the owner of this skull when an infant with the head supported on the right side; and this distortion ${ }^{3}$ appears to have been increased by

1 Archiv für Anthropologie, ii. p. 54, 1867.

${ }^{2}$ Broca, Mémoires d'Anthropologie, vol. i. p. 76. Mr. Prescott Hewett, Medical Times and Gazette, p. 106, Aug. 4, 1855, says these cavities do not begin to develope till the fourteenth or fifteenth year. In some of these early skulls, however, I have seen them largely developed as early as when the first true molar has only just come into use.

${ }^{3}$ The following observations made by Vesalius in 1543 (De Corporis Humani Fabrica, lib. i. cap. 5. p. 16, tom. i. Opera Omnia, Leyden, 1725) as to the production of artificial though unintentional cranial deformation bear on this point and some others raised at the present moment: 'Germani vero compresso plerumque occipitio, et lato capite spectantur, quod pueri in cunis dorso semper incumbant ac manibus fere citra 
some posthumous pressure. Owing to this distortion the line of maximum breadth can only be taken approximatively; we are, however, justified in saying that it lay low down in the skull-walls, and that the parietal tubera were not well marked, though they are so sometimes even in male skulls of this type.

fasciarum usum, cunarum lateribus utrinque alligentur, Belgis oblongiora cæteris propemodum reservantur permanentve capita, quod matres suos puerulos fasciis involutos in latere et temporibus potissimum dormire sinant.' The American ethnologist, Morton, in his 'Crania Americana,' p. 115, 1839, referred the production of the parieto-occipital asymmetry, which he observed as often on one side as the other, in the skulls of modern Peruvians, in part at least ' to the manner in which the child is placed in the cradle.' See also Nott and Gliddon, 'Types of Mankind,' p. 325, 1854; 'Indigenous Races,' pp. 334-336, 1857. Dr. Gosse in his 'Essai sur le Déformations artificielles du Crâne,' p. 74, 1855, refers both to Vesalius and to Morton, and speaking of l'action prolongée de ce genre de berceau, le compagnon des peuples nomades sur l'aplatissement du derrière de la tête, he adds, Les anciens habitants de la Scandinavie et de la Caledonie devaient s'en servir si l'on en juge par la forme de leurs crânes. Professor Daniel Wilson of Toronto, who does not seem to have been acquainted at this time (1857) with Dr. Gosse's work, explained the asymmetry of certain ancient British brachy-cephali similarly. See Canadian Journal, vol. ii. p. 406; Edinb. Phil. Journal, N.S. vii. p. 25, Jan. 1858. In 1862 (Canadian Journal, Sept., 'On Ethnical Forms and Artificial Deformations') he suggested that peculiar modes of carrying the infant during suckling, or peculiarities of head-dress, or carriage of burdens on the head might, as well as the use of the cradle-board, produce this undesigned though artificial deformity. In a later paper (Canadian Journal, 1864, p. 403) Professor Wilson says that this deformity is usually on the left side. Dr. E. Zuckerkandl (Reise der Öster. Fregatte Novara, p. 43 seqq., 1875) has also found parieto-occipital asymmetry to be usually sinistral; and more frequent in brachy-cephalous and large than in dolichocephalous and small skulls; he explains its occurrence by a reference to pressure inter partum. It appears to me to be more reasonable to explain the greater frequency of sinistral deformation in children by a reference to 'dextral pre-eminence' in the mothers. Savages are at least as distinctively 'right handed' as civilised races. See Weisbach, Reise der Österr. Fregatte Novara, 1867, Abtheil. ii. p. 181, where the author speaks of 'die stärkere entwickelung der rechten Seite die wohl bei allen Wilden beobachten war ;' and Ogle, Med. Chir. Trans. 1871, vol. liv. of Andamanese, Fuegians, and Eskimos. The wish to keep the right arm free causes the left arm to be usually employed for carrying a child; the pressure of a sling used in aid of the left arm would come to bear mainly on the left side of the child's head, and the observed flattening would thus be accounted for. It is by no means rare, as Professor Wilson has observed, to find instances of unilateral parieto-occipital deformity produced artificially, though unintentionally, in modern times. A modern skull, as it is believed of an Italian, with very well marked flattening of the right side of the region specified, may be seen in the Oxford University Museum, No. 865 a. A cast of the interior of this skull shows that the flattening has not affected the occipital lobes proper, i. e. the parts of the brain which are lodged in the superior occipital squama and lie behind the internal perpendicular fissure, but has left them overlapping the cerebellum just as in typical dolicho-cephalic brains. The part of the brain which has been flattened is that which lies between the plane of the apex of the fissure of Sylvius and that of the internal perpendicular fissure. It has often been suggested, and, as regards alterations of nervous structures, not altogether unreasonably, that such artificially produced alterations may in course of time become hereditary. And it may be possible to explain the brachy-cephalism of most nomad and indeed of some other races by a reference to the mode of carriage in infancy. For Artificial Cranial Deformities purposively produced, see pp. 594 seqq, infra. 


\section{FLIXTON WOLD.}

[1xxi. 5. p. 275.]

SKULL OF A YOUNG WOMAN OF FROM TWENTY TO TWENTY-FOUR YEARS OF AGE AND 5 FT. 1 IN. IN STATURE.
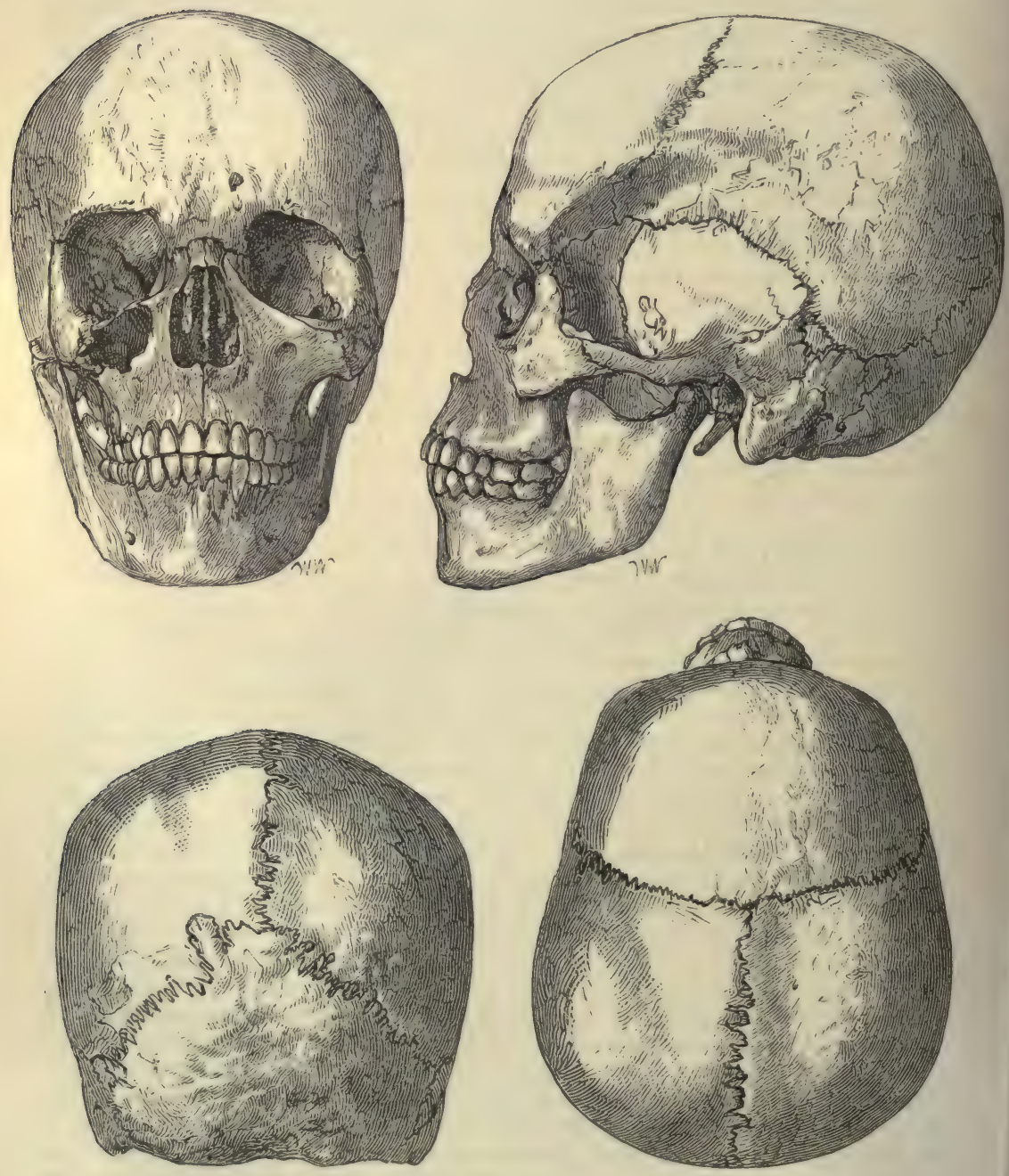


\section{FLIXTON WOLD.}

[1xxi. 5. p. 275.]

SKULI OF A YOUNG WOMAN OF FROM TWENTY TO TWENTY-FOUR YEARS

OF AGE AND 5 FT. 1 IN. IN STATURE.

\section{Measurements of Calvaria.}

\begin{tabular}{|c|c|c|c|c|c|c|c|}
\hline Extreme length & & & $6 \cdot 8^{\prime \prime}$ & Cubical capacity & - & - & $90.5 "$ \\
\hline Fronto-inial length & & & $6 \cdot 7^{\prime \prime}$ & Frontal arc. & • & & $5 \cdot 2^{\prime \prime}$ \\
\hline Extreme breadth . & & . & $5 \cdot 6^{\prime \prime}$ & Parietal arc & • & & $5 \cdot 1^{\prime \prime}$ \\
\hline Upright height & & . & $5 \cdot 9^{\prime \prime}$ & Occipital arc . & . & • & $4 \cdot 2^{\prime \prime}$ \\
\hline Absolute height. & . & • & $5 \cdot 6^{\prime \prime}$ & Minimum frontal & width & • & $3 \cdot 8^{\prime \prime}$ \\
\hline Basi-cranial axis & . & • & $4^{\prime \prime}$ & Maximum frontal & width & . & $4 \cdot 8^{\prime \prime}$ \\
\hline Circumference & . & . & $20^{\prime \prime}$ & Maximum occipit & 1 width & ․ & $4 \cdot 5^{\prime \prime}$ \\
\hline
\end{tabular}

II. Measurements of Face.

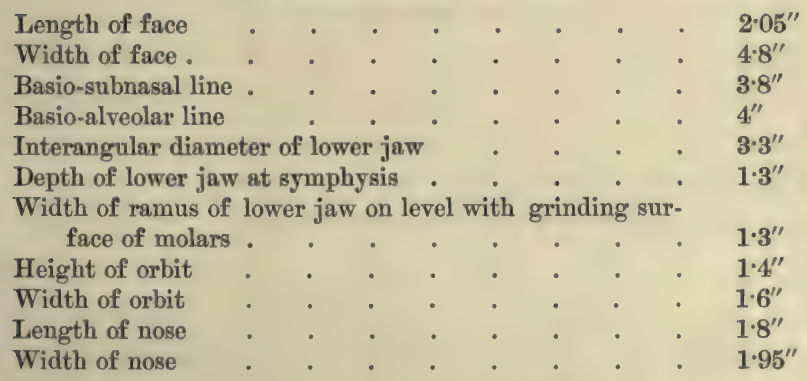

III. Indices.

Cephalic (length-breadth) index . . . . . 82

Antero-posterior index . . . . . . . . 49

Basilar angle of Broca . . . . . . . 26

Facial angle at nasal spine $. \quad . \quad . \quad . \quad .70$

Facial angle at alveolar edge . . . . . . . 65

The form, size, and the condition of development of the skeletal taken together with the cranial bones enable us to say that their owner was a woman between 20 and 24 years of age. The femur and tibia, which are respectively $16.8^{\prime \prime}$ and $13 \cdot 4^{\prime \prime}$ in length, have their proximal and distal epiphyses anchylosed, with faint traces of the lines of junction still remaining; the epiphyses are adherent in the cases of the fibulæ, but the traces of their lines of junction are very evident, as is also the case with the proximal end of the 
humerus, which however has its olecranic fossa perforated, and with the distal epiphysis of the radius. The sacrum is not complete, nor the os innominatum, nor the clavicle, but the basi-sphenoid suture is perfectly closed, though the wisdom teeth are not yet quite come into actual use.

This skull contrasts with the first-described in points characteristic of sex, as also in its state of more perfect preservation, in which point indeed it differs from most other skulls in this series, as it does also in its alveolar prognathism. The supraciliary ridges are smaller, the frontal and the parieto-occipital regions more vertical, the height, though considerable, less, and the lower jaw less powerful than is the case in the male skull of the same age. In the norma verticalis the left half of the skull is seen to be, as is not uncommonly the case, a little fuller and longer than the right; the parietal tubera are placed far back and prominent, but they do not constitute the broadest part of the skull, which, as is usual in well-filled brachy-cephalic skulls, lies on a level with the upper and posterior angle of the squamous part of the temporal bone and in a plane considerably anterior to that occupied by the parietal tubera. The sides of the occipital pentagon converge somewhat rapidly, a sexual characteristic, from this level of maximum breadth. The slope, on the other hand, from the mesial sagittal line to the parietal tubera on either side is a little more pronounced than is usual in female skulls. The mesial sagittal line maintains its elevation up to the coronal suture, and some little way forward on to the frontal bone. A broad undulation may be observed on either side in the vertical aspect of the skull between the parietal tubera and the coronal suture; it appears however to be due rather to the prominence of the parietal tubera than to any depression such as is often observable in this part of the parietal. Owing to the nondevelopment of an occipital tuberosity, there is a difference of $\frac{1}{10}$ of an inch between the extreme and the fronto-inial lengths, a point often observable in young brachy-cephalic skulls, but of no real importance as compared with such points as the vertical direction and flatness of the superior occipital squama, the backward position of the parietal tubera, and the abrupt dip downward of the parieto-occipital region immediately posterior to the level of these tubera, and the very considerable relative height, all characteristic of the brachy-cephalic type, and all recognisable in this skull.

The skull Weaverthorpe (Smith, xlvi) has not admitted of having 
its cubical capacity taken; a male brachy-cephalic skull (Goodmanham, No. xcviii, p. 305), however, of strikingly similar contour in its smaller as well as its larger outlines to this, which belonged to an individual about $5^{\prime \prime}$ taller than the owner of the skull here described, exceeds its cubic capacity by only 10 cubic inches. The cubic capacity of the Flixton female skull being 90.5 inches, is somewhat larger than that (1484:23 cub. cent. $=90 \cdot 276$ cub.inches) found by Professor Broca to be the average of 90 Parisian skulls, presumably of both sexes, of the present century, 'qui provenaient tous des sépultures particulières.' See Mémoires d'Anthropologie, i. pp. 354, 355, 1871; or Bull. Soc. Anthr. de Paris, vol. ii. Sér. i. p. 510 . 


\section{HESLERTON WOLD.}

[v. p. 142.]

SKULL OF A MAN IN THE EARLIER PORTION OF THE MIDDLE PERIOD

OF LIFE.
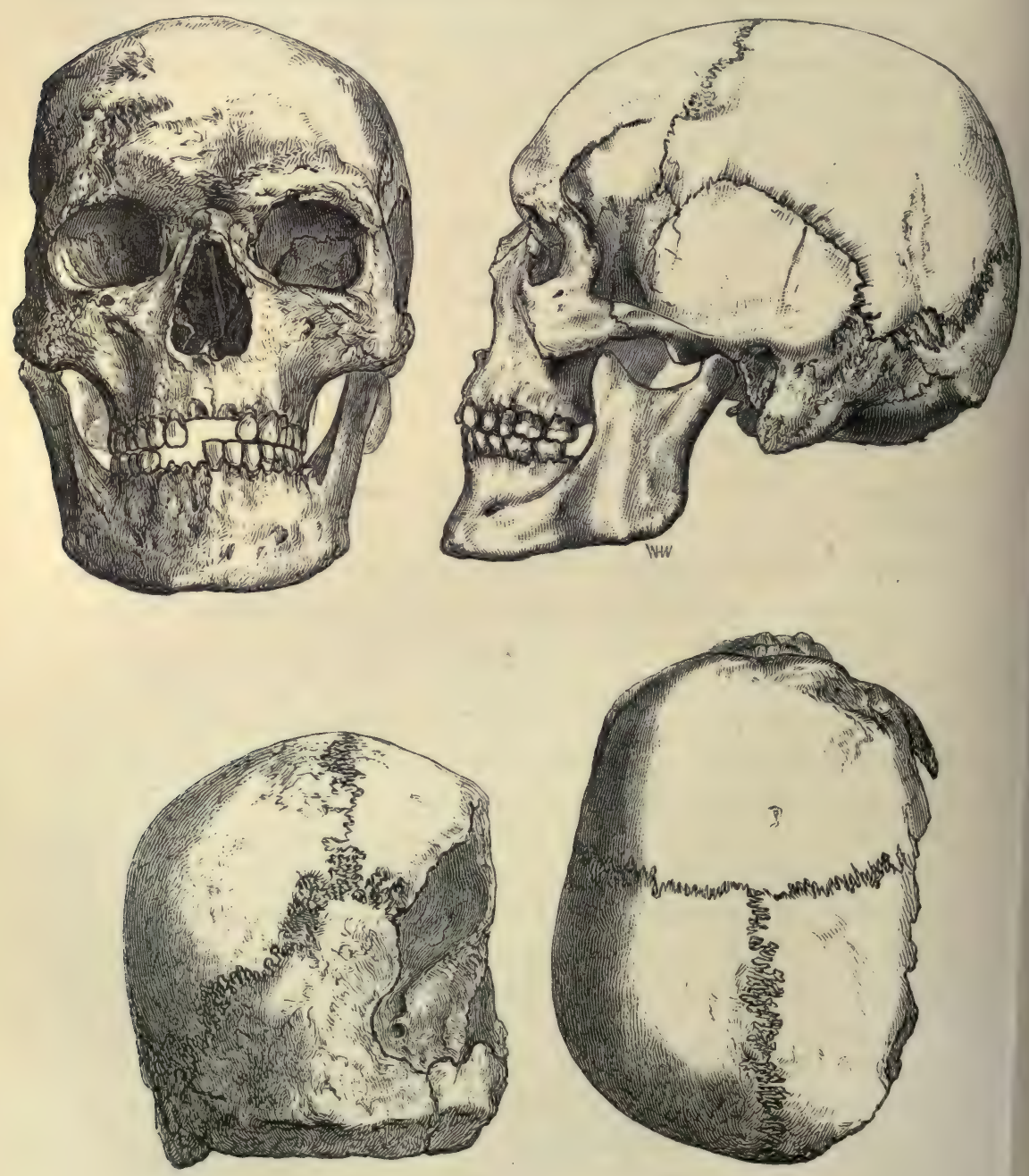


\section{HESLERTON WOLD.}

[v. p. 142.]

SKULI OF A MAN IN THE EARLIER PORTION OF THE MIDDLR PERIOD

OF LIFE.

\section{Measurements of Calvaria.}

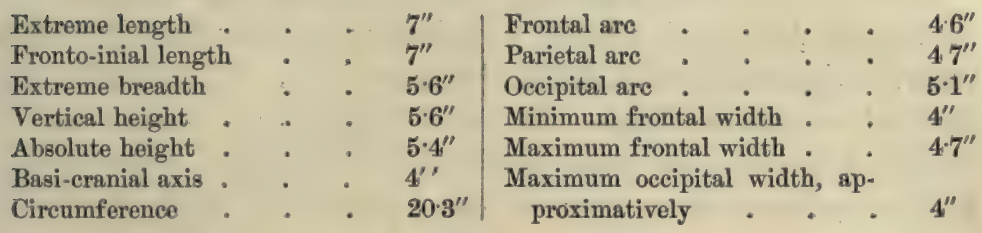

\section{Measurements of Face.}

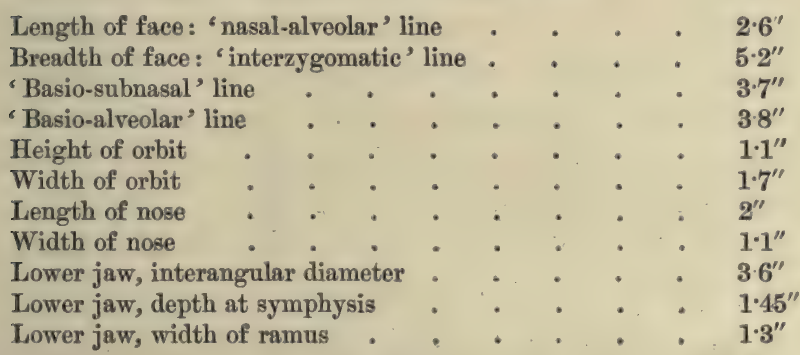

\section{Indices.}

Length-breadth index : 'cephalic index' . . . . 80

Antero-posterior index . . . . . . . 54

Basilar angle . . . . . . . . 25

Facial angle to nasal spine . . . . . 70

Facial angle to alveolar border . . . . . 66

This skull presents many of the peculiarities distinctive of a male brachy-cephalic skull of pre-historic times, and in a form which is by no means extinct at the present day. It has lost considerable portions of the left parietal and temporal bones, as also of the left half of the occipital, by water-wear; the rest of the skull however, and the jaws, are in good preservation. The forehead has the obliquity so usually found in the skulls of strong male subjects; the parieto-occipital region, on the other hand, shows the abrupt dip characteristic of the brachy-cephalic type. The external occipital 
protuberance is the most backwardly placed portion of the skull; and the extreme length and the fronto-inial length therefore coincide. The absence however of the portions of the skull walls specified enables us to see that the cerebral hemisphere of the left side has overlapped the cerebellum by a considerable length. The point of maximum transverse width lies at a lower level than and anteriorly to the faintly-marked parietal tubera which are situated far back in the norma verticalis. In this view the skull itself is seen to be little more bluntly oval and more globosely rounded out than the figure given of it. The supraciliary ridges are largely developed, a broad but shallow and transversely sutured furrow representing the glabella between them. The muscular and mastoid ridges are large, the teeth however are small, and the wisdom teeth have not been developed in either jaw. The sagittal and coronal sutures are open in both tables of the skull. This skull represents in an early period of life the same modification of the brachy-cephalic type which we have represented to us in advanced life by such forms as that of ' Rudstone, lxiii. 9,' figured and described below at pages 590-594, and in which we find a markedly oblique frontal combined with a parieto-occipital region as markedly vertical. The lesser obliquity of the frontal slope ${ }^{1}$ in the skull now before us is, like the smaller development of its frontal sinuses, the patency of its sutures, and some other peculiarities, to be explained by a reference to the lesser age of its owner.

${ }^{1}$ See Cleland, Phil. Trans., 1870, pp. 136, 163, and p. 591, note, infra. 



\section{ILDERTON, NORTHUMBERLAND.}

SKULL OF A MAN IN LATER PART OF MIDDLE PERIOD OF LIFE AND 5 FT. 9 IN. IN HEIGHT.
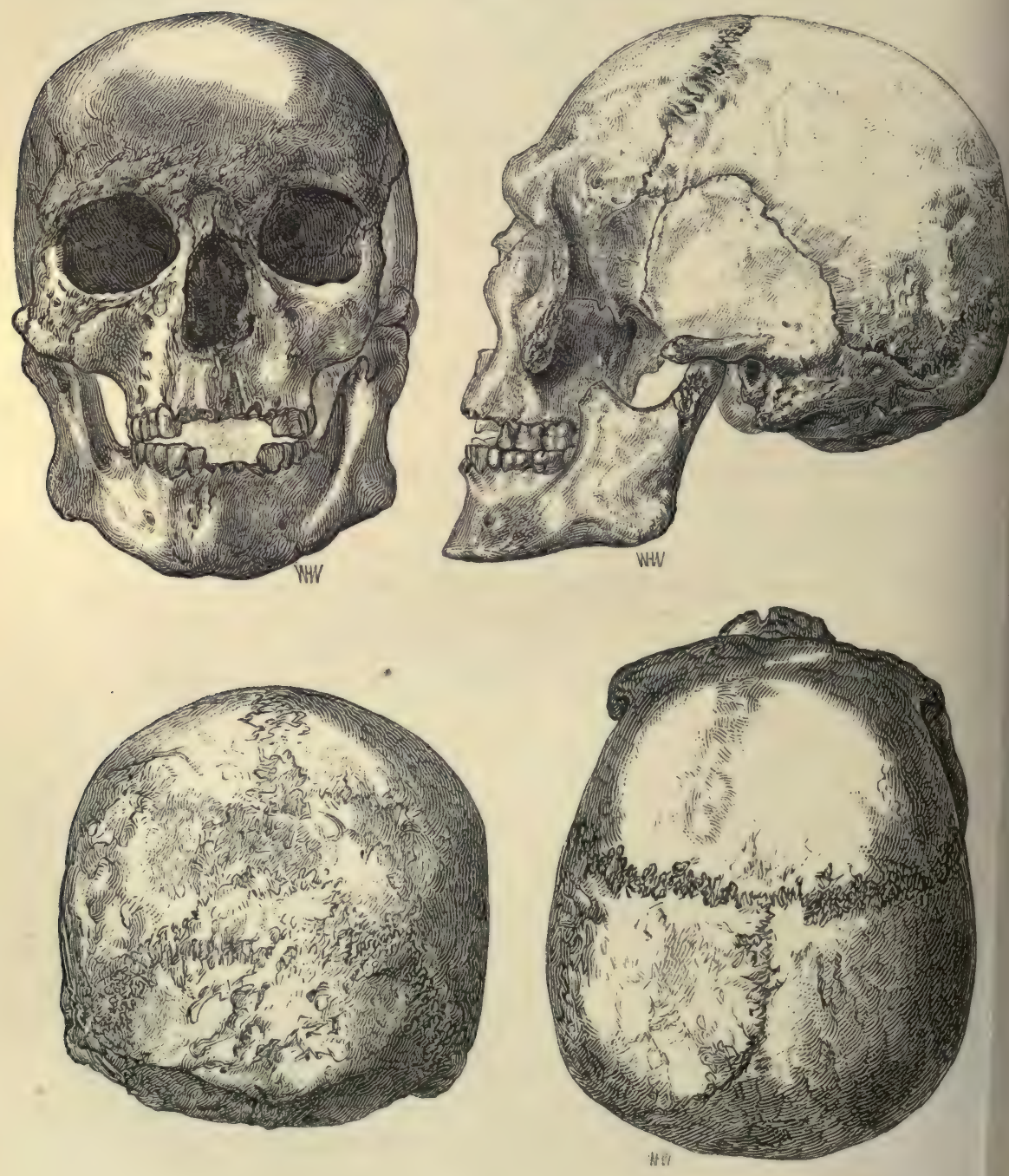


\section{ILDERTON, NORTHUMBERLAND.}

\section{SKULI OF A MAN IN LATER PART OF MIDDLE PERIOD OF LIFE} AND 5 FT. 9 IN. IN HEIGHT.

\section{Measurements of Calvaria.}

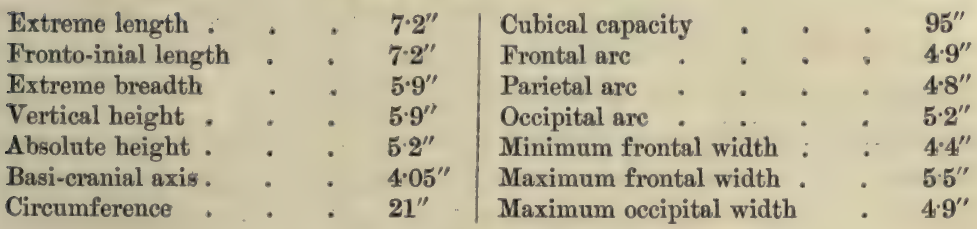

II. Measurements of Face.

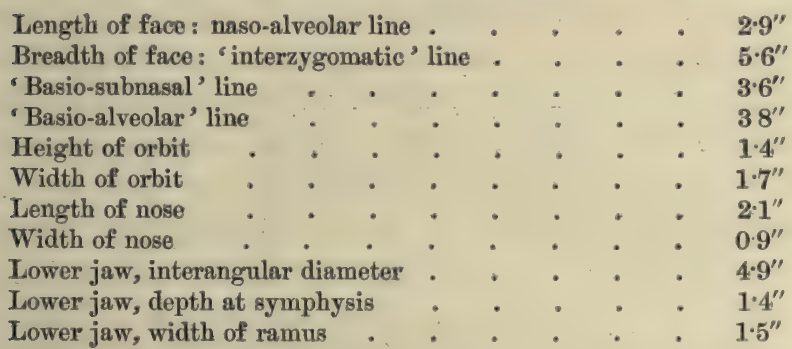

\section{Indices.}

Length-breadth index: 'cephalic index' . . . . 82

Antero-posterior index . . . . . . . 54

Basilar angle . . . . . . . . : 14

Facial angle to nasal spine.$\quad$. . . . . 65

Facial angle to alveolar edge : $\quad . \quad+\quad . \quad 61$

The femur of the skeleton to which this skull belonged is $19 \cdot 1$ " in length, and has its various ridges, and especially that which is in relation with the insertion of the glutæus maximus, considerably developed. The humerus is $12 \cdot \gamma^{\prime \prime}$ long, and by examination of this bone, of the femur, of the skull, and the lower jaw, we are enabled to say that they belonged to a strong male in the later part of the middle period of life, probably about 50 years of age and $5^{\prime} 9^{\prime \prime}$ in height. In the greater obliquity of its forehead and the larger development of its supraciliary ridges this skull differs from the one which precedes it, and forms a connecting link between such skulls as that 
and the one which is described at pages 590-594, viz. 'Rudstone, lxiii. 9.' The relations between the basi-cranial axis, the basio-subnasal line, and the basio-alveolar respectively, as well as the verticality of the pterygoids, show that this skull is essentially orthognathous, as His and Rütimeyer in treating of skulls of a similar type, viz. their 'Disentis' type, say (Crania Helvetica, p. 27) all pre-historic skulls of widely-spread races have been. The comparative lowness therefore of the facial angles, 65 and 61 , as obtained by M. Broca's goniometer, is to be ascribed to the slope of the forehead, not to any thrusting forward of the jaws ; and the slope of the forehead is to be viewed as correlated with the powerfully developed and heavy lower jaw, the downward gravitation ${ }^{1}$ of which has been counterbalanced by a backward rotation of the brain and its containing case. The fronto-inial and fronto-postremal diameters are identical, so are the maximum height and the maximum width; the point for the latter measurement lies low down on the parietal bones, on a level with the posterior superior angle of the squamous part of the temporal bone, and in a plane which would touch the anterior edge of the faintly marked tubera parietalia. There is a considerable downgrowth of the occipital condyles, as is often observed to be the case in skulls with heavy lower jaws, especially in the later half of life; the skull however is supported by the conceptacula cerebelli and the grinding edge of the molar teeth when it is placed upon a flat surface without its lower jaw. The extent of its cranial eurvature is spoken to by this last fact, as also by the lowness of its basilar angle, 14, as obtained by the occipital goniometer of Prof. Broca. In the occipital and vertical norme this skull shows the rounded outlines characteristic of well-filled skulls. In the latter of these norma it shows the characteristic proportions, and in the norma lateralis the characteristic contour of the brachycephalic skull. The lower jaw, with its great width, flanged-out angles, and prominent bifid mentum, shows that its owner was a man of considerable strength. The teeth are comparatively small, and not as much worn as the teeth are usually in skulls of individuals of this period and the age of this subject. The cranial sutures, especially the sagittal, have undergone extensive obliteration.

This skull has been figured and deseribed by the Rev. W. Greenwell, M.A. and D. Embleton, M.D., in the Natural History, Transactions of Northumberland and Durham, Tyneside Field Club, vol. i. pl. xiii.

${ }^{1}$ See Cleland, Phil. Trans., 1870, pp. 136, 163. 



\section{COWLAM.}

[lix. 3. p. 226.]

SKULL OF A MAN IN LATER MTDDLE LIFE AND 5 FT. 7 IN. IN HEIGHT.
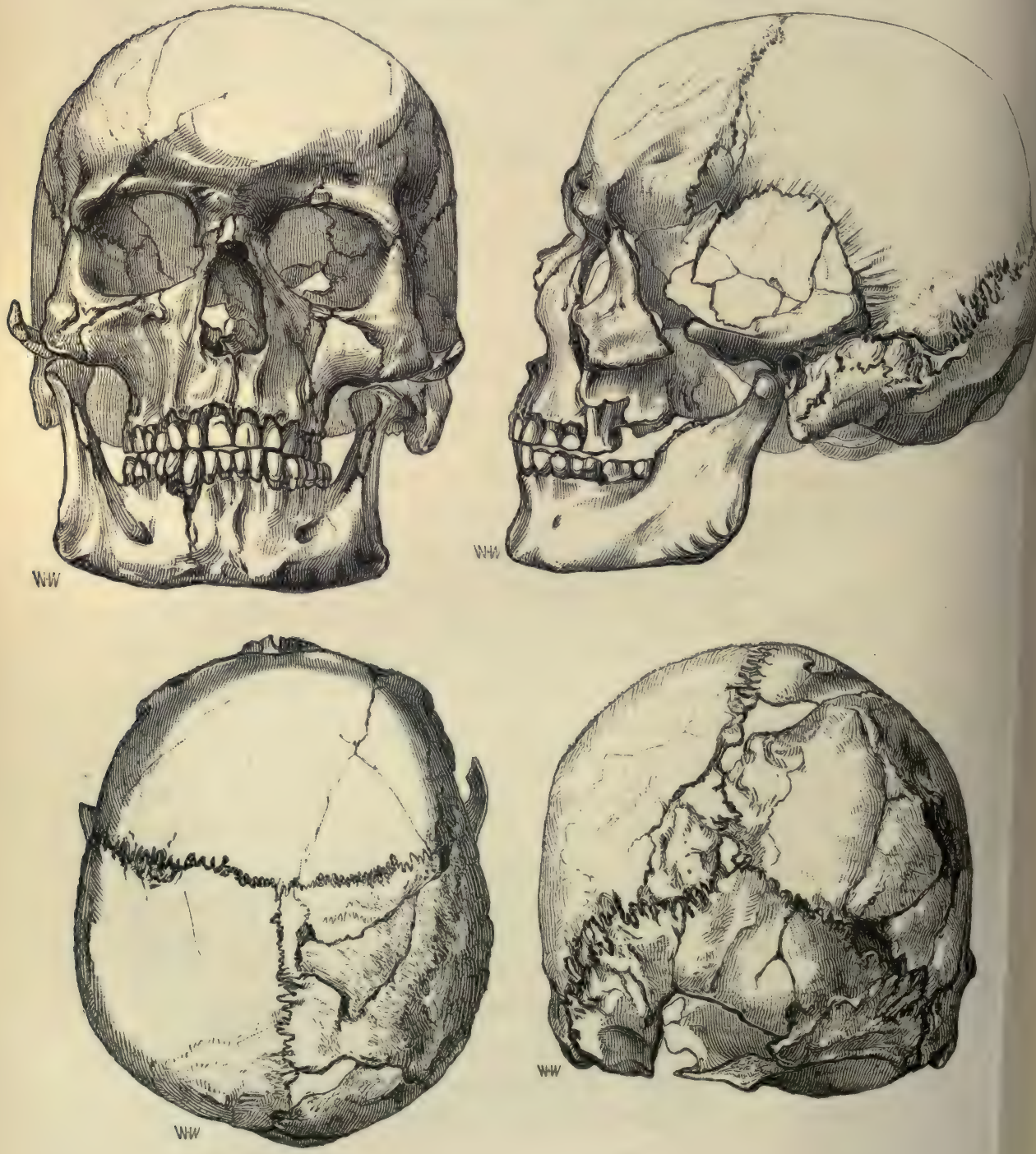


\section{COWLAM.}

[lix. 3. p. 226.]

SkULl of a MAN IN LATER MIDdLE LIFE AND 5 FT. 7 IN. IN HeIGHT.

\section{Measurements of Calvaria.}

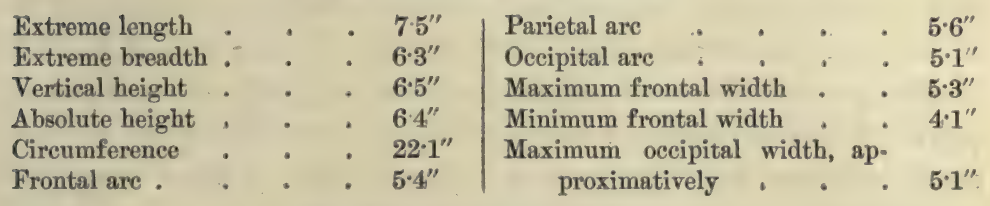

II. Measurements of Face.

\begin{tabular}{|c|c|c|c|c|c|c|c|c|c|}
\hline \\
\hline \multicolumn{8}{|c|}{$\begin{array}{l}\text { Length of face: 'naso-alveolar line' } \\
\text { Breadth of face: 'interzygomatic line,' approximatively . }\end{array}$} & & \\
\hline Height of orbit & - & . & . & . & . & . & . & $\cdot$ & \\
\hline Width of orbit & . & . & . & - & . & & - & • & \\
\hline Léngth of nose & - & . & & - & . & & - & & \\
\hline Width of nose & . & & & . & . & & $\cdot$ & & \\
\hline Lower jaw, inter: & ingula & dian & ceter & . & . & & $\cdot$ & & \\
\hline Lower jaw, depth & at sy & nphy: & & & & & & & \\
\hline \multicolumn{10}{|c|}{ Lower jaw, width of ramus on level of grinding surface of } \\
\hline molar teeth & . & . & · & . & - & & - & . & \\
\hline \multicolumn{10}{|c|}{ III. Indices. } \\
\hline \multicolumn{8}{|c|}{ Length-breadth index : 'cephalic index' } & & \\
\hline Intero-posterior i & ndex & & . & - & - & ${ }^{\circ}$ & . & . & \\
\hline \multirow{2}{*}{\multicolumn{3}{|c|}{$\begin{array}{l}\text { Facial angle to nasal spine } \\
\text { Facial angle to alveolar edge }\end{array}$}} & . & : & - & & - & & \\
\hline & & & & . & . & . & . & & \\
\hline
\end{tabular}

A fragmentary femur gives a probable length of $18.5^{\prime \prime}$ for the perfect bone, from which we may calculate the stature as having been $5^{\prime} 7^{\prime \prime}$, about an inch and a half less than the average stature assigned to the brachy-cephalous British by Dr. Thurnam upon an examination of twenty-seven femora. The femur in question shows its owner to have been a man of considerable strength and to have been in the later period of middle life, conclusions to which the condition and character of the skull would likewise point. The articular surface of the head of the femur has encroached a little way on to its neck anteriorly, which may indicate the existence in early life of some disease of the joint which was recovered from.

The sagittal and coronal sutures are still patent, both internally and externally, for a considerable part of their extent. The skull itself is a most favourable specimen of the brachy-cephalic type, combining as it does indications of strength with great size, and yet showing no marks of savagery. It assuredly merits the titles of Kräftigkeit und Würde which His and Rütimeyer (Jahrbuch der 
Schweizer Alpen for 1864, p. 398) bestow upon the better developed skulls of their 'Sion Typus;' though it belongs to the class of skull assigned by those anthropologists to their 'Disentis Typus.' The skull as a whole is sub-quadrate or sub-cubical in outline, but being filled out in each individual region it gains an appearance of general smoothness and globosity. The supraciliary ridges are less in size and the forehead is less oblique than is at all usual in skulls of this period which belonged to owners of such strength as the powerful and well-defined lower jaw speaks to. The point of maximum height when the skull is in its normal position lies a little way behind the coronal suture; and by the greatness of this height, both absolute and relative, and by its situation at this point, one of the most characteristic features of this type of skull is constituted. In this the ancient British brachy-cephali resemble the neolithic Danes, as pointed out by Professor Busk ${ }^{1}$.

The occipital squama occupies a plane a little posterior to that occupied by the posterior half of the parietals, as is the case in some of the brachy-cephalic skulls just referred to and others : the occipital protuberance having been lost, together with a large part of the occipital bone, it is not now possible to say with safety whether the fronto-inial line was or was not shorter than the fronto-postremal. The cerebral overlap however has certainly been considerable, and the conceptacula cerebelli are more horizontal than is usual in skulls of this type. This however may be partly due to the commencement of senile gravitation ${ }^{2}$ changes. The posterior part of the parietals show the normal brachy-cephalic perpendicularity, the small foramina emissaria, not seen in the drawing, being entirely on the posterior aspect of the skull. In spite of the very considerable frontal width the zygomatic arch still comes into view in the norma verticalis, and this width, together with that of the interangular diameter of the lower jaw, must have given the face a marked expression of strength during life. The sockets of the canine give a square outline to the front of the upper jaw. The norma occipitalis, like the norma verticalis, is remarkable for the rounding off of its outstanding angles. Skulls strikingly similar to this, both in contour and measurements, are to be found in modern European races, e.g. in the Grisons " amongst the Roumansch-speaking populations, for a specimen of

${ }^{1}$ See Journal of the Ethinological Society, p. 468, Jan. 1871.

${ }^{2}$ See Cleland, Phil. Trans., 1870, pp. 136-137.

${ }^{3}$ For a memoir on the population of the Grisons, see V. Baer, Bull. Acad. Imp. des Sciences St. Petersburg, p. 38 seqq., 1860. 
which see skull 768 in Oxford University Museum, obtained from the neighbourhood of Andeer by Dyce Duckworth, Esq., M.D., or amongst the Finns ${ }^{1}$, for a specimen of which see a skull $e$ Diocesi Saarijärvi presented to the University Museum by Professor E. Eichwald.

Still closer is the resemblance to this prehistoric British type borne by the prehistoric Danish brachy-cephalic crania in which the height is, contrary to what we see in modern European skulls of the same type, greater than the breadth. A comparison indeed of such a series as that which has been obtained from the small Danish island of Moen, figures and casts of some of the crania of which are readily accessible ${ }^{2}$, with such a series of skulls as that which Canon Greenwell has presented to the Oxford Museum from the British round barrows, is instructive in many ways. By going over the entire number of specimens contained in such series we learn, firstly, that forms so widely different at first sight as the skull 'Cowlam, lix. 3,' and the one next to be described, or the one from Borreby figured in Sir Charles Lyell's 'Antiquity of Man' (p. 91, 4th ed. 18\%1), are nevertheless found in company and contemporaneity with each other in many barrows. Secondly, we find that in many cases they are connected by transitional forms. Thirdly, in series containing either well-developed and capacious skulls, such as 'Cowlam, lix. 3,' or rough-hewn crania such as ' Rudstone, lxiii. 9,' the one next to be described, or both, we find in England ${ }^{3}$ as well as in Denmark skulls differing from them in being at once themselves 'ill-filled,' and in being indicative of feebleness in their owners. The existence of such skulls in such series in Denmark has often been explained by supposing them to have belonged to a Lapp population. This explanation however will not account for their presence in the Bronze-Period barrows of this country.

1 For the Ethnology of the Finns, see Virchow, Archiv für Anthropologie, vol. iv. p. 78; Zeitschrift für Ethnologie, vol. v. p. 320.

${ }^{2}$ For figures of crania from the tumuli in Moen, see Nilsson's 'Stone Age' (trans. Lubbock), 1868, pl. xii. figs. 230-232, pl. xiii. fig. 240, pp. 121, 126; Sir John Lubbock's 'Prehistoric Timess ' (3rd ed.), p. 159; Retzius' Ethnographische Schrifte, pl. iii. fig. 2. A cast, No. 5710, of a small skull from Moen is to be seen in the Royal College of Surgeons in London, and another of a larger one from Udby in the same island was procured from the late Professor Thomsen through the kind offices of Dr. F. Krebs for the Oxford University Museum. The original of this east has been measured and described by Professor Virchow in the Archiv für Anthropologie, tom. iv. pp. 68,84 , where he draws especial attention to its ' capsuläres Hinterhaupt mit starken Schaltknochen der Lambdanaht' points observable in 'Cowlam, lix. 3.'

${ }^{3}$ The series from Cowlam, Rudstone, Weaverthorpe, Goodmanham, and some others furnish specimens of small delicate skulls in company with one or other of the larger and stronger varieties of the brachy-cephalic type. 


\section{RUDSTONE.}

[1xiii. 9. p. 248.]

SkUll of a Man past Middle Period of Life; OF 5 Ft. 9 in. IN Stature.
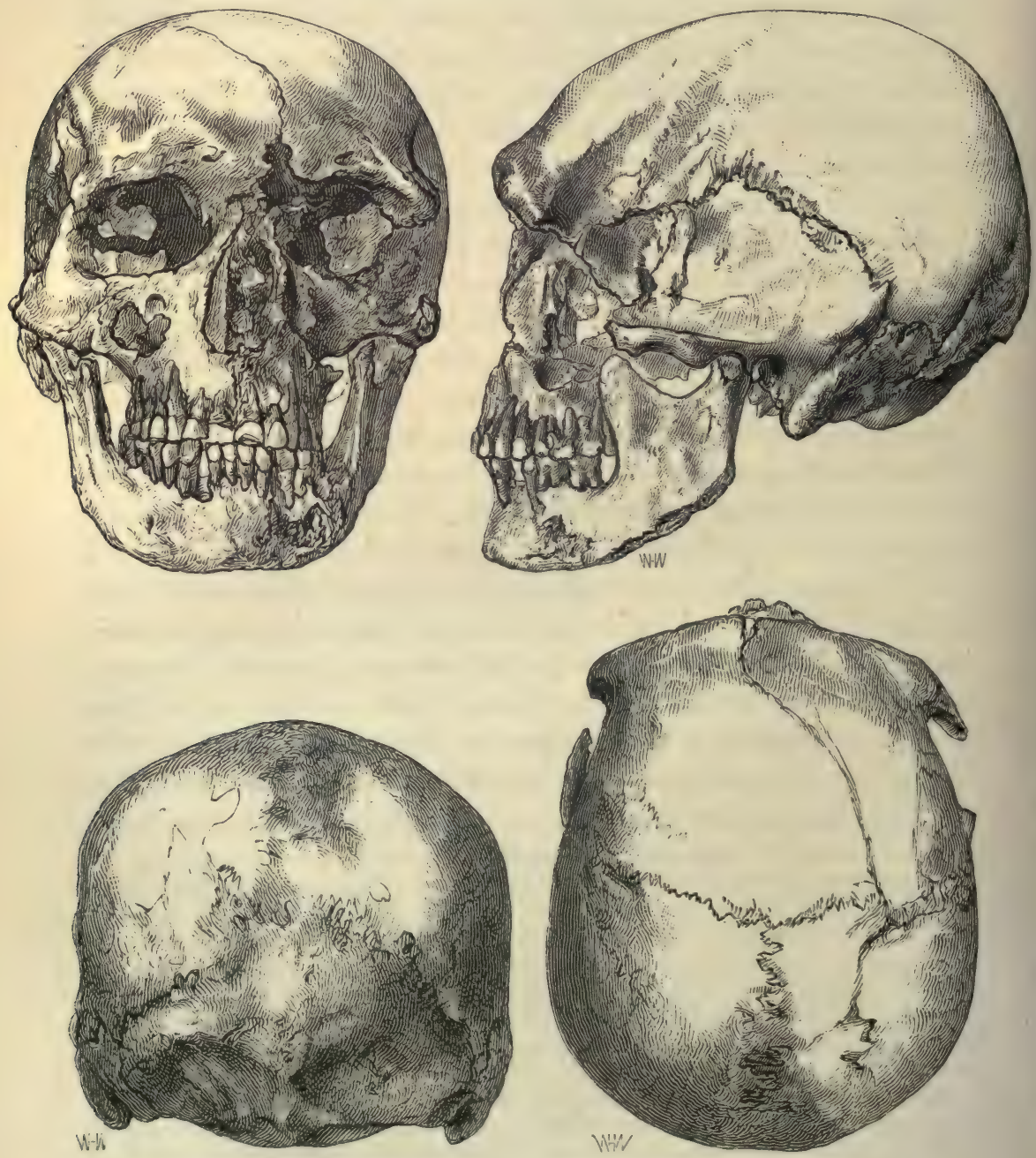


\section{RUDSTONE.}

[lxiii. 9. p. 248.]

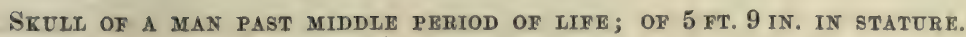

\section{Measurements of Calvaria.}

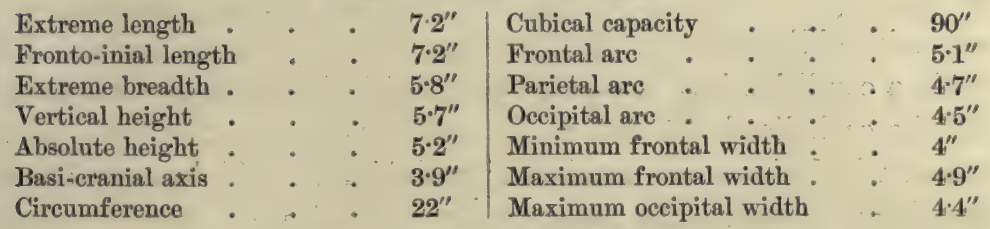

II. Measurements of Face.

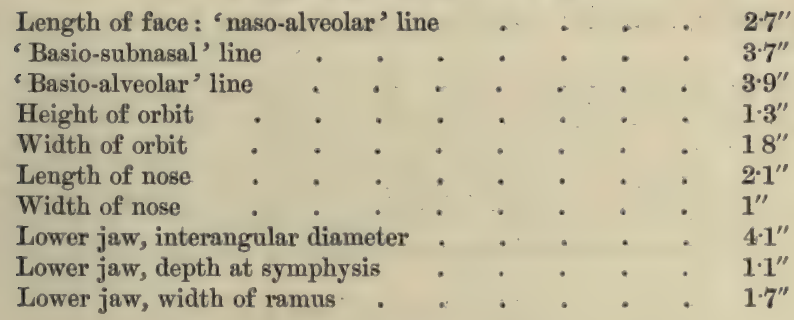

III. Indices.

Length-breadth index: 'cephalic index' . . . 81

Antero-posterior index .. . . . . . 55

Basilar angle . . . . . . . . . . 19

Facial angle to base of nasal spine . . . . $\quad . \quad 65$

Facial angle to alveolar border of upper jaw . . . 60

With the cranium, 'Rudstone, lxiii. 9,' there came into my hands two femora, the length $\left(19 \cdot 1^{\prime \prime}\right)$ and strength of which, as also the character of the skull, show that we have here to deal with the remains of a man of great muscular strength, of about 5 ' $9^{\prime \prime}$ in stature, and 'past the middle period of life,' if not indeed 'aged.'

The skull itself is a good example of one form of the brachycephalic cranium, which is distinguished by having a very oblique and low-lying frontal region, and large supraciliary ridges, which, if covered with large eyebrows during life, would have given a somewhat beetling and forbidding expression to the countenance. In the skull now before us the obliquity of the forehead is probably somewhat increased by the commencing ${ }^{1}$ of the senile settling

1 There can be no doubt that with the atrophy of the brain which sometimes accompanies other senile changes some substance must, in the nature of things, be 
down of that region as it follows after the retreating brain, but the brachy-cephalic form with retreating and low forehead is recognisable in quite young skulls both of early, as in the case of the 'Heslerton Wold Hall Grave' skull already described, and of present times.

Other senile changes are beginning to show themselves in this skull in the way of loss of compactness of tissue and consequently of gloss and smoothness on the external surface, in the very extensive obliteration of sutures even in the external table of the skull, a condition less frequently observed in brachy-cephalic than in dolicho-cephalic skulls, and in the wearing down of the teeth to an extent which, in an ill-nourished ${ }^{1}$ individual, would have produced alveolar abscesses. The conceptacula cerebelli are larger relatively to the space occupied by the superior squama occipitis in this than in most skulls, and the occipital protuberance is very considerably

developed to fill up the void thus caused. In some cases an effusion of subarachnoid fluid occupies the space as fast as it is formed, and in a case of a very aged man, Dr. Holyoke of Salem, Massachusetts, a person known to be a centenarian, whose body was examined after death, and whose symptoms of intra-cranial fluctuation during life were recorded by himself (see Memoirs, p. 48 seqq., Boston, U. S. A., 1829), this fluid must have been exuded in great abundance to occupy the space rendered available by the shrinking of the brain.

In other cases, as also to a considerable extent even when fluid is poured out in the subarachnoid space, the inner table of the skull appears to secrete fresh laminæ of bone, and is found closely adherent, as in infancy, to the dura mater. In such cases the grooves for the meningeal arteries appear to be deeply sunken into the substance of the skull, having been in reality converted into deeper channels, or even tubes, by the upgrowth of bone around them. This was the case in the body of a man supposed to be 106 years old examined by me, as recorded in the British and Foreign Medico-Chirurgical Review, p 508, April 1863. A skull of a very aged person may under such circumstances attain a thickness of as much as 15 millimetres, forming thereby a striking contrast to equally senile skulls in which the cranial walls may have been reduced to paper-thinness or actual fenestration by atrophy.

In a third class of cases the retreating brain is followed up by the skull walls; and especially in the frontal region is this concomitance of involution observable, both in the living subject and in the skull, as has been noted by Lavater and Froriep, eited by Cleland, Phil. Trans., p. 136, 1870. In some of these cases the inner table of the skull will thicken simultaneously with the gradually sinking down of the cranial vault. In a skull of an aged man, probably a Roman officer, eminently dolichocephalic, forwarded to me by the Rev. W. Lukis, F.S.A., from Wath, near Ripon, I find, coincidently with an extraordinary obliquity of the os frontis, two raised areæ, covering a space of a little more than an inch square on each side, as though they were growing down into the space vacated by the atrophying frontal convolutions. Some of the appearances which have been dwelt upon as characteristic of 'Neanderthaloid' crania are, I am well assured, to be ascribed to these purely physiological, though senile, changes of form, and have absolutely no ethnological significance whatever, except in so far as the texture of brachy-cephalic crania is usually stouter and more resistent to gravitation changes than is that of the dolicho-cephalic, amongst which most of the skulls just mentioned are to be classed.

' See J. Mummery, On the Relations of Dental Caries in Aboriginal Races. Trans. Odont. Soc., Nov. 1869. 
developed and devoid of any traces of division into linece superiores and linea suprema, as, V. Baer ${ }^{1}$ observes, is usually the case when the inferior preponderates in size over the superior squama occipitis.

In the norma basalis we have to note the width of the basilar process of the occipital bone, a point often remarkable in the lower races of mankind, and the roughness and thickening of the posterior border of the occipital foramen, a development often noticeable in skulls with the brain-case rotated backwares, and correlated with the maintenance of the balance of the head by giving attachment to ligaments.

The wisdom teeth are very much less worn than the two first molars; only one wisdom tooth however has been developed in the lower jaw.

The lower jaw has lost by water-wear a good deal of its angle on the side figured; the angle on the side not shown in the figure, though it would even by itself have been assigned to the male sex, has by no means the boldly defined outlines and large size usually seen in the brachy-cephali of this series. The inter-angular diameter however of the entire jaw is as large as that of even larger skulls of this type.

The parieto-occipital dip is eminently brachy-cephalic ; the point of maximum height is anterior to the coronal suture, the point of maximum width is the region representing the faintly marked parietal tubera.

This skull does not show any traces of the not uncommon asymmetry of the parieto-occipital region produced by careless one-sided carriage in infancy; but it has a singular and suggestive resemblance to many of the artificially deformed skulls of the New World, though it is not likely that it was subjected to any such process purposively carried out. Skulls like this resemble some of the purposively deformed skulls, firstly, in general antero-posterior contour from the large supraciliary ridges over to the similarly developed transversa crista occipitis; secondly, in the general relations of maximum breadth to the extreme length; thirdly, in the position of that plane of maximum breadth far back in the plane of extreme length; fourthly,

${ }^{1}$ Crania Selecta, Mém. Acad. Imp. Sci. St. Petersburg, Ser. vi. tom. viii. 1859. His words are, 'Cristam (transversam occipitis) in plurimis hominibus in binos arcus sub angulo manifesto inter se conjunctos dividi patet; attamen in animalibus multis crista transversa occipitis etiam binis arcubus constituitur, et in homine angulus medius non raro fere evanescit, et quidem ubi pars inferior ossis occipitis magnam habet evolutionem, pars superior vero parvam.' 
in the width and strength of the upper and lower jaws; and, fifthly, in the minor yet not wholly unimportant point of the disparity of size between the upper and lower squamce occipitis with their respective nervous contents. Nor is prognathism, which is almost always absent in these priscan skulls, by any means always present in the artificially deformed ones of modern times. Skulls like the one just described have a calculable brain weight of $54 \mathrm{oz}$. avoirdupois, which is considerably above the average weight $49.5 \mathrm{oz}$. for European males in modern times; their powerful lower jaw and the bones of their limbs show them to have been possessed of muscular strength at least as much superior to that of average men ; and their owners, for these as well as for other reasons which it is not my purpose to discuss here ${ }^{1}$, may be very reasonably supposed to have been chiefs of their clan or tribe. The physical peculiarities however of individuals in such positions are very usually imitated by other members of their clan, tribe, or nation; and it may be suggested that the habit of artificially deforming the head, at all events as we see it most commonly done when it results in the production of a form like the one just described, may have arisen from the wish to give a child from the first the outlines which distinguished some adult whose vigour had placed him in a position of eminence and command ${ }^{2}$.

${ }^{1}$ See Address to Anthropological Subsection, British Assoc. Report for 1875, p. 150.

${ }^{2}$ It is not entirely easy even with a large number, as in the Oxford Museum, of artificially deformed skulls to be perfectly certain that such a skull as the one above described cannot have owed its peculiar contour to compression purposively exercised upon it during the period of infancy. Some sort of à priori probability in favour of this skull having been endowed with its peculiar shape by this means arises of course from its very close resemblance to the Oregon, Peruvian, and other antero-posteriorly compressed skulls which we know as a matter of fact to have been so treated, and which we see to be as free, if they be skulls of aged individuals, from any traces of the severe treatment they underwent in the first two years of life, as in the skull now before us. It is obvious, whatever may be said to the contrary, that a deformation which goes so far as materially to alter the relative proportions of the several lobes of the brain to each other without materially altering the anatomical relation of those lobes to the skull bones covering them, which M. Broca has (Bulletin de la Société d'Anthropologie, 1870, p. 115) shown that the 'Deformation Toulonnaise' actually does, must be put in play in these early days. For of the 22 inches or so $(=555 \mathrm{~mm}$.) which may be taken (Bischoff, Sitzungsberichte Kon-bayer. Akad. Wiss. München, $1864, \mathrm{Bd}$. i. p. 39) as the average head circumference of a living male adult, no less, but a little more, than nineteen inches and a half $\left(=500 \mathrm{~mm} .=19 \cdot 685^{\prime \prime}\right)$ have been shown by Liharzig (Gesetz des Wachsthums, 1862, p. 17, Taf. 5) to be attained by the male child of twenty-one months old. And between twenty-one months and the age to which the owner of such a skull as this must have attained, abundant time would have been afforded for smoothing down, rounding off, and removing any such traces of the action of any deforming apparatus as are sometimes to be seen in younger skulls (e.g. in a skull from Vancouver's Island, No. 826 a. Oxford Museum) which 
Professor Busk has, loc. infra cit., felicitously suggested the restoration of the Linnæan term 'plagio-cephalic' to this strongly marked variety of a strongly brachy-cephalic type. Skulls of similar proportions and contour have been procured from three or four other round barrows in the East Riding, viz. from barrows in the Goodmanham, Flixton, and Marr series; and two others, also of the same conformation, 'Rudstone, lxiii. 6,' and ' Rudstone, lxviii. 7,' have been procured from this very series. The latter of these two skulls, which belonged to a man past the middle period of life and of about $5 \mathrm{ft} .8 \mathrm{in}$. in stature, goes farther

have been subjected to it. Further, the fact that in a country so near as France a practice of depressing the head has lasted in Normandy (Retzius, Ethnograph. Schriften., p. 130) and in the non-Iberian parts of Southern France (Foville, cit. Retzius, $l . c$.) even into our own days, - and in the Tolosan portion of this latter district has been supposed (see Broca, l.c.) to have been a survival of the practice of the Tectosages, - may make us hesitate before definitely refusing, as so many other writers from the times of Haller (cit. Blumenbach, De Gen. Hum. Var. Nat., l.c.) down to that of Virchow (see Congrès Internat. d'Anthropologie, 1876, tom. i. p. 318) have refused, to accept artificial deformation as the explanation of the conformation of a particular skull, whether it be plagio-cephalic as this skull, or annularly constricted like the well-known Avar skulls of Grafenegg and Atzgersdorff. It must however be said, on the other hand, that both these forms of skull, though now well known to be producible artificially, do yet arise spontaneously even in our own day; and it is here suggested that unless a considerable number of skulls of one or other or both of these forms are found together it is unsafe to assert, in the absence of still persistent marks of the action of a compressing or constricting apparatus, that any single skull has been artificially deformed. For in most cases in which we have undoubted evidence of the existence of this practice, skulls of both forms, the plagio-cephalic, in which the skull has been compressed from before backwards, and the annularly constricted and elongated form illustrated by the Avar skulls above-mentioned and described by many of the authors enumerated below, have been found together: and in spite of the tendency shown by many writers to make multitudinous divisions of artificial cranial deformities, it is plain from a consideration of the history of the rapid growth of the brain and of the restlessness of children in early life, that it must be exceedingly difficult to prevent, with whatever care and whatever apparatus, the plagio-cephalic form from lapsing into the annularly constricted form. A comparison of the account given by M. Dumoutier of the practice (Bull. Soc. Ethnograph. de Paris, vol. i. 1847, cit. Gosse, l.c. p. 154), as carried on in Patagonia with the description given by Professor Huxley of a skull brought from Gregory Bay, Patagonia, by Dr. Cunningham of H.M.S. 'Nassau,' or of that given by Ellis, l.c. infra, of the Tahiti method with that given by Camper, $l . c$. of a calvarium brought to Oxford by Captain King (No. 827. University Museum), will show that both forms of artificial deformity existed side by side with each other in Patagonia and in Tahiti. Annularly constricted and elongated skulls, such as the one spoken of by Camper as 'tout pareillement conformée' to the one from Tahiti, have been constantly found in the region of the Nootka Sound in company with the plagio-cephalous variety. And the same is notoriously the case with the Peruvian series, though here it must be said that several authors have attempted to show, though not in the writer's opinion successfully, that these two forms of distorted skull may be taken as distinctive either of two different races, or of chiefs as opposed to the common people. See Forbes, $l . c$. infra, pp. 12, 13. The annularly constricted skulls which have come into the present writer's hands appear to have belonged to females whose treatment, even in matters of this kind, is often, amongst savages, different from that of males. 
than most even of the roughest hewn skulls of the Bronze Period to justify the comparison which Dr. Thurnam ${ }^{1}$ instituted between them and the macrognathous Maori crania. This skull having been much broken, most of its measurements, as reconstructed, have to be taken with qualification; its great weight however, $2 \mathrm{lb} .4 \cdot 9 \mathrm{oz}$. av., the lower jaw included, but much loss of other bone having been incurred, as against a weight for the much more nearly perfect skull and lower jaw, here figured, of $1 \mathrm{lb} .10 \mathrm{oz} .10 \mathrm{grs.}$ av., is unambiguously indicative as to its great size. Skulls differing from these mainly in the comparatively unimportant particular of a lesser frontal obliquity will be found figured in the 'Crania Helvetica' of His and Rütimeyer, t. ii. p. 130, and in V. Baer's description of the crania and people of the Graubündten ${ }^{2}$. Even more closely similar are the figures of the Borreby skull and of the Ledbury skull given by Professor Huxley in Sir Charles Lyell's 'Antiquity of Man,' p. 91, 4th ed. 1873, and in 'Prehistoric Remains of Caithness,' 1866, p. 114. In none of these cases however, with the single exception of the Borreby skull, have we decisive proof of their having belonged to a Præmetallic Period. No skulls resembling them in their distinctive characters have come into my hands from any British burial-place belonging to the Stone Age. On the other hand, there is no doubt that this variety of the brachy-cephalic skull has survived and is represented amongst us in modern days. Dr. Beddoe ${ }^{3}$, for example, and Professor Virchow ${ }^{4}$, have both specially remarked upon the likeness borne by certain modern Danish heads to some of the ancient Borreby crania; and their characteristics are even exaggerated in a presumably modern cranium figured by M. Topinard in his L'Anthropologie, 1876, p. 298, fig. 37.

A few references have been given above, pp. 572, 573 note, to memoirs bearing upon the production of cranial deformities artificially though undesignedly.

The bibliography of artificially and designedly produced deformities is very much more extensive. The following list will be found to comprise the most important notices of and memoirs upon the practice.

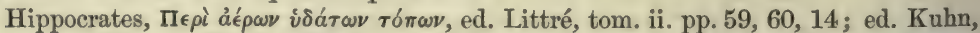

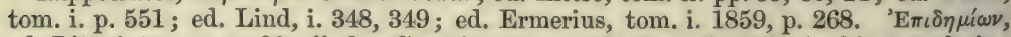
ed. Littré, tom. v. p. 80 ; ii. 8 . Coray's note, p. 224 , tom. ii. 1800 , in his translation of the former treatise is worth reading.

Strabo, xi. 16. p. 520.

${ }^{1}$ Principal Forms of Ancient British and Gaulish Skulls, 1865, pp. 31, 102.

2 Bulletin de l'Acad. Imp. des Sciences de Saint Pétersbourg, vol. i. 1860; or Mélanges biologiques tirés du Bulletin, $t$. iii.

${ }^{3}$ Mem. Soc. Anth. London, vol. iii. p. 383.

4 Archiv für Anthropologie, vol. iv. p. 71, 1860. 
Hiuen-Thsang, $f$ l. A.D. 629-645, cit. V. Baer, loc. infra cit. p. 22; of practice existing at Kashgar, in Histoire de la vie de Hiouen-Thsang et de ses voyages, par Stan. Julien, Paris, 1853, 8vo. p. 396.

J. Bulwer, Anthropometamorphosis, London, 1653, pp. 74-85.

Forster, Observations made during a Voyage round the World, 1778, p. 267, of Mallicollo.

P. Camper, Différence des traits du Visage, Autrecht, 1791, p. 23 seqq. The works of the late Professor Camper, translated by Dr. Cogan, 1794, also at p. 23.

Blumenbach, Decas Craniorum prima, 1790, iii.p.17; x. p. 27. De generis humani varietate nativa, 1795 , p. 255 seqq., ibique citata -in his own words ' nubem testium.' Nova Pentas, 1822, p. 10, ibique citata.

Ellis, Polynesian Researches, vol. i. pp. 80, 261, 2nd edit. 1831.

Tiedemann and Pentland, Zeitschrift für Physiologie, 1833, Bd. v. p. 108.

Bulletin Soc. Ethnograph. Paris, 1847, tom. i. pp. 262-273.

Foville, Déformations du Crâne, 1834. Systême Nerveux, i. 632, 1844, pl. 23, figs. 1 and 2.

Williams, Missionary Enterprize, 1837, p. 539.

Morton's Crania Americana, 1839, pp. 117, 203 et passim.

Rathke, Müller's Archiv, 1843. Tschudi, Ibid., 1844, 1845. Retzius, Ibid., 1849, or Ethnograph. Schrift. p.94.

Morton, cit. Waitz, Anthropologie, iv. 2, p. 386, On the Ethnography and Archæology of the American Aborigines, New Haven, 1846, p. 18; Schoolcraft, ii. 326.

Meyer, Müller's Archiv, 1850.

Thierry, A., Révue des deux Mondes, 1852, tom. xxxv. p. 533. Ibid., 1854, p. 241.

Fitzinger, Denkschriften, v. 1854; Akad. Wiss. Wien.

Retzius, Müller's Archiv, 1854, p. 439, and Proc. Acad. Nat. Sci. Philadelphia, vol. vii. p. 405. Ethnograph. Schrift. p. 125.

Morton, in Nott and Gliddon, Types of Mankind, 1854, pp. 436, 440.

Gosse, Essai sur les Déformations artificielles du Crâne, 1855.

Nott and Gliddon, Indigenous Races of the Earth, 1857, p. 335.

Wagner, A., Geschichte der Urwelt, 2nd edit. 1858, p. 39.

Retzius, Müller's Archiv, 1858, p. 106. British and Foreign Med. Chir. Rev., 1860, p. 228. Ethnographische Schriften, 1864, pp. 160, 161.

Von Baer, Mémoires de l'Academie des Sciences de St. Pétersbourg, Sér. VII. tom, ii. $\mathrm{n}^{\text {ro }} 6$, ibique citata, 1860 .

Turner, Nineteen Years in Polynesia, 1861, p. 175.

Van der Hoeven and Pruner-Bey, Bull. Soc. Anth. Paris, tom. ii. 1861, p. 449.

Wilson; On Kerteh Skulls, Edinburgh Phil. Journal, April, 1861.

Sproat, Scenes and Studies of Savage Life, 1862, pp. 28-30.

C. C. Blake, Trans. Ethnolog. Soc. London, vol. ii. 1862, ibique citata.

Thurnam, Crania Britannica, Decade V. pl. 45, July 1862. Davis, Ibid., chap. ix. p. 233.

His and Rütimeyer and Troyon, Crania Helvetica, 1864, pp. 56 -59.

Broca and Lagneau, Bulletin Soc. Anth. Paris, 1864, tom. v. pp. $385-421$.

Ecker, A., Archiv für Anthropologie, i. 75, 1866; ix. 1, pp. 61-76, 1876.

Forbes, D., On the Aymara Indians, Journ. Ethn. Soc. Lond. ii. 3, pp. 12, 13 and 205,

Oet. 1870. Broca, Ibid., 1871, p. 115. Sur la Déformation Toulonnaise.

Busk and J. B. Davis, Journal Anthrop. Instit. iii. 1, April 1873, p. 86 seqq.

Hutchinson, Consul T. J., Journal Anth. Inst. iii. 3, iv. 1, 1874. Simms, Ibid., iii. 3, p. 327, 1874. Telfer, Commander, Ibid. iv. 1, p. 57, with figure of annectent form.

Wood, 'Cruise in the South Seas,' 1875, p. 41, of Futuna Islanders, Horne Islands, citing Marsden as to Sumatrans, and Captain Cook (see 'Voyage towards the South Pole, 'i. p. 366, 1777) as to natives of Ulietea, who however are only represented as flattening the nose, a particular omitted by Forster, 'Observations,' p. 472 , in his account of the same proceedings.

Zuckerkandl, Reise der Novara, Anthrop. Theil, 1875, p. 46.

Bancroft, Native Races of Pacific States, vol. i. pp. 158, 228 (where occasional

failures are spoken of); vol. ii. 1875, pp. 731, 732; iv. p. 740 .

Dupont and Virchow, Congrès international d'Anthropologie et d'Archéologie Pre-

historiques; Compte Rendu, Stockholm, 1876, pp. 316 and 318.

Wilson, 'Prehistoric Man,' 3rd edit. 1876, chap. xx. ibique citata, esp. Blake, p.

156 , for finding of short and long forms together.

Topinard, Anthropologie, 1876 , p. 194.

Busk, Journal Anth. Inst, January 1877, p. 202, on skulls from Mallicollo. 


\section{CASTLE CARROCK, CUMBERLAND.}

[clxiii. p. 379.]

SKULI OF A MAN ADVANCED IN YEARs.
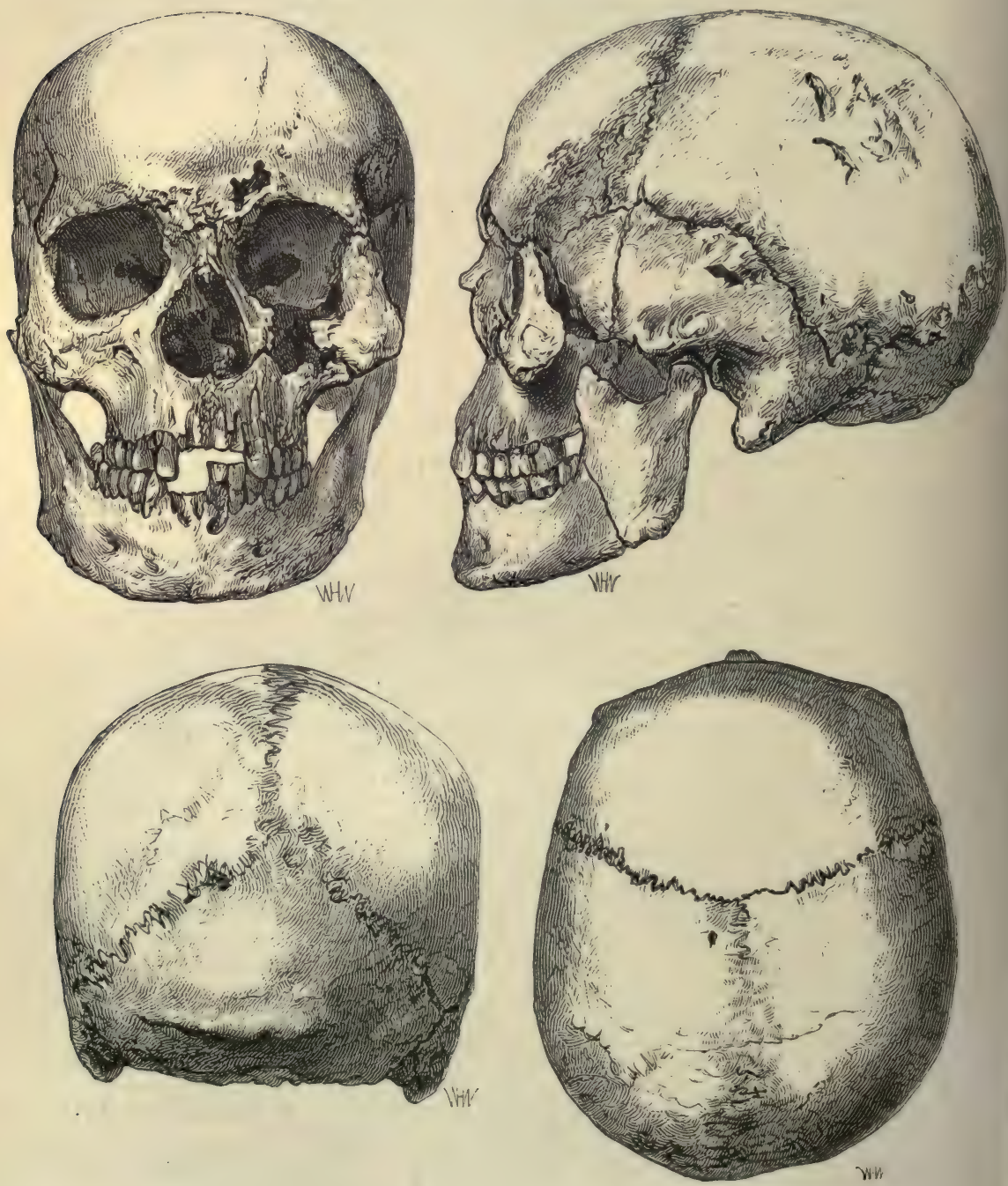


\section{CASTLE CARROCK, CUMBERLAND.}

[clxiii. p. 379.]

Skull of a maN ADVANCEd IN Years.

I. Measurements of Calvaria.

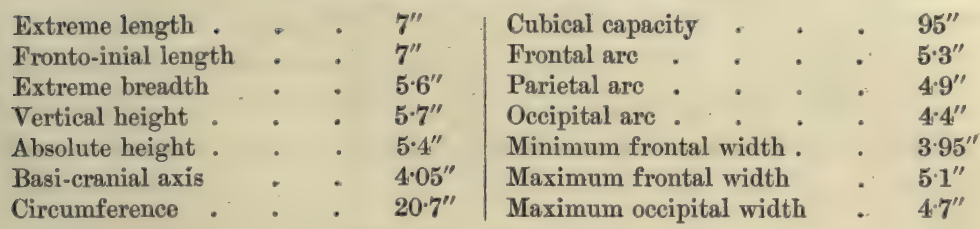

II. Measurements of Face.

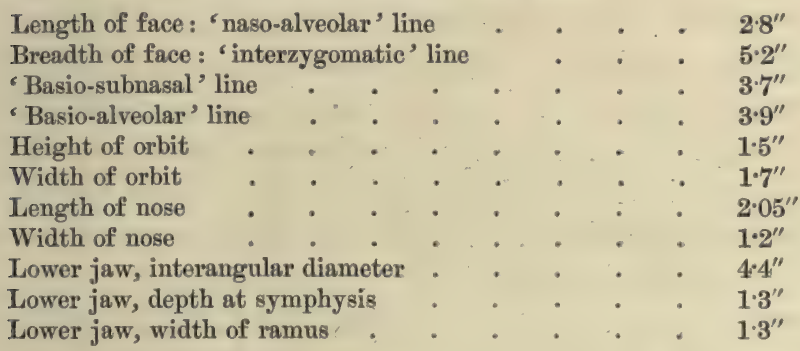

III. Indices.

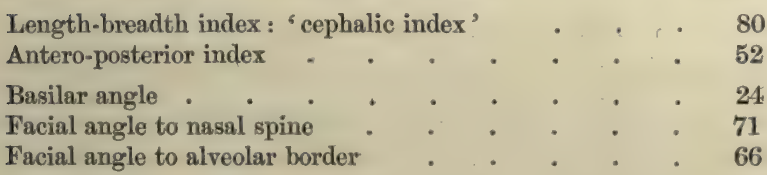

With the skull 'Castle Carrock, Cumberland,' no bones of the trunk or limbs have come into my hands; there is considerable reason however, from the eonsideration of the skull alone, for saying that this skull belonged to a man much 'past the middle period of life,' if not to an 'aged' man. The still outstanding muscular and other processes in the lower part of the skull and the still powerful lower jaw show that the owner of this skull was a person of considerable strength, whilst the general rounding off of the angular portion of the vault of the skull seems referable to the working of senile absorption. The diploic sinuses are exposed on either side in 
the region of the parietal eminences, as is the case in advanced senile atrophy; the cavities exposed are undoubtedly larger than they would, in almost any circumstances, be until some time after the prime of life; the skull however has suffered somewhat from water-wear, and it is not easy to be sure that some of the excavation and exposure shown in the drawing on the left parietal bone may not be due to this posthumously working cause. The down-growth of the occipital condyles, and of the mastoids, and the spiny roughnesses developed generally at the base of the skull, and specially around the posterior border of its foramen magnum, are points indicative of its advance in age. A somewhat similar skull, from Tosson in Northumberland, presented to the University Museum by Canon Greenwell, has been described by Dr. Barnard Davis in the 'Crania Britannica,' vii. Pl. 54; its sex however does not seem to be quite so certainly male as that of the skull from Castle Carrock, and its age to be a little greater, as is also its cubical capacity, $97 \cdot 5$ as against 95 cubic inches. The two skulls are specially useful as showing the modifications, especially in the way of rounding off of outlines, which the advance of old age produces upon the more capacious brachy-cephalic skulls, which when young might have been spoken of as 'têtes carrées,' 'subcubical,' or 'subquadrate.' Both of them have retained comparatively vertical foreheads and the characteristic dip of a slightly asymmetrical parieto-occipital region, the Castle Carrock skull in company with a powerful lower jaw, and the Tosson skull in company with a feebler one; both have their points of maximum transverse width low down upon the parietal bone, both have vertical pterygoids; but the lateral bulging produced by senile change has advanced further in the Tosson specimen, and the plane of maximum width has advanced further forwards relatively to the long axis of the skull. Some of the peculiarities to be seen in the norma basalis and lower jaw of the Castle Carrock skull are very exactly reproduced in the Tosson specimen, even to such points as the non-development of some of the wisdom teeth and the small size of the entire dental series. The lower jaw of the Tosson skull is feebler than that of the Cumberland skull, and its coronoid fails, as is more usually the case in dolicho-cephalic than in brachy-cephalic skulls, to reach the level of the zygomatic arch, points which, taken together with the remarkably small size of its mastoids and its lesser absolute and relative height, may seem to indicate that it is a female skull. However this may be, there can be no doubt that 
they both are what Dr. Barnard Davis has said one of them, viz. the Tosson skull, is, 'of the typical series of ancient British crania,' and of the typical series, I should add, of the Round Barrow or Bronze Period. As an individual peculiarity in the Castle Carrock skull not observed among the other brachy-cephalic skulls here figured, may be noted ${ }^{1}$ the fact that when placed without its lower jaw, but with the grinding surface of its upper molar teeth upon a horizontal surface, it touches that surface posteriorly, not with its conceptacula cerebelli, but with its occipital condyles. This is mainly due to the downgrowth of these processes, but also in part to the upward slant of the cerebellar fossæ, a point more common in brachy-cephalic than in other crania, and not indicative of deficient cranial curvature when coupled, as in this case, with a vertical forehead.

This skull and the five here described before it are all alike brachy-cephalic by contour as well as by mere measurement. In all of them, with the exception of 'Rudstone, lxiii. 9,' the 'vertical height' is greater than or at least equal to the 'extreme breadth ;' in all of them the posterior part of the parietal bones curves downwards more or less vertically, making thus the distance between the plane of the parietal tubera and that of the back of the head shorter than it is in dolicho-cephalic skulls and throwing the foramina emissaria entirely on to the back aspect of the cranium. In none of them, whether young or old, is either the coronal or the lambdoid suture entirely obliterated, showing that the form of the skull in them, as we shall hereafter see it is also in the dolicho-cephalic variety, is dependent upon that of the brain and not upon any synostosis.

With this skull, undoubtedly the oldest of those as yet described, the series of brachy-cephalic skulls here figured ends; in the arrangement of the dolicho-cephalic series, next to be entered upon, similar regard has been had to age; and the first skull of that series, 'Langton Wold, ii. 1,' differs from the skull 'Castle Carrock' in the matter of age as much as in any other of its distinctive peculiarities.

${ }^{1}$ See Ecker, Archiv für Anthropologie, iv. p. 301, cit. p. 567 supra. 


\section{LANGTON WOLD.}

[ii. 1. p. 136.]

SkULL OF A MAN OF FROM THIRTX TO THIRTY-FIVE YEARS OF AGE, AND 5 FT. 9 IN. IN STATURE.
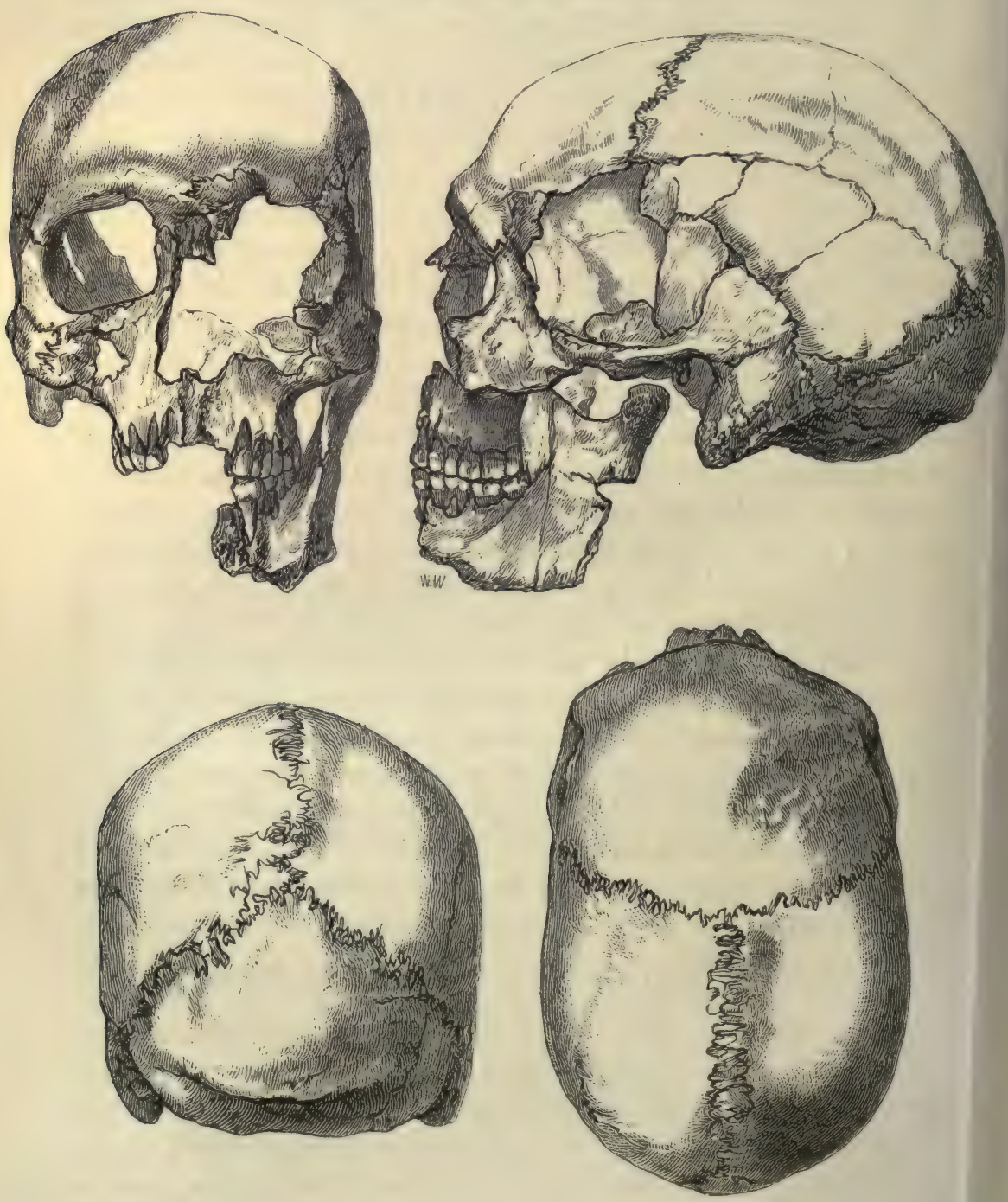


\section{LANGTON WOLD.}

[ii. 1. p. 136.]

SKULL OF A MAN OF FROM THIRTY TO THIRTY-FIVE YEARS OF AGR, AND 5 FT. 9 IN. IN STATURE.

\section{Measurements of Calvaria.}

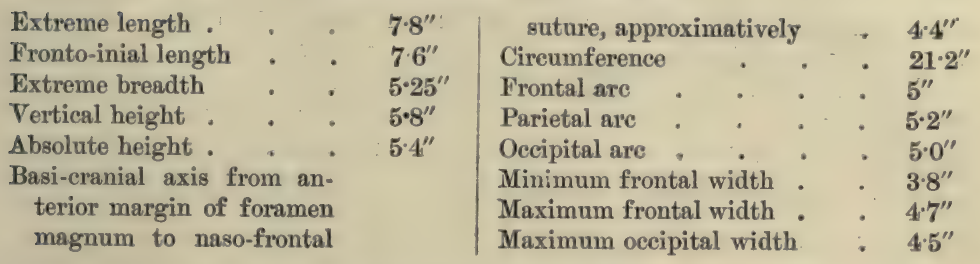

II. Measurements of Face.

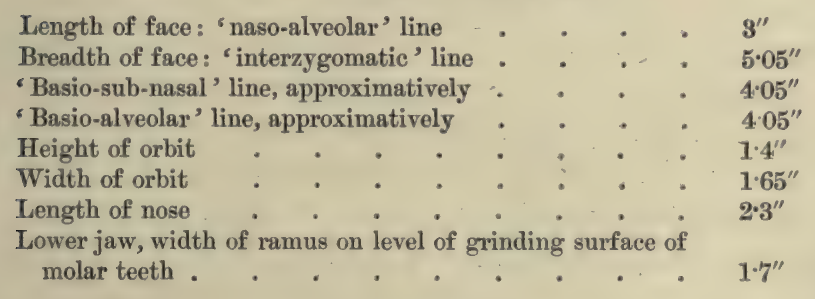

III. Indices.

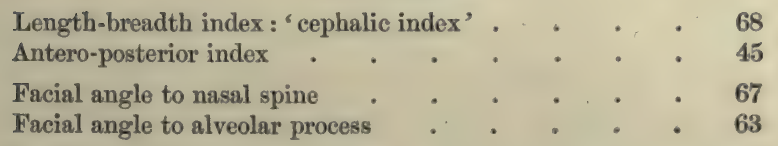

The femora and pelvic bones taken together with the cranium show that the skeleton, Langton Wold i, belonged to a strong man in the early part of middle life, that is to say probably between 30 and 35, of very considerable muscular strength, and about $5 \mathrm{ft} .9 \mathrm{in}$. in stature. The sacrum and ossa innominata have their sutures and epiphyses completely anchylosed. The two posterior molars however on each side of the jaws are comparatively worn. The femur is of great strength, flanged out in the region of the upper insertion of the glutæus maximus so as to give this part of the bone a flattened appearance ; the inner division of the upper bifurcation of the linea aspera is prolonged into a spiral ridge continuous 
with the anterior intertrochanteric line, a peculiarity much more marked in the much smaller femora of the skeleton next to be described; whilst the size of the linea aspersa in the area over which its two lips are combined is such as to give the fluted appearance to the posterior aspect of the femur which has procured for such bones the name of ' fémurs à colonnes ' 'Topinard, L'Anthropologie, p. 324, 1876).

This skull, and the one next to be described, Duggleby i. 2, may be taken as typical representatives of the male and female form respectively of the Hohberg type of His and Rütimeyer as described and figured in the 'Crania Helvetica' of those authors. There can be no doubt as to the respective sexes and ages of these two skulls, the trunk and limb-bones of both having been available for examination as well as the crania, though many of both sets of bones in both cases have suffered considerably from posthumous injury, and have to be spoken of as reconstructed.

There are several modifications of the dolicho-cephalic type found in barrows of the Neolithic Period which do not correspond with the Hohberg type just mentioned; that type however is found in those barrows, and these skulls, though of a later date, very fairly represent it, and their respective sexes being certainly fixed they enable us to distinguish in this type the characters which have an ethnographical from those which have merely a sexual significance.

The skull, Langton Wold $i$, is distinctly and essentially orthognathous, as shown by comparison of the basi-cranial with the basiosubnasal and basio-alveolar lengths; the supraciliary ridges owe their large size to the masculine character of the skeleton they belong to, they meet, however, as these ridges are said to do in this type by the ethnologists just referred to, without that depression in the middle glabellar line which is usual in the brachy-cephali; the median vertical contour describes the characteristically equable dolicho-cephalic curve from the point where the glabella sinks into the oblique facies frontalis of the os frontis to the centre of the superior squama occipitis, where a spot $\frac{2}{10}$ " anterior to the upper side of the external occipital protuberance, and $\frac{3}{10}$ "anterior to the commencement of a linea nucha mediana, separated by a slight interval from that largely developed ridge, marks the back of the skull. This occipital dolicho-cephaly, plain enough also on simple inspection, is further made manifest by its low antero-posterior index, 45, though it is right to say that the skull has probably undergone some compression with the usual result of producing a lengthening, and 
in this case owing to its intrinsic wall-sidedness in the temporal and parietal regions, especially in the posterior half of the skull. The parietal and occipital ares each exceed their normal length by $\frac{4}{10}$ ths of an inch. The lower jaw being imperfect it is not easy to form an accurate estimate of the amount of compression which may have been effected here. This bone appears to have been more powerfully developed than is usually the case in skulls of this type, its angle having been square and everted and its coronoid having reached above the level of its zygoma. The mastoids are of an extraordinary length. There is a broad but shallow undulation on either side of a raised sagittal carina posteriorly to the coronal suture. Viewed in the norma verticalis, the skull is remarkable for the very gradual way in which it grows narrower along the long straight lateral boundaries from the barely recognisable region of the parietal tubera up to the external orbital processes of the frontal. This contour has been supposed ${ }^{1}$ to characterise the Anglo-Saxon rather than the Celtic type of head; there is however no room for doubting that this cranium belonged to an inhabitant of this country in the Bronze Period. The skull is phænozygous. The sagittal and coronal sutures are both obliterated internally, and the sagittal is obliterated on the outside of the skull in the region where such obliteration usually shows itself first, viz. in the region of the foramina emissaria. On the right half of the frontal bone there is a wound $3^{\prime \prime}$ long and $1^{\prime \prime}$ wide, sloping downwards from a point about an inch in front of the point where the sagittal meets the coronal suture very nearly to the point where the temporal line passes from the lateral cranial wall on to the external orbital process. The floor of the wound is formed for a little over $2^{\prime \prime}$ by the diploe, the eavities of which are filled with black earth of the same kind, apparently, as that which has given the entire exterior surface of the skull its dingy appearance. The outer table forms the lateral boundaries and the floor at either end of the wound. The inner table of the skull does not appear to have been affected by the blow, and the wound may be taken as an instance of ' undepressed gouged out fracture,' for accounts of which kind of injury

1 See Professor Daniel Wilson, Canadian Journal, New Series, vol. liv. Nov. 1864; or Anthropological Review, vol. iii. Feb. 1865, London. The skull described below, under the name of Weaverthorpe, Smith, iii. 3 , is of the type which, while equally long with the one described above, is distinguished by a sudden tapering in front of the parietal tubera, and is supposed by the writer just cited to be characteristic of the 'Insular Celt.' There is however no reason for holding that it belongs to a period anterior to that of the skull Langton $\mathrm{i}$. 
see United States Reports, Circular No. 6, War Department, Surgeon-General's Office, Washington, p. 12, Nov. 1, 1865. A spear or celt of metal if driven with force at a living head might very well raise a splinter of bone out of the two external layers of the bony cranium, especially if the recipient was lying on the ground and rolled his head as much out of the way as he could as the blow descended. The splinter would probably, in the first instance, be left adhering to the scalp, and might have taken up its old place again. Here it has been lost; but that the patient survived its separation, at least from all connexion with the bone of which it once formed a part, the state of that bone furnishes fair evidence. On looking carefully with a lens at the edges of the wound formed by the external table of the skull, it will be seen that, though the mæandering channels formed for themselves by plant rootlets have had something to do with making the surface what it is, still some process of smoothing down due to the vital operations of the skull itself is recognisable upon them. The lamellar arrangement of the outer table is still distinctly visible, nevertheless the surface is not as sharply defined anywhere as it must have been when the wound was first inflicted. To allow of this smoothing down being effected not more than two or three months would be required; in the very instructive histories given of the owners of skulls in the Berlin Museum (see Walter's Museum Anatomicum, 1805, p. 468) which had had sword-cuts inflicted upon them, a process of healing effected novo succo osseo affluente et annitente ut vulnus claudat takes only paucos menses, and in one case (2394) only two months. Yet this process is one requiring more time than the process of absorptive smoothing which is all we have signs of here. The unclosed vacuities in the diploe show that the wound was never healed, unless we are to suppose that the rootlets above mentioned have removed away cleanly and entirely that glaze of bone which in skulls so wounded is deposited over the injured area. The death of the man therefore, though occurring within a comparatively short time from the receiving of this wound, must have been due to some other cause than the mere wound itself.

In the occipital norma the wall-sidedness of the lateral boundaries of the pentagon described by the contour lines in this aspect and the vertical carination characteristic of male skulls of this type are eminently noteworthy ${ }^{1}$.

${ }^{1}$ A female skull, 'Langton Wold ii,' very closely resembling the one just described, has been obtained from the same barrow. It belonged however to a very much older 
individual, and some of the characteristics of its sex, which was established mainly by an examination of its trunk and limb bones, have been, as female cranial characters sometimes are, masked by the inroads of senile changes. It is interesting to note that the femora of this aged woman resembled those of this young male subject and those of the young woman next to be described, in having the spiral line joining the linea aspera and the anterior intertrochanteric line well marked. The aged female skull, 'Langton, ii. 2,' differs from both the others with which it has been compared in retaining the prominence of the parietal tubera so commonly observable in skulls up to the time when, with the evolution of the second set of teeth, the lower part of the skull widens out with the widening of the jaws. The absence of prominence of the region of the parietal tuberosities is one of the characters given by His and Rütimeyer as characteristic of the Hohberg type, an undoubtedly old form of skull; the presence of such prominence, on the other hand, is given by Schaafhausen (Die Urform des menschlichen Schädels, p. 7) as characteristic of priscan skulls. A consideration of these three skulls taken together with that of some of the facts of skull-development, will show how these statements may be reconciled. The parietal tuberosities are as distinctively characteristic of the human cranium as is the lobule of the marginal convolution called 'lobulus tuberis' by Huschke (Schaedel, Hirn, and Seele, p. 142, 1854); the full distance between them (135 mill.) however, within some three millimeters, is attained to as early as ten years of age. See Welcker, Wachsthum und Bau, p. 127. They are prominent in the skulls of quite young human subjects even of savage races, as $e . g$. the Australians and Coles (see skulls mentioned in note on p. 615 infra), whilst on the other hand they are only very faintly indicated in the skulls even of the antheropomorphous apes. Further, it is, as might have been expected, a fact (see Weisbach, Archiv für Anthropologie, iii. p. 71) that the intertuberal diameter is identical for the two sexes, or nearly so. It is now easy to see how female skulls which fail to attain the 'rounding out of the sides of the skull which occurs from the latest expansion of the brain' (see Cleland, Phil. Trans. 1870, p. 149), and which retain in this particular of comparative narrowness of the transverse diameter of the basis cranii (see Weisbach, $l . c$. p. 68), as in some others, childlike characters, will have their parietal tubera relatively prominent; and how ill-filled male skulls in ill-fed races may come to resemble them in this point. In well-filled male skulls, on the other hand, the prominence of the parietal tubera is lost in the general globosity produced by the widening out of the lower parts of the brain. 


\section{SHERBURN WOLD.}

[vii. 1. p. 146.]

SKOLL OF $\triangle$ WOMAN OF FROM THIRTX TO THIRTY-FIVE YEARS OF AGR, AND OF 4 FT. 8 IN. IN HEIGHT.
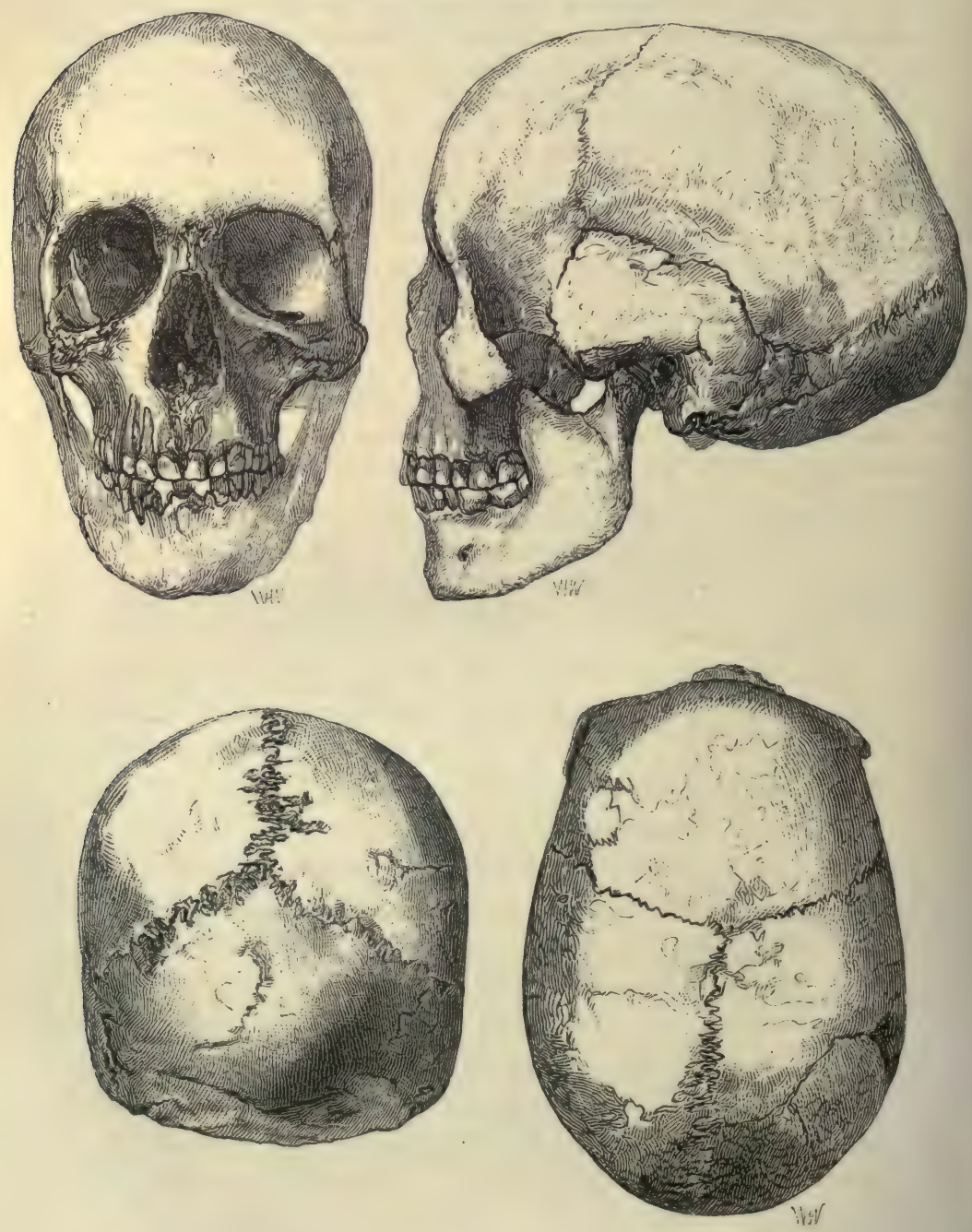


\title{
SHERBURN WOLD.
}

\author{
[vii. 1. p. 146.]
}

\begin{abstract}
SKULI OF A WOMAN OF FROM THIRTY TO THIRTY-FIVE YHARS OF AGE, AND OF 4 FT. $8 \mathrm{IN}$. IN HEIGHT.
\end{abstract}

\section{Measurements of Calvaria.}

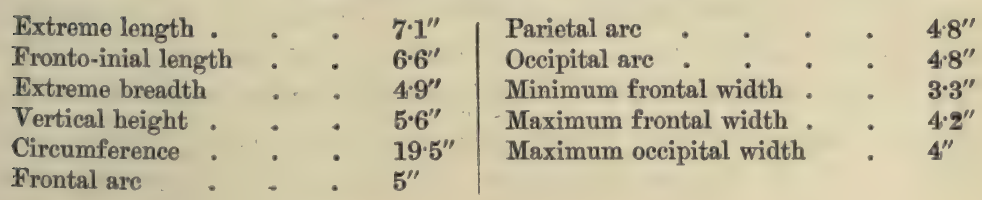

II. Measurements of Face.

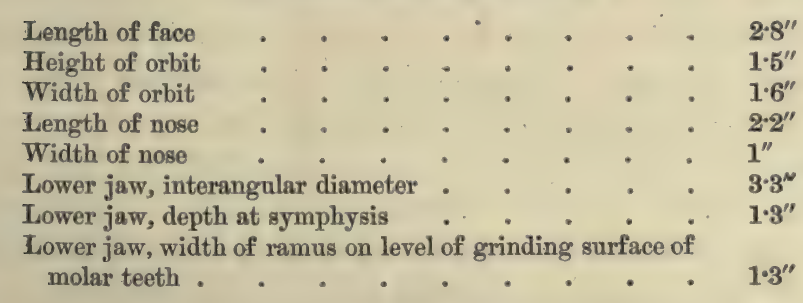

III. Indices.

Length-breadth index : 'cephalic index' . . . . 68

Antero-posterior index . . . . . . . . 46

Facial angle to nasal spine . . . . . . . . 63

Facial angle to alveolar edge $\cdots \quad . .60$

The condition of the femora and pelvis and of the teeth enable us to say with certainty that we have in 'Sherburn Wold, vii. 1' the skeleton of a woman who was of about the same age as, or perhaps a little older than, the man to whom the preceding skeleton ('Langton, ii. 1') belonged, i.e. about thirty or thirtyfive years of age, and who was $4^{\prime} 8^{\prime \prime}$ in stature. The femora are much slighter and much more curved, as well as much shorter, than those of 'Langton Wold, ii. 1 ;' they resemble them however in the curious point of having the inner of the two upper lips 
of the linea aspera prolonged spirally round into the anterior intertrochanteric line. The pelvis and sacrum are completed; the wisdom teeth however are comparatively little worn.

The verticality of the forehead and the absence of large supraciliary ridges are feminine characters, as are also the comparative feebleness of the lower jaw and the smaller size of the mastoids, seen in the profile view. The parieto-oceipital slope however is a little more oblique than is usual in women's skulls. The pterygoids are perfectly vertical. In almost all its measurements this skull is smaller than the male skull with which it is compared; the more important, however, of the proportions which subsist between these dimensions are the same for both. The point of maximum width is situated a little higher up than in the preceding skull, and the mesial vertical carina is less clear in the occipital pentagon. But it resembles that skull in the faintly marked parietal tubera and the absence of any rounding out of the lateral cranial walls below the level of those eminences. Viewed from above this skull presents a somewhat more tapering outline in both directions, both towards the forehead and towards the occiput, than the preceding one, and would have been more phænozygous if the zygomatic arches had not been extensively lost. The sagittal and coronal sutures are more extensively obliterated than in the preceding skull, and the lambdoid, which was unaffected in that skull, is largely obliterated in this. There is a depression in the region of the left lateral fontanelle, the spot called 'asterion' by Professor Broca, and the maximum occipital width is half an inch less than in the other skull with which it has been compared. These points and the closure of the lambdoid may suggest that the occipital lobes ceased to grow early in life; their length however must have been great. In the norma basalis the absence of any crista transversa occipitis enables us to give a more favourable measurement to the fronto-postremal as compared with the fronto-inial diameter of the skull than in skulls where the commencement of the linea nucha mediana is masked by a large development of that outgrowth. The palate is deep; the external alveolar border of the upper jaw is ellipsoidal ; the disproportionate smallness of the upper wisdom teeth gives the inner border of the dental series a parabolic outline. There is a spot of caries on the right wisdom tooth in the lower jaw. The absence of any occipital spine enables us to see the distinctness of the curves described by the superior squama from those of the parietal above and the conceptacula cerebelli below, 
and produces the 'facettirte Absetzung des Hinterkopfs' dwelt upon as characteristic of the Hohberg type of skull. The absence of the process in question is however rather a sexual than an ethnographical difference; but it enables us to see the peculiar conformation of the back-head which is common to both sexes to great advantage. 


\section{RUDSTONE.}

[cexxiv. 4. p. 501.]

SkULI OF A MAN PAST MIDDLe PERIOD OT LIFE.
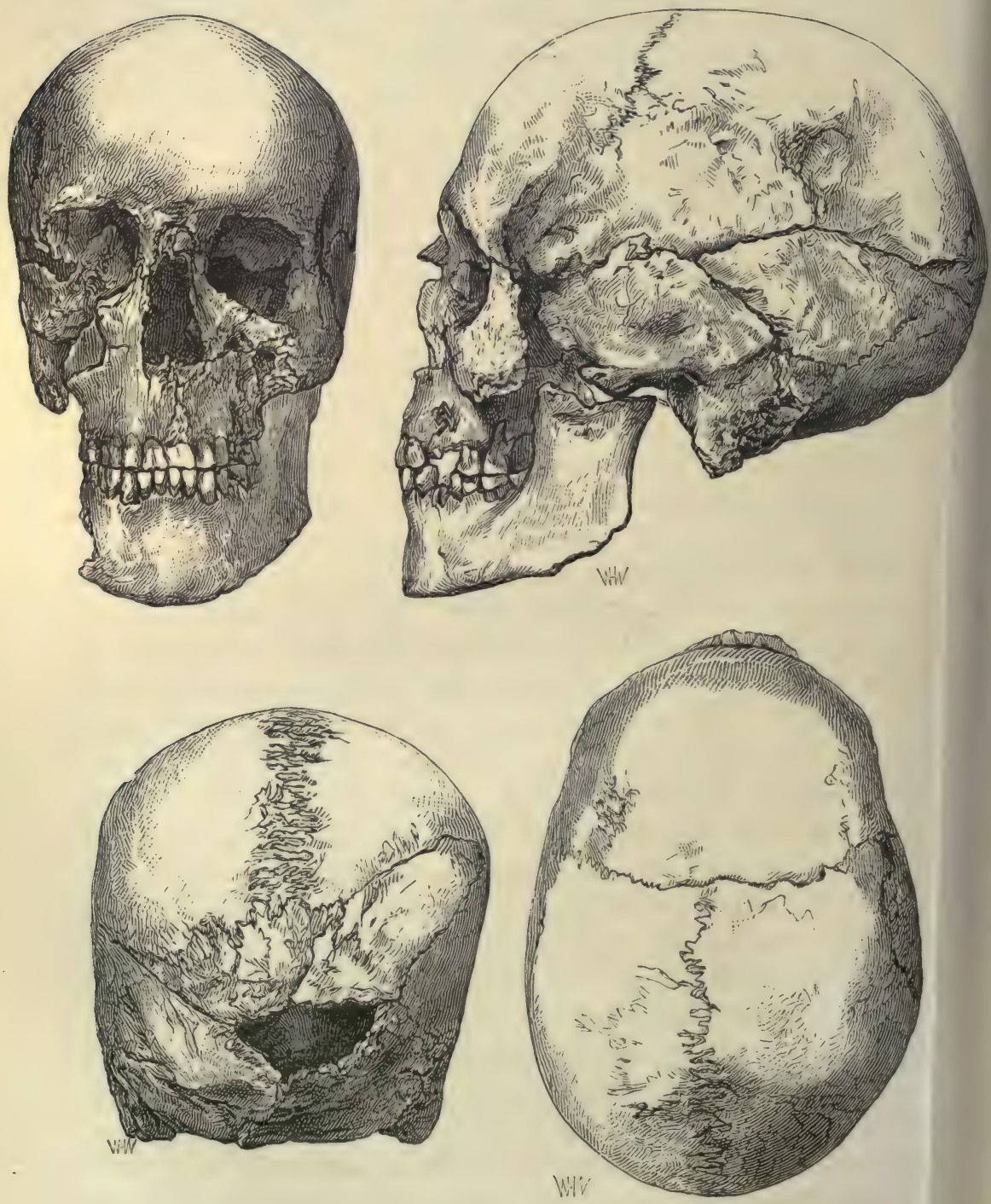


\title{
RUDSTONE.
}

\author{
[ecxxiv. 4. p. 501.]
}

SKULL OF A MAN PAST MIDDLE PERIOD OF LIFE.

\section{Measurements of Calvaria.}

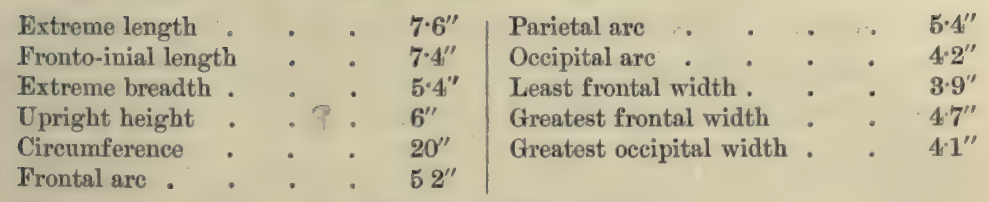

II. Measurements of Face.

\begin{tabular}{|c|c|c|c|c|c|c|c|c|}
\hline Length of face & & • & $\cdot$ & & . & • & • & $3^{\prime \prime}$ \\
\hline Depth of lower jaw & at & symphysis & & $\bullet$ & & - & - & $1 \cdot 7^{\prime \prime}$ \\
\hline Width of ramus & . & . & • & * & • & • & . & $1 \cdot 5^{\prime \prime}$ \\
\hline Height of orbit & • & • & 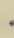 & • & • & • & - & $1 \cdot 45^{\prime \prime}$ \\
\hline Width of orbit & - & . & . & • & - & - & - & $1 \cdot 6^{\prime \prime}$ \\
\hline Length of nose & 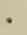 & - & . & . & - & - & - & $2^{\prime \prime}$ \\
\hline Width of nose. & . & . & . & . & . & . & • & $0 \cdot 9^{\prime \prime}$ \\
\hline
\end{tabular}

III. Indices.

\begin{tabular}{|c|c|c|c|c|}
\hline $\begin{array}{l}\text { Cephalic index } \\
\text { Antero-posterior index }\end{array}$ & . & 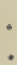 & . & - \\
\hline Facial angle at nasal spine & & & & \\
\hline Facial angle at alveolar border & . & . & . & . \\
\hline
\end{tabular}

The lower jaw which has been drawn with this skull was not found in connexion with it, but was lying, in the long barrow whence it came, at no very great distance from it. It may very well have belonged to it, inasmuch as, though its colouration is somewhat different, it shows the same male characters; has a somewhat similar amount of wear upon the grinding surface of its teeth, which otherwise correspond in the way of co-adaptation to those of the upper jaw of the skull; and has been similarly channelled externally by rootlets. It has not been possible to say anything as to the long bones of the skeleton to which this skull belonged, but the skull taken by itself enables us to say positively that we have here to deal with the remains of a man 'past the middle period of life' who was probably of considerable muscular strength. The skull is eminently long and lofty, and specially interesting as showing how 'occipital dolicho-cephaly,' as here measured by drawing a line at right angles to the line of extreme length so as to lie as a tangent to the anterior 
border of the auditory foramen, is really dependent more upon the length of the parietal than upon that of the occipital bone. This is plain enough upon simple inspection of the skull in its norma lateralis; and it is shown, secondly, by the very small difference, only amounting to $\frac{2}{10}$ ths of an inch, which subsists between the extreme length, $7 \cdot 6^{\prime \prime}$, and the fronto-inial length, $7 \cdot 4^{\prime \prime}$, taken to the commencement of the linea nucha mediana; the measurements of the frontal, $5 \cdot 2^{\prime \prime}$, parietal, $5 \cdot 4^{\prime \prime}$, and occipital, $5 \cdot 2^{\prime \prime}$ arcs, are not so clearly indicative. Professor Jeffries $\mathrm{Wyman}^{1}$ by a measurement of eleven normal crania obtained an average of $125 \mathrm{~mm}$. $\left(=4 \cdot 92^{\prime \prime}\right)$ for the frontal are, $124 \mathrm{~mm} .\left(=4 \cdot 88^{\prime \prime}\right)$ for the parietal, and $117 \mathrm{~mm}$. $\left(=4 \cdot 60^{\prime \prime}\right)$ for the occipital; whilst three adult synostotic crania gave for the frontal, parietal, and occipital ares respectively $129 \cdot 2 \mathrm{~mm}$. $\left(=5^{\prime \prime}\right), 142 \mathrm{~mm} \cdot\left(=5 \cdot 59^{\prime \prime}\right)$, and $119 \mathrm{~mm} \cdot\left(=4 \cdot 68^{\prime \prime}\right)$. Welcker ${ }^{2}$ similarly obtained, as against an average from normal crania for the sagittal suture or parietal are of $126 \mathrm{~mm}\left(=4 \cdot 96^{\prime \prime}\right)$, an average from eleven skulls with premature obliteration of the sagittal suture (Dolicho-cephali ex synostosi sagittali) of $137 \mathrm{~mm} .\left(=5 \cdot 39^{\prime \prime}\right)$. His average from three 'scapho-cephali' for the sagittal suture is $139 \mathrm{~mm}$. $\left(=5 \cdot 47^{\prime \prime}\right)$. The skull now before us resembles those measured by Wyman and Welcker in the great length of its parietal arc; but its occipital shows an equal excess over the normal. As its sagittal suture is closed along the inner table of the skull, though it is complexly denticulated externally, a condition of things observable in two other very closely similar skulls from the same locality, 'Rudstone, cexxiv. 1' and 'Rudstone, lxi. 3,' it is not possible to say whether here an elongation of the cerebral lobes produced the elongation of the brain case, or a premature sagittal synostosis produced an elongation of the brain in the way of compensatory outgrowth. An examination however of other similarly elongated calvariæ from long and other barrows, as well as from interments of modern dolicho-cephalic savage races, puts it beyond a doubt that the elongation of the brain is the first term in the series, and that the synostosis observable in such skulls as these is not a cause but a consequence merely, the sutures closing because the brain does not grow in the direction at right angles to their long axis ${ }^{3}$.

1 See Observations on Crania, p. 32, Boston, 1868.

${ }^{2}$ Wachsthum und Bau des menschlichen Schädels, p. 15, 1862.

${ }^{3}$ A calvaria from the long barrow at Upper Swell, mentioned at p. 528 of this book, as found under the skull 'No. 2, Upper Swell,' has a parietal arc of 5.9', being one 
The elongated oval contour of the vertical norma and the pentagonal of the occipital are very characteristic. In the frontal norma the great relative development of the alveolar, as opposed to the mental portion of the front of the lower jaw, is very striking. In this, as also in the backward position of its foramen mentale in a plane corresponding to that of the last premolar, this lower jaw resembles many other lower jaws of skulls of this period. It is however a larger and powerful bone, as, it must be said ${ }^{1}$, many lower jaws from very early burials have been found to be. The eanines are greatly developed in both jaws, and give a squareness to the lower part of the face. There has been much decay of the teeth, and alveolar abscesses with the left upper premolars and wisdom tooth.

inch longer than the normal length of this arc, with a frontal of $5 \cdot 1^{\prime \prime}$ and an occipital of $4.9^{\prime \prime}$, with both frontal and sagittal sutures open both internally and externally and for their entire lengths. The sex of the owner of this calvaria cannot be spoken to positively, the age however must have been somewhere between sixteen and twenty, and probably nearer the latter than the former of those years, the sphenoidal sinuses being largely developed, and the spheno-basilar synchondrosis entirely closed. In this latter particular this skull is a more striking example in illustration of the view given above than the skull from Norton Bavant, adduced in favour of that view by Dr. Thurnam ${ }^{1}$, in which the spheno-basilar suture was still open.

Four other dolicho-cephalie skulls were obtained from the same barrow of Upper Swell, in which the sagittal suture was patent, though they had belonged to as old or older individuals, but in them the parietal are though long is not so long as in the one spoken of above. The same remark applies to some adult Eskimo skulls in the Oxford University Museum; and two skulls in the Oxford University Museum (representative of two other races in which the boat-shape, denoted by the title 'Scapho-cephalic' or 'Cymbo-cephalic,' is very eminently and very frequently represented, the Australian, namely, and the Coles of India), the elder of the owners of which cannot have attained more than sixteen years of age, whilst the younger was only ten years old, have each attained that shape with every suture patent throughout. In like manner the Gentoo skull, No. 5558 in the Museum of the Royal College of Surgeons of England, with every suture open, is all but identical in its outlines with the Gentoo skull 5556, which is 'synostotic.' Per contra, in brachy-cephalic skulls of the Bronze as of other periods the coronal suture is far too frequently open throughout to allow us to suppose that its synostosis has, when present, been the cause of the skull's shortness.

1 Though the lower jaw figured with an ancient British skull from a barrow at West Kennet, North Wilts, pl. 50, 'Crania Britannica,' and stated by Dr. Thurnam, in loco, 'to deviate considerably from the normal type,' does, as I convinced myself by an examination of it in the Cambridge University Museum, most undoubtedly belong to some quite modern skull, still similarly powerful jaws have not rarely been found with very ancient skulls. Such were the lower jaws found by Schmerling in the Engis Cave, see Virchow, Archiv für Anthrop, vol. vi. p. 90 ; and in the cairn of Get, Caithness, as recorded by C. Carter Blake, Esq., Mem. Anth. Soc., vol.iii. p. 243.

1 See Mem. Soc. Anth. London, vol. iii, or 'Further Researches,' separate copy. p. 31. Also ibid., vol. i, separate copy, p. 69; and Nat. Hist., p. 242, 1865 ; and Virchow, Archiv für Anthropologie, vol. v. p. 535, 1872. 


\section{HELPERTHORPE.}

[xli. 3. p. 191.]

SKULL OF A FTRONG MAN PAST MIDDLE PERIOD OF LIFE.
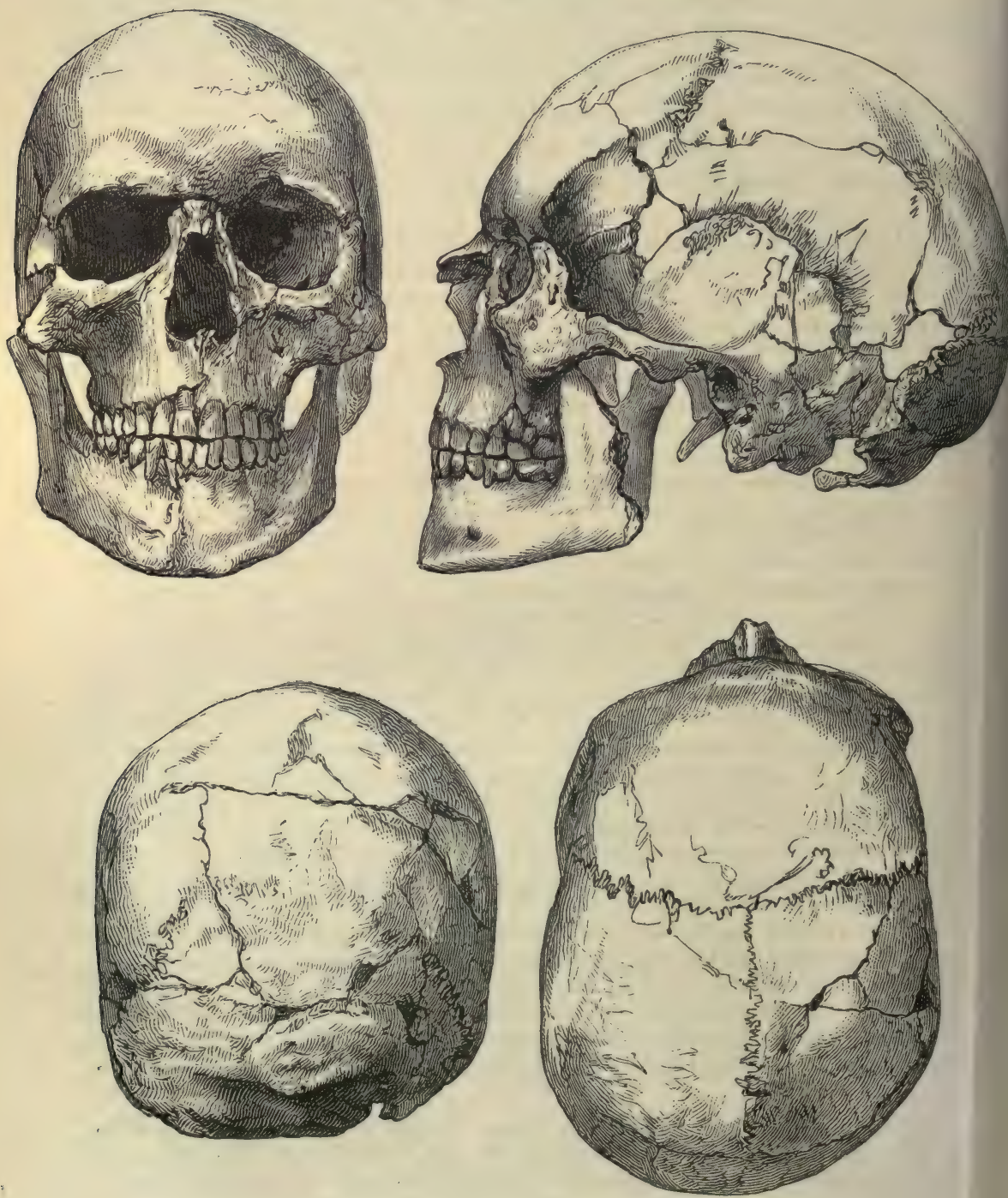


\section{HELPERTHORPE.}

[xli. 3. p. 191.]

SKULl of A strong MAN PAST MIDDLE PERIOd OF LIFE.

\section{Measurements of Calvaria.}

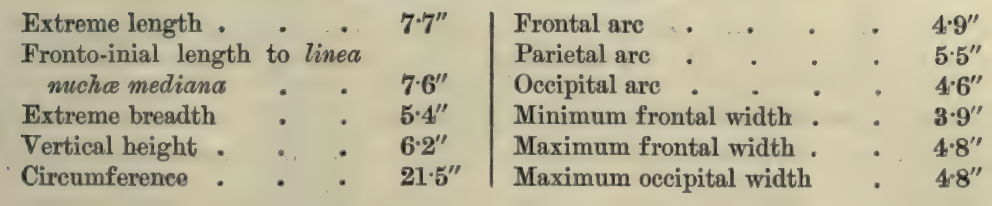

\section{Measurements of Face.}

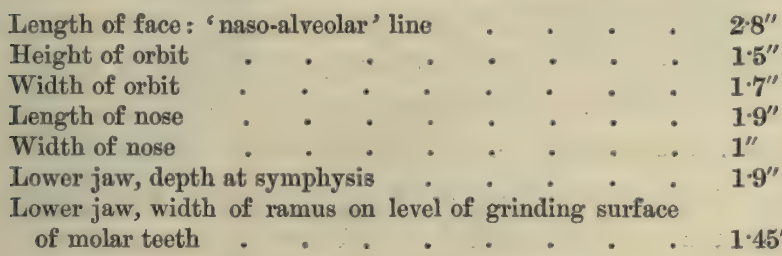

III. Indices.

Length-breadth index : 'cephalic index' . . . 71

Antero-posterior index . . . . . . . 51

Facial angle to nasal spine $\quad$. . . . . . 75

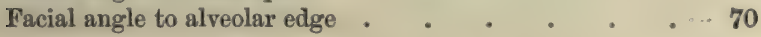

The skull 'Helperthorpe, xli. 3,' is one which, except for a certain asymmetry in its parieto-occipital region and a certain wall-sidedness in its lateral temporal regions, might have passed, if we were not acquainted with its archæological surroundings, for a modern skull. The curve described by its mesial antero-posterior contour from the moderately developed supraciliary ridges to the middle of the superior squama occipitis is much more equable than is usual even in dolicho-cephalic skulls; and the comparatively small development of the frontal sinuses and supraciliary ridges makes us hesitate in ascribing any of the retreating of the frontal region to the commencement of senile gravitation-changes. The difference between the fronto-postremal length and the fronto-inial length, measured in this case to the commencement of the linea nuche mediana, which is distinguishable from the external occipital 
protuberance, is only $\frac{1}{10}$; and the dolicho-cephaly of the skull depends upon the length of the parietal bones; the length of the parietal are, $5 \cdot 5^{\prime \prime}$, being more than half an inch over the average, whilst that of the occipital, $4 \cdot 6^{\prime \prime}$, is identical with it. The mastoids are large, the jaws orthognathous, the lower jaw well formed, lying evenly on a horizontal plane, with a bifid mentum, a long coronoid, and a square angle. The nasals are saddle-shaped, the nose in life may have been, judging from the rise of these bones distally, a 'Roman' one; but at any rate it must have differed from the all but Grecian profile given to the Celtic face in the A\&s grave ${ }^{1}$ of Rimini, a work of art of probably the fifth century B. C.

In the norma verticalis this skull presents a bluntly oval contour, remarkable for very considerable asymmetry ${ }^{2}$ on the right half of the parieto-occipital region, due probably to the mode of carriage in infancy. This distortion is less common in the dolicho-cephalic than in the brachy-cephalic variety of crania, both in ancient and in modern times. The posterior part of the sagittal and the upper part of the lambdoid sutures are extensively obliterated, both externally and internally. As in many skulls with long parietals, the apex of the lambdoid suture forms a widely open angle. The parietal tubera are well marked, and one of them is the seat of an exostosis; the walls of the skull below widen only very slightly as they pass down to the mastoids ; the point however of maximum width lies below that of the parietal tubera and on a level with the posterior and superior angle of the squamous. A dilatation in the line of an accidental fissure running about midway between the upper and lower borders of the left parietal bone marks the exact position of the parietal tuberosity of that side; which, as is the rule in skulls of this type, is seen to be both further forward and lower down than it, with the part of the brain which it covers (for which see Huschke, l.c. p. I42), would be in brachycephalic forms. The upper linece semicirculares for the origin of the temporal muscles are plainly seen above the parietal tubera.

1 See Frontispiece to Ethnogénie Gauloise, par Roget Baron de Belloguet, 1861. Sambon, Recherches sur les Monnaies antiques de l'Italie, 1870, p. 71. The backward position of the ear in this figure is nearly as clear an indication of its having been intended for a representation of a brachy-cephalic head as the torc round the neck is of its having been intended for a Gaul of early Roman history.

${ }^{2}$ For a discussion upon the mode of production of such asymmetry, see note, pp. 572, 573, supra ibique citata. 


\section{WEAVERTHORPE.}

[xliv. 3. p. 198.]

Caltaritu and lower jaW of a man probably in middie period of hife.
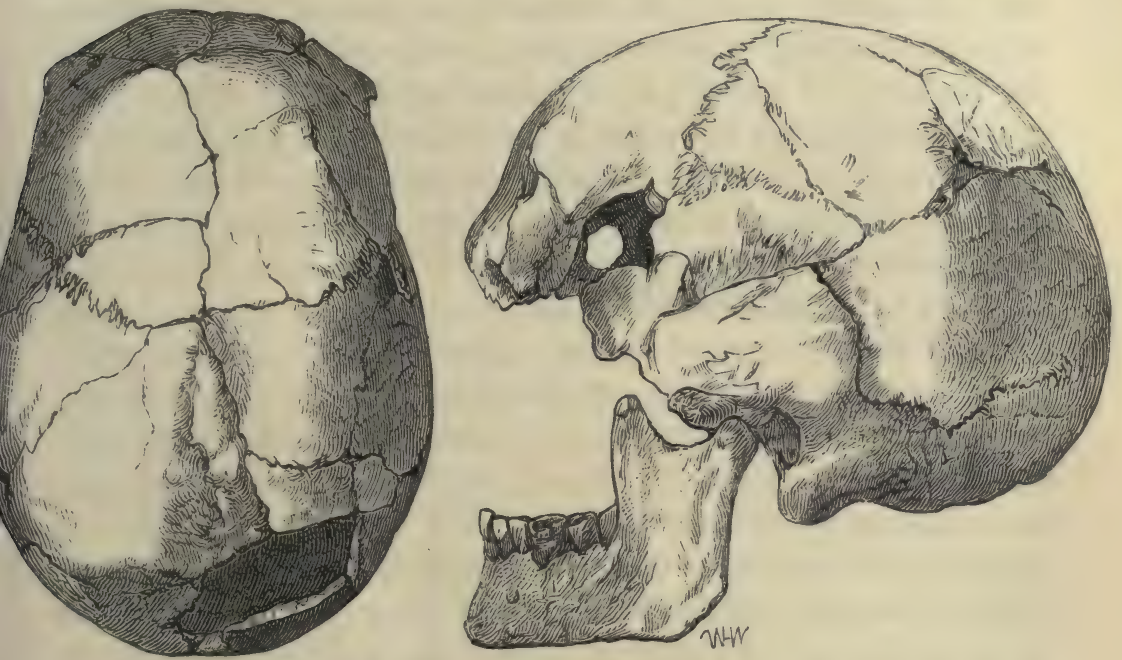

I. Measurements of Calvaria.

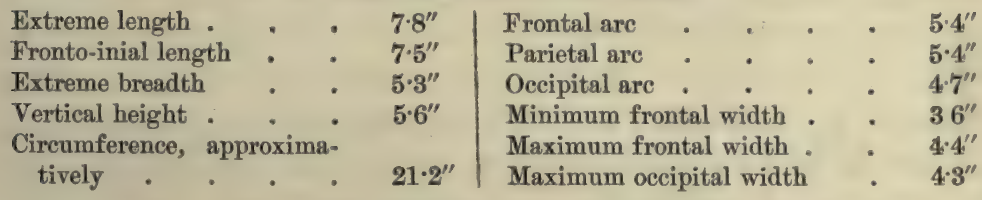

II. Measurements of Face.

Lower jaw, depth at symphysis . . . . . 1.2"

Lower jaw, width of ramus on level of grinding surface of molar teeth

III. Indices.

Length-breadth index: 'cephalic index' . . . . 69

Antero-posterior index . . . . . 53

The calvaria and lower jaw, 'Weaverthorpe, xliv. 3,' may firstly be taken to illustrate the fact that a type existed in the Bronze Period which is recognisable amongst modern Celtic populations ; and, secondly, may throw some light upon the various questions which have been raised as to the famous skull from the cave at Engis, as it resembles that skull in many important particulars. 
In the profile view we have the characteristically equable dolicho-cephalic curve, beginning after a vertical course for a short distance above the upper edge of the supraciliary ridges, and sweeping round to the centre of the superior occipital squama, which then bends downwards and forwards to a transversely running but not largely developed protuberantia externa, which is distinguishable from, though continuous with the commencement of the linea nucha mediana in a tuberculum linearum. The frontal length taken to this last point is shorter than the extreme length taken to the centre of the occipital squama by as much as $\frac{3}{10}$ ths of an inch. The mastoids are largely developed, and what is of some importance to state, as the sex of the Engis calvaria has been supposed to be female, these processes, which in the Engis specimen are only imperfectly represented, taken together with the lower jaw, which in the case of the Engis calvaria has not been identified, leave no doubt as to the sex of their owner having been male. Had this calvarium been as imperfect as is the Engis, there would have been more justification than there is in the case of that specimen for suggesting that it may have belonged to a woman. There is no doubt that the lower jaw belonging to this skull justifies us in speaking of its owner as having been a strong male subject, its angle, mentum, and coronoid being all alike powerfully developed, and its ramus showing on its lower edge the undulation anterior to its angle and the ridges on the internal surface of that area which are distinctive of muscular men. The one wisdom tooth, remaining on the left side, shows some wear from use upon its two anterior cusps, the absence however of wear upon the posterior may perhaps have been due to the absence of any wisdom tooth on the left side above, a point which cannot now be determined. The other teeth are much worn, the mastoids are very large, and, though the sutures are often very extensively obliterated in skulls of this type before middle life, their very extensive obliteration here, both internally and externally, coupled with the two other points just specified, make it safe to speak of this skull as one of a man of at least the middle period of life. In the norma verticalis this skull is seen to taper somewhat rapidly forwards from the point of maximum width which lies in the plane of the mastoids, but on the level of the upper edge of the squamous; it tapers even more rapidly backwards, as the measurement of the extreme occipital width shows when compared with the measurement of extreme width; a depression existing on either side at the 'asterion' or site of the 
posterior lateral fontanelle. The contour consequently presented by this skull when viewed from above is that described ${ }^{1}$ by Professor Daniel Wilson as characteristic of the 'Insular Celt,' and called by him 'pear-shaped' or ' coffin-shaped.'

Skulls, it may be said with truth, very closely similar to this skull and to the Engis skull have, like it, been found in caves; three strikingly like them; one from the mountain limestone cave at Llanebie in Caermarthenshire, mentioned by Dr. Buckland, Reliquir Diluvianæ, p. $166^{2}$, and filled with stalagmite; a second from a cave at Cheddar; and a third, presented by James Parker, Esq., from a small cave at Uphill, near Weston-super-Mare; all, of considerable, though, as is often the case with other objects of the same kind from the same sort of locality and deposit, of uncertain antiquity, may be seen in the Oxford University Museum. But very similar skulls are to be found in perfectly modern interments. The Engis skull has been compared by its discoverer Professor Schmerling ${ }^{3}$ and by Professor Virchow ${ }^{4}$ to Ethiopian skulls; and by other authorities to Eskimo and Australian skulls. Principal Dawson ${ }^{5}$, F.R.S., of McGill College, Canada, remarked to me of a skull of the dolicho-cephalic variety of the Red Indian race and of the Iroquet tribe from Hochelaga near Montreal, that it resembled the Engis cranium, and as this cranium has been presented to the Oxford University Museum it is available there for comparison with a cast of that famous calvaria. Resemblances so strong as are some of these should, as they are also so widely scattered over the globe, make us careful as to speaking as to the ethnographical affinities of any calvarix, or even, inasmuch as the absence or presence of prognathism varies a good deal within the limits of a single race, of skulls, until we have a very considerable number of representatives of both objects of comparison to place alongside of each other; and it may be added until we have also succeeded in bringing other lines of evidence from archæology, philology, and, when available, history, to bear upon the question.

1 Canadian Journal, New Series, vol. liv. p. 393, Nov. 1864 ; and Dr. Beddoe, Mem. Soc. Anth. London, vol. ii. p. 349.

${ }^{2}$ An account of this cave, with a figure, may be found in Mr. L. W. Dillwyn's History of Swansea, p. 52, and may be advantageously compared with M. Dupont's similar discovery near Grendon, recorded at p. 229 of his work, cit. p. 537 supra.

3 Recherches sur les ossements fossiles découverts dans les Cavernes de la Province de Liege, p. 59 seqq., 1833. Cit. Professor Huxley, Man's Place in Nature, p. 121, 1863.

4 Archiv für Anthropologie, vol. vi. p. 92, 1873.

${ }^{3}$ See also Canadian Naturalist, vol. v. No. 6, Dec. 1860. 


\section{EBBERSTON.}

[No. III.]

CALTARIA OF PROBABLT a WOMAN IN OR PAST THE MIDDLE PERIOD OF LIFE.
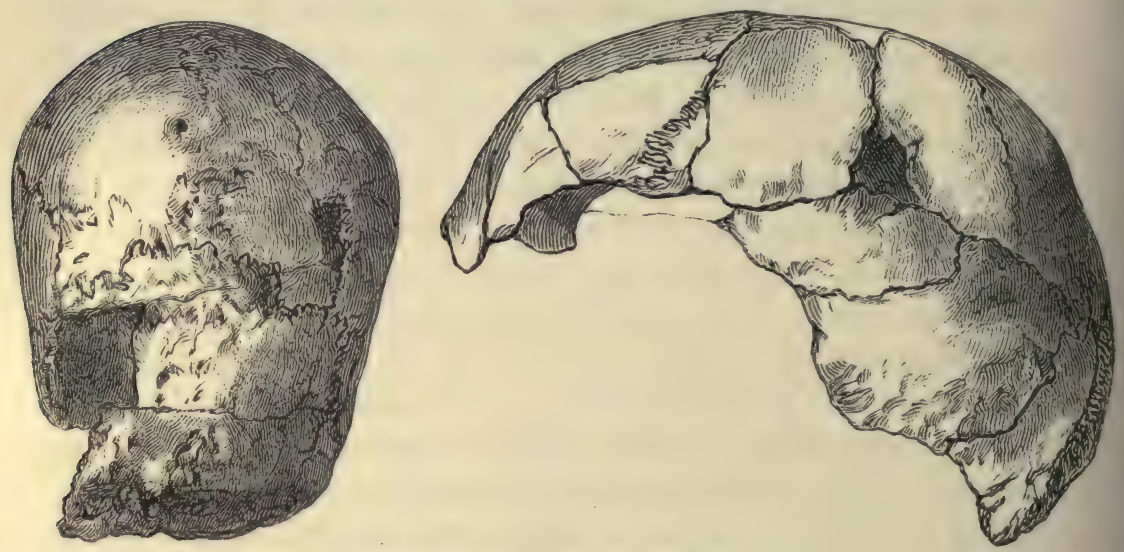

Measurements of Calvaria.

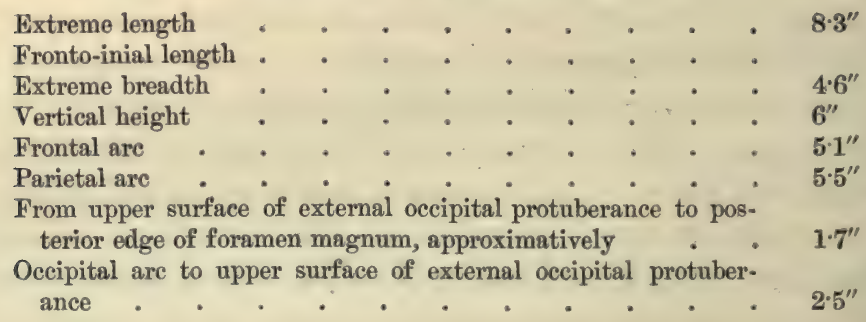

The very imperfect calvaria, 'Ebberston iii,' has been described by Dr. Thurnam in the Archæological Journal, vol. xxii. 1865, and also in the Memoirs of the Anthropological Society of London, vol. i. It has suffered very much from posthumous pressure, and the measurements given of it must be taken as being merely approximative. Still, there is abundant evidence furnished by its form in its present condition for saying that it formed part of an exaggeratedly dolicho-cephalic skull to which the name 'cymbocephalic,' proposed by Professor Daniel Wilson ${ }^{1}$ in 1850 , may very appropriately be applied. No limb nor trunk bones

1 See British Association Report for 1850, p. 142. 
have been assigned to this calvaria, and some doubt may exist as to the sex of its owner; it is most probable perhaps that it belonged to a woman. As regards the age of its owner there is also room for doubting whether the full term of 60 years assigned by Dr. Thurnam had really been attained to. All the sutures are 'ossified and nearly effaced' in some dolichocephalic skulls from long barrows and of this period, e.g. 'Rudstone, cexxiv. 1,' a skull from the same long barrow as 'Rudstone, cexxiv. 4' described above, whose owners had certainly not attained half that age. Comparatively little however need or ought in this case to be staked upon a determination of these two points of sex and age.

The denticulations of the posterior fifth of the sagittal suture can be seen in spite of the closure of the suture to have been long and complex, as they often are in these synostotic skulls; in the penultimate fifth the suture is entirely obliterated, and its course is partly occupied by a nodular exostosis, to the left of which a large foramen emissarium is to be seen; the rest of the suture is barely traceable. The squamosal suture however and its additamentum have escaped anchylosis; and the coronal suture is complexly denticulated on both sides.

The frontal bone is slightly carinate over the segment corresponding with the junction of its 'facies frontalis' with its vertical aspect. The sites of its tubera are scarcely identifiable, though those of the parietal can still be recognised. The ectorbital process which is preserved is strong, the frontal sinuses are only moderately developed.

Among the fragmentary bones from the Ebberston long barrow there came into my hands a portion of a lower jaw which combined, as jaws from these barrows not rarely do, great thickness in the molar region together with ${ }^{1}$ a feebly developed chin. If this jaw, or one equally weighty, belonged to this skull, as it may very possibly have done, we may then explain the fact of the low and retreating forehead by a reference to the principle of balance already (p. 593) referred to; a very low basis cranii may also have contributed to its formation. It may have been to skulls like this that Sir Richard Colt Hoare ${ }^{2}$ referred when speaking of crania from a long barrow at Stoney Littleton in the county of Somerset as being fronte valde depressa.

1 Also a canine with socket bifid for a doubly fanged tooth.

${ }^{2}$ Archæologia, vol. xix. p. 46, 1821. 

GENERAL REMARKS UPON THE SERIES OF PREHISTORIC CRANIA,

BY

G. ROLLESTON, M.D., F.R.S. 



\section{GENERAL REMARKS UPON THE SERIES OF}

\section{PREHISTORIC CRANIA.}

A LARGE series of skulls from prehistoric burial-places in the north of England, and chiefly in the East Riding of Yorkshire, having, together with many others from other localities, been presented to the Oxford University Museum by the Rev. William Greenwell, F.S.A., I undertook to select a certain number of these skulls for figuring and description. There is room for the addition of some general remarks to the account contained in the preceding pages 559-623 of the craniography of the skulls thus selected, a considerable quantity of additional material having come into our hands during the time which has elapsed since the commencement of this work.

A craniographer with Canon Greenwell's series before his eyes in a coup-d'ceil view would be impressed with the fact that out of the series, two sets, the one by its length typically illustrative of the dolicho-cephalic, the other by its breadth as typically illustrative of the brachy-cephalic form of skull, could at once be selected, even by a person devoid of any special anatomical knowledge. An antiquary similarly inspecting this series with a knowledge of its archæological history would, if he separated it into two groups, the one containing all the skulls of the stone and bone age, the other containing all those of the bronze period, perceive that, while the latter group comprised both dolicho-cephalic and brachy-cephalic crania and in very nearly equal proportions, none but dolichocephalic skulls were to be found in any set of skulls from the barrows of the premetallic period ${ }^{\text {. }}$.

1 Sir Wm. Wilde, in a lecture on the Ethnology of the Ancient Irish, delivered at the College of Physicians in $\mathbf{1 8 4 4}$ and originally published in the Dublin Literary Journal, promulgated the idea that two races, one dolicho-cephalic, the other a round or globular headed race, existed in that country in the earliest times, apparently simultaneously. Examples of both races, but especially of the former, he thought were still to be found among the modern Irish. The evidence before Sir Wm. Wilde is 


\section{Facts of nearly equal generality and obviousness would be pre- sented in the observation of the comparative rarity of the inter-}

given at pp. 40, 228-232 of his 'Beauties of the Boyne and Blackwater,' the second edition of which was published in 1850. In this year Professor Daniel Wilson, in a paper read before the British Association and published in the Transactions of the Sections for 1850, p. 142, put forward the following statement as to the succession of races in Scotland, in opposition to the views of Professor Nilsson which may be found in the British Association Report for 1847 at p. 31 : ' The earliest Scottish race differed entirely from the earliest Scandinavian race as described by Professor Nilsson, being rather dolicho-cephalic, or perhaps more correctly cymbo-cephalic, to adopt a term which I venture to suggest as most appropriate to the peculiar boat-like shape of the crania. ..... The second race decidedly corresponds with the brachy-cephalic of Retzius, though in the few examples I have been able to obtain the cerebral development appears considerably greater than in the primitive race of Scandinavia.' These races Professor Daniel Wilson appears to have considered to be Preceltic; and of the 'true Celtic type,' he says, 'nearly all ethnologists are agreed in assigning to it an intermediate form, shorter than the true dolicho-cephalic and longer than the brachycephalic.' These views were expounded by him at greater length in the first edition of his 'Prehistoric Annals of Scotland,' pp. 163-187, 695-696, which was published next year; cit. Nott and Gliddon, 'Indigenous Races,' p. 293. With Professor Wilson's conclusion that the earliest race in Great Britain was eminently dolicho-cephalic, and I would add exclusively so, all archæological anatomists are now agreed; and the tendency to extend this conclusion to other regions of the world's surface is now so strong as to have suggested a comparison between the progress from dolicho-cephaly to brachy-cephaly, which is taken for granted, and the gradual widening of the skull which, it is asserted, takes place between childhood and adult age in modern races. See Schaafhausen, Urform menschl. Schädels, p. 5, 1868, or as cit. Welcker, Archiv für Anthropologie, i. p. 151, 1866.

Professor Wilson's views were adopted by Mr. Bateman in his 'Ten Years' Diggings,' p. 147, published in 1861; and he himself reaffirmed them in his paper on 'Ethnical Forms and Undesigned Artificial Distortions of the Human Crania,' published in the Canadian Journal, No. xli. Sept. 1862, p. 41, and in his paper on 'Ancient British Skull Forms,' published in the Edinburgh Philosophical Journal, vol. xviii. July, 1863, p. 62 seqq.

Still Professor Nilsson's views as to the priority of the brachy-cephalic races maintained their hold upon the beliefs of the great majority of at least continental anthropologists until the publication of Dr. Thurnam's memoir on 'The Principal Forms of Ancient British and Gaulish Skulls' in 1865, in the Memoirs of the London Anthropological Society.

Professor Broca, Bull. Soc. Anth. Paris, ser. ii. tom. viii. 1873, p. 827, in his memoir 'Sur les crânes de Solutrè,' thus sums up the present state of opinion upon this question: ' En effet dans les gisements les plus anciens de l'Europe occidentale, tous les crânes sont dolicho-céphales, et dans les gisements moins anciens qui ne remontent qu’à l'âge du renne, la dolicho-céphalie est encore la règle la plus générale ; quelques faits, il est vrai, établissont qu'à cette dernière époque il y avait en outre un race au crâne plus arrondi ;' some Solutrè, like some Hungarian, skulls contravening this rule.

I do not know what foundation there may be for the statement of Professor Canestrini, given by Mr. Darwin, 'Descent of Man,' p. 39, second edition, to the effect that brachy-cephalic crania have been found in the Drift. The cranium from Olmo in the valley of the Arno, supposed to belong to the post-pliocene age, was said to be brachycephalic, but has been shown by Professor Broca to have an index of $72 \cdot 72$, i.e. to be distinctly dolicho-cephalic. See his Mémoires, Tom. ii. p. 354, 1874.

Professor Nilsson, in the third edition of his 'Primitive Inhabitants of Scandinavia,' the first edition of which was published in 1838, says at p. 121 of the English translation, edited by Sir John Lubbock, 1868, 'Some isolated brachy-cephalous crania have 
mediate forms, the 'Misch-Formen' of the German anthropologists, in the slightness and shortness of many of the limb bones of the skeletons of the earlier periods, in the very frequent appearance of a certain 'ill-filledness' in the skulls appertaining to those skeletons, and an equally frequent ruggedness in the skulls of the later ages, and finally in the presence, in both series, of skulls which, while retaining their respective type, were very much smaller than the great majority of those classified with them.

Questions of some difficulty as to the affinities of these two sets of crania to those of contemporaneous, of succeeding, and of still existing races of mankind, are suggested by an inspection of them in connexion with some other skulls; and with these questions is intimately connected the choice of the name, whether 'Iberian' or 'Silurian,' 'Brigantian' or 'Cimbric,' which we may for the sake of convenience impose upon the one or the other variety of skull.

The effects which the mode of life possible to the inhabitants of this country in the earlier and indeed also in the later of the two periods of stone and of bronze, with which we have to deal, exercised upon their bodily structure, form a further subject for thought and enquiry, the materials for the prosecution of which however, being

been occasionally found in our stone sepulchres; but it may be taken for granted that the people who constructed these sepulchres belonged to one of the dolicho-cephalous races which still inhabit the greater part of the country.'

Baron von Düben (Compte Rendu-Congrès internat. d'Anthropologie, Stockholm, 1874, tom. ii. 1876, p. 691), speaking of these brachy-cephalous skulls, says, 'Parmi les cent crânes que j'ai examinés du Danemark et de la Suède il s'en trouve une dizaine de cette forme dont 5 du Danemark et le reste de la Suède depuis la Scanie jusqu'en Vestergötlande. Ils ont tous été exhumés des tombeaux de l'âge de la pierre, les crânes sont très arrondis, très courts d'un indice allant jusqu'à 84:2. Grâce à cette forme ils contrastent au premier abord et fortement avec les autres crânes qui sont dolicho-céphales, et évidemment ils appartiennent à une race différente. Ce sont les crânes que MM. Nilsson et A. Retzius ont attribués aux Lapons ; et certainement quelques uns de ces crânes ressemblent tellement à ceux des Lapons que nos connaissances crâniologiques actuelles ne suffisent pas pour y constater des différences. Cependant d'autres faits montrent que les Lapons ont immigré par le nord de la Baltique et qu'ils n'ont jamais habité la péninsule Scandinave audessons du $62^{\circ}$. Par cette raison il faut attendre avant de décider sur ce point. Au reste si ce sont des Lapons il se peut très-bien qu'ils soient arrivés comme esclaves ou comme amis de la race dolicho-céphale établie de l'autre côté de la Baltique où vraisemblablement ont existé aux temps préhistoriques des relations intimes entre les Lapons et les races gothiques.'

As already stated, p. 589, there appear to me, so far as an examination of various casts, figures, and descriptions enables me to form an opinion, to be two forms of brachy-cephalic skulls reported to have been found in Danish tumuli of the stone period. I cannot however perceive any close resemblance between either of these forms and that of any one of several Lapp crania which the University Museum owes to the kindness of Professor Eichwald and Mr. A. J. Evans, F.S.A., of Brasenose College. See also infra, p. 665 . 
limited to the bones and teeth, are, from the point of view of a pathologist, comparatively scanty. Something has also to be said as to the sources whence the food of these races came, whether from domestic or from wild animals exclusively, or in combination with each other and with agricultural produce.

It will be convenient to begin by saying that I should speak of the crania of the long barrow period, not as belonging to the 'Iberian',' as it is becoming the fashion to style them, but as belonging to the 'Silurian' type; and the brachy-cephalic crania of the round barrow I should similarly speak of, not as belonging to a 'Ligurian,' but to the 'Cimbric' type.

Tacitus, Agricola, xi, tells us that there was a tribe of people called Silures living in the district which we know now as the South Welsh counties of Glamorgan, Monmouth, Brecknock, Hereford, and Radnor; he tells us further, as a matter of fact, that the complexion and hair of this tribe could be described as 'colorati vultus, torti plerumque crines,' words which Jornandes alters slightly, making them a little clearer but perhaps less accurate, as (Get. 2) 'Silurum colorati vultus, torto plerumque crine et nigro nascuntur.' And we know that the black-haired type of the West of England at the present day ${ }^{2}$ is shorter in stature and feebler in development, and at the same time longer in skull-form than the lighter haired and lighter complexioned variety. Therefore the longer skulls found with shorter skeletons, but in the long barrows and there to the exclusion of brachy-cephalic forms, I should speak of as belonging to this 'Silurian' type.

The brachy-cephalic skulls of the bronze period which, as already stated, are found in the round barrows mixed up with long skulls, I shall speak of as belonging to a 'Cimbric' type; firstly, because there is no doubt that a similar form of skull is found at the present day to be the skull form of the inhabitants of Denmark,

1 The earliest paper with which I am acquainted in which this name was adopted for one division of the population of Great Britain is a paper, not without its merits, by Dr. Hibbert Ware, to be found in the Proceedings of the Royal Society of Edinburgh, vol. i. March 4, 1844. Keyser, in a letter of date April 21, 1847, addressed to Retzius and published by him in Müller's Archiv, 1849, or see Ethnol. Schrift. p. 103,1864 , suggests that the Iberians may have been the primitive stone age inhabitants of Great Britain and Ireland. This stock was then considered to be Turanian and brachy-cephalic. Weinhold, who in his 'Altnordisches Leben' had called the stone-age race 'Finnish,' adopted the name 'Iberian' in his memoir 'Die heidnische Todtenbestattung in Deutschland,' published in the Sitzungsberichte d. K. Akad. 才. W. phil. hist. Cl. Wien. bd. xxix. hft. 2. p. 131.

${ }^{2}$ Dr. Beddoe, Mem. Anth. Soc. vol. ii. p. 350. 
once called the 'Cimbric' Peninsula ${ }^{1}$; and, secondly, because, as I have elsewhere pointed out ${ }^{2}$, there are other reasons for thinking

${ }^{1}$ Dr. Beddoe, Mem. Anth. Soc. vol. iii, and Handelman und Pansch, Moorleichenfunde, p. 26. The skull-form of the Danes was eminently brachy-cephalic 800 years ago also, if we may judge from the skulls of Flambard and some other distinguished ecclesiastics of the early Norman period in this country. These skulls were exhumed, and, after being measured by me, reinterred in the course of certain excavations close to the eathedral in Durham in 1874. The skulls of the Anglo-Saxon interments disturbed in these excavations were of the dolicho-cephalic type usual in that race.

${ }^{2}$ See British Association Report for 1875, Bristol Meeting, pp. 148-149, where it is suggested that in addition to the à priori probability which the fact of so many immigrations from Denmark into Great Britain having taken place in the way of invasions in historic times lends to such a view, we have some more definite likelihood given to it by the discovery in Yorkshire of monoxylic coffins with similar contents and fashion to those found in South Jutland; and by the existence in the same country of earth-works, which remind us of the 'castra ac spatia' of the Cimbri in their native land (Tacit. Germ. 37), but which have been shown by Colonel Lane Fox to have been thrown up by invaders advancing inland from the sea. I was not aware when I made these suggestions that Münch in his 'Det Norske Folks Historie,' p. 11, German translation by Claussen, 1853, had drawn an argument for the same suggestion from the words of Ammianus Marcellinus, xv. 9, relating to one of the 'Cimbric Deluges,' taken in connexion with the well-known words of the Welsh Triad, 4. p. 57, cit. Sharon Turner, History of the Anglo-Saxons, vol. i. book i. chap. ii. and iii. pp. $32,42,48$ and 49 , 7 th ed. 1852 , which say that $\mathrm{Hu}$ Gadarn 'led the nation of the Cymry first to the isle of Britain; and from the country of Summer which is called Deffrobani they came; this is where Constantinople is; and through the hazy ocean (the German Ocean) they came to the island of Britain.' Whatever may be the value of these words from the Triad, it is of importance to recollect that there are geological reasons for holding that the so-called 'Cimbrian Deluge' was but one of a series of submersions each of which may have caused an emigration. Sir Charles Lyell has recorded an opinion to this effect in his Principles of Geology, vol. i. pp. 558, 559, citing the traditions recorded by Strabo, vii. 2, and Florus, iii. 3, as to the occurrence of such catastrophes in the Cimbric Peninsula, and in 'extremis Galliæ.' Other references to the Cimbric Deluge will be found in Professor Nilsson's Early Inhabitants of Scandinavia, ed. Lubbock, pp. 252-259, in Maack's Das urgeschichtlich Schleswig-Holstein Lande, Berlin, 1860, also in Koner's Zeitschrift für Erdkunde; in Pallmann's Die Cimbern und Teutonen, Berlin, 1870, pp. 27, 28, 32, and Duncker's Origines Germanicæ, 1840, p. 99. It may be well here to give the exact words of Ammianus Marcellinus, which, as he is not referred to by Sir Charles Lyell, are not so well known to English readers as they deserve to be. Writing of the Gauls he says, xv. 9. 4, p. 56, ed. Eyssenhardt, Berlin, 1871, 'Drasidae memorant se vera fuisse populi partem indigenam, sed alios quoque $a b$ insulis extimis confluxisse et tractibus transrhenanis, crebritate bellorum et adluvione fervidi maris sedibus suis expulsos.' Münch supposes that two waves of population passed over into Britain from the Continent in prehistoric times, and that the Gael were the earlier and the Cymry were the later in order of invasion. This view, or one closely approximating to it, is the one usually taken by writers on this subject, as for example by the present Bishop of St. David's (Vestiges of the Gael in Gwynedd, p. 48, 1851), and by Niebuhr (History of Rome, vol. ii. Eng. Trans., p. 522 seqq.), Thierry (History of the Norman Conquest, book i), E. Lluyd, and to some extent by Prichard (Phys. Hist. iii. ed. 3, p. 150), cit. in loco; and O'Brien (Preface to Irish Dictionary), referred to by Prichard. Many writers have laid much weight upon the similarity of the names Cimbri and Kymry as an argument for the conclusion that the Kymry came from the Danish peninsula. Münch, for example, $l$. c., says, 'Der Name Cimbern oder Cimren für die ältere Hauptbevölkerung der jutischen Halbinsel bezeichnet diese hinlänglich ais 
the tribes who brought bronze into England, with the fashion of burning or burial in round as opposed to long barrows, may very probably have been of the same stock as the Cimbri whom we know from history.

This division in this nomenclature is proposed entirely independently of any consideration drawn either from philology or, to borrow a phrase from the Triads, from the 'hazy ocean' which they and similar documentary traditions make up. As regards philological considerations, I apprehend that it may cost some trouble to reconcile the fact that very many of the long skulls found in the

kymrisch;' and Prichard, whose other arguments do seem to me to deserve the epithet 'hinlänglich,' adds to them, l. c. p. 104, 'the name of Cimbri, corresponding and nearly identical with that of the Cymru or Cumri of Britain.' This latter name he, further on, p. 168, says on the authority of Adelung, Mithridates, ii. 157, is not altogether forgotten by the present Bretons. Professor Rhys, however, informs me that "the words "Cimbri" and "Kymry" are not related at all; if "Kymry" were translated into Cæsar"s time, it would assume the form "Combroges," to be analysed like "Allobroges," and meaning probably Compatriots. The word is unknown to the Bretons, nor can it be traced on the other side of the Bristol Channel : so I am inclined to think it was only adopted by the Welsh as their national name while under English pressure. I do not mean by this to offer any opinion whatever on the question whether the people called "Cimbri " were nearly related to the ancestors of the Welsh or not."

At the meeting of the British Association already referred to, thinking it might be of some consequence towards settling the much vexed question of the Germanic or Celtic origin of the Cimbri as known to us from the time of Marius, I gave references in parallel columns to the various more or less nearly contemporary writers who had spoken of them as Germans or Celts respectively. These references I may reproduce here.

For the Celtic origin of the Cimbri, see

Cicero, De Oratore, ii. 266.

Sallust, Jugurtha, 114.

Florus, iii. 3.

Appian, De Bell. IIl. 4.

" Bell. Civ. i. 29.

", iv. 2.

Diodorus, v."3. 2.

" xiv. 114.

Plutarch, Camillus, 15.

Dio Cassius, xliv. 4. 2.

Justin, xxiv. 8.

Orosius, v. 16.

Livy, Epitom. 77.
For the German origin of the Cimbri, see

Horace, Epod. xvi. 7.

Inscript. Ancyran. Tab. v. 16.

Strabo, vii. 1. 3.

Cæesar, De Bell, Gall. i. 40.

Velleius Paterculns, ii. 12.

ii. 19.

Tacitus, Germania, 37.

, Hist. iv. 73.

Plutarch, Marius, 11.

Pliny, iv. 28.

$$
\text { Crassus, } 9 .
$$

Mela, iii. 3.

Justin, 37. 4.

Seneca ad Helv. 6.

Most of the modern German writers on this subject, with the distinguished exception of Niebuhr (Kleinere Schriften, p. 383), claim the Cimbri as their kinsfolk. It may be sufficient to name Zeuss, D'Ukert, Grimm, Duncker (Orig. Germ. 79-92), and Dahlmann, and a monograph containing many references and other valuable matter by Dr. Pallmann, Die Cimbern und Teutonen, Berlin, 1870. Baron de Belloguet agrees with these writers; see Ethnogen. Gaul. iv. p. 87, 1873. For the Celtic origin of Cimbri we have, with Niebuhr, among English writers Prichard and Latham, among French writers Thierry, H. Martin (Sur l'Ethnogenie Gauloise, iv. p. 89, 1873), and amongst Northern writers Münch and Nilsson. The craniographer will incline to the Celtic hypothesis. 
round barrows of the bronze age lying peacefully in company with brachy-cephali are indistinguishable from very many of the long skulls found in long barrows together with implements of bone and stone (see p. 527 supra), with the conclusion drawn from the Celtic and other words signifying metal to the effect that all the Celts were in possession of metal from the first time when they came into Europe, unless we agree to speak and think of the Stone Age as Preceltic. In other words, it is of importance to keep in mind that a division of skulls into skulls of a Silurian and skulls of a Cimbric type is, probably, not coincident with that division of the Celtic race into Gaels and Cymry which is, I suppose, the division usually adopted by historians and literary antiquarians. The race which used stone and bone implements may, so far as the naturalist's investigations teach him, have spoken either a Turanian or an Aryan tongue; what he sees in their skulls and their surroundings impresses him with the notion of an antiquity which may have given time enough and to spare for the more or less complete disappearance of more than one unwritten language. The bronze period again, though its term of duration in these islands was no doubt almost infinitely shorter than that of the stone and bone age, or rather ages, was yet long enough, as the antiquary may assure the philologist, to admit of quite as great a differentiation in any single language as that which exists between Gaelic and Cymric at present, or to allow of the importation of more than one already differentiated dialect in more than one not recorded invasion. But if the bronze age may have been of very long duration, and if the stone and bone age as represented to us in the long barrows may have been of very much longer, the antiquary who may have explored one of these latter tumuli on a hill, the sides and bottom of which may contain in their gravels the implements, if not the bones, of still earlier races, knows and feels that in dealing even with human phylogeny, he has to keep constantly in mind in all his speculations that the permutations and combinations of races possible in such lengths of time are conceivably and even practically infinite. The consideration of distance in space when we are dealing with a question of geographical distribution is inseparably connected with the consideration of length of time, and the great interval of space which separates Spain from Great Britain should make us careful as to borrowing a name from the tribes of one of those countries and imposing it upon a tribe in another without the most definite historical or archæological reasons. 
Without going into the arguments which the Rev. Wentworth Webster has (see Journal Anth. Inst. London, v. p. 5, July, 1875) brought forward against the view which would identify the Basques with the earlier dark-haired dolicho-cephali of Great Britain, it may be well to state the history of the opinion which connects certain Welsh and Irish inhabitants of Wales and Ireland with the Iberian inhabitants of Spain. This, so far as I have been able to make it out, is as follows. Tacitus, in the eleventh chapter of his Agricola, says with reference to the Silures that their 'colorati vultus,' their 'torti crines,' and 'posita contra Hispanica, Hiberos veteres trajecisse easque sedes habitasse fidem faciunt.' The boldness of this suggestion contrasts strongly with the caution of the opening sentence of the same chapter, 'Ceterum Britanniarum qui mortales initio coluerint indigence an advecti, ut inter barbaros, parum compertum;' nevertheless, Jornandes, as quoted p. 630, and Irish and Spanish histories and traditions are constantly (see, e.g., Professor Morley, English Writers, 1867, vol. i. pt. i. p. 159) referred to as agreeing in asserting that the Irish Gael came from Spain; and it is even added, as if the process had been actually observed in the Bay of Biscay, that 'by means of their small ships, slowly and in the course of years, the Spanish Gaels colonised Ireland and our western coasts.' It seems obvious enough that what is thus put forward as a consensus of evidence means merely that a number of inferior writers repeated, as is so often the case, with particular emphasis and increase of precision one of the very few rash suggestions which a really great writer may have made ${ }^{1}$.

I Prichard, Phys. Hist. iii. 108, who speaks of Tacitus as having been 'under the mistake of supposing Spain to be opposite to South Wales,' and of 'undue stress' having been laid by various writers, including Niebuhr, upon 'the idea of attributing an Iberian origin to the Silures,' seems to think that it was not his 'deliberate opinion that the Silures came from Spain.' A good deal depends upon the reading of the over-terse phraseology of the historian; I incline to think that by the words 'proximi Gallis et similes sunt' Tacitus meant to indicate that a third division of the inhabitants of Great Britain, in opposition to the Caledonians and the Silures, was constituted by those inhabiting the south-east corner of the island, next to Gaul, of whom Julius Cæsar had spoken in a parallel passage, B. G. 5. 14. If this be the true meaning of those five words, the words which Prichard refers to as qualifying the suggestion as to the Silures, ' in universum tamen astimanti Gallos vicinam insulam occupasse credibile est,' would not really have any relation to them. Zeuss, Die Deutschen, p.202, is as distinctly condemnatory of his suggestion as is Prichard: 'Mit eben so ungenügendem Gründen wie die Völker von Caledonien von Germanien werden diese Silures von 'Tacitus von den Iberern abgeleitet.' As regards the Irish tradition of a connection between Ireland and Spain, Professor Rhys writes to me to the effect that it is not a genuine tradition at all but only an etymological one, all turning on $(\mathrm{H})$ iberus and Hibernus or Gallicia and Gael. 
The duality of type presented to us by the intermingling of dolicho-cephali and brachy-cephali in the interments of the bronze period has been continued down to the present day amongst the inhabitants of Wales and some other Celtic localities in forms which, however real, are yet happily compatible with their occupying the same area both in life and after death. The present Bishop of St. David's, in his book, 'Vestiges of the Gael in Gwynedd,' 1851, pp. 72, 73, whilst accepting the usual philological and physiological arguments against the singleness of origin for the entire British population of Wales, adds certain evidence, based upon the differing moral phenomena manifested at the present day by the inhabitants of the Principality in the form of mutual repulsion and dislike, which points in the same direction. For this the reader may be referred to his book. A similar history is given by Professor Broca of the inhabitants of le pays de Leon and le pays de Cornouaille in Brittany (Memoires de la Société d'Anthropologie de Paris, tom. i. 1860, p. 21), and readers of other French writers on Ethnology are abundantly familiar with the question of la dualité gauloise ${ }^{1}$.

Against calling the brachy-cephalic people of the round barrow and bronze period by the name of the Ligures, a people so much and, probably, so unjustly abused by the ancient Latin writers, arguments of the same general kind as those already brought against calling the dolicho-cephali of the stone age Iberians might be adduced at considerable length. It is however superfluous to do

1 It may be well to supply evidence from times intermediate in date between the present and the bronze age to show that, whatever proneness the Celtic race and its subdivisions may, as testified to by the two authors just cited, manifest to quarrels and disagreements of a minor kind, they have in practice found it more possible to make such differences compatible with joint occupation of the same country than have some other races. Diodorus Siculus, v. 33, cit. Zeuss, p. 163, writes thus of the

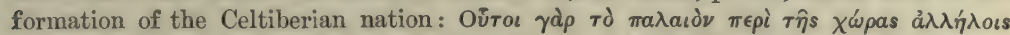

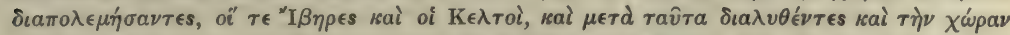

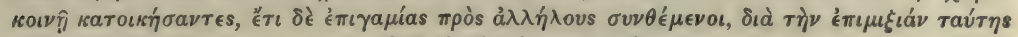

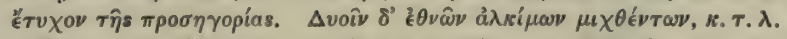

The words of Skylax, cit. Zeuss, p. 167, respecting the Ligurians and Iberians are similarly to the purpose: 'A

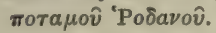

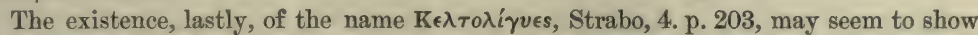
that a fusion was effected between the Celts and the Ligurians similar to that which was effected between the Celts and the Iberians. The earlier relations between the Celts and the Ligures are represented in tradition to the following effect in the lines of Avienus, Ora Maritima, v. 432:-

$$
\text { ' Cespitem Ligurum subit }
$$

Cassum incolarum, namque Celtarum manu

Crebrisque dudum proliis vacuata sunt

Liguresque pulsi.’ 
this, as the brachy-cephali for whom the name 'Ligurian' has been proposed of late by the Baron de Belloguet ${ }^{1}$, Herr Hölder ${ }^{2}$, M. Léon Vanderkindere ${ }^{3}$, and Professor S. Nicollucci ${ }^{4}$, are short of stature and dark of complexion, whereas the brachy-cephali with whom we have to deal were certainly tall, and all but equally certainly light in hair and complexion.

The skulls from the earlier British barrows have been stated to be invariably dolicho-cephalic, whilst the skulls from the barrows of the bronze period, though in some cases exclusively brachycephalic, may belong to either one or other of these two types. The few skulls which I have been able to examine or to read of from interments of what is called the late Celtic period, the period intervening between the close of the bronze age and the establishment of the Roman power in this country, have been dolichocephalic, a fact which may be explained either by a reference to the well-known persistence with which 'les types autochthones survivent à la domination étrangère et au mélange des sangs ${ }^{5}$,' or, though with less probability, by the hypothesis of a preponderance having been given in this iron age to the still surviving dolichocephalic stock in the way of invasions from the continent. The dolicho-cephalic late Celt however differed probably from the dolicho-cephalic inhabitant of these islands in the stone age in being light- instead of dark-haired ${ }^{6}$. See pp. 658, 683 infra.

1 Ethnogenie Gauloise, cit. Virchow, Archiv für Anthropologie, vi. p. 107, 1873.

2 Archiv für Anthropologie, ii. p. 56, 1867. In his Zusammenstellung der in Württemberg vorkommenden Schädelformen, 1876, p. 8, Herr Hölder has given up the title 'Ligurian,' and replaced it by the titles 'Turanian' and 'Sarmatian.'

${ }^{3}$ Recherches sur l'Ethnologie de la Belgique, p. 58. The skulls, with a cephalic index of 85, described by Dr. Sasse from South Beveland, Archiv für Anthropologie, vi. p. 76, had a cubical content of 1323 cub. centim. = about 80 cubic inches, as against an average content of 98 cubic inches obtained by Dr. Thurnam from twenty-five British brachy-cephali. Probably this inferiority was correlated with an additional inferiority in the matter of stature.

- Le stirpe ligure in Italia, Napoli, 1864.

s Broca, Mémoires, i. 340, 341.

- Broca, Bull. Soc. Anth. Paris, ser. ii. tom. viii. Avril, 1873, p. 319, says that certain districts of modern Brittany, in which the British refugees from the Saxon invasion of the fifth century settled in great numbers, are still distinguished by the tallness, light complexion, and dolicho-cephaly of their inhabitants. He calls this stock ' Kymrique,' in the application of which word I differ from him. Similarly, at least as to the cephalic index, certain interments from the period of transition from bronze to iron described by Kopernicki, cit. Ecker, Archiv für Anthropologie, ix. p. 118,1876 , as examined by him in South-east Galicia, were found to furnish skulls 'exquisite orthognathe dolicho-cephalen' (C. I. =73), contrasting strongly with the pronounced brachy-cephalism $($ C. I. $=81)$ of the modern Ruthenian inhabitants of that district. 
It is undoubtedly an important fact that in no skull from any long barrow, that is to say, in no skull undoubtedly of the stone age, examined by us, has the breadth been found to bear so high a relation as that of $80: 100$ of the length; for this alone would suffice to show that Retzius's classification of skulls into two great divisions of dolicho-cephalic and brachy-cephalic cannot, even when taken to connote merely the strictest geometrical proportions, be summarily set aside as an artificial one. But, as Professor Cleland has well pointed out in a memoir (Philosophical Transactions, 1870, vol. 150, p. 145), the value of which is in the inverse ratio of the attention it has received, at least from foreigners; by 'dolicho-cephaly' and 'brachy-cephaly' respectively, Retzius intended that much more should be connoted than that 'ordinarily the longitudinal diameter of the dolicho-cephalous skull surpasses the breadth about one fourth, while in the brachy-cephalous the difference varies between a fifth and an eighth ${ }^{1}$.' I propose here to enumerate the various points, mostly, though not entirely, those specified by Retzius, which characterise the two sets of dolicho-cephalic and brachycephalic crania with which I have here to deal, besides and beyond those which are etymologically implied by these names; and having done this I shall attempt to give some rationale of the existence of these differences.

The peculiarities of the contour of the brachy-cephalic crania already described have been repeatedly alluded to above, pp. 571601 ; of these peculiarities the most important as well as the most constant is, I incline to hold, the relation held by the posterior aspect of the skull to the plane of the parietal tubera. In the brachy-cephalic skull the parietal tubera are usually situated high up on the sides of the skull, and almost invariably the profile

1 Retzius confined himself to this binary division of skulls, and I have in the foregoing Description of Skulls followed his example in this matter. Other writers have made many subdivisions of the two primary divisions of Retzius, which may be seen given in a tabular form by Ihering, Zeitschrift für Ethnologie, bd. v. 1873, p. 12. The subdivision suggested by Ihering himself, p. 141, has claims upon the attention of those who wish for additional subdivisions constituted upon the principle of actually existing proportions. He proposes to call

Skulls with a relation of breadth to length of 80 and upwards, 'Brachy-cephalous.'

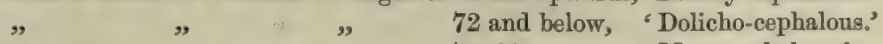

72-80, 'Meso-cephalous.'

And of 'Meso-cephalous,' those with index from 72-76, 'Meso-dolicho-cephalous.'

" " " 76-80, 'Meso-brachy-cephalous."

A far more important subdivision has been suggested by Professor Cleland, $l$. $c$. p. 148, whereby each of the two primary divisions would be subdivided according as they are 'latiores' or 'angustiores,' whilst retaining the contour characteristic of their respective types. 
line of the vertical arch as viewed in the norma lateralis dips into the posterior aspect of the skull at a point very little behind the plane of these tubera. The skull, in other words, and from another point of viewing it, that namely of the norma verticalis, rounds itself off somewhat abruptly from the level of the parietal bosses, instead of tapering as in the other type somewhat gradually towards the squama occipitis. This latter portion of the posterior aspect of the skull is not, as usually stated, by any means invariably flat; it is, on the other hand, very frequently markedly convex, the more markedly so, of course, on account of the flattening of the parietals to form the dip into the back aspect of the skull. As above pointed out in the description of the skull 'Cowlam' (lix. 3, p. 226), p. 589, note 2, the occipital squama may so project as to constitute what has been called a 'capsuläres Hinterhaupt' in typically brachy-cephalic crania. In casts of such skulls the parts of the brain which were lodged in the fossæ of the superior squama occipitis may be seen to project as well defined mamillary out-growths beyond the plane of the curve of the upper part of the posterior aspect of the cerebral lobes, and to overlap the cerebellum proportionately ${ }^{1}$. Now it was shown long ago by Huschke (in his Schädel, Hirn und Seele, 1854, p. 142), and has been repeatedly confirmed since by other investigators of the relations of the brain to the brain-case, that the parietal eminence covers a particular lobule in the brain beneath it, the lobule, to wit, which is called by Gratiolet in his better known ${ }^{2}$ Mémoire sur les Plis Cérébraux, p. 60 , the 'lobule of the marginal convolution;' and which is called by Huschke, l.c., the 'lobulus tuberis.' Similarly Huschke (pp. 62 and 142) pointed out that a particular part of the brain was limited

${ }^{1}$ See p. 573, note, supra, and compare figure of skull from Wetton Hill Barrow, Cran. Brit. xiv. pl. 12, and pl. 16 and 27 : and in 'Crania Helvetica,' E. xvi. and xvii.

${ }^{2}$ Huschke, owing to certain faults of style and arrangement, and also to his investigations of facts being very largely interlarded with questionable philosophy, has not obtained all the credit which his laboriousness merited. Besides allocating the lobulus tuberis, and the occipital lobes proper, to particular parts of the skull, he also defined the true position of the fissure of Rolando relatively to the coronal suture, p. 139, and that of the superior frontal gyrus relatively to the frontal tubera, p. 154, in the same year in which Gratiolet, l.c.p. 101, wrote as follows : ' La boite crânienne forme une vaste et libre cavité. C'est une voûte sons laquelle les plis et lobes cérébraux s'avancent, se reculent, s'étalent, se resserrent, s'écartent, se refoulent; ces mouvements, n'ayant aucune relation absolue avec les éléments dont cette voate se compose !'

Huschke's own countrymen, to whom his writings must be easier reading than they are to readers of other nationalities, have not always rendered him full justice. Professor Meynert however forms an exception to this rule; see his paper on Die Windungen der convexen Oberflache des Vorderhirns, Archiv für Psychiatrie, bd. vii. hft. 2. 
in front by a line corresponding to the upper part of the lambdoid suture, and, similarly, subsequent writers have coincided with his observations. There is of course no greater à priori improbability attaching to the view, that as fixed a relation should subsist between particular parts of the cerebral hemispheres and the bony capsule thrown over them as every one knows to subsist between the various factors of the dental series and the maxillary and intermaxillary bones respectively of a marsupial or a placental mammal. The fact however, when demonstrated, gives a fresh interest to cranioscopy, and I shall revert to it further on, p. 666 et seqq. infra.

The conceptacula cerebelli in the brachy-cephalic type are said by some authorities ${ }^{1}$ to take a more vertical direction than they have in the dolicho-cephalic; and they are also supposed to be more ${ }^{2}$ globose externally in female than in male skulls. An examination of the strong male skulls of the bronze period bears out neither of these views. It is true that such skulls may have the lower part of the occipital bone flat and semivertical, but they often have the convexity downwards of the inferior squama occipitis as marked as we sometimes see it to be in skulls of feebler texture in which it might be considered to be a 'déformation plastique, ${ }^{3}$, and to be due to downward pressure of the superincumbent brain. And this convexity of the conceptacula cerebelli, when viewed in the light which Professor Cleland ( $l . c$. pp. 136, 162) has thrown upon the extent to which 'gravitation changes' can remodel the cranium after adult life has been reached, may very reasonably be considered to be due, in some measure at least, even in this robust type, to the operation of the same downward pressure. Be this as it may, the convexity of the inferior occipital squama of the British brachy-cephali, a peculiarity which would not have been visible to the eye during life, is, if not correlated with, at any rate accompanied very often (see p. 601 supra) by another peculiarity, which must have been eminently striking in their living heads, to wit, their great relative height, which has been called 'hypselocephaly,' or 'acro-cephaly,' and must have put them into sharp

1 Cleland, Phil. Trans. 1870, p. 147. Thurnam, Principal Forms, p. 37.

${ }^{2}$ Welcker, citing J. B. Davis, A. A. i. 126, 1866, per contra Huschke, l. c. p. 21, says:- Die fosse cerebelli der Hinterhauptsschuppe beim Manne weit ausgegrabener sind und daher aiisserlich mehr hervorragen als die weiblichen welche, wie im Kinde mehr horizontal liegen.'

${ }^{3}$ The true 'deformation plastique' of Dr. B. Davis I have never seen in these series. 
contrast with the 'tapeino-cephalic ${ }^{1}$ ' or 'low-lying' heads of at least the female descendants of the long-barrow people who were still living amongst them. It puts these skulls into a similar position of contrast when compared with most of those of the dark-haired brachy-cephalic stocks now existing in Europe; and, taken together with their much larger cubical capacity, with the greater stature, and with the different complexion of their owners, it shows us that we have to deal, if not with two exceedingly different races of men, at least with two exceedingly different sets of individual men ${ }^{2}$. But we must never lose sight of the fact that in dealing with a series of skulls from these prehistoric barrows we are all but certainly dealing with the skulls of a set of individuals from the upper classes of times when members of those classes were, as are the chiefs of many modern savage races, from the operation of one or both of two causes, larger and more powerful, and pro tanto ${ }^{3}$ larger-brained men than were the mass of the population.

${ }^{1}$ For the use of this word see Professor Busk, Journ. Ethn. Soc. Lond. vol. ii. pp. 467, 468, where it is suggested that tapeino-cephaly may indicate lowness of type among ancient as it does among the modern Bushmen and Tasmanian races.

2 The average cubical capacity of the ancient British brachy-cephali, as given by Dr. Thurnam, is 98 cub. in., as against 94 cub. in. for modern English skulls; as against 80 cub. in. (=1323 cub. cent.) obtained by Dr. A. Sasse for a series of probably comparatively recent brachy-cephalic skulls, with an index of 85 , from South Beveland, Archiv für Anth. vi. p. 76, 1873; as against an average of about 90 cub. in. (=1480 cub. cent.) for the modern Parisian skull, with an index of about $\cdot 79$; as against an average of $83 \mathrm{cub}$. in. $(=1377 \mathrm{cub}$. cent.) for the Disentis type of His and Ruitimeyer, with an index of 86 , which includes most of the modern inhabitants of Switzerland, together with some skulls of Roman, if not of earlier times; as against an average of $89 \mathrm{cub}$. in. $(=1478)$ for the modern Roumanians, with an index of 82 ; as against an average of $92 \mathrm{cub}$. in. (=1521 cub. cent.) for the modern German (Weisbach); and as against an average of $80 \mathrm{cub}$. in. for modern Red Indians. Herr Hölder, in his earlier paper, Arch. für Anth. ii. p. 55, 1867, gave for his 'Ligurian' type, with a cephalic index of from 84 to 90 , a cubic capacity varying from 79 cub. in. (= 1300 cub. cent.) to 97 cub. in. (=1600 cub. cent.). In his monograph published last year the two types 'Turanian' and 'Sarmatian,' into which the single form 'Ligurian' is divided, are both said to have their height less than their breadth.

${ }^{3}$ One of these causes was no doubt their possession of a greater command of the material comforts of life; the other was the necessity which a wild tribe under a severe struggle for existence had for putting itself under the guidance of the ablest men it could find. A statement as to the operation of the first of these verce causse is given us by Bastian, Ethnologische Forschungen, i. 335, on the authority of Logan as to Scotland, to the following effect: 'The common Highlanders from hard and often scanty fare are usually inferior in stature to the chiefs and better sort.' A statement as to the operation of the second as to Africa is given us by Mr. F. Galton in his 'Hereditary Genius,' p. 339,1869 , in the following words: 'A native chief has as good an education in the art of ruling men as can be desired; he is continually exercised in personal government, and usually maintains his place by the ascendancy of his eharacter shown every day over his subjects and rivals.' Professor Daniel Wilson says (Canadian Journal, March, 1863, p. 151): 'I assume the unimpaired 
In dealing with a series of modern skulls we are not so dealing with the skulls of the upper classes only; but ordinarily just the reverse.

This source of fallacy however does not vitiate the comparison to be instituted between the tenants of the long barrows and the more recent but still prehistoric tenants of the round ones. Indeed, as regards the point of social superiority, the larger cubical bulk of many of the long barrows relatively to the number of skeletons contained in them would seem to indicate that the owners of these skeletons had been during life, and indeed after it, in a position to command more of the labour of their fellow-men than the men of the bronze period. And there is no doubt that some of the earlier, or indeed as the Les Eyzies skull, with a cubic capacity of 100", reminds us, earliest skulls can compare favourably with the very largest of the bronze or indeed of any other age. Dr. Thurnam's measurements gave him an average of 98 cub. in. for the British brachy-cephali as against 99 cub. in. for the older race; and the largest prehistoric skull which I have been able to cube was a woman's from the stone age excavations at Cissbury ; see Journal of Anthrop. Institute, vol. vi. p. 35, 1876. Nevertheless, with my unhappy knowledge of the very large number of skulls from all prehistoric tumuli which are not recovered in a condition admitting of cubage, and for other reasons to be gathered from what has been said above, I feel that the result of the application of the method of averages to the question of the relative cranial capacity of the two prehistoric races under comparison is eminently unsatisfactory, as being eminently amenable to the question, Ubi sunt illi qui perierint? And I must express it as my distinct conviction, that if we could have before us a more fairly representative series of each of the two varieties of prehistoric crania in question than their social habits and the wear and waste of many centuries of lying in stony graves have left us, we should find that the bronze brachy-cephali had been not only the taller and stronger bodied, but also the larger skulled ${ }^{1}$

intellect of the Nasqually chief from his rank.' For further evidence as to one or other of these lines of action see the Göttingen Report of Zusammenkunft einiger Anthropologen in 1861, at p. 21; in the British Association Report for 1875, p. 150; Förster's Observations, pp. 229, 410; Ellis, Polynesian Researches, i. 82, ii. 26; Tour through Hawaii, p. 7; Erskine's West Pacific, pp. 155, 240; Brenchley, Cruise of the Curacoa, 1873, p. 137; Whitmee, Contemporary Review, Feb. 1873, p. 392 ; Journal Anthr. Institute, vol. v. p. 127, Oct. 1875; Moseley, H. N., ibid. p. 36, May 1877.

${ }_{1}^{1}$ For the purposes of a comparison made upon such a basis it would be safe to take the largeness of the skull as furnishing a measure of the largeness of the brain it 
and larger brained race of the two. The well-filled character of the typical brachy-cephalic skull is nowhere and no way better shown in a single view of it than in the norma occipitalis, where in spite of the well-developed tubera parietalia it is rare for any very marked convergence of the lateral walls of the pentagon to be observable.

The forehead of a brachy-cephalous skull is sometimes vertical, sometimes, and especially in cases where the whole skull and skeleton are marked by great strength or even ruggedness, it is markedly sloping. It has been well remarked by Professor Cleland, l. c. pp. 163 and 138, that it is 'a grave mistake to predicate deficient development of the anterior lobes of the brain from a retreating forehead or great development from a vertical forehead without reference to the rest of the form of the head.' And in a preceding page (p. 160) he has pointed out that to secure the balancing of the head on the vertebral column, when the anterior lobes of the brain and the bones of the face increase in weight, without any unnecessary or constant call upon muscular force, a certain amount of 'tilting or rotation backwards' is mechanically necessary, and is physiologically effected. Another explanation has been given ${ }^{1}$ of the sloping of the forehead by supposing it to be caused by increase in length of the basicranial axis, and a consequent throwing forward of the lower half of the frontal bone; and, as Professor Cleland has himself pointed out, l.c. p. 124, a long base line is eminently characteristic of the skulls of uncivilised nations. But though the operation of this cause may account for the retreat of the forehead in the heads of some dolicho-cephalic races, as also for the readily observable fact that in male skulls even of eivilised races a sloping forehead is much more common than in female skulls, in which (see Cleland, p. 125, l. c.) the growth of the base line ceases much earlier, I do

contained. The thickness of the skull-walls to be estimated by weighing the skull or, by preference here, the calvaria, would probably not differ very much, and, if at all, to the disadvantage, I incline to think, of the brachy-cephalic type. Allowance would of course have to be made for any difference set up either by the removal of organic matter or by the infiltration and deposit of inorganic salts of iron or of lime. It may be true, as Professor Bischoff has shown, $l . c$. pp. 36, 45, that extraordinary individual variations in the brain-weight may be noted in brains from skulls with the same circumference, and that no fixed relation can be affirmed to exist between the variations of brain-weight and those of cubical contents as measured by other than brainsubstance; but this want of concomitance would be as likely to occur in the one as in the other set of subjects of comparison.

1 Welcker, Wachsthum und Bau, p. 76. 
not think that it accounts for the obliquity so often observable among the British brachy-cephali. In them I incline to consider it as the result of counterpoise to their heavy lower jaws ${ }^{1}$. Many of the bronze period skulls with sloping foreheads are yet skulls

1 It is interesting to reproduce here some remarks on this subject made nearly forty years ago by a French writer, M. Lafargue, in a journal the early volumes of which I have had some difficulty in getting access to, and procured ultimately from the library of the Royal College of Physicians. They run as follows (Archives Générales de Médécine, iii. 2, 1838, p. 135): 'Etant données des mâchoires volumineuses et saillantes la totalité du crâne se porte specialement en arrière en se distribuant avec uniformité autour de l'axe s'il est allongé comme chez le nègre, en se concentrant à l'extremité postérieure de cet axe s'il est raccourci comme chez le Calmouk et le Malais.'

P. 137. 'Les crânes des différentes races humaines trouvent comme on voit la raison de leurs formes dans les proportions respectives de la face et du cerveau et dans certaines conditions d'équilibre qui varient avec ces proportions.'

The following remarks deserve attention for their bearing upon some wider questions, as well as upon the particular one referred to in the two preceding ones.

P. 141. 'Il resulte de ce qui procède que la forme du crâne des différentes variétés humaines a deux significations réelles: l'une se rapporte à certaines conditions d'équilibre, variables suivant la proportion de la face au cerveau; l'autre exprime le degré de perfection intellectuelle et morale, en indiquant le volume de ce dernier organe. Mais la cérébroscopie comparée ne justifie pas les trois grandes localisations phrénologiques.

' Si l'on compare entre eux les sujets de la même race, on trouve un grand nombre de faits exceptionnels qu'il est nécessaire d'apprécier, avant d'examiner le système de Gall dans son application anx individus de la race blanche.

' L'intelligence et le moral sont d'autant plus complets que le cerveau l'emporte davantage sur la face: telle est la loi qui resulte de la comparaison des espèces animales aux races humaines, la loi dont Camper, Daubentin et Cuvier ont reconnu la réalité. Quelques hommes plus logiciens qu'observateurs pensent que le volume absolu de l'encéphale détermine seul la puissance intellectuelle; que deux individus dont les hémisphères sont égaux doivent manifester la même capacité, bien que l'un d'eux l'importe sur l'autre par le volume des mâchoires : car, ajoutent ils, ce volume n'a aucun rapport avec les fonctions de l'encéphale. Les raisonnements a priori se brisent contre les faits, et le rapport direct des facultés avec la masse, non pas absolue, mais relative des hémisphères est un fait d'histoire naturelle, un fait assez constant pour établir une loi.

'Cette loi, franchement exprimée par les caractères généraux de chaque type, ressort encore de la comparaison des individus de la même race; ainsi, dans la variété blanche, il est bien reconnu que les hommes supérieurs ont le plus souvent un crâne bien développé et des mâchoires peu saillantes; qu'au contraire, le plus grand nombre des hommes simples, obtus ou idiots se distinguent par l'étroitesse de la cavité cérébrale, et par la proéminence de la face, signe proverbial de stupidité.

' L'angle facial, expression de cette proéminence, a de tous le temps fixé l'attention des sculpteurs et des physionomistes. Telle est la règle : voyons les exceptions. Si beaucoup d'hommes éminents, comme Gall, Cuvier, Bacon, se distinguent par un cerveau très développé, un large front, une face petite et verticale, quelques autres, comme Mirabeau, Buffon, ont le crâne étroit, le front fuyant, et les mâchoires très prononcées. Au contraire, on voit assez souvent des individus remarquables par le développement du crâne, par les proportions harmoniques et la beauté de la face, manifester néanmoins une déplorable incapacité. Leurs traits immobiles ou niaisement expressifs, leurs yeux mornes ou pétillants d'une joviale nullité, concourent à démentir la noblesse du front. Peut-on attribuer l'infériorité de ces hommes au vice de l'éducation, si celle-ci a été la même pour eux que pour les autres?' 
of large capacity, and we have no reason for doubting that their owners may have been, as men with such foreheads often are now, persons at once of considerable intellectual and of considerable physical power. It is not easy to understand why in some cases we should find brachy-cephalic skulls with fairly powerful lower jaws maintaining nevertheless the same or nearly the same verticality of forehead which characterised them in childhood and early boyhood. It is obvious however that in cases such as these ${ }^{1}$, the length of the base line of the skull remaining as it does practically the same, or differing by merely the tenth of an inch or so, and the length of the frontal, parietal, and occipital ares, which make up the cranial vault resting on this base line, remaining also practically constant, the position of the true vertical line of the cranium must, as already mentioned (p. 559 note), change its position relatively to the coronal suture. And with this change there must have followed during life a somewhat different mode of carriage of the head relatively to the horizon, a difference observable enough in living heads at the present day.

As regards the characteristics of the facial skeleton, I find my observations upon the brachy-cephali of the East Riding of Yorkshire in entire accordance with those given picturesquely as well as scientifically of the facial characters of the brachycephali of the South-west of England by Dr. Thurnam in his papers in the Memoirs of the London Anthropological Society, vols. $\mathrm{i}$ and iii, 1865-1869. Distinctive as must have been the characteristics already pointed out of the living calvaria and its hairy scalp, the characteristics of the living face, from the supraciliary ridges to the chin and transversely from one cheek bone to the other, must have put the men of the round barrow time into even sharper contrast with the surviving descendants of the men of the stone and bone ages. The eyebrows in the powerful men of the later period, if developed at all in correspondence with the large underlying frontal sinuses and supraorbital ridges, must have given a beetling and probably even forbidding appearance to the upper part of the face, whilst the boldly outstanding and heavy cheek bones must have produced an impression of raw and rough strength and ponderosity entirely in keeping with it. Overhung at its root, the nose must have 
projected boldly forwards, not merely beyond the plane of the forehead, but much beyond that of the prominent eyebrows themselves. In some cases, but not by any means in so many as might à priori have been expected, the somewhat lengthy upper jaw had its anterior or incisive segment projecting so as to constitute alveolar prognathism, whilst the sockets of the caninés and those teeth themselves attained such a development as to give a somewhat square appearance to the jaw when viewed from in front. The lower jaw, which in every well-marked variety of the human species contributes very importantly towards the making up of its distinctive character, was in the brachy-cephalous Briton usually a very different bone from the lower jaw of his Silurian predecessor. Its chin was prominent, and contributed a greater proportion to the entire depth of the bone in front than the alveolar portion. Its ramus might not be thicker and stouter than the ramus of the other variety with which it is compared, but as the eye follows the lower line of two such lower jaws along to their angle the superior strength of the later type is made manifest, not merely by the muscular markings and eversion of the angle, but by the much greater width of the entire bone at this point.

We may now pass from the brachy-cephalic British skull of the bronze period, leaving some of its minor characteristics to be gathered in the way of contrast from the ensuing general description of the dolicho-cephalic variety, and summing up the general impression which an inspection of a series of such skulls makes upon an observer by saying that it suggests the application of such epithets as 'well-filled,' ' eurycephalic,' 'sub-cubical ;' or when the rounding'-off effect of senile change has begun to tell, 'sub-spheroidal ;' and finally of 'massive and powerful' in an eminently emphatic manner.

When a considerable number of skulls from any one barrow of the stone and bone period, such as those spoken of at pp. 539-541 supra, are arranged in a single line upon a long table along another line of the surface of which a corresponding number of the brachycephalic crania of the bronze period, and along a third a corresponding number of Anglo-Saxon crania are similarly arranged, the following remarks suggest themselves to the craniographer. It might be said, firstly, that the two sets of pre-Saxon skulls were well nigh as distinct and as sharply contrasted as any other sets of skulls which it is possible to put alongside of each other from 
either ancient or modern times; that the Tasmanian skull could scarcely be said to differ more from the modern European, nor the Eskimo from the Andamanese, than some of the typically elongated and wall-sided long barrow skulls differ from the broad and sub-spheroidal skulls of the bronze period. And (whatever may have been averred to the contrary) it might be said, secondly, that though the Saxon series agreed with the longbarrow series in being dolicho-cephalic, and though in a few instances skulls from these two series were very closely like each other, there was nevertheless no great difficulty in distinguishing between these two series also, and even that in the individual cases of similarity it was very rare not to be able to point, when all the peculiarities of each skull were taken into account, some one or more than one important point of difference either in the calvariæ, or in the facial bones, or in the lower jaws of the older and of the more recent skull ${ }^{1}$.

A third remark of equal generality and importance would be suggested by this survey of these three sets of crania, to the effect that though skulls very closely similar to the typical representatives of either of the pre-historic series might be found upon living shoulders amongst the present population of this country, the elongated and fairly well-filled oval Anglo-Saxon cranium was the prevalent form amongst us in England ${ }^{2}$ at the present day.

1 Many authorities may be cited for the proposition that the typical dolicho-cephalic Scandinavian is not to be distinguished from the typical dolicho-cephalic Celtic skull. Amongst these may be named Retzius and Sir William Wilde in Retzius' Ethnologische Schriften, p. 8, cit. Huxley in Prehistoric Remains of Caithness, p. 129; Nilsson, Ancient Inhabitants of Scandinavia, ed. Lubbock, p. 117, and British Assoc. Report, 1847, p. 32 ; Omalius d'Halloy, cit. Virchow, Archiv für Anthrop. vi. 1873, p. 114; Virchow himself, Berlin Abhandlungen, 1876, p. 3 ; Ecker, Archiv für Anthrop. iii. 155; Schaafhausen, Die Urform des Menschlichen Schädels, p. 5. Against all these weighty authorities I have to set the fact that if I place a skull of one or other of these two races before the skilful and very extensively experienced articulator and restorer of prehistor:c crania, Mr. W. Hine of the University Museum, without giving him any hint of the archæological surroundings in which it was found, he will ordinarily be right in his reference of the skull to one or other of these races. The points of difference which thus guide to a right conclusion will appear in the description to be given in the text.

${ }^{2}$ In Germany anthropologists are not as yet at one as to whether the dolicho-cephalic form of skull, which when combined with tall stature and light hair and complexion has been usually considered to constitute 'Das Germanische Typus,' is at the present day both outnumbered and qualitatively excelled by the brachy-cephalic type or not. Ecker, in the Archiv für Anthrop. ix. 4, p. 259, 1877, expresses himself thus : - Wissen wir doch z. B. dass die in unserem Lande einst so verbreitete Schädelform der Reihen-Gräber die wohl unzweifelhaft auch mit einer bestimmten Körperstatur verbunden war, jetzt fast ganz einer anderen Form Platz gemacht bat, deren Träger 


\section{A fourth general observation would arise out of such an inspec- tion of these three series of crania to the effect that, though in each}

in ihrem ganz physischen Habitus anders geartet sind, als jene es wahrscheinlich waren. Waren jene hochgewachsen vorherrsehend blond, so sind diese gedrungener, dunkler von Haar und Augen.' Virchow, who has repeatedly expressed himself to the effect that brachy-cephaly is a higher form of skull than dolicho-cephaly (see Arch. für Anth. v. 4, 1872, p. 536, where Calori is quoted to the same effect as regards the Italians; or, Zeitschrift für Ethnologie, iv. 2, p. 36, where Cortese is similarly cited as to the smaller size and stature of modern Italian dolicho-cephali ; or, Sammlung, ix. 193, 1874, p. 45), would appear, from his saying, Arch. fuir Anth., l. c. p. 540, that the broadening which the dolicho-cephalic modern German skulls of which Herr Hölder writes have attained to as compared with the ancient dolicho-cephali may bring them within the limits of brachy-cephaly by measurement, to neglect the difference which Professor Cleland (Phil. Trans. l.c. p. 146) has so well insisted upon as existing between dolicho-cephaly of type and contour as opposed to that constituted by mere measurement of the single relation of breadth to the length, and that too irrespectively of the height. Herr Hölder appears to have proved that the Germanic type as ordinarily understood has the larger and better developed brain, at all events in the parts of Germany known to him (see his Memoirs, Archiv für Anthropologie, ii. pp. 53-55, and Zusammenstellung der in Württemberg vorkommenden Schadelformen, 1876, and the discussion at the meeting of the German Association for Anthropology held in Stuttgart in August 1872, reported in the Arch. für Anth. v. p. 539). His words in the Report just quoted are, "In Würtemberg finden sich aber unter den seit Generationen geistig beschäftigten Ständen viel mehr dolichocephale Formen als unter den Handarbeitern.' The facts, so far as I can collect them as regards Germany, appear to me to be that the genuine Teutonic type, as we know it from undoubtedly Anglo-Saxon, and from Frankish skulls, has, in the course of centuries (some of which have been times of culture, and all of which may have been times admittedly of crossing with a brachy-cephalic stock), intermediate in archæological date between the Reihen-Gräber period and the earliest graves, become relatively somewhat broader, but without losing its primitive contour. Throughout Germany however there exists a brachy-cephalic stock, usually but by no means always, darker haired and of shorter stature and of less cranial capacity than the typically dolicho-cephalic variety; and this stock, whatever its other disadvantages, has at all events a numerical preponderance in South Germany (see Huschke, l. c. p. 98; Virchow, Beiträge, 1876, p. 6; Huxley, in Prehistoric Remains of Caithness, p. 108). Persons who will verify the references I have given will find that a good deal of other than purely scientific interest has come to attach itself to this discussion. Professor Broca's views as to the superiority of the brachy-cephalic type appear to coincide with Professor Virchow's. They may be found in his 'Memoires,' vol. i. 1871, p. 342, and Bull. Soc. Anth. de Paris, Tom. vii. Ser. iii. Fasc. v. Dec. 5, 1872. Dr. Hölder's last summing up of the question, Zusammenstellung, pp. 34, 35, runs thus :-

'Die Bewohner des heutigen Europa sind ein buntes Gemisch der oben angefïhrten 4. Rassen zu 2, 3 oder 4, und nur von dem Vorherrschen der einen oder anderen dieser Elemente hängen die Eigenthümlichkeiten der verschiedenen Nationen ab. Nur in einem theile von England, Schweden und Deutschland herrscht der germanische Typus vor, ganz unvermischt ist aber wohl nirgends mehr. In dem grösseren Theile des letzteren stehen die germanischen Elemente den brachycephalen in ziemlich gleicher Zahl gegenüber, oder sind sogar in entschiedener Minderheit. . . .

'Mit der unverwüstlichen Zähigkeit welche ihm eigen ist, kommt er selbst in den am meisten brachycephalen Bezirken Deutschlands immer wieder auf die Oberfläche, wie die von mir zusammen gestellten Mischformenreihen zeigen. Welches das End resultat sein wird, kann niemand wissen, nur so viel ist sicher, dass alle Mischrassen so lange in Fluss bleiben, bis sie zu Grunde gegangen sind oder bis das schwächere Element von dem kräftigeren umgewandelt ist; aber nur bis zu einem gewissen Grade, 
of them a certain number of what Professor Cleland has expressively called 'ill-filled skulls' were to be pointed out, the larger proportion was to be found in the earlier of the two series. To this subject we shall revert further on, and we may now proceed to make some more detailed remarks upon the particular characteristics of the long-barrow-period skulls.

Viewed in the norma lateralis, skulls of this kind most usually present us (see figure of 'Langton Wold, ii. 1,' p. 602) with a contour line describing a more or less even oval curve from the upper boundary of the supraciliary ridge to the centre of the prominent occipital squama. A few instances however will be found in which the upper contour line, instead of describing the curve, will, after sinking into a broad undulation posteriorly to the coronal suture, rise to its highest point in the middle third of the parietal arc before passing on to the back aspect of the skull. They thus reproduce on a small scale the peculiarities of the annularly constricted variety of artificially deformed skulls (see p. 595 supra), and, like these skulls, will be usually found to belong to individuals of slight build and feeble physique. They resemble even more closely in this point and some others the 'hypsistenocephali' of Dr. Barnard Davis. The one eminently distinctive and characteristic point of these dolicho-cephalic skulls is the forward position of the parietal tuberosities, and of the ear, with which is correlated even in female skulls (as for example 'Sherburn Wold, vii. 1,' p. 610) an oblique slope as opposed to a precipitous vertical dip in the parieto-occipital region. The temporal lines and the half of the lambdoid suture are seen laterally in nearly or quite their entire length. The forehead may be, and indeed often is, low as viewed in the norma lateralis and narrow as viewed in the norma verticalis, and may very well merit the description frons valde depressa which Sir R. C. Hoare bestowed (Archælogia, xix. p. 46) on some long-barrow skulls dug up by him; but it rarely manifests that pronounced obliquity, 'le front fuyant,' so common in brachycephalic skulls, and shown so plainly in the figure of the skull ' Rudstone, lxiii. 9,' p. 590 supra. In many, and especially in the weaker, dolicho-cephalic skulls the more strictly calvarial portion of the frontal bone rises from a plane considerably posterior to that of the supraciliary ridges, a peculiarity which, when the frontal rises nearly vertically to the level of its tubera, and when, as is very

denn auch das stärkere erleidet Veränderungen, welche nur unter ganz ausnahmsweisen Bedingungen wieder verschwinden könnten.' 
often the case in this variety of cranium, the supraciliary ridges are confluent across the middle line, gives a very characteristic appearance to these skulls. Just as the line of the os frontis in these cases lies some way within the line which the contour of the supraciliary ridges would describe if produced, so the line of the posterior half of the parietals lies often well within the line which the produced contour of the upper occipital squama would give us. This peculiarity is 'die facettirte Absetzung des Hinterhaupts' spoken of as eminently characteristic of the Hohberg type of skull by Professors His and Rütimeyer. It is however, though common, not by any means constant in otherwise typical dolicho-cephalic skulls of the stone age, as might have been expected, the occipital segments proper, both of brain and of skull, being exceedingly variable ${ }^{1}$ in development; and the 'capsuläres Hinterhaupt,' as pointed out above, p. 589, or as seen in such a skull as the one figured xiv. Pl. xii. Cran. Brit. from Wetton Hill Barrow, being by no means rare in brachy-cephalic series.

Whatever differences may exist amongst craniographers as to the existence of sexual differences in the matter of the 'length-breadth index,' there is no room for questioning the fact that the height in women's skulls ${ }^{2}$, very variable though this measurement is in

${ }^{1}$ Aeby, Schädelformen, p. 12 ; Welcker, Wachsthum und Bau, pp. 36, 46, 65, 141 ; Huschke, l. c. pp. 19, 21, 94, 96, 98, 152, 153, 156; B. Davis, Thesaurus Cran. p. 351 ; Gall. Syst. Nerv. iii. 160; Virchow, Gesamm. Abhandl. p. 916; Cleland, Phil. Trans. 1870, p. 132; Wundt, Physiolog. Psychologie, 1873, p. 229, citing H. Wagner; Weisbach, Arch. für Anthrop. iii. 74, 75, 81; Broca, Rev. Anthr. ii. 1, 1873, pp. 30-32. Very conflicting statements have been put forward as to the relative development in males and females of the posterior part of the cerebrum. I incline to hold that in most dolicho-cephalic races what Huschke calls the Zwischen-Scheitel-Hirn qua in fossis cerebri ossis occipitis liegt' is absolutely sub-equal to and therefore relatively greater than the homologous segment in males. As against this may be set the greater relative length of the basis cranii in males of our own as of other species. This is a difference however which amounts at most to about two millimeters, an excess insufficient to counterbalance that frequently observable in the female interparietal region. On the other hand, in typically brachy-cephalic races this absolutely and relatively shorter basis cranii and the absolute equality of the male and female intertuberal diameters in the parietal region do not rarely give female skulls a higher lengthbreadth index than male skulls of the same race possess.

${ }^{2}$ This point is well put forward by Weisbach, Archiv für Anth. iii. 1. 66, 1868, in his account of the German female skull, which in this particular admits of wider application : 'Die Höhe unserer Weiberschädel von der Mitte des vorderen Randes des Grossen Hinterhauptloches zum Scheitel welche im Mittel nur $125 \mathrm{Mm}$. in den einzelmen Fallen 118 bis $139 \mathrm{Mm}$. beträgt ist wie alle bisberigen Maasse weniger veränderlich (16.8 Proc.), als beim Manne (21.8 Proc.), jedoch unter den drei Hauptdimensionen den Meisten Schwankungen zugänglich, die Breite den geringsten; während am männlichen Schädel die Länge die geringsten, Breite und Höhe fast die gleichen individuellen Schwankungen erleiden. Das Minimum der Höhe haben 
women's skulls, holds usually a less favourable relation to the length and breadth than it does in males. The only three instances in which I have in this series of dolicho-cephalic skulls found the latitudinal to be less than the altitudinal index, or, in Professor Cleland's (l. c. p. 148) and Professor Busk's (Journ. Ethn. Soc. 1871 , p. 467) language, found the skull to be 'tapeino-cephalic,' were skulls of women. One of these was the woman (see Journ. Anth. Inst. vi. p. 36) found in one of the flint mines under the line of the fosse round the British fort at Cissbury, which were shown by Colonel Lane Fox (Journ. Anth. Inst. vol. v) to be of earlier date than that fort, itself of the stone age. The second of these was a woman's skull from the famous Rodmarton barrow, from the collection of the late Rev. Canon Lysons (see Proc. Soc. Antiq. 1863; Thurnam, Crania Britannica, Pl. 59); and the third of these was the skull of the single undisturbed skeleton found in the long barrow 'Upper Swell, cexxxi,' described by me at p. 529 supra. It is true that in many of the long-barrow skulls the loss of the anterior portion of the occipital bone renders it impossible to take the 'absolute' as opposed to the ' upright' height', except approximatively ; still I am well assured that the great majority of the longbarrow crania resemble in the favourable relation of their height to their length rather the South Sea Melanesian 'hypsi-stenocephali' of Dr. Barnard Davis ('Natuurkundige Verhandelingen,' Haarlem 1866, and Thesaurus Craniorum, p. 309) than the low-lying Tasmanian and Bushman skulls described by Professor Busk (Journal Ethn. Soc. Lond. Jan. 1871, p. 476). The conceptacula cerebelli lie horizontally in male and female skulls of the stone age both alike, differing herein markedly from the other type in which they are usually either globular and convex downwards or slope more or less obliquely upwards. In the norma occipitalis we often find given us the most characteristic peculiarities of the stone-period

beide Geschlechter gemeinsam, wogegen die Maximalhöhe des Weiberschädels sich nur wenig über das Mittel des Männerschädels (133 Mm.) erbebt, dessen Maximum (147 Mm.) jenes des weiblichen Geschlechtes weit übertrifft. Die Höhe des Weiber schädels hat im Vergleiche zu der des männlichen noch das eigenthümliche vor den anderen Hauptdurchmessern voraus, dass sie von der selben sich viel weiter ( $₫ 1000$, ㅇ 939) entfernt, daber auch der Weiberschädel im Verhältnisse zu seiner Länge (1000: 729) viel niedriger als der männliche (738) ist.' Dr. Thurnam (Further Researches, p. 25) found as many as 8 out of 48 male skulls, and as many as 7 out of 19 female skulls, of the long-barrow period to be 'tapeino-cephalic.' For 'the latest accession of height in the male skull being wanting in the female' see Cleland, l.c. 148, 164; for the reverse from the Caverne de l'Homme Mort, see Rev. d'Anthr. ii. p. 29.

${ }^{1}$ See p. 562 supra. 
skull, and especially of the male skull. The sides of the pentagon described by the skull's contour are in such skulls (see 'Langton Wold, ii. 1,' pp. 136, 602) either quite vertical or even converge a little from the level of the tubera parietalia downwards, whilst they slope upwards with well-marked obliquity to a mesial vertical carina along the sagittal line. The tubera parietalia in 'ill-filled' male skulls are relatively more prominent than in the better developed, in which their site may be only very faintly marked; they are usually more distinct, whilst the mesial vertical carina is less distinct, its position indeed being only feebly indicated, in female skulls (see 'Sherburn Wold, vii. 1,' pp. 146, 608 supra). It is in the norma occipitalis as well as in the norma verticalis that the premature obliteration of the sutures to which Dr. Thurnam drew attention in the Natural History Review of 1865 (see also Virchow, Archiv für Anthrop. v. p. 535, 1872) as being very frequent in this type of cranium is specially obvious; and not rarely, though by no means universally, in the skulls of individuals in quite early stages of adult life (see pp. 614, 615 supra). It is rare in the brachy-cephalic series to see any traces of such anchylosis until many other senile changes have set in with advancing years.

In many of the stone age dolicho-cephali, by combining the view given in the norma verticalis with that given in the norma occipitalis, we realise to ourselves very vividly the force of the epithets 'scapho-cephalic' and 'kumbe-cephalic' (see p. 615 supra) which have been applied to them. The keeled mesial ridge and the lateral wall-sidedness given in the back view are often combined with a rapid tapering, both forwards and backwards, from the plane of the anteriorly situated parietal tubera, which suggests the comparison to a long and narrow boat which the epithets just quoted embody. On the other hand, it must be said that the contour presented by these skulls in the norma verticalis does, whilst always retaining the length in a relation of advantage to the breadth, yet vary considerably, as the other epithets 'birnformig,' pear-shaped, ' keulenformig,' club-shaped (='elongate oval'), and coffin-shaped (='cuneate oval') by various writers applied to them plainly indicate. In other words, these skalls when viewed in this as also in other aspects are seen, whilst remaining always dolichocephalous, to vary considerably as to being well or ill-filled, globular or pinched, phænozygous or aphænozygous, rounded off or angular in the plane of greatest breadth, and finally to some extent even as to the relative position of this plane in the long axis of the skull. 
As has been however already said, the conformation of the lower jaw in every well-marked variety of the human species is an eminently distinctive element in the complex aggregate of peculiarities which make up its cranial character. The presence of prognathism in the upper jaw is by no means a point of such consequence for distinguishing crania of prehistoric series inter $8 e$, as it is for distinguishing them from those of later and of modern races. For, as a matter of fact, prognathism, which is not always constant in its presence even in modern races reputedly prognathic, is by no means common in crania from the early interments of Britain and France, nor, according to His and Rütimeyer ${ }^{1}$, from those of Switzerland; nor, according to Virchow (Archiv für Anth. vi. pp. 92, 93), from those of Belgium. The dolicho-cephalic skulls with which we are now dealing contrast in no point more markedly with the Anglo-Saxon skulls to which so many authors have stated that they bear a very close resemblance, than they do in their eomparatively slight and orthognathic upper jaw. And it may be emphatically asserted that in the after all not so very common cases in which the early British calvariæ do closely resemble the Anglo-Saxon, the upper and lower jaws will almost invariably be found to furnish means for distinguishing them. The lower jaws procured from long barrows, as from other interments, very ordinarily far outnumber the calvariæ which have been recovered in such a condition as to admit of reconstruction, and there is never the slightest difficulty in distinguishing such a series viewed as a whole from a similar series from an Anglo-Saxon cemetery simply by a reference to the more powerful development of the latter series. It is true that occasionally powerful lower jaws have been found belonging to prehistoric dolicho-cephalie crania. The existence of a 'frons valde depressa' (a conformation not usual in such skulls) noted by Sir R. C. Hoare (Archæologia, xix. p. 46, 1821) as present in a skull from a long barrow at Stony Littleton may suggest the presence in that skull of a heavy jaw, to counterbalance which the brain-case may have been rotated backwards (see pp. 615 and 623 supra). In the eminently dolicho-cephalic (cephalic index 69) Ben-Djemma skull, rendered famous by the history given (Types of Mankind, p. xl) of its presentation by the Oriental scholar Fresnel to the American anthropologist Morton, a strikingly

${ }^{1}$ Herr Mandach, writing of an ancient skull in the Museum at Zurich, says, ' Räthselhaft aber bleibt immerhin das Auftreten dieses fast negerartigen Kopfes inmitten der sonst orthognathen alten Helvetier.' Crania Helvetica, p. 63. 
retreating forehead is correlated, Dr. Daniel Wilson informs us (Edinburgh Philosophical Journal, xviii. 1, July 1863, p. 61), with a lower jaw which is 'large and massive, but with less of the prognathous development than in the superior maxillary.' In the Horned Cairn of Get, Caithness, which though not one of the oldest of those cairns did yet contain, as described by Mr. J. Anderson (Mem. Soc. Anth. Lond. iii. p. 220; Proc. Soc. Ant. Scot. June 1868, p. 500), no metallic implements, but on the other hand with other worked flints an arrow-head of the early leaf-shape, a dolichocephalic skull (cephalic index 76) was found, of which Dr. C. Carter Blake writes, locc. citt., 'The inferior maxilla is very large and massive, the chin being excessively prominent; the inferior border is very thick and rounded, the posterior angle of the ascending ramus being rather obtuse. The sigmoid notch is not shallow.' And Virchow has (Archiv für Anthropologie, vi. p. 90, 1873) remarked of the numerous fragments of jaws recovered by Schmerling from the Engis Cave, that the upper jaws have usually a very wide, almost semicircular contour described by their alveolar processes, and have also their teeth very much worn away; and also that the lower jaws are strong, and their middle region much rounded out. Some of these cases may no doubt be considered to have been 'exceptional;' exceptional developments being by no means unknown in pure and pristine races; but $I$ incline to think that in the great majority of cases in which such jaws have been procured from interments of the stone and bone age the epithets 'thick' and 'heavy' rather than 'well-developed' and 'powerful' will be found to be applicable to them. The segment of the body of such jaws which corresponds to their molar series is very often strikingly strong and even tumid, a development which one is tempted to refer to the stimulation hard food throws upon the teeth firstly and the jaw secondly. The jaw when placed upon a horizontal surface will be found in many cases to touch it by this segment only, the angle and symphysis both lying above it. The chin however and the angle of such jaws are found to contrast greatly to disadvantage with the similar regions of the powerful jaws of male subjects of races such as the Anglo-Saxon; either the depth of the prehistoric jaw of the middle line in front may be found to be markedly short; or when it is, as is sometimes the case, the very reverse of this, this depth is due much more to the alveolar part of the bone than to any increase in size of the triangular raised area of the mentum. A chin conformed in either of these two ways 
would have given an expression of feebleness to the face during life. In a really powerful jaw again the inter-angular diameter is wide, the angles approximate to right-angles, and in the region of these angles the jaw itself is flanged outwards, whereas the very reverse of this is usually the case in the jaws from the long barrows. A point less distinctly connected with the physiological development and therefore of proportionately greater morphological value is presented to us in the shortness of the coronoid process relatively to the condyle-bearing portion of the ramus.

In this point these ancient dolicho-cephalic resemble many modern Eskimo crania, indeed the frequency, almost amounting to constancy, with which it oecurs in these modern savages is such as to render of less importance the fact that it is sometimes observable in other races both savage and civilised ${ }^{1}$. A second morphological peculiarity of similar significance is sometimes though by no means so frequently constituted by the backward position of the foramen mentale, an orifice which in modern European lower jaws opens in the plane of the anterior premolar, but in these priscan jaws sometimes occupies the more backwardly placed position not unusually noticeable in Negros.

The skeletons from the long barrows differ as markedly from those of the round as do the skulls. I have never found the stature to exceed $5 \mathrm{ft} .6$ in. (see p. 539 supra; Journal Anthrop. Instit. v. Oct. 1875, p. 121) in any skeleton from a barrow which was undoubtedly of the stone and bone period. In this point my results are in close accordance with those of Dr. Thurnam (Further Researches, p. 32), who found the mean stature of the dolichocephalic men of the long barrows to be $5^{\prime} 5 \cdot 4^{\prime \prime}=1 \cdot 661$ metre, and that of the brachy-cephalous men of the round barrows to be $5^{\prime} 8 \cdot 4^{\prime \prime}=1.737$ metre ; the brachy-cephali having thus an advantage of no less than $3^{\prime \prime}=7 \cdot 6$ cent. in the matter of height ${ }^{2}$. To this I

${ }^{1}$ Schaafhausen, cit. Ecker, Archiv für Anthropologie, iii. p. 134, 1868, speaks of a massive lower jaw with almost vertically ascending broad and short ramus, the processes of which are almost of the same height as causing us to recognise the rough more aboriginal type of conformation as it is known to us in the old Scandinavians, Celts, and Britons, and as it is in part at least presented to us in an exaggerated degree among modern savages. See Journal of Anth. Institute, July 1876, vi. p. 34, for description of such a lower jaw from the Ancient British Flint-mine at Cissbury.

${ }^{2}$ Mr. J. R. Mortimer, Journal Anthrop. Institute, vol. vi. 3, p. 333, Jan. 1877, has found that the mean stature of his skeletons with dolicho-cephalic skulls is as much as $5^{\prime} 9 \cdot 4^{\prime \prime}$, as against $5^{\prime} 5^{\prime}$ for the brachy-cephali, a very different result from those attained to by Dr. Thurnam and myself. The discrepancy however is very easily explained; Dr. Thurnam and I, when we speak of dolicho-cephali, are referring only 
would add that whilst this very striking difference is brought out by taking the average length of the two sets of femora, a simple inspection of the two sets of bones puts them into even sharper contrast. The longer femora very often are also the stronger in a most marked degree, and amongst them are to be seen bones with muscular ridges, and processes indicating the possession by their owners of strength far exceeding that usually observable in the skeletons of the earlier race. In like manner other bones indicate unmistakeably that the earlier was also the feebler folk as a whole, though humeri and femora are forthcoming from long barrows which show that men of great muscular power, even if not of great stature, were not wanting amongst the British tribes of the longbarrow period. In some cases the muscular ridges on the longbarrow bones are so well developed on comparatively ill-developed shafts as to suggest the idea of a poorly or only intermittently well-fed population which was constantly worked hardly. The large size of the deltoid ridge on some small humeri has suggested the perhaps fanciful hypothesis that the owners of such bones had been employed in lifting the stones of the huge barrows in which they were found entombed. The linea aspera on the femora of the British long barrows examined by me never attains the enormous development which caused Professor Busk and Dr. Falconer to call the femora from the Genista Cave at Gibraltar 'carinate' (see Trans. Internat. Congress, Prehistoric Archæology, 1868, p. 160), and which has suggested the name 'fémur à colonne' (Broca, Mémoires sur les Ossemens des Eyzies, pp. 14-21, Paris 1868; Topinard, Anthropologie, p. 324, 1876) for similar femora from early sepultures. In the absence of this peculiarity ${ }^{1}$, as also of the

to dolicho-cephali from long barrows, in which no metallic instruments are found, and all of which are anterior in date to the round barrows with which $\mathrm{Mr}$. Mortimer is dealing. In these latter barrows, as the craniography of them shows, we have, in Yorkshire commonly and to some extent even in the South of England, to deal with a mixed race; and the effect of crossing, as will hereinafter be pointed out in the text, is very usually to increase the size of the mixed races. The only cremation long barrows which have been examined in Yorkshire are those described in this book from Rudstone, Ebberston, and Kepwick. The great majority of the statements here made as to the characteristics of the dolicho-cephalic stock are based upon the examination of skeletons of an unmixed race from the pre-metallic tumuli of Gloucestershire.

1 Topinard has remarked, $l$. $c$. p. 325 (if I am right in supposing that the word crânienne, line 11 from top of page cited, stands by a misprint for the word olécrânienne), that the fluted femur is not found in the same collections of bones as the perforated olecranic fossa. No humerus with such perforation was found in the Genista Cave at Gibraltar, where so many carinate or fluted femora were found by Messrs. Busk and Falconer. I should be slow however to think, as M. Topinard 
fluting of the fibula and of the sabre-shape of the tibia which are found to accompany it, these skeletons contrast with many of the probably earlier skeletons described by the authors just referred to.

It has been stated above, p. 646, that many craniographers have found it difficult to distinguish between the crania of the Celtic and the Teutonic races, or, in the words of the German antiquary, between the crania of the 'Steingräber',' the analogues of our long barrows, and the 'Reihen-gräber' period. It is almost needless to say that the strength and length and other characteristics of the Anglo-Saxon skeletons found buried with such accompaniments ${ }^{2}$ as to justify us in referring them to early periods in the AngloSaxon conquest of this island will enable any osteologist to distinguish them from the stone period skeletons.

A more detailed comparison of these two sets of skeletons with each other and with those of the bronze age brings out further points of difference between them, and throws a most instructive light upon the social condition of the respective periods. One of these points is the great inferiority of size of the female skeletons belonging to the earlier period as compared with those of the later, or with the male skeletons of their own times. It is easy to understand ${ }^{3}$ how the German women came to be almost equal to the men

does, that the presence or absence of one or other of these peculiarities indicates a difference of race. As I have said in a detailed account (Journ. Anthrop. Instit., Oct. 1875, p. 149) of the Osteology of the long barrow at Nether Swell, I should agree with M. Broca in assigning such perforated humeri to female skeletons, and their presence there I should explain by what follows pp. 659, 660 infra, as to the harder lot and slighter build of the females in savage tribes.

${ }^{1}$ A very copious list of synonyms for graves of the stone period is given by Weinhold (Sitzungsberichte d. k. Akad. der phil. hist. Cl., Bd. xxix. Heft. 2, 1859, pp. 119, 121). His words are - 'Sie heissen in Dänemark Steendysser, in England Cromlechs, in Frankreich Pierres plates oder Grottes aux fées, in Deutschland gewöhnlich Hünengräber. Andere Namen sind Hünenkeller, Hünentritte, Hünenberge, Riesenbetten, Riesenkeller, Zwerg- oder Quargberge, Teufelsbetten, Teufelsaltäre, Teufelskanzel, Teufelsküchen, Steinhaüser, Steinöfen, Carlsteine, Schluppsteine, Weinberge.' For the single variety of Steingraber which is known as Hünenbetten, and corresponds to our ' long barrows with peristaliths' (for which see Thurnam, Archæologia, xlii. 1869, p. 51), there exist the following German (l. c. p. 121) synonyms: Hünenhügel, Hünenstatt, Hünenburg, Hühnentritt, Hühnenkirchoff, Riesenbetten, Riesenberg, Teufelsberg, Bulterbelt, Dansenstein, Danzelstein, Danzelberg, Steintanz, Sonnenstein, Wulfstein, Steinkirche, Steinkreis. This multitude of names is a proof of the age of these monuments, nearly as convincing as the presence of stone- and bone- and the absence of metallic implements.

${ }^{2}$ For an account of these accompaniments see Archæologia, xlii. 1870; Excavations at Frilford, p. 436 seqq.

3 Dr. Leonard Schmidt, art. 'Germania ;' Smith's Dictionary of Greek and Roman Geography, p. 995. 
both in strength and in size when we read (Tacitus, Germania, cap. 16) that their marriage-presents of juncti boves, paratus equus, data arma were intended to teach them symbolically venire se laborum periculorumque socias, idem in pace, idem in pralio passuras ausurasque. In women subjected to such equal trials, and incited to such equal aspirations, the great sexual disparities at once of a physical, moral and intellectual nature, which have so often been noted as well in more civilised as in more savage communities, would on principles of natural selection tend to disappear. That the series of skeletons from the bronze period also contrasts and in the same way with the series from the stone and bone period, may be gathered from the fact that in the series from the later period there is from time to time a difficulty in distinguishing the sex of the skeletons when the entire number of the bones are not preserved, a difficulty which scarcely ever arises in the cases of pre-metallic skeletons. The subequality in size of the sexes in the Gallic races was expressly noted by Diodorus, and many other writers, ancient as regards our times but entirely modern as regards the long-barrow era, have, as I have pointed out above, p. 565, remarked that in Celtic, no less than in German tribes, both sexes exposed themselves to the same risks in war. To the British of the time of Boadicea, Tacitus ${ }^{1}$ tells us (Ann. xiv. 35), it was solitum feminarum ductu bellare ${ }^{2}$; and the presence and participation of women in governments, battles, and massacres is repeatedly mentioned by the same writer (see Agricola, 16, 31, 32 ; Germania, 8; Ann. xiv. 30 . See also Diodorus, v. 32, 39; Strabo, iii. 4, 17, 18, vii. 2, 3; Dio Cassius, lxii. 4; and supra, p. 565).

The words of Dio Cassius ${ }^{3}$, a historian deserving, even as

1 Tacitus of course is writing (locc. citt.) of races whom the antiquary would speak of as 'late Celts,' but the physical subequality which this community of risks as incurred in his days must have entailed had existed in the much earlier bronze age; and the brachy-cephalic type persisted not only through the late Celtic period, but, as the examination of the Oxfordshire Crawley tumulus carried on by Mr. Akerman, Dr. Thurnam, and myself have shown, to a much later period. Indeed in this tumulus the crania were almost exclusively brachy-cephalic, and to a most marked degree, while the skeletons possessed the size and strength already described (pp. 641, 655 supra) as being usually found to characterise the trunk and limb bones to which such crania appertain. For an account of the Crawley tumulus, see Akerman, Arehæologia, xxxvii. p. 432 ; Thurnam, ibid. xlii. p. 175.

${ }^{2}$ See p. 565 supra, and Bates, 'Naturalist on the Amazons,' ii. 132; Clements Markham, 'Travels in Peru and India,' p. 159; Rochholtz, Deutsche Glaube, ii. 289.

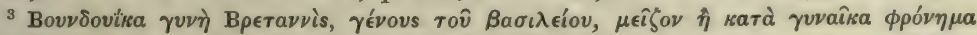

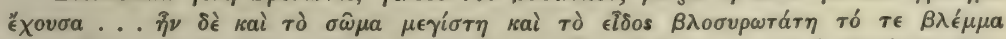

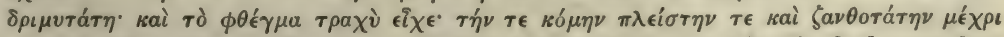

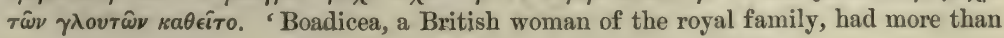


abridged, of being more frequently quoted than he is, as to the size and appearance of the British heroine, give us some colour of reason for suggesting that Boadicea may have possessed the cranial conformation characteristic of the bronze age, rather than that which we have at Arras in the East Riding and elsewhere found in interments with the archæological accompaniment of the late Celtic or early Iron period in this country.

On the other hand, a collection of the trunk and limb bones from one of the long barrows described above as examined in the neighbouring county of Gloucester (as e.g.p. 538 supra) contrasts in no point more strikingly with a similar collection from such a tumulus as the one at Crawley than in the disproportionate slightness and shortness of the female skeletons. The average difference in civilised races in the stature of men and women may be taken as about four inches, being in England at present the difference between about $68^{\prime \prime}$ and $64^{\prime \prime}$; twice this difference will very usually be found to exist between the male and female skeletons of the stone and bone period, being the difference between about $66^{\prime \prime}$ and $58^{\prime \prime}$. The male skeletons of this period contrast to disadvantage with the male skeletons of each and all of the races who have inhabited this country since the introduction of metal into it; but the difference between the female and the male skeletons of this early period is a very much greater difference than any which can be shown to arise out of the comparison of any other two sets of adult human bones from cemeteries in this country. This difference is perhaps more strikingly shown by a comparison of the male and female collar-bones than by that of any other bones of the skeleton; and it enables us to reproduce for ourselves the narrow chest and drooping shoulders which must have given their owners an appearance of great feebleness during life. It has been noted by Professor Busk in the skeletons from the Gibraltar caves (see Trans. Internat. Congress, Prehist. Archæology, 1869, p. 158), and $I$ have noted it in every case in which the trunk bones have been recovered from long barrows. It is as marked in the

a woman's spirit. She was of very large bodily proportions; the fierceness of her appearance struck beholders with awe; the expression of her countenance was exceedingly severe and piercing. Her voice was harsh, and she had a profusion of very light hair, which reached down to her hips.' Lib. 1xii. 701, ed. Leunclavii, 1606. It is not impossible to reconcile this account with Martial's lines, xi. 53-56:-

- Claudia cæruleis quum sit Rufina Britannis Edita quam Latiæ pectora plebis habet. Quale decus formæ, Romanam credere matres Italides possunt, Atthides esse suam.' 
female clavicles from the cremation long barrows of Market Weighton and Crosby Garrett as in the non-cremation long barrows of Gloucestershire.

As regards the skeletons of the stone age which have been examined in this country, the aphorism enunciated by Dr. Kuhff (Révue d'Anthropologie, iv. 3, 1875, p. 435) to the effect that 'plus s'on se rapproche des origines de l'homme, et plus l'on voit s'effacer les caractères différentiels sexuels dans la squelette' appears to me to be the very reverse of the actual state of the case, though the skulls are not rarely subequal in the two sexes. The reason for this disproportion ${ }^{1}$ lies in the facts of the earlier attain-

1 The greatest discrepancy in the stature of the two sexes recorded by Weisbach in his measurements in the Anthropological part of the Voyage of the Novara (1867, p. 217) is that observed in the Javanese, where the males were found to average $1679 \mathrm{~mm} .=$ nearly $5^{\prime} 6^{\prime \prime}$ in stature, as against $1461 \mathrm{~mm} .=$ nearly $4^{\prime} 9^{\circ} 5^{\prime \prime}$ for the females. The Rev. Richard Abbay, Fellow of Wadham College, tells me that the Javanese women are put to very hard labour, carrying enormous weights upon their backs. The philologist who may be inclined to explain the existence of Turanian or nonArian traits in Welsh and Irish grammar, by supposing that these traits are the result of the assimilation by bronze-importing Celts of the supposed non-Aryan tribes of the stone age, may be interested in comparing the following account of the treatment of the Mongolian female in modern days with the foregoing description of the osteological characters of the female of our long-barrow period. The Rev. James Gilmour, Medical Missionary at Peking, writes thus in the Eleventh Report of the London Missionary Society's Hospital at Peking, 1875, p. 37: 'The women of Mongolia are hardy and capable. They look ruddy and strong-limbed. They work hard, and are badly treated. Woman's place in the tent is next the door; the felt she sleeps on is the thinnest and poorest. She does the milking and the drudgery generally, and when she sits in the tent, usually has nothing better than a worn cowhide to protect her from the damp and cold of the ground. She jumps into the saddle and rides over the plains as recklessly as a man. She takes little eare of herself, and has little care bestowed upon her. An old woman spoke some truth, at least, when she said to me, "The women are treated like the dogs which are fed outside the tent." The result is as might have been expected: strong, hardy and healthy as the women look, almost every one who has passed the stage of girlhood has some chronic malady or suffering. There are many exceptions, especially among the richer class; but as a rule, women suffer more, age sooner, and die younger than the men; and there is little prospect of a change for the better in this respect, till women are treated more considerately, and have accorded to them a fair share of the meagre comforts of tent-life.' Diodorus Siculus, again (v. 39), after dwelling with emphasis on the hard life of the race which Vergil speaks of as assuetum malo Ligurem, says that the wives take an equal share with their husbands in all their toils and endurances. The craniographer may object to the relevancy of these striking passages, on the ground that the Mongolian are a brachy-cephalic and the long-barrow folk, like the Basques, a dolicho-cephalic stock. To this the non-anatomical enquirer might reply that the question was not one of human osteology, but of human motives and behaviour; but writing as a craniographer I will answer, firstly, that I have received from Professor Eichwald a Tartar skull from Kazan with a cephalic index of 76, and a very close general resemblance to the Eskimo type; and secondly, that most ethnographers are agreed, dolicho-cephaly notwithstanding, to consider this latter stock as unmistakeably Mongolian. For the Australians, whom their mode of life and command 
ment of puberty by females than by males in our species, and the earlier consequent consignment of the females, in savage varieties of it, to the growth-arresting processes of child-bearing, and of hard work on a frequently poor and intermittent supply of food.

It has often been stated that in savage races the cubic capacity of the skulls of the women makes a nearer approach to that of the men than it does in modern civilised nations, and there is no doubt that this has often been found to be so. But I have to repeat (see p. 565 supra) that this is by no means invariably the case, and that in the long barrows, alike of Gloucestershire and Yorkshire, I have found female adult crania which contrast with the male skulls by their disproportionate smallness, almost, or altogether as forcibly as do the clavicles or the long bones. Having taken up these diminutive skulls myself, I can point out that they were found together with other skulls, male and female, which differed from them greatly in size, but in no way as to the archæological surroundings; and that there is no reason for supposing, therefore, that their smaller size is to be explained by reference to any inferiority of rank which among savages has so often been observed to entail inferiority of bulk (see British Association Report, Bristol Meeting, 1875, pp. 150-152). We are prone, as I think, by a certain confusion of thought, to imagine that savage life is as unvarying and monotonous, and as little relieved by alternations, as is the 'dull grey life' of the lowest ranks of highly civilised communities, and that in consequence greater uniformity of physical conformation is to be expected and

or want of command of its comforts as well as some other peculiarities have caused to be compared with the stone age inhabitants of this island, Dr. Barnard Davis gives an average male stature of $5^{\prime} 6^{\prime \prime}$, and an average female stature of $4^{\prime} 11 \cdot 5^{\prime \prime}$, - measurements showing a disproportion nearly identical with that which $I$ have pointed out as characterising the race we are here dealing with. The Amakosa Kaffirs of the Cape of Good Hope have, I was assured by the late Sir A. Smith, an average stature of $5^{\prime} 8 \cdot 5^{\prime \prime}$ for the males, as against one of $5^{\prime} 05^{\prime \prime}$ for the females. On the other hand, amongst the Eskimos, to whom, as to the Australians, these prehistoric races have been compared, I do not find that a similar disproportion exists in the stature of the two sexes, though Sir John Richardson (Polar Regions, 1861, p. 303) does speak of 'the discomforts which age entails in savage life, especially on the weaker sex,' as having made the old women 'frightfully ugly,' and 'the presence of a cheerful and pleasantlooking old woman' as 'rare indeed among them.' The stature of the male Eskimo as given by Peschel (Volkerkunde, p. 87), citing Beechey, is on an average $5^{\prime} 5^{\prime \prime}$, and exceeds that of the female by only $4^{\prime \prime}$. I must express my regret that Dr. Emil Bessels should have been so unfortunate as to lose his measurements of the stature of the Eskimos, whose ethnology owes so much to his interesting paper in the Archiv für Anthropologie, viii. 1875, p. 109. The results of these measurements might perhaps have given us a different average from that just quoted. A few additional references to the significance of this disparity of stature in the sexes may be found in the Archæologia, xlii. 1870, p. 457, and Journal Anth. Inst. Lond., Oct. 1875, p. 121. 
to be found among all the members of wild and prehistoric races. The assumption, and the inference based upon it, are equally unsubstantial ; savages are exposed to greater vicissitudes in their battle alike with inanimate and animate forces than are the veriest outcasts of civilised society; and as regards the means of meeting these emergencies, compared with savages 'our basest beggars are superfluous.' 'The action of the environment,' 'l'influence des milieux,' counts really for more instead of for less upon savage than upon civilised man; and as a matter of fact this more potent working is as distinctly verifiable upon the living modern savage as it is upon a series of bones from the stone-age barrows. Mr. Bates, e.g. says, when (Naturalist on the Amazons, vol. ii. p. 129), writing of a Brazilian tribe, the Mundurucús (whom, he says indeed, p. 131, it would be a misnomer to call 'savages; their regular mode of life, agricultural habits, loyalty to their chiefs, fidelity to treaties, and gentleness of demeanour giving them a right to a better title,' but who nevertheless, on his own showing as to details such as dress, \&c., p. 125, appear to have owed very little to civilisation and the arts): 'The great difference in figure, shape of head, and arrangement of features amongst these people struck me forcibly, and showed how little uniformity there is in these respects amongst the Brazilian Indians, even when belonging to the same tribe. The only points in which they all closely resembled each other were the long thick straight jet-black hair, the warm copperybrown tint of the skin, and the quiet rather dull expression of countenance. I saw no countenance so debased in expression as many seen amongst the Múra tribe, and no head of the Mongolian type, broad with high cheek bones, and oblique position of the eyes, of which single examples occur amongst the semi-civilised canoemen on the river.' The fact, finally, of the existence in certain uncivilised races of a far greater difference between the skulls of the women and those of the men than that which exists in European races, is put forward with emphasis by Dr. Zuckerkandl, in the Reise der Novara, Anthrop. Thiel. i. 1875, p. iii; and, besides proving, when compared with the utterances of Retzius, Huschke, and Broca, to precisely the opposite effect, the variability of savage female crania, brings, when compared with the results of an examination of female long-barrow crania, a fresh illustration of the importance of collecting, while yet we may, all the available facts for the illustration of ancient savage life.

In saying that the dolicho-cephalic skeletons of the long-barrow 
period contrast in the points of strength and stature to disadvantage with those of the bronze age, it is by no means intended to assert that ill-filled skulls and stunted skeletons are never to be found in the brachy-cephalic series. The very reverse of this indeed has been already, p. 589, pointed out as being the state of the case. The races of the bronze age were in possession of larger means for carrying on the battle of life than those of the stone age; still, they lived in latitudes which we are sometimes tempted to think are only made endurable by the command of glass, and coal, and iron ; and they must, like races in more modern times in a somewhat similar stage of development, have from time to time suffered greatly from famines. Suffering from scarcity of food at a critical period of growth is sufficient to stunt the stature of individuals even of tall races who may be subjected to it. The chiefs would be less liable than the common people to be so affected; Mr. Bates indeed tells us of a Brazilian tribe (Naturalist on the Amazons, ii. p. 127), how the 'footmarks of the chief could be distinguished from the rest by their great size and the length of the stride;' still, a long continued succession of murrains and bad harvests would affect all classes alike, even in the bronze as well as the stone age. The stature would be more likely to be affected by the operation of such times of scarcity than would the size of the head, as it goes on increasing for so many years, possibly years of scarcity, after the full proportions of the cranium are attained to ${ }^{1}$. But small and ill-filled skulls as well as short skeletons are to be found in the brachy-cephalic ${ }^{2}$ as well as in the dolicho-cephalic series, even if not

1 The average circumference of the head has been shown by Liharzig (Das Gesetz des Wachsthums, Tab. v. and vi.) to be but a little over an inch less in either sex at the age of fourteen than it is in adult life, the exact measurements giving a difference of 3 centimetres $=1 \cdot 181^{\prime \prime}$ for each sex, and being $54: 57$ centimètres for males, and $52.5: 535$ for females. The potential increment of the stature subsequently to the age of fourteen averages, according to the same authority, 12 centimètres $=4 \cdot 72$ inches for males, being the difference between 163 centimètres $=64 \cdot 17$ inches, and 175 centimètres $=68.89$ inches ; and 12 centimètres $=4.72$ inches for females, being the difference between 161 centimètres $=63 \cdot 38$ inches, and 173 centimètres $=67 \cdot 11$ inches. But here Liharzig appears to underestimate the average difference between the sexes at the age of twenty-five. See Taff. iv. and v. and p. 15.

${ }^{2}$ Such for example are the brachy-cephalic skulls of which a record is given under the following titles and at the specified pages of this work :- 'Goodmanham, exvii. 1,' p. 326 ; 'Rudstone, lxiii. 3,' and ' 6 ,' p. 248 ; ' Rudstone, lxvi. 1,' p. 254; ' Rudstone, cexxxiv. 4,' p. 555; 'Weaverthorpe, xlvi. 4,' p. 200 ; 'Weaverthorpe, xlvii. 5,' p. 195; 'Brough, xxi. 6,' p. 163 ; 'Flixton, 1xxi. 6,' p. 276 ; 'Sherburn Wold, ix. 2,' p. 148. With these skulls may be compared the Ancient British Skull from Codford figured in the Crania Britannica, pl. xiv., by Dr. Barnard Davis ; in the Canadian Journal, No. xli., Sept. 1862, by Professor Daniel Wilson, and stated to have a cubical content of 
in equal proportion; their smaller numbers being correlated with their greater command of means, such as metal and cerealia. I have elsewhere given ${ }^{1}$ at length the peculiarities which are

82 cub. inches, a circumference of 20 inches, and a cephalic index of 83 . Such again is the Danish cranium from Moen, a cast of which (No. 5710) may be seen in the Museum of the London College of Surgeons; and such would appear to be the skulls described by Hölder as the female form of his 'Ligurian' type, Archiv. für Anthropologie, ii. p. 55. As also the female skulls described by me, Archæologia, xlii. p. 457.

1 See Journal Anthrop. Instit. Oct. 1875, vol. v. pp. 124, 125, where I write as follows:-

"By an "ill-filled" skull, Professor Cleland tells us, he means a skull the exterior surface of which is marked by a "mesial and two lateral ridges on the roof, with flatness of the adjacent surfaces," which has "its position of greatest breadth high up upon the parietal bones." The mesial carina may, I would add, be prolonged in such skulls over the frontal bone, and the frontal tubera may retain their infant-like prominence. To these peculiarities I would further add the presence of two depressions on the exterior of the skull, corresponding to convexities on its interior surface, as completing in many ancient and modern savage crania the character of "ill-filledness." One of these depressions is well known as the "post-coronal furrow," but inasmuch as the mesial vertical carina often developed in male skulls may be, and often is, continued along the line of the sagittal suture, so as to divide the so-called "furrow" into two parts, this name is not a happy one. The second of these depressions corresponds to a part of the parietal bone which lies a little above its posterior inferior angle, and immediately, therefore, above the part of the bone which is furrowed internally for the lateral sinuses. As in the former case, an inward growth corresponds to the outwardly visible concavity, so that much such an appearance is produced as we can inagine would have resulted from pinching in the skull walls over this area, had they been plastic. I have been able to demonstrate the rationale of these depressions in the following manner. By removing from a skull, with its brain in situ, the greater part of its roof, but leaving of this structure one antero-posteriorly-running arch of bone, corresponding to the sagittal, and two transversely-running half-arches, corresponding respectively to the half of the coronal and the half of the lambdoid sutures on one side, the exact position of all the main convolutions and fissures of the brain can be shown in their normal relations to these landmarks in the vault of the skull. It will make the matter plainer, and at the same time facilitate the production of similar preparations in other museums, to say that a brain under such surroundings, presents something of the appearance in the skull which a living head does when subjected to measurement in such a cephalometer as that of M. Antelme (see Mem. Soc. Anthrop. de Paris, tom. i. pl. vi. fig. 2). By means of such a preparation it is easy to show that the post-coronal depression in the roof of the skull does not correspond, as supposed by the late Dr. Thurnam (Nat. Hist. Review, April 1, 1865, p. 267), to the fissure of Rolando, but to the deep, often wide, fissure which divides the superior frontal convolution into two well-defined lobes, and abuts upon the ascending frontal convolution by a terminal bifurcation into two arms of considerable length. This fissure, as is well known, exists, and has often been described and figured, in the brains of the anthropomorphous apes, in the crania of which animals the post-coronal depression is sometimes indicated when the sagittal carina is absent. Similarly, the second of the depressions which $\mathrm{I}$ have noted as commonly present in the posteroinferior part of the parietals of "ill-filled" skulls, may be seen to correspond to a certain multi-radiate fissure frequently noticeable on the posterior or convex aspect of the middle tempero-sphenoidal convolution, but as far as I know, not named by any of the numerous writers who have followed Gratiolet in describing the convolutions and fissures of the cerebrum.

"Professor Bischoff however, in his well-known paper on "Die Grosshirnwindungen des Menschen" (in the "Abhandlungen der k. Bayer-Akademie der Wiss." ii. Classe, 
intended to be implied by the application of Professor Cleland's expressive epithet 'ill-filled ;' I may here add that a good rationale of most of them, such for example as their wall-sidedness, their retention of the prominence of frontal and parietal tubera, and the stops on either side of their sagittal vertical line, is given in the metaphysical expression 'the retention of an infantile type,' which refers us to causes such as scarcity of food which arrested potential growth. The fact that the dimensions of the parietal bones are usually less affected by any general stunting to which skulls may have been subjected than those of either frontal or occipital is a very striking illustration of this, it being well known that the two latter factors of the brain-case attain their normal relation to the parietal only after several years of childhood with its numerous liabilities to disease and distress have passed away. None, however, of these prehistoric skulls have exhibited that extreme lowness and smallness and precoronal depression of the frontal bone which is seen in some of the skulls from the Melanesian Islands and Australia, though in some of the hypsistemo-cephali of the long barrows we do observe that relatively greater prominence of some one segment in the anterior half of the parietal in the sagittal line which is often observable in skulls of this kind (see Dr. B. Davis, Natuurkund. Verhand. Haarlem 1866, Deel 24, Pl. i. fig. i; Busk, Anthrop. Instit. vi. 3, Jan. 1877, Pl. ix-xii).

The small skulls of which $\mathrm{I}$ am speaking are sometimes, and especially when belonging to males of the brachy-cephalic type, of considerable textural solidity ${ }^{1}$, but I incline to think that it is more

x. Band, ii. Abtheil. 1868, pp. 448, 450, 495 ; or "Separat Abdruck," pp. 58, 60, 105, Tafel x. fig. 7), speaks of certain fissures, without any well-defined character, which appear on the boundary between the parietal and occipital lobes, and says that they correspond to a "fissura occipitalis externa" which appears in the human fœtus, but is normally limited in duration to the seventh and eighth months of intra-uterine life. Though brachy-cephalic skulls have not, as yet, been proved to have been found in Great Britain in any primary interments in the barrows of which I am writing, and though brachy-cephalic skulls from the United Kingdom, and indeed, I am inclined to think, from European countries generally, are ordinarily well- and not "ill-filled" skulls, it may, nevertheless, be allowable to say here that the "brachy-cephalic angustiores" (see Phil. Trans. 1870, p. 148), as Professor Cleland would call the brachycephali of several other parts of the world, frequently present the depressions of which I have been writing. An excellent instance of the postero-parietal inward pinching of the skull-walls was furnished to me quite recently by a Maori skull presented to the University Museum by Dr. Batt, the skull having a latitudinal index of 79, and possessing also markedly the contour which induced Retzius to class the Maoris as brachy-cephali.' Since writing as above, I have noted on both sides of the brain of a Malay a depression which must have had a very considerable posteroparietal depression of the cranial walls corresponding to it.

${ }^{1}$ Such is the Ancient British Skull from Codford described by Dr. B. Davis, Cran. 
usual to find their ill-nourished character expressed by a slighter structure and a lesser relative weight as well as by their smaller dimensions. As I have already hinted (see pp. 589 and 640 supra), I am inclined to think that it may have been the mal-nutrition of such skulls as these which gave origin to the hypothesis of a Lapp population having existed in prehistoric times in Denmark, South Sweden, and in these islands. Latitudes much further south than Great Britain went undoubtedly through a reindeer period, but, without questioning this, we can stop short of averring that the men who domesticated these animals in prehistoric Southern Europe were of the same stock as the men who domesticate them now in Northern Europe. The skulls of the modern Lapps do not closely resemble either the stone and bone period skulls, or our bronze period skulls; neither of these periods coincided with the reindeer period, whilst in both of them small stunted crania are found mixed up with large ones, and that too in the tombs 'of the kings ${ }^{1}$ ?

To obtain however any really satisfactory rationale of the difference between brachy-cephaly and dolicho-cephaly we must go beyond examination simply of the texture, relative proportion, and capacity

Brit., pl. 14, as being 'dense in its structure and rather heavy ;' and such are a considerable number of skulls of the Romano-British period described by me as found at Frilford, Archæologia, xlii. p. 458.

${ }^{1}$ A considerable amount of discussion upon the subject of the Lapp hypothesis took place at the Meeting of the International Congress of Prehistoric Anthropology and Archæology held at Stockholm in 1874; the opinions of the following authors, mostly in disfavour of the hypothesis, will be found at the pages of the Compte Rendu of the Congress (published last year, 1876) which I append to their names:- Rygh, pp. 178-179; Montelius, p. 194; Worsaae, p. 208 ; Gustav Retzius, pp 231-233 ; Schaafhausen, p. 841 ; Virchow, p. 848; Baron von Düben's views, pp. 691-692, have already been quoted, p. 629 supra, and the following extract from Mr. Smiles' 'Life of a Scotch Naturalist, Thomas Edward,' 1876, p. 357, looks a little strange when compared with it: ' It is probable that a great part of Europe was originally peopled by Lapps, and that they were driven North by the incoming of a more civilised race from the East. There are still remnants of the Lapps in the island of Malmön off the coast of Sweden, in North Connaught, and the Island of Aran in Ireland; in the Island of Lewis off the Western Coast of Scotland, and in several of the Shetland Islands.'

So far as I know, Professor Nilsson's (Skandinaviska Nordens Ur-invanare, Lund 1838-1843, Hft. 3, p. 12) and Professor Rask's names are connected with the origination of this hypothesis. The views of the former of these authors appear to have been considerably modified in the thirty years' interval between 1838 and the publication of an English translation of his work under the editorship of Sir John Lubbock (see p. 122 of this translation).

The views of the elder Retzius may be seen in Müller's Archiv, 1845, or Ethnologische Schriften, 1864, p. 20; and Müller's Archiv, 1849, and Ethn. Schriften, p. 102. The small skulls described by Retzius, from Marly and Meudon near Versailles (Müller's Archiv, 1847, p. 499, and Ethn. Schriften, pp. 62-64), furnish instances of stunted skulls the existence of which can be explained as in the text. 
of the skulls, and must enquire what the conformation of the covering skull can teach us of the conformation and character of the contained brain. As I have already pointed out (p. 638), Huschke, nearly a quarter of a century ago, stated of certain readily recognisable landmarks on the skull, such as the frontal and parietal tubera and the coronal and the lambdoidal sutures, that certain equally definite and recognisable brain-convolutions would be found to correspond with them. These important observations, owing probably to their being mixed up with a vast mass of matter of less precision and interest, failed to attract the attention which they deserved, and a considerable number of investigators, including myself ${ }^{1}$, have subsequently to the appearance of Huschke's memoir in 1854 examined the relation of brains and skulls in situ without any knowledge of his precedence, but with the result of confirming his statements. Of these there are two which are of eminent importance for our present purpose, the one namely which allocates the supra-marginal convolution of the brain to the parietal eminence in the skull (see Huschke, Schädel, Hirn, und Seele, p. 142); and a second, according to which the internal perpendicular or parietooccipital fissure ${ }^{2}$ holds a similar relation to the lambdoid suture (Huschke, l.c. pp. 62, 142). For as I have already said (p. 637), of all the peculiarities distinguishing the brachy-cephalic from the dolicho-cephalic skull, at least in European races, there is none more important and more striking, even from a merely craniological point of view, than the difference existing between them as to the distance intervening between the plane of the parietal eminences and that of the back of the skull. When however we come to look

${ }^{1}$ Professor Broca in France, Professor Turner in England, M. Ferdinand Heftler in Russia, and Professor Bischoff in Germany, have connected their names with this investigation; an account of their labours is given by Professor Broca in his memoir 'Sur la Topographie Cranio-Cerebrale,' published in the Revue d'Anthropologie, tom. v. No. $2,1876$.

${ }^{2}$ Professor Turner (Journal of Anatomy and Physiology, Series ii. No. xiii. Nov. 1873, p. 145) says that the 'exact distance of the parieto-occipital fissure from the apex of the lambdoidal suture varies, partly from variations in the brain itself, and partly from the not infrequent variations in the mode of ossification of the upper squamous part of the occipital bone. About 0.7 or 0.8 of an inch will express its average distance from the apex of that suture.' In this Professor Turner differs from Ecker, Arch. für Anth. ix. 1876, pp. 72 and 76; and from Broca and Bischoff, citt. in loco. Broca, in the Revue d'Anthropologie, tom. v. No. 2, 1876, says : 'La scissure occipitale externe correspond assez ordinairement chez les adultes de notre race à la suture lambdoide, à quelques millimètres pres; toutefois elle peut s'en écarter davantage, soit en dessus, soit en dessous.' These statements are mainly of importance as bearing upon the variability of the occipital lobes, to which reference has been made above and will be also in the next note. 
into this difference a little more closely, we find that if we take for our posterior limit, not the posterior aspect of the skull but the plane of the lambdoid suture, the two varieties of skull are just as clearly differentiated as before. For the relative proportions of that portion of the cerebral cranium which is constituted by the superior squama occipitis and lodges the occipital lobe proper, and the relative proportions of that lobe itself, are exceedingly variable ${ }^{1}$

1 The occipital lobe is supplied exclusively by the posterior cerebral artery, which, on account of the angle which it makes with the main trunk whence it arises, the basilar, namely, or, on the right side, very frequently the internal carotid, as also on account of its great length, must work at very considerable hydraulic disadvantage. What the peculiar course of the artery would lead us to anticipate, the peculiarities of the veins of this portion of the cerebrum confirm us in holding. One of the largest of the Pacchionian bodies is ordinarily found at the point where the veins of the occipital lobe enter the superior longitudinal sinus, this point being upon the line of the parieto-occipital fissure, and corresponding with what is usually the most posteriorly placed of the fovece glandulares in the skull. Now the bodies known as Pacchionian glands are growths which in their normal state are but $\frac{1}{10}-\frac{1}{2}$ mill. in size, and which owe the increase in size which makes them prominent to the eye and impresses them on the skull to venous congestion. The very constant presence therefore of a largely hypertrophied Pacchionian body upon the embouchure of the occipital veins is a significant fact as regards the retardation of their current (Wilks and Moxon, in their 'Pathological Anatomy,' p. 208, compare these bodies to the papillose outgrowths sometimes seen on the surface of the liver in cases of extreme cardiac congestion). The amenability of the Pacchionian bodies to pathological change is recognised by Rokitansky, 'Pathological Anatomy,' English translation, 1850, vol. iii. p. 329, or 2nd German edition, 1856, vol. ii. p. 407; by Jones and Sieveking, in their 'Manual of Pathological Anatomy,' edited by Dr. J. Frank Payne, 1875, p. 237; by Wilhelm Krause, in his 'Handbuch des Menschlichen Anatomie,' 3rd ed., 1876 , p. 460 ; and finally by Luschka, who was, as far as I know, the first to draw attention to the fact that in their earlier stages and smaller size these bodies could not be considered other than normal growths, in his 'Anatomie des Menschen,' 1865, Bd. iii. Abtheilung ii. p. 240.

The histological inferiority of the occipital lobe is well known, and though $\mathrm{Mr}$. Lockart Clarke may slightly overstate the case when he says (Maudsley, Physiology of Mind, 3rd edition, 1876, pp. 112 and 114) that 'all the nerve-cells are small,' both Professor Turner (Introduction to Human Anatomy, part i. 1875, p. 283) and Professor Henle (Handbuch der Syst. Anatomie, iii. 2, p. 276) would allow that 'the greater number of the cells of the occipital lobe are small and nearly uniform in size,' and, what is of equal importance, that the superficial layer, which is everywhere poor in cell-elements, is of greater width in the occipital than in any other region of the brain. Meynert's words (Stricker's Manual of Human and Comparative Histology, English translation by Power, vol. ii. p. 391, 1872) are eminently to the purpose: 'The brain of monkeys, which is distinguished by excessive development of the occipital lobes, contains this type of tissue (the pyramidal cells) in much greater abundance than the human brain.' Dr. Herbert C. Major has given an instructive account of the histology of the brain of the Chacma Baboon in the Journal of Mental Science, Jan. 1876, and refers therein to Meynert's memoir, $l . c$.

As regards the connexion of the occipital lobes with mental functions, it is well known that Neumann (cit. Cruveilhier, Anat. Descript., ed. 1836, iv. p. 668; Longet, Système Nerveux, i. 691, and Traité de Physiologie, 1869, iii. p. 444) was induced from his examination of the brains of some fifty insane persons to hold that intelligence had its seat in the occipital lobes; and Cruveilhier is also quoted as speaking in the 


\section{in each variety of skull, and are not (see p. 638) distinctive of either. A zone therefore bounded in front by a line drawn over}

same sense (Anat. Descript., l.c., and $2^{\mathrm{d} \theta}$ ed., Paris, 1845, tom. iv. p. 346) from having noticed that in senile dementia the occipital lobes are much more atrophied than the frontal. These arguments, like so many in the same sphere, are amenable to the objection that the atrophy in question may be merely a concomitant change, correlated in the way of mal-nutrition with some other really causative change, without being itself the first term in the series of evils. It is however by no means necessary to shelter ourselves behind this suggestion, for few if any mental alienists would be found to take this view at the present time. In the last edition indeed (1870, iii. 2, p. 454) of Cruveilhier's Anatomie Descriptive I find the words ' C'est sur ces circonvolutions occipitales que porte principalement l'atrophie sénile,' standing without note or comment or inference in connexion with them, and the reference to Neumann is omitted. But what is of much greater consequence is to find an authority with the vast experience which Dr. J. Crichton Browne possesses (see West Riding Lunatic Asylum Reports, 1876, vol. vi.p. 218) averring that the exemption which the occipital lobes on his showing enjoy from the lesions characteristic of the general paralysis of the insane, is 'as it were only part of a wider immunity from visible pathological change' which they enjoy 'in all varieties of chronic insanity,' inclusive (p. 178) of 'senile, simple, and consecutive dementia.' Dr. Fox in like manner in his 'Pathological Anatomy of the Nervous Centres,' 1874, p. 41, tells us that 'the posterior lobes are less often affected than the middle, and hemorrhage there seems to be of far less serious import.' To these statements it may be well to add the following made by Professor Schröder van der Kolk (Pathology and Therapeutics of Mental Diseases, English translation by J. T. Rudall, Melbourne, 1869, p. 46), 'In insanity proper, in cases of confusion of ideas, and of haughty insanity, I have always found the anterior lobes of the brain suffering, but on the contrary in the melancholic and those who condemned themselves with or without religious admixture, I have found the upper and posterior parts of the lobes diseased, and that in the latter cases the understanding often showed no traces of disturbance, inasmuch as the individuals judged correctly and disputed acutely. The pathological affection limits itself then to the upper and hinder parts of the lobes, and in the fore parts nothing abnormal is seen in regard to colour, firmness, and connexion with the pia mater. In those who at last finished with dementia I never found the anterior parts of the lobes intact.' Cf. also pp. 24, $41,44,59,63,93, l . c$.

Dr. Lelut, the author of a memoir 'Du développement du crâne dans ses rapports avec celui de l'intelligence,' published in the 'Gazette Médicale de Paris,' has been referred to by M. Foville (Systeme Nerveux, 1844, p. 649) and by Virchow (Gesamm. Abhandlungen, p. 916) as having shown that in the cases of idiots the greatest diminution of the skull takes place in the posterior part of its circumference. Neither of the authors who refer to M. Lelut accept this conclusion; and a reference to Professor Marshall's paper in the Philosophical Transactions for 1864 (p. 543, pl. xxi, xxii, xxiii), 'On the Brain of a Bushwoman and on the Brains of two Idiots of European Descent,' will show that the facts upon which it is based may very readily be overstated, the real state of the case as regards the brains of these idiots being that "whilst all parts have been more or less arrested, the frontal and occipital lobes have suffered more than the temporal or parietal.'

The comparative anatomy of the brains of men and apes shows that the occipital lobes have a greater relative development in the lower than in the higher apes, and it has been maintained by Dr. A. Pansch (De Sulcis et Gyris in Cerebris simiarum et hominum, 1866, p. 25 ; Archiv für Anthropologie, 1869, iii. p. 252) that the 'operculum ' which bounds the parieto-oceipital fissure posteriorly is to be considered an upgrowth which is sometimes much diminished in the Anthropomorpha, and which is only rarely to be seen, except rudimentarily represented, in man. In other words, the external perpendicular or occipito-parietal fissure is a valley formed not by depres- 
the centre of the parietal eminence and parallel to the line of the lambdoid suture, and behind by that line itself, may, with the zone of brain which has been shown to underlie it, be taken as eminently distinctive, according to its lesser or greater width, of the brachycephalic and dolicho-cephalic types of skull respectively.

As some difference is found in the statements of different writers as to the constancy, if not of the relations held by the supramarginal lobule to the parietal tuberosity, still of those of the parieto-occipital fissure to the lambdoid suture, it is well to say here that I have examined these relations as existing between the skull and the brain while in situ, and have measured the width of the zone in question in many brains removed from the skull. The ordinary width of this zone in the brains of the almost exclusively dolicho-cephalic population of this part of England is from $1 \cdot 5^{\prime \prime}$ to $2^{\prime \prime}$; in such a skull, with a breadth-length index of $\cdot 76$, having ascertained by boring that the centre of the supra-marginal lobule corresponded to the centre of the parietal eminence, I found that the distance from the former spot to the line of the parieto-occipital

sion or excavation but by upheaval of cerebral substance, and this upheaval is less marked in the higher than in the lower Simiadæ, and in Hominidæ is usually entirely absent. As Gratiolet summed the matter up in his Mémoire sur les plis Cérébraux de l'homme et des Primatès, 1854, p. 97, 'Le lobe occipital atteint le maximum de son développement dans les Cynocephales. Beaucoup moins développé dans les Macaques il diminue de plus en plus en passant des Guenons aux Semnopithèques, et de ceux-ci aux Gibbons et aux Orangs-Ajoutons qu'il atteint son minimum dans l'espèce humaine.'

As variability in a structure or organ is justly considered to be some sort of an indication that it is tending towards becoming rudimentary, the variability of the occipital portions of the skull and of the brain attains some significance. Of this variability I have already spoken, p. 649 supra. Since writing as above, a human brain has been added to the series in the University Museum (No. $950 \mathrm{~g}$ and h), the occipital lobes in which are remarkable for the extreme scantiness of their fissures and convolutions, the very reverse, extreme complexity, to wit, and sinuosity, being usually found in this part of the human brain, at least in Europeans, and being very ordinarily stated to be characteristic of it. See for example Cruveilhier's Anatomie Descriptive, iii. 2. p. 454, ed. 4; Pansch, Abhandl. Naturwiss. Verein. Hamburg, Altona, 1876, p. 25; and Gratiolet's words applied to this lobe, 'Ses plis, d'une extrême irregularité, semblent devoir échapper à toute description' (Mémoire, 1854, p. 61).

Taking all these considerations together, that namely of the inferiority of the hydraulic character of the vascular supply of the occipital lobes, that of their histological inferiority, that of their lesser amenability to disease, a privilege which we do not find to be enjoyed by organs of great functional importance, and that finally of their great variability, and coupling them with a comparison of the homologous lobes in the Simiadæ, I am inclined to consider the occipital lobes proper of the human brain as being semi-rudimentary structures. A parallel case appears to me to be furnished by the history of the fourth (the azygos or post-caval) lobe of the right lung in the Primates. This small lobe retains its independent vaseular and bronchial supply till we reach the higher Anthropomorpha; it is lost in them and in us. 
fissure was $2^{\prime \prime}$ on both sides. In the brain of a Malay.(No. '950 $\mathrm{i}$ and $\mathrm{j}$ ' in the Oxford University Museum), the skull belonging to which has not been accessible to me, but which may be supposed to have been brachy-cephalic, and from the measurements here given to have been sinistrally flattened (see p. 573 supra) in the parieto-occipital region, I find the width of this zone to be $0.95^{\prime \prime}$ on the left and $1 \cdot 7^{\prime \prime}$ on the right side. In Negroes, who are usually spoken of as being 'occipitally dolicho-cephalic,' but in whom the position of the parietal tubera is more variable than in any other race of men with which I am acquainted, I have found the width of this zone vary correspondingly. In one Negro brain I found it to be $2^{\prime \prime}$ on both sides; in the cast of another, presented by R. Garner, Esq., F.L.S., to the University Museum, I find the width to be $2 \cdot 3^{\prime \prime}$ on the right side and $1.9^{\prime \prime}$ on the left; in another, in which the posterior cerebral arteries on both sides were very largely contributed to by the carotids and the convolutions generally broad and coarse, I found the width of this belt of brain to be $0.4^{\prime \prime}$ on the right and $1 \cdot 1 "$ on the left side. It is rarer to find great differences in the width of this zone in dolicho-cephalic than in brachy-cephalic brains, which indeed the most superficial examination of the skulls would lead us to expect would be the case.

When, however, we have gained the knowledge that particular sets of convolutions in the brain underlie particular areas of the surface of the skull, and correspond generally in extent and limits with them, we have gained after all but little unless we can go further and show that particular functions, or at least that a greater power for activity in functions generally, can be assigned to the portions of brain thus localised. To attain either of these ends we must enter upon the following lines of enquiry. We must ask, firstly, whether any portions of the brain-surface have such a differentially advantageous blood-supply as to render it but reasonable to suppose that they have either differentially important functions, or a differentially greater amount of functions generally, to undertake. Secondly, we must discover whether the microscopical structure and connections of the several convolutions can be shown to differ in such a way and to such an extent as to justify us in conjecturing that important differences of function, either qualitative or quantitative, must be correlated with such differences of structure. Thirdly, we may learn much from observations as to the sequence of certain mental upon certain cerebral changes produced either by disease or by accidents. Fourthly, the comparison 
of the brains of human beings of various known capabilities and ages with each other and with the brains of the lower animals which are nearest to man casts a diffused, if not a concentrated light upon the entire enquiry. Arguments bearing upon this question may be procurable from other sources; of the four specified the first furnishes us with the least ambiguous and the most readily verifiable indications; with these the indications furnished by the other three, if not connected in the way of effect with cause, are at all events correlated in the way of concomitant growth.

A survey of the distribution of the several arteries ${ }^{1}$ supplying the cerebrum appears to show unmistakably that the particular zone of convolutions in question is at unmistakable disadvantage in the matter of irrigation as compared with the segments of the hemisphere which lie in front of it, and that of two brains of equal or approximately equal length that one is the more favourably conditioned which has this segment contributing the smaller factor towards making up its total length.

The belt of convolutions which interposes itself between the line of the lambdoid suture and another line drawn parallel to either half of that suture over the parietal tuberosity of that side receives its main arterial supply from the terminal twigs of that branch of the internal carotid which is known in this country as the 'middle cerebral' artery, but which for the present purpose might bear one of its foreign names, viz. 'arteria fossa Sylvii.' For it is only after having supplied the very numerous and extensive convolutions which form the floor and the walls and the margins of this great fossa that terminal branches of this artery emerge on to the exterior convex surface of the brain and distribute themselves to this zone of the hemisphere. In following up the distribution of the two terminal branches of the carotid we are impressed with the differentially favourable condition as regards vascular irrigation of

${ }^{1}$ Some difference of opinion exists between the two investigators, MM. Duret and Heubner, who have (Archives de Physiologie Normale, 1874, tom. vi., and Centralblatt für die Med. Wiss., 1872, Die luetische Erkrankung der Hirnarterien, 1874, pp. 172-175) been investigating the cerebral circulation, as to the degree of freedom with which the arteries in question anastomose with each other. Heubner however, who specially insists upon the formation in the pia mater of a common retiform reservoir by all the brain-supplying arteries in a common solidarity, nevertheless allows, as the facts of pathological embolism even more than those of experimental injection compel him, that the different parts of this reticulation are filled from the different main arteries with differing facility; 'von dem entfernterem naturlich schwerer und langsamer als von dem naheren.' This is all that need be asked for justifying the argument in the text. 
the lower parts of the frontal lobes which receive supplies of blood from the anterior cerebral as well as from the middle cerebral arteries; the deep fissure of Rolando, though the convolutions bounding it may not be quite so advantageously supplied as the horizontal convolutions just spoken of, has nevertheless a double supply both from the middle and from the anterior cerebral artery; but it is from the middle cerebral artery alone that the area immediately posterior to and on the same level with the supramarginal convolution, and this convolution itself, are supplied. When we consider the length and the direction relatively to the carotid of the fissure of Sylvius, the extent of the area to be supplied within it, and the tortuosities necessarily described by an artery passing along it to emerge on to the convex surface of the brain, in the words of Duret, $l$. $c$., the "pli très accuse dans le sillon profond qui sépare le lobule de l'insula de la circonvolution marginale;' it is obvious to us that the current of the blood in the terminal arterial twigs supplying the part of the brain in question must be considerably slower than that in any portion of the brain situated anteriorly to it. This would be the case even with a system of tubes which were neither contractile nor elastic; that these properties of the arteries supplying this part of the brain may count for much is sometimes rendered strikingly plain to us by their embedding themselves in the substances of the cerebral cortex of brains preserved in chloride of zine and alcohol. Several authors ${ }^{1}$ have remarked upon the great variability of the cerebral convolutions in the area of which we are treating; there are several reasons however for hesitation as to referring this variability of the topographical disposition of the vesicular neurine to the less vigorous character of the circulation of the blood in the arteries supplying it: but if this peculiarity does not explain the greater morpho-

${ }^{1}$ Bischoff, Die Grosshirn Windungen des Menschen, Abhandl. bayer. Akad. der Wiss., cl. ii. bd.x. abth. ii. p.432, S.A.42; Ecker, The Convolutions of the HumanBrain, English translation by J. C. Galton, p. 33. In support of the view that great differences in functional activity may depend upon hydraulic differences such as those described in the text I may refer to the now usually accepted explanation of the phenomenon of right-handedness, to wit, the advantage which the left side of the brain obtains in the matter of irrigation by virtue of the origin of its carotid directly from the arch of the aorta. I take this opportunity of observing that the right cerebral hemisphere is very frequently put at a second disadvantage by the fact that the basilar artery gives it scarcely any supply at all, but distributes itself almost wholly to the left, leaving the carotid to give off the posterior cerebral artery of the opposite side. This arrangement I had noted previously to becoming acquainted with M. Duret's mention of it (Archiv. de Phys, 1874, p. 68). He does not connect it however with the hydraulic explanation of right-handedness. 
logical variability of these convolutions, it does justify us in ascribing to them a lesser physiological activity.

Leaving now the consideration of the distribution of arteries over this particular area of the cerebral cortex as detectible by the naked eye, we come to a consideration of the histological characters of this zone as compared with that of the fronto-parietal convolutions which lie anteriorly to it. And it is a fact of cardinal importance that it is in this anteriorly situated part of the brain that the large pyramidal cells, the 'cornu ammonis formation' of Meynert, so characteristic of the healthy human brain, are chiefly, if not exclusively, found. The largest indeed of these pyramidal cells, 'Riesenpyramiden,' have been said by Professor Betz to be limited in their distribution posteriorly by the line of the fissure of Rolando (see Centralblatt. Med. Wiss. 1874), and Dr. Achille Foville (Medical Examiner, Feb. 1, 1877, p. 85) does but extend the area in which they are all but exclusively to be found, just so much further back as is the second ascending central convolution which forms the posterior boundary of that fissure. Dr. Major (Journal of Mental Science, Jan. 1876) has justly insisted upon the indications with which human pathology firstly, as shown by him in the West Riding Asylum Reports, 1872, vol. ii. pp. 41-52, and comparative anatomy secondly, furnish us as to the functional importance of these pyramidal cells; it being in these cells that 'degenerative changes first occur when age is beginning to do its work and pari passu the intellect is failing,' whilst 'as we proceed downwards in the scale of development it is these cells which vary most distinctly from the corresponding bodies in the human organ.' To this I would add that the histological characters of these cells when compared with those of other cells known to discharge important functions with great activity are such as to vindicate their claim to a high rank amongst such cells. As seen in a microscopic specimen prepared by the ordinary reagents, these cells are remarkable, firstly, for their large size; then for their freedom from the limitation of a cell wall ; thirdly for the clear lacunar spaces in which they lie; fourthly, for their angular nucleolated nucleus prolonged at its angles into processes somewhat like those of the cell itself; fifthly, for these processes themselves, apical, basal, and lateral. Those who are impressed with the value of the hypothesis put forward by the late Professor Parkes ${ }^{1}$ to the effect that in a

${ }^{1}$ Proceedings of the Royal Society, June 20, 1867, xvi. 94. Dr. Parkes having discovered that though active exercise produced no immediate increase in the elimina- 
living body activity of function entails certain processes of growth, whilst in rest the temporarily enlarged organ returns slowly to its normal size, will be inclined to consider the clear lacunar space which surrounds these large cells as eminently significant of their activity as allowing room for increase of their dimensions. Nor will any dispute as to whether these lacunar spaces are arte facta due to action of hardening and contracting reagents or natural, whether lymphatic or non-lymphatic, spaces affect this view. For the contraction which, on the former of these views, the cell undergoes in histological preparation may be very well taken as reproducing after death a similar contraction which, ex hypothesi, would accompany rest and abeyance of function in life.

Coming in the third place to a consideration of the evidence which processes of disease or other injury may give us for the conclusion that the parts of the brain anterior to the plane of the parietal tubera are more active and important in function than those situated posteriorly to it, I would refer the reader to the instructive Plates iii-viii given by Dr. J. Crichton Browne in his most valuable paper, already referred to, in the West Riding Asylum Reports, vol. vi. 1876, on the pathology of the general paralysis of the insane. In those plates a number of brains from such patients are figured, and so coloured as to indicate the regions of the brain upon which the stress of the disease has fallen. There is in these plates scarcely an instance in which a single patch of colour is given on a spot situated posteriorly to the fissure of Rolando. And I submit that as it is but reasonable to suppose that the parts of any organ which are found to be the most liable to suffer from irritation, inflammation, and other morbid action are so because normally they are the seats of habitual activity, this distribution of the signs of disease over the area in question is of cardinal significance.

In the last place, I will mention very briefly the indications which the comparative anatomy of some of the various races of mankind, and of the developing skull and brain in the human species, as also the proportion of two segments of the parietal bone anterior and posterior to the line of the primitive centre of ossification, furnish to us in this investigation.

tion of nitrogen, such increase did nevertheless take place when a certain interval had elapsed after such exercise, explained (p. 55, l. c.) this succession of phenomena by suggesting that 'during action a muscle takes nitrogen and during rest gives it off,' or that, 'in other words, the action of a muscle would seem from these experiments not to be connected with disintegration but with formation; when it is in exercise the muscle increases, when it is quiescent it lessens in bulk.' 
The most typically dolicho-cephalic modern race, not even excluding the Esquimaux, is beyond doubt the Australian. As was pointed out long ago in the Osteological Catalogue of the Royal College of Surgeons, vol. ii.p. 838, No. 5385, brachy-cephalic skulls are to be found amongst Negro tribes, and (see p. 670 supra) instances may be found among Negro brains of excessive narrowness in the zone of brain between the supra-marginal and the occipital convolutions, though some of the most forwardly placed parietal tubera which I have ever met with are from series of Caffre crania; and though, secondly, these tubera are sometimes backwardly placed even in dolicho-cephalic Negro heads. Confining ourselves therefore to the consideration of the Australian cranium, which furnishes us with a simple case, as its uniformity and also the degraded character of the race are alike beyond dispute, we have to say that the parietal eminences all but always occupy a relatively forward position in the parietal bone and in the skull of the Australians ; and that to the unvarying dolicho-cephaly of their brain the segments lying posteriorly to the plane of the 'lobulus tuberis' always contribute a quantitatively large though not a qualitatively superior proportion. Without going further into the controversy alluded to at $\mathrm{pp}$. 646-647 supra, as to the relative superiority of the dolicho-cephalic or brachy-cephalic type, it may suffice to say here that not only would the inferiorly irrigated and histologically inferior segments of the modern European dolicho-cephali found in Germany, England, and Ireland form a smaller proportion of the entire length of their brains than, judging from their skulls or from such casts as those labelled 6 and 7 in the Museum of the College of Surgeons, the homologous segments do in the Australian brain, but that the anterior segments of the European brain are broader, with their fissures therefore deeper, and their aggregate square area of grey matter much more extensive than those of the Australian brain; the Europeans specified being dolicho-cephali latiores, and the Australians dolicho-cephali angustiores. But the dolicho-cephalic 'Silurian' type which characterised the inhabitants of Great Britain and Ireland, and of a very great part of Europe also, in the stone age, included crania resembling the Australian in the points of which we are speaking, for the long-barrow-builders were not rarely 'dolicho-cephali angustiores ${ }^{1}$.'

${ }^{1}$ If Schröder van der Kolk's calculation as to the extent of that difficultly measurable area made up by the surface of the convolutions within and without the fissures from the fissure of Rolando to the front of the brain in men of various degrees of 
The argument from the history of the growth of the skull which comes under this head eannot be given better than in the following words of Gratiolet (Bull. Soc. Anthrop. Paris, tom. ii. Avril 18, 1861, p. 253): 'Chez l'enfant nouveau né le centre du point primitif d'ossification du pariétal est plus distant de l'extremité occipitale du crane que de son extremité frontale. Le cas inverse est realisé dans l'adulte. On deduit de ces faits une conséquence rigoreuse savoir que dans le passage de l'enfance à l'âge adulte les parties antérieures du cerveau s'accroissent plus rapidement que les parties postérieures. Cet accroissement marche d'arrière en avant de l'occipital au frontal, il se propage comme une ondulation d'une vertèbre à l'autre.'

The maintenance therefore by the part of the parietal posterior to its tuberosity, a part representing its primitive centre, of a pro-

intelligence had been accepted and confirmed by other anatomists, another argument would have been available under this head. According to these calculations (Pathology and Therapeutics of Mental Diseases; Australian translation by J. T. Rudall, 1869, preface, p. vi), based upon measurements of the figures given by Rudolph Wagner in the first part of his 'Vorstudien zu einer wissenschaftlichen Morphologie und Physiologie des Menschlichen Gehirns als Seelenorgan,' 1860, the 'lobus anterior before the gyrus centralis' held to the 'lobus anterior behind the gyrus' the relation,

in the mathematician Gauss _. of $88.5: 100$.

in the mathematician Lejeune Dirichlet of $100: 100$.

in the philologist Hermann - . of $75: 100$.

in the artisan Krebs . $\quad . \quad \quad . \quad$ of $69: 100$.

Schröder van der Kolk in writing to this effect, Nov. 21, 1861, to Dr. Theile of Weimar, l. $c$., remarks that ' it will be understood that this gives only a relative value and a relative accuracy, for I measure the plane and not the arched surface, but after all that occurs in a tolerably equal degree in all the measured brains. I am convinced it would lead to good results if comparisons were made in this way between the brains of persons of talent and those of less mental capacity.' But Rudolph Wagner, to whom the actual brains were available, whilst Schröder van der Kolk's estimate was based merely upon Wagner's figures of them given in his 'Vorstudien' of 1862, repudiated (Vorstudien, 1862, ii. p. 21) the Dutch anatomist's conclusions. And Hermann Wagner, following up mathematically his father's researches in his 'Maasbestimmungen der Oberfläche des grossen Gehirns,' 1864, p. 36, averred that the only difference which his more exact method of measurement, as applied to the difficultly measureable area in question, in four brains examined by him, including those of Gauss and Krebs, had enabled him to discover was that with the increase of intelligence the complexity of the convolutions increased in the frontal, but not demonstrably in the other lobes of the brain: 'Eine Bevorzugen eines einzelnen Lappens und zwar des Stirnlappens gegenüber dem ganzen Gehirns hat sich für die intelligenten Gehirne aber doch durch diese Messungen herausgestellt; die Oberfläche des Stirnlappens derselben besetzt eine starkere Zerkfluftung als die übrigen Lappen.' It is obvious, I may remark, that any argument which could be based upon mere mensuration of the square area made up by the convolutionary sheet of gray matter in various segments of the brain would be more amenable than any of the lines of argument given in the text to objections on the ground that such measurements took no account of possible variations in the thickness firstly, and in the quality secondly, of the sheet of gray matter. 
portion at all approaching equality with the part anterior to it is a retention of infantile proportions, and pro tanto a sign of inferiority.

Mutatis mutandis a comparison of the skulls of the anthropomorpha leads us to a similar conclusion. In those apes though the lobule of the marginal convolution and the parietal eminence corresponding to it are only faintly marked; and, though the Asiatic Orang is often less dolicho-cephalous than its African allies; still the primitive centre of ossification of the parietal bone which may be supposed to hold the same relation to the subjacent brain which the homologous area in the human skull is wont to do, divides the bone, in all of these Simiadæ, into two much more nearly equal segments than is usually the case in the adult human subject.

Thus from the four points of view furnished by considering their irrigation, their histological structure, their relative activity as indicated by their greater amenability to the incidence of disease, and their comparative anatomy, the anterior parts of the brain of which we have been treating can be shown to be superior in importance to those which lie posteriorly to them. The convolutions which are curtailed in the posterior part of a brain with its anterior segments relatively large are those which underlie that zone of the skull which is interposed between parallel lines drawn over the parietal tuberosity and over the line of the lambdoid suture. Hence the importance of the two craniographical peculiarities, viz. the posterior position of the parietal tubera (p. 637 supra) and the vertical dip of the posterior half of the bone (p. 638 supra ibique citata) so characteristic of the brachy-cephalic skull, and so clearly indicative of a brain, pro tanto and ceteris paribus, favourably conditioned and advantageously constituted. And the rationale of a third craniographical distinction, that, namely, which is given in the 'Antero-posterior Index' (p. 563 supra), lies in its furnishing us with a more or less exact numerical expression of the relative extent of the more favourably conditioned segments of such brains. The average antero-posterior index of the dolichocephalic skull as obtained from the measurements, given with the descriptions, of the small number of 'Silurian' skulls figured in this book, is 47 as against 52 for the average of the brachy-cephalic 'Cimbric' skulls, also figured here; and this disadvantageous proportion is only reduced by a fraction amounting to $\frac{1}{6}$ when we compare the average obtained from six other prehistoric Silurian 
skulls not figured in this book with the average obtained from six other brachy-cephalic skulls taken from Swiss, English, and Tamil series. These figures may be taken as being strongly confirmatory of the other evidence for the inferiority of the Silurian dolichocephalic to the Cimbric brachy-cephalic race which is furnished by several other physical peculiarities (see p. 641 seqq. supra and p. 680 infra), as well as by the historical or rather prehistorical fact of its having been conquered and in some parts of this country displaced. and replaced by the later stock.

To obtain, however, a complete idea of the characteristics of a people, it is necessary not only to know what their stature and what the proportions of their skull measurements may have been, both in themselves and in relation to the brain-segments they covered; but to be able to reproduce to our view their complexion and the colour of their eyes. These latter points indeed, of which the barrows can tell us nothing, are to the ordinary traveller an enquiry at least as interésting as even the stature, and though it is possible to overrate their value and importance to the ethnologist, at all events when he is dealing with races as capable of complete fusion as those whose remains we are here concerned with, they still possess, even for him, an interest which is little inferior to that of the less perishable remains.

In Europe at the present day we have the following combinations of complexion and stature and cranial indices. We have, firstly, in certain parts of Great Britain and of Germany light hair and complexion combined with considerable stature and with dolicho-cephaly, so as to preserve for us what excavations, combined with measurements and with traditions, justify us very entirely in speaking of as the Teutonic or Germanic type ${ }^{1}$. Secondly, we have the same hair, complexion, and stature combined with brachy-cephaly in the Finns ${ }^{2}$, in the Danes ${ }^{3}$, in some Sclavs, and in many of not the least vigorous of our own countrymen. Thirdly, hair, complexion, and stature, all alike of just the opposite character, may be found combined with brachy-cephaly in South Germany, and in some other parts of the Continent, as,

${ }^{1}$ See Hölder, Archiv für Anthrop. ii. p. 51; v. p. 538; Zusammenstellung der in Wurttemberg vorkommenden Schädelformen, 1876, p. 6 ; and Cleland, Phil. Trans. 1870, p. 148.

${ }^{2}$ Virchow, Beiträge zur physischen Anthropologie des Deutschen 1876, pp. 9, 10; Zeitschrift für Ethnologie, iv. 380, v. 320; Archiv für Anthropologie, iii. 553-555, iv. 78 .

${ }^{3}$ Dr. Beddoe, Mem. Soc. Anth. Lond. vol. iii. p. 382. 
for example, Brittany ${ }^{1}$. Fourthly, and as regards the earlier of the two prehistoric races with which we are dealing, most importantly, we have in this country dolicho-cephaly combined with low stature and with dark complexion in a very considerable number of our population, even in districts such as the Midland Counties, where the names of the towns and villages show that the Saxon and Danish conquerors occupied it in for the time entirely overwhelming numbers. The fact of the existence of this stock, or, we may perhaps say, of its survival and its reassertion of its own distinctive character in the districts of Derby, Stamford, Leicester, and Loughborough, was pointed out in the year 1848 by the late Professor Phillips, at a meeting of the British Association at Swansea (See Report, p. 99). More extended observations, but to the same effect, are put on record by Dr. Beddoe (Mem. Soc. Anth. London, ii. p. 350) in the following words: 'Of twenty-five Englishmen having black or brownishblack hair, the average index of head-breadth is so small as 76.5 , which is the lowest I have met with in any set of men. Eight Welshmen having black hair yielded the same modulus to a

I Hölder, Zusammenstellung, p. 6, says, 'Aus dieser Zusammenstellung geht nun mit Sicherheit hervor dass Haare und Augen um so heller werdem je naher der Index des Germanischen Typus kommt, und desto dunkler je brachycephaler der Schädel ist. Blaue und graue Augen und blonde oder hellbraune Haare so wohl hier als in Waiblingen häufiger mit hoher Statur vorkommen als dunkle Augen und Haare. Der Hauptmasse der letzteren fällt nämlich auf die grossen Classe von 166-176 cm. $\left(=65 \cdot 35^{\prime \prime}-69^{\cdot} \cdot 29^{\prime \prime}\right)$; Zwischen 176 und $182 \mathrm{~cm} .\left(=69 \cdot 29^{\prime \prime}-71 \cdot 6^{\prime \prime}\right)$ fanden sich nur blaue und graue Augen und der grosste von ihnem mit $182 \mathrm{~cm}$. war blond und blauaugig.' Ecker (Archiv für Anthropologie, ix. 1877, p. 259) says, writing from Freiburg im Breisgau, ' Die in unserem Lande einst so verbreitete Schädelform der Reihengräber die wohl unzweifelhaft auch mit einer bestimmtere Körperstatur verbunden war, jetzt fast ganz einer anderen Form Platz gemacht hat deren Träger in ihrem ganzem physischer Habitus anders geartet sind als jene es wahrscheinlich waren. Waren jene hoch gewachsen vorherrschend blond so sind diese gedrungener dunkler vom Haar und Augen.' Of the Bretons, Dr. Beddoe (Memoirs Lond. Anth. Society, iii. p. 362) says they are of low stature, being remarkable for this even among the French, that in about three-fourths of the people the hair is very dark, and is about one-fourth coalblack, and that the head is, as Broca had pointed out, short and broad, with the exception of the Léonois district. Broca, writing of Bretons (see Mem. Soc. Anth. Paris, i. 1859, or Mémoires d'Anthropologie, i. p. 297 ; and Bull. Soc. Anth. Paris, Ser. ii. tom. viii. p. 313, Avril 1873), contrasts the Celtes $s$. Armoricains, being petits, bruns, brachy-cephales, with the peuples Belges $s$. Kymrys, who are grands, blonds, dolichocephales. Sir Henry Dryden, Bart., writes to me of the Bretons to the following effect:- 'As compared with the English the whole race are brachy-cephalic, but the Breton peasantry much less so than the middle class. The Bretons are taller than the other French. I noticed in the regiments many very short small men, and I think almost all the swarthy men were small. Many were very swarthy. Many of the middle class not Bretons are ludicrously brachy-cephalic, and their necks often thicker than most English besides.' 
fraction as thirty-eight who had hair of other colours, though I must concede that eight black-haired Kerrymen had heads broader by $\frac{1}{2}$ per cent. than twenty-four others. The observations of my friend Mr. Hector Maclean on the islanders of Islay and Colonsay bear me out on this point very strongly, his black-haired men, twenty in number, yielding a modulus of seventy-six, or 3 per cent. less than that of their lighter-haired neighbours. $M r$. Maclean's measurements and my own both indicate that a notable, though not very great inferiority in stature and bulk, does, on the average, characterise the black-haired tyne.'

The tall powerfully-made brachy-cephalous Briton of the roundbarrow period all but certainly presented much the same combination of physical peculiarities as the modern Finn and Dane, whilst of the feebler folk of the long-barrow times we may say with nearly equal probability that they possessed, like the modern English, Irish, Scotch, and Italian of similarly low stature, the colorati vultus ascribed by Tacitus to the Silures, and supposed by him to furnish some ground for connecting them with the Spanish. The indications in favour of these views are as follows. The bronzeperiod Briton very closely resembles in his osteological remains the brachy-cephalous Dane of the neolithic period, and the likeness between these and some of the modern Danes has been noticed by Virchow in his valuable Memoir on Die altnordischen Schädel zu Kopenhagen Arch. für Anth. iv. p. 71, 1870. There are not wanting, as already pointed out, p. 631 supra, reasons for supposing that the brachy-cephalic people of the round-barrow period may have immigrated into this country from the Cimbric Peninsula ${ }^{1}$, that, in other words, the historical invasions of Cnut and Swegen

1 Of the modern Danes we know from Dr. Beddoe's paper in the Memoirs of the Anthropological Society, vol. iii. p. 382, that with the cephalic index of 80.5 they combine a stature of $5^{\prime} 69^{\prime \prime}$, which would be a fair average for Great Britain, eyes which are almost always light and either blue or bluish-grey, and hair which is generally either pale yellow or light brown. It would be interesting to know whether in the exceptional cases, in which the hair is black, as in the Moen man of whom Dr. Beddoe writes, the colour was not light in infancy; this change being one which is often observable amongst us now, as indeed it was among the Gauls in the time of Strabo and Diodorus Siculus (and, as Mr. A. J. Evans informs me, among both the Finns and the Lapps), and being one which, upon the principles of modern zoology, should be taken to indicate that the parent stock was originally light-haired perma-

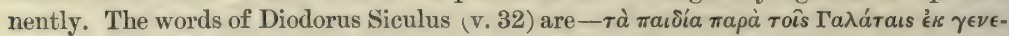

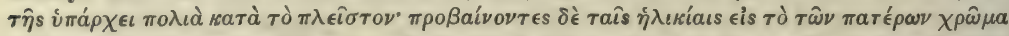

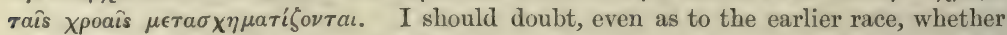
Jornandes, when he, in the words of Lipsius, adspexit imo transuripsit the chapter xi. of 'Tacitus' Agricola relating to the Silures, had any real reason for substituting ' torto plerique criue et nigro nascuntur' for the exact words of the great historian. 
may have been but repetitions of prehistoric invasions of the bronze period, of, in other words, earlier 'Wikingzüge.' This being so, it becomes of consequence to recollect that though the ancients, the contemporaries of the Cimbric invaders, differ as to speaking of them as 'Gauls' or 'Germans,' they are unanimous as to describing them as light-haired and blue-eyed, as well as tall of stature, in comparison at least with the Italian population, Horace's line, 'Nec fera cærulea domuit Germania pube' (Epod. xvi. 7), being supported by parallel ${ }^{1}$ passages nearly infinite in multitude.

I have already remarked, pp. 628-629 supra, that intermediate forms, belonging distinctively to neither the one nor the other of the two great types of dolicho-cephaly or brachy-cephaly, are not common in these series. In the skulls of the stone age in Great Britain we find no unambiguous traces at all of any admixture with the brachy-cephalic type; and even amongst skulls from barrows of the bronze age, when the two races were living and dying together, it is rare to find skulls which combine, as the 'Mischformen' of the German anthropologists do, the contour and picturesque peculiarities of the one type with the proportions and measurements of the other. Still such forms are to be found, and there are two principal varieties of skull from the later period, the existence of which it is perhaps better explained by the hypothesis of their being the result of intercrossing than in any other way. And, firstly, I should be inclined to consider the very large size $^{2}$ of certain crania of the bronze period as due to an

${ }^{1}$ For these see Ukert's Germania, pp. 198, 199, 345, 347, 348, 353, 362 ; Zeuss, Die Deutschen, p. 51 ; Perier, Fragments Ethnologiques, pp. 43-82 ; Prichard, Physical History, iii. 3rd ed. 1841, pp. 189-200. The Chevalier Bunsen is referred to by Prichard as saying that he had 'often looked in vain for the auburn or golden locks and the light cærulean eyes of the old Germans, and never verified the picture given by the ancients of his countrymen till he visited Scandinavia, and that there he found himself surrounded with the Germans of Tacitus.' Exact investigation has however recently shown (see Virchow, p. 11, Beiträge zur physischen Anthropologie der Deutschen, 1876, Berlin Abhandlungen) that the physical characteristics of light hair, blue eyes, light skin, so constantly spoken of by the ancient writers, make up still no less than 35.47 per cent. of the children at school in Prussia, though the proportion falls to $20 \cdot 36$ per cent. in Bavaria, brunettes being in this latter country $21 \cdot 09$ per cent. against 11.63 in Prussia.

${ }^{2}$ Without extending our view to the lower animals, it is easy to convince ourselves that a great increase of size is very often at the present day a result of the intercrossing of two varieties of our own species. V. Baer, on the occasion of the famous meeting of anthropologists at Göttingen in 1861 (see Zusammenkunft einiger Anthropologen, p. 22), drew attention to the increase of vigour which Baron Osten Sacken had observed amongst North American half-breeds; and Professor Daniel Wilson, in his Memoirs on Hybridity, p. 27, 1875, writes with great particularity to 
intercrossing of the two stocks. Such skulls are all found in barrows of the later period, and all, while retaining both the contour and the proportions of the brachy-cephalic type, still exceed the great majority of such skulls in the matter of cubical capacity. His and Rütimeyer consider the largest of the skulls treated of by them in their Crania Helvetica (p. 44), skulls to wit with an average capacity of 1638 cc. $=$ circa 100 cub. in., a maximum of $1820 \mathrm{cc} .=$ circa 111 cub. in., and a minimum of 1430 cc. $=87 \cdot 27$ cub. in., to be the result of the intercrossing of their 'Sion typus,' which is the skull of the 'Pfahlbauten' and (p. 34) 'unserer Keltischer Vorfahren' and corresponds to many of our long-barrow skulls, with their 'Disentis Typus,' which corresponds to many of our round-barrow skulls. It is of great importance to note this coincidence as to the facts observable in Switzerland and in Great Britain respectively.

A second variety of skull, which I incline to consider a 'Mischform,' is found in round barrows containing both dolicho-cephalic and brachy-cephalic crania, lying together peacefully and in equally honourable positions within their precincts. These skulls differ from those just spoken of in being dolicho-cephalic by measurement, but they resemble them in combining with this proportion of breadth to length the precipitous dip downwards of the posterior half of the parietals which is so characteristic of brachy-cephaly generally,

the same effect in the following words: 'The Half-breeds are a large and robust race, with greater powers of endurance than the native Indian. Mr. S. J. Dawson, of the Red River Exploring Expedition, speaks of the French Half-breeds as a gigantic race as compared with the French Canadians of Lower Canada. Professor Hind refers in equally strong language to their great physical powers and vigorous muscular development; and the venerable Archdeacon Hunter, of Red River, replies in answer to my inquiry, "In what respects do the Half-breed Indians differ from the pure Indians as to habits of life, courage, strength, increase of numbers, \&c. ?" "They are superior in every respect, both mentally and physically." Much concurrent evidence points to the fact that the families descended from mixed parentage are larger than those of the whites; and though the results are in some degree counteracted by a tendency to consumption, yet it does not amount to such a source of diminution on the whole as to interfere with their steady numerical increase.' Similarly, Mr. Huth (Marriage of near Kin, 1875) writes, p. 308, that 'crosses are beneficial in very often effecting an increase of size in the progeny, exceeding that of either parent, is established beyond doubt.' pp. 324 and 325. 'The Zamboes, or offspring of Negroes and American Indians, are, according to Dr. Hancock, remarkable for their physical superiority over their progenitors on either side, and this he says is a well-known fact.' Per contra, 'Most of the criminals of Nicaragua are, according to Squier, Zamboes, bigger and better made than their parents, without possessing any of their good qualities.' Dr. Beddoe's investigations into the stature and bulk of man in the British Islands (Mem. Anth. Soc. iii. 553) have led him to say, 'on the whole, the results of my tables tend to support, but only in a feeble way, the current opinion as to the advantageous effect of crossing upon size.' Professor Broca (Mémoires, i. p. 342) says, 'L'amélioration des races par des croisement est fortement contestée aujourdhui ;' but he should have added, I think, words limiting the dispute to France. 
and the great height which is so characteristic of the brachycephaly of prehistoric times. A skull figured by Dr. Ad. Pansch (Arch. für Anth. vi. 3, p. 175, 1873) as found in a deposit cut into in the excavations for the new harbour at Kiel and in surroundings which, without definitely proving the skull to have belonged to the stone age (pp. 174, 179), did yet vindicate for it claims to a very considerable antiquity, gives a very good representation of this form of skull. Another may be found in the ancient British skull from a barrow at Kennet, near Abury, North Wilts, figured and described in the Crania Britannica, Pl. 11, by Dr. Thurnam. Some additional probability for the view which would consider these skulls to be 'Mischformen' is on the principle laid down in note 3, p. 636 supra, gained from the fact that this latter skull had belonged to a skeleton with a thigh of $205^{\prime \prime}$, and by consequence to a man of not less than $6^{\prime} 2^{\prime \prime}$ in stature. Neither of the authors touch upon this point in treating of these skulls; they coincide with each other in observing upon the great height and the vertical dip of the posterior part of their parietals. As regards the series of prehistoric crania with which I am dealing, I have to say that whilst skulls of this kind are by no means rare in interments of the bronze period (e.g. ' Flixton, lxxi. 12,' p. 278 ; 'Jarrett, civ.' p. 315 ; 'Sherburn Wold Prodham, ix. 1 ;' 'Paulinus, cxiii. 3,' p. 322), they form a considerable proportion of the skulls from Canon Greenwell's series of the late Keltic or early iron age of Great Britain, and are entirely wanting, so far as I have observed, in the series from the long barrows. The skull from Grimthorpe in the East Riding of Yorkshire, described in the Proceedings of the Society of Antiquaries, March 18, 1869, by Dr. Barnard Davis, and now in the Oxford University Museum; the skull from Arras in the same locality, figured and described by Dr. Thurnam in the Crania Britannica, Pl. 6; and a skull from Crosby Garrett (see p. 386 supra) in the county of Westmoreland, may be mentioned as combining the peculiarities above spoken of with the archæological surroundings of the comparatively short period between probably, at the utmost, 200 B.C. and 100 A.D. Mere etymology might lead a reader to suppose these lofty yet dolichocephalic skulls might resemble the 'Hypsisteno-cephali' of the Melanesian islands described by Dr. Barnard Davis (locc. citt. supra, p. 650), they differ however from these skulls in being larger in cubical contents; in being better filled out, especially in the frontal region; in being orthognathous; and above all, in having their parietal tubera far more backwardly placed. See p. 454 supra. 
I will now pass from the consideration of the skulls as found in a more or less perfect condition, or at least in one which has admitted of their being, partially at least, restored, to a consideration of certain conclusions which have been based upon the appearances presented by the fragments into which the prehistoric skulls are, so often and so unfortunately, found to be broken.

Dr. Thurnam has in several memoirs ${ }^{1}$ argued from the appearances presented by the breakages observable in the skulls from long barrows to the existence of the practice of human sacrifice upon the occasion of the interment of the chiefs in the stone age. We have a large mass of literary evidence in favour of the continuation of this practice into historical times amongst the Gauls and other foreign races with whom the Romans and Greeks came into contact. The story of the funeral of Patroclus preserves for

${ }^{1}$ As regards the literature of the supposed discovery of skulls cleft ante mortem, the following references may be given:-

Mr. Cunnington in 1801 (Ancient Wilts, Sir R. C. Hoare, i. 87, cit. Thurnam, Archæologia, xxxviii. p. 420) found in a long barrow near Heytesbury, called Bowl's Barrow, a number of skeletons crowded together at the east end, the skull of one of which appeared to have been cut in two by a sword.

Sir R. C. Hoare writing in 1817, Archæologia, xix. p. 48, says, 'Only one or two instances have occurred where we have found any defect or pressure on the skull, indicating a mortal wound : but in one of the barrows near Stonehenge, we dug up a skull which appeared to have been cut in two by some very sharp instrument, and as nicely as any instrument of Savigny could have effected. This skull was reinterred in the same barrow.' A Round Barrow, Tumulus 36, Ancient Wilts, p. 163.

Dr. Thurnam, writing in 1855 in the Crania Britannica, pl. 24, Littleton Drew, says (p. 3) of the fragments of a skull, that 'the fractured edges were very sharp, suggesting the idea of having been cleft during life.' Writing in the Archæologia, xxxviii. 1860, of the long barrow at West Kennet, Wiltshire, Dr. Thurnam dwelt at greater length upon this subject, saying that the occurrence of such cleft skulls was curious and had 'an important bearing on the estimate to be formed of the general grade of civilisation of those who must be regarded as our remote ancestors.' His views were still further developed in the Memoirs of the London Anthropological Society, 1865, as also in the Journal of the Archæological Institute of the same year, vol. xxii. p. 107, in which he describes the appearances presented by the Ebberston skulls now in the Museum of this University. In the Crania Britannica, pl. 59, Dr. Thurnam, in his account of the skulls from the chambered long barrow at Rodmarton in Gloucestershire, examined by Canon Lysons in 1863 (see Proc. Soc. Ant., N. S. ii. p. 275, or his work, 'Our British Ancestors,' p. 137, 1865), describes and figures from that barrow a skull now in this Museum as an example of a skull cleft ante mortem; remarking ( $\mathrm{p} .4$, note) that another of these supposed cleft skulls, from West Kennet, was like the Rodmarton specimen in having the frontal suture open, whilst the uninjured skulls were of a considerably more elongate type. Finally, in the Archæologia for 1869 , vol. 42 , pp. 185-188, we have the evidence as to human sacrifices restated with many references, and we have also appended to it the allied subject of anthropophagism; at p. 227 we have the Rodmarton skull, now before me as I write, figured; and the author states that the chambered barrows of Nympsfield and Charlton Abbots are the only instances of such barrows examined by him in which traces of violent cleavage of cranial bones had not been found. 
us a tradition of its existence amongst the Greeks themselves ; and from Virgil's allusions (Eneid, x. 518-520, xi. 81, 82) and Tertullian's suggestion (De Spectaculis, xii) as to the origination of gladiatorial shows from the sacrificing of men at funerals, we know that the Italian races were at one time guilty of the same cruelty. 'Necdum ea ætate,' says Heyne, Virg. l.c., 'metuendum fuit Maroni ne displiceret immane facinus lectoribus,' such sacrifices having been abolished, as Pliny (H. N. xxx. 3.4) tells us, by the Romans, only in the year 97 в.c. Still, in spite of these familiar and a cloud of other testimonies ${ }^{1}$ of the literary kind in favour

1 As regards the literature of immolation at funerals, the following references may be given in addition to those given in the text :-

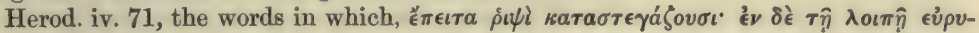

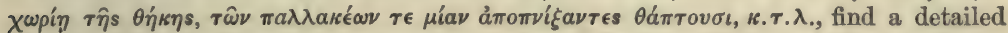
illustration in Mr. Joseph Anderson's translation of Professor Holmboe's Danish version of the Arabic account by Ahmed Fozlan of the cremation of a Norse chief, Proc. Soc. Ant. Scot., May 13, 1872, especially p. 525. Dr. Joseph Anderson, l. c. p. 522, refers to the Volsunga Saga as giving an account of the erection of a tent by Brynhild Gunnar over the pile on which she was to be burnt with Sigurd's corpse. J. C. F. Baehr, vol. iv. p. 560 of his 1832 edition of Herodotus, supplies the following references from Clarke's Travels in illustration of the account given by Herodotus of the funeral of a Scythian chief : i. pp. 32, 38, 199, 316, 338 coll., 354, 399, 432 seqq. I have not been able to verify these references, and they are omitted in Baehr's later edition, $l$. $c$. I owe to him however many of the following references bearing principally upon the practice of widow-immolation :-

Hdt. v. 5 .

Cicero, Tusc. Disp. v. 27.

Diodorus Siculus, xvii. 91, and xix. 33, 34 .

Strabo, xv. 1. 30. 699; xv. 1. 62. 714.

Propertius, iv. 12-15.

Nicolaus Damascenus, fragm. 143, 155-161; 3. 463.

Valerius Maximus, ii. 6.

Plutarch, ii. 499.

Mela, ii. 2; iii. 2.

Pausanias, iv. 2. 5.

Allian, V. H. vii. 18.

Servius, fl. A.D. 390, ad Verg. AEn. vi. 228.

Theodoret, Or. ad Græecos, ix. p. 129.

Stephanus Byzantinus, s. v. Гєті́⿱一土㇒.

With reference to this last-cited author it may be remarked that he makes no mention of any competition existing between the widows for the right of immolation on the occasion of the husband's death. To the fact, however, of such a competition existing we have the evidence, whatever it may be worth, of Herodotus v. 5, Cicero, Propertius, Diodorus, Strabo, Valerius Maximus, Nicolaus Damascenus, and Mela, loce. citt.

Grimm, Das Verbrennen der Leichen, Kleinere Schriften, p. 300, agrees with Strabo, xv. 1. 30, in considering as inadequate the reason reported or assigned by both Strabo and Diodorus, xvii. 91, for the origin of widow-burning, an institution for the establishment of which, as we know from Professor Max Mäller, 'Chips from a German Workshop,' ii. 34, ibique citatis, it was necessary to falsify the Vedas. He does not say why he repudiates the reason mentioned by those two writers, ö $\tau \iota$ é $\rho \hat{\omega} \sigma a$ l

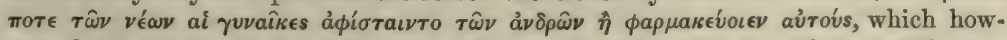
ever does not appear a wholly improbable one; nor, though he refers, p. 296 note, 
of the practice of human sacrifice having persisted in this part of the world into perfectly historical times, 'paullo supra hane memoriam,' as Julius phrases it, Bell. Gall. vi. 19, I have to say that the bones found in the long barrows of England do not seem to me to bear the interpretation which Dr. Thurnam has put upon them. Two of the sets of bones from long barrows which Dr. Thurnam has described as furnishing evidence which would 'convince the most incredulous,' those, to wit, from the Ebberston and those from the Rodmarton long barrows, are now in the Oxford University Museum, and I have compared them with a considerable number of skulls about the ante mortem character of the lesions on which, whether recovered from or not, there is no doubt whatever. Amongst these latter skulls I may specify a number of dried and prepared New Zealand 'heads' in the Oxford University Museum, and the skulls numbered $2880 \mathrm{~A}, 2880 \mathrm{~B}, 2880 \mathrm{C}$, and $2902 \mathrm{~A}$ in the Museum of the Royal College of Surgeons. - By the kindness of Professor Humphry I was allowed to examine Dr. Thurnam's collection in the Anatomical Museum at Cambridge.

The first point in which the fractured portions of skulls known to have been fractured ante mortem contrast with several of those described by Dr. Thurnam is their great inferiority in mere number. The skull of a man whom we know to have been hewn down by a metal sabre, or to have been killed, as the New Zealanders are known to have been, by a stone axe, may have some two or three

to Professor Max Müller's article, Zeitschrift der morgenl. Gesellschaft, bd. ix. 1855, does he specially mention the fact of the falsification of the Vedas. It is less excusable that Grimm should have written of the practice of widow-burning, of which both Strabo and Diodorus had spoken with reprobation, in the following terms, p. 307 :-

'Wie hat sich die oft gefühllose Weichherzigkeit der neueren Luft gemacht gegen den herben Brauch des Mitverbrennens der Frauen im Alterthum, und doch billigen wir, dass die Ehe, wenn sie ihres (Gesetz ausdrückenden) Namens werth sei, ewig und unauflösbar heisze, und preisen als seltnes Glück, dass hoch-bejahrte Ehleute auf denselben Tag hingerafft werden. Denn erhebend ist es wenn gesagt werden konnte

'Bis sex lustra tori nox mitis et ultima clausit,

Arserunt uno funera bina rogo.' Martial, 10. 71.

Further references may be found in the Antiquitates Danicæ of Thomas Bartholinus, 1689, who says, p. 556, 'pleni sunt Historicorum libri, varias apud nationes, uxores maritis superstites simul cum defunctis crematos, vel super corpora eorum interfectas.'

In a later work on Danish antiquities, Arnkiel's Cimbrischen Heyden-Religion, 1702, four chapters, $x v-x$ viii. pp. 97-135, are devoted to the four subjects of the burial of wives with their dead husbands, the burial of friends, the burial of captives, and the burial of slaves in honour of great men deceased.

Professor H. Schaaffhausen's article, 'Die Menschenfresserei und das Menschenopfer,' in the Archiv. für Anthropologie, iv. 1870, p. 245, is the most recent and one of the most valuable memoirs upon this subject. 
broken surfaces in its vault; in the skulls on which Dr. Thurnam bases his inferences 'the angular fragments are so numerous that one might suppose the gashes had been inflicted in sheer wantonness ;' Cran. Brit., pl. $59^{1}$.

Now I submit that the principle of least action is at least as likely to have regulated the proceedings of ancient as of modern manslayers, and that the very fact of these ancient skulls being broken into such a multitude of fragments, a comminution which would have entailed an amount of trouble as purposeless in the eyes of those who would have had to go through it as it is repulsive in ours, is a prima facie improbability of the very first magnitude against the interpretation in question.

Leaving purely quantitative considerations and coming to the character of the fractures in each of the two sets of skulls, I have in the second place to say that the broken surfaces in the skull fragments described by Dr. Thurnam are, in spite of the very considerable variety which is observable in skull-surfaces, howsoever and whensoever fractured, very different as a whole from those of skulls which we positively know to have been cut into and through during life or immediately after death. It is true that the cut surfaces described by Dr. Thurnam may have a 'clean' and 'porcellanous' appearance; but in answer to this I have to say, firstly, that I have seen perfectly similar surfaces produced in the very old and altered skulls in question by accidental falls or impact or pressure; and that it was an occurrence of this kind happening in the case of a skull-bone from the cremation long barrow at Market

1 A nearly equally valuable standard of comparison is furnished to us by the figures and description of chopped horses' bones given by Professor Engelhardt in his 'Denmark in the Early Iron Age,' pp. 70-71 (Eng. Trans. 1866). Of two of the skulls of these horses it is said that the incisions upon them are 'both deep and numerous,' one of them showing as many as six, the other as many as ten different cuts. The skulls from the long barrows are, unhappily for the interests of reconstruction, broken into much more numerous fragments; and Professor Steenstrup does not believe that the horse-bones in question were so cut while the animals were living, or had their flesh upon them; for ' a minutely-splintered fracture has been produced by the chip having been broken away from the bone by a vigorous twist of the sword, leaving a smooth sharply-cut surface; and this circumstance seems to indicate that these violent blows had been inflicted when the bones were no longer covered by flesh; for, if the flesh had still been on the bones, these would probably have presented a more jagged or roughly splintered fracture.' The words in italics relate to a state of things quite different from that quite correctly described by Dr. Thurnam (Principal Forms of Ancient British and Gaulish Skulls, 1865, p. 70) as presenting us with 'the edges of the divided bones perfectly sharp and clean, and the fragments themselves having a porcellanous character,' The reference to Engelhardt's work I owe to John Evans, Esq., F.R.S. 
Weighton which first opened my eyes to the questionableness of Dr. Thurnam's theory. But, secondly, the broken surfaces in the skulls from Ebberston and Rodmarton have both their tables broken in the same or very nearly the same plane, and though an incision of this kind can be effected in a living skull by a vertically delivered blow, as it is not rarely effected in a dead and buried skull by a spade, the immense majority of wounds which we find on skulls known to have been struck by sword or axe have been inflicted in the way of oblique impact, as proved by the prismatic chip of bone which they have forced up out of its proper relations. It is well known that it is common enough even for a well-directed thrust with 'that queen of weapons the bayonet' to be deflected into innocuous obliquity even by such a surface as that of a rib; much more then would a stone-weapon be liable to be deflected from the denser and more resistent surface of the more mobile skull. Hence if these prehistoric crania had really been battered by prehistoric weapons we should expect to find a very large proportion of obliquely received wounds upon them. Just the reverse of this is the case with the fragmentary skulls which Dr. Thurnam and I myself have obtained from the long barrows both of the cremation and the non-cremation kinds. Numerous as are the fragments into which these skulls are broken up, it is rare for the line of fracture to pass otherwise than vertically through both tables, or to leave the inner table either projecting beyond the plane of the broken surface of the outer one or broken away for a greater square area than that lamina. The appearance presented by an aggregate of such skull-fragments is not unlike the aggregate of fragments resulting from the discharge of a firearm, pistol or other, so close to the base of the skull as to subject its vault to the sudden and enormous tension resulting from the explosion of the gunpowder. The results of such an injury may be seen in the multitudinously fractured skull No. $2902 \mathrm{~A}$ in the Museum of the Royal College of Surgeons of England, and will be found described at p. 64 of $\mathrm{Mr}$. Heath's Jacksonian Prize Essay for 186\%, published 1872. The instantaneous tension of the explosion may be seen in this case to have produced a great number of fragments with their broken surfaces even and vertical; but what such violent expansion produces momentarily on a tough skull, that, compression or other strain due to the settling of the soil, or indeed shock from disturbance in secondary burial, may very readily be understood to be competent to produce on a skull rendered fragile by the lapse of centuries. The 
Ebberston barrow and the Market Weighton barrow, in which these fractures have been noted, were both of them cremationbarrows, and the action of fire, even when as at Ebberston imperfect, would be distinctly in favour of making the bones more brittle; and in these and in the other barrows the great age of the interments, which are undoubtedly of premetallic times, may be taken in part-explanation of the loss of resistance testified to by these fractures. It is remarkable that Dr. Thurnam (Cran. Brit., pl. 59) should have observed that 'the perfect skulls from these barrows, inferred to be those of chiefs, are of considerably more elongate type than those which are cleft,' and should have put on record the fact that two of his supposed cleft skulls should have had the frontal suture persistent and have possessed thus a broader and less dolicho-cephalic form,' i.e. have been a better filled and larger skull 'than the rest.' For, as is well known ${ }^{1}$ and may be readily verified, better filled and larger skulls differ from smaller ones in having thinner walls and being more fragile; and to this, and not to any such cause as their having been the skulls of 'serfs of less pure blood than their lords,' a view contra-indicated by their size (p. 640), we may reasonably refer the fact of a large proportion of the broken skulls being broader than the unbroken.

I have further to remark that fractured surfaces such as those described by Dr. Thurnam, and interpreted by him as indicating slaughter of victims at the funeral of a chief, may be and often are found in skulls of skeletons buried singly and in skulls buried with relies ${ }^{2}$, provided that they have been subjected to pressure from the shifting of soil or the downward settling of stones upon them. The first effect of such agencies appears to be the forcing inwards of the basi-cranial bones, a process analogous to that which Dr. Barnard Davis has described as taking place in the senile living body, and which other writers have spoken of as impressio baseos cranii. The second effect upon the vault of the skull thus deprived of its basal support may take either the direction of flattening out of the arch or that of compression of it from side to side. Those who are most familiar with the multiform and even grotesque shapes into which skulls thus crushed are distorted, and with the cleanness and sharpness

${ }^{1}$ See Weisbach, Schädelform der Rumänen, pp. 8, 12, 30.

${ }^{2}$ For example, the skull already spoken of at p. 596 as 'Rudstone, lxviii. 7,' had been broken into a very large number of fragments with even and vertical edges, and this though its walls were of great thickness. But with it the following relics were associated - a bronze knife, a perforated stone axe, a hammer of micaceous grit, and a flint implement. 
and extent of the fissures, which pass sometimes more than half over their transverse ares, will be slowest to accept Dr. Thurnam's interpretation of the fractured skulls in question. Until the fractures of which Dr. Thurnam has written are shown to me in a skull with its basi-cranial bones left, as they might be in a sacrificed victim, uninjured and in situ, I shall hesitate to refer them to the working of any but one of the two following verce causce, viz. (a) settling or sinking of the soil or stones in which the skulls have been laid; $(b)$ the disturbance and violence necessitated by successive interments, and resulting, as has often been said, in a 'strangely huddled,' 'irregular confused' packing together of a great many skeletons in a very small space. The first of these causes I believe to have been the most frequent; the second, I am well assured, accounts for the injuries observable in the Rodmarton ${ }^{1}$ and the Swell crania. Desiccation and other alterations of various kinds may often have powerfully co-operated towards the production of fissures in these skulls; but whilst the cracking of other organic bodies forbids us to forget the influence of drying, the way in which skulls are often found almost entirely 'perished' makes it clear that we must not leave chemical activities out of sight. These however would not be competent alone to produce lesions which could anyhow be mistaken for wounds.

There can, I allow, be no doubt that skeletons, burnt and unburnt, are frequently found so buried together as to leave no doubt that they were interred simultaneously. The very structure of a cremation long barrow as described above (p. 495) by Canon Greenwell shows that all the bodies it contains must have been subjected at one and the same time to the action of fire. Burnt bones again are not rarely found ${ }^{2}$ in the cists and also in the urns

1 Of the chamber in the Rodmarton barrow, which contained no less than thirteen skeletons, Canon Lysons wrote thus:- 'Although most of the human bones exhibited no traces of cremation, some few had been burnt. The bones were all in great confusion, and some had been dragged into a corner.'-Proc. Soc. Ant. Lond., 1863, vol. ii. p. 278.

${ }^{2}$ Interments in urns giving proof of the presence in them of more than one body are recorded in the accounts given above of-

Barrow cxlv. 2. Two skeletons in one urn.

Barrow elxxxii. Woman and child in one urn.

Barrow excvii. Two adults in one urn.

Barrow eev. 1. Two women and child.

Barrow cev, 2. Two or three adults.

Interments in cists giving similar proof of the presence in them of more than one burnt body are recorded in the accounts given above of-

Barrow lxii. Two bodies. 
of the ages subsequent to those of the long barrow builders which give unmistakeable evidence of the presence of more than one skeleton intimately intermingled. Finally, burnt and unburnt bodies ${ }^{1}$ are sometimes found so interred together as to show certainly that the two modes of disposing of the dead body were from choice or necessity practised simultaneously. All this however does not prove that of the bodies thus found lying together one set belonged to one and another to another class of men. If one set of bones had really given evidence of the reception by their owners of injuries ante mortem, whilst the other was free, from any marks of such lesions, there would have been some reason for accepting this view. This however I have shown not to be the case. Or, if it could be shown that in certain barrows one or more skeletons were arranged apart and carefully, whilst other skeletons were disposed around such principal interment but in such a way as to show that less care and trouble had been bestowed upon them, much probability would have attached to the view that these latter skeletons might have been those of captives or of slaves slaughtered in honour of the chief represented by the central interment. But I have shown above, pp. 530 and 535, that where a single undisturbed interment has been found in company with, though distinguishable from, a number of bones giving evidence of the presence with it of several other bodies, these latter bones give evidence of their having been placed as we find them with a certain pious painstaking which arranged them, when parts, not of a body, but of a skeleton, without anatomical knowledge, though obviously with a view to making room for the skeleton found undisturbed. What we have to deal with in such cases as those described above l.c. are cases of successive

Barrow lxxxii. Woman and child.

Barrow lxxxv. Two children.

Barrow exxxiii. Two adults.

1 See for this account of barrows $x$, xi, xiii, xxvi, lxix, clxi, clxxvi. For the practice of cremation and inhumation simultaneously, see Kemble, Horæ Ferales, p. 918; Neville's Saxon Obsequies, p. 11; Wylie, Archæologia, xxxvii. p. 456; Akerman, Archæologia, xxxviii. p. 85; Inventorium Sepulchrale, pp. 165, 195; Weinhold, l.c., bd. xxix. p. 138, bd. xxx. p. 176 ; Lindenschmidt, Archiv für Anthropologie, iii. 114. Burning and inhumation are carried on simultaneously now amongst the Gonds. The women and children of the Mária tribe are always buried, and Colonel Dalton, Ethnology of Bengal, p. 283, suggests that unmarried males may be similarly disposed of. In the Report of the Ethnological Committee of the Jubbulpore Exhibition, Nagpore, 1868, p. 81, it is stated that burning is considered most honourable amongst the Gonds, but being expensive is usually confined to the old. 
interments; and if we figure to ourselves how the mingled and allied feelings of reverence and of terror would act upon the otherwise excitable nature of uncivilised men engaged in such a work, we shall have little difficulty in interpreting the phenomena presented to us by the bony remains without having recourse to the hypothesis of human sacrifices, a hypothesis incompatible at once with the care bestowed upon some and the injuries received by others of these remains. The question however here naturally arises, how is it that in the very large number of interments recorded in this book we have never come upon any bony remains bearing their evidence to the existence of a practice which is spoken of by such a very large number of literary witnesses? In answer to this I have to say that the literary evidence when duly considered proves simply that slaves and captives were slaughtered at the funeral of their lords without proving that they were allowed to lie beside them afterwards. The only passage I have met with which might be held to speak of a contiguity in the graves as well as a contemporaneity in the deaths of the masters and of the slaves is the passage in which Cæsar writes, as follows, of the funeral ceremonies of the Gauls, B. G. vi. 19: 'Funera sunt pro cultu Gallorum magnifica et sumptuosa; omniaque quæ vivis cordi fuisse arbitrantur in ignem inferunt, etiam animalia, ac, paullo supra hane memoriam, servi et clientes, quos ab iis dilectos esse constabat, justis funeribus confectis, una cremabantur.' These two last words might seem to justify us in holding that of the burnt bones packed together in a cremation long barrow with no detectable differentiation indicative of distinctions of rank or position, some nevertheless may have belonged to conquerors, others to captives, or some to masters, others to slaves. If we compare however the words of Homer used in the account of the funeral of Patroclus we shall see that the words of Cæsar must not be interpreted too strictly. Achilles, Il. xxiii. 182, says distinctly that the twelve noble Trojan youths were burnt together with Patroclus-

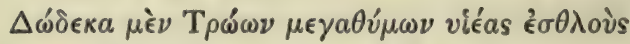

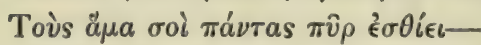

using words as precise at first sight as Cæsar's una cremabantur; but a little further on, 1. 239-243, we find him telling the other Greeks that they would have no difficulty in distinguishing the bones of Patroclus, for that they were in the middle of the funeral 
pile, whilst the bones of the human and brute victims were lying apart from them at its edge-

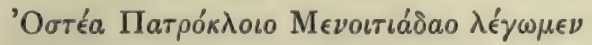

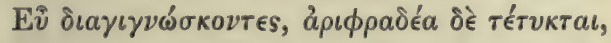

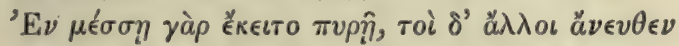

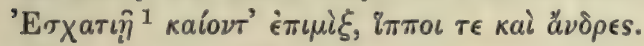

According to the legend given by Bartholinus in his Antiquitates Danicæ, 1689, pp. 291-292, the spirit of the Icelandic Asmundus was unable to rest until the body of a slave, who had killed himself from unwillingness to survive his master, was removed from his tomb; and we may be quite sure that the haughty and harsh sentiment attributed to that hero, Animoso vacuus locus melius placet quam mali comites, must have been too strong in every age and country which tolerated human sacrifices to allow of any equality between master and slave being set up even in the grave. In two words, I can understand how the bones of slaughtered slaves or captives might lie 'scattered at the grave's mouth,' I cannot understand how they would be likely to find entrance into the tombs of the kings.

There would be no repugnance felt even by men most strongly imbued with those feelings of exclusiveness which Professor Nilsson ('Early Inhabitants of Scandinavia,' ed. Lubbock, p. 167, note) assures us are eminently characteristic of savage life, for joint burial with an equal, a relative, a friend, a wife or a favourite. The words of the prophet of Bethel (1 Kings xiii. 31), 'Lay my bones by his bones,' show us, as do the repeated notices in the same history of successive monarchs coming or not coming into the tombs of their fathers, the Hebrew feeling on this point; $\sigma \phi a \chi \theta \epsilon i \sigma a \sigma v v$ -

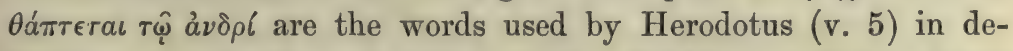
scribing the death and burial of the Scythian widow; Greek sentiment has usually a distinctive beauty of its own, but the prayer of Patroclus, Il. xxiii. 83, 84, 91,

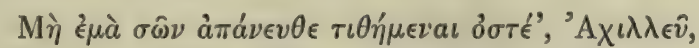

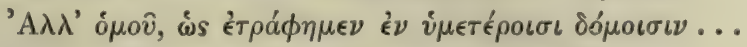

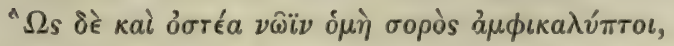

is not more Greek than it is Turanian or Semitic; it expresses

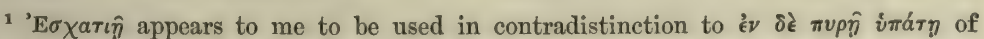
line 165 supra and line 787 of book xxiv, and to furnish a good commentary on the

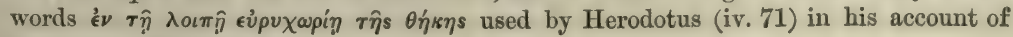
the similar Scythian rites. 
merely the feeling common to all humanity that they who were lovely and pleasant in their lives in their death should not be divided.

It still remains for me to put on record the little which $I$ have been able to note in the way of abnormalities, pathological and other, in these prehistoric skeletons and skulls.

Of the non-pathological abnormalities observable in this series the persistence of the frontal suture is the only one which needs special notice. It is exceedingly rare for this suture to remain open in the earlier of the two series with which we have been dealing, whilst it is by no means uncommon to find it retaining its infantile patency after the coming of the brachy-cephalic race. Dr. Thurnam, writing in 1865 (Nat. Hist. Review, April, p. 245), said that of all the long-barrow skulls which he had examined, four only, one from the chambered-barrow at West Kennet, a second from the Rodmarton barrow (which has been frequently figured, e.g. Cran. Brit., pl. 59; Archæologia, xlii. pl. xiv.; Thesaurus Craniorum, p. 8), and two from the Dinnington long barrow (described by me in the Journal of Anatomy and Physiology, vol. iii. 1868, p. 254), had been found possessing this peculiarity. To this very small number $I$ have, from all the Silurian skulls exhumed since 1865 , only been able to add the skull of one adult, this one being the skull of the single skeleton found undisturbed in the long barrow at Upper Swell, as described by me at p. 529 supra; and one skull of a child of about 7 or 8 years of age, being one of the children found in the chamber of the long barrow at Eyford, described above, p. 518, and Journ. Anth. Institute, Oct. 1875, p. 158. Coupling these facts on one side with the well-known fact of the extreme rarity of the persistence of this frontal prolongation of the sagittal suture in the skulls of modern savages ${ }^{1}$; on another side with the fact that this

1 This suture persists in a skull of an Andaman Islander presented to the Oxford Museum by Professor Wood Mason of the Indian Museum, Calcutta; it has been noted in an Abyssinian skull by Zuckerkandl, l.c. p. 65; it is seen in the figure of a skull given by Professor Busk (Natural History Review, April, 1861, pl.v. p. 174) of a Red Indian from an ancient burial-place in Tennessee, in which skull, Professor Busk informs us, ' the supra-orbital prominence is most marked of all the crania in our possession ;' and fourthly, it is seen in the figure of the skull treated of by Professor Broca in his paper (in the Bulletin de la Société d'Anthropologie de Paris, Août, 1871), 'Sur la D'formation Toulousaine du Crâne,' of which we find it recorded that 'l'os frontal est trèspetit dans toutes ses dimensions.' But though small frontal bones may oceasionally retain this suture, there is no doubt that it is much more usually found in broad foreheads, and that the rationale of its formation lies in the early widening of the frontal lobes of the brain, of the segments, that is, of that organ which are most indubitably 
suture persists with comparative frequency in the skulls of brachycephali as observed by His and Rütimeyer in the skulls of their 'Disentis Typus' (Cran. Helvetica, p. 27), and by Dr. Thurnam and myself in the skulls of the bronze and later periods; and on a third with the fact that frontal bones with a persistent suture are all but invariably broader than allied skulls not bifid, we may feel ourselves justified in considering the extreme rarity of this suture in Silurian skulls as another indication of their inferiority to those of the later or Cimbric race. And we are further justified in saying that Mr. Darwin has been misinformed when he says of this suture (Descent of Man, 1st ed. p. 124, 2nd ed. p. 39) that it persists 'more frequently in ancient than in recent crania, especially, as Canestrini has observed, in those exhumed from the Drift and belonging to the brachy-cephalic type.' The true rationale of the persistence of the frontal suture would appear to be that it is a teleological accommodation to the needs of the enlarging brain of an advancing civilisation, with which enlargement is correlated a diminution of the size of the jaws, and of the necessity for the rotation of the brain and the frontal bone backwards which has been so often noted here (see p. 643 supra) as occurring in macrognathous men, and which is carried out still further in the 'villainously low foreheads' of the apes.

We may now pass to the consideration of the few pathological deformations which have been noted in these prehistoric skulls and skeletons; and we may begin by recording

\section{Abnormal Ossifications.}

Dr. Thurnam in his 'Further Researches and Observations on the two principal Forms of Ancient British Skulls,'p. 33, suggested that some ethnical importance might attach to the fact that in

shown (see p. 676 supra) to increase in complexity and extent with increase of intelligence. This principle was laid down in the year 1740, by Hanauld in the Mémoires de l'Academie royale de Paris, p. 371; it has been reaffirmed by Dr. Theodor Simon, to whom I owe the foregoing reference, in an excellent though short paper in Virchow's Archiv, tom. 58, 1873 ; by Virchow himself, l.c., tom. 13, 1858; Abhandlungen Akad. Wiss. Berlin, 1876, Ueber einige Merkmale niederer Menschen Rassen am Schädel, p. 112, ibique citata; and by Hyrtl, Lehrbuch der Anatomie des Menschen, 8th ed. 1863, p. 245. Welcker's views (given in his Wachsthum und Bau des Menschlichen Schädels, p 99) as to the hereditary transmission of this peculiarity are confirmed by the presence of it in four out of the sixteen skulls recovered by me from the Dinnington tumulus. In two of these not mentioned by Dr. Thurnam the traces of the suture are only rudimentary; and in none of the four does it reach the inner table, which it does however in the Rodmarton and in the Upper Swell crania, both also in this Museum. 
remains from the long barrows an ' anchylosed condition of two or more of the cervical or upper dorsal vertebræ' had been not rarely observed by him, whilst it was within his experience very uncommon and almost unknown in the round barrows. This condition of things he thought was indicative of some peculiarity, and that peculiarity the troglodytic mode of life of the people in whose remains it had been observed, and whose heads and necks he supposed would have been very much exposed to violent concussions against the sides and roofs of their narrow passages and doorways. Without discussing whether 'anchylosis of the vertebræ may have resulted from such violence,' I would say that I have observed the morbid condition of which Dr. Thurnam writes in many vertebral columns of much later times than those of the cave-dwellers. The Pathological Department of the Oxford University Museum contains, under the Catalogue-numbers 159-165, seven specimens with every appearance of being of modern date; and the magnificent Catalogue of the Leyden Anatomical Museum ${ }^{1}$ has ten Plates (Taf. xxxviii-Taf. xlvii) devoted to this particular form of disease. Of the two specimens of this anchylosis which I have met with amongst prehistoric skeletons, one came from the long barrow at Upper Swell, described by me at p. 533 supra, and the other belonged to the skeleton 'Paulinus, iv. 2, cxiii. 5,' which came from a round barrow, and indeed may be taken as being a strikingly good representative of the skeletons of the bronze-period. The

1 Museum Anatomicum Academiæ Lugduno-Batavæ. Descriptum ab Edvardo Sandifort. 1793-1835. There can be no doubt that this morbid condition is the same as the one spoken of by Rokitansky (Manual of Pathological Anatomy, vol. iii. pp. 133, 134, and 247), and described by him as presenting an appearance as if the 'bony matter had been poured in a stream over larger surfaces of a bone and had then coagulated.' Rokitansky adds, 'We are quite ignorant of any general condition of the system to which this can be attributed.' In default of any suggestion of his, it may be well to add the following short account of the malady from a later writer, Genezig, who in an Inaugural Dissertation (Ueber Exostosen und Osteophyten) read in 1846 speaks of the malady as follows, p. 14: 'Exostosen der' Wirbelknochen. Am kaufigsten findet sich ein Osteophyt welches in der Form einer im Flusse erstarrten Masse die vordere Flache der Wirbelkörper in geringerer oder grösserer Ausdehnung mit einander verbindet. Bisweilen findet sich dies Osteophyt ein höheren Alter ohne anderweitige Krankheiten der Wirbelsäule, bisweilen aber auch bei Caries oder Tuberculose der Wirbelkorper.' I have myself observed this condition in the vertebral column of a Newfoundland dog and of a horse, which are preserved in the University Museum; it is said to be normally present in the dipodidæ and dasypodidæ, animals, it is right to add, of burrowing habits; but it is also present in many cetacea ; and I find that its occurrence as an abnormality is so well known, as to have furnished commentators with a not very satisfactory explanation of Aristotle's twice repeated statement as to the cervical region of the lion consisting of one single bone (see A F. A. Wiegmann, Observationes Zoologicæ Criticæ in Aristotelis Historiam Animalium, Berolini 1826; Arist. Hist. An. i. 1, ad fin.; De Part. An. iv. 10). 
skull was noted by me as being 'typically brachy-cephalic both by contour and by measurement (cephalic index $=\cdot 82$ ), and as having belonged to a strong man, $5 \mathrm{ft}$. $9 \mathrm{in}$. in height, and past the middle period of life.' Three of the dorsal vertebræ are glued together by bony deposit on the anterior, and to some extent on the lateral aspects of their centra. In this skeleton, as in two others, also of tall men, from the same neighbourhood and possibly the same clan, viz. 'Paulinus, viii. 2, xv. 2,' and 'Goodmanham, xiv, ci,' it is noteworthy that the last lumbar vertebra has anchylosed with the first sacral, and must, as it enters by its lateral outgrowths continuously into the mass of bone supporting the articular surface which abutted upon the ilium, have so anchylosed at an early period in development. The ensiform cartilage of this skeleton is also ossified, and other bones besides those already specified are similarly hyperostotic. Some of the skeletal bones on the other hand, and notably the scapulæ, show signs of senile atrophy and thinning, a point of importance to note, as regards both the cause and the time of the production of the vertebral and other hyperostoses.

A skeleton of a Little Andaman Islander described by Dr. Barnard Davis, Supplement to Thesaurus Craniorum, 1875, p. 95, appears to have exemplified almost every possible form of exostosis and synostosis, except the important form of bony anchylosis which consists in the more or less complete coalescence of the first cervical vertebra with the occipital bone. On this Professor Virchow has written at some length in his recently issued volume, Beiträge, pp. 340-345. Professor Virchow puts on record five cases of this variety, three of which have come under his own observation, whilst the other two have been described by Bogstra in conjunction with Boogaard and Friedlowsky. A somewhat larger number are described in the already cited Catalogue of the Leyden Anatomical Museum (vol. i. pp. 143, 144; vol. ii. Taf. xiv, Taf. xv; vol. iv. pp. 31, 46, Taf. clviii. fig. 1, 2, 3), with the remark that ex descriptis speciminibus diversimode cranium cum atlante concrescere constat. There are two specimens of this anchylosis in the Museum of the Royal College of Surgeons of London; one being an artificially distorted skull from Vancouver's Island, No. $5412 \mathrm{~A}$, and the other, the existence of which was notified to me by Professor Flower, being the partly-burnt skull, No. 5903, which was supposed, but probably erroneously, to have belonged to a native of Van Diemen's Land. We have five specimens of this very interesting pathological deformation in the Oxford University 
Museum, three in the Pathological Museum, and two in the Ethnological Series. Of the three in the Pathological Museum, one, No. 157, belonged to a man who died at the age of 73 , and the second, third, and fourth cervical vertebræ are anchylosed to each other just as the atlas is anchylosed to the occipital. In this case, as in Friedlowsky's, the posterior arch of the atlas is left incomplete, an interval of two millimètres separating it into two halves. The second belonged to a boy who, after suffering from various scrofulous affections, died with cough, purulent expectoration, hectic, and vomicæ in the right lung, as well as extensive paralysis from, no doubt, encroachment effected by the odontoid upon the medulla oblongata. Of these two cases the first resembles one of the two recorded by Virchow from the Berlin Museum, in that death took place at an advanced age and without any recorded symptoms of disease connected with the lesion in question; the second resembles the second of those cases, in that long disease was the cause of death. The third specimen from the Oxford Pathological Department, No. 261, is the skull of a lunatic, purchased with the Collection of Schröder van der Kolk, the calvarial bones of which present, according to the Catalogue, 'a rugous wormeaten appearance, a consequence either of syphilis or tinea.' Our fourth specimen was obtained from a Roman cemetery at York, in which large numbers of skeletons were found buried in putei with very little regard to any consideration, except that of making the largest possible amount of room for the largest possible amount of bodies to be interred. No clue to its nationality, except in the political sense of subjectdom, therefore is available. The specimen however is of interest with reference to the question of the foetal or congenital origin of the anchylosis, as not only the sphenobasilar synchondrosis would appear never to have been closed, but also the basilar portion of the occipital bone would appcar to have been entirely absorbed, and the arch of the atlas to have coalesced all but perfectly with the occipital, two eircular orifices only remaining for the outlets of the first spinal nerves. It is of interest further, as combining with this anchylosis, firstly the 'plastic deformation' of Dr. Barnard Davis, the 'basilar impression' of Virchow (l.c.); and secondly, a flattening and widening out of the cranial vault, the height from the edge of the anterior arch of the atlas next to the base of the brain up to the vertex being only $44^{\prime \prime}$ as against a maxim width of $6 \cdot 2^{\prime \prime}$, as to give the skull what Dr. Barnard Davis calls a 'discoid,' and Virchow (l.c.) a 'molen- 
förmig' appearance. Our fifth skull belonged to a man (Cowlam, lvii. 3, p. 215) of from twenty-five to thirty years of age, whose shortness of stature $\left(5^{\prime} 1^{\prime \prime}\right)$ and ill-filledness of skull (with cephalic index of 76) would point to his having belonged to the stone age, a supposition which his archæological surroundings do not, I apprehend, contradict (see pp. 215-6 supra). In this skull a considerable part of the occipital bone has been lost, but on the left side its condyle has been left with the articular process of the atlas anchylosed to it without any trace of recent discontinuity.

Professor Virchow appears to consider these cases explicable by the action of an arthritis chronica deformans; Friedlowsky (Wiener Med. Jahrbücher, 1868, Bd. xv. p. 241 ; cit. Virchow, l. c., p. 343) is inclined to believe them to be due to intra-uterine disease; in some cases I should suggest that they were the result of strumous disorganisation occurring in early life but recovered from, as we have seen recorded in two of the cases here referred to, so completely as to allow of a goodly old age being attained to. It is perhaps difficult to assign any other ethnological bearing to them than that which they have had conferred upon them by being discussed in the important ethnological memoir referred to.

The skeleton 'Goodmanham, xiv, ci,' already mentioned as having had the last lumbar vertebra anchylosed to the first sacral, presented another form of exostosis, which, as it did not affect the joints, cannot be ascribed to an arthritis (see Adams, cit. Paget, Lancet, Nov. 18, 1875). An osseous upgrowth on the tibia, $2^{\prime \prime}$ long by $\cdot 6^{\prime \prime}$ in height and $\cdot 35^{\prime \prime}$ in width, roughened and perforated here and there, occupies the part of the popliteal line which is common to the popliteus and the inner head of the soleus; the bone is further beset by rough and by smooth exostosis on its border below this level, and is finally joined, by a stalactitic growth $1 \cdot 25^{\prime \prime}$ long and $\cdot \gamma^{\prime \prime}$ thick, to the fibula.

That particular form of exostosis which produces in its most usual form what is called the puerperal osteophyte is by no means unrepresented in prehistoric series. As in modern times also, it is not confined to the female sex exclusively; a typically male skull of the brachy-cephalic type from a grave in a barrow at Gardham exemplifying it.

Finally, we have in the long barrow series from Market Weighton, Rodmarton, and Swell, that form of hyperostosis which developes masses of bones along the supraciliary ridges, as repeatedly observed in Australian and Tasmanian skulls (see Catalogue Ost. Series, Royal 
College of Surgeons, vol. ii. 1853, Nos. 5317, 5318, 5324, 5345), as also in foreign skulls of prehistoric times, e.g. the Danish skulls from the Island of Seeland, as noted by Virchow (Arch. für Anthr. iv. p. 66; see also Spengel, ibid. viii. p. 59, 1875, and Journ. Anth. Inst. Oct. 1875 , p. 170).

\section{Rickets.}

I am inclined to believe that we have an example of the working of what has been called an 'English disease,' viz. Rickets, in one skull of the bronze period, 'Rudstone, lxiii. 4,' p. 248. The calvaria of this cranium is so large relatively to its small facial skeleton and lower jaw, and has so distinctly the subquadrate outlines which we have learnt ${ }^{1}$ to recognise as indicative of that false cerebral hypertrophy the essence of which consists in an increase, not of the nerve cells, but the interstitial neuroglia, that we are probably justified in considering it to have taken this shape and size in accommodation to a rickety brain.

The skull appears, from its small mastoids and small teeth and jaws, to have belonged to a woman, and somewhat difficult though the size and weight of the entire skull and the considerable development of the supraciliary ridges may make it to believe this, the existence of a considerable quantity of stalagmite-like exostosis on the interior of the frontal bone lends some additional probability to this view as to its sex, as does also the comparative verticality of the forehead and of the posterior part of the parietals. As rickets may appear, as Dr. Jenner ( $l . c$. p. 466) has shown, in any child whose mother may have been in a depressed condition during the period of gestation, no matter whether the father may have been in ' robust health and the hygienic conditions most favourable,' there is no need for wondering at its appearance in a semi-civilised community, where early childbearing and hard labour would usually be the lot of the females. In the present case the malady had been outlived, and the subject of it, to judge from the great wear of the teeth and the obliteration of the skull sutures, had reached old age. The teeth are small in size, and only three molars appear to have been implanted in the jaws, two on the left, one on the right side.

${ }^{1}$ West, Diseases of Children, Lectures $\mathrm{X}$ and XLI, pp. 134 and 729, 5th edition, 1865; Jenner, Lectures on Rickets, Med. Times and Gazette, 1860; Virchow, Untersuchungen ueber die Entwickelung des Schädelgrundes, Berlin 1857, pp. 99102, ibique citata. 
The measurements of this skull are as follows:-

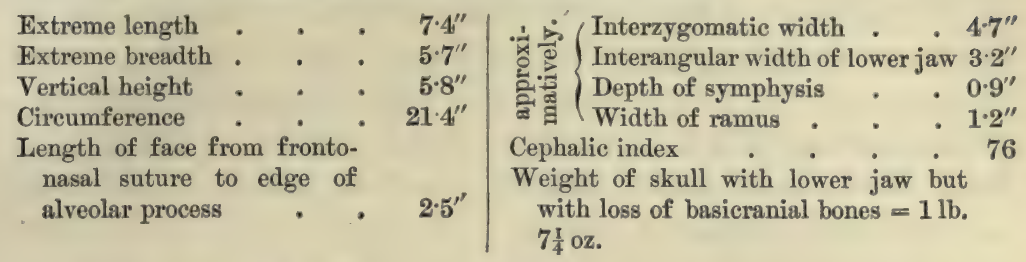

A second skull, to which the foregoing description as to age, sex, contour and other characters, with a slight alteration as to the supraciliary ridges being smaller, would apply almost word for word, was obtained by Canon Greenwell from a cave at Ryhope in the county of Durham. With this skull and lower jaw there came to the University Museum from this cave a second lower jaw, which had belonged to a strong man, and resembles in many particulars the lower jaws of the earlier British prehistoric race; and the lower jaw of the skull altered by cerebral hypertrophy, has its angles inverted in a manner frequently noticeable in lower jaws of early races. These points have some importance, as some doubt exists as to the date of this 'cave-find.' The measurements of this Ryhope skull are as follows:-

\begin{tabular}{|c|c|c|c|c|c|}
\hline Extreme length & . & & $7 \cdot 4^{\prime \prime}$ & Interzygomatic breadth & $4 \cdot 7^{\prime \prime}$ \\
\hline Extreme breadth & . & . & $56^{\prime \prime}$ & Interangular width of lower jaw & $3 \cdot 1^{\prime \prime}$ \\
\hline Vertical height & - & & $5 \cdot 3^{\prime \prime}$ & Width of ramus & $1 \cdot 3^{\prime \prime}$ \\
\hline Absolute height & . & . & $5 \cdot 0^{\prime \prime}$ & Depth of symphysis & $0 \cdot 9^{\prime \prime}$ \\
\hline Circumference . & . & 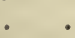 & $20 \cdot 8^{\prime \prime}$ & Weight of skull $1 \mathrm{lb} .5 \mathrm{oz} .70 \mathrm{grs}$ & \\
\hline Length of face & . & 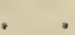 & $2 \cdot 3^{\prime \prime}$ & & \\
\hline
\end{tabular}

\section{Diseases and irregularity of teeth in Prehistoric Series.}

Mr. Mummery in a valuable paper published firstly in the Transactions of the Odontological Society of Great Britain, vol. ii. p. 1, Nov. 1869, and subsequently (18\%0) in a separate form with additional notes, has given at considerable length, and also tabulated, the results of his observation upon dental disease as existing in prehistoric races, having examined for this purpose a large proportion of the series in the Oxford Museum and also several other collections. In the same paper he has also recorded the results of his investigation of dental disease in various existing savage tribes, such as the Australians, the Eskimos, the Negroes, and the Red Indians. Mr. Mummery has pointed out that amongst as many as 68 Wiltshire skulls of the long-barrow period in Dr. Thurnam's collection he could find only two cases of decay, whilst amongst 32 skulls in the 
same collection from the round-barrow period there were 7 cases. In 60 Yorkshire dolicho-cephali, however, Mr. Mummery says no less than 24 exhibited more or less disease ; and in 44 other skulls ranged with the long-barrow series, some from Mr. Bateman's Derbyshire series and some from other sources, much wearing down of the teeth and 9 cases of caries were noted; but alveolar abscesses were comparatively rare. In the Park Cwm tumulus in the peninsula of Gower, South Wales, described by Sir John Lubbock (Journal Ethn. Soc. London, vol. ii. 1870, pp. 416-419), and of the same 'horned' character and possibly of the same race and time as the Gloucester tumuli next to be spoken of, amongst skeletal remains representing 24 individuals, 21 of whom were adults, Dr. D. M. Douglas found 'the teeth wonderfully preserved, very good and regular,' and 'only two that exhibited signs of decay during life.' In my examination of the entire series of bones, fragmentary as well as perfect, from several chambers in long barrows in Gloucestershire, I find very much the same state of things which Mr. Mummery has described from the Wiltshire burials of the same period. Ten lower jaws, nine of which were from persons beyond the age of puberty, were recovered from a chamber in the long barrow described by Canon Greenwell, pp. 514-520 supra, and by me in the Journal of the Anthropological Institute, Oct. 1875 , p. 160 ; and of them I write (l.c.), 'In none of these lower jaws had any teeth been lost before death, in only one is there any caries visible, and in one other (of an old woman, see p. 165) there is a cavity formed by an alveolar abscess in connection with a lower front molar worn down to the fangs and with its pulp cavities almost obliterated by osteodentine.' Similarly of the six lower jaws, all but one of which must have belonged to strong adult men, recovered from a chamber in the long barrow at Upper Swell described by Canon Greenwell at p. 521 supra, and by me at p. 168 of the Journal Anth. Soc. (l.c.) I write, 'In every case but one the full number of teeth was retained up to the time of death, even though the teeth are very much worn in most cases, and in some even down to close upon the fangs. There was only one case of caries.' I should have added that some traces of an alveolar abscess are to be seen in the jaw which had lost teeth before death, and that this jaw appears to have belonged to a man, whilst the jaw with caries belonged probably to a woman.

On the other hand, of the teeth of three females, also already described by me and all undoubtedly from the stone and bone 
period (Journal Anth. Inst., vol. v. p. 152, and vol. vi. p. 34), a very different history has to be given. Of the first of these, from the barrow 'Nether Swell, cexxix,' I write, 'The lower jaw is feeble. The mental foramen corresponds to the interval between the second bicuspid and first molar. The teeth are very much worn down, and there are two or three alveolar-abscess cavities in the jaw. One very large one occupies a great part of the molar region of the left upper maxilla.' One of the male skulls from this barrow shows the cavity of a small alveolar abscess; and in another several teeth had been lost before death. The second of these cases is that of the woman recorded at p. 518 supra, and Journal Anth. Soc., l. c., p. 158, of whom in the latter place I say, 'The lower jaw of the old woman was feeblish as compared with some of the male jaws, but not with all, from these barrows. It had lost no teeth, from the half we recovered, during life, though the teeth were very much worn down, and the first molar, notably, down to its fangs; in connection with both of which there were alveolar abscesses.' Of the femur and other bones belonging to this skeleton I say that they 'give the idea of their owner having had hard work and poor food, viz. as they are slight, but with rough ridges.' The third instance is furnished by the history of the young woman found at Cissbury (Journ. Anth. Inst., vol. vi. p. 34), in whom an alveolar abscess existed in relation with a lower premolar, which had had its pulp cavity exposed by being broken across midway between its grinding surface and its neck. Here the two anterior molars were very much worn down, though their owner was not more than twenty-five years of age, and the wisdom teeth were scarcely worn at all. Subsequently to these excavations two lower jaws affected with alveolar abscesses, both of aged females, were found in the long barrow No. ccxxxii, described by me above, p. 524; another similarly affected, but from a powerful old male subject, was found in the same barrow. A third as yet undescribed skull of an old woman of the stone period, with extensive traces of the same mischief, was presented to me by the late Rev. Canon Lysons, having been obtained by him from a long barrow in Gloucestershire; and three of the Rodmarton long-barrow skulls, also from the collection of that antiquary, one of an old man, one of the young man already referred to (p. 694 supra), and one of an old woman, have suffered similarly. Of eight lower jaws, of all ages and both sexes, discovered by Edward Laws, Esq., in a cave near Tenby (see Journ. Anthrop. Institute, July, 1877), 
to the early date of which their possession of the 'priscan' peculiarities specified above (pp. 645-652) speak as decisively as their arehæological surroundings, one only, a lower jaw of a man, had been affected by alveolar abscess. From the Westow long-barrow series (see p. 494 supra) no lower jaw thus affected has been recovered; from the Rudstone long barrow (see p. 497 supra) only one, (the one described above, p. 613, as) of a man; from the Ebberston long barrow (see p. 484 supra) only one of a woman ${ }^{1}$.

Further investigations may possibly reverse this relation of numerical superiority on the side of the female sex in the matter of alveolar abscesses. I am inclined however to connect it with the harder life and scantier fare which are the lot of women in most savage races, upon which I have here (p. 659 supra) and elsewhere ${ }^{2}$ insisted as accounting for the greater inferiority in stature and in bulk which existed and exists between men and women in many ancient and in many modern savage races.

Feeble general physique is correlated, as Mr. Mummery's examination of modern savage races (pp. 47, 51-54,60,63) in Africa, China, Australia, and elsewhere has shown us, with deterioration of the state of the teeth, and this, howsoever, whether by too small a proportion of animal to vegetable food in their dietary, by frequent privation of food altogether, or by general antihygienic conditions, this feebleness may have. been produced. To realise the working of the two former of these causes among the prehistoric inhabitants of these islands, and especially the women, there is little need of imagination; I think however that from our present familiarity with the production of anti-hygienic conditions by the crowding of a superabundant population within solid walls, from our lack of familiarity with tent life and savage life, we may underrate the extent to which unhealthy conditions may, or indeed must have prevailed in the dwellings even of sparse populations in days so long before the invention not merely of glass but of many other things in which in these days ' our basest beggars are superfluous.' It is obvious however upon the smallest

\footnotetext{
1 In none of these cases have I seen any traces of the simple but relief-producing operation of extraction, or of other evidence to show that in this, any more than in any other sphere, 'the former days were better than these.' The same lesson may be gathered analogically from observations made upon the remains of modern savages, Mr. Mummery informing us (l. c., p. 47) that he has 'met in Australian jaws with every form of dental disease with which we are familiar amongst the English race.'

${ }_{2}$ Journal Anth. Inst., Oct. 1875, p. 121 note ; British Association Report, 1875, p. 152 ; Archæologia, xlii. 1870 , p. 457.
} 
consideration, even in the absence of any personal acquaintance with present savage life, that the dwellings of the races we are dealing with must have been dark and crowded to secure warmth, and that the female portion of the tribe would have a larger share of these as of other depressing influences to contend with than the males. And the effects of these influences would show themselves as surely and clearly in the teeth, a system most closely correlated with the general state of the whole organism, as in their feebler trunk and limb bones ${ }^{1}$. The great frequency of the perforation in the olecranic fossa of female prehistoric humeri, noticed by Broca (Mémoires, ii. p. 366, and Rev. d'Anthropologie, 1873, ii. p. 15) and instanced by me (Journ. Anth. Inst., v. pp. 149-159, 161-169) in four cases from the Swell long barrows, is to be similarly explained; and, conversely, its absence in the Cro-Magnon and Mentone skeletons, which belonged to the 'giants' of tradition.

I have not, though constantly careful in looking for irregularities in dentition, found many in either of the prehistoric series which I have examined. Three of retardation of one or both bicuspids with retention of the second milk molar in persons of fourteen to fifteen years of age ('Jarrett, cxix,' p. 328, 'Money Hill, exxi. 3,' p. 330, and 'Flixton, lxxi. 1,' p. 275) may be mentioned and compared with the similar cases given at p. 237 of the second edition of the System of Dental Surgery by J. Tomes and C. S. Tomes. Another of the retention of a wisdom tooth, with its upper surface only just visible above the alveolus in an aged female skull, 'Cowlam, lvii. 3,' p. 216, may be mentioned as exemplifying another kind of retardation which is perhaps more common among women than men, as is also, I incline to think, the entire obsolescence of the wisdom teeth.

1 The slovenly habits of savages, carnivorous as well as vegetarian, by allowing of the admixture of sand with their food, furnish a very efficient means for wearing down of the teeth. But the inland tribes, who, like the outcasts described in the book of Job (chap. xxx. ver. 3-8), 'cut up mallows by the bushes, and juniper roots for their meat,' suffer more from the secondary consequences of such wear, which we have been speaking of as alveolar abscesses, than do the game-, fish-, or shellfish-eating races, such as the tribes represented by the Cro-Magnon and Mentone skeletons, or the Eskimos and Vancouver Island Red Indians. For the action of unintentionally introduced sand, see Wilson, Canadian Journal, Sept. 1862, p. 12, March, 1863, p.151; Mummery, l.c., pp. 35, 36; Pengelly, Trans. Devon Association, 1874, vi. p. 307, compared with p. 302, where the cave earth of the Mentone Cave is described as being 'a perfectly dry, very fine, incoherent, greenish sand.' For the wear of the teeth in the Cro-Magnon skeletons, see Broca, Mémoires, ii. pp.166-168; for that of the skulls from the Caverne de l'Homme Mort, see Revue d'Anthropologie, 1873, ii. p. 17. The similar sufferings of later races in possession of cerealia may be referred to the detritus of their querns and grain-crushers. 
The somewhat rare anomaly constituted by the presence of two roots to the lower canine has been noted by me in lower jaws from no less than five of the earlier interments treated of in this book; from, to wit, the long barrow cexxix. at Nether Swell, described above at p. 513, and by me in the Journal of the Anthropological Institute, Oct. 1875, vol. v.; from the cremation long barrow at Ebberston (p. 484 supra); from the chambered long barrow at Rodmarton (Cran. Brit., pl. 59); from the Dinnington ${ }^{1}$ barrow, described by me in the Journal of Anatomy and Physiology, 1863, vol. iii. p. 254; and, fifthly, from the Longberry Cave, near Tenby, examined by Mr. Laws (see p. 703 supra). The importance of this, which may appear to some readers to be a curious rather than a significant fact, will be seen very plainly when I add that all the other lower jaws from every period, inclusively of the bronze down to the present day, and from almost every variety of our species available in the ethnological series of the Oxford Museum for this comparison, have only furnished to me seven specimens with similarly bifid canine-fangs, and that of these seven only one belonged to a modern civilised race. This one presented other anomalies in its dentition which should render it perhaps unnecessary to consider it here, and the same may perhaps be said of yet another of these seven, inasmuch as it belonged to the skull 'Rudstone, lxiii. 4,' which has already been referred to (above, pp. 700-701) as fur-

1 Some doubt may attach to the assignment of the Dinnington barrow to the longbarrow period. I was not an eyewitness of the examination of it, though I, subsequently to the removal of it, made inquiries on the spot from persons concerned in that work, and recorded them $l$. $c$. Eighteen more or less perfect skulls had been reinterred after the removal of the barrow; these, through the kindness of $\mathrm{J}$. C. Athorp e Esq., I recovered; they are all dolicho-cephalic, and measurements of them were taken by Dr. Thurnam and recorded in the Memoirs of the Anthropological Society of London, vol. i., and Crania Britannica, tab. ii. p. 242. Casts of one of these skulls have been taken and are referred to by Welcker, Archiv für Anthropologie, i. 1, p. 149, and by Ecker, ibid. i. 2, p. 283, as illustrating well the 'Reihengräber' form of the latter anthropologist; and Dr. Barnard Davis has described this cast in his 'Thesaurus Craniorum,' p. 10, as being 'very large, even enormous,' and 'subscapho-cephalic.' I may mention in support of the view, which however I do not hold to be absolutely proved, that this barrow should take rank with those of the neolithic age, that out of twelve lower jaws recovered by me from the reinterment, no less than six combine the wide ramus, the short coronoid, and shallow sigmoid notch so characteristic of priscan jaws, with a rounded and slightly inverted angle; whilst in three of the other six the same rounding of the angle of the jaw is present with the same inversion, sometimes considered peculiarly significant; and that whilst in many cases the chin has an eminently feeble, in none of them has it the powerful development so common in the lower jaws of the later occupants of this country.

For other references to this Dinnington barrow, see Bulletin Soc. Anthrop. Paris, ser. i. vol.v. pp. 541, 578; Natural History Review, April, 1865, p. 245; Archæologia, xlii. p. 171. 
nishing some evidence for the existence of the disease rickets in the bronze period. Of the other five, one was found amongst more than a hundred Peruvian crania obtained from the collections made by Consul Hutchinson; two came to me from among six lower jaws collected for me in South Africa by the late Mr. Frank Oates of Christ Church, the small size, low coronoids, and feeble chins of which indicate that they probably belonged, as reported, to an outcast tribe, probably Bushman; a fourth belonged to a "pureblooded Gond,' as guaranteed by the donor, Captain H. A. Hammond, from Chindwara in Central India; the fifth, curiously enough and also suggestively, belonged to one of the South Welsh skeletons buried in the time of Charles $I$, as referred to above, pp. 565-566, note.

Pruner Bey (Bull. Soc. Anth. Paris, ser. ii. tom. ii. p. 244, 1867) has recorded the discovery of a similarly bifid canine from the famous cave-find of Naulette, in which, it may be added, evidence of a lower-jaw wisdom tooth with quinquefid fangs, and of extremely small incisors, was also found (ibid. tom. i. p. 587). The transversely placed sockets of these fangs are very frequently represented rudimentarily by raised ribs on the walls of undivided sockets, and the same may be said of the sockets of the lower premolars, which however I have never seen bifid, but which, judging from the position of these raised ridges, would have had such double fangs placed transversely to the jaw like those of the canines, not anteroposteriorly like those of the molars behind them, or of their homologues in Simiadæ.

If the importance of the fact of the greater relative frequency of bifidity of the lower canine-fang in 'priscan' races and modern 'Naturvölker' is plain enough, the same cannot be said of the interpretation or signification of the fact. In none of the recent, nor, so far as I can learn from plates, in any of the fossil Simiadæ, has any fission of the fang of a canine been observed ; indeed the lower-jaw canines in this family with their single fangs and the lower-jaw premolars with their invariably double ones differ from their human homologues more strikingly than do any of their other teeth. It is true that in some even of the Cynomorphous Simiadæ the fang of the lower canine is laterally grooved as well as laterally compressed; and in the gorilla the long diameter of the oval section of this fang forms a much more widely open angle mesially with the long axis of the molar series than it does in the chimpanzee or orang. Still these are but approximations to what is fully carried 
in the bifidity of the human canine fang; and though we may speak of them, therefore, as 'anthropoid,' we cannot speak of it as 'pithecoid.' To my thinking a fair expression of the facts may be given by saying, the interchangeability of form which exists between 'canines' and 'premolars,' but which ordinarily requires for its illustration the comparison of two distinct species, is exemplified by different varieties within the limits of our own single species. If in this instance we have to go as far afield as are such animals as Galeopithecus, Erinaceus, and Talpa, to understand how a so-called 'canine' can become 'premolariform' and develope two fangs, it is but one instance out of many which show that many questions in anthropology can be read only in the light furnished by comparative anatomy ${ }^{1}$.

I have not observed in these series any wisdom teeth with that larger development which is so commonly noticeable in the dental series of Australians as compared even with other black races, not to say with Europeans. Rather indeed the reverse, the wisdom teeth being often very small, especially in female skulls of the earlier series. Nor in spite of the grinding down which is so marked a feature in many of these skulls, as for example in the skull of the woman from Cissbury, described by me in the Journal of the Anthropological Institute, vol. vi. p. 34, have I ever observed the eruption of these teeth to have been provoked, as is sometimes the case in savage races, into taking precedence of the union by ossification of the occipital and sphenoid bones. Such precedence has been noted by Professor Broca ${ }^{2}$ in one of the Cro-Magnon skulls; and from his comparison of the skulls of various modern savages between the ages of eighteen and twenty-five with skulls of modern Europeans at the same period of life, it results that this peculiarity must be considered as a mark of degradation.

Several other notes of inferiority which are commonly found in savage races of modern days, and which have been described as existing in the remains of troglodytic man, are wanting in the neolithic skeletons which I have examined. Foremost amongst

\footnotetext{
1 For a philosophical discussion of the homologies and nomenclature and the interchangeability of form in mammalian teeth, see Messrs. Moseley and Lankester, Journal of Anatomy and Physiology, Nov. 1868, ser. ii. No. iii. p. 73, and Mr. C. S. Tomes, Manual of Dental Anatomy, 1876, p. 260.

${ }^{2}$ See Revue d'Anthropologie, 1873, ii. p. 20. Dr. Barnard Davis in his 'Thesaurus Craniorum,' 1867 , p. 309, observes of a Loyalty islander, 'æt. c. 25,' that 'the synchondrosis sphenobasilaris is not quite ossified, yet all the teeth have been cut.' This is the ordinary sequence in the lower animals.
} 
these may be mentioned prognathism; a peculiarity which our knowledge of the extent to which the jaws are modifiable and modified by the nature of the dietary alike in the lower races of man and in the lower animals, would certainly lead us to expect to find amongst a stone- and bone-using people. But, as it has often been remarked ${ }^{1}$, the facial angle of these early races is by no means small, and their jaws have none of that pithecoid elongation which is so striking and prominent a characteristic in the crania of many still existing savages. On the other hand, prognathic and macrognathic jaws are not rare, though they are not the rule, in series from the bronze, and also from the early iron period in this country.

A second mark of inferiority, not entirely unexampled among modern savages, the junction, namely, of the squamous to the frontal bone, has never to my knowledge been observed in any prehistoric crania. If this peculiarity had been present its significance would have been very great, as denoting a curtailment of the part of the brain which, corresponding to the great ala of the spheroid in the skull, is eminently favorably conditioned, both as regards vascular supply and histological constitution.

I have already remarked (pp. 640, 650 supra, and Journ. Anthrop. Inst., vol. v. p. 126) that a third mark of inferiority, that, namely, which is constituted by diminution of the height of the skull, absolutely as well as relatively to its long and transverse diameters, is not usually noticeable, except in the female skulls of the dolichocephalic long-barrow race. To this may be added that in the series from the Caverne de l'Homme Mort, belonging to an early period of the neolithic age, Professor Broca found the height of the female actually exceeding that of the male skulls in the proportion of 132 millimètres to 131 .

If we miss in these neolithic crania the diminution of the height of the skull which Professor Busk has, under the name of 'tapeinocephaly,' noted in certain modern savages, we look almost equally in vain amongst them for a fourth point of degradation, the elongation, to wit, of the basicranial axis; a peculiarity which Professor Cleland has rightly insisted upon (Phil. Trans., 1870, p. 124) as being strikingly and remarkably characteristic of uncivilised nations as distinct ethnographically as the Esquimaux, the Kafirs, and the Caribs.

${ }^{1}$ Broca, Mémoires, ii. p. 197; Rev. Anth., l. c., p. 19; Thurnam, Principal Forms p. 32 . 
I have already (p. 639 ${ }^{1}$ ) noted that the basis cranii in these ancient crania has never been found by me to have suffered from that pathological degradation which is known as the "plastic deformation ' of Dr. Barnard Davis, the 'basilar impression' of Virchow, the 'impressio baseos cranii' of other authors.

The nasal index, which fails to separate the Eskimo from the civilised races, fails equally with the long-barrow skulls, and, as has been pointed out by Professor Broca (Rev. Anth., 1873, ii. p. 19), with other prehistoric European skulls. On the other hand, the orbital index, which does put the prehistoric crania from CroMagnon and the Caverne de l'Homme into a position of similarity to skulls such as those of the Tasmanian, Australian, and Melanesian races, puts the neolithic skulls of British barrows into a position of superiority as compared, not merely with the modern savages just mentioned, but even with the skulls of the bronze period. As regards these latter skulls however, it should be remarked that the transversely oblong outline which their orbital border sometimes assumes, as in the skulls 'Heslerton Wold,' described and figured at pp. 579-580, and 'Rudstone, lxiii,' described and figured at pp. 590-591, is due to an excessive downgrowth of the supraciliary ridges, rather than to any curtailment of the distance between the actual roof of the orbit and its inferior or maxillary border. In other words, just as the prognathism of modern savages may depend simply upon increase in size of the anterior alveolar segment of the upper jaw, so a low orbital index may be and often is due to a downgrowth of the upper border of the orbit, which comes thus to lie in a plane much lower than that which the true roof of the orbit occupies.

Professor Broca, in his account of the skulls from the Caverne de l'Homme Mort (Rev. Anth. l.c. pp. 26-28), after enumerating the various points in which those nineteen crania contrast and agree severally with those of the earlier race represented at Les Eyzies on the one hand, and with those of later races on the other, declares himself of opinion that the race to which they belong, whilst affined to the palæolithic man, has no longer any distinct representatives upon

1 The references made by me elsewhere (pp. 689-698 supra) to this interesting pathological change were made merely for the sake of illustration. Dr. Barnard Davis's paper was read before the Anthropological Society of Paris, June 5, 1862, and may be found in Mem. Soc. Anthrop. de Paris, tom. i. p. 380. Subsequently a memoir upon the subject was published by Dr. Boogaard in the Nederland Tijdschrift voor Geneeskunde, 1865 , 2. p. 81, an analysis of which by Dr. W. D. Moore appeared in the Cambridge and Edinburgh Journal of Anatomy and Physiology, Nov. 1866, p. 179. 
the area which it once, however imperfectly, occupied. It must be very difficult to attain to anything like perfect certainty upon such a point in view on the one side of the tenacity with which so-called 'indigenous' or 'autochthonous' races retain, in whatever political or social status, a foothold in their 'aboriginal' country; and, on the other, of the modifying influence which the introduction of agricultural and other improvements may have exercised in the course of many centuries. Without going, however, further into this question, I will say that a comparison of the skulls here dealt with from the stone and bronze periods with those of the mediæval and modern tenants of these islands, coupled with other considerations and carried on for a considerable number of years, has inclined me to hold that the two prehistoric races, though outnumbered greatly by Anglo-Saxons, are still represented in the population of Great Britain and Ireland. The short-statured, dark-haired, long-headed race which is found not only making up nearly the whole population of large 'Welsh'speaking districts in Wales itself and in the Highlands of Scotland, but also mixed up, and in very large proportions, with the population occupying midland-county districts usually held to have been entirely Saxonised and Danicised, as pointed out long ago (see p. 679 supra) by Professor Phillips, we have many reasons for holding to be the lineal descendants of our long-barrow people. In the north of England we find that the neolithic race amalgamated peacefully with the brachy-cephalic stock which taught them the use of bronze; and in the early iron period (see p. 683 supra) the earlier race appears to have regained some of its numerical preponderance, the late Celts from the East Riding and elsewhere north of Yorkshire having been mostly dolicho-cephalic. The bronze-using race seems, in the southern parts of this country, to have more completely absorbed or destroyed the dolicho-cephalic than it did in the north, resembling in this the dolmen-builders of France, whose predominance brought about an almost entire disappearance of their neolithic and troglodytic predecessors (see Broca, Revue d'Anthropologie, ii. pp. 49, 50, iv. p. 608). Still a race with many of the physical peculiarities of the long-barrow people is represented in great abundance in the cemeteries of the centuries during which this country was divided into Roman latifundia and forest-land; and whatever may have been their social or political status, the dolichocephali enjoy in such interments a great numerical superiority as compared with the brachy-cephali. The 'Saxon' or 'English' conquerors of this country have been shown (see Archæologia, xlii. 
p. 460 ; Proceedings of the Royal Institution, 1870, p. 118) from the examination of their burial-grounds, as well as of other evidence, to have displaced the population they found in occupation of it as entirely and completely ${ }^{1}$ as it has ever been found possible for invaders to do. The existence in the England of those days of large woods and forests and marshes, a point dwelt upon by Professor Pearson at pp. 4 and 24, and illustrated by several of his 'Historical Maps of England,' must have made the entire extirpation of the Romano-British population an impossibility ${ }^{2}$; and enables us to understand how even in the time of Canute British outlaws carried on brigandage even in such counties as Huntingdonshire.

There is of course no need to adduce any argument in favour of the self-evident proposition that the brachy-cephalic metal-using Celt was in date but of yesterday as compared with the troglodytic men of the continent; but the line of argument which may be employed in favour of this conclusion as regards the neolithic man of our long barrows, that, namely, such as it is, which rests upon the continuity of descent which appears to connect this stock with the dark Welsh and Gael of our own days and country, would not admit of being so used as regards the later race. For, as has been above (pp. 126, 630,631, 681) pointed out ${ }^{3}$, the cranial and skeletal characters of the bronze-using Celt are very closely similar

${ }^{1}$ In this, which appears to have been a very thoroughly Teutonised district, the crania of the present agricultural population appear to me to be very closely similar to or indeed scarcely distinguishable from those of the Saxons of the times when they first discontinued cremation.

${ }^{2}$ Captain Thomas (Proc. Soc. Ant. Scot., April, 1876, xi. part ii. p. 504) may be quite right as to his 'theory of the entire removal by slaughter or flight of the Celtic people' of the Hebrides; but the evidence from 'place-names' is not by itself sufficient to support this conclusion. The 'place-names' in many districts of England in which the so-called 'Black Celts' are still largely represented, will be found to be exclusively Scandinavian or Saxon. Small islands of course which have neither dense woods nor lofty mountains to serve as refuges to their occupants may, as the miserable history of the Greek Archipelago has shown from the time of Datis and Artaphernes (Hdt. vi. 31) down to our own, have their inhabitants entirely extirpated. And this may have been the case when the Hebrides were invaded by the Northmen. But as regards larger islands and continental areas the lines from Wordsworth's 'Poems dedicated to National Independence and Liberty,'

'Two voices are there; one is of the sea,

One of the mountains,'

need to be supplemented by a mention of woodlands.

3 The very frequent discovery of amber ornaments in round barrows may be fairly considered as an argument in favour of their 'Cimbric' or 'Baltic' origin. Mr. Spence Bate (see Trans. Devon Assoc. 1872) considers the beautiful amber dagger-pommel found in a round barrow on Dartmoor as evidence for the 'Scandinavian' character of the interment. For amber-ornaments on bronze weapons, see Montelius, Congr. Internat. Anth. C. R. Stockholm, ii. 833, and Catalogue, Stockholm Museum, 1876, p. 40. 
to those of the mediæval and modern Dane; and this similarity must of course make it difficult to decide whether the brachycephalism of many crania procurable from mediæval and especially urban mediæval interments, is to be referred to the persistence of such a brachy-cephalic prehistoric stock, or to the admixture of Danish blood in historic times upon which writers such as Worsaae (The Danes and Norwegians in England, Scotland, and Ireland, 1852) and Isaac Taylor (Words and Places, 1865, p. 183) have insisted with so much force. The discovery however by Dr. Thurnam and myself ${ }^{1}$ of numerous skeletons of a typically brachyeephalic tribe in a tumulus belonging to a period close upon that of the Saxon invasion, and situated at Crawley in Oxfordshire within the shadow of the protecting Forest of Wychwood, renders it exceedingly probable that this vigorous race, after surviving three centuries of Roman rule, may have endured till, at the commencement of the historical Danish invasion and immigration, there came into this country a stock to which they are beyond doubt physically, and probably also ethnographically, most closely allied.

The probable continuity in the way of descent of the long-barrow people with certain varieties of our present population, considered together with the fact that in these series we miss certain marks of degradation which are recognisable in the confessedly more ancient remains from certain continental 'finds' may tend to produce in the mind of a reader an exaggerated as well as a somewhat mortifying notion of their inferiority in the matter of antiquity. I will therefore, in conclusion and very shortly, enumerate the various physical peculiarities of an anatomical, to the exclusion of an archæological, kind which have in spite of all the considerations just put forward impressed me very deeply with a conviction of the immense distance which separates our time from that of the long barrows. First amongst these I should put the smallness of many of the skeletal and of the cranial bones both, which I have obtained from the long barrows alike of the cremation-kind, as in the East Riding of Yorkshire, and of the inhumation-kind in Gloucestershire. It is true enough that powerful skeletons and very large skulls have been found by me in these British as well as by many other investigators in many other interments of the same and of earlier ages. So generally accepted ${ }^{2}$ indeed is this a priori surprising fact that we find writers such as Virchow (Archiv für Anthro-

1 Archæologia, 1870, xlii. p. 175, and supra p. 657.

${ }^{2}$ See British Association Report for 1875, p. 150. 
pologie, 1873 , vi. p. 92) speaking of the notion that savagery and inferiority are characteristics of the aboriginal population of Europe as being simply an arbitrary preconception, der vorgefassten Meinung von der Wildheit und Inferiorität der europaischen Urbevolkerung.

But against this criticism we have to set the following considerations; firstly, that the male skeletons in these tumuli are the skeletons of men who were chiefs, and chiefs in times and under conditions when such a position was held and kept only by men of force at once of character and physique (see supra pp. 640, 662, ibique citata); secondly, that even in these 'tombs of the kings' we find (see supra pp. 658,660, 704) female skulls and female skeletons of disproportionate smallness; and, thirdly, that (see pp. 615, 651, 675 supra), mixed up in these tumuli with the large and well-filled male skulls there are not wanting 'ill-filled,' 'boat-shaped' crania, to parallel which we have to go far afield amongst modern 'Natur-völker ;' or that, in technical language, the crania of the neolithic period were not rarely dolicho-cephalic in a way which justifies us in speaking of them as being steno-cephatic ${ }^{1}$ and of their owners as being in contrast to modern civilised dolicho-cephali, angustiores rather than latiores. To the narrowness of the ill-fed brain the simplicity or obliteration of the sutures testifies often, even in the most fragmentary of the neolithic crania; in more perfect specimens we have the same conditions more forcibly impressed upon our imagination by the

1 Professor Aeby in 1863 (Verhandl. Naturforsch. Gesell. Basel., iii. 4) proposed to divide all skulls into the two classes of Steno-cephalous and Dolicho-cephalous, having regard simply to the differences of breadth. In 1867, in his Schädelformen des Menschen und der Affen, p. 32, he again argues that this division should be substituted for that of Retzius, according to which skulls are similarly divided into two classes, but into Dolicho-cephalous and Brachy-cephalous by reference to the relation subsisting between their length and breadth. His words are as follows:- 'Was er (Retzius) also für lang und kurz gehalten ist nichts anders als schmal und breit, und es scheiden sich die menschen nicht nach Dolicho-cephalie und Brachy-cephalie sondern nach Steno-cephalie und Eury-cephalie.' As there appears to be some tendency in recent writers, e.g. Zuckerkandl, Novara Reise, 1875 , p. 65, to adopt this classification, it may be well to say here that with dolicho-cephaly and brachy-cephaly respectively many more properties are correlated than those which their mere etymology connotes. Some of these are of primary morphological (see p. 637 supra), others of primary physiological (see p. 677 supra) importance. Neither is it possible to overrate the ethnographical importance of the fact insisted upon (pp. 589, 648, 662, 664,665 supra) that within the circumscription of dolicho-cephaly and brachy-cephaly both, a natural subdivision may be made by reference to this very matter of breadth. There are 'ill-filled' brachy-cephalic skulls as well as 'well-filled;' 'well-filled' dolichocephalic skulls as well as 'ill-filled;' and to use, as is now sometimes done, the word 'steno-cephalous' or 'schmalkopfige,' as convertible with dolicho-cephalous and as opposed to brachy-cephalous, is simply to ignore facts. These are excellently expressed by Professor Cleland's proposed quadrifid division of dolicho-cephali and brachycephali into latiores and angustiores respectively. See Phil. Trans. 1870, p. 148. 
sight of the parietal and frontal eminences standing prominently out in relief upon the wall-sided and vertically-ridged cranium. If a contrast such as this ean be shown to exist between a series of what were all but certainly the crania of the most favourably conditioned and best developed of the neolithic population and any mixed series of later times down to this day from cemeteries in this country, the contrast would undoubtedly have been very much more sharply pronounced if we had had before us representatives of all classes from those early times.

Secondly, though well shaped and capacious calvariæ with orthognathous upper jaws do abound in the series from the stone and bone ages, and after bearing a comparison, and by no means always to their own disadvantage, with modern specimens, may be only with difficulty distinguishable from them, the same can hardly be affirmed of that most distinctive bone, the lower jaw ${ }^{1}$. Enough

1 The caves of Cro-Magnon and Mentone have furnished us with similar lower jaws from the palæolithic men whose remains have been found in them, but, as in the cases of the Bushman and the Tasmanian, these lower jaws were combined with the low orbit so different from that of the Esquimaux, the wide opening of which in the skull contrasts so strikingly with the oblique, slit-like aperture of the eyelids in their living heads. And the prognathism of the Esquimaux, though it is possible to lay too much weight upon this point, as also the convex malar portions of the maxillaries, will be held by many to differentiate him from the palæolithic and neolithic races both. On the other hand, Professor Broca (Rév. d'Anth., 1873, ii. pp. 26-28), with the remains from the Caverne de l'Homme Mort before him, has no difficulty in connecting these neolithic with the palæolithic men, and Professor Boyd Dawkins so long ago as 1866 (see 'Cave Hunting,' p. 359, ibique citata) collected a set of coincidences between the implements, works of art, and animal surroundings of these latter men and those of the Esquimaux, the number and variety of which it is difficult to explain except upon the hypothesis of some connection having subsisted between them. Colonel Lane Fox and Mr. C. E. Rance are cited in the 'Reliquiæ Aquitanicæ,' p. 284, as accepting and corroborating this view; and Sir John Lubbock at p. 262 of his edition of Nilsson's 'Early Inhabitants of Scandinavia,' whilst pointing out that Mr. Busk's identification of Ursus priscus with Ursus ferox gives us some additional 'reason for the belief that the Esquimaux once inhabitated Western Europe,' uses language of a more cautious character as regards this conclusion than perhaps he might have done had not the author whose work he was editing expressed himself (pp. 104, 141) as being so very distinctly opposed to it. Mr. Alexander C. Anderson, 'Reliquiæ Aquitanicæ,' p.49, and M. Sauvage, ibid. p. 220, would appear to be of the same opinion as Nilsson; most recent anthropologists, however (see for example Mr. E. B. Tylor, 'Primitive Culture,' vol. i. pp. 64, 95, ed. 1873, or the various authorities, old and recent, cited in the Address to the Biological Section, British Association, Liverpool, 1870, p. 103), incline to accept the argument from identity of custom to identity of race.

As regards the language of the Esquimaux, Professor Sayce has told us (Contemp. Rev., April 1876, p. 722) that ' if we turn to the grammars of those savage tribes who best represent the infancy of mankind we shall find them marked by the greatest synthetic complexity. The involved and monstrous words of the polysynthetic languages of North America, where the Esquimaux aglekkigiartorasuarnipok, for instance, represents our " he goes away hastily and exerts himself to write," are really examples 


\section{has been said above (pp. 541, 645, 654,655, 706) of the peculiar characteristics of the 'priscan' human lower jaw, of the tumid}

of those primæval undecomposed sentences out of which the logical precision of a French grammar or the severe grandeur of a Semitic prophecy were eventually to come. Their cumbrous barbarism is due to poverty, not to profundity of thought. Relatively to the Bushman language, however, the same authority writes in answer to an enquiry of mine; 'As regards phonology, the Bushmen with their clicks certainly stand on a far lower level than the Esquimaux. . . . . In some grammatical points, moreover, the Bushman language is what you aptly term "poor stuff." Thus the plural is denoted by reduplication, and the verb has not been developed. However, we do not yet know as much about the Bushman dialects as is desirable. Where the Esquimaux-like most of the other inhabitants of the Old World-best represent the primitive condition of speech is in the structure of the sentence. The independent word has not yet been evolved out of it.'

I have above (p. 633) expressed my feeling of the strain which is put upon the imagination by the effort to think even of the neolithic races as genealogically connected with the palæolithic; and a still greater effort is of course required for putting in thought any still existing races into a similar relationship. The exertion necessary will however become lighter in proportion to the hold which the uniformitarian doctrines of modern geology obtain upon our minds, and in the meantime what is going on in the world at the present day may teach us that it has not always been easy, and may sometimes, even now, be impossible, entirely to extirpate a wild race of men in a wild country. Such were of course the men and the country of the cave and other palæolithic periods. Neither, I apprehend, is it meant by speaking of affinity as existing between these ancient races and the modern Esquimaux, that these stone- and bone-using men are to be connected together at all in the same way as the Massaliotes were connected with the Phocoeans, or the Galatians of Asia Minor with the Gauls. No one supposes that an immigration has ever taken place from the district inhabited by the Esquimaux into the regions now occupied by the French, English, and Belgians. Nothing that is suggested by the facts goes beyond making us suppose that the countries in question were in the times in question occupied by a race of very considerable uniformity of physical structure, of habits, and of appliances for fighting their hard battle of life; and that the great changes which have since those 'unhappy far-off times' taken place alike in their inorganic and organic environment have broken those tribes up into fragments, of which some infinitesimal traces are perhaps still detectable amongst us, and of which the still widely-spread Esquimaux may, however altered in the course of ages, be with some probabilify held to be the most characteristic remnant.

I take this opportunity of drawing attention to two instances of the tenacity with which certain customs and practices have maintained themselves amongst some of the races which we have had under comparison, leaving to the reader the task of deciding

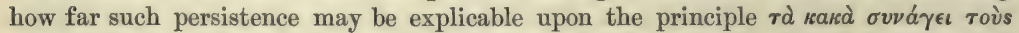
ảv $\theta \rho \omega$ movos (Arist. Rhetor., i. 6. 22), that community of needs and distresses brings all men together, and makes all men alike. First of these, as being less amenable than the other to the objection just referred to, I will put the singular aversion to fish as an article of food which has characterised certain of the inhabitants of Scotland from the time of Severus down to our own time and has been noted as something remarkable in the history of the modern Esquimaux. Dio Cassius (fl. A. D. 230), lib. 1xxii. 21, p. 866 c, ed. Leunclavii, observes with the surprise not unnatural to an Italian, that the two most powerful British tribes, the Mratæ and the Caledonii, though they have no agriculture, but are dependent upon the produce of pastoral and hunting life and fruits, such as nuts and acorns, make nevertheless no use of fish for food, though fish are avail-

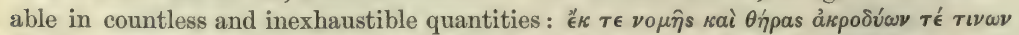

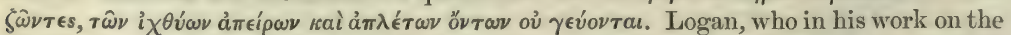
Scottish Gael (vol. ii. p. 125) says that Herodian, a contemporary of Dio Cassius, makes the same observation, a statement which I have not been able to verify, writes (l.c.) as 
horizontal segment corresponding to its molar teeth, of its wide ramus, of its short coronoid process, of its feeble chin, of its rounded,

follows of the modern Highlanders:- 'The Highlanders, notwithstanding the mention of fish in several old poems, certainly did never willingly make use of such food. It was a matter of astonishment to an English resident among them a century ago that the trout with which their streams were teeming remained entirely disregarded, but they retain a proverb which implies their contempt for fish-eaters, and the encouragement of government has not yet induced either the Scots, Welsh, or Irish to enter with spirit into the fish trading.' Later evidence is not wanting to the same effect.

The same peculiarity is recorded by Mr. Whymper in the Alpine Journal of May, 1870, with the same indications of surprise, as distinguishing the Esquimaux :- 'Fish are plentiful on most parts of the Greenland coast, particularly cod, holibut, and salmon. But, although their quality is little, if at all, inferior to the best we can obtain in this country, the Greenlander does not care for them, he will eat them and does eat them, but he will seldom do so unless there is a great necessity. . . . . It is certain that in his heart of hearts he cares for none of them as food.'

Neither modern research among still existing savages (see 'Reliquiæ Aquitanicæ,' p. 95) nor ancient literature justifies the scepticism which has been expressed (see Sturzius in ed. Dio Cassius, 1824, vol. vi. p. 812; Selden, Mare Clausum, ii. p. 127, ed. 1635) as to the abstinence from fish-food on the part of wild races living by the sea-side. Irrespectively of notices in the classical writers as to the prohibition of such food for religious reasons by Pythagoras, or in the cases of priests as in Egypt (Hdt. ii. 37), or as in the service of the Bona Dea (Julian, pp. 176, 177, ed. Lipsiæ, 1696), we have such abstinence on the part of early races repeatedly mentioned by them as a matter of wonder and contrast. Marsham (Can. Chron., Leipzig, 1676, p. 220) has improved upon the well-known remarks of Plato (Rep. iii. 404, or Trans. Jowett, ii. p. 231) and of Athenæus (Dipnosoph. iv. p. 157, ed. Leyden, 1612), following Meleager of Gadara, to the effect that the warriors of the Iliad did not eat fish, by pointing out that the same may be said of the luxurious Phœnicians and the Ithacan suitors of the Odyssey, and that it was only under the pressure of necessity that the sailors of Ulysses betook themselves to fishing (Od. $\mu$. (xii.) 329-331) :-

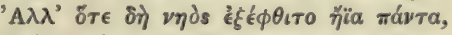

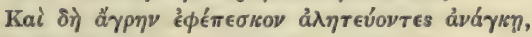

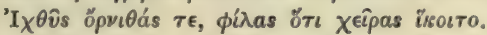

Similarly the lines of Horace (Sat. ii. 2. 46-48),-

'Haud ita pridem .....

Tutus erat rhombus tutoque ciconia nido,-

and those of Ovid (Fasti, vi. 173-179) show that even in the times of Augustus a tradition remained of the period when fish and fowl were not used in supplementation of mammalian meat, when ' Piscis adhuc illi populo sine fraude natabat,' though 'Sus erat in pretio.'

The second peculiarity which I wish to note is one recorded by the ancient Strabo (iii. 4, 16) and by his contemporaries Diodorus Siculus (v. 33) and Catullus (xxxv, xxxvii) as distinguishing the Iberians and Celtiberians of their time; and by the modern Egede (Description of Greenland, second edition, London, 1818, p. 127; French edition, г 763, p. 98, cit. Sir John Richardson, 'Polar Regions,' 1861, p. 304) as distinguishing the Esquimaux; and it may be best given in the words of the first-named of those

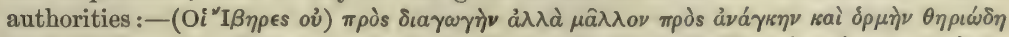

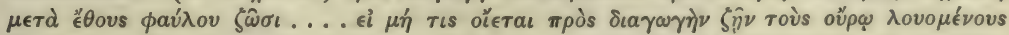

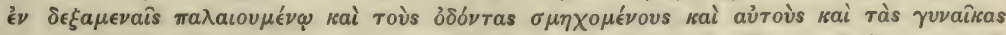

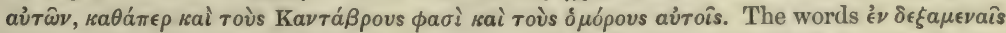

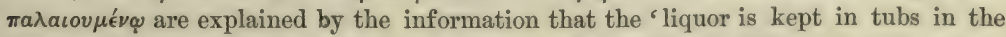
porches of their huts for use in dressing the deer and seal skins.' It is clear from Catullus's use of the word mane (xxxvii) that he did not understand the rationale of the process he refers to, and that he was inaccurate as well as otherwise offensive. 
often inwardly bent angle; the outcome of the investigation may be summed up by saying that though lower jaws combining all these marks of degradation may be found amongst such races as the Bushman, the Tasmanian, and the Melanesian, it is only amongst the Eskimos that we find such jaws combined with the widely open orbit and vertically elongated nasal cavity so characteristic of the long-barrow race. And there are many reasons for supposing that the Eskimos are a race which still retains and preserves for us in the structure and grammatical peculiarities of its language, its life-history, and physical peculiarities, the very closest likeness to what we believe some of the earliest races of mankind must have been.

The disproportion which I have dwelt upon (p. 658 et seqq. supra) as existing between the male and female limb- and trunk-bones from the long barrows is a striking feature in the comparison of that series with any other from later interments in this country. This however is a skeletal character reproduced in and reproducible by modern savagery. But the 'platycnemy' or peculiar flattening out of the shin-bones, which we know from the researches of Professors Busk and Broca and others to have characterised other early and earlier races of men, has stronger claims to be considered a note of antiquity; it is possible that such tibiæ may be hereafter found amongst modern savages; but they will not, I anticipate, be found amongst such races in the numerical proportion to normal bones which I have found them to possess in neolithic skeletons. 


\section{A P P E N D I X.}

I HAVE thought it well to put together in an appendix a few remarks upon the flora and fauna of the prehistoric times with which I have been dealing, with the view of supplementing rather than of summarising the already existing and very extensive literature of this subject. Having had numerous opportunities of examining, not merely the collected contents of barrows, but the barrows themselves whilst still containing them in situ, I have come to feel that the history of the prehistoric flora and fauna may have been somewhat analogous to that of the barrows themselves, and may therefore receive some elucidation from it. Firstly, the barrows survive mainly in parts of the country into which agricultural improvements with their levelling tendencies have not penetrated as thoroughly as they have into less rugged, less hilly, more arable districts. But the same causes which have allowed these sometimes large masses to remain undisturbed may be reasonably supposed to have been equally favourable to the living organisms which were their contemporaries. Secondly, when we come to look at the structure of the barrows in various parts of this country and the character of their manufactured contents, we are impressed with the existence in them of a similarity and uniformity the more striking as it is not paralleled by any very marked similarity in the analogous human creations of the present day; whilst it is reproduced more or less closely in the flora and the domesticated fauna of those localities. The sheep, oxen, and swine of the Scotch and Welsh highlands, even if not as closely alike as are the horned cairns of Caithness, of Gloucestershire, and of the Peninsula of Gower (see pp. 536, 537, 702 supra), are nevertheless far from dissimilar; vegetable being more dependent upon inorganic influences than animal life, the flora at present in occupation of those districts may perhaps, when we make allowance for very recent disturbances in the way of planting, be held to be even as exact a reproduction of that which occupied them in neolithic times 
as the pottery of that period found at one end of this country is of the contemporaneous pottery found in the other. If we are to reason about these as we do about other facts of distribution in space and time, we must hold that a greater uniformity existed in the forms of vegetable and a much greater in the forms of animal life over the whole of this country in prehistoric than in recent times; and that the districts in question may be likened to islands which have been separated from each other by the encroachments, sometimes more, sometimes less gradual, of an invading sea. If a greater mass of material has been available to me in the barrows themselves than has been to some other writers upon the subject of the fauna of prehistoric times, it must be said on the other side that my investigations have been confined to the 'houses of the dead;' and that I am not here writing of the relies to be found in such greater abundance in what were 'the houses of the living,' viz. cave- and pile-dwellings. In the largest long barrow indeed, that at Crosby Garrett (see p. 510 supra), which I have examined, I noted that of all the animal bones found, only one single fragment could be said to have been proved to have owed its introduction to the race which reared the barrow. And though in many barrows considerable numbers of such bones have been found, the remains of the funeral feast have not been so productive, as indeed they could not have been expected to be, as the rubbish-pits or the floors of the dwellings of ancient times have been to other investigators.

\section{Of the Prehistoric Flora of this Country in the Neolithic Period.}

The palæolithic man had before his eyes a country, the hills, valleys, and plains of which had somewhat different contours from those upon which the neolithic man lived his hunting or pastoral life. But the position of the long barrows and forts, reared by the later race of men in places of vantage as regards prospect and elevation, shows us that the solid earth on which they trod has had its escarpments and its river-courses subjected to but little change since their time.

The landscape however upon which his eyes rested was nevertheless a very different one from that which meets ours now in any but the wildest districts of this country. The characters of a landscape at various periods depend mainly upon its vegetation, and if the indigenous trees of Great Britain have not been so entirely out- 
numbered and the character of its summer and indeed winter clothing of leaves so entirely changed by foreign immigrations, as Victor Hehn in his interesting work, 'Kulturpflanzen und Hausthiere,' 1870, pp. 2, 314, 392, is inclined to think that of Italy has been, the changes which the woodlands of this country have undergone since prehistoric times have been very great indeed.

Much weight must in the first place be laid upon the enormously greater proportion of the entire surface of the country which was in early times occupied by trees, though England is even at the present day one of the best wooded of civilised countries; for the influence of this quantitative difference upon both man and beast must have been important and many-sided to a degree which, in spite of all that has been written by others, it is difficult to exaggerate. Qualitatively the character of the trees which filled the plains, clothed the hillside, and formed the sky-line of the neolithic period was a very different one from that of those which stand at intervals in our hedges and enclosures and bound our horizon, at least in our midland and southern counties. Some difference of opinion exists among botanists as to whether the 'common' elm, which is now perhaps the most abundant of our southern and midland trees, is or is not indigenous ${ }^{1}$. I cannot but think that the facts of its absence from parts of Great Britain which are separated either by moorland or mountain from the southern and midland counties, whilst it flourishes in such districts when once introduced into them, coupled

1 For the changes which have been produced in our indigenous flora by the successive immigrants into or conquerors of this country, see De Candolle's Géographie Botanique Raisonnée, 1855, vol. ii. pp. 645-705; the Rev. C. A. Johns, Forest Trees of Great Britain, who says (p. 42), 'If in my history of forest trees I were to confine myself to those which are universally acknowledged to be indigenous to Britain, I should soon bring my labours to a close. England, though once a well-wooded country, never probably could boast of containing within it any great variety of species ;' and Pearson, 'Historical Maps of England,' 1869, pp. 48, 49.

For the question as to the indigenous character of the common elm, see De Candolle, l. c., p. 690, and Watson and Bromfield, citt. in loco; Pratt, Flowering Plants and Ferns of Great Britain, vol. iii. p. 98 ; Johns, l.c., p. 227. The history of the common elm, which, though multitudinous and prominent in our landscapes, has yet failed, as its rarely seeding shows, to become really naturalised in our soil, may be taken as corresponding, and curiously, if it be really a Roman importation, to that of the Latin element in our language, which, though outnumbering by mere words the Teutonic or Saxon element in the proportion of 29,354 to 13,330 (Thommerel, cit. Max Müller, Lectures on the Science of Language, 1861, p. 74), has never established itself in our grammar. The wych-elm, which in spite of its more rapid growth and greater beauty has nevertheless, owing probably to the lesser durability of its timber, had its area of distribution in Great Britain curtailed by successive invaders, may in like manner be considered to typify the history of the indigenous British races as encroached upon by Teutonic and Scandinavian conquerors. 
with the fact of its rarely seeding here, should incline us to the latter view. It is obvious, as has often been suggested, that the Romans who introduced the vine may have introduced with it the 'piller' elm, the two plants being so commonly wedded in Italian husbandry, as in both Italian and English poetry. On the other hand, the readiness with which the wych-elm ripens its seeds, and its power of maintaining itself and flourishing even in the highlands of Scotland, to say nothing of its trivial name, the nationality of which is disputed, would appear to show that it at least is an indigenous tree; and it may consequently have contributed in larger proportions and given pro tanto a larger share of beauty to the prehistoric landscape than it does now to ours.

Dwellers on or near the chalk districts of England are too familiar with the conspicuous and beautiful, though common, seedlings of the beech not to feel considerable doubt as to the accuracy of Julius Cæsar's statement that the tree though present in Gaul was wanting in Britain. Antiquaries who are familiar with the fact of the great abundance of the bones of the domestic pig in British barrows, both of the stone and of the bronze age, will find it difficult to believe that, in the latter of those periods at least, beech-mast and beechtrees had not been made available for feeding that animal; especially when they consider how freely intercourse was carried on between Britain and Gaul, and how easily the seeds in question could and would have been carried across the Channel. Botanists at least (see De Candolle, l.c., pp. 154, 689, and Johns, l.c., p. 144) appear to be agreed that the words 'Materia cujusque generis, ut in Gallia, est, prater fagum atque abietem' (De Bello Gallico, v. 12) contain one of the few errors fallen into by Cæsar. Had this statement related to Scotland it would probably have been correct, beech-mast never having been found any more than ash-seeds in the peatmosses of Scotland, though both plants are now to be found even in the extreme north of that country, and though both, I think, must be held to be indigenous in South Britain.

For these considerations and some others seem to me to outweigh the views of Dr. Daubeny, expressed in 'Trees of the Ancients,' 1865, p. 7, to the effect that the beech 'was not known in Holland nor probably in England or Ireland at the time of the Norman Conquest ;' views against which, as pointed out by Professor Pearson, l.c., p. 48, the mention of a 'bochholt' in a charter of Offa, and of 'the old beech' in one of the Confessor, can be urged as regards Saxon times. It is difficult also to reconcile them with the general fact stated by 
De Candolle, l. c., p. 689, on the authority of Davies (Welsh Botany, p. 90), that dans le pays de Galles Ffa-wydden (wydden étant une désinence commune aux arbres et Ffa le nom proprement dit) was the name for this tree; or with the special exemplification of this with which the Welsh name for Hereford, a city with beech-trees near it, 'Tre fawydd,' furnishes us (see Camden's Britannia, p. 476, cit. Professor Pearson, $l . c$.). As there is however no question that the beech fails to form any very large proportion of our South Britain peat-mosses, it may be suggested that this transference to the beech by the Welsh of a name which originally belonged to the oak (see Max Müller, Science of Language, ser. ii. p. 236) must have taken place in a country where a preponderance had been gained by the former over the latter tree. If therefore Denmark was the country, see supra, p. 631, whence the bronze-importing invaders of this island came, the beech must have been a prominent tree there at an earlier period than is usually supposed ${ }^{1}$. Or it may have abounded here at that time and yet left, as in Denmark, no remains in the uncongenial peat.

1 As against the prominence, though not against the existence, of the beech in our own country at a much later period might be urged the fact that it is not mentioned by Chaucer in three places, 'The Assembly of Foules' (ed. Bell, 1855, vol. iv. p. 195), 'The Romaunt of the Rose' (vol. vii. p. 59), and 'The Complaint of a Lover's Life' (vol. viii. p. 8), where he does mention nearly all the other trees which in the fourteenth century entered largely into the composition of the English landscape; to wit, the 'oke,' the ' asshe,' the 'elme,' the 'boxe,' the 'firre,' the 'ewe,' the 'aspe,' 'notes,' $s$. 'philbert' (hazel), the 'bolas,' the 'pyn,' the 'maples,' the 'popler,' the 'lyndes,' the 'hauthorne.' And it might be said that in a Welsh poem ascribed to Taliessin, but referred by Professor Pearson (l.c. p. 48), to the fourteenth century, the beech and lime are both left unmentioned in describing a battle of the trees; and that the beech is omitted from a much earlier Welsh poem ascribed to Llywarch Hen in the sixth century. See Skene, 'Four Ancient Books of Wales,' i. pp. 279 and 576, cit. Pearson, l.c. As against the evidence furnished by a fourth passage from Chaucer, 'The Knightes Tale,' vol. i. ed. cit. p. 182, in which, as in Spenser's 'Faery Queen,'i. 7, 8, 9, the beech and also the birch and the willow are added to the tree above enumerated, it might be objected that 'the whole description of the funeral and games is taken from the sixth book of the Thebais ;' and as a matter of fact we have the words 'gli alti faggi' standing in the parallel passage, 'Teseide,' xi. 22, col. 237, ed. Ven. 1838. But Professor Earle writes to me upon this matter to the following effect: 'In the Knightes Tale, the marshalling of the trees in a catalogue is in manner Chaucer's own; and the majority of the trees, also, are his, and not Boccaccio's. ... But as far as philological and literary evidence goes, it is all in favour of the trees being at Chaucer's time familiarly English. The word beech was ready to hand, and in its final form which has no' since been modified. Yet that word was a considerable remove from the Anglo-Saxon bóc, and such modification postulates warm and constant usage. The word is ancestral, older, I mean, than our distinct national existence; it is so like in Anglo-Saxon to what it is in Icelandic and in German as to prove that there was no breach of continuity in its use from the earliest time.' 
By the word 'abietem' Julius meant probably the Abies pectinata, s. Pinus picea L., our 'silver fir,' a tree with which, as being a Swiss, a French, and a Pyrenean pine, and climbing those heights in company with the beech, his campaigns in Western Europe had sufficiently familiarised him. The Scotch fir, Pinus sylvestris, was for many centuries later the only representative in these islands of the Abietinece, and indeed the yew, Taxus baccata, and the juniper, Juniperus communis, the only other representatives of the entire natural order Coniferce 1 .

In a round barrow at Kepwick examined by Canon Greenwell (see supra p. 337) and myself the grave was found lined with the bark and branches of the birch; much as the Lapp graves, described in the Compte Rendu of the Stockholm International Congress of Anthropology, 1876, tom. i. p. 181, or Mestorf's Report of it, 1874 , p. 13, contained bodies entirely covered with several layers of birch bark sewed round them to protect them as much as possible. It is interesting to add that in these tombs, constructed of stones and with much pains, 'on y a retrouvé . . . des pointes de flèche et des cuillers en bois de renne ainsi que des fragments de poterie ....' and that 'quelques-uns de tombeaux renfermaient une ou deux pièces de bronze et de fer.'

Herr Victor Hehn has in two passages, l.c. pp. 11 and 425, laid so much weight upon the importance of the lime or linden tree (the 'lyndes faire' of Chaucer, Tilia europcea, grandifolia, and parvifolia of botanists) to man in early stages of culture, at once for the manufacture of matting, an invention of older date than weaving, and for the

1 The Scotch fir, P. sylvestris, must have met Cæsar's eyes in great abundance in the parts of Britain which he traversed. Still he, not being a botanist, may have failed to recognise it as an abies; and it may, in the other countries in which he might have seen it, have been, then as now, overgrown and obscured by its natural allies. Or indeed it may have been represented in those regions at that time only by that dwarf marsh-haunting variety which, following zoological analogies, I would call $P$. sylvestris, var. palustris. The Swiss spruce, $P$. abies, on the other hand, which as much excels our English spruce in size and beauty as our Scotch fir excels the Swiss, may very easily have been confounded with the silver fir, P. picea, by Cæsar, as when old it comes to resemble it both in general facies and in the colour of its bark. I have thought that the spruce may, like our common elm, have attained its present numerical preponderance in recent times and owing to man's help and its superior serviceability. And Dr. Uhlmann tells me it is less abundantly represented in the stone-period lake-dwelling of Münchenbuchsee than the silver fir. Dr. H. Christ, on the other hand, says the reverse is the case in the station of Robenhausen, which, according to Rütimeyer, Fauna der Pfahlbauten, p. 161, bears other evidence of belonging to a later ' Kulturzustand.' For the geographical distribution of the Abietinece, see De Candolle, l.c., pp. 158, 190, 192; Fischer, Flora von Bern, 1863, pp. 227, 228; Heer in Keller, ed. Lee, p. 349; Dr. Christ in Rütimeyer, l. c., pp. $228,229$. 
supply of honey to bees, to say nothing of its other uses, that in view of the indigenous character of the tree being disputed it becomes of importance to note that De Candolle (l.c.p.658), with the arguments of Messrs. Leighton and Bromfield and with the philological evidence furnished by Davies (Welsh Botany, p. 53) before him, inclines to the affirmative side of the question. As regards the small-leaved lime-tree, Tilia parvifolia, the claims of which to be considered indigenous Mr. H. C. Watson (Cybele, i. p. 243) allows, it may be added that Mr. Edwin Lees (cit. Johns, l. c. p. 260) informs us that there is in the neighbourhood of Worcester a wood remote from any old dwelling or public road, of about 500 acres in extent, the greater part of which is composed of the small-leaved lime.

\section{Of the Prehistoric Fauna of Neolithic Times.}

But though the lime may have been available in these islands for the use of the bee, and though both the laws (Wotton, Leg. Wallicæ, i. 22. p. 43) and the literature (Sharon Turner, Vindication of the Ancient British Poems, p. 59; Stephens, Literature of the Kymry, 2nd ed., 1876, p. 80) no less than the reputation (Holinshed, England, ed. 1807, i. 286) of the Welsh tell us that they made 'no less accompt' of metheglin or mead 'than the Greeks did of their ambrosia or nectar,' I should for several reasons be slow to think that the bee was domesticated in this country before the Roman era, or that the Celtic mead was made of any but wild honey. If we consider however, firstly, that even to the Romans themselves sugar was mainly procured from honey, beet-root and maple-sugar being wholly unknown and cane-sugar having been heard of only in some tradition from the expedition of Nearchus (Strabo, xv. 1.20); and, secondly, how largely now separated sugars ${ }^{1}$ enter into the dietaries even of the poorest amongst us, we shall

1 See address to the Physiological Subsection of the British Association, by Edward Smith, M.D., F.R.S. Report, Bath Meeting, 1864, p. 110. 'Separated sugars were obtained by 98 per cent. of the farm labourers in England, 92 per cent. in Wales, 96 per cent. in Scotland, and 82 per cent. in Ireland; and the quantity per adult weekly was-England $7 \frac{1}{2}$ ozs., Wales $7 \frac{3}{4}$ ozs., Scotland $5 \frac{3}{4}$ ozs., and Ireland $4 \frac{3}{4}$ ozs.; so that Wales occupied the head, and Ireland the foot of the list, both in frequency and quantity. Of in-door operatives, silk-weavers obtained $7 \frac{1}{2}$ ozs., needle-women $7 \frac{1}{4}$ ozs., kid-glovers $4 \frac{1}{4}$ ozs., shoemakers $10 \mathrm{ozs}$., and stocking-weavers $11 \mathrm{ozs.}$; and hence the average was higher than that of out-door labourers, as $8 \mathrm{ozs}$. to $6 \cdot 6 \mathrm{ozs}$. The frequency with which they were obtained was the same in both classes on the whole average.' 
come to see that this at first sight trifling matter would, if we could transport ourselves back into the days of even Caractacus, constitute for us as constantly felt a difference between ancient and modern life as would the absence or extreme rarity of glass and coal. The only evidence which I have met with which may seem to show that the British in pre-Roman times obtained the honey which the authority I am about to quote calls an 'excellent succedaneum' for

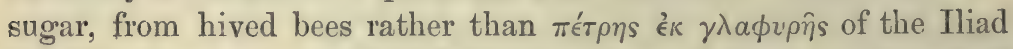
( $\beta .88$ ), the 'stony rock' of Scripture ${ }^{1}$, or the mountain oak of Hesiod's Works and Days, 230, is the following passage in Mr. Logan's 'Scottish Gael,' ii. 147. 'The Celtic Britons,' says this authority, 'kept their bees in a bascaud formed of willow plaited. About fifty years ago one of these was found in Lanishaw Moss; and about eighteen years since another was discovered about six feet underground in Chat's Moss, both in Lancashire. This last was a cone of about two yards and a half high and one yard in diameter at bottom, and was divided into four floors or separate hives.' No references are given in loco, and I have not been able to find any more detailed account of this discovery elsewhere. The older editions of Sir Charles Lyell's 'Principles of Geology,' e.g. ninth edition, 1853, chap. xlv. p. 721, familiarised us with the belief that Roman roads were to be found in Yorkshire and Kincardineshire covered under peat of eight feet in thickness; but in his tenth edition of 1868, vol. ii. chap. xliv. p. 499, as also in his 'Antiquity of Man,' 1863, p. 110, we find some distrust expressed upon this point, and in the last cited work the author inclines to accept M. Boucher de Perthes' estimate of three centimètres being the

${ }^{1}$ I have not been able to convince myself that there is any allusion in either the Old Testament or the Homeric poems to the invention of the hive any more than there is to the common fowl. The earliest mention of hives which I have met with is in Hesiod (fl. 700 B. c.), who in five lines of the Theogonia, 594-598, speaks of them

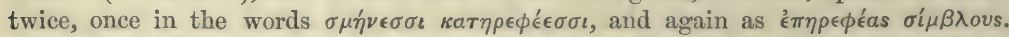
An eminent scholar has however suggested to me that hives seem to be referred to in the words from the description of the cave in Ithaca (Odyssey, $v$. xiii. 106) :-

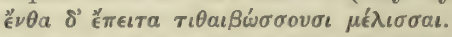

But nothing that I can find recorded of the habits of wild bees is inconsistent with what we can see of the fearlessness with which swarms of our bees will enter places tenanted by man. As regards the force of the words, I find that Virgil in his paraphrase of the passage Fneid, i. 159 seqq., as also Quintus Calaber in his vi. 470, omit to give any equivalent whatever for them, whence perhaps we may infer that they were not quite certain what they meant. Mr. Worsley however, in his translation of them, gives us the simple words, 'Wild bees make honey there.' The two passages in the Iliad, $\beta$. ii. 87-89, $\mu$. xii. 167 , obviously refer to wild bees; and I submit that

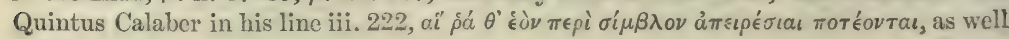
as elsewhere, was guilty of an anachronism. 
rate of increment for every hundred years. The following summary, however, of the facts known as to the growth of peat, given by Professor McK. Hughes in a lecture given before the Royal Institution, Friday, March 24, 1876, on 'Geological Measures of Time' (see Proceedings of the Royal Institution, p. 6), will justify us in setting aside the imperfectly recorded history given above from $\mathrm{Mr}$. Logan's work:-

'He explained the growth of peat, pointing out that there are two kinds of peat; that which is formed in water, as in mountain tarns or old river-courses, and the peat that grows all over the slopes of moorlands, high and low. The first is partly formed from drifted vegetable matter in the deeper parts, and from the decay of plants that grow on the spot all round the margin, which therefore encroaches rapidly. Here at the outset we meet with a source of error. The rate is very different in these two cases, the quantity of vegetable matter that drifts far in being generally very small. On the hill-sides the growth is to be referred almost entirely to two or three species of moss, and in a smaller degree to the heather and other plants. As the lower part of the mosses sphagnum and hypnum decay away and add to the layer of peat below, the upper part grows on, and so a thick layer of vegetable matter is at length accumulated. Workmen tell us that when they have dug a trench into a peatmoss, if they leave it alone it fills up again, or, as they would say, the peat grows again. This happens when the peat is apt during some seasons to be full of water, so as to become a kind of slush or ooze. It is perfectly clear that the apparent rate of accumulation where such filling in occurs must often be deceptive. A good example of a similar thing happening on a large scale in nature is the case of the Solway Moss, and many other instances as recorded by Lyell.

' $S o$ we see that while the peat is being formed it is subject to all kinds of variations, and when it has been formed it is liable to be soaked with water and run, destroying the value of all evidence to be derived from any observation on its rate of growth elsewhere.'

On the other hand, my own excavations in Roman rubbish-pits have furnished me with something of an argument to set against the reported discovery of hives under peat. When excavating in 1868 (see Archæologia, xlii. p. 476) a very large pit of that kind at Frilford, I was much struck with the relatively great abundance amongst the various kinds of earthen vessels there represented by 
larger or smaller fragments of small, often nearly perfect, pots of hard black ware of about the size of a large swan's egg, with the smaller end truncated and flattened and the larger usually provided with a recurved lip for tieing a cover over its contents. Now I have never found any of the various and well-known varieties of Roman funeral ware in a Roman rubbish-heap; every article of daily life, of the coarsest and of the finest kind, whether in pottery or metal, may be found in such deposits; but within my experience they never contain anything which was destined for the tomb or could bring to mind the invisas cupressos. It is obvious however that such jars might be supposed to be intended for the cosmetic rather than the culinary needs of the luxurious Romans. But for the purposes indicated by Horace (Od. iii. 29) and Persius (Sat. iv. 37), for the balanus capillis and the balanatum gausape, finer ware than that of these diminutive amphoræ would, I think, have been used, for finer ware is usually present in abundance in such collections, and was, as I have noted, $l_{0} c_{\text {. }}$, specially abundant in the case specified; whilst, as was pointed out to me by Mr. Wm. Hatchett Jackson, of the University Museum, small jars of much the same contour, if not of the same paste, are still largely used in the honey trade of Narbonne. The sale of honey was amongst the patrias artes of the Ligurian of the times of Diodorus and Strabo ${ }^{1}$, and fashions and

${ }^{1}$ Diodorus (v. 34) writes thus of the Celtiberians (in the connection already referred

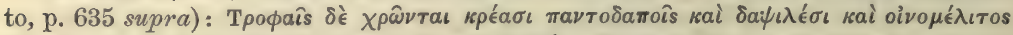

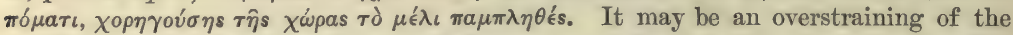
words to suggest that the six last quoted may be considered to indicate that wild rather than hive honey was in the mind of the writer. The words of his contemporary Strabo are in a parallel passage (iv. 6, 2, p. 168, ed. Müller, 1853) to the following effect:-

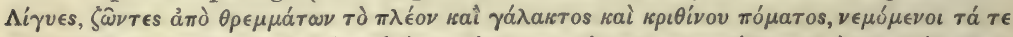

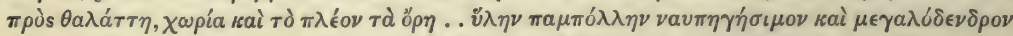

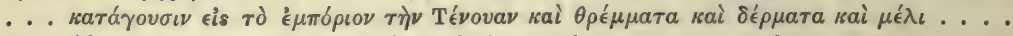

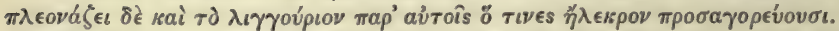

M. Escher vom Berg, Mittheil. Ant. Gesell. Zurich, Rapp. vi. Pfahlbauten, p. 34, suggests that the straining of honey off the comb may have been the use to which such perforated dishes as that figured by Keller, l.c., taf. v. fig. 26, p. 270, or ed. Lee, pl. lii. B, fig. 1. See also Désor, Le Bel Age du Bronze, p. 12, fig. 22, and Schliemann, Trojanische Alterthümer, tab. 174, fig. 3377. Usually such perforations are held to have been intended for filtering whey off curds, in accordance with the Homeric words, Od. ix. 222, 223 :-

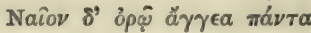

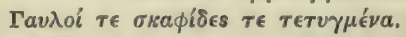

But, as hinted above, p. 705, we may suppose that in such descriptions as this we have traditions of a much earlier period than those we are here concerned with, preserved for us. It is right however to add that Herr Edmund v. Fellenberg; Bericht über die Pfahlbauten des Bielersees, S. A. 1875, pp. 55-61, suggests yet another application, that of fumigation, for these vessels. Honey however is so strained in certain Swiss valleys at the present day. 
patterns which have once been in vogue in such trades are often very persistent.

Strong evidence of the literary and historical kind $\left(q . v_{0}\right)$ is brought forward by Mr. J. Thrupp, in his interesting article on the 'Domestication of Animals in England' (Trans. Ethn. Soc. London, 1865, New Series, vol. iv. p. 169), in favour of the conclusion that 'in the sixth and seventh centuries bees were altogether wild' in this country. The history of the words used for ' hive' appears to show that the first step towards the domestication of the bee by the English was 'the formation of imitations in bark (rusca, see Ducange, sub voc.) of the hollows of the trees in which they were found.' About the middle of the tenth century we read of Anglo-Saxon 'beo-churls ;' and we find 'the Anglo-Saxon word "beo-cist" (bee-chest) and the Latin "alvearia" (bee-hives) usually substituted for "rusca," from which it may be inferred that these rough constructions were superseded by regular hives.'

Hehn (Cultur-Planzen und Hausthiere, p. 425 ed. i. p. 505 ed. ii), referring to an 'erschöpfend' article by Pott in Kuhn and Schleicher's Beiträge, ii. 265, in which the Slavonic word for hive is stated to be ulei and the Lithuanian awilys (as according to Grimm (1819) the Bohemian word is aul and the Polish $u l$ ), suggests that these words may be loan words modelled from the Latin alveus, and mediæval Latin apile. The Welsh scholars in Oxford, the late Principal of Jesus College and Professor Rhys, inform me that the common Welsh word for beehive is cwch-gwenyn, literally boat of bees, and that these are not loan words. If the words are not borrowed words, the idea which they express is borrowed, and shows that the employers of the metaphor used boats before hives. If the boats to which they compared the beehives were the North Welsh coracles with 'subspheroidal' rather than so-called 'scaphoid' outlines, this may further indicate that the earliest form of beehive with which the Welsh were acquainted was one which was late to be attained to in the development of the invention ${ }^{1}$. If we are right in holding, on the authority of Logan, $l$. c., that the Cornish word for hive is kauelh, which in Welsh means a large basket, this would go some way to show that the Cornish were not acquainted with, or at least did not adopt the hive until it had been developed beyond

${ }^{1}$ I learn from Professor Westwood that according to Spinola our domestic species Apis mellifica rarely occurs in Liguria; and he suggests that this shows either that the Ligures were not the colonisers of Wales, as has been affirmed, or that they did not bring their bee Apis ligustica with them. 
the stage of 'rusca,' 'corticibus suta cavatis,' into that of the 'Iento alvearia vimine texta' of Virgil. I have, finally, the authority of Professor Rhys for the possibility of the Welsh word for wax, viz. cwoyr, being a loan word from the Latin.

I searched, as I had expected, in vain, for any figure of a hive in Mr. Evans's ${ }^{1}$ 'Coins of the Ancient Britons,' 1864.

The currently, and as I believe correctly, accepted view that the common fowl, Gullus gallinaceus, is never mentioned by, and may with some considerable likelihood be supposed to have been unknown to the Old Testament writers and to Homer and Hesiod also, is confirmed by the negative evidence of the neolithic interments in this country ${ }^{2}$.

1 In answer to an enquiry of mine as to the existence of a figure of a hive on any ancient coin whatever, Mr. Evans informs me that he does not know of any such coin which has certainly a hive upon it. The figures upon two coins of Dyrrachium given by Beger (Thesaur. Brandenberg. Select. vol. i. p. 459) and by Goltz (ed. Nonnius, 1620, pl. i. fig. 7, p. 4) amongst the coins of Greece, the Islands, and Asia Minor, though described locc. citt. as 'apiaria' and 'alvearia,' Mr. Evans thinks may be merely the caps of the Dioscuri. And to me these figures, as given in the latter of the books referred to, appear with their pendent strings to suggest the mitra with redimicula of the Eneid, ix. 616, rather than the alvearia of the Georgies.

Professor Westwood has furnished me with certain references from hagiological literature which bear on the question of the recent date of the domestication of the bee in these islands. In the Life of St. Cadoc (Bibl. Cotton. Vesp. A. xiv) it is stated that he chose a solitary place for his monastery, having seen aprum sub arbore jacentem, apes venientes et intrantes in cavam arborem. In the first Life of St. David we are told that his father was told by an angel that he would find gifts by the river Teivy; a certain stag; apumque examen in arbore positum, \&c. And in the second Life of the same saint there is a curious legend of a swarm of bees settling on a ship going to Ireland, the bees following St. David from place to place ; and it is added that 'Hibernia in qua nunquam usque ad illud tempus apes vivere poterant mellis fertilitate ditatur.' See also Lanigan, Ecel. Hist., iii. 82-84; Life of St. Molaga, cap. 22; Notes on Irish Architecture, by the Earl of Dunraven, i. pp. 63, 64 .

${ }^{2}$ It is a little difficult to reconcile the passages which stand in our authorised version of the Old Testament (1 Kings x. 22; 2 Chron. ix. 21), to the effect that a navy of Tarshish brought 'once in three years gold and silver, ivory, and apes and peacocks' to king Solomon, with the view held, I should suppose, by most modern Hebraists, as by Bochart (Hierozoicon, ed. 1682, lib. i. cap. xvi. p. 111), that when the Latin 'interpretes multa prophetarum loca ad gallinaceum genus referunt,' it is, in the words of the writer just eited, conjecturis non satis certis. For the servants of Hiram and Solomon would have found it at least as easy and profitable to import Gallus bankiva and indeed Sus indious as apes and peacocks. But as against this utilitarian consideration we may suggest that the words of Cæsar quoted in the text render it not wholly improbable that to the Tyrian sailors the fowl may have been a forbidden food, as it was to many other races; and as, in fact, Sus was to their Hebrew comrades on those ships of Tarshish. Antiquaries who hold that it was from intercourse with Phœnician rather than with Etruscan traders that the Britons learnt certain other things will think this an argument in their favour. A long sea-voyage however, as the absence of the fowl from New Zealand in the time of Captain Cook shows us, made the introduction of domestic animals very difficult to such navigators. And the history of the words makes me suspect that it was by the way of Babylon rather than that of the Red Sea that the peacock itself, to say nothing of the common fowl, the $\pi \epsilon \rho \sigma \iota$ ò $^{\circ}$ opvis, found its main route of immigration into Palestine and Greece. For, during the 
Negative evidence is perhaps stronger in this case than in most of the others in which I have had to refer to it. For it is difficult

Babylonish captivity the word tukhi-im, the Hebrew representative of the Malabar name for the peacock, had become obsolete, and, like many other Hebrew words, was nearly forgotten in the time of the LXX, who have given what the Targum, using a word, tavass, almost identical with raws, holds to be its true meaning, only once and in a various reading (Cod. Alex.), sai ra $\omega v \omega \nu$. And Minayeff (cit. Caldwell, Dravidian Grammar, ed. 1875, p. 92) has discovered in the Buddhistical writings that the ancient Indian merchants took peacocks to Babylon. Probably the fowl was carried with them.

As regards the absence of any mention of the common fowl in the Homeric poems, I have been told that an eminent and voluminous writer upon this subject is of opinion that in the line, $\mathrm{Il} . \zeta$. (vi.) 513,

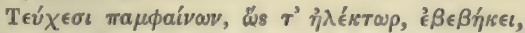

we have Paris, in his ill-supported character of warrior, compared to this bird. A somewhat similar passage in the Proverbs of Solomon (xxx. 31) has been similarly misconceived of ; and it is true that we do find this comparison used by Aschylus (Agamemnon, 1671) for a man with a character not wholly unlike that of Paris. This however proves nothing. I have not enquired what the balance of commentatorial authority may be upon this point; for I cannot understand how any unprejudiced person who will compare the passage already referred to, Il. vi. 504-514, with the ten lines I1. $\chi$. (xxii.) 22-32, deseribing the armed Achilles, can doubt that the two passages are the work of one poet; that he uses in them two metaphors in illustration of one phenomenon; and that in neither of these metaphors is the bird in question alluded to. Theognis (fl. 540 B. C.) is the earliest Western writer, so far as I know, in whom any indisputable allusion to this bird has been found; and to him the cock-crowing appears to have become already a familiar mark of the passing of time. We have also Payne Knight's authority (Prolegomena, ed. 1820, Paris and Strasburg, p. 3) for saying that in the same sixth century B. c. the coins of Himera and Samothrace bore evidence of its establishment in Mediterranean countries. See for coins, Goltz and Nomnius, Græcia, Insulæ et Asia Minor; Carystus, tab. xi. et xii.; Massieu, p. 500; Rasche, Lex Numn. ii. 2. p. 311.

Whilst upon the subject of the importation of animals from the East Indies, I would draw attention to the fact that the area of the world's surface which M. Mortillet (in his most suggestive paper, 'Sur l'Origine de Bronze,' in the Révue d'Anthropologie, 1875, iv. p. 653) has pointed out as the region in which the largest and most readily available deposits of tin were and are to be found side by side with copper, the region namely which extends from 'La Birmanie Anglaise' to the Sunda Straits, lies entirely within the area of distribution of the Gallus bankiva (see Sclater, Proc. Zool. Soc., April 21, 1863, p. 122), the undoubted parent stock of the common fowl. This coincidence appears to me to add something to the force of M. Mortillet's argument in favour of the East Indian origin of bronze; but it must be added, on the other side, that if the domesticated bird followed bronze westwards, this order of events was reversed in the easterly and south-easterly direction, the introduction of the bird having preceded all importation of metal into Polynesia.

So much has of late been written upon the Indian or African origin of our domestic animals, mammalian and avian, that it may be well to add in this comnection that too much weight may in this question be given to the principle laid down by Link in his usually excellent though now old treatise, Die Urwelt, 1821, i.p. 201, to the effect that the domestication of birds indicates a higher condition of civilisation than the domestication of mammals. The Indians deseribed by Mr. Bates (l.c.supra) domesticate not only the common fowl which will, but curassows which will not breed in captivity; and the same authority is referred to by Mr. Francis Galton (Trans. Ethn. Soc, 1865, New Series, vol. iii. p. 125) as having given him a list of birds tamed by the same tribes which is more extensive than the list of quadrupeds tamed by them, though that list contains twenty-one species. And this they do, at the same time that they 'do not 
to think on the one hand as regards literature, that poetical writers would have omitted to use for illustration the habits and bearing and peculiarities of a creature which all later poets, gnomic and other, have so constantly and multifariously alluded to; and on the other as regards excavations, that an animal which Captain Cook found in occupation of Polynesia, from Tahiti to the Sandwich Islands, and which has since been adopted everywhere, even by the non-progressive Indians of the Amazons (see Bates, l.c., ii. 193), and 'by remote tribes on rivers rarely visited by white men,' would have been missing in them if it had existed on the spots at the period concerned. There is of course no question that the common fowl was known to if not used by the Britons when Cæsar made his short acquaintance with them and found that 'Leporem et gallinam et anserem gustare fas non putant; hæc tamen alunt animi voluptatisque caussa.' (See De Bello Gallico, v. 12.)

Nor, on the other hand, does the discovery of the bones of Gallus as described by Alphonse Milne Edwards (Reliquiæ Aquitanicæ, p. 241) in association with 'those of Ursus spelæus, Rhinoceros, and large Felis' in the caves tenanted by palæolithic man make it at all more likely that the bird has, any more than the mammals, been continuously represented upon that area since those times down to those of Cæsar and ours. The struggle for existence with rival animals, to say nothing of that to be waged against inorganic forces, may well have exiled and exterminated during the neolithic age animals which the men of the bronze and iron have found it their pleasure or their interest to introduce again, or which may themselves have succeeded in reoccupying their lost territories. The history of the fallow deer, and possibly those of the rabbit and horse, might, if we could read them out of the records in the soil, illustrate this principle, just as the recent history of the capercailzie, Tetrao urogallus, does.

On the other hand, though M. Alphonse Milne Edwards (l.c., pp. 243-247) appears to think otherwise, I should incline to think the Crane, Grus cinereus, may have occupied this country con-

show themselves so sensible of the advantages derivable from the ox, sheep, and hog, all of which have been introduced into their country.' Few Englishmen will be found to agree in Guizot's comparison (Hist. Civ. Franc., lect. vii. tom. i., cit. Merivale, Conversion of the Northern Nations, p. 185) of their Anglo-Saxon forefathers' condition, social and political, to that of the modern Red Indians; still as against Link's principle quoted above it is worth while to recollect that they, in the words of Mr. Thrupp (l. c. p. 172), 'kept as pets and probably attempted to domesticate' ravens, rooks, cranes, and peacocks. 
tinuously from palæolithic down to the comparatively recent period of its extinction here. Difference merely of size is not sufficient in this case to establish a specific difference. The bones of more than one specimen of this bird were found by two of my former pupils, Mr. W. Bruce Clark and Mr. Randal Johnson of Pembroke College, in a rubbish-pit at Wytham, near Oxford, mixed up with the skeletons of three dogs, with bones of ox, pig, roe, horse, teal and wild-swan, and with coarse culinary nail-marked and other British pottery, by which the date of this 'find' is fixed to the bronze age. I have not met with any remains of this bird in any excavations of an earlier date in this country; though it is difficult to think that neolithic man would have neglected it as an article of diet unless debarred by superstition from making use of it.

The rabbit, Lepus cuniculus, finds a place in several catalogues of British Prehistoric Mammalia; Mr. Pengelly, however, writing of the discovery of the cave man at Mentone (Trans. Devon Association for the Advancement of Science, vi. 1874, pp. 318, 801,818 and 840), says that the discovery of its bones in that deposit does 'not strengthen the evidence for its antiquity:' though there is of course no doubt that the remains of this animal, which still survives as a member of the fauna of North Africa, form an essential and not merely an accidental constituent in the quaternary deposits of Mediterranean caves (see Prof. Busk, Zool. Trans. x. 2, p. 128), and though it is difficult to set aside the evidence of their holding a similar relation to some of our own caves. Professor Rogers, who in his 'History of Agriculture and Prices in England' has given us (vol. i. pp. 33, 65, 123, 340, 341,583 , vol. ii. 558-9 ${ }^{1}$ ) records of the high prices paid for these

1 In Daniel's 'Rural Sports,' 1801, vol. i. p. 347, there is the following statement:'In an account of the prices of provisions, \&c. at the installation feast of Ralph de Borne, abbot of St. Austin's, Canterbury, A.D. 1309 (contained in the fourth volume of Dr. Henry's valuable History of Great Britain), we have among others the following articles :-

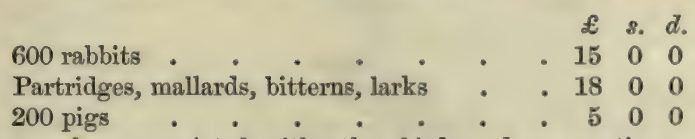

As partridges are here associated with other birds and no mention made of their number, their price in these times cannot be ascertained, but a rabbit appears to have been sold at the same price as a pig, viz. sixpence each. Their relative value has considerably altered in the interval between that day and this.'

I should not agree with the view put forward $(l . c .341)$ by my friend and former tutor Professor Rogers, to the effect that rabbits when once introduced ' would spread very slowly over the country.' We have good natural history evidence, both direct and analogical, for holding that starting even from a single centre, and as individuals 
animals in the middle ages, declares himself of opinion that ' rabbits were introduced into England in or just before the thirteenth century.'

I have never found the remains of the rabbit in any surroundings earlier than those of Saxon times; but difficult as it may be to prove the positive fact of the contemporaneity of a burrowing animal with a deposit into which it is possible it may have burrowed, it is more difficult still to prove the negative fact of its absence from an entire country at any one particular period. Further, the comparatively small size of the rabbit makes the matter still more difficult than it is as regards the fallow deer, or the elm and vine and chestnut, which we may speak of as having been probably introduced or reintroduced by the Romans. And, thirdly, as a much larger portion of Britain was occupied in earlier than in later times by woodland which would furnish protection and harbour to the mustelida, the martens, weasel, stoat, and polecat, the natural enemies and most effectual destroyers of the rabbit, we can understand how this latter animal has escaped the ordinary fate of ferce naturce and become more abundant in this country concomitantly with the increase of its buman occupants, and the curtailment of its woods and forests ${ }^{1}$. The re-

ranging only for short distances, they would form a circle with a very rapidly widening circumference in the absence or paucity of natural enemies. Literary evidence in the same direction is furnished by the beautiful lines of our fourteenth-century poet, Chaucer, in the 'Romaunt of the Rose,' ed. Bell, 1855, vol. vii. p. 60 :-

'Conies there were also playing

That comen out of her claperes,

Of sondry coloures and maneres,

And maden many a turneying

Upon the freshe gras sprynging.'

So also in the 'Assembly of Foules,' vol. iv. p. 196, in a parallel passage of equal beauty we have the line

'The pretty conies to hir playe gan hie.'

Whence it would appear that the animal in question was a familiar object to English eyes in those days. I take this opportunity of remarking that an acquaintance with the line next but one to that just quoted,

'The dredeful roe, the buck, the hart, the hind,'

would have made the suggestion that the fallow deer was introduced into England no earlier than the time of James I. an impossibility. For the introduction of the fallow deer into Britain, see Professor Boyd Dawkins, Proc. Geol. Soc. Lond., June 17, 1868, p. 515 ; 'Nature,' Dec. 10, 1874, Jan. 21, 1875 ; Jeitteles, ibid., Nov. 26, 1874; ;ir V. Brooke, ibid., Jan. 14, 1875.

${ }_{1}$ From British coins the rabbit is as entirely absent as is the beehive; see p. 729 supra. Of Spanishcoins, on the ot her hand, Spanheim (De Præstantia et Usu, vol. i. p. 179), in a passage pointed out to me by Mr. Evans, says it may be taken 'index velut ac tessera,' much as the dolphin is of Italian seaports and the owl of Athens and her colonies. Dr. Whitaker however, in his 'History of Manchester,' may overstrain the 
lations of the Mustelide to the Rodentia generally, are expressed accurately in the Batrachomyomachia, 51-52:-

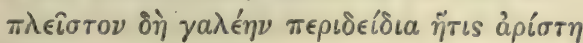

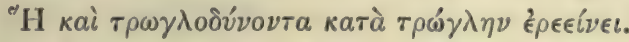

The bones of water-rats, Arvicola amplibius, I have found lying in great quantities in a barrow together with a few remains of the polecat, Mustela putorius, which latter animal had used the place as a lair and probably nest for a considerable period. The upper and lower jaws of the water-rats had been left intact, their strong teeth, which should have prevented what I am well assured were similar remains in other barrows from being spoken of as ' rats' bones, having been found over-resistent by their destroyers, who had however, with the characteristic instinct of their genus, never spared the brain-containing calvariæ.

The dog has only rarely been met with in British interments either of the stone or of the bronze age, a circumstance worthy of note when we recollect how very commonly the dog has in all countries kept his master or mistress company in the tomb as faithfully as during life. One instance however of such an interment I noted and have described (Journai Anth. Inst., v. p. 157; see p. 517 supra) in the neolithic barrow at Eyford; the dog had undoubtedly been buried together with a woman, whose skeleton was, like that of the dog, still partly in situ. The characters of the dog's skeleton, like those of many other objects found even in interments most undoubtedly of the stone- and bone-age, are such as, irrespective of any reference to what we know of palæolithic times, to impress upon us the conviction that the men even of those faroff days had yet been preceded by many generations who had made weapons and domesticated animals. This dog bears no resemblance to the wolf-like Esquimaux $\mathrm{dog}$ on the one side, nor to any such small terrier-like breed on the other, as might suggest that it represents a lately domesticated jackal. It may be conveniently spoken of, as Rütimeyer (Fauna der Pfahlbauten, p. 118) does speak of the dog, similarly rare in the relies from the Swiss lakedwellings, as a 'middle sized' dog, 'einen Hand von mittlerer

words of Varro (iii. 12), 'Et quod in Hispania annis ita fuisti multis ut inde te cuniculos persecutos credam,' by supposing them to show that the writer held that all rabbits in Italy had been imported from Spain. For a disquisition on the history of the rabbit, see Houghton, Ann. and Mag. Nat. Hist., 1869, iv. Ser., vol. xv. p. 179. For one on that of the martens, see Cambridge Journal of Anatomy and Physiology, 1868 , pp. $47,62,437,438$, where the historical relations of these animals to the rabbit, and also to the Felis catus, are considered. 
Grösse ;' a description which, however vague, is decisive as to its representing a long-domesticated breed. The lower jaw, the only part of the head which had been left undisturbed in situ, had the stoutness and was about the size of that bone as seen in some of the smaller English mastiffs ; its trunk bones are still incomplete, but may be supposed to have made up the framework of a body about the size of that of an ordinary shepherd's- $\operatorname{dog}^{1}$. The dogs of the bronze period referred to, supra p. 732, are about the same size.

In the same chamber with the bones of this dog a single bone of a fox, Canis vulpes, was found, which escaped notice when the contents of the chamber were first examined and described, l.c. Its texture and weathering are so similar to those of the other bones, human and canine, found in the chamber, as to suggest that it must have been nearly or quite of the same age ; and its slenderness and slightness, as compared with those of modern foxes, illustrate the principle that the bones of the carnivora of times when game-preserving was unknown, and when they had consequently more of their own congeners to compete with and fewer of their victims available to prey upon, are smaller than those of our days when these conditions are exactly reversed. The bones of the martens and polecats which $I$ have found in various barrows bear out this view. Similar facts have been noted by Rütimeyer in the 'Fauna der Pfahlbauten,' p. 231.

As in the earlier pile-dwellings of Switzerland, so in the stoneage barrows of this country, the horse is less frequently found than from what we know of the discovery of its bones in cave-dwellings on the one hand, and in interments of later date than the stone age on the other, we should be inclined to expect ${ }^{2}$. I have never found the bones or teeth of a horse in a long barrow, and I would remark that, whilst such bones are very likely to be introduced into such barrows in the way of secondary interments, I have not met with

1 The dog was abundantly represented in the Norfolk fint mines known as 'Grimes Graves,' and described by Canon Greenwell, Journal Ethnol. Soc. 1870, p. 431. I do not know the size of the animals to which these remains belonged, but the ingenious argument which Ruitimeyer has drawn from the supposedly uniform inferiority in size of the stone-age dog for the singleness of race of his human masters is invalidated by the discovery in the very early lake-dwelling of Luscherz by Dr. Studer of more than one race of dogs. See Bericht uiber die Pfahlbauten des Bielersees, 1875, p. 24.

${ }^{2}$ For the history of the prehistoric horse, see Rütimeyer, Fauna der Pfahlbauten, 1861, p. 122 ; Archiv für Anthrop., 1873, vi.p. 60 ; 1875, viii. p. 125 ; Veranderungen Unserer Thierwelt, 1876, pp. 69, 92 ; Naumann, Archiv für Anthrop., 1875, viii. p. 12; Merk, Excavations at the Kesserloch, translated by J. E. Lee, 1876, pp. 9, 47, with figure; Dupont, Congrés Internat. Stockholm, C. R. 821 ; Kinberg, ibid., p. 830. 
any exact record as to the finding of them in surroundings which left no doubt as to their being contemporaneous with the primary interments. The bones of the horse are both durable and conspicuous, and it is difficult to think that if the neolithic man had used the animal either for purposes of food or for those of carriage, as his predecessors and successors did, we should not have come upon abundant and unambiguous evidence of such use.

As regards the wild boar, Sus scrofa, var. ferus, I have to say that in this country, whatever has been the case elsewhere, it has been but rarely found in the barrows either of the bronze or of the stone period. Until indeed the discovery of it at Cissbury, as described. in the Journal Anth. Inst., vol. vi. p. 20 seqq., I had never met with its remains in any barrow, though the domesticated variety had been represented in several of both periods. Subsequently the tusk of a wild boar was found in the Nether Swell long barrow. The lower part of the horizontal ramus of the lower jaw of a wild boar found at Cissbury had been broken away, as has so often been noted in other instances, for the purpose of extracting the marrow; and the same practice had been put in force with the remains of two tame pigs found (as described above, p. 454) immediately behind the head of a female skeleton of the late Celtic period. The domestic British pig does not seem to me to differ in any important particulars from the races which we believe to be the descendants of the wild boar. Two bronze statuettes of the Gallo-Roman period given me by Mr. John Evans, as also many antique Italian terra cotta figures, show that the Romans in Gaul knew both the longsnouted wild-boar-like breed and the shorter-snouted better-bred race. The same contrast is shown in two plates (pl. iii. 4, pl. v. 5) of Sambon's 'Recherches sur les Monnaies Antiques de l'Italie,' Naples, 1870, the former of which gives us a pig with a very long and slender snout, whilst in the latter, which represents a sow suckling three young ones, we have, together with the pendent ears, so usually though not invariably characteristic of domestication, the short snout bent upwards so as to form, as in our best breeds, an angle with the plane of the sagittal suture along the roof of the skull. Columella may be cited in support of the same view, as he (lib viii. cap. 9) says that pigs with such short and recurved snouts were preferred to those of a different frontal profile; 'Quare in suillo pecore probandi sunt .... rostris brevibus et resupinis.' But I have not found the skulls of this 'Cultur-Race' in British burial-places, and the tenacity with which 
very different races have maintained themselves in very many parts even of our less wild districts up to quite recent memory make this the less remarkable. The figures of the boar upon coins and shields of the late Keltic period, i.e. from circa 200 B.c. to circa 80 A.D., might perhaps be taken as confirming the conclusion which my examination of the osteological remains (given at length in the Transactions of the Linnæan Society, Zoological Series, vol. ii. 1877) had led me to, had they been more frequently and more distinctively than they are, figures of domesticated as opposed to wild animals. Still, what Mr. Franks writes (Horæ Ferales, p. 188, pl. xiv.) is to the purpose in this connexion, especially if we compare the plate referred to by him with plates vi, viii, xii, and xiii of Mr. Evans's 'British Coins.' Mr. Franks's words (l.c.) are as follows:- 'The boar as seen on the Witham shield appears only on the older or autonomous coins of Gaul and Britain; on Roman civilisation being introduced, this national symbol was no longer a gaunt lean animal, as it appears on the shield, but a well-conditioned boar of a natural form and in a classical attitude ${ }^{1}$.'

The small Scottish Highland and Island breed of pigs described by Low ('Domesticated Animals of the British Islands,' Eng. ed. p. 429, Fr. ed. pl. iii) and by Youatt ('The Pig,' 1847, pp. 50-52) as having sharp-pointed suberect ears, remarkably strong muscular snouts, an arched back (the 'Carp' back of the Germans), and

1 The following passage from De Blainville's 'Osteographie,' 1847, fasc. xxii. p. 170, may be quoted as being a good instance of the folly of relying in these questions upon negative evidence, especially when the existence of that evidence is due simply to neglect of the three lines of enquiry available here, viz. the examination of bones; the excavation or other discovery of coins and works of art; and, thirdly, the examination of literature. Writing of Sus he says, ' $\mathrm{Du}$ temps de César il parait cependant qu'elle n'était pas encore parvenue dans les Gaules, car il n'est nullement question de cet animal dans ses Commentaires; elle s'y est donc propagée depuis la conquête d'où elle a passée en Angleterre qui ne possédait pas même de sanglier dans ses forets.' It is needless to refer to the innumerable discoveries of Sus, both wild and tame, in preRoman deposits in this country; and the unanimously accepted result of arehæological enquiry may be shortly summed up in the following words of M. Montellier's 'Mémoires sur les Bronzes Antiques' (Paris, 1865, p. 41), 'Le de symbole sanglier était un symbole Celtique le plus ancien de tous les symboles adoptés dans les Gaules.' The evidence of literature tells even more strongly in the same direction. From Mr. Thomas Stephens's 'Literature of the Kymry' (second edition, 1876, pp. 236-270) I learn that this animal was taken by the Kymric poets as typifying the past and future fortunes of their race, and the number of odes translated in the pages referred to in which the persons addressed by those bards are apostrophised in its character is very great. Neither Mr. Stephens nor Mr. Davies can, I apprehend, be accused of want of sympathy with the race which they write of; but I note as regards this particular point that the only difference between them is that (pp. 237 and 270) whilst according to $\mathrm{Mr}$. Davies in the Hoianau the pig is 'the symbol of Druidism,' it appears to Mr. Stephens that it 'allegorically represents the Kymry who inhabited the Principality.' 
a forest of stiff bristles arising from it, may perhaps be taken as representing to us now what the ancient British domesticated pig was. The old Welsh pig resembles the Scotch in various points characterising an unimproved breed, but its large ears, spoken of familiarly by breeders as being 'as large as newspapers,' indicate that it has been more thoroughly domesticated. Its colour also is more constantly and deeply dark than is that of northern form ${ }^{1}$. But the size of the ears and the colouration are both exceedingly variable points. The condition of neglect and comparative freedom in which the still surviving Scotch breed is described as living has no doubt been constant since the earliest times; and we may, after making some allowances, fairly suppose that it must have produced the same changes in the soft and perishable parts, and so in the entire appearance of the swine of those days, that we can see it has done in those subjected to it now. The bones of the

1 It is not safe to assume that any appearance of a black colour in a pig of this country shows it to be modern, as if this colour could only be due to some cross with the breed known as 'Neapolitan,' and called conveniently by Nathusius, on account of its distribution over the Mediterranean area occupied by Rome in her best days, the 'Roman' pig. For the colour of the pig is not only exceedingly variable per se, as stated above, and for reasons which we do not know; but it changes, as regards entire breeds, under the selective action of certain foods, viz. the paint-root, Lachnanthes tinctoria, and buckwheat, Polygonum fagopyrum (see Wyman, Spinola, and Heusinger, citt. Darwin, 'Origin of Species,' sixth edition, p. 9 ; 'Domestication,' second edition, ii. p. 332). The 'Roman' pig is now, as figured in Low, $l$. c., of a deep black colour almost universally; but in classical times it was not so any more than the domestic Greek pig was of which Aristotle tells us (H. A. ii. 2. 14) the wild boar differed from it in being black. It is true that the sow of Eneid iii. 392 and viii. 45, 'Alba solo recubans, albi circum ubera nati,' is spoken of (viii. 81) as 'subitum atque oculis mirabile monstrum ;' but Servius in loco, who from his date, A. D. 400, must have been familiar enough with 'Roman' pigs, explains the word monstrum thus, 'quia et subito et cum triginta porcellis est visa,' which is quite an adequate explanation. Columella also contrasts (vi.9) a 'grex nigra sete quam durissima densceque' with a 'glabrum peous vel etiam pistrinale album' as being better suited for a 'regio frigida et pruinosa.' Hence, though there is no doubt that one of the earliest effects of domestication upon the wild boar stock not uncommonly is to make the colour white or at least what Youatt calls 'dirty white' or ' yellowish brown,' there is also no doubt that the reverse of this may be effected by the same process in later stages or through the introduction of new disturbing influences. I incline to think that, though the reverse must have been the case with several of our common domestic animals, immigrating races of men have usually provided themselves with tame pigs by having recourse to the young of the wild-boar stock available on the area which they have occupied. For whilst wild swine everywhere lend themselves readily to domestication, it must in early times have been very difficult to transport or import even already domesticated pigs. The contrast in this latter point between the pig and the two animals, which most certainly of all must have been imported into Europe as domesticated, did not escape the notice of the ancient fabulist who, as referred to by Bochart, Hierozoicon, ii. 57, p. 698, spoke of the 'porcus, qui cum agno et lupra ad urbem deferebatur et quum illi pacate degerent solus se distorquebat.' 
domesticated prehistoric pig, it is almost needless to say, are the bones of small animals; nor does the early age at which the great majority of domestic swine were then as now slaughtered entirely explain this fact away.

As regards the sheep, Ovis aries, I have to say, firstly, that I think the caution with which any identification of any ovine or caprine bone from a prehistoric 'find' is usually recorded, should be so worded, or at least received, as to make us think it is at least as likely to be a sheep's bone as a goat's. The reverse is ordinarily taken as being implied. But anybody who will study the coloured drawing given by Low (Hist. Nat. An. Dom. de l'Europe, pls. i, ii, French ed.) as referred to by Rütimeyer (Fauna des Pfahlbauten, p. 129) of the 'dun-faced,' 'flounder-tailed,' 'brevicauda,' 'goathorned' variety of the sheep still existing in the islands north of the Pentland Firth, will see how difficult it must be to decide the question as to the absence or presence of the sheep at any particular prehistoric period, unless an entire skull be available for deciding the question. Nor is the variation which gives to the horns of the sheep, usually considered the most distinctive portion in the prehistoric skeletons left us, the shape of those of the goat, by any means confined to the Orkney or Shetland sheep. The same approach to the goat's character is noted of the horns of the Welsh higher mountain breed (Low, Fr. ed. p. 20, Eng. ed. p. 65) of sheep. Hence it is entirely unsafe to decide from the often fragmentary and detached horn-cores which we obtain from neolithic burials that the animal they belonged to was not a sheep.

But, secondly, though a sheep may have the horn-cores usually found in goats, a goat never has the horn-cores usually found in sheep. But such may be found in prehistoric interments ${ }^{1}$.

1 Since writing as above I have, through the kindness of Herren Edmund von Fellenberg and Grossrath Bürki in Bern, of Professor F. A. Forel of Lausanne, and of Dr. Uhlmann at Münchenbuchsee, had opportunities for examining the very rich collections of animal bones from the various lake-dwellings which owe so much to their protecting care. And I found that the caution which is necessary in dealing with the scanty and often imperfect remains available to me from our prehistoric graves is superfluous in face of their abundant and more complete specimens. The goat is richly and unambiguously represented in the stone-age lake-dwellings, and more abundantly indeed than the sheep in the early stone-age lake-dwellings of Moosseedorf. It seems however to have lost this numerical preponderance towards the end of the stone period, and to have become comparatively scarce in the bronze age. And I find that M. Kinberg, Stockholm Internat. Congres Anth., p. 831, tells us of Sweden that ' La Chêvre Capra hircus h. parait avoir été primitivement plus rare que le mouton. Elle est rare du moins dans les sepultures de l'âge de la pierre de la Vestergötlande.' These facts are entirely in keeping with the sus- 
As regards the ox, Bos taurus, I have little to add to what has been written by others with the much larger stores available to their hands which the Swiss pile-dwellings and other habitations of the living prehistoric man have furnished. Rütimeyer, Fauna des Pfahlbauten, p. 127, and Naumann in his interesting memoir, Archiv für Anthropologie, viii. 1, 1875, p. 30, suggest that the variety of ox known in this country as Bos longifrons, and known abroad more correctly as regards structure, if not more conveniently as regards the appropriation of the name, as Bos brachyceros, is probably the oldest domestic animal with which we are acquainted. The older zoologists held (see Buffon, Hist. Nat. xi. 312 , ed. 1755), perhaps rather as an article of faith than as the result of enquiry, that 'on a soumis le brebis et le chèvre avant d'avoir domptè le cheval, le bœuf ou le chameau.' The dog and the pig have on the grounds of their present and their pristine distribution in space, of their readiness to attach themselves to

picions hinted at in the text, and with the view that our domestic animals, though coming in the ultimate resort from the East, like nephrite and jade in the stone-, and bronze probably in the bronze-period, did not reach the regions north of the Alps directly from the East, but only by passing northwards from the Greek and Italian peninsulas. For the goat, as has been repeatedly observed from the time of Aristotle (Hist. An. ix. 4) down to the present, bears cold less well than the sheep, whilst every traveller in sunburnt barren countries may observe with gratitude and wonder what copious supplies of milk are obtained from it, often off but limited areas in these surroundings, and from but shrubs and weeds. The sheep on the other hand, is, as its resting-places on the 'Schatten-seite' of a mountain show us, more sensitive to heat and more appreciative of the 'shadow of a great rock in a weary land' than most animals. As described in the beautiful translations of a modern Greek ballad, by Niebuhr and Miss Winkworth (Life and Letters, vol. ii. p. 23, ed. 1852), it loves the

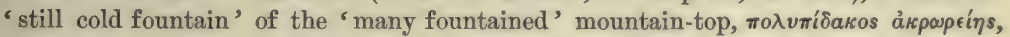
whilst, as a visit to the hungry and thirsty, stony and light-soiled, island of Rhenea showed me, the goat will retain its vigour and independence of bearing with but the scantiest supply of succulent vegetation and of pure water. The goat possesses certain advantages over the sheep as a domestic animal in a 'barren and dry land where no water is,' but in a palustrine or lacustrine district it possesses none. And I submit therefore that the abundance of it in the Swiss lake-dwellings can be reasonably explained by supposing that it was carried thither by a people or tribe migrating northwards from the Mediterranean countries. Uncultivated races, as is well known and can still be observed, will adhere with a persistence which, if not wholly intelligent, is yet not wholly unpleasing, to their own domesticated animals even when their inferiority to other available breeds is demonstrated; and the goat, on its side, will, as Buffon has remarked (Hist. Nat. v. 66, ed. 1755), attach itself to man with an irrepressible fixity correlated with its traditional petulance.

The importance of these points in the natural history of the goat is impressed upon us from the purely anatomical point of view by the absence of any well-marked Western varieties of it; whilst the greater utility of the sheep in our latitudes is shown contrariwise by the multitude of such varieties into which it has effloresced under domestication in a period throughout which the goat has remained as unchanged as the weeds it feeds upon. 
man and share his fortunes, and, I incline to think, most of all, of their solidarity with him in supporting the alternation of generations of certain entozoa, perhaps equal claims in this matter with the other five animals specified. For my own part I should incline to favour the claims of the dog, on the general grounds of the hunting stage having been earlier in date than the pastoral and of the facility with which commensalism would be set up between the two species when they happened to enter into partnership in the chase. What I saw at Cissbury (see Journal Anth. Institute, July, 1876, vol. vi. p. 22) impressed me very much with the idea that the pitfall counted for much more in the earliest times than I had previously imagined. A wild animal was much more easily mastered in that way ${ }^{1}$ than in any other available to the man to whom

'Arma antiqua manus, ungues, dentesque fuerunt

Et lapides et item sylvarum fragmina rami.'-Lucret. v. 1282.

The wild dogs which fed themselves or were allowed to feed upon the remnants of the animals thus caught and slaughtered would not be slow to learn the lesson of attachment to place, and out of, or upon this, might very readily grow the feeling of attachment to person. It requires a greater effort of imagination on our part to imagine a pack of wild dogs co-operating with priscan men in driving a herd of wild cattle or wild pigs (both of which were represented in the Cissbury pits) along a track in which a pitfall had been dug and covered over. Still what we know of the relations subsisting between savage men and dogs or dingoes

${ }^{1}$ Cæsar's words (B. G. vi. 28) used of the Germans capturing Bos primigenius, 'hos studiose foveis captos interficiunt,' I had commented upon (Journ. Anth. Inst., l. c.) before learning that Keller ('Lake Dwellings', pp. 298, 299, trans. Lee) had written as he has done. The Old Testament writers make innumerable references to the use of the pitfall. The tradition of its employment by the Ancient Britons survived into the days of Henry V., and of Hardyng who in his 'Chronicle in Metre fro the first Begynning of Englande,' cit. Youatt on the sheep, speaks of 'pitfalles and trappes' as well as

'Arrows and boltes

To slee the deere, the bull, also the bore,

The bear, and byrdes that were therein before.'

For the use of the pitfall by the Esquimaux, see an excellent paper by N. L. Austen, Esq., in the 'Reliquir Aquitanicæ,' p. 217. 'The fact that the Esquimaux have fitted their pitfall for the reindeer with a trap-door revolving on two short axles of wood, as is done in the so-called 'tipe' or ' tip' in rabbit warrens, together with other considerations, makes me doubt whether Daniel (Rural Sports, vol. i. p. 351) can be right in holding that this last is 'a modern invention.' The Norway reindeer is similarly taken in a 'rengraven' (see Austen, $l . c$. ), and the kangaroo in Western Australia (see Eyre, Central Australia, ii. 278; Nind, Journ. Royal Geog. Soc. i. p. 30, 1831). 
(see Nind, l.c., p. 29) justifies us in holding that this second stage of co-operation may have been attained to very early in the history of our species.

The contrast, common in ancient writings, both sacred and profane, between Bos primigenius, ' magnitudine paullo infra elephantos,' as Cæsar wrote of them (De Bell. Gall., vi. 28), and the tamed variety or varieties of the species, with the 'tenue et miserabile collum' which Juvenal (Sat. x. 270) half pathetically deseribes, were seen in eminently instructive contrast in the Cissbury pits, the filling up of which with chalk rubble had very effectually preserved the bones. By the spar-like hardness and lustre, by the sharplydefined ridges and sculpturing of the surface, and, finally, by the huge size of the wild animals' bones when viewed in contrast with those of the tame races, we are helped as effectually as by almost any other means to realise the immense difference which exists between those times and ours; in which last the representatives of the wild ox, still surviving under Lord Tankerville's care at Chillingham in an at least half-wild state, are so much smaller, and the domestic races so much larger. The wild animal of prehistoric times to attain and sustain its vast bulk must have had command of good pasturage which even the cherished and protected herds of modern wild cattle might envy, but with this, itself a thing possible only in a district occupied but sparsely by man, there co-operated another agency distinctive of a wild country. This agency was the selecting agency of carnivora, in the Britain of those times chiefly wolves, which would weed out the weaker members of each herd, long before they attained the sexual maturity which might have enabled them to bring into being a stock of weakness and smallness like their own. The rifle-bullet, on the other hand, of modern days selects the monarch of the herd, and leaves the sustentation of the race to the despised smaller representatives of it. The differences between the conditions affecting the domestic breeds of ancient and modern times respectively are at least as striking. The range available to a savage tribe ever at war with its neighbours, as is the habit of modern, as it was of ancient uncivilised tribes, must have been limited and small relatively to the number of the cattle which a tribe devoid of cerealia must have had for their sustentation. This would affect the animal during the whole period of its growth, and very materially. And we have to add to this the consideration that not only were such articles as turnips wholly unknown to the ancient Briton, but that even such an art as that 
of making and storing hay was as yet uninvented. The contemplation of a herd of dark-coloured mountain cattle in the north of this country, of small size and yet with ragged, 'ill-filled' out contours, standing on a wintry day in a landscape filled with birch, oak, alder, heath, and bracken, has often struck me as giving a picture which I might take as being very probably not wholly unlike that which the eyes of the ancient British herdsman were familiar with. But the treatment which the domestic ruminant is all but necessarily and universally subjected to in the very earliest days of its life when owned by a savage, is found in modern days and in very different climates from ours to be sufficient to stunt its growth effectually, even in the absence of the unfavourable conditions alluded to. The milk which naturally should have gone to build up the body of the newly-born animal is, in great part at least, taken for the use of its owner and his human family. The vast difference in size between the domestic buffalo of Hindostan, Bos bubalus, and the wild variety" or Arnee ${ }^{1}$, is due, I apprehend, to the working of this agency upon the former as against the selective agency of the carnivora upon the latter; and the like causes must have produced the like effects in former times.

I take this opportunity of putting on record the points in which the collections of various objects from the Swiss lake-dwellings seen by me under the favourable conditions above specified (p. 740, note) differ from those procured from British prehistoric graves.

The absence of any traces of cerealia in our neolithic barrows puts them at once into sharp contrast with the Swiss lake-dwellings even of the early stone age such as Moosseedorf and Wangen; and though the frequent occurrence of unthrashed-out ears in the specimens from these habitations shows, as Dr. H. Christ (l.c.) has observed, that their tenants were in a very primitive state, still the presence and botanical characters of these 'Kultur-

' An anonymous but excellent naturalist in the 'Zoologist' (1858, 1859, vol. xvi. p. 6554) writes thus as to the great difference in size existing between the wild and tame buffalo to the advantage of the former: 'We believe the main reason of it to be that the tame calves are deprived of their due supply of milk. The importance of an ample supply of suitable nourishment in early life, as bearing on the future development of any animal, cannot be over-estimated.' He also states on the authority of a friend that the Burmese domestic buffalo is ' much larger than in Bengal, with splendid horns, and altogether a vastly superior animal, in fact, resembling the wild buffalo. The Burmese never milk them; having the same strange prejudice to milk which the Chinese have, though otherwise both peoples are nearly omnivorous.' See Specimens 1350 and 1351, Oxford University Museum, the one from a wild, the other from a tame buffalo. 
planzen,' as also of the weeds accompanying them, proves that these men had at one time or other some direct or indirect communication with Mediterranean regions. (See Prof. Heer in Keller's Lake Dwellings, trans. Lee, p. 342 seqq.) The textile flax-fabrics so prominent in every series from the Swiss lake-dwellings, even from the very early one of Schaffis, are as completely wanting in British stone-age barrows as the cerealia.

A second point of equally striking contrast is furnished to us by the great inferiority of all British pottery of the stone- and bone-periods to that at least of the later stone age in Switzerland. It is true that from such a very early lake-dwelling as that of Schaffis, pottery of the most primitive kind possible, imperfectly burnt, coarse alike in composition and contour, may, as the series in the University Museum obtained through the kindness of Herr E. von Fellenberg and the exertions of the Rev. H. B. George shows, be obtained; and that speaking generally all the pottery of the Swiss stone age is inferior in shape, paste, and size to that of the bronze age. Still with my recollection of the best specimens of British long-barrow pottery, such as those referred to pp. 536-537 supra, as found by myself and others, I needed when at Morges a very definite assurance from that entirely indisputable authority Professor F. A. Forel, to make me believe, as I do, that certain pottery of a much higher degree of excellence had really belonged to the stone age.

Thirdly, even in the very early lake-dwelling of Schaffis, barbed and tanged arrow-heads have been found, as indeed also in Danish and Breton stone-age interments; whilst our long barrows have, as Dr. Thurnam remarked, never furnished us with any arrow-heads perfected beyond the leaf-shape.

Fourthly, the practice of boring, however roughly and by whatever process, the stone axe for the reception of the haft was not unknown even to the lake-dwellers of Schaffis (see Herr E. v. Fellenberg's Bericht über die Pfahlbauten des Bielersees, 1875, p. 78), whilst, as Mr. John Evans (Ancient Stone Implements of Great Britain, p. 49) has remarked, the stone axes of this period, at least in Britain, were rarely perforated.

The similarly all but, if not entirely, complete absence of nephritand jadeit-implements from our British prehistoric series constitutes a fifth point of contrast between them and those procured from the Swiss lakes; and to the 'Ethnographisch-archæologischer Bedeutung' (to use the words of Prof. H. Fischer in his model 
monograph 'Nephrit und Jadeit,' 1875, p. 1 ; see also pp. 48, 49, $54,355,367,377$ ) of this negative fact, we must under all the circumstances of the case assign a very high place.

Wild animals, sixthly, are but sparingly represented in early British graves, whilst in some at least of the earliest Swiss lakedwellings they have a numerical preponderance over the domesticated breeds. It is right however to add that in the early British dwellings for the living and in early British excavations such as the flint mines at Cissbury, this numerical inferiority of the wild fauna is by no means so distinctly pronounced (see Journal Anthrop. Institute, vol. vi. p. 20, 1876).

Seventhly, as regards the craniography of our own species, the skulls of the Swiss lake-dwellers of both stone- and bronzeperiods alike belong to that 'massive and grandiose' variety of the dolicho-cephalic type which the Swiss ethnographers, His and Rütimeyer, have in their often-referred to 'Crania Helvetica' called the 'Sion Typus.' In other words, we have in Switzerland no such evidence for the immigration of a fresh race of men at the commencement of the bronze period as we have furnished to us in Great Britain by the appearance contemporaneously with metal implements of brachy-cephalic crania in preponderating numbers. It may however be objected here that this seventh point of difference, like indeed all the other six, depends simply on negative evidence; and that the entire number of human skulls recovered from the lake-dwellings has been, as might from the very nature of the case have been expected, very small. On the other hand, I have to say that an English ethnologist, convinced, as due examination of the evidence (see p. 712 supra) will convince him, that a very thorough, if not absolutely exhaustive, displacement of the races previously in occupation of what is now his country was effected by the Teutonic immigration of the fifth and succeeding century, may very easily be over-ready to believe that other invasions may have been similarly overwhelming. The Swiss ethnologists, at all events, after fairly stating the two opposed views, declare themselves to be of opinion that one and the same dolicho-cephalic stock persisted through the two periods in question. Their words run thus (Crania Helvetica, p. 37):'Wir sind durch diese Unterbringung des Meilen- und des Auvernier-Schädel zu einem hochst erfreulichen Resultate gelangt heinsichtlich der Bevolkerung die die Pfahlbauten, während der ersten Zeit ihres Bestehens in der sog- Stein- und Bronze-Periode 
bewohnt hat. Bekanntlich haben unsere hervorragenderen Alterthumforscher über dieser Punkt sich noch nicht geeinigt; eines theils vertritt Herr Troyon in seinen Habitations lacustres die Ansicht, es habe in den verschiedenen Perioden der Pfahlbau-Zeit eine Succession von verschiedenen Bevolkerungen stattgefunden; es sei die Bevolkerung der Steinzeit durch eine völlig neue der Bronzezeit, und diese durch eine solche der Eisenzeit verdrängt worden: anderntheils aber hat Herr Dr. Ferd. Keller aus dem allmähligen Fortschreiten der Kultur in der Pfahlbaustationen, aus der mannigfachen Formübereinstimmung der Stein- und der Bronze-, dieser und der Eisenobjecte, und aus dem Vorhandensein manniggfacher Uebergangstationen wahrscheinlich gemacht, dass die Pfahlbau-Bevolkerung der verschiedenen Kulturperioden doch nur einen und demselben Stamm, dem Keltischen, angehört habe. Die Ergebnisse der craniologischen Forschung sprechen, wie man sieht, für diese letztere Annahme, und wir dürfen, gestutzt auf die ober mitgetheilte Schädelvergleichen, allerdings mit Bestimmtheit aussprechen, dass die Pfahlbaubevölkerung der Stein- und Bronzezeit desselben Stammes gewesen sei, wie die, später dies Land behauptenden Helvetier.'

Some Swiss historians (see Crania Helvetica, p. 34) are inclined to hold that remnants of the Cimbric invaders still survive in their country; and the light hair combined with typically brachycephalic skull (see p. 680 supra) which so constantly meets the eye in Switzerland may incline us to favour this view. It may seem to be going out of the way to take up with this hypothesis when there is a characteristically brachy-cephalic stock occupying at the present day, as it has done no doubt uninterruptedly from prehistoric times, the conterminous region of the Grisons. The Roumansch race, however, is dark-haired, whilst the Swiss brachycephali are, especially as compared with the French, light-haired; the relations between the Rhæti and the Helvetii was in historic times (see Crania Helvetica, p. 33) ordinarily the reverse of amicable; and what appears to me a most convincing argument of all, rye, a cereal the place of origin of which is supposed by De Candolle (Geograph. Botan. Raisonnée, ii. 938-940) to be in the district to the east of the Alps, and which has been the staple food of the Grisons, has, like oats and spelt, never been found in the lake-dwellings.

Eastern Switzerland is known, both from linguistic and from historical evidence, to owe a very large part of its population to the 
Alemannian invasion; the physical characters however of this race were different from those of the Cimbric probably, and certainly from those of the Roumansch, and of the brachy-cephalic stock (see p. 679 supra) abundant in South Germany at the present day.

From the phænomena presented by the pottery, by the implements, by the cultivated plants and domesticated animals of prehistoric times in this and other countries, arguments have been drawn in favour of one or other of three theories, which may for the sake of brevity be spoken of as the theory of Immigration with more or less displacement of any population previously in occupation, the theory of Importation without immigration, and the theory called by its supporters the 'Autochthony' of these products. It may be well here to give references to authorities who have pronounced themselves in favour of one or other of each of these three views.

In favour of the first theory we may cite Rütimeyer, who (Fauna des Pfahlbauten, pp. 160-162, 1861) speaks of the introduction of bronze as being a 'Wendepunkt der möglicherweise mit dem Auftreten neuer Völkerstämme in Verbindung stand;' and suggests that the appearance of a new race of domestic dogs at the commencement of that period indicates the setting up of intercourse with or replacement by a fresh race of men. In the same sense we find Prof. E. Désor (Le Bel Age du Bronze Lacustre, p. 11, 1874) speaking of the weeds, such as Centaurea cyanus and Silene cretica, which accompany the cerealia of the lake-dwellings as those of modern Switzerland, thus, 'Etrangères à notre flore comme les céréales ellesmême elles sont suivi le sort de ces dernières, et nous sont venues d'Orient, peutêtre avec les premiers colons lacustres.'

Dr. Oswald Heer, however, a botanist of whose investigations Switzerland may justly be proud, in laying these facts before the world, as in Troyon's 'Habitations lacustres,' p. 443, and Keller's 'Lake Dwellings,' transl. Lee, p. 344, appears to adhere to the second of the two views above stated; as indeed Keller himself does (l.c. pp. 56 and 309) in the following words used of another product foreign to Switzerland, namely, nephrit, 'It was not brought by the settlers with them from their earlier abodes, but was acquired by barter in later times, after they had lived for centuries in the lake-dwellings of our country.' In the second of the two passages referred to Keller says distinctly, 'There is no ground for concluding that successive peoples of different races or civilisations have occupied these lake-dwellings, one of which 
has chased the other from its abodes in order to occupy them themselves.'

In spite of this, however, scientific opinion in Switzerland seems to me to gravitate rather in the direction of the former of these two views. And this I say, though Herr Edmund v. Fellenberg (Bericht, l. c. p. 15) puts both of them forward without distinctly indicating to which of the two he inclines. He points out that the two minerals nephrit and jadeit are found only in Central Asia, China, New Zealand, and South America; that only a single unworked block, and that one probably dropped by the importers, has been found in Europe at Schwemmsal in Saxony; and that the usually sharp and little worn-down implements and weapons made of these two highly resistant minerals are found in somewhat different proportions in different parts of Switzerland, the nephrit- preponderating in the eastern and the jadeit-weapons in the western lake dwellings; but he sums up the discussion by asking impartially, 'Sollten Einwanderungen von verschiedenen Seiten stattgefunden haben, oder hatten diese Stämme Handelsbeziehungen nach verschiedenen Richtungen hin ${ }^{1}$ ?'

The third view, diametrically opposed to the two first enunciated, was put forward by M. Dupont, with the protection of the honoured name of Steenstrup, at the meeting of the International Anthropological Congress at Stockholm in 1874, in the following words (Compte Rendu, p. 821):-

'Dans la précédente session du Congrès, M. Steenstrup a émis l'idée après avoir examiné les collections recueillies dans les cavernes belges, que nos principales espèces domestiques pourraient à la rigueur être originaires du sol qu'elles habitent et y avoir été directement assujéties par l'homme. Cette solution est loin d'être improbable. Elle a ceci de frappant de se trouver en accord avec les principes qui tendent à s'établir dans l'anthropologie, et d'après lesquels les conquêtes violentes et les déplacements des peuples auraient joué dans la constitution de nos populations, un rôle fundamental moins important que celui qu'on avait été d'abord - porté à leurs attribuer; la grande masse des habitants d'un pays étant composée par les très anciens occupants du sol et non par les envahisseurs. Ces principes ont été surtout soutenus avec convic-

1 Mr. H. Cayley's valuable account of his own visit to the old Jade quarries of Kúenlún given in Macmillan's Magazine for October, 1871, appears to have escaped the all but exhaustive research displayed in Dr. Heinrich Fischer's 'Nephrit und Jadeit' already referred to, p. 746. 
tion par MM. de Quatrefages et Virchow durant ces dernières années pour les peuples Européens. La même thèse a été défendue récemment à l'aide d'une grande érudition et d'une argumentation persuasive, pour les langues occidentales ${ }^{1}$. Je crois, pouvoir prouver de nous côté que notre âge de la pierre ${ }^{2}$ polie n'est pas le résultat d'une importation, mais qu'il apris naissance dans nos regions mêmes.'

Professor Steenstrup is reported as having expressed himself entirely to the opposite effect in the Compte Rendu (p. 163) of the International Congress held at Copenhagen in 1869; and unless he changed his opinion in the interval between 1869 and 1873 , it must be through some error that his name is quoted as in the above extract from the Stockholm Compte Rendu. There is no room however for suggesting that the reference to M. Granier de Cassagnac's work is made through inadvertence; and I must remark therefore that no conclusion however much in want of support can gain much by a reference to that production. On the other hand, the respectable, authority of Dr. H. Christ (in Rütimeyer's Fauna des Pfahlbauten, pp. 225-226) can be brought forward for 'die Autochthonie' theory.

I cannot understand how any one with the evidence properly before him can doubt that the goat, sheep, horse, and dog were in the earliest neolithic times imported as domesticated animals into this country and into Switzerland. The ease with which the calf of a pit-fall-taken Bos primigenius would be domesticated, as well as some other reasons, may make it just possible that the domestic cow of those times may not in all cases have been imported already tamed. But I incline to think that this really was most commonly the case.

On the other hand, having been convinced by what I saw in the Swiss collections from Schaffis and elsewhere that the small race of swine Sus scrofa, var. palustris, existed there as a wild race; and coupling this with the facts, on the one side, of the exceeding readiness with which this species lends itself to domestication, and on the other side, of the considerable difficulties which attend its transport over great distances in space, I incline to think that this animal may have had a different history from the others just mentioned, and may have been domesticated upon the spot.

${ }^{1}$ Granier de Cassagnac, Les origines de la langue Francaise. Paris, 1872.

2 Compte rendu du Congrès de 1872, p. 459. 


\section{INDEX OF AUTHORITIES}

\section{REFERRED TO IN DESCRIPTION OF AND GENERAL REMARKS}

\section{UPON THE SERIES OF PREHISTORIC CRANIA.}

Abbay, Rev. R., p. 659 .

Achille, Dr., 673 .

Adams, W., 699 .

Adelung, 63r.

Aeby, Prof., 559, 566, 644, 649, 714.

Alian, 685 .

Aitken, Dr., 566 .

Akerman, 657,691 .

Anderson, Joseph, 525, 526, 536, 537, 653,685 .

Antelme, $66_{3}$.

Appian, 632 .

A ristotle, 7I 7, 739 .

Arnkiel, 686.

Athenæus, 718.

Austen, N. L., 742.

Avienus, 635 .

Bacon, 643.

Baehr, J. C. F., 685.

Baer, Prof., 562, 566, 588, 593, 596, 597, $68 \mathrm{r}$.

Bagehot, 537.

Bancroft, 597 .

Bartholinus, T., 686, 693.

Bastian, Prof. A., 640.

Bate, Spence, 7I 2.

Bateman, 628, 7or.

Bates, 661, 662, 667, 73 I.

Batt, Dr., 664.

Beddoe, Dr., 538, 596, 621, 630, 631, $678,679,680,682$.

Beechey, 660.

Beger, 729.

Belloguet, Roget Baron de, 6r8, 632, 636 .

Bessels, Dr. E., 660.

Betz, Prof., 673.

Bischoff, Prof., $642,663,666,672$.

Blainville, de, 737 .

Blake, Dr. C. C., $597,615,653$.

Blumenbash, 697 .

Boccaccio, 723.

Bochart, 730, 739 .

Bogstra, 697 .

Boogaard, 697, 7ro.

Brenchley, $64 \mathrm{r}$.

Broca, Prof., 532, 538, 561, 562, 563 , $564,567,572,577,584,594,595,597$, $628,635,636,647,655,656,661,666$, $679,682,694,705,708,710,711,715$, 716.

Bromfield, 72 I.

Brooke, Sir V., 733.

Browne, Dr. J. C., 668, 674.
Buckland, Dr., 532, 537, 540, 62 r.

Buffon, 643, 74I.

Bulwer, J., 597.

Bunsen, 68I.

Bürki, Grossrath, 740.

Busk, Prof., 559, 588, 595, 597, 640, 650, $655,658,664,694,715,716,733$.

Cæsar, J., 632, 634, 692, 722, 724, 731, $732,737,743$.

Caldwell, Bishop, 730 .

Calori, 647.

Camden, 723 .

Camper, P., 597, 643 .

Candolle, De, 721, 722, 724, 747 .

Cassagnac, Granier de, 750 .

Catullus, 718.

Cayley, H., 749 .

Claucer, 723,733 .

Christ, Dr. H., 724, 744, 750.

Cicero, 632, 685 .

Clark, Bruce, 733

Clarke, Lockart, 667, 685 .

Claussen, 63I.

Cleland, Prof., 560, 566, 568, 580, 584, $588,592,637,639,642,647,648,649$, $650,663,664,678,709,71_{4}$.

Cogan, Dr., 597 .

Columella, 737,738 .

Cook, Capt., 730, 731.

Cortese, 647.

Cruveilhicr, 667, 668, 669 .

Cunningham, Dr., 595 .

Cunnington, $68_{4}$.

Cuvier, 643 .

Dahlmann, 632.

Dalton, Col., 69r.

Daniel, 733, 742.

Darwin, 628, 695 .

Davies, 723,724 .

Daubentin, 643 .

Daubeny, Prof., 722.

Davis, Dr. J. B., 560, 597, 600, 601, 639, $648,649,650,659,662,66_{4}, 68_{3}, 689$, $697,698,706,708,7$ 10.

Dawkins, Boyd, Prof., 716, 734.

Dawson, J. S., 682.

Dawson, Principal, 62r.

Désor, Prof. E., 728, 748 .

Dillwyn, L. W., 62I.

Dio Cassius, 632, 657,716 .

Diodorus, $565,63^{2}, 635,657,680,685$, 686. 
Douglas, D. M., Dr., 702.

Dryden, Sir H., 524, 679.

Diben, Baron Von, $629,66_{5}$.

Ducange, 728 .

Duckworth, D., 589 .

Dumoutier, 595 .

Duncker, $631,63^{2}$.

Dunraven, Lord, 730.

Dupont, E., 537, 597, 621, 736, 749.

Duret, $671,672$.

Earle, Prof., 723.

Ecker, Prof., 540, 562, 566, 567, 597 , $601,636,646,654,666,672,679$.

Edwards, Milne A., 732.

Egede, 718.

Eichwald, Prof., 589, 629, 659 .

Ellis, 595, 597, 64 r.

Embleton, D., 584 .

Engelhardt, Prof., 687.

Erskine, 641.

Evans, A. J., 629, 680, 745.

Evans, J., 687, 730, 734, 737 .

Falconer, Dr., 655 .

Fellenberg, E. von, 728, 745, 749.

Fischer, Prof. H., 745, 749.

Fischer, Prof. L., 724.

Fitzinger, 597.

Florus, 565, 631, 632 .

Flower, Prof., 697.

Forbes, D., 595, 597.

Forel, Prof. F. A., 745.

Forster, 597, 641.

Foville, Dr., 597, 668, 673 .

Fox, Dr., 668.

Franks, A. W., $73^{8 .}$

Fresnel, 652.

Friedlowsky, 697, 698, 699 .

Gall, 643 .

Galton, F., 640, 731.

Galton, J. C., 672 .

Garner, R., 670.

Gausse, 676 .

George, Rev. H. B., 745.

Gilmour, Rev. J., 659.

Gliddon, 573, 597, 628 .

Goltz, 729, 731.

Goodsir, Prof., 559.

Gosse, Dr., 559, 573, 595, 597 .

Gratiolet, 561, 638, 669, 673, 676.

Greenwell, Rev. W., 627, 683, 690, 7or, $702,736$.

Grimm, 632, 685, 686, 729.

Guizot, $73^{2}$.

Haller, 595 .

Halloy, Omalius de, 646.

Hanimond, Capt., 707.

Hanauld, 695.

Hancock, Dr., 682 .

Handelman, 631 .

Hardyng, $74^{\circ}$.
Heath, 688.

Heer, Prof., 724, 745.

Heftler, F., 666.

Hehn, V., 721, 724, 729.

Hen Llywarch, 723.

Henle, Prof., 667.

Henry, 733.

Hermann, K. F., $53^{8}$.

Herodian, 7 I 7.

Herodotus, 685, 693, 718.

Hesiod, 726.

Heubner, $67 \mathrm{~s}$.

Heusinger, 738 .

Hewett, P., 572 .

Heyne, 685 .

Hind, Prof., 682.

Hine, W., 646 .

Hippocrates, 597.

His, Prof., 562, 587, 596, 597, 604, 607, $640,649,652,682,695,746$.

Hiven-Thsang, 597.

Hoare, Sir R. C., $5^{25}, 623,640,648,65^{2}$, 684 .

Hoeven, Van der, 597.

Holder, Dr, 57 I, $636,640,647,678,679$.

Holinshed, 725.

Holmboe, Prof., 685.

Holyoke, Dr., 592.

Homer, 692,730 .

Horace, 632, 681, 718 .

Houghton, 735 .

Hughes, Prof., 726.

Humphry, Prof., 565, 566, 686.

Hunter, Archdeacon, 682.

Huschke, 607, 6r8, 638, 639, 647, 649, 66r, 666.

Hutchinson, Consul T. J., 597, 707.

Huth, 682.

Huxley, Prof., 564, 595, 596, 621, 646, 647.

Hyrti, 695 .

Ihering, Dr., 559, 637 .

Jackson, W. H., 728 .

Jeitteles, 734.

Jenner, Dr., 700.

Job, 705.

Johns, 72 I, 722, 723 .

Johnson, R., 733.

Jones, W. B., $631,635,667$.

Jornandes, 630, 634, 680 .

Jowett, The Rev. B., Master of Balliol College, 7 I 8.

Julian, 718.

Justin, 632 .

Juvenal, 743.

Keller, 740, 745, 747, $74^{8}$.

Kemble, 691.

Keyser, 630 .

Kinberg, 736, 740.

King, Capt., 595.

Knight, Payne, 730.

Koner, 63I. 
Kopernicki, $6{ }_{3} 6$.

Krause, W., 607, 667.

Krebs, Dr., 589, 676 .

Kuhff, Dr., 659 .

Lafargue, 643.

Lagneau, 597 .

Lane-Fox, Col. A., 631, 650, 7 I6.

Langer, ${ }_{564}$.

Lanigan, 730.

Lankester, Prof., 708.

Latham, 632.

Laws, E., $703,706$.

Lee, J. E., $736,740,745,748$.

Lees, 725 .

Leighton, 724 .

Lelut, Dr., 668 .

Liharzig, 564, 594, 662 .

Lindenschmidt, $69 \mathrm{I}$.

Link, 73I.

Lipsius, 68 o.

Lissauer, 564 .

Livy, 632.

Lluyd, E., 63г.

Logan, $640,717,726,726$.

Lord, 738,739 .

Low, D., 738, 739, 740.

Lubbock, 665, 702, 716, 723 .

Lukis, Rev. W., $59^{2}$.

Luschka, 667.

Lyell, Sir Charles, 589, 596, 631, 729 .

Lysons, Rev. Canon, 650, 690, 703.

Maack, 63r.

Maclean, H., 680.

Major, Dr. H. C., 667, 673 .

Marcellinus, A., 565, 63 I.

Marius, 632.

Markham, C., 657.

Marshall, Prof., 668.

Marsham, 7 I8.

Martial, 658,686 .

Martin, H., 632 .

Mason, Prof. W., 694.

Massieu, 73I.

Maudsley, 667.

Mela, 632, 685 .

Meleager, 718 .

Merk, 736 .

Merkel, Dr., 56 r.

Mestorf, 724 .

Meyer, 597 .

Meynert, Prof., 638, 667, 673 .

Minayeff, 730.

Mirabeau, 643 .

Montelius, 665 .

Montellier, 738 .

Moore, W. D., 710.

Morley, Prof., 634 .

Mortillet, 73I.

Mortimer, J. R., 654 .

Morton, 573, 597, 652 .

Moseley, H. N., 64I, 708 .

Moxon, 667 .
Máller, Prof., 597, 630, 665, 685, 686, 705,721 .

Mummery, J., 592, 701, 702, 703.

Munch, 631,632 .

Naumann, 736, 739 .

Nearchus, 725 .

Neville, 69 I.

Nicolaus, Damascenus, 68.

Nicollucci, Prof. S., 636.

Niebuhr, 631, 632.

Nilsson, Prof., 527, 532, 536, 540, 628, $632,646,665,693,716$.

Nind, 742,743 .

Nonnius, 730, 731.

Nott, 573, 597, 628, 629 .

Oates, F., 707 .

O'Brien, 631 .

Ogle, 573 .

Orosius, 632 .

Ovid, 7 I8.

Paget, Sir J., 699.

Pallmann, Dr., 631, 632.

Pansch, 631, 668, 669, 683.

Parker, J., 621.

Parkes, Prof. E., 673.

Paterculus, V., $63_{2}$.

Pausanias, 685.

Payne, Dr. F. J., 667.

Pearson, Prof., 71 2, 721, 722, 723.

Pengelly, W., 705, 733 .

Pentland, 597 .

Perier, 68I.

Persius, 728 .

Perthes, B. de, 726 .

Peschel, 673.

Phillips, Prof., 679, 7 II.

Plato, 718.

Pliny, 632, 685 .

Plutarch, $565,566,63^{2}, 685$.

Pott, 729.

Power, 667 .

Pratt, 721.

Price, W. H., 565.

Price, W. P., 566.

Prichard, 631, 632, 634, 681.

Propertius, 685 .

Pruner-Bey, 597, 7I 7 .

Quatrefages, Prof. A. de, $75^{\circ}$.

Quintus Calaber, 726 .

Rance, C. E., 7 16.

Rasche, 731.

Rask, Prof., 665.

Rathke, 597.

Retzius, A., 595, 597, 629, 637, 646, 66r, 665.

Retzius, G., 665 .

Rhys, Prof., 632, 634, 729, 730.

Richardson, Sir J., 660, 718 .

Rochholtz, 657 . 
Rogers, Prof., 733.

Rokitansky, 667,696 .

Royce, Rev. D., 524, 526, 528, 529 .

Rudall, J. T., 668, 676 .

Rütimeyer, Prof., 540, 587, 596, 597, 604, $607,640,649,652,682,695,735,736$, $739,746$.

Rygh, 665.

Sacken, Baron Osten, 68I.

Sallust, 632 .

Sambon, 737 .

Sammlung, 647 .

Sandifort, 696 .

Sartoris, A., 524.

Sasse, Dr., $564,636,640$.

Sauvage, 716.

Sayce, Prof., 7I6.

Schaafhausen, Prof. H., $607,628,646$, $654,66_{5}, 686$.

Schliemann, 728.

Schmidt, Dr. L., 559, 656, 658.

Schröder, Van der Kolk, Prof., 668,675 , 676,698 .

Sclater, 73I.

Selden, 7 I6.

Seneca, 632 .

Servius, $685,73^{8}$.

Sieveking, 667 .

Simmo, Dr. T., 694.

Skene, 723.

Skylax, 635 .

Smiles, 665.

Smith, Sir A., 66o.

Smith, E., 725 .

Spanheim, 734 .

Spengel, 700 .

Spenser, 723 .

Spinola, 728,738 .

Sproat, 597.

Squier, 682.

Steenstrup, Prof., 687, 749, 750.

Stephanus Byzantinus, 685 .

Stephens, Thomas, 725,738 .

Strabo, $565,597,631,632,635,657,680$, $685,686,725,728$.

Stricker, 667 .

Sturzius, 716.

Tacitus, $565,630,631,632,634,657$, $680,68 \mathrm{r}$.

Taliessin, 723 .

Tankerville, Lord, 74..

Taylor, I., 7I3.

Telfer, Com., 597.

Tertullian. 685 .

Theile, Dr., 676 .

Theodoret, 685 .

Thierry, 597, 631, 632 .

Thomas, Capt., 7I 2.

Thommerel, $72 \mathrm{I}$.

Thomsen, Prof., 589 .

Thrupp, J., 729, 73I.

Thurnam, Dr., 526, 537, 567, 587, 596,
$597,615,622,623,628,636,639,640$, $641,644,650,651,654,657,663,683$, $684,686,687,688,689,690,694,695$, $696,701,706,709,713,745$.

Tiedemann, 597.

Tomes, C. S., 705, 708.

Tomes, J., 704.

Topinard, $562,564,567,596,597,604$, 655.

Troyon, $747,74^{8}$.

Tschudi, 597.

Turner, Prof., 597, 666, 68\%.

Turner, S., 631, 725 .

Tylor, E. B., 7 I6.

Uhlmann, 724, 740 .

Ukert, $632,68 \mathrm{r}$.

Valerius Maximus, 685.

Vanderkindere, M. Léon, 636,

Vesalius, 572,573 .

Virchow, Prof., 560, 563, 564, 567, 569, $589,595,596,597,6$ I $5,636,646,647$, $649,651,652,653,66_{5}, 668,678,681$, $695,698,699,700,710,713,750$.

Virgil, $659,685,726,729$.

Wagner, A., 597.

Wagner, H., 649, 676.

Wagner, R., 676 .

Waitz, 597 .

Walter, 606.

Ware, Dr. H., 630.

Watson, H. C., 72I, 725 .

Webster, Rev. W., 633 .

Weigmann, A. F. A., 696.

Weinhold, 630, 656, $69 \mathrm{I}$.

Weisbach, $566,573,607,640,649,689$.

Welcker, $565,566,567,607,614,628$, $639,642,695,706$.

Wesley, W. H., 559.

Westwood, Prof., 728, 729.

Whitaker, 734 .

Whitmee, 64I.

Whymper, 717 .

Wilde, Sir W., $627,628,646$.

Wilks, 667 .

Williams, 597 .

Williams, Principal, 729.

Wilson, Prof. D., 528, 534, 540, 573, 597, $605,621,622,628,653,662,681,705$.

Wood, 597.

Wordsworth, 7 2.

Worsaae, 665, 713.

Worsley, 726 .

Wotton, 725 .

Wylie, 69 I.

Wyman, Prof., 614, 738.

Youatt, 738, 739, 740.

Zeuss, 632, 634, 635, 68r.

Zuckerkandl, Dr. E., 567, 573, 597, 66r, 694,7 I 4 . 


\section{N D E X.}

Adzes, stone, found in barrows, p. 34, 181 . Alcuin, $5^{8}$.

Alwinton, parish of, $422,476,477$.

Amber, 55, 55 n.; beads, 55 n., 178 ; buttons, $56 n_{0}$; cup, found at Hove near Brighton, 97; pendants of, $297 n$.; termination of knife-dagger handle, found on Dartmoor, $207 n$.

Amulet or charm found with a skeleton, 249.

Ancestors, worship of, 10.

Anderson, Mr. Joseph, 239 n., 480 n., $525,526 n$., 536, $537 n$.

Angles, 123, 124; burial-place of, 178 , $261,371,385,386,3^{87}, 395,43^{2}, 435$; buried in the contracted position, 136 .

Anglian cemetery, I 23, I $_{35}$.

Animal bones, found amongst human, $\mathbf{1}_{5}$, I 53 n., I55, I62, 240, 274, 275,278 , $283,298,353,427$; found at Grime's Graves, IIO, II 5 ; found in barrows, 9, Io9.

Animals, domesticated, II5; used for food, Io9; wild, not much used for food, Iog, I I 3 .

Another life, belief in, $57 \mathrm{seq}$.

Armlets, bronze, of the early iron age, 208, 2 I0, 386.

Arreton Down, find of bronze articles there, $46 n$.

Arrow-points, bronze, not found in Britain, $360,360 n_{0}$; flint, found with burnt bodies, $352,368,369,4 I_{2}$; flint, found with unburnt bodies, r63, I7 I, I9 I, 2I 8, 249 ; flint, rarely found south of the Thames, $444 n$.; flint, when found with burnt bodies usually burnt, 174 .

Art ornamentation, 268.

Arthur's Round Table at Penrith, 38r.

Articles, identical, found in different localities, 279 ; why deposited with the dead, $59,4^{2} 5$.

Asby, parish of, 386,474 .

Askham, parish of, 400,475 .

Atkinson, Rev. J. C., of Danby, $6 n$, I4 $n ., 80$ n., $84,333,42 \mathrm{I} n$.

Avebury, stone circle at, $6 n$.

Awls, or drills, of bronze, 38,46 ; found with an interment, $x_{3} 8,1_{50}, 235,236$, $275,283,313,321,324,366,373$, 404 .

Axes, bronze, 44, 47; found with an interment, $188, \mathbf{I} 88 \mathrm{n}$; the plain one only found in barrows, 47 .

Axes or hatchets, stone, 34, 35, I60; found in a barrow, $136,179,319$.

Axe-hammers, stone, 35, 39, 42 ; found with burnt bodies, 158, 158 n., 298 ; found with unburnt bodies, 222, $222 n_{\text {., }}$ 265 ; probably weapons, 39,42 , I 59 .

Badgers' earth in a barrow, $3 \mathbf{I}_{5}$; head in a grave, 200.

Bæda, 58.

Bamborough, parish of, 413,476 .

Barrows, added to from time to time, $196,294,491$; burial-places of persons of note, II 2 ; date of round, $45,46,49$, I30; elevated position of, 8 ; form of, 3,4 ; groups of, 8 , I I 2, 420, 42 I $n$. ; large, frequently contain a single burial, 12, 312; large, frequently without a grave, 3oo; long, 3, 479 seq. ; made of different materials in the same locality, 394 ; made piecemeal, 5 ; materials of, 5 ; popular names of, 2 ; size of, 4 ; size of, no criterion of number of burials, I 2 ; small and of low elevation, 327, $35 \mathrm{I}$; small often destroyed by cultivation, 327 ; table of, $45^{8}$; widely diffused, $x$; without any trace of an interment, 27, 202, 301, 337, 340, 346.

Bascaudæ, 65 .

Bate, Mr. Spence, F.R.S., $207 n$.

Bateman, Mr., 2 I $n$., passim.

Beads, amber, 55 n., I 78 ; animal's tooth, 52, $13^{8}$; bone, 53, 275, 278, 279; clay, 55, 394; glass, 52 n., 55, 55 n., I 78, 208, 208 n., 384 ; gold, 55 n., 436 ; in long barrow, 519, 520 ; jet, 32 n., 52, 53, I38, I42, I98, I98 n., 330, $334,366,392,407,419$; shale, 419 , 519 ; shell, $1_{3} 8,139$; vertebra of fish, I39.

Beaver's tooth, implement of, $3^{8}, \mathbf{1} 3^{8}$.

Bee-hive, houses, 450 ; roof, $5^{2} 3$.

Belemnite, piece of, used as an ornament, I39.

Bielbecks, animal remains found there, 505 .

Binnington, parish of, I 79.

Birch branches on bottom of barrow, 337.

Birch, Mr., Ancient Pottery, 3 n., 8I. 
Bits, bridle, of bronze, $455,455 n$.

Boar's tusk, implement of, 389 ; knife of, 37, 2I5, 215 n., 274; pin of, 33, $138,274$.

Bodies buried facing the sun, 26 ; buried in a contracted position, 22, 136 , passim; buried in an extended position, 22, 22 n., 261, 269, 299, 303, 386, 395, 435 ; buried in a hollowed tree trunk, 13,23 , $32,375,376 n ., 3^{8} 4$; buried in every part of a barrow, 12,16 ; buried in leather or hide, 32, $32 n$., I42, 4 II ; buried in the dress, 3I; buried in woollen cloth, 32,376 ; buried usually on the sunny side of barrow, I3; burnt and unburnt buried together, I49, I52, I53 n., I 72 , $240,269,329,372,391,441$; disturbed by the introduction of later interments, $16,1_{4} 1,157,167,1_{69}, I_{72}, 1_{75}, 1_{76}$, I82, 184, 193, 200, 206, 2 I 4, 223, 228, $230,232,237,243,249,252,253,255$, $258,275,277,305,308,321,322,323$, 330,367 ; fire possibly applied to all, 29 , $30,30 n$.; how burnt in long barrows, 495, 499, 502, 506, 5II ; inperfect when interred, $172,195,221,226$, $260,325,326,363,3^{88}$; more than one buried together, $I_{5}, 27, I_{4} 8, I_{5} I_{\text {, }}$ $I_{52}, I_{55}, I_{5} 6, I_{3}, I_{72}, I_{75}, 1_{82}, I_{3}$, I9I, 2I 4, 240, 259, 269, 273, 285, 290, 297, 299, 308, 329, 364, 372, 391, 399, 399 n., 406, 427; partly burnt, 29, $29 n ., 3 \circ, 30$ n.; placed in contact, I48, I 5 I, I 56 , I 56 n., I63, I63 n., I 72, I 75, $182,183,191,214,240,259,273,297$, 299, 3०8, 391; placed on a small mound within barrow, I40; placed on a wooden platform, I3, I70, I8I ; preserved before burial, 17,244 ; protection of, in barrows, 2, $\mathbf{1}_{3}$; re-interred, $\mathrm{I}_{7}$, I 73, I 96, 2 I 5, 2 I6, 2 I $8,244,260,326$, 5I9, 546; re-placed, I 8, 226, 244, 255 , 275 ; side on which laid, 25,26 ; sometimes buried without having the bones removed after being burnt, 23,283 , 29I, 29 I $n$.

Bone, beads, 52, 53, I38, 275 ; button, 278 ; fibula, $33,117,35^{2}, 35^{2} n$.; implements, $37,138,25^{2}, 274,392$; orna. ments, 55, 392; pins, 33, passim termination of knife-dagger handle, $207,207 n$.

Bones, colour of burnt, I6; decayed totally, 28, $185,202,301,33^{8}, 340$, $34 \mathrm{I}, 346,35^{8}, 359,4^{\mathrm{I}} 4,4^{\mathrm{I}} \mathrm{7}, 4 \mathrm{I} 9,42 \mathrm{I}$, $423,430,437,438$; decayed when buried in wood, $203,375,376 n ., 3^{84}$; impression of, 185 ; preserved well in chalk, I85 ; showing signs of disease, 312,323 ; stained by manganese, 5 I 7 .

Boniface, the Apostle of Germany, $5^{8}$, $120 n$.

Borlase, Mr. W. C., 96, 222 n., $266 n$.

Bowl, bronze, $3^{8} 4$.
Brittany, dolmens of, 13 ; pottery of, 62 ; parts of body kept there in a deadhouse, 17 .

Brixham Cave, pottery found there, $77 n$.

Broca, Professor, 532.

Bronze age, bodies not always then burnt, I9; burials of the later period of, 50 .

Bronze and stone implements associated, $187,225,236,265,265$ n., 359

Bronze, armlets, 208, $210,3^{86}$; awls or drills, $38,46,138,1_{50}$, $187,235,236$, 275,283 , 3I 3, 32I, 324, 366, 404; axes, $43,44,47$, I 88 ; bowl, 384 ; buckle, II 7 , $43^{2}$; casting, skill in, II 7 ; daggers, 4I, 42, 42 n., 220, 359; drills, $3^{8}$; ear-rings, 52 , $117,223,223 n ., 324$; fibula, 178, 208; found with burnt bodies, I9, I 50, $283,366,404,446$, 446 n.; found with unburnt bodies, I9, $138,178,186,187,188,207,208$, $210,223,235,236,264,265,275,3$ I 3 , $321,324,359,361,373,3^{84}, 3^{86}, 455$; implements, 38,1 I 7 ; implements found at Westow, 490; implements rarely found in Wold barrows, 43 ; implements, relative age of, 44 seq.; knife-daggers, 38, 40, 42 n., 47, 186, 207, 264 ; knives, $38,265,446,446 n$.; rings, 433,455 .

Burial, after cremation, $18,20,2 \mathrm{I}$; by inhumation, I8, I9; importance of rite of, II9, 243; persons killed at, 244; places of the common people, I I $2, I_{3}$; primary, placed above the surface, 334 , $335,336 n ., 345,349,356,382$.

Burials, number of in barrows, 12 ; without a mound over them, II 2.

Burning of the body, a religious rite, 83 ; site of place of, I4; sometimes partial, $29,30,30 n$.

Burnt and unburnt bodies, buried together, I 49, I 52, I 53 n., I 72, 240, 269, $329,37^{2}, 391,44 I$; relative proportion of, 19, 20, 2I, 2 I $n$.

Burnt bones, carefully collected from the pile, 15; colour of, 16; enclosed in cloth, I5, 453; enclosed in urns, 14 ; enclosed in wood, $14 n$.

Burnt clay, \&c., layer of in barrow, 281, $349,349 n$.

Butterwick, parish of, $186,46 \mathrm{r}$.

Buttons, 31,32 , I16; of amber, $56 n$.; of bone, 278 ; of gold, 56 , II 7 ; of jet, $32,174,187,223,227,229,229 n$, $264,26_{5}, 431$; of stone, 32,187 .

\section{Cædmon, $5^{8}$.}

Cæsar, account of Gaulish burials, 16 .

Caithness, 'horned' cairns of, 480,536 ; long barrows of, 480 ; round barrows of, $4^{8} \mathrm{I}$.

Calculus, urinary, found in barrow, 286, 313.

Callernish, stone circle at, $6 n$.

Cannibalism, 544. 
Castle Carrock, parish of, 379, 474, 599 .

Castles, none in England before Norman Conquest, 125.

Celts of bronze, socketed, $43,44 n .48$, 49 ; not found in barrows, $44 n$.

Cemeteries, Anglian, I23, I35 ; 'AngloSaxon,' 58 ; in Illinois, $13 n$.

Cenotaphs, 27, 28 n., 202, 301, 340.

Chalk, preservation of bone in; 185 .

Chamber, in barrows, 2, 3 ; circular, in round barrow, 448 ; copy of dwellingplace, a n. ; different from cist, 45I, 479 n., 5I5; earlier than cist, 45I, $480 \mathrm{n}$.; in long barrows, 449, 479, 5 I 5 ; oval, in long barrow, 5I4.

Channel Islands, pottery of, $6 \mathbf{2}$.

Charcoal, found in Christian graves, $29 n$.; found in connection with burials, 28 , $28 n$. 29.

Chariot in barrow, 454,455 .

Charm or amulet, 249.

Chatton, parish of, 4 I2 $_{2}, 476$.

Cherry Burton, parish of, $279,467$.

Child, interment of, the principal one in a barrow, I 18, I4I, I4I $n ., 260,260 n$., $290,408,409$.

Children, several buried in a barrow, 196.

China, bodies kept unburied there, 2 I $n$.

Chisels, stone, found in barrows, 35, 225 , 396.

Chollerton, parish of, 435,477 .

Cinerary urns, $62,66,8 e q$. ; cross pattern found on them, 70; mouth stopped with clay, I4; ornamentation of, 7I ; perforated, 69 ; projections round, 69 ; rare on the Wolds, 74; reversed, I4; size of, 67 ; vessels of type of, $62,7^{2}$, I 39, I6I, 277, 284, 287, 288, 289, 290, 291, 297, 318, 370, 428 .

Circles, of stone or earth, connected with barrow, 4, 6; incomplete, 6, 6 n., 7, 7 n. ; sometimes double, 6 ; surrounding the base of barrows, $4,6,7,8$, $369,400,412,429,434$; within barrows, $8,344,35^{8}, 363,363 n$., 408 .

Cireular-marked rocks and stones, 7,343 , 403,4 IO 4 18, 422, 429, 430 .

Cists, burial in, I3, I3 $n$.; distinction between chambers and, 45I, 479 n., $5{ }^{I} 5$; in a grave on the Wolds, 238 ; later than chambers, $45 \mathrm{I}, 480 n$.

Clasp for waist-belt of bronze, 178 .

Clasp or fibula of bone, 33, II $7,35^{2}$, $35^{2} n$.

Cleveland, 21, 333 ; bronze very rare in, 333 ; cremation almost universal in, 21 ; inhumation very rare in, 333.

Cloth, woollen, body wripped in, 32, 376.

Club of wood, 278 .

Cochet, Abbé, 28 n., 44 n.

Coffins, made from hollowed tree trunk, I 3, 23, 32, 375, $376 n$., 384 ; throwing earth on, at funerals, $5 n$.
Cold Kirby, parish of, 337,47 r.

Colour of burnt bones, I6.

Conquerors rarely extirpate the conquered, 2 I 3, $45 \mathrm{I}$.

Constantine, coin of, found in a barrow, 5 I4.

Contracted position, bodies so placed when burnt, 23, 283, 29I, $291 n$.

Contracted position of the body, almost universal, 22 ; reason of, 23,24 .

Cop-stone (monolith) on Moor Divock, 400.

Coquet, valley of, 422 .

Cotswold Hills, cremation the most common practice there, 445 ; large stone implements uncommon there, 444.

Cover of vessels of pottery, $89,164,164 n$., 305.

Cowlam, parish of, $208,4^{62}, 4^{6} 3,587$.

Cowry shells (Cypræa Europæa) in bar. row, I 39

Craven, West Riding of Yorkshire, 374.

Cremation, and inhumation practised at the same time, 20, 21, 392, 542; burial after, $18,20,21$; the rule in some districts, $21,333,339,347,356$, 445 .

Crosby Garrett, parish of, $386,474,475$, 510.

Crosby Ravensworth, parish of, 396, 475 .

Cross, as an ornament, $56,76,77 \mathrm{n}$., $228 n .268,268 n, 276,278$; on bone beads, 276 ; on buttons, $188,228,264$; on cinerary urus, $70,76,77 \mathrm{n}$; ; on 'drinking cups,' $98,9^{8} n_{a}$; on 'food vessels,' $77 n ., 424,424 n$. ; on 'incense cups,' 76 ; on a stone, $34^{2}$.

Cumberland, 378 .

Cunnington, Mr., $54^{2}$ n., 543 n.

Cup, of amber, 97; of gold, 98.

Cup-markings on rocks and stones, 7,341 , $34^{2}, 34^{2} n ., 343,402,422,430,433$.

Daggers, bronze, 4I ; found in barrows, 42,42 n., $220,359$.

Dawkins, Mr. W. Boyd, F.R.S., II.

Dead, articles buried with, I2I ; dislike of using what belonged to, 59, $59 n$. ; fear of spirits of, 8, 10 ; offerings made to, IO, IO n., IO2; provisions placed with, $93,93 n$.; reason why articles were buried with, $57 \mathrm{seq}$.; reason why 'drinking cups' and 'food vessels' were buried with, roo; worship of, ro.

Dead houses in Brittany, parts of bodies kept in, I 7.

Deer's-horn, hammers of, 37, 2 I 7, $217 \mathrm{n}$., 390,390 n.; implements of, 37,192 , 211 ; picks of, $5,37,37$ n., 20I, 23I, 23 I n., 253, 258, 304, 329, 432.

Defensive works on the Wolds, II I, 123 , $x_{34}, x_{36}, 274$.

Dekhan, cairns there, $6 n$, I $20 n$. 
Denmark, bodies buried in dress, 32 ; bodies burnt during bronze age, I9; bronze swords found with interments, I90; burials in tree-coffins, $377 n$.

Dennis, $\mathrm{Mr}_{\text {., }}$ of Rosebrough, 4I5.

Denny, Mr., of Leeds, $337 n$.

Deposit of burnt bones containing more than one body, 285, 290, 399, $399 \mathrm{n}$., 427 .

Distinction between chambers and cists, 45I, 479 n., 5 I 5.

Ditches, circular or square, round base of barrows, 4, 369, 370 $n$.

Doddington, parish of, $4 \mathrm{10}, 476$.

Dolmen-builders, 482 .

Dolmens of Brittany, $\mathbf{3} 3$.

Domesticated animals, II5.

Domestic vessels of pottery, ro6; sometimes used for burial purposes, rog.

Dorsetshire, form of cinerary urns there, 67.

Dotchon, Mr., of Whitby, $352 n$.

Dress, bodies buried in, 31 ; of people of bronze age in Denmark, 32, $377 n$. ; of people of Wolds, 116 ; remains of leathern, $14^{2}, 4 \mathrm{II}$; remains of woollen, 32,376 .

Dress-fasteners, $32,116,352,35^{2} n$.

Drills, bronze, $38,187,236,275,324$; flint, 35, $25 \mathrm{I}$.

'Drinking cups,' 62, 94 seq.; forms of, 95 ; not found in Ireland, 94; ornamentation of, 98 ; ornamented on bottom, 98,98 n., 326; rarely found with burnt bodies, 99,245 ; size of, 95 ; with handle, 95, 96, 32I; with horn spoon in one, ror.

Dryden, Sir Henry, Bart., 524.

Duggleby Wold, 140.

Dunbill, Mr., $488 n$.

Durandus, his reason why charcoal was placed in graves, $29 n$.

Durden, Mr., of Blandford, $77 n$.

Durham, county of, 440 .

Early Iron Age (' Late Keltic'), barrows of, $5 \circ \mathrm{n} ., 208 \mathrm{seq}$.; burials of, $50 \mathrm{n}$., $212,286,386,454$; skull form of people, 129, 212.

Ear-rings, bronze, 52, II 7, 223, $223 n$., 324 ; gold, 55 n., $223 n$.

Ebberston, parish of, 484,622 .

Eglingham, parish of, 418,476 .

Egton, parish of, 334, $47 \mathrm{I}$.

Egspt, Pyramids of, I ; Tau symbol of, 8.

Elevated position of barrows, 8 .

Elf Howe, $27 \mathrm{x}$.

Elliot, Sir Walter, $20 n$.

Enamelled bronze articles, $50 n$.

Entrenchments on the Wolds, I II, I23, I 34, I 36, 274.

Eskimo, crania of, 54I; houses of, $3 n$.
Etall Moor, parish of Ford, 403.

Etton, parish of, 282, 467 .

Evans, Mr. John, F.R.S., 24 n., 33 n., 36 n., 44 n. passim.

Extended position, bodies interred in, 22, 22 n., 261, 269, 299, 303, 386, 395, 435 .

Eyford, parish of, 5I4.

Fastenings of dress, $32,116,35^{2}, 35^{2} n$.

Fauna, ancient, at Bielbecks, 505 .

Feasts at funerals, xo, 145.

Feasts at graves, enactments against, Io, 10 n.

Ferrybridge, 371.

Ferry Fryston, parish of, 371,474 .

Fibulæ, bone, 33, $117,35^{2}, 35^{2}$ n. ; bronze, 178, 208.

Figure engraved on side stone of cist, 423.

Fiji chief, burial of, $\mathbf{2} 20 n$.

Fire, how applied to bodies in long barrows, $495,499,502,506,5 \mathrm{II}$; how produced in bronze age, $266,266 n$.; in connection with burial, 29, 30, 3 I $n$.

Fires, remains of, in barrows, 232.

Fitch, Mr., of Norwich, F.S.A., 98 n.

Flint arrow-points, found with burnt bodies, $352,368,369,4 \mathrm{r} 2$; found with unburnt bodies, 163, I7I, 191, 218, 249.

Flint blades probably knives, 36r $n$.

Flint drills, 35, 25 I.

Flint flakes in barrows, II ; large number in a barrow, 166; not gathered up with the material of barrows, II $n$.

Flint implements found with interments usually new, 50,60 .

Flint knives, 35 ; with burnt bodies not usually burnt themselves, 174,285 , $363,380,407$.

Flint saws, 35 ; large number found in a barrow, 262 .

Flint and steel, 36, 264, 265, $266 n$., 391 .

Flixton Wold, 27 I, 575.

Flouest, M. Ed., 2 I 7 n.

Flues in long barrows, 487 n., 496, 5I I.

Folkton, parish of, 27I, 466, 467 .

Fondouce, M. P. Casalis de, 9 .

Food, deposited with the dead, I0, 274, $275,278,283,427$; remains of, found in sepulchral vessels, 240,303, 311 , 3I2, 313; why placed with the dead, 102.

'Food vessels,' 62, 66, 83 seq.; clay of which made, $9 \mathrm{I}$; common in the Wold barrows, 66,84 ; deposited with both burnt and unburnt bodies, 83 ; form of, 84 ; ornamentation upon, 92 ; ornamented on bottom, $424,424 n . ;$ peculiar forms of, 88 ; provision for suspending them, 85 ; rare in Wiltshire, 66; size of, 84 ; with a cover, $89,164,164 n$, 
305 ; with feet, 88, 194; with perforated ears, 84,314 .

Forden, 272.

Foreign substances used in construction of barrows, 5, 6 n.

Fox, Colonel A. Lane, F.S.A., 9 n., 123 , $34^{2} n$.

Funeral, persons slain at, II9, I77, 243 .

Funeral feasts, Io, I 45 .

Future life, belief in, 57, 60, x21, 425 .

Fylfot, $77 n$.

Ganton, parish of, $155,459,460$.

Gardham, village of, 279 .

Garments of wool, 32, 376 .

Gaul, people of, I30.

Gaulish custom of burning animals with the dead, 16.

Giants' Graves, 344.

Gilling, parish of, $343,47 \mathrm{x}, 472,550$.

Gill's Vallis Eboracensis, 347,550 .

Glass, $55,55 n$; beads made of, $5^{2} n$., 55 , $55 n ., 178,208,208 n ., 384$.

Glaze on pottery, 65,3 IO.

Gloucestershire, 443 .

Gold, $55,55 n$.; beads, 55 n., 436; buttons, $56,1_{17}$; cup, 98 ; ear-rings, 55 . $223 n$.

Goodmanham, parish of, $286,467,468$, $469,470,47 \mathrm{I}$.

Gower in South Wales, $45 \mathrm{I}$.

Grain cultivated by people of the Wolds, II4.

Graves, connected by an opening, 223, $223 n_{0}$; floored with wood, I3; in barrows, I2; lined with wood, 13, I70; size of, 12 ; three oonnected together, 265.

Grime's Graves (flint workings), $37 n$., I IO, 23 I $n$.

Grimston Moor, 343, 550 .

Grimthorpe, 'Late Keltic' burial there, $50 n$.

Gristhorpe, burial in tree-coffin, 13, 23, $207 n_{0}, 377 n$.

Groups of barrows, 8, II 2, 420, 42 I $n$.

Habitation, place of, used for burial, 316.

Hall, Rev. G. Rome, $436 n$.

Hambleton training-ground, near Thirsk, 337.

Hammer of deer's-horn, 37, 2 I 7,2 I $7 \mathrm{n}$, $390,390 \mathrm{n}$.

Hammer-stones, 35, 200, 239, 242, $25 \mathrm{I}$.

Hand-made, vessels of pottery, all, 63 .

Handle, of 'drinking cup,' 95, 96, $32 \mathrm{I}$; of knife-dagger ornamented with bronze, 56 ; ornamented with gold, 56.

Handle-termination of knife-dagger, made of amber, $207 \mathrm{n}$; made of bone, 207, $207 n$.

Hands, position of, 25 .

Hartburn, parish of, 434.

Hatchets, stone, 34 .
Head, direction of, 25 ; form of, 122.

Headship of tribe, hereditary, Ir9, 260.

Heathery Burn Cave, bronze articles found there, $49 n$.; pottery found there, I07.

Hector, burial of, $x_{5} n$.

Helperthorpe, parish of, 19I, 205, 46I, $4^{62}, 617$.

Herodotus, his account of the burial of a Seythian king, I20.

Heron or bittern, pin made from bone of, I 77 .

Heslerton, parish of, $\mathbf{1 4}$ I , 458, 579 .

Hoare, Sir R. Colt, 4, I4 n., 25 n., 28 n., passim.

Holes in barrows, 9, 137, 137 n., 140, $I_{4} 6,1_{47}, I_{74}, I_{99}, 204,210,225,229$, 321, 328, 497, 498, 554, $554 n$.

Homer, burial of Hector, $15 n$.; burial of Patroclus, $16 n$.

Horn spoon in 'drinking cup,' IOI.

'Homed' cairns, 480, 5I5, 521, 536.

Horse, bones of, in barrows, 136, 220, $262 n_{\text {. }}$; buried with body, 456 .

Hove, near Brighton, amber cup found there, 97.

Huddersfield Museum, urn in, 169.

Humbleton Hill, near Sunderland, urns found there, 440 .

Hunebedden in Holland, 483.

Hut urns, $3 n$.

Hutton Buscel, parish of, $357,472,473$.

Ilderton, Northumberland, 583 .

Illinois, cemeteries in, $13 n$.

Implements, of boar's-tusk, 37, 138, 215 , 215 n., 274, 389; of bone, 37, 138, $25^{2}, 274,39^{2}$; of bronze, 38 , II 7 ; of deer's-horn, 37, 192, 20I, 211,231 , $253,258,304,329,432$; of stone, 34 , 35,36 ; position of, with reference to body, 39 ; rarely found with an interment, $38,51,425$; used in the making of cists, 239, $239 n ., 242$; why buried with the dead, 57, I 21 .

Impression of bones the sole remains of a body, 185 .

'Incense cups,' 62, 66, 74 seq.; common forms of, 74,75 ; cross on, 76 ; found always with burnt bodies, 80 ; found frequently in Wiltshire, 66; found inside a cinerary urn, 80,405 ; ornamentation of, 76; ornamented on bottom, 76, 355,384 ; peculiar forms of, 79 ; perforated, $78,7^{8} n ., 82$; rare on the Wolds, 66; size of, 74; sometimes burnt with the body, 80 ; supposed to be lamps, 81,82 ; use of, $81,82,83$. Incompleteness of circles, 6, 6 n., 7, $7 n$.

Inhumation, burial by, 18, 19; alternating with cremation, 302 ; and cremation practised at the same time, 20, 21 , 
$39^{2}, 54^{2}$; the most frequent mode of burial on the Wolds, I9, 20.

Inscribed rocks, $7,343,403,410,412$, 422, 429, 430 .

Interments, secondary, I 2, I6, I7.

Invading people absorbed by an invaded one, $213,45 \mathrm{I}$.

Ireland, 'drinking cups' not found in, 94.

Ironstone (calcined), pieces of, in grave, 240.

Isolation of people of the Wolds, Ir 8 .

Jet, $55,55 n$.; beads, $32 n .52,53,138$, I 42, I 98 , I 98 n., 330, 334, 366, 392, 407, 419; buttons, 32, I 74, 187, 223 , $227,229,229 n ., 264,265,431$; necklaces, 55 n., II 7, I98, 198 n., 330, 334, 403, 419; pendants, 198, 198 n., 297, 297 n., 330, 362; rings, 32, I I6, 227 , 229, 229 n., 25 I, 263.

Jewitt, Mr. Llewellyn, F.S.A., 50 n., $69 n ., 99 n$.

Joass, Rev. J. M., of Golspie, $421 n$.

Kaffir, uses assagai for various purposes, 40.

Kemble, Mr. J. M., 27, 30 n., Iо6.

Kepwick, North Riding of Yorkshire, 336.

Kilburn, parish of, 339,47 r, 5 or.

Kilham, parish of, 553 .

Kiplingcotes Race-course, 325 .

Kirby Grindalythe, parish of, 140,458 .

Kirby Stephen, parish of, 382, 474 .

Kirby Underdale, parish of, 135,458 .

Kirk Whelpington, parish of, 433,477 .

Kirwan, Rev. R., 44 n.

Kneeling position of body, 24 .

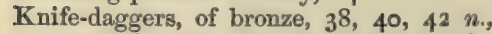
$47,186,207,264$; of bronze mistakenly called spear-heads, 45 ; of flint, 35 .

Knives, of boar's-tusk, 37, 215,215 $n$., 274 ; of bronze, $38,265,446,446 n$.; of flint, 35 ; of flint, serrated, 285 ; of flint found with burnt bodies usually not burnt, $174,285,363,3^{80}, 407$.

Lalande, M. Philibert, $29 n$.

Langtoft, parish of, 204,462 .

Langton, parish of, $136,45^{8}, 603$.

'Late Keltic' (Early Iron Age) burials, 50 n., 21 2, 286, 386, 454 .

Lead pommel of bronze sword-handle, 433 .

Leather or skin in graves, $3^{1} n ., 3^{2}$, 32 n., I42, $4 \mathrm{II}$.

Logan, Mr. James, F.S.A., $7 n$.

Londesborough, Lord, 5 n., 56 n., 180, I 86, $227,286$.

Londesborough, parish of, 331, 47 I.

Long barrows, 3, 479 seq.; earlier than a knowledge of metal, $4^{8} 3,54^{8}$; earliest form of sepulchral mound, $54^{8}$; fire how applied to bodies in, 495, 499, 502, 506,5 II ; form of skull found in, 122 , $482,543,549$; imperfect skeletons found in, 543; pottery rare in, 543 ; turned into round barrows, 205, 49I ; werpons and implements rarely found in, 543, 547.

Long Meg and her Daughters (stone circle), $38 \mathrm{r}$.

Lordenshaws Camp, near Rothbury, 430.

Lubbock, Sir John, F.R.S., $45^{\mathrm{I}} n_{\text {, }}$ $526 n$.

Lucker Moor, Northumberland, $4{ }^{1} 3$.

Lukis, Mr. F. C., 62 n.; Rev. W. C.,

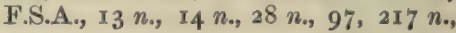
352 n., $377 n$.

Man and wife interred together, $\mathbf{1}_{54}$, I65, 224,44 I.

Manganese, bones stained by, 5 I 7.

Mapleton, Rev. R. J., 7 .

Market Weighton, parish of, 505 .

Mayburgh, near Penrith, $38 \mathrm{r}$.

Menhir in a barrow, 5II.

Mirror, iron, 454, $455 \mathrm{n}$.

Money Hill, barrow so called, 329.

Monkman, Mr. Charles, 28 n., I 45.

Monolith, Cop-stone on Moor Divock, 400 ; at Humbleton, 403 ; at Flodden, 402 ; at Rudstone, 233 ; at Swinburne, 436 ; at Yevering, 403 .

Moor Divock, parish of Askham, 400.

Mortillet, M. Gabriel de, $269 n$.

Mortimer, Mr. J. R., $5 \circ$ n., $377 n$.

Mother and child interred together, ${ }_{5} 6 n$., 260, 309, 391, 399, 399 n., 523.

Mound (circular) surrounding barrow, 4 .

Necklaces, $\mathbf{5}^{2}$; of glass beads, $5^{2} n$, 208 ; of gold, 55 n., 436 ; of jet, $55 n$. . II $7,198,198$ n., 330, 334, 403, 419; of shells, I $38 n$. ; of teeth, $327,327 n$.

Nether Swell, parish of, $445,478,5^{\text {I } 3}$.

Nilsson, Professor, 527, 537, 540, 546, 547.

North side of barrow, burials rarely found there, 13 .

Northumberland, $378,402$.

Ochre, in grave, 328,33 r.

Old Bewick, camp at, 42 I.

Ophelia, burial of, I2.

Ord, Mr., History of Cleveland, 333.

Orkney, stone sepulchral vessels found there, 73.

Ornamentation, of bronze articles, 66 ; of iron knives from Africa, 66 ; of pottery, 65 , II 7 .

Ornaments, 5I, II7; why buried with the dead, 57.

Urton, parish of, 394,475 . 
Ossuaries, I7, I8, 221, 504, 546.

Ossuary Theory, 53.3.

Overhanging rim of cinerary urns; 14,67 , I04.

Over Silton, parish of, 336,47 I, 509 .

Ovingham, parish of, 437,477 .

$\mathrm{Ox}$, head of, in barrow, I68, $168 \mathrm{n}$, 230.

\section{Paalstabs, 48.}

Palæolithic times, no evidence of Wolds being occupied then, I22 $n$.

Paley, F. A., Homeric tumuli, $4 n$.

Partial burning of the body, 29, $29 n$, $30,30 n$.

Patagonians, bodies kept by, before burial, I7.

Patroclus, burial of, $16 n$.

Paulinus, 286, 403, 426.

Peacock, Mr., $5 n$.

Penannular rings, 7 .

Pendants, of amber, $297 n$. ; of gold, $297 n$; of jet or lignite, 198, $19^{8} n$. , 297, 297 n., 330, 362.

People of the Wolds, not rich, 57; their physical characteristics, 121,127 ; two stocks there, I 22, I 26.

Perforations, in cinerary urns, 69; in ' incense cups,' 78.

Persons slain at funeral, I I9, I 20, I 77, 243.

Petrie, Mr. George, $239 n$.

Picks of deer's-horn, 5, 37, 37 n., 20I, 23I, 23 I n., 253, 258, 304, 329, 432 .

Pig, bones of, in graves, $274,275,278$, $283,298,454$.

Pig's tooth, perforated, 53, 326.

Pile, funeral, I4.

Pins, 3I, 3 I n., 33 ; with burnt bodies, I $5,31 n$.

Pious rites of one religion accursed in another, II.

Pit or cup maxkings on rocks and stones, $7,341,342,342$ n., 343, 402, 422, 430, 433 .

Platform of wood in grave, 13, I 7o, I8I.

Porter, Rev. Fred., I45.

Position of the body in barrows, 22, 23, 24.

Potsherds in barrows, II, 108.

Potter Brompton Wold, 155.

Pottery, 6r; always burnt, 63 ; of barrows different from 'Anglo-Saxon' and Roman, 63; of Brittany, 62 ; of Channel Islands, 62 ; clay of, 64 ; colour of, 64 ; domestic, I06; none made on wheel, 63 ; numerous fragments of, in barrows, II, 108, 221; ornamentation of, 65 ; position with reference to body, 61 ; rare in long barrows, 508; skill in manufacture of, 117,306 .

Prickers, vide Awls and Drills.

Proctor, Rev. William, junior, 4I I.
Prominent position of barrows, 8.

Proportion of burnt to unburnt bodies on Wolds and elsewhere, 19, 20, 21, 2 I $n$, Provisions placed with dead, 93 .

Puddled earth in barrows, 202, 246, $246 n_{*}, 262$.

Pyramids of Egypt, $x$.

\section{Querns (hand-mills), I 5 .}

Raiset Pike (long barrow), 5 IO.

Rau, Mr. Charles, I $3 n$.

Ravenstonedale, parish of, 393,475 .

Religion of people of Wolds, 120.

Rillaton, gold cup found there, $9^{8}$.

Rings, of jet and lignite, 32, I16, 227 . 229, $229 n, 251,263$; penannular, 7.

Rolleston, Professor, I22, $35^{2}$ n., 505. $510,513 n ., 515,521$; description of figures of skulls by, 559; essay on skulls by, 625 .

Rosehill, Lord, $266 n$.

Rothbury, parish of, 428,477 .

Rowtin Lymn, inscribed rock there, 403.

Royce, Rev. David, 443, 513, $5^{24}$.

Rudstone, parish of, $229,464,465,497$, $59 \mathrm{r}, 613$.

Rylston, parish of, 374,474 .

Sandstone, burnt, pieces of, in barrows, $168,220$.

Saws, flint, 35 ; large number in a barrow, 262.

Scale House in Craven, barrow at, $3^{2}$, 375.

Scamridge Dykes, 484 .

Scandinavia, bodies interred there in a sitting posture, 2 n., 24 ; chambered tombs of, 2 n., 3I6, 481,482 .

Scotland, stone circles there, $7 n$.

Scrapers, flint, $\mathbf{3 5}$.

Scythian king, burial of, $\mathbf{r} 20$.

Seal Howe, Oddendale, 398.

Secondary interments, $12,16,17$; in long barrows, $4^{85}, 488,491,502$.

Seeds in a grave, I $4 \mathbf{I}, I_{4}$ I $n$.

Selby, Major Luard-, 4I3, 4I4.

Shap, stone circle and avenue there, $38 \mathrm{I}$.

Sheath, wooden, of a bronze dagger, 359 , $359 n$.

Shells, perforated, I38; necklace of, $13^{8} n$.

Sherburn, parish of, $145,45^{8}, 459,609$.

Side on which bodies were buried, 25, 26.

Silbury Hill, 2, $2 n$.

Simpson, Rev. James, LL.D., $3^{82}$; Sir J. Y., $7 n$.

Sitting posture, bodies buried in, $2 n_{.}, 24$, $24 n$.

Skill of wold-dwellers in bronze-casting; II7; in manufacture of pottery, I17, 306. 
Skin or hide, body interred in, $3 \mathrm{I} n$., $32,3^{2} n_{\text {. }}, \mathrm{I}_{42} 2,4 \mathrm{II}$.

Skull showing signs of a wound, 137 .

Skull-form, of people of early iron age, I 29, 2I 2; of people of long barrows, I 22 n., $482,543,549$; of people of Wolds, I 22; of Scandinavian chambered barrows, 482 .

Skulls placed together without bodies, $206,206 n$.

Slaves and others killed at funeral, $\mathrm{r}_{20}$, $177,243$.

Sleep, people buried as they lay during, 24 .

Slingsby, parish of, 347,472 .

Sling-stones, 35 .

Small mounds within barrows, $137, \mathbf{r}_{37} n$., I40, 247.

Social state of people of Wolds, I I I, I I8.

Socketed celts, bronze, 49.

Soden-Smith, Mr., $396 n$.

South Shields, parish of, 442,478 .

Space, saving of, not the reason why body was contracted, 22, 293.

Spear-heads of bronze, not found in barrows, 45 ; belong probably to an advanced period of the time of bronze, 49 ; of iron, $43^{2}$.

Spindle-whorls, I 16, I78, 196.

Spinning, people of Wolds acquainted with, II6.

Spirits of the dead, fear of, 8, ro.

Spoon of horn, found in a 'drinking eup;' IOI.

Stakes supporting a platform in barrow, I 70.

Stanley, Hon. W. Owen, 77 n., 81, 83.

Steeple Hill, near Sunderland, 44I.

Stillingfleet, Rev. E. W., $5 \circ$ n., 208, 454, $455 n$.

Stone, adzes, 34 ; hatchets, 34 ; implements, 34; implements still used in bronze age, 361 ; pieces of, mixed with clay of pottery, 64 ; rows (alignments), 402, 430; vessels containing burnt bones, 73 .

Stone and bronze implements associated, $187,225,236,265,265$ n., 359.

Stonehenge, $6 n ., 18$.

Stones for polishing or grinding, 4I4, 4I6.

Successive Interments Theory, 527,546 .

Sun, bodies placed facing, 26 .

Sun-dried, urns not merely, 63 .

Surface soil removed under long barrow, 510,5 II.

Suttee, 120.

Swiss Lake Dwellings, people of, II4.

Swords of bronze, belong, probably, not to the earliest time of bronze, 49 ; found in Danish barrows, $44 n$.; not found in British barrows, 44, $44 n$.

Swords of iron, $5 \circ \mathrm{n}$.

Symbolic representations connected with burial, 343 .
Table of barrows, $45^{8}$.

Taboo, 8.

Tait, Mr. Lawson, $342 n$.

Tate, Mr. George, F.G.S., 7 n.

Tau symbol of Egypt, 8.

Taylor, Colonel Meadows, 6 n., $120 n$.

Terraces for cultivation, 114,374 .

Teutons not a fortifying people, I 25.

Three Tremblers (barrows), 357.

Thurnam, Dr., F.S.A., I $27,485 n_{\text {。, }}$ $508,526 n ., 542 n ., 543 n$., 544 .

Thwing, parish of, 226,464 .

Tindall, Mr., of Bridlington, I43.

Tool-stone, oval, in bairrow, 248 .

Tooth of pig, perforated, 326 .

Tosson, Great, parish of Rothbury, 431.

Toy weapons, \&c., 36 I $n$.

Traffic amongst people of Wolds, 56 .

Tree-coffins, I 3, 23, 32, 375, 376 n., 384 .

Trench, along the sides of long barrows, 488 ; circular, round base of barrows, 6, 369; within barrows, 6, 166, 201, $227,245,245 n$.

Troyon, M. Fréd., $23 n$.

Tunstall Hill, near Sunderland, 440.

Unburnt and burnt bodies, buried together, $149,15^{2}, 153 n_{\text {a }} 17^{2}, 240,269$, 329,372 , 39I, 44I; relative proportion of, 19, 20, 2I, 2 I $n$.

Uncleby, parish of Kirby Underdale, 135 .

Upper Swell, parish of, 52 I.

Urn, burnt bones placed in, I4.

Urns of cinerary type not containing bones, 62, 72, I39, 161, 277, 284, $287,288,289,290,29 \mathrm{I}, 297,318,370$, 428.

Urns, smaller, placed inside larger ones, $7^{2}, 3^{6} 4,367,405,408 n$., 428 .

Vase, Anglian, I78; diminutive, 3I 7 , $317 n$. ; found apart from any interment, 193, 199, 219, 301, 302, 309, $345,35 \mathrm{I}$; of great beauty, $3 \circ 7$; with cover, $89,164,164 n$, 305 ; with feet, 88, I94; with rounded bottom, I43, $143 n$.

Vases, two made by same workman, 314 .

Vessels of pottery, how manufactured, 64; made for burial purposes, 103, 108 ; probably domestic, 143 n., I 74 .

Villages on the Wolds now destroyed, 279.

Vole, bones of, 199, 391.

Wall surrounding long barrow, 513, 515, 521 .

Walls within barrows, $137,139,173,284$, $485,504,514,52$ I.

Warcop, parish of, 385,474 .

Wass Moor, 339,5 or.

Way, Mr. Albert, 77 n., 81, 83, 103, 397. 
Weapons, 33, 39, I59; frequently decorated, I60; rarely found in barrows, 5I, 190; why buried with dead, 57 .

Weaverthorpe, parish of, $192,46 r, 462$, 571,619 .

Welburn, parish of, 356,472 .

West side of barrow, burials rare on, $\mathbf{x}_{3}$.

Westmoreland, 381, 510.

Westow, parish of, 490 .

Whetstones, 35, 263, 263 n.

Wife slain at funeral of husband, 120 , I $20 n$.

Wilfred, $5^{8}$.

Willerby, parish of, 180, $460,461,487$.

William Howe, parish of Egton, 334.

Williamson, Professor, F.R.S., $377 n$.

Willy Howe, near Wold Newton, 5 ., 227.

Wilson, Dr. Daniel, 44, 53 n., I 16 n., 190, 528, 534 n., 540 .

Wiltshire barrows, $4,8,38,54,56$.
Wold dwellers, not possessed of much wealth, 57 ; social condition of, III 118; their physical characteristics, I 2 I, 127 .

Wolds, defensive condition of, $123, \mathbf{x}_{34}$; description of, 133 ; dry, I34; numerously occupied, 133; two stocks of people living on, 126; wanting in water, I33; wanting in wood, I34.

Women, social position of, 120 .

Wood, absence of, conducive to early occupation, I 34 ; grave lined with, I3, I 70.

Wooden club, 278 .

Woollen garments in grave, 32,376 .

Worsaae, J.J.A., $3 \mathbf{I}$ n.

Worship of ancestors, Io.

Wrist-guard of stone, $36,36 n$.

Wykeham Moor, 357 .

Wylie, Mr. W. M., F.S.A., 3I n., 57 n., $93 n$. 

<smiles>CCCCC1CCC1</smiles> 


BINDING $\quad \ldots$ APR 301974

PLEASE DO NOT REMOVE

CARDS OR SLIPS FROM THIS POCKET

\section{UNIVERSITY OF TORONTO LIBRARY}

GN

796

Greenwe11, William

G7G7 
